\title{
Reports of the Research Committee
}

of the Society of Antiquaries of London

\section{ALALAKH}

An Account of the Excavations at TELL ATCHANA in the Hatay, I937-1949

By Sir Leonard Woolley D.Litt., LL.D., F.S.A., Hon. A.R.I.B.A.

With sections by Professor C. J. Gadd, D.LITT., F.S.A., F.B.A. and R. D. Barnett, F.s.A.

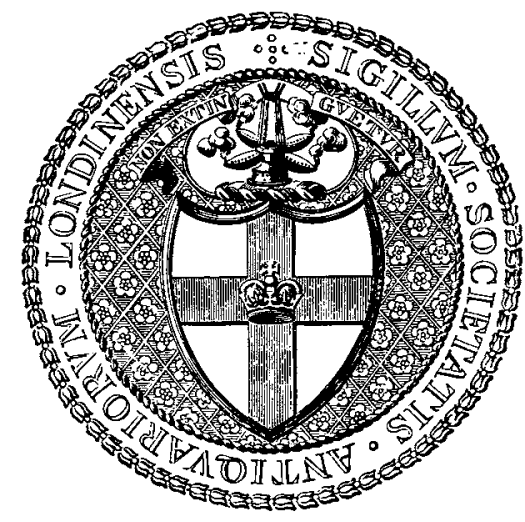

Oxford

Printed at the University Press by Charles Batey for

The Society of Antiquaries

Burlington House, London I 955 


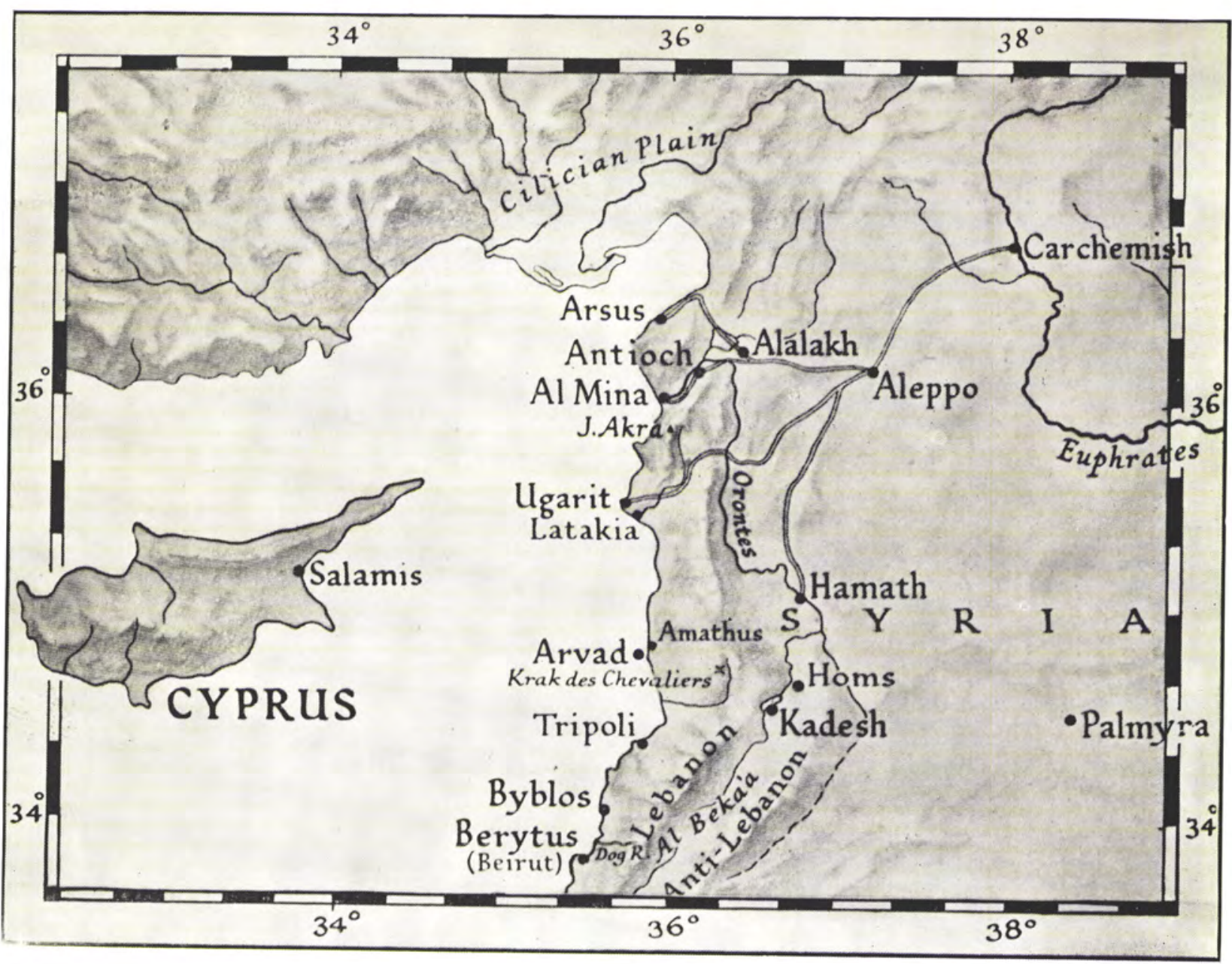

Map of Northern Syria 


\section{Reports of the Research Committee}

of the Society of Antiquaries of London

\section{ALALAKH}

An Account of the Excavations at TELL ATCHANA in the Hatay, I937-1949

By Sir Leonard Woolley D.Litt., LL.D., F.S.A., Hon. A.R.I.B.A.

With sections by Professor C. J. Gadd, D.LITT., F.S.A., F.B.A. and R. D. Barnett, F.s.A.

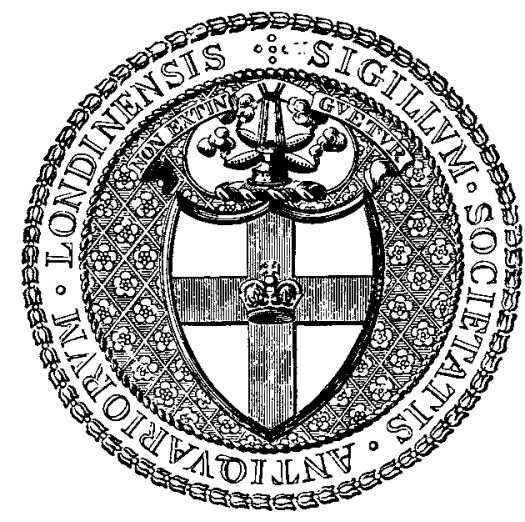

Oxford

Printed at the University Press by Charles Batey for

The Society of Antiquaries

Burlington House, London I 955 
PRINTED IN GREAT BRITAIN 


\section{LIST OF CONTENTS}

INTRODUCTION

I. (a) The Pre-Alalakh Periods

(b) The Archaic Levels, Houses and Palaces

II. The Temples, Levels XVI-O

III. The Palaces of Levels VII and IV

IV. The Town Defences .

V. The Private Houses

VI. The Graves

VII. (a) The Architecture

(b) The Frescoes .

VIII. (a) The Stone Sculpture

(b) The Terra-cottas

(c) A Model Liver for Divination. By C. J. Gadd • • • 250

IX. (a) The Cylinder Seals and Seal-impressions • . $\quad . \quad 258$

(b) The Beads and Amulets . $\quad . \quad$. $\quad . \quad$. $\quad . \quad 268$

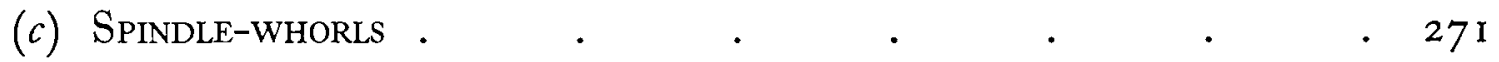

X. (a) Gold and Silver Objects . . . . . $\quad$. 272

(b) Metal Tools and Domestic Instruments . • 275

XI. (a) IVORy ObJects

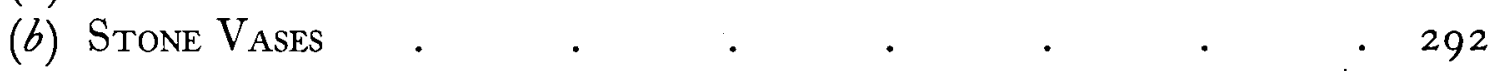

(c) Glazed Ware and Glass $\quad$ • $\quad$ • $\quad$ • $\quad$ • 297

XII. The Pottery

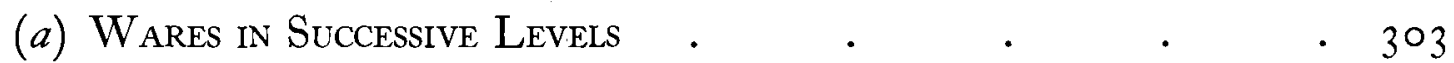

(b) Pottery Types $\quad . \quad$. $\quad$. 
iv CONTENTS

(c) The Early Local Painted Pottery . . . . 340

(d) The Black Impressed Ware . • . . . . $\quad$. 342

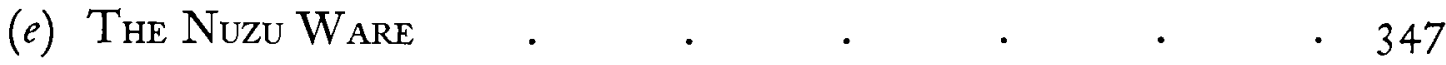

$(f)$ Zoomorphic Vases and Vases with Relief or Incised Decoration $35^{\circ}$

(g) White Slip and Base-Ring Wares . . . . . 354

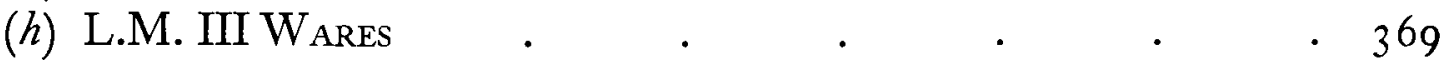

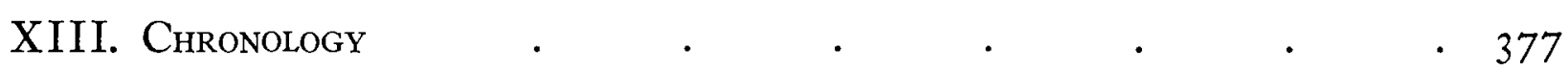

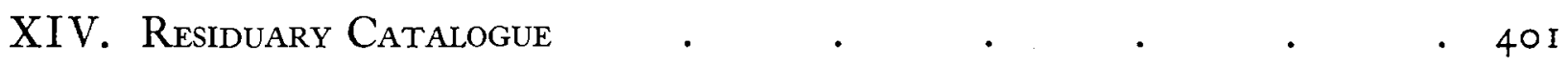

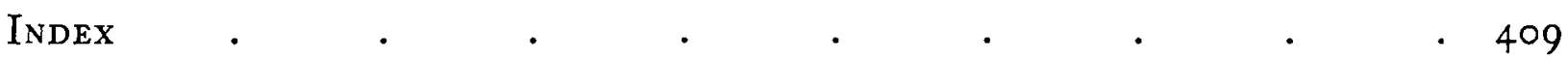




\section{LIST OF PLATES}

I. Map of northern Syria (Frontispiece)

II. a. Level XV, general view. The columns of Level XII are seen in section in the background

b. Level XIII, the NW. room (I), showing walls, doorway, and pot-base

III. a. Level XIII, general view

b. Level XII; general view looking NW.

Iv. a. Level XII, the row of columns as first found

$b$. Level XII; section of column showing the later shaft built in the core of the old

v. a. Level XII; column C, showing the clay foundation below the brickwork

b. Level XII $b$; oven in room 3

vi. a. Level XI, general view looking NW.

$b$. Level $\mathrm{X}$, general view looking $\mathrm{NW}$.

vir. $a$. The temple site; digging below water-level, I 947

$b$. The Level XVI temple; the tiled floor.

viII. a. The Level XVI temple; stonework in front of the gabled block

b. The Level XVI temple; the brickwork of the 'mastaba' and the Level XV stonework in front of it

IX. $a$. The Level XII temple; the buildings of the sanctuary block

b. Terra-cotta model of a temple, from Selemiyeh

x. $a$. The Level VII temple; general view showing the altar, the boxes under the benches, and the intrusive rubbish-pits of Level VI

b. The Level V temple; the benches and altar of the Mithraeum

XI. $a$. The Level III temple, showing the altar and threshold of Level II

b. The Level I temple, general view

xII. a. The Level I c temple; the sanctuary steps and the lions

$b$. The Level I $c$ temple; the statue of Idri-mi buried beneath the floor

xIII. a. The Level $\mathrm{O}$ temple foundations

b. Basalt tables of offering from the Temples of Levels $\mathrm{I}$ and $\mathrm{O}$

c. The Level VII palace; the entrance (room 7) from the outside

xIv. The buildings of Level VII, general plan

$\mathrm{xv}, a$. The Level VII palace; the cement threshold between rooms 5 and $5 \mathrm{~A}$

$b$. The Level VII palace; view from the central court across room 8 to the NE. staircase

xvi. a. The Level VII palace; rooms I 2 and I I ; an elephant tusk lying on the threshold

$b$. The Level VII palace; room I I, showing tusks and tablets

xVII. $a$. The Level VII palace; view from the NE. staircase across room 8 and the central court to the stair-chamber (10) and the passage beyond

b. The Level VII palace; room Io; the stairs leading up to the long passage (I 4)

xvin. a. The Level VII palace; room ro; looking down on the first and second flights of the newel staircase 
xvirI. $b$. The Level VII palace; the NE. stair-chamber (3) showing the vitrified wall and also the finger-print keying of the plaster for the intonaco

xIx. a. The Level VII palace; room 15

b. The Level VII palace; room I8, showing sunken tank, wash-basin, and drain intake

xx. a. The Level VII palace; the stairs and the shaft below room I 7

$b$. The Level VII palace; the stone doorway of the shaft blocked by boulders

xxI. $a$. The Level VII palace; the NE. corner of the stone-lined shaft with clay and alabaster vessels in situ

$b$. The Level VII palace; the NW. corner of the stone-lined shaft with four skeletons in a box

xxir. The buildings of Level IV; general plan

xxirr. a. The Level IV palace; the foundations of the NE. corner cut down into room 2 of the Level VII palace

b. The Level IV palace; the domestic wing

xxiv. $a$. The Level IV palace; the forecourt and the façade

$b$. The Level IV palace; view from room 2 across room 13 to room 22

$\mathrm{xxv}$. a. The Level IV palace; the lavatory in room 5

$b$. The Level IV palace; the doorway of room 9 showing the wooden sill-edge and the packing of the raised threshold

xxvi. a. The Level IV palace; the bath in room 9

$b$. The Level IV palace; room 27, showing the stair newel and cupboard under the stairs

xxvir. $a$. The Level IV palace; room 28 , with the sunken column-base

$b$. The Level IV palace; room 32, showing the half-timber construction of the wall

xxvirr. a. The Level IV palace; room 33 , the palace archive

b. The Level IV palace; room 35, the wine-cellar

XxIx. $a$. The Level VII city gate; general view from inside

b. The Level VII city gate; the guard-chamber

xxx. a. The Level VII city gate; the sentry-box

b. The glacis of the Level VI castle

XxxI. a. The glacis of the castles of Levels VI, V, and III

$b$. The castle of Levels $\mathrm{V}$ and IV; general view looking $\mathrm{E}$. from room 6 across the barrack square to room $\mathrm{W}_{\mathbf{I}}$

xxxIr. $a$. The gate tower of the Level IV castle, from the outside

$b$. The Level IV castle; room I I

xxxiII. $a$. The Level IV castle; room $\mathrm{I} 3$

b. The Level III castle; the wine-cellar

xxxiv. a. The brickwork and stone foundations of the Level III castle sunk in room 2 of the Level IV palace, and a brick-lined sump-pit of the Level I castle

$b$. The podium of the Level $\mathrm{V}$ shrine

$\mathrm{xxxv}$ a. Level IV houses; entrance of house 37

b. Level II houses; room I of house $37 / \mathrm{C}$

xxxvi. a. Site $\mathrm{H}$; attached half-column in the Level $\mathrm{V}$ gateway buildings

b. Fresco remains in situ in room 12 of the Level VII palace 
xxxvir. Fragments of fresco from the Level VII palace

xxxviri. a. Fragment of fresco with naturalistic grass motive

b. Fragment of fresco showing a bull's horn

xxxix. a. 'Architectural' fresco from Level IV, house 39/A; general view

b. The same, detail of the upper part

c. The same; restored sketch

xL. $a, b$. Full-face and profile view of the 'Egyptianizing' head AT/47/62 from the Level VII temple

XLI, xLII. Full-face, back, and profile views of the portrait head (of Yarim-Lim?) AT/47/74, from the Level VII temple

xLIII. a. Basalt head of a bull, AT/47/73

b. Steatite wig, $A T / 47 / 78$

c. Steatite wig, AT/46/155

d. Steatite wig, AT/47/90

e. Steatite beard fragments, AT/47/77

XLIV. Crude stone figures

XLV. Ram's head carved in dolomite, $\mathrm{AT} / 38 / 147$, from the Level IV palace

xLvi. The dolomite statue of King Idri-mi, AT/39/33I, found in the Level I temple

xLVII. $a$. 'The feet of the Idri-mi statue showing the sculptor's use of the drill

b. The basalt throne of the Idri-mi statue, AT/39/288

XLVIII. The basalt relief of Dudhalia, AT/40-45/2, side and front views $(a)$ as found, $(b)$ muddied

xLIx. $a$. Lions flanking the steps of the Level I temple sanctuary

b. The first lion, $A T / 39 / 3$ I 4

L. Two views of the second lion, AT/39/315

LI. Two views of the third (incomplete) lion, $\mathrm{AT}^{\prime} / 40-45 / \mathrm{I}$

LII. a. Basalt altar, $A T / 39 / 287$, from the Level I temple

$b$. Limestone statue of a goddess, AT/39/31 7 , from the Level I temple

LIII. a. Fragment of diorite head from a relief, AT/40-45/6, from the Level I temple

b. Fragment of drapery from a diorite statue, AT/39/33

c. Fragment of drapery from a diorite statue, $\mathrm{AT} / 48 / 9$, found in the Level V temple

LIV-LVII. Terra-cottas

LVIII. $a, b$. Clay vase-stand with applied figures, AT/47/128, from the Level VII temple

c. Zoomorphic vases and model phallus (?)

d. 'Terra-cotta gryphon's head, AT/48/36

LIX. A clay model of intestines marked for purposes of divination; AT/47/75, from Level VI

LX-LXvi. Cylinder and other seais and seal-impressions

Lxvir. Cylinder seals, stamp seals, and Hittite bulla seals

LXViIr. a. Bead types

b. Amulets

c. Spindle-whorls

LxIx. Gold objects 
Lxx. Bronze figurines and weapons

LXXI-LXXIII. Types of bronze tools and weapons

Lxxiv. Bronze vessels

LXxv. Ivory toilet-boxes

LXxvi. Objects in bone and ivory

Lxxvir. Objects in bone and ivory

Lxxvir. Ivory objects and inlay, and basalt lamp

LxxIx. Red marble lamp of Cretan style, AT/39/280

LXxx. Stone vases

LXXXI, LXXXII. Types of stone vases

Lxxxir., $a$. Obsidian vessels

b. Glazed earthernware bottle AT/39/197

c. Engraved shell AT/38/6

d. Glass fragment with horns in relief, AT/48/99

e. Fragment of Egyptian faience vase, $\mathrm{AT} / 46 / 223$

f. Vase of lapis lazuli paste, $\mathrm{AT} / 48 / \mathrm{I} 8$

LXXxIv. Local painted pottery, Levels XIV-XIII

LXXxv. Local painted pottery, Levels XII and XI

Lxxxvi. Local painted pottery, Levels VI and IV

Lxxxvir. Local painted pottery, Levels $V$ and IV

LXxxvirI. Local painted pottery, Levels V-III

LXxxix. Local painted pottery, Levels IV-I

$\mathrm{xc}-\mathrm{xc}$ IIr. Designs on local painted pottery

xcIx. Examples of plain local pottery

c, cI. Black pottery with impressed designs

cII, cIII. Nuzu and Atchana painted wares

civ-crir. Designs on Nuzu vases

cVIII. Relief and incised ornament on pottery, and potters' marks

cIX-cxxiv. Types of local pottery vessels

cxxv, cxxvi. White Slip and Base-ring wares

CXXVII-CXXIx. L.M. III wares

cxxx, cxxxi. Types of White Slip, Base-ring, and L.M. III vessels 


\section{LIST OF FIGURES IN THE TEXT}

I. The SW. end of the Amq Plain

2. Section of the stratification-pit, Levels XVII-I . . . . . . I I

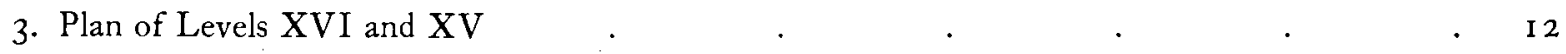

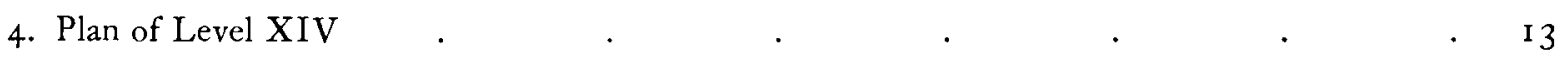

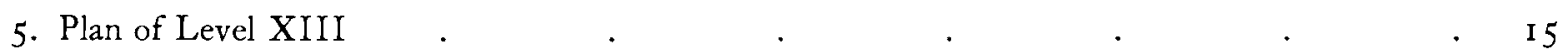

6. Lamp-stand in room 6, Level XIII . $\quad . \quad$. . . . $\quad$. 16

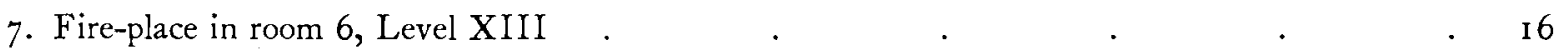

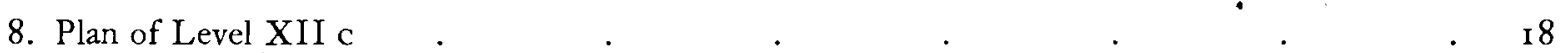

9. (a) The columns in Level XII; (b) Section of column B . . . . . . $\quad$ I9, 20

10. Plan of Level XII, $\mathrm{A}$ and $\mathrm{B} \quad$. $\quad . \quad$. $\quad . \quad$. $\quad 22$

I I. Fire-place in Level XII . $\quad$. $\quad$. $\quad$. $\quad$. $\quad$. 23

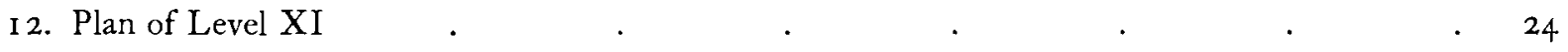

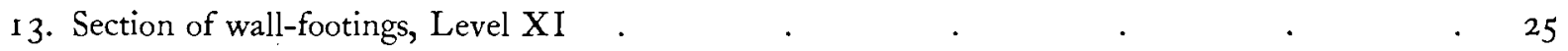

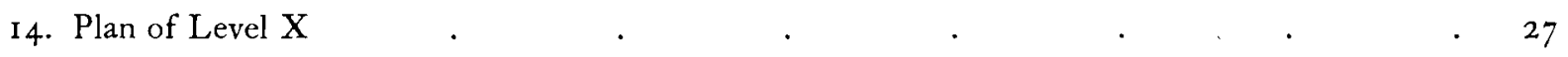

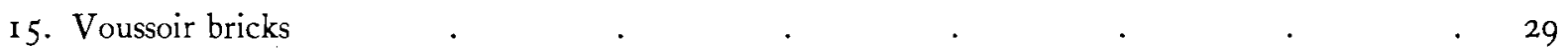

I6. The method of brick-vaulting construction . . . . . . . . $\quad$ 3I

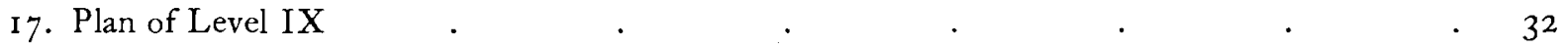

I8. Sections of the temple sites, Levels XVI-VII . $\quad$. $\quad$. $\quad$. $\quad 34$

I9. Plan of the Level XVI temple . $\quad . \quad$. $\quad . \quad$. $\quad . \quad 36$

20. The gabled construction in the Level XVI temple $\quad$. $\quad$. $\quad$. 37

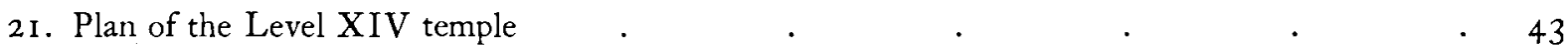

22. Plan of the Level XII temple . . . . . . . . . 47

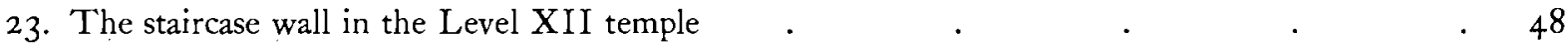

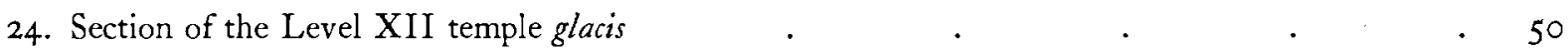

25. Timber foundations of Levels XI and X, laid over the ruins of the Level XII temple $\quad 54$

26. Basin in the platform of the Level IX temple . $\quad$. $\quad$. 56

27. Timber foundations under the front part of the Level VIII temple . $\quad$. 57

28. Channelled stone in the Level VII temple altar . $\quad$. $\quad$. . . . 63

29. Plan and section of the Level V temple $\quad . \quad \ldots \quad . \quad 0 \quad$. $\quad . \quad 67$

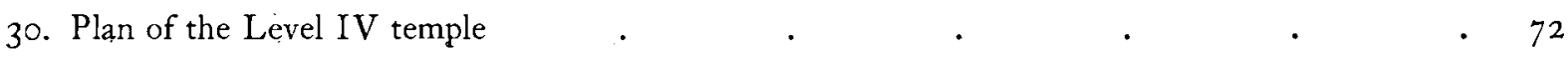

3I. The temples of Levels III and II; existing remains $\quad . \quad$. $\quad . \quad$. 74 
32. Restored plan of the Level III temple

- 76

33. Restored plan of the Level II temple

34. The Level I temple; (a) General plan; (b) Plan of phase A; (c) Plan of phase B .

. 83

35. Plan of the Level VII palace of Yarim-Lim

facing 92

36. Stairway and underground chamber, room 17 of the palace

- 96

37. Threshold between rooms 5 and $5 a$ of the palace

38. Wooden tenon

39. Shaped orthostats in the palace wall .

40. Stone tank

41. Section through the cupboard below the palace stairs

42. Stone column-base from an upper window

I 00

43. The remains under the Level IV palace

IOI

44. The Level IV palace of Niqme-pa; plan of the ruins

IOI

- IOI

- 102

103

107

45. The Niqme-pa palace; restored plan .

- 1 I 3

46. Elevation and section of the palace entrance

- II 5

47. The palace of Niqme-pa; suggested restoration .

- II 6

48. (a) Copper hinge-shoe and socket; (b) Overhanging brickwork

49. Staircases in the palace of Niqme-pa.

I 7

- 1 I 8

50. Detail of room $\mathrm{C}_{3}$, palace of Niqme-pa

125

- 128

51. Terra-cotta hearth-stand, loom-weight, and jar-stopper

129

52. Section and restored section of the city rampart

53. Plan of defence works in Sqq. M 8, \&c.

54. Site $\mathrm{H}$, plans and sections

55. Plan and restored elevation of Level VII city gate

56. Stairs and roof of guard-chamber in the city gate

57. Plan of the Level IV castle

58. Plans and sections of the castle façade

59. Plan of the Level III fortress

60. Detail of the Level I fortress wall

6I. Private house plans, Levels VI and V

62. Plan of house 37 , Level IV

63. Plan of houses $39 \mathrm{~A}$ and $\mathrm{B}$, Level IV

64. Plan of house $39 \mathrm{c}$, Level IV

65. Plan of houses $37 \mathrm{~A}, \mathrm{~B}$, and c, Level II

66. Plan of house $39 \mathrm{c}$, Level II

- 136

- $\quad 3^{8}$

I 4O, I 4 I

. 146

. 149

- 152

- $\quad 54$

facing 167

. 170

- 173

- $\quad 176$

- 179

- $\quad 18 \mathrm{I}$

- $\quad$ I 87

- 190 
LIST OF FIGURES IN THE TEXT

67. Plan of house 38 a, Level I

68. Plan of houses $37 \mathrm{~A}$ and $\mathrm{B}$, Level I.

69. Plan of house $38 \mathrm{~B}$, Level I

70. Objects from grave ATG/38/2

7 I. Methods of half-timber wall-construction

72. Stamp seals

73. Jewellers' moulds and crucible

74. Glazed ware and glass

75. Mixed varia .

76. Carved stone base

77. Bone implements

78. Clay model of a liver (?)

79. Stone offering-tables

80. Stone objects

8 I. Bone toggle 


\section{INTRODUCTION}

FTER the conclusion of work at Ur I was, in the spring of I 935 , commissioned by
the Trustees of the British Museum to look for a new site for excavation. The
object that I had in view was, primarily, to trace early cultural relations between
the Aegean and the Asiatic mainland, throwing light, if possible, upon the development of Cretan civilization and its connexions with the great civilizations of Nearer Asia; this meant that my search must be conditioned by political and economic history, by harbours and overland trade-routes. Geographical considerations led me to the Amq plain in north Syria, a plain dotted with something like two hundred ancient mounds, through which the river Orontes flows before breaking through the barrier of the Amanus mountains to reach the Mediterranean. Finally I selected one mound, Tell Atchana, which I believed to be the site of a royal city commanding the principal traderoutes, including the pass to the sea, and controlling too the timber-supplies of the northern mountains - the continuation of the Lebanon forests exploited by the Phoenician cities of the south coast; and also the insignificant little mound of Sheikh Yusuf at the mouth of the Orontes, which I believed to have been the port of the capital city.

When the scheme was put forward the Trustees of the British Museum decided, much to my regret, that the funds at the Museum's disposal did not warrant their financing an expedition whose commitments it was difficult to calculate and whose avowed purpose was admittedly speculative. Fortunately at this juncture Major-General Sir Neill Malcolm came forward and raised a fund for dispatching the expedition under the aegis and in the interests of the British Museum; to all those whose generosity made possible the inception of a piece of work destined to prove of such importance I wish here to express my sincere gratitude.

Thoughout the I 936 season work was confined to the harbour site. The results of the excavation have been published in the Fournal of Hellenic Studies; they were of such interest that the Trustees felt justified in making a handsome contribution to the expenses of the following season, and in time they took over the major responsibility for the financing of the expedition although technically it never ranked as a British Museum Expedition. After I 947 the Museum's available funds were exhausted and I was obliged to close down the work at a stage at which various important problems were yet to be solved; most opportunely H.M. Treasury offered to see the work through to a point at which its scientific objects could be said to have been secured, and did actually supply all the funds required for the I 948 and I 949 seasons.

The original permit for the excavations was granted by the Department of Antiquities of the French Mandatory Power, and on those terms the work, which at Atchana began in I 937, was continued in the course of the next two years, when it was interrupted by the war. In 1939 the former Sandjak of Alexandretta became, as the Hatay, part of 
Turkey, but when after the war a resumption of archaeological work was possible the Turkish Government granted every facility and took so active an interest in it as to lend the services of Turkish scholars as assistants on my staff; under these pleasant auspices three more seasons were devoted to the excavation of the site.

I have throughout been deeply indebted to the members of my staff for their valuable and ungrudging help. Before the war my wife was always with me, and I had the assistance in 1937 of Mr. E. A. Lane, of the Victoria and Albert Museum, Mr. A. F. Gott as architect, and Mr. P. W. Murray-Thriepland; in $1938 \mathrm{Mr}$. Murray-Thriepland and, as architect, Mr. Ralph Lavers; in 1939 Colonel A. H. Burn, C.I.E., O.B.E., and Mr. Peter Ollard; my old foreman Hamoudi was in charge of the workmen, helped by his sons Yahia and Alawi, the former of whom was responsible for the photographic work also. After the war, in 1946 the British Museum kindly lent the services of Mr. C. J. Gadd and the Ashmolean Museum those of Mr. P. L. Shinnie; in I 947 Mr. W. C. Brice joined me as a volunteer, and from Turkey I had Dr. Bahadir Alkim of the University of Istanbul, Dr. Tahsin Özgüç of the University of Ankara, and Bay Ahmet Dönmez of the Department of Antiquities; in 1948 Mr. Sinclair Hood came as volunteer, Dr. Alkim and Dr. Özgüç each came for half the season and Ahmet Dönmez for the whole of it, together with Bay Baki Ögün, also of the Department of Antiquities; in I $949 \mathrm{Mr}$. Hood, Ahmet Dönmez, and Baki Ögün; and during all those three years Bay Ruhi Tekán, Director of the Antioch Museum, was with us acting as Commissaire for the Government and did all in his power to help our work. Hamoudi retired after the war, on the grounds of old age, and his place was taken by his two sons Yahia and Alawi, who proved admirably competent.

My special thanks for help at various stages of the work are due to the late $M$. Claude Prost, Inspector of Archaeology for North Syria, to the Department of Antiquities of the French Mandatory Power, and in particular to its Director, M. Henri Seyrig, to Hamit Bay Zübeyr Koșay, General Director of Antiquities for Turkey, to H. E. Cevat Bay Açikalin, Turkish Ambassador in London and formerly Envoy Extraordinary to the Hatay, to Sir Alan Barlow and to Mrs. P. M. Rossiter of H.M. Treasury Office. In preparing this volume for the press I have been much helped by Mr. Brice, who has redrawn for me all the pottery and stone-vase types, and in various sections $I$ have benefited by the advice of Mr. F. H. Stubbings, Professor Sidney Smith, Mr. D. J. Wiseman, and Mr. C. J. Gadd. To all these I am personally indebted; but the gratitude not only of myself but of all interested in the archaeology of the Middle East must be accorded to the Society of Antiquaries of London who in 1937 agreed to publish the results of the excavation and are solely responsible for the appearance of this volume. I have already made my general acknowledgement of the generous help which enabled the expedition to take the field in 1936 , but feel that my account of its work would be incomplete did I not record the names of the donors; they were
F. R. S. BALFOUR, ESQ.
J. SPEDAN LEWIS, ESQ.
A. E. BOND, ESQ.
D. O. MALCOLM, ESQ.
THE COUNTESS BUXTON.
MAJOR-GENERAL SIR NEILL MALCOLM. 
ALFRED CLARK, ESQ.

SIR PERCIVAL DAVID, BT.

GEORGE EUMORFOPOULOS, ESQ.

SIR ARTHUR EVANS

C. H. ST. JOHN HORNBY, ESQ.

A. JOHN HUGH SMITH, ESQ.

OWEN HUGH SMITH, ESQ.
SIR JOHN STERLING MAXWELL, BT.

P. A. MOLTENO, ESQ.

P. MURRAY-THRIEPLAND, ESQ.

H. J. OPPENHEIM, ESQ.

O. C. RAPHAEL, ESQ.

A. L. RECKITT, ESQ.

J. W. WHEELER-BENNETT, ESQ.

and also THE ASHMOLEAN MUSEUM

THE ROYAL GEOGRAPHICAL SOCIETY

THE BRITISH SCHOOL OF ARCHAEOLOGY IN IRAQ

The present volume constitutes the final record of all the archaeological material resulting from the excavations. The inscriptional material is published in two independent volumes, viz. The Statue of Idri-mi, by Sidney Smith, and The Alalakh Tablets, by D. J. Wiseman, Occasional Publications of the British Institute of Archaeology in Ankara, Nos. I and 2. 


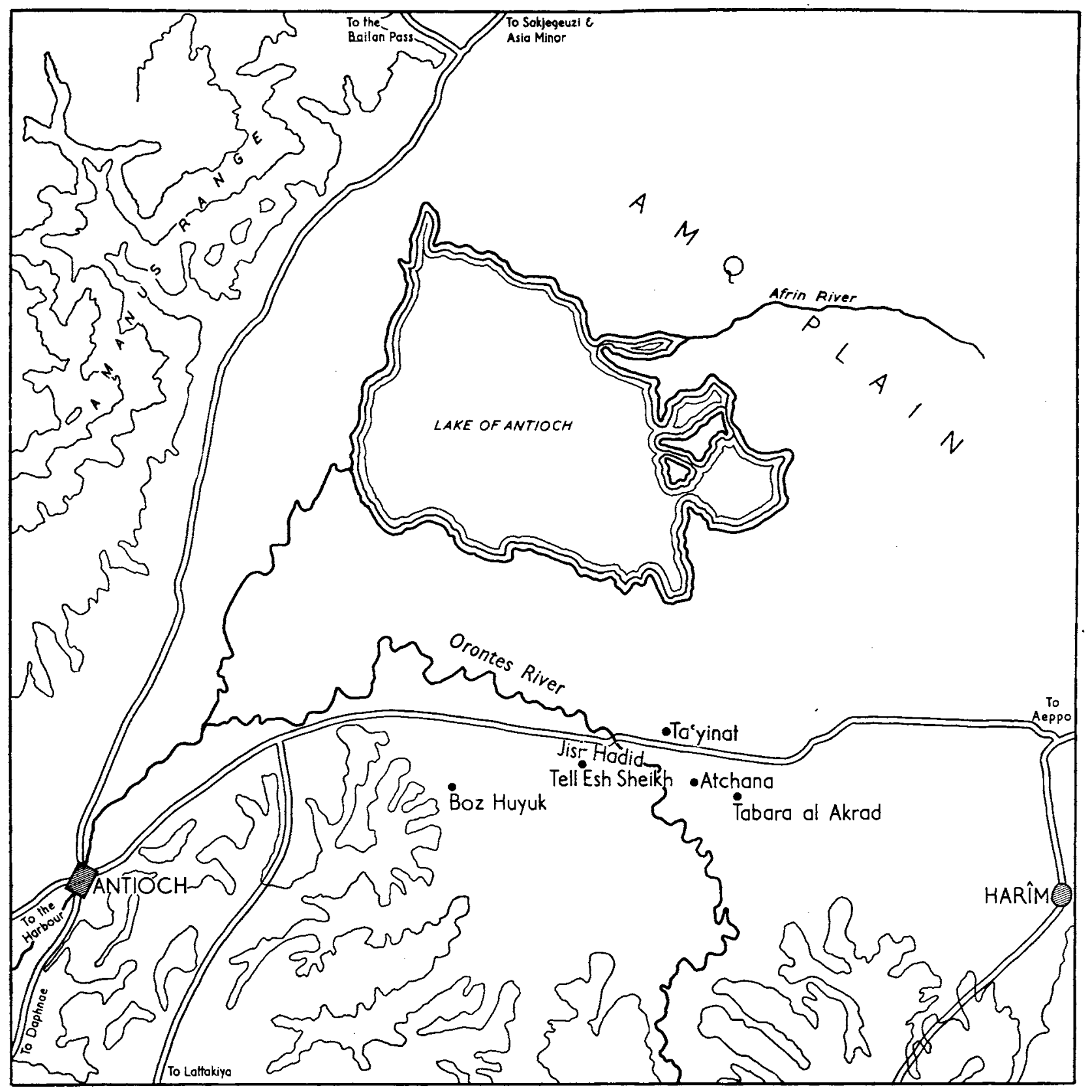

FIg. I. The SW. end of the Amq Plain 


\section{CHAPTER I}

\section{(a) THE PRE-ALALAKH PERIODS}

$T$

ELL ATCHANA lies on the western side of the Amq plain, close to where that plain begins to narrow towards the Antioch pass. A little more than 400 metres to the west the Orontes winds with incredible involutions on a general northwestern course to swing round at Jisr Hadîd and force its way through the Amanus mountains south-westwards to the sea. To the east and north stretches the wide plain, dotted with ancient mounds, enclosing the glittering expanse of the Antioch marshes; to the west and north-west the horizon is formed by the peaks of Amanus and Anti-Taurus, snow-clad for the greater part of the year; to the south one looks up the Orontes valley and, to the east of it, to the tangled hill-country on whose verge show up the white buildings of Harîm with its crusading castle. Tell Atchana itself is a mound irregularly oval in shape, measuring about 750 metres in length by about 300 in width, its axis being roughly NW. $\times$ SE.; at the NW. end it rises abruptly to a height of just under nine metres, at the SW. end sinks almost imperceptibly to the plain (Pl. XIV). These measurements of the existing mound are somewhat misleading. Not only has the upper part of the tell suffered from the denudation caused by rain, wind, and agriculture, but the plain itself has since antiquity risen by no less than five metres, so that ane time the ruins stood half as high again as does the mound today. The earthquakes which in the sixth century A.D. destroyed Antioch threw a rocky barrage across the ravine through which Orontes runs to the sea and thereby changed the character of the country far inland. The waters of the Orontes and the Afrin had no exit to the Mediterranean, filled all the valley above the huge dam, and turned the Amq plain into a lake; and when at last they surmounted the obstacle, the Forum of Roman Antioch, lying on the old river's bank, was buried under more than eight metres of silt and five metres depth of mud and sand covered the Amq plain, while in the centre, where the running streams scoured a passage, spread a wide and shallow lake through whose waters one can look down into the ruins of buildings of the early Christian time. The silt which masked the proportions of Tell Atchana buried altogether many of the smaller mounds. In his archaeological survey of the plain Braidwood ${ }^{\mathrm{I}}$ records $\mathrm{I} 78$ ancient sites; but the real number is considerably greater; a number of smaller mounds, village sites whose occupation was limited to only one or two of the historical periods, are completely hidden or rise so little above the general level as easily to escape notice. We excavated two of these small mounds in order to complete the historical record supplied by our main site.

There are at Atchana no remains earlier than the Bronze Age. Excavation has been carried down to virgin soil in a part of the mound which must certainly have been within the limits of the oldest settlement and proved beyond question that the town was founded by Bronze Age immigrants to the Amq plain.

I R. J. Braidwood, Mounds in the Plain of Antioch, University of Chicago Oriental Institute Publications, vol. xlviii. 
Before the coming of those immigrants there had been a long period of occupation to which a number of tells bear witness. Immediately adjoining Atchana lies the large citymound of Ta yināt which was inhabited both before the foundation of Alalakh and after its desertion; two miles to the west is Tell esh Sheikh, a mile and a half to the east is Tabara al Akrad, towards the eastern end of the plain are Catal Huyuk and Tell al Judaidah, all of which have been excavated, and others listed by the Oriental Institute of Chicago can on the evidence of surface pottery be assigned to the same early date. ${ }^{I}$ All the excavated sites except Atchana have shown heavy deposits of the chalcolithic period, but in the present state of knowledge it is not possible to assert definitely that any one of them, even in its lowest levels, is really neolithic. It stands to reason that neolithic sites must exist. The hunters of the Old Stone Age were perhaps confined to the mountains and foot-hills where game was more abundant; but as soon as agriculture was introduced man cannot fail to have been attracted by the well-watered deep-soiled Amq plain, and he should have left there at least some evidence of his occupation. A steatite female figurine found by a peasant on one of the southern tells has by general consent been assigned to the early part of the neolithic period, and if that be correct it is the one monument of the time that we possess, ${ }^{2}$ but I must admit that the steatite rams' heads found at Tell esh Sheikh ${ }^{3}$ might well belong to the same phase of art, and they are chalcolithic. Since the statuette is in any case undocumented, and its date is a matter of opinion, its historical importance is small compared with that of the stratified sites.

Tell esh Sheikh was excavated by Ahmet Dönmez for the expedition in 1947 and r 948, and in r 948 and 1949 Mr. Sinclair Hood made sondages at Tabara al Akrad.4

Tell esh Sheikh gave us twelve building-levels, implying in all a considerable lapse of time; the two lowest contained predominantly burnished black pottery but with a certain infiltration of imported painted wares first of the Tell Halaf type and later of the 'Northern al 'Ubaid'. Almost at once we find local imitations of these, and in Level $\mathrm{X}$ the black pottery has been virtually replaced by local wares of the new type, much of it painted in a style which while clearly based on the two imported fabrics has achieved a marked individuality of its own. This 'Tell esh Sheikh' ware, always hand-made and with a large proportion of painted examples, continues right up to the surface soil, subject to such minor developments of shape and decoration as would be expected with the passage of years but with no radical change. Then the site was abandoned, and a few pieces of wheel-made pottery of the Bronze Age types found at Atchana which occurred in the worked top-soil and also in a few pits dug down into the upper prehistoric levels only bore witness to a long period of desertion.

It is fairly safe to assume that the inhabitants of the two lowest levels at Tell esh Sheikh were the last representatives of those primitive settlers who had been attracted to the Amq plain by the promise of an easy livelihood held out by its rich alluvial soil; but whether they were still in the neolothic stage of culture or had emerged from it we

I R. J. Braidwood, op. cit.

2 Mélanges Syriens offerts à M. René Dussaud, Paris, I939, i. I 36 . course to be published in Belleten.

4 Sinclair Hood, 'Excavations at Tabara el Akrad', in

3 'The report on the Tell esh Sheikh excavations is in due Anatolian Studies, vol. i (I95 I), p. II 3 . 
cannot say; the negative evidence of the absence of any sign of metal is not conclusive. Similarly the pottery, which is quite plain and has none of the incised decoration that distinguishes the neolithic (?) wares of Sakje-geuzi, ${ }^{1}$ Mersin, ${ }^{2}$ and Tarsus ${ }^{3}$ as well as of Ras Shamra, cannot be taken as proving a meolithic date; on the other hand, it can be argued that plain black burnished ware does not belong to the lowest levels in Mesopotamia but does seem to be generally the product of a wooded hill-country (it is largely a question of the fuel used in firing), so that the population of Tell esh Sheikh XI and XII are more likely to have had affinities with Anatolia.

The painted Tell esh Sheikh ware is certainly chalcolithic. As certainly it is derived from Tell Halaf and Northern al 'Ubaid; its affinities therefore are with the eastern plateau that extends, south of the Anatolian hill-country, right across northern Mesopotamia to beyond the Tigris. A poorer version of it characterizes the chalcolithic levels at Mersin; ${ }^{4}$ it does not occur at the nearest excavated site to the east, Carchemish, where there is only Tell Halaf ware; its centre therefore should probably be not very far away, possibly in the Amq plain.

This painted pottery has nothing whatever in common with the black ware found in the two lowest levels of the mound, and the transition from the one to the other can be followed clearly. The earliest painted fragments are imports, as is shown by their clay and by their finish; in Level XI there is a mixture of imports and local imitations of the imported wares. In Level $X$ the local painted pottery and plain wares of the same character have altogether ousted the primitive black fabrics, and foreign imports also drop out. Inspired by the two very different models, Tell Halaf and al 'Ubaid, the Amq potters had very quickly evolved a decorative style of their own which possesses no little artistic merit; this style (whose influence can be traced as far away as Mersin) persists with no more change than the lapse of time would naturally effect from Level X to Level I; on the whole there is a progressive decadence in the pottery, the general run of decoration in the upper levels tending to be rather slovenly and mechanical, but to this there are notable exceptions such as the prevalence in Level II of one of the most striking of the designs, while the falling-off in the pottery is compensated for by the steady improvement in the technique and variety of the stamp seals which are another characteristic of this culture. To the ten occupation-levels which it occupies we must assign a reasonably long period, perhaps as much as three centuries or more.

At Tabara al Akrad there were seven levels. The lowest contains pottery and small objects of the sort found in the upper levels of Tell esh Sheikh; this established the cultural continuity of the two sites. In Levels VI and V there appears a new cycle of pottery with carinated forms and red-washed and burnished surface which shows affinities with the Uruk wares of Mesopotamia and, to some extent, with the Early Bronze Age pottery of Palestine. As Mr. Hood says, 'while it may have been introduced by invaders or immigrants from abroad, there is nothing to prove that it did not develop on

I J. Garstang, Liverpool Annals, vol. i, p. I I 4.

2 J. Garstang, American Fournal of Archaeology, and series, vol. li ( I 947), p. $37^{\circ}$.

3 Hetty Goldman, American Fournal of Archaeology, and series, vol. li ( r 947), pp. 370 sqq.

4 J. Garstang, op. cit. 
the spot through changes of fashion doubtless inspired by examples from further East'. From Level IV upwards the pottery is identical with that found at Khirbet Kerak and other sites in Palestine as well as at Ugarit and in the Amq plain. In the uppermost level there occurred with the Khirbet Kerak pottery a few sherds which both by their shape and by their painted decoration linked up with Level XVII at Atchana; the evidence does not point to more than a brief overlap, but it is sufficient to give the sequence Tell esh Sheikh-Tabara al Akrad-Atchana.

Regarding the Anatolian origin of the Khirbet Kerak pottery there can be no reasonable doubt; judging by the discoveries of $\mathrm{Kuftin}^{2}$ its original habitat is in the Araxes valley in south Caucasus. Since examples of this pottery are found in the early Hittite 'Royal' tombs of Alaca Höyük, ${ }^{3}$ it is definitely associated with the Hittites, as would seem also to be implied by its presence in Palestine, where, according to the Old Testament, there were Hittite communities surviving as late as the patriarchal period. ${ }^{4}$ In the Caucasus area the pottery belongs to the chalcolithic period but seems to have had a long floruit; in Syria and Palestine, though different excavators have assigned to it very different dates, all agree that it comes in immediately before the Bronze Age proper, i.e. at the end of the chalcolithic. From the south Caucasus area there started one of those mass movements that have on so many occasions upset the economy of the Middle East. Skirting, probably, the foot-hills of southern Anatolia (for no sign of them has been found farther south, in the valleys of the Habur or the Euphrates), they came into the Amq and swerving southwards swept over Syria and Palestine. That they were fighters is shown by the destruction which in Palestine so often was the prelude to their settlement; the fact that they did settle and maintain their identity shows that the fighting men brought their families with them; it was not a raid but a migration. As even a superficial survey of the Amq has sufficed to identify Khirbet Kerak pottery on some fifty mounds, we may conclude that here their settlement was fairly dense as against the scattered communities which appear to have been the rule in Palestine; the Amq indeed may well have become the headquarters of the Khirbet Kerak people or, as I think we should call them, the proto-Hittites. They could, of course, acquire land only by dispossessing the former owners, and they must have done so on a large scale; but there are no grounds for saying that they drove out the old inhabitants entirely; on the evidence available it is at least equally likely that very many of the latter continued to live in their own villages side by side with the victorious interlopers, and the fact that a site like Tell esh Sheikh was not taken over by the proto-Hittites and the apparent fact of some proto-Hittite settlements being new foundations are in favour of this. But by the time that the immigration was complete the proto-Hittites must have been the dominant power in the country.

Their domination, however, was but temporary. The Early Bronze Age is introduced

I For Ugarit v. Schaeffer, Stratigraphie comparée et Chronologie de l'Asie Occidentale, where many other sites are quoted; for the Amq ข. Braidwood, op. cit., but no detailed publication of the main sites, Judaidah and Ta'yināt, is yet forthcoming.

2 B. A. Kuftin, Urarskii 'Kolumbarii' u podoshvy Ararata i Kuro-Araksskii Eneolit, Acad. Sci. U.S.S.R., Tiflis, I 943. 3 Hamit Zübeyr Koșay, Ausgrabungen von Alaca Höyük, Ankara, I 944 .

4 I have dealt with this in Middle East Archacology, Bryce Lecture for I 949, Oxford. 
by a new people with an entirely different culture who sometimes (as apparently at Judaidah) seize and occupy a proto-Hittite site, sometimes as at Alalakh build a new town on virgin soil leaving derelict the ruins of a proto-Hittite town, Ta ${ }^{e}$ yināt, only a kilometre away. ${ }^{\mathrm{I}}$

With their coming all material evidence of the Khirbet Kerak culture disappears. But the fact cannot be taken to mean that none of the proto-Hittite population survived, because it was inevitable that such evidence should disappear. The proto-Hittites were no more civilized than the older inhabitants of the Amq whom they had conquered; they were still in the chalcolithic stage and the only monuments of them that are left are their stone implements (with an occasional bronze) and their hand-made burnished black pots; now they were up against a people much more advanced and their primitive handicrafts could not compete with the superior goods produced by the foundry and the potter's wheel; the complete supersession of the old order does not necessarily mean any more than that. It can be argued with far more probability that a large number of the protoHittites did remain after the conquest. On the other hand, since, as the evidence of the number of 'Khirbet Kerak' sites implies, the plain had been thickly inhabited, many must have been dispossessed by the conquerors. It is tempting to believe that it was this pressure by the Bronze Age people that drove the proto-Hittites-at least the more warlike and recalcitrant of them-southwards into Palestine and also farther to the west and so led to their invasion of Asia Minor; that theory would agree with the fact that in Asia the Hittite capital shifted by stages from south to north until it was finally established at Bogazköy. But that a proportion of them were left behind in north Syria seems to be certain, because only by the fact of the population being mixed can later history be rationally explained. The close political relation that always existed between north Syria and Hittite Cappadocia was due to a pro-Hittite element in the former country whose political views may well have been based on racial affinities; but the conclusive argument is that had there not been in the population of north Syria a Hittite stratum which had throughout history preserved its identity and its traditions there could never have been, after the fall of Bogazköy in the twelfth century, that Syro-Hittite renaissance whose monuments are to be found in the Amq plain and from Carchemish to Hamath; undoubtedly an influx of refugees from Anatolia strengthened at that time the Hittite tradition, but if the tradition had not already existed and been deeply rooted in the sentiments of north Syria, those homeless exiles could have effected nothing.

The population therefore of the Amq plain, or at least of that western part of it which adjoined Alalakh and was to be the kingdom of Mukish, was in the Early Bronze Age composed of three elements-a residuum of the north Mesopotamian Tell esh Sheikh people, 'proto-Hittites' from the Caucasus, and the latest invaders who were the Bronze Age people proper. Who these last were we have not yet the material to decide.

Since no graves of the early period have been found our knowledge of it is derived only from the relatively small house- and temple-areas touched by our excavations, and

I At Ta'yinat there appear to be no occupation-levels between the Khirbet Kerak pottery level and the eighth-century Syro-Hittite palace. 
the ruins have produced a great deal of pottery but very little else; in the lower levels there are practically no metal objects. From Level XVI, right up to Level VIII, the pottery, as will be shown hereafter, is remarkably uniform. All is wheel-made; a fair proportion is painted. The painted decoration, which is perhaps finest in the lowest levels, is virtually confined to a very limited range of shapes, principally jugs and shallow bowls, and for each of them there is an appropriate scheme of decoration which admits of very little variety. One would expect parallels to be forthcoming elsewhere to a pottery so individual and so persistent, but such are very few ${ }^{1}$ and unhelpful in so far as they are relatively late and therefore may illustrate the extension rather than the origin of the Alalakh ware. ${ }^{2}$ Only further excavation in other Middle East sites is likely to throw light on its origin and therefore on the racial character of the Bronze Age people of Atchana; all that we can assert at present is that it is not in any way derived from the painted wares of the chalcolithic inhabitants of the plain from which it differs in toto.

In describing parallels from elsewhere as 'relatively late' I have prejudged the date of the inception of the Bronze Age at Atchana, implying that it is earlier than perhaps some authorities would be prepared to assume. In the absence of other evidence it might, of course, be argued that as Level $\mathrm{H}$ at Hama, which produced potsherds comparable to the Atchana pottery, is dated by Ingholt to 2000 B.c. there is no justification for putting the earliest of the Atchana pieces any earlier than that. Actually they must be very much earlier, but the evidence depends upon the stratification of the site, and the problem of chronology must be deferred until the stratification has been put fully upon record.

\section{(b) THE ARCHAIC LEVELS}

By the close of our 1946 season we had excavated a number of buildings and had found a great deal of material in the form of pottery and other objects belonging to all the upper strata, Levels I to VII, i.e. from $c$. I I 90 to I 800 B.c. and in addition had dug under the south end of Yarim-Lim's palace (Level VII) and had laid bare the very fragmentary ruins of what had once been important buildings of Levels VIII and IX. As it was an essential part of our programme that we should trace the history of the site to its beginning, half of the I 947 season was devoted to this task. Starting with the Level IX buildings already exposed we dug a pit ${ }^{3}$ having an area at the top of some twenty-five metres by thirteen and a depth of 8.30 metres; at this point, which was about $13.75 \mathrm{~m}$. below the top of the Atchana mound, we reached water-level, ${ }^{4}$ and work in consequence had to stop; Fig. 2 shows the complete section. Between Level IX and water-level we cut through seven building strata (Levels X to XVI), one of which was subdivided into three

I By far the closest analogy is with fragments found at Hama (L. Ingholt, Rapport préliminaire sur sept campagnes de fouilles à Hama en Syrie, Pl. xvir, 3) in Level H, which Ingholt dates to $2000-1750$ B.c.

2 Thus some painted bowls from Tarsus Level II (Middle Bronze) closely resemble examples from Atchana Levels VIII and IX which are contemporary. The Habur pottery, which is dated to the fifteenth century, has analogies not with the Atchana Early Bronze Age pottery but with its descendent ware found in Levels VI and V.

3 Squares L-K I $3-15$ in the general plan, Pl. XIV.

4 We were digging in the spring when the water-level is relatively high. 
phases (Levels XII A, B, and C). Since there still remained approximately four metres to virgin soil, we must allow for more building strata as yet unexcavated.

Fortunately, although this pit was our main source of information for the earlier levels and as regards the beginnings of things was inconclusive, circumstances elsewhere enabled us to supplement it in that respect. On the temple site (sqq. N-P I 3-I 5), we dug down to an even greater depth; the tile-paved floor of the lowest building there corresponded exactly in level with Level XVI on the house site and since it was the ninth building-stratum below Level VII could safely be termed Level XVI and correlated

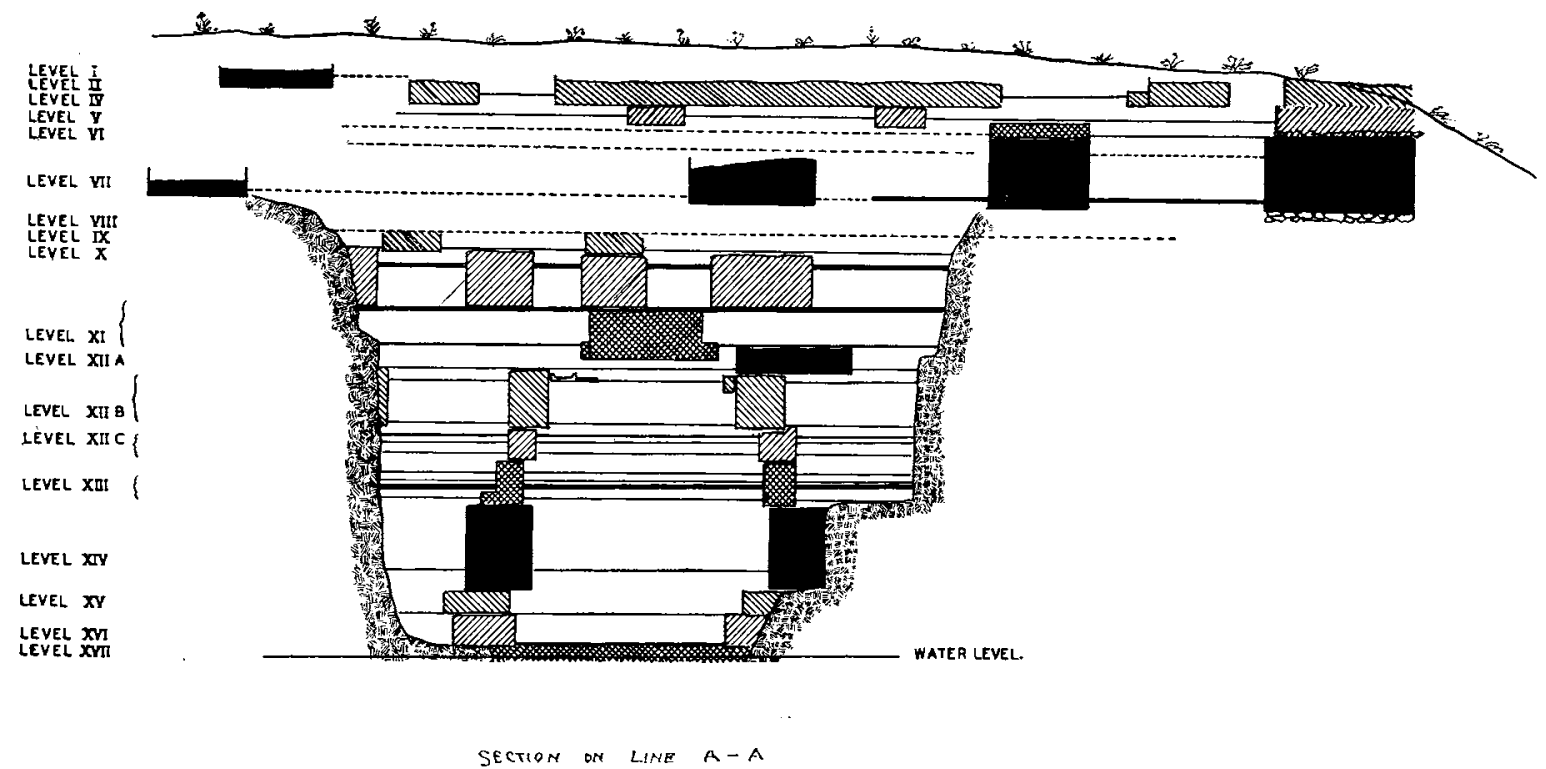

FIG. 2

with the houses; but we dug below that floor to virgin soil and thereby obtained evidence which the 'stratification pit' had failed to produce. Some of the earlier temples yielded good examples of painted and other pottery which conformed with and confirmed the discoveries from the houses. Below Level XVI, where we were digging under waterlevel, it was difficult to observe stratification, but taking the material en bloc as representing one or more phases we could at least say that it illustrated the culture of the first settlers on the site of Alalakh.

Another source from which early painted pottery was freely forthcoming was the embankment supporting the two walls of Level VII, ${ }^{\mathrm{I}}$ but in that case there was no stratification and the sherds were of no help for chronological purposes; their dating depends on the results obtained from our stratification pit.

The building-levels in that pit must now be described, and it will be most intelligible if they are taken in historical order, beginning at the bottom; the analysis of the pottery found in them will be given elsewhere (v. p. 306 ), for to deal with it level by level would 
entail much repetition and would not bring out such evidence as does exist of differences and developments.

\section{LEVELS XVI AND XV (Fig. 3)}

The area excavated was small, only $10.00 \mathrm{~m} . \times 8.00 \mathrm{~m}$; this was due not only to the inward slope of the pit's sides but, still more, to the fact that, in order to save labour in

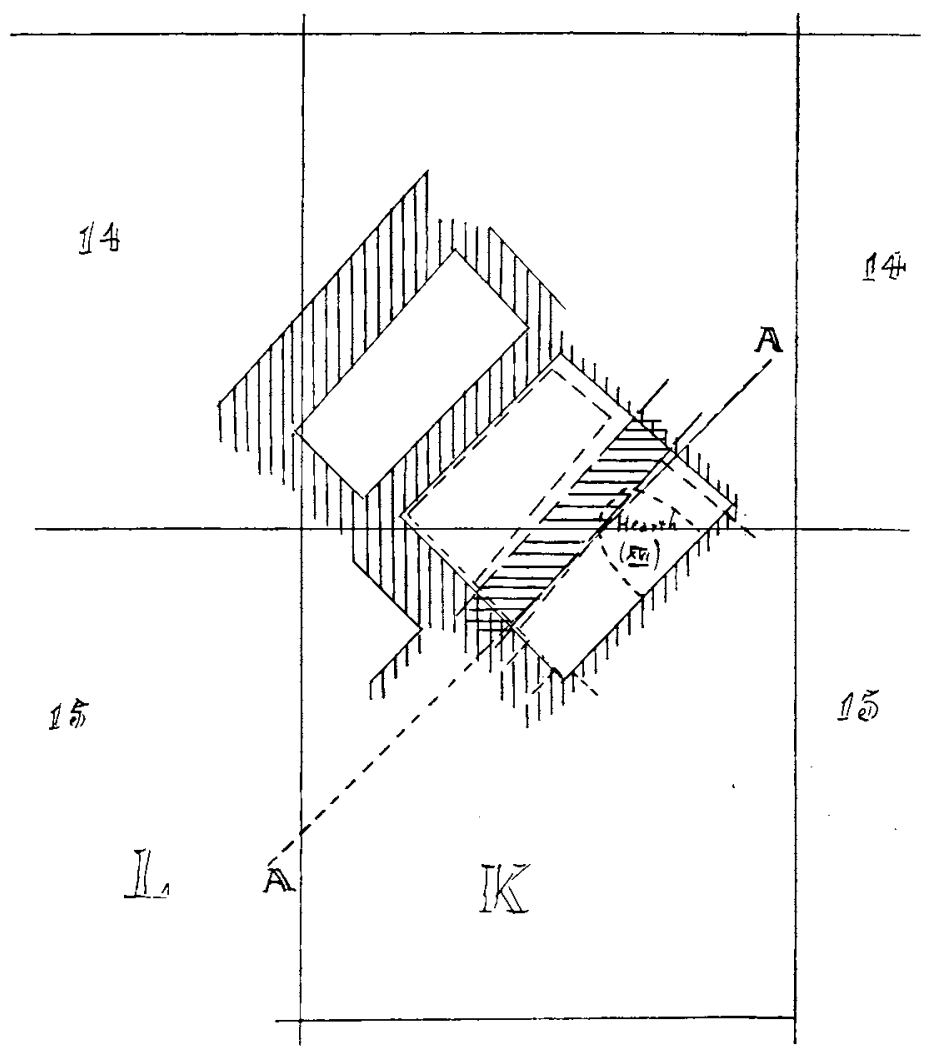

FIG. 3. Levels XVI and XV. I:200

the carting away of earth, only the SE. end of the pit was dug while the NW. end was used as a dump. ${ }^{\text {I }}$ Of the Level XVI building two rooms and part of a third were cleared. The walls, standing to a height of about $0.60 \mathrm{~m}$., were in bad condition, being only just above water-level; the NW. wall was thicker than the others and was probably the outer wall of the house. In the (unfinished) room 3 there was a large oval mud hearth, let into a floor made of mud bricks whose courses ran at a slightly different angle from that of the walls; the surface of the floor lay $0.50 \mathrm{~m}$. above the bottom of the wall-foundations. On the floor were found two clay spindle-whorls (AT/47/I 58), a basalt rubbing-stone, hammer head and hone (AT/47/I 59, I60, I6 I), a curious basalt object which is perhaps a handle (AT/47/I 57), a palette of grey steatite (AT/47/1 76$)$ which resembles the com-

I A further reason was our unwillingness to destroy the columns of the Level XII building. 
mon predynastic Egyptian type, ${ }^{\mathrm{I}}$ and a fragment of a basalt mould, worked on both sides, for casting metal chisels $(\mathrm{AT} / 47 / \mathrm{r} 62)$.

The cross-wall between rooms 2 and 3 was found to rest on an older wall belonging to Level XVII; as this was in water, the excavation was not carried farther.

Level Xv Building (Fig. 3, and Pl. II $a$ ) was to all intents and purposes a reconstruction at a higher level of XVI; rooms 2 and 3 were thrown into one by the omission of the

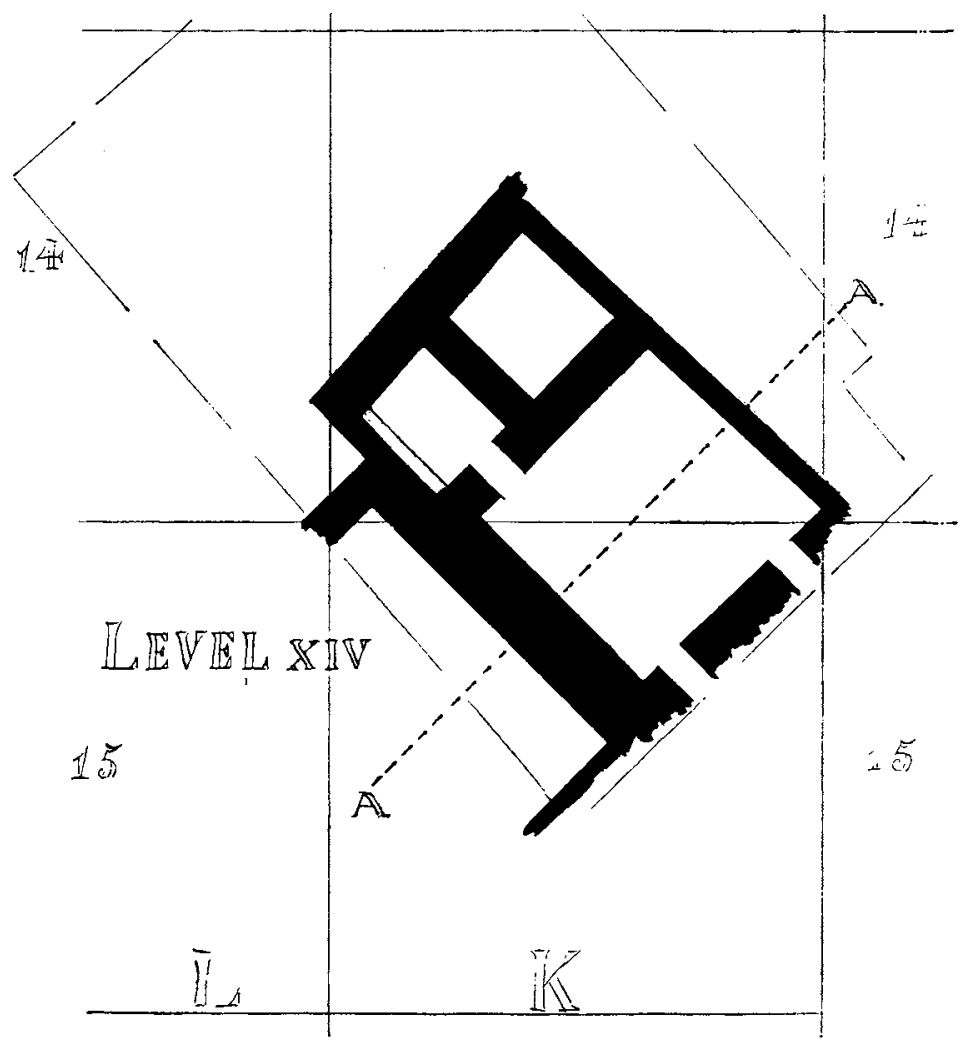

Fig. 4. Level XIV. I:200

cross-wall, but otherwise the new walls were laid immediately on the old; they were slightly thinner, they were standing to a height of $0.40 \mathrm{~m}$., and the bricks measured $0.50 \mathrm{~m} . \times 0.44 \mathrm{~m}$. The NW. wall had been cut into by the pits sunk to take the columnfoundations of Level XII. In the building was found a collection of forty-two small disk beads of white shell (AT/47/I 34) and a basalt rubbing-stone (?) with roughly incised ornament round its sides (AT/47/133, Fig. 80d); these lay on a mud floor, and just below the floor was a flint flake sickle-blade fragment ( $\mathrm{A}^{\prime} \mathrm{T} / 47 / \mathrm{I} 53$ ).

LEVEL XIV (Fig. 4), gave us part of what seems to have been a courtyard house having small rooms at the NW. and SE. ends of a large open (?) court; the size of this, $4.60 \mathrm{~m}$. $\times$ 
$4.90 \mathrm{~m}$, is against its having been roofed, but, on the other hand, the wall surfaces were covered with a heavy lime wash, which was not the case with the smaller rooms, and one would have expected such a treatment on an internal rather than on an external wall. The thick SW. wall was curiously built with an inner skin of mud bricks measuring $0.50 \mathrm{~m} . \times 0.44 \mathrm{~m}$. and an outer skin of bricks $0.34 \mathrm{~m} . \times 0.27 \mathrm{~m}$. between which was a core of broken mud bricks in mud mortar; its total width was $1.45 \mathrm{~m}$. No brick rubble was used in the other walls. In the west room there was a narrow brick bench along the SW. wall. The building was well preserved, standing to a height of about $\mathrm{I} \cdot 40 \mathrm{~m}$.; the floors were of beaten mud. In the rooms were found several bronze objects, one being a pin with spiral head ('Type P. I I, AT/47/I I 5), a fragment of a plain-headed eyeleted pin (Type P. 3), a heavy nail (AT/47/I I6), part of a chisel (?) (AT/47/I 20) and slender fragments probably from the shafts of pins, a fragment of a lead pin resembling one (probably of the same date) found in the filling of the great temple pit of Yarim-Lim (AT/47/I 45), a chert flake with slight secondary working (AT/47/I $2 \mathrm{I}$ ), and a terra-cotta figurine of a ram with curling horns $(\mathrm{AT} / 47 / \mathrm{I} 24)$ and a basalt hammer grooved for hafting (AT/47/ I 37 ); also examples of the clay bowl Type I 3 .

LEVEL XIII (Fig. 5 and Pl. III $a$ ) supplies a much more interesting plan, mainly because the area excavated was much larger, measuring $20.00 \mathrm{~m} . \times \mathrm{II} \cdot 50 \mathrm{~m}$., the full extent of our pit at this depth. We found a considerable part of one large house and one room of a second house separated from the first by a lane or open space.

The building at the NW. end of our pit must have been an important one, for the only room of it excavated was $3.90 \mathrm{~m}$. wide and more than $7.40 \mathrm{~m}$. long; the walls, which were standing to a maximum height of $\mathrm{I} \cdot 40 \mathrm{~m}$. above floor-level, were well built and coated with a thin lime plaster; the floor was of clay set over a foundation of a single course of neatly laid potsherds. ${ }^{\text {I }}$ In the east corner of the room there was a pot-basis rising five centimetres above the floor built, before the floor was laid, with $0.07 \mathrm{~m}$. of puddled clay topped by a hard black clayey mixture $0.02 \mathrm{~m}$. thick; in the flat top of it was a hollow for the pot, diam. $0.25 \mathrm{~m}$., $0.04 \mathrm{~m}$. deep. At the NE. end of the NW. wall there was a doorway $0.83 \mathrm{~m}$. wide with projecting jambs which must have given it something of a monumental appearance (PI. II $b$ ).

To the south-east of this building there was what seemed to be a lane (marked ' 2 ' on the plan) and then the irregular frontage of another house or houses-the change in the alignment of the façade and the fact that there is no communication between the part containing rooms 5 and I I implies that there was a row of attached buildings.

The main house-plan (Fig. 5) gives us a central room, Io, probably an open court, with two rooms at its NW. and two at its SE. ends and four more rooms (if those indeed belong to the same house) along its SW. side. The plan therefore is similar to that of Level XIV and deliberately reproduces it, the walls being based on the levelled tops of the walls of the older building, though they are not of the same thickness. The floors of the rooms lay I $40 \mathrm{~m}$. above those of Level XIV and were virtually flush with that of the

I An old-established practice; we find it not uncommonly in the houses of the chalcolithic period at Tell esh Sheikh. 
other building north-west of the lane, being only $0.05 \mathrm{~m}$. higher than it. During the lifetime of the building the floors were relaid at a higher level.

Room Io, the central room, had a pavement of mud bricks $0.45 \mathrm{~m}$. square; against the NW. wall was a low brick bench $0.10 \mathrm{~m}$. high and $0.07 \mathrm{~m}$. wide; the walls were

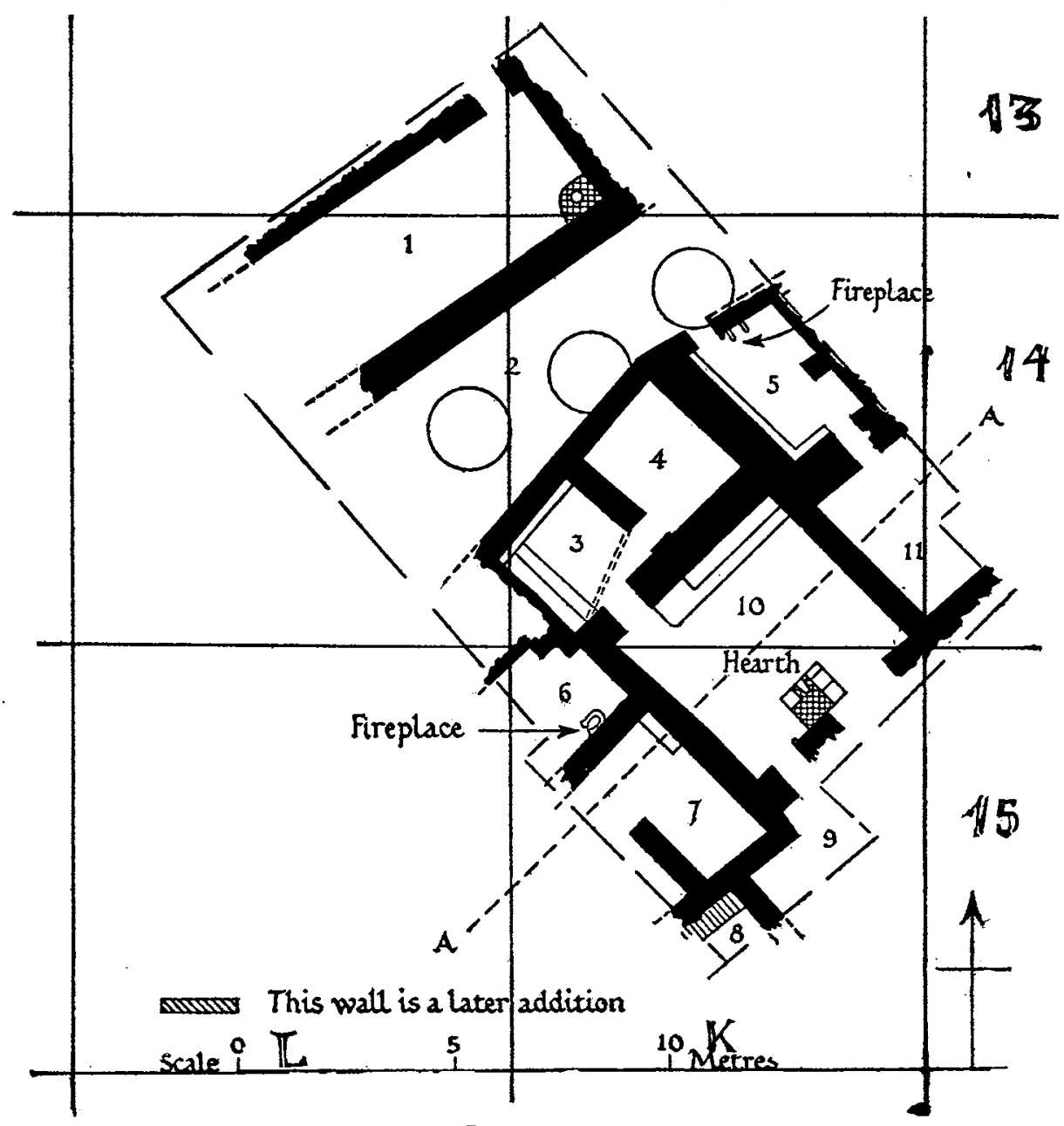

FIG. 5. Level XIII. I :200

covered with a lime wash. Against the SE. wall, partly blocking an unusually wide doorway (?), there had been a hearth of which only the base was preserved. The brick pavement was not an original feature, for the whitewash on the wall continued down below the pavement level, and that pavement lay $0.30 \mathrm{~m}$. above the threshold of the door leading into room 3 and therefore $0.40 \mathrm{~m}$. above room 3 floor. But it was itself superseded later; a new mud floor was laid down $0.25 \mathrm{~m}$. above it; against the $\mathrm{NW}$. wall a new bench was built, $0.40 \mathrm{~m}$. wide and standing $0.20 \mathrm{~m}$. above the new floor, and the walls were replastered, this time with a greenish mud plaster about a centimetre thick. The details are of interest as showing that the house must have been in use for a reasonably long time. 
On the SE. wall, against the corner of the $\mathrm{NE}$. jamb of the doorway leading to room 9, there was a semicircular projection, like an attached pilaster, $0.16 \mathrm{~m}$. in diameter and

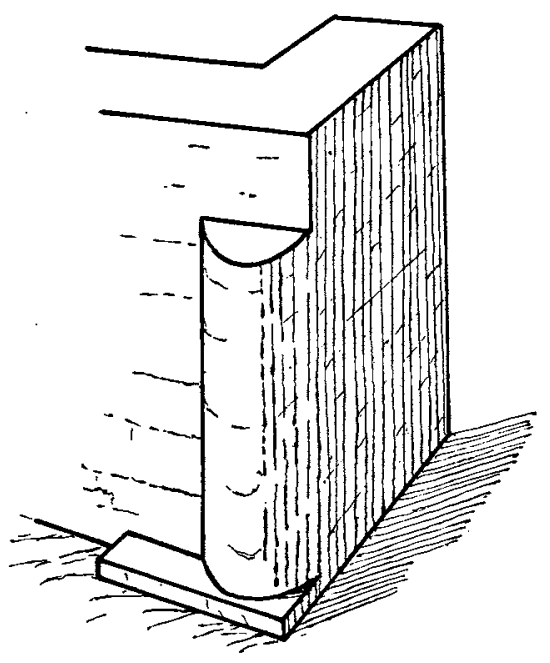

FIG. 6 standing I. I $5 \mathrm{~m}$. high; it had a flat top and above it the wall-face was plastered, so that it can never have been higher than it is now. It probably served as a lamp-stand; v. Fig. 6.

Room 3 had (originally) a clay floor $0.10 \mathrm{~m}$. lower than the threshold of the doorway into room Io; against the NW. wall was a bench (or offset in the wall-construction) $0.20 \mathrm{~m}$. above floor-level, ${ }^{\mathrm{r}}$ and against the NE. wall a narrow shelf or off-set $0.60 \mathrm{~m}$. above the floor. The walls, standing $I \cdot I 5 \mathrm{~m}$. high, were lime-washed. Diagonally across the room there ran a $\circ .1 \circ \mathrm{m}$. high mud coping which looked as if it had been intended to prevent water spilled upon the floor from running on to the passage-way between the two doors.

Room 4 had no features of interest.

Room 6 had a clay floor $0.50 \mathrm{~m}$. below the level of the brick pavement of room I 0 . On the floor was a circular clay fire-place, $0.30 \mathrm{~m}$. high, open in front and flat-topped-i.e. it had not been domed as an oven but had had cooking-pots placed on it; it was $c .0 .30 \mathrm{~m}$. in diameter (Fig. 7). Room 7 had a bench in its north corner. The walls, which were not based on those of Level XIV, had very deep
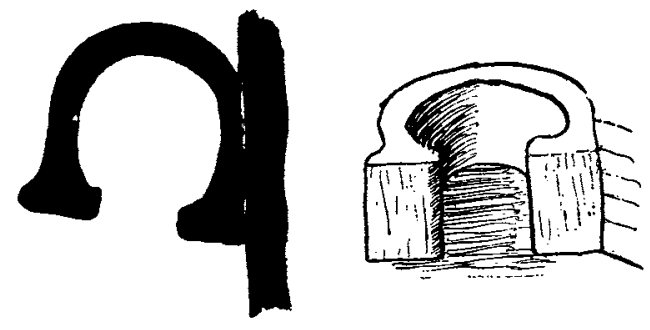

FIG. 7 foundations going down $0.70 \mathrm{~m}$. below floor-level; a secondary floor above the fire-place was of gritty concrete $0.10 \mathrm{~m}$. thick. Rooms 8 and 9 were not excavated. Room 5, apparently a separate building, had a doorway on to the lane (2). Against the NW. wall, by the door, was a brick fire-place consisting of two projecting side-pieces $0.40 \mathrm{~m}$. high and $0.55 \mathrm{~m}$. apart. In the middle of the NE. wall there was a pilaster. In the brick jamb of the doorway into room I I there remained the semicircular impression of the wooden door-frame upright. Along the SW. and SE. walls there ran a brick off-set which was apparently only a thickening of the wall-foundation because it was on the same level as the base of the fire-place. The pilaster was not architectural, for it stood only $\mathrm{I} \cdot 30 \mathrm{~m}$. high, as was proved by the fact that the greenish plaster of the wall-facing was preserved above it on the flat face; it was therefore a pedestal, possibly for a lamp. Room I I had no features of interest.

The most important object found in the building was a cylinder seal of black steatite (AT/47/I 22; Pl. LX, No. I) engraved with a banquet scene, two persons drinking through tubes, and an attendant, a type characteristic of the Sumerian Early Dynastic

I There was a second off-set $0.40 \mathrm{~m}$. below the floor which was really the stump of the Level XIV wall on which the new wall had been built. 
period. The bronze objects were a pin with spirally coiled head (Type P. I I AT/47/ I 00), one with flattened plate head and eyeleted shaft, Type P. 5, broken (AT/47/ I I 9 ), one with plain knob head, Type P. 3 (AT/47/104), a plain pin (AT/47/108), and a stout hook of uncertain use (AT/47/I I I). There were five bone awls (Fig. 77), simple pieces of animal bone cut to a point but otherwise unshaped (AT/47/I I 4); also a terra-cotta animal's head (AT/47/Io6, Pl. LVII $h$ ) and the head of a female figurine (AT/47/ I 25) modelled in the 'snow-man technique', together with a small fragment of another head.

LEVEL XII (Pl. III $b$ ) seems to witness to a social change at Alalakh almost amounting to a revolution. It was remarked that in Level XIII the building at the NW. end of the excavation was, judging by the size of the one room cleared by us, a building of some importance; if it was a private house it must have been that of a relatively rich man. But in Level XII its place is taken by something vastly more pretentious in itself, and in order to give it the dignity of isolation the houses on the SE. side of the lane were cut back and their NW. rooms destroyed so as to create an open space.

As a foundation for the new building (Fig. 8) the long room of Level XIII was filled in solidly with mud bricks $0.44 \mathrm{~m}$. square and $0.082 \mathrm{~m}$. thick to a depth of $\mathrm{I} .75 \mathrm{~m}$., filling the room and carried over the top of the standing wall, which had been trimmed to a height of $\mathrm{I} \cdot 25 \mathrm{~m}$. Along the front of this platform was built a mud-brick wall $2.25 \mathrm{~m}$. thick; behind it, on the filling, were laid three courses of paving-bricks $4.85 \mathrm{~m}$. sq. and the pavement was drained by a drain through the wall's thickness, at first a mere hole, but half-way through the wall there was put a roughly cut white stone channel which sloped down to the south and projected $0.30 \mathrm{~m}$. beyond the wall's face; the channel was $\mathrm{I} .60 \mathrm{~m}$. long. The limits of the paved court to the north-west and south-west were not found, but on the north-east there was a heavy cross-wall which met the containing wall and had corresponding to it a shallow buttress on the outer face of the latter. Outside the building there was a row of mud-brick columns (Pl. IV a). Four columns were found; they did not form a continuous row but were in pairs; two stood $1.75 \mathrm{~m}$. apart at $0.90 \mathrm{~m}$. from the wall-face; to the north-east, at an interval of $\mathrm{r} .75 \mathrm{~m}$., came two more, but these were only $0.90 \mathrm{~m}$. apart and were set back $0.40 \mathrm{~m}$. and came against the angles of the buttress already mentioned, the brickwork of which had been trimmed to allow of their construction; they appeared therefore as engaged columns. From the columns southwards the area was paved with a single course of mud bricks measuring $0.485 \mathrm{~m}$. sq. and $0.085 \mathrm{~m}$. thick; against the façade of the southern building, in the recessed part, the character of the pavement changed, the $0.485 \mathrm{~m}$. sq. bricks giving place to one row of bricks $0.43 \mathrm{~m} . \times 0.20 \mathrm{~m}$. and then two rows of bricks $0.50 \mathrm{~m} . \times 0.29 \mathrm{~m} . ;$ in the second recess at the NE. side of the excavation two other types of brick were used, one $0.405 \mathrm{~m}$. sq. and one of $0.30 \mathrm{~m} . \times 0.23 \mathrm{~m}$.; clearly these varying types were chosen for convenience in filling odd corners.

Columns are a feature so unexpected in a north Syrian building of this early period that a detailed description of them is necessary; see Fig. $9 a$. 
The builders first dug circular holes for the foundations which, owing to the nature of the soil here-mixed rubbish containing a great deal of broken pottery-had to be deep; in the case of the free-standing columns B and C they went down about $2.50 \mathrm{~m}$.

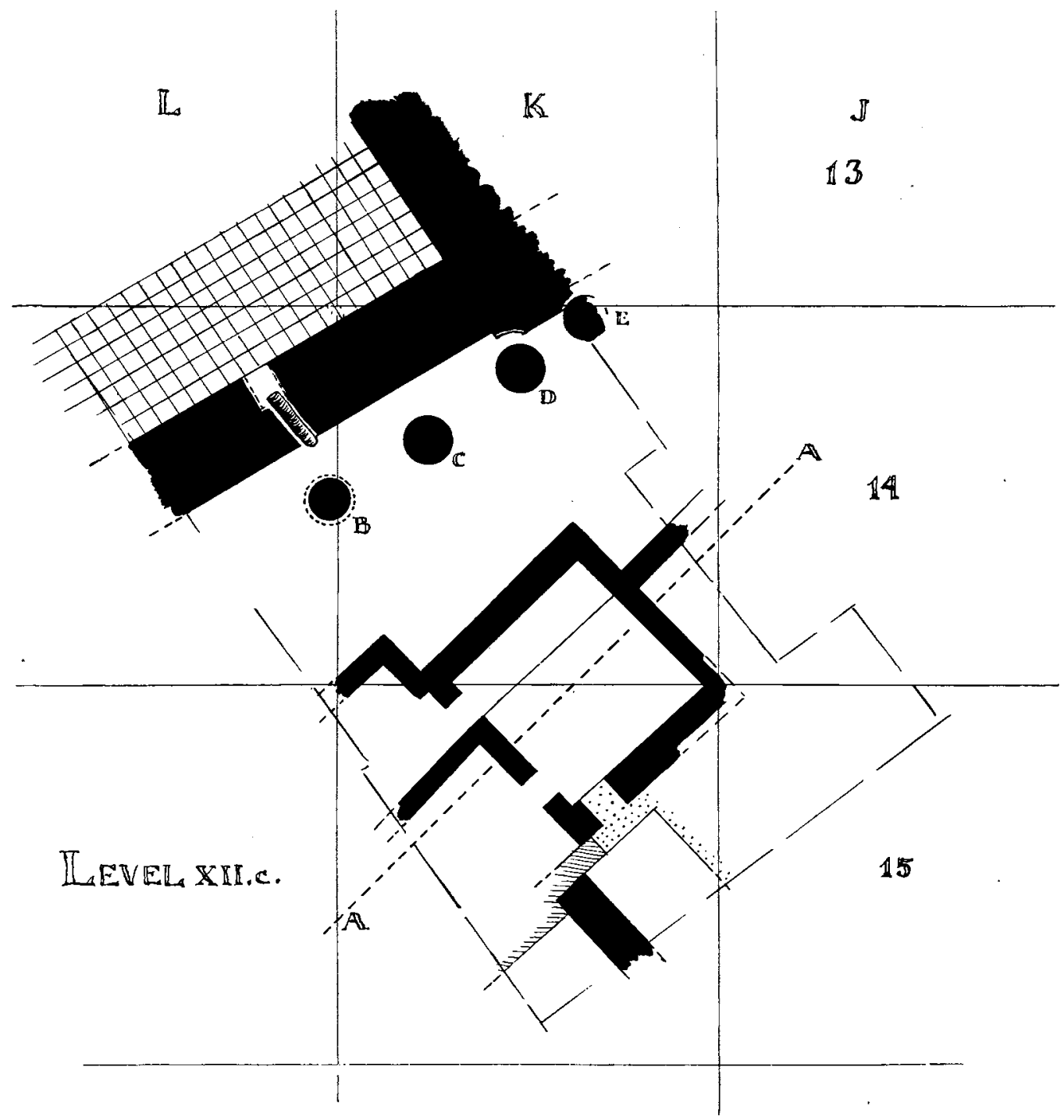

FIG. 8. I:200

through Levels XIII and XIV, in the case of the attached columns D and E to little more than $\mathrm{I} \cdot 70 \mathrm{~m}$. Unfortunately the line of the first two coincided with the frontage of a buried wall (of Level XV?), so that while the NW. half of the foundation rested on solid brickwork, the SE. half had beneath it only loose earth and potsherds and ashes. In the hole they put a foundation of puddled clay, $0.30 \mathrm{~m}$. to $0.40 \mathrm{~m}$. thick, and on this bricks of greenish clay measuring $0.36 \mathrm{~m}$. sq. $\times 0.075 \mathrm{~m}$. with a curved outer face were laid in the form of a circular drum whose diameter was $\mathrm{r} \cdot 85 \mathrm{~m}$. for column $\mathrm{B}, \mathrm{r} \cdot 65 \mathrm{~m}$. for 
column $\mathrm{C}(\mathrm{Pl} . \mathrm{V} a)$, and $\mathrm{r} \cdot 90 \mathrm{~m}$. for column $\mathrm{D} ;{ }^{\mathrm{I}}$ but whereas the sides of column $\mathrm{B}$ were vertical, the other two columns show a marked bulge near the base of the foundation and then an inward slope reducing the diameter at ground-level to $\mathrm{I} .50 \mathrm{~m}$. and at a metre or so above ground-level to $\mathrm{I} .25 \mathrm{~m}$., which seems to have been the diameter of the shaft proper $;^{2}$ above ground-level the shafts were built with bricks slightly radial in form, $0.4 \mathrm{I} \mathrm{m}$. long and in width diminishing from $0.40 \mathrm{~m}$. at one end to $0.37 \mathrm{~m}$. at the other.

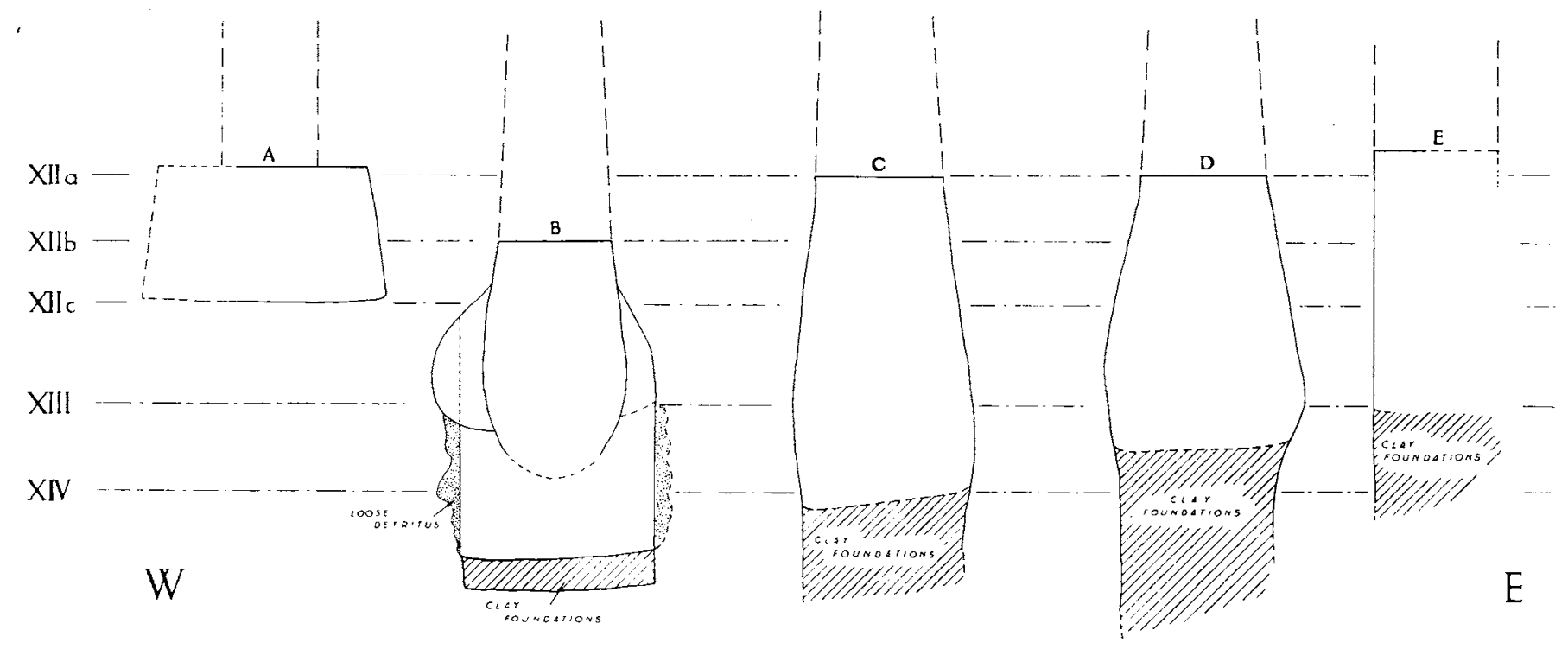

WEST-EAST SECTION OF THE COLONNADE IN THE DEEP CUT (AT/47)

FIg. $9 a$

The natural weakness of the foundations due to the character of the subsoil was increased in the case of column B by the lack of foresight on the part of the builders who laid the drain-pipe from the paved court directly against the column $;^{3}$ the result was that both columns $B$ and $C$ began to lean outwards to the south, $B$ to an extent that was positively dangerous. A first attempt to correct this was made by adding a skin of brickwork to the north side of the base-presumably the shaft was taken down and rebuilt on this broader foundation. But the movement continued, and in time the clay foundation of the column was so tilted that it was $0.50 \mathrm{~m}$. out of the straight. Then more radical steps were taken. Column $C$ was cut down, its stump trimmed to a level, and a new shaft built on it. For column B a new foundation-pit was sunk in the solid brickwork of the old base, a round-bottomed pit with slightly in-sloping sides in which the new bricks

I Column $\mathrm{E}$ was only partly excavated, as it lay on the extreme limit of our pit, so that its exact diameter below ground-level could not be taken.

but this is due to rebuilding; the original shaft has disappeared.

3 'The colour of the soil here proved it to have been per-

2 The diameter of the shaft of column B is only $\mathrm{I} \cdot 00 \mathrm{~m}$., manently sodden. 
were laid to rise vertically to the shaft, ${ }^{\mathrm{I}}$ in horizontal courses which disregarded the slope of the surrounding brickwork (Fig. $9 b$ and Pl. IVb).

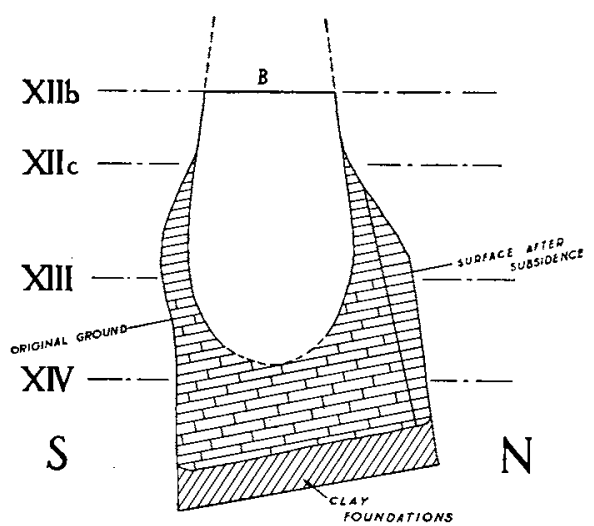

SOUTH-NORTH SECTION OF COLUMN B

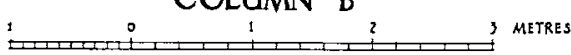

FIG. $9 b$

This description, here given as a whole so as to avoid repetition later, anticipates events, for the rebuildings took place only at intervals of time which saw many other changes; the length of those intervals cannot be fixed, but the total life of the columned building was undoubtedly long. The depth of the column-bases might be thought to be evidence for their having been constructed first in Level XIII (such was indeed our first idea), but it is conclusively countered by the fact that in sinking the pits for the foundations the builders cut into and almost cut away the NW. wall of the Level XIII house; a comparison of the ground-plans is quite enough to demonstrate the correctness of attributing the columns to the Level XII building when the NW. rooms of Level XIII had been razed and the stumps of their walls buried out of sight.

The unsymmetrical arrangement of the columns is, of course, apparent only, due to the fact that so small a part of the total façade of the building has been excavated. A reasonable explanation of it would be that the buttress with its attached columns is one jamb of a monumental entry which was flanked by two free-standing columns on either side; the thickness of the NE. wall would agree with its being a semi-external wall enclosing the entrance porch or passage. This explanation receives a certain amount of support from the history of the site. The building lies immediately below the Level VII palace of Yarim-Lim, of which we have the general plan, and between the two come the only partially known buildings of Levels XI, X, IX, and VIII, all of which are buildings of quite unusual importance. It would be inherently likely that Yarim-Lim's palace should occupy what was traditionally the site of the royal palace of Alalakh. 'That all are similarly orientated is true, but cannot be stressed as an argument because in the layout of the town the alignment was consistent throughout its history ${ }^{2}$ but it is noteworthy that such an entry as I have suggested, central to the building, would come exactly in the centre of the area occupied by the palace of Yarim-Lim. The coincidence is striking; but it must be borne in mind that Yarim-Lim's palace fills the whole space between the city wall on the north-east and the temple on the south-west; the line of the city wall can be taken as constant, and since the Level VII temple stood on a traditional site where there had been older temples going back as early as Level XVI, the intermediate area available for a palace would have been of the same dimensions NE. $\times$ SW., and a position central to Yarim-Lim's building would have been equally so for a building of Level XII. The

\footnotetext{
I As the new bricks were of a reddish colour contrasting with the greenish bricks of the original the section showed very clearly the phases of construction; see the photograph
}

on Pl. IVb.

2 An exception, so far as we know the only exception, to the rule was the Level IV palace of Niqme-pa. 
reconstruction is therefore plausible, and without unduly straining the evidence we may adopt the working assumption that the columned building is the royal palace of the period.

In working out the stratification it seemed best to identify Level XII with the palace, i.e. to take the lifetime of the palace as fixing the limits of the period represented by the archaeological level. To the south-east of the colonnade there are, corresponding to the palace, three distinct building strata, the private houses there having been constructed and twice reconstructed at different levels, so that it would have been possible to speak of three levels instead of one; but the fact that the palace was contemporary with all three gives a unity which could scarcely be disregarded. It is true that the palace itself was repaired and even remodelled, but it preserved throughout its outstanding feature of the colonnade and to that extent at least was the same palace. We therefore gave the one number, Level XII, to the whole stratum, which was $2.28 \mathrm{~m}$. thick, but subdivided it into Levels XII A, B, and C, these being in the order of discovery.

LEvel XII C (Fig. 8). The palace was as described above. The paved area in front of it ran right up to the walls of the private houses. These were on the same lines as the houses of Level XIII except for the omission of the NW. rooms; their earliest floors lay $0.70 \mathrm{~m}$. above the brick floors of Level XIII, but their walls were based on the brickwork of the old walls. ${ }^{\mathrm{I}}$ The walls stood to a height of $0.60 \mathrm{~m}$., and the rooms showed no less than three floors, all of clay; the lowest was $0.13 \mathrm{~m}$. thick, then came $0.22 \mathrm{~m}$. of mixed rubbish, a clay floor $0.08 \mathrm{~m}$. thick, three centimetres of rubbish, and a top floor $0.04 \mathrm{~m}$. thick; it might be interpreted as evidence of gradual impoverishment. The doorway in the SE. wall of the main room was blocked at the time when the later floors were laid, and beyond it to the south-east there were signs of further changes of plan-there was at least a change of brickwork-but nothing of which we could make sense. No objects other than pottery were found in the rooms, nor had they any features of interest.

LEVEL XI в (Fig. Io). The front wall of the palace was razed and rebuilt on the old foundations but without the projecting buttress; behind it the floor-level was raised by $0.60 \mathrm{~m} . ;$ on the floor lay a large stone, roughly squared, which was apparently in situ, but its purpose could not be understood. In front of the palace the old open space was now largely built up, the houses encroaching upon it by the addition of new rooms and completely spoiling the monumental effect of the colonnade; moreover, the remaining space was filled up to a depth of nearly a metre with rubbish containing a very high proportion of pottery. None the less the columns continued in use, and it is probable (though not certain) that the first patching of the columns and rebuilding of column $B$ date from this phase.

I This reconstruction, with the old walls used as foundations, seems to imply that town houses conformed to a more or less stereotyped traditional plan. The area available for a house site was, of course, in a crowded city, limited by the rights of neighbouring house-owners, and since the site of the new building would be the same as that of the old, the ground-

plan, being traditional, could not depart much from the old. That being so, there was every advantage to be gained by using existing wall-stumps as foundations. No chronological argument can be drawn from such rebuilding on identical lines. 
The houses, built with mud bricks $0.43 \mathrm{~m}$. sq. $\times 0.09 \mathrm{~m}$. thick, were enlarged during the period by the addition of room $I O$, and at the same time there were alterations at the SE. end where, at the limit of our excavation, a long wall was built with a branch

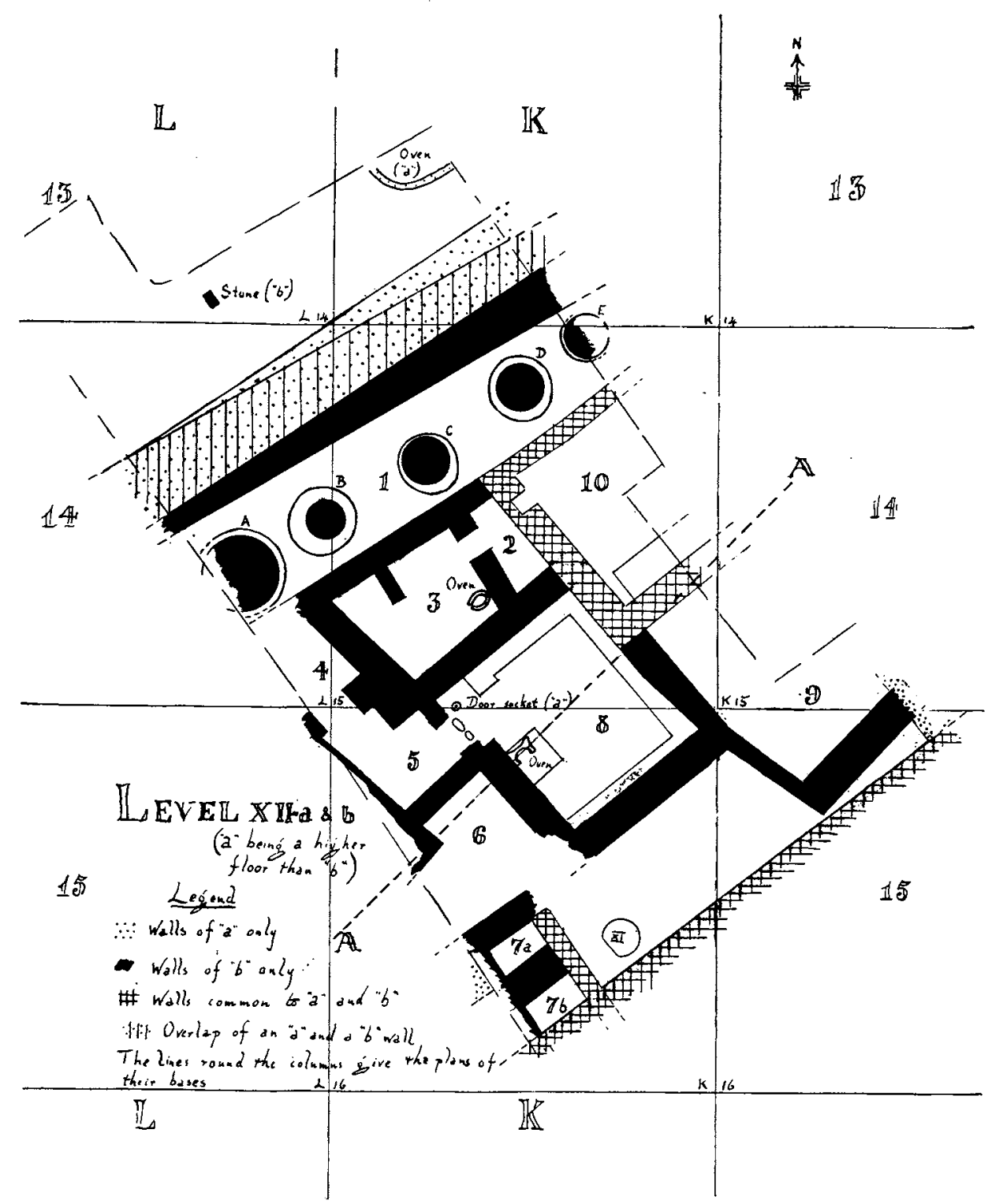

FIG. IO. I:200

incorporating two very small rooms, $7 a$ and $b$. The central part of the main building, room 8, was taken over from Level XII c; the walls of the room, like all the walls throughout the house, were coated with lime plaster; along three of them ran a brick bench $0.12 \mathrm{~m}$. high. The floor, which sloped from west to east, was black, smooth and hard, made, apparently, of a mixture of mud containing chopped straw, wood ash, and cow- 
dung; ${ }^{I}$ it had been four times relaid, the four layers giving a vertical thickness of $0.15 \mathrm{~m}$. The threshold of the doorway to room 5 had been strengthened by a sill made of two parts of a broken saddle-quern. Close to the door, against the SW. wall, there was a baked clay fire-place standing on a square base $0.15 \mathrm{~m}$. high; the walls of it were $0.19 \mathrm{~m}$. high (Fig. I I). There seemed to be no communication with the two rooms 2 and 3 which (perhaps because there had been no building here in Level XII c) lay at a lower level, the floors being nearly $0.40 \mathrm{~m}$. below that of room 8 . In room 3 there was an oval clay oven with a narrow opening and a flat top, $0.40 \mathrm{~m}$. high (Pl. $\mathrm{Vb})$. In room io the floor was of the same composition as that in room 8 ; in the $\mathrm{SW}$. wall there was a small cupboard-like recess in which were found fragments of pot of buff clay and about fifty loom-weights of lightly baked clay.

LEVEL XII A (Fig. IO). The façade wall of the palace was again rebuilt; it was slightly set back and re-aligned, the angle being

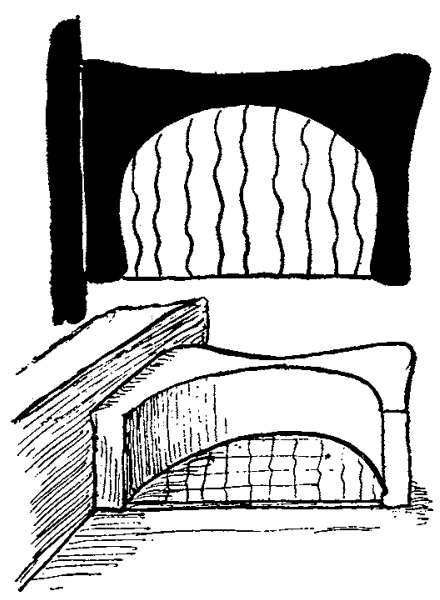

FIG. I I somewhat more exactly NE. by SW.; behind it was a clay floor, raised I $\cdot 20 \mathrm{~m}$. above the floor of Level XII B, on which was an oven, $0.85 \mathrm{~m}$. high, built of bricks $0.37 \mathrm{~m} . \times$ $0.19 \mathrm{~m} . \times 0.10 \mathrm{~m}$. It was at this time (or earlier?) that column $\mathrm{B}$ was rebuilt for the second time, the foundations for the new shaft being cut into the brickwork of the old, and it was probably now, too, that the colonnade was prolonged, a new column being added at the SW. end of the row-on the ground-plan this column looks disproportionately big, but only the foundation ${ }^{2}$ is left and it would probably measure a good deal more in diameter than the shaft, so that the latter may have been on the same scale as the old columns. The rebuilding of the palace in an embellished form must imply the greater prosperity of the ruling family, and a natural corollary of it was the sweeping away of the private buildings which had encroached upon and marred the dignity of its predecessor. ${ }^{3}$ Room Io of Level XII в .was preserved as an isolated structure for some purpose or other, but nearly everything else was razed to the ground and a floor laid down over the whole area; this floor was of the same black composition found in rooms 8 and $\mathrm{r} O$ of the old building and it was twice renewed, giving a total thickness of $0.30 \mathrm{~m}$; t the original surface lay $0.70 \mathrm{~m}$. above the Level XII в floor of room 8. The long wall at the SE. end of our excavated area remained together with the (late) XII в branch, and just an angle of a new XII A wall was found apparently connected with it, but could not be followed up; but

I Floors of this composition were made until recently in north Syria; the surface was pebble-burnished and the floor was virtually water-proof, so that it was used for'bathrooms, \&c.; I had one laid at Carchemish. We could not be sure that the Level XII в floor had been burnished.

2 This rests on the floor-level of XII $c$; the construction might therefore date $D$ the latter part of the period of Level XII в.
3 The degradation of the palace in the Level XII в period was shown by the fact that the lower part of the columnshafts was buried in rubbish-ashes, household refuse, and broken pottery-whose regular stratification proved that it had accumulated gradually; the palace colonnade therefore was used as a midden. The Level XII a floor was laid over this rubbish. 


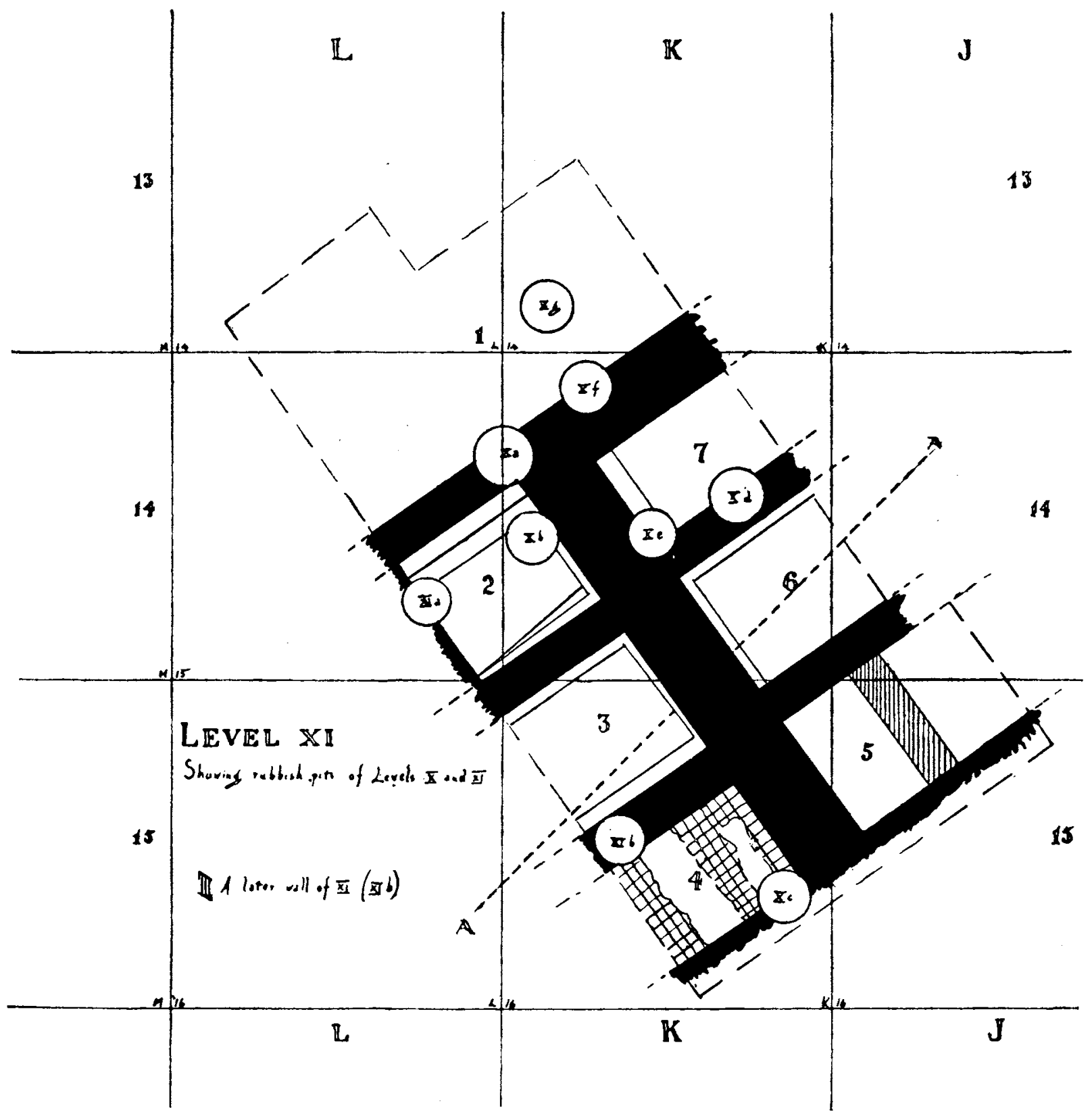

FIG. 12. 1:200 
apart from this there was a wholesale clearance leaving a wide open space in front of the palace. ${ }^{\mathrm{I}}$

On the XII a floor, immediately above one of the buried walls of XII в, was found a standard lamp of coarse-grained basalt having a shallow bowl on a trefoil pedestal (AT/47/45, Fig. 80) which might be a prototype of the Cretan examples with "quatrifoil' stems ${ }^{2}$ in a later age. A number of bronze fragments were found in the filling of the colonnade; two silver objects, a thick rod with flattened and coiled end (AT/47/87) and a pin (AT/47/85), two bone awls (AT/47/48 and AT/47/88, Fig. 77), a fragment of obsidian (AT/47/9I), and a clay sling-bolt (AT/47/I I 0 ) belonged to the level, and the upper part of a clay 'goddess' figurine, AT/47/63.

LEVEL XI (Fig. I 2 and Pl. VI $a$ )

From the highest floor of Level XII A to that of Level XI the rise was $c .2 .25 \mathrm{~m}$; at the bottom of the foundations at Level XI it was only $0.48 \mathrm{~m}$. The new building shows a complete change of plan. At the NW. end of our excavation, where the palace façade had been, we found no walls at all; it was an open space, perhaps an interior courtyard, and where there had been private houses with small rooms and relatively thin walls we find a single complex with large rooms and walls of a most solid character ranging in thickness from $\mathrm{I} \cdot 40 \mathrm{~m}$. to $2 \cdot 30 \mathrm{~m}$. This was not the case of the reoccupation of a deserted site; on the contrary, the palace and the houses of Level XII a had been deliberately pulled down and the area cleared expressly for a new building which we can assume to have been in its turn a royal palace on a larger scale.

The wall-foundations were generally stepped out with one, two, or even three off-sets to give them greater width and solidity; the brick-laying was very good and much care was shown in bonding. The mud bricks measured $0.43 \mathrm{~m}$. sq. (a few were $0.44 \mathrm{~m}$.) by $0.06-0.07 \mathrm{~m}$. thick, and there were halfbricks $0.43 \mathrm{~m} . \times 0.24 \mathrm{~m}$.; rather thick mortar was used, about half a centimetre in the vertical joints and more between courses, three courses of bricks giving about $0.24 \mathrm{~m}$. of wall height. The foundations went down $\mathrm{r} \cdot 80 \mathrm{~m}$. below floor-level as given by the brick pavement in room 4 ; in some of them a different type of mud brick was used, measuring $0.39 \mathrm{~m}$. in length and $0.075 \mathrm{~m}$. in thickness ( 4 courses to $0.33 \mathrm{~m}$. of wall height). The section on Fig.

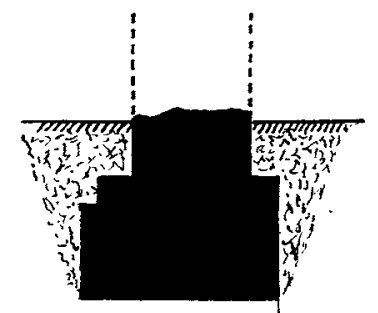

FIG. I 3 13 shows the character of the off-sets which increase the wall thickness to $2.00 \mathrm{~m}$. Only in room 4 was the pavement at all well preserved; it was of burnt bricks $0.32-0.33 \mathrm{~m}$. sq. and $0.07 \mathrm{~m}$. thick with frog-holes on the lower surface. In room 3 there were a few bricks from a similar pavement (at a level $0.10 \mathrm{~m}$. below that of room 8) and also in room 2, but nearly all had disappeared. There were, too, a few voussoir bricks of the sort to be described in connexion with Level X; several were on floor-level, but in room 2 
some were found at nearly $2.00 \mathrm{~m}$. below what had been the level of the pavement; either they belonged to Level XII (for which there is no supporting evidence) or they had been dropped by the Level XI builders when they were preparing the terrain for their building.

The walls of the palace had been razed down to and in some places below the floorlevel, so that few objects were likely to be found in situ; apart from potsherds there was the head of a terra-cotta 'goddess' figurine (AT/47/40, Pl. LV), a fragment of a male figurine (AT/47/49) and a chalcedony bead (AT/47/18); and, much more important, part of a jar-sealing in black clay bearing the impression of a cylinder seal engraved in the style of the end of the Early Dynastic or the beginning of the Sargonid period (AT/47/27, P1. LX, 5); this lay on the floor of room 2, i.e. at the level of the brick pavement but on the soil from which the bricks had been removed; it must have come there at the time of the destruction of the pavement, i.e. when the foundations of Level X were being laid.

There was evidence to show that although the palace had been so thoroughly destroyed it was not the case of a standing building being demolished to make room for a new; it had fallen into ruin before any new work was taken in hand. The site was pierced by a number of rubbish-pits most of which could be dated to Level X; but in the south corner of room 3 there was a pit cut down into the wall, but the wall of Level $X$ ran unbroken over the top of it, so that it was earlier than the Level $\mathrm{X}$ wall. But when the pit was dug the top of the palace wall must have been flush with the ground surface, for no one would dig a pit into a wall standing up above ground. If we assume that the pavements of Level $\mathrm{X}$ were laid at what was approximately ground-level when building started then, as those pavements are $0.80 \mathrm{~m}$. above the pavements of Level XI, the walls of the Level XI palace must have been ruined down to not more than 0.80 or $0.90 \mathrm{~m}$. above their floors and to that height were buried in fallen rubble. Another pit, in the west corner of room 2, proves the same thing: in this pit was found the fine painted fragment $\mathrm{ATP} / 47 / 72$ (P1. XCII). There was therefore a period when Level XI palace lay in ruins, so much so that its site could be used for digging rubbish-pits. When the Level X palace was to be built the workmen cleared the site down to the floors of the former building, which gave them a good base for their foundations; where they came on a brick pavement they left the bricks along the lines of their proposed walls, as a bedding, and where the walls would not run pulled up the good burnt bricks for their own use. That accounts for the sporadic survival of the pavements.

LEVEL $x$ (Fig. 14). The new building again shows a complete change of ground-plan. At the SE. end of the excavated area there was an open courtyard and the whole of the rest was occupied by rooms of what was evidently a very large and important structure; the rooms are large, the walls are heavy, one being as much as $2.90 \mathrm{~m}$. in thickness, and the foundations go down at least $0.80 \mathrm{~m}$. below floor-level. The bricks average in size $0.40 \mathrm{~m}$. sq. $\times 0.09-0.10 \mathrm{~m}$. The floors were of clay and had been relaid, the second floor lying $0.25 \mathrm{~m}$. above the first; the walls were nowhere preserved for more than $0.30 \mathrm{~m}$. 
above the higher floor. This was presumably the domestic quarter of the building, for the courtyard was little better than a midden. For a depth of rather more than $\mathrm{I} \cdot 20 \mathrm{~m}$.

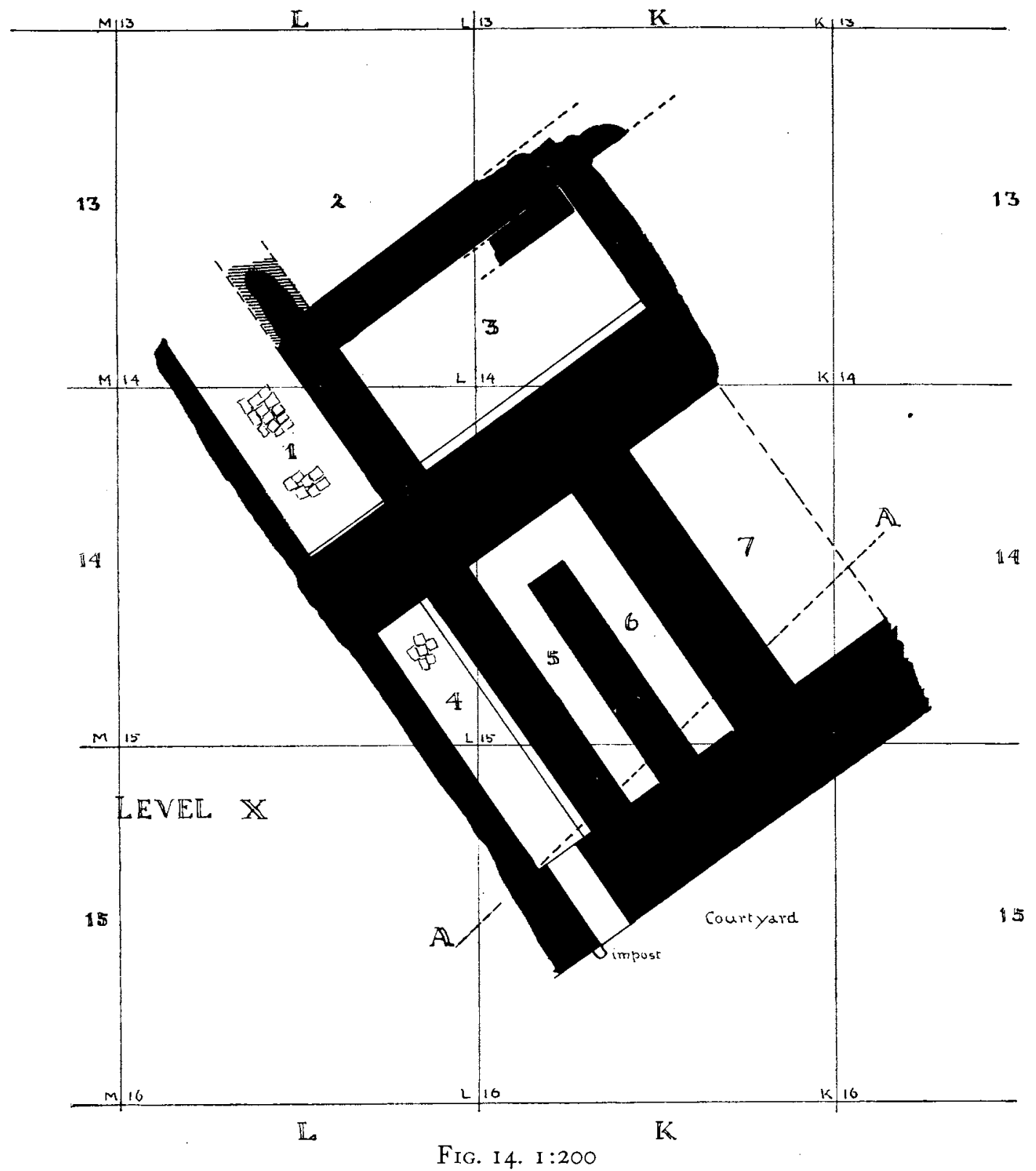

there was an unusually clear stratification of alternate layers of black decayed rubbish containing numerous potsherds and clean yellow clay, the latter representing surface levels; the yard had been refloored in this way six times. There was a doorway in the SE. wall of the building, leading into the court, and against the SW. jamb was a burnt brick partly built into the mud brickwork but projecting for two-thirds of its length; 
it was certainly an impost for the door-frame; the top of it was flush with the threshold, which was clearly given by a stratum of black trodden mud, and agreed with the lowest of the six floor-surfaces of the court.

The courtyard door led into what is obviously a passage (room 4). The floor had disappeared, but its approximate level was given by an offset of the NE. wall (it was $0.35 \mathrm{~m}$. below the existing wall-top), and at this level towards the SE. end of the room there were two burnt bricks (voussoirs) set one against either wall directly opposite one to another; their purpose was uncertain. At the NW. end of the room there was a patch of half a dozen baked voussoir bricks deliberately laid probably as floor-strengthening in front of a door; the walls were (here as in all the rooms) ruined down too low for doorways to be traced, but there must have been a door at the NW. end of the NE. wall opening on what was clearly a passage across the ends of 5 and 6 -and there must also have been a door at the end of that passage into room 7. Rooms 5 and 6 are a staircase. Room 6 is filled in solidly with mud brick. The normal plan at Alalakh is for the bottom flight of a staircase to be solid while the upper flights are supported on wooden beams; in this case the stairs must have turned at the SE. end of 6 and returned again (with wooden treads and supports) over room 5 , which would have been a cupboard under the stairs; its floor was sunk below the general level of the floors. On the floor of room 7 there were more voussoir bricks set at floor-level. In room 3 there was a mud-brick wall built inside the room against its NW. wall, abutting on it; its foundations went down $0.70 \mathrm{~m}$. below floor-level (as against $0.85 \mathrm{~m}$. for the room wall) and it probably ran the whole length of the room; ${ }^{\mathrm{I}}$ it was too heavy to be a bench and its use is doubtful. In room I there were two patches of brick paving (voussoirs) let into the lowest clay floor, which was $0.50-0.70 \mathrm{~m}$. below the top of the standing walls; there were at least two higher floors of clay, under the upper of which was a good deal of pottery. The patches showed no signs of burning, so they were not for hearths.

There were various rubbish-pits cut down into the rooms or through the walls of the building; they belonged to Level IX, because the inward curve of the sides came below that level. ${ }^{2}$ There was therefore in the case of Level X, as of Level XI, a time interval after the destruction of the palace during which the site was used for rubbish-pits. ${ }^{3}$

-The most important object found in the ruins (objects were very few in the building itself, owing to the razing of the walls almost to floor-level; most were found in the midden in the SE. court) was a cylinder seal of dark grey steatite $(\mathrm{AT} / 47 / \mathrm{r})$ with no figures but a cuneiform inscription of the scribe Adad-bani; the writing is correct on the stone and therefore reversed on the impression (Pl. LX, 6) and the script is in the style of the Cappadocian tablets from Ganeš. It lay in the very top of the debris of the mud-brick

I We cut away part of it before recognizing it.

2 Rubbish-pits are shaped more or less like beehives; the opening at the top is relatively small and then the sides are scooped out, the diameter rapidly increasing, until the requisite size has been attained, after which the sides are vertical. If therefore the sides are found to curve inwards it means that the top of the pit was not far off.

3 The argument has to be used with caution. Rubbish- pits were always being dug, in any vacant plot of ground, in the back-yards of houses, \&c., so that a Level IX pit could as easily be late as early in the period represented by Level IX. Everything depends on the position of the pit, and only if it comes under Level IX buildings or is inconsistent with the layout of such can it be attributed to the early part of the period. 
walls of Level $\mathrm{X}$ but below the foundations of a Level IX wall; it therefore belongs to Level $X$, but may have been from an upper room of that building. Of terra-cottas, two heads of figurines of the 'goddess' type, AT/47/IO and 29 (Pl. LVc), came from the

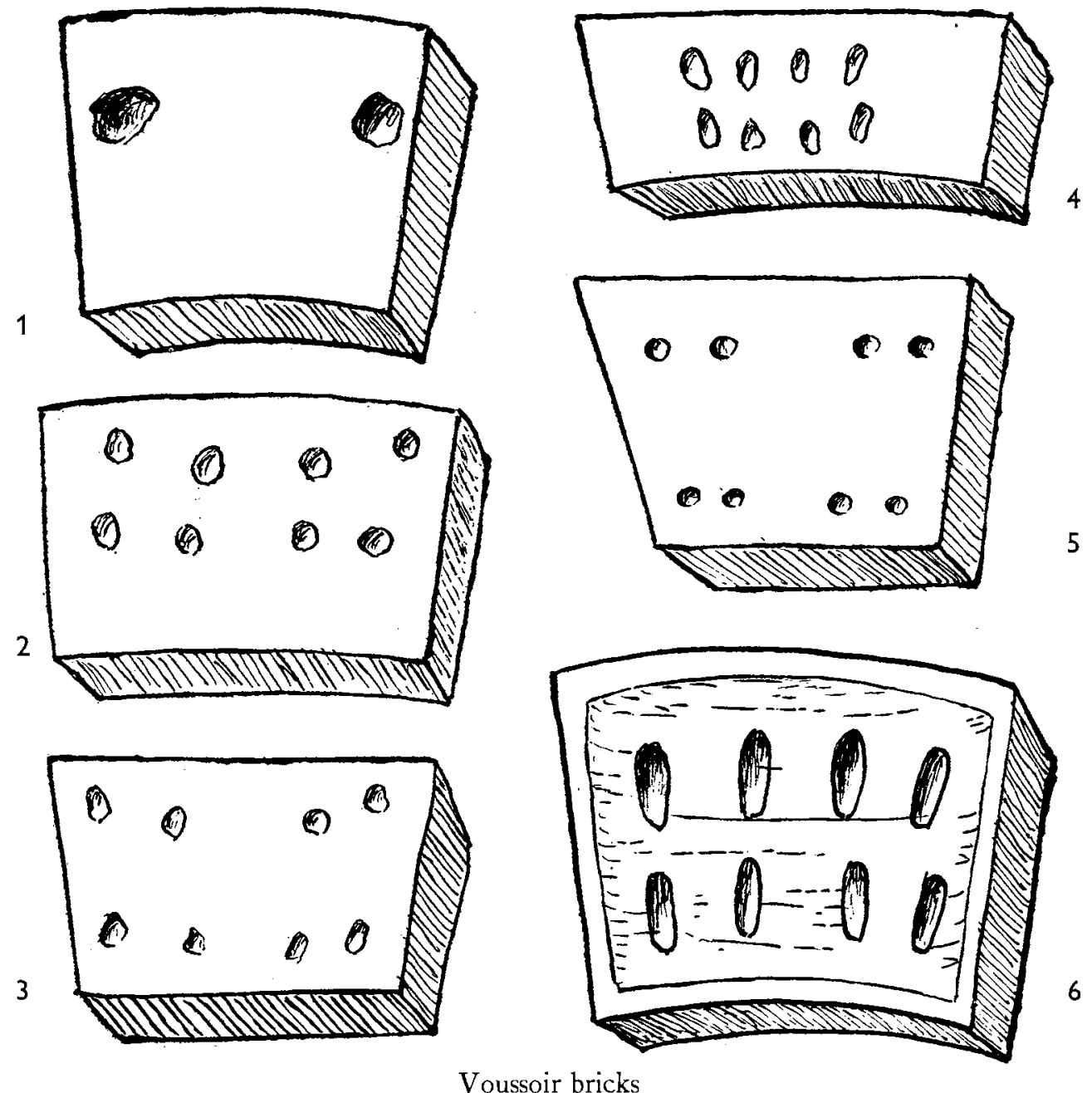

Fig. I 5. All from Level $\mathrm{X}$ except No. 6 which is from Level VIII

courtyard, two bodies of similar figures, A'T/47/9 from inside the building and A'T/47/28 (Pl. LVf) from the court, and two animal figurines, AT/47/I I from the building and AT/47/ 2 from the court; a third animal figurine, AT/47/26 (Pl. LVIIj), was from the Level X rubbish-pit sunk into the wall of room 4 of the Level XI palace. From another early Level X pit, that in the west corner of room 2 of the Level XI palace, came the fine example of painted pottery $\mathrm{A} T / 47 / \mathrm{I}_{3}(\mathrm{Pl}$. XCIII $c$ ); other objects were a dark green steatite bead, AT/47/22, and a clay loom-weight, AT/47/ 6 .

Apart from those mentioned as forming patches of pavement in rooms $\mathrm{I}$ and 4 voussoir bricks (v. Fig. I 5) and fragments of such were found loose in those rooms and also in 
rooms 5,6 , and 7 , for the most part close to the walls. The bricks in the pavement patches belonged to the earlier (original) floor of the building and most of them were complete; it can safely be assumed that they had come from the Level XI palace, in which also voussoirs were found, and had been re-used here regardless of their functional purpose. The same is not true of the bricks and fragments of bricks (the fragments were far more numerous) which occurred along the walls of the Level $\mathrm{X}$ rooms, some of them being definitely above the higher (secondary) floor-level; they may have been removed from the ruins of Level XI, but they were certainly not re-used in the Level X floors but in some other way-and it is at least as likely that they were manufactured in the Level $\mathrm{X}$ period. The discovery of voussoir bricks in north Syria at this early date is of great importance for the history of architecture in that country and requires discussion.

Radial bricks can be used for building columns and had actually been so used in an earlier period at Alalakh; v. above, p. I9, on the mud-brick columns of Level XII. This is not the case here. In the first place we found no such columns, or column foundations, in Levels IX or X, and in the second place bricks made for column-building would have a curved face, if at all, on the outer or wider edge, but our bricks, if curved at all, have the curve on the inner (narrower) edge; if the bricks are laid together in arch form the curved edges form an arc having a height of $0.175 \mathrm{~m}$. in a length of $\mathrm{I} \cdot 35 \mathrm{~m}$.

Radial bricks can be made for the lining of a well. That is not the case here because, apart from the fact that we found no trace of a well anywhere, a complete circle made with these bricks would have a diameter of about $26.50 \mathrm{~m}$., which is absurd; moreover, bricks for a well-lining, being laid flat, have no need of the elaborate frogging for which these bricks are peculiar-there are normally eight deep frog-holes in one side of each

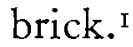

The bricks could have been used for arches over the doorways of the rooms in which they were found, but the shape of them is against this, the radial effect being applied not to the thickness of the brick as is usual in arch voussoirs but to its extremities, and also if the bricks were to be set vertically on edge to form an arch there is no point in the elaborate frogging. On the other hand, everything about them is in favour of their being meant for ring-vaulting ${ }^{2}$ - the shape is right, the curve is consistent, and the frogging is a wise precaution to obviate the tendency of the bricks to slip before the ring is completed. In both buildings, IX and X, the shape of the rooms, long in proportion to their width, suggests vaulting, as does the great thickness of the side walls, and the thickness of the end walls may have been in part at least dictated by the demands of ring-vault construction since the slope of the rings involves a heavy thrust on the wall against which they lean. The bricks found by us are relatively few in number;

\footnotetext{
I That such frogs are unnecessary for bricks for a welllining is technically true, but in the only brick-lined well that we have found at Alalakh the (burnt) bricks are precisely like those now in question and have eight deep frog-holes. The well ( $\boldsymbol{v}$. infra, p. 85) was dug for the temple of Level I A; it is possible, though perhaps not likely, that the bricks are old ones re-used. In any case the difference of date, a matter
}

of 400 years, makes it hazardous to argue from one case to the other.

${ }^{2}$ For a description of the method of ring-vaulting see Karanòg, The Romano-Nubian Cemetery, by C. L. Woolley and D. Randall-MacIver (Eckley B. Coxe Junior Expedition to Nubia, vol. iii), University Museum, Philadelphia, r 9 ro, p. 18 , from which the drawing in Fig. I6 is taken. 
the rest have been removed because burnt bricks had a distinct value and a succession of vaulted chambers were a precious quarry; the workmen pulling them out would inevitably break some, and that is why we find mostly fragments along the lines of the walls. We are, I think, forced to conclude that the ground-floor rooms of the palaces both of Level XI and of Level X were vaulted with burnt brick; in both cases the bricks were carried off for re-use, perhaps in each case to build new vaults, but superfluous bricks might be employed for any purpose, such as the patching of a floor. ${ }^{\mathrm{I}}$ The vaulted ground-floor rooms may have been domestic quarters or magazines, the piano nobile being the second floor built above the magazines, as was the case with the later palace of Yarim-Lim (v. infra, p. 94), and for the upper floor, where the rooms may have been larger, there is no need to suggest vaults. That the upper floor did exist is made more probable by the

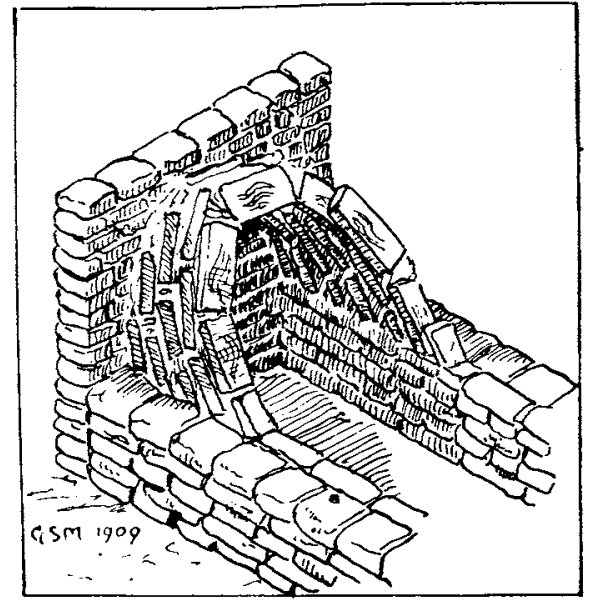

FIg. I6 fact of there being a staircase in the Level IX palace (in view of later analogies it is not likely that it led merely to a flat roof) and the importance of the buildings is greatly enhanced thereby, and the conclusion that this was the traditional site for the royal palace is unavoidable.

LEVEL IX (Fig. I7). Of this level disappointingly little was preserved. In the first place the builders of Level VIII did their work of clearing the terrain so thoroughly that the total remaining depth of the Level IX stratum was a trifle less than fifty centimetres-only in two rooms was the floor left, and in all the others everything was destroyed to below floorlevel, and in the second place the site was so cut up by graves and rubbish-pits of Levels VI and V, which had been sunk through Levels VII and VIII, that only scraps of walls remained at either end of our excavated area and nothing at all in the middle of it.

All that we have is the SE. end, lacking the SE. enceinte wall, of one building (A) and, at the SE. end of our excavation, the north corner of what is shown by its different orientation to be another and a separate building (B); the latter does not extend eastwards to the city wall, but between it and the wall (C) there was an open area paved with mud bricks one or, in places, two courses thick. The pavement continued northwards of the corner of (B), but then broke away, the ground here having been disturbed, and instead of it there was a mass of burnt and decayed stuff, a refuse-dump, which ran over what should have been the enceinte wall of (A) up to the surviving SE. wall of room 4 .

In building (A), room I was much destroyed; no floor remained; in it were found fragments of coloured wall-plaster. Room 2 (only the east corner dug) was better preserved,

\footnotetext{
I Isolated voussoir bricks identical with those from Level $\mathrm{X}$ are not uncommonly found in Levels VIII to V, but never in circumstances that suggest a vault belonging to those levels.
} 
the floor being lower and the walls having, with their foundations, a total height of $\mathrm{I} .00 \mathrm{~m}$. The floor was of clay. The walls had been heavily lime-plastered and painted,

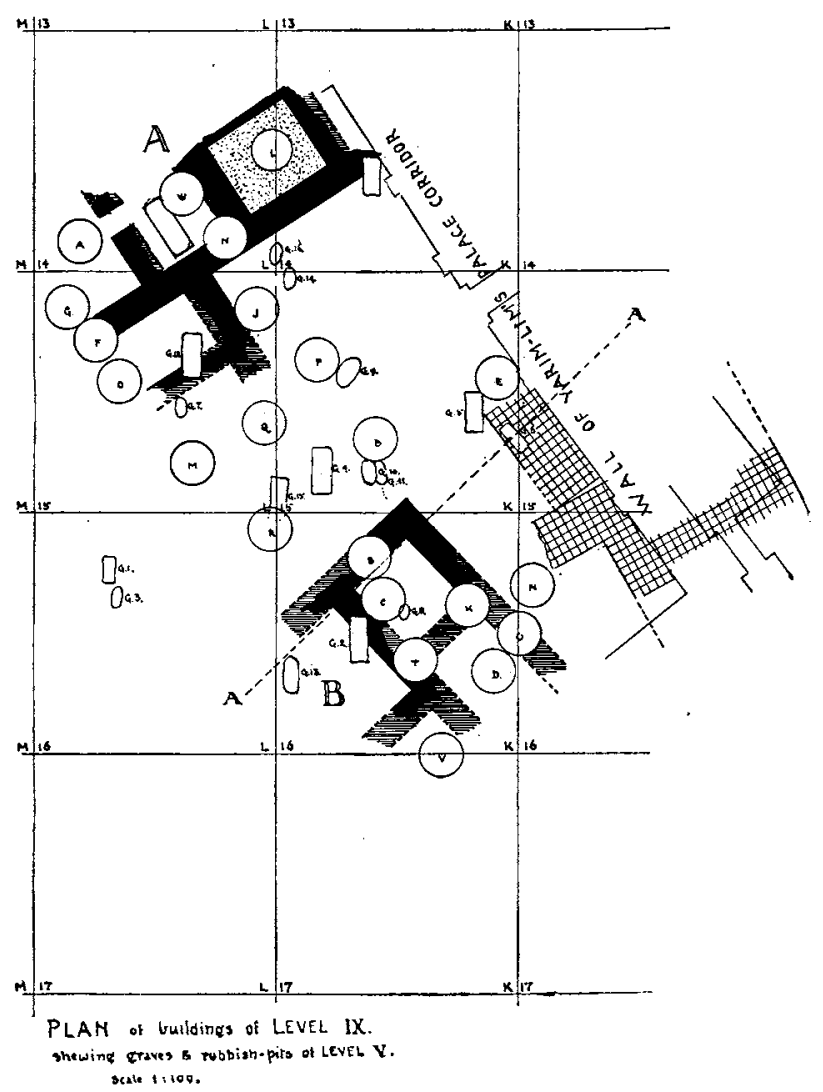

FIG. I 7. I :400 some patches of Pompeian red being left on them, whereas on the floor were numerous fragments of fallen plaster, red and white; no pattern could be distinguished. A doorway led into room 3 , but this had had a high floor now destroyed; under the floor was a furnace, occupying most of the room. The furnace was a pit, $2.50 \mathrm{~m}$. long and $\mathrm{r} \cdot \mathrm{I} O \mathrm{~m}$. wide, with rounded ends, its present depth $1.30 \mathrm{~m}$. At the bottom it was merely cut in the soil, but from $0.40 \mathrm{~m}$. upwards from its clay floor was lined with mud bricks, these, like the earth surface below them, heavily plastered with clay. The brickwork sloped inwards making a false arch; at $1 \cdot 30 \mathrm{~m}$. the width had been reduced to $0.70 \mathrm{~m}$. and the total height therefore of the arch would have been $\mathrm{I} \cdot 80 \mathrm{~m}$. The walls were heavily burnt, especially at the SE. end, the discoloration going back $0.10 \mathrm{~m}$. from the back of the clay plaster; the whole furnace was full of stratified burnt wood and rubbish. No stoke-hole and

no flues for draft were found; but as the NE. side had been destroyed for a length of $\mathrm{I} \cdot 20 \mathrm{~m}$. by a later rubbish-pit the evidence is not complete and there may have been here a small pit with an entrance to the furnace; but the purpose of the furnace as well as its method of working and ventilation cannot be decided.

Room 4 had a good concrete floor lying rather high but preserved by the character of its material except in the centre where it had been pierced by a rubbish-pit. The walls were ruined down to or below floor-level.

It is, of course, impossible to be certain of the character of a building so terribly ruined, but a concrete floor is a feature which appears constantly in the palace of Yarim-Lim and has not actually been found in a private house, and the fact of frescoed walls is an argument in favour of the building's being unusually important. As there are palaces below this and above it on the same site, it is not unreasonable to assume that this is the palace of the period of Level IX. 


\title{
CHAPTER II
}

\section{THE TEMPLES, LEVELS XVI-O}

\author{
THE TEMPLE SITE (sqq. M-Q, I2-I6)
}

$\longrightarrow$ HE principal temple of Alalakh, that presumably dedicated to the city goddess invoked by King Idri-mi, lay, as one would expect, in the NW. quarter of the town close to the royal palace and to the garrison fort. Here we found the superimposed remains of no less than seventeen temples which had successively
occupied the same or virtually the same site. It would not be correct to correlate these buildings exactly with the house levels; it is obvious that a State temple might outlive more than one generation of domestic dwellings, and it is equally clear that a change of policy in the middle of a period represented by one of our building-levels might entail the remodelling of the temple without in any way affecting the houses of the private citizens. None the less, the two sequences are reasonably consistent. In the case of Levels I, III, and VII the temples can be proved to be strictly contemporary with the houses. Below Level VII the synchronism is less certain, but the lowest temple of which the ground-plan could be to any extent recovered did seem to give a fixed point. Its pavement, which was not raised on an artificial platform but rested on accumulated debris, was precisely at the level of the floors of houses of Level XVI (both were at about five centimetres above the modern water-table), so that assuming the terrain to have been even over the short distance that separates the two sites, the buildings should have been contemporary; more conclusive was the fact that the pottery in and above the temple was of the types normal in Level XVI and upwards, whereas immediately below its pavement the wares were markedly different. ${ }^{\mathrm{I}}$ This was accordingly defined as the Level XVI temple.

Between Level XVI and Level VII the site did not produce the ruins of eight distinct temple buildings, so that we could not simply number consecutively the five which could be distinguished as superimposed, but had to argue from what evidence there was. ${ }^{2}$ Of the two best preserved temples the uppermost corresponded fairly well in level with Level XII in the house area-not in itself a strong argument-and so far as the pottery afforded any indication at all it accorded with such a date. Level XII had given us the great columned palace façade which outlived three generations of private houses (v. p. I7), and it was natural to expect that there should have been a temple built to match;

I See 'Level XVII pottery', p. 307.

2 It was only in 1949 that evidence was forthcoming to show that there was a series of superimposed buildings of different dates. Up to that time I had believed that the apparently homogeneous mass of mud brick underlying the Level VII temple was the work of a single period whose successive phases were really contemporary; I had therefore B 2501 completely misunderstood the character of the site. In the Illustrated London News for 25 Oct. 1947, p. 470, and also in the American Fournal of Archaeology, and series, vol. li ( I 947), p. 427, I put forward the quite erroneous conclusions which I drew from the facts then available. I must apologize for that premature publication. 
actually our temple was very large and very solidly constructed, and as it had twice been restored or remodelled it corresponded very well with the palace in this respect. If the identification be accepted, as I think it should be, the other ruins seem to fall into place

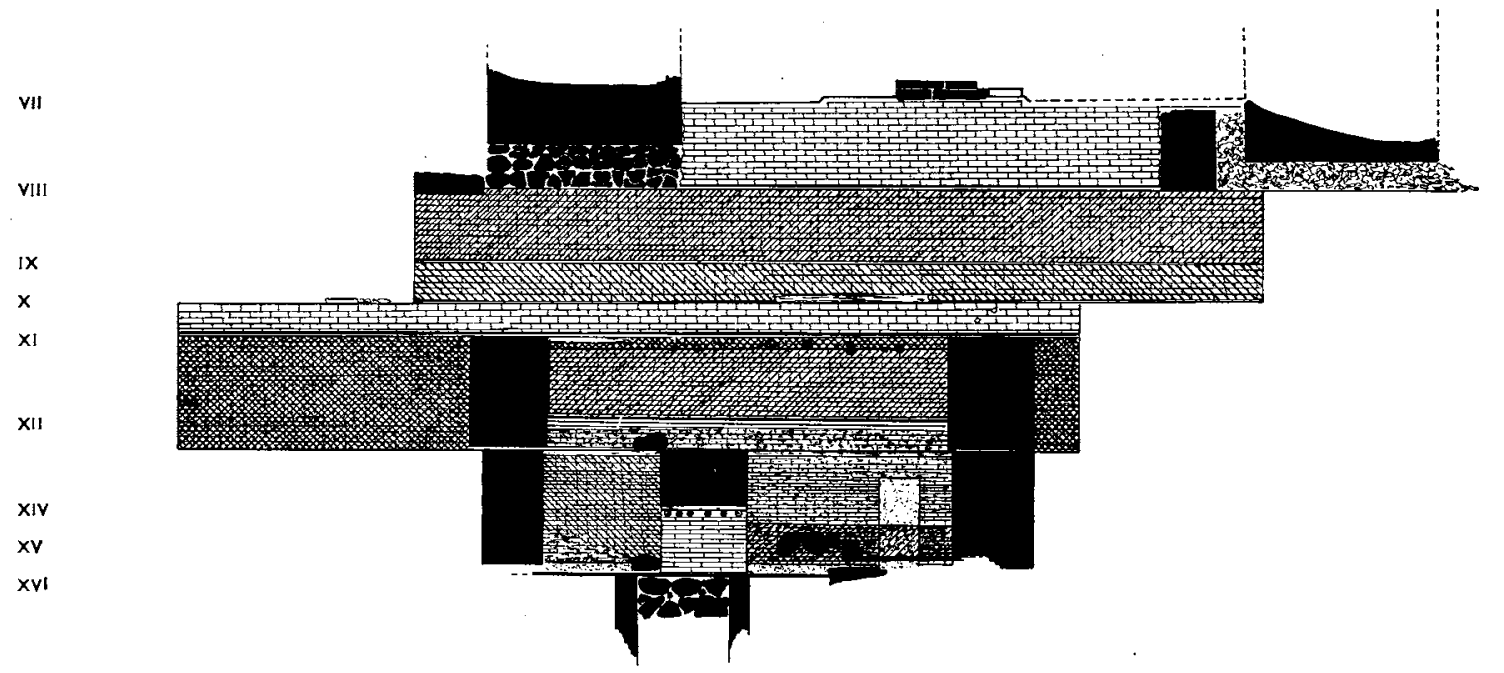

(a) Section NE. $\times$ SW.

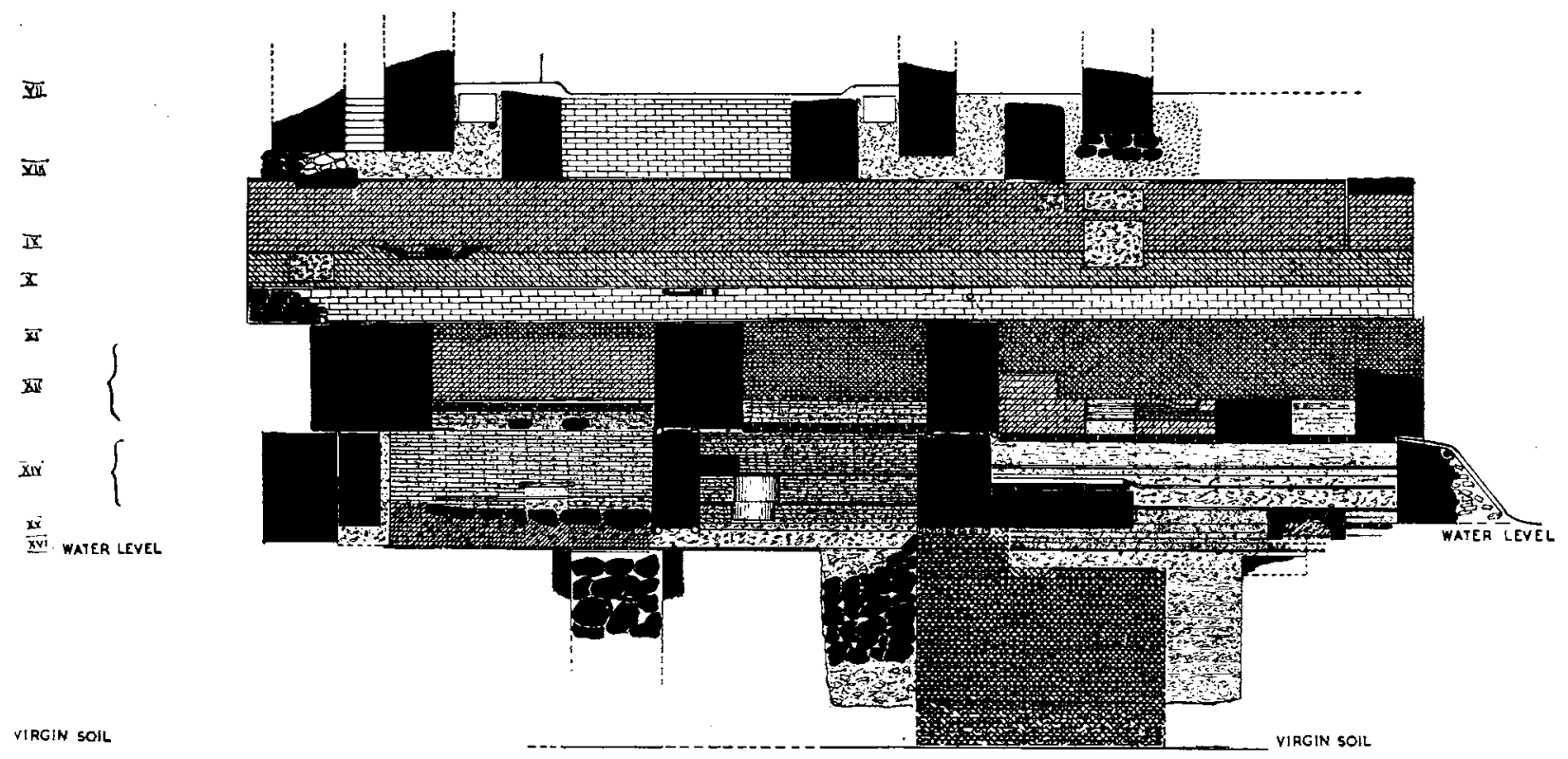

(b) Section NW. $\times$ SE.

FIG. I 8. Sections of the temple site, Levels VII to XVI. Scale $1: 200$

without any serious difficulty. Level VII temple rests on the burnt ruins of a massive building set on a brick platform which must be the Level VIII temple (the Level VIII palace also was burnt) but may quite well have been built in the Level IX period and have lasted until the end of Level VIII. Below this there remains, of the next building, 
only the platform; but the pottery associated with it is definitely that of Level X. Another platform lying below this and immediately on the ruins of Level XII can only be that of the Level XI temple. Under Level XII comes a well-preserved and interesting temple which clearly had a long life in that it has twice been radically remodelled; since the house site gives us no reason to suppose that Level XIII lasted very long, we can fairly interpret the evidence of the temple site as meaning that the building originally set up in the Level XIV period continued in use-subject to certain structural changes-until the end of XIII. For Level XV there is very little to show, but there are certain features intermediate between Levels XIV and XVI for which it is difficult to account except on the supposition that there was a building there which was destroyed to make room for the Level XIV temple. Finally, there had been, below Level XVI, a temple which, since its brickwork rests on virgin soil, must belong to the earliest days of the city.

We can then, with a fair degree of confidence, correlate all the older buildings on the site with the 'Levels' observed in the residential quarters of the town, and throughout the entire period the buildings are superimposed one on another, all scrupulously confined to a virtually identical area, the traditional site of the city's sanctuary. But after the destruction of the Level VII temple this tradition was for some reason abandoned. The break with the past was not indeed complete, but from the middle of the eighteenth century onwards there is a shift to the south, so that the old sacred plot is left vacant and the new sanctuary overlies what had been the forecourt of Yarim-Lim's temple, with its new forecourt extending beyond the limits of what had been regarded as holy ground. But that change having once been made, custom was as conservative as before and the position of the sanctuary remained the same as long as Alalakh stood. During that time fresh temples were built corresponding to each in turn of the periods represented by the house levels. Of the Level VI temple we found only a scanty trace, of the Level V temple only the altar and sanctuary; the walls of the Level IV temple were thickened and re-used for the shrine in the Hittite style put up in Level III, and this served as a foundation for Level II; the only discrepancy between temple and house site is that the Level I temple, once remodelled and afterwards deformed by long neglect, implies for the period a much longer span than we should have inferred from the denuded houses, while the great stone foundations of Level $\mathrm{O}$ must remain to some extent an enigma to be bracketed with the one grave that is definitely later than the destruction of the city.

\section{THE LEVEL XVI TEMPLE (Fig. I9)}

The excavation of the lowest levels of the temple site was a matter of great technical difficulty and its results were neither complete nor satisfactory. Below the floor of the Level XIV temple the earth was sodden and waterlogged; the floor of Level XVI was flush with the water-table and all work below it had to be done under water (Pl, VII $a$ ). The buildings, representing apparently several phases of construction, had been systematically razed almost if not quite to ground-level, and the scanty remains of crude brickwork had resolved themselves into mud and could be recognized with difficulty if at all. 
The only possible method of digging was for the men to work inside a steel caisson with motor-pumps carrying off the steady inflow of water, and although we were able in this way to go down about five metres and reach virgin soil, no detailed stratification could be

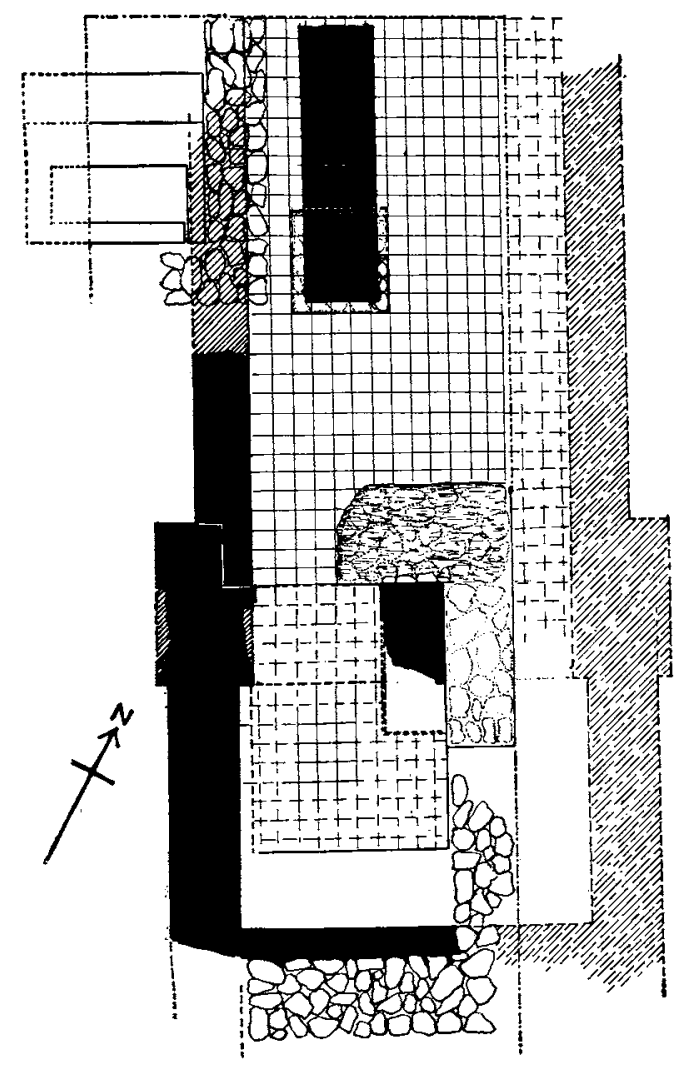

TEMPLE

LEVEL XVI

With additions dating to Level $\mathrm{XV}$

Fig. 19. Scale I:200 observed in the semi-liquid mud which collapsed with each bucketful that was removed. In view of all this, the best course is to describe first the Level XVI temple, which did at any rate give us certain fixed data, and to deal next with the fragmentary remains of what lay beneath it and afterwards with the-equally fragmentary-evidence of intermediate work between Levels XVI and XIV; this neglects the historical order of the buildings but makes for clarity of description.

The 'fixed datum' of the Level XVI temple was a relatively well-preserved pavement of terracotta tiles set in mud mortar (Pl. VIIb); owing to subsidence caused by the irregular packing below it and the weight of buildings above, it was no longer very level, its undulations giving a maximum variation of $0.45 \mathrm{~m}$., but it was for the most part continuous. The tiles had originally been red, but their upper surface was now black and powdery (though there were patches where they were still red) and the mud mortar was bright red; clearly this was due to a fire that had spread over the pavement. The tiles measured $0.42 \mathrm{~m}$. square. Unfortunately the NE. and NW. limits of the pavement could not be found; the tiles ran on under the walls of the Level XIV building and it was impossible for us to follow them, since those walls coincided with the sides of our excavation, except at a cost altogether incommensurate with the importance of such results as might have been obtained. Therefore the NE. side of the plan (Fig. I9) is a purely theoretical reconstruction based on the supposition that the building was symmetrical in ground-plan. On the SW. side the limits of the pavement could be fixed; towards the west corner of the court it ran up against a brick wall which was preserved for a stretch of rather more than four metres, and beyond this to the north-east the tiles ended in a straight line although no trace of the wall survived. The wall was of mud bricks varying in size from $0.53 \mathrm{~m}$. to $0.60 \mathrm{~m}$. sq., reddened by fire; its face giving on the courtyard was plastered and whitewashed (it stood $0.10 \mathrm{~m}$. high) and it was $\mathrm{I} \cdot 10 \mathrm{~m}$. thick; on the other side of it there was a whitewashed floor at approximately the same level as the tiled pavement. The SE. end of the wall seemed to abut on a previously 
existing wall $\mathrm{I} \cdot 30 \mathrm{~m}$. wide having on the north-east a reveal with the face of which the new wall was aligned; the reveal was $2.00 \mathrm{~m}$. wide and beyond it the old wall, $\mathrm{r} \cdot 40 \mathrm{~m}$. in thickness and with its face rather more advanced, ran on to enclose the SE. chamber of the temple. On the SW. face of the old wall there appears to have been a similar reveal, but we could find no face to it nor any corresponding feature to the northwest. The NE. reveal, together with a change of floor-level to be described later -and there may well have been a corresponding reveal on the vanished NE. wall-serves to divide the existing building into two parts, which I would call the main court and the SE. chamber. On the line of the buttress reveal the pavement of the main court ends against a low coping, plastered and whitewashed, $2.50 \mathrm{~m}$. long, from which three steps lead down to the SE. chamber. This chamber seemed to have had an all-over pavement of tiles like that in the main court but $0.40 \mathrm{~m}$. lower; it was in very bad condition-in patches it was easy to recognize the individual tiles (burnt black, but not so

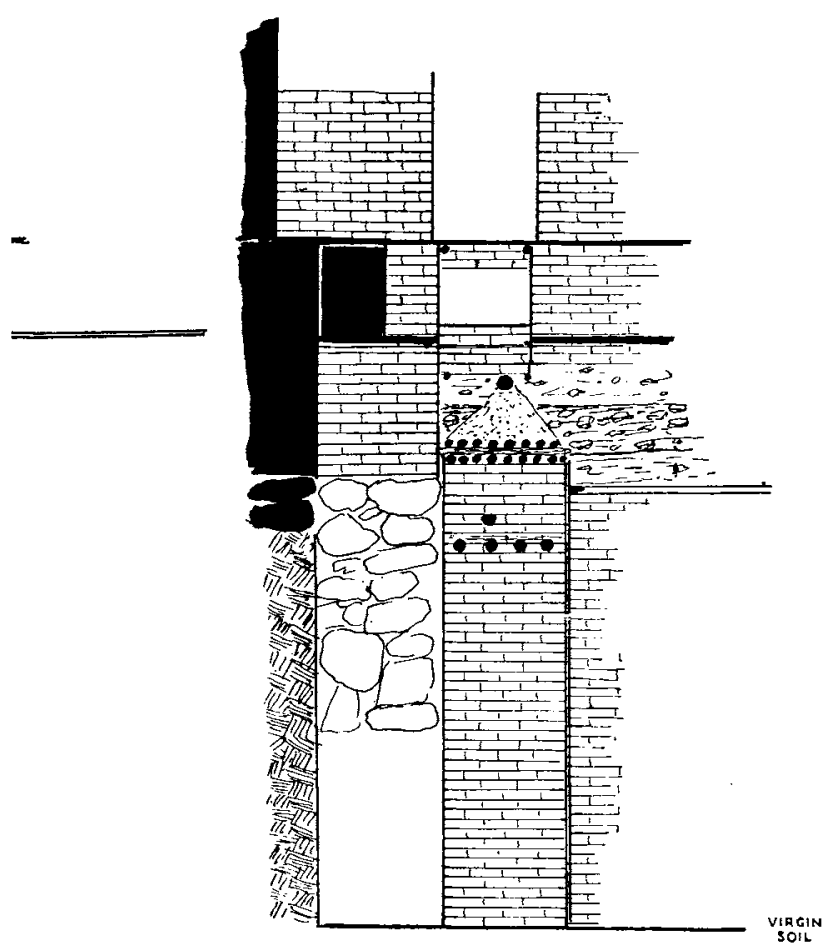

FIG. 20 violently as those in the main court, and the mortar was more black than red), but over a great part of the area it had disappeared altogether. It was overlaid with a deposit of rubbish containing some potsherds.

The coping at the top of the steps filled the space between the NE. face of the reveal in the SW. wall and a separate rectangular of mud brick, plastered and whitewashed, measuring $\mathrm{I} .20 \mathrm{~m} . \times 3.00 \mathrm{~m}$., rising $0.20 \mathrm{~m}$. above the pavement, on which were three courses of stout timbers up to $0.25 \mathrm{~m}$. square, set in alternate directions, and above these a wooden gable about $0.60 \mathrm{~m}$. high ; ${ }^{1}$ see the elevation on Fig. 20 . At a depth of $0.80 \mathrm{~m}$. below the timbers the mud brickwork of this rectangular structure rested on a course of wooden beams, four in number, each about $0.20 \mathrm{~m}$. square, running NW. $\times \mathrm{SE}$., with

\footnotetext{
I The evidence for this must be given in detail. There had been a roof-tree beam, the decay of which had (as usual) left a horizontal hole in the hard-packed soil. It formed the apex of a triangle with sharply defined edges enclosed by the soil and filled with a very soft, light mixture of burnt ash and infiltered dust. This rested on the heavier timbers; the latter had been burnt, but the burnt wood had been petrified by impregnation with lime. We have constantly found, in mud brickwork or in brick debris, holes left by decayed wood, and often these contain slight traces (little more than a dis-
}

coloration) of the wood; in no other case have we found petrifaction, and I am assured that it could be due only to the carbon being exposed to the action of 'free' water, which was the condition here where the timbers formed the base of a hollow gable. As carbon, the wood could have survived until the time when the water-table rose, and as with the seasonable variations of water-level the gable would have been alternately above and below water, the lime content of the water in the gable would have been as regularly renewed. 
more brickwork below them; they may possible mark a break in construction, i.e. new work built on old.

In front of this gabled structure there was a gap in the tiled pavement $3.50 \mathrm{~m} . \times$ $2.00 \mathrm{~m}$.; along the SW. side the tiles were broken (so that the original width may have been less than $3.50 \mathrm{~m}$.), but it was quite certain that the pavement had never run across the whole area and that the gap as such was intentional. It was really a pit which had been filled with big boulders and pebble packing up to a level $0.50 \mathrm{~m}$. below the pavement, i.e. precisely to the level of the lower course of beams in the brick structure. More stones had been set on the top of the main filling, leaned up against the brickwork, at a slope; the top row of four stones rose above pavement level (Pl. VIII $a$ ) and came against the bottom course of the upper timbers belonging to the gabled roof. These stones were split by heat and smoke-blackened. The hollow in front of the sloped stones was filled to pavement level with a mixture of burnt earth, ashes, bits of burnt animal bones, and a small amount of potsherds. The pit extended round the NE. side of the brick structure, but here the stone filling was about flush with the pavement (none of the stones rose above it) and there was little or no wood ash; it was in fact a higher filling which continued the line of the front of the brickwork and formed the limit of the deeper ash-filled pit north-east of it. This stone-filled trench measured something over $3.00 \mathrm{~m}$. in length ${ }^{1}$ by $\mathrm{I} \cdot 40 \mathrm{~m}$. in width.

There was another feature apparently belonging to the Level XVI temple, namely, a solid block of mud brickwork standing isolated in the main (NW.) court. It was a rectangle $2.50 \mathrm{~m}$. high, measuring $5.75 \mathrm{~m} . \times \mathrm{I} .45 \mathrm{~m}$. lying NW. $\times \mathrm{SE}$. The bricks were very large, $0.54 \mathrm{~m} .-0.57 \mathrm{~m}$. sq., and showed no signs of burning-which was natural if the block stood in the centre of an open court; they were laid directly on the tiled pavement which here, and only here, was two tile courses thick; at the NW. end there was a bedding of heavy timbers between the sixth and seventh courses from the bottom. Through the block, rather to the south-east of its centre, there was a doorway $\mathrm{I} \cdot 25 \mathrm{~m}$. high and $\mathrm{I} .00 \mathrm{~m}$. wide, ${ }^{2}$ its lintel formed of six joists spanning the door-passage; later this had been blocked with two or three courses of mud brick at the base and an upper filling of earth contained by facing walls at either end, and the whole had then been mudplastered and whitewashed. ${ }^{3}$ Behind the block (which we called the 'mastaba' on the strength of its 'false door') there was a single line of boulders from the north corner to the doorway, resting on the pavement and leaned against the brickwork, and some rather doubtful traces of wood above them suggested a bench. South-east of the doorway the tiled paving stopped at $0.25 \mathrm{~m}$. from the brickwork and was replaced by large stones set flush with the tiles, and a gap between the stones and the edge of the tiles showed deep water; this stonework was found to run right under the SE. end of the 'mastaba' and was

I The measurement is approximate as the back fell in after we had dug away the front stones.

box or compartment orginally contrived in the core of the block; but the fact that the outer lintel-joists were flush with

2 The exact width was uncertain because we were not able to trace the faces of the jambs and were guided only by the length of the lintel-joists.

3 The description might seem to apply equally well to a the face of the brickwork (which they would not have been in the case of an internal compartment) proves it to have been a doorway. 
the filling of a shaft. ${ }^{\text {T }}$ The upper part of this was a brick-lined rectangle about $2.00 \mathrm{~m}$. sq. going down for perhaps two metres, after which there was no trace of brick lining and the shaft seemed to be circular ${ }^{2}$ and was filled with earth instead of stones. At $4.25 \mathrm{~m}$. below the pavement the shaft entered virgin soil and it appeared to stop at about $5.50 \mathrm{~m} .{ }^{3}$ No objects were found in it.

Now it is evident that the shaft is constructionally older than the tiled pavement, but the fact that the stone filling is about flush with the tiles suggests that the filling at any rate is contemporary with the Level XVI temple. The 'mastaba' is constructionally later in that it is built over the already laid tiles and over the stone filling too; but, on the other hand, its bricks are of a size elsewhere found only in the SW. wall of the Level XVI temple court, and it was already in existence when fresh features were added to it at a time which was later than Level XVI but older than Level XIV. ${ }^{4}$ On the whole I am inclined to believe that the 'mastaba' is an original feature of the Level XVI building, perhaps of a second rather than of the original phase. As regards the shaft, it can, of course, be urged that it may have been an old well which the temple builders found there and, because it had nothing to do with their plan, simply filled it in and built over it; the fact of its being underneath the 'mastaba' would by itself prove this to be the case. On the other hand, it cannot possibly be much older than Level XVI because it is cut down through the stratified debris of the preceding periods and its top is flush with the Level XVI floor, so that between the building of that temple and the digging of the shaft there had been no time for rubbish to accumulate and raise the floor-level. Moreover, the character of the filling is suspicious; big stones-necessarily brought from some distance, for there are no stones near Alalakh-must have been expensive, and the weight of the 'mastaba' was not such as to require so lavish a use of them; a single course would have been ample. Further, if the shaft had been simply abandoned at the time of the building of the temple, why were the tiles not carried uniformly across it? Granted that most of it lay beneath the 'mastaba', the small part beyond it was deliberately left exposed, and one of the stones was actually on the top of the pavement, which suggests that the filling was put in after the pavement was laid. Clearly the filled-in shaft could not serve any practical purpose; but it seems to me equally clear that its existence was for some reason necessary and visible evidence of its existence was desirable; also that there was some

I The field notes state: 'The stones were of all sorts and sizes, many weighing up to half a ton and some to $\frac{3}{4}$ ton ... from the way they were wedged together it appeared that the stones had not been just thrown into the well but had been carefully laid and all the interstices filled with small stones and mud mortar (it was certain that not nearly all the mud could be due to infiltration from above and from the sides, and the larger lumps were drier inside than on the outside).'

2 It will be understood that as all the work here was done under water ( $v$. Pl. VIl $a$ ) and was complicated by the need to break up and remove stone boulders weighing anything up to three-quarters of a ton accurate measurement were impossible. Below the stones the filling of the shaft could be distinguished from the fallen earth of its sides only by the former being clean and the latter containing ashes or sherds.
3 In the conditions in which we were working it was very difficult to decide upon this, but since in our other deep excavation virgin soil was found at the same level, our observation in the first case was probably correct. If the shaft was not sunk into virgin soil for much more than a metre's depth it can scarcely have been a well, because at that time the water-table had not risen to its present height and the original buildings of Alalakh must have been more than a metre and a half above water. That objection holds good against the theory that the shaft was a well from which water was to be got; it does not apply equally to the view that it was a purely symbolic well dug for ritual purposes, because in that case ritual might have been satisfied as soon as the first sign of water appeared. On the whoie, the non-committal expression 'shaft' seems the safest.
4 See below, p. 4 I. 
connexion between it and the brickwork above it. What the connexion was and what was the character of the 'mastaba' I do not know.'

A very similar problem attaches to the curious gabled structure at the $\mathrm{SE}$. end of the court. What was visible above the pavement was only the upper part of a structure going down almost if not quite to virgin soil $4.45 \mathrm{~m}$. below the pavement; and the low coping between the gable and the SW. wall ran along the NW. edge of a much larger block of brickwork going down to the same low level, distinct from the gabled part in that it was separated from it by a straight joint but clearly connected with it. ${ }^{2}$

The mass of mud brickwork measured $5.50 \mathrm{~m} . \times 4.00 \mathrm{~m}$. Along the NW. edge it rose to about $0.20 \mathrm{~m}$. above the tiled pavement and the top of it was plastered and whitewashed; at $\mathrm{I} .50 \mathrm{~m}$. from the face the top sloped gently down for $0.25 \mathrm{~m}$., and at $3.40 \mathrm{~m}$. and again at $3.90 \mathrm{~m}$. there were two more sloped steps bringing the surface of the brickwork to a level $0.50 \mathrm{~m}$. below the pavement of the main court. The tiled pavement of the Level XVI chamber was laid directly on this brickwork, though it extended beyond it to the walls of the chamber. The steps seemed to have belonged to the older building but to have been re-used (presumably repaired) in Level XVI.

On the NW. side the stone-filled pit sunk in the pavement of the Level XVI temple went right down to virgin soil, but at $2.80 \mathrm{~m}$. below the pavement the stone filling stopped and the pit (whose sides we were able to trace with reasonable assurance) was filled with animal bones, wood ash, and fragments of coarse pottery; conditions below the stones therefore virtually repeated those above them. Against the NE. side the stones ended at the same level $(2.80 \mathrm{~m}$. below pavement $)$, but this was the bottom of the trench, and there was below them no deposit of bones and ash, any more than there had been above them. Along the rest of the NE. side and on the other two sides of the brick block there was normal 'occupational deposit', i.e. stratified soil containing ashes and occasional potsherds. ${ }^{3}$

\footnotetext{
I As will be seen hereafter, the 'mastaba' was re-used in succeeding periods. We were quite unable to decide whether the plaster and whitewash covering it was original or added in one of those later periods, and there was the same uncertainty about the blocking of the door. When we excavated the building the plaster was intact (except that near the base the whitewash had vanished owing to water) and the door was quite invisible; we only discovered it by tapping the surface and noting the hollow sound where the decayed roof-joists had left an empty space. It seems unreasonable to go to the trouble of making a doorway and then conceal it altogether (though perhaps not more unreasonable than to dig a shaft and then fill it up again), and it may be that in the Level XVI temple the doorway was open; but even so, the lowness of the doorpassage would imply that it was not intended for the normal uses of a doorway.

2 In the conditions in which we had to excavate it was not possible to decide how far that straight joint ran back, i.e. whether it continued to the back of the brickwork dividing it into two parallel elements of unequal width but the same length, or turned, corresponding to the end of the stone-filled pit on the north-west, as suggested in the plan.
}

3 As my conclusions derived from digging in mud might reasonably be called in question I will quote the field notes: 'Work went down over the greater part of the area through solid brick. At the beginning this was clear enough, but lower down it became very difficult to determine whether it was brick or not. The edges of individual bricks could not be distinguished in horizontal section but in a vertical cut there could be seen bands of brick (not more than $0.10 \mathrm{~m}$. thick) of varying colours. At $2.50 \mathrm{~m}$. below the tiled paving this was the case. . . . Amongst the undisturbed stones' (on the southeast; many had been displaced by subsidence resulting from our former excavations) 'came fragments of pottery and bone. The brickwork seemed to go down uninterruptedly until it came to an end on a bed of sand' (at $4.45 \mathrm{~m}$.); 'at the same level approximately the pottery fragments in the stratified soil beyond the brickwork gave out. 'The sand appeared to be absolutely natural and unworked; as we went deeper it was stratified with belts of greenish clay and it contained occasional lumps of extremely hard red clay, water-shaped. Finally we came to harder clay with reddish veins in a greenish body which seemed undoubtedly virgin soil; this was circ. $5.00 \mathrm{~m}$. down. . . . For the last $\mathrm{I} \cdot 00 \mathrm{~m}$. or more work had been more 
There is no reason to think that the brick mass was constructed in a pit sunk into the stratified soil; on the contrary it had been built upstanding on an original surface and the 'occupational deposit' had formed round ${ }^{\mathrm{I}}$ it; it was therefore very much older than the Level XVI temple, though it survived in that building. From the outset the bones and ashes of sacrifice were laid against the NW. face of the smaller element of the brick block, this space being kept free as the ground-level rose so that in the end it took the form of a pit. When the Level XVI temple was built the pit was partly cleared out and a solid bedding of large stones put in to serve as a base for a new sacrificial deposit; probably the smaller block of brickwork was raised in height and topped with a wooden gable while most of the larger block was buried below the pavement of the SE. chamber, only the front of it remaining; against the NE. side a trench was dug and filled with stones coming up flush with the pavement. Whatever the brick block was originally, a peculiar sanctity must have been attached to it, so much so that it had to be reproduced in the new temple.

Although disappointingly little remains of the actual temple of Level XVI, it is perhaps not rash to assume that its ritual demanded $(a)$ in connexion with burnt sacrifice, a solid brick structure the foundations of which traditionally (for the structure actually used was inherited from an older temple) went down to rest on virgin soil; and (b) a solid brick structure fashioned as a gateway part of which must rest on (but not wholly cover) a well going down to the waters under the earth; this may be connected with libation-offerings.

\section{LEVEL XV (Fig. I9)}

The temple of Level XVI was destroyed by fire and its successor, built at a higher level, was swept away by the builders of Level XIV; but that there was such a successor is proved by the survival of certain features which are sufficient to show that to some extent at least it reproduced the Level XVI plan.

The whole of the tiled pavement disappears under a clay floor or floor-level of mixed mud and wood ash which could be traced over the greater part of the area; it lay from $0.20 \mathrm{~m}$. to $0.40 \mathrm{~m}$. above the tiles, the difference being due to the irregularity of both surfaces. At the NW. end the 'mastaba' remained in use, but $0.70 \mathrm{~m}$. to the south-west of it there was a belt of large stones carefully laid to give a flat surface (Pl. VIIIb); at the

or less guesswork. We could not be sure of the mud-bricks (though the foremen were convinced); the best argument for them was that the brick earth came to a clean end against the stratified rubbish and ended at the same level. We dug deeply enough ... to show that nothing was buried under the brickwork.'

I Working in the south corner of the chamber, between its walls and the brickwork mass, we obtained the following data, of no particular interest in themselves but confirming our view of the soil as representing gradual accretion. The SE. wall showed a whitewashed face at the top, but could not be traced down more than $0.40 \mathrm{~m}$., owing to the sodden condition of the bricks. At $0.60 \mathrm{~m}$. from the top there was under the SW. wall either an older wall or an off-set, $0.50 \mathrm{~m}$. wide, of bricks upwards of $0.53 \mathrm{~m}$. sq. resting on stones. At this level there were quantities of broken mud bricks with one face whitewashed, clearly fallen from the wall. At $0.75 \mathrm{~m}$. down, the level of the sunken tiles pavement over the brick mass, there was a beam with matting above it running from the SE. wall to a line of bricks, perhaps a wall, $0.80 \mathrm{~m}$. wide, which was parallel to the $\mathrm{SE}$. wall and $\mathrm{I} \cdot 50 \mathrm{~m}$. from it; on each side of the beam was a mass of hard black stuff like dried bitumen. Below this came soil containing potsherds. At $0.95 \mathrm{~m}$. there was a single beam and a layer of matting; a number of beams and more matting came at $\mathrm{I} \cdot 45 \mathrm{~m}$. The soil was now very mixed and potsherds fairly common. 
SE. end, which agreed with the SE. end of the 'mastaba', it was flush with the black mud-and-ash floor, but sloped upwards very gently to within two metres of its NW. end (which agreed with the NW. end of the 'mastaba'), after which it was horizontal; the stones were only one course deep and at the NW. end rested on brickwork, ${ }^{\mathrm{I}}$ while at the SE. end they had only earth beneath them; this ramp was $\mathrm{I} .25 \mathrm{~m}$. wide and $0.80 \mathrm{~m}$. above the tiled pavement at its highest point. There was a good deal of black (carbonized) deposit on and between the stones. On the SW. side of the ramp, directly opposite the doorway in the 'mastaba', there was a rectangular compartment whose sides, of burnt brick, rose flush with the top of the stones; the mud floor to the north-west was at the same level; on the SE. side the floor was reinforced with one or two courses of mud brick. The NW. wall of the compartment was very thick ( $\mathrm{I} \cdot 95 \mathrm{~m}$.) and seemed to have had a higher mud-brick wall resting on it; the SE. and NE. walls did not quite meet but left a narrow channel open between them; the SW. part of the compartment had been cut away by the Level XIV wall, so that its full dimensions are unknown. Inside there was no floor; it was filled with mixed soil below which was black rubbish and then cleaner clay; we dug through this and found a very solid and sharply curved mass of carbonized matter which ran under the SE. wall, dipping ever more sharply. We could not explain this, but it certainly had nothing to do with Level XV; it may have been wreckage from a former building. The walls of the compartment did not go down for more than a few brick courses and there was nothing to show for what it could have served. There was some evidence for a later floor running over the top of the compartment.

At the SE. end of the building the old gabled structure was buried in the debris of broken and burned bricks from the Level XVI temple. Behind it the old sunken pavement of the SE. chamber was first hidden beneath a mud floor $0.40 \mathrm{~m}$. above it and later by a succession of mud-brick floors. The most striking thing, however, was a stone ramp (very much like that by the 'mastaba') I.60 m. wide, formed of a single course of large stones laid over mud brick and earth, giving a smooth surface which was $0.80 \mathrm{~m}$. above the level of the pavement of the main court of Level XVI, i.e. exactly flush with the top of the ramp by the 'mastaba'. The ramp followed the SE. edge of the chamber and then turned north-west exactly in line with the outside of the old gabled structure, and from the angle sloped gently up and then was broken away. To the south-east of the ramp and 0. I $5 \mathrm{~m}$. to $0.25 \mathrm{~m}$. below its top there had been a floor consisting of a single layer of mud bricks with matting stretched over it; on it lay a large saddle-quern $0.50 \mathrm{~m}$. across; both below this floor and above it was finely stratified rubbish denoting gradual accumulation. At $\mathrm{I} \cdot 30 \mathrm{~m}$. to the south-west of the ramp there was, at $0.20 \mathrm{~m}$. above the mattingand-brick floor, a layer of white lime (probably the scanty remains of a somewhat later floor) in which was a circular oven or furnace of fire-clay cut down through the brick.

Since the existing features of Level XV are unintelligible except in relation with the peculiar ritual (?) arrangements of the older building, they seem to point to a continuity of tradition.

\footnotetext{
I This brickwork was perhaps the remains of the Level XVI courtyard wall.
} 
THE LEVEL XIV TEMPLE

See Fig. 2I; also Fig. I 8 and Pl. VIII $b$.

The temple was relatively well preserved as regards the main lines of its groundplan; it consisted of an inner chamber, nearly square originally (its proportions were somewhat changed in a second phase of its use), which included and was practically divided into two by the brick 'mastaba' surviving from Level XVI; an outer chamber, a good deal wider than it was deep (here again the proportions were later modified), and in front of the entrance a courtyard with a raised podium along the façade of the building $0.35 \mathrm{~m}$. higher than rest of the courtyard floor; the courtyard was surrounded by a wall or parapet, but this could be traced only along parts of the SE. and SW. sides and was not found at all on the north-east. ${ }^{I}$

The floors of the temple chambers lay from $\mathrm{r} .00 \mathrm{~m}$. to $\mathrm{I} \cdot 55 \mathrm{~m}$. above the tiled pavement of Level XVI; the wall foundations went down sometimes to $0.45 \mathrm{~m}$. and sometimes to $0.25 \mathrm{~m}$. of the pavement.

The Inner Chamber. The floor was of clay with a coating of whitewash; the walls also were mudplastered and whitewashed. The west corner showed a break in bond and the whitewash on the $\mathrm{SW}$. wall was found to run on past the corner; we cut away part of the NW. wall to a depth of 0.60 $\mathrm{m}$., but before we got so far the whitewash failed us, and although there seemed to be a change in the look of the bricks we could not distinguish any return of the SW. wall. However, farther to the east and at a higher level the expected break in the bonding was found, and it became evident

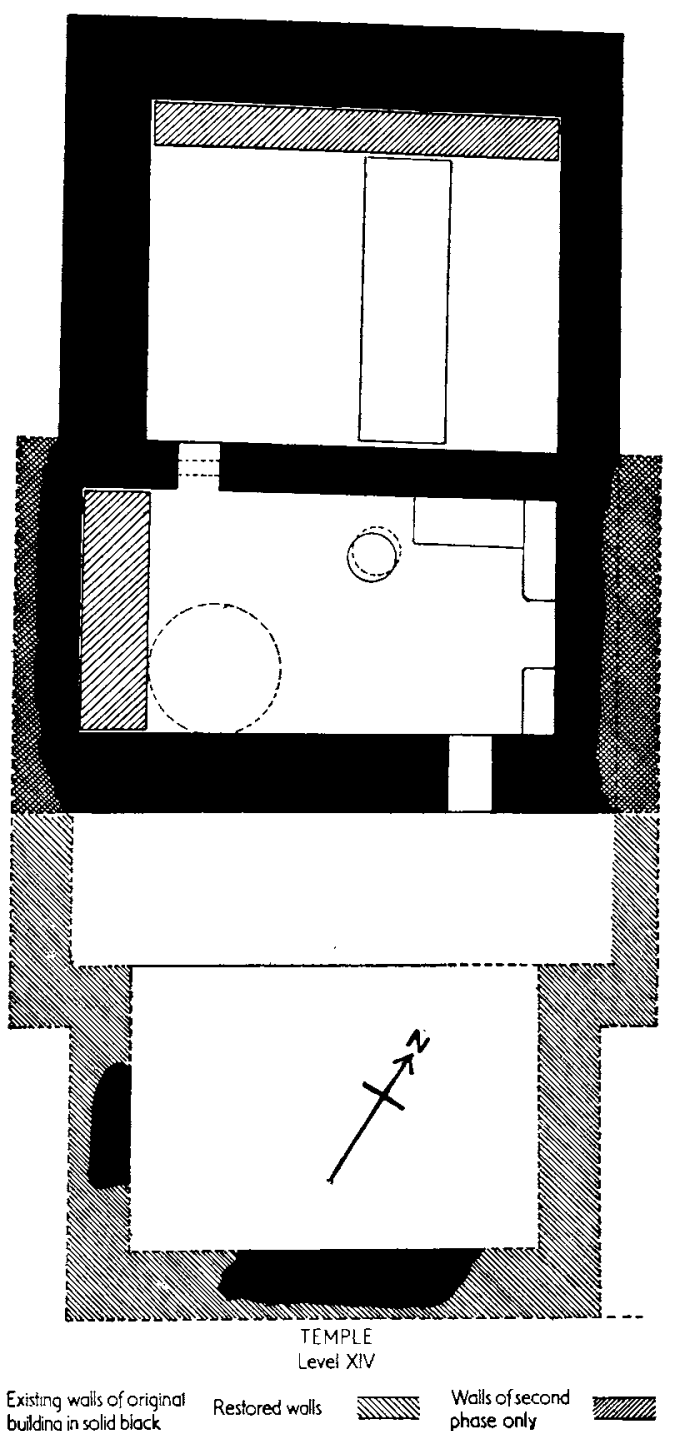

FIG. 21. I: 200 that the original wall of the room had at a later period been refaced by the addition of a skin of brickwork of $0.90 \mathrm{~m}$. thickness. ${ }^{2}$ As a result of this the $\mathrm{NE}$. end of the chamber was entirely cut off from the $\mathrm{SW}$. end by

I The whitewashed face of the front wall of the temple was followed up to the east corner and showed no signs of any return south-east; the temple must have been built and whitewashed before the parapet-wall of the courtyard was added abutting on it. We were deceived by the absence of any joint, and if there was anything left of the wall destroyed it, failing to distinguish it from the brick filling of the Level XI platform. 2 The lowest brick course of the new work came at $0.45 \mathrm{~m}$. above the tiled pavement, the same level as the corresponding course in the SW. wall. On the other hand, the SW. wall 
the 'mastaba', this stood $\mathrm{I} \cdot 50 \mathrm{~m}$. above floor-level, $\mathrm{r}$ and while the SE. wall of the room was built virtually against the end of the 'mastaba' there was at the NW. end a gap of about $0.40 \mathrm{~m}$.; before the new brickwork was added to the wall-face this gap had been at least $1.00 \mathrm{~m}$. wide and therefore afforded a reasonable passage between the two parts of the room, but this had now become impracticable. Accordingly the whole of the space behind the 'mastaba' was filled in with mud bricks; near the 'mastaba' these went down to, or almost to the old tiled pavement, but towards the NW. wall the filling stopped at $0.75 \mathrm{~m}$. above the tiles and below it was stratified rubbish and, at $0.30 \mathrm{~m}$. above the tiles, a fairly heavy $(0.003-0.008 \mathrm{~m}$.) stratum of lime about $0.50 \mathrm{~m}$. wide continued by a thinner stratum of grey ash which ran, rather irregularly, about half-way across to the 'mastaba' - this was apparently an intermediate floor-level and corresponded to a stratum of black ash and rubbish which could be traced over the whole of the NW. end of the room, where it ran under the Level XIV walls. The brick filling was carried up to the same height as the 'mastaba' and on the top of it there were two large rather flat boulders set immediately over the front edge of the new work; since the brick filling went right up to the NW. wall of the chamber it should be of the same (late) date.

During the time that the temple was in use the inner chamber-presumably the sanctuary - was remodelled. In the first phase the old 'mastaba' was retained unchanged, standing in the middle of the room against the SE. wall with a passage between it and the $\mathrm{NW}$. wall. In the second phase the room was narrowed so as to do away with the passage $^{2}$ and the 'mastaba' was enlarged so as to occupy the whole of the NE. end of the room. The level of the floor of the room was not altered. The base of a large clay pot was found let into the floor in the corner between the 'mastaba' and the SE. wall; in the corner between the 'mastaba' and the NW. wall, just below the top of the former, there was, tilted in the filling, a semi-cylindrical wooden trough $0.95 \mathrm{~m}$. long by $0.63 \mathrm{~m}$. wide and $0.34 \mathrm{~m}$. deep, the wood two and a half centimetres thick, with mud brick against either end of the trough; inside it were loose earth and potsherds.

The outer chamber of the temple gave evidence of two distinct phases. The most important fact was that a new wall had been built against the face of the original SW. wall, reducing the length of the room by $1.40 \mathrm{~m} .{ }^{3}$ precisely as the inner chamber had been reduced in depth.

rested in part at least on a foundation of wooden beamsone could be measured, $1.75 \mathrm{~m}$. long $\times 0.15 \mathrm{~m}$. sq. Further, the depth of foundation is not an argument for date; the SE. wall (perhaps because it was an internal wall) had a foundation of wooden beams, but this was $0.70 \mathrm{~m}$. above the tiles.

I The floor of this chamber was only $\mathrm{I} \cdot 00 \mathrm{~m}$. above the Level XVI pavement, $0.20 \mathrm{~m}$. above the top of the stone ramp of Level XV.

2 The remaining gap was filled with earth and broken brick and it seemed that mud plaster had been carried over this; it was difficult to be sure on the point owing to the dampness of the brickwork, but the whole thing was so homogeneous that we did not at first realize the existence of the gap. The new work at the back was easily distinguished be- cause the bricks there measured $0.42-0.43 \mathrm{~m}$. in contrast with the big bricks of the original mastaba.

3 This necessitates there having been a projection of the outer face of the temple wall as suggested in the plan; this was not actually found because the outer face lay beyond the limits of our excavation. It is reasonable to suppose that there was a corresponding projection on the south-east and that the SE. wall of the room as found by us was also an addition plastered against the old wall; I did not detect any straight joint in the east and south corners, and as our work did not go beyond the inner face of the wall no evidence was forthcoming. On the plan I have suggested an alteration at this end also, but it is purely theoretical. See on this the note on p. 45 following. 
The façade wall of the temple, from the west corner to the doorway, had a foundation of timber resting directly on the whitewashed coping of the ancient brickwork mass preserved in Level XVI; ${ }^{\text {T }}$ the NE. jamb of the doorway and about half of the NE. wall had heavy stone foundations-rough boulders-resting on the stone filling of the Level XVI pit; clearly the builders had some doubt as to the solidity of the subsoil here; the NW. half of the same wall had plain brick foundations on or just above the old tiled pavement, rising towards the north-west so that at the north corner it, like the NW. wall, ended $0.45 \mathrm{~m}$. above the pavement at a stratum of white lime, probably the remains of a floor, below which came a black ash stratum traceable all over the room at $0.25-0.30 \mathrm{~m}$. above the pavement. Between the black floor (?) and the Level XVI pavement there was mixed rubbish, mostly bits of mud bricks, a few fragments of bricks accidentally burned, and some ash; above the black floor and below the floor of the Level XIV room there was a solid mass of accidentally burned bricks coming from the destruction of a building which (in view of the cleaner rubbish below) should be not the Level XVI temple but a later building on the same site. This red mass had been levelled and a clay floor laid over it - the original floor of the Level XIV room-lying $0.90 \mathrm{~m}$. above the Level XVI tiled pavement; above it was mixed building-rubbish (not burned) and then at $\mathrm{I} \cdot 60 \mathrm{~m}$. the floor of the second phase, also of clay, very well laid and whitewashed. In connexion with the earlier floor there was, near the middle of the NW. wall, a sunken circular fire-place or oven, clay lined, its rim standing $0.25 \mathrm{~m}$. above floor-level.

The upper or second-phase room was well preserved. Since its floor had been raised by $0.70 \mathrm{~m}$. and was therefore half a metre above the floor of the inner chamber, there must have been steps in the thickness of the doorway between them; we did in fact find brickwork at the threshold but could not distinguish separate treads. The entrance-door in the SE. wall was curiously narrow, only $0.95 \mathrm{~m}$., with a raised brick threshold which, like the jambs, was plastered and whitewashed. Against the NE. wall there was a brickbuilt bench, plastered and whitewashed, $0.95 \mathrm{~m}$. high ${ }^{2}$ and $0.60 \mathrm{~m}$. wide, with a gap in the middle, the bench-ends here being neatly rounded; against the NW. wall there was another bench $0.40 \mathrm{~m}$. high and $0.90 \mathrm{~m}$. wide which ran from the face of the higher bench for a distance of about $2 \cdot 10 \mathrm{~m}$. and then broke away-there was some reason to think that it had been much longer. On the line of this bench, and therefore, if it had originally been longer, partly underneath it, ${ }^{3}$ there was a sunken circular fire-place or oven, of fire-clay, almost directly superimposed on the oven of phase I; it had been filled in and the floor had presumably been carried over it, but the floor here was too broken for evidence to be satisfactory. In the south corner of the room there was a very much bigger fire-place, circular and built of bricks; its base was I.25 m. below the floor of the

I The door-jamb itself, being beyond the coping, was on burnt brick rubbish.

2 As preserved; actually the 'bench' top had disappeared and its brickwork was flush with the existing top of the wall against which it stood. It is possible that it was not really a bench at all but a later addition to the wall face, corresponding to that at the SW. end of the room, but having a central niche; this seems the more likely because it would make the total thickness (including the assumed external projection) of the two end walls of the chamber the same. The thickening of those walls would imply their heightening also, and a central niche suggests a statue; it may therefore be that in the later phase of the temple's use the entrance-room was remodelled as a cult chamber.

3 The field notes state that 'the bench ran directly over the top of it'. 
room, the sides, rather roughly built, were vertical for $0.25 \mathrm{~m}$., after which they were corbelled inwards; nearly all the corbelled part had collapsed but as the corbelling $(0.20$ in 0.25 vertical) was not so abrupt as to connect with the lower (phase I) floor, the oven must be assigned to phase II. Indeed it looks very much as if there had been three phases; in (I) we have the lower floor with its small oven; in (II) the upper floor with its corresponding oven and a bench along the SE. wall; in (III) an extra bench is built along the NW. wall, obliterating the oven, and a new and bigger furnace was contrived in the west corner to replace it.

In front of the temple entrance there was a solidly constructed mud-brick platform, the top of it $0.30 \mathrm{~m}$. above the level of the 'phase I' floor of the entrance-chamber, against the façade wall ${ }^{1}$ and constructionally later than it. It was just over $3.00 \mathrm{~m}$. wide, and beyond it there was a clay floor half a metre lower. ${ }^{2}$ The floor had been much patched and repaired and its surface was far from even; on the top of it there was a thick deposit of rubbish-ashes, animal bones, and fragments of pottery, seemingly the throwout of sacrifices. ${ }^{3}$ In the late phase of the Level XIV temple the whole court was repaved. Against the façade of the building a new pavement was laid over the top of the old platform, a strip $3.35 \mathrm{~m}$. wide of bricks $0.52 \mathrm{~m}$. sq. with very broad mud-filled joints; in front of this was a whitewashed clay floor which ran level for a metre and then sloped down to a similar floor O. $15 \mathrm{~m}$. lower. The court was contained by a parapet wall; it was noted that on the SW. side this wall 'never stood more than $1.50 \mathrm{~m}$. high', and on the south-east it was found to be standing to just that height above the original floor of the Level XIV courtyard; when the courtyard was raised the parapet was only a metre high. The ground surface outside seems to have been about one metre lower than the floor of the court. There was no sign of an entrance, which may have been on the NE. side.

Two points call for notice. First, the repairs to the building and the raising of its floor-level must imply a certain lapse of time; in the adjoining house site Levels XIV and XIII are each represented by a single stratum of private buildings, and it is therefore not unreasonable to assume that the temple was contemporary with both-that it was built in the Level XIV period and survived throughout that period and the next. There is good reason to attribute the succeeding temple to Level XII; there must have been a temple in the Level XIII period, and if we find no distinct construction answering to such, then we can surely suppose that the repaired Level XIV temple was still in use. In the second place, although this temple certainly does not follow the constructional lines of its predecessor, it none the less seems to preserve its ritual character. The retention of the 'mastaba' is in itself almost enough to prove that; and it would not have been so scrupulously preserved if the traditions attached to it had not been preserved also. In the Level XVI temple the 'mastaba' was connected with the well and lay to the north-

I I could not distinguish the joint in the brickwork, but a course of matting in the wall did not go through into the platform, and the foundations of the latter were shallower and did not have the timber courses of the wall.

${ }^{2}$ It was tempting to connect this with the stone ramp previously described and to regard the sloped top of the latter as bridging the gap between the lower court and the platform; but this is not possible; the ramp definitely belongs to an earlier period and the clay floor runs well above it.

3 The pottery included numerous fragments of cookingpots, a few rims of shallow bowls, some painted sherds, and part of the stem of a 'champagne-cup'. 
west, while to the south-east of it was the place for burnt sacrifice; in the Level XIV temple rooms replace the open court, but the inner or NW. room contains the 'mastaba' (and the existence of the well below it can scarcely have been forgotten) and in the SE. room are the ovens or furnaces for burnt offerings. There seems to be here a continuity which is the more interesting in view of the complete change that was to follow.

\section{THE LEVEL XII TEMPLE (see Fig. 22)}

Of all the temples excavated on this site that of Level XII is the best preserved. It lasted for a long time and in the course of its existence was twice remodelled, ${ }^{\mathrm{I}}$ but the ground-plan emerges fairly clearly and it is even possible to restore the elevation with tolerable accuracy.

Widely as this temple differed from that of Level XIV, it was founded directly upon it and its external lines were identical. For its construction the old walls were trimmed down to a uniform level and the rooms of the old sanctuary were filled up to that level, the outer room with mixed rubbish, the inner room with peculiarly clean, light soil (there was not a single potsherd in the whole of it), the top of which was flush with the top of the old 'mastaba'. The Level XIV temple thus became a solid podium. Then new walls were built on the stumps of the old, following the same lines but having a different character; for the back wall of the new inner room a thickness of $2.90 \mathrm{~m}$. and for the front (or intermediate) wall $\mathrm{I} \cdot 90$ $\mathrm{m}$. instead of the $\mathrm{I} \cdot 00 \mathrm{~m}$. of Level XIV; in view of this greater width a certain amount of timber was used for its foundations, a beam being laid along the entire length of the NE. face and two transverse beams through the $\mathrm{SE}$. end of the wall with one beam between them on the wall face. In the other walls the new brickwork was laid directly on the old. The side walls and the façade wall were of the same thickness as in the older building. The outer chamber was reduced in width by a cross-wall on the southwest, I.00 m. thick at its $\mathrm{NW}$. end but narrowed at its SE. end to a screen only $0.50 \mathrm{~m}$. thick ( $v$.

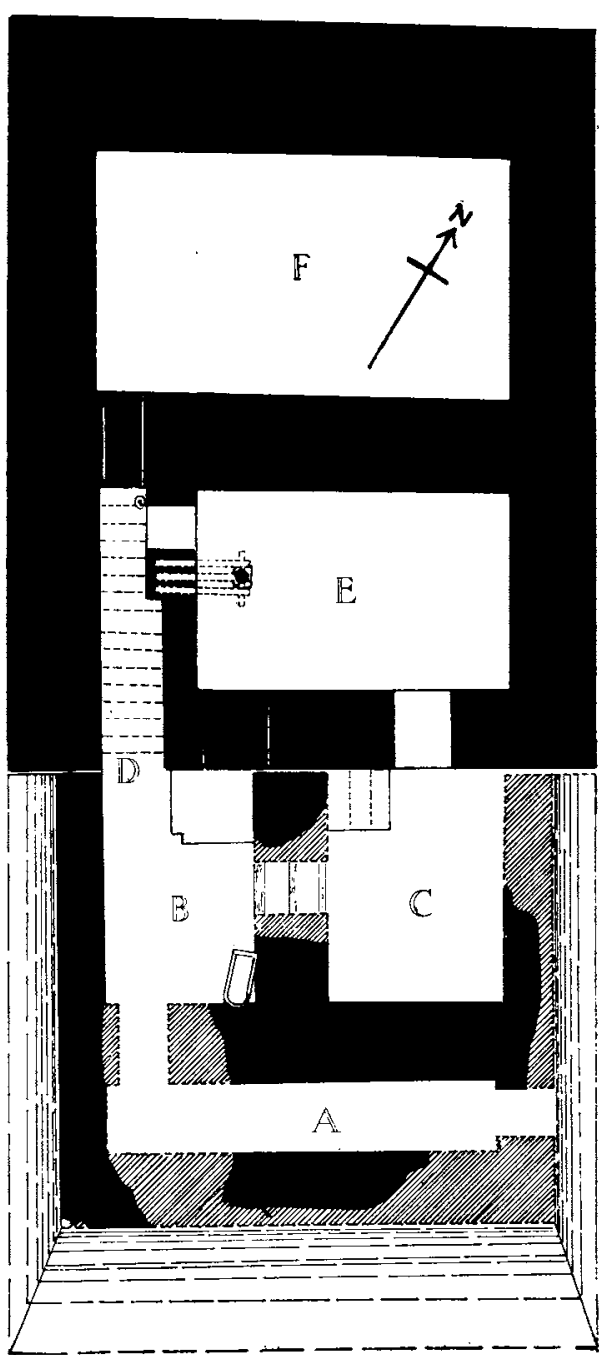

FIG. 22. The Level XII temple. I:200 note on next page); the narrow space between it and the outer wall of the building was filled by a flight of stairs, the lower part solid, the upper treads added later in timber

I As was the Level XII palace; see P. 2 I. The parallel is a good justification for assigning the temple to this level. 
(Pl. IXa). Over the outer chamber was laid a floor consisting of two courses of mud bricks topped with clay. In the inner chamber a layer of mud, containing a little pottery, was spread to a depth of $0.40 \mathrm{~m}$. over the clean earth filling and above it were laid two courses of mud brick over which a 'floor' of black mud. That this did serve as a floor seemed to be proved by the fact that over it lay a thin-a very thinlayer of rubbish containing some fragments of fine painted pottery. But it can only have been a provisional affair since the rubbish was no more than two centimetres deep, and there was no access to the room. Immediately afterwards the chamber was filled by a

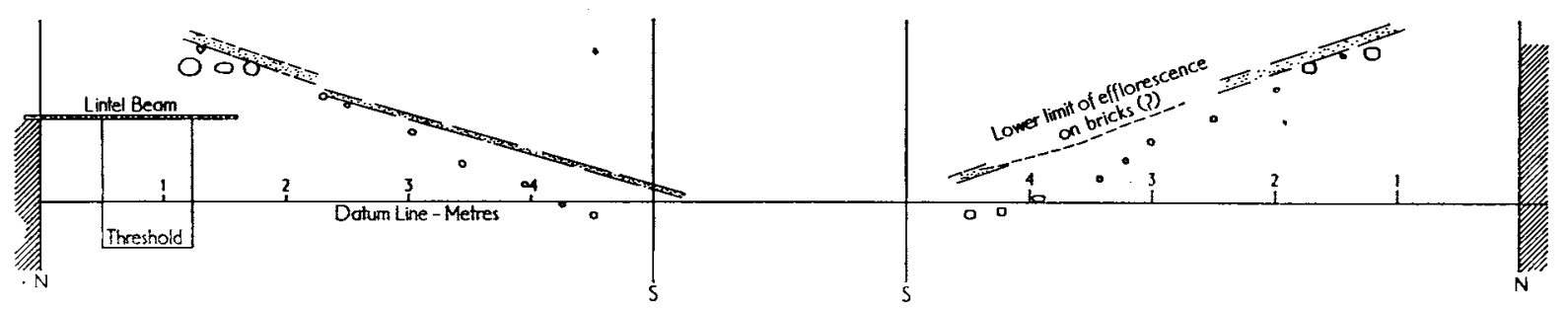

(a) The NE. wall

FIG. 23. Traces of stair supports

(b) The SW. wall

solid mass of carefully laid mud bricks to a height (as we found it) of $2.00 \mathrm{~m}$. This was done after the walls were built, for the bricks of the filling were laid against the face of the wall, not bonded into it; but that it was part of the original plan and not a later modification was proved by the fact that the chamber had no doorway at all at the level of the platform from which the walls rose; the doorway had been, from the first, at the top of the stairs. In the side walls of the narrow staircase passage (but better preserved in the outer wall) there were in the brickwork the holes left by the decay of the wooden joists which supported the stair-treads. In the SW. wall (v. Fig. 23) there were fifteen holes visible, twelve of which were in a straight line and three (nos. 5,6 , and 7 ), slightly below that line as if they had supported the rise and the others the front of the treads; the spacing is generally even, $0.30 \mathrm{~m}$. from centre to centre, but the gaps between the top three are wider, nearly twice as wide; but here, where the wall surface was more damaged, holes may have existed which are not now traceable. The total length of the line given by the holes is $5.20 \mathrm{~m}$., i.e. the length of the passage less $0.40 \mathrm{~m}$. allowed for the set-back of the first step from the line of the façade; the total rise is $2.00 \mathrm{~m}$., which agrees exactly with the height of the brick filling found by us in the inner chamber; that should therefore be the original height of the chamber floor. ${ }^{I}$

The building proper is then a rectangular block measuring fifteen metres in depth and just under twelve in width. At the SE. end there are two doorways, that on the right

I The floor of the passage (used as a cupboard, $v$. infra) was of mud mixed with lime; it rested on a brick packing and, at one point, on the top of the razed part of the Level XIV temple façade wall. The stair-treads were of the same width throughout; the change of thickness of the right-hand-side wall affected only the upper part, the lower part being of the same thickness all along; but for a distance of $3.50 \mathrm{~m}$. there seems to have been a bench (possibly stepped up with the stairs) from which the whitewashed face of the wall proper was set back $0.30 \mathrm{~m}$. The holes for the supports of the lower treads were in the brickwork of the bench, below the bottom of the whitewashed wall, and then failed, to begin again in the 'buttress'; the more complete flight of holes was given by the opposite wall. 
leading into the outer chamber, that on the left to the staircase whereby access was had to a chamber raised two metres above the other. Further there was in the façade, at $0.80 \mathrm{~m}$. from the corner of the staircase, a window set $\mathrm{I} \cdot 40 \mathrm{~m}$. above floor-level; its whitewashed sill could be traced for $0.70 \mathrm{~m}$., but thereafter the wall was broken away so that the full width of the window could not be established; its remaining jamb stood $0.80 \mathrm{~m}$. high.

The only explanation of the deliberate thickening of the walls of the inner chamber is that they were intended to be of great height. The chamber proper starts at $2.00 \mathrm{~m}$. above platform level so that even if it had been no loftier than the outer chamber it would still have risen that much above it, but the wall thickness proves that this minimum limit was much exceeded and we can safely picture the room as forming a considerable tower. An interesting parallel to this is furnished by the clay model of a temple found at Selemiyeh and now in the Aleppo Museum $(\mathrm{Pl}$. IXb $) ;^{\mathrm{I}}$ it is not accurately dated but is certainly early. This gives us the low flat-roofed antechamber with side windows and a door at the end, and a tower-like rear chamber also with windows and a door on to the flat roof of the room in front. In this case the tower is two stories high (i.e. there is a lower room instead of the solid packing) and no staircase is shown, although there must obviously have been one-it would be absurd to expect complete architectural accuracy in a clay model-and there is a decoration of rope-pattern and appliqué birds to which there is naturally nothing corresponding in our ruins; but the two buildings are unquestionably similar in type and give us what we may assume to have been a very early form of temple characteristic of northern and central Syria. ${ }^{2}$

Of the internal arrangements of the inner chamber there is no evidence, everything having been razed to floor-level by the builders of the next age. The outer chamber doorway had a threshold, slightly raised, made of a framework of stout timbers with a central filling of packed clay; the floor of the room also was of clay. In the SW. wall, near the north corner, there was a doorway $0.85 \mathrm{~m}$. wide and only a metre high; ${ }^{3}$ its sill was at about $0.30 \mathrm{~m}$. above the floor; the wooden door had opened outwards, its hingestone being found against the NW. jamb in the stair-passage; it was a door to a cupboard under the stairs. Inside the room, to the left of the cupboard door, there had been something in the nature of a shelf. Three parallel joists whose ends were embedded in the brickwork of the wall (at this point a metre thick) projected into the room for about a metre $^{4}$ and were then supported-presumably with the intervention of a cross-bar-on an upright post; the base of the latter went down into the floor and rested on an impoststone which was actually a fragment of a basalt altar (?), Fig. 80g. The 'shelf' was circa

\footnotetext{
I I am indebted to the kindness of the Director, $\mathrm{Mr}$. Sawaf, for the photograph and for his permission to publish it.

2 It is tempting to suggest that this was related to the lofty and windowed bit hilani which the Assyrians admired and took over from the Hittites; as the Assyrian contacts were with the Syro-Hittites, not with Anatolia, the 'Hittite' temple might well have been of local Syrian origin and have nothing to do with Bogazköy.

3 The whole doorway was preserved, the bricks of the wall B 2501
}

above not having fallen; they had been supported on a number of not very thick timbers set closely together, the imprint of which on the mud bedding of the brickwork above was quite clear. 'The preservation was due to the doorway's having been subsequently bricked up from the inside with two courses of bricks below and one above, flush with the face of the room wall but rough behind. The high sill may have been an afterthought; under it lay sherds including part of a 'champagnecup'. $\quad 4$ 'This, at least, is as far as we could trace them. 
I. $50 \mathrm{~m}$. above the floor and had a width, as given by the joists, of at least $0.75 \mathrm{~m}$. Between the wooden upright and the $\mathrm{NW}$. wall of the room there was in the clay floor a roughly circular depression, diam. I.50 m., outlined by a narrow curved channel; the bottom of the depression was mud-floored, and it was full of burnt ashes; it had apparently been a fire-place.

In front of the temple there was a walled courtyard corresponding exactly to that of Level XIV. But whereas the temple seems to have maintained its character unchanged throughout the period of its use, the courtyard saw many changes. At least four floors could be distinguished in it, accounting for a total rise in level of $0.70 \mathrm{~m}$.; and corresponding to the later floors there were modifications, sometimes radical modifications, of the buildings in it.

The courtyard wall was built after the temple proper was finished; the plastered and whitewashed face of the temple façade runs through to the corners of the structure and

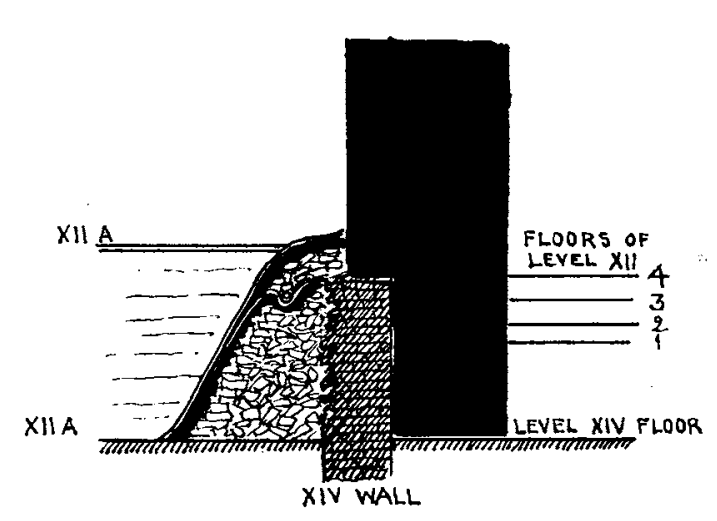

FIG. 24 the brickwork of the court wall abuts on it. ${ }^{\mathrm{I}}$ The two side walls reproduced those of Level $\mathrm{XIV}$, which were utilized as foundations; the SE. wall, however, was set farther in, thus reducing somewhat the area of the Level XIV court. The old wall was still standing to a height of rather more than a metre and a half above the (raised) ground-level outside the temple, but it was in a ruinous condition, the whole of its face having fallen away; the Level XII builders therefore heaped brick rubble from the wall against the broken face and plastered it thickly with greenish clay, adding a final coat of lime plaster, so as to make a steeply sloping glacis the top of which curved over the top of the standing brickwork; above this glacis rose the new wall, built partly on the inner edge of the old wall and partly on the courtyard floor. ${ }^{2}$ The slope of the glacis was $0.55 \mathrm{~m}$. in a metre vertical. The clay-revetted glacis seems to have been a regular feature of Alalakh architecture; we have it in the city wall (v. p. I 53) and perhaps also in the little shrine described on p. I75. But this is by very much the oldest example, and its early date accords with the theory ${ }^{3}$ that the glacis type of construction is northern by origin (Anatolian or north Syrian) and that the derivatives in Palestine and at Tell el Yahudiyeh in Egypt are evidence of northern influences.

\footnotetext{
I Actually we did not find the abutting ends; the workmen following the whitewashed façade through the later mudbrick filling of the courtyard failed to distinguish any onthge when they came to the boundary wall and cut it awaying very pardonable mistake in the circumstances; farther back the wall was recovered and there can be no question as to the accuracy of the statement in the text.

2 The work was done in two stages. The original glacis plaster curved inwards sharply about $0.20 \mathrm{~m}$. below the top
}

of the ruined wall-face and then was scooped down so as to make a sort of trough $0.15 \mathrm{~m}$. wide and $0.15 \mathrm{~m}$. deep parallel to the wall, and then was carried up almost vertically to hide the broken brickwork. Later-it is impossible to say how much later-the main face of the glacis was replastered and more rubble was heaped up above the trough and the plaster carried up over this to the footing of the new wall; $v$. the sketch, Fig. 24.

3 W. F. Albright, The Archaeology of Palestine, pp. 88-89. 
Conditions beyond the glacis are of interest as testifying to the longevity of the Level XII temple. Originally it stood one metre high, i.e. the temple platform was a metre above the level of the ground immediately in front of it. Against the foot of the slope there was a certain amount of brick rubble, but this was overlaid by dark-coloured rubbish very irregularly stratified with lighter rubbish above which evidently had accumulated gradually; this had attained a depth of two metres before it was levelled and a white lime floor laid over it. During the temple's lifetime therefore the groundlevel outside it had time to rise no less than two metres; whereas the building originally stood on a platform a metre high, in the end its courtyard (in spite of its having itself risen $0.70 \mathrm{~m}$.) was actually lower than its surroundings. It is quite possible that at the outset there was no real wall along the SE. end of the court but that the glacis (the top of which was a metre above the floor) formed a mere parapet, and that the wall proper was added later as the ground-level on both sides of it rose; this would certainly agree with the depth of the wall-foundations; but it was difficult to be sure of this.

Against the façade of the temple there is a square of mud brickwork, like a buttress, which is constructionally later than the temple in that the whitewash on the face of the latter runs on behind it; but since its foundations go down to the same depth as those of the temple, the difference in date may be very slight. ${ }^{\mathrm{I}}$ The 'buttress' is a jamb of a doorway $^{2}$ of which the corresponding jamb is a member of a heavy wall running parallel to the SW. wall of the courtyard and only $\mathrm{I} \cdot 35 \mathrm{~m}$. away from it; it seemed to be bonded into the SE. wall of the court, and its deep foundations showed that it was virtually contemporary with the temple. On the SE. face of it, at the NE. end, there was a reentrant angle; no corresponding angle was found, since the east corner of the court lay just outside the limits of our excavation, but it seems fairly safe to restore one, and in that case we have a doorway leading out from the courtyard. If this was the entrance to the temple-and it is difficult to imagine any other position for such - then there must have been another doorway between the SW. end of the intermediate wall and the SW. wall of the court, and I have accordingly restored one on the plan, but no trace of it was found owing to the complete destruction of the SW. end of the wall; nor did we find any reveal on the face of the courtyard wall, but here again one may have existed and been cut away by us when we were digging through the mud-brick filling to follow the line of the mud-brick wall of the court. ${ }^{3}$

\footnotetext{
I It was by no means easy to unravel the evidence for the arrangement of the courtyard at different times. The impression which I got was that the courtyard with its building was part of the original plan but it was important that the temple should be ready for use as soon as possible; the temple block therefore was completed before anything else was started, but in the meantime there had to be some provisional arrangement for the temple approach. The existing floor of the Level $\mathrm{XIV}$ temple was therefore patched and made good and its ruined wall masked by the new glacis, so that there was actually an open court in front of the temple; but after a very short interval work was started on the courtyard buildings. In that case the interim arrangement should be described as
}

a constructional stage rather than as a phase in the history of the temple.

2 The inner faces of the jambs had disappeared, but between them, at floor-level, there were three wooden beams, parallel to the line of the wall, which were the frame of the threshold.

3 This was originally done by tunnelling, and in the dark it would have been impossible for the workman to distinguish between the laid brickwork of the filling and the laid brickwork of a cross-wall. Tunnelling is, of course, a thoroughly bad system; it was only adopted here because our excavated area covered only part of the temple and had to be extended, but as any extension meant digging down for about 
The form of the temple then was, originally, a sanctuary block of different heights, as described above, with walls rising vertically from their foundations, and in front of it a 'courtyard block' whose walls rested on a sloped glacis. ${ }^{I}$ The entrance was by the east corner, on the side neighbouring on the royal palace. An entrance-passage (A) ran along the SE. end; its thick walls suggest that it was roofed, possibly vaulted. A door on the right led into a small court (B) which certainly was not roofed, seeing that a window of the outer room looked into it; moreover, a roof could not have been supported by the sanctuary wall, which was finished before this court was built, and the SW. wall is too thin. Immediately in front of the entrance-door was the staircase leading to the upper sanctuary room; on the right was a door leading into a second small court (C) which also would seem to have been open; through this court one went into the lower and outer chamber (E) of the sanctuary building; a bench $0.50 \mathrm{~m}$. wide and $0.25 \mathrm{~m}$. high ran along the SE. wall of the court (C); both wall and bench were whitewashed.

The original floor was fixed by our finding the lowest step of the staircase with the wooden plank of the tread still lying on the cross-timber of the support; in front of it was a whitewashed floor of clay mixed with lime. Patches of the same floor were preserved in court (B) connected with the temple façade and on each side of the doorway into court (C);0.25 m. above it was a second whitewashed floor, at $0.40 \mathrm{~m}$. above it a clay floor, at $0.70 \mathrm{~m}$. a brick floor, and there were traces of other intermediate floors as well. The lowest floor in court (B) showed signs of burning towards the east corner and was littered with ashes and with animal bones both burnt and unburnt; the whitewashed and clay floors above it were heavily burnt and covered with wood ash; in connexion with one of these upper floors (I could not determine which) there was a rectangular fire-place in the corner of the court-a mere hollow sunk in the floor-full of ashes. ${ }^{2}$ It would appear that the rites of burnt offering which in the Level XIV temple took place in the outer room of the sanctuary itself were in the Level XII temple shifted to the courtyard; this may be due to the fact that in Level XIV the outer chamber led into the inner sanctuary whereas in Level XII the outer chamber had no access to the inner and in this respect the court (B) had taken its place; it remains true that in each building the place for burnt sacrifice is not in the Holy of Holies but as close as possible to the door leading to it. The same is the case even in the final phase of the Level XII building.

The final phase is marked by the demolition of all the internal walls so that the whole area became a single open court, paved with mud bricks. In spite of this, tradition was so

ten metres it was essential in the interests of economy to settle
in advance exactly how fat that extension had to go. A tunnel
therefore, following the SW. wall, was driven as far as the
glacis of the temple platform. Later all this was properly
excavated.
I Only that at the SE. end was excavated, but it must have
had a return of some sort, and the set-back of the thin SW.
wall of the court from the external line of the heavy temple
wall seems to show that the glacis ran back to that wall-angle
as suggested on the plan.
2 We were at one time much exercised by finding a heavy deposit of ashes, potsherds, and bones in the passage (A), just in front of the entrance-door; it occupied the space between the two walls of the passage and was regularly stratified in a way which showed that it was due to gradual accretion, not to dumping. It was overlaid with a course of mud bricks. This seemed to extend the sacrificial area, and also to conflict with the theory that (A) was the entrance to the temple. Finally it was proved that the deposit dated from Level XIVXIII, the foundations of the intermediate wall went down into the rubbish and the brick floor was the original floor of the passage 
persistent that immediately over the rectangular fire-place in the corner of court (B) there was set a new fire-place, coffin-shaped with an oval end, which is so carefully placed that at first sight it would seem to be connected with the courtyard walls; it is, however, proved to be later than those walls by the fact that it is dug into them to an extent impossible had they been still standing. The NW. jamb of the doorway between courts (B) and (C) seems to have been demolished and then partly restored but for a different purpose. Apparently it was a platform $0.85 \mathrm{~m}$. high approached by a flight of three steps on its NE. side, the lowest step (the only one preserved in recognizable shape) coming against the jamb of the door of the outer room of the temple; between the platform and the corner of the staircase entrance there was a square hole in the brick floor, brick-lined, neatly plastered, and whitewashed, its bottom $0.70 \mathrm{~m}$. below floor-level. ${ }^{1}$ We could suggest no explanation of it. ${ }^{2}$

The destruction of the Level XII temple was certainly not due to fire; inside the building none of the walls showed any signs of burning, nor was there any deposit of burnt rubbish in the rooms. On the other hand, the outer face of the SW. wall of the temple proper had been burnt; this is the wall-face visible in the foreground of the photograph on Pl. IX $a$. In the construction of this wall a good deal of rather small timber had been used, the beams being laid along the wall-face sometimes so closely that the brick and wood courses were alternate; there were no timbers running through the thickness of the wall. The whole face had been mud-plastered, so that none of the woodwork could be seen-it was purely constructional. From a point about $0.60 \mathrm{~m}$. from the west corner of the building the wall-face from the level of the interior room floors upwards was heavily blackened by fire; there was a lot of soot deposit and, especially higher up, fragments of light brushwood, carbonized, adhering to the bricks; here the bricks were blistered and expanded by the heat so that much of the plaster had come away and the wall's surface was irregular. The heat, however, had not been very great; immediately below the black surface the bricks were only slightly reddened and this dull red quickly faded off into grey - a striking contrast to the effects of burning on the temples of Levels VIII and VII where the walls were bright red and crumbling all the way through. So far as I could see, brushwood had been heaped against the wall of the temple ${ }^{3}$ and set alight; the fire was not enough to destroy or even seriously to damage the building and I can only suggest that it was in some way symbolic. ${ }^{4}$

I The hole had been carefully filled with mud bricks and its existence was only detected by observing and following the thread-like line of whitewash seen in section. The brick flling might have been due to the Level XI builders making their new temple terrace.

2 The platform was not the solid start of a staircase which continued in wood with the whitewashed pit below it, for there were no beam-holes in the temple façade wall, and such would have been essential.

3 The evidence is confined to the NW. wall because the outer faces of the NE. and SE. walls were not excavated. Since there were no signs of burning below the level of the floors of the inside rooms, the ground-level outside must have been the same as that of the floors; and since the glacis of the SW. courtyard wall went down a metre below floor-level, the temple may have stood on a slope.

4 Not purificatory, for purification would scarcely be necessary for a temple that had been standing for a very long time. Could it be that the old building was still intact when the Level XI temple was planned to replace it and its destruction-even in a good cause-would be in itself an act of impiety, but this stigma might be removed by the legal fiction of an accidental burning? 


\section{THE TEMPLES OF LEVELS XI, X, IX, AND VIII}

Nothing was left of the actual structure of these temples, but their existence could be deduced from the remains of the platforms on which they severally stood, $v$. the Sections, Fig. 18.

The temple of Level XI must have been planned on lines very different from those of Level XII because the platform which was to serve as its foundation was of a very different shape; while its depth from NW. to SE. was the same, its width was nearly double that of the old building. The outer room of the Level XII temple, and its forecourt, were filled with carefully laid mud bricks up to about the level of the high floor of the inner sanctuary ${ }^{\mathrm{I}}$ and the walls were trimmed down to about the same level; but on the SW. side a skin of bricks was added against the burnt face of the Level XII outer wall and on the NE. side the new platform extended for $6.00 \mathrm{~m}$. beyond the limits of the old temple. On the SW. side the addition was not of the same width throughout; at the NW. end it was only $0.85 \mathrm{~m}$. (two bricks) thick, at the SE. end $\mathrm{I} \cdot 3 \circ \mathrm{m}$., the change

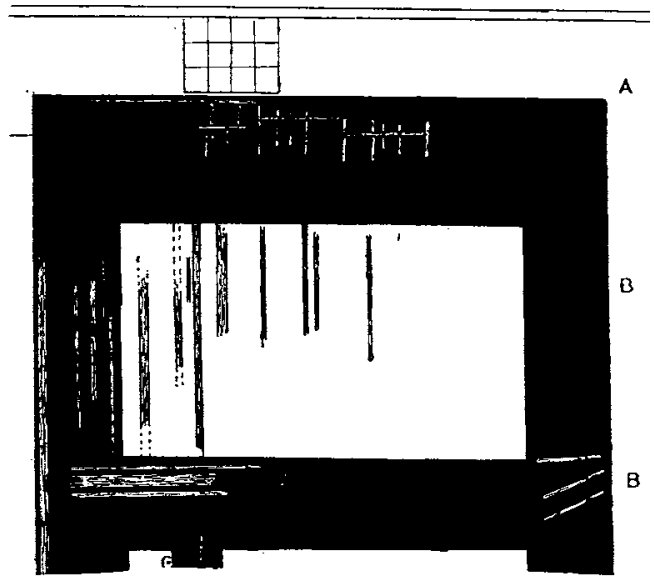

FIG. 25. Constructional timber work overlying the ruins of Level XII temple: groups B-B belong to Level XI, group A, and the brick base adjoining, to Level $\mathrm{X}$. $1: 200$ in thickness corresponding almost exactly to the face of the SE. wall of the Level XII inner sanctuary $;^{2}$ this presumably had some relation to the shape of the superstructure. ${ }^{3}$

I do not think that it is overstraining the evidence to suggest that in the Level XI period the old Syrian type of building, the indigenous type, was abandoned in favour of the Breittempel with its broad and shallow sanctuary characteristic of Babylonia. ${ }^{4}$ The only other feature that throws any possible light on the nature of the vanished temple is the occurrence of foundation-timbers (Fig. 25). A long beam or beams lying on the top of the SW. wall of the Level XII temple close to the wall-face may belong to that wall, seeing that timber was freely used in its face (v. supra, p. 53), but the rest all belong to Level XI. This was made quite clear by the fact that over the whole of the flat base afforded by the brickwork which filled the old rooms and extended beyond the walls of Level XII there was spread a course of reed matting to serve as a foundation, and the timbers lay above this matting

\footnotetext{
I The complete absence of any rubbish or loose dirt on that floor suggests that one or two of its brick courses-which in a building so old would presumably have shown signs of wear-were taken up so as to secure a better surface on which the new brickwork might be laid.

${ }^{2}$ We were inclined to think that this was not merely a re-entrant angle but the start of a branch wall; there certainly seemed to be a few bricks beyond the alignment of the (broader) wall but they did not run on to the SW. It is pos-
}

sible that there was a shallow buttress here at the wall junction, but the projecting bricks (if they were in position at all) may have been merely for strengthening the foundations.

3 Whether there was a similar projection on the NE. side we do not know because on that side the limit of the platform was reached by us only at one point.

4 e.g. in the Anu temple at Erech; v. J. Jordan, UrukWarka, 5 I Wissenschaftliche Veröffentlichung der Deutschen Orient-Gesellschaft, Leipzig, I928, Tafel I 8. 
incorporated in the new brickwork. What is noteworthy is that only a single slender beam was found over the outer chamber of Level XII (at its east corner), whereas on the tops of the walls of the inner chamber they were plentiful and over the brick filling of that chamber the parallel timbers lie close together. ${ }^{\mathrm{I}}$ The timbers were the bedding for the brickwork which in fact overlaid them, and in our experience of these buildings such bedding was employed only for walls, where there was to be a great weight of brickwork above, and is never found under floors. In the outer room there was no timber. This marked difference may imply that, as in the Level XII temple, the inner chamber had its floor raised on a solid mass of brickwork, for which a wooden foundation was deemed advisable.

Of the Level XI temple more than this cannot be said because its superstructure had disappeared altogether. The Level X builders, instead of trimming the stumps of the old walls and filling up what remained of the chambers, tore down the walls to their foundations and may even have removed the upper courses of the bricks of the platform, for there was no litter on or wearing of the Level XI brick surface and they actually exposed the tops of the walls of Level XII. So far as we know they did not appreciably alter the dimensions of the temple platform ${ }^{2}$ nor did they raise it, the total thickness of the new platform being only $0.80 \mathrm{~m}^{3}$ The distinction between Levels XI and X was given by a matting course spread over the whole area by the Level $\mathrm{X}$ builders; the top of their platform was adequately shown by actual building remains. Over the SE. wall of Level XII and also over its central wall there were in the Level X brickwork beamholes which should indicate wall-foundations, and the timbers would be not more than three courses of brick below floor-level; on the NE. side of the area, beyond the limits of the Level IX building and therefore undisturbed, we found in situ on the top of the platform a large stone door-sill against which were cobble foundations of the sort generally used under stone door-jambs; close to the NW. edge (Fig. 26), in a position above the 'mastaba' of Level XIV, there was a rectangle $2.00 \mathrm{~m}$. $\times \mathrm{I} \cdot 50 \mathrm{~m}$. of mud bricks of a size larger than was used for the filling $(0.47 \mathrm{~m}$. sq. as against $0.4 \mathrm{I}-0.42 \mathrm{~m}$.) in which it was embedded; 4 in front of it there were short wooden beams, about one metre long, lying NW. $\times$ SE. and supporting longer transverse beams-probably these timbers are again wall-foundations and the brick rectangle was something outside (to the north-west) of the

I We planned only those of which the traces were fairly continuous, but discontinuous signs of carbonized wood were common over the whole room. I would point out that where the holes in the brickwork left by the decomposed timbers had been filled up by infiltered mud it was extremely difficult and sometimes impossible to recognize them with the certainty that would justify the planning of them.

2 On the NE. and SW. sides it was identical; on the SE., where it rested on the Level XII wall, it may well have been the same, and on the NW. there was very little difference, if any.

3 The raising of the successive platforms was, of course, dictated by the rise of the surrounding ground-level; the fact that in this instance the increase of height was very small (especially if several courses of the old platform had been removed) would imply that the Level XI period was short.

4 I have not as a rule relied upon brick measurements as an argument for date because on the temple site they were by no means an infallible guide. The Level VII bricks are generally $0.4 \mathrm{I}-0.42 \mathrm{~m}$. sq.; in Level VIII there are bricks $0.32 \mathrm{~m}$. sq., $0.35 \mathrm{~m}$. sq., $0.43 \times 0.35 \mathrm{~m}$. In Level IX the $0.4 \mathrm{I}-0.42 \mathrm{~m}$. sq. brick is most common: Level $\mathrm{X}$ has bricks $0.42 \mathrm{~m}$. sq. and $0.47 \mathrm{~m}$. sq. Level XI has bricks $0.42-$ $0.43 \mathrm{~m}$. sq., Level XII has bricks $0.47 \mathrm{~m} . \times 0.44 \mathrm{~m}$. as well as $0.42 \mathrm{~m}$. sq., but in every level there are variants-as is bound to be the case with mud bricks-which make exact figures unreliable. The succession of building levels is far more safely judged on the evidence ( $a$ ) of matting courses, (b) of the outline of the platform, and occasionally $(c)$ of timber foundations. 
wall. The remains are too fragmentary to have any interest except in so far as they give the level of the $\mathrm{X}$ temple. Towards the south corner we found at this level in the brickwork a hand-made painted miniature jug (ATP/48/1 7), a small lump of lapis lazuli, a carnelian lentoid bead, and a fragment of gold-leaf. Near the east corner of the platform, south-east of the threshold mentioned above, a small amount of pottery (including the remarkable vase $\mathrm{AT} / 48 / 4$ r ; v. p. 3 I I and $\mathrm{Pl}$. XCIII $a$ ) was found associated with a section of mud-brick wall which judging from its position may have been a wall of one of the service-rooms flanking the temple courtyard.

With the reconstruction in the period of Level IX the whole temple was shifted four or five metres to the south-west; on that side the new platform extended $3.75 \mathrm{~m}$. beyond that of Level X, on the north-east it left $4.75 \mathrm{~m}$. of the old unoccupied; the front and back limits were, however, unchanged. Whether this means that the design of the building was altered there is no means of saying, for of the superstructure nothing remains at all except, near the east corner of the platform, one corner only of what may have been a service-chamber facing on the front courtyard. The platform itself was preserved only to a height of $0.80 \mathrm{~m}$. from the matting course with which it started, and perhaps it was never any higher, for on the top of the existing brickwork-which was not very regular and to the south-east was $0.30 \mathrm{~m}$. lower than the rest of the area-there was a scattering of mud-brick rubble, some of which was burnt. The presence of this rubbish stratum seems to show that we have here the original platform surface, while it suggests that the temple was destroyed by fire. Towards the north corner there were found together a few bird's bones, apparently burnt, a large gold bead, a spangle of thin gold plate with concentric circles in relief, a disk formed of a spiral coil of gold wire, a gold nugget weighing $2.2 \mathrm{gr}$, and a carnelian ball bead (AT/47/r 80 ); these objects were either on the top of the platform or just below it, between the brick courses.

At $3.00 \mathrm{~m}$. from the NW. limit of the platform and directly above the 'mastaba' of Level XIV there was, sunk in the platform, a rectangular basin (Fig. 26) $0.15 \mathrm{~m}$. deep,

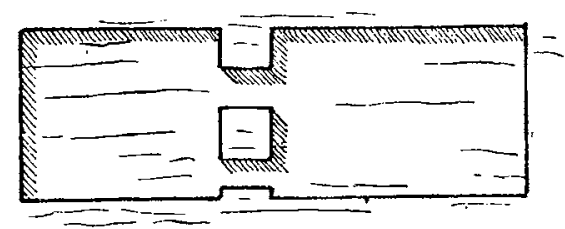

FIG. 26. I:50 the inside carefully mud-plastered, divided into compartments communicating by channels cut through the dividing ridges; it was filled with a light, clean soil of a greenish colour and below this the sides and base were coated with a number of layers of deposit of organic salts. In the basin were found a gold bead, a lentoid agate bead, and the pupil, in white limestone and grey steatite, of the eye of a statue $\left(\mathrm{AT} / 48 / 5^{6}-5^{8}\right)$, two small carnelian beads, one of jaspar and one of shell, a clay sling-bolt, a fragment of bronze, a lump of lapis paste, and a small clay pot, much crushed. Above the basin, instead of the regularly laid bricks of the Level VIII platform, there were broken bricks loosely packed. Between the basin and the edge of the platform there was a square compartment in the Level IX brickwork filled with rubbish, including a lot of coarse potsherds.

Almost facing this, close to the SE. edge of the platform, there was a roughly rectangular patch $(\mathrm{r} .05 \mathrm{~m} . \times 0.90 \mathrm{~m}$.) of burnt bricks, whole bricks forming the border and 
broken bricks the centre; just by it were three more burnt bricks laid in a curve suggesting a large circular base or basin. Alongside the rectangle there were found two beads, of carnelian and of crystal, a fragment of bronze, a flat clay platter, ATP $/ 48 / 30$, a fragment of an open clay bowl, and some animal bones lying in a patch of wood ashes. This suggests an altar of burnt sacrifice in front of the entrance to the temple, i.e. in the position in which such sacrifices were made in Levels XIV and XII; the continuity of tradition in ritual would accord with that which preserved the one site for the temple throughout so many centuries of rebuilding.

THE TEMPLE OF LeVel virr (Fig. 27 and see Fig. 35)

The Level VIII builders kept exactly to the outlines of the Level IX platform; over the site of the temple proper they swept away every vestige of the former walls, ${ }^{1}$ spread
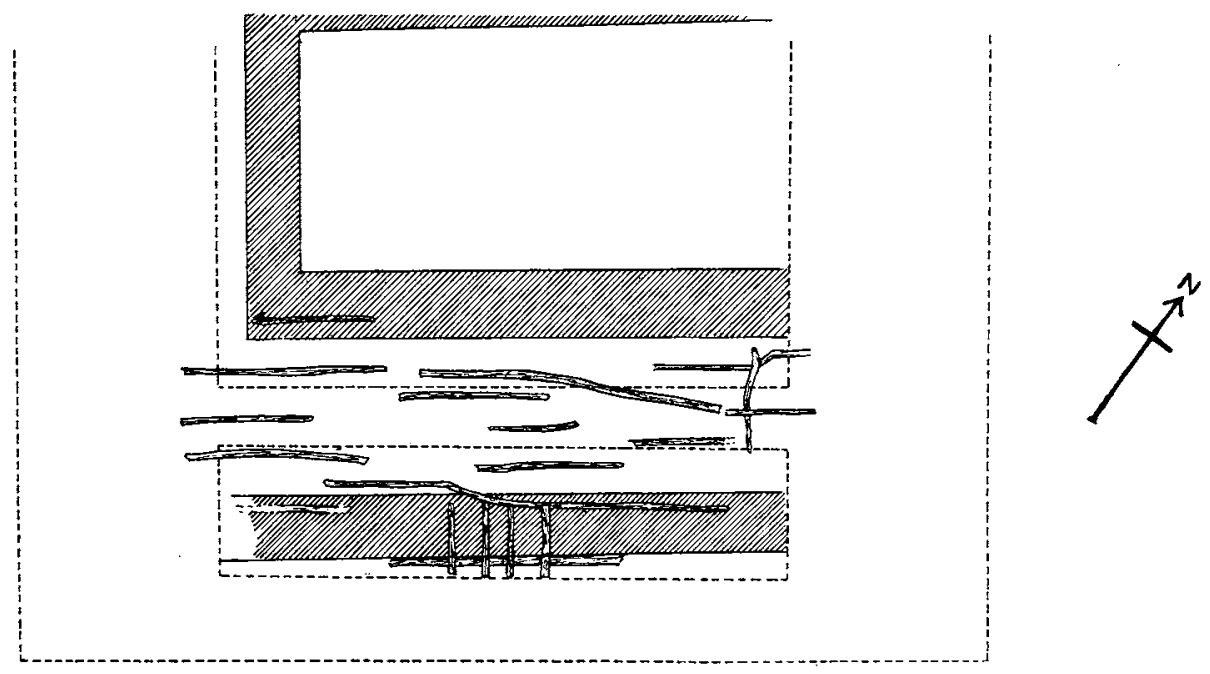

FIG. 27. Timbers underlying the front part of the Level VIII temple. The dotted lines are the walls of Level VII, the hatched walls are of Level VIII. I:200

a course of matting over the surface of the old floors, and laid their bricks above this to a height of $\mathrm{r} .80 \mathrm{~m}$. On this they built their temple, one wall (the SE. wall on the plan) having wooden foundation-beams, the others resting directly on the platform. We found still standing remains of the SW. wall, the outer wall of the building; only part of the inner face survived, and if the wall thickness was the same as that of the others, then the wall was set back a metre from the platform's edge. The NE. wall we found at one point only, close to the east corner ${ }^{2}$ where a Level VI rubbish-pit showed it in section; it came right at the edge of the platform and the ballast of the Level VII foundations comes up against its face. Unlike the other walls, it bore little or no signs of burning.

I These had been based directly on the platform floor so that their foundations were part of the platform, and when the upstanding walls went there was nothing to show their position. We found only one wooden beam that could be attributed to Level IX.

2 It is possible that there had been more of it and we cut it away, confusing it with the Level VII filling. 
Three parallel walls ran NE. $\times$ SW., ${ }^{\text {I }}$ but they do not come anywhere near the edges of the platform, and if we may take the SW. wall as a standard (which is at least reasonable), all these three are internal walls and the two outside walls are missing. There is indeed concrete evidence for this. When we were cutting away the Level VIII platform we found a break in the bond of the brickwork running parallel to the SE. edge and at a distance of $\mathrm{I} \cdot 40 \mathrm{~m}$. from it. I noted at the time that this might be simply the result of the workmen laying their bricks first along the edge to serve as the retaining-wall of the filling, but noted also that there seemed to be a cross-wall running out to the north-west; I assumed it to be part of the platform and not of the superstructure because it did not rise above platform level, as did the walls to the north-west, and did not show any signs of burning as did those walls. This may be true, but it does not exclude the possibility that the retaining-wall for the platform filling also rose above platform level as the façade of the temple-and the existence of a cross-wall is otherwise difficult to explain. The standing walls have not only been burnt but they have been so burnt that the bricks all the way through are bright red and powdery and the heat has even reddened the bricks of the platform below the walls to a depth of over a metre. The fact that the SE. 'wall' has not been similarly affected is a difficulty, but it might be met by the assumption that it was the wall of a small outer court where there would not be the same amount of inflammable material. At the NW. end of the platform there was a discoloration of the bricks consistent with the existence of a wall which would almost inevitably have been swept away by the Level VII builders to make room for their own foundations. If this be so, the ground-plan of the temple would be: a small forecourt, perhaps divided into a central entrance-passage flanked by side rooms, a very wide and shallow first room, a deeper central chamber and a third shallow room behind it; in these rooms there was no sign of any cross-walls. The walls are not thick (never more than $\mathrm{I} \cdot 50 \mathrm{~m}$.), so that the building cannot have been more than one story high. This is unlike any of the earlier plans and the change should correspond to a change of ritual.

This building, the temple proper or sanctuary, occupied the whole of the platform, but it is certain that the temple buildings extended beyond that. Just outside the (assumed) NE. wall, under the Level VII room $48 / \mathrm{I}$, there were remains of what were evidently subsidiary chambers; a floor of white cement had been laid on the brickwork of the platform; on the line of the platform edge there was a thin wall $(0.65 \mathrm{~m}$. thick) of mud brick on pebble foundations, its NE. face well plastered and whitewashed, beyond which was a clay floor (secondary, in that it was $0.10-0.15 \mathrm{~m}$. above the bottom of the whitewash on the wall) littered with potsherds. Connected with this were a terra-cotta drain which ran under the SE. wall of the Level VII room and some wall-remains SE. of the door of that room, the angle of a chamber full of clay pots which seemed to be throw-outs from the temple. Farther away to the south-east, under the walls of the rooms surrounding the

I The scanty remains can best be understood through their relation to the plan of the Level VII temple, 0 . Fig. 35 and the sections on Fig. I 8. The NE. wall ran under and partly outside the NE. wall of Level VII and under the NW. wall of Level VII there were what seemed to be remains of the

Level VIII NW. wall. Two walls running NE. $\times$ SW. and also the Level VIII SW. wall (only a few bricks of its inner face left) are given by the benches in the Level VII sanctuary, and another NE. $\times$ SW. wall underlies the Level VII anteroom. 
Level VII temple court, there were traces of Level VIII walls following the same linesthey served as foundations for the walls of Level VII. ${ }^{I}$ On the whole therefore it is probable that in front of the Level VIII temple proper there. was a large open court surrounded by service-chambers just as there was in the succeeding period.

A curious feature in the construction of the SE. part of the platform, below the 'forecourt' of the temple, was that it was built not solidly but in compartments of which one, just inside the face of the 'containing wall', was $3.00 \mathrm{~m}$. wide and $0.75 \mathrm{~m}$. deep; while inside of that again there were two narrower compartments one above the other separated by courses of brickwork, all covered with the brickwork that formed the floor of the 'court'; the compartments were filled with mixed rubbish containing quantities of potsherds of Level VIII types. Our workmen recognized these as evidence of scamped work by a dishonest contractor who was economizing bricks, and indeed this appears to be the only explanation; the platform here was to be merely a floor with no weight to support, so that the fraud was not likely to be detected.

\section{THE LEVEL VII TEMPLE (Fig. 35 and Pl. $\mathrm{X}$ a)}

The temple of Level VIII was destroyed by fire. The building which replaced it was slightly smaller in area, was not centred on it but shifted somewhat towards the southeast, and was altogether different in plan. The SW. wall of the new temple stood outside the limits of the Level VIII platform, its NE. wall was set back from the platform edge; its NW. wall virtually followed the line of the old, but the SE. wall, the façade of the temple, was more than five metres behind the edge of the platform. The ground-plan was much simpler. The sanctuary block, entered from a courtyard surrounded by service chambers, consisted of a $2.50 \mathrm{~m}$. wide entrance-lobby set at right angles to the axis and, behind it, a single room I I. $50 \mathrm{~m}$. across and $9.65 \mathrm{~m}$. deep; the walls of this inner room were no less than four metres thick. The methods of construction used were unusual and interesting. The workmen were at the outset faced with a ruin whose brick walls were burnt and crumbling, unfit to serve as foundations, and the floor piled high with brick rubble. They razed down to floor-level such walls as ran where their own walls were to run; those that did not stand in the way of their new plan they merely trimmed down to a height of about a metre and a half and left standing; they then removed all the loose rubbish and over the clean floor laid matting as a foundation. The main chamber of the new temple was to include almost the whole of the third room of the old building, three of whose walls therefore had been allowed to remain, well inside the lines proposed for the new; this room they proceeded to fill solidly with mud brick up to the floor-level of the new building, a height of $1.90 \mathrm{~m}$. The narrower Level VIII rooms along which their walls were to run they filled to a depth of $0.60 \mathrm{~m}$. with good concrete and on this bedding laid the bricks of the walls; as the latter rose more concrete was poured in as if to strengthen the foundations against any lateral thrust. ${ }^{2}$ At a later stage in the building

I See below, footnote I on p. 6I.

2 In the case of the NW. wall, which ran along the old platform edge, two or three courses of heavy stones were laid along the line of the NW. face and the concrete was put between those and the Level VIII wall. Under the façade wall concrete was only sparingly used, mixed with a lot of ballast, 
the gap that was left between the chamber walls and the old walls containing the central floor-mass was filled up in a curious way; the concrete half-filling the gap was smoothed and a long timber was laid on it along (apparently) each side; resting on the timbers was placed a long wooden box, or series of boxes, with fresh concrete packing between them and the wall-faces, and over the box-lids were added two courses of bricks, bringing the whole up to the level of the tops of burnt Level VIII walls.

There was one other constructional feature to be mentioned. In the NW. wall, towards the north corner, there was a chimney-like structure built of unusually large bricks $(0.62 \mathrm{~m} . \times 0.42 \mathrm{~m} . \times 0.15 \mathrm{~m}$.), kiln-fired, set in cement mortar, a square enclosing a $0.65 \mathrm{~m}$. circular hollow shaft whose sides of chipped brick were neatly cement-plastered; the hole went down to the (rather loose) concrete wall-foundations but had no proper exit. The stack was entirely concealed in the mud-brick wall.

Temple Plan and Contents. In front of the temple, i.e. to the south-east of it, extended a large open court measuring approximately $16.00 \mathrm{~m} . \times 13.00 \mathrm{~m}$; it was floored with cobbles which we found remaining only in patches. The NE. wall, not at right angles to the rest, really belonged to the royal palace whose orientation differed slightly from that of the temple; it was in bad condition and only near the north corner was the face of it preserved. The other walls had suffered even more severely; of the SE. wall only a short stretch remained and of the SW. wall nothing at all; only the projection of a few foundation-boulders from the line of the temple façade gave a clue to its position. The façade itself was much destroyed; from the east corner nearly to the entrance-door a little of the true face survived, then came a large rough block which probably had served as the impost for the door-frame, ${ }^{\mathrm{I}}$ and next to it three flat stones belonging to the threshold; but the SW. jamb of the door had perished and only part of the heavy rubble of the foundation-course was left. Towards the north corner, between the temple and the palace, there was a small room belonging to the former-its NE. wall abutted on the palace wall - with a door provided with good basalt orthostat jambs opening on the courtyard. ${ }^{2}$ At the east corner of the court was a group of rooms whose orientation was a compromise between that of the temple and that of the palace; no entrance-doors were

and a wood foundation was laid below the brickwork; the NE. wall was again different, having pebble ballast below and two or more courses of heavy boulders above as foundation.

I It was a limestone quarry-dressed block probably $\mathrm{I} \cdot 25 \mathrm{~m}$. long (the outer end had been broken away) by $\mathrm{I} \cdot 00 \mathrm{~m}$. wide and $0.50 \mathrm{~m}$. deep; in the upper surface was a shallow square depression. It projected slightly from the wall-face and originally had projected a good deal more; it rested on other stones which went down $0.75 \mathrm{~m}$. below the bottom of the rest of the wall-foundations. In front of it, below groundlevel, there were well-squared stones projecting from the wall line and then making a right-angle return SW.; I take this to be the box for the hinge-stone of the door, the SW. side of it being broken away.

2 The doorway had basalt jambs $0.47 \mathrm{~m}$. high, only quarry-dressed, not ground smooth, resting on projecting plinths; the threshold had been of wood with the sides plastered with clay, slightly raised; remains of burnt wood against the inner face of the SW. jamb showed that the door had opened inwards. The floor was of clay. The north half of the room had been destroyed by a Level V rubbish-pit and of the NW. wall there remained only part of the foundations of the outer face bonded into the temple wall. In the east corner there were found below floor-level (but the floor was broken) a few fragments of bone inlay decorated with dotted incised circles, $\mathrm{AT} / 48 / 27$. Before the room was built the area was used for mixing lime. On the Level VIII platform there was a very heavy deposit of lime (not a floor) and a quantity of loose pebbles, flints, \&c. It was here, on the spot, that the Level VII builders prepared the concrete for their wallfoundations. Above the lime and quite distinct from it was a mass of carbon centred on a shallow pit; possibly this was, at a later stage in the building, a carpenter's shop. 
found communicating with either, but they should probably be assigned to the temple. ${ }^{I}$ It should be noted that if the position of the SW. wall of the courtyard is rightly shown on the plan there is beyond it ample room for chambers whose back wall would align with the outer face of the SW. wall of the temple proper; but nothing of the sort now exists except for some scanty remains beyond the south corner of the temple. Here there was found a patch of pavement made of cement over heavy shingle foundations which did actually extend south-west of the inner face of the SW. temple wall (the shingle replacing the concrete of the temple foundations) and south-east to a short isolated stretch of wall running NE. $\times$ SW.; the fact that this wall was burnt red throughout certainly connects it with the temple. The wall fragment, lying immediately under Post P. I 5, seems $^{2}$ to align with the façade wall so that the floor should be that of the narrow entrancepassage; in that case its extention to the south-west shows that the south corner of the building resembled the east corner in that the four-metre-thick SW. wall belongs exclusively to the inner chamber and that its continuation enclosing the entrance-passage and service-rooms beyond was a normal wall only $\mathrm{r} .50 \mathrm{~m}$. thick.

The enormous thickness of the walls of the inner room or shrine must imply that it was of great height and presumably therefore of more than one story. For a second story a staircase would be essential, and the obvious place for such would be in the narrow $(2.80 \mathrm{~m}$. wide) entrance-passage. It has been said that at the SW. end of the passage we found remains of a cement floor, so that there can have been no stairs there; north-east of the doorway, however, we found no floor of any sort, the walls, where they survived

I The cobbled floor of the courtyard had twice been remade with clay, the top floor being $0.20 \mathrm{~m}$. above the original. In front of the doorway of room $48 / 1$ stones had been set to contain the upper floor so that there was a step down to the threshold instead of a step up. In the north corner there was a large rectangular basalt basin apparently belonging to the original floor-level, which had served as an intake for a vertical drain bringing the water from the roof of the building.

Room 48/3. The walls, much ruined, showed marks of fairly heavy burning; the wall-plaster, a mixture of mud and lime, was rough like that in the domestic rooms of the palace. The clay floor had been twice remade. The wide doorway to room $48 / 4$ had two steps made of clay covered with boards; the doorway, also very wide, to the south-east prolongation of the room had a raised threshold of mud-brick and clay with a plank above. About $0.80 \mathrm{~m}$. above the floor close to this doorway there was a basalt column-base which could not have belonged to this room. In the burnt rubbish on the floor were a few fragments of large, coarse, clay pots, and also a few pieces of ivory inlay like those found in room $48 / 4$.

Room 48/4. The walls stood not more than 0.10 m. high; a projection from the $\mathrm{NE}$. wall almost dividing the room into two seemed to be original, but had been largely destroyed by one of the many rubbish-pits in this area. There was a good clay floor. On it were found a clay jar (ATP/48/6, Type I $04 a$ ), some fragments of a large vessel, apparently an open bowl, of black ware with vertical ribbed sides, a very thin strip of gold inlay and many fragments of carved ivory (AT)
$48 / 17$, Pl. LXXVI), together with one or two fragments of carnelian and obsidian also for inlay. As this inlay was clearly from the same source as the pieces found in room $48 / 3$, on the other side of the party wall, it is likely that they had fallen from an upper room, and the same is possibly true of the column-base mentioned above.

Room 48/5. The entrance was unusually narrow and there were no doorway reveals and no signs of a wooden doorframe. In the filling there were fragments of painted plaster, white, pale blue, and red, apparently in patterns since one piece showed a curved outline. These, too, may have come from an upper room, though there was no constructional evidence for a second story. On the floor was a fair amount of pottery including five more or less complete 'champagnecups' the bowls of which bore signs of oil burning, so that they must have been used as lamps (ATP/48/20 A-C, 6r, 62). Excavation in this area stopped short at Level VII, but a hole sunk in the east corner of room $48 / 5$ produced a large rectangular terra-cotta chest standing in the angle of two older walls of which the SE. was set back $0.85 \mathrm{~m}$. behind that of Level VII, while the NE. lay about $0.50 \mathrm{~m}$. inside the Level VII wall; the floor connected with these walls was at $\mathrm{r} \cdot 10 \mathrm{~m}$. below that of room $48 / 5$. It is clear that the Level VII building here reproduces more or less a similar building which we must date to Level VIII; accordingly we must credit the Level VIII temple with a forecourt surrounded by servicechambers very much on the lines of Level VII.

2 Its face was so damaged that no positive statement is warranted. 
at all, had no face, and the space between them was rubble packing very difficult to distinguish from the walls; the packing may well have been the solid bedding of the stairflight, ${ }^{\mathrm{I}}$ and the absence of a floor is consistent with this. If there was an upper chamber with a door immediately above that of the lower chamber-which is what one would expect-then a return flight of stairs is needed to reach the door; the stairs cannot have ended in a cul-de-sac against the blank NE. wall, for a doorway there leading into the upper room is impossible in view of the thickness of the NE. wall of the shrine. The passage is really too wide for a single flight and it is not too narrow to contain a return; the treads would be $1.40 \mathrm{~m}$. wide, and in the newel staircase of Yarim-Lim's palace, leading up to the grand salon, the treads are $\mathrm{I} \cdot 50 \mathrm{~m}$. wide.

The thickness of the passage walls shows that they did not rise to any great height; the passage was only one story high. The stairs then would lead on to its flat roof which (enclosed presumably by a parapet wall) would serve as the entrance-passage for the upper room. If the stairs came right through to the door of that room they would, assuming the maximum measurements of each tread, $0.15 \mathrm{~m}$. high and $0.30 \mathrm{~m}$. deep, give a total height of $6.00 \mathrm{~m}$. or, if the tread were $0.40 \mathrm{~m}$. deep, of $4.50 \mathrm{~m}$.; but the return flight could, of course, have stopped at any point short of the doorway, so, that we can only say that $6.00 \mathrm{~m}$. is the maximum for the height of the passage roof and $4.00 \mathrm{~m}$. is just as likely. What is important is that the shrine itself was much higher, so that we have to imagine a very lofty building of two stories of which the upper story is set back by a quarter of the depth of the whole, the projection serving as an entrance-platform to the upper floor. Such a building would seem to be in the direct line of descent from the temple of Level XII and from that represented by the Selemiyeh terra-cotta model ( $v$. Pl. IX $b$ and p. 49), but the proportions of its ground-plan are very different and its appearance would have differed correspondingly. A much close analogy is afforded by the clay models of shrines found at Ashur, ${ }^{2}$ some of which may be contemporary with our building, and by the (later) examples from Bethshan in Palestine; ${ }^{3}$ certain of its features are reproduced in the Level III temple at Atchana (v. infra, p. 75), but there the ground-plan is more complicated, and Yarim-Lim's temple, while it had perhaps the simple fenestration of the Bethshan model, in this respect resembles most the Ashur shrines, a resemblance which might be explained by the king's political relations with Mesopotamia.

Owing to the destruction of the SE. wall the doorway of the inner shrine had disappeared, but its position could be fixed with tolerable certainty as coming directly in front of the outer door from the court. The floor was of fine cement laid over clay; it survived only in patches. Along the NW. and SE. walls ran long benches; the former was $2.45 \mathrm{~m}$. wide and $0.25 \mathrm{~m}$. high, the latter seems to have been only about $\mathrm{I} \cdot 00 \mathrm{~m}$. wide and $0.20 \mathrm{~m}$. high. ${ }^{4}$ There was no bench along the NE. wall, and for the SW. side

\footnotetext{
I The lowest flight of a staircase was almost invariably solid.

2 W. Andrae, Die Archäischen Ischtar-Tempel, Taf. I 4c, I 5a. The models have been described as those of houses, but the presence of snakes, \&c., seems to me to make them defi-
}

nitely religious.

3 Alan Rowe, 'The Temples of Dagan and Ashtoreth', in The Museum Fournal (Philadelphia) for September 1926.

4 Near the east corner a patch of cement floor survived at a distance of $1.40 \mathrm{~m}$. from the $\mathrm{SE}$. wall and a second patch at 
evidence was lacking. The cement which covered the floor was carried up, with a chamfer, over the face and top of the benches. Of the walls, the NE. wall retained its under-plaster but the others none at all. In the north corner there was against the NE. wall a shallow buttress against the SE. side of which was a hole in the NE. wall circa $0.10 \mathrm{~m}$. above floor-level, the lodgement for a beam which, resting upon four flat stones, formed apparently a step up to the top of the bench. The purpose of the buttress was not clear.

As has been stated above, the benches were in part hollow, containing long wooden boxes; these were circa $\mathrm{I} \cdot 00 \mathrm{~m}$. wide and $0.50 \mathrm{~m}$. deep, rested on and were embedded in concrete; ${ }^{\mathrm{I}}$ they had been hermetically sealed with brick courses and cement above the bricks.

Against the NW. bench and almost in the centre of it was the stepped altar, solidly built of basalt. Only the NE. end of it was preserved so that its exact width cannot be known; if the last surviving stone gives the SW. angle (which is likely, as in that case the altar would be equidistant from the side walls) it was $2.75 \mathrm{~m}$. wide. It stands out $2.00 \mathrm{~m}$. from the line of the bench but seems to overlap that line, and so far as the evidence goes, since both bench and wall are at this point ruined down to below floor-level, may have continued right back to the NE. wall of the temple.

The altar ( $\mathrm{Pl} . \mathrm{X} a$ ) has a foundation of uncut blocks rising only just above floor-level; the cement of the floor is taken up against these in a rolled fillet, but no attempt was made to get a straight line, the cement following the contours of the stones. A bove these comes ashlar, which was probably not cement-faced but exposed. A single ashlar block remains giving a first step $0.15 \mathrm{~m}$. high; behind this come two blocks of the second step, giving a height of $0.35 \mathrm{~m}$. Behind these again, but flush with them, are rough stones which seem to imply a third step. Behind them are three stones, partly overlapping the line of the bench, only 0. I $5 \mathrm{~m}$. above floor-level; the outer one is a limestone block the top of which is roughly hollowed and has a spout emptying flush with the side of the altar; ${ }^{2}$ if the altar

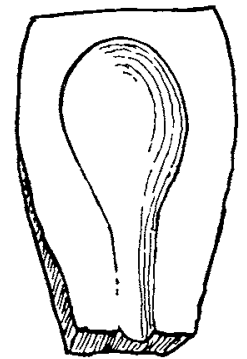

FIG. 28 ran back across the bench to the back wall there may have been a recess here in its side with the drain at the bottom of the recess.

$3.00 \mathrm{~m}$. from that wall lay $0.40 \mathrm{~m}$. lower; but this apparent evidence in favour of a bench of the same width as that against the NW. wall was contradicted by the plaster on the face of the NE. wall which had, of course, stopped at floor-level. The plaster showed a perfectly horizontal line ending against a $0.20 \mathrm{~m}$. rise at I.IO $\mathrm{m}$. from the SE. wall, and this evidence is confirmed by other; the 'box' construction below the bench ended at the doorway, and from the SW. door-jamb to the south corner of the room there was against the wall a mass of mud brick (not bonded into the wall) I I $5 \mathrm{~m}$. wide which should represent the bench. The witness of the cement floor was deceptive; owing to the shrinkage of the brick packing underneath, the floor had sunk everywhere, and towards the $\mathrm{SE}$. side as much as $0.45 \mathrm{~m}$, but where it was supported by the walls of Level VIII it retained its original level; the "high patch' therefore had to be disregarded.

I The concrete which lay below the boxes and the temple walls was of flints and broken bricks over which liquid cement had been poured (the concrete had not been mixed and then shovelled in) so that it was of varying consistency with some loose patches which the cement had not reached; the concrete put in later on either side of the boxes was of rather finer texture and had been already mixed.

2 It is possible that the stone is merely re-used here as packing; but its roughness is due at least in part to splitting caused by heat, and in view of its careful alignment it is more likely to be functional. The sketch, Fig. 28 , is a reconstruction disregarding the accidental damage to the stone. 
The part of the floor on which the altar stands is raised nearly ten centimetres above the ordinary floor, its neatly chamfered edge forming approximately a semicircle which extends $1.75 \mathrm{~m}$. to the north-east and $\mathrm{I} \cdot 50 \mathrm{~m}$. to the south-east of the altar but on the south-west runs back under it; the circumference is interrupted by two roughly shaped gaps. Close to the SW. gap there was found the greater part of a basalt pedestal lamp (AT/47/82, Pl. LXXVIII $q$ ) the base of which would fit almost exactly into the gap; it is tempting to assume that the other gap, the edges of which were too damaged for accurate measurements to be taken, shows the position of the remarkable clay pot-stand $\mathrm{AT} / 47 /$ I 28 (Pl. LVIII), which it would be natural to associate with an altar.

The floor of the shrine ${ }^{\mathrm{I}}$ was covered with a thick deposit of burnt debris, wood ash, pulverized brick, \&c., in which were found many objects, including the magnificent diorite head AT/47/74 (Pls. XLI-XLII), the 'Egyptianizing' head AT/47/62 (Pl. XL), the basalt bull's head AT/47/73 (P1. XLIIIa), part of the beard and hair, in steatite, of a composite statuette, AT/47/77 (Pl. XLIIIe), part of the wig of a similar statuette, $\mathrm{AT} / 47 / 78$ (Pl. XLIIIb), and a fragment of a second wig AT/47/90 (P1. XLIIId), showing a different style of hair-dressing, of which another fragment was found outside the door of the shrine. It was quite clear that there had been wanton destruction and looting in the temple before it was burnt; ${ }^{2}$ most of the fragments lay under rather than in the burnt debris on the floor and their distribution was eloquent-fragments of the great basalt lamp were five and six metres apart, the clay pot-stand was in more than a hundred pieces, widely scattered. Moreover, the boxes in the benches had been violently torn open, presumably because they had contained treasure, and were full of broken bricks and brickdust. In the NW. bench-box we found fragments of the original wall-plaster of the shrine painted with plain 'Pompeian' red, several cuneiform tablets (others ${ }^{3}$ had been found on the floor of the room), the cylinder seal AT/47/1 32 (Pl. LX8), part of an ivory comb (AT/47/ $3 \mathrm{r})$, quantities of fragments of inlay in bone and ivory, one, $\mathrm{AT} / 47 / \mathrm{I} 30$ (PI. LXXVIII $i$ ), with the figure of a seated monkey, but the rest either plain strips or pieces with rows of concentric circles, cross-hatched circles, or bands of cross-hatching; there were similar plain strips or shaped pieces in rock crystal and one in obsidian; two stone eye-sockets from a statue of considerably more than life size (AT/ 47/79); a few small fragments of gold foil; a number of beads-large balls and flattened lozenges of carnelian, chalcedony lentoids, glass balls (including millifiori glass), paste

\footnotetext{
${ }^{1}$ So far as it was preserved. The plan, Fig. 35 , shows the extent of the cement floor facing, but over a good deal of the area the clay floor-foundation remained although the cement (perhaps from mere wear) had disappeared. On the other hand, the plan also indicates the extent to which the floor had been cut up by rubbish-pits of Levels VI and V, and west of the altar everything had been denuded below floor-level.

2 The NE. wall was not so heavily burnt as were the other walls. Above floor-level the bricks were reddened, but below it they showed no signs of burning at all. The burning on the NW. wall came right up to the north corner of the room, but was more severe on the outside than on the inside; on the outside (where there was no timber in the construction) the
}

bricks were bright red and crumbling; on the inside (where the holes left by beams were apparent) they were hard and greenish in colour. The difference would seem to be due to the outer wall-face having been subjected to an intense clear heat whereas on the inside it was a case of the slow combustion of the wood embedded in the brickwork. It looks as if the temple had been deliberately destroyed by heaping wood against the outside of the walls and setting fire to it, but for some reason this was not done on the NE. side. It is curious that the phenomena are the same in the Level VIII temple; cf. also the temple of Level XII.

3 ATT/47/1-20 (v. Wiseman, Tablets, Nos. 176, 365 , $373-8,382-4,386-9)$, and seal-impressions ATT/47/2 I, 22. 
rings and a paste scaraboid and part of a lapis lazuli fish amulet (AT/47/76); fragments of an alabaster vase, completely calcined; an ivory object shaped as an egg with four holes in the side; two shell whorls and some small potsherds. In the SE. bench-box there were more fragments of inlay. Outside the door of the shrine there were found further fragments of bone inlay, some being plain petal-shaped pieces, others with an arcading design with the ground cut away and filled with niello (AT/47/r 78, Pl. LXXVIIIj). These were inside what I have described as the hinge-box of the door from the courtyard.

Not the least peculiar feature of the building is the shaft contrived in the thickness of the NW. wall. When we first discovered it I inclined to the obvious explanation that it was meant to carry away rain-water from the flat roof of the temple, but $(a)$ there is no parallel for that in any building of any period at Alalakh; roofs were certainly drained by projecting gutters like gargoyles and the water fell free of the wall either directly to the ground or into a stone trough; and $(b)$ there is no outlet at the bottom of the pipe so that any water coming down it must have been simply dispersed in the (rather loose) concrete foundations, and with the water from so large an area as the temple roof this would have endangered the whole wall. That theory therefore must be abandoned. Up to the level of the top of the bench at any rate there is no inlet from the ground-floor room of the temple, no connexion, for example, with the spouted stone at the back of the altar, and the position of the pipe in the middle of the wall and its elaborate construction are against its having been a short pipe turning into the room at the height of a metre or so. So solid a structure has all the appearance of having been intended to rise to a quite considerable height; and if it did not serve the roof it must at least have served the upper room of the temple. If the lack of an outlet means that the amount of liquid going down the drain at any one time would never be great, the only explanation I can suggest is that the pipe opened into the upper room and was for ritual libations. The importance of the ritual might justify the elaborate character of the channel, and religion might demand that 'drink-offerings' should find their way to the foundations of the sacred building. ${ }^{1}$

\section{THE TEMPLES OF LEVELS VI, V, AND IV}

Throughout the long period represented by our Levels XVI to VII the site of the city temple had remained unchanged; the courtyard might indeed be lengthened or shortened and of any buildings surrounding it we know really nothing, but the temple proper, the sanctuary block, in all its rebuildings never shifted more than a metre from the original spot. But after the sacking and burning of the Level VII temple there was a radical change. Tradition could not be altogether flouted and the new temple must needs stand on what had been from time immemorial holy ground, but it would seem that to Yarim-Lim's shrine there attached a stigma that prevented its re-use. The site of that shrine was left desolate and its ruins were riddled with the rubbish-pits of Levels

\footnotetext{
I It is tempting to associate this more or less directly with the 'basin' in the platform of Level IX, which lies almost immediately below the drain-stack, and ultimately with the well of Level XVI. There is certainly no physical con- 
VI and V; the back wall of the new sanctuary was built over the façade of Yarim-Lim's sanctuary, and from now on the temple site is that of his temple courtyard.

Of the Level VI temple we can only say that it existed; nothing remains to show its character. We have a mere fragment of its NE. wall-foundations, against which comes a patch of pebble floor $1.50 \mathrm{~m}$. above Yarim-Lim's courtyard floor and a metre above the floor of the rooms that bordered it on the north-east, and we have, farther to the southeast, meaningless stretches of walling which probably belonged to the service-chambers surrounding the new court; ${ }^{\mathrm{I}}$ and rubbish-pits prove that it did not extend over the old sanctuary, where indeed no wall-remains were found. Outside the building, in Sq. P I 4, there was a patch of hard mud floor with which were connected three water-channels proving repairs and a rise of level; they all belong to Level VI and should imply a fairly long floruit. ${ }^{2}$

Outside where the NW. wall presumably ran, in Sq. O I 3 , there was found, below the level of the Level $\mathrm{V}$ foundations, a millifiori bead of dark blue glass inlaid with flowers in white $(\mathrm{AT} / 47 / 60)$. At the same level was found (in Sq. $\mathrm{P}_{\mathrm{I}} 3$ ) a fragment from the rim of a bowl in blue lapis lazuli paste with a handle in the form of a couchant lion exactly like that of the fine vase AT/46/I 8 (Pl. LXXXIII) found in the temple treasury of Level II. This very fine work in glass and paste evidently goes back to the time of Level VI, to which indeed $\mathrm{AT} / 46 / \mathrm{I} 8$ itself may quite well belong in spite of its late find-spot, since the temple treasuries would include objects of very different dates. It is clear, too, that we cannot regard the scantiness of building remains from Level VI as evidence for the poverty of the period.

\section{THE LEVEL V TEMPLE (Fig. 29, and Pl. Xb)}

The complete destruction of the Level VI temple is fully explained by the character of its successor. In all previous temples the sanctuary had either been flush with the surrounding ground-level or, more often, raised above that level on a more or less high artificial platform. The sanctuary of Level $\mathrm{V}$ was sunk below ground-level. The builders excavated the site to I.I $5 \mathrm{~m}$. below the (earliest and lowest) floor of Level VI-that found outside its NE. wall, and in so doing they naturally swept away the whole of the old building. Outside the Level V NE. wall we found ( $v$. the section, Fig. 29b) a strip of pebble floor running alongside a foundation-trench in which was a single line of mud bricks, the outer face of the lowest course of the temple wall of Level VI. The rest of the width of the wall had been cut away by the trench dug to take the foundations of Level $\mathrm{V}$, and there we found the Level $V$ wall and beyond it the undisturbed floor only about $0.15 \mathrm{~m}$. above the courtyard floor of Level VII and actually below the floors of the Level VII rooms facing on that court; allowing for normal soil accretion it must have been at least $\mathrm{I} \cdot 80 \mathrm{~m}$. below the general ground surface of Level $\mathrm{V}$.

The sunken chamber had a depth from front to back of $3.80 \mathrm{~m}$. and a width (from

I The attribution is based on the assumption that the temple had a courtyard surrounded by service-chambers as

had the later temples.

2 But see the footnote no. 2 on p. 74 . 
NE. to SW.) of more than double that amount, ${ }^{\mathrm{I}}$ so that it was of the type of the Breittempel. A brick-built bench $0.80 \mathrm{~m}$. wide and $0.50 \mathrm{~m}$. high ran along the NW. and NE.

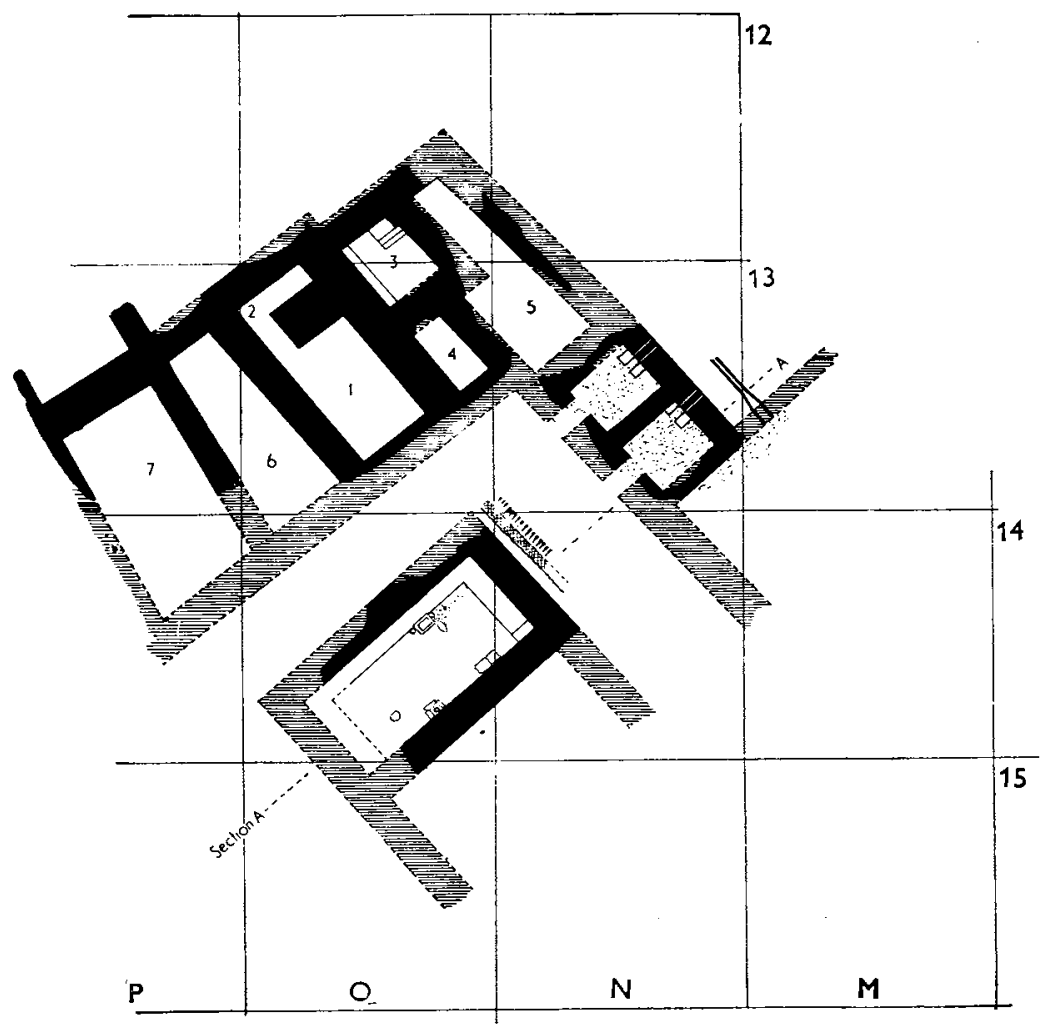

1

FIG. 29a. Plan of Level V temple. I:400

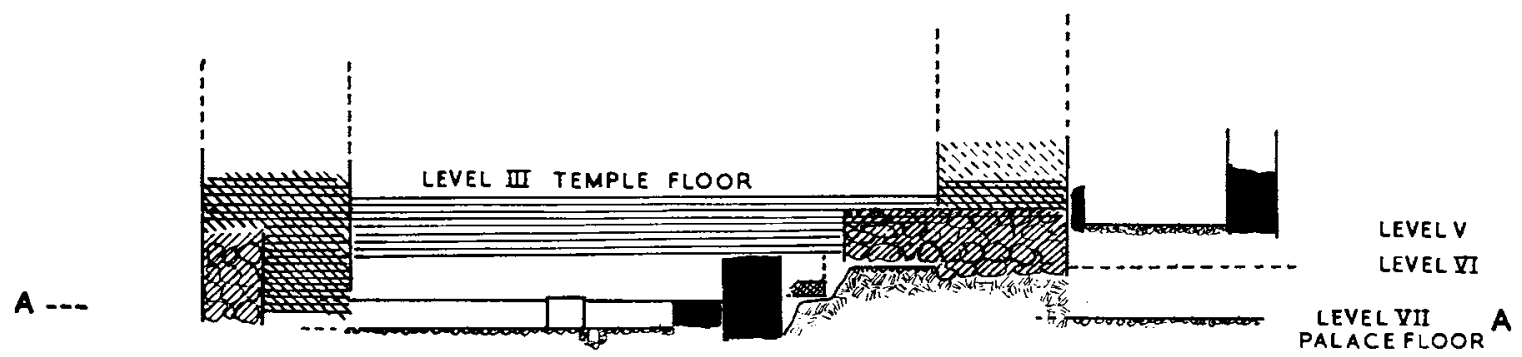

FIG. 29b. Section on line A-A, scale double that of the plan

walls; walls, bench, and floor were neatly mud-plastered. Against the bench on the NW. side was a rectangular altar, built of mud brick and plastered, standing $0.57 \mathrm{~m}$. high with a box-like depression in the top which showed marks of heavy burning ( $\mathrm{Pl}$. X $b$ ). Against the SE. wall there was a hinge-stone for a door, its top $0.20 \mathrm{~m}$. below floor-level, protected against the surrounding earth by a box formed of three stones set on edge, their

I The whole of the SW. end had been destroyed by the deep-laid foundations of the Level IV wall; but judging by the position of the hinge-socket of the door the minimum width was $8.00 \mathrm{~m}$. and the maximum circa I I.60 m. according as that socket was on the right or the left side of the doorway. 
tops coming just above the floor. A metre and a half farther to the south-west but $0.75 \mathrm{~m}$. away from the wall was a circular basalt column-base, half a metre in diameter, its top (in which were two shallow cup-marks) rising slightly above the level of the floor. ${ }^{\mathrm{I}}$ On each side of the altar there had been an upright wooden post; on the SW. side there was a circle of carbonized wood, on the NE. a hole $0.30 \mathrm{~m}$. deep in the floor lined with stones rammed down to wedge the upright.

The door-socket was at first difficult to understand because the wall against which it was set still stood to a height of $0.80 \mathrm{~m}$. above the floor and there was not and never could have been any doorway in it; yet the socket was certainly in position. The explanation is that the antechamber or courtyard (whichever it was that lay south-east of the wall) was at ground-level and the cella being sunk about $\mathrm{r} \cdot 80 \mathrm{~m}$. below that level could be entered only by a flight of steps. There was no exterior flight of steps and the wall line was uninterrupted; therefore the steps must have been internal and the door would be at the floor-level of the antechamber. This theory received confirmation from the discovery of the outer south angle of the cella; here the NE. wall, which was well preserved, returned south-west and did not run on south-east to enclose an outer chamber; either therefore the sunken room was an isolated building-which is not likely-or the room adjoining it to the south-east was at ground-level, in which case the foundations of its walls would have been at least a metre above the floor of the cella and would have been destroyed (together with the upper part of the cella wall) by the builders of Level IV. It is therefore perfectly consistent with the evidence to assume a temple built at groundlevel, with its cella alone sunk below-ground, entered through a door high up in its wall by an internal wooden staircase. ${ }^{2}$

I know of no temple of the second millennium B.c. in Egypt, Mesopotamia, or Syria that has its cella below ground-level, nor of any cult that would require such with the single exception of the Mithraic. The Mithraic temples do have the underground chapel

\footnotetext{
I These are the main features, but there were other details not easy to understand. Against the SE. wall was a line of stones, in the east corner a flat square stone $0.20 \mathrm{~m}$. high, then three flat stones $0.20 \mathrm{~m}$. high, making a sort of bench $0.40 \mathrm{~m}$. wide; all the stones were fragments of a very large basalt trough which had measured $0.70 \mathrm{~m}$. in width by more than $0.80 \mathrm{~m}$. by more than $0.35 \mathrm{~m}$. high; in the packing between them was a fragment from the skirt of a diorite statue apparently of Sumerian type (AT/48/9, P1. LIII). The stones forming the hinge-box were fragments from the same trough; it would seem that the Level $\mathrm{V}$ builders digging down into the Level VII courtyard found the trough and made use of it.

The column-base was surrounded (see detailed plan, Fig. 25) by an irregular patch of rather large cobble-stones forming a surface about $0.15 \mathrm{~m}$. lower than the top of the base; they had been below the mud plaster of the floor. The arrangement of some of the cobbles suggested (if it was intentional at all) that it was a reinforcement of the floor where pots were to stand. Immediately SW. of the base was a patch with no cobbles but bare earth with two larger stones (yet other fragments of the basalt trough) beyond, where were ashes and fragments of pottery. To the north and east, at a
}

lower level than the cobbles but not overlapped by them, there was another patch of cobble paving made with smaller stones; on part of this there were marks of burning, ashes and burnt bones of some small animal, and potsherds. Between this patch and the altar, and again just below floor-level, there was set a large flat oval-topped slab of basalt $\mathrm{I} .00 \mathrm{~m} . \times 0.70 \mathrm{~m}$, looking like a stela, but plain. In front of the bench $\mathrm{SW}$. of the altar there was a post-hole in the floor going down for $0.40 \mathrm{~m}$.; it was not vertical but sloped sharply to the SW.

The altar was built on the clay floor. Below this there were stone blocks forming three sides of a rectangle of which the SW. side was missing; the NW. side was continued by a line of stones for the whole remaining length of the room, running not quite parallel to it; this was part of the façade of the Level VII temple and the rectangular projection from it was also of Level VII; it was tempting to regard it as the base for the big basalt trough. In it were found the fragments of inlay and part of a stone wig mentioned in the description of the Level VII temple.

2 I was tempted to suppose that some of the larger stones set in the floor might be connected with the stairs, as bedding for timbers; there is, however, no warrant for that. 
with side benches, and an altar for burnt offerings, ${ }^{\mathrm{I}}$ but they are of the Roman period and the time gap cannot easily be bridged. At the same time it must be remembered that Mithras was one of the Indo-European gods who were introduced at just about this time to the Middle East by the founders of the Mitanni power; and there is no doubt but that in the Level $V$ period Alalakh was, politically and culturally, in close touch with its eastern neighbours. It is then possible that in this unique building we have the earliest example of a Mithraeum.

The building thus described is, of course, the shrine only. Beyond its north corner and along its NW. side there is a range of rooms built on the western edge of the plateau formed by the ruins of the Level VII palace and terraced on the slope of the mound, the floors rising gradually from south-east to north-west; the range is L-shaped; there are two lavatories and the remains of a bathroom (?) in the SE. member, larger chambers in the NW. member. In my preliminary report for the 1946 season I stated that there was here no temple of the Level IV period, the site being then occupied by 'houses of the better sort' which had been cut away by the foundations of the Level III temple; subsequent excavations showed that there was a Level IV temple, the remains of which were incorporated in that of Level III, and it was the Level IV foundations that cut through the supposed houses. The date of the latter must therefore be put back, and since the site was continuously occupied by temples from the period of Level VI, apparently, onwards, they can hardly be private houses. There is indeed no reasonable objection to the idea that the service-chambers of a temple should include lavatories or washing-rooms-the isolated lavatory farther south (in Sq. $\mathrm{L} I 6^{2}$ ) which is definitely of Level IV lies within the temple area and may well have been part of its range of service-chambers-but if the whole of this building is to be associated with the Level $\mathrm{V}$ temple, then the ground-plan is radically different from that of its predecessors in that the sanctuary would not be as usual at the back of the temple complex but would have a range of rooms behind it; on the other hand, the temple of Level II did possess a back annexe covering precisely this site. As regards the date, the whole building belongs together in spite of the different levels of the floors, and cannot belong to Level VI because the area occupied by the NW. rooms is riddled by Level VI rubbish-pits and therefore must have been open ground at that time. It must be older than the Level IV temple which has destroyed the outer face of its walls and blocked its doorways. It is then of Level $V$ foundation, and scanty as are the remains of that period, there is enough to show a reasonable ground-plan, for there is ample space for a passage between the sunken sanctuary and the outbuildings enclosing

I The Mithraeum is nearly always small, e.g. $5 \cdot 20 \mathrm{~m} . \times$ $3.55 \mathrm{~m}$., or $10.55 \mathrm{~m} . \times 5.50 \mathrm{~m}$; t the benches generally run round three sides; the steps are inside the cella, beginning in the wall-thickness; the altar faces the steps, set against or close to the back bench. So far the analogy with Atchana holds good. On the other hand, the Mithraeum usually if not always has its cella in depth, which is the reverse of the Atchana temple, and the tops of the benches are sloped instead of being flat as here. As regards the depth under the ground-surface, a Mithraeum at Carnuntum is identical with
ours-I. $80 \mathrm{~m}$. below-ground.

2 Immediately below the oldest Level III floor there was a rectangular floor $2.20 \mathrm{~m} . \times \mathrm{I} \cdot 40 \mathrm{~m}$. of very good cement; in the north corner were the two standing-blocks with the hole between them out of which led a well-preserved terracotta drain-pipe. The chamber seems to have been sunk, for no trace of its walls survives although the pipe must have run beneath the wall-foundations. There were no other remains of the building. 
it; it still remains true that the sanctuary may have been in the traditional position, at the back of the main temple complex.

Overlying the Level $\mathrm{V}$ sanctuary there were remains of a clay floor (no walls were found associated with it) which was recorded in the field notes as evidence of a building intermediate in time between the Level $V$ and the Level IV temples, i.e. either a restoration of the Level $V$ structure or an independent building all the walls of which were swept away by the Level IV builders; the former explanation is the simpler. We cannot therefore exclude the possibility that the rooms enclosing the sanctuary, together with the sanctuary itself or a building on much the same lines, survived into the earlier phase of Level IV, but the evidence does not really warrant that conclusion; the later floor may belong to a restoration of the sanctuary carried out in the Level $V$ period, and since Idri-mi says nothing about building a new temple (and the domestic revolution that led to the burning of Ilim-ilimma's palace would not necessarily have been directed against the temples also) it is safest to regard the 'Mithraeum' with its service chambers as being exclusively of Level $V$ and to assume that the Level IV temple as we have it dates from the early part of that period.

The two lavatories were, as can be seen on the plan, Fig. 29, of normal type with cemented floors and walls. To the south-east of them was a larger room (its limits unknown, all the walls being gone) also with cemented floor and with a terra-cotta drain through its NW. wall, clear of the adjoining lavatory. Regarding the other rooms, the mud-brick walls, which are heavier than is usual in private houses, rest upon heavy stone foundations to which the brickwork does not always strictly conform, so that there seems to have been some rebuilding; the marked difference of angle in the walls of the SW. rooms seems also to imply two periods of construction. The floors of these rooms are below the level of the ground beyond the building, the site for which was cut down into the slope of the mound resulting from the destruction of Yarim-Lim's palace, and the bounding walls have no true outer face at the height to which they are preserved. Room I was almost entirely destroyed. Room 2 had been whitewashed, but was in bad condition; it may have had a doorway into room 3 as there was in the NW. wall a breach going down to floor-level. Room 3 had a good clay floor, whitewashed walls, a bench $0.30 \mathrm{~m}$. high along the SW. wall, and in the north corner a stepped pedestal (?) plastered and whitewashed; the face of the SE. wall had perished, leaving only the core of the brickwork. Room 4 had a clay floor; its walls, standing to nearly $\mathrm{I} \cdot 00 \mathrm{~m}$., were well plastered, with a secondary plaster and whitewash corresponding to a rise of about $0.30 \mathrm{~m}$. in floor-level. At the NW. end was a staircase (only the lowest tread preserved) which turned round a brick newel. There was no door in the SW. wall of the room, so that wall may well be the boundary of this part of the building; beyond it the NW. $\times \mathrm{SE}$. walls are otherwise orientated and appear to belong to a different scheme of building.

All the rooms were filled with mud-brick rubble consolidated into a uniform mass of quite astonishing hardness. This could have resulted only from the site having been unoccupied for a long time after the collapse of the walls, so that a succession of winter rains and the constant treading of people over open ground disintegrated the bricks and rammed the mud into a homogeneous block. It is not surprising that we found here no building remains whatsoever of Levels IV and III.

In Sqq. L I6, M I 6 there were numerous rubbish-pits which belonged to Level $V$ and must have been associated with the temple. They were very close together and had been in use all at the same time, as was proved by our finding fragments of the same pot 
in as many as three different pits. Their contents were unusually rich, including the fine gold filigree brooch AT/46/I 8 I (Pl. LXIXf), fragments of an Egyptian (?) faience vase with hieroglyphic inscription, AT/46/223 (Pl. LXXXIII), and a number of beakers of black ware with impressed decoration; v. Pl. C. Either at some time in the Level V period it was necessary to get rid of broken or superfluous ex voto's from the shrine, and, since they had been dedicated and ought not to leave the temple, pits for their disposal were dug within the temple precincts; or, after the destruction of the Level V temple, the pits were dug to receive the broken fragments that littered the site and so to make a clearance for the building of the new shrine.

One object found in the ruins of the temple itself deserves mention; this is a small potsherd of rather sandy drab clay on which is a spiral roughly drawn in red paint, ATP/47/ r6, Pl. CXXIXa. Both in its ware and in its decoration the sherd is unlike any local ware known to us. Mr. Sinclair Hood noted: 'This might conceivably come from a Middle Minoan III import. Rather rough spirals in matt red on a plain ground are quite characteristic of M.M. III.' See on this p. 370.

\section{THE LEVEL IV TEMPLE}

It was only when we started to dismantle the Level III temple with a view to deeper excavation that remains of the Level IV building incorporated in it came to light. The two structures coincided exactly, but their distinction presented no great difficulty.

The existing temple (Fig. 30 ) consists of two chambers, a wide and shallow entrancechamber and a much deeper cella; the side walls project in front as if for a porch. ${ }^{\mathrm{I}}$ Both doors, that of the entrance-chamber and that of the cella, are central, and are unusually wide $-3.30 \mathrm{~m}$. On the axis of the doors there is in the back wall of the cella a recess $0.60 \mathrm{~m}$. deep of precisely the same width as the doors. ${ }^{2}$

The NW. and SW. walls are quite thin-the latter only I. I $5 \mathrm{~m}$. thick, actually thinner than the cross-walls, whereas the $\mathrm{NE}$. wall shows the astonishing thickness (vouched for by the stone foundations; none of the brick superstructure survives) of $4.75 \mathrm{~m}$. At the $\mathrm{SE}$. end, where the wall fails, destroyed by the Level III builders, there is in its core, at foundation level, a drain lined on one side with stones and on the other with burnt bricks (re-used, $0.26 \mathrm{~m}$. sq. $\times 0.04-0.07 \mathrm{~m}$. thick) which begins on the line of the front wall of the entrance chamber and turns south-west to come out $2.50 \mathrm{~m}$. from that wall into the supposed 'porch'.

I It is tempting to restore this as a temple in antis, with two columns between the projecting walls (or between reveals from those walls) on the analogy of Niqme-pa's palace front. But there was no evidence for anything of the sort other than the fact of the side walls corining forward.

2 It is not, as might appear probable, a blocked doorway; the niche is allowed for in the stone foundations (as also in the trench cut for them) and the stones at the back of it are bonded into the main wall.

All the walls had stone foundations. In the NW. wall these were two courses deep but were stepped down at the west corner to five course, probably because of some weakness in the subsoil; on the SW. the foundations were correspondingly stepped up from the corner. In the cross-walls

the stonework was not carried across the door-openings; elsewhere it was one course deep only, but the NE. jamb of the cella door was strengthened by having a second course above floor-level which included a good quarry-squared block at the inner angle; the SW. jamb of the same door had been destroyed; the hinge-stone was found out of position. Both thresholds were paved with mud brick; the floors of the rooms were of clay, that of the cella being $0.15 \mathrm{~m} .-0.20 \mathrm{~m}$. lower than that of the outer chamber; the brick threshold formed a step between them. At $0.12 \mathrm{~m}$. below the floor of the cella (which was $0.05 \mathrm{~m}$. thick) there was an older floor or surface showing signs of use; in it were two shallow depressions containing ashes, one of which overlay the top of the ruined wall of Level $\mathrm{V}$. 
The only explanation that suggests itself for the anomalous width of the foundations on one side of the building only is that they are the foundations not of one wall but of

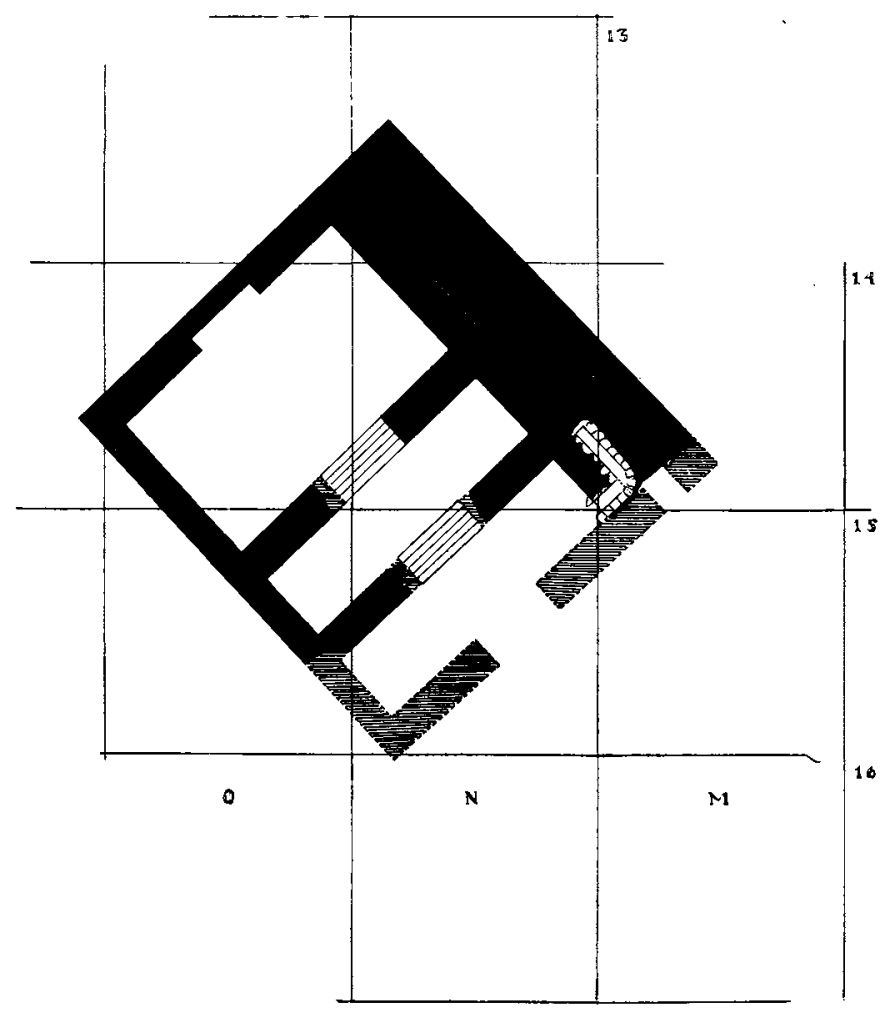

Fıg. 30. Level IV temple two, with a staircase between them; seeing that the stairs would be built as a solid block, an overall foundation would be the easiest form of construction. It is worth noting that the measurement from the SW. face of the 'wall' to the SW. edge of the drain is $\mathrm{I} \cdot 30 \mathrm{~m}$., the average width of the outer walls of the building; there would be ample room on the foundation for a staircase and a second wall of about the same dimensions. The objection to this theory is that the building was certainly only one story high-the walls are too thin to carry a second story, and the niche in the back wall of the cella is fairly good evidence for this, rather than a room above, having been the cult chamber. A staircase therefore could lead only to the roof. This, however, is not impossible. If we assume (and there is nothing against it) that the antechamber was relatively low and the cella, though only one story, considerably higher, we could then have a staircase with a door half-way up giving on the roof of the antechamber and a door at the top leading on to the roof of the cella. Such a reconstruction would gain support from its partial resemblance to the clay model from Bethshan, ${ }^{2}$ where human figures are seen both on the narrow lower roof and on the roof of the high shrine. 'There remains the difficulty of the drain. So long as it is regarded as being in the middle of the wall's thickness, as from the groundplan it appears to be, I cannot explain it. ${ }^{3}$ But if the theory of the staircase be accepted, then the drain comes against the outer face of the external wall of the building proper (the stairs being an external appendage) and that is the natural place for a roof drain, coming at the corner of the building and fed either by a gutter or by an external stack-pipe; if the

\footnotetext{
I It is clear that the roofing-beams were laid NW. $\times$ SE., that being the shorter span. This would account for the varying thickness of the walls; the SW. wall, having no weight to carry, would naturally be thinner, and the same applies to the supposed NE. wall.

2 Already cited above, p. 62. Alan Rowe, 'The Temples of Dagon and Ashtoreth', in the Museum Fournal (Philadelphia), Sept. I926. The model as restored (and only parts
}

\begin{abstract}
of it were found, but the restoration is probably correct) is very much schematized. Constructionally it is impossible since the upper walls have no support other than the roof; consequently no real building would resemble it in all its details, though the general effect may have been similar.

3 See above, p. 65, where I have argued against the likelihood of the roof drainage being carried down by an internal drain.
\end{abstract}


stairs led first to the antechamber roof they must have started at a point well beyond that at which the existing remains break away, and the lower treads would pass over the top of the drain channel.

A reconstruction on these lines seems to me best to meet the facts supplied by the somewhat scanty ruins.

In the cella recess, below floor-level, were found a few scraps of burnt bone, two short strips of lead, and some beads-one flat disk of amber, disks and cylinders of glass paste, glazed frit fluted or ribbed balls, and grooved biconical beads. In the wall-foundations was a (re-used) stelashaped limestone slab, oval-topped, $0.83 \mathrm{~m}$. high $\times 0.35 \mathrm{~m}$. wide and $0.16 \mathrm{~m}$. thick.

\section{THE LEVEL II I TEMPLE (Figs. 3 I and 32 and Pl. XI $a$ )}

The Level III temple was planned to occupy precisely the same site as its predecessor, scrupulously preserving its outline, but to be a building of an entirely different character; and to meet this change the whole of the interior had to be remodelled. To do this the builders pulled away nearly all the old mud brick, leaving the stone foundations, but since those were not nearly strong enough for the lofty building which they had in view, new brickwork (stone was not used) was laid against the inner face of the foundations to make them of the required width. On the NE. side the old stonework which had served for two walls and a staircase was too wide, so the inner wall-foundations were left unused; on the NW. side the skin of new brickwork obliterated the niche, which was not needed in the new temple because the cella was to be upstairs; on the south-west a thicker skin was added to bring that thin wall up to a thickness of three metres; the cross-wall between antechamber and cella was rebuilt with (on the NW. side) stepped-out foundations giving a total width of $3.50 \mathrm{~m}$., probably a good deal more than the width of the superstructure wall; the front wall of the antechamber was thickened from $1.40 \mathrm{~m}$. to $2.70 \mathrm{~m}$. While the walls were being built the rooms which they enclosed were filled up to a height of $2.00 \mathrm{~m}$. with a solid packing of mud bricks carefully laid in mud mortar; in the back room and in the narrow front room or passage this was definitely a filling put in against the faces of already existing walls; but in the south corner of the building we could distinguish no break of bond, the whole mass is homogeneous and as such is clearly just as essential to the plan of the building as is the differentiation of rooms from walls in the rest of its area.

As we found it, the ruin was virtually a solid mass of brickwork with no wall rising above floor-level; it was a raised platform on which the temple proper was to stand, a platform two metres high and conforming precisely to the outlines of the Level IV temple, i.e. to its sanctuary and antechamber. In front of it there was a portico which being at ground-level was better preserved, and in front of the portico an open court, cement-floored, which sloped up very gently towards the south-east. The portico was not central to the building. It was very shallow, measuring only two metres in depth; the SW. wall lined up with that of the temple, but its NE. wall was three metres from the temple's east corner; its front was formed by two jambs of unequal length (the SW. jamb being $\mathrm{r} \cdot 60 \mathrm{~m}$. longer than the other), between which were two square wood-encased 
brick pillars; ${ }^{1}$ the white cement floor of the outer court $^{2}$ extended between the jambs right up to the footings of the sanctuary wall and covered the short NE. recess but not the SW. recess.

The NE. side of the courtyard was formed by the (slightly askew) outer wall of the

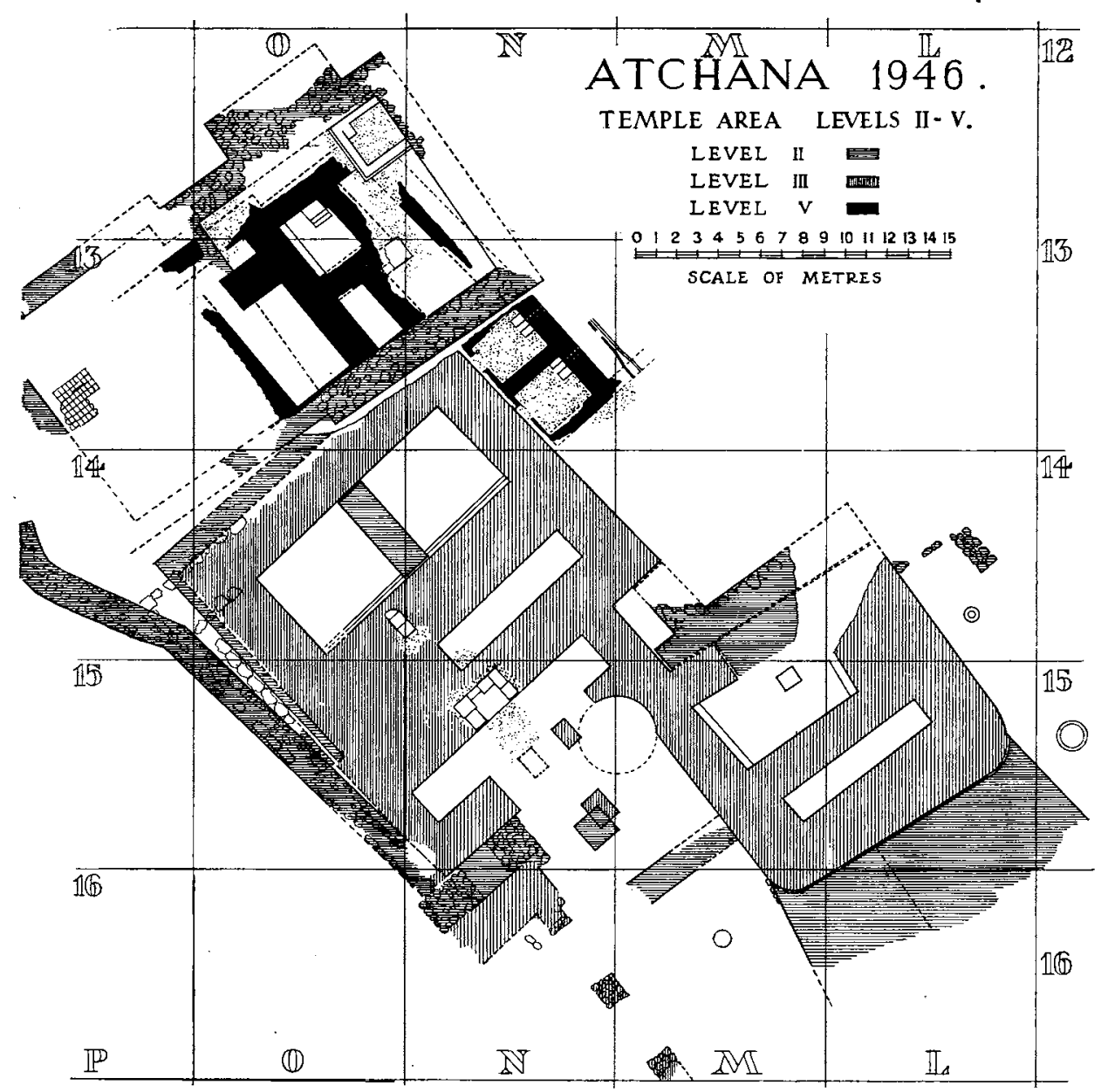

FIG. 3I. Plan of existing remains

building described below as 'Shrine B'. Its SE. limits are unknown. On the south-west there are three isolated blocks of rubble foundations which, since the intervals between them are exactly identical, appear to be not the broken remains of a continuous wall but a series of pillars presumably supporting an architrave $^{3}$ of wooden beams. The NW.

I Only one of these survived; the second had almost certainly been cut away by us when we were removing the brickwork of Level II in which it was buried.

2 The original floor was of hard white cement laid over fine gravel. It was repaved on various occasions, twice with cement and two or three times with clay, these additional coatings accounting for a general rise in level of about $0.20 \mathrm{~m}$. during the lifetime of the building. Since that lifetime does not seem to have been very long ( $v \cdot$ p. 396), we have here a useful reminder that the repeated mendings of a floor may be evidence that the building was well looked after rather than proof of great longevity.

${ }^{3}$ The interval, $3.00 \mathrm{~m}$., is well adapted for this. 
block is attached to a heavy mud-brick wall running NE. $\times \mathrm{SW}$. which leaves space for a passage between it and the SW. jamb of the portico. In the court, exactly central to the two portico pillars, there was a mud-plastered brick altar $0.70 \mathrm{~m}$. high.

The outstanding points about the sanctuary building are $(a)$ that the floors of its rooms were two metres above the level of the court; $;^{\mathrm{I}}(b)$ that its containing walls have no doorway and are standing up to floor-level except at the south corner where the SE. wall rises to a height of $\mathrm{I} \cdot 25 \mathrm{~m}$. only; $(c)$ that the thickness of the walls implies a great height for the building; $(d)$ that the brick-filled space at the back allows of a reasonable room, but that in front is too narrow to have been anything but a passage; and (e) that this 'passage' does not extend for the whole length of the building but leaves at the south corner an area constructionally (and therefore functionally) different.

The means of access to the sanctuary are obvious. It must have been reached by stairs. There cannot have been a central flight between the pillars of the portico because there is not there room for a flight of the requisite length and the presence of the cement flooring proves that the space was open. But the cement ends on the line of the NE. face of the longer jamb of the portico and there steps can be restored between the jamb and the sanctuary wall. Given the proportions of tread and rise normal in staircases at Atchana, the jamb is long enough to allow of a total rise of $\mathrm{r} \cdot 30 \mathrm{~m}$. followed by a square landing as high as the existing top of the façade wall; from this a rightangled return with steps through the thickness of the façade wall would easily bring one to platform level. The reconstruction explains, what is otherwise anomalous, the unequal length of the two jambs and the fact of the portico's not being central to the building.

The great thickness of the walls must mean that the building was two stories high, so that a staircase is necessary. The 'passage' was undoubtedly a staircase with its treads supported in the normal fashion ${ }^{2}$ on solid brickwork; its length, allowing for a landing at the top, would give a total rise of $4.00 \mathrm{~m}$., which is sufficient for the height of the groundfloor room at the back. In view of this, it is at least explicable that the south corner of the platform should have been built as a solid block-it is not, properly speaking, a room but a landing-a real part of the platform as such, affording access from the entrance-stairs both to the back room and to the main flight of stairs which led to the sanctuary in the second story. Naturally it was enclosed by walls, and it will be noted that the position of the entrance-stairs ( $v$. the restored plan, Fig. $3^{2}$ ) requires the SW. wall to be thinner than the other external walls of the temple; but that difficulty disappears if we assume that there was a window here; the landing needed light, and this is the only place where a window could have been.

I The only floor remains found belonged to Level II. But the Level II builders did not add to the height of the platform and they are not likely to have pared it down any more than was necessary to obtain a uniform surface, i.e. to have removed more than one course of worn bricks. The figure of $2.00 \mathrm{~m}$. for Level III must be approximately correct.

2 With the possible exception of the north staircase in the palace of Yarim-Lim (and that is not certain, v. p. I00), all the staircases found at Atchana have their lower flight solid and only the upper flight supported on timber with a cupboard underneath; and the general rule is that the supporting block is not bonded into the side walls but added after their construction. 
Since all the external walls are of the same thickness it is reasonable to conclude that they were of the same height-that the building was not, like the temples of Levels XII and VIII, in two steps, but a simple flat-topped block. The only difficulty is the still greater thickness of the central wall, which would seem to be constructionally unnecessary. It is tempting to suppose that the SE. half of it was really not walling but the

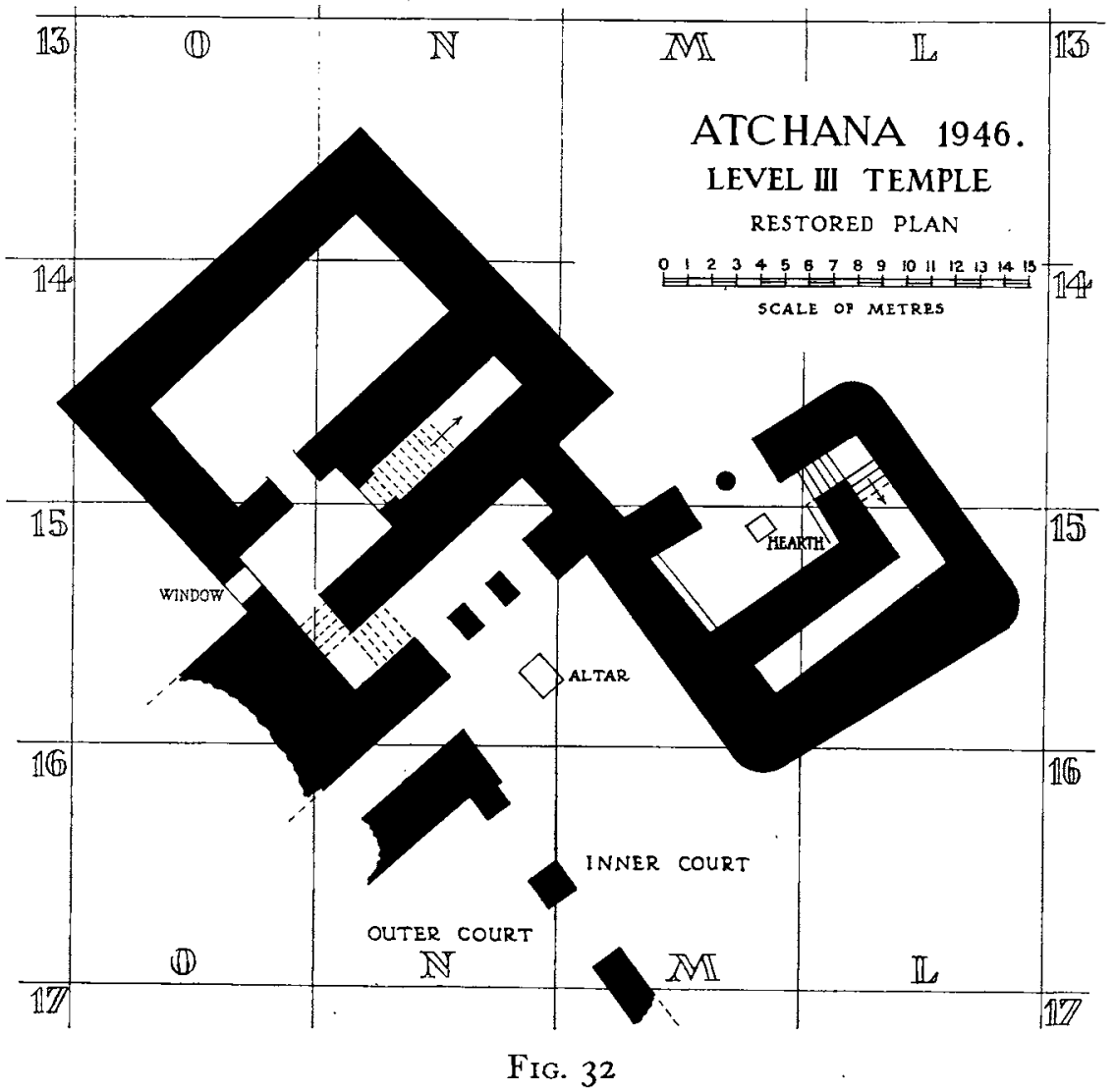

support for a return flight of the stairs starting from the landing at the top of the lower flight; the true wall above that point would have had the normal thickness of about I. $50 \mathrm{~m}$. If there were a return flight, then either the ground-floor room was considerably higher than the $4.00 \mathrm{~m}$. suggested above, or there was a third story.

Shrine ' $B$ '. The building was a second shrine, not altogether unlike that already described, but orientated in the reverse direction. It was almost a square with its east and south corners rounded; its walls were of varying thickness but never less than $2 \cdot 10 \mathrm{~m}$. (as against the $2.50 \mathrm{~m}$. of the shrine A walls), so that here, too, great height is implied, but there was no brick packing of the main room to make a raised platform; the floor of that room was flush with the ground-level outside. The narrow back 'passage' on the contrary was brick-filled, the $\mathrm{NE}$. end with bricks on a stone rubble foundation the bottom of which came just above the top of the stone foundations of the walls on both sides of it, 
the SW. end with brick only. 'The north corner was built as a solid block. The entrance had been on the north-west. Of the doorway the SW. jamb, very smoothly mud-plastered, alone remained; beyond it came the brick filling of Level II and then this, as well as the whole of the north corner of the building, had been destroyed, ${ }^{2}$ so that the width of the door must remain conjectural; but there is enough left of the Level II filling to prove that it was wider than the ordinary doorway and it is possible that it had a central column between the door-jambs on the analogy of the 'audience-chambers' in the palaces. The restoration suggested on the plan (Fig. 32) includes such a column, but further makes it come immediately in front of a square hearth made of burnt tiles, $0.26 \mathrm{~m}$. sq. $\times 0.095 \mathrm{~m}$. thick, which stands on the clay floor of the room; the hearth was $0.15 \mathrm{~m}$. high and there were traces of ashes on it. Along the NE. and SW. walls ran a brick bench $0.35 \mathrm{~m}$. high; the plastering of this and of the walls above it was very poor. The mass of mud brickwork north-east of the chamber appeared to be uniform (we could not distinguish any brick-filled space such as there is on the SE. side), but it must be considered certain that there was here a staircase ${ }^{3}$ which at the back of the building took a right-angled return over the brick-filled 'passage'. Owing to the destruction of the north corner of the building it cannot be determined whether the stairs started (as suggested in the plan) in the corner of the ground-floor room, where there is just space for them, or had a separate entrance in the façade of the temple. For the same reason it is impossible to say whether the NE. wall ran on beyond the corner and there was a portico in front of this as in front of the ' $A$ ' shrine.

The area immediateiy to the north-east of 'Shrine B' does not seem to have been occupied by buildings in the Levei III period; we found what seemed to be the surface of an open court, and on it two superimposed hearths. The area to the south-east was certainly an open court showing several clay-floored surfaces between which were layers of burnt ashes, animal bones, and potsherds; it had been a temple rubbish-dump, a one-brick-thick wall serving to keep the rubbish within bounds. Here was found a small stone offering-table (AT/46/303, Fig. 79); there were a few small animal bones in one of the compartments. Also found here, under the mud brickwork of Level II, was the crude stone figure AT/46/I 34 (Pl. XLIV).

Under the floor of the shrine B room there were large lumps of copper slag; they cannot have had anything to do with the building. Similarly under the NE. end of the staircase in shrine $A$ there were two super-imposed furnaces of fire-clay, $0.50 \mathrm{~m} . \times 0.25 \mathrm{~m} . \times 0.20 \mathrm{~m}$. deep, very roughly made, which seemed to have been used during the time of the building of the temple; they were not part of its furniture, and actually came circa $0.30 \mathrm{~m}$. below the level of the top of the platform. In the furnace ashes was a clay lamp of Type I 679 .

The whole of the Level III temple was destroyed by fire. In shrine B there was plenty of evidence for this; in the case of shrine $A$ it was less obvious owing to the razing of all the walls to floor-level, but the wooden casing of the portico pillar was burnt and there was burnt brick rubble against the outside of the platform walls below the Level II floors.

I We were able to trace the sides of the passage before excavation by scraping the surface and observing the wider line of mortar between the wall sides and the filling, but for the ends this indication failed us and the measurements given on the plan are approximate. All bricks were $0.38 \mathrm{~m}$. sq.
2 In part at least by us when following the wall of the Yarim-Lim palace before the discovery of the temple.

3 We can allow $2.10 \mathrm{~m}$. for the outer wall, $1.50 \mathrm{~m}$. for the stairs, and $0.75 \mathrm{~m}$. for the screen wall between the stairs and the room. 
An interesting parallel to the Level III temple is afforded by the 'Hilani' at Carchemish. There we have the portico with two columns at the entrance set between square jambs, a wide inner door probably also with columns, a single chamber on the ground floor and a staircase behind it leading to the upper room. It is not a reproduction of either of the Alalakh shrines, but those do between them give all the characteristic features of the Carchemish building.

To the Level III temple we must assign the remarkable tablet of Bogazköy type, a Hittite divination text, ATT/46/2 A-C (Wiseman No. 454); it comes from a burnt building, and the Level II temple in which it was found had not been burnt. ${ }^{1}$ Apparently the tablet ATT/46/3 (Wiseman No. 3 I7) found in Sq. N I 4 belongs to Level III.

\section{THE LEVEL II TEMPLE (Figs. 3 I and 33 and Pl. XIa)}

The character of the Level III temple had, I think it is safe to say, been decided by the Hittite conquerors of Alalakh; that of Level II may be a symbol of a nationalist revival, for it departs altogether from the Level III lines and seems to revert to those of Level IV. The most obvious change was that the new building was only one story high, but in addition to that the entire arrangement of the interior was altered.

The walls of the old temple were razed to floor-level. A mud-brick facing $\mathrm{I} \cdot 20 \mathrm{~m}$. thick was added to the back or NW. wall. The front of the portico was walled up (the old pillars were incorporated in the new wall) and the NE. wall was prolonged to the south-east so as to complete the rectangle, and the whole of the portico thus enlarged was filled with mud brick up to the level of the floor of the building. The builders had thus a rather larger podium as the base for their temple; so far from making it any higher they preserved its original surface but raised the level of the courtyard in front of it by $\mathrm{I} .40 \mathrm{~m}$. above the (original) Level III court so that their platform was only $0.60 \mathrm{~m}$. above the new cement floor which they laid over the court. For their walls they utilized the old walls as foundations, but made their internal walls much thinner and added one new wall which divided the sanctuary into two chambers side by side. In the courtyard they set up a mud-brick altar on the top of but slightly to one side of the Level III altar.

Although nothing of the walls remains above floor-level the reconstruction of the temple, at least in its main lines, is certain. On the top of the first internal wall (the outer wall of the Level III building) we found ( $v$. Pl. XI $a$ ) a threshold of stone slabs with a patch of cement floor on each side of it, north-west and south-east; the fact that the cement floor ran on beyond the inner face of the front wall, over the old portico, was sufficient proof of the threshold's belonging to Level II. The threshold gave us the width of the doorway and the thickness of the wall, and as the slabs left a gap in the middle it is likely that there was a central wooden column, for which the door's width of $3.00 \mathrm{~m}$. just gives room. Lying on the top of the inner cross-wall there were two basalt slabs in situ, clearly part of another threshold, probably of a narrower door. These two doors and the altar in the courtyard were on the same axis; it was certainly to effect this that the

\footnotetext{
I It was in a pocket of burnt rubble used for levelling a depression in the Level I site.
} 
altar had been shifted $0.75 \mathrm{~m}$. from the position of its predecessor, for since the cella was divided into two rooms of the same size the door of the SW. room could not be nearer to the centre of the building than the threshold shows it to have been, and if altar and doors

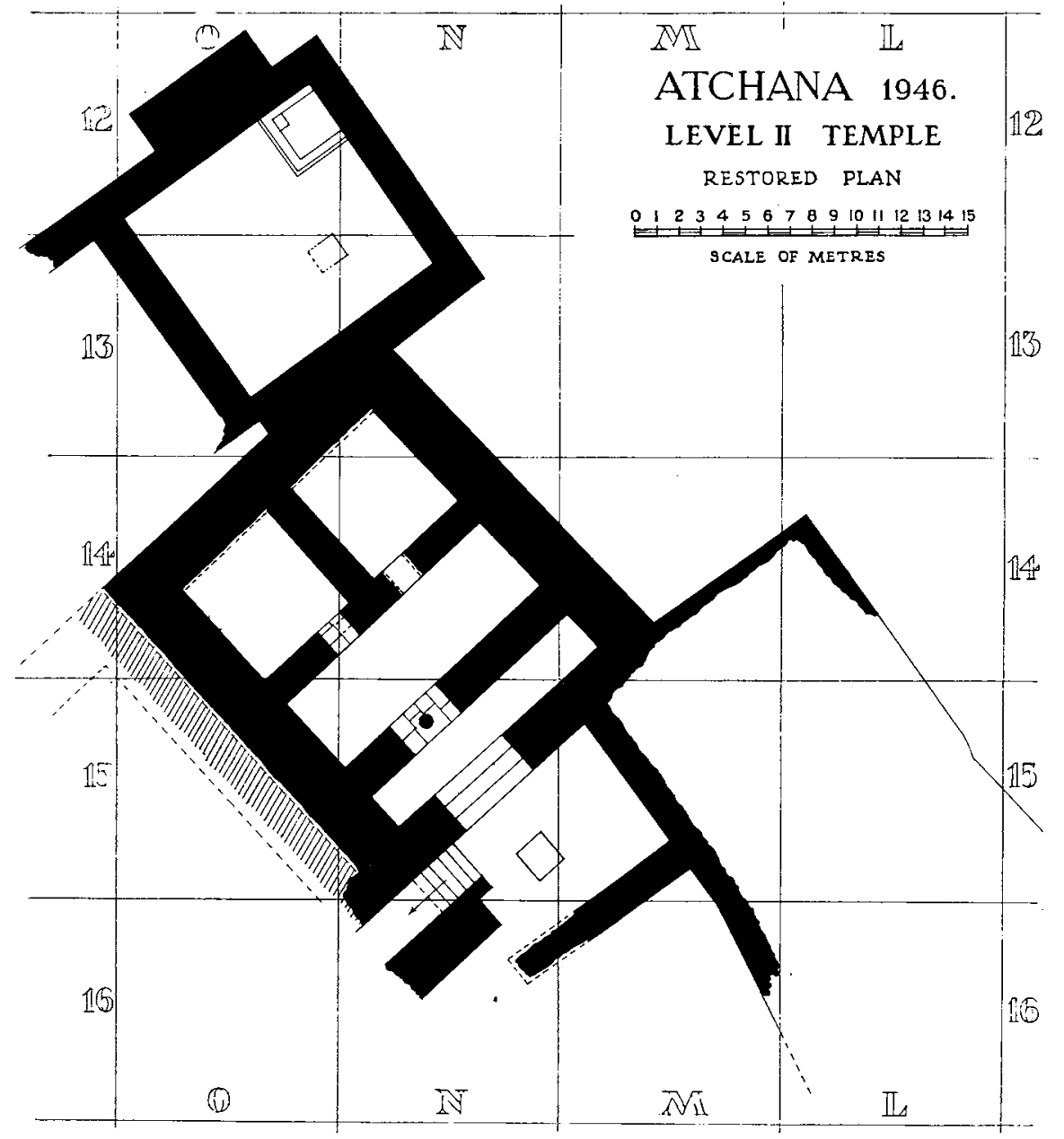

FIG. 33

had to be in a straight line, then it was the inner door that fixed the line and the altar had to be shifted to agree with it. Owing to the ruined state of the building we could find no trace of a doorway into the NW. chamber; the symmetrical arrangement on the plan (Fig. 33) is conjectural. Since the floor of the building was $0.60 \mathrm{~m}$. above that of the courtyard there must have been steps at the entrance bridging the gap; they cannot have projected into the courtyard, owing to the position of the altar, and the entrance-lobby is too shallow for them to have been inside it; they must therefore have been in the thickness of the wall, which is enough for the four steps required and is also a normal place for steps.

In our long series of temples this is unique as having a double cella. Evidently that in 
the west corner was the more important, in view of its relation to the temple entrance and to the altar, but the second can hardly have been other than a shrine, so that the building is intended for the worship of two deities. Probably a third was worshipped in the eastern annexe.

This new building was erected over the ruins of the Level III 'Shrine B', which were transformed for the purpose into a solid mud-brick platform. ${ }^{I}$ A new wall with stone foundations was built against the NW. front, masking the old doorway which, like the room, was filled with mud bricks $(0.38 \mathrm{~m}$. sq. $\times 0.13 \mathrm{~m}$. thick $)$. On the SE. side an entirely new platform was built on, hiding the original rounded corners, the solid brickwork being laid over the former open court and the rubbish-strata of Level III; its SW. face continued, but at a slightly different angle, the SW. wall of 'Shrine B'. The result was a low platform I $3.50 \mathrm{~m}$. wide and over $20.00 \mathrm{~m}$. long from north-west to southeast, ${ }^{2}$-but of the building that stood upon it not a vestige remained. Over the north corner were found three large clay vessels, Type 39.

The old courtyard was now divided into two by a cross-wall (only in part preserved) which ran out from the side of 'Shrine B'; the area south-east of it must have been open, judging from the fact that there was under its floor a surface drain formed of a large pot buried bottom upwards-there was a hole in the bottom of the pot. On the SW. side of the inner cement-floored court the Level III mud-brick wall that runs $\mathrm{NE} . \times \mathrm{SW}$. was retained, but what had been a passage between that wall and the temple façade was now altered. The entrance to it was blocked by a square mass of stone boulders; behind this was brick filling and behind that again, another square mass of stones; ${ }^{3}$ the facts were difficult to explain, but possibly this was still, as in the earlier period, a way of access to the temple court, though now complicated by changes of level both in that court and in the ground outside the temple.

Starting with that second stone block a wall was built abutting on the south corner of the temple platform (its end prolonging the SE. façade), but diverging slightly from its SW. side until near the west corner it turned out from it at an angle and then curved round again to run NNW. more or less parallel to the wall of the NW. annexe of the temple building. The wall had shallow stone foundations with mud brick above and

\footnotetext{
I The excavation of this was difficult and the method not without interest. Under the Level I ruins we found nothing but a mass of apparently homogeneous brickwork, flat and featureless; the most careful work failed to distinguish any walls. We discovered, however, that if the surface was scraped smooth the colour of the slightly damp bricks was at the beginning uniform throughout, but after a certain length of time showed differences of tone, seemingly due to the fact that the wall bricks, having more courses beneath them, dried more quickly than the bricks of the filling which had only five courses and then soil below; at one stage then the area took on the appearance of a drawn plan with the walls of a lighter tint than the interior of the rooms. The effect was not longlasting, but gave us the only guidance that the site afforded. In the end we found that all the walls were those of Level III.

2 Its SE. end was not found; it lay beyond the limits of
}

our excavation. There was a break in the bonding (NW. $\times$ SE.) which I cannot explain.

3 The first block of stones rested on earth, $0.20 \mathrm{~m}$. above the Level III floor; its top sloped, the NE. edge being $0.70 \mathrm{~m}$. above that floor and its back edge I. IO m., only a little below the level of the top of the second block of stones. In the brick blocking there were, against the SE. wall, two basalt blocks, $0.60 \mathrm{~m} . \times 0.60 \mathrm{~m} . \times 0.50 \mathrm{~m}$, carefully laid, flush with the top of the stone mass; there was mud brick above them. The first block is shown by its sloped top not to be a wall-foundation; it looks more like a ramp, but was below the level of the cement floor of the court so that it could not be more than the foundation for a ramp (or steps) now disappeared; the second block may have been the foundation of a landing, but we have nowhere found any anälogy for so solid a substructure of stairs or ramp. 
seemed to have been of a very shoddy sort. To the south-west of it there were no buildings and the ground was extremely hard, thanks evidently to repeated water action and to being trodden; it was an open space and a thoroughfare. The curious curved wall (Fig. 3 I) can therefore be explained as an enceinte wall for, the temple area, intended not only to keep people from the temple but also to protect it from the gradually accumulating rubbish which raised the level of the street. It was under the street surface that we found the fine ivory staff-head (?) AT/47/24 (Pl. LXXVId). ${ }^{\mathrm{I}}$

The NW. annexe was a late addition to the temple; it was slightly differently orientated, and for the laying of its wall-foundations the NW. wall of the temple platform, near its north corner, had been hacked away. ${ }^{2}$ The foundations were of stone, where they were preserved at all, but they were preserved only in patches, and it is likely that some internal wails (perhaps without stone foundations) had vanished completely.

The building covered an area of about $23.00 \mathrm{~m}$. $\times 13.00 \mathrm{~m}$ and was orientated NE. $\times$ SW. The SW. half of it was an open court, brick-paved, with relatively thin walls very much ruined; there was nothing to show where the entrance had been, and as of the medial wall less than three metres' length survived, the position in it of the door from the court to the building proper is also not fixed. That building had far more solid outer walls ${ }^{3}$ and on the north-west the wall was strengthened by a massive buttress; construction on this scale implies a roofed building, not an open court, and the same can be argued from the different character of the floor which, where it is preserved towards the $\mathrm{NE}$. end, is of cement, or rather of concrete with a cement finish, ${ }^{4}$ but it is most unlikely that the whole area, measuring as it does about ten metres square, should have been a single chamber, although there is no evidence whatsoever for its subdivision. On the cement floor there was left the $\mathrm{NE}$. part of a brick base $0.15 \mathrm{~m}$. high with whitewashed sides and cemented top on which (especially at the broken SW. end) there were marks of burning. ${ }^{5}$ In the north corner of the area was what had evidently been a cupboard; 6 in it we found a number of objects which are likely to have been part of the temple treasury, a lapis-lazuli figurine of a goddess (originally enriched with gold (?), AT/46/20, Pl. LXIXj), a bone figurine (AT/46/8, Pl. LXXVIe), a human head in glazed frit $(\mathrm{AT} / 46 / \mathrm{I} 4)$, the bone head, wings, and tail of a bird belonging to a wooden (?) toiletbox $\left(\mathrm{AT} / 46 / \mathrm{I}_{5}, \mathrm{Pl}\right.$. LXXV $b$ ), a fine vase of blue paste with a handle in the form of a couchant lion $(\mathrm{AT} / 46 / \mathrm{I} 8, \mathrm{Pl}$. LXXXIIIi) and fragments of glass vessels of quite

I The street, and the wall-foundations, rested on a mass of rubbish, mostly ashes and reddened fragments of accidentally burnt bricks, going down to Level III. This, while undoubtedly derived from the ruins of the Level III temple, was none the less filling put down in the Level II period; near the bottom of it were found fragments of fully developed 'Atchana' ware. The ivory staff-head therefore might belong either to Level II, at which time it was lost, or to Level III if it was an heirloom; but the Level II attribution seems the safer.

2 That this was possible at all is proof that the new building was considered part of the temple. In the finished work, of course, the joint would be hidden and there would be

B 2501 nothing to show difference of construction.

3 Judging from the two sides; the thickness of the medial wall is not known as only the inner face could be identified.

4 A patch in the west corner was of clay only.

5 I would suggest the possibility that this was not a freestanding base but was against a wall which, together with the SW. end of the base, has been destroyed.

6 It was only $2.20 \mathrm{~m}$. sq., too small for a room, and the sides standing to $0.40 \mathrm{~m}$. were merely screens one brick thick, mud-plastered and whitewashed, as was the floor inside. The sides were built on the top of the cement floor; they were neatly chamfered on the outside and I took them to be only the skirting for partitions in wood. 
exceptional quality. These objects, being temple property, are not necessarily contemporary with the building in which they were kept; some are likely to be much earlier (see above, p. 66). Equally fine glass was found in Levels V and VI and in a Level IV deposit under the floor of the Level III temple. Such things therefore cannot safely be used for dating evidence except within very wide limits, nor can this cache in Level II witness to any superior craftsmanship in that period.

The lion figures which we found re-used in the latest version of the Level I temple must have formed part of the architectural decoration of the Level II temple; one of the fragments was underneath the Level I A foundations and therefore must have belonged to an earlier building. It is, of course, possible that they were taken over by the Level II architect from the temple of Level III (the Idri-mi statue found in the same conditions as the lions is of Level IV date), but any attempt to restore the superstructure of the Level II temple must take the sculptures into account. In that temple the successive doorways, narrowing as they recede, are peculiarly adapted for the display of gateguarding lions.

\section{THE LEVEL I TEMPLES (Fig. 34 and Pl. XIb)}

By the time of the building of the Level I temple the ground all round had risen considerably and the old podium had ceased to exist as such. The new construction was planned to be of the same size as the old, utilizing the stumps of the latter's walls as foundations, but in fact this intention was only partially carried out. In the first place the retaining-wall which protected the SW. side of the Level II temple from the street seems to have been mistaken by the new builders for the wall of the temple itself, and it was on the ruins of that rather shoddy wall that they laid out their line, and measured from that; consequently the SW. side of the Level I temple lies outside the old platform and the NE. side is set well back from its edge. Again, the new building was to be of a very different character, so that the internal walls could not correspond to those of the old temple. Lastly, the orientation was slightly changed. Really then we have a new building on an old site; the overall dimensions are similar, but only the back wall is identical. As if to emphasize this the builders, even where they had the old walls as a base, as a general rule put in new stone foundations, two or three courses of unshaped rubble blocks weighing on the average upwards of half a ton each; on these the walls were carried up, as usual, in mud brick with a certain amount of timber.

The temple as originally planned (I A, Fig. $34 b$ ) was a simple one-story building consisting of a large cella and an antechamber giving on a courtyard that lay to the southeast of it. It had been destroyed by fire and rebuilt (temple I в) and the clearing of the site for rebuilding had resulted in further destruction of the original structure; it was therefore in bad condition, and practically the whole of the west corner had disappeared.

In the cella the back (NW.) wall had been built with three recesses $2.00 \mathrm{~m}$. deep separated by heavy buttresses. The central recess was open and had been lined with wood-there remained in the brickwork the grooves left by wooden uprights against which the panelling had been fixed. The buttresses on each side of it were faced with 


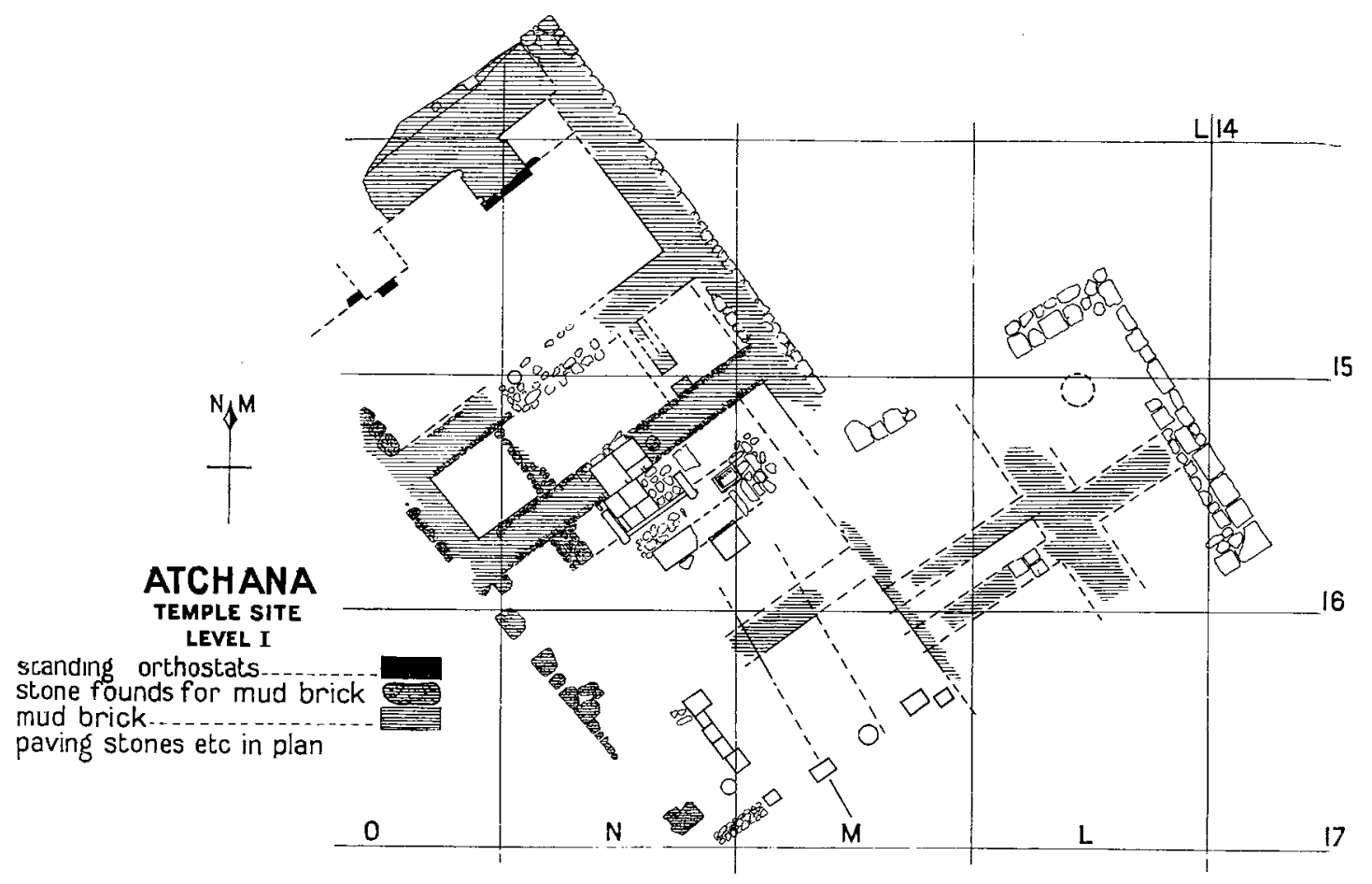

FIG. $34 a$

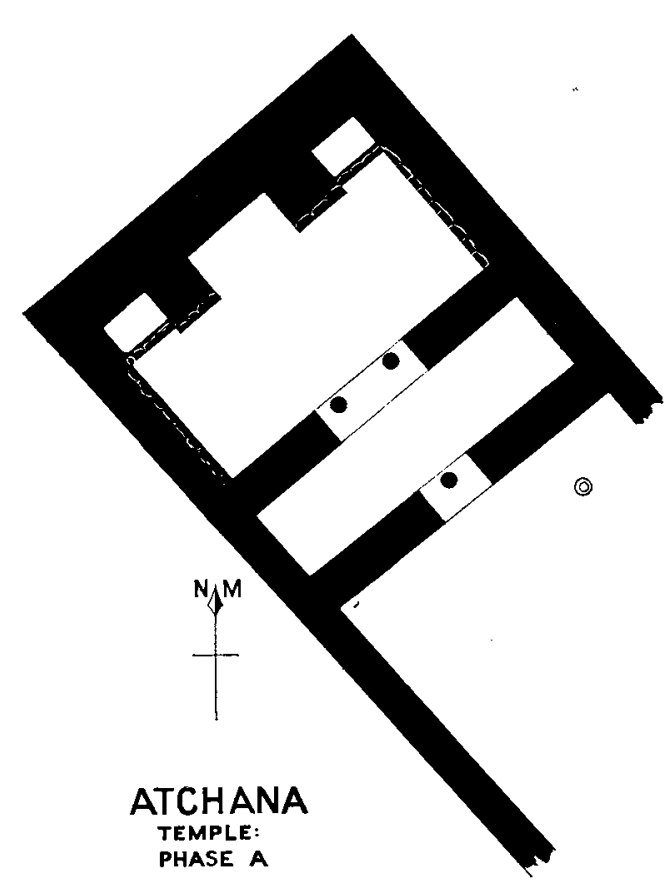

FIG. $34 b$

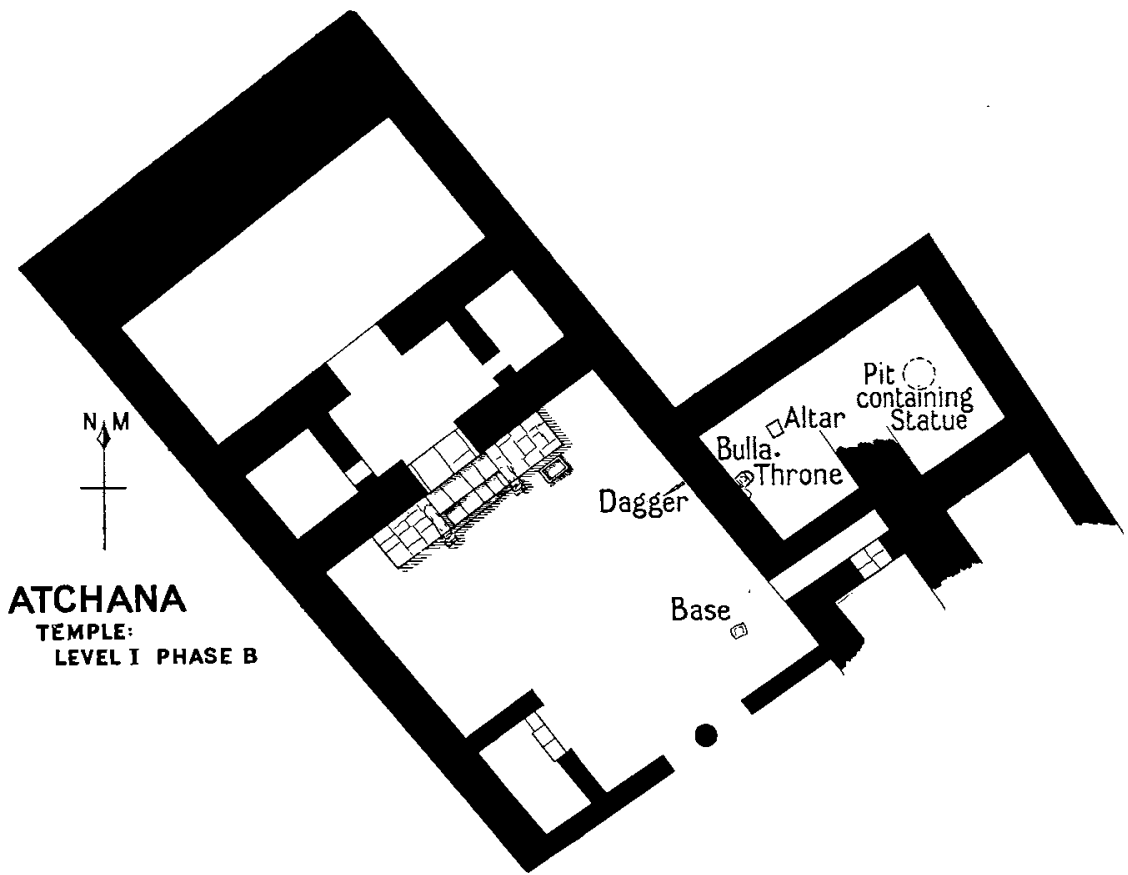

FIG. 34c 
basalt orthostats a metre high above which there had been mud brick, the bricks measuring $0.40 \mathrm{~m}$. sq. $\times 0.14 \mathrm{~m}$. thick, perhaps also masked with wood. The side recesses, judging by that in the north corner, the only one remaining, had also been wood-lined, but had been closed; a single orthostat set back $0.25 \mathrm{~m}$. from the buttress face (there is a corresponding one in the west corner recess) is certainly in situ and its line must have been continued by others; we could find no trace of brickwork behind this orthostat, on the contrary there were signs of timber instead, and we could only conclude that there was merely a screen of stone below and probably wood above; ${ }^{1}$ the recess therefore would have been blocked, but the shallow niche in the face of the back wall would have betrayed-or symbolized-its existence.

It is tempting to regard these concealed 'cupboards' as intended to receive foundation-deposits, but we have absolutely no analogy for anything of the sort, nor were any objects found in them. Immediately behind the NE. recess, in the core of the mud-brick back wall, we found a fine bronze dagger, $\mathrm{AT} / 46 / 24$, Type Kn. 4, an alabaster vase, $\mathrm{AT} / 46 / 38$, Type 20 , almost destroyed by fire, fragments of a vase of variegated glass, and pottery fragments, also burnt. These had been deliberately put into the brickwork while the building was in progress, and they are the nearest thing that we have got to a foundation-deposit; but their connexion with the recess is doubtful.

We were inclined to believe that the other walls, at least the NE. and SW. walls, had also been provided with basalt orthostats, but could not be sure of it. No stones remained. The walls-or rather, the NE. wall, for the SW. wall was virtually non-existent-had lost the whole of its face and there was left only the mud-brick core standing to a height of $\mathrm{I} \cdot \mathrm{I} \circ \mathrm{m}$., the lower courses scorched and reddened, the bricks above $0.35 \mathrm{~m}$. from the floor burnt almost white and crumbling; the stone foundations, at floor-level, projected enough to give a lodgement for orthostats, but this may have been due merely to the crumbling of the brick wall-face. There had been a lot of timber in the wall, and this accounted for the character of the burning and for the fact that the upper courses had collapsed and the bricks were loose and in disorder. Of the SE. wall the stone foundations remained, running continuously across the room with mud brick upon them at either end but a gap in the middle where there must have been the doorway; here the stones were smaller and rose higher, and were clearly the foundations of a door-sill. Towards the SW. end of the gap-not quite at its end-there was let into the stones a roughly circular basalt slab which was discoloured and cracked into five pieces evidently by the burning of a wooden upright for which it had served as impost; judging from the position of the stone the wood had been not part of the door-frame but a free column.

Fragments of a tablet of Bogazköy type, ATT/46/2 a-c, were found under the stone foundations of the NE. part of this wall; on this see above, p. 78 .

The antechamber had been divided into two by a cross-wall towards the NE. end; this was of mud brick only, with no stone foundations, and of the brick very little remained, discoloured by fire; it did not rise above floor-level and therefore there was no sign of a door. The antechamber walls had no orthostats; the walls were simply mud-

\footnotetext{
I This was the impression we got, but the destruction was so complete that there might have been brickwork which we
}

failed to distinguish from the mud-brick debris that filled the recess. 
plastered. The entrance-door was $2.50 \mathrm{~m}$. wide (as against $4.30 \mathrm{~m}$. for the cella doorway), so that at most it can have had only a single column; but there was no sign of such on the slightly raised threshold.

The courtyard was at the same level as the floors of the temple rooms and had originally a floor of white cement which was preserved only in a few patches. On the SW. side some of the stone foundations remain of the enclosing wall, which continues the line of the SW. side of the temple building; on the NE. side there is left only a little mud brickwork in the north corner, enough, however, to show that there was here, too, a wall continuing the NE. wall of the temple. It was impossible to decide whether the disconnected remains at the SE. end belong to this early Level I temple or to its successor; ${ }^{1}$ similarly there must have been at this time some building on the annexe lying north-east of the courtyard, but the existing ruins there were by use, if not by foundation, part of the later temple. In the north corner of the court there was a large and deep well (we never got to the bottom of it), circular in plan and brick-lined; the hole dug for the construction of it, which could be traced quite clearly, cut away part of the Level III temple and came up above the floor-level of Level II; there was therefore no question but that the well belongs to Level I, and as it was disused and filled in in Level I в, it is a feature peculiar to the Level I A temple.

LeVel i b (Fig. 34c, and Pl. XIb)

The Level I A temple was destroyed by fire, but before it was burnt it had been, apparently, systematically wrecked; in no other way can we explain how it came about that most of the basalt orthostats blocking the recesses in the cella had been pulled away and carried off while one from each recess and all those of the NE. buttress were left in situ. Had the builders of Level I в been responsible they would have removed all the stones; moreover, the mass of fallen mud brick that filled the room had not been disturbed where the facing-slabs were missing but was uniform throughout, and it was evident that the stones had been taken before the walls fell and buried those that were left.

The new builders did not clear that rubbish away but took advantage of it to raise the level of their temple; their clay floor, $0.75 \mathrm{~m}$. higher than the old, was flush with the tops of the remaining orthostats. But they kept the courtyard almost at its original level, ${ }^{2}$ so that the temple now stood on a low podium.

Although the new temple presented a very different appearance from the old its ground-plan was almost the same. In the cella the recesses in the back wall disappeared and the wall line was brought forward flush with the fronts of the old buttresses; to that extent the chamber was smaller. The cella door was narrowed to $2.50 \mathrm{~m}$. (there was no evidence for a central column). The antechamber was now divided into three by crosswalls so that one had a small entrance-chamber flanked by other small chambers; the

\footnotetext{
I As in any case they were in use in the later period they are included in the description of Temple $B$.

2 It had been repaved during the lifetime of temple I A.
}

The Level I B pebble pavement was only $0.25 \mathrm{~m}$. above the first I A floor. 
door to that in the east corner was preserved at the SE. end of the wall. The entrancedoor was $2.30 \mathrm{~m}$. wide and certainly had no column, for the three basalt slabs forming the threshold were found in situ and bore no mark of anything of the sort. The distinctive feature of the building was its approach. The threshold was $0.50 \mathrm{~m}$. above the courtyard level; accordingly, to make access possible, there was built against the front of it a platform through the centre of which ran a flight of stone steps; these were flanked by figures of lions whose heads projected from the front of the platform.

The arrangement whereby a flight of steps is flanked by flat-topped platforms of the height of the stair-head has a precedent in the palace of Niqmepa ( $v$. Pl. XXIVa) and there is a later example of it at Carchemish; ${ }^{\text {I }}$ the Level I в builders therefore were here following an established tradition. The lion sculptures are old material salved from the former temple and are used here not in the way for which they were intended but as well as their condition allowed. They were, as is usual with such figures, corner-stones, with the animal's head, chest, and forelegs carved in the round and the body rendered in relief on one side of the stone; here they were built into the platform so that the foreparts were visible but the carved sides were hidden. This was inevitable because one of the two beasts, that to the north-east, was incomplete, his hindquarters having been broken away; the pair therefore could only be used on condition that the foreparts alone were exposed to view. 'That they should have been used at all seems to show the builders' pious regard for the relics of their city's past. ${ }^{2}$ It was perhaps the same sentiment that induced the very different treatment of another ancient monument. One of the two basalt slabs left in the upper stair proved to be a Hittite royal relief representing one of the Tuthaliyas and his wife (AT/40-45/2, Pl. XLVIII); it had been used upside down as a paving-slab, and it is not too fanciful to assume that this was a deliberate insult to the foreigners who had once been the masters of Alalakh.

The surroundings of the courtyard were terribly ruined and any reconstruction of the scanty remains is hazardous, but its entrance at the SE. end did seem to be constructionally certain, though we could not be sure whether it was originally built in the Level I в period or had been inherited from the previous age. A plain basalt column-base of unusually large size (it was $0.65 \mathrm{~m}$. high and its diameter was $0.75 \mathrm{~m}$. at the top and $0.83 \mathrm{~m}$. at the base) stood on the pebble floor ${ }^{3}$ exactly centred between two large basalt blocks which seemed to be door-jambs; but they were sunk $0.45 \mathrm{~m}$. below the floor, $0.75 \mathrm{~m}$. of

I Carchemish, iii, Pl. 3 г $a$.

2 In my preliminary report, $A . \mathcal{F} . \mathrm{xxx}$ (Jan.-Apr. I950, p. I I), on the strength of the Dudhalia relief being incorporated in the stairs, of the lions being incomplete and of other lion fragments being found in the filling of the well, I argued that 'the misuse of the old monuments makes it evident that piety played but a small part in the preservation ... of such relics; it was rather an attempt to attain magnificence with the minimum of expense'. This is a false view and disregards the fact that the well was not filled in by the builders of the new temple.

3 The courtyard was repaved several times and both its original and its latest floors were of pebbles. The latest floor sloped down from NW. to SE., and whereas in front of the lions it was half a metre above the first, at the SE. end they were indistinguishable. The column-base stood on the pebbles and might therefore have belonged to either phase, or, as I assume, to both. Close to the column-base were found a jug of drab clay, Type $42 a$, a bronze chisel (AT/39/290), and an iron arrow-head of Type Ar. 6, AT/39/294. Elsewhere in the courtyard were found two bronze loop handles for a bucket (AT/39/332), a vase of drab clay, ht. $0.085 \mathrm{~m}$., Type I 22, a bronze arrow-head of Type Ar. 2 (AT/39/16BB), a red clay saucer of Type $4 b$, an open-work 'wheel-hub' bead in glazed frit (Type 25). 
their height standing above it. To the south-west there were rubble wall-foundations virtually on the line of the two jambs but set slightly back from it; probably this was the $\mathrm{SW}$. wall of the courtyard with a columned gateway $4.00 \mathrm{~m}$. wide forming a slight salient. In the gateway was found the ivory libation-pourer AT/39/304, Pl. LXXVII $b$, and just by it was a (broken) basalt tank divided into two compartments each $0.60 \mathrm{~m}$. sq. and $0.30 \mathrm{~m}$. deep.

In the south corner of the court there seems to have been a small independent building of which only the raised basalt threshold between two imposts remains. In the north corner there was a square basalt tank (certainly in situ) and against it a number of large stones some sunk in the floor and some standing above it which might be the foundation of a raised pedestal but could not be explained satisfactorily.

\section{Details}

There were two steps of ashlar basalt and at the base a narrower step $0.25 \mathrm{~m}$. deep of rough rubble originally cement-plastered. Of the flight one half remained, of the other half only the rubble core. Of the platform south-west of the stairs we found a facing-stone in position, masking the lion's body, with earth and mixed rubble behind it, and the foundations of the platform end; of the other platform practically nothing was left except one big block in the core: presumably it had been of the same length. This block in the core of the NE. platform agreed in measurements with that in situ in the face of the SW. platform and has perhaps merely fallen away from a corresponding position. As regards the height of the platforms nothing can be said. Originally the lion sculptures were built into the angle of a wall which rose above them and the relief profile of the lion's body, incomplete on the single block, was finished on the adjoining stones. Re-used as they were in the staircase, the incompleteness of the body did not matter because the side of the block was hidden, but it is none the less possible that (as originally intended) there were further courses of masonry resting on the lion blocks and that the 'platforms' were higher than appears, even rising up as solid buttresses framing the stairs. There were on the top of the lion blocks scanty traces of mud brick of the type used in Level I в (black mud with fragments of white lime embedded in it) which give countenance to this possibility.

In front of the lowest step there were rough cobble foundations just below floor-level, and beyond them, flush with the floor, a large basalt slab and another one beyond it but not in the same line; all this we took to be reinforcement of the floor where traffic would be too heavy for the mere cobbles.

South-east of the tank (v. Fig. 34a) were two basalt orthostats set upright and back to back; that to the north-east, which lined up with the NE. edge of the tank, rose above floor-level and showed signs of having been plastered with cement, while the other was flush with the floor; it looked as if they formed part of a raised base connected with the tank. North-east of this and of the tank was a line of rubble flush with the floor and then a single standing orthostat with rubble behind it; the orthostat seemed to be in position. It is possible that this one standing stone is all that is left of the NE. wall of the court. The raised mud-brick podium of the eastern annexe comes too far forward for the courtyard wall to have continued the line of the NE. wall of the temple, though not far forward enough to agree with the position of the single orthostat. If the orthostat gives the wall line, then there may have been a wall with orthostats all along it enclosing the podium; if, on the other hand, the (very much broken) edge of the podium gives the wall line, then the orthostat must belong to some feature projecting from the wall. It is worth remarking that the line given by the orthostat comes almost exactly to the corner of the NE. platform, which in that case would have filled the corner of the court. There were traces of cement flooring over the stones 
between the orthostat and the tank and similar traces between the tank and the NE. lion. It is likely that the pebble flooring over the whole court was really a foundation for cement.

In the south corner of the court the threshold was made of three small basalt orthostats re-used, their outer, NE. edges carefully aligned, the irregular backs carried on by a pebble floor $0.35 \mathrm{~m}$. above that of the court, a level which agreed with the top of the heavy rubble foundations of the $\mathrm{SW}$. wall. The line of cobbles south-east of and at right angles to the threshold is a foundation for a stone wall; one orthostat rested on them and two were found loose just alongside; it could be traced almost up to the SW. jamb of the entrance-door.

Of the eastern annexe very little remained. The greater part of the heavy stone foundations of the NE. and NW. outer walls was found, but inside them the whole area was an apparently uniform mass of mud brick. By scraping the surface we were able to distinguish vague lines of a slightly different colour, but only in one case and for a distance of only about three metres was there anything so definite as a wall-face. In one of the lines, however, three flat stone slabs in situ gave us the threshold of a door and thereby proved that the discoloured line was indeed a wall, and assuming that this was always the case it was possible to restore a ground-plan giving a short entrance-passage with a door on the right and probably a corresponding door on the left side (though there was no evidence for this); the two doors led into rooms flanking the passage; a heavy wall running NW. $\times$ SE. divided the building into two parts; this wall blocked the passage end and through it there must have been two doors leading from the side rooms into two larger chambers that formed the NE. half of the building. That the plan was more or less of this character is, I think, certain, but we were quite unable to decide which period was responsible for it. We know that there had been a platform here in the Level II period, and therefore the fact that the platform top is $0.50 \mathrm{~m}$. higher than the level of the $I_{\mathrm{B}}$ courtyard cannot be used in argument. It was noted that the reddish colour of the bricks of the platform would agree with Level II; the wall bricks, also reddish but darker, might have belonged to Level II or to Level I A; they were definitely not characteristic of I B. ${ }^{\text {I }}$ While the platform must be, in part at least, of Level II date, and while the walls are probably of Level I $A,{ }^{2}$ at least in their foundation, the rooms were in use in Level $\mathrm{I}_{\mathrm{B}}$, because all the objects which date from its destruction were found on the room floors.

Just outside the NE. jamb of the entrance-door stood a (broken) basalt block $0.45 \mathrm{~m}$. wide by more than $0.60 \mathrm{~m}$. long having a shallow recessed panel in its upper face; it may have been a base for a statue. A second socketed stone, also perhaps a statue-base, lay in the courtyard towards its east corner. On the line of the NE. wall was the splendid ritual bronze spear-head AT/39/305, Pl. LXX; in the small west room of the eastern annexe there were found a bulla seal inscribed with Hittite hieroglyphs, AT/39/322, P1. LXVII, No. I 5 5, a basalt altar decorated with swans' heads, AT/39/287, Pl. LII $a$, a much-damaged limestone statue of a seated goddess, AT/39/3 I 7, Pl. LIIb, and (AT/39/

I The use for bricks of a black mud with flecks and lumps of white lime in it is common in Level $I \mathrm{~B}$, but also in the great fortress building of Level III. I believe that it results from breaking up and puddling old wall debris, the lime being the old wall-plaster. Such bricks are always of a loose texture and decompose easily.
2 Since the Level I a builders did not incorporate any older wall remains in their platform and we could find traces of one building system only, they probably pared down the old platform so as to get a good level foundation for their own work, thus making a clean sweep of the Level II annexe. This was the impression that we got while excavating the site. 
288) an (also much damaged) basalt throne for a statue, its arms supported by lions, $\mathrm{AT} / 39 / 288, \mathrm{Pl}$. XLVIIb. In the inner (northern) room of the annexe a hole had been dug into the brickwork of the platform, starting at Level I в; at the top it was disguised by bricks, below the bricks were earth and stones, including two large orthostats and a basalt footed column (perhaps the stem of a large columnar lamp, but it was rather rough) a metre high and $0.43 \mathrm{~m}$. in diameter, and below these, in the bottom of the pit, the carefully assembled fragments of the statue of King Idri-mi, AT/39/33 I, PIs. XIIb and XLVI. ${ }^{I}$ That the breaking of the statue was contemporary with the destruction of the Level I в temple was manifest not only from the observation that the pit in which it was hidden was dug from the floor-level of that temple but even more clearly from the fact that the statue belonged to the lion throne found broken on the floor. It looks as if the two annexe rooms on the left of the entrance-passage formed the memorial chapel of Idri$\mathrm{mi}$; in the debris that filled them were found several clay vase-stands (Type 85) that might have been used for offerings.

The last phase of the temple preceding its violent destruction was one of complete decadence. There were no new walls or modifications of plan, but the courtyard was repaved time after time until the highest floor was about $0.35 \mathrm{~m}$. above the original. There was a corresponding rise of levels $(0.30 \mathrm{~m}$.) inside the temple, so that the relation of court and podium was preserved; but the courtyard floor now buried not only the lower steps but also the bodies of the flanking lions so that only their heads showed, the lower jaw scarcely above ground-level (PI. XII $a$ ). Decadence could hardly go farther. ${ }^{2}$

\section{LEVEL O}

The temple was rebuilt. Along the whole of the NE. wall of the temple itself and of the annexe there ran a massive foundation (Pl. XIII a) of mixed stones-boulders, old orthostats, \&c.- - on and behind which were traces of mud bricks accidentally burned; in two or three spots we found patches of cement flooring connected with this wall. The whole thing lay very high; over the annexe the foundations come nearly a metre above the Level I в floor, and farther to the north-west the trench cut to take the stones does not go to the bottom of the brickwork of the Level I temple wall. No more than this remains of the building, but it is clear that it was planned to follow the lines of the Level I temple (the stumps of whose walls may well have been visible above ground); ${ }^{3}$ it is also clear that the work was of a rather poor and hasty description because although the

I See p. 240, and also, for the full account of the inscription, \&c., Sidney Smith, The Statue of Idri-mi, Occasional Papers of the British Institute of Archaeology in Ankara, No. I, 1949.

2 A note in my preliminary report might be quoted here. 'Lest it be thought incredible that the decorative features of a sacred building should be so maltreated I quote an exact parallel. In the great temple of Madura, southern India, there projects from the columned hall a flight of stone steps leading down to a garden court. On either side of the steps there stood at ground-level the figure of an elephant carved in stone of rather more than half life-size. The level of the garden has so risen that of one elephant only the top of the head and rump and of the other only the crown of the skull appear above ground.'

3 At the SE. end the foundations return SW. over the top of the Level I ruins, suggesting that the annexe of Level $O$ enclosed a slightly smaller area. Immediately after the return the stonework stops in a straight line as if for a doorway. Just beyond this (as if against the SW. jamb of the door) there lay a very large and rather rough basalt offering-table (P1. XIIIb) of a kind familiar to us from Carchemish (v. Carchemish, ii, Fig. 27, p. 94) and paralleled by a fragmentary example found loose in the ruins of the Level I temple AT/46/302, Fig. 79. 
foundations were solid enough they were ill laid, or not laid at all, the re-used material being simply thrown into the trench and not arranged in any way, while no attempt was made to clear up the site but the new floors were laid on the top of the old debris. Further, it would seem that there was a definite break, probably a fairly long time-interval, between the destruction of the old temple and the rebuilding, because although such care had been taken to preserve the Idri-mi statue with a view to its future recovery, no attempt was made to recover it; the statue, and the other monuments lying just below the surface of the ruins, had passed out of memory. 


\title{
THE PALACES OF LEVELS VII AND IV
}

\author{
(a) THE LEVEL VII PALACE
}

(Pls. XIIIc-XXIII $a$ and Fig. 35)

W

E define our archaeological Level VII as beginning and ending with the existence of the great royal palace which is its outstanding monument. Numerous tablets were found in the building; some are of Hammurabi of Yambad, more are of his son Yarim-Lim, the latest are of his grandson Niqme-epukh. The first was probably the actual builder, but in view of Yarim-Lim's greater prominence it is his name that we attach to the building. 'The temple of Level VII abuts on the palace and on constructional evidence must be more or less contemporary with it; this is confirmed by the temple tablets, which again are those of Yarim-Lim. Palace and temple do not stand alone. The Level VII city gate is stratigraphically proved to be contemporary, and it is a matter of course that a ruler so important as Yarim-Lim should have refortified his city; the same is true of the interior of the castle. The only other building of Level VII whose existence is known to us (for no private houses of the time have been excavated) is the massive structure underlying the Level IV palace, a mere fragment, which again could safely be dated, on stratigraphical evidence, as contemporary with the palace. All these buildings were destroyed by fire, and in every case the fire was clearly intentional and was followed by an interval during which the site remained desolate. All therefore were built within a short time of each other, probably by one and the same man, and all perished at the same time. The temple shows no signs of remodelling; in the palace there are a few changes and additions, but they are no more than a new ruler might be expected to make when he inherited the buildings of a generation before; the archaeological evidence favours a short rather than a long floruit for the palace, and therefore for the Level as a whole. The series of tablets ends with those of Niqme-epukh, Yarim-Lim's son, the length of whose reign we have no means of telling; but in any case we can say that our archaeological Level VII corresponds to an historical period strictly limited to three human generations. It was a short period but magnificent; the remains of the palace testify to the state in which the kings lived. ${ }^{2}$

The palace (Fig. 35) was built on the site of the older palaces of the kings of Alalakh in an angle of the city wall, the wall itself being incorporated in the structure of the royal residence; the area covered measured about $100.00 \mathrm{~m}$. from $\mathrm{NW}$. to $\mathrm{SE}$. and about $30.00 \mathrm{~m}$. from NE. to SW. ${ }^{3}$ South-east of rooms I $5^{-I} 7$ there is a change of orientation

I It was at first thought that Yarim-Lim preceded Hammurabi on the throne; their true relationship was discovered only later.
2 Sidney Smith, Alalakh and Chronology, p. 35.

3 The SE. end was so completely destroyed that its exact limits could not be ascertained. The width, from NE. to SW., 
which at first made me think that everything beyond this point was a later addition, but it is more likely to be due to the palace builders having adapted their plan to the existing line of the city wall. ${ }^{\mathrm{I}}$ Owing to the character of the older buildings which had successively occupied the site the ground level sloped down from SE. to NW.; the Level VII builders cut this slope into a series of terraces and the palace is divided into three sections which more or less correspond to them.

On the lowest terrace, at the NW. end, there is a complex of buildings (rooms I-I 3 ) which seem to form the official quarter of the palace; it is a self-contained unit consisting of a main block, an open court, and, beyond the last, a row of magazines. The original entrance was by a great gateway in the SW. wall of the courtyard; the court, $2 \mathrm{I} \cdot 00 \mathrm{~m}$. $\times$ $9.00 \mathrm{~m}$. had a concrete floor in the centre of which was a raised hearth; a single doorway in the SE. side served the row of three magazines; otherwise the layout was symmetrical, doors in the north and east corners leading respectively to the residential quarter and to the official block of which room 8 seems to have been the entrance-chamber. At a later date the original entrance was elaborately walled up, the inner face of the blocking brought forward in a double salient and adorned with polished basalt orthostats to match those which ran all the way round the old court, and a new entrance was made in the SW. wall of room 7 (Pl. XIIIc), this too flanked with basalt orthostats and having double reveals. ${ }^{2}$

The centre of the official block was occupied by a 'Chamber of Audience' divided into two parts by projecting wood-panelled brick piers between which was a row of four wooden columns set on a concrete threshold (rooms $5,5 \mathrm{~A} ; \mathrm{Pl}$. XVa); the whole opening could be closed by folding-doors set on the inside of the threshold. The walls of the inner part (5)., apart from the piers, were lined with basalt orthostats with fine plaster above; but at a later time the plaster facing was carried right down to the floor and on it was painted an 'architectural' fresco exactly like that in the Level IV house 39/A ( $v$. Pl. XXXIX) in creamy yellow, brown, and black; the light-coloured mortar-lines between the painted orthostats did not correspond to the mortar-joints between the real stones concealed by the plaster. Opening out of the 'Chamber of Audience' were three rooms which on the analogy of the Level IV palace might be called the withdrawing-room, the secretariat, and (possibly) the archives; but there was really nothing in their contents to throw any light on their real use. ${ }^{3}$ Room 2 had a good floor of cement over concrete, as had the other two, and a central wooden column which is a unique feature; it was badly ruined through the collapse of the city rampart which had carried away the whole

varies, the building widening out at the SE. end, but here it was difficult to say of some rooms whether they belonged to the palace or to the temple.

I The NE. wall, i.e. the city wall, has already changed its direction slightly between rooms 9 and 10; and it will be noted that the NE. and NW. walls are not at right-angles, evidently for the same reason.

${ }^{2}$ I found no constructional proof that the room 7 entrance is late and was made to replace that in the courtyard. But it is unlikely that there should have been two entrances from outside in use at the same time, so close one to the other, and unlikely that the NW. block should have been entered both directly from outside through room 7 and by the courtyard through room 8 . There is proof of the remodelling of room 7 , and the addition then made of basalt orthostats in the NW. and SE. walls (which originally had not got such) harmonizes with the use of orthostats in the blocking of the court gate and also on either jamb of the room 7 gateway; the old courtyard gateway was not flanked by orthostats. If, as I assume, the wall of room 7 was cut through to make the doorway, the wall-ends would have had to be refaced, and the refacing with orthostats is in keeping with the other late work.

3 See below, p. 99. 
TEL ATCHANA 1939-46

PLAN OF THE PALACE OF KING YARIM-LIM

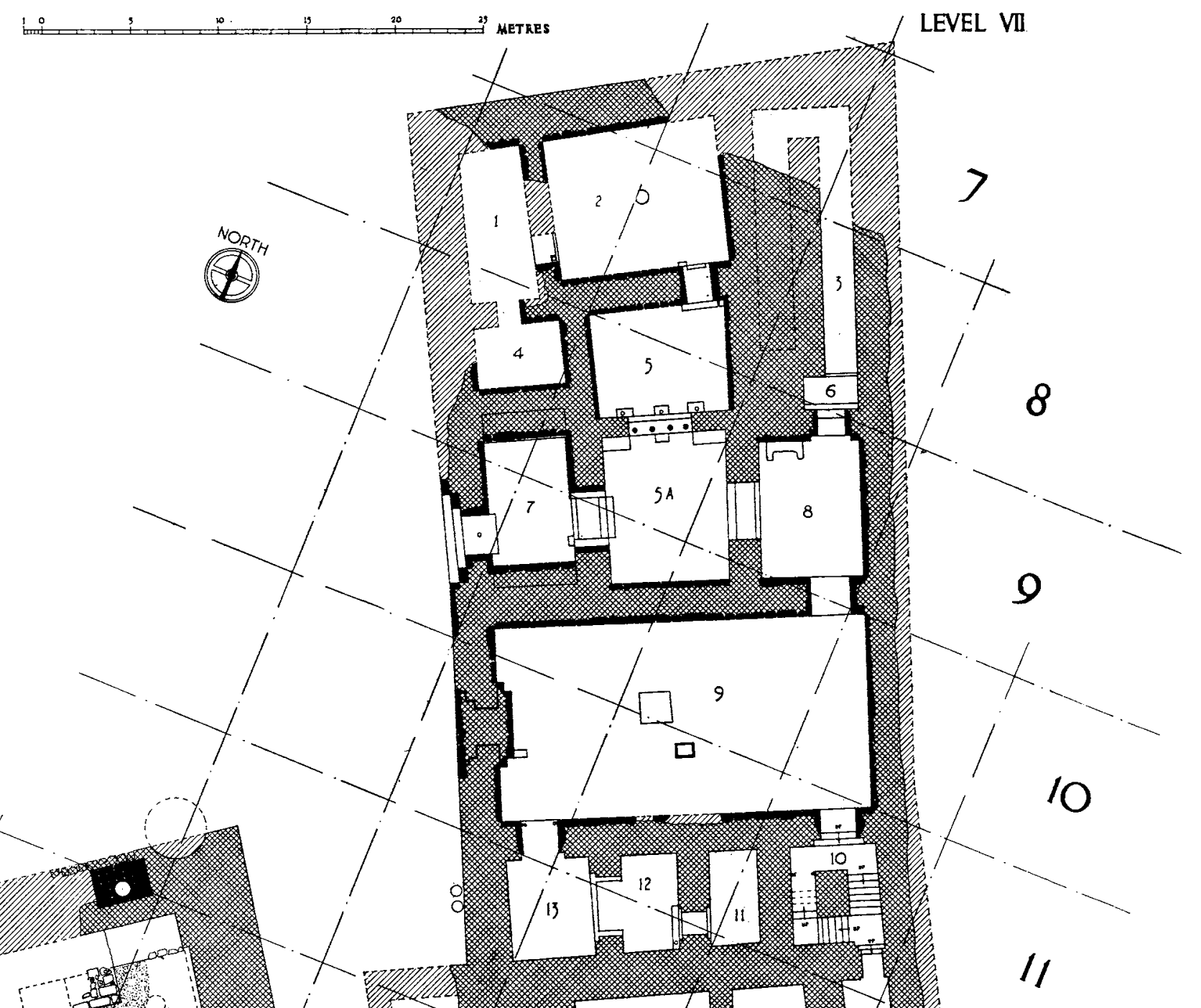

I.
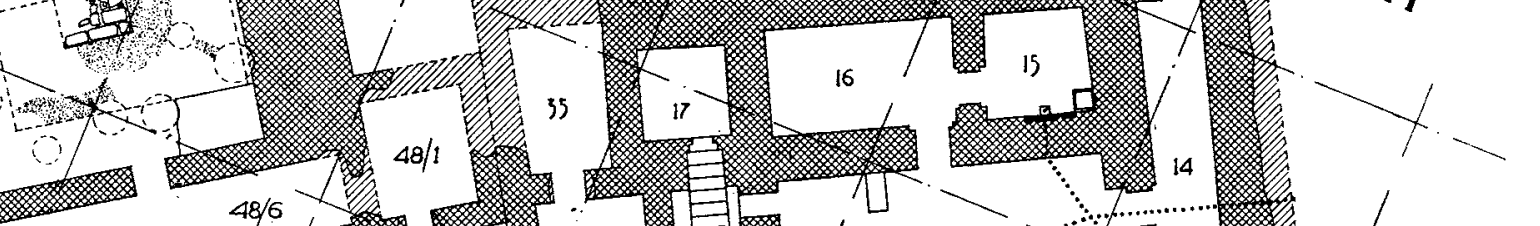

12

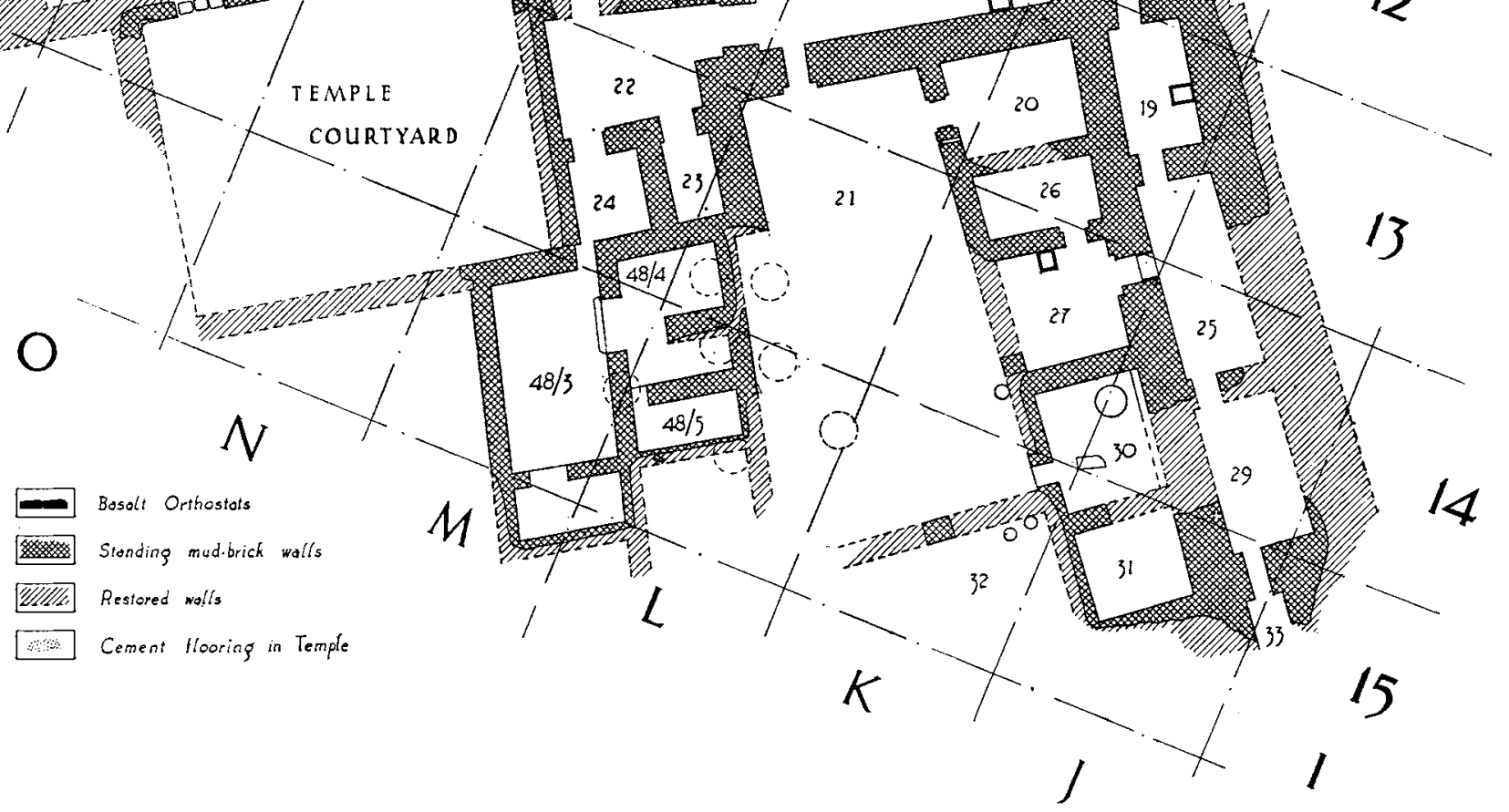

FIG. 35 
north corner of the palace. Rooms I and 4 were well preserved-the walls of the latter stood as much as $2.75 \mathrm{~m}$. high-but could be only partly excavated because they were overlaid by the north corner of the Level IV palace which we were anxious not to destroy; scraps of fallen plaster showed that they had been either frescoed or at least painted with a wash of plain colour. In the north corner of the building was the staircase. A small lobby(6) opening out of room 8 gave on a long narrow passage (Pl. XVb) whose floor sloped gently up and at a distance of $3.50 \mathrm{~m}$. from the doorway gave place to a normal flight of steps built on a solid bedding with a return flight which would bring one to the first-floor rooms. The whole of the SW. wall of the lobby and the walls of the stairpassage above step level had been subject to such intense heat that the wall-face (the plaster rather than the actual bricks) has been vitrified, fused into what looked like green bottle-glass that ran down the wall and even out on to the floor (Pl. XVIII $b$ ); I can only explain this by the theory that an upper staircase of wood (the usual thing in an Alalakh building) had fallen at the time of the fire and the mass of timber had generated this great heat; but that implies that the building was three stories high, for the solid staircase would allow of a total rise of at least $4.50 \mathrm{~m}$. and if there were a wooden flight going yet higher it must have served a second floor. The thickness of the walls, $2 \cdot 00 \mathrm{~m}$., is quite consistent with this.

We have then to imagine the NW. block of the palace as a lofty building rising like a tower at an angle of the city's rampart. It thus possessed a military importance which was more in keeping with the use of its lower rooms for official purposes than as residential, and the official character seems to be borne out by the nature of the three rooms I I-I 3 on the opposite side of the court. That these go with the NW. block is obvious, for they are on the same level and could not be approached from the central block of the building, which lay higher; they had only the one door to the court, and since the walls were found standing to a height of $2.85 \mathrm{~m}$. and showed no signs of any window opening the windows must have been very high up and probably small-for storerooms it would be a natural safeguard to have the windows as inaccessible as might be; their contents showed that they were storerooms, for on the concrete floors lay quantities of business tablets and also elephants' tusks as well as weapons and fragments of alabaster vases (Pl. XVI $a, b)$. We may suppose that here were deposited the gifts, tribute, or other goods passed on from the Chamber of Audience.

The central block of the palace (rooms IO-I 8, 22-24) stood partly on the terrace and partly above rooms I I-I 3 . It was entered only from the courtyard (9) so that in the later phase of the palace, when the original SW. gate of the court had been closed, the approach to the residence was through the SE. rooms of the official block (PI. XVII $a$ ).

In the east corner of the court a doorway with a four-step threshold led into a little lobby ( $\mathrm{IO}$ ) in the opposite side of which there was on the visitor's right a cupboard and on his left a flight of seven timber-and-concrete steps with a square landing at the top (Pl. XVII $b$ ); from this, continuing in the same line, three more steps led into a long partitioned corridor which for the whole of the remaining length of the palace ran against the inner face of the city wall, while to the right more stairs (Pl. XVIII $a$ ), the 
first flight solid, of timber and concrete, the upper flights beyond the first turn of wood, turned round a square brick newel, over the cupboard whose door has already been mentioned. The stairs led of course to the upper story, which we may assume to have been the living-quarters of the royal family, the ground floor being given over to the domestic staff. The upper floor, the piano nobile, no longer exists, but its principal room, the grand salon, can safely be reconstructed. It lay above the magazines ( $11,12,13$ ) and if, as is probable, it occupied their whole area it was a room $20.00 \mathrm{~m}$. long by $6.00 \mathrm{~m}$. wide divided into two parts by projecting piers with columns between, in the recognized style of the 'audience-chamber'; this accounts for the unusually wide doorway between the basement rooms I 2 and I 3 , the door-jambs being the foundations for the piers in the room above. ${ }^{\mathrm{I}}$ Outside the building, against the SW. wall of room I3, there were found resting on brick rubble and painted plaster from the upper part of the wall (which here stood to a height of nearly $3.00 \mathrm{~m}$.) two basalt column-bases consisting of a drum on a square plinth (Fig. 42) intended to take a wooden column with a diameter of anything up to $0.60 \mathrm{~m}$., and three blocks of limestone, two carefully cut, one rough; these were certainly not the columns which had divided the salon, for such could not possibly have fallen or been thrown down into the position in which the stones were found; they had fallen directly from the wall itself and must be from the window of the salon, a big loggia-window with two columns dividing the lights and a frame of ashlar stone. ${ }^{2}$ Inside rooms I 2 and I 3 there were quantities of fragments of coloured plaster and a few coherent masses of brickwork fallen from the upper story which still preserved their coating of plaster bearing fresco decoration $(\mathrm{Pl}$. XXXVI $b) .{ }^{3}$ In the doorway between rooms I I and I 2 and in the SE. end of the latter all the fragments (which lay at about $2.10 \mathrm{~m}$. above the floor on which were the tablets) had a white ground with bands of blue and yellow and, in one case, bull's horns (Pl. XXXVIII and p. 23I); the fragments in room I 3 all had a Pompeian red ground with, apparently, naturalistic designs in other colours (Pls. XXXVII, XXXVIII; p. 23I); the fragments found outside the SW. wall were of this latter sort. It would seem that the outer part of the salon was decorated in light colours and the inner part beyond the columns was more richly painted with red as the predominant colour and subjects of a more complex nature less formally treated.

Nothing can be said about the other upstairs rooms, but I would suggest that the long corridor was of two stories, as is indicated by the thickness of the SW. wall which contrasts with the flimsy character of the single-story rooms $20,26,27,30,3$ I built up against it; the newel stairs would lead to its upper floor, and an ambulatory along the city wall is almost a military necessity. ${ }^{4}$

I 'The wall between rooms II and I 2 was primarily intended to divide the magazines, but incidentally would greatly facilitate the laying of the floor of the salon, making a. shorter span for the floor-joists.

2 No other column-bases were found, so presumably the wooden columns dividing the salon rested directly on a cement threshold as is the case in room 5 .

3 These did not belong to the magazines whose walls had a smooth yellowish-white plaster, unpainted.
4 It is true that one might expect the ambulatory to be continuous all round the circuit of the walls, for the convenience of the defending troops, whereas here it would be merely an appendage of the palace, but it is quite possible that the palace guard should have been responsible for the defence of their own section of the rampart. New College, Oxford, is bound by the royal licence of its foundation to keep in repair and to defend in time of war that part of the city wall which lies within its grounds. 
On the ground floor rooms I 5 (Pl. XIXa), I 6 and $\mathrm{I} 8$ (Pl. XIX $b$ ) were certainly domestic. Room 18 was probably unroofed, for otherwise no light could have come to rooms I 5 and I 6 ; its walls were of plain plaster, its floor of concrete laid rather thinly over clay. Against the NW. wall was a cement-plastered bench of basalt blocks; against the SE. wall was a large basalt basin or trough with a spout in front of which a flat stone with a round intake-hole was let into the floor; below it was a stone-built drain which connected with that from room I 5 and with another from the outlet of the basin in the east corner of room $r 8$ and then went out through the doorway, under the corridor and through the city wall to empty on the glacis. The basin in the east corner was sunk flush with the floor and had its outlet on the NW. side; between it and the face of the SE. wall there was a gap filled with cement which was worked up to a smooth face and brought down in a curve over the edge of the stone; in the flat surface there was a shallow circular depression intended as a stand for a large round-bottomed vessel; between the basin and the NE. wall there was a similar cement ledge, raised slightly above floor-level, in which there were two shallow oblong depressions sloping downwards from the wall and with outlets to the basin, very much like the soap-troughs of a modern pedestal wash-basin. The drain intake in room I 5 was a flat stone with two holes in it sunk flush with the very good cement and concrete floor; this was right against the SE. wall, and three basalt orthostats were set in the wall here obviously to protect it from wet; in the east corner of the room, sunk in the floor but rising $0.20 \mathrm{~m}$. above it, was a terra-cotta tank reinforced externally with cement. The room was certainly a washing-place, possibly a bathroom; as it could be entered only through room I 6 , the two would seem to have had a common or a connected use, but in room I 6 there was nothing to explain what this use could have been. Similarly there was nothing to show the use of rooms 22,23 , and 24 , which also opened off from room I 8 ; in room 24 three broken terra-cotta figurines were found, but it would be rash to lay much stress on them.

Room I 7, on the other hand, presents only too many features and remains so far as I am concerned an unsolved mystery. The room had passed through two phases. Originally the entrance was by a doorway in the SE. wall. In the thickness of the doorway there began a flight of steps (made with a half-log for the front of the rise with a packing of clay and cobbles behind it, the whole rendered with white plaster) which ran steeply down-the average rise of a step was $0.25 \mathrm{~m}$. and the depth $0.40 \mathrm{~m}$.- between walls of rough limestone liberally but roughly plastered with cement to a depth of $2.30 \mathrm{~m}$. below the level of the palace floor (Pl. XXa and Fig. ${ }_{3} 6$ ). At the bottom of the steps there was a doorway of which the jambs and lintel were each formed by a single slab of finely worked basalt and the door itself was a basalt slab, $\mathrm{r} .07 \mathrm{~m}$. high $\times 0.85 \mathrm{~m}$. wide, turning on boss hinges $(\mathrm{Pl} . \mathrm{XX} b)$; it opened inwards to the stairs and was secured by a peg bolt inserted in a hole in the stone threshold; we found it ajar and cracked, but in situ. The door had been blocked on the other side by a heap of large stones. Behind the door was a square shaftchamber with a floor of unusually solid concrete and walls consisting of three courses of basalt ashlar masonry, cement pointed, rising to the level of the top of the door lintel $(\mathrm{r} .65 \mathrm{~m}$.); above the slabs was a single course of rubble foundations on which rested the 
mud brick of the palace walls preserved here to a height of nearly three metres. Along the top of the stone lintel there had been a wooden beam and the cement plaster of the staircase walls had been brought round over the ends of it in a curve; it was enough to show that above the doorway there had been a wooden screen ${ }^{I}$ separating the shaft from the stair-well.

On the floor of the shaft in the north corner there was a heap of wood ash and charred wood, numerous animal bones, most of them heavily burnt, four alabaster vases of which

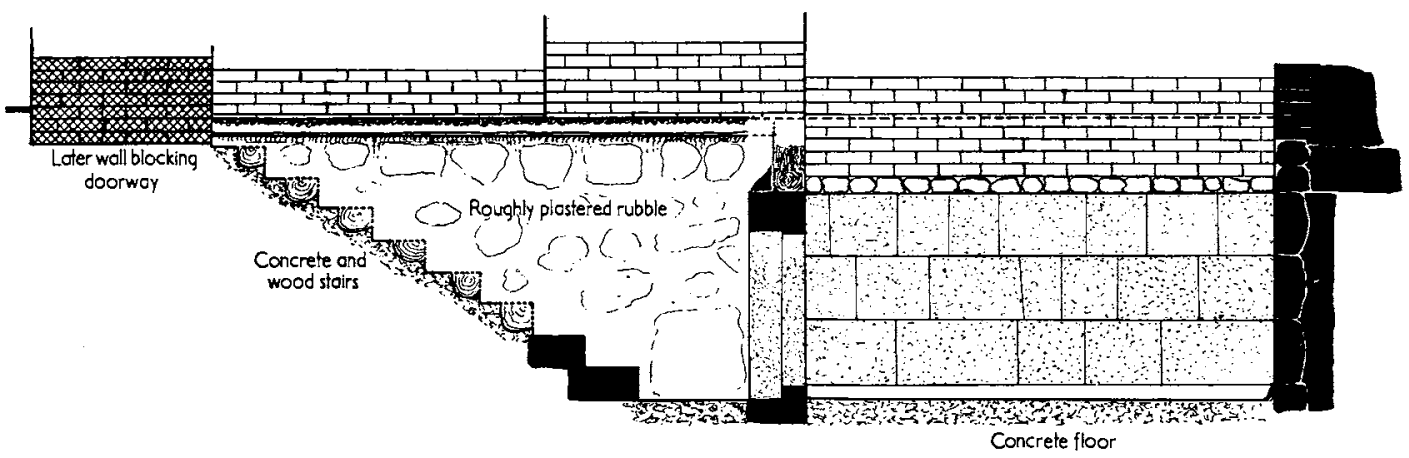

Fig. 36. I:100

one was destroyed by fire (AT/39/244, 252, 26I; Pl. XXI $a$ ), and three clay vessels; there were no marks of burning on the floor, so that everything here must have been collected from a pyre elsewhere and been deposited here. Against the SW. wall there had been a wooden box $1.35 \mathrm{~m} . \times 0.65 \mathrm{~m}$. containing four human skeletons so arranged that there was a skull in each corner, the leg-bones overlapping in the middle (Pl. XXIb); a fragmentary skull of a small child found here just above the box, before the latter was recognized, probably belonged to it. There were no objects with the bodies, nor were any others found in the shaft.

In the second phase of the room the blocking of rough stones was set against the door and the shaft was filled with peculiarly clean earth which rose to the level of the top of the lintel and had been beaten hard; this we found undisturbed except in the north corner, where there was a pocket of softer soil in which were a few fragments of mud bricks accidentally burnt; the pocket was not deep and had not disturbed the offerings on the floor in this corner. ${ }^{2}$ Above this level the filling was more mixed and, still higher, had definitely been disturbed and of any later floor we found no trace at all. ${ }^{3}$ The masonry of

1 The beam, only $0.23 \mathrm{~m}$. wide, was too narrow to be a base for brickwork.

2 One or two pieces of burnt wood found below what seemed to be the bottom of the pocket, fairly close to the floor, were judged to be part of the offering-deposit. We considered the possibility of a hole having been dug through the filling to floor-level and the vases, \&c., having been deposited at the bottom of this hole, which was subsequently filled in again, i.e. that the deposit belonged to the second phase; but decided that the evidence of the soil seemed to be against this.

3 Room i 8 was covered with fragments of concrete flooring ( $v$. below, p. I03) and it was tempting to assume that this had been pulled up from room I 7 ; but it is hard to suggest why anyone should have gone to such trouble and (if they were treasure-hunters) not have dug down into the lower filling of the shaft-unless indeed the treasure of which they were in search lay only just below the floor and the robbers having secured that knew that there was nothing else worth digging for. 
the staircase walls ends in a straight horizontal line $2 \cdot 15 \mathrm{~m}$. above the shaft floor, $0.15 \mathrm{~m}$. below the floor of the palace; along this line the wall-plaster is brought forward in a hollow curve which implies a wooden ceiling, plastered below, over which the concrete floor was laid on a bed of earth; since the ceiling closed the staircase and the plaster is taken up against it, this must have been done before the shaft was filled with earth. ${ }^{\mathrm{I}}$ The stair-well remained empty but unusable. ${ }^{2}$ At the same time the doorway leading to the stairs was very carefully bricked up-with bricks of a different texture from that of those used in the room walls-and a new and very narrow doorway was cut through the NE. wall and the concrete floor laid over the whole of what was now a small room; apparently there was still a wall with a door corresponding to the basalt door underneath dividing this room from that which overlay the shaft, but of the latter we can say nothing since there was left neither floor nor wall-plaster.

It is, I think, clear that what I have termed phase I was purely provisional; the shaftchamber and its staircase were constructed to answer to some particular need, or particular ritual, and went out of use as soon as that had been fulfilled; it is only phase 2 that is a permanent feature of the palace building. A construction so elaborate and on the whole so well preserved ought to be self-explanatory, but I must admit that I fail to explain it. ${ }^{3}$

I This fact accounts for the stones blocking the door; the door had to remain open until the ceiling of the staircase was finished, and then from inside the shaft-chamber it could only be pulled to and not bolted-it was indeed impossible to pull it quite shut-so the stones were added as a precaution.

2 We found it filled with burnt mud bricks belonging to the palace, below which were the fragments of the collapsed concrete floor.

3 In his Stratigraphie comparte (p. I04) Dr. Schaeffer briefly discusses this 'chambre souterraine, appelée par le fouilleur mystery chamber' and decides: 'La comparaison avec les trouvailles analogues de Ras Shamra montre qu'il s'agit en réalité d'un caveau funéraire installé dans le sous-sol de la résidence et contemporain de celle-ci. Son architecture, son appareil et ce qui, sur la photographie, est visible de son mobilier indiquent que ce caveau doit être de l'époque des caveaux de l'Ugarit Moyen 2 de Ras Shamra.' It is quite true that the date of Yarim-Lim falls within the Ugarit Moyen 2 period, and it is true too that the shaft-chamber is contemporary with the building of the palace, but the explanation of it as a tomb-chamber, perfectly obvious though it beso much so indeed that almost as soon as its excavation started the field notes were headed 'Royal Tomb'-I was in the end unable to retain, and the superficial analogy with Ras Shamra which I had in mind does not hold good. The Ras Shamra tomb is a stone-built chamber under but constructionally independent of a house-a point insisted on by M. Dunand ('Jamais aucun des murs des maisons n'est le prolongement de ceux des tombeaux'), who even doubts there being any real connexion between house and tomb (Revue Archéologique, xxxvi (1950), p. 15); the chamber is roofed with stone and is entered by a stepped dromos which could be reopened when desired, and the dead, on each occasion when the tomb was used, were brought down the steps and laid in the chamber

B 2501 together with the usually very rich funeral furniture; in cases where the roofing-stones had not collapsed Dr. Schaeffer found the tomb-chambers clear of anything except a little infiltered dust (e.g. Syria, xvii ( 1936), pl. xx). So far as the ground-plan goes the Atchana chambre souterraine with its stepped dromos and square chamber does seem analogous; but the chamber was never roofed at all. It is not a case of a roof having fallen or been removed by plunderers-no roofing-stones were found, and, what is conclusive, the stone walls could not have supported a roof because they were the foundations of the palace walls whose rubble and brickwork rested on them and rose flush with them leaving no possible lodgement for roofing-stones or even timber; moreover, since the earth filling was put in after the stairs had been closed, there could not have been a roof or the workmen would not have been able to get out. That deliberate filling of the shaft constitutes another crucial difference from the Ras Shamra tombs. Again, the Ras Shamra tomb is not only constructionally independent of but it postdates the house with which it is associated; according to Dr. Schaeffer's view, when the rich householder died a pit was dug within the house area and the tomb was built in it. Here, though no use was made of it until the palace was built, as is shown by the blocking of the SE. doorway (which proves that the superstructure was standing at the time when the stairs were covered up), yet the stone sides of the shaft were finished before the palace itself could be built, since its walls rested on them. The filling-in seems to have been done soon after the palace was built, for one cannot imagine a deep pit in the middle of a building being left open for very long. Had this indeed been a royal tomb prepared by the builder of the palace in anticipation of his death we should have found evidence of it, seeing that the earth filling was undisturbed; but I cannot believe that the four skeletons ignominiously packed in a box with no insignia 
The third section of the palace embraced everything to the south-east of room $\mathrm{I} 8$. This lay on high ground (from the steps in room Io the corridor slopes gently upwards throughout its length) and, since as the buildings were for the most part only of one story, the walls were much thinner; consequently the destruction has been much more thorough and the ground-plan had to be reconstructed sometimes on very scanty evidence. Built against the corridor was a range of rooms which-or most of which-opened on to a court or courts occupying the middle of the building ( $2 \mathrm{r}, 28$, and 32 on the plan); they were quite clearly of a domestic character, used either by the servants or by the craftsmen who were the retainers of the lord of the palace and carried out their trade on the palace premises, just as was the case in the great medieval houses of England; thus room 30 was a stone-mason's workshop and room 33 was a storeroom for pottery.

Judging by the irregularities of the ground-plan the buildings of this domestic wing are not strictly of one date; as might be expected where purely utilitarian rooms of a relatively flimsy character are concerned, alterations and additions seem to have been made whenever and wherever they might be required. But the condition of most of the walls in the south part was so bad that the exact relation of the rooms could not be satisfactorily determined, and regarding some of them we were left very much in doubt. When we excavated the group of chambers $48 / 3,4$, and 5 we assumed that they belonged to the temple in that they bordered the temple courtyard, although no doorway opening on to the courtyard was found; actually we found no door leading from them to the rest of the domestic quarter of the palace, but the ground-plan makes it fairly obvious that it is to the palace that they must be assigned. The independent construction of the temple block is clearly shown by the way in which the wall of room $48 / \mathrm{I}$ abuts on the wall of the palace room 34 (incidentally the orientation of the temple is slightly different), but the whole of the NE. wall of the temple court is really the palace wall, and the same seems to be true of the SE. wall also. If that be so, it emphasizes the very close relation between the two structures and may throw light on the character of the Yamhad dynasty. Our excavation of the earlier levels has proved that this had always been the site of what

or offerings represent a royal burial-and the few objects in the north corner are quite unworthy. Should it be urged that the disturbance in the north corner was greater than I supposed, that a king had been buried there and that robbers, having dug down and removed everything, threw back a few valueless objects, I can only say that the evidence was against this, the hole was not deep, and the theory would not account either for the burnt animal bones or for some of the objects being burnt and others not; I am quite sure that the deposit was laid on the floor while the chamber was open. In spite therefore of certain points in common with the (very much later) tombs of Ras Shamra I cannot accept Dr. Schaeffer's explanation. To me the whole thing looks more like an elaborate foundation-sacrifice, but in the absence of any parallels it would be most rash to claim it as such.

On the chance of the concrete floor of the shaft being a 'stopper' set over something at a lower level we dug down through it to a depth of $3.50 \mathrm{~m}$. The concrete rested on a bed of large river pebbles; then came $0.10 \mathrm{~m}$. of clean red earth, and then a floor roughly paved with bricks, mostly broken. Below this was earth, not particularly clean, and at $\mathrm{I} \cdot 4 \circ \mathrm{m}$. from it another rough pavement of broken bricks and potsherds on which were a few bones; it was bordered on the NE. by a mud-brick wall rising almost as high as the upper pavement; on the floor, at the foot of the wall, were fragments of a large painted clay pot, ATP/39/305, and a fragment of another with 'metope' design and an animal figure more or less of the type A (Pl. XCIII $c$ ). Below this was another wall somewhat differently orientated going down to about $3.00 \mathrm{~m}$. below the floor of the shaft; in the soil against it there were fairly numerous sherds of painted pottery the most noteworthy of which had a bluish-white slip on which geometrical designs (hatching, \&c.) in black paint looking rather like Cypriote White Slip ware. Between $3.00 \mathrm{~m}$. and $3.50 \mathrm{~m}$. pottery was scarce. Here we have ordinary occupation-strata, proving that the Level VII work ended with the floor concrete. 
can safely be assumed to have been the principal temple of the city; if Hammurabi of Yamhad rebuilt the old temple after his palace had been at least begun, if not entirely built, but so extended his palace as virtually to enclose the temple within it and make it an apanage of the royal residence, he may have been asserting thereby his own peculiar relation to the god; the analogy of the deified Mesopotamian kings of the Third Dynasty of Ur may have had its effect on the ambitious and successful ruler of Yamhad.

An unexplained feature is the isolated room 34 in the west corner of the domestic wing. It was not an outside room (though to the north-west of it everything was so ruined that we could not definitely say how much farther the building extended), but at least there was a doorway-originally provided with fine basalt jambs-in the NW. wall and there was no other door at all; the room had therefore nothing to do with the domestic quarter; if, as is suggested on the plan, the limit of the building were marked by the short return in the NW. wall of the central block of the palace, then room 34 with its supposed entrance-chamber room 35 makes, with room I 7, a single square block within but distinct from the palace proper. The actual floor of room 34 had, like most of its walls, been destroyed by later rubbish-pits, but the floor had had a foundation of very large and heavy boulders, closely packed; this was a feature unique in the palace and must mean that the room had some special character. It is certainly possible that the two rooms, 34 and 35 , are to be connected with the 'mysterious' room I 7 , but that does not help to explain the purpose of either.

\section{Detailed Notes on Rooms}

The following notes give all the detailed information recorded in the field notes except in so far as it has already been dealt with in the general description or, in the case of measurements, \&c., when it is incorporated in the plans or sections.

Room 2. The floor, of smooth white cement over concrete, sloped very gently to the centre, where was a basin-like depression $0.25 \mathrm{~m}$. deep carefully lined with cement, possibly a columnbase, possibly for water (?); against the SW. wall two shallow rectangular depressions $0.15 \mathrm{~m}$. and $O .10 \mathrm{~m}$. deep, unlined. The door to room 5 had a wooden rise to the threshold, a beam $0.22 \mathrm{~m}$. wide $\times 0^{\circ} \mathrm{I} 5 \mathrm{~m}$. high, with concrete behind; against the $\mathrm{SW}$. jamb orthostat a basalt hinge-stone set $0.35 \mathrm{~m}$. below the floor, the hole apparently wood-lined; against the SE. jamb a hole in the floor $0.45 \mathrm{~m} . \times 0.30 \mathrm{~m}$. $\times 0.12 \mathrm{~m}$. deep originally filled with wood wherein a hole for the bolt. In the doorway to room I the threshold, $0.10 \mathrm{~m}$. high with wood in front and cement behind, had its hinge-hole in the cement surface. The orthostats, of basalt, $0.62 \mathrm{~m}$. high, were whitened by fire; their trimmed limestone foundation-blocks were about flush with the floor. The floor was covered with ashes. In those lay two human skeletons, the bones much burnt; also several clay tablets and seal-impressions (ATT/39/4, \&c.), a clay pot, ATP/39/96, Type I 37, much burnt, and a number of stone vases all in fragments and all damaged by heat: a shallow tripod bowl, diorite (cf. Pl. LXXXIII), diam. 0.40 m.; a black steatite bowl, AT/39/ I 57, Type 6; in alabaster, AT/39/I 55, Type 8, AT/39/ I 56, Type Io; AT/39/I 58, Type I 2 , and fragments of, approximately, Type I 4 ; and fragments of an obsidian vase, AT/39/I 35 .

Room 3. The lobby (room 6) had a poor-quality concrete floor stepped down $0.15 \mathrm{~m}$. from the threshold with a $0.05 \mathrm{~m}$. step up to the passage proper, the rise being faced with wood. The NE. wall much destroyed, the SW. preserved up to $2.40 \mathrm{~m}$. and vitrified; the bottom of the vitrification (i.e. of the exposed wall-face?') forms a straight line sloped up very slightly from the horizontal 
for $3.20 \mathrm{~m}$. and then for $2.50 \mathrm{~m}$. slopes up at an angle of I in 5 . For the first three metres the passage floor (of fine cement) is broken into disconnected pieces; beyond that there is only cobble packing rising to $0.30 \mathrm{~m}$. above the level of the lobby floor. No actual return of the stairs was found, there being on the SW. simply a solid uniform mass of mud brickwork, but the width of this allows exactly for a stair-flight between walls of the normal thickness. It is most unusual for the second flight of stairs to be solid (instead of being in wood), and the fact that it is so here suggests that the stairs went on higher to a third story.

Room 4. Not all the room was excavated; the fine cement-over-concrete floor is taken up to the wall-face with a concave fillet which suggests a bathroom or lavatory. Small orthostats, $0.45 \mathrm{~m}$. high, of limestone; above these a beam, but less timber than usual in the walls (the next comes at $2.00 \mathrm{~m}$.); the SE. wall preserved up to $2.90 \mathrm{~m}$. with no sign of ceiling-beams or window. The wall-plaster is rather coarse and is closely covered with impressed finger-marks for keying the final coat. Two tablets $(A T T / 39 / 3)$, and fragments of several alabaster vases too calcined for their shapes to be distinguishable, and a conical stone gaming-piece, AT/39/82, were found here.

Room 5. The floor, which was in bad condition and much broken, was of fine white lime plaster which round the room was a top-dressing over concrete but in the middle was much thicker and

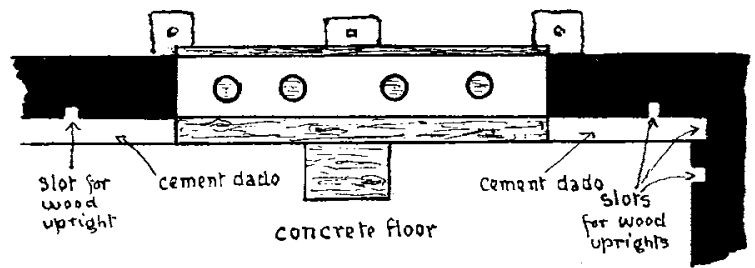

FIG. 37 laid on clay; this seemed to be due to patching after heavy use. The threshold to room $2,0.20 \mathrm{~m}$. high, had in front of it a projecting step of concrete, the rise plastered, the tread overlaid with a wooden plank and a wood rise to the threshold proper. The wide opening to room $5 \mathrm{~A}$ has a $0.10 \mathrm{~m}$. high threshold of concrete with cement above set between a narrow plank in room 5 and a $0.25 \mathrm{~m}$. sq. beam in $5 \mathrm{~A}$. In the cement, at $0.50 \mathrm{~m}$. from the NE. end, is a sharply defined circular depression, diam. $0.25 \mathrm{~m}$., clearly the imprint of a wooden column set up while the cement was still somewhat soft; at $0.50 \mathrm{~m}$. from the SW. end is a circular burnt patch, and two other circular burnt patches are spaced equally between these; the burning is certainly that of the wooden columnshafts, of which there were four, the end ones closer to the pier-jambs, the rest with an intercolumniation of $0.75 \mathrm{~m}$. Against the angles of the jambs there are holes in the concrete, square above and circular below, containing wood ash; the circular hole is $0.30 \mathrm{~m}$. deep with diam. $0.25 \mathrm{~m}$.; they may be post-holes for a door-frame, or perhaps for hinge-poles turning in a reinforced wooden socket, Fig. 37. There was a central hole, presumably a bolt-hole. The walls have limestone orthostats $0.40 \mathrm{~m}$. high and were in half-timber; they were standing to an average height of $2.65 \mathrm{~m}$. The piers had no orthostats. As they were quite thin the woodwork of the columned threshold projected beyond them into room 5 ; to fill the gap a broad fillet or dado of cement was taken along the foot of the piers. In room 5 A the floor, cement over concrete, was badly broken up; against the middle of the columned threshold was a low step of concrete set against the woodwork. The threshold to room 8 was of concrete with a basalt edging; that to room 7 was wood-cased. Only the outer (SE.) wall had orthostats. An unusual feature was the use in the walls of upright timbers; there was one in the NE. pier, one in the north corner, and one in the SE. wall at $0.35 \mathrm{~m}$. from that; there may have been more, but the walls, although standing to a maximum height of $3.20 \mathrm{~m}$., were very ruinous and the wall-faces had for the most part fallen away.

The secondary decoration with 'architectural fresco' mentioned above was found on the NW. wall of room 5 .

In the room were two fragmentary seal-impressions, ATT/39/5, and a tablet, ATT/39/35.

Room 7. The entrance-doorway (PI. XIII $b$ ) had a high threshold with three steps. The outer step, on the line of the wall-face, was partly of stone, partly of concrete, and may have been flush 
with the ground outside. On the line of the middle reveals of the jambs a second step and a third cut from the same stone-small stones $0.45 \mathrm{~m}$. sq. in the reveals and between them a single limestone block $2.75 \mathrm{~m} . \times 0.80 \mathrm{~m} . \times 0.20 \mathrm{~m}$., behind which was the threshold proper, of basalt, $2.07 \mathrm{~m} . \times \mathrm{I} \cdot 30 \mathrm{~m} . \times 0.35 \mathrm{~m}$, having in its centre a circular hole diam. $0.28 \mathrm{~m}$., depth $0 \cdot$ I $0 \mathrm{~m}$., which has been filled with a carefully cut basalt stopper flush with the stone's surface. The orthostats of the jamb-faces are of basalt, slabs $\mathrm{I} \cdot 67 \mathrm{~m}$. long $\times 0.88 \mathrm{~m}$. high. The doorway to room $5 \mathrm{~A}$ had a hinge-hole diam. $0.40 \mathrm{~m}$. at the top with a smaller hole continuing it down to $0.45 \mathrm{~m}$., originally going through

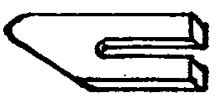

FIG. 38 a rectangular wooden plate; on the threshold was a fragment of wood cut apparently for a tenonjoint (Fig. 38). The floor, of fine white cement over concrete, slopes towards the east corner. The basalt orthostats of the NE. and SW. walls, $0.65 \mathrm{~m}$. high, rest on roughly dressed blocks rising O. I $5 \mathrm{~m}$. above the floor which were hidden by a coat of cement plaster; the joints of the orthostats were cement-pointed. In one case, a foundation-block being higher than the rest, the orthostat resting on it had been cut to fit it (Fig. 39). The NW. and SE. walls, added later against the old walls, were made as much like them as possible, with the same plastered plinth; the bricks of these walls measure $0.54 \mathrm{~m} . \times 0.39 \mathrm{~m}$. $\times 0.12 \mathrm{~m}$. The fitting of the orthostats in the south corner ${ }^{1}$ suggests that the new walls and the entrance-door were contemporary. Only a few patches of the (late) plastering of the walls are preserved, plain yellowish-white with no paint; the original walls had had several coats of plaster, some showing colour.

On the floor were found five skeletons, the bones in all cases burnt and crushed, and a bronze

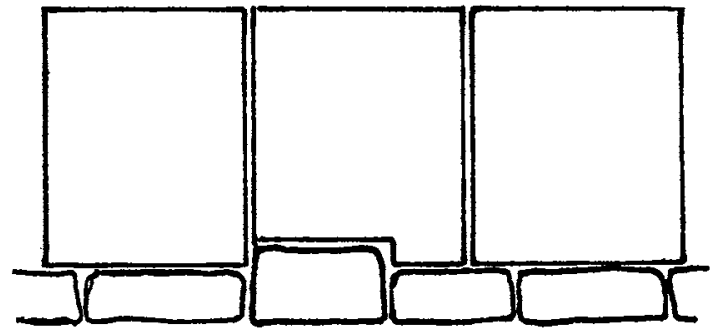

FIG. 39 spear-head, Type Sp. Io, AT/39/16 . In the rubbish $0.50 \mathrm{~m}$. or more above the floor were fragments of smooth-faced concrete from the floor of the room above; also in the rubbish three haematite weights, AT/39/I I 4, I I 5, I I 6; numerous fragments of plain ivory inlay, some broken jar-sealings with seal-impressions, a three-legged copper cauldron, AT/39/ I 42 , Pl. LXXIV, fragments of a vase of black and white granite, AT/39/ I 54, Type 9, and fragments of clay pots.

Room 8. Against the NW. wall there were on the cement-covered concrete floor marks of burnt wood which suggested a wooden bench with stretcher feet.

Room 9. Floor of cement over concrete; in the centre a brick platform $0.30 \mathrm{~m}$. high, plastered, with rounded edges and corners; much of the plaster was vitrified by burning. Close to it was a rectangular basalt tank $\mathrm{I} \cdot 00 \mathrm{~m} . \times 0.85 \mathrm{~m} . \times 0.50 \mathrm{~m}$. deep, the sides $0.08 \mathrm{~m}$. thick with nicks in the upper edges and a vent-hole low down at one end (Fig. 40); it was broken and so badly burnt that the basalt was partly melted. By this were fragments of a very large alabaster basin, fluted on the outside as if in imitation of a shell, most of it completely calcined. At $\mathrm{I} \cdot 20 \mathrm{~m}$. from the north corner of the platform there was a circular post-hole (diam. $0.30 \mathrm{~m}$.) in the floor, the cement round it vitrified as if the wooden post had

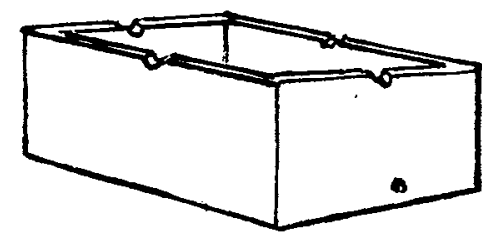

FIG. 40 been burnt in situ. In the NE., SE., and SW. wall as far as the old entrance-gate the basalt orthostats were $0.70 \mathrm{~m}$. high; those of the NW. wall and the west end of the SW. wall were $0.45 \mathrm{~m}$.

1 'The two last orthostats of this wall in the east corner are displaced, those in the corner being twisted out of the straight not outwards but backwards into the wall. I cannot explain this as due to anything but an earthquake, but even an earthquake could only have produced the effect if the room were already filled with solidified rubble, i.e. if the pressure on the two sides of the stone were fairly equal. 'That being so, the earthquake (a) cannot be credited with the destruction of the palace and $(b)$ cannot be dated except as coming after the destruction of the palace and before the time of our excavations. 
high; there was no reason for thinking that this implied a difference in date-it is more likely that contractors for different parts of the building employed slightly different materials. There was a very heavy beam laid along the tops of the orthostats but no transverse timbers in the brickwork, though the burning of the wall made it probable that there had been more horizontal beams higher up in the wall-face. The blocking of the old gateway was peculiarly obvious because the bricks, being of a different clay, had burnt to a bright yellowish-green in contrast to the uniform red of the old walls; it had probably contained a greater proportion of timber. On the floor of the court were found one cuneiform tablet (ATT/39/36), a haematite weight in the form of a lion's head (AT/39/ i 26), a terra-cotta stamp seal (AT/39/ i 30, Pl. LXI, No. I 6), a bowl of grey steatite (AT/39/I 47, Type 5), and a few pottery fragments.

Room Io. The threshold of the courtyard doorway is a single stone in which are the hinge-holes and bolt-hole for folding-doors; from the position of the bolt-hole it appears that the door-flaps overlapped and the NE. door secured the other; behind the stone a beam $0.35 \mathrm{~m}$. wide forming a low step, and a second step made in the cement of the floor which shows a down-curved edge, laid over flat stones. The floor proper was of cement over clay. In the door reveals are traces of wooden jambs, and the brickwork is in part vitrified.

The first seven steps, leading to the landing, are made each with a wooden beam $0 \cdot 16-0.17 \mathrm{~m}$. wide and $0.10 \mathrm{~m}$. thick forming the rise, the back of the tread being of mud-brick coated with

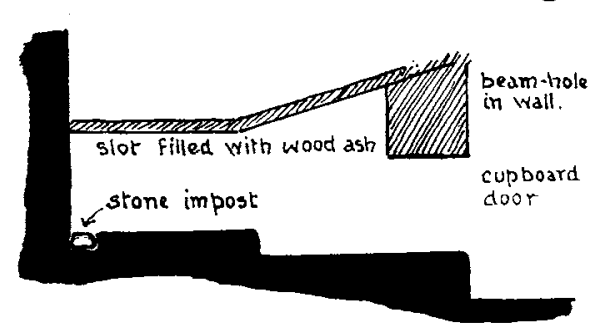

FIG. 4I cement; the tread is $0.42 \mathrm{~m}$. deep and the total rise of the flight $0.70 \mathrm{~m}$. In the second flight the construction is similar, but the beams are $0.14 \mathrm{~m}$. sq., so that the six steps give a total rise of $0.84 \mathrm{~m}$. The landing and stairs beyond this were of wood only, with the cupboard below; the line was clear, for between the plaster on the cupboard walls and that on the staircase walls above there is an unplastered band of rough brickwork with wood ash adhering; the elevation of the SW. wall is given on Fig. 4I, but it should be remarked that the marks on the wall are so wide as to give a good deal of latitude in estimating the exact slope of the stairs; if the steps turned $I \frac{1}{4}$ times round the newel so as to end up facing along the upper corridor, the total height would be not less than $4.00 \mathrm{~m}$.; the NE. wall of the lobby stands to $3.25 \mathrm{~m}$. and shows no sign of any ceiling. The cupboard floor is raised $0.50 \mathrm{~m}$. above that of the lobby and at $2.20 \mathrm{~m}$. back in it rises again by $0.25 \mathrm{~m}$. In the south corner a block of stone is let into the floor, probably the impost for an upright stay-beam of the wooden stair-flight. On the floor was a quantity of coarse pottery, all much broken; also a cylinder seal, AT/39/ I 29, Pl. I.X, No. I 4, which lay about $0.30 \mathrm{~m}$. above the floor and may have fallen from the room above, and, also above floor-level, a steatite toilet-box, AT/39/ I 24, Pl. LXXXI, Type 7, and a bronze dagger-blade, AT/39/I25, Type Kn. 4; on the floor a terra-cotta figurine of a humped ox, AT/39/127, Pl. LVII, a bronze pin, Type P. I I, and three small stone rubbers.

Room II. The concrete floor was well preserved but curiously undulating, the difference in height of different parts being as much as $0.40 \mathrm{~m}$.; the cement overlay is taken up in a cavetto against the footings of the walls. The walls have the normal lime plaster laid over an under-plaster of mixed lime and mud; the NW. wall rises to $2.30 \mathrm{~m}$. with no sign of a window. In the NE. wall there are beam-holes at floor-level close to either corner. Most of the fragments of fresco with coloured bands and bull's horns were near the doorway to room I 2 from $\mathrm{I} \cdot 20 \mathrm{~m}$. to $2 \cdot \mathrm{I} 0 \mathrm{~m}$. above the threshold; they had scaled off the walls of the room above after the magazine had been halffilled with fallen rubble. The layer of ashes on the floor was unusually thick; in it were a human skull, a quantity of tablets strewn all over the room, five elephant tusks (Pl. XVI $b$ ), a cylinder seal, $\mathrm{AT} / 39 / \mathrm{i} 84$, Pl. LXI, No. I 7, a bronze dagger, AT/39/1 85, shapeless, another, AT/39/262, Type Kn. 3, two bronze spear-heads, AT/39/254 A and в, Type Sp. 3; no pottery. 
Room I2. Concrete floor with cement overlay carried up in a cavetto against the wall-footings. Walls preserved to maximum height of $2.65 \mathrm{~m}$; horizontal timber course at $\mathrm{I} \cdot 25 \mathrm{~m}$. above floorlevel, but a great deal of timber in the piers between this room and room I 3 . The threshold to room I I was of concrete in a wooden frame, $0.25 \mathrm{~m}$. high; against it was a wooden step $0.35 \mathrm{~m}$. wide and $0.125 \mathrm{~m}$. high which ran on to the east corner of the room and had a hole for the doorhinge. The walls were plastered with plain yellowish-white plaster; the fresco remains were high up in the debris, above the ruins of the NW. pier; the piers, owing to the amount of wood in their construction, were terribly ruined and the line of their inner faces was given only by the fact of the cement stopping against the timber. About forty tablets were found in the room, all lying between the two doors. Apart from them there were only a few potsherds.

Room I3. The concrete floor was lower than that of room I 2 , the threshold between the piers being stepped up $0.22 \mathrm{~m}$. from the floor of I 3 but flush with that of $\mathrm{I} 2$. The beam forming the front of the step ran on into the reveals to support the door-frame; against the NW. pier a square stone was let into the concrete with a square hole in it; a similar stone without a hole was against the SE. pier. The floor had sunk much in the centre. The sill of the courtyard door was flush with the floor, had a wooden beam between the reveals of the jambs, then a basalt threshold of which the outer stones had each two hinge-holes close together as if the doors had had to be rehung. On the floor were burnt fragments of at least two alabaster vases, a quantity of pieces of bone inlay, narrow strips with incised concentric circles, burnt, and fifteen tablets all lying between the two doors. It is clear that the tablets were kept in room I I and those found in rooms I 2 and I 3 , and the one in the court (room 9) had been dropped by people who were trying to salve them from the burning building. About $0.40 \mathrm{~m}$. above the floor (fallen from the upper room) was a clay vase, Type I $4 b$, ATP/39/2 I 5. For tablets from rooms I I, I 2, I $3 v$. ATT/39/43-I 84 .

The outer face of the SW. wall of the palace was in very bad condition. From the entrance in room 7 to the blocked gateway in room 9 the plastered wall-face rises about $\mathrm{I} \cdot 00 \mathrm{~m}$. above the orthostats and the low rubble foundations which succeed them; of the door-blocking the stone foundations $(0.50 \mathrm{~m}$. higher than those of the wall) have little brickwork above, and from there on there is none. Outside room I 3 the entire wall-face has split away at an acute angle exposing a slanting core; this explains the position of the column-bases (Fig. 42) which lay, one upright and one slightly tilted forwards, almost on the wall-line about $0.30 \mathrm{~m}$. above the stone foundations-they had slipped down almost vertically instead of falling outwards to a distance. The two ashlar stones $(0.62 \mathrm{~m} . \times 0.27 \mathrm{~m} . \times 0.365 \mathrm{~m}$. and $0.76 \mathrm{~m} . \times 0.3 \mathrm{I} \mathrm{m} . \times$ $0.385 \mathrm{~m}$. respectively) and the rough block lay touching each other 3.40

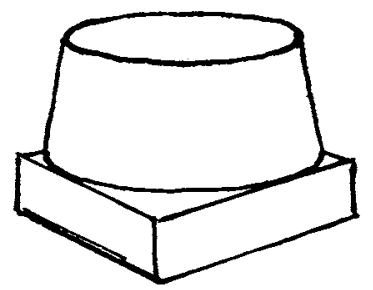

FIG. 42. I:25 m. NW. of the bases. Fragments of coloured wall-plaster, mostly of the same sort as that found inside the room, but some painted plain bright blue, were found by and below the bases and nowhere else.

Room I4. In the filling a cylinder seal of black steatite, AT/39/I69, Pl. LX, No. IO.

Room I5. Good smooth concrete floor much depressed along the NW. by reason of the sinking of the wall-foundations; round the drain-intake the floor sloped (intentionally) down to it. On the floor were a bronze dagger, AT/39/203, Type Kn. 4, a bronze spear-head, AT/39/202, Type Sp. 3, a clay bowl, ATP/39/ I 57c, Type 2 I $b$, and a saucer of coarse grey clay, Type 3 .

Room I8. The concrete floor was tolerably well preserved at the NE. end of the room, but over the SW. half there. were only traces of concrete and the surface (to which the wall-plaster went down) was of clay. On this was a layer of ashes containing a number of broken but usually complete clay vessels and above these, forming an irregular surface, large and small pieces of floor concrete all laid upside down; the debris of the burnt building, reddened brick rubble, \&c., lay undisturbed over the inverted sheets of concrete. The walls, plainly plastered, were much ruined, 
standing to a maximum of $\mathrm{I} .25 \mathrm{~m}$. on the NW. and $0.40 \mathrm{~m}$. on the SE. On the floor were found a bronze pin, AT/39/246, Type P. 9, a bronze sickle-shaped blade, AT/39/228, Type as on Pl. LXXIV, and fragments of the haft of a riveted bronze blade; a serpentine pestle or rubber, $A T / 39 / 227$, a fragment of glazed frit with a hand in relief, $A T / 39 / 234$, a quantity of grain, and fragments of clay vessels of Types I $5,93 b, 104 b$, I $66 b$, I $32 a$; under the inverted concrete were clay vessels of Types 5, 1066, I 37 .

Room I9. Floor of beaten clay. Against the NE. wall a basalt tank I.00 m. $\times 0.80 \mathrm{~m} . \times 0.25 \mathrm{~m}$. deep sunk flush with the floor; in front of it had been a pocket which was later filled (largely with broken pottery) and the floor relaid over it; amongst the pottery was a bird vase, AT/46/180, Pl. LVIII. Other vessels were ATP/39/242, 243 (Type I 37), 248 (Type 62b), 249, $25^{\circ}$ (Type I 47), 254, 255 (Type 5), 256 (Type 3), 259 (Type 106b), 298 (Type 3); and fragments of a large coarse pot approximately Type I I I; also a bronze needle, AT/39/6x, and fish-hooks $\mathrm{AT} / 39 / 265$.

Room 20 . Almost completely ruined, of the SE. and SW. walls only pebble foundations preserved; through the SW. wall ran a terra-cotta drain-pipe $0.40 \mathrm{~m}$. long; against the SE. wall there had been a sunken box built of basalt slabs. A second concrete floor had been laid $0.40 \mathrm{~m}$. above the original, possibly in the palace period, possibly later. A pit which had destroyed most of the SE. wall was, judging by its pottery contents, very little later than the palace; it might be associated with the upper floor. There were wall remains and bits of concrete floors belonging to two rooms overlying room 2 I which by level went with the upper floor in room 20; all were too low down to have anything to do with Level VI, and it looks as if we have to allow for overlapping phases which in this case involve a re-use of some of the palace walls such as the NE. and NW. walls of room 20 , for the higher concrete ran up against those walls whereas it could be traced above the top of the SE. wall. In the room were found a glazed frit lid of a toilet-box, AT/39/248, Fig. 74, a saucer of coarse grey clay, ATP/39/29 I, Type 3I, and fragments of two small clay bowls.

Room 2I. Completely ruined-the SE. wall is conjectural; a high-level floor ( $v$. room 20) extended over the whole area, but there was no trace of an older floor below it.

Room 22. Floor of clay only. Along the foot of the NW. wall a beam had been let into the floor clear of the wall-face, bedded on cobbles. The walls are less badly burnt than is usual in the palace. There was a great deal of pottery in the room, mostly small thin-walled vases; recognizable types were ATP/39/165, Type I $3 b, A T P / 39 / 166$, Type I 39, ATP/39/297, Type Io6b, $A T P / 39 / 302$, Type 3, and two wish-bone handles from milk-bowls, one of red clay, the other of grey Base-ring ware; also fragments of three small terra-cotta figurines of animals and one human.

Room 23. Clay floor; the raised threshold was of clay in a wooden frame. Walls very ruinous. No objects.

Room 24. Good concrete floor; little of the walls left (SW. wall maximum of $0.80 \mathrm{~m}$., SE. $0.50 \mathrm{~m}$., NW. one course only) with upper coating of white cement mostly fallen away and undercoat of mud plaster much blackened by fire (so that the cement had fallen before the fire attacked the walls). The foundations of a Level VI wall ran above the SE. wall at $\mathrm{I} \cdot 00 \mathrm{~m}$. above the floor. On the floor a terra-cotta figurine of a man, AT/39/303, fragments of another similar, and of a sheep, AT/39/306, and a seven-rayed bronze star, AT/39/307; cf. Pl. LXX.

Room 25. Mud floor. The walls were burnt, but not so severely as in the NW. blocks of the palace; the SW. wall was reddened on the side of this room but showed no signs of burning on its SW. face.

Room 26. Cement floor preserved only near the north corner; of the SW. wall virtually nothing remained.

Room 27. Floor originally of cement over clay, now perished. The door-way from the corridor 
(room 25) had been blocked by a screen wall; the doorway from room 26 had a good cement threshold, but beyond it to the SW. the wall had disappeared and was traced only by the floor (here of clay only) and by a terra-cotta bath $0.40 \mathrm{~m}$. deep sunk $0.30 \mathrm{~m}$. into the floor.

Room 28. Probably an open court. The SE. wall had entirely disappeared; it is restored in the plan on the strength $(a)$ of a patch of paving tiles I. IO m. across, rectangular, roughly laid, with traces of burnt brick on either side; this may have been a threshold; and $(b)$ two clay pots buried flush with the floor-level (in the north corner of room 32) which were more likely to be against a wall than otherwise.

Room 29. Clay floor. The walls blackened by fire but not burnt red. Over the floor was a thick layer of potsherds, all of coarse 'domestic' ware including numerous cooking-pots (Type I 53); also a cylinder seal, AT/46/1 99, P1. LXI, No. I 9.

Room 30 . Over most of the room there was a good cement floor, but at the NW. end a floor of clay only in which was sunk a circular unlined pit, diam. I.70 m., depth I.70 m., the bottom of good worked clay; on the bottom was a layer of decayed vegetable matter and the filling was of particularly clean earth. Between the pit and the SE. wall were six small basalt orthostats $0^{\circ} 40 \mathrm{~m} . \times$ $0.25 \mathrm{~m}$., lying flat. In front of the doorway was a basalt slab I. IO $\mathrm{m} . \times 0.45 \mathrm{~m}$. let into the floor (the cement was brought up against it with a neat chamfer) and rising $0.15 \mathrm{~m}$. above it. Round this were very many stone blocks and fragments, amongst which two small fragments from a diorite statue of the Gudea type, AT/46/1 72-3, a mace-head of white limestone, AT/46/I 49, and a fragment of a second, AT/46/I 56, and a haematite weight AT/46/222.

Room 3I. Clay floor; of the SW. wall only the cobble foundations remained and the position of the door is unknown. On the floor a number of stone implements-six pounders $(A T / 46 / 292-5)$, two hammers (AT/46/283-4), a drill-handle $(\mathrm{AT} / 46 / 282)$ and a plain drill-head, a polished stone cylinder partly pierced from one end $(\mathrm{AT} / 46 / 285)$, a haematite weight $(\mathrm{AT} / 46 / \mathrm{I} 84)$, a marble object of uncertain use (AT/46/189, Fig. 80) and a (broken) seven-pointed bronze star (AT/46/ I 8 , cf. Pl. LXX).

Room 32 . Nothing is known of this room, whose existence was only deduced from the discovery of a patch of brickwork which we took to be the threshold of a doorway in a wall, which had otherwise disappeared, separating room 32 from the courtyard 28.

Room 33 was only partly excavated. It was a continuation of the long passage running against the inner face of the town wall, but was much narrower; possibly the east corner of the palace came here and, at the corner, the outer walls might be thickened (at the expense of the passage) to strengthen the angle.

The two passage sections, rooms 29 and 33, were of interest as showing the continued use of the Level VII town wall after the destruction of the Level VII palace. In the palace period, as has been said, room 29 was used for the storage of pots and the floor was thickly covered with their fragments; there was a good deal of pottery on the floor of room 33 also. But at $\mathrm{I} \cdot 30 \mathrm{~m}$. above the floor there was a second floor-level and, corresponding to it, a rebuilding or repairing of the walls; the NE. wall of room 29 had been patched with new brickwork, on the SE. a continuous wall ran over the old (Level VII) wall dividing rooms 29 and 33 and obliterated the old doorway, while on the SW. side a new doorway had been contrived between rooms 29 and $3 \mathrm{I}$. The new room had, like the old, been used as a pottery store, and the potsherds-all of plain ware-favoured a Level $\mathrm{V}$ rather than a Level VI date. In the upper room there was a fragment of a human skull.

Room 34. Of the doorway in the NW. wall the western jamb was missing, the eastern was a well-cut basalt slab resting on a projecting limestone plinth; the threshold foundation of rough slabs remained and gave the width of the opening. The NE. wall scarcely rose above floor-level; the SE. wall had one course of brick only, flush with the floor; the SW. wall stood $0.50 \mathrm{~m}$. high. Two rubbish-pits covering the whole area of the room had ruined the floor but stopped short at the floor-foundations, which were of heavy boulders. 
Room 35. The SW. wall ran for about a metre from the south corner and then broke away, destroyed by a rubbish-pit; there was no trace of the NW. wall, and no floor.

When Yarim-Lim's palace was burnt the ruins of the NW. and of the central block, with their thick walls and several stories, made two high mounds separated by a slight depression marking the site of the courtyard; but the domestic wing (whose character is sufficiently proved by the character and the contents of the rooms $20,26,27,30,31$ ), being thin-walled and of one floor only, produced but little debris, so that there resulted a sunken area bounded on the north-west by the mound of the central block, on the north-east by the still upstanding mass of the city wall, reinforced as the latter was by the solidly constructed corridor running along it, and on the south-west by the temple wall and court. Being thus shut in, the area became more or less waterlogged and was of small value as a building site; we found it riddled with rubbish-pits of Levels VI and V. The earlier buildings of Level VI were confined to the higher ground, and only as this area was raised by the accumulation of rubbish did the houses encroach upon it; the city wall, on the other hand, continued in use, and we actually find that room 29, part of the corridor, was still in the Level $\mathrm{V}$ period essentially the same room remodelled, ${ }^{\mathrm{I}}$ and like its predecessor was filled with pottery. For some quite different reason the actual palace mound itself was not built over for a long while; it remained a ruin-field in which the upstanding walls of reddened and crumbling brick were left to weather away, and when at last it was decided to build there fresh rubbish was brought in from elsewhere to fill the hollows, and that rubbish is of Level VI and not of Level VII date. For a generation or more Yarim-Lim's house was left unto him desolate.

\section{(b) THE NIQME-PA PALACE SITE: LOWER LEVELS}

The importance of the Level IV palace and also its anomalous orientation made it a matter of interest to discover what type of structure it had replaced. On the other hand, we could not, even had we wished to do so, destroy the well-preserved ruins of Niqmepa's building. Ruhi Tekán, Director of the Antioch Museum, who from I 946 onwards acted as Commissaire to the expedition, accordingly arranged a compromise whereby we might sink a trial shaft in the central courtyard of the palace (room 4 on the plan, Fig. 45 ); in view of what we there found a second shaft was sunk through rooms I I and I 2 (the former of which had been completely destroyed by the deep-laid foundations of the Level III fortress) and a third in the NW. part of Ilim-ilimma's courtyard, room 22 on the plan. The whole of this work amounted to no more than a sounding, the free area being far too small for proper excavation, and no real plan could be recovered; but the results, so far as we could interpret them, were valuable.

At I. I $5 \mathrm{~m}$. below the cement floor of room 4 were found mud-brick walls and floors of beaten clay which must be attributed to Level $\mathrm{V}$, the obvious date being confirmed by

. 1 The floor was raised by $\mathrm{I} \cdot 30 \mathrm{~m}$.; new walls were built exactly aligned with the old, which served as their foundations, the only difference being that the old doorways were not used

and a new doorway was made in the SW. wall, ø. supra, room 33 . 
sherds of black impressed pottery (v.p. 345). The orientation of the walls (Fig. 43a) was fairly close to but not the same as that of the Level $\mathrm{V}$ rooms (C $\mathrm{r}-9$ ) incorporated in the Niqme-pa palace; they were only $0.60 \mathrm{~m}$. thick and roughly built and seemed to be the

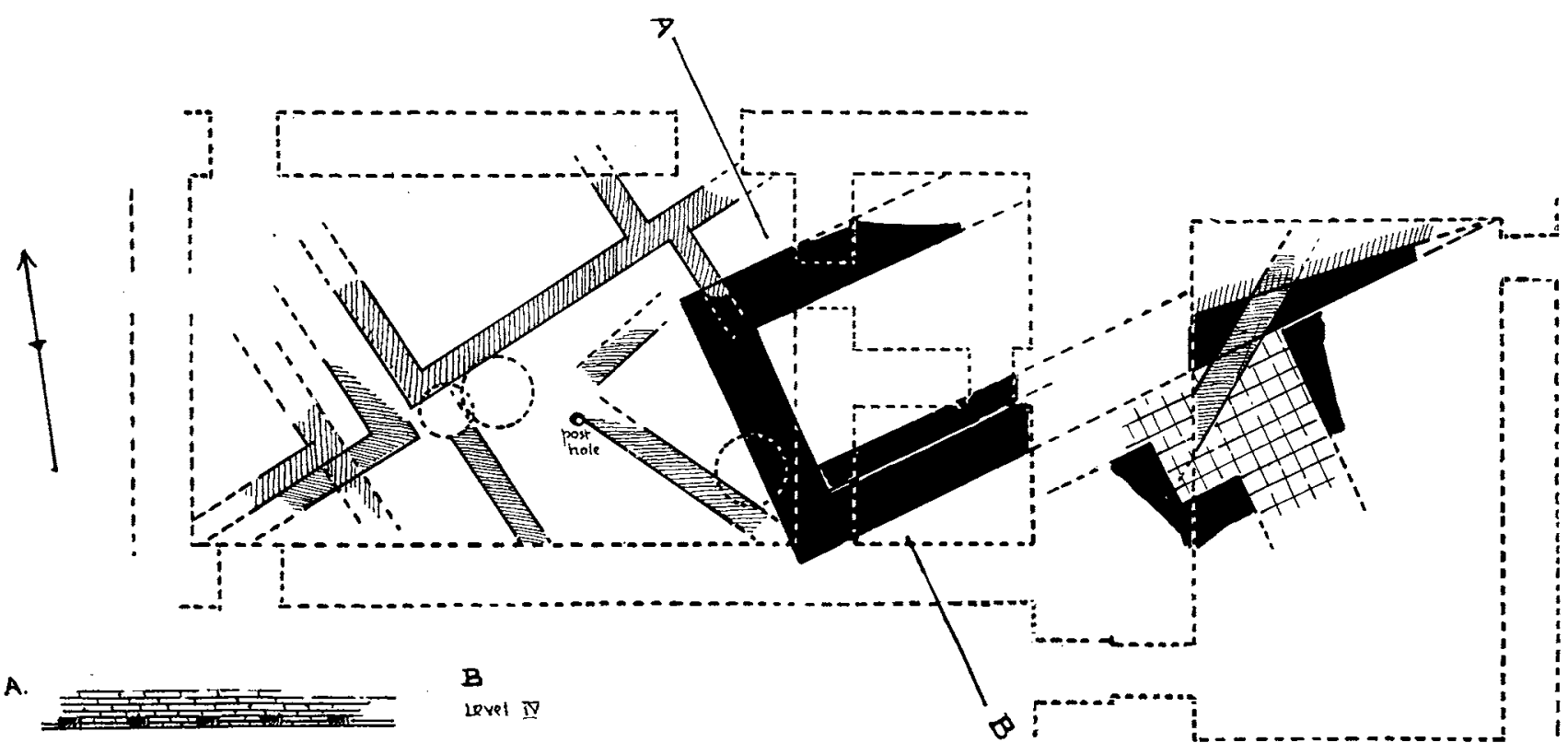

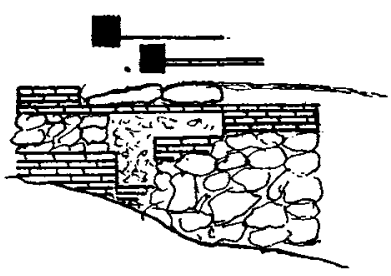

FIG. $43^{b}$
Level $\overline{7}$

Level VII.

FIG. 43a. I:200

walls of outbuildings rather than of a proper house. At $0.50 \mathrm{~m}$. below these came an earlier building-level with mud-brick walls and floors paved with a single course of mud bricks; the walls had been deliberately and thoroughly razed and further cut about by rubbishpits; even their direction was not easy to determine and they made no coherent plan, but while some of them were orientated on the same lines as those of Level $V$, two seemed to run at quite different angles; but it was certain that here again we were dealing with the flimsy and ill-constructed walls suitable only to outbuildings (Fig. $43^{b}$ ).

In the Ilim-ilimma courtyard (22) at $0.20 \mathrm{~m}$. below that king's cement floor ther elay a perfectly preserved and very fine floor of solid concrete; on the SW. side it had been cut through by the foundations of Ilim-ilimma's courtyard wall, on the north-west it ran up against a heavy mud-brick wall whose orientation was nearly though not quite in agreement with that of the range of rooms C. I-9 of Level V. Below the concrete floor and the heavy wall containing it there was a flimsy wall of mud bricks, having a clay floor against it, which agreed in its angle and clearly formed part of one construction with the anomalous wall of Level VI under room 4. The two soundings, $9.00 \mathrm{~m}$. apart, give results which, meagre as they are, appear to be consistent. In what we can provisionally call Level VI (though the vertical interval is so small that it might easily be early Level 
V) the site was occupied by shoddy one-storied buildings. In the later part at any rate of Level $\mathrm{V}$ there was a new range of outbuildings on the west half of the site (under room 4), but on the eastern half there had been set up a building of considerable importance, as witnessed by the solid concrete of its floor. ${ }^{I}$ King Niqme-pa built his new domestic palace on the relatively open site of the outbuildings, destroying only the western edge of the great house of Level $\mathrm{V}$, and the whole of the rest of it, lying to the east, he incorporated in his palace complex just as he did the service-chambers C. I-9 of the SE. wing. When Ilim-ilimma decided to substitute a properly planned administrative building for the makeshift adaptation that had satisfied his father he could not use the old concrete floor, perfectly good though it was, because it lay askew to his ground-plan and therefore, since he did not want to raise the level, he laid his new cement almost directly on it.

Up to this point the site presented no great difficulty, but the lower levels were much more complicated. In the process of clearing one of the late Level $\mathrm{V}$ rubbish-pits near the east end of room 4 we encountered heavy stonework that called for further investigation. We found, at a depth of $3.00 \mathrm{~m}$. below the Niqme-pa pavement, the top of a line of walling, or wall-foundation, built of very large rough stones of which there were seven courses giving a total height of $3.00 \mathrm{~m}$.; some of the stones were as much as a metre long. ' The 'wall' ran at the same angle as the walls of the existing Level $\mathrm{V}$ palace building, was $6.40 \mathrm{~m}$. long, and at each end had returns running north-east; the returns were followed up by us through rooms I I and I 2 and, in the case of the SE. wall, under room 22. In the SE. wall the tops of the stones were level throughout the whole of its length (c. I $3.00 \mathrm{~m}$.) as exposed by us, but the bottom of the stonework was stepped up from SW. to NE. so that whereas there were seven courses at the SW. end there were at the $\mathrm{NE}$. end under the Ilim-ilimma courtyard only two, and those of smaller stones; either because of a slope of the ground surface or because the subsoil here was loose or wet extra strength of foundation was needed for the SW. end of what seems to have been a long projecting wing of an important building. That projection would seem to have been in the nature of a tower of great weight and presumably therefore of some height, for at the SW. end the mass of stone was solid right across the width of the building; in the middle the stones were simply tumbled in, not laid, and earth poured round them as packing, only the top being well finished with very large flat slabs set side by side with stiff clay filling the joints; ${ }^{3}$ the packing filled the whole space between the inner faces of two mud-brick walls built along the NW. and SE. edges of the stone foundation; along the SW. end of the foundation no brickwork was observed by us, but the packing stopped in a straight line $\mathrm{I} \cdot 50 \mathrm{~m}$. from the face of the stonework.

The removal of the big flat stones revealed further features most difficult to understand-see the section, Fig. $43 b$. The stone packing sloped down sharply to the NW. and ended against the face of a mud-brick wall apparently $\mathrm{I} \cdot 90 \mathrm{~m}$. thick (this judged from the stonework above it; its

I One can fairly surmise that the concrete floor was that of an inner courtyard and that to the SW. of it lay a single row of small chambers with the outer wall under rooms I I and 12 of Niqme-pa's palace.

2 In contrast with this the foundations of the Nigme-pa palace consisted of two courses only of relatively small stones.

3 These sloped steeply (at a gradient of nearly I in 4) down from NW. to SE.; probably this was due merely to subsidence, but the effect was deceptively like a roof. 
outer face was not actually found), the inner face of which was plastered and whitewashed. The $\mathrm{SE}$. wall, which was $\mathrm{I} \cdot 30 \mathrm{~m}$. thick, was built with bricks of a reddish clay measuring $0 \cdot 70 \mathrm{~m} . \times$ $0.42 \mathrm{~m}$., an unusually large size; behind it the sloping surface of the stone filling had been levelled with similar bricks which did not run right across to the NW. wall but ended at $0.75 \mathrm{~m} .{ }^{\mathrm{I}}$ from it, making a wall-face which like that immediately in front of it had been plastered and whitewashed; but the two whitewashed faces were not quite at the same level; between them was a packing of grey mud-bricks with rubbish above on which rested the big sloped stone slabs.

On the top of the NW. mud-brick wall were stone foundations $\mathrm{I} \cdot 75 \mathrm{~m}$. thick and $0.75 \mathrm{~m}$. high on which was a wall $\mathrm{I} \cdot 20 \mathrm{~m}$. thick of (grey) mud-brick; from the wall's foot there ran out a pavement, composed of a single course of (grey) mud-bricks, which was broken away at a maximum distance from the wall of $\mathrm{I} \cdot 40 \mathrm{~m}$. Clearly this was a case of reconstruction over the older work. The SE. wall did not give such conclusive evidence, ${ }^{2}$ but we could detect on its inner side under the stonework traces of mud-brick which may imply similar reconstruction on this side, although nothing of the sort was obvious on the outer face of the structure.

Digging down in room I 2 against the SE. side of the stone foundations we came almost at once on burnt rubbish, i.e. reddened mud-brick and carbonized beams; at about $2.00 \mathrm{~m}$. below the top of the foundations there could be distinguished the remains of a wall of half-timber construction with a foundation-course of rather small flat stones on which the lowest timber rested directly. This rubbish came right up to the stones of the big foundation and had evidently been cut through by the trench dug for the laying of those stones; the rubbish therefore, and the wallremains associated with it, were older than the big foundation. In the rubbish were found fragments of painted pottery of the type common in Level VIII and earlier, but some which are most characteristic of Level VIII. The half-timbered construction was orientated differently from the big foundations and agreed rather with the lines of the Niqme-pa building.

Digging in the Ilim-ilimma courtyard (room 22) we found, at $\mathrm{I} \cdot 20 \mathrm{~m}$. below the (earlier) concrete pavement, a floor or surface covered with white ash into which was let a cooking-pot of Type I 53; this seemed to correspond with the wall-remains found under room 4 and provisionally attributed to Level VI. At I·40 m. below the bottom of the stone foundations of Ilim-ilimma's courtyard wall came the red mud-bricks (here standing $0.40 \mathrm{~m}$. high) which rested on the big stone foundation, though here the foundation was reduced to two courses. Against the red brickwork there was a thick stratum of burnt and broken brick and carbonized wood lying on a brick floor that was flush with the top of the stone wall-foundations and therefore presumably.contemporary with the wall; this floor or pavement ran up against a wall of plain mud-brick that ran parallel to and at $2.65 \mathrm{~m}$. distance from the foundations and at its $\mathrm{SW}$. end returned towards them, but left a gap as if for a doorway; at its NE. end there was another return (perhaps only the end of the wall) and at $2.20 \mathrm{~m}$. from that there was a wall at right angles, thus enclosing a small paved chamber built up against the main structure and having, apparently, doors in its SE. and SW. sides. The walls of the chamber had been burnt, but the heat had blackened the bricks only, not baked them red; the pavement lay $0.70 \mathrm{~m}$. below the ash-covered floor mentioned above, and the walls, standing to a height of $0.85 \mathrm{~m}$., may have been re-used in that later period. 3 In the middle of the chamber there was let into the pavement 4 a large clay pot, ht. $0.75 \mathrm{~m}$., of Type I 54 ; it was

I This was the measurement between the faces proper, but the SE. plastered face was curved outwards like the soffit of an arch, reducing the interval at the top to about $0.60 \mathrm{~m}$.

2 We were working in a very confined area and under difficulties involved in the preservation of the Niqme-pa walls; also, as this was a mere sounding, I did not want to destroy any feature of a building which might one day be properly excavated.

3 But the ash-covered floor seemed to run on over the top of the (ruined) wall of the main structure and so to post-date it, whereas the burnt rubbish beneath simply lay against the wall-face.

4 On removing it we found that below the floor there ran a well-built wall of mud-bricks $0.4 \mathrm{I} \mathrm{m} . \times 0.40 \mathrm{~m}$. with plaster and whitewash on its NE. face; the wall was at least $2.50 \mathrm{~m}$. wide, so should belong to an important building, probably of Level VIII. Our excavation went no farther than this. 
empty except for fragments of a basin of thin brown clay and a fragment of an obsidian tray. The room had been the workshop of a maker of obsidian vases; its contents are described in the section on Stone Vases, p. 293.

Our soundings, which it was not possible to carry farther, prove that on the site of the Ilim-ilimma part of the Level IV palace there was a building whose foundations, the most massive found by us at Alalakh, testify to its great importance. The date of the building is tolerably well fixed; its foundations were dug down into a stratum which on the strength of the pottery we can assign to Level VIII; in that it was destroyed by fire it shared the fate of the Level VII palace on the east and of the Level VII city gate on the north-west; it is separated from Level IV palace, by three building phases the last of which belongs to the later part of the Level $V$ period, i.e. the building part of whose main structure was incorporated by Niqme-pa in his palace (to be supplanted later by Ilimilimma's new wing), while its outbuildings were razed to make room for his residential quarter; the two remaining building-strata ${ }^{I}$ should then be assigned either to Level VI or to Level VI and the early part of Level V. ${ }^{2}$ It is certainly to Level VII that we must attribute the great stone foundations and, incidentally, the stoneworker's shop built against them.

\section{(c) THE LEVEL IV PALACE (see Figs. 44 and 45)}

I have explained elsewhere (p. 387 ) that the term 'Level IV' was originally applied to a stratum in the residential quarter of the town. As soon as the palace was discovered it was obvious, both from the facts of stratification and from the character of the objects found in it, that it belonged to Level IV; but it is equally clear that the floruit of the palace is not conterminous with the historical period represented by the private houses; it falls within that period, but is only a part of it. There is a definite advantage in associating our archaeological levels with political events and thereby obtaining more or less positive dates for them, and it is permissible to equate the beginning of 'Level IV' with the rise to power of Niqme-pa and the building of his palace; but even so it must be remembered that the transition from 'Level $V$ ' to 'Level IV' was peaceful and gradual, so that both socially and culturally the actual dividing line between them is difficult to determine and, so far as the archaeological strata are concerned, is here drawn arbitrarily. Moreover, it is quite certain that the palace was shortlived, enduring indeed for no more than two generations, whereas the Level IV period goes on until the capture of Alalakh by Subbiluliuma(s) introduced a new political phase to which the next archaeological stratum exactly corresponds.

The very many tablets found in the palace ruins are dated to the reigns of two kings, Niqme-pa and his son Ilim-ilimma; it can safely be assumed that the former was the builder of the palace, it is at least convenient to assume that his son was responsible for the

\footnotetext{
I The upper of these is represented by the shoddy walls under room 4 and the associated fragment of walling under room 22 ; the lower is the brick wall with stone foundations resting on the mud-brick walling of the NW. side of the big
}

foundation.

2 This presents no difficulty since in the castle (v. pp. I $53 \mathrm{sq}$. ) we find two phases of construction in Level VI and two in Level V. 
later additions made to it; there can be no doubt but that it was burnt in a civil rebellion which did not affect the private buildings of the period.

Between the temple area and the NW. gate of the city there was a large and important building which may well have been the royal palace of Level $\mathrm{V}$. The main block was to the north-east, standing at the foot of the deserted mound which had been the palace of Yarim-Lim; the service-wing was on the south-east; on the south-west there was a courtyard, containing a few outbuildings, divided by a wall from the 'parade-ground' of the Level $\mathrm{V}$ castle. This was the site chosen by Niqme-pa for his new palace. His programme was not an ambitious one. He required a house for himself, and it had to be in keeping with his position, but beyond that he was not prepared to go, and so far as possible the existing buildings were to be retained and incorporated in the new; but he made one innovation which entirely upset the unity of the combined plan. The layout of the town of Alalakh had for a very long time been determined by the long line of its NE. rampart; in the area that we have excavated all the buildings are orientated alike and all conform to the direction of that NE. wall. Niqme-pa's palace breaks the tradition and is set askew. Why this should have been done it is hard to say, for there was no obvious advantage to be gained by the change of angle, whereas the disadvantages are manifest both in the awkward joint between the old and the new wings of the palace and in the shape taken by the courtyard, which ruins the symmetry of the façade; I can only suggest that Niqme-pa, wishing to connect his palace with the town defences against which it backs, decided to make it parallel to the section of the NW. rampart immediately concerned; there does not seem to be anything else that could have dictated the line which he actually chose.

The new palace was planned to occupy an area measuring $33.00 \mathrm{~m}$. from east to west and $30.00 \mathrm{~m}$. (maximum) from north to south. Since it was desired to retain as much as possible of the main block (the NE. block) of the Level V building and the space between that and the 'parade-ground' was not great, a large part of the latter had to be sacrificed; about a third of Niqme-pa's building overlies it. On the east and south so much as was necessary of the old building was hacked away and the new walls were built abutting on the cut ends of the old.

This is clearly seen in the south corner of the palace, where C. 3 has been turned into an irregular polygon; the broken ends of its walls could easily be distinguished. Similarly the SW. corner of the palace is very clumsily incorporated in the jamb of the castle gateway. Beneath the courtyard of the palace (room 4), at I. I $5 \mathrm{~m}$. below the pavement, there were remains of the Level $\mathrm{V}$ building-mud-brick walls $0.60 \mathrm{~m}$. thick, with no stone foundations, and clay floors; these were on the same level as the existing buildings on the NE. and SE. of the courtyard, and similarly orientated, but of more flimsy construction, so that they should be outbuildings rather than any part of the structure proper; $v$. the detailed description, p. 107. Excavation under the NW. corner of the Ilim-ilimma courtyard (room 22 on the plan) produced a very finely-finished and solid concrete floor running up against a lime-plastered wall; the latter was orientated similarly to the Level V rooms on the NE. and SE. of Niqme-pa's front court and was evidently part of the Level $V$ building which had occupied the site before the Niqme-pa palace was put up but had not been destroyed until Ilim-ilimma added his new wing. The quality of the construction proves that 
these are the remains of the main block of the original building and justifies the suggestion made above that that had been the palace of the Level V period. For further detail $v$. p. IO8.

Niqme-pa's palace was a two-storied building with a single entrance set in the south wall and facing on an open court of irregular shape; it contained a central courtyard or light-well surrounded by chambers opening on to it, a single range on the north, east, and south sides, and a double range on the west, three of the rooms there occupying a salient from the north wall of the building; in the SW. corner there was a staircase leading to the upper floor and, presumably, to the flat roof, and in the east wall there was a doorway giving access to what was left of the main block of the old Level $\mathrm{V}$ palace; east of the entrance there ran out at an angle the kitchen wing of the old palace, forming two sides of the front court.

This is quite clearly a residential building. It is larger than the normal private house and more formal in its layout, but the only architectural feature that distinguishes it from the house of a wealthy citizen is the entrance with its flight of steps and columned portico. The contents of the rooms show that the ground floor was very largely if not altogether given over to the domestic staff, who had also the use of the courtyard range; the family must have lived upstairs - and it is noticeable that the use of polished basalt orthostats for purely decorative purposes is confined to the entrance and the anteroom leading to the imposing staircase. ${ }^{\mathrm{I}}$ We do not, of course, know anything about the character of the old building still standing on the east-it may have contained the official offices of the former régime-but it certainly was small and its different orientation must have given it a rather makeshift air; in any case Niqme-pa's own building was, as a royal palace, comparatively modest.

The size of the palace was more than doubled when-probably by Ilim-ilimma-new buildings were erected on the north and west. On the west the Level $\mathrm{V}$ building was swept away and the site was enlarged by cutting into the flank of the high mound which concealed the ruins of Yarim-Lim's palace ${ }^{2}$ and was extended northwards to the city wall; on the north the space between that wall and Niqme-pa's palace was filled in with rooms and a corridor leading to a high tower contrived on the foundations of one of the chambers of the Level $\mathrm{V}$ gateway buildings now reinforced into an almost solid mass of stone and brick. The northern addition therefore served a military purpose; the new west block, which, though separately constructed with its own outer west wall simply plastered against the face of the outer east wall of Niqme-pa's building, was essentially a part of it and could be entered only through it, was purely official; the ground floor at least was taken up with reception-rooms and business offices. The entrance (from Niqme-pa's

\footnotetext{
I Professor Sidney Smith has pointed out to me that the Crown Prince of the State of Kussar seems to have borne the title 'Chief of the Stair'. The staircase of a palace, as being the only means of access to the private apartments of the king and royal family, was likely to have special significance in court life; see 'T. Lewy in Revue Hittite et Asianique, iii. I ff. I would add as perhaps apposite the reference 2 Samuel xvi. 22 .

2 The facts are very clearly given by the outer face of the east wall of Ilim-ilimma's building; $v$. Pl. XXIIIa. The lower
}

part of the mud brickwork is quite rough; then along the face runs a horizontal black line due to decomposed matter lying on the surface at the wall's foot, and above that the wall is neatly plastered. 'The black line is $\mathrm{r} \cdot 60 \mathrm{~m}$. above the level of the floors of the rooms inside the wall; farther to the east the ruin-mound rose rather higher in places, but the general height as shown by the earliest wall-foundations agrees with this. 


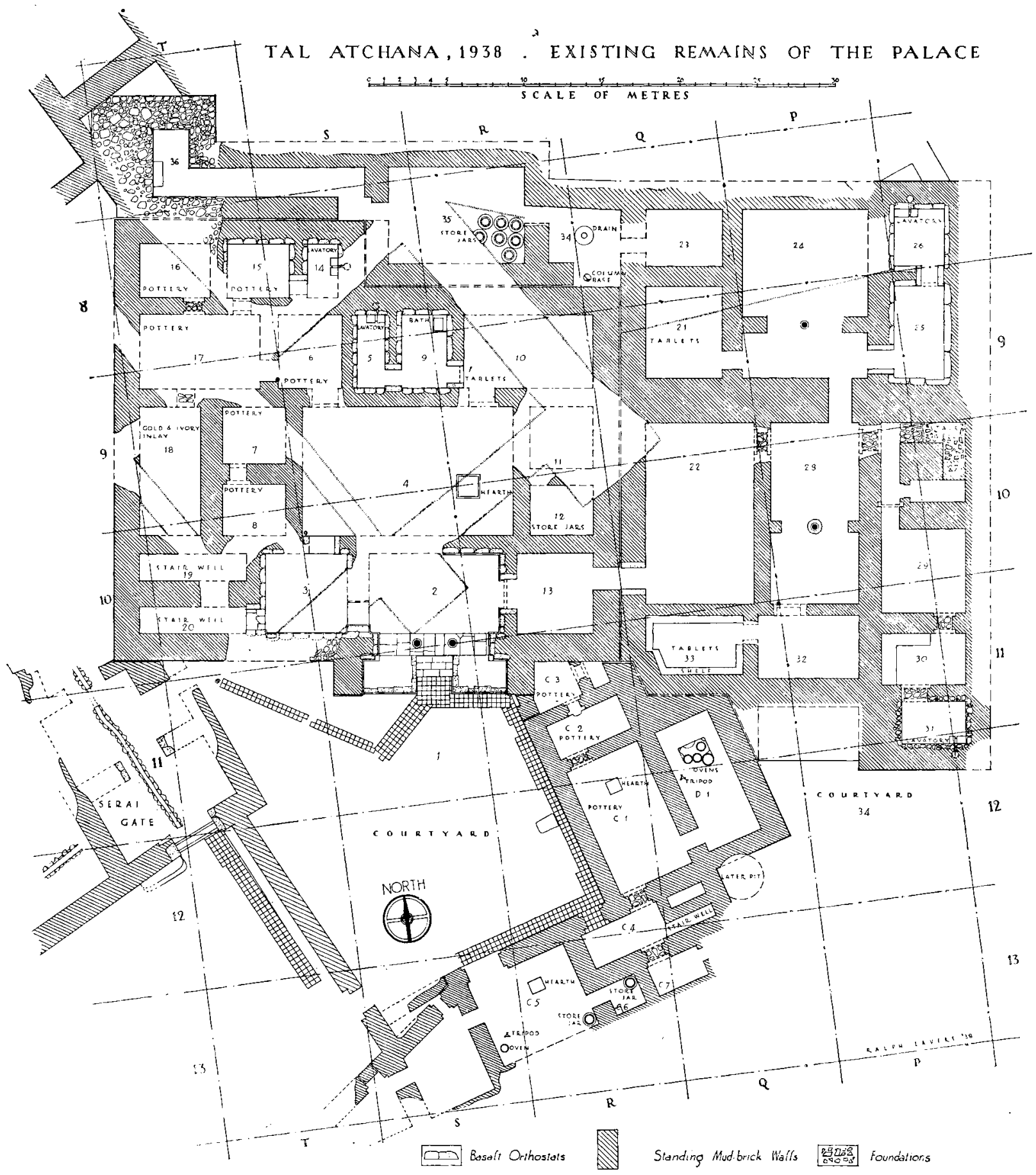

FIG. 44 
room I 3) leads into an open court; beyond this the greater part of the building is given over to two suites in each of which the principal room is of the type divided by piers and columns into two sections which is first met with in the 'audience-chamber' of the official block in the palace of Yarim-Lim. Here the southern audience-chamber has behind it a room which may have been the secretariat and, opening out of that, an archive room with a low bench round it on which the tablets were stored; the northern audience-chamber has on the west of it two perhaps similar rooms (though there is no evidence of archives) and on the east what may be a withdrawing-room and a lavatory behind it. Three other rooms, one of which is a lavatory, and a spiral staircase complete the ground-floor plan. Evidently here there is nothing domestic. It is of course possible that the rooms of the upper floor served as extra living-quarters for the royal family, but it is much more likely that as in the Level VII palace so here, one block was residential and the other devoted to the business of court and State; the elaboration of the first simple plan would seem to indicate the growing prosperity and power of the Level IV dynasty.

The site chosen by Niqme-pa had been uneven, sloping down towards the west; he had therefore started by making a terrace (using for this the debris of the old buildings) which was flush with the floor-level of the eastern block of the Level V palace but was a metre above that of the front court. When the palace was burnt the collapse of the lofty walls filled the ground-floor rooms with a mass of debris well calculated to preserve their contents intact; from some of them we did indeed recover an astonishing amount of material. Unfortunately, however, the east corner of the huge castle built by Subbiluliuma(s) lay immediately above Niqme-pa's palace; its foundations were deeply laid, so much so that, the palace being raised on a platform, they went down to and even below its floor; as the plan (Pl. XXII and Fig. 44) shows, wherever a Level III wall ran every vestige of the Level IV palace is obliterated. Ilim-ilimma's annexe lay beyond the limits of the later castle, but its northern end lay under the Level III city wall and had to a large extent disappeared. In spite of this it was possible to recover the whole of the ground-plan, with only one doubtful point of detail (see the restored plan, Fig. 45), and in very many cases to establish the purpose of the individual rooms by their character or their contents.

The courtyard (room I on the plan) was entered from the SW. by a gate giving on what seems to have been a public square outside the castle. A second and much smaller gate apparently led into the 'parade-ground' of the castle because otherwise there would be no reason for the paved walk which runs from the palace steps into the west corner of the courtyard, but the wall here was completely destroyed (see above), and apart from a single displaced orthostat material evidence for a doorway was lacking. The floor of the court as found was of beaten clay only, but a few patches of cement should mean that it had at one time been cemented all over; if so, the covering had worn out and not been replaced but instead of it pathways of terra-cotta tiles $0.285 \mathrm{~m}$. square had been laid down from the palace steps, one to the suggested gate in the west corner, one along the walls of the buildings which form the NE. and SE. sides of the court (Pl. XXIIIb), this for the convenience of the kitchen staff in wet weather. In the centre of the court was a circular pit filled with broken pottery, a sump-pit for surface drainage.

A little south of the steps there were several large tablets, ATT/38/34-42, 72, broken in pieces, 


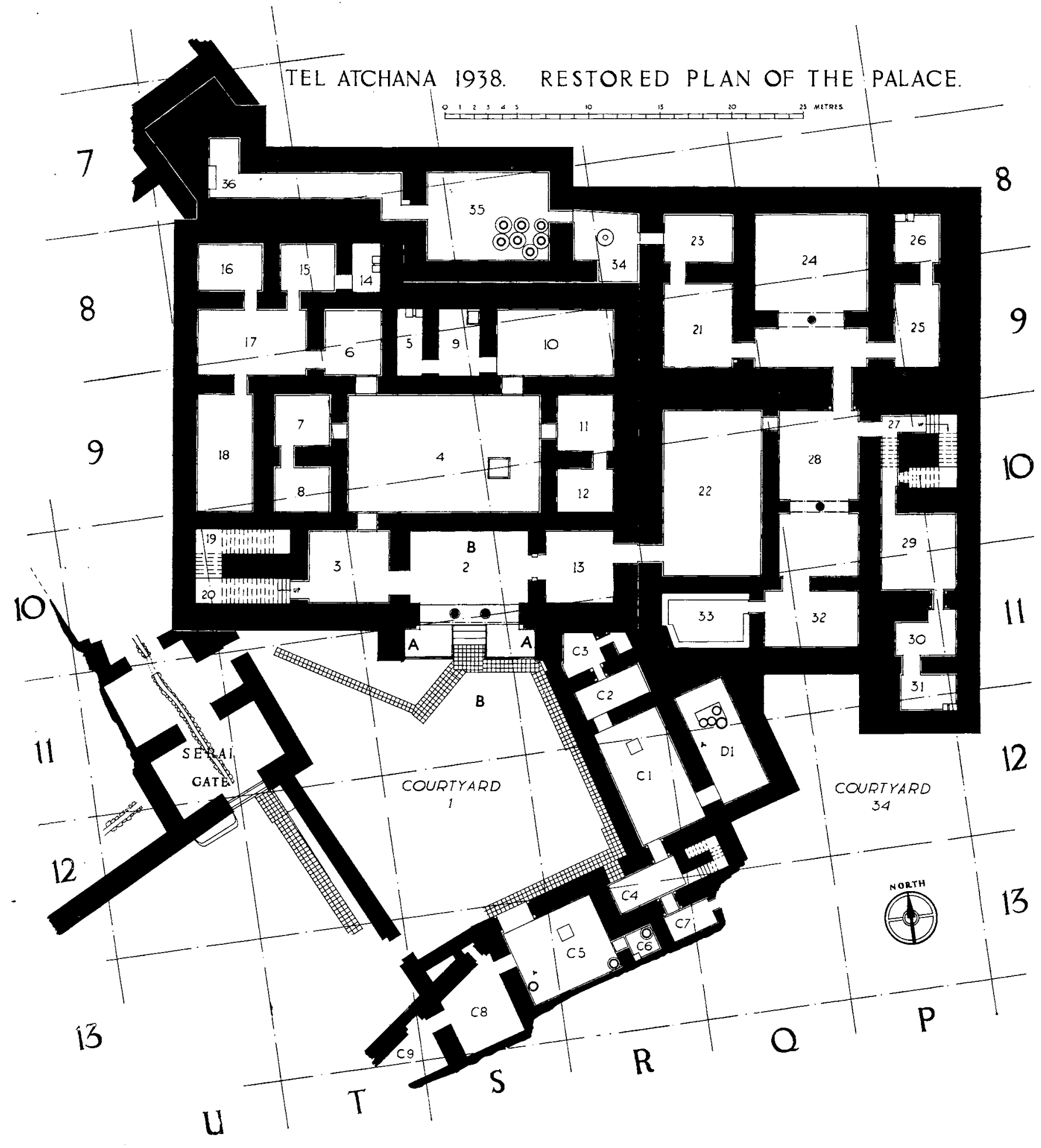

FIG. 45 
lying all together; they seem to have been the contents of a basket dropped by someone who was trying to save the palace archives at the time of the fire. There were no other objects in the court.

Room 2. The entrance to the palace ( $\mathrm{Pl}$. XXIVa) is by a flight of steps set in a projection from the façade ${ }^{I}$ formed by two solid mud-brick piers the fronts and inner faces of which were smoothly cement-plastered and the inner corners rounded. These were $9.25 \mathrm{~m}$. apart. In the centre was a flight of three basalt steps, $2 \cdot 40 \mathrm{~m}$. wide, with a fourth step made by a threshold, of limestone, $7.00 \mathrm{~m}$. in length, set between jambs enriched by polished basalt orthostats. The spaces between the stairs and the piers are filled by solid platforms whose flat tops are flush with the threshold; the fronts of these, which are almost on the line of the pier-fronts, and their sides flanking the steps, were faced with basalt orthostats above a $0.20 \mathrm{~m}$. high plinth. In situ on the threshold were two

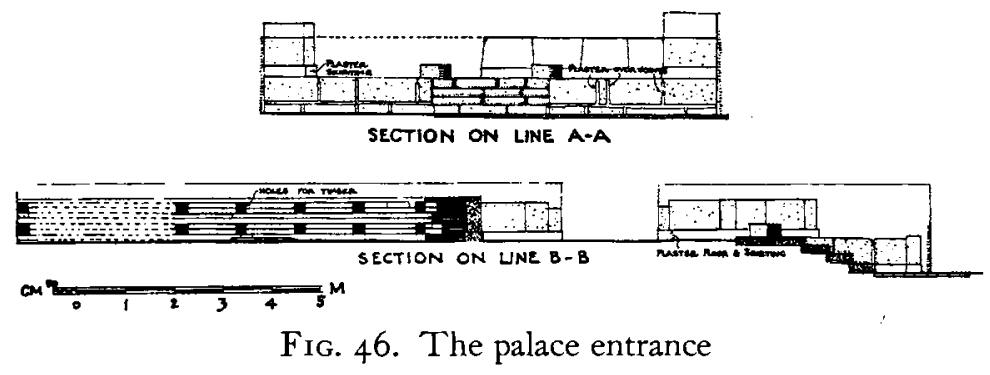

basalt column-bases, plain drums $0.70 \mathrm{~m}$. diam. at the bottom (they were very slightly conical), on the top of each of which was visible the mark of a wooden column-shaft having a diameter of $0.48 \mathrm{~m}$. The clay floor of the room was sunk very slightly below the level of the threshold; its walls had been lined throughout with basalt orthostats $0.72 \mathrm{~m}$. high set on a low plinth of rubble concealed by a rolled cement fillet; a beam rested on the stones and above it the wall went up in mud-brick and half-timber construction.

In the two platforms the plinth instead of being of rubble is of large and carefully shaped blocks (as much as $0.75 \mathrm{~m} . \times 0.45 \mathrm{~m} . \times 0.20 \mathrm{~m}$.) of basalt in the east platform, but in the west only the corner-stone is basalt and the rest limestone; they had been covered by a cement fillet, and four coats of cement could be distinguished showing repairs at different times. The joints between the orthostats had all been cement-pointed, very carelessly, the cement being smeared over the edges of the stones; the tops of the platforms were of clay, but patches of cement near the edges suggested that at one time they had been plastered all over. It is quite certain that they were platforms and never rose any higher; we have a close analogy to them in the platforms flanking the lowest flight of the great staircase at Carchemish. ${ }^{2}$ Each of the steps was built of three slabs of basalt, the front of the rise being plastered with. white cement. The jambs of the entry had reveals at the outer angles of the basalt orthostats; the plinth, however, made a plain square as if for an impost or a hinge, but there was no hinge-hole, nor did the appearance of the stone suggest that the reveal was for a wooden frame upright, though that is a possibility. When clearing the room we found between the basalt jambs a coherent mass of mud-brick rather more than a metre wide and I.70 m. high; it had no face, but was evidently walling which at first we took to be in situ and therefore hesitated to move $;^{3}$ only when we had done so did the threshold, with its column-bases,

I The architectural effect of this was really ruined by the fact of the kitchen wing's coming up against the end of the eastern pier and thus masking the eastern set-back. All that the architect could do in the circumstances was to cut a small recess in the old wall of the kitchen so as to expose the rounded corner of his pier and emphasize its independence.

${ }^{2}$ Carchemish, iii. Pl. XXX I $b$.
3 Since I emphasize elsewhere (v. p. 228) the resemblance between Cretan architecture and constructional methods and those of Alalakh, it is perhaps of interest to record that it was the recognition of such resemblance that decided us to move the apparent wall; before doing so we marked the positions in which columns ought to be found and told our workmen to look for them; they were found exactly under the marks. 
come to light. The wall was evidently that which had rested on the architrave supported by the columns, evidence that the upper-story room had its front wall flush with the main façade of the building and did not project over the stairs. ${ }^{\mathrm{I}}$ Against the north wall of room 2 there were fragments of at least seven heavy beams (burnt) lying more or less at right angles to each other,

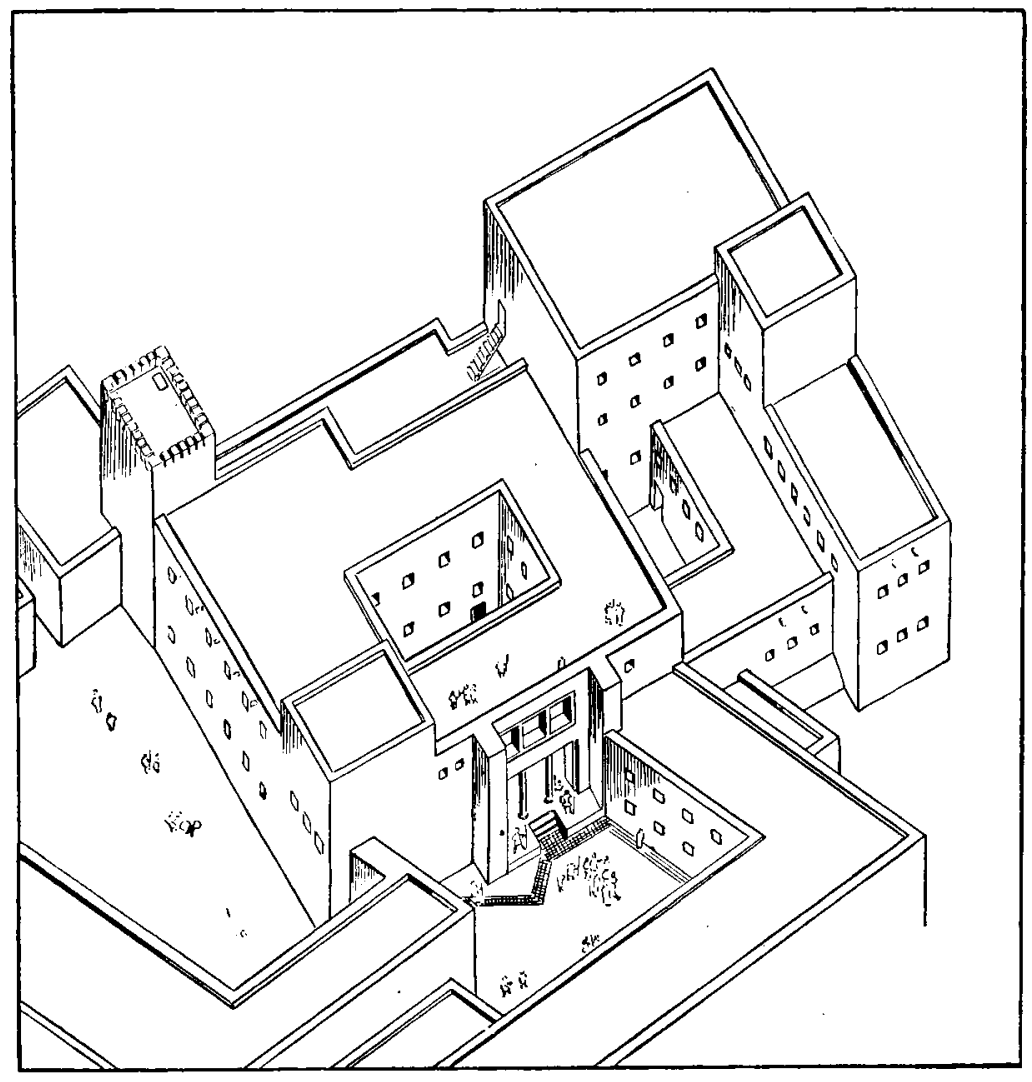

FIG. 47. Suggested restoration of the palace

presumably from the ceiling of the room; all over the undisturbed part of the room there were in the debris on and above the floor fragments of thick concrete faced on one side with smoothly floated cement; this was the ordinary flooring material of the ground-floor rooms and evidently was used for the upper rooms also, laid over timbers and either planks or matting. ${ }^{2}$ In the same debris were numerous fragments of fine wall-plaster, plain white or painted red or blue (the fragments showed only plain colours, no evidence of design), these too fallen from the upper room.

The orthostats round the room (Pl. XXIVb) were $0.72 \mathrm{~m}$. high set on a raised limestone plinth

I See Mr. Laver's reconstruction on Fig. 47. I do, however, think it likely that the piers on either side of the stairs instead of rising to the roof-line in the form of buttresses stopped at the first floor and supported a wooden balcony in front of the window of the upper room. Admittedly the span is much greater than the Alalakh builder was used to allow for -it would require beams of $10.50 \mathrm{~m}$. as against the maximum of $8.00 \mathrm{~m}$. (in room 24); but it was quite feasible to run out brackets over the columns to give central support.
2 There were also many lumps of hard clay, one side flat and smooth, the other concave and showing marks of matting. I imagine that for the upper floor poles were laid fairly close together and matting spread across them on which clay was spread, exactly as in the case of a modern cottage roof-the slight 'give' of the matting between the poles would account for the concave impression in the clay. The concrete would be laid over the clay bedding. 
covered by a rolled cement fillet. The doorway to room I 3 had a clay threshold with a wooden edging which was the lower member of the timber door-frame; the uprights of the latter, posts $0.13 \mathrm{~m}$. thick, have left their mark on the face of the jambs and the cement plaster was brought up against them from the skirting fillet; the frame was strengthened by having joists laid along the base of either jamb (these concealed by the skirting) presumably to a second cross-piece at the back of the threshold (cf. the similar threshold of room 9, Pl. XXVa). In the doorway to room 3 the only surviving jamb was a single slab of basalt $\mathrm{I} \cdot 06 \mathrm{~m}$. high $\times \mathrm{I} \cdot 27 \mathrm{~m}$. wide.

Room 3. The basalt orthostats lining the walls were small, only $0.56 \mathrm{~m}$. high, resting on dressed basalt blocks, but the latter were below floor-level so that there was no plinth or fillet. The floor had been of cement. The threshold of the doorway to room 4 was a single slab of limestone; the big orthostat of the east jamb had a beam resting on it; in the top of the stone there was a small drilled hole in which was no trace of wood or metal-it was a lewis-hole used for adjusting the stone. ${ }^{I}$ The heat set up by the burning of the palace was such that the basalt has melted; the face of this jamb is covered with trickles of glassy slag; the opposite jamb is in the same condition and also cracked into fragments.

Room 4. The floor was of beaten clay covered with a good cement mixed with a small proportion of fine gravel. Over much of the (surviving) floor area the cement had disappeared owing to use, but a fair amount remained, especially in the northern half of the room, and here it had been

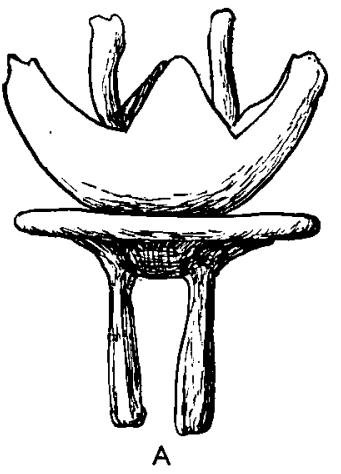

FIG. 48

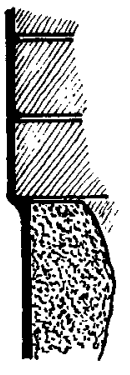

B vitrified by the heat of the burning building. A slight circular depression, apparently a post-hole (there was wood in it, and round it the vitrification of the cement was particularly marked), near the north wall and some fragments of beams lying well away from the wall-face towards the east corner suggested the possibility of there having been a wooden roof over the northern half, in which were the doors to rooms 6,7 , IO, and I I ; but generally speaking this was an open courtyard acting as a lightwell for the rooms surrounding it. Towards the east end of the court there was a $O .10 \mathrm{~m}$. high rectangular hearth made of mudbricks, mud-plastered; close to it was a circular clay-lined fireplace sunk about $\mathrm{I} .00 \mathrm{~m}$. in the floor. In the SE. corner, against the jamb of the doorway leading from room 3 , at $0.40 \mathrm{~m}$. below the floor, was the door-hinge, a heavy bronze disk, trimmed straight on one side so as to fit close to the wall, with a shallow cup in the upper surface and below two tenons which secured it to a horizontal beam of which we found traces running under the threshold; on this rested the bronze shoe of the hinge-pole, flower-shaped, with two tenons inside for fixing; AT/48/77, Fig. 48A. A similar hinge, but lacking the shoe, was found in the NW. corner against the jamb of the doorway to room $6, \mathrm{AT} / 3^{8 / 20} \mathrm{I}$. The walls had no orthostats but were constructed with a liberal use of timber; along the base of the north wall ran a cement fillet (which we did not observe in the case of the other walls).

Objects: fragments of tablets (ATT/37/2 I I, ATT/48/I, ATT/49/2); two fragments of gold binding (for a staff?) decorated with vandycks in remarkably fine granulated work, $\mathrm{AT} / 37 / 204-5$, Pl. LXIX; fragments (fused) of a White Slip ware milk-bowl.

Room 5 (Pl. XXVa). The floor, of white cement throughout, sloped fairly sharply from all directions to the drain against the north wall; the latter was the normal lavatory with two brick foot-stands $0.32 \mathrm{~m}$. high which had been cement-plastered time after time, all edges and corners being carefully rounded; the passage between them and the hole through the wall which continued it were cement-faced. The door had had a wooden frame only. The walls were lined with basalt

I I have discussed the use of these lewis-stones in Hittite building in Carchemish, ii, pp. I 47 seqq. 
slabs merely quarry-dressed which were covered with a coat of cement more than once renewed. In all except the west wall there was a timber baulk laid over the stones with the mud-brick above, and the whole was cement-plastered; the cement remained up to a height of $\mathrm{I} \cdot 23 \mathrm{~m}$. and up to this point there was no more woodwork in the wall. A curious detail was the overhang of the bricks beyond the line of the orthostats; even in the west wall where there was no timber the bricks project about $0.02 \mathrm{~m}$; the angle has been filled with a cement chamfered fillet and the cement plaster applied in one coat over stone, fillet, and brick ( $v$. Fig. $48 \mathrm{~B}$ ).

Objects: bowls of Types I 5 , yellow clay, and $4 b$, red clay; fragments of a jug in yellow clay, Type $4 \mathrm{I} b$, ht. $0.4 \mathrm{I} \mathrm{m}$; these on the floor; at $0.20 \mathrm{~m}$. above the floor, probably fallen from the room above, part of a Base-ring ware jug.

Room 6 . The doorway from the courtyard (4) had a wooden frame and sill. The floor was of clay only; let into it by the doorway to room I 7 was the stone hinge-socket. The wall-foundations were of small rough stones rising only to floor-level; on them were beams laid parallel to the wall-face, with brick above; in the east wall there were below the beam short timbers running through the thickness of the wall, and there was one such transverse timber at $0.60 \mathrm{~m}$. above floor-level in the south wall, but otherwise there was no woodwork below the point $\mathrm{I} \cdot 30 \mathrm{~m}$. to which the walls stood. The wall-plaster was mud with a lime wash over it; near the courtyard door it had been vitrified.

The room was full of objects of many sorts, pottery, and especially plain pottery, predominating. Some of them, coming fairly high in the filling, must have fallen from the room above, but of the bulk of the pottery it can safely be said that it belonged to the room and had been stored on wooden shelves running along the walls. There was an unusual amount of wood ash in the room, particularly near the walls; most of the pots lay in the ashes above floor-level, and it was noted that the plates were generally right way up but sloping down from the wall line; as in a number of cases they were still in piles of half a dozen or more, they could not have fallen far, and the shelf theory is the only one that meets the case.

Objects: Gold: circular pendant with embossed decoration, a lily in Cretan style, AT/37/ I66; Pl. LXIX; roundel, diam. O.OI $5 \mathrm{~m}$., with border of dotted triangles, AT/37/200(A); a cap for a cylinder seal, and some small fragments; a ball bead of cloisonné work, scale pattern, set with lapis lazuli and green and yellow stones, AT/37/22 I, Pl. LXIX. Ivory: toilet-box in form of a duck, AT/37/2 36, Pl. LXXV; another similar, AT/38/ I I 7 ; circular box, AT/38/73, Pl. LXXVIII; engraved spindle-whorls, AT/37/198, 207, AT/38/292, Pl. LXVIII, and plain whorls with spindles, AT/37/239; Stone: a number of small carnelian ball beads (AT/37/22 I); two alabaster lids for vases, AT/38/67, 77. Metal: bronze lance-head, AT/37/209, Type Sp. 5; hemispherical bronze bowl, AT/38/72. Pottery: fragments of a Nuzu goblet with design of birds in white on red, $\mathrm{ATP} / 37 / 4$ I 5 , found on the floor and one fragment actually crushed into the clay of the floor; jug, Type B.M. 26, with incised ornament, ATP/37/4I 3; White Slip ware milk-bowls, numerous, including $\mathrm{ATP} / 37 / 4 \mathrm{I} 2,404, \mathrm{ATP} / 38 / 92,93$, I 45; Base-ring ware, bowl, $\mathrm{ATP} / 37 / 409,408$, $4 \mathrm{I} \mathrm{I}$, and fragments; plain vessels including examples of Types $3 b, 4 b, 6 a, 7 b$, I 58, I $63 b, \mathrm{~B} . \mathrm{M} .30$.

Room 7. Clay floor. The doorway from the courtyard is restored; there is here a gap in the wall due to the Level III builders, and even the foundations have been destroyed, but the restoration is certain since there is no other place in which a door could have been-there was none in the north wall, which also was breached but not enough to have obliterated all signs of a doorway had there been such.

Objects: bone spindle-whorl, engraved, AT/38/ I28, Pl. LXVIII; ivory comb, AT/38/82; a fragment of carved ivory, perhaps a human hand (?), AT/38/98, Pl. LXXVIII; a tube of glazed frit, $\mathrm{AT} / 3^{8 / 88}$; a quantity of bone inlay, plain strips, triangles, $8 \mathrm{c}$., from furniture; quantities of plain pottery including Types 94 (over 20 complete examples), $4 b, 26 a, 4$ I $a$, I $63 b$; cylinder seal, $\mathrm{AT} / 38 / 83$, Pl. LXIII, 55 ; tablets, ATT/38/63, ATT/38/3I. 
Room 8. Clay floor; the walls mud-plastered and lime-washed, the skirting also of mud; doorframe and threshold of wood.

Objects: a few pieces of gold foil and many pieces of bone or ivory (mostly pierced squares) for inlay, resembling those found in room I 8, q.v.; an ivory figurine of a lioness, AT/38/ I I6, Pl. LXXVII; five bone spindle-whorls, AT/37/2I,$A T / 38 / 85$ and IOI; bronze spear-head, Type Sp. I, AT/37/2 I0; bronze arrow-head, Type Ar. 3, AT/38/97; copper ingot (?), AT/37/208; lumps of mixed iron and copper, shape uncertain, one suggesting an iron knife-blade with copper handle, another in the form of the crucible in which it had been melted; bronze disk, AT/38/100; silver pin, Type P. I6, AT/38/84; cylinder seal, AT/38/6 I, Pl. LXIV, 80; glass paste pendant, pear-shaped, and two ball beads; a whetstone, AT/37/237; a clay lamp, ATP $/ 38 / 54$; fragments of White Slip bowls and Base-ring ware, and plain pottery including Types $3 b, 6 a$, 158 , and B.M. 22 .

Room 9. The doorway from room IO (Pl. XXVb) had a $0.18 \mathrm{~m}$. step up, the front of it formed by a wooden plank, behind which were stones and clay (apparently with wood above) making a threshold flush with the floor of room 9. The floor was of clay overlaid with white cement, sinking towards the middle; the walls had basalt orthostats $0.47 \mathrm{~m}$. high, the bottoms flush with the floor, no plinth or fillet, faced with cement plaster of which five distinct coats could be distinguished. In the NE. corner was a rectangular terra-cotta bath or box, $0.40 \mathrm{~m}$. high with two loop handles at each end (Pl. XXVIa). On the floor were: part of a clay goblet, Type I i $8 a$, bowl of Type I I and dish of Type $3 b$; about $0.50 \mathrm{~m}$. above the floor and therefore presumably fallen from the room above were three clay saucers, Type $3 b$, a vase of Type I 4 , and a White Slip ware milk-bowl. In the doorway between rooms 9 and Io was a tablet, ATT/38/2.

Room IO. Floor of clay with lime plaster above. Most of the room destroyed by the Level III builders, only the NE. and SW. corners being left. In the SW. corner were found a tablet and a seal-impression (ATT/38/23-24), in the NW. corner numerous tablets (ATT/38/16-22, 25, $27-30$ ) at floor-level, and fragments of a large store-jar, diam. $0.70 \mathrm{~m}$. Also on the floor, in the layer of ashes covering it, a ring-stand, Type 85 , and a saucer of Type 3 . Higher up, fallen from the upper room, parts of a Base-ring ware jug and a White Slip milk-bowl, and tablets ATT/ $38 / 4-\mathrm{I} 5$.

Room II. Completely destroyed by the Level IV builders.

Room I2. The north wall together with the whole of room I I had been destroyed by the corner buttress of the Level III fort; there had presumably been in that wall a doorway from room I I. Floor of mud-plaster. There were horizontal beams in the faces of the walls at floor-level (concealed by a cement fillet) and no more timber in the brickwork up to $\mathrm{I} \cdot 40 \mathrm{~m}$., the highest to which the walls were standing; the walls were mud-plastered and judging by traces on the east wall had had a very thin coat of white cement over the mud. A seal-impression in clay was the only object found, apart from pottery; there was a goblet, Type 94, with painted red bands, $\operatorname{ATP} / 38 / 20$, parts of two Base-ring ware jugs and two plates, Type $3 b$, one with painted red bands on pink clay; but the vast majority of the fragments belonged to big store-jars which must have occupied a large part of the room.

Room I3 (Pl. XXIVb). Clay floor. The walls, standing up to $\mathrm{I} \cdot 35 \mathrm{~m}$. maximum, had originally been cement-plastered with at the base a rolled cement skirting $0.12 \mathrm{~m}$. high which hid the rough rubble foundations. There was no timbering in the brickwork except in the west wall where long timbers $(1.40 \mathrm{~m} . \times 0.20 \mathrm{~m} . \times 0.08 \mathrm{~m}$.) ran from the corners of the room to the back of the doorjamb orthostats at floor-level and others at $0.75 \mathrm{~m}$. above the floor. A later wall-plaster was of mud, $0.05 \mathrm{~m}$. thick; this (and probably the original cement plaster also) had been carried right over the timbers, which accordingly were not seen, and must have been purely constructional. ${ }^{\mathrm{r}}$

I Probably meant to obviate any sideways thrust of the brickwork due to compression which might have displaced the basalt door-jambs, the latter being only $0.20 \mathrm{~m}$. thick. 
Over the floor were ashes and rubble $0.45 \mathrm{~m}$. thick, then a $0.40 \mathrm{~m}$. thick layer of wood ash, and above that burnt brick rubble. In the last were many fragments of very large store-jars obviously fallen from the room above; in the lower rubble fragments of two Base-ring jugs, a plate (Type $3^{b}$ ) with concentric bands of red paint, and part of a strainer-pot of painted Nuzu ware almost entirely destroyed by fire.

Room I4. Lavatory like room 5 ; a cement floor sloped from every direction down to the drain, which has its foot-stands of burnt brick overlaid with cement and the cement-lined pipe going out through the wall. The walls have basalt orthostats $0.42 \mathrm{~m}$. high covered with cement plaster which was taken down in a rolled skirting to the floor; judging by the fallen fragments the whole wall had been cement-plastered, but none was left actually on the brick surface. Amongst the pottery fragments could be identified the bases of three Nuzu goblets, Type I i 8, a Base-ring ware jug, a burnished red tripod bowl of Type I 6 I, two burnished red bowls of Type 2 I, and at least four examples of Type 3 .

Room 15 . Cement floor, higher than that of room I 4, there being a cement-faced step down to the threshold and a second from the threshold to room I 4. The walls had basalt orthostats of varying heights (they were usually laid lengthwise), e.g. the stone next to the doorway in the east wall was I. IO m. long and $0.55 \mathrm{~m}$. high, those in the north wall $c .0 .35 \mathrm{~m}$. high, and those in the west wall $0.42 \mathrm{~m}$.; all were concealed by a coating of cement above which over the brickwork was mud plaster showing no traces of cement. The destruction of the SE. corner of the room meant that it was impossible to be sure of the position of the door, but if this was in the west wall, then we have in rooms I 4, I 5, and I 6 an exact parallel to the suite IO, 8, and 5; in each case there is an inner lavatory, a central room with orthostats and cemented walls which should have been a bathroom, and a larger room which may possibly have been a bedroom, or, if we are to judge from the contents, a store-chamber with a service pantry opening off it.

In the rubble fallen from above were fragments of four red-burnished saucers of Type 3 , one of Type 6, and a tripod bowl of Type i63. On the floor were: a bronze vase, AT/38/62, Pl. LXXIV; a bronze knife, AT/38/63, Type Kn. 4; a stone bowl (fragments of), ht. O. IO m., diam. $0.282 \mathrm{~m}$; f fragments of a White Slip ware milk-bowl and of two goblets of Type I I 8 , one plain, one painted Nuzu ware (the design not recognizable); jug of Type 68, ring-stand of Type 85 , jar of Type I IO, and bowls of Types 6, I 5, 94, I63, and about fourteen examples of Type 3.

Room I6. Floor of clay with a coating of white plaster. The walls showed no timberwork other than a single lodgement for an upright close to the doorway in the south wall; they were mudplastered, with no cement. Of the vast amount of objects found here some may have fallen from the room above, ${ }^{\mathrm{I}}$ but the great majority certainly belonged to the ground-floor room. These included: two cylinder seals, AT/38/92, Pl. LXIII, 57, and AT/38/I I 9, Pl. LXIV, 75; a gold tassel with decoration of granulated work, AT/38/103, Pl. LXIX; a roundel (buckle?) of bronze plated with silver and inlaid with red stones, AT/38/ I I 5, Pl. LXIX; bronze spear-head, AT/38/ I I 8, Type Sp. 3; arrow-heads AT/38/I I 4, I 26, Types Ar. 5 and Sp. I I; knives AT/38/70, I I I, I I 2, Type Kn. 4; spear-butt (?), AT/38/1 I 3, Type Sp. 5; skewer, AT/38/65; knife-handle $\mathrm{AT} / 38 / 95$; bronze cooking-pot, anciently patched, AT/38/7 I, Pl. LXXIV; ivory toilet-box and lid decorated with Isis head, AT/38/74, Pl. LXXVI; fragments of an ivory wand, AT/38/78; two white shell cones, possibly for attachment to a belt, $\mathrm{AT} / 38 / 102$; an alabaster vase, AT/38/66, Pl. LXXX; a basalt tripod bowl; bone spindle-whorls, AT/38/78; a limestone cone set in bronze, $\mathrm{AT} / 3^{8 / 87}$; four handles of bone in the form of fish-heads, AT/38/94, Pl. LXXVIII; fragments of an inscribed tablet, ATP $/ 38 / 50$; a plain rough basalt bowl, diam. $0.325 \mathrm{~m}$; fragments of L. $\mathrm{M}$.

I This was difficult to determine because (a) many of the objects had been on shelves round the room and fell only after a certain amount of rubbish had accumulated on the floor, and (b) the ceiling gave way early and there was not in this, as in some rooms, a thick layer of rubbish distinguishing the contents of the upper and the lower rooms respectively. 
III pottery, $A T P / 38 /$ I $79 ;$ ' fragments of tall red-burnished 'Cypriote' type lekythos, $A T P / 38 / 52$; fragments of a painted Nuzu vase, ATP/38/16; vessels of Type $3 b\left(\mathrm{ATP} / 3^{8 / 5} \mathrm{I}\right)$, 2 I examples; Type I 63, 24 examples; Type I67, 3 examples; Type 7, 3 examples; Type 4, 2 examples; Types $4 b, 37,42,84$, I IO, I64, and B.M. 30; White Slip ware milk-bowls (ATP/38/2 I I, 2 I 4, \&c.); Base-ring ware, ATP/38/13, \&c., Type B.M. 24; Nuzu ware, ATP/38/72 (Type I 28 (?)) and Type I I 8 and the painted fragment $A T P / 38 / 94$. Besides these there were great quantities of unidentified sherds.

Room I7. Floor of white cement. The walls were heavily timbered, with a beam resting on the stone foundations, which rose $c .0 .10 \mathrm{~m}$. above floor-level and were concealed by a cement ovetto fillet, transverse beams immediately above that at intervals of $0.90 \mathrm{~m}$. from each other, and the second beam parallel to the wall-face resting on those; the walls had been cement-plastered at least for some height, but as with the decay of the woodwork all the wall-face had fallen away it remained only at the base of the walls. The room contained a quantity of pottery, \&c., but owing to its being largely destroyed by the Level III walls, which came down to floor-level, not nearly so much as did room 16.

Objects: Ivory spindle, AT/38/29 I four bone and thirteen stone spindle-whorls, AT/38/93; carnelian ball beads and three glazed frit ditto, $\mathrm{AT} / 38 / 86$; pottery types including Type 3 ( 3 examples), Types 4, 6, I 45, I 59, I 63, and fragments of White Slip ware milk-bowls and Base-ring jugs. Also part of a broken bronze blade and a cylinder seal, AT/38/69 (defaced).

Room I8. Cement floor. The wall-foundations of rough stone had at intervals of $0.95 \mathrm{~m} .-$ I. $20 \mathrm{~m}$. transverse beams laid between and on the level of the stones and on them rested the beams parallel to the wall-face at $0 \cdot 10 \mathrm{~m}$. above floor-level (this is an unusual feature, the transverse timbers generally coming above the longitudinal timbers); in the upper part of the walls (preserved up to $\mathrm{I} \cdot 00 \mathrm{~m}$.) there was no more woodwork except in connexion with the doors-in the NE. corner there had been a wooden upright let into the face of the east wall and projecting $0.17 \mathrm{~m}$. from it, its foot resting in a slight hollow in the floor, which was certainly part of the door-frame. The wall-foundations were plastered with cement, the longitudinal timber and the brickwork with mud only. The doorway had been destroyed, but its position was given by a few stones of the threshold on which was a layer of ashes.

The room was filled with wood ash to a depth of $0.50-0.60 \mathrm{~m}$. ; it contained very little pottery, but the ashes were full of fragments of thin gold binding or edging and some sheet foil, and with fragments of ivory or bone inlay, mostly plain strips and triangles; there were also many small stud- or nail-heads of gold and two ivory roundels carved in relief and decorated with gold stars, $\mathrm{AT} / 38 / 79$ (for the gold and ivory inlay $v$. AT/38/I 34, I 4 I, I 45, Pl. LXXVII). These objects were distributed over the whole room, though some patches were richer than others; they certainly came from the room above, when the fire destroyed the floor of that room, and there was really no doubt but that they belonged to various pieces of furniture of which the woodwork had perished. It would appear that the modern Damascus tables and stools encrusted. with mother-of-pearl and brass wire are in the direct line of descent from the gold-and-ivory-inlaid furniture of north Syria in the second millennium. ${ }^{2}$

A silver pin, AT/38/68, and a clay saucer (Type $3^{b}$ ) were also found in the room together with a few unidentifiable sherds.

Room I9-20 (see Fig. 49). These two go together as the stair-well. The doorway from room 3 had a basalt threshold with, behind it, clay and small stones retained by a wooden sill and then a clay floor $0.20 \mathrm{~m}$. lower than the threshold; at this point the walls had mud-plaster starting at $0.35 \mathrm{~m}$. above floor-level, and farther along there was no plaster on the rough stones but a solid

I $v$. p. 370 .

2 The modern furniture employs mostly plain strips and triangles. Our carved roundels could well have been the ends of chair-arms. For another analogy between the ancient and modern furniture $v$. AT/47/1 54, p. 29I, and Pl. LXXVIII . 
filling. As the walls nowhere stood to more than $0.55 \mathrm{~m}$. no further evidence was available, but the fact of the staircase is of course undoubted. The only objects (found on the level of the wall tops) were part of a steatite roundel, AT/38/60, and a small white paste scarab, AT/39/247; the latter might possibly belong to Level VI.

Room 2 . This, the courtyard and light-well of Ilim-ilimma's new palace wing, overlay what seems to have been the courtyard of the Level V palace ( $v$. supra, p. I I I); the floor, of white cement spread over clay, is in places as little as $0.065 \mathrm{~m}$. above the concrete pavement of the older building. The west wall is simply built up against the cemented face of the east wall of the Niqme-pa palace. A liberal use of timber was made in the construction throughout - thus in the north wall which stood to $\mathrm{I} \cdot 65 \mathrm{~m}$. there were three courses of transverse beams (generally $\mathrm{I} \cdot 30 \mathrm{~m}$. apart) with longitudinal beams between the courses, but the east wall had apparently only transverse and no longitudinal woodwork, though certainty on this point was made impossible by the ruinous condition of the wall. In every case the burning of the wood had caused practically the whole of the wall-face to fall away; the upper part of the east wall had crashed down turning a somersault in the process, the south wall had flaked through the centre and its outer half had slid down at an angle. The stone foundations were masked by a low rolled cement fillet.

The only objects found were two tablets partly vitrified by the fire.

Room 22. Floor of clay with a thin coating of white cement, most of which had perished; there was a cement skirting over the stones of the wall-foundations and a white cement plaster seems to have covered the whole wall surface but remained only on a short strip of the west wall near the $\mathrm{SW}$. corner. The construction is: on the stone foundations a longitudinal beam, on this two courses of mud-brick interrupted by transverse beams at $\mathrm{I} \cdot \mathrm{I} O \mathrm{~m}$. intervals, then a second longitudinal beam and the two brick courses as before; this is the extreme of half-timber work.

In the brickwork fallen from above was the lower jaw of an elephant. On the floor were tablets, ATT/38/43,44, 45, 46, 5I-57, 59-62, 64; a bronze lance-head, AT/38/8 I, Type Sp. I; a miniature stone celt, AT/38/80; the pottery fragments included those of White Slip ware milkbowls, Base-ring jugs and Base-ring bull vase (cf. Pl. CXXXI), tall red-burnished lekythus, and plain types 3 and 4 .

Room 24. Clay floor with no sign of cement, but the room had been so heavily burnt that the negative evidence was not conclusive. ${ }^{\mathrm{I}}$ The walls had been fully timbered and were very ruinous; the plaster had been of clay with a lime wash over it. The column between the piers had a wooden shaft resting on a plain basalt drum. In the room were one tablet, ATT/38/66; a small fragment of gold-leaf; part of a basalt Base-ring bowl with lug; fragments of Base-ring jugs; of at least four Base-ring bull vases; of a tall red-burnished lekythus; of a beaker (Type 94) with bands of black paint; of plain types 3 ( 3 examples) and 26.

Room 25. Floor of very fine clay which may have had a lime wash over it but was not cementfinished. The walls had a stone foundation-course almost flush with the floor, on which basalt orthostats $0.65 \mathrm{~m}$. high which appear to have been rather roughly cut (but the surface was so flaked by fire that this was not certain) and had certainly not been polished; they were covered with white cement. A longitudinal beam rested on the stones with brickwork above and a second beam at $\mathrm{I} \cdot 3 \mathrm{O}-\mathrm{I} \cdot 40 \mathrm{~m}$. above the floor, with no transverse timbers; the wall-face had been mud-plastered and lime-washed. One tablet was found in the room, ATT/38/67.

Room 26 . Concrete floor made of cement and small crushed stone; the walls had basalt orthostats $0.60 \mathrm{~m}$. high covered with white cement; no walling remained above the stones, all having been cut away by the Level III builders. The latrine in the NW. corner has foot-stands of burnt brick originally lime-plastered; the channel between them slopes down into the wall thickness,

I Thus in room 4 field notes dealing with the south half describe it as having a clay floor; only when the north half was excavated was the cement covering found, and there only where it had been vitrified. 
where is a vertical shaft contrived in the stone of the foundations, both channel and shaft being thickly plastered with cement. On the floor were tablets, ATT/38/68-7 I.

Room 27. The centre of the room was occupied by the brick newel (Pl. XXVIb) of the staircase; between the newel and the west wall was a passage leading to rooms $29-3 \mathrm{I}$; between the newel and the south wall, under the third flight of steps, was a cupboard. The floor of the passage and of the approach to the stairs was of cement, as was that of the cupboard. The west wall, which stood up to 2 . IO m., had a mud plaster over which a thin coat of cement originally painted red. The cupboard had mud-plastered walls and a wooden door-in the plaster on the inner face of the brick jambs the impression of the wooden frame-uprights was preserved. In the cupboard were found a small vase of grey and white marble, AT/38/ i 46, Pl. LXXX, two clay rattles, AT/38/ i 48, and a terra-cotta wheel, diam. $0.075 \mathrm{~m} ., \mathrm{AT} / 38 / \mathrm{I} 47$.

In the north wall, on the line of the east face of the newel, there was at floor-level a recess in the brickwork for a horizontal timber $0.60 \mathrm{~m}$. long and $0.15 \mathrm{~m}$. thick; between this and the newel there was a packing of flat stones and clay against the straight west edge of which the cement flooring stopped; the stones run back for $1.50 \mathrm{~m}$. At $0.60 \mathrm{~m}$. from their west edge, i.e. from the inner end of the horizontal beam, there is smoke-blackening on the wall-face which gives an upward slope of $0.40 \mathrm{~m}$. in $1.50 \mathrm{~m}$., after which there is no plaster left on the wall. Beyond the stones there is light packing back to the east wall; at $0.75 \mathrm{~m}$. from the NE. corner there was in the north wall a vertical lodgement for a wooden upright going down to foundation-level and containing wood ash. On the east side of the newel there was solid packing contained by rough stone walling (which at the south end formed the wall of the cupboard). In the construction of the newel a good deal of timber was used. On the stones and on the lighter filling behind them, north of the newel, there was a great deal of wood ash mixed with numerous fragments of pottery.

The stairs started on the north side of the newel, and the stones there are the foundation of the lowest treads, probably encased in wood for the securing of which the timber in the north wall was required. The wooden stairs ran on up to a corner landing; the return second flight was solid, and the third, in timber, formed the roof of the cupboard. The upright beam near the NE. corner must have been for the support of the top of the first flight (Fig. 49).

The pottery found in the ashes of the first flight included fragments of a Nuzu goblet, ATP/ $38 / 82$, and another (Type I I 8), plain; of a beaker, Type 93, with bands of red paint; Types 3 (4 examples) and 4 .

Room 28 (Pl. XXVIIa). The floor, of white cement, had been twice relaid, each time directly over the old, with no real change of level. The walls, being fully timbered, had suffered much from the fire and were very ruinous, particularly near the doorways, the jambs of which had fallen so that they could be recognized only by the thresholds. There were no orthostats. The doorway to room 2 I had a raised threshold with wooden sills and clay filling; that from room 24 had a flush threshold and the frame was set back in the wall passage instead of being in the inner reveals; that from room 27 had a raised threshold of stones and clay with wooden sills. The column-base, a plain basalt drum, instead of resting on the floor was set in a circular stone-lined hole diam. $0.85 \mathrm{~m}$; t the drum being $0.42 \mathrm{~m}$. diam., there was a space all round it which was filled with wood ash. The cement floor was carried over the stones lining the hole but not farther, sloping down there to a smooth edge. It looks as if the drum (re-used?) supported the weight of the column but the foot of the shaft was enriched by a wooden base, decorative, not practical, applied to it and sheathing the drum.

The room had originally been lime-plastered, but with the destruction of the wall-face the plaster had disappeared except for one patch on the north face of the east pier. Above floor-level was a tablet, $\mathrm{ATT} / 38 / 65$.

Room 29. The floor, which had a thick layer of cement over clay, lay $0.10 \mathrm{~m}$. below that of room 27 . In the doorway to that room there was no brickwork jamb on the west side, but vertical 
TAL ATCHANA 1938 THE PALACE COMPARATIVE DIAGRAMS OF THE MAIN STAIRCASES.

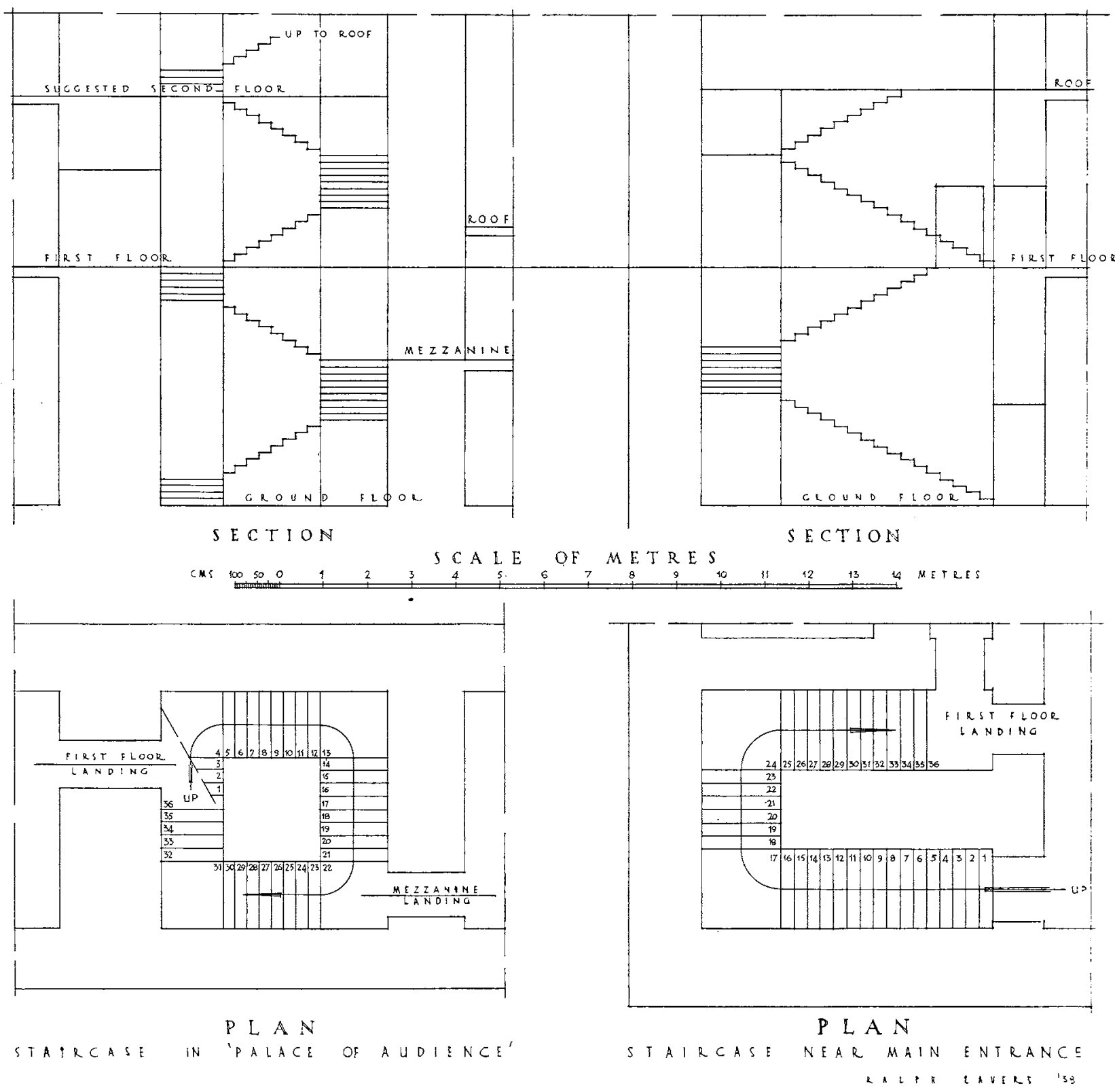

FIG. 49 
slots in that wall and in the end of the north wall showed where there had been a wooden doorframe the lower member of which acted as the sill for the stepped threshold; a layer of ashes ${ }^{\mathrm{I}}$ implied that it had been wood-sheathed. The north and east walls had no timbering other than the one longitudinal beam at the base of the brickwork; the two other walls had an upper longitudinal course (and perhaps more than one), but no transverse beams showed. All the walls were cement-plastered, and on the plaster were faint traces of a light red or pink colour-wash.

Close to the door to room 27 was found the limestone ram's head, $\mathrm{AT} / 38 / \mathrm{I} 49, \mathrm{Pl}$. XLV, on which see p. 239. The only other objects in the room were fragments of plain pottery, four examples of Type 3, one of Type I 39, and pieces of a very large jug.

Room 30 . The door from room 29 had a raised threshold with wooden sills and stones with clay packing between. The floor was of clay with no trace of cement; the walls, mud-plastered, showed only one longitudinal beam resting on the stone foundations, which rose to $0.50 \mathrm{~m}$. above floorlevel; only in the north wall was there a second beam (at $\mathrm{I} \cdot 3 \circ \mathrm{m}$.). Along the north and west walls ran a brick bench, mud-plastered, apparently $\mathrm{I} \cdot 30 \mathrm{~m}$. high throughout, but most of the top of it destroyed.

Objects: Two limestone pieces of inlay for knife-handles, $A T / 38 / 198$; three fragments of polychrome glass vessels, $\mathrm{AT} / 38 / \mathrm{I} 8 \mathrm{I} \mathrm{B}$; a quantity of pottery including fragments of Nuzu ware with dotted design (ATP/38/1 30), and of the tall red-burnished lekythus, and plain examples of Types 4, 7, 2 I $a, 4$ I, 93b, I08, I 29, I 63; also fragments of a limestone dish, AT/38/203.

Room $3 I$. The doorway had a wooden sill $0.10 \mathrm{~m}$. above the floor of room 30 , and the rest of the floor, which was of concrete (lime and small stone chips), was flush with it. The walls up to $0.35 \mathrm{~m}$. were of rough stone cement-plastered; above that was a longitudinal beam and then mudbrick mud-plastered and lime-washed, with no further timbering. The lavatory foot-stands were of burnt brick cement-plastered.

Objects: Part of ivory toilet-box lid with engraved rosette pattern, AT/38/1 78 ; fragments of a vase of variegated glass, combed pattern in yellow on blue, AT/38/ I 76 ; pottery fragments, including those of a Nuzu goblet with dotted design, ATP/38/143, of a painted example of Type $94 b(\mathrm{ATP} / 38 / \mathrm{I} 42)$, of plain examples of Types $3,4 \mathrm{I}, 48,60,69$, and of many large jugs or handled jars too fragmentary to be typed.

Room 32. The door in the north wall is unusually wide. The floor is of clay with no trace of cement, but along the south wall is a ledge, only just above floor-level, $0.20 \mathrm{~m}$. wide, built of bricks and lime-plastered, then a shallow channel, also of lime, $0.20 \mathrm{~m}$. wide and $0.05-0.10 \mathrm{~m}$. deep, and then the clay floor. The walls, which seem to have been cement-plastered (but there was very little left to judge by), gave the best illustration of half-timber construction ( $v$. Pl. XXVII $b$ ). A longitudinal beam rested on the stone foundations; on that was brickwork alternating with transverse beams, the holes left by which are $0.30 \mathrm{~m}$. high and $0.18 \mathrm{~m}$. wide and run back into the wall for about $0.60 \mathrm{~m}$. Immediately above these came the second longitudinal beam, the impression of the rounded back of which can be clearly seen in the mud-mortar behind it; then more transverse beams directly above those in the lower course, another longitudinal beam $0.30 \mathrm{~m}$. wide, and a third row of transverse beams; the description holds good of all the walls except the north wall which had no timbering.

Near the SE. corner was a basalt tripod bowl, diam. $0.3^{8} \mathrm{~m}$. On the floor one small tablet, ATT/38/75, fused by the fire; jar-stoppers with seal-impressions, AT/38/196; fragments of a large handled jar, type uncertain.

Room 33 (Pl. XXVIII $a$ ). The clay floor was higher than that of room 32 , there being a step at the threshold with wooden sill. Round the room ran a bench or shelf, brick-built and cementplastered with rounded edge, $0.32 \mathrm{~m}$. high, above which there was a $0.10 \mathrm{~m}$. high cement skirting

I Charred wood from room 29 and other rooms of the palace came from a coniferous tree and almost certainly from

Pinus Halepensis, which is native to the region. I am indebted for this identification to F. R. S. Balfour, Esq. 
on the wall, the upper part of the wall-face being mud-plastered and lime-washed. In the east wall there was a $0.18 \mathrm{~m}$. wide slot running up to the full height of the wall $(1 \cdot 35 \mathrm{~m}$.) for a timber upright, possibly a support for wooden shelves; the other walls showed no trace of woodwork, but were not standing high enough for this to be any conclusive argument. The skew wall in the SE. corner is obviously dictated by the older building. The floor was covered with wood ash up to the level of the top of the brick shelf. In and under these ashes were found very many tablets, ATT/ $38 / 73,76-92,244-61,263-5,267-7 \mathrm{I}$; none were on the shelf which was clearly meant for them. I There were also on the floor a bronze arrow-head, AT/38/237, Type Ar. 6; fragments of a tall red-burnished lekythus and of a painted Nuzu goblet, ATP/38/ I 29, Type I I 8 .

Room 34 . This room, together with rooms 35 and 36 , lay directly beneath the later fort and city walls and was almost entirely destroyed by them, nearly all the north wall having disappeared.

The outer wall of the Niqme-pa building was standing up to $0.40 \mathrm{~m}$., its face plastered; the new wall of Ilim-ilimma was built up against it. The floor of white cement, well preserved over most of the room's area (a strip about $\mathrm{I} \cdot 30 \mathrm{~m}$. wide along the east wall had been cut away), was well made and sloped down to a circular terra-cotta drain. A line of bricks at $0.50 \mathrm{~m}$. from the east wall, at about floor-level, suggests a bench along the foot of that wall; it stops, on the north, where a patch of cement breaking the wall line shows the position of the (destroyed) doorway to room 23 . On the south side of the room the new wall was not carried through to the SE. corner but stopped, leaving a recess. In this was found a basalt column-base, diam. $0.35 \mathrm{~m}$., which was not in situ but lay on fallen brick rubble, tilted at an angle, and must have come from an upper room.

Room 35. Except for the SE. corner the room had virtually disappeared. It had been a storeroom and in the angle between the foundations of the Level III walls the great terra-cotta storejars were found in position ( $v . \mathrm{Pl}$. XXVIIIb).

Room 36. The long E. $\times W$. passage had, for the most part, to be restored on the basis of its wellpreserved cement floor; of the north wall a stretch $2.00 \mathrm{~m}$. long was standing up to $0.40 \mathrm{~m}$. at the east end and disappeared thereafter; part of the south wall stood up to $0.75 \mathrm{~m}$., but of the east wall nothing was left. It is noticeable that here, as in Room 34, the new wall stops short, exposing the Niqme-pa wall at one point. In the western turn of the passage the cement floor was taken up in a cavetto moulding to the wall-face; this part of the building was fitted into and probably took externally the form of a room in the Level $\mathrm{V}$ gate building.

A fair number of tablets, mostly very small or fragmentary, were found in the room, ATT/38/ $240-3,262$.

The rooms on the $\mathrm{NE}$. and $\mathrm{SE}$. sides of the palace courtyard were at the time of excavation given a different series of numbers, partly because that simplified our records, partly because we were not at first quite sure of the relation between them and the palace proper. I have retained those numbers advisedly because they usefully distinguish the buildings which by their foundation belong to Level $V$ from those actually constructed under the orders of Niqme-pa; but in their use they are contemporary with his palace and, since the transition was peacefully made and involved no reconstruction, not even reflooring, and since they were burnt together with the rest of the palace, all their contents must be dated to Level IV.

Room C. I (Pl. XXIIIb). Floor of cement over clay. The east wall was of stone rubble up to a height of $\mathrm{I} \cdot \mathrm{O} \mathrm{m}$., the other walls stone foundations with a longitudinal beam at floor-level and mud-brick above with no more woodwork; there was a chamfered skirting of cement along the base of the wall and above that mud-plaster lime-washed; the plaster had been renewed several

I Precisely similar bench-shelves are found in archive-rooms in Mesopotamia. 
times. Door-frames were of wood, thresholds made with two half-logs for the sills with a filling between them of rough stones and clay, raised a little above floor-level. On the floor stood a square hearth of mud-brick plastered with mud, $0.10 \mathrm{~m}$. high, all edges rounded; there were marks of heavy burning on it and on the floor round it. There was a great deal of pottery in the room, including many complete or nearly complete vessels, most of them being near the walls and especially along the east wall.

Objects: Two cylinder seals, AT/38/1 90, I 9 I, Pl. LXIII, 60, 6I ; four basalt tripod bowls, diams. $0.315 \mathrm{~m} ., 0.25 \mathrm{~m}$., $0.25 \mathrm{~m}$., and $0.17 \mathrm{~m}$., together with a number of basalt pounders; three complete tablets, ATT/38/47-49; several mud jar-sealings; pottery, a White Slip ware milk-bowl; two Base-ring ware jugs; two beakers (Type 94), one with red and one with black horizontal bands; four ring-stands of Type 85 and one of Type 84 ; and plain vases of Types $3,4,7,55,60,68,73,89,9 \mathrm{I}, 99$, 102, 104, 107, I63.

Room C. 2. Clay floor; no sign of any timber in the walls, which were mud-plastered and limewashed, the plaster several times renewed; the plaster was taken down to the floor in a rolled skirting. The front of the threshold of the door to room C. 3 was curved and the rise was mudplastered with secondary curves at the sides rounding off the uprights of the door-frame.

In the room a bull-vase of Base-ring ware, ATP/38/1 4, cf. Pl. CXXXI; two jugs, incomplete; a lamp, Type $72 b$; red-burnished jug of Type 60; Type 94 , brown ware lightly burnished, and Type 3 .

Room C. 3. The junction between the old and the new work in this room is complicated (Fig. 50 ). The Level $\mathrm{V}$ room had had a doorway in its south corner leading into the courtyard; the doorway,

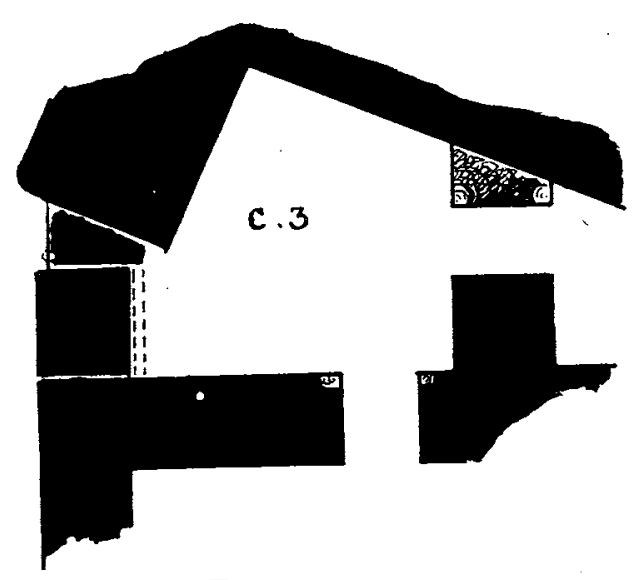

FIG. 50. I : I.00 which was I.IO m. wide, had no brick jamb on its SE. side but, presumably, a wooden door-frame slotted into the brickwork. ${ }^{I}$ At a later period, probably at the time of the building of Niqme-pa's palace, the doorway was bricked up. For that building the greater part of the $\mathrm{SW}$. wall of the room had to be cut away to make room for the pier flanking the steps; there was left only an irregularly shaped triangle of brickwork which was really the NW. jamb of the blocked doorway. The stair pier was built against the cut end, its rounded corner projecting very little beyond the line of the old wall; as if to emphasize it, the face of the jamb-fragment was cut back so as to form a recess; the cement plaster on the face of the pier was carried round the corner only as far as the line of the old wall and the recess was apparently mud-plastered. On the other side of room C. 3 the whole of the NE. wall was removed down to the doorway.

Inside the room the floor $(0.35 \mathrm{~m}$. above that of room C. 2$)$ is of cement. Because the new palace wall has stone foundations rising to $0.65 \mathrm{~m}$. and masked by cement, a cement dado of the same height was applied to the other walls; above this is mud-plaster with a lime wash. The tiny closet on the east has a cement floor $0.35 \mathrm{~m}$. above that of the room; the narrowness of its door is due to the fact that the NW. jamb of the original door had been taken down by the new palace builders; now a wooden door-frame (of split logs) was set up against the SE. jamb and the space between it and the face of Niqme-pa's wall was filled with broken bricks and clay, disguised by a

I 'The NW. jamb had the door-passage face rendered with fine cement plaster; by the outer corner the plaster bore the imprint of the wooden upright of the door-frame, and at I.05 m. up there was behind the plaster a hole for a short transverse baulk intended to secure the frame in position. We did not remove the blocking to examine the SE. jamb, but there can be no doubt regarding the doorway. 
cement coating, in the form of a door-jamb. Against the blocking of the doorway giving on the courtyard there is under the floor cement a runnel apparently representing the wooden sill of the original threshold; in it was found the remarkable inscribed steatite disk AT/38/1 36, Pl. LXVIIb.

Room D. I. Clay floor. The walls, built without any timber, showed marks of heavy burning underneath the mud-plaster of the palace period, which also had been burnt. Towards the NW. end of the room were remains of a rectangular clay base on which had been three circular clay ovens, a shallow open clay hearth, and a fire-place made of two large fragments of terra-cotta (parts

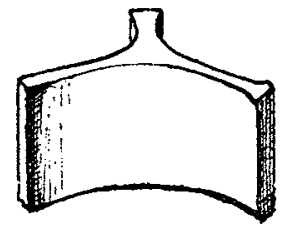

A

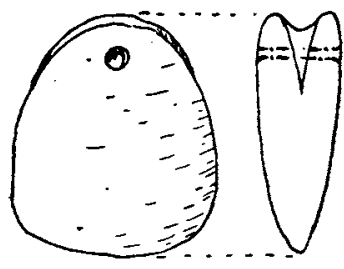

B

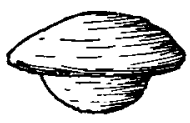

C

FIG. 5I

of a big bowl ?) set parallel to each other, the space between them filled with wood ash. Close to this was a clay cooking-tripod, ht. $0.30 \mathrm{~m}$. (Fig. $5 \mathrm{I} \mathrm{A}$ ).

In the room were three basalt tripod bowls, two basalt rubbers or pounders, and a quantity of pottery; the latter included fragments of several cooking-pots (brown clay heavily tempered with white grit), several White Slip ware milk-bowls, and very many large store-jars; also examples of Types $69 c$ (painted with black bands), 3, 4, 60, 69, 85, 94a, I03, I 30 .

Room D. 2. Only one corner of this room, lying SE. of room D. I, was excavated. In that corner were found a basalt tripod bowl, diam. O. I $5 \mathrm{~m}$., and clay vessels of Types 3, 82, 93, I04b.

Room C. 4. This was the entrance-room to the wing described above; it had one doorway giving on the courtyard and one leading to room C. I, and at the NE. end was a staircase going to the upper story or to a flat roof. The floor was of clay; the walls were untimbered and plastered with mud only.

In the room were found a cylinder seal, AT/38/1 84 , Pl. LXIII, 54 ; a tablet, ATT/38/33; a basalt bowl, diam. $0.20 \mathrm{~m}$., four rubbing-stones, of which one had fluted sides, and abundant pottery including several White Slip ware milk-bowls of normal type (ATP/38/I $4 \mathrm{I})$ and two with tubular spouts (ATP/38/9 I), Base-ring ware jugs, a small Base-ring ware oenochoe, $\mathrm{ATP} / 38 / \mathrm{I} 2$, Pl. CXXXII, fragments of a Nuzu ware vase with design as Pl. CVII $g$ (this above floor-level, in the fallen rubbish), a beaker, Type 94, with alternate bands of red and black paint, ATP $/ 3^{8} / 2 \mathrm{I}$; and plain examples of Types $3,4,6,7,26 a, 60,63,64,68,82,84,85,87,93,94$, I 08, I I O, I 2 I, I 53 , I 63 .

Room C. 5. Clay floor, on which a brick-built mud-plastered square hearth showing signs of burning. In the east corner were remains of a very big store-jar, in the south corner a circular terra-cotta oven and near it a terra-cotta cooking-tripod like that in room D. I, cf. Fig. 5 I A. In the room were three basalt tripod bowls, diams. $0.32 \mathrm{~m} ., 0.27 \mathrm{~m}$., and $0.20 \mathrm{~m}$., a flat basalt Basering bowl, diam. $0.47 \mathrm{~m}$., a copper ring, and a mass of pottery including White Slip ware milkbowls, Base-ring ware jugs, a jug, Type 60a, painted with black bands, a small oenochoe of burnished grey ware, ATP $/ 38 /$ I $55, \mathrm{Pl}$. CXXXII, and plain pottery Types 3, 4, 23, 54, 55, 60, 8 I, 85 , $9 \mathrm{I}$, $93,94,99$, I 2 , I 5 , I 08, I 3 I, I 53, I 63 , and a clay jar-cover, flattened hemispherical with loop handle, diam. 0.2 I m., Type I 68 .

Room C. 6. A cupboard rather than a room; cement floor, raised above that of C. 5, on which in the south corner a square base $0.05 \mathrm{~m}$. high built of fragments of burnt tiles and clay and coated with cement. In the north corner, in situ, a big store-jar (crushed) circa $0.60 \mathrm{~m}$. high, Type I 53. In it were a cylinder seal, AT/38/1 89, Pl. LXIV, 72; fragments of an alabaster vase, AT/38/289; 
fragments of many large jars of uncertain type, and other plain pottery, including Types 26,49 , 93, 94, I08, I 52, I 63, and a White Slip ware milk-bowl, ATP/38/ I 72 .

Room C. 7. Clay floor; on it a bronze implement (broken) with handle in the form of a duck's head, AT/38/200; fragments of a White Slip ware milk-bowl; a clay bowl with bands of rope pattern in relief, $\mathrm{ATP} / 38 / \mathrm{I} 68$; plain pottery Types $4,23,26,85,108,163$.

Room C.8. A curiously irregular room of which, in the condition of the mud-brick walls, it was difficult to make any sense. The NW. wall running at an oblique angle is original; presumably the sudden and marked change of angle was due to the need to conform with something farther west of which we have no knowledge-but the orientation has no parallel in the neighbouring Level V buildings excavated by us. The unusually narrow doorway in that wall (it is only $0.60 \mathrm{~m}$. wide) is also original, and it certainly was a doorway; the impression of the wooden frame in the mud mortar was unmistakable. Later it was carefully bricked up, but only on the outside, so that the door-passage remained as a deep niche in which wooden shelves had been set. The brick blocking extended beyond the doorway on either side and seemed to have taken the form of a wall which on the outside corrected the line of the old building and carried on the SE. wall of the palace courtyard to the south corner; the triangular space between the two walls was a solid mass of brick filling. Whether the SE. and SW. walls were of the same date as the skew wall or were later I could not determine. The room had a clay floor and its walls were mud-plastered. In it were found part of a tablet, ATT/47/27, three jeweller's moulds in steatite, AT/47/ I 39, I 46, I 47, Fig. 73; a shallow basalt bowl, diam. $0 \cdot$ I 5 m., AT/47/I 79; two basalt tripod bowls, AT/47/I 8 I, I 82 ; a basalt pestle, diam. $0.07 \mathrm{~m}$., length $0.095 \mathrm{~m}$.; eight pounders or rubbing-stones, AT/47/I 40, I 42, I 48; a basalt drill-handle, AT/47/ I 50; a terra-cotta loom-weight, AT/47/I 4 I (Fig. 5 I B); a terra-cotta jar-stopper (Fig. 5 I c); a beaker, Type 94, with red paint bands on the drab clay, A TP/47/I 40; and plain pottery of Types $3,4,6,7,17,48,55,60,6 \mathrm{I}, 80,85,87,93, \mathrm{I0} 4, \mathrm{I} 60, \mathrm{I} 63, \mathrm{I} 67$.

That the palace was destroyed by fire is of course obvious. We can safely go farther and state that it was looted before being burned; the vast amount of domestic pottery, \&c., found in the ruins contrasted with the few odd items of material value means that the bulk of the latter had been carried off; the remains of inlaid furniture in rooms 7 and I 8 show that only the more portable things had been removed and the larger and heavier left behind; the condition of the archives bespeaks haste; since no other buildings of Level IV were destroyed at the same time, ${ }^{\mathrm{I}}$ the destruction of the palace was not the work of an enemy from outside, and since the palace was not rebuilt it was not the result of accident; the only conclusion at which we could arrive was that there had been a civil rising against the king of the city. The evidence of the tablets make it clear that the event took place in the reign of Ilim-ilimma; it cannot therefore have been much later than I 4 I 5 B.C. and may have been ten years earlier; between the destruction of the royal palace and the end of the Level IV period in circa I 370 B.c. there was therefore a time gap of over forty years. Naturally this very important central area of the city would not have been left untouched during that long period, a wilderness of mounds and hollows encumbered with fragments of upstanding fire-reddened walls, but on the other hand the evidence that the site was not built over before the time of Level III was convincing. The stratification, which was extremely difficult to follow owing to the area being so cut up by the deep-laid foundations of the Level III walls, showed the palace rooms in general filled with wood ash and crumbled or broken reddened bricks up to the height

\footnotetext{
I The castle was burnt at a much later time, as is evident from the stratification.
} 
of the standing walls, but the surface was not uniformly flat; there was a distinct hollow . where the palace courtyard had been, and on the east there was a definite upward slope to the high mound over the Yarim-Lim palace. The hollows had been levelled with mixed material, e.g. over the old courtyard of Niqme-pa there was a layer of midden stuff, bones, \&c., together with a certain proportion of fire-reddened brick rubble; over the Ilim-ilimma inner court also there was a layer of rubbish above the palace ruins, then a layer of burnt brick rubble $0.25 \mathrm{~m}$. thick, and then rubbish again. In Sq. $Q$ i 2 , against the outer wall of the palace (Level $V$ construction) a cement floor contemporary with the later days of the building was covered with a layer $0.45 \mathrm{~m}$. thick of mud-brick and clay making an extraordinarily hard mixture above which was burnt brick debris. Towards the south corner of Niqme-pa's courtyard the SW. wall had been trimmed down to a definite level, and over it and over the adjacent ruins of the castle gateway there was, over the fallen brickwork which was flush with the tops of the walls, a layer of very hard burnt brick rubble, over which again were three courses of re-used bricks, accidentally burnt, forming a flat surface. Three courses of bricks-generally plain unburnt mudbricks-overlay all the strata hitherto described over the whole of the palace area. The three courses of laid brick are quite certainly connected with the Level III fortress; they were the pavement of the wide open space which separated that fortress from the other buildings of the town. I had long supposed that the reddened brick debris immediately below them $(a)$ was part of the same Level III levelling process and $(b)$ came from the Level IV palace and was obtained by pulling down so much of its burnt walls as were still standing above ground. But since in some parts both that red debris and the mixed rubbish forming a lower stratum run over the tops of the palace walls, my second conclusion cannot hold good in every case; some of the red debris must have come from other buildings burnt at a later date; and as the Level IV castle was burnt at the very end of the Level IV period it is most likely that the Level III levellers took their material from there. But it is also fairly evident that the main work of levelling had been done some time previously, and for it both rubbish brought from elsewhere and burnt brick debris from the palace had been used. This levelling of the palace area is stratigraphically one with the raising of the level of the castle parade-ground and of the road across it which we could confidently assign to the later, post-palace, part of the Level IV period and could with good reason connect with the remodelling of the interior of the castle itself; ${ }^{1}$ whereas Niqme-pa's building had encroached on the old parade-ground it was now suppressed altogether and its site included in the wide open space in front of the castle façade. By the time of the Hittite capture of the town in I 370 B.c. there would inevitably have been a good deal of subsidence so far as the filling of rooms and courts was concerned; the surface would have become far from regular, and a fresh process of levelling was undertaken by the builders of the new fortress; they were responsible for the upper layer of red-brick debris laid down in the hollows as a bedding, and for the three courses of laid brick over the whole area; but they were merely repairing an artificially levelled barrack square which had been in use for half a century.

$$
\text { I v. p. I63. }
$$




\section{CHAPTER IV}

\section{THE TOWN DEFENCES}

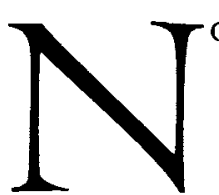

true idea of the defences of the city of Alalakh can be obtained unless we take into consideration the changed conditions of the surrounding plain. At present the mound representing the ancient city rises, at its highest, a little more than eight metres above that plain. At the north end and along the north-east its steep sides still present a formidable obstacle to attack (Fig. 52 , and Pl. XXII), but at the south end and along part of the south-west it slopes down so gently that its limits are not easy to determine and it would appear to have been to all intents and purposes undefended. It is therefore essential to remember that the level of the plain has risen, in relatively recent times, by ${ }^{\mathrm{I}}$ more than five metres, so that the height of the town mound was more than half as much again as it is now, and further that the mound itself has been seriously denuded by weather along its SW. side where, as excavation proved, all the upper levels have disappeared and the topmost surviving remains are those of Levels IV and V. A yet more important consequence of the sudden rise of level is that it has obliterated everything except the actual mound. The mound is of a considerable size, its oval measuring about 750 metres in length by 300 in width, but since quite a large proportion of its area was taken up by walls, palaces, and temples, and since Alalakh was the capital of a kingdom of some importance, that area seems none too big, and it is not improbable that there was on the low ground an outer town with its own system of defence. If such did exist it is now too deeply buried for any trace of it to be visible. ${ }^{2}$ There are many sites, e.g. Carchemish, where the massive walls of an outer town have disappeared altogether owing to denudation; in the peculiar conditions of Alalakh where denudation went on for I,500 years and was followed by inundation and burial, the lack of evidence is not surprising or conclusive.

Another result of the flooding and raising of the plain is that the course of the Orontes here must certainly have changed, but there is no means of identifying its ancient bed. We can, I think, safely assume that Alalakh was founded on the river bank, but we cannot prove it. The present tortuous course of the Orontes, cut through the silt, is at its nearest point nearly 500 metres from the mound.

\footnotetext{
I Of course there must have been a gradual accretion at the foot of the mound during the city's occupation. But the main rise was due to the earthquakes of the sixth century A.D. which dammed the channel of the Orontes where it passes through the Amanus; as a result, all the silt brought down by the Orontes and by the Afrin $\mathrm{Su}$ was depogited by the stagnant waters in the Amq plain and in the Antioch valley. See above, p. 5 .

2 We made no attempt to discover it; the mound gave us more than enough to do, and the plain lay outside our concession. A few (but very few) surface finds lent some support
}

to the theory of a lower town. Occasionally, in certain climatic conditions, I fancied that I could see differences of colour in soil and crops which seemed to show the line of a rampart running more or less parallel to the NE. slope of the mound and at a distance of about $300.00 \mathrm{~m}$. from it; here there was a certain amount of pottery on the surface and peasants reported that they had found building remains. In other directions nothing of the sort could be distinguished and the only surface find recorded, a small tablet, could easily have come from the mound. 
Whether or not there was an outer fortification such as I suggest, the city proper, represented by the mound or tell of Atchana, was elaborately defended. It was not enough that a huge rampart should enclose the whole of the lofty platform whereon were built the temples of the gods and the houses of the citizens; on the higher ground at the platform's NW. end there rose, in every period of which we have knowledge, a castle or military fortress, the keep as distinguished from the inner bailey, which was planned as the city's last line of defence. The city wall consisted of a steep-faced rampart of earth revetted with clay along the top of which ran a thick and presumably high wall-at one period a triple wall-of mud brick; the rampart was the side of the city mound, rising from the level of the plain to that on which the houses stood, and the wall went up above the house-tops. The fortress walls, on the other hand, rose directly from the top of a rampart of solid brickwork which might be anything from sixteen to twenty-two metres wide, whose surface sloped gently down from the foot of the fortress wall-this would be useful for draining the mud brick in the rainy season and certainly afforded an ideal field of fire for the defenders should an enemy succeed in scaling the rampart-and ended in a glacis whose smooth clay-plastered face, built at an angle of fifty-one degrees, was as unclimbable as a vertical wall and far more easy to hold; probably there was a breastwork along the lip of the glacis, but naturally no trace of such survives. ${ }^{I}$

The amount of work that we could devote to the study of the defences was small. In I 937 we cut a section through the town wall and rampart; in most of the following seasons stretches of the inner face of the wall were cleared; in I 938 the Level VII (Yarim-Lim) gateway in the NE. wall was excavated and, in Site H, a short stretch of the SW. wall was identified; the SE. part of the Level III fort was cleared in 1938 and additions to its plan were made in later years; finally, in I 949, a trench cut in the extreme NW. corner of the site and subsequently enlarged gave us such information as we possess about the castle, that information dealing with all the levels from I to VII.

Our scheme of stratification at Atchana is based on the succession of houses in the residential area, and it was hardly to be expected that changes in the military defences of the city would exactly synchronize with the vicissitudes of private buildings. Actually we found that there were more rebuildings of the fortress than there were building-levels in the domestic quarter, but in spite of this the changes fitted in with the scheme quite unexceptionally. The third stratum in the fortress site gave us a building which was simply the continuation of the already familiar great fort of Level III; here, as elsewhere, it had been remodelled in Level II, and the foundations of Level I superimposed on it were precisely the same as had been found in other parts. The scanty remains of the fourth stratum were constructionally connected with excavated buildings to the south-east which were rebuilt in the Level IV period on Level V foundations. Below these came two strata similarly aligned to the Level IV building, both dated by their pottery to Level V; the lower must have belonged to an early phase of that period, the upper, later in date, continued in use into the Level IV period when it was replaced by a new building at the same time as the rooms to the south-east were remodelled. Below came two strata with buildings different in plan and alignment from those above, but one clearly a reconstruction of the other, re-using its main walls; both were dated by their distinctive pottery to Level VI. The ninth stratum gave us the reddened

I The character of these defences recalls the detailed and measured description given in a Sumerian text of the wall of the north Syrian town Sikumal (? num); 2 . Gadd and Legrain, Ur Texts, vol. i, Royal Inscriptions, No. 275. 
ruins of a building completely destroyed by fire above which alternate layers of crumbled brick and wind-blown ash bespoke the desertion of the site; it was impossible not to connect this with the palace of Yarim-Lim, his temple, and his city gate, in all of which the signs of destruction are identical.

The sequence-dating of the nine building strata on the fortress site is therefore satisfactorily fixed and all of them can be described in terms of our scheme of Levels. The town rampart presents greater difficulties; the series of buildings is not nearly so complete, and while the walls crowning the rampart can be assigned to their proper levels the rampart itself-known to us only from a single section-can be dated only by the pottery found in it. When we cut the section, in 1937, little had been found out about the pottery of Alalakh and my dating of it was rather intuitive. I correctly judged the outer rampart to be a little earlier than Level IV, but unduly minimized the time-gap between the pottery in it and that in the original (sic) rampart; and I described the outer rampart as being inherited by the Level IV wall-builders and as continuing in use as late as Level II, thus making no allowances for the possibility of a later rampart's having disappeared. It is, however, obvious that an earthwork of this sort is peculiarly liable to denudation. To this extent I must modify not of course the observations but the conclusions drawn from them in my provisional report in $A . \mathcal{F}$. xviii (1938).

THE TOWN WALL

In I 937 and I 939 we excavated part of the domestic quarter of Level II lying just inside the town wall. The houses (Figs. 65,66) were not built against the wall-face but were set back so as to leave an open space between them and the fortifications; as their alignment was very different the houses were built with a series of salients intended to make full use of their respective ground-plots, but the nearest that they come to the wall is a metre and a half; evidently there were rules against further encroachment. The wall was definitely of Level II, for its foundations lay at exactly the same depth as did those of the houses; it was built of mud brick and at this point had no stone foundations, though in other places a single course of moderate-sized stones might be employed. The wall, which we followed for a distance of $45.00 \mathrm{~m}$., stood here eight courses high and measured $4.80 \mathrm{~m}$. in thickness. ${ }^{1}$ Along its outer face ran a path $1.40 \mathrm{~m}$. wide of cobbles set in stiff red clay. Beyond this there had been a second wall of which very little remained-two mud bricks were found in situ against and flush with the path, resting upon light ash; at $\mathrm{I} \cdot 50 \mathrm{~m}$. from the path these ashes gave place to solid red clay whereon were scanty traces of mud brick, and after another $1.50 \mathrm{~m}$. the clay came to an abrupt end and there were ashes thinly and vaguely stratified with clay and other more solid rubbish going down to a depth of $4.25 \mathrm{~m}$. but near its top interrupted by a second straight-sided belt of stiff clay at $\mathrm{I} \cdot 40 \mathrm{~m}$. from the first. ${ }^{2}$ From just above this clay mass a stratum of mud-brick debris runs downhill at an angle of about thirty-five degrees; above it is the made soil of the mound's surface, below it the horizontally stratified ashes and rubbish already described; but between the ashes and the brick rubble there could be distinguished a very

I The wall was re-used in Level I and then a brick revetment $\mathrm{I} \cdot 20 \mathrm{~m}$. wide was added against its inner face, at least in places; about half of the length of the stretch cleared by us was thus revetted and the other half not; probably the addition was made only where the decay of the face of the old work made it desirable. The fine dagger, AT/37/57, P1. LXX, Type Kn. 4, was found behind the revetment.

2 This was cut away diagonally by the denudation of the mound so that in the section it appears as a triangle. 
thin stratum of red clay which thickened as it went down the slope until, at the limits of our trench, it was half a metre thick. Below the stratified rubbish (at $4.25 \mathrm{~m}$. below the Level II passage) we encountered a hard level floor in which silos or grain-pits, neatly made and lined with white cement, had been cut to a considerable depth-we went down in one to $3.25 \mathrm{~m}$. and did not get to the bottom. Just beyond the outermost silo the hard floor in which it was cut began to run downhill almost as steeply as did the red clay stratum above it.

Complicated as the facts may sound, the section (Fig. 52 ) is in fact quite easy to follow. The surface stratum, which naturally thickens towards the base of the mound, is the black soil in part due to the decay of the vegetation on the slope, in part brought down by water action from the top of the mound; this is absolutely distinct from the mass of grey decomposed brick which underlies it. The red band is obvious, and stands out well from the mixed unstratified mass of black ash and broken pottery below it. The latter is no less clearly differentiated from the lower slope, demarcated by the floor and consisting of clay, rubbish, and a certain amount of ashes horizontally stratified, the strata occasionally dipping or forming pockets and always tending to drop as they approach the surface of the slope. As regards the contents of the various strata, that of grey brick rubble is virtually clean. The ash stratum contains a great deal of broken pottery, including many painted pieces; there is no Nuzu ware, and none of the horizontally banded local types characteristic of the later levels; there are a few examples of red burnished ware, and a few of the White Slip milk-bowls; most of the painted vessels are bowls of Types 23 or I 9 with the 'triglyph' decoration in black or brown, sometimes with bird or animal motives; of the unpainted wares the most informative are examples of Types $2 \mathrm{I} a$ and $23 a$ in white or light drab clay. In the stratified rubbish below the floor the pottery is again abundant; the red burnished ware, the white jars of Types $2 \mathrm{I}$ and 23 , and the painted bowls recur, and there are examples of painted jugs with bird and animal motives combined with the 'triglyph' scheme of decoration (PI. XCVII) and sometimes with trefoil mouths carrying the eye ornament (Type 70); there are no instances of White Slip ware; of the unpainted wares the larger bowls with carinated rims often have two or more pairs of elongated bosses applied vertically to the shoulder (Types 23 and 29); very numerous are fragments of large store-jars with flat grooved rims and bands of rope pattern in relief or three or four widely spaced incised lines round the body.

Clearly we have here remains of at least three constructions of very different dates. The wall is of Level II, the embankments can be dated by their pottery content. Since both ramparts are constructed of rubbish, ashes, pottery, and debris of all sorts collected from wherever it was most easily available, in each case the vast bulk of the material used, if not the whole of it, will have been older than the date of the rampart's building but need not at all necessarily have been of one period; the rampart therefore must be dated a little later than the latest date possible for the pottery it contains.

Most of the pottery found in the lower stratified rubbish is of the sort commonly occurring in Levels XII and X; but the types are too persistent to be of great dating value (ข. Pp. 340-2); on the other hand, both the bowls (Types 2 I and 23 ) and the white jars 


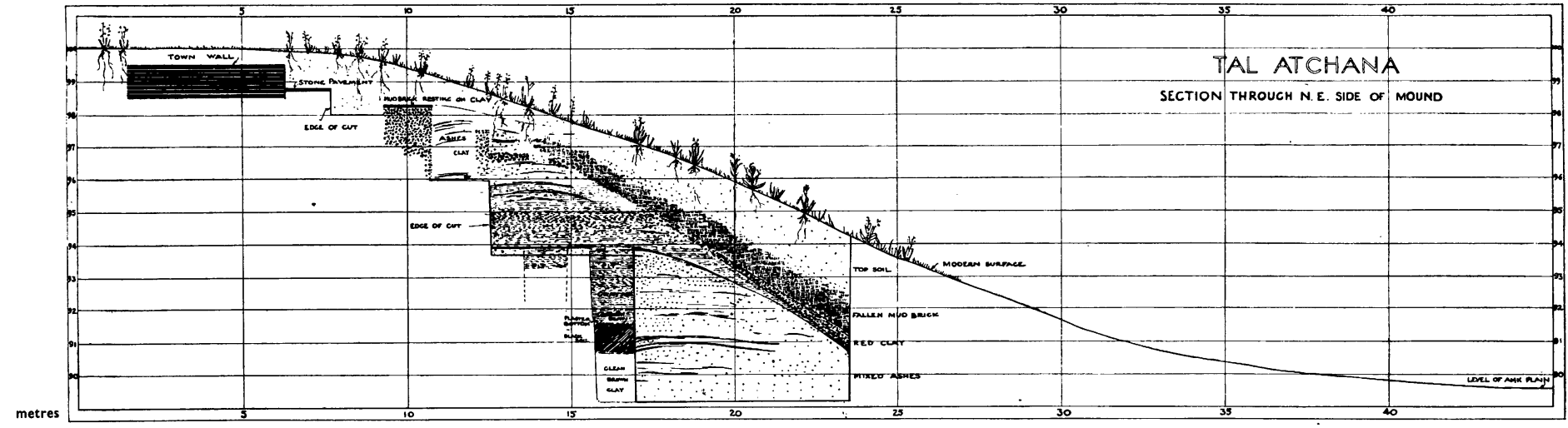

FIG. 52a

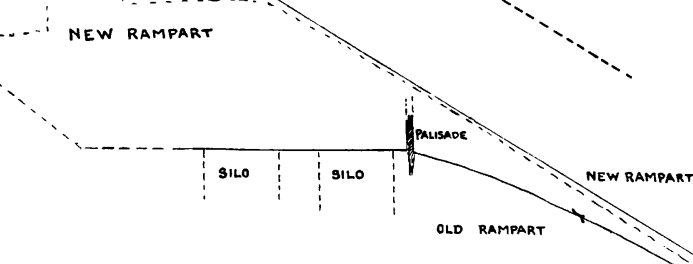

Fig. 52b. Scale I:250 
(Type I00) and the big store-jars with ribbed rims and rope-pattern ornament are much more characteristic of Levels IX and VIII. The lower rampart then should be dated to Level VII.

The pottery in the ash stratum, mixed as it is, cannot be so late as Level IV because it includes none of the banded ware which is in that period the commonest of the local painted fabrics; but it does include pieces of White Slip ware which are rare before Level $\mathrm{V}$; the material as a whole therefore dates to Level $\mathrm{V}$ at the latest and the making of the rampart must be attributed to Level IV or, more probably, Level V B.

We can then interpret our section as follows.

In Level VII the earth rampart which must have existed long before was widened by a mass of earth and rubbish piled against its face making a mud-plastered glacis which sloped at an angle of about thirty-five degrees; this rose to a height of approximately eight metres ${ }^{\mathrm{T}}$ and then ran back horizontally for about ten metres, either to the foot of the brick-built town wall or to a second short glacis slope in front of the wall's foot. ' The fact that grain-pits were sunk in the flat top of the platform (and the pits are contemporary) means that the platform was included in the lines of defence, i.e. that there was a bulwark along the edge of the glacis; but since one of the silos is too close to that edge to allow room for a brick wall, we may fairly suppose that the bulwark was in the form of a wooden palisade. ${ }^{3}$

In our section nothing appears that can be attributed to Levels VI or V. Farther to the north-west, in Sq. J I 4, v. the plan, Pl. XIV, it was found that the passage-room 29 of Yarim-Lim's palace was re-used as late as Level V, only the floor being raised; the whole of this palace passage is really in the thickness of the city wall, and it is therefore obvious that the massive defences of Level VII were as far as possible re-used in the two succeeding periods. In Sq. K I 2 it was found that the town wall of Level IV rested immediately on the brickwork of Level VII, the inner faces of the two coinciding (v. Fig. 2, p. I I), which is additional proof that the walls of Levels VI and V were at this point the re-used walls of Level VII. Still farther to the north-west, however (Fig. 53), the 'official' block of Yarim-Lim's palace had been so effectually destroyed that the debris of its upper stories formed a high mound overtopping the ruined ramparts; here then new building was essential. The remains that we found were very scanty and difficult to understand, for in a vertical interval of not more than one metre there were the more or less disconnected fragments of five constructional systems; ${ }^{4}$ but it appeared probable that the

\footnotetext{
I It stands $4.00 \mathrm{~m}$. above the present level of the plain, $9.00 \mathrm{~m}$. above its original level, which, however, would have risen somewhat by the time of Level VII.

2 We nowhere excavated the outer face of the Level VII town wall. The NE. wall of Yarim-Lim's palace was also the town wall, but its outer face was so denuded that we failed even to discover its width. At the SE. end of the palace the foundations of this wall were $\mathrm{r} \cdot 65 \mathrm{~m}$. above the level of the platform at the top of the glacis, so that one would suppose the platform to have been stepped up to the requisite height; but at the NW. end of the palace the room floors were rather
}

more than a metre lower than at the SE. end, and the wallfoundations were low in proportion so that a slight slope of the platform would have sufficed to bring it up to their level. There is no reason to assume that the rampart was uniform in character throughout its length.

3 The free use of heavy timbers in the walls of important buildings makes this not improbable.

4 The evidence was complicated by the fact that as the buildings were set up on the irregular surface of the ruinmound the foundations of contemporary walls were not at the same level. 
Level IV building which alone made tolerable sense followed fairly closely the lines of buildings in Levels V and VI. The outer face of the town wall corresponded to that of

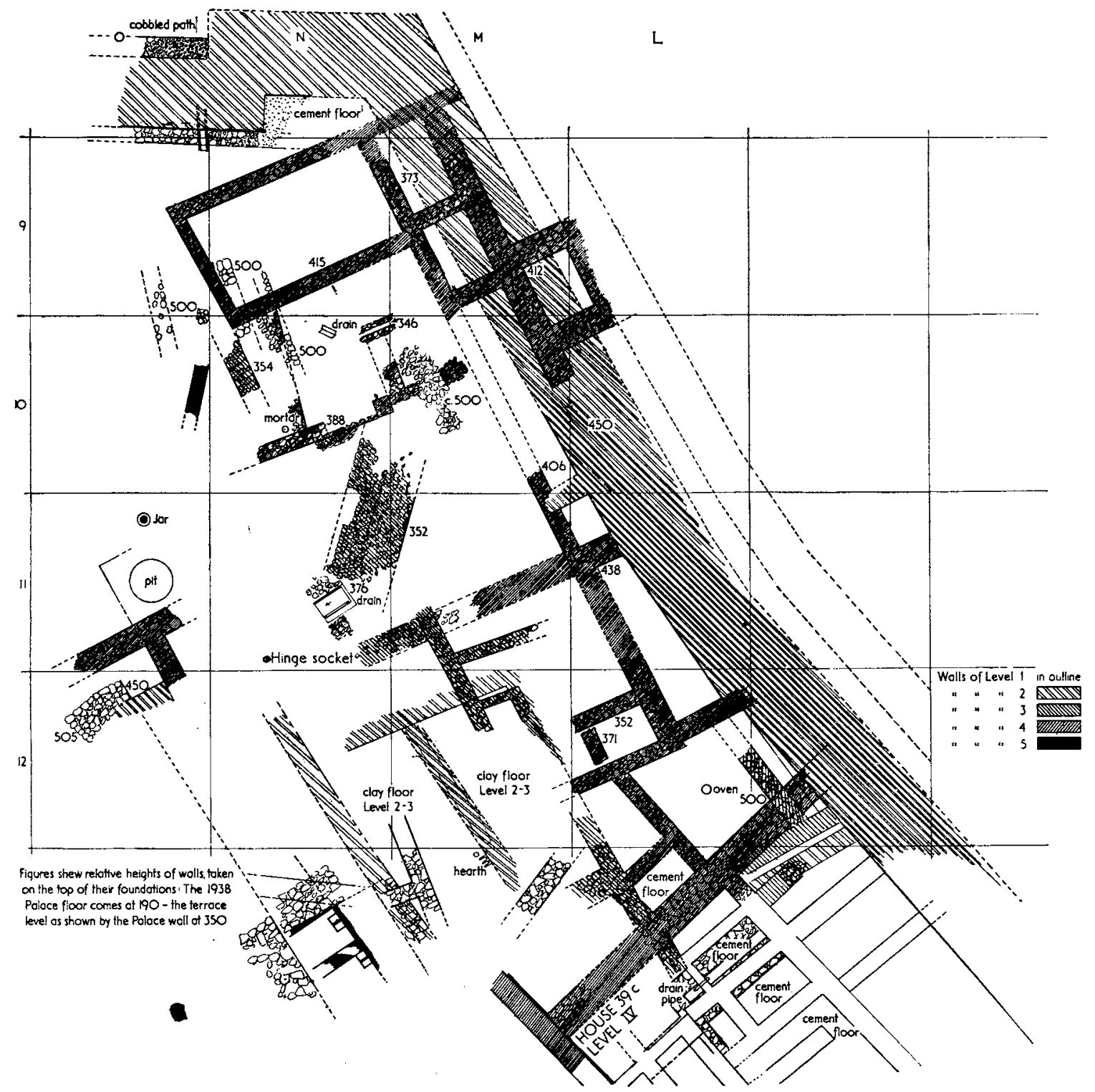

FIg. 53

Level VII, but because here (in Sq. M 8; v. Fig. 53) there was an angle in the defence line extra strength seemed to be called for; from Sq. L $\mathrm{r} 2$ to Sq. $\mathrm{N} 9$ therefore the Level IV wall was made treble instead of double and there are two parallel series of intramural chambers. Inside the wall-line there were more chambers presumably connected with the defences-one large chamber occupying nearly the whole of Sq. $\mathrm{N} 9$ definitely belongs to Level IV, possibly only to the latter part of that period; to the south of it, in 
Sq. $\mathrm{N}$ ro, there are remains of walls which may well be parts of older buildings (for at least two periods are represented) of much the same type though covering a larger area. In Sq. $\mathrm{L}$ I 2 there is preserved the SE. corner of another interior chamber of which the NW. wall may be identified with a small patch of stone foundations in Sq. M I I, overlaid by later foundations (Sqq. M I I-I 2) which may or may not belong to a similar system. The open drain, of which a single section is preserved in Sq. N 10 , is of later date judging by its level; it runs over a mass of rubble and cobbles which gives little in the way of a true face and may be part of a pavement and not the foundations of a (skew) wall. On the evidence available all that we can say is that on this section of the defences the outer wall of Level VII continued in use, either simply re-used or rebuilt, in the next two periods, although there were innovations on the space behind it; in Level IV at least there was added an inner range of intramural chambers whose existence in the preceding periods cannot be proved; and the whole thing was swept away and a new scheme substituted by the builders of Level III.

This conclusion, however, is based on the evidence of two points only on the NE. side of the town, and it cannot apply to the entire circuit. We know that the castle fortifications were rebuilt or remodelled four times in the Level VI-V period, ${ }^{\mathrm{I}}$ so that there was no scamping of necessary work, and some parts of the defence lines may have required more radical repairs than did the rampart and wall along the NE. side. There is no doubt but that the system of fortification was not identical all the way round the city but was adapted to meet changed conditions.

The contoured map of the site (Pl. XIV) shows that on the SW. side there is at the SE. end high steep-sided ground which reproduces the conditions of the NE. rampart-line; but towards the NW. end there is a marked depression where from the northern part of the tell the ground slopes gently down to the plain. While making all due allowances for denudation we must still admit that the modern slope bears some relation to the original contours-actually we find that the buildings are stepped down in terraces-and it is impossible to accept the disappearance through erosion or other means of a rampart of the nature and on the scale of that on the north-east of the town. ${ }^{2}$ Excavations here (Site 'H'; Fig. 54a,b) showed that there was indeed no such rampart; in its place we found a wall of mud brick on stone foundations which instead of being four metres above the modern surface of the plain lay nearly two metres below it; the wall was fifteen metres thick, built in compartments which were filled with broken bricks, mud, and rubbish; it seemed 'to be not so much a wall as a platform from which the wall

\footnotetext{
I There were good reasons for this. The Level VII castle had been very thoroughly destroyed, much more so than the town walls, and from the Government's point of view the repair and maintenance of the castle was far more important than the protection of the town in general.

2 Although there is no evidence other than the form of the mound, I am inclined to the view that this apparent gap in the defences is where the Orontes came up against the town. We should expect to find along the bank not a high earth rampart but a river wall (as, for example, at Carchemish) like the wall
}

of which traces exist. A river wall being a weak point, military considerations would require that either end, where it joins the land rampart, should be strengthened by a commanding tower or fort; this was obviously the case here. The theory therefore goes far to explain the contours of the site in general. I should perhaps add that the obliteration of the defence lines at the SE. end of the mound, where is the modern village of Atchana, is the inevitable result of many centuries of agriculture; no one, looking at the site, would demand any other explanation. 


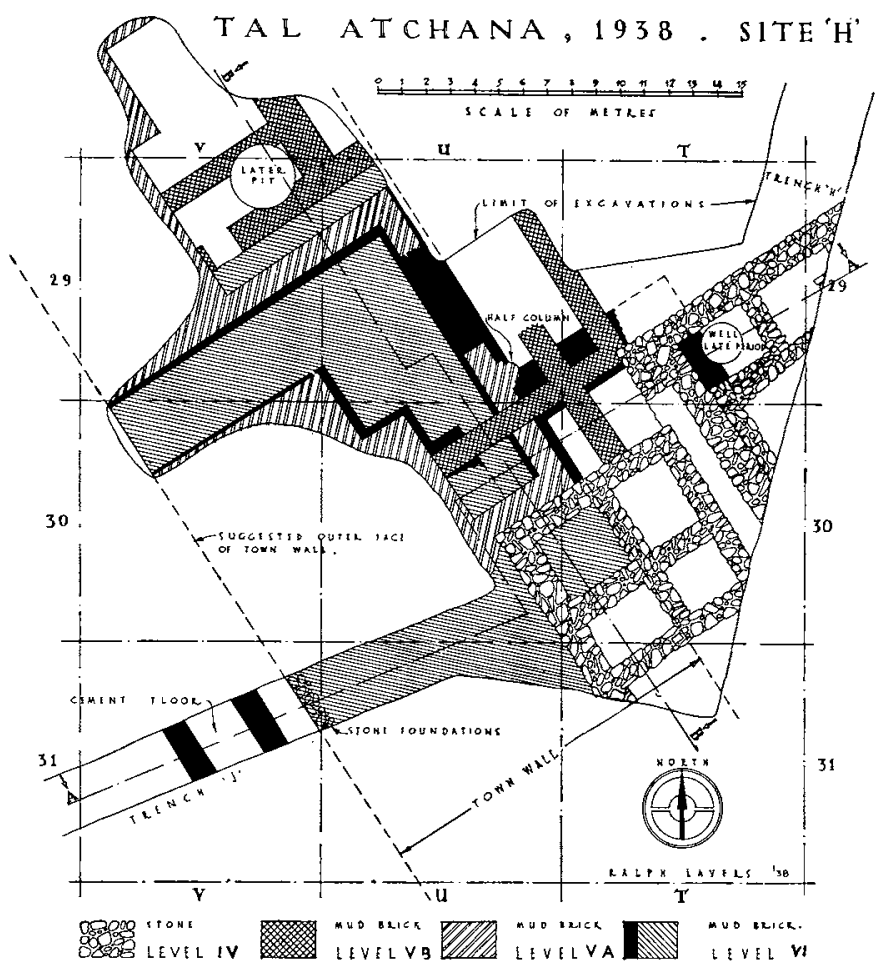

(a) General Plan
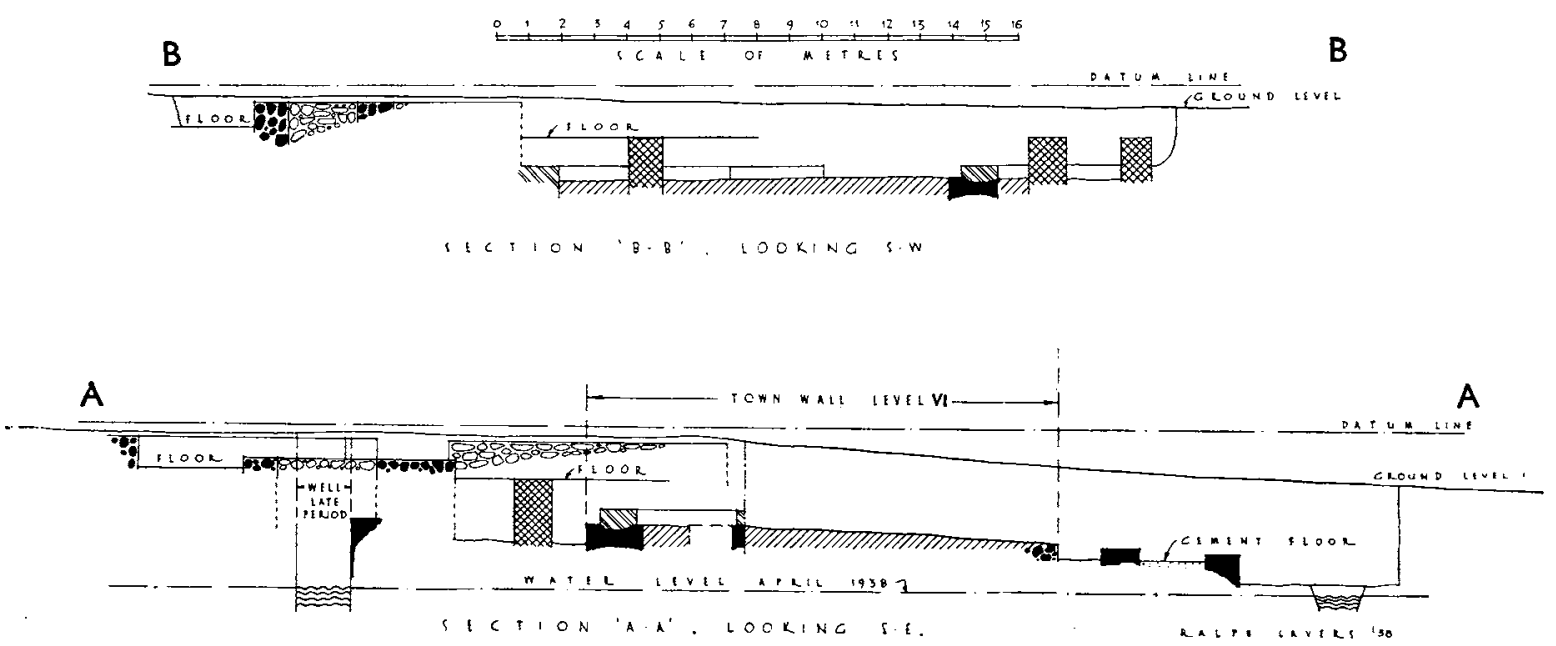

(b) Sections

(larger scale)

FIG. 54 


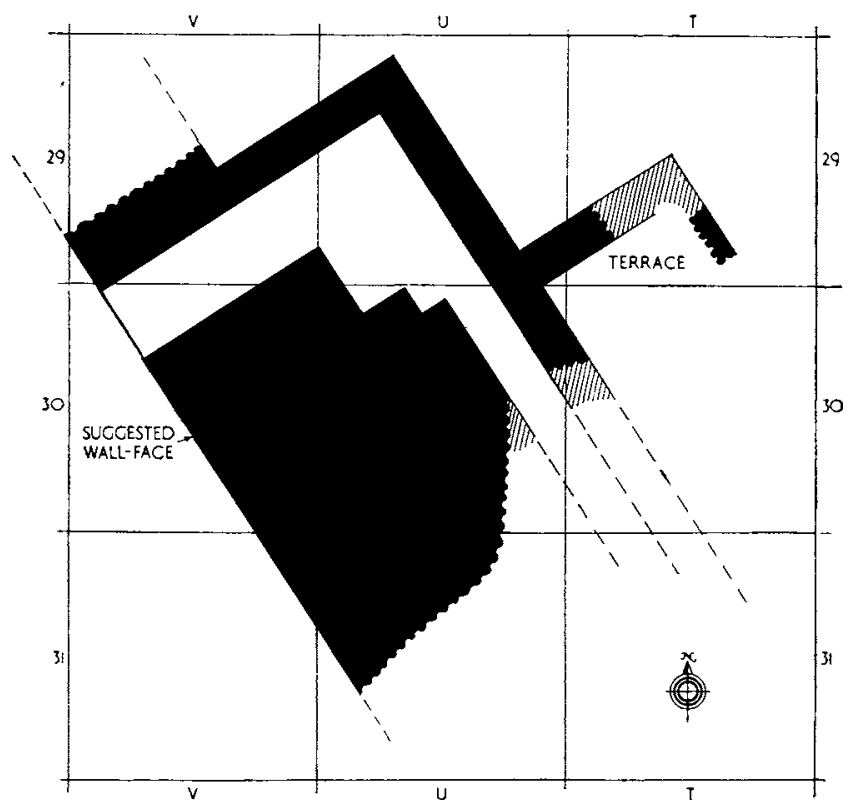

(c) Level VI Plan

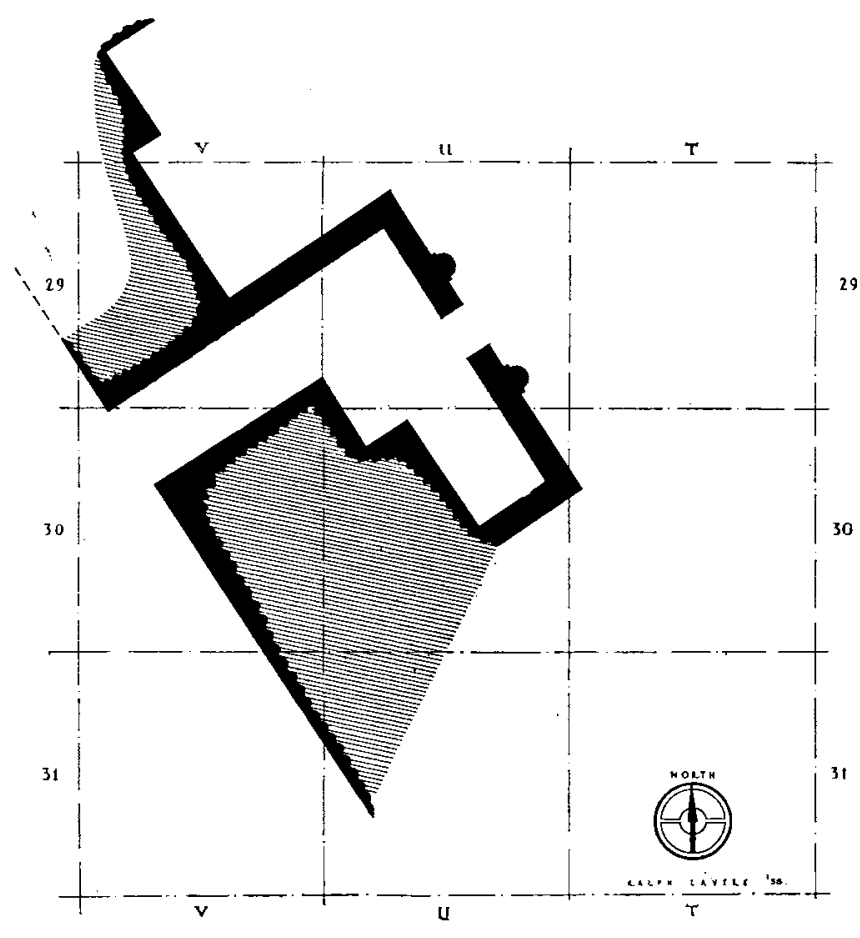

(d) Level V Plan

FIG. 54 
rose' and in a later period did serve as such, there being a new wall built over it, but its upper courses had been pared down and there could be no certainty as to its original character. But whether it was itself the town wall or a low brick-built platform on which the wall stood, it was very different from the NE. rampart, and the fact that in the second period the new wall was pierced by a passage, a postern-gate, which seems to be a replica of one in the older building, proves that the wall ran across level ground.

The dating of this Site $\mathrm{H}$ presents certain difficulties. There were four building strata closely superimposed, ${ }^{\mathrm{I}}$ and the only evidence for a positive chronology was that of the

I Since this part of our site had, unavoidably, to be used as a dumping-ground it was first trenched to assure us against the risk of burying what might merit investigation. The lowest trench, $\mathrm{H}$, showed close to the southern limits of our concession buildings which might possess interest and was therefore expanded into an excavation covering most of Sqq. T and $U$ 29-30 and $V$ 28-29, and another trench, J, was run out across Sq. V 3 I. Further work done in 1948 and I 949 extended the area eastwards and produced a few graves and some very scanty wall-remains of an earlier date than those found in $193^{8}$; judging by the pottery some were to be assigned to Level V but some to Level VII, but the work added nothing to our knowledge of the town wall. In the original excavation the earliest remains were found in trench J. At the extreme SW. end of the trench work was carried down to (spring-time) water-level; very little above that level there ran two parallel walls of mud-brick with cement plaster on their inner faces, enclosing a cement floor. Behind the inner wall was a floor of beaten clay covered with a thin layer of ashes and then, resting on the ashes and consequently of a later date than the cement-plastered walls, there were some very rough stone foundations with mud-brick above; we followed the top surface of this brickwork, which rose as it went inland, for a distance of $10.00 \mathrm{~m}$. A cut in Sqq. V 2930 produced the same mass of mud brickwork; its SW. edge corresponded more or less with the line of the stone foundations in trench $\mathrm{J}$ (Sq. $\mathrm{V}_{3} \mathrm{I}$ ), though it was so denuded that only approximate measurements could be taken, and it was followed inland up to a heavy wall running NW. $\times$ SE. across Sq. U 29. This wall, which on its NE. side showed a clean face going down almost to water-level, was interrupted by a branch wall running $\mathrm{NE}$. with almost equally deep foundations which was peculiar in that its $\mathrm{SE}$. face was not quite vertical but inclined as would be the inner face of a retaining-wall.

Thus far then we have ( $v$. the restored plan Fig. 54c) a solid mass of mud-brick whose line is exactly parallel to the present contour of the foot of the mound; it is about $15.00 \mathrm{~m}$. wide; it occupies the position in which we should expect to find the enceinte wall of the upper city, but its character is not so much that of a wall as of a platform from which the wall would rise. The obvious parallel is with the rampart of the castle, but it seems unlikely that there was any comparison with that in the matter of height. The original walls have been destroyed beyond recognition, but the massive mud-brick walls of later date that do remain are based not directly on the flat surface of the platform but on mud-brickwork rising above its level, and although this has been terribly hacked about and preserves no definite line, there is enough to justify us in saying that the original structure must have been virtually a prototype of the later.

The platform then, which was built in compartments filled with broken bricks, mud, and rubbish, was probably rather, but not a great deal, higher than it is now, but may have sloped, or been stepped up, to the foot of the wall proper, i.e. what we have got may be the core of a glacis. In Sq. V 29 the line was broken by a narrow and, apparently, winding entrance which passed between two solid bastions with reentrant angles on their inner faces (this is true of one side at least), then turned sharply to the SE. and perhaps by a doorway on the left led to the higher platform lying behind the retaining-wall in Sq. U 29 .

Such is certainly, at least in part, the arrangement in the succeeding period (v. Fig. 54d). For this we have the inner faces of the bastions preserved to a height of a metre and a half. Beyond the 'rampart' the passage is contained on the NW. by a wall of ordinary thickness ( $\mathrm{I} \cdot \mathrm{I} \circ \mathrm{m}$.) which turns $\mathrm{SE}$. and again SW. to abut on the inner face of the SE. bastion and enclose a room which may have been in the nature of a guard-room; in its wall there was a door (it has been breached and the NW. jamb is entirely destroyed together with a certain length of walling, but the SE. jamb is preserved) leading through in to the city by a passage more direct than seems to have been allowed for in the older plan. On the outside this doorway was flanked by attached half-columns only one of which, that to the SE., remains, the other having been destroyed by the wall-breach; this half-column is built of mud-brick, has a diameter of $0.80 \mathrm{~m}$., and projects not directly from the wall-face but from a rectangular pilaster attached to the wall (Pl. XXXVI $a$ ).

In this period levels had been raised a good deal. Along the entrance-passage and in the 'guard-room' there was a mass of trodden clay and rubbish about $\mathrm{I} \cdot 00 \mathrm{~m}$. thick which was recognizably the packing for a road surface, and this continued through the doorway in the NE. wall of the "guardroom'; the wall was built over the remains of that of the previous period and the base of the half-column was $0.60 \mathrm{~m}$. above the base of the older wall. The rise must have gone far to obliterate the distinction between the floor of the room entered by the door and the old terrace beyond the retainingwall to the SE. Trenches cut by us farther to the east on the line of the axis of the doorway uniformly produced low-lying ground entirely devoid of buildings; there would therefore seem to have been what the present contours would indeed 
numerous graves, which again had to be dated by their pottery content. The bulk of the graves found in I 938 definitely belonged to the houses of the top stratum; they were dug inside the rooms, against the walls, and lay at or just below the wall-foundations. These houses were built above the ruins of the town wall, whose first phase forms the lowest stratum and its second the second stratum. The pottery in the graves ( $v$. ATG/38/1 5 , I 6, I 7, 34, 35, 36, p. 2 I 2) is unmistakably of Level IV. One Level IV grave had been dug down into the entrance-passage of the (later) town wall, evidently after the wall was in ruins. On the other hand, a fragment of a White Slip milk-bowl was found under the stone foundations of the earlier wall. I have argued elsewhere (v. p. $\left.{ }^{6} 64\right)$ that the wall must therefore be attributed to Level VI. In view of the evidence given by the castle site (p. I 55) we may put the founding of the wall to Level VI B, its rebuilding to Level V A, and the third stratum, which is also a rebuilding on much the same lines, to Level $V$ в. In no other way can we reconcile the vicissitudes of the site with the terminus post quem

suggest, a broad roadway leading uphill to the higher ground on the NE. side of the city's area, flanked by buildings which would rise from a succession of terraces. Between the earlier and the later of the two periods described the road-level had risen enough to mask the front of the old terrace flanking it, but the rise would not have been confined to the road, and it is probable that the general character of the site remained much the same.

This was not the case in the following period. The next series of walls found by us (stratum 3) lay very little higher than did those of the second period NE. of the 'guard-room', and the slightness of the difference was best shown by the fact that a cement floor of the new building ran over the top of the columned wall but was only $0.50 \mathrm{~m}$. above the base of the half-column. Where the new wall overlies the guardroom its foundations are slightly above the old road-level, but it abuts on the reveal of the gate bastion, implying that the latter was still standing and could be re-used. Similarly on the NW. side of the gate the new walls abut on the old and a doorjamb has even been added (in Sq. V 29; $\%$. the general plan, Fig. 54a) against the old wall-face. The walls enclosing the 'guard-room' have been razed, but new walls which enclose cement floors and are clearly the walls of living-rooms run out across the old roadway and seem to block it altogether. The upper filling between the jambs of the gateway proved, on excavation, to be remarkably hard and uniform, and although no proper mud-brick blocking could be recognized, it looked none the less as if the gateway had in this period been closed, a deduction which is supported by the other evidence. The wall itself was still in existence, as is proved by the fact of the new walls abutting on it, but they suggest private houses lying just inside a continuous rampart rather than anything connected with a city entrance. One other fact may point in the same direction. In the 'guard-room' a heavy layer of burnt rubbish sloping down from $\mathrm{SE}$. to $\mathrm{NW}$. (i.e. towards the entrance) lies over the remains of stratum 2 buildings and below the foundations of stratum 3 ; for the laying of the latter fresh rubbish had to be brought and dumped here to level the existing slope. This looks like violent destruction and whole- sale replanning, and if there were replanning the elimination of the gateway is at least understandable.

The third stratum may have been shortlived, but it was followed by a phase of neglect - here it was not a case of buildings being pulled down to make room for new, but of new buildings being erected on a site encumbered by ruins which hat had time to get weathered into heaps. This is shown by the manner in which the foundations of stratum 4 were laid; the base of the stonework rises and dips with what were obviously the accidents of an irregular surface, so much so that in a $4.00 \mathrm{~m}$. length of wall there may be a difference of $0.80 \mathrm{~m}$. in the depth of the foundations. It was at first difficult to believe that we had not to deal with walls of different dates, but though in one case (in Sq. T 29) there was proof of rebuilding, for the rest the consistency of the plan was beyond doubt. The walls are orientated to the same angle as the old but have no other connexion with them; they disregard the groundplan of stratum 3 and they actually overlap the stratum 2 bastions which in stratum 3 were still in use. Of a city wall there was no sign at all, nothing but the rather flimsy walls of private houses, shown to be such by the graves under their rooms; in this period the position of the city wall had been changed.

In Sqq. T-U 29-3o there were numerous graves dug, for the most part, under the floors or against the walls of stratum 4 at or very little below the level of the wall foundations; that they are definitely associated with the buildings of that stratum is certain. In very many cases the graves contained examples of the tall red burnished 'spindle-vases' (Type B.M. 25) and one contained a jug and one a beaker of Base-ring ware, Types B.M. 23 and 38 , evidence sufficient to prove that stratum 4 is to be identifed with our archaeological Level IV; in a grave dug down into the entrance-passage there were two milk-bowls of White Slip ware, further proof that in the Level IV period at any rate the passage was already filled in. A fragment of a White Slip I ware milk-bowl was found under the stone foundations of the rampart in Sq. V $3 \mathrm{I}$ and gives a terminus post quem for the beginnings of stratum $\mathrm{I}$. 
of the milk-bowl fragment and the terminus ante quem of the superimposed Level IV houses. ${ }^{\mathrm{I}}$

Site $\mathrm{H}$ gives us what the NE. rampart does not give: evidence of fortification work carried out in the periods of Levels VI and V. It is worth noting that outside the wall and at a lower level there were remains, walls and floor, which both by position and by character (the wall-faces and floor were cemented) would suit Level VII, while the Level IV houses run over the top of the wall; the defence line of Levels VI-V therefore is not that of Levels VII and IV but lies farther back, by how much we do not know.

In our 1937 section (Fig. 52) the Level IV wall does not appear; we cleared the houses of that level up to the face of the Level III town wall which cut across them but did not excavate under that wall and therefore did not arrive at the face of the Level IV wall which lay well outside that of Level III. Farther to the north-west, however, the wall was found, aligned with that of Level VII. It was a single wall, $2 \cdot 50 \mathrm{~m}$. thick, of mud brick on a single course of stone rubble foundations. As these foundations were $\mathrm{I} \cdot 65 \mathrm{~m}$. above the Level VII floor the earth rampart in front of the footings must have been raised proportionately, and it is clear that it conformed to the Level VII model, having a flat or nearly flat berm ending in a glacis, the clay-revetted glacis which figures in our section. Both the rampart and the wall upon it were beyond question in use in the time of Niqme-pa and must therefore be called Level IV defences; but their foundation may well go back to Level $V$ B, from which period Niqme-pa inherited a number of his public buildings.

The town wall was rebuilt in the Level III period, presumably by the Hittites after their capture of the city and destruction of its monuments. The difference in level was not great - scarcely a metre-and one would have expected the builders to take advantage of the old wall as a foundation for their own work. The fact that they did not do so but built well back of the old line ${ }^{2}$ rather suggests that they needed space, and this may have been because they planned a double wall with a passage between the two such as that at Sinjirli. We did not actually find a double wall. In Sqq. L Io, I I, I 2, M I 2, the inner face of the wall was followed and its top cleared, but the outer face had been denuded away so that even its width was uncertain. In Sqq. N 8, O 8 the conditions were better; here the wall was preserved to its full width of $3.90 \mathrm{~m}$. Against the inner face there was a footing $0.80 \mathrm{~m}$. wide of rough rubble (v. the plan, Fig. 53, Sq. O 8-9) on which was a topping of brick earth coated with cement; judging by the disposition of the rubbish above it, this was not an exposed bench but an underground footing. Against its outer face ran a cobble pavement I.I $5 \mathrm{~m}$. wide, after which the ground broke away in the denudation talus. The pavement is very strong evidence in favour of a second wall ( $v$. Level II, p. I 45), for it is most unlikely that there should have been an open path of the sort along the edge of the glacis. Of the glacis nothing was left.

I Further work done on Site H in I 948 and I 949 produced earlier house remains behind the wall and graves at lower levels than those found in I 938 ; some of those must be assigned by the evidence of their pottery to Level $\mathrm{V}$ and even to Level VII. Since, however, they could not be associated with the phases of the town wall, they do not really come into the discussion.

2 By how much is uncertain, but we have to allow for the $\mathrm{NE}$. ends of the Level IV houses plus an open space between them and the town wall. 
A set-back of the inner face of the wall in Sq. N 8 (Fig. 53), with a cement pavement in the recess, suggests that where the wall changed its direction as here there were towers to strengthen the angles.

The Level II wall system has been described above, in so far as it is preserved, but the remains are not complete. The inner wall and the cobbled pavement outside it exist, and beyond the pavement was a second wall $3.25 \mathrm{~m}$. thick. For rather more than half its width that wall rested merely on the piled rubbish of the rampart, but its outer half has a deep-set foundation of clay-a trench $1.50 \mathrm{~m}$. wide and. $2.25 \mathrm{~m}$. deep had been dug down into the rubbish and filled with clay, on the top of which the bricks were laid. Obviously the builders distrusted the light rubbish and were afraid of their wall slipping downhill. But at $\mathrm{I} \cdot 50 \mathrm{~m}$. beyond the clay foundation (precisely the width of the passage between the first and second walls) there had been a similar clay-filled trench; only the inner side and the bottom remained, the outer side had disappeared. ${ }^{I}$ This I can only explain as the foundation for a third wall. Since it stands above and beyond the lip of the Level IV glacis the Level II builders must have widened the rampart considerably. As is described above, on the top of the old clay revetment we found a heavy stratum, increasing in thickness as it went down, of grey mud-brick rubble; this (which I originally took to be the fallen debris of the wall itself) must be the core of the Level II rampart. At no time was the town rampart built of laid bricks, as was that of the fortress, and brick rubble was actually a far more solid material than had been employed before. If it be argued that it was a bad foundation for a wall, the answer is that the wall-builders took precautions which would have been unnecessary if the foundations had been good. The face of the rampart has been completely weathered away, at least in the upper part which is all that our excavations exposed, so much so that the outer wall was undermined and collapsed; but there must have been a berm in front of the wall (which would never have risen directly from the edge of the slope) and then came the glacis, presumably revetted with clay, giving a height of at least ten metres. ${ }^{2}$ If this reconstruction is at all correct, then the Level II town wall was the most elaborate and the most imposing that Alalakh ever had. It continued in use throughout the Level I period, patched as might be required; the only new work that we found was a revetment against its inner face ( $v$. supra, p. I 34).

\section{THE CITY GATE}

Level VII (Fig. 55). The NE. gate of Level VII was the only city gate found by us. As mentioned above, we have, in Site $\mathrm{H}$, what seems to be a postern-gate of Levels VI and $V$, but that is not of the monumental character that should distinguish the main entrances of a city; a fuller account of it will be given hereafter. We have also the

I As can be seen on the section, Fig. 52, it is broken off approximately on the line of the Level IV glacis (which, however, could not be traced so high up as this) and about where the grey brick rubble stratum begins. In my provisional report I misunderstood this clay triangle and tried to connect it with the clay revetment of the slope lower down;

B 2501 this is certainly not correct, as the two cannot be contemporary. 2 Ten metres would allow for a three-metre rise in the base level since the Level VII period; the ground at the foot of the rampart was likely to rise fairly fast with the throwing out of rubbish over the town wall. 

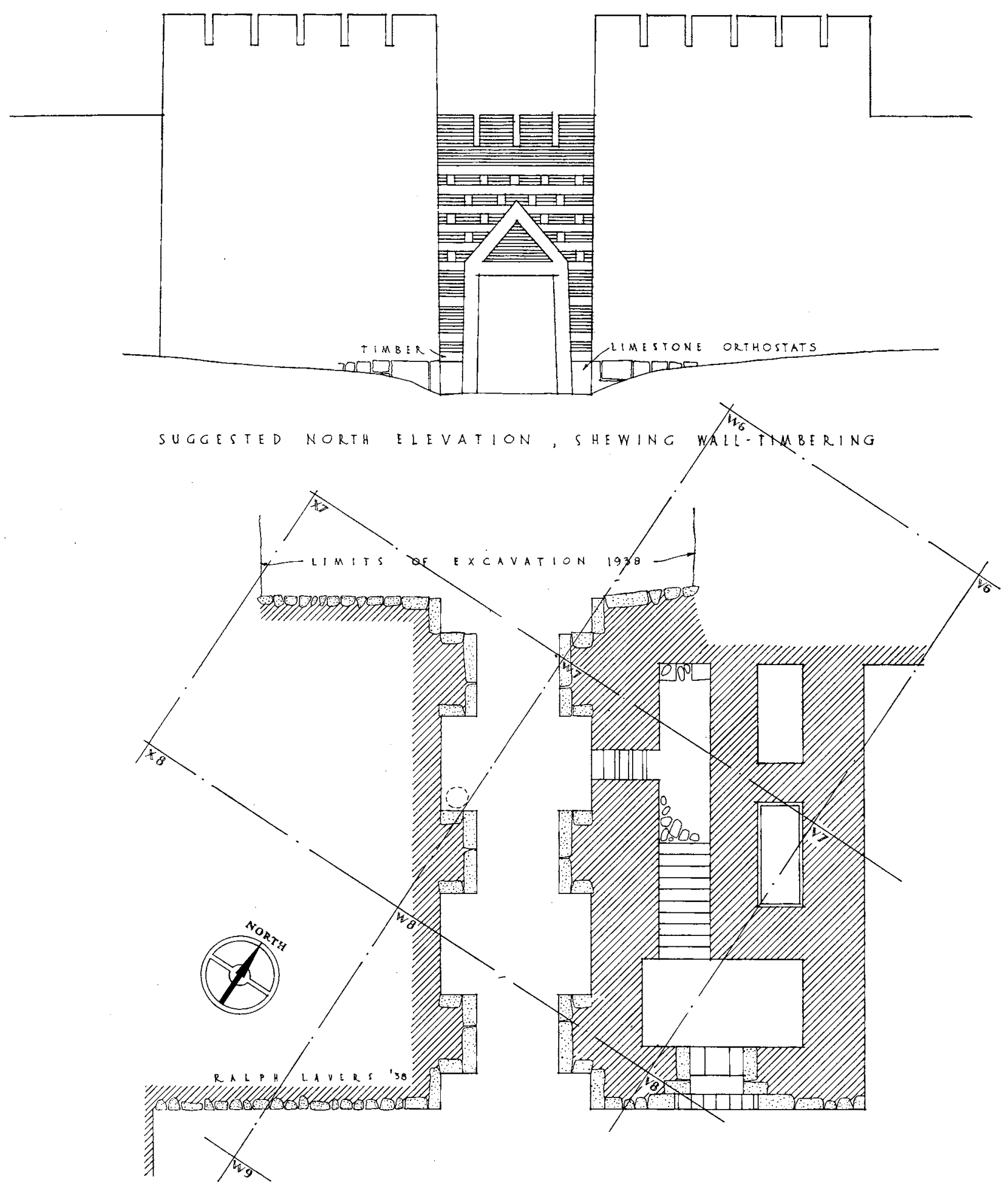

TAL ATCHANA

1938

EXISTING REMAINS OF CITY GATE, LEVEL 7

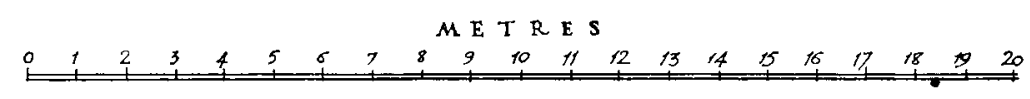

FIG. 55 
approaches to the NE. gates of Levels V and IV, but of the actual doorway of those periods nothing survives.

The Level VII gateway, based as it necessarily was upon the ruins of older fortifications, stood high; a fairly steep ramp led up to it on the outside, and on the inside the clay and brick-earth road through the city sloped up to it at a moderate gradient. The line of the rampart was here interrupted by the gate-tower, a massively built rectangle with an overall width of $23.00 \mathrm{~m}$. and a depth of $17.00 \mathrm{~m}$., set back from the foot of the glacis so that its front wall coincided with or projected but little from the line of the city wall and the approach to it was between the sloping ends of the rampart. Through the middle of the tower ran the gate-passage, blocked by three doorways set between projecting piers (Pl. XXIXa); it is the prototype of later Hittite gateways such as we have at Bogazköy, Carchemish, Sinjirli, and Tell Halaf.

The whole tower was built of mud brick on stone rubble foundations, but the entrance reveals, the door piers, and part of the SE. (inner) face were enriched with unusually large orthostats of white limestone or of limestone conglomerate; the biggest stones measured $\mathrm{I} .65 \mathrm{~m} . \times \mathrm{I} .03 \mathrm{~m} . \times 0.50 \mathrm{~m}$. thick. There was a timber course along the top of the orthostats and also above the stone foundations, at floor-level, where the wall was of mud brick, but the walls were not standing high enough for us to know whether the timbering was limited to this single horizontal course or whether it was repeated throughout the upper brickwork, as later analogies would lead us to suspect.

The brickwork nowhere stood more than $1.50 \mathrm{~m}$. high. The rubble foundations as a rule came only up to floor-level, e.g. in the NE. wall; but from the east corner along the SE. front for a distance of $2.30 \mathrm{~m}$. there is an upper course of four large roughly quarry-trimmed blocks, after which comes the ashlar orthostat of the guard-chamber door reveal. On the other side of that door, next to the corner-stone of the reveal, there are two courses of hammer-dressed blocks for two blocks, and then ashlar again. All the quarry-dressed stones on the upper courses show traces of cement plaster. On the far side of the entrance-passage there is a single ashlar orthostat next to the cornerstone, then two courses of quarry-dressed blocks, and then a single foundation-course which slopes up $0.80 \mathrm{~m}$. in the total length of $9.30 \mathrm{~m}$. On each side of the approach-road the ground sloped up (at the east corner of the tower it was a metre higher than in front of the guard-chamber door) so that the stones were mostly out of sight and ashlar was unnecessary. Similarly on the front NW. face the orthostats give place to rough blocks which were hidden by the talus of the embankment. That the orthostats were regarded as of value is shown by the fact that one of them (in the outer pier on the NE. side), the top corner of which had been broken, has been neatly patched, a stone $0.40 \mathrm{~m}$. sq. being let into it-an expedient not uncommonly used at Carchemish.

The face of the orthostats at the pier ends is not vertical but slopes slightly inwards; that this is intentional is shown clearly at the entrance, where the back of the stone at the pier end is cut at an angle, and the adjoining stone in the reveal cut to fit it, and the result is that the inclination of the passage orthostat is most pronounced. At the same time the stone in the reveal is set back $0.05 \mathrm{~m}$. (this is true on both of the outer piers, so cannot be accidental), possibly to allow for an upright beam of the door-jamb-wood ash was found in the corner of the reveal, but there was no impost stone such as one would expect for a door-frame, but merely clay. For the most part the jointing of the orthostats was good, but in the outer piers there was a gap between the two facing-blocks (of $0.045-0.06 \mathrm{~m}$. on the NE. side and of $0.06-0.095 \mathrm{~m}$. on the SW.) which is difficult to explain; 
it seems insufficient for timber. A hole, clearly for a door-socket (but the socket was missing), was found against the outer face of the central pier on the SW. side.

There were a few traces of burning on the upper brickwork, but no lodgements for wood between the bricks; the strongest evidence was the mass of very heavily burnt fallen brick which filled the gate-passage, whereas the standing brickwork there was for the most part not at all discoloured; that certainly looks as if there had been timbering in the upper part of the walls.

In view of the inward slope of the pier-head orthostats we have in the restored drawing (Fig. 55) suggested a form of gateway resembling the (later) gate at Bogazköy, with sloped jambs and a pointed arch. At Bogazköy the arch was corbelled, a natural method for stone construction where the varying length of the stones gives every opportunity for counterpoise; it is a difficult method to employ with mud bricks of uniform size, but easy enough if timber be used in the mud-brick construction, as was most probably the case here. We have therefore restored a flat lintel with a false arch above built in wood and brick as a relieving-arch; the effect is not altogether unlike that of the Lion Gate at Mycenae.

The SW. part of the gate-tower seems to have been solid; so far as we dug down into it we found only a uniform mass of mud brick, and there was certainly no entrance to any room in it on the ground floor; it was simply the built end of the NW. rampart and wall. On the other hand, the NE. part was a proper building containing a guard-chamber with a door facing on the town (Pl. XXIXb), two small chambers or cellars of uncertain use, a flight of stairs leading to the upper part of the tower, i.e. to the room or passage above the entrance and, presumably, to the ambulatory of the city wall, and, below the stairs, a small chamber with a door giving directly on the entrance-passage between the outer and the central gate-piers, obviously meant for the sentries on duty.

The guard-chamber had a $2.00 \mathrm{~m}$. wide doorway with orthostat jambs $0.60 \mathrm{~m}$. high. There was a step up, and then a raised threshold formed of a single stone $\mathrm{I} \cdot 90 \mathrm{~m} . \times 0.60 \mathrm{~m} . \times 0.27 \mathrm{~m}$. in the front and behind it two stones (which also serve as foundations for the inner orthostats), with between them a square of clay which had wood at its edge. The floor, slightly lower than the threshold, was of clay. The mud-brick walls, with a beam below the brick at floor-level, were in very bad condition and in parts completely dug away by a later rubbish-pit. In the back wall was the staircase opening; there had never been a door here; the first part of the flight, ten steps, was of solid brick, the treads cased in wooden planking of which the remains could be seen on the treads and against the rises; beyond that point the stairs had been of wood only. In the NE. wall there were no lodgement-holes for cross-timbers, but the bricks were burnt red in a straight line which continued the slope of the lower steps. In the little sentry-room underneath there were on the clay floor at the SE. end rough stone blocks (up to $0.30 \mathrm{~m} . \times 0.20 \mathrm{~m}$. sq.) tumbled together in confusion, and at the other end of the room against the NW. wall there were two mud-brick bases $0.10 \mathrm{~m}$. high and $0.25 \mathrm{~m}$. apart and projecting $0.60 \mathrm{~m}$. from the wall-face; over the gap between them were three large rough lumps of limestone and between these was a great deal of wood ash. The 'bases' are not a fire-place, for they show no signs of burning, and they are not (as we first supposed) a lavatory because the gap between them is not cemented and has no outlet at all. I It

\footnotetext{
I We did not dig here below floor-level, so I cannot definitely assert that there was no sump-pit; but we looked for
} an intake to such, and could find none. 
is possible that they are imposts for two uprights supporting the bearer-beams of the upper part of the stair-flight, the lower ends of those beams resting on a T-shaped support the upright of

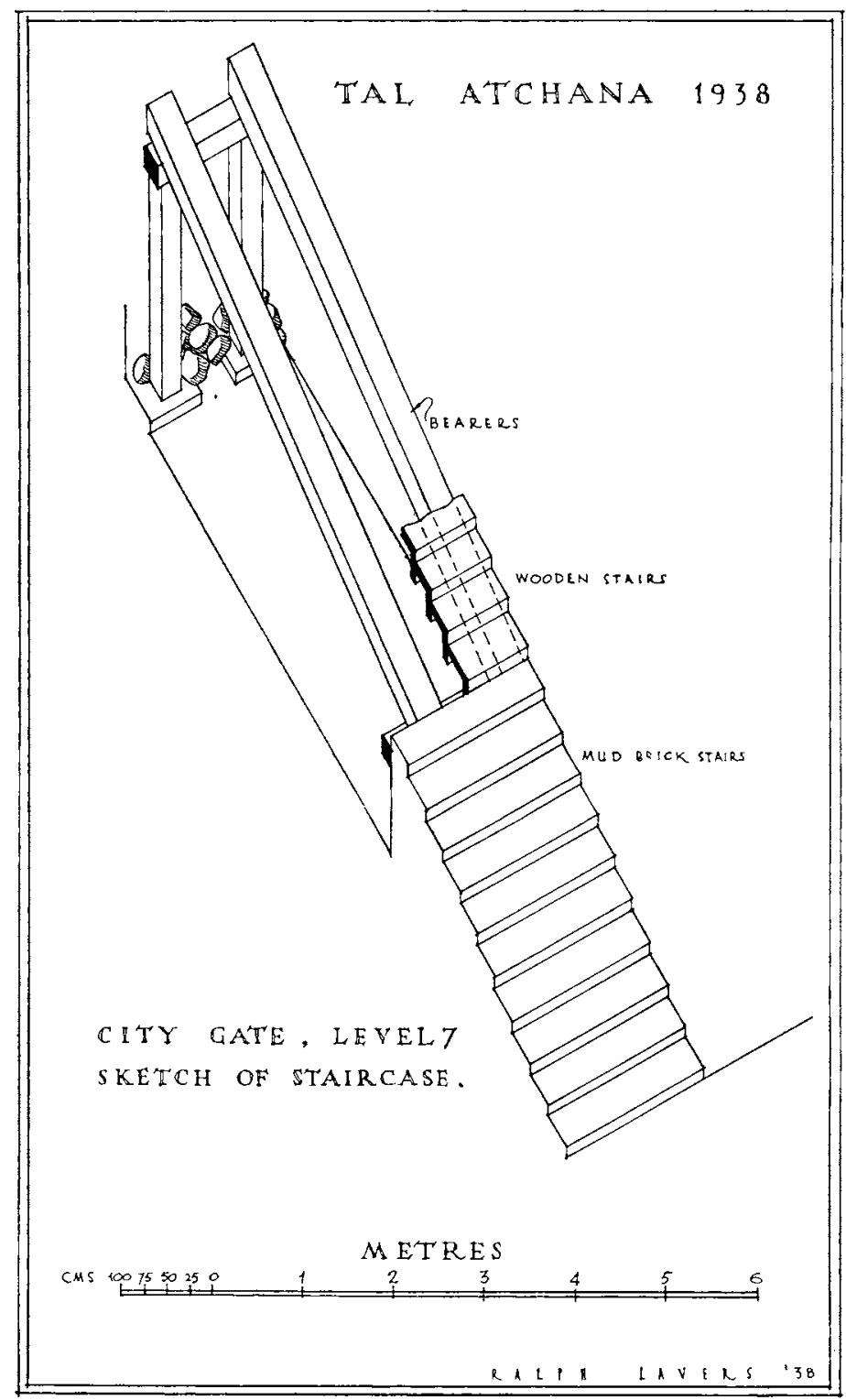

FIG. 56

which was secured by a stone packing (v. the sketch, Fig. 56). This is not a very convincing theory, but I can suggest no other.

The doorway of the little sentry-room $(\mathrm{Pl} . \mathrm{XXX}$ a) was narrow-one metre wide-and had a sill formed of a single limestone slab with behind it mud brick at a slightly lower level on which were traces of carbonized wood; then came three steps which had been of wood (parts both of the rise and of the tread survived in all cases) over a packing of rough stones and mud; at the actual door threshold there was a slot for a cross-beam and remains behind it of a plank that had formed 
the inner threshold. With the slope of the bearer-beam of the stairs, there was in front of the door head-room of $\mathrm{I} \cdot 70 \mathrm{~m}$.

The difficulty was with the two small rooms ( 3 and 4 on plan) lying, as they obviously did, beneath the return of the staircase. They had no doors or visible means of access. Room 3 had a floor of white cement which at the narrow ends was rolled up to form a raised skirting $0.05 \mathrm{~m}$. high and $0.15 \mathrm{~m}$. wide, and along the sides of the rooms was on the contrary taken up to the wall in a plain cavetto moulding; the walls were cement-plastered, at least below, but they are much ruined first by fire and afterwards by wall-foundations cut across them, and the face is nowhere preserved to a height of more than $0.20 \mathrm{~m}$. There was a great deal of carbonized wood in the room. Room 4 had no plaster on walls or floor and showed no signs of burning. In the absence of doors at ground-level one can only suppose that these were not rooms, properly speaking, but store-pits accessible from the upper floor of the gate-tower.

It is a curious weakness in what is otherwise an admirable design that the entrance to the sentry-chamber is between the first and second piers of the gateway; whereas three gates secured the entry to the city an enemy had only to break through the outer gate to have the whole gate-tower at his mercy, for a fire lit under the wooden stairs would have made further resistance impossible. Judging by the state of the ruins, this is very likely what happened.

The effects of burning were most marked in the sentry-chamber and guard-room, where the bricks of the walls were red in colour and much pulverized. Between the outer and the central piers there was a fairly heavy stratum of ashes and burnt wood lying on the floor-level. Over this, and in the rest of the entrance-passage at floor-level, there was a mass of grey mud-bricks fallen in lumps and still cohering as fragments of wall; above this, up to a height of about I. $25 \mathrm{~m}$., there was mixed rubbish, grey brick, brick burnt red, and wood ash, in more or less horizontal strata; at the top was a very definite stratum of grey ash and above this laid mud brick forming a solid mass over the whole of the gateway, covering both the entrance-passage and the ruined piers; its surface sloped gently down to the north-west as far as the front line of the old tower, where the laid brickwork stopped abruptly and was replaced by fallen brick or brick rubble. The bricks were grey in colour, but their surface had been exposed long enough for it to become black. Over this black surface later walls had been built, one, above the central piers of the Level VII gate, of brick over rough stone foundations, and a second, over the outer piers, without stone. Three phases are manifest. First there is the violent overthrow of the Level VII gate-tower, which was set on fire and razed. Then comes a period during which the site was left desolate, long enough for the crumbling of the ruins to form the horizontal strata of debris. It is only after this that new work was undertaken on the site and a covering of mud bricks laid over the rubbish, and then again some time must have passed, first for the brick surface to be blackened and secondly for it to be buried in its turn; for since one of the walls running across it had stone foundations ${ }^{\mathrm{I}}$ which would have been underground, and they rested on the brickwork, the latter must have been hidden by some thirty centimetres of accumulated soil.

In the hole by the central pier from which the door-socket had been removed was found the small bronze figurine of a god seated upon an eagle, AT/38/277, Pl. LXX, and a haematite weight, $\mathrm{AT} / 38 / 276$. At ground-level in front of the gate were found a broken dagger-blade of uncertain type and a bronze lance-head, AT/38/262, Type Sp. I 2; against the SE. face of the gate-tower, near the south corner and on the clay

I Visible in the photograph, Pl. XXIXa, over the start of the outer pier. 
floor that ran out from the wall-foundations, was the bronze dagger AT/38/282, Type Kn. 3, with which were fragments of a human skull, and a bronze 'bodkin' and starheaded nail (?), AT/38/274, v. Pl. LXX.

Level VI. Of the Level VI NE. gate nothing at all remains. If, as I think must be the case, the mass of grey brickwork that overlies both the entrance-passage and the gatepiers of Level VII is part of the Level VI rampart, then the position of the gateway had been changed; probably its axis had been shifted to the east and the building was more of the type of that of Levels V and IV. In the SW. wall, Site H, there seems to have been a gateway which was reproduced in the Level V defences, Fig. 54 D.

Levels $V$ and $I V$ (Fig. 57). The details of Site $H$ have been described above, p. I 42 , and from those it would appear that the gateway of the Level $V$ period was in its plan completely different from the great Level VII gate. Ruined as it is, enough survives to show that instead of the roadway passing straight through the triple doors of the tower the passage is broken by two right-angled turns designed to break the impetus of a

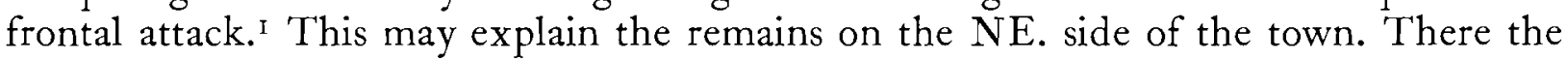
wall-foundations of Level $V$ run right across the entrance-passage of the Level VII gate, and we find (see the plan, Fig. 57, Sq. V.6) two buildings with between them a narrow roadway ( $160 \mathrm{~m}$. at its narrowest) which passes over the NE. building of the Level VII gate-tower and so, necessarily, through the line of the town's defences. This should therefore be the gate-passage. Judging by the remains of the NE. building, which alone is preserved sufficiently to be cited in evidence, the line of the road was broken by two rightangled turns; the outer room of the building has a much more solid wall $(2 \cdot 40 \mathrm{~m}$. thick) and is strengthened by a tower at its west corner; if the outer room of the SW. building be restored on the same lines ${ }^{2}$ we have a long and narrow entrance-passage flanked at the exit by strong towers forming a salient from the line of the wall, obstructed by a double turn and running between the blank walls of buildings from whose roofs an attacking force that had broken through the gate would be exposed to fire from above. ${ }^{3}$

This gateway, which must be dated to Level $\mathrm{V}$ in that a part of its buildings is cut away by Niqme-pa's palace, continued in use throughout the period of Level IV.

No remains were found of any gateway later than Level IV.

\section{THE FORTRESS}

Level VII. The fortress or castle which occupied the NW. corner of the city site stood, so far back as our evidence goes, on an artificial platform dominating the rest of the town. In the description of the Level VII gate it has already been said that on the inner face of the gate-tower the stone foundations are sloped up from the gate-passage to the south corner; at $9.30 \mathrm{~m}$. from the passage (v. Fig. 55) there is in front of the wall a cement pavement lying nearly a metre above the level

I A later example of this type of defence is given by the older (early-ninth-century) gateway at Tell Halaf. $v$. R. Naumann, Tell Halaf, ii, Abb. 58 .

2 The only 'restoration' involved is that the NE. wall of the room, whose outer face is missing, should be made thicker than it is in the case of the room to the SE.; this is largely justified in that that thickening, coming on the line of the cross-wall between the rooms, would make the NE. return of the passage of just about the right width, and the same with the second (NW.) return.

3 Since the gateway is constructionally, as well as in plan, part of the great fortress complex covering the whole area NW. of the Niqme-pa palace the description of its archaeological details is given under the heading of the Fortress, $P$ I 56. 


\section{THE NORTHWEST GATE OF THE TOWN AND PART OF THE CASTLE}

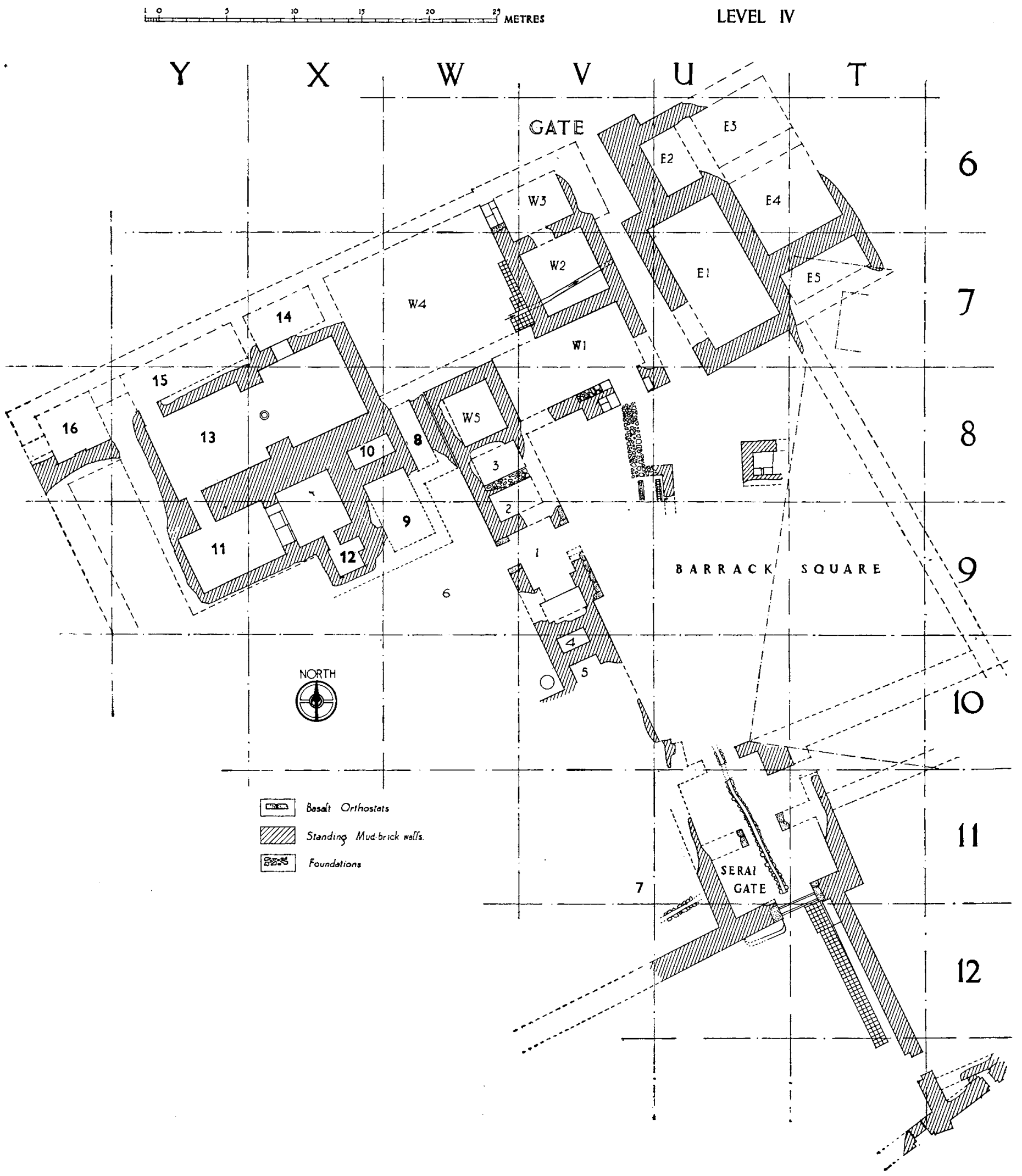

FIG. 57 
of the road. At this point we found the stone foundations of a wall running south-east, at right angles to the tower façade; the pavement, littered with burnt brick rubble from the ruined tower, ran up to the stonework, but beyond the stones there was grey earth filling still preserved to the height of about a metre. The wall (of which only a short stretch was left) had been the retainingwall of a terrace; and judging by the analogy of the later buildings it was also the enceinte wall of the Level VII castle. The only information that we have about the outer defences of that castle is derived from the cross-trench, dug in 1949 (v. Fig. $58 \mathrm{~A}$ ), which exposed a short stretch of the NE. outer wall just at a point where it changed its line and ran in a more easterly direction; the wall was $2.10 \mathrm{~m}$. thick and the exterior angle was masked by a buttress with a double salient; in front of the wall was the flat (or nearly flat) top of the rampart.

The wall stood just about I.00 m. high. Its outer face was blackened (not reddened) by fire; against it was a rubbish talus, the lower part consisting of broken bricks, mostly burnt red, the upper of ashes and brick dust which filled the hollows of the rubble and above it were horizontally stratified. At $0.20 \mathrm{~m}$. from the offset of the buttress there ran out from under the wall and nearly but not quite at right angles to it a mud-brick wall only $0.60 \mathrm{~m}$. wide, not burnt, its NW. face plastered and whitewashed; it was definitely older than the Level VII wall, but as it stood $0.20 \mathrm{~m}$. above the terrace top and the base of the wall it looked as if it had been re-used in the Level VII period; but as the burnt rubbish did not come down quite so low as this, there may have been a second floor, covering this wall fragment, which we failed to distinguish. At one point there was a big coherent lump of mud brickwork, heavily burnt, lying on the top of the light stratified rubbish of the talus. This is useful evidence for a building interregnum after the fall of the YarimLim dynasty. It means that the burnt walls were left standing long enough for wind and rain to level the rubbish at their feet so that the bricks which fell at the time of the building's destruction were buried before the upper parts of the ruined walls collapsed. This is entirely consistent with what we find on the palace site.

A Level VI в rubbish-pit dug against the inner face of the wall gave a vertical section of some interest. The lowest $0.60 \mathrm{~m}$. was cut partly into the wall-face and partly through the rubbish against it; it was difficult to say where the one ended and the other began, for with the burning of the timber in the wall the bricks had collapsed in disorder. Above this (Fig. $5^{8 \mathrm{~A}}$ ) came a stratum of decomposed unburnt bricks $0.40 \mathrm{~m}$. thick on which rested a thick bed of black ash; then $0.20 \mathrm{~m}$. of unburnt brick rubble with an irregular surface and on it another layer of ashes. On this layer rested the foundations of the Level VI A walls, and above it came three clay floors separated by black ash strata.

The Level VI A internal walls rested then on the debris of Level VII; the outer wall was built directly on the old. The walls stood to an average height of $0.85 \mathrm{~m}$., and the very irregular orientation of the internal walls is due to the fact that our section comes at an angle of the fortifications and the buildings are a compromise between two systems. The outer face of the outer wall reproduces exactly the character of the old, having the same stepped buttress. In front of the buttress are flat stones laid as if for a pavement, and at $2.40 \mathrm{~m}$. from it are remains of a wall whose foundations go down to within $0.40 \mathrm{~m}$. of the top of the Level VII platform, while the surviving brickwork is about flush with the pavement-stones; a rather doubtful outer face gave it a thickness of $\mathrm{r} \cdot 60 \mathrm{~m}$. According to this evidence the Level VI A castle had a double wall enclosing a narrow passage. Beyond it the rampart, raised $\mathrm{I} \cdot 40 \mathrm{~m}$. above that of Level VII, is built entirely of mud brick. In front of the wall the bricks are laid directly against the face of the rubbish-talus of Level VII, the clearing-away of which would have involved unnecessary labour; it sloped down very gently for $\mathrm{I} 3.20 \mathrm{~m}$. to the lip of the glacis, the upper part of which was weathered away but the lower part well preserved, $v$. Pl. XXX $b$; towards the front of the rampart there is a layer of matting between every two courses of brick, to strengthen the glacis face, and the latter was smoothly mud-plastered. 


\section{SECTION OF NE FRONT OF FORT LEVELS I-VII}
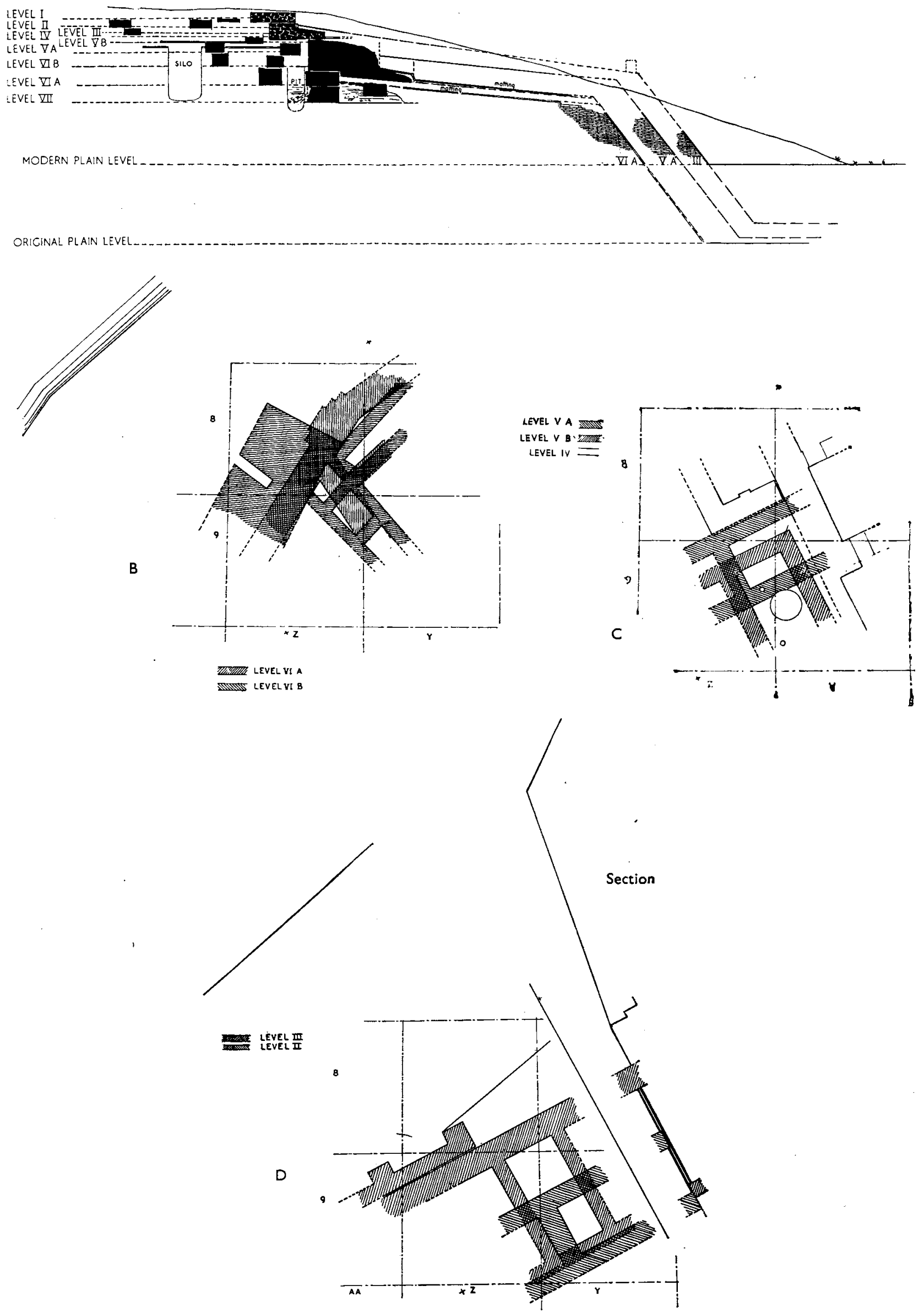

Fig. $5^{8}$ 
Level VI в shows a rise of level inside the building of $\mathrm{I} \cdot 20 \mathrm{~m}$., but outside it the rise is only $0.30 \mathrm{~m}$., i.e. the old rampart was re-used and merely repaved; we could distinguish no addition to the face of the glacis. For the repaving, matting was spread over the top of the old brickwork, the surface of which had become very irregular, as a foundation for the new work, but no attempt was made at proper levelling so that the new bricks lie far from flat. The new building, however, was quite different from the old. For part of its length the Level VI в outer wall, based directly on that of Level VI A, extended beyond it in the form of a solid buttress more than $6.00 \mathrm{~m}$. thick; in the front of it there was a deep narrow slit-like recess which may possibly have accommodated a drain from the upper part of the tower. To the north-east of the buttress salient the wall is set back behind that of Level VI A and consists of two quite thin parallel walls with a $\mathrm{r} \cdot 30 \mathrm{~m}$. space between them; the contrast with the solidity of the buttress is such that one is tempted to regard this as a single wall built on the compartment system, as was the town wall of this period on Site $\mathrm{H}$ (v. p. I 42 ), but of this there is no proof.

It is worth noting that the angles at which the walls of the Level VI в building run does not agree so well with the lines of the glacis; the builders treated the rampart merely as a platform and did not aim at any structural conformity between it and the new type of castle which they were to erect on it.

Level $V_{A}$. From the beginning of the Level $V$ period we have a complete change in the aspect of the castle. Its orientation is different and accords with that of the Level V-IV buildings that occupy the area between our section-trench and the SE. front of the fortress. This is clear from what was found in our trench, but the actual remains are slight. The change in orientation is given by two interior walls (joined by a cross-wall) which certainly were parallel to the façade, but in the short stretch exposed by our trench the real Level $V_{A}$ façade wall does not exist; instead, we have the Level VI в buttress with its front cut back by $2.00 \mathrm{~m}$. serving as the base of the new wall and rising about $0.50 \mathrm{~m}$. above ground; one would presume that the cut face was aligned with the new wall that rose above it, but in the present condition of the ruin it is impossible to assert that it was so, the brickwork is too rough to allow of any argument. But the evidence of the rampart is more decisive. The top of this was raised I. $20 \mathrm{~m}$. above that of Level VI в and the glacis lip was $\mathrm{I} \cdot 85 \mathrm{~m}$. outside the old; for this a layer of mats was put down over the old platform and on the higher step made by the cutting down of the front part of the old buttress; the bricks laid over this were not only of a different texture to those below the matting but also differently aligned, their direction agreeing with the orientation of the interior walls of Level V .A. It is obvious that the laying of the bricks started against the foot of the outer wall, and therefore that that wall was in line with those behind it. Where our trench chanced to come the Level V A wall ran over the Level VI в buttress, using it as a foundation; elsewhere the two would not have so coincided and the Level $V$ a wall would have had deeper foundations of its own. At this level there was good evidence for relative dating. The deep recess in the Level VI buttress was filled with bricks identical in texture with those of the new rampart; and amongst them and covered by them there was a grave with definitely Level $\mathrm{V}$ pottery. Inside the building the fragmentary walls gave us parts of several rooms all of which had good clay floors. Under the floors and dug from floor-level were graves (see ATG/49/I7, p. 2 I8) containing characteristic Level $V$ pottery. In one room there was, sunk in the floor, a large silo, empty.

Level $V_{B}$. Inside the building the floor was raised about $0.30 \mathrm{~m}$. and the rooms were remodelled; we exposed the greater part of one room with a good clay floor on which were two hearths. The outer wall (probably that of Level V A re-used) had entirely disappeared, and there was no change in the rampart. Satisfactory dating evidence was given by a sherd of black impressed ware found on the floor (v. p. 345).

Level IV. Whereas the rise in ground-level was very slight-only about $0.20 \mathrm{~m}$., the buildings followed a wholly new plan of which the most important feature that we could recover from the 
meagre remains was its extension north-westwards over what had been the rampart. Just inside the line of the Level $\mathrm{V}$ B outer wall there was a wall running SE. $\times$ NW.; at the SE. end it abutted on the heavy enceinte wall of the range of buildings excavated in 1947 and at the NW. end it had a return to the north-east which together with the 1947 wall enclosed a room lying above the Level $\mathrm{V}$ outer wall and extending beyond it for an uncertain distance. Nearly the whole of the room had been destroyed; there remained little more than the south and east corners and a strip of good cement flooring along the SW. wall. The floor lay $0.40 \mathrm{~m}$. higher than that of the adjoining room to the south-east, on the other side of the 1947 wall. The SW. wall had no orthostats, but rough stone foundations which rose nearly $0.20 \mathrm{~m}$. above floor-level and were masked with a smooth coating of cement plaster, an uncommon constructional feature which it shares with the walls of the rooms to the south-east. There was a shallow pilaster projecting from the middle of the wall. Here, as in the SE. rooms, a considerable amount of timber had been used in the wall construction; the room had been destroyed by fire and the surviving brickwork was red and pulverized; actually there was little of it, for the wall had been razed and the back of it had disappeared altogether. We could get no information regarding the rampart as the Level III builders had made a clean sweep of everything.

THE LEVEL IV FORTRESS (Fig. 57; cf. also Fig. 44)

The existence and something of the character of the fortress during the periods of Levels VII, VI, and V have been deduced from the scanty evidence afforded by a single trial trench; the earliest version of the fortress of which really considerable remains have been excavated is that which was in use in the period of Level IV. But although it is convenient to call the building 'the Level IV Fortress' it is not literally correct. In our stratification-sequence Level IV was correlated with the palace of Niqme-pa as the principal monument of the period, and this is not only justified by the emergence in the palace period of types of pottery which are not found earlier and by the disappearance of types characteristic of Level $\vec{V}$, but has the further advantage of giving a fixed date for the beginning of Level IV and associating it with political history; Niqme-pa is a dated character and his accession, symbolized by the building of his palace, fitly marks the. transition from Level $V$ to Level IV. But, as a glance at the plans will show, the fortress now to be described is in its foundation older than the palace; the latter has been planted down in the middle of a building complex otherwise orientated and has upset the entire symmetry of the original ground-plan. The fortress therefore could properly be assigned to Level V. But, together with other contemporary (Level V) buildings it was re-used in Level IV; in the case of the domestic quarters on the north-east and south-east of Niqme-pa's front court the dovetailing of the two constructions is obvious, and in the case of the fortress there is definite proof in the form of tablets found in room W. I. Further, there have been additions to and modifications of the fortress building which are actually later than the palace; the palace was destroyed in the revolution that occurred in the days of Niqme-pa's son Ilim-ilimma, but Level IV continues until the Hittite conquest introduced a new political and cultural phase in the history of Alalakh. There is evidence, to be discussed later, p. I 63, showing that the later additions should be attributed to a time after the destruction of the palace but during the Level IV period; and if that be so, then the building in its present form can only be called the Level IV castle. 
The passage of the NW. gateway (v. supra, p. $15 \mathrm{I}$ ) led originally into a great open court. On the north-west this was bounded by the gateway buildings; on the north-east by a building which has been swept away to make room for Niqme-pa's palace; it was perhaps the royal palace of Level $V$. On the south-east the main feature was a great triple gateway (Fig. 57, Sqq. T, U, I I) through which ran the road from the NW. gate of the city; this was on lower ground, for the road sloped downhill from where the NW. gate stood high over the piled ruins of Yarim-Lim's old gate-tower. On the south-west too the ground-level rose from the roadway to a long chambered wall, pierced by one double doorway, which was the façade of the fortress. But it is an interior façade. The fortress includes and is structurally one with the buildings of the NW. gate, and it includes also the massive triple gateway on the south-west, leading into the town, for the outer jambs of that gateway are but a continuation of the SE. wall of the fort; these are in fact projecting wings of the fortress, and the open court, measuring some $30.00 \mathrm{~m}$. by $23.00 \mathrm{~m}$., might be called the barrack square or the parade-ground. It is true that the road from the city gate passes across the square and was presumably used for civilian traffic; but if was essential that the fort should command the entrance to the city, and the fact of the parade-ground straddling the road made it an admirable place for falling-in the troops either to repel an attack from without or to crush an émeute within.

Although the eastern half of the court has been obliterated by the palace building, the restoration of it on the plan (Fig. 45) cannot be far from the truth. It will be noticed that the wall which bisects the NE. tower of the NW. gate (the NE. wall of room E. I) continues into the court and is clearly its NE. boundary; if this wall, of which only a short stretch survives, be prolonged fit meets the slightly divergent NE. wall of Niqme-pa's court, which is of Level $\mathrm{V}$ foundation, precisely at the point where it meets also the SE. wall of the fortress if that too be prolonged across the palace area. This coincidence cannot be accidental. The fact that the courtyard, thus restored, is not quite rectangular is not a serious objection seeing that there is a similar irregularity in the NW. gate-passage itself and in the Level V buildings surrounding Niqme-pa's court.

What remained of the 'barrack square', i.e. its western half, was very difficult to understand. The original irregularity of the surface and the absence of any recognizable floor would have been puzzling in any case, but here there was the further complication that levels were closely superimposed, IV, V, and VI being apparently all within a vertical interval of $0.30 \mathrm{~m}$., and the whple was terribly cut up by the deep and wide foundations of the Level III walls. In front of the doprway of room W. I there were found stone wall-foundations running at an angle that does not agfee with anything else in the area; it made two right-angled returns, the last section retaining wwo courses of mud brick with plastered face, and in the angle there were the remains of two drain or water-channels made of burnt tiles. A patch of mud flooring showed that this wall had been below floor-level, and it must be attributed to Level VI. Close to it was found a tablet ATT/38/266, below Level IV. From the buried plastered wall a quite good mud floor with ashes on it sloped up eastwards and came up against the wall of a small lavatory more or less similarly orientated; the south wall was partly ruined, the east side of it had been cut away by Niqme-pa's palace. The lavatory had cemented walls and a sunken cement floor which sloped sharply to the south where there were two cemented stands $0.30 \mathrm{~m}$. high with the usual cemented channel between them; immediately against the eastern stand was a raised mud floor, cut away by Niqme-pa. This too must have belonged to Level VI and been buried in Level V (its walls stood only about $0.35 \mathrm{~m}$. high on the inside and much less on the outside), though there was nothing to prove this except 
the mud floor joining it to the undoubtedly buried wall to the west. The interest of these scanty remains is that in Level VI, although the city gate was probably much where it was to be in Level $\mathrm{V}$, the buildings inside the gate were differently orientated and wholly different in character. A little to the south of the lavatory there lay two large rectangular limestone tanks having spouted holes low down in one side; neither was in position (they lay at a tilt) and neither could be assigned to any one level.

Since the gate-passage necessarily cuts through the city rampart the rooms in the gate-tower are stepped up from it; thus in the NE. part of the tower the floor of room E. I is higher than the passage but lower than the floor of room E. 4. As a natural result the northern part of the building was particularly ruinous. Room E. I had no floor left; the NW. wall was of mud brick and seemed to be an old wall re-used; of the other walls only stone foundations remained, but for part of the SW. wall even these had been destroyed by the Level III builders; no doorway was found-it might have been where the wall is breached, but as the foundations would as likely as not have been carried across the doorway it might equally well have been in the SE. wall, opening into the court. In room E. 2 only the stone foundations of the corner buttress were preserved; the NE., SE., and SW. walls were built over earlier walls and in the case of the first only the old work remained. Under the floor was found a pot burial, ATG/38/33, belonging to Level IV; about $0.40 \mathrm{~m}$. below it was a cement floor which should be that of Level VI. The old brickwork forming the NE. wall of the room was traced to the north-east for over six metres and was found to be continuous; it is certainly the brick top of the Level VI-V rampart.

On the other side of the gate-passage room W. I rested on the grey mud-brick filling laid by the Level VI builders over and in the ruins of the Level VII gate; this brickwork was in itself quite formless (there was no means of distinguishing filling from wall-foundations), and if the upper part of it had been added or patched in Level $\mathrm{V}$ there was nothing by which we could recognize the fact. Immediately below the white cement floor of the room there was a hole filled with rubble and pebbles, amongst them a fragment of a basalt block with reeded panels on two faces; below the rubble were two boxes, apparently foundation-boxes (if one can argue from Mesopotamian analogies; we have never found any foundation-deposits under an Alalakh building), with the sides and ends built of thin basalt slabs (re-used) resting on a carefully prepared level clay base; they had had wooden lids covered with smaller bits of stone which we found in the boxes lying on a layer of decayed wood. The boxes measured $0.50 \mathrm{~m} . \times 0.25 \mathrm{~m}$. internally; inside one were a few fragments of a large clay pot and some ashes; in the other ashes only. Also below the floor were found part of a black ring-burnished clay bottle, Type I 37, and the body of a painted pot, ATP/38/198. On the floor there were clay tablets, for the most part in very bad condition (ATT/38/93-234, 274), all of the Niqme-pa period. ${ }^{\mathrm{A}}$

Of the walls much had been destroyed by the Level III builders and of the SW. end of the room very little was left. All were of brick on stone foundations. In the north corner the walls showed signs of burning, but the SE. wall did not, and its foundations lay at a higher level, so that it looked as if there had been a partial rebuilding of the room after damage by fire; the NE. and NW. walls (standing in the corner up to $0.80 \mathrm{~m}$.) had longitudinal beams at $0.25 \mathrm{~m}$. above floorlevel and also transverse beams higher up incorporated in the brickwork, and the wall-faces were covered with a cement plaster like that of the floor which ran up against them; the SW. wall had no such plaster and its foundations were actually above the level of the floor which was broken away at a little distance from them. No second (higher) floor could be distinguished. On this showing the tablets in the room should belong to its earlier stage; all deal with the distribution of grain first to the gods and then to various individuals, and it is tempting to assume that the grain

I Mr. Wiseman notes: 'Where evidence for dating is present these appear similar to others from Level IV, e.g. $\mathrm{ATT} / 38 / 103$, I06, I 36 are contracts made before Niqme-

pa; ATT/38/104 is a letter to Ballanua, who elsewhere appears frequently as a witness to Niqme-pa's seal.' 
might be rations for the garrison and that the offerings to the god (Hepat) were connected with the statues found in the adjoining room which I believe to be of Level V.

The doorway in the SE. wall is peculiar. The entry (visible on $\mathrm{Pl}$. XXXIb) is flanked by projecting brick buttresses which are not equidistant from the door, that on the north-east being much closer to it than the other. On this NE. side the angle between the buttress and the doorjamb is filled with a (re-used) basalt orthostat laid face upwards; on the other side the bigger reentrant is filled-or paved - with three similar stones. The NE. jamb is of plain brick whereas the SW. jamb has a foundation $0.15 \mathrm{~m}$. high above the threshold consisting of a well-trimmed basalt block almost as long as the wall's width, and this is continued for a short distance along the inner face of the wall by rougher stone foundations above floor-level. The exterior re-entrant angles formed by the buttresses are cement-faced.

Room W. 2 was much ruined. Of the walls there remained little more than the stone rubble foundations, and in the NW. wall even those were cut away by the Level III builders, probably where a doorway had been, for there was no sign of any elsewhere; where there was brickwork (three courses in the SE. wall) the bricks were burnt red. Across the room runs an open drain with rough stone sides and bottom which goes through the NE. wall to empty into the gate-passage. There was no cover to it. It was well below the level of the floor judging by the thick layer of wood ash spread over the room-no proper floor surface could be recognized and presumably it was a clay floor much worn and then further damaged by the destruction of the building-and we were inclined to suggest a wooden floor above the drain, but there is nowhere any analogy for such.

Room $W .3$. The whole NW. end of the room was destroyed; in the east corner the wall (the inner face only preserved) stood $0.60 \mathrm{~m}$. high, the bricks burnt red. The restoration suggested on the plan (Fig. 57) with the NE. wall thickened and a buttress on the north-west is of course purely arbitrary and does not even achieve the merit of being symmetrical; but as the building north-east of the gate-passage seems to be based on and to follow the lines of an earlier structure whereas this on the south-west was a new construction and in any case differently orientated from the old, as is shown by the divergent lines of the fragmentary walls under the courtyard in front of the doorway of room W. I, exact symmetry is not to be expected. In the SW. wall there remains part of a doorway, one jamb with basalt orthostat $\mathrm{I} \cdot 00 \mathrm{~m} . \times 0.55 \mathrm{~m}$. and a threshold made of four basalt slabs. Near the east corner, in the debris above the clay floor, was a basalt column-base, a plain drum, ht. $0.12 \mathrm{~m}$., diam. $0.34 \mathrm{~m}$., showing the mark of a wooden column, diam. $0.30 \mathrm{~m}$.; it was not in situ and as it had rubbish below it seems to have fallen from an upper room.

Room $W .4$. The room was not completely excavated; only the east half was preserved. The walls, so far as they existed, gave no evidence of half-timber construction and showed very slight signs of burning except by the drain in the NE. wall, where the bricks were red. The floor was of clay, but in the east corner and along the NE. wall there was a strip paved with burnt clay tiles $0.30 \mathrm{~m}$. sq. $\times 0.09 \mathrm{~m}$. thick and enclosed by a low coping of stiff clay; the drain started at the edge of the tiled area and sloped sharply down through the wall. At $0.60 \mathrm{~m}$. above the floor was a later clay floor with its own system of walls virtually on the lines of the old (the new NE. wall overhung the old by $0.30 \mathrm{~m}$. and the south-east was set back $0.15 \mathrm{~m}$.) made of bricks of dark clay with white lime lumps and spots, characteristic of the Level III fortress; above the floor were some fragmentary tablets of which Mr. Wiseman remarks 'one fragment, ATT/38/239, is part of a list of householders in a place the name of which does not survive. There are marked differences of dialect between this list and similar lists from Level IV.' The existing eastern half of the Level IV room had subsequently to be destroyed by us for the excavation of the Level VII gate. During the war the vertical earth face limiting the excavated gateway area collapsed and exposed the two basalt statues $\mathrm{AT} / 4 \mathrm{O}-45 / 3$ and 4 (Pl. XLIV $a, b$ ). The impression in the soil, which was still visible on my return to Atchana in 1946 , showed that they were standing upright, side by side, facing north-east, about in the centre of Sq. W 7 , i.e. in room W. 4 , but it was not possible to fix 
their relation to the floor-level of that room exactly (all the neighbouring walls of the period having gone) or to say more than that they seem to have belonged to Level V or IV. As the tiled pavement suggests an open court rather than a roofed chamber room W. 3 may be judged an unlikely place for the setting-up of statues of this sort; our very unsatisfactory evidence does not exclude the possibility that they had really been buried under the room floor, though I think that that could be the case only if the floor were that of Level IV, not Level V, and if in the Level IV period the floor had been raised; actually we did find remains of a mud floor overlying the tiled pavement, $0.60 \mathrm{~m}$. above the level of the floor in room W. I, and on it several tablets (ATT/38/237) of the Level IV period. The date of the statues must therefore remain doubtful so far as the evidence of the site goes, but for other arguments see pp. $238,3^{8} 7$.

Room $W .5$ had no proper floor and no plaster remained on the walls, which were in bad condition.

The long range of buildings consisting of rooms I to 6 which formed the façade of the fortress facing on the 'barrack square' stood, as has been said above, considerably higher than the level of the road passing through the square; $v$. Pl. XXXI $b$. The entrance was through room $\mathrm{I}$, which was not so much a room as a double gateway enclosing a guard-chamber. The outer doorway had had basalt jambs of which that on the south-east had disappeared, I but that on the north-west was preserved in situ; there was a second basalt orthostat abutting on the jamb in the outer face of the wall, beyond which the whole wall had been destroyed; it may be that the orthostats continued along the entire façade. The SE. part of the guard-chamber shows signs of remodelling. The door pier forms a salient from the main line of the front of the building and is as a matter of fact an addition plastered against the face of that wall, whose stone foundations could be traced across the door opening and behind the NW. jamb, but the wall had been trimmed down so that its foundations served as a step in the entrance. The front of this salient, so far as it was preserved (the jamb itself had gone), was of rough stones with mud brick above, but the SE. corner-stone was a limestone orthostat polished on both faces and trimmed on its NE. face in a manner that suggested that it had had another orthostat next to it, set back from it and running at right angles to it; behind this there were rough stone foundations running out at right angles for a distance of $2.00 \mathrm{~m}$. The base of the limestone orthostat was $0.65 \mathrm{~m}$. below the level of the threshold of the doorway. In front of the NW. jamb of the doorway, at $0.75 \mathrm{~m}$. from it, there was a more or less rectangular block of rough stones parallel to the façade whose fairly level top stood higher than the door threshold. In view of the slope of the ground it looks as if something in the nature of a short terrace wall was needed to support the road leading up to the entrance of the building and that the limestone orthostat with the rubble foundations behind it are the remains of such. But the roughness of the foundations of the whole SE. pier implies that they were not visible, and this, together with the presence of the stones in front of the NW. pier, suggests that the retaining-wall of the terrace was elaborated beyond its functional requirements into a rectangular platform with a corresponding platform on the other side of the doorway, so that the entrance to the fort would be on the same general lines as that of the contemporary palace of Niqme-pa.

The inner doorway lies I. OO m. higher than the outer, so that either there were steps across the guard-chamber or the floor sloped pretty steeply upwards; as to this no evidence remained. The doorway, which was unusually wide, had basalt jambs; it had a raised sill formed of two wooden bars with stone packing between them. Towards the SE. end of the chamber there are pilasters $0.35 \mathrm{~m}$. deep attached to the two side walls; they were originally faced with cement and the floor between them was also of cement which on the SE. side ended against a solid mass of mud brickwork that seemed to be one construction with the SE. wall; it was probably a raised dais filling the alcove behind the pilasters.

I It had been cut away by the foundations of the Level III fort, which was also responsible for the fragmentary state of the walls of rooms $I, 2$, and 3 . 
The two next rooms, 4 and 5 , presented no points of interest; 5 was only partly excavated. On the NW. side of the guard-chamber room 2 was very badly destroyed (a tablet, ATT/38/94, was found in it), and of Room 3 little more than the north corner survived. At $0.60 \mathrm{~m}$. below the bottom of its stone foundations there was a patch of good cement flooring, partly cut away by a rubbish-pit but associated with burnt walls which aligned exactly with the NW. and SE. walls of room 3. It lay at about the level of the buried wall under the court in front of the door of room W. I and presumably belonged to Level VI. It rested on a solid mass of grey mud brickwork which went down I. $60 \mathrm{~m}$. to the cement floor in the corner against the SE. face of the Level VII gate-tower; $v$. supra, p. I 5 I.

Behind these rooms, I-5, there was an open court (6) entered by the gateway through room I, but the fortress façade continued farther to the south-east, enclosing the rooms that lay on the SE. side of the court (rooms not excavated by us), and joined up with a great gateway leading into the city.

The great gateway leading into the city was not directly opposite the gateway through the NW. rampart but was set in the south angle of the 'barrack square', the gate-tower being simply a projection from the castle façade; the road therefore, sloping downhill fairly rapidly, ran diagonally across the square ${ }^{\mathrm{I}}$ and then turned to pass through the gate. This (Pl. XXXII a) was a nearly square building ( I $3.00 \mathrm{~m}$. $\times$ I I.00 m.) two stories high containing three doorways whose jambs had heavy basalt orthostats with a timber doorframe above; the tops of the doorways were flat, of horizontal beams supporting the upper brickwork; a covered stone-built drain ran through the gates, under the road, to carry away the water from the sloping surface of the barrack square. ${ }^{2}$ Between the first and the second doorways a small door in the NE. wall of the tower seems to have afforded more direct access to the royal palace than did the main door which lay farther along the road beyond the limits of the castle. ${ }^{3}$ Outside the tower the road continued to run downhill; there was no real road surface-it was simply a dirt track-but the tiled footpath by the wall gave a slope of $0.50 \mathrm{~m}$. in seven metres from the threshold of the outer door. Here was a large open space bounded on the north-west by the blank wall of the castle (which we followed for about $17.00 \mathrm{~m}$.), on the north-east by another wall, part of the original layout but later re-used as the boundary-wall of the Niqme-pa palace courtyard, on the south-west by a range of buildings whose façade, so far as we traced it, ran at an oblique angle to everything else, and its SW. side being beyond the limits of our excavation is unknown but it probably extended to the south-west as far as the line of the town rampart, for the castle would almost certainly be isolated from the private houses so as to have an open field of fire from its walls.

The first or inner doorway has been terribly destroyed by the foundations of the Level III fortress which directly overlaid it; on the SW. side some rough stone foundations represent the

I That was the original arrangement. Later on the road ran under the NW. wall of Niqme-pa's palace, the corner of which was incorporated in the gate-tower.

2 The drain could be traced only to the outer doorway and it is possible that it discharged merely into the open area beyond; if that were so it would explain the narrow brick pavement which runs along the foot of Niqme-pa's courtyard wall to its entrance, for the open area is likely to have B 2501 been unpleasantly muddy in wet weather.

3 The wall here had been completely eradicated by the Level III fortress foundations, so that no structural evidence for a doorway was possible; but it can, I think, safely be deduced from the otherwise unmeaning tiled pavement which leads from the entrance of Niqme-pa's palace directly to this spot. 
door-jamb, and on the NE. side there is a certain amount of brickwork projecting from the corner of Niqme-pa's palace which gives the return of the jamb from a more solid block built against the face of the original wall_-if one may judge from the line of that wall where it is preserved farther south, for here virtually nothing of it remains. The Niqme-pa palace so far overlapped the corner of the gate-tower that the latter must have been almost entirely pulled down and rebuilt though, as the break in the bond shows, part of the foundation was left undisturbed. The best evidence that the gateway was rebuilt is given by the numerous fragments of burnt beams and a quantity of burnt brick which lay across the door-passage and obviously came from the door-frame and lintel; moreover, the drain is covered with flat stones here as in the central gateway, which is natural in a threshold. ${ }^{I}$ Of the central gateway there remain on each side the stone foundations of the orthostats, but behind them, where the piers were of brick, nothing is left. The outer gateway is the best preserved. Each jamb was faced with two basalt orthostats (one is missing from the $\mathrm{SW}$. jamb) which are trimmed to take the wooden door-frame (which came on the outer edge of the jamb) and are badly burnt where the wood came; the uprights were beams $0.35 \mathrm{~m}$. broad. There seem to have been two steps in the threshold ( $v$. the plan, Fig. 57) each with a timber rise backed by a solid clay and rubble packing. Just inside the door there were many fragments of burnt beams (mostly $0.2 \mathrm{I} \mathrm{m}$. sq.) lying at various angles, and across the door opening a very heavy wooden beam or beams on which rested a coherent mass of (accidentally burnt) brickwork, three or four courses all in order, the whole tilted forward; this clearly was the lintel which had supported the wall-face above the door. In front of this and all over the eastern gate recess there were masses of fragments of plain white plaster sometimes in layers four or five deep; it did not resemble the wall-plaster in the Niqme-pa palace and there was no fallen brick associated with it; it lay directly on the floor, beneath the fallen mud-brick, \&c.; we were inclined to think that it came from the ceiling of the gate-chamber. Against the inner face of the SW. jamb (close to the gap left by the removal of the inner orthostat) there was a basalt column-base, a plain drum ht. $0.35 \mathrm{~m}$., diam. $0.70 \mathrm{~m}$., tilted up against the foundation-stones of the missing orthostat with rubbish beneath it; it was therefore not in situ but fallen probably from the upper room, though it seems large for an upper story. The whole gateway had had a cement floor which sloped from the sides to the centre where ran the drain; this had stone sides and a base of burnt tiles and had certainly been covered, at the thresholds with stone and elsewhere apparently with wood, the remains of which were consistently found in the drain channel.

Outside the gate there were benches against the walls of the castle and of the palace court. The latter was a simple bench of mud brick, mud-plastered, $0.70 \mathrm{~m}$. high; the former has a moulded footing $0.25 \mathrm{~m}$. high and a flat top $0.70 \mathrm{~m}$. wide (v. Pl. XXXII $a$ ); its SW. end was broken away.

A small structural feature links the gate-tower with the large rooms excavated by us in the interior of the castle (see below, p. I63). Whereas in many of the Alalakh buildings orthostats rise directly from floor-level, their stone foundations being below ground, in the castle and in the gatetower the rough stone foundations stand as much as $0.40 \mathrm{~m}$. above the floor and are faced with white cement plaster. As in the case of the castle rooms, the gate-tower had been partly rebuilt. We cleared a corner of the room south-west of the outer gate recess ( $v$. the plan, Fig. 57); here there ran across the room a drain with rough stone sides and clay bottom which was just below the level of the wall-foundations and beneath a cement floor connected with those walls; the walls had

\footnotetext{
I The evidence here is not easy to interpret. The foundations of the corner of Niqme-pa's palace were cut down through an older (Level $\mathrm{V}$ ) roadway which lay $\mathrm{I} \cdot 00 \mathrm{~m}$. below that of Niqme-pa. The burnt timbers, \&cc, belonged to Niqme-Fa's gateway of which the inner pier had been rebuilt when the palace was constructed. We found traces of another roadway overlying those ruins and the field notes record the impression that the inner gateway had not been
}

rebuilt after its destruction by fire, only the two outer doors being retained in use in the later Level IV period. This suggestion, involving the theory that the gateway was twice burnt, on the occasion of the revolt against Ilim-ilimma and again when the Hittites laid waste the palace area, is at least consistent with the fact that in the outer gate-tower and in the courtyard wall beyond it both the earlier and the later walls had been burnt. 
been trimmed down to a height of $0.75 \mathrm{~m}$. above the bottom of the foundations and on them new walls had been built which overhung the old by $0.20 \mathrm{~m}$. and actually rested, to that extent, on the old cement floor. Similarly outside the gate-tower the wall of the palace courtyard showed two periods; the original wall stood to $0.75 \mathrm{~m}$. and on it was a later wall giving a total height of $\mathrm{I} \cdot 65 \mathrm{~m}$. In the barrack square there had been a considerable raising of the ground-level against and over the Niqme-pa palace wall (v. p. I 3 I) and there a road surface could be detected at the higher level; in and to the south-east of the gate-tower no high-level road surface could be seen, and it is quite possible that in the late Level IV period there was a downward slope from the barrack square over the ruins of the inner (abandoned) doorway and that outside the tower the levels remained constant. ${ }^{\text {I }}$

\section{THE INTERIOR OF THE CASTLE}

Between the range of chambers $(\mathrm{I}-5)$ forming the NE. façade of the castle and the trench which gave us the character of its rampart an area measuring approximately $28.00 \mathrm{~m}$. $\times 20.00 \mathrm{~m}$. was excavated in I 947 down to Level V. In this there was a block of buildings fairly well preserved, though complicated by the fact that, belonging originally to Level $\mathrm{V}$, they had been used and partly remodelled during the Level IV period. The greater part of the area was taken up by two large rooms ( $v$. Pls. XXXIIb, XXXIII a), each divided by pilasters into two sections, of the type that we find both in the eighteenth-century palace of Yarim-Lim (v. Pl. XV) and in the fifteenth century annexe to the Level IV palace added by Ilim-ilimma (Pl. XXVII), where they would seem to be audience-chambers. The two rooms are not of the same date. Their walls show different methods of construction, those of room I I being of brick and timber only, with a horizontal beam laid in the brickwork at floor-level and rising $0.05 \mathrm{~m}$. above the floor, concealed by a cement plaster, and timber was freely used higher up; those of room I 3 had stone foundations (amongst which were re-used basalt orthostats) rising $0.20 \mathrm{~m}$. above floor-level and smoothly cement-plastered and the lowest timbers came at not less than $0.50 \mathrm{~m}$. above the floor. In the little room Io, which is constructionally one with room I I, the NE. and SW. walls abut on that of room I 3, showing a clean break of bond, and their stone foundations are nearly half a metre deeper, the single layer of small stones forming the foundation of the room I 3 wall coming against the third or fourth course of the room Io brickwork; either therefore rooms Io and I I were built up against the already existing room I 3 , their wall-foundations being laid deeper perhaps because of the slope of the ground, or rooms Io and I I are the older and their $N W$. sides were trimmed down to accommodate the subsequent building of room I 3. Which was the case it was hard to decide. Room I 3 should be earlier than room I 6 as the latter is built on to the room I 3 wall and its floor is $0.40 \mathrm{~m}$. higher; the NE. wall of room 8 ,

I The stratification was really very difficult to understand. The lower filling was of burnt brick rubble and included large masses of coherent brickwork fallen en bloc from the upper parts of the walls; this made a fairly flat surface, presumably artificially levelled, at rather more than $1.50 \mathrm{~m}$. above the original roadway; the long wall of the courtyard bordering the roadway outside the gate had been trimmed down consistently to $1.65 \mathrm{~m}$. On the top of the brick rubble filling, coming flush with the top of the trimmed-down wall, was a layer of fragments of white plaster rather like that which was found on the roadway below the rubble, and above that layer were three courses of laid bricks, the bricks having been (accidentally) burned red before being laid. On the top of this came a layer of grey unburnt brick. The grey brick was the floor of the Level III barrack square; but I was unable to decide whether the lower filling was also the work of the Level III builders or not. 
which should be contemporary with rooms $9-1 \mathrm{r},{ }^{\mathrm{I}}$ is definitely later in date than the range of rooms forming the castle façade seeing that room W. 5 was remodelled when room 8 was built; moreover, the wall dividing rooms I I and I 3 seems to belong constructionally to the latter-the small room io gives the original external face of that wall and in room I I a $0.60 \mathrm{~m}$. thick skin of brick and timber has been built against it. ${ }^{2} \mathrm{On}$ the whole, then, it would seem safe to say that room $\mathrm{I} 3$ is part of the original Level $\mathrm{V}$ ground-plan and that everything to the south-east of it was added later, during the Level IV period.

Room 8. Of the NW. wall there remain only the stone foundations (a single layer of rather small stones) which connect with those of the room I 3 wall but slope down from it, probably owing to the slope of the ground surface. The NE. wall is of brick and shows signs of burning; it duplicates the SW. wall of room W. 5, which had been cut down to floor-level and the NW. and SE. walls rebuilt over its line to the new wall, thus increasing the size of room W. 5. The brickwork of the $\mathrm{SW}$. wall south-east of the corner of room I 3 showed signs of burning. No trace of any SE. wall was found; if it existed where it is suggested on the plan it would have been destroyed by a Level III wall whose foundations come here below the Level IV floor; for the same reason it is impossible to say how far the NE. wall continued in this direction. Since the space between the walls is only I. $50 \mathrm{~m}$. 'room' Io must be a passage, and since it has no floor and there are no doors opening into the rooms alongside, I suggest that it was a staircase entered from the courtyard (6) and leading to the upper story of the building.

Room 9. This was almost entirely destroyed by the Level III fortress wall which went down below its foundations. There was no door in that part of the walls which survived, no sign of burning on the walls, and no floor. Judging from the absence of burning the floor (as in room 10) must have been at a higher level.

Room IO. The mud-brick walls showed no signs of burning, although there were such on the outer face of the NE. wall, and there was no floor and no doorway. Consequently the floor must have been at a higher level and what we have is substructure only.

Room II (Pl. XXXIIb). The floor was of cement (not concrete) laid over clay. The walls, nowhere more than $0.50 \mathrm{~m}$. high, had been built with a great deal of timber including a heavy beam at floor-level, $0.05 \mathrm{~m}$. high, against which the cement of the floor had been brought up as a footing; owing to the burning of the timbers the wall-face had gone and the bricks were red and crumbling. The two projecting piers had bases of large well-cut limestone blocks with half-timber construction above, as was shown by the burning of the stones at the front angles, cased or panelled with wood of which the ashes formed a burnt strip along the edges of the stone base. The raised threshold between the piers was of fine basalt slabs; this showed marks of heavy burning as if from a wooden column that had stood directly on the stone, but there was no definite impression to give the position and size of a column.

Room I2. This had a good cement floor and lime-plastered walls, but there was nothing to explain its character.

Room I3 (Pl. XXXIIIa). The floor was of cement. The stone foundations of the walls rising $0.20 \mathrm{~m}$. above the floor were neatly cement-plastered; there was no woodwork in the lower parts of the walls, which in consequence were fairly well preserved, but above $0.50 \mathrm{~m}$. there was a mass

I The NW. wall belongs to the room I 3 system, as is slown by the remaining foundations, and the $\mathrm{SE}$. wall has disappeared, so that the connexion with rooms 9-I I cannot be proved, but it is most probable.

${ }_{2}$ The break in bond was discernible in the west corner of room Io but I could not find any corresponding break in the jambs of the door between rooms I I and I 3 ; but it is quite possible that the door was only made when room I I was built and in that case the breach through the old wall would necessarily be faced with new brickwork to make the door-jambs. 
of burnt brick rubble witnessing to the existence of timber higher up in the brickwork. The two piers were similarly built on stone foundations; in their outer corners there were recessed lodgements for wooden uprights of which the ashes remained in the angles. The column-base between the piers was of basalt, partly sunk in the floor, diam. $0.65 \mathrm{~m}$., but marks of burning on the stone seemed to show that the wooden shaft had had a diameter of not more than $0.35 \mathrm{~m}$. A flat plate and a 'pilgrim-bottle' (Type 44) of clay blackened by fire were the only objects found in the room.

Rooms I4 and 15 lay outside the limits of our excavation. Room I 6, of which very little remained, has been described above, p. I 56 .

Soundings were made beneath the floors of rooms I I and I 3 .

Under room I I : at I.00 $\mathrm{m}$. below the floor there were several small rubbish-pits (or sewagepits?) containing nothing, and at the same level a grave containing an adult body lying on its right side, head north-west, legs flexed, with which a vase (Type I $06 b$ ) of greenish-drab clay, water-smoothed, ht. O I 2 m., the rim broken in antiquity, and, by the legs, a bowl of dark steatite, $\mathrm{AT} / 47 / \mathrm{I} 69$. The pottery type does not occur after Level $\mathrm{V}$, and the grave cannot be earlier than Level $V$ because it lies above the ruins of Level VI; it is therefore a Level V grave, and as it must have been dug before the cement floor was laid above it, it strongly supports the view that room I I should be dated to Level IV. At I. $35 \mathrm{~m}$. below the cement floor, at the SW. end of the room, we found the tops of mud-brick walls standing 2-3 courses high and resting on wider mud-brick foundations a metre deep; two parallel walls $2.00 \mathrm{~m}$. apart and two small cross-walls were found. These certainly belong to Level VI. Between the walls were found three human skulls (no other bones with them), a vase, Type I 37, of black clay, smother-kiln ware, and a cylinder seal, AT/47/ I 72, Pl. LXI, 23.

Under room I 3 : towards the south corner of the room and partly underlying the wall, at $0.50 \mathrm{~m}$. below the cement floor came the top of a mud-brick column (?), diam. $2 \cdot 20 \mathrm{~m}$. Its total height was $\mathrm{I} \cdot 85 \mathrm{~m}$., but only the upper part had ever stood above ground; in this the bricks were well laid and the surface was smoothly mud-plastered, but below that for the greater part of its height it was a mixture of bricks and brick clay roughly shaped and with no true face, this being the underground foundation. The solidity of the base suggests that it was indeed a standing column like those of Level XII (v. p. I 7), but this cannot be proved, and it may have been a circular base. Close to this and going down to the same level was a mass of mud brickwork having no true face in which was a cut-out compartment $\mathrm{I} .00 \mathrm{~m}$. deep, rectangular, but having in one corner a circular recess; the sides were heavily lime-plastered; the sides of the recess showed signs of burning and the recess itself was full of light ash, whereas there was no evidence of burning elsewhere. The whole thing had been underground, the top of the brick mass flush with groundlevel; on the top of it was a layer of ashes about $0.60 \mathrm{~m}$. thick. There was nothing to indicate what purpose this served.

The frequent remodelling or rebuilding of the castle is in itself a valuable commentary on the political history of Alalakh, but to correlate its vicissitudes with known historical events is not easy.

The grave found under room I I belongs to Level V. In the small area cleared by us in r 949 on the NE. edge of the fortress there were several graves all of which lay below the floor of the Level V A building and were contemporary with it; there was also a silo. No graves have been found associated with the fortress buildings of any other period, so that it is curious that in the very limited area dug there should be no less than eight, including graves of women and children which seem out of place in a military stronghold. In private house sites graves are not uncommon but they are not numerous; it is clear that 
the greater proportion of the people of Alalakh were buried in cemeteries outside the town. I would suggest that these Level V A people were not taken outside for burial because it was impossible to take them outside; if there was a siege and Alalakh, or the castle of Alalakh, was 'straitly shut up, none went out and none came in', then both the graves and the silo would be easy to explain. In the faience bowl AT/46/223, Pl. LXXXIII, which was thrown out from the city's temple before the end of the Level V period, we seem to have evidence that at some time during that period Alalakh was subordinate to Egypt, and I would associate the fact with the 'siege' of the city. At first sight it would appear natural to suggest that this resulted from Tuthmosis II's Syrian campaign of circa I 456 (according to Albright's chronology) which brought him as far north as Niy, ${ }^{1}$ a district ${ }^{-}$forming part of the kingdom of Alalakh, ${ }^{2}$ but archaeologically speaking I $45^{6}$ B.c. is an impossibly late date for the end of Level $\mathrm{V}$ A; it leaves only twenty years for Level $V$ в, whereas for the two phases of Level VI and for V A we should have the long period from a little before 1700 to $145^{6}$ в.с. The alternative-which I think we must necessarily adopt-is to attribute the siege and capture of Alalakh to Tuthmosis I's campaign in Naharina when he set up his boundary stela on the Euphrates; that campaign of conquest is perhaps more likely to have put Egyptian officials in power at Alalakh than Tuthmosis II's punitive raid which was occasioned by the revolt of peoples supposed to be subject to Egypt. I am discussing, of course, something that took place during the Level $\mathrm{V}$ period; neither alternative theory affects the conclusion arrived at by Sidney Smith $^{3}$ that Level V (i.e. V в) ends with the new Egyptian domination in the 38 th year of Tuthmosis III when, it is recorded, he received tribute from Alalakh. I would, however, note here again that the event is not evidenced by any destruction of the city's monuments. Whether the recognition of Egyptian overlordship resulted from a defeat of the army in the field or from prudent anticipation, the transition from Level $V$ to Level IV was domestically peaceful; the old buildings continued in use and the changes that were made in them later were due either to dilapidation or to the demands of changed conditions.

In the end they were, as has been made clear above, destroyed by fire. Since the palace of Niqme-pa also was burned it might seem only natural to connect the two facts, but that is, archaeologically speaking, not admissible. The date of the burning of the palace is fixed by the tablets found in it, of which the latest fall within the reign of King Ilimilimma; it took place in or about the year 1400 в.c. ${ }^{4}$ On the other hand, all our evidence shows unmistakably that the building of the great Level III fortress followed immediately on the destruction by fire of the Level V-IV castle, and the fortress was certainly built under the orders of Suppiluliuma; the old castle must have been burnt by him to punish the city for its treachery in revolting after its king Takua had formally submitted to the Hittites.

Levels III-II. The Level III fort erected by the Hittites occupied the whole NW.

1 Breasted, Ancient Records of Egypt, ii. I 25.

2 Sidney Smith, The Statue of Idri-mi, p. $4^{\mathrm{I}}$.

3 Alalakh and Chronology, p. $3^{8 .}$

4 According to Albright's shorter system of dating, which I

have followed throughout. Sidney Smith (The Statue of Idri-mi, p. 6r) would put the event in or about the year I 4 I 4 B.C. I shall discuss the two systems in my chapter on Chronology, p. 377 . 

quarter of the city, including the old palace area. The excavation of it has been the intermittent work of many years and is even now not complete (Fig. 59). It was first discovered in 1937 , when a short section of its SE. outer wall was found overlying the Niqme-pa palace; in my report for that season ${ }^{\mathrm{I}} \mathrm{I}$ correctly identified it as a military fortress and stated that 'the construction must date from the time of our Level III, and the walls were re-used, with floors at a higher level, in the Level II period'. In later seasons we have added very much to the ground-plan-we have a building extending for more than eighty metres in either direction-and have confirmed what was said about its date, but apart from that not a great deal of new information about it has been secured. Since the fort was in continuous occupation during the whole of the Level III and Level II periods, in the latter of which it was in part remodelled but not rebuilt, one could not expect to find in it any objects of Level III, and actually only very few were forthcoming. It lay high, and when at the end of the Level II period it was destroyed the Level I builders made a particularly clean sweep of the platform on which they proposed to set up a building of their own; consequently only in the extreme south, where the less important wing of the old fort stood on lower ground, and in the NW. castle rooms where the Level I people wished to raise the level, did anything at all of the superstructure survive. For the most part we found only foundations, even the floors having disappeared; this meant not only a lack of objects but also that, since no doors could be located, the plan gives a very incomplete idea of the character of the building.

The fortress was built of mud brick upon stone foundations; it was of very solid construction, the outer walls being from four to upwards of five metres in thickness, and their foundations went down as much as three and in places three and a half metres. The method of construction was unusual. After the site had been levelled (which was done in terraces decided by the existing lie of the ground) trenches were cut to take the foundations but these, instead of being square in section, were $V$-shaped; they were partly filled with very heavy rubble, boulders, limestone blocks, and even basalt orthostats pulled out from the old ruins, and bricks, with a great deal of mud mortar, were laid over the stones, the width of the brickwork increasing with the slope of the sides of the trench as it rose; but, as the trench was not cut to the full width intended for the walls of the superstructure, when ground-level was reached the next course of bricks was laid overlapping the course below and resting on the soil on either side of the trench. Instead therefore of the normal procedure whereby the foundations are broader than the superstructure we have a superstructure which is wider than its foundations and the latter actually diminishing sometimes almost to a point. After the walls had reached a certain height the spaces between them were filled with a solid mass either of brick earth or of laid mud-brick to a depth of at least three metres; the surface of this mass made the floors of the rooms, but the general effect was as if the building had been erected on an artificial platform dominating its surroundings. In front of the building, i.e. to the southeast of it, there was a very large open space kept clear of houses, which also was levelled and brick-paved but not raised to the height of the inside of the fort; it was bounded on 
the north by the city wall and on the south-west by a projecting wing of the fort built on lower ground.

The Level III builders reverted to the normal NE. $\times$ SW. orientation in lieu of that adopted by Niqme-pa. The main façade of the building seems to be that facing southeast, which is enriched by great square buttresses $(5.00 \mathrm{~m} . \times 4.00 \mathrm{~m}$.); judging from the foundations which alone survive one would suppose that the entrance was in the centre, between the second and third buttresses, with behind it a small lobby with doors leading to the rooms on either side and beyond it to the north-west. But it is idle to speculate as to the detailed arrangement of a building for which so little evidence is forthcoming; the only real probability is that the room in Sqq. V I O-I I was a staircase, because there the brick filling rose higher than elsewhere, above what appeared to be floor-level, and so may well have been the packing for a flight of steps. Only the SE. wing gave definite information regarding its character. Here the rooms were stepped down, following the slope of the ground; the first, only a little below the general level of the fortress, was completely ruined, and the one point of interest about it was that it had been served by an exterior drain of which the open channel beyond the intake survived against the SW. wall; the second, coming at the back of a lower terrace, was well preserved, and of the third, nearer to the terrace edge, about half remained, the SE. end being denuded. Both these rooms were cellars. The better preserved had its NW. wall standing up to $\mathrm{I} \cdot 80 \mathrm{~m}$., its SE. wall to $0.30 \mathrm{~m}$.; the floor was of clay and there were rows of big terra-cotta store-jars let into it, generally to a depth of about $0.30 \mathrm{~m}$., but one at the SE. end was sunk to its rim (v. Pl. XXXIII $b$ ). Scattered about in the soil beneath the clay floor were fragments of a large tablet of the Bogazköy type (ATT/47/25); above the floor was a fragment of a painted vase with the characteristic 'Atchana' decoration (cf. Pl. CII $a, b$ ) which is peculiar to Level II whereas the tablet certainly belongs to the preceding period; presumably therefore the cellar as found dates (as indeed one would expect) from Level II, though it is quite possible that its use in Level III had been similar.

Owing to the complete destruction of the eastern part of the fortress there was no evidence of repairs or alterations carried out during the Level II period except that the courtyard to the south-east had been refloored with a clay floor lying $0.80 \mathrm{~m}$. above the original mud-brick pavement. The fragments of pottery found between the two were predominantly and in some cases exclusively of Level II date, but as only patches of the upper (clay) floor remained and the brick floor was by no means continuous the stratification was unreliable and objects found here could be dated on internal evidence only. Most of the potsherds with papyrus and rosette design of 'Cretan' type did in fact come from the upper levels, though one or two were low down. ${ }^{\mathrm{I}}$ The ivory statuette $\mathrm{AT} / 3^{8} 8 / 3^{8}$, Pl. LXXVI, was found high up in the court, and should therefore be of Level II; an inscribed bulla seal, AT/38/1 35, Pl. LXVII, was found below the level of the brick

I It was quite impossible to tell how much, if any, of the $0.80 \mathrm{~m}$. of soil above the brick pavement was due to gradual accretion and how much to artificial levelling with imported material; whether such accretion occurred during the Level III period or early in Level II, before the clay floor was laid down; and whether that floor was laid at the beginning of the Level II period (in which case the imported material would be of Level III date) or later in it, in which case Level II rubbish might have been used. 
pavement (which here, in Sq. S I 2, no longer existed) and so should by position as well as by character belong to Level III, but a second bulla seal, AT/38/1 53, Pl. LXVII, was quite high up in the filling and therefore out of its true horizon. A cremation burial of an infant $\left(\mathrm{ATG} / 3^{8 / 7}\right)$ in a fine amphora of painted Nuzu ware (ATP/38/17, Pl. $\mathrm{CIId}$ ) was in a pit dug through the brick pavement almost down to the Level IV palace rubbish, but the pit was certainly dug from Level II, to which period the grave must therefore belong. Two other objects, an ivory relief, AT/38/204, Pl. LXXVII, and an ivory handle engraved with curvilinear design, AT/38/225, Pl. LXXVII, were found immediately above the ruins of the fortress itself and can by this their position be assigned with reasonable certainty to Level II.

Just beyond the east corner of the fort there abuts on its NE. wall a $5.00 \mathrm{~m}$. thick mud-brick wall which appears to be the inner line of the city wall of Level II. It had no stone foundations and lies too high in relation to the fort to belong to Level III, and we have evidence to show that the Level III wall lay farther out towards the rampart-edge than did that of Level II. I Very little of the brickwork remained, and we found no sign of any outer wall; but the identification seems assured. The wall had been deliberately razed and the remains of a Level I house ${ }^{2}$ lay immediately above it; under the house floor and close to the inner face of the great wall (in Sq. Q 9) were found half of a tablet and fragments of a zoomorphic vase of $\mathrm{Nuzu}$ ware, ATP/38/4, Pl. CIII, which effectively date the house and by inference at least date the wall. We have nothing to show how far the Level II builders were following an older precedent for the city's defences, but it is obvious that the fortress of Level III must have been planned in close relation to the city wall of the period, as is indeed proved by the evidence got from the trench dug in 1949 in Sqq. W-Z 7-9 (v. Fig. 58). As there the fort did not extend quite so far to the north-east as the Level IV building had done, the builders trimmed down the tops of the old walls and cut away the floors so as to lay above and against the old work the bricks of their wide and sloping-topped rampart which they also extended beyond the line of Level V and (presumably) of Level IV; see the section, Fig. 58 A. Inside the building they raised the level very little, but their wall-foundations cut deeply down into the earlier strata. Only the outer wall had stone foundations; the bricks both of the walls and of the rampart were of the black clay containing spots and lumps of white lime familiar to us in the buildings of Levels III and I. On the NE. side of our trench the surface of the rampart was well preserved for a distance of $3.00-4.00 \mathrm{~m}$. from the façade, after that it was weathered down and although its unmistakable brickwork was continuous it was only well down the glacis-about $3.50 \mathrm{~m}$. below its lip-that a face could be distinguished, and even there it was rough and most of the mud plaster had fallen away (v. Pl. XXXIa). At some time a change was made in the defences; part of the outer wall

\footnotetext{
I v. p. I 45 .

2 'There were remains of two parallel walls orientated rather differently from those of Levels II and III; they had shallow foundations of rather small stones, a single course; one of them was $c .2 .00 \mathrm{~m}$. thick and ran up as far as the face of the fort wall, so that it may have been connected with the
}

Level I wall which ran on the top of the fort wall at a slightly different angle, $v$. Fig. 69. A layer of black rubbish in which the foundations were laid ran over the top of the fort, which must therefore have been (like the Level II city wall) destroyed before the Level I building was erected. 
was widened by a new wall I I $5 \mathrm{~m}$. thick and strengthened by buttresses (Fig. $58 \mathrm{D}$ ) built against its face. Only the heavy stone foundations remained, and after about $8.00 \mathrm{~m}$. even these, together with the foundations of the wall proper, had been denuded away; the ends of the buttresses came to the edge of the sloped rampart (as given by the short stretch preserved farther to the north-east) and in this exposed angle of the tell the whole of the top level had disappeared.

Level II. It is of course possible that this reinforcement of the wall belongs to Level II. The interior of the castle was remodelled in that period, but in most parts the changes made were of a minor character. Here the floor-level is raised $0.50 \mathrm{~m}$. and the rooms are differently planned, old walls being buried and new walls not resting on but cutting through them. These new walls are of the same white-spotted material as the old and have no stone foundations, which is in marked contrast with the very heavy foundations of large stones under the buttressed wall.

Level $I$. On the top of the outer wall of Level III there were rough stone foundations of a $2.90 \mathrm{~m}$. wide wall running in the same direction, and against it on the inside a drain

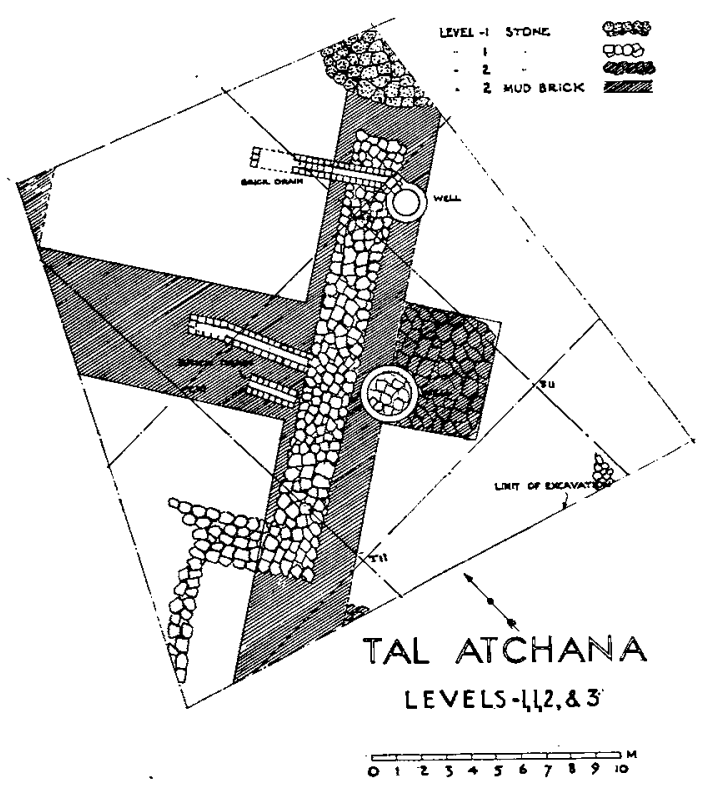

FIG. 60 built of burnt tiles. The whole remaining stretch was scarcely $4.00 \mathrm{~m}$. in length; the stones lay just below the modern surface and with the slope of that surface the three courses of stone at the NE. end were stepped down to two and then to one course and so petered out. In most cases it would be rash to assign a particular character to remains so scanty as these, but the analogy which they present to what we had found in Sqq. $\mathrm{R}$ 9-U Io (v. Fig. 44) was so exact that we had no hesitation in recognizing here the Level I rebuilding of a castle on the ruins of that of Level III-II.

The remains in Sqq. S-U, 9-10, Fig. 60 (see also Fig. 69), were indeed unmistakable although there was very little of them. Here the façade of the great Level III-II fortress had been overthrown, the wall had been trimmed to a flat surface below ground-level, and on this there had been built a new wall of which we found the stone foundations. The new wall, orientated in the same way as the old, was not nearly so massive, but it still possessed a thickness of $2.20 \mathrm{~m}$., much more than is found in private houses. It has a wide re-entrant which suggests a gateway only a little removed from the assumed gateway of the Level III fort, and the suggestion is perhaps strengthened by the presence of a brick drain (leading to a sump-pit) which apparently came from the centre of the re-entrant as a road-drain would. The brick-lined sump-pit was sunk through the mud brickwork of the Level III wall and buttress and went down nearly as low as the Level IV floor; on 
Pl. XXXIVa the remains of the three periods are clearly seen. Close to the wall-face, farther to the north-east, there were two other sump-pits into which emptied tile-built drains that crossed the top of the stone foundations and must therefore have started approximately at floor-level, i.e. at the level at which the brick construction of the wall began.

The stone foundations consisted of three courses of fairly large stones, giving a total height of $0.60-0.70 \mathrm{~m}$, , but behind them, to the north-west, there was no trace of stone; the interior walls of the building therefore must have been of mud brick only. It would seem that at the end of the Level II period the fortress was razed to the ground; that the Level I people rebuilt it on something like the old lines, but that they had not the means at their disposal to match the quality of the old building and while they did their best with the outer walls had to be content with inferior work inside.

For the date of the building there was good evidence. The soil into which the trench for the stone foundations had-been sunk contained both L.M. III sherds and fragments of Nuzu pottery with the 'Atchana' type of decoration, i.e. it was definitely of Level II. The Level I house lay just clear of the new fort, but its NW. corner (in Sq. Q 9) actually overlay one of the buttresses of the Level II fort, which therefore must have been already destroyed. The NE. end of the stone foundations had been destroyed, the stones (or most of them) being pulled up and re-used at a higher level for a curious curved structure of which not enough was left to make any sense; between what remained of the old stone foundations and this new one-course-thick layer of stones there were numerous sherds of L.M. III B pottery, many of them of the type B.M. 59 which at Atchana does not appear before Level I. The curved structure must be assigned to Level $\mathrm{O.}^{2}$

\footnotetext{
I The stones used were larger than usual and, being unshaped, would by themselves have made a very bad bedding for brickwork. The foundation-trench was deep and the stones did not nearly fill it; on the top of the stones the ordinary mud used for brick-making (black with white spots) was poured in liquid form into the trench until its surface was flush with the ground, by which time it was at least $0.40 \mathrm{~m}$. thick. This was given time to dry and then the bricks were laid upon its flat surface. We found a perfectly uniform mass, quite different from laid brick, whose 'face' was simply a cast of the side of the trench.

2 The Level I house, house $38 / \mathrm{B}$ (Fig. 69), underwent a structural alteration during the Level I period; a heavy wall of mud brick (with no stone foundations) constructed at a rather higher level cut off-or seems to have cut off-its SW. side; only a short length of this wall survived, but as
}

farther to the SE. the house walls are cut away just on its line it is natural to suppose that this was done in connexion with the building of the wall. The wall runs NW. beyond the limits of the house and was much destroyed by but could be traced beneath the late stonework, and it is possible that originally it abutted on the façade of the fort, enclosing a courtyard in front of it. But that is not certain. The curve of the late stonework seemed to be original, though some of the stones were missing; we were not able to decide whether it was a pavement or a foundation, and the same doubt held for the two patches of similar single-course stonework to the north of it. The chief interest of these very fragmentary remains was that they gave us good dating evidence; the fort and house are of Level $I_{A}$, the single mud-brick wall of Level I $\mathrm{B}$, and the rough upper stonework is one of the two surviving testimonies to a Level $\mathrm{O}$ building period. 


\section{THE PRIVATE HOUSES}

\section{THE PRIVATE HOUSE SITES}

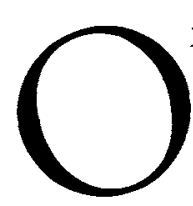

F the total area excavated at Atchana between I 936 and I 949 only a relatively small proportion was occupied by private houses; all of them (with the exception of the scanty remains on Site $\mathrm{H}$ ) are comprised within a belt about 200 metres long and seventy metres wide lying along the NE. wall of the city. For the purpose of the dig I had, in I 936, arranged with the then landowner a lease of considerably less than half the tell; and I naturally selected the NW. end because it was there' that the most important buildings would be found-the NW. end commanded the road leading eastwards to Aleppo and westwards through the Antioch pass to the Mediterranean port at al Mina, so was the right place for a fortress, the palace was bound to be here because with the fresh NW. wind blowing regularly from the snow-clad mountains of the Amanus range it was the healthiest site and free from the smoke and smells of the crowded town, and the temple was sure to be fairly close to the palace. Accordingly a very large part of our concession was given over to military and State buildings. These had never extended over the south and south-west half of our area, but trial trenches showed that there denudation had been so serious that only the lower levels remained; from ground weathered to a slope it is difficult to obtain reliable stratification, and we therefore concentrated our efforts on the NE. part of our half of the tell where buildings were directly superimposed. Even there our efforts were conditioned by time and expense. Generally speaking we did not go down below Level IV (Sqq. A 20-E 23, $\mathrm{F}_{\text {I 4 }}$ - J I 6), and where we did dig deeper it was because private houses had given place to an older royal palace; Levels $V$ and VI therefore are very scantily represented and VII to XI not at all; for Levels XII to XVI we have the buildings already described in Chapter $\mathrm{I} b$.

It should be made clear from the outset that where private houses are concerned, while it is correct to speak of the 'level' of each one caution must none the less be used in arguing from one to the other. On two neighbouring house-sites there may be the same number of superimposed buildings representing in sum the same length of time, but the synchronization between the individual buildings of the two series is not necessarily exact; there is no reason to suppose that the reconstruction of the building occupying one site should have been undertaken at precisely the same moment as that of the building on the other, and it is far more likely that there was a more or less considerable overlap. Thus, for example, in Level IV, house 39/A was definitely older in its foundation than its neighbour, house 38 , and part of it was actually pulled down to make room for that neighbour; but the remaining part was in contemporary use with house 38 and, as was shown by the stratification and by the pottery contents, both alike must be referred to Level VI. The 
fact that the buildings are not always contemporary in their foundation explains why different houses in the same level may vary greatly in the degree of their preservation and why on adjoining sites the best-preserved ruins may occur in different levels; the demolition of out-of-date houses and the raising of their sites by means of the old debris to make a platform for the new building was done at different times as occasion demanded,

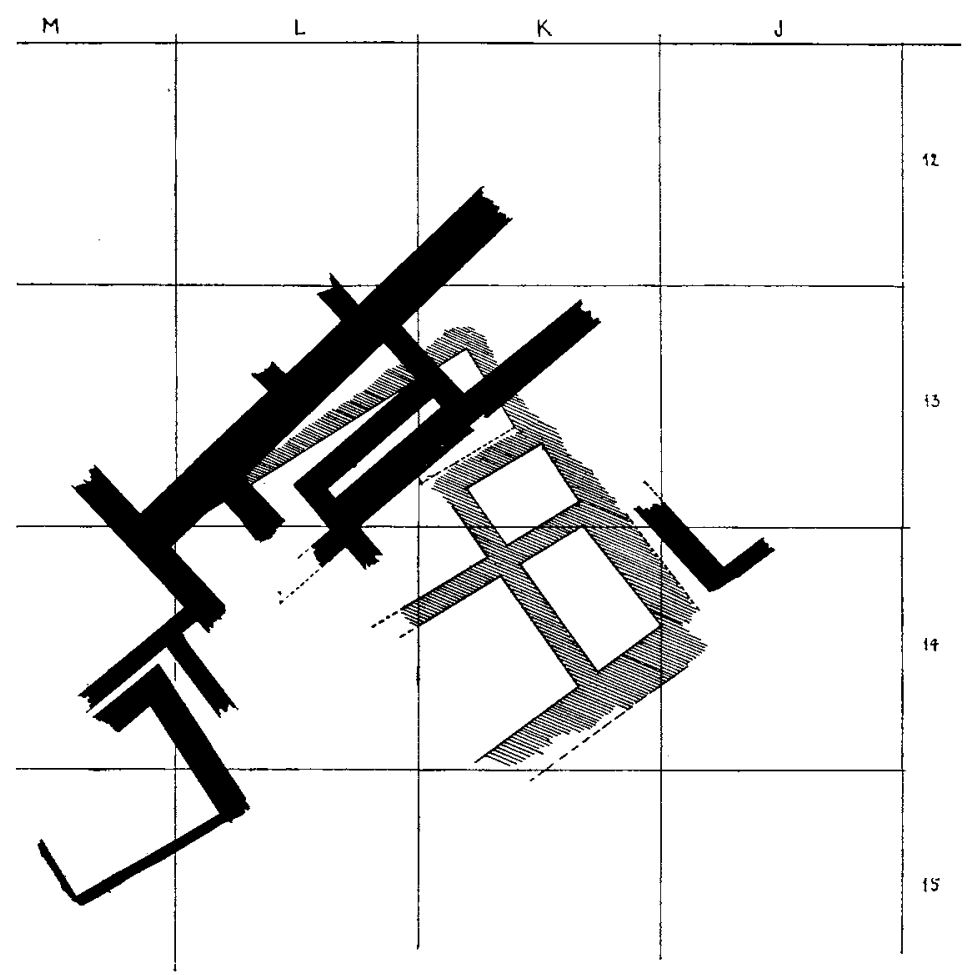

FIG. 6I

and the height of the new platform (on which depends the degree to which the walls of the old structure are preserved) would vary in each case with the circumstances of the moment.

As was the case with buildings of other sorts, the description of the houses will be most readily intelligible if it follows the historical order, starting with the oldest level and working upwards, rather than recording the process of discovery from the surface downwards.

\section{THE LEVEL VI HOUSES}

The only considerable remains of such were found overlying the SE. end of YarimLim's palace, in Sqq. K-M I 3-1 5; v. Fig. 6r. Here there were some heavy walls, of which, however, nothing but the foundation-courses remained, together with patches of concrete flooring. There was not enough to make an intelligible ground-plan; the main interest of the remains lay in the fact that there were two easily distinguished buildings in the one period; the earlier of them, shown by hatched walls on the plan, 
apparently incorporated a few upstanding walls of the Level VII palace but none the less seemed to have been built some considerable time after the palace's destruction, since over the ruins of the palace there were numerous thin strata of water-laid mud that could only have accrued during a phase of desertion. So little of the first Level VI building was left that there were no means of deciding whether it had been violently destroyed (in which case its floruit might have been quite short) or had fallen gradually into decay; but it was replaced by what was clearly a large building well constructed on very different lines, and that building did not outlast Level VI; the two ruins together are evidence for the Level VI period having been a long one, in which they agree with the two phases of construction in the fortress (v. p. I 54). A few fragments of wall-plaster painted red might have belonged to either of the two buildings and the few other objects found were simply in the Level VI stratum and could not be more closely dated. These include a figurine, nude female, AT/39/242, cf. Pl. LIV $a$; a fragment (AT/39/243) of a second similar but with horizontal lines of red paint across the vulva; a figurine of a humped cow, AT/39/293; a clay pot of Type I 066 containing four flat lumps of lead (AT/39/229), and plain clay vessels of Types $9 c, 60,68 c, \mathrm{I}_{4} 4, \mathrm{I} 3 \mathrm{I}$, and $\mathrm{I} 53$.

\section{THE LEVEL V HOUSES}

In the same area, Sqq. J-M I $3-$ I $_{5}$, there were scanty remains of houses of Level $\mathrm{V}$. These lay well above the Level VI houses and the bottoms of the lowest foundations were from $0.90 \mathrm{~m}$. $-\mathrm{I} \cdot \mathrm{I} O \mathrm{~m}$. below the cement floor of the Level IV building, but they were in very bad condition. Very little stone was used in the wall-foundations. The plan of the building in its last phase seems to have been practically reproduced by the Level IV house (see Fig. 67), the walls of which were mostly built on the stumps of the old walls; but there are definite signs of rebuilding within the Level $\mathrm{V}$ period. In Sq. K I 5 one wall, askew to the rest, is apparently later than the main building but is earlier than Level IV; in Sq. K I 5 a grave, ATG/39/97, cuts into an early Level V wall but the pit sunk for it comes against the face of a later Level. $V$ wall at a higher level and seems to belong to it. In this area, as elsewhere over the whole site, Level IV follows closely on Level V with what is clearly a gradual and a peaceful transition.

Few objects were found. In Sq. K I 4 there was the cylinder seal AT/39/286, Pl. LXII, No. 37 , the unique terra-cotta relief AT/39/240, Pl. LIV, some fragments of milkbowls of White Slip I ware, and plain clay vessels of Types $4 b, 6 a, 32,42$, I 02, I 22, I 53 , and I 66. In Sq. M I I was a small bronze amulet in the form of a pig's (?) head, AT/39/ 78 , and a bronze arrow-head AT/39/I 6E, Type Ar. 5; in Sq. L I 4 was one of the bronze strainers (?) for drinking-tubes, AT/38/26, Pl. LXXIII; and in Sq. J I 5 a female figurine, fragmentary, AT/39/295, of the type of AT/49/1 7 on Pl. LIV.

To these scanty remains must be added a building in Sqq. G-H I 7 , underlying part of the Level IV house 39/B (see Fig. 63); perhaps because of its character, for it certainly was not a private house but seems to have been a small chapel, it was not destroyed and built over at the beginning of the Level IV period but was preserved as an 'ancient monument' at least throughout that period's earlier phase. 
The building (Pl. XXXIVb), of which the SW. end was not found, being outside the limits of our excavation, consisted primarily of a platform measuring $6.80 \mathrm{~m}$. in width and more than $12.40 \mathrm{~m}$. in length, orientated in the usual sense, NE. $\times \mathrm{SW}$. The core of the platform was of mixed rubbish against which had been built a revetment of mud brick, generally only one course thick but reinforced at the angles, battered at a slope of $0.15-0.40 \mathrm{~m}$. in $\mathrm{r} .00 \mathrm{~m}$.; over this battered face was laid matting and over the matting a plaster of stiff reddish clay $0.03-0.04 \mathrm{~m}$. thick. As the ground on which the platform was built was not regular its height was not uniform; towards the north corner it was $\mathrm{r} \cdot 40 \mathrm{~m}$., towards the east corner the matting ran out almost horizontally at $\mathrm{I} \cdot \mathrm{I} \circ \mathrm{m}$. from the top. This height is taken to the existing top of the battered revetment, which would seem to have been originally carried up rather higher; but it formed a raised parapet round the platform proper whose level was $0.35 \mathrm{~m}$. below the standing brickwork ( $v$. the photograph, Pl. XXXIVa). The surface of the platform was covered with matting and on it stood a building whose walls, $\mathrm{I} \cdot 20 \mathrm{~m}$. thick, had a lower course of quarry-dressed limestone blocks with mud brick above, plastered inside with lime plaster. On the NW. side, near the west corner, was a wide doorway of which one stone jamb and part of the stone threshold and the door-socket remained; the chamber, $2.00 \mathrm{~m}$. wide, was paved with stone slabs; only the SW. end of the room remained. At the NE. end a hinge-stone for a door was found in situ just inside the parapet; either then there had been a second door to the building or it had not run the length of the platform but had left at the NE. end an open space accessible from outside; the latter seems more probable as there was here no stone paving but a floor of clay over a cobble foundation. By the NW. door was found a small gold crescent pendant, AT/39/103, Pl. LXIX, and at $2.40 \mathrm{~m}$. from the north corner, close to the NW. face of the battered wall, was the curious semibaetylic figure AT/39/I I, $\mathrm{Pl}$. XLIV, v. pp. 238 and 3.87 . At a distance of $2 \cdot 10 \mathrm{~m}$. from the NW. face of the platform there was at the same level a mud-brick wall having a vertical face to the north-west but on the SE. side the face vertical for the upper $0.30 \mathrm{~m}$. only, below which it sloped forward, the battered face being covered with matting plastered with red clay; the wall was traced for $10.00 \mathrm{~m}$., but broke away at both ends.

We seem to have here the very fragmentary remains of a small shrine, stone-built and set on a raised pedestal, ${ }^{\mathrm{I}}$ with which the baetylic idol is to be connected; the wall to the north-west may be part of a second similar shrine.

\section{THE LEVEL IV HOUSES}

House 37. See plans, Pl. XXII and Fig. 62. Sqq. E-H $18-20$.

Only part of the plan was recovered; the NW. rooms of the house lay outside our excavated area, the SW. end had been completely destroyed, and the NE. end had

I In I 939 the novelty of the battered wall gave me the idea that it had probably been below ground-level and acted merely as a foundation, for which I was able to quote modern north Syrian analogies ( $A . \mathcal{F}$. xxviii (I 948), p. 4 ). Now, with such parallels as the city wall and the temple of Level XII, there is no difficulty in admitting that the sloped and clayrevetted pedestal was visible above ground, though by the time of Level IV it may well have been buried by accumulated soil. 
suffered severely though one wall fragment gave us what were apparently its limits in that direction. What did remain was tolerably well preserved, the walls, of mud brick on rubble foundations, standing to an average height of $0.60 \mathrm{~m} .-0.70 \mathrm{~m}$. with some of the contents of the rooms still in position. The house had been a large one and well

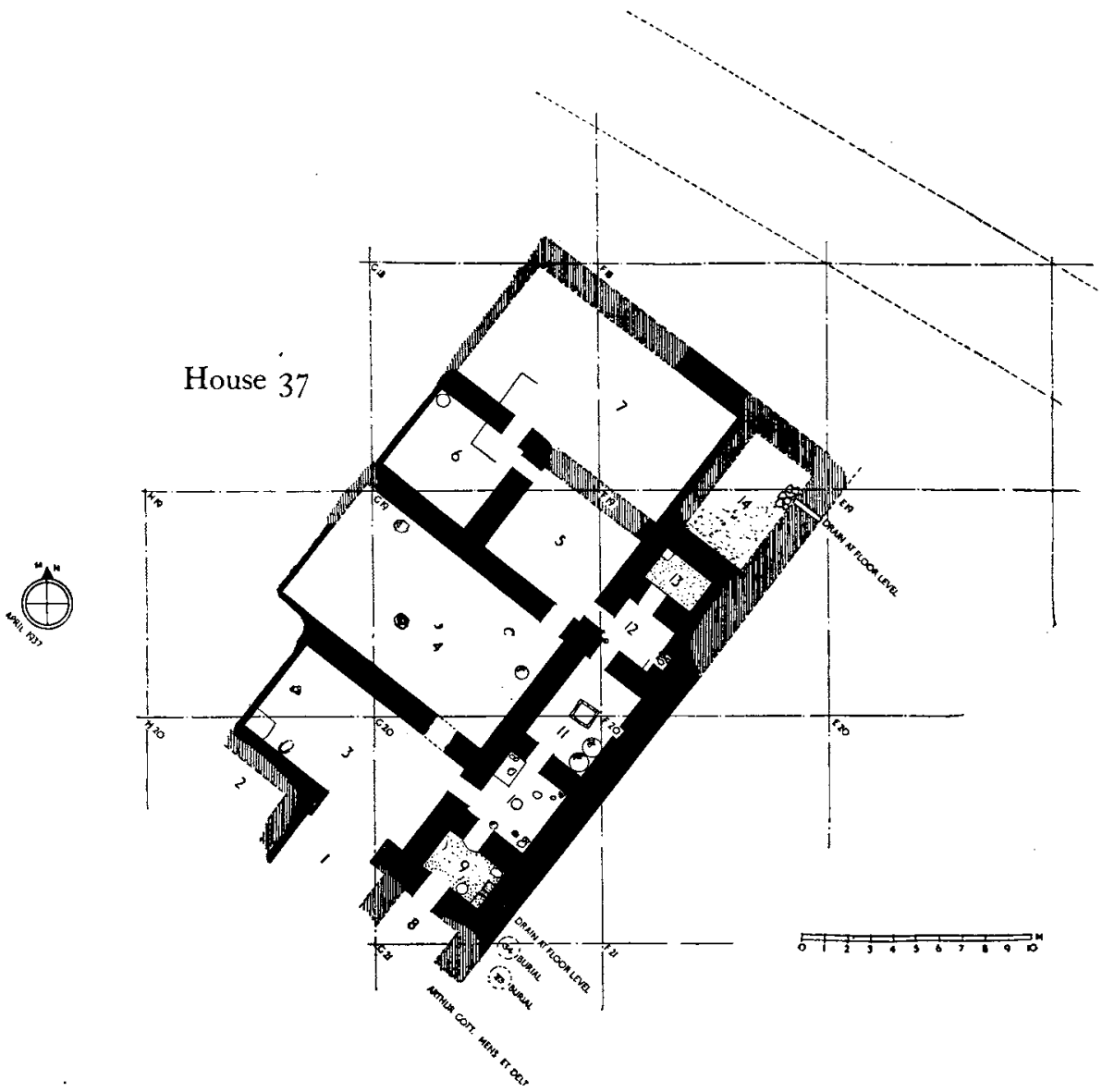

Fig. 62

built. Along the SE. wall was a range of small rooms of a domestic character, then larger rooms of which one, No. 4, was very likely an open court and light-well, and there may have been another range of (larger) rooms to the north-west, not found by us, but as we could trace no doors in the NW. walls of rooms 4 and 6 it is quite likely that the house ended on that line and was prolonged only on the south-west. Judging by the thickness of the walls the building was two stories high, and the surviving ground-plan suggests a staircase alongside room 3 , on the north-west, but for that we have no real evidence; there is also no evidence for the existence of the suggested room 8 , apart from the fact of the doorway from room 9 , and it is quite possible that 8 and $\mathrm{r}$ were really one room.

The doorway from room I to room 3 was unusually wide $(3.30 \mathrm{~m}$.) with basalt ortho- 
stat jambs; no sign of a central column was found, but the width of the opening seems to require such (Pl. XXXVa). No other private house of any period possesses a columned doorway, so that its presence here would seem to indicate a building of exceptional importance.

Room 3 had a clay floor and mud-plastered walls, the former çovered with ashes and the latter showing signs of burning. In the west corner was a large built fire-place and a smaller hearth stood close to the SW. wall; the doorway to room 4 was not original but had been cut through the standing wall; wood ashes in the cut proved that the doorway had been made before the destruction of the building and was not an accidental breach. On the floor were a basalt tripod bowl, an unusually large White Slip ware milk-bowl, fragments of a beaker (ATP/37/3r2) of Type 94a, of very coarse buff clay, greenish-white on the surface, fragments of two more milk-bowls and of a trefoil-mouthed jug, type uncertain, and examples (plain) of Types $4 b$ and I 53 .

Room 4. Mud-plastered and clay-floored; littered with fragments of pottery mostly of plain domestic type, including large store-jars; in some cases the fragments of a single vessel were widely scattered as if either intentionally flung about or else fallen from an upper room. There were several examples of Type $4 b$ and of Types $22,76,84 a$, I I I, I 53, I $63 b$.

Room 5. Clay floor; walls much ruined; a good deal of pottery, all very fragmentary, plain ware, with many examples of Type $4 b$ and of large store-jars, but also some fragments (ATP/38/4 I 5 ) of painted Nuzu ware. In the doorway to room $x_{2}$, on the brick jambs of which the impression of the wooden door-frame was very clear, was found the twirl-pin, neatly made of black steatite, $\mathrm{AT} / 37 / \mathrm{I} 96$, with which the door was latched.

Room 6 was also much ruined. On the clay floor was a badly worn cylinder seal, AT/39/60; in the ashes a good deal of pottery, the fragments including those of large store-jars, Types 76 and I I I, a bowl of Type $26 a$, Types $4 a, 82$, I 53 , and a spouted jar resembling Type $72 b$ but apparently without a handle; all were plain domestic ware, except two Nuzu bits, ATP/37/4 I 6 . A bove floor-level was found the gold pendant, AT/37/ 66 , Pl. LXIX m.

Room 7 was completely destroyed, only the foundations of the walls remaining in parts, and the floor too had disappeared. Room 8 is really conjectural.

Room 9, a lavatory of normal type, was well preserved; the walls were cement-plastered and the floor also of cement; in the east corner there was a circular depression in the floor to hold a roundbottomed water-jar; the drain, with its two usual foot-stands against the SE. wall, had an exit of terra-cotta pipes running out through the thickness of the wall into the street which came between the house and the town wall. A good deal of pottery in the room, including AT/37/225, a red burnished libation-pourer, Pl. CXXXI, a beaker of Type $94 a$ the upper part painted reddishbrown and burnished, a three-handled flask, Type $44 c$, covered with black slip and burnished, ATP/37/340, plain examples of Types $55 a, 68 c, 99 c$, I03a, one of Type $94 a$ of light red ware with bands of dark red paint, ATP $/ 37 / 3$ IO, and ATP $/ 37 / 307$, of very thin black clay, and a Basering ware jug, v.p. 357 . All these lay in a bed of wood ash c. ${ }^{\circ} .10 \mathrm{~m}$. thick containing fragments of heavy beams above which came the decomposed mud brick of the walls; they had probably all fallen from the room above.

Room Io. Clay floor; in the north corner a square bench $c .0 .30 \mathrm{~m}$. high, by it a flat stone $0.50 \mathrm{~m} . \times 0.35 \mathrm{~m}$, possibly from the top of the bench. In the room a three-legged basalt bowl, and much pottery, including examples, all plain, of Types $4 b, 55,60 b, 68 c(3), 7 \mathrm{x}, 103 a$.

Room II. Clay floor, in the middle of which a rectangular compartment $0.95 \mathrm{~m} . \times 0.85 \mathrm{~m}$., its base sunk slightly below floor-level, its sides made of tiles set on edge and covered with a rounded clay coping; it suggested a basin for the storing or decanting of some liquid, but in view of the wood ash in and round it may have been merely a hearth. Against the NW. wall, at $0.50 \mathrm{~m}$. from the north corner, there was a bench $0.60 \mathrm{~m} . \times 0.50 \mathrm{~m}$. and $0.30 \mathrm{~m}$. high the core of which was a big 
stone covered with brick clay and over it a thick coat of white cement. Two very large store-jars stood in the south corner, their bases sunk in the floor, and there were fragments of a third, somewhat smaller, which seemed to have stood between the brick compartment and the SE. wall; one of the large jars contained wheat, and there were also in it a few beads which presumably had been dropped into it by accident. On the floor was a cylinder seal of white paste engraved with two goats and a bird, in very poor condition; also pottery, including two beakers, Type $93 b$, covered with a wash of red paint and lightly burnished (ATP/37/309, 3 I 3), plain examples of Type $4 b$ and $68 \mathrm{c}$, and fragments of a tubular libation-pourer (cf. Pl. CXXXI) in brown clay, burnished.

Room I2. Clay floor. The jambs of the doorway to room I 3 showed two coats of cement, the lower very smoothly floated, the upper thick and rough. Against the corner of the NW. jamb of the doorway from room I I was a three-legged basalt mortar which may have been used as a hingesocket for the door but perhaps was there only by accident; a similar mortar lay upside down near the middle of the room. In the SE. wall was a small cupboard contrived in the thickness of the wall in which were several clay vases, Types 90 (two, plain), 63, red-painted and burnished, r 53 (large example in coarse red clay), and a small saucer, Type $4 \vec{b}$, plain. Scattered over the room was a good deal of pottery, including a tubular libation-pourer, AT/37/226, cf. Pl. CXXXI, a White Slip milk-bowl, three red burnished jugs of Type $48 a(A T P / 37 / 327-8-9)$, and a brown burnished pilgrim-flask Type 44, a beaker (Type 94) with bands of orange-brown paint, ATP/37/3 I 4, two red burnished jugs of Type $48 a$, and plain examples of Types $4 b, 63,99 c, 108 b, 143$, and 153 (cooking-pot ware).

Room I3. In the north corner a low bench rising from a floor of real concrete made with small black pebbles. Much pottery in the room, including a fragment of a tubular libation-pourer, a White Slip ware milk-bowl, ATT/37/306, a red burnished jug of Type 6ob, a beaker, Type $93 b$, with bands of red paint on a light ground, two unpainted but burnished jugs (Type 48a) of pinkish-buff clay, miniature size, ht. c. $0.15 \mathrm{~m}$., a large and a small cooking-pot, Type I 53 , a vase-stand, Type 86, painted red and vertically burnished, ATP/37/386, a jug, Type 60b, of red burnished ware, and three plain examples of Type $4 a$, and one of Type 90.

Room I4, which had had a concrete floor, was almost entirely destroyed; there remained a terracotta drain (five sections) under the SE. wall, each 'section' being really a clay ring-stand of Type $84 c$, and the rough stones at the intake seemed to be the foundations-for foot-stands (but the room is unduly large for a lavatory and there may have been here a different type of drain, possibly a washing-basin). No objects or pottery could be attributed to the room except one fragment of a Base-ring ware jug, Type B.M. 24 with oblique strokes of white paint round the belly.

house 39/A. See plans Pl. XXII and Fig. 63. Sqq. E-G i 7, i 8

The house had been soundly built with mud brick over rubble foundations and what remained of it was fairly well preserved, the walls standing to an average height of a metre; but the whole of its NE. side had been destroyed by the town wall of Level III, and its SE. side by the later houses; it was therefore impossible to estimate the size or recover the ground-plan of the building as a whole. It had been founded early in the Level IV period, so much so that the destruction of its SE. quarter had been effected to make room for its neighbour, house 38 ; but the rest of it had been rebuilt and was in contemporary use with that neighbour through the remainder of the period. Presumably the entrance had been from the south-east; certainly the large room I seems to have been the central court and light-well, but as there was no access from it to the range of rooms 4 , 5 , and 6 it is possible that rooms I, 2, and 3 formed a kitchen wing with a separate 
entrance, or indeed that they are part of a separate building and that rooms 4 , 5 , and 6 belong to another house.

The small room 2 contained a hearth set on the clay floor; in room 3 there was an oblong raised clay base, apparently also a fire-place; a plain basalt column-base against the SW. wall was not

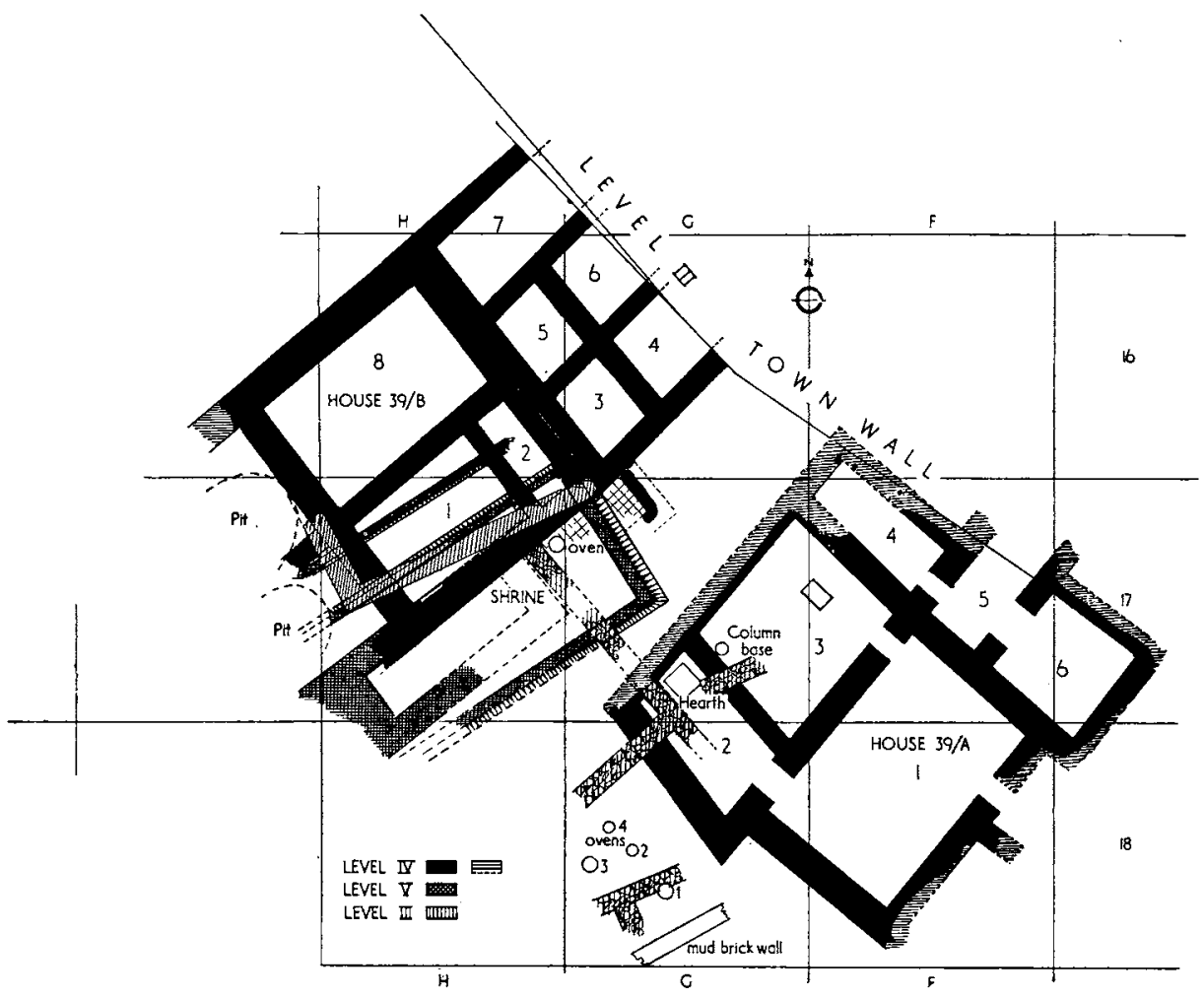

FIG. 63. Houses 39/A and 39/B, Level IV

in situ and does not necessarily belong to the room. In room 3 were found the cylinder seal AT/ $39 / 72$, No. 76 , Pl. LXIV, lying on the floor, and a red clay saucer, Type $4 b$. Room 4 was much destroyed and presented no features of interest. In room 5, but above floor-level and therefore belonging either to a Level IV upper room or, perhaps, to Level III, there was a lump of black clay (from a tablet?) bearing a seal-impression, AT/39/40. Room 6 was remarkable in that it preserved much of its original decoration, an 'architectural' fresco representing in colour the stone orthostats, beams, and plaster characteristic of a palace or temple; on this v. pp. 23 I sqq. and Pl. XXXIX.

In the room was found the terra-cotta figurine AT/39/7I, Pl. LVI.

House 39/B. See plans, Pl. XXII and Fig. 63

The building was remodelled at least once and probably twice during the Level IV period. In the NW. half of it some of the walls may go back to Level $V$ or are founded on Level V walls; the south part, however, is later and runs over the top of the Level V shrine which itself persisted into the Level IV period; ${ }^{\mathrm{I}}$ that the house as a whole belongs to the Level IV period was conclusively shown by the fact that its $\mathrm{NE}$. wing runs underneath

\footnotetext{
1 For this reason we at first attributed the house to Level III, but were mistaken.
} 
the Level III town wall. The original house was L-shaped and was built up against the little Level $\mathrm{V}$ shrine, but over the top of the other Level $\mathrm{V}$ platform to the northwest of the existing shrine; the ground-level in and round the house rose $0.50 \mathrm{~m}$. to $0.60 \mathrm{~m}$. during its occupation and at some time when this rise was in progress the shrine was abandoned and buried and the bend of the $L$ was filled in by the construction of rooms I and 2. Although the ground-plan could be recovered completely so far as the walls were concerned, there remained of the latter no more than the foundation-courses and in no case was it possible to trace features such as doorways.

$\operatorname{Room} x$. This, with room 2 , is the addition made to the original house, only the NW. wall being old-in the case of room 2 the NE. wall seems to have new brickwork plastered against what had been the outer wall-face. Two floor-levels were noted, one $0.15-0.20 \mathrm{~m}$. above the other, both of beaten clay mixed with rubbish. At a later period the shape of the room was altered, a new exterior wall being built askew, and new stone foundations were laid over the surviving brickwork of the NE. wall of the room; this change was posterior to the upper floor-level in the room and probably is part of a general remodelling in the Level III period. To the south-west of rooms I and 8 large rubbish-pits apparently belonging to Level III had destroyed the whole of this end of the house. Immediately below the lower floor of the room were found sherds of milk-bowls of White Slip ware I and II indiscriminately. In the room were found a gold crescent pendant, cf. AT/39/IO3, Pl. LXIX, and a bronze awl set in a bone handle, AT/39/ 100 .

Room 2 . The floor or floors had gone, and the faces of the walls had disintegrated. In Room 3 only the upper floor-level could be distinguished; the walls were cement-plastered. In Room 4 the lower floor survived, but the walls were destroyed down to its level; a belt of rubbish flush with the floor ran across the line of the NW. wall and suggested a doorway into room 6 , but there was no brickwork left to confirm this. The wall-foundations ran on to the north-east under the Level III city wall. Below the wall dividing rooms 3 and 4 there was a basalt bath, $0.96 \mathrm{~m} . \times 0.56 \mathrm{~m}$. $\times$ $0.60 \mathrm{~m}$., its base $0.90 \mathrm{~m}$. below Level IV floor-level; it must belong to Level VIII. In room 4 were found two cylinder seals, AT/39/89 and AT/39/93, Pl. LXIV, 73 and 87. Room 5 had had cement plaster on its walls; its floor was $0.20 \mathrm{~m}$. lower than that of room 3. Room 6 had two floors $0.20 \mathrm{~m}$. apart; both of them, and the walls, ran on under the foundations of the Level III city wall. On the lower floor there lay in the south corner a plain tripod bowl of basalt and also a tripod saucer (Type I 63) of red clay. Room 8 was certainly part of a Level $V$ house incorporated in that of Level IV, for its walls went down, and connected with them there was a clay floor nearly o.80 $\mathrm{m}$. below the normal level of the Level IV floors; a line of rubbish $0.90 \mathrm{~m}$. above it corresponded with the upper floor of room $I$.

Between this house and house $39 / \mathrm{A}$ there was an open space approximately $5.00 \mathrm{~m}$. wide which was presumably a street leading to the city wall. Late in the Level IV period there was an encroachment on this. Since the early part of the period there had been in the 'street' outside house $39 / \mathrm{B}$ a bread-oven standing on a patch of pavement made with baked tiles $0.29-0.30 \mathrm{~m}$. sq. $\times 0.045 \mathrm{~m}$. thick. Subsequently this was enclosed by a shed or outbuilding with walls of burnt bricks measuring $0.38-0.39 \mathrm{~m}$. sq. $\times 0 . \mathrm{I}_{4} \mathrm{~m}$. As only a short length of the NE. wall was preserved, the dimensions of the building are unknown, but no traces of wall or pavement could be found at more than $3.00 \mathrm{~m}$. from the house-front. It is worth noting that the floor tiles are of the same type as is found in the floor of the forecourt of Niqme-pa's palace.

house 39/C. See plans, Pl. XXII and Fig. 64

Between houses $39 / \mathrm{B}$ and $39 / \mathrm{C}$ there was a street $3.50 \mathrm{~m} .-4.00 \mathrm{~m}$. wide leading to the town wall. The house $39 / \mathrm{C}$ had been very large, but its NE. side underlay the Level III 
town wall and was not excavated by us and the SW. side was hopelessly ruined, so that the full extent of the building cannot be known. It was well built, the mud-brick walls always having rubble foundations, and there were stone door-jambs (not in situ) probably belonging to it; the fact that it possessed a newel staircase (in room 14 ) would seem to

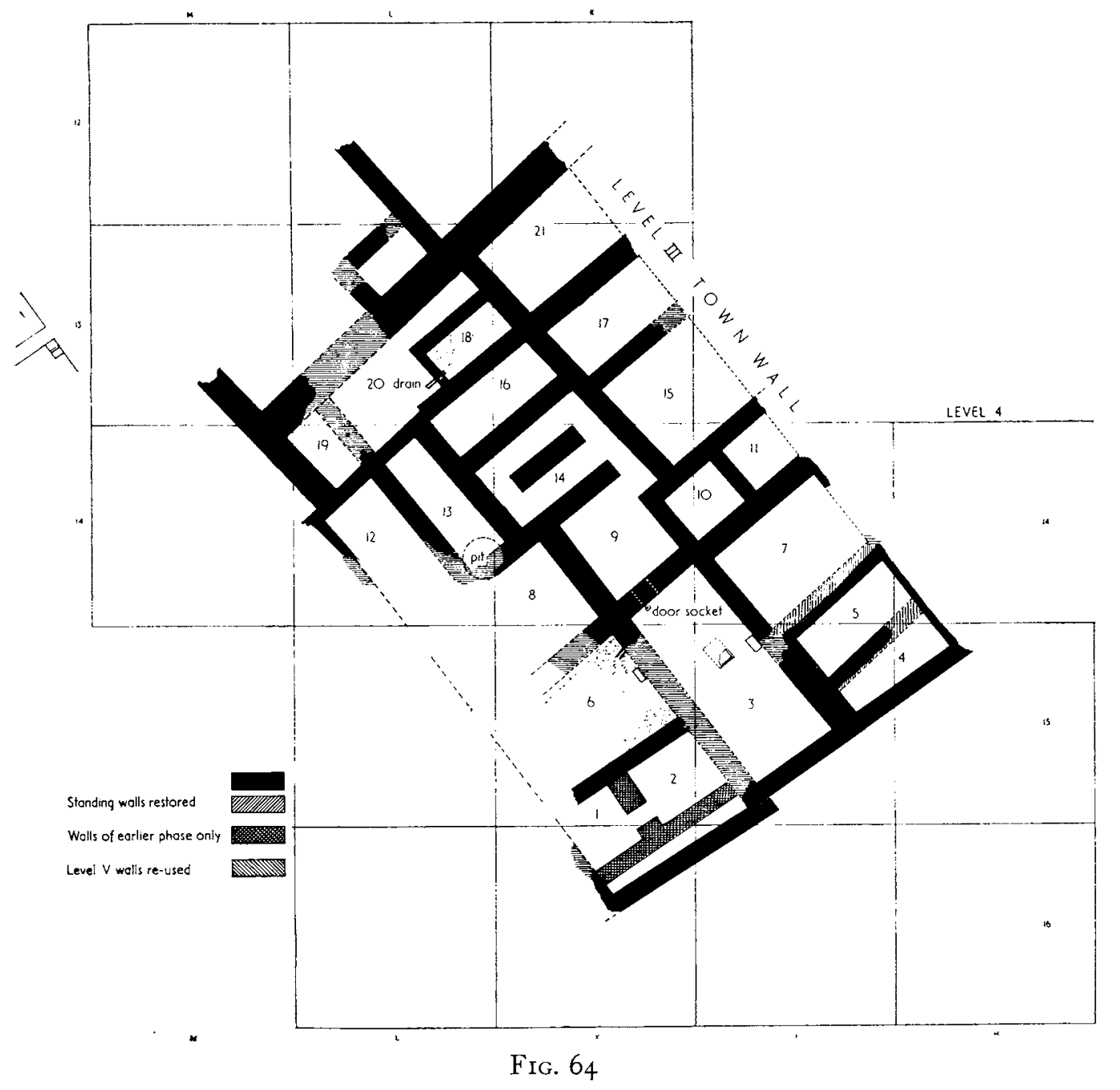

show that it was of unusual importance. But it was terribly ruined, the walls being so destroyed that the emplacement of the doorways could seldom be determined, and the stratification was so complicated that it was seldom possible to assign objects to a definite level. It lay immediately above a Level $\mathrm{V}$ building, some of whose foundations were re-used in the Level IV house-e.g. the skew walls between rooms 4, 5, and 7 are taken over from the earlier period-and in the Level IV period the house was practically rebuilt, though with very little change of plan, the most important change being in the south corner where rooms $I$ and 2 of the original building were thrown into one by the elimination of the cross-wall and the area of the new room enlarged by razing the old 
outer (SE.) wall and building a new one outside it. Further, there was very little interval between Level IV and Level III, and some of the later walls of Level IV were re-used in the following period, though for a building of an entirely different character.

Room 3. Clay floor; towards the centre part of a rectangular hearth; a large square stone set against the NE. wall may have been a sort of table. Against the NW. wall a hinge-socket stone apparently in situ gives the position of a doorway. A bronze spear-head, Type Sp. Io (AT/39/ I 6AA) probably belongs to this room but may be of Level III. A small clay pot with perforated base, Type I 29a (ATP/39/264), was found more or less on the line of the broken wall between rooms 3 and 6.

Room 6. Traces of a cement floor. Practically nothing left of the walls. Just where the NE. wall breaks away near the north corner there was one section of a terra-cotta drain coming out from the wall-line; a little farther on there was a square stone embedded in the floor which may have been an impost for a door-frame. In the room was found a rather well-modelled terra-cotta figurine of a humped ox, AT/39/272, Pl. LVII. Fragments of wall-plaster coloured white, red, and blue were found in rooms 6,8 , and 9 .

Room 7 . Only the outlines of the room partly preserved. In it a beaker, Type 93c, painted with bands and figures of ducks, $A \mathrm{TP} / 39 / 273$.

Room 13 . Remains of a clay floor. A little above it (and therefore possibly of Level III, but more probably fallen from the upper floor of the Level IV house) the curious terra-cotta relief AT/39/ 240, Pl. LIV o.

Room $x$ 4. Certainly a staircase room, the central block of brickwork being the newel. This shows that the house was of two stories.

Room 18 . Cement floor. The drain running out through the SW. wall shows that this muchruined little room was the normal lavatory. Two cylinder seals, AT/39/20I and 2 I5, Pl. LXIV, Nos. 86 and 85 , were found in and just outside the room and judging by their stratification were more likely to belong to Level IV than to Level III. In the same area and at the same level was found the gold pendant, AT/39/209, Pl. LXIX.

To the north-west of the lavatory everything was inextricably confused; a number of short lengths of disconnected walling running in various directions with very little difference of level could not be accurately dated. Some were probably of Level V but may have been re-used in the next building to occupy the site; others which seemed by their level to belong to Level IV were difficult to reconcile with any consistent constructional scheme. On the plan are entered such walls as at the time of excavation were marked as being of Level IV or V-IV and could possibly connect with the rest of the building; but it must be admitted that the lavatory drain virtually precludes the idea of the irregularly shaped 'room 20' being a room; possibly the rooms marked as 19 and 20 belonged to an older layout and when the house was remodelled and the lavatory built were dismantled and became an open court-but for this there was no other evidence. The heavy wall bounding rooms $\mathrm{I} 9$ and 20 on the north-west may, by virtue of its unusual thickness, reasonably be taken as the party wall between two houses. It is definitely an old wall, belonging to Level $\mathrm{V}$ by its foundation and re-used in Level IV, and the branch walls from it running north-west may well belong to Level V only; the longest one, in Sq. $L_{\mathrm{I} 2}$, runs up to and is cut away by the SE. wall of the military building in the angle of the town rampart which is certainly part of the Level IV defences. ${ }^{1}$

I See Ch. IV, 'The Town Defences', p. I 38. 
On Site $\mathrm{H}$ the house-remains in the highest stratum were shown by the associated graves to belong to Level IV, but only the stone wall-foundations survived, nothing like a complete house-plan could be recovered owing to the small area excavated, and no objects were found which could safely be assigned to the rooms; no detailed description therefore is necessary.

\section{THE LEVEL III HOUSES}

On the 1937 site, Sqq. B I 9-2 I, G I 8-20 (plan on Fig. 52), the Level III houses had been largely obliterated by the builders of the succeeding period. For the most part those builders reproduced exactly or nearly exactly the old houses; they levelled the walls and on the trimmed stumps of them laid their new brickwork, only occasionally departing from the original plan to the extent of enlarging one room at the expense of another or turning two rooms into one by the omission of a cross-wall. ${ }^{I}$ But on the NE. part of the site there was complete destruction. A new town wall was to be built, and its line was to be well inside that of the wall of the Level III town; and along the back of the wall there was to be an open space, a gangway at least, between it and the houses. The NE. end of the Level III housing-area therefore was either swept clear to make the roadway or was wiped out by the foundations of the town wall.

Nothing is to be gained by publishing the disconnected fragments of walls and floors which alone represent the Level III houses; in so far as they could be traced they are shown in outline on the Level II plans, or at least the more coherent remains are shown there, but many quite isolated or doubtful wall-remains have been deliberately omitted although in the course of the excavations they were duly recorded for the certifying of the stratification; their evidence for stratification constitutes indeed their only value, since they have no architectural significance, and whatever information they yielded in that respect has been fully utilized, especially in the analyses of pottery, bronze tools, and weapons, \&c. Certain general statements, however, must be put on record.

Nowhere could we detect any alterations to or rebuilding of the Level III houses, nor anywhere more than a single floor-level. The whole level was contained in a thin stratum. Where, as was so often the case, the Level II walls were built directly upon the old, little more than the foundations of the latter were used. The normal thing upon this site is that where a late wall is based on an earlier the lower part of that earlier wall was buried in the debris of the building to which it had belonged and the later builders merely trimmed the top of it and laid their bricks on the flat top; consequently when we come to excavate we find the old wall standing to a height of anything up to a metre. But in the case of the Level III buildings there was very little debris, so that the Level II builders either utilized the standing walls or else cut them down virtually to floor-level. Taking this evidence as a whole, one must conclude $(a)$ that there was no violent overthrow of the

\footnotetext{
I Thus in house 37/A the NE. half of the Level II building is a replica of the old and therefore none of the old walls appear independently on the ground-plan; in the SW. half (where the walls in solid black on the plan are those of Level
}

II and the Level III walls are shown in outline) there have been considerable changes, but they are changes of detail and the general character of the house has not been altered. 
Level III houses leaving a ruin-field over which the next generation had to build; rather, the houses remained standing and in use until they were sufficiently out of date to justify replacement; and $(b)$ that the period during which they were in use was not unduly long. As illustrated by the house ruins the process of transition from Level III to Level II was not so marked as that between Level XII $\mathrm{A}$ and Level XII B, or between Level XII $\mathrm{B}$ and Level XII c, or again between Level I A and Level I в.

In the area Sqq. J-M i 4-i 6 there had been houses of the Level III period, but very little of them remained; the field notes record that here "the levels lay close together and were mostly in bad condition, so that little sense could be made of the plan. Level II here petered out on the surface and of Level III there were only a few bits of walls.' In view of this the disentanglement of the surviving remains was difficult, but it did become evident that some belonged to Level III properly so called, some to what we called provisionally an 'intermediate' level distinct from the Level II stratum which we had followed up from the neighbouring area of house $39 / \mathrm{C}$ where the Level II buildings (v. p. I 89) were well preserved. The intermediate walls did not agree with the layout of either of the systems above and below them-i.e. they imply not the patching of an original building but a new construction which in its turn was disregarded by the authors of the main Level II houses; whether they belonged to a late phase of Level III or to an early phase of Level II the archaeological evidence did not suffice to prove (the best dating evidence, fragments of White Slip II ware milk-bowl and of a Base-ring ware 'bull' jug like ATP/38/ i 4 on Pl. CXXXI, came from 'below Level II' in Sq. L I 3 where there was a patch of clay floor of doubtful date but no intermediate or Level III walls), but since the evidence of the site generally is that Level III was shortlived it is safer to attribute the intermediate phase in this area to the early part of Level II. In Sq. L I 4 were found, in the Level III stratum, plain clay vessels of Types $3,55 b, 68 b$, and I 53; in Sq. K I 4 an alabaster stand or pommel, AT/39/264, Pl. LXXXII, 29; in Sq. M I 4, low down in the stratum, two pottery ring-bases of Type 85 , part of a tall red burnished lekythos of B.M. Type 25, fragments of Nuzu ware and of L.M. III в vases.

In Sq. L I 3 , on the patch of clay floor already mentioned, were clay vessels of Types $4 b, 18,2 \mathrm{I} a, 32,103 b, 104 b, 140$, and 165 ; but it is uncertain whether these belong to Level III or to the early part of Level II.

\section{THE LEVEL. II HOUSES}

The largest area dug was that along the NE. wall of the city, in Sqq. B-J I 6-23; v. the plan, Fig. 65. The city wall runs askew to the general layout of the houses, and as a clear space, presumably a roadway, had to be left along the inner face of the wall, the housebuilders had to accommodate their plans to it and the NE. ends of the houses are irregularly stepped with salients intended to make the fullest possible use of the ground but leaving a passage between them and the fortifications. We cleared for a length of about $45.00 \mathrm{~m}$. a street running NE. $\times \mathrm{SW}$. between blocks of buildings each of which represented two or more houses built one against another, and our work was subsequently 
extended to the north-west to cover the greater part at least of another house backed on to those facing the street, house $38 / \mathrm{B}$.

The ground-plan of this area and of house $39 / \mathrm{C}$, Fig. 66, show clearly enough that the private houses of Level II do not conform to any recognized pattern; each householder seems to have had his own ideas as to what constituted a desirable residence. We have always to make allowances for the fact that occupation of the site was continuous; the buildings were repaired more often than they were rebuilt, and even when the ground-plan was changed might incorporate some elements of the older structure or, for economy's sake, utilize the stumps of old walls as foundations for the new-a tendency which is well illustrated by rooms 8-10 of house 37/A. Unfortunately throughout our main area the walls were not standing to any height; their stone foundations could as a rule be traced, but most of the mud brickwork had disappeared so that such details as the position of doorways could seldom be ascertained and thereby the plans, complete as they seem at first sight, lose greatly in interest and the comparison of the internal arrangement of the different houses becomes much more hazardous. It is, however, clear that neighbouring houses might be of very different sizes-rich and poor lived cheek by jowl-and so far as the fabric was concerned rich and poor houses were much alike. The mud-brick walls generally rested on foundations of a single course of limestone rubble rising just above floor-level and presumably acting as a damp-course, for the stone is sometimes used even where a new wall is built upon an old. The walls were generally mud-plastered and whitewashed. Floors were in most cases of beaten clay, but occasionally a layer of white cement was laid either directly on the clay or on a course of baked tiles, and in the latter event the cement would be carried a little way up the face of the wall as a skirting, usually over a row of tiles set on edge against the face of the mud brickwork (v. Pl. XXXVb). The walls are usually more solidly constructed than the size of the rooms would seem to require, suggesting a second story, and though in the ruined condition of the buildings it was not to be expected that any actual stairs should survive, there was generally (e.g. room 3 in house $37 / \mathrm{A}$ and room 5 in house $37 / \mathrm{C}$ ) a narrow space between walls which might well have contained a staircase; it is likely that there was an upper floor over part of the building at any rate, though that need not be true of the smaller houses. The ground-plan further makes it clear that some of the 'rooms' of these closely packed houses must have been open light-wells.

Many of the walls of this group of Level II houses showed signs of fire, and it was noted that some of the room floors were littered with ashes. Over the whole area, but especially in the street between houses $\mathrm{A}$ and $\mathrm{C}$ and in rooms $\mathrm{I}$ and 2 of house $\mathrm{C}$, there were quantities of bronze arrow-heads and some clay sling-bolts; room 5 of house $\mathrm{C}$ (which was perhaps a cupboard under the stairs) was full of baked clay sling-bolts and ballista-balls; of the considerable quantity of 'Atchana' ware-the luxury ware of the period-collected from the site the bulk came from the street and most of the rest from the front room ( $\mathrm{I}$ ) of house $\mathrm{C}$. The evidence therefore is strongly in favour of the quarter's having been destroyed as the result of a struggle after which the houses were sacked and burned. It should be stressed that in these Level II houses the painted Nuzu 
ware, including that with the specific 'Atchana' decoration, is very common; the position in which it is found, the bulk of it either outside in the street or just inside the front doors of the houses, implies that its destruction was in some way connected with what led to the fighting and to the destruction of the houses; and the ware disappears abruptly and completely with that destruction; it is never found in the Level I houses which immediately succeeded those of Level II. This requires an historical explanation.

HOUSE $37 / \mathrm{A}$

The most remarkable feature of the building was its front door, flanked by large attached halfcolumns in mud-brick. The only other example of an attached half-column found at Atchana is of very much earlier date ( $v$. p. I $42, \mathrm{Pl}$. XXXVIa) and I do not know of any on any other site. It is curious that so rare an architectural feature should be found in a private house which does not seem to have been very large. So far as can be judged in the absence of most of the doorways the house contained only the 'rooms' numbered on the plan I to I I, of which room 3 is certainly a staircase and room 2 perhaps a light-well. The solidity of the outer walls enclosing this rectangle suggests that they give the limits of the building; but on the one hand rooms IO and I I might belong to another house (with a doorway through a lobby at the NW. end) and on the other as we found no separate entrance to house $37 / \mathrm{B}$ it is possible that they are all parts of the same structure; but there were no doors in the dividing wall.

In room I were found fragments of the 'Atchana' vase ATP/37/2, Pl. CII $a, b$. The jambs of the doorway to room 2 had been destroyed; the NE. and SW. walls were too ruined for doorways to be traced. In room 7 there was a rectangular brick base (? hearth) in the west corner and against the NE. wall a brick-edged mud-filled bench which may originally have run the entire length of the room. At a late date in the lifetime of the building a thin mud-brick wall with no stone foundations had been built NE. $\times \mathrm{SW}$. across the middle of room 7 , and another, NW. $\times$ SE., across room 6 ; these additions are not shown on the plan.

In rooms 8,9 , and Io most of the walls rest on the stumps of much heavier walls of Level III (shown in outline on the plan); generally speaking the plan seems to have been much the same, but the Level III wall underlying the SW. wall of room Io is differently aligned. The SE. (street front) wall also has not quite the same orientation in the two periods. In room ro were plain pottery jugs of Types 40 and $69 b$; in room I I a bronze arrow-head, AT/37/I 48 , Type Ar. I3, and a piece of scale armour AT/37/37, of the longer type figured on Pl. LXXII.

South-west of the house the building continued but the walls no longer rested on those of Level III, but both their bonding and the fact that they bore the same marks of burning show that they are contemporary with House $37 / \mathrm{A}$.

\section{House $37 / \mathrm{B}$}

This was a small building whose walls were for the most part much thinner than those of house $37 / \mathrm{A}$; we therefore judged it to be a separate building, the more certainly because the wall between them was sufficiently preserved to have given the position of doors had there been any. The building itself was so badly ruined that not even the entrance door on the street could be identified; the rooms are few, the layout very simple, and the thin walls can hardly have taken an upper floor; it was either a very poor dwelling-house or a shop.

In the foundations of the SE. (street) wall was found a fragment of a L.M. III vase with the design of a snake spotted in white (Pl. CXXXIV), together with which were numerous fragments of White Slip ware milk-bowls. In room 5 was found the splendid 'A tchana' style krater ATP/37) $230, \mathrm{Pl}$. CIII - it was broken, and fragments of it were found in the adjoining rooms-while the 


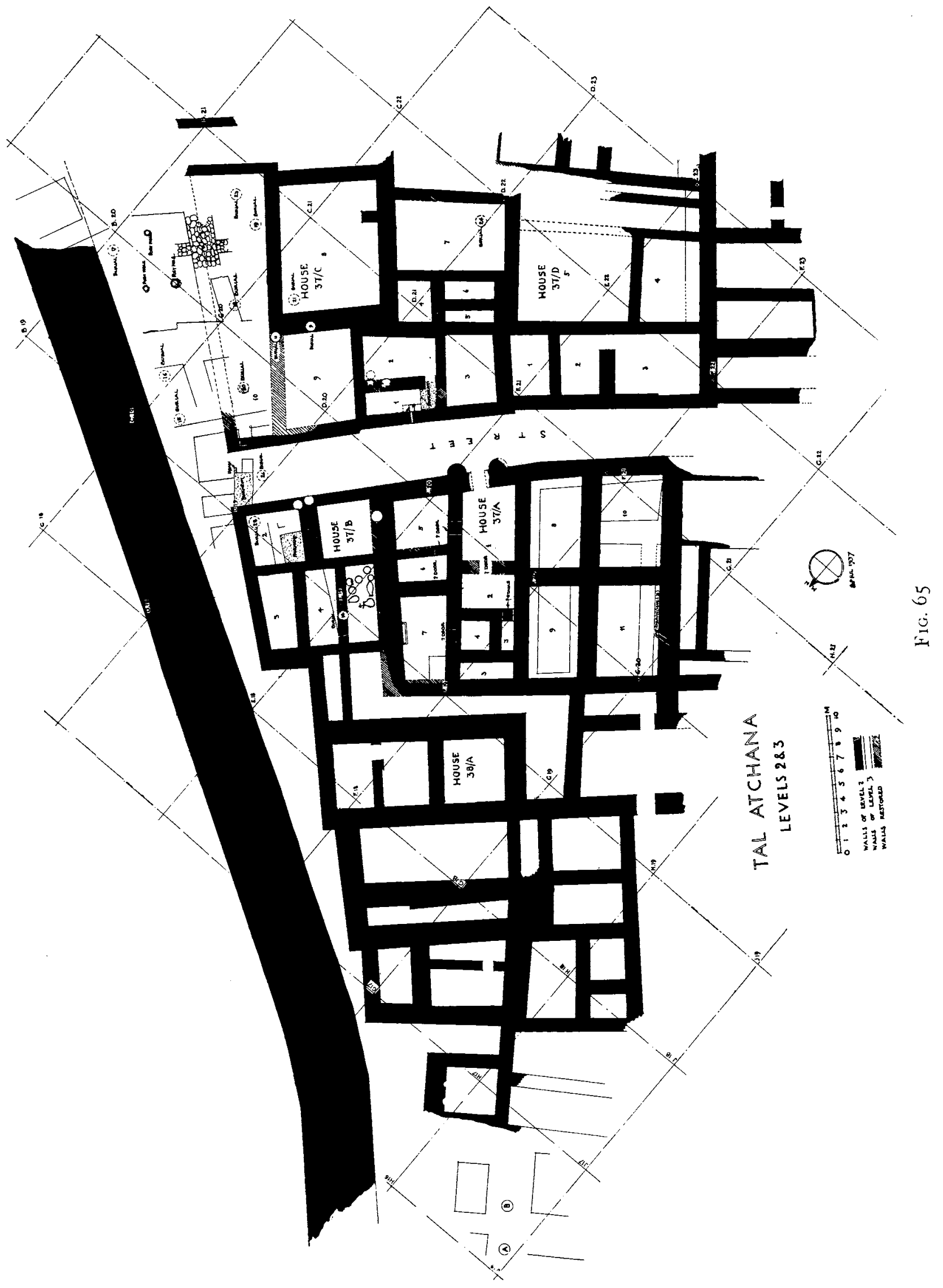


SE. end of it was filled with a collection of store-jars including an example of Type $\mathrm{I} \circ 8, \mathrm{r}$ and also fragments of a L.M. III stirrup-vase.

\section{HOUSE $37 / \mathrm{C}$}

When we excavated the house, in 1937 , I was guilty of a serious misunderstanding. Although some of the walls were unusually well preserved there was found, according to my statement in the preliminary report $(A . \mathcal{F}$., loc. cit.) 'only one door opening on the street; there was at this point a breach in the wall and the NE. jamb had disappeared, but the existence of the doorway was made certain by the fact that SW. of the breach the wall had footings of burnt brick running through its thickness and proving that it ended here in a door-jamb', and I went on to say how curious it was that the paved and sloped area (implying that a liquid might be split here) 'came directly in front of a door which could only be reached by stepping across what was presumably a wet spot'. We had not at that time learnt the character of the Alalakh lavatory. Here we have just such a lavatory; but the breach through the wall has removed one of the two foot-rests and one half of the bricklined exit drain - it was the remaining half of that drain that I mistook for the footings of the doorjamb. ${ }^{2}$ There was no door here, nor did we anywhere find the entrance to the building; but it is most likely that this isolated breach in an otherwise well-preserved wall is a breach made by the assailants who captured and sacked the house; it would indeed be difficult to explain it otherwise. ${ }^{3}$ The whole of the NE. part of the building has been swept away to clear the ground for later constructions; the entrance to the house may well have been on that side.

Room I was then a lavatory. The floor $(\mathrm{Pl}$. XXXVb) was of cement over clay; the walls had a dado of tiles set on edge and cement-plastered; the foot-rests were of tiles, also plastered, with a brick-lined drain through the wall - the sinking of the floor, visible in the photograph, which makes the drain run in the wrong direction, is certainly due to later accident ${ }^{4}$ and, in addition, there was let into the pavement a large clay jar (only the lower part of it is preserved) for water. The pavement stops at the threshold of the door to room 3 but continued across the threshold of the door to room 2. The tiles used measure $0.27 \mathrm{~m}$. sq. $\times 0.05 \mathrm{~m}$. thick. On the floor of the room were very many fragments of painted vessels of Nuzu ware. Room 2 had a floor of greenish clay covered with wood ash, which was most plentiful against the walls; the NW. wall was almost entirely destroyed by two burials and by two circular ovens which had been dug down into it from a higher level. In the room was a pot of Type I 02, apparently of Nuzu ware (the paint had scaled off), and fragments of two other Nuzu vases. In room 5, probably a cupboard, were two sling-bolts and a quantity of baked clay throwing-balls or ballista-balls. In room 7 there were two vases, one of Type 64, one of Type I 53. Room 8 showed evidence of the house having been remodelled, as one wall simply abutted on that of room 2 (see plan), but so little of the construction was left that nothing beyond the mere fact could be established.

To the north-west of this everything was completely ruined and even the outlines of the building could not be satisfactorily fixed. On the plan no attempt has been made to reconstruct this area; there were patches of floors at successive levels, fragments of walls, all cut about by late burials, hearths, and post-holes none of which made any sense. Immediately below the foundations of the revetment added in Level I to the town wall there was found the fine dagger, AT/37/57, Type Kn. 4, belonging to Level II, and also a clay lamp, Type I67a, and a cooking-pot of Type I 53;

\footnotetext{
I These first appeared in Level $I$ and were attributed to that level, but subsequently they were found to be resting on the clay floor of the Level II room. In the plan in my provisional report, $A . \mathcal{F}$. xviii ( 1938 ), Pl. Ir, they still appear as in the Level I house.

2 I know no instance of a door-jamb having burnt brick footings.
}

3 The trial trench cut by us in I936 did nearlv coincide with the breach; but (a) it was at a higher level and $(b)$ it did not interfere with the immediately adjoining SW. wall, and it could not have destroyed one without destroying the other.

4 It was noted at the time that the slope was due to subsidence. 
a group of pots including the Types $54,62 b$ (one plain, one with red bands), $9 \mathrm{I}$, and 99 were found standing together beside a small circular hearth set on a patch of cement pavement which judged by its level seemed to belong to Level II but might have been earlier; this was in Sq. C I 9 , within the area of room 10 of house $37 / \mathrm{C}$, and a few fragments of Nuzu ware found with the pots were at least consistent with a Level II date, but do not confirm it. Over the whole of the space between the house and the town wall our digging was really unremunerative; neither coherent plans nor consistent stratification rewarded us and the voluminous notes taken proved in the end to have no value. Between house $37 / \mathrm{B}$ and the town wall the lane was paved with small cobbles, but farther to the south-east nothing of the kind was found; this disappearance of the road surface shows how much the site had been disturbed.

The surface of the long street between houses $37 / \mathrm{A}-\mathrm{B}$ and $37 / \mathrm{C}-\mathrm{D}$ was quite well preserved, a level of hard trampled mud. That surface, especially close to the entrance of house $37 / \mathrm{A}$, was littered with debris which included many bronze arrow-heads, a complete beaker of Type 94 with bands of dark red paint, an example of Type 4I, plain, and numerous painted vessels (all broken) in the Nuzu and 'Atchana' styles.

\section{HOUSE $37 / 0$}

This ill-preserved and rather irregularly constructed house looks as if it were of the simple type with a central courtyard (room 5) having chambers round three sides of it and a staircase in the west corner; but the walls were much ruined, most of the doorways untraceable, and the plan therefore uncertain. In room I were found fragments of 'Atchana' ware and a plain jug of Type 69. In room 5, at just about floor-level, slightly above it, was found half of a milk-bowl of White Slip II ware, an unusually late occurrence of that ware. An example of the curious spouted bowl Type 38 was found in the room bordering the street south-west of room 3, probably part of the neighbouring house.

\section{HOUSE $38 / \mathrm{A}$}

This is a large building, or buildings, backing on the two houses $37 / \mathrm{A}$ and $37 / \mathrm{B}$; the NE. face is built in a series of offsets to allow of a lane running between the house and the differently orientated town wall. The walls vary very much in thickness; stone foundations were used only occasionally, and in many cases the walls rest on the stumps of Level III walls or are themselves Level III walls rebuilt or re-used. The building is ruined down to a level at which no doorways remain; apart from one entrance (?) door at the SW. end it is quite impossible to suggest the use of the various rooms or to make sense of the ground-plan. In the small room under post $G$. I 7 there were two clay ovens let partly into the face of the NE. wall, but it was not certain that they were contemporary, though blackening on the wall-face did suggest that they were. No floors were left, nor were any objects of interest found that could be safely associated with the ruins.

\section{HOUSE 39/C. Fig. 66}

The house was fairly well preserved and the complete ground-plan was recovered. The walls had no stone foundations but were unusually heavy; evidently there had been an upper story, and the house was one of importance. The walls were generally ruined down so low that the door openings could not be detected, so that the details of the plan are missing; judging by the layout, room I I must have been unroofed, serving as a light-well, and it is likely that the main entrance was through the small room I 2. Room I was certainly an open court and gave light to rooms 2, 4, and 6; a bronze pin, Type P. I I, 
was found here. There must have been a staircase, of which no trace remains; but as most of the walls of rooms $2,3,4,5, \mathrm{I}$, and $\mathrm{r} 2$ were represented only by their underground foundations no evidence of the stairs was to be expected.

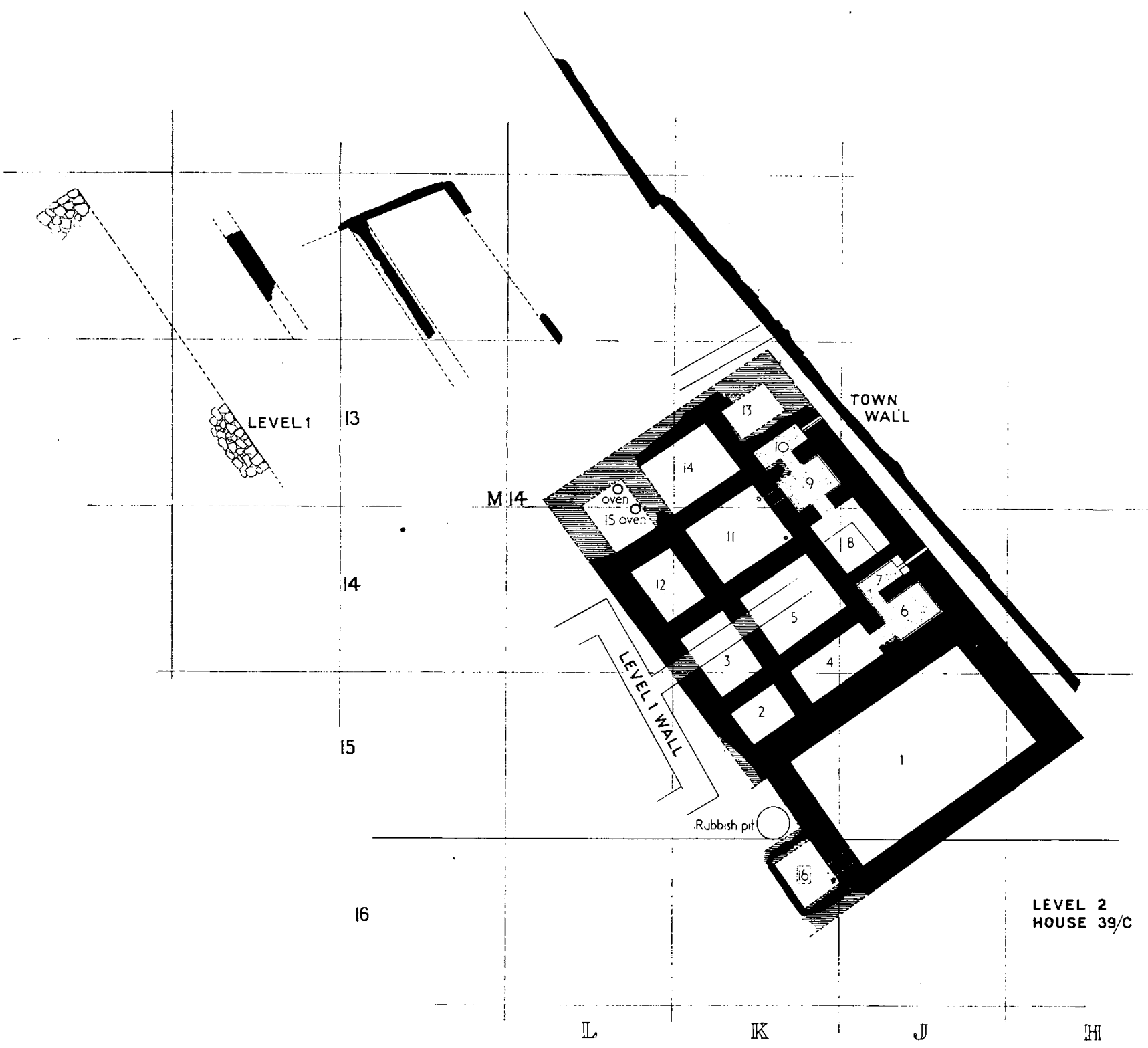

FIG. 66

Three saucers of red clay (Type 32, ATP/39/193A-C) were found together on the clay floor of room 5. Room 6 had a cement floor and round the walls and against the door-jambs a dado of burnt tiles set on edge and faced with cement, the top of the cement having a rolled finish. Room 7 had a similar floor and dado and against the NE. wall the ordinary lavatory arrangement with a tile-paved outlet through the wall; the foot-stand was of three courses of brick. During the life- 
time of the house a new cement floor was laid down in the lavatory $0.25 \mathrm{~m}$. above the original; in the filling between the floors were a fragment of a White Slip ware II milk-bowl and numerous fragments of painted goblets painted with the Atchana design; the 'Atchana' ware therefore should belong to the early part of the Level II period or, at any rate, was introduced then. Room 8 had a clay floor only, but $0.20 \mathrm{~m}$. below it was a smaller room with cement floor and tiled and cemented dado; if it belongs to Level II it witnesses to a remodelling of the house for which there is no other evidence, and more probably it is to be assigned to a late phase of Level III. Room 9 had had a cement floor and cemented tile dado, but only two tiles and part of the floor remained, as owing to local denudation the room lay very close to the modern surface. Room Io, a second lavatory, was similarly floored and equally ruinous; the foot-stand had disappeared; the outlet through the wall was a channel made of two tiles set $V$-fashion; a vase, Type 447, of red clay by it. In room I I (the central courtyard?) there was against the NE. wall near the north corner a doorsocket stone in situ which must have served the door leading into room 9; a second socket-stone near the east corner was apparently displaced and may have belonged to the door to room 5 . Of room I 3 scarcely anything remained, even the faces of such walling as survived having gone. A fragment of a plain vessel, Type I $5^{8}$, and a bronze pin, Type P. $4, \mathrm{AT} / 39 / 32 \mathrm{~K}$, were found in the room.

Room I 4 contained a great deal of pottery, including fragments of a burnished red clay 'spindlevase' of 'Cypriote' type, a jug painted with a plain red wash, Type 60a (ATP/39/I 47), a cookingpot, Type I 52 , and plain examples of Types $4 b, 7 a$, I I, I 5, I $8,42 b, 64 a, 68,9$ I $b$, I $08 b$, I $52 a$, I 58 ; also a bronze arrow-head, Type Ar. 5 (AT/39/I 6), and the horns of a large bull. Room I 5 had a circular clay oven in the north corner and a second against the NE. wall; on the clay floor were several clay ring-stands (Type 85). Three cylinder seals were found in the room, AT/39/167 (Pl. LXVI, I I 8), AT/39/166 and I 67, these much worn and designs illegible; also a Mycenaean piriform vase, ATP/39/168, Type B.M. 5 I, some beads (AT/39/I 75), and piain examples of pottery types 77 and I 58 , a goblet of Type $94 a$ with bands of red paint, and a cooking-pot.

Room I 6, which seems to have been a small shed (or lobby?) opening off the large court, had in its east corner a hinge-stone for a door in the NE. wall. On the clay floor was a quantity of broken 'Atchana' ware goblets; one fragment was found to fit on to a fragment from fairly deep down in a rubbish-pit dug (in Sq. K I 5) in the angle between the NW. wall of room $\mathrm{I} 6$ and the SW. wall of the main building; it was at the bottom of that rubbish-pit that we found the red marble lamp of Cretan style, AT/39/280, Pl. LXXIX (v. p. 294). The lamp was of course thrown down into the pit as being an old, broken, and unwanted object; it is not dated by its find-spot; but it was thus discarded in the early part, apparently, of the Level II period. In the same pit were several examples of pottery ring-stands, Type 85 , a plain jug of Type $64 b$. Near the pit and in the Level II stratum was a bronze chisel, Type Ch. I, AT/39/160, also three pottery ring-stands, Type $84 c$, and a basalt rubbing-stone.

HoUse $38 /$ A. Fig. 67

\section{THE LEVEL I HOUSES}

The walls were built with no stone foundations, of mud-bricks, made of a dark blackish mud full of lumps and grains of white lime, a characteristic material for bricks of the late period; such are crumbly in texture, with a bad surface, and are extremely difficult to follow. None of the walls stood more than $0.20 \mathrm{~m}$. high and most of them, where they existed at all, stood only up to or below floor-level; for the most part they were based on walls of the Level II building and had to be restored according to the older plan. It was possible to recover a large part of the ground-plan, but in very few cases could the 
emplacements of the doorways be determined, and as most of the floors had been broken up stratification for objects was none too satisfactory.

The house lay just inside the town wall, its NE. side built in a series of set-backs to accommodate it to the different orientation of that wall. The only entrance found was on the lane running along the inner face of the wall; here, room I, the hinge-stone of the door was found in situ. Just outside the door, in the lane, was found a (poor) cylinder

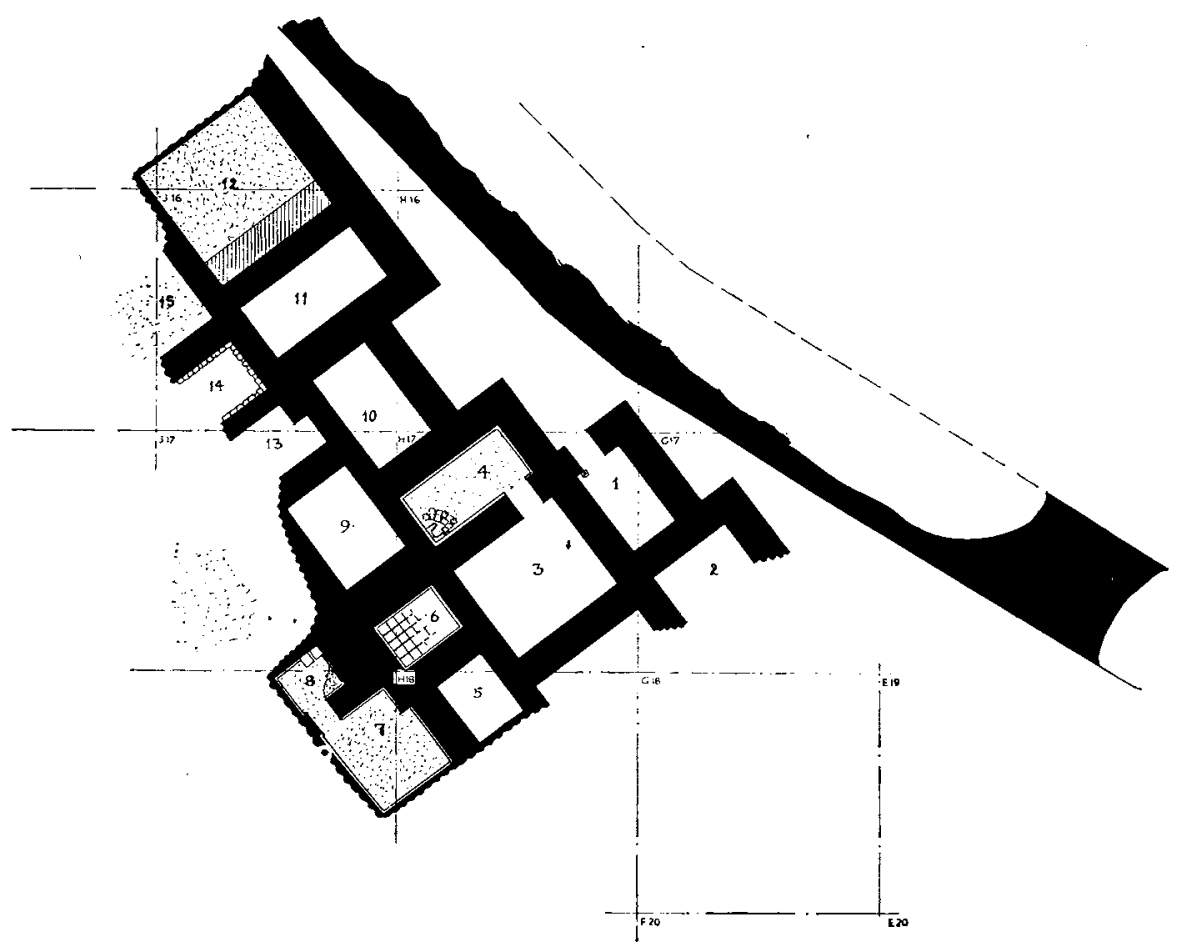

FIG. 67. House 38/A, Level I

seal of white frit, $\mathrm{AT} / 3 \dot{9} / 73$ (not illustrated); it should belong to Level I. In room 3 were found, at floor-level, a bronze arrow-head (AT/39/33), Type Ar. I I, and a bronze pin, AT/39/32, of Type P. 4; at $0.50 \mathrm{~m}$. below the floor was half of a Nuzu painted goblet, definitely in Level II. Room 4 had had a cement floor and round the walls a dado of tiles set on edge and cement-faced; in the south corner there was a three-sided tile and cement raised compartment (? a pot-stand) in front of which a curved trough or runnel also of tiles. Room 6 had had a tiled floor. Room 7 had had a cement floor and a tile dado; room 8 was a lavatory of the traditional type with cement floor, tile dado, and cement plaster on the walls (not only on the dado) and the raised lavatory stand of tiles and cement. The whole of the western side of the house had disappeared, so that only the corners of rooms I 3, I 4 , and I 5 remained; but although the walls had gone the floors could be traced for some distance; in Sq. J I 6 there was a white cement-faced floor belonging to Level I and about $0.30 \mathrm{~m}$. below it a floor of small pebbles which must be of Level II; fragments of Nuzu pottery were found between the two floors. There were 
remains of the same white floor in room $\mathrm{I} 2$, which proved that the house had been partly remodelled during the Level I period. The original walls of that room are shown in black on the plan; they go down below floor-level (the SE. wall had stone foundations where it did not rest on Level II brickwork) and the floor is laid against them; but a later wall, hatched on the plan, was built to change the shape of the room, and this wall rests directly on the white floor. There were traces of a higher floor-level connected with the late wall. There are therefore at least two phases represented here of the Level I period, both of which seem to be anterior to the latest graves dug into the ruins, several of which contained L.M. III pottery. Of the ruined area in the west half of Sq. H I 7 the field notes record that a good deal of it was effectively 'corked' by patches of intact Level I floor; the patches lay at circa I.30 m. below the modern surface, and in that $\mathrm{I} \cdot 30 \mathrm{~m}$. there was not found a single sherd of Nuzu pottery; but there were Mycenaean sherds, including fragments of a 'chariot' krater. Below the floors there was a stratum of ashes and brick rubble crossed in one place by a belt of pebbles which seemed to be a Level I wall-foundation; under the pebbles was found part of a L.M. III piriform vase (Type B.M. 5 I) and by it part of a Nuzu goblet with rosette decoration.

For one object possibly connected with the house the dating evidence was not satisfactory; this was the fine cylinder seal AT/39/68, No. I 35 , Pl. LXVI. It was found just outside the building, about $3.00 \mathrm{~m}$. from it, on the line G I6-I , actually lying on the brickwork of the ruined town wall; it was more likely to belong to Level I than to Level II, but the find-spot is not decisive.

HOUSE 37/A. Fig. 68

This was a large and originally well-built house, but was found in very bad condition. The walls, resting almost always on the stumps of the walls of Level II, did not, for that reason, have any stone foundations. The building had been destroyed by fire and not only were the walls and floors reddened by heat but the brickwork had been reduced almost to powder, so that it was difficult to distinguish the wall-faces from the burnt debris filling the rooms; and with denudation so little of the walls remained that the position of doorways was in many cases doubtful. It was, however, possible to recover the greater part of the ground-plan.

The house lay close to the town wall, separated from it by an irregular alley, and it faced on a fairly wide street running $\mathrm{NE} . \times \mathrm{SW}$. The entrance from the street was through a recessed doorway of which the jambs had disappeared but could safely be restored by the analogy of the older building on the site.

The door gave on a clay-floored lobby (room I) from which a door led into room 2 and perhaps a second door into room 4 . In room 2 there was a big cooking-pot, Type I 53 , serving as a store-jar let into the floor, and on a heap of ashes by it were plain clay jugs of Types 68 and 69 .

Room 3, probably an open court, clay-floored, had against its NE. wall two large and one small bases built of bricks and clay; by the side of the NW. base there was a brick-edged hearth; between the large and small bases was found a hinge-stone, but it was not necessarily in situ-if it was for a door it must have been a cupboard door. Between the NW. base and the corner of the 


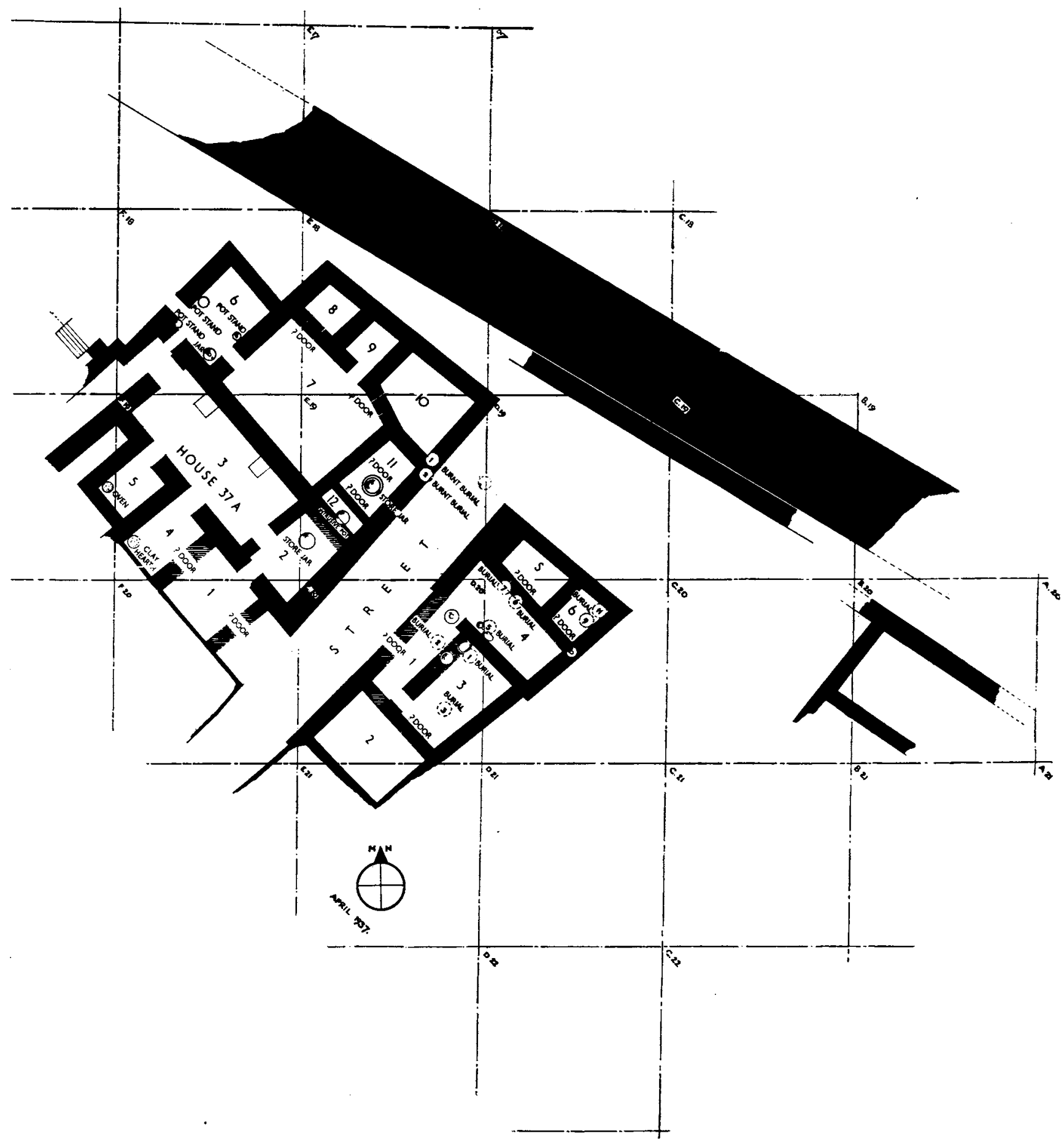

FIg. 68. Houses 37/A and 37/B, Level I 
room was the base of a large jar sunk in the floor as a hearth; close to this stood a basalt tripod bowl and there was a second towards the SE. end of the room; a pottery ring-stand, Type 85 , and a socketed bronze chisel lay near the NW. wall, and inside the clay hearth-pot were a bronze axe, Type Axe I, and a bronze sickle, Pl. LXXIV.

Room 4 contained a clay hearth and room 5 a bread-oven. In the NW. wall of room 3 there was a wide doorway leading into a recess on the right of which was a doorway into room 6 and on the left a long narrow passage closed by a doorway; there were no brick jambs, but the charred planks of the lower part of the actual door were found in situ encased in the burnt debris. I It is tempting to suggest that the 'passage' was really a cupboard under the second or return flight of a staircase the lowest treads of which, in solid brickwork, can be seen on the other side of the NW. 'passage' wall.

In room 6 there were three clay ring-stands, two of Type 85 , one of Type 88 , and a large (broken) jar. The threshold of the door from the recess was of stone overlaid with clay; another door to room 7 had a flush threshold.

Room 7 was certainly an open court and light-well with rooms opening on to it on three sides; owing to the ruinous condition of the walls the doors had for the most part to be arbitrarily restored. All the walls are of Level II rebuilt (i.e. use the Level II walls as foundations) except for the SE. wall and the short skew bit of the NE. wall near the east corner; these have shallow foundations of broken brick and a little stone only $0.35 \mathrm{~m}$. below floor-level. A group of large store-jars was found in the room ( $v$. the plan) but finally proved to be lying on a lower floor belonging to a late version of the Level II house; amongst them was ATP/37/2 30 , part of a krater, Type 82, painted in the 'Atchana' style. This lower floor was traced under room 9 also, and there was on it a fragment of a figure or zoomorphic vase of Nuzu style, while on the upper (Level I) floor was a fragment of a L.M. IIIb flask like ATP/38/37 on Pl. CXXXIII. In room i i there were the remains of a store-jar let into the floor. As several intrusive cremation-burials had cut down into the house walls (e.g. in rooms IO and I I) from an upper level which, owing to the presence with them of L.M. III vases, must belong to Level I, the house as we have it must be assigned to the earliest phase of Level I, the graves to the latest; such a dating would accord with the fact of there being a Level II (late) floor only $0 \cdot 40 \mathrm{~m}$. below the floors of the Level I building.

The plan of the house is interesting. It is divided into two parts between which there is only one connecting door (in room 6); the SW. half with its hearths and oven seems to be definitely domestic, but even the NE. half with its store-jars and the shoddy bit of crooked building in the east corner of the court hardly seems to afford living-quarters fit for the owners of so large a house. If, however, the NW. door of room 6 does not mark the limits of the house but led into another room or court, and if my suggestion is correct that the steps there are the beginning of a flight of stairs that returned over the long passage-cupboard, we should then have a building quite in the old tradition of Alalakh, two stories high, with the owner living on the piano nobile whose rooms would run round the SW. and SE. sides of the light-well formed by courts 3 and $7 .^{2}$

There are no remains of Level I to support or to contradict this suggestion; beyond the

I In my preliminary report in the $\mathcal{F} . H . \delta$., vol. lvi (I 936), part ii, p. I $3 \circ$, I suggested that this was panelling, a view which subsequent excavation disproved. In the same account I failed, where the actual floor of Level I had disappeared, to distinguish between the Level I and the Level II strata, seeing that the same wall was in use in both periods; consequently I attributed to Level I some 'Atchana' sherds which lay in fact, as indeed I remarked, below the level of the Level I room floor.

2 In my preliminary report $(A . \mathcal{F}$. xviii, I938, p. 3 ) I put forward a different explanation - that the NE. half was the domestic section and the SW. intended for social functions. At that time we knew nothing of the old two-story house. 
steps the last traces of the walls of the period have been denuded away and there is a complete gap between house $37 / \mathrm{A}$ and house $38 / \mathrm{B}$ of the same date. On the other hand, the walls of Level II do run continuously across this gap, and since house $37 / \mathrm{A}$ is very largely a replica of the Level II building on the same site, it can fairly be assumed that in this gap also the later building followed more or less the lines of the earlier. I have suggested this on the plan, and it will be seen that with the addition only of a side wall for the staircase a very reasonable plan emerges; the new NW. boundary wall is suitably solid; the double return by the staircase, which was anomalous in an exterior wall, is unobjectionable in an interior wall, and the staircase falls into place at the back of a courtyard; possibly that court had a doorway on to the lane by the town wall.

HOUSE 37/B. Fig. 68

The house faced 37/A across the street and, like it, followed closely the lines of a Level II building, using the stumps of its walls as foundations. Unfortunately it was too ruined to present any great interest; it had been burnt, and the red and powdery brickwork had been so weathered away that really no more than a corner of what may have been a large building could be traced; moreover, the area was honeycombed with the pits made for later burials (themselves often denuded) which had disturbed the levels as well as destroying the standing walls. Even the entrance-door on the street was problematical and had to be restored as shown on the plan, a gap in its length making this possible.

In room 5 there was found what was clearly the stock-in-trade of a working jeweller, a number of long bars of gold, $0.0075 \mathrm{~m}$. wide and $0.003 \mathrm{~m}$. thick, lumps of gold, molten and dropped into water, some of which had been clipped, and two pairs of earrings, AT/37/29, Pl. LXIX. In room 6 there was a plain jug of Type $67 b$, but it may have belonged to a later burial as it lay very close to a cremation-urn.

House $38 /$ B. Sqq. P-Q 9-1 2. Fig. 69

The house belongs to the earliest phase of Level I. It is in part overlaid by the walls of buildings of two later periods of which the latest, mere rough rubble foundations of a curiously irregular type, a large horse-shoe curve being its most prominent feature, may perhaps be assigned to Level $\mathrm{O}$, but the other, a heavy buttressed wall which alone survives of a building that had apparently extended over the whole house site, must also belong to Level I. In Sq. P Io there was found a group of L.M. IIIB pots, ATP $/ 38 / 5,6$, 7 , in a grave dug down into the ruins of room 2; it is therefore obvious that there was a thirteenth-century occupation-level later than the destruction of the house; on the other hand, it is not possible to put the building so early as Level II because the whole of the stratification was against this and also the house, which did extend farther to the southwest, could not have been contemporary with the great fortress of Level III-II, ${ }^{\mathrm{I}}$ but could have existed side by side with the reduced fortress of Level I.

I Its NW. corner would have overlapped the fortress wall. Actually a clear space was always maintained round the fortress. 
What remains would seem to be the central part of a very large building of which the SW. limits have disappeared, ${ }^{\mathrm{I}}$ and the SE. end, if it belongs, is incomplete. It is well and regularly laid out and the walls are fairly solid, but have no stone foundations.

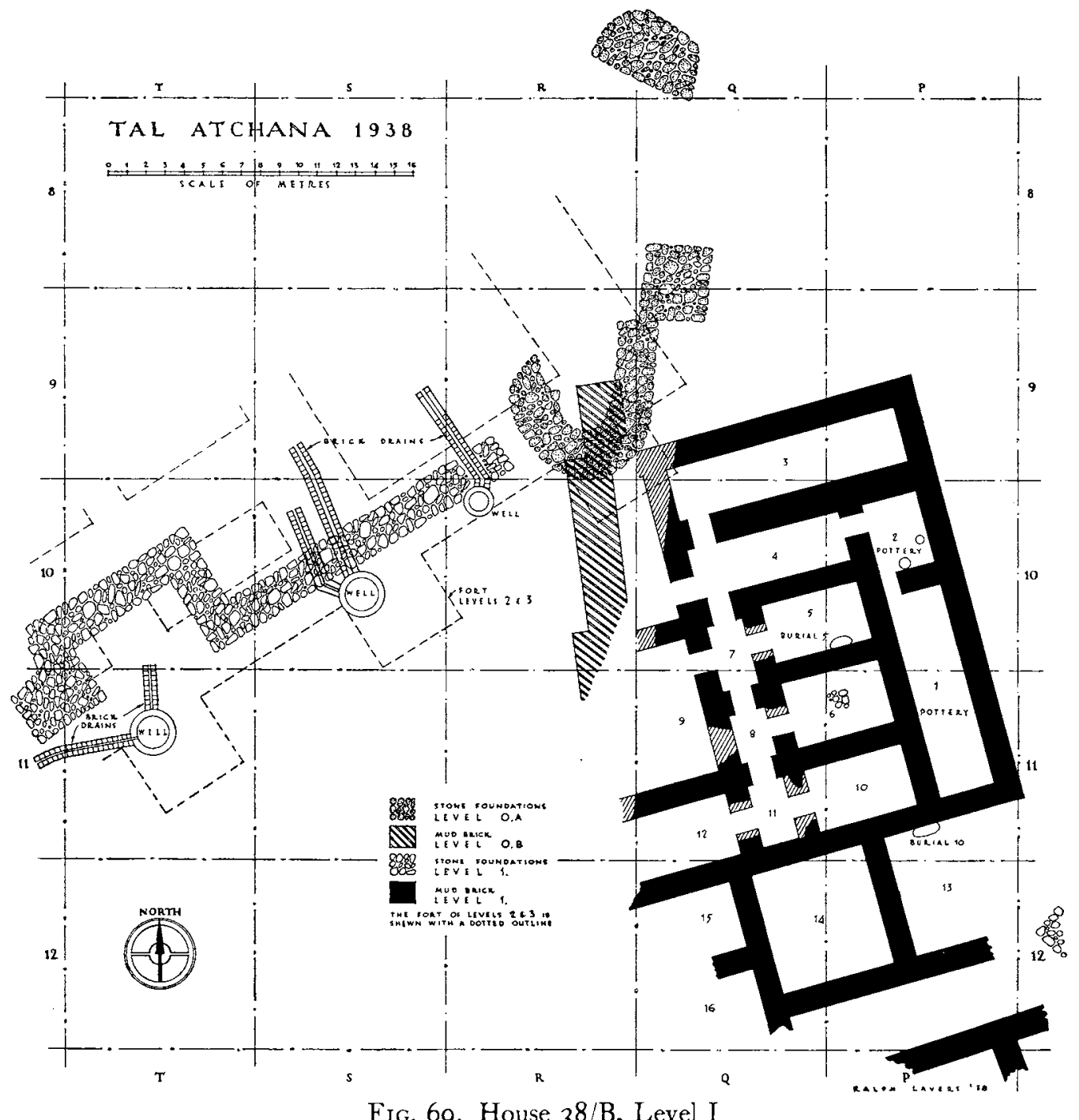

Room $x$. In the room, but above floor-level, there were numerous pots including a L.M. IIIB piriform bugelkanne, $\mathrm{ATP} / 38 / 226$, and plain examples of Types $69 b$ and $9 \mathrm{I} b$, fragments of large store-jars and a rough basalt bowl. In room 2 were two large bowls inside one of which a L.M. IIIB two-handled flask, ATP $/ 38 / 8$. In room 4 there were several fragments of 'Atchana' ware together with L.M. IIIB fragments; the Atchana pieces represented at least three vases; it was noted that while they lay apparently above floor-level there was really no floor preserved and 'their appearance here might be accidental'-it would indeed be the only known occurrence of this ware in Level I. There was also in the room a piece of bronze scale armour, AT/38/ 37 .

I This on the supposition-not necessarily correct-that the rooms 7,8 , and I I form a corridor more or less central to the house. 
Room I3. The NE. wall and the east corner had been destroyed. Near the face of the NW. wall was a group of clay pots, all plain, of Types $44 b, 68 c, 85$, and I $07 a$ and two practically flat platters, $\operatorname{ATP} / 38 / 146$.

Room I4 had in its NW. corner a small patch of stone paving; near the SE. corner, at the same level, was a patch of pavement of burnt tiles $0.27 \mathrm{~m}$. sq. $\times 0.05 \mathrm{~m}$. thick (the tiles laid diagonally to the room); in the room were a very roughly cut basalt bowl and a clay saucer of Type $3 b$; in the brickwork of the wall in the SE. corner was a horseshoe-shaped ingot of copper, diam. $0.19 \mathrm{~m}$. In room 16 there was a patch of white lime pavement.

\section{THE YARIM-LIM SITE AFTER THE DESTRUCTION OF THE PALACE}

The palace of Yarim-Lim occupied a position of such importance both strategically and from the point of view of amenities that one would have expected it to be succeeded at once by a new palace or public building. In fact, nothing of the sort happened. The collapse of the two main blocks resulted in the formation of two mounds about five metres high, composed of fire-reddened brick rubble with stumps of standing walls rising yet higher, separated by a depression representing the central courtyard; beyond them to the south-east there was a larger and a deeper depression running along the foot of the city wall where had been the servants' quarters, low-roofed and thin-walled. The city wall, which in this area was apparently not seriously damaged, continued in use during the following periods, ${ }^{I}$ but for a long time the palace site itself was for the most part left desolate. At the extreme SE. end we found very scanty remains of buildings of Levels VI and V, remains too scanty to make sense (v. Fig. 6I), which in some cases incorporated standing walls of the servants' quarters; the hollow in which they lay cannot have been a very salubrious site for houses (we found evidence in the shape of repeated strata of water-laid soil showing that in wet weather the place was a morass) and a great deal of it was used simply for digging rubbish-pits. ${ }^{2}$ But over the main blocks we found no trace at all of Level VI and only a few disconnected wall fragments of Level V (in Sqq. N Io, $\mathrm{N}$ I I, O Io, and O I I); only in the Level IV period does there seem to have been any systematic building, and then a good deal of it was, judging by appearances, of a military character connected with the town defences. ${ }^{3}$ Obviously, before any building could start, the site had to be levelled. Digging down from the surface we came upon a stratum of crumbly red brick earth diversified with patches of grey; the latter proved to be pockets in the surface of the ruin-field which had been filled by the builders with imported soil. But the 'levelling' was very perfunctory. Not only was the surface as we found it most irregular, but contemporary wall-foundations were laid at remarkably different depths-the foundations of one and the same wall would dip and rise with the inequalities of the ground surface. ${ }^{4}$ On this high terrace the

I v. supra, p. I 37 .

2 Fig. I7, the plan of the remains of the Level VIII and IX buildings underlying the kitchen courtyard of YarimLim's palace, makes this clear; all the pits are of Levels VI and $\mathrm{V}$.
3 v. supra, p. I 38 .

4 As we were dealing very often with disconnected walls, this fact made our dating of them the more diffcult. In a vertical interval of about $1.50 \mathrm{~m}$. five building periods were represented, but in trying to distinguish these the relative 
builders of successive periods tended to make a clean sweep of any older buildings which they proposed to supplant rather than to create a new level by filling in between the old walls; there was little accumulation of soil, the building-strata came very close together, and only where the foundations had been more deeply laid did isolated fragments survive; and lastly, on this exposed area denudation of the surface after the fall of Alalakh in II 94 B.C. was unusually severe. Our excavation of these upper strata was therefore disappointing. It would be unprofitable to describe it in detail. Elsewhere I have dealt briefly with what appear to be the military buildings of Level IV (v. p. I 38 ), but of the yet more fragmentary remains of Levels III, II, and I nothing could be said. Such objects as were found could not be associated with buildings when the buildings themselves were so indeterminate; sometimes they could not be dated at all, sometimes their right level could be distinguished or, more vaguely, they could be described as coming from below or above the only tolerably clear stratum of Level IV. The more important of them are described below in the order of the squares in which they were found.

Sq. M ro. AT/39/6r. Torso of a terra-cotta figurine, female, Type of AT/49/I 7, Pl. LIV. Level $\mathrm{V}$.

AT/39/9. Bronze saw, 1. O.4 I m. Above Level IV, close to Level I foundations.

AT/39/1 3. Bronze lance-head, Type Sp. I, 1. 0.125 m. Above Level IV.

ATP/39/44. Jug of red clay, Type $69 b$, ht. $0.20 \mathrm{~m}$.; close to it was a large lump of iron. In the upper soil.

Sq. MII. AT/39/4B. Bronze arrow-head, Type Ar. I6, 1. ०. I0 m. In the top soil.

AT/39/25. Bronze arrow-head, Type Ar. I $7,1.0 .057 \mathrm{~m}$. A bove Level IV.

ATP/39/ I I 7 . Bowl of red clay, Type $26 a$, ht. $0.25 \mathrm{~m}$. Just below Level II.

Sq. MI2. Jugs, of red and of drab clay, Types $44 c$ and $69 a$. From Level II-III.

Fragment (the spout) of a libation-pourer in grey steatite (cf. Pl. CXXXI). Close to remains of Level II wall.

AT/39/58. Terra-cotta, a ram's head. Below Level III.

ATP/39/49D. Jug, of drab clay, Type $69 b$, ht. $0.27 \mathrm{~m}$. Below Level III.

Fragments (several) of black impressed pottery. At $3.00 \mathrm{~m}$. below the Level II floor.

ATP/39/I 82. Jar of reddish drab clay, Type 82 , diam. $0.33 \mathrm{~m}$., with a saucer of red clay, Type $6 a$, as cover. Below the Level II-III floor.

ATP $/ 39 /$ I $54 \mathrm{~A}$. Vase of red clay, Type I 50 , ht. $0.46 \mathrm{~m}$. Just below Level II.

Of Sqq. M I 2-I 3, N I 2-I 3 the field notes record that down to a depth of $1.80 \mathrm{~m}$. there were scarcely any walls, at best lines of stones giving no true face; but there were clay floors the limits of which were indeterminate. Several cremation-burials had been cut down into or through the main distinguishable clay floor (which was at $1.60 \mathrm{~m}$. from the modern surface) and were therefore later in date than the floor, but one, in the angle of two walls in Sq. M I2, was contemporary, with the use of the building. On the floor there were Mycenaean sherds and pieces of 'Atchana' ware. The floor must be attributed to Level II, the graves to Level I. Some very heavy stone foundations in Sq. $\mathrm{N}_{1}$ 3, continued in Sq. O I2, should be of Level I or perhaps of Level O. In Sq. M I 3 approximately at Level II there were found examples of pottery types I I and I 46.

depth of wall-foundations (there were no floors left) was, we found, of doubtful assistance. I have, however, retained on the plan a number of levelling-data which may help to explain my attribution of walls to periods; but it may be observed that three points measured on the inner defence-wall of
Level IV give such different figures as $3.73 \mathrm{~m} ., 4.06 \mathrm{~m}$., and $4.38 \mathrm{~m}$. Broadly speaking, Level $\mathrm{V}$ comes at about $3.50 \mathrm{~m}$., Level IV between $3.50 \mathrm{~m}$. (minimum, generally $3.85 \mathrm{~m}$.) and $4.40 \mathrm{~m}$., Levels III and II at about $4.50 \mathrm{~m}$., Level I at about $5.00 \mathrm{~m}$. 
$S q . N 9$. A cuneiform tablet was found in the NE. corner of the square slightly above the level of the top of the Level IV stone foundations close to which it lay.

In $S q . N$ Io the stratification seemed to throw some light on the state of the site when the 'terrace' was levelled. The pockets in the red surface of the ruin-field had been very roughly levelled and the ground was still irregular; over the top of the hard imported grey soil therefore further filling had been laid, and this was red burnt brick rubble precisely like that below the grey. It was fairly evident that at the time of the filling stumps of the Level VII palace walls still rose above ground, and these had been demolished to provide the material required to finish the job. In this square there were found in the filling one tablet, ATT/39/2, a pot of drab clay, ht. $0.08 \mathrm{~m}$., Type 2 I c, fragments of three bowls with strainer spouts, probably Type 37 , and AT/39/48, a bronze kohl-stick of Type I, and some fragments of gold foil.

$S q . N_{I I}$. Over the south end of the square there was a cobble pavement $0 \cdot 40 \mathrm{~m}$. below the modern surface and, associated with it, a stone door-socket; these should be of Level I. Below this, at $\mathrm{I} \cdot 30 \mathrm{~m}$. down, there were scanty remains of a pavement of burnt tiles $0.27 \mathrm{~m} . \times 0.26 \mathrm{~m} . \times$ $0.05 \mathrm{~m}$. thick, probably of Level II or III. A bronze needle (AT/39/6c) was found at this level, another $(\mathrm{AT} / 39 / 6 \mathrm{~B})$ had been found at $0.70 \mathrm{~m}$. down, and at approximately the same level but exactly in the middle of the square, the cylinder seal, AT/39/I 7, Pl. LXVII, I 4I. At I.50 m. down was a (broken) Nuzu ware painted goblet, ATP/39/5, with design rather like that of Pl. $\mathrm{CIVb}$, which is therefore later than Level IV; at $\mathrm{I} \cdot 60 \mathrm{~m}$. down an iron fibula, AT/39/20, Pl. LXXIII; underneath the stone foundations in the NE. corner of the square, which apparently belong to Level $\mathrm{V}$, were fragments of a milk-bowl with wish-bone handle. Impressions of two Hittite bulla seals, AT/39/39, found in the hard grey packing of the terrace filling, are unexpectedly early if so be that they were in their true horizon-but with small objects in this confused area it would be unwise to put too much faith in levels.

$S q . N_{12}$. Below a clay floor of Level I came the good cylinder seal, AT/39/1 70, Pl. LXV, I03; on grounds of style, since it is definitely Hittite in character, one would assign it to Level III, so that it was not far from its true horizon. From much the same stratum came a gold lunate ear-ring, AT/39/I 7 I , and from just below a Level II clay floor a clay goblet of Type $93 b$ with bands of red paint and a clay lamp of Type i $67 a$.

$S q . N_{13}$. There was a good deal of pottery here; at $0.70 \mathrm{~m}$. down were examples of Types $68 c$ and $107 a$; at I.00 m., three ring-bases, Type 85 ; at $2 \cdot 10 \mathrm{~m}$. examples of Types $3 b$, I $5,42 a$, I 50 . Close to some very fragmentary foundations probably of Level III was a very crude stone figure, AT/39/204; conditions show no more than that it is earlier than Level III.

$S q . O_{I I}$. Immediately above the terrace filling were a few bricks apparently from a pavement in which was a large circular pit, $0.30 \mathrm{~m}$. deep, unlined; close to this and with its rim at the same level was a large pot containing a bone pin, two beads, and some potsherds; there were no bones, but it may have been a burial, in which case it could not be related to the pavement. In the south part of the square the walls shown on the plan were of Level V or early Level IV; they had been cut away when Ilim-ilimma dug away part of the terrace to make room for his palace annexe. Associated with the walls was a pin with coiled head, AT/39/ I I. On a clay floor close by were found fragments of a Mycenaean flask; under the same floor fragments of a White Slip ware milk-bowl. 


\section{CHAPTER VI}

\section{THE GRAVES}

LL the graves found by us at Atchana were on the town site; no cemetery outside
the residential area was discovered. The graves lay under or close to the houses.
The earlier levels, IX to XVI, produced no graves at all. We dug through
the house sites and had there been any burials there they could not have escaped us; it is true that the area excavated was not very large, but in most levels it included the remains of from one to three houses, so that had it been at that time the custom to bury the dead below the house floors we had every opportunity of finding them. The fact that none were found would seem to imply that the custom only developed later.

But even at a later date the practice cannot have been universal. The number of graves is very small in proportion to that of houses and to the total period of time which the houses represent. The vertical interval between our levels is not very great-it averages a metre, but that is only an average and very often the floor-levels come much closer together; consequently each level is liable to disturbance by the people of the level immediately above and wall-foundations and rubbish-pits have contributed much to the destruction of the underlying remains. A number of recorded graves had been disturbed in this way and their contents removed or smashed; a very great many more, probably, had been completely destroyed and so were not recorded by us. But if all allowances be made for the disappearance of graves and even if it be assumed that the original number was twice that actually found, the total remains small for the area and for the period of time. The practice of burying under the houses can hardly have been general. It is perhaps worth mentioning that some graves were quite definitely not underneath the houses proper but in open courtyards attached to the houses, and sometimes rubbish-pits had been dug in the same courtyards; this may imply that the place for the grave was not dictated by any religious consideration (as was certainly the case at Ur in the Larsa period). Again, graves were more numerous in association with the smaller houses of the poorer members of the population, e.g. on Site H ( $v$. p. I 43). Motives may therefore have been economic rather than sentimental or ritualistic. I suspect that there were cemeteries outside the city walls which were patronized by the more well-to-do citizens; but since it was easier and cheaper to bury people in one's own freehold many poor folk, and a large proportion of the children, would be interred at home. Just as the orientation of the graves was a matter of indifference, so, I think, the place of burial was one of convenience only.

I publish here only a selection of the graves. Many of those found and recorded were originally very poor, or had been plundered, and a burial whose surviving furniture consists of a single clay vessel of common type adds little or nothing to our knowledge; if such graves were dated by stratification, \&c., they were utilized for the dating of pottery 
types, and they can serve no further purpose. The photographs taken of the graves and the drawings in the field notes showing the position of bodies and objects are not so informative as the written description (especially as so many of the clay vessels were in fragments) and would not repay publication.

The majority of the graves are simple inhumation burials, almost always direct inhumation, but there is at least one case, ATG/46/2, of Level V, of the use of a wooden coffin. The body was laid upon its side with the legs more or less flexed (sometimes so little as to be described in the field notes as 'extended') with the hands brought up in front of the face, or occasionally only as far as the breast. The grave furniture is extremely simple. The dead were buried, seemingly, in their ordinary clothes, for there is generally a pin, sometimes two pins, near the shoulder; they wear their beads, ear-rings, fingerrings and amulets (in the case of the women) or, less often, a cylinder seal. But apart from these personal possessions objects are very few, merely one or two (seldom as many as four) clay vessels; if there was anything else it would be more or less of the personal type such as a spindle-whorl for a woman, knuckle-bones or a doll for a child; there were no weapons. This paucity of offerings to the dead does not appear to be due to any ordinances of ritual, because in one or two cases the norm is exceeded-ATG/38/34, attributed to Level IV, contains eight vases, and ATG/39/7, of Level IV, a double grave, eleven-it is much more likely to be due to the fact that our graves are those of poor people whose grave furniture was limited by reasons of economy. I believe, as I have stated above, that the richer citizens were normally buried in cemeteries outside the city and only the poor under their houses. There is a fair number of urn-burials (unburnt) almost all of which are burials of small children; child-burials in pots are found side by side with adult inhumation-burials in so many countries and at so many periods that their occurrence here calls for no comment. Also there are cremation-burials-of adults-in clay pots. This difference of ritual is obviously important and must be due to some foreign influence. Only thirteen burials of the sort were found and most of them belonged to Level I, being found very near the modern surface and sometimes dug down into the walls and floors of Level I A buildings, but dated to the thirteenth century by the Mycenaean pottery associated with them. A single grave of the sort, ATG/37/2, was an exception, being actually dated by a scarab of Ramses VI to the middle of the twelfth century; but others go back to Level II or III and one must by its position be ascribed to Level V. Cremation would seem to have been an intrusive custom practised by foreign residents a few of whom came to Alalakh as early as the fifteenth century B.c.; later they came in greater numbers and at the end of the city's history formed quite a large proportion of the citizens. The facts are on the whole consistent with those recorded from other sites in Syria and Palestine, where cremation becomes the rule after I 200 в.c. but occasionally occurs at any time after the middle of the fifteenth century. ${ }^{\mathrm{I}}$ The only

${ }^{1}$ At Carchemish cremation is general after 1200 . At Hama the same is true according to Ingholt, but Schaeffer would make the cremation-burials fill up the whole time-gap between 1200 and I 450 (Stratigraphie Comparée, p. I I 2). Single instances at Jericho and at Beit Mersim belong to the fifteenth or fourteenth centuries. At Troy there is a cremationcemetery dated to Troy VI (I 400 B.c.), and the rite is mentioned in a Hittite document from Bogazköy of the fourteenth century. 
difficulty is with our earliest (Level V) burial (ATG/46/9) which cannot be later than the middle of the fifteenth century and may well be of the sixteenth century; but the difficulty is not serious. From whatever area the custom of cremation was introduced into Syria and into western Anatolia, in that area the custom must have been prevalent for a very long time; and if isolated individuals came from that area to Syria in the fifteenth century there is no reason why some should not have come to Alalakh a hundred years earlier; Alalakh, on the borders of Anatolia, would naturally be one of the first places to have contacts with a cremation-practising people if, as is agreed, cremation was of Anatolian origin.

The graves here described are grouped according to their levels, i.e. in historical order, but under two categories. The conditions of some graves enabled us to ascribe them unhesitatingly to a certain level; these accordingly come first on the list and are classified as 'belonging to Level ... ${ }^{\text {I In }}$ other cases the evidence of position justified no more than an approximate attribution-the choice being between two or, very occasionally, between three levels-and here the only course was to be guided by the contents; if amongst the clay vases there were any which the chronological list showed to be peculiarly characteristic of one or other of the levels concerned, the grave was entered as 'attributed to' that level. ${ }^{2}$ There was a residue of graves which could not be dated by either method, and those are described only if their contents merit description.

\section{GRAVES BELONGING TO LEVEL O}

In the field notes a number of graves, including several with pottery or other objects (the majority were empty), were recorded as belonging to Level $O$ because they had been dug down into the walls or floors of Level I buildings. These were found in our first season, before we had reason to think that Level I had more than one building phase; when the three phases of Level I had been established the attribution of the graves to Level $O$ was no longer necessary. In the case of some of the graves that attribution was indeed untenable, because they contained L.M. III vases and therefore could not be later in date than the destruction of Alalakh in I 194. On the other hand, one grave, ATG/37/2, containing a scarab of Ramses VI, could not be earlier than the middle of the twelfth century. Level $\mathrm{O}$ was then definitely post-destruction. In the following description I have classed ATG/37/2 by itself, as the only grave of which we can be sure that it dates to Level $O$; but the possibility remains that one or two of the graves listed under Level I really belong to the later period.

ATG/37/2. Clay jug, Type $63 ;$ ht. $0.40 \mathrm{~m}$. (top broken) with a broad band of red paint round the shoulder. In it, calcined bones and

(a) a steatite scarab with cartouche of Ramses VI (AT/37/47), Pl. LXVI, No. I 3 I ;

(b) a gold pendant with impressed cruciform design (AT/37/46), Pl. LXVIII, No. I 2;

(c) fragments of an ivory comb, the upper part of the handle cut in rectangular cloisons, probably for inlay with coloured paste, AT/37/48, Pl. LXXVIII

(d) a gold ear-ring set with a globular pendant of blue glass (decayed), AT/37/33, cf. $\mathrm{AT} / 37 / 28$, Pl. LXIX

(e) beads; a gold striated ball, an amber ball pendant bound with gold wire, a plain short

I Here, where position was decisive, the grave could be used to date its contents and its evidence has been employed in the chronology of pottery types. In the second case the evidence of the pottery is invoked to date the grave.

2 Such a grave was not admitted as evidence for dating the pottery types found in it. 
tube of gold, a tube and ball of variegated glass, a plain glass ball and scaraboid, frit balls, one striated, the others plain, AT/37/33.

\section{GRAVES BELONGING TO LEVEL I}

\section{Cremation Burials}

ATG/37/ı. Clay jug, Type 63; ht. $0.40 \mathrm{~m}$., with a broad band of red paint round the shoulder. In it, calcined bones and $(a)$ a plain cylinder of glazed steatite, $(b)$ a steatite spindle-whorl, plain, with fragments of the wooden spindle, and $(c)$ one frit bead.

ATG/37/3. The burnt bones lay with burnt earth and charcoal round them; they were not in an urn, but fragments of a large vessel much broken and burnt may once have contained them. With the bones were

(a) a Mycenaean vase, Type B.M. 59, ATP/37/10;

(b) clay jar, Type 95b, with bands of red paint, ATP/37/90;

(c) a plain saucer, Type $7 a$, of coarse ware, $\mathrm{ATP} / 37 / 74$;

(d) fragments of a bronze vessel, shape unrecognizable;

(e) 24 rectangular pieces of bone inlay, $0.034 \mathrm{~m}$. $\times 0.0 \mathrm{I} 4 \mathrm{~m}$., each pierced with 2 holes; with them a number of bone pins for fixing them; $A T / 37 / 66$;

$(f)$ beads; 4 glazed frit tubular spacers for 4 strings, 4 glazed frit balls, I chalcedony dateform bead, I square-section shell tube, I paste dumb-bell, $\mathrm{AT} / 37 / 67$.

ATG/38/2. Bones of a small child, heavily burned, contained in a large vase of coarse pink clay with horizontal bands of red paint; the upper part missing and type uncertain. With them a number of objects (v. Fig. 70) catalogued together as $A \mathrm{~T} / 3^{8} / 5^{2}$.

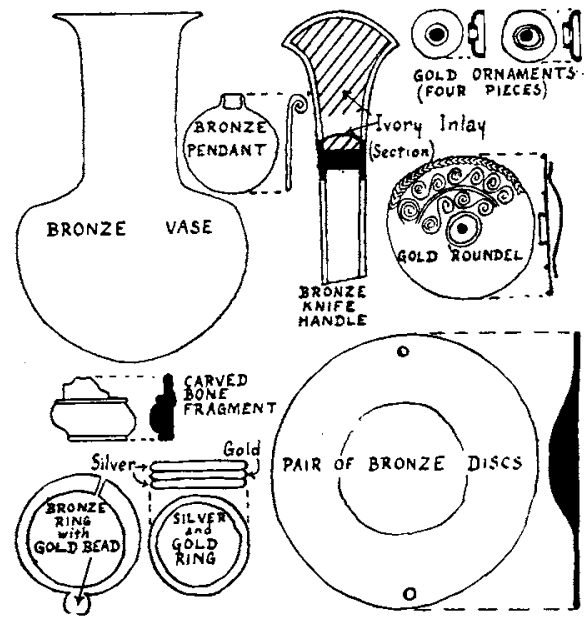

Fig. 70 . ATG $/ 38 / 2$

(a) a gold roundel, diam. $0.03 \mathrm{~m}$., decorated with applied gold-wire filigree, concentric bands of double spirals, P1. LXIX $d$

(b) 4 small gold 'button' ornaments;

(c) a very small knife-handle of bronze inlaid with bone (or ivory?), $1.0 .056 \mathrm{~m}$., and fragments of the blade;

(d) (e) 2 bronze disks with embossed centres, diam. $0.054 \mathrm{~m}$. and $0.056 \mathrm{~m}$;

(f) ring, diam. $0.02 \mathrm{~m}$. triple, the outer rings silver and the central gold;

(g) bronze ring, diam. $0.026 \mathrm{~m}$, with a gold bead pendant;

(h) a miniature bronze vase, ht. $0.07 \mathrm{~m}$. (approximately), in very bad condition, Pl. LXXIV;

(j) bronze pendant, a disk with projecting tang rolled for suspension;

(k) 3 bronze hoops, diam. $0.022 \mathrm{~m}$;

(l) 4 bronze bracelets, plain hoops, diam. $0.056 \mathrm{~m} ., 2$ broken;

(m) 3 plain gold wire loop ear-rings;

(n) 4 similar ear-rings in silver;

(o) fragments of a small bronze knife-handle and of the blade;

$(p)$ beads; small frit rings, 2 stone rings, and some faience open-work beads of Type 28.

ATG/39/68. A bowl of drab clay, Type 82 , ht. $0.26 \mathrm{~m}$., diam. $0.265 \mathrm{~m}$. (ATP/39/ 56 ), containing burnt bones of an adult. The bowl was covered by a red clay saucer, Type $4 b$, diam. $0.30 \mathrm{~m}$. (ATP/39/I I 5). Inside the bowl, with the bones, was 
(a) a cylinder seal of green serpentine, AT/39/ I 76, Pl. LXVI, No. I 26. Outside the bowl

(b) beads; balls of pebble, carnelian and glass paste; frit serrated balls, frit serrated wheels, paste dumb-bells and a paste spacer, and cowrie shells, AT/39/1 96;

(c) fragments of a drab clay jug, Type $68 c$;

(d) ATP/39/1 89, vase, drab clay, Type 95a, ht. 0.089 m.;

(e) ATP/39/1 86, Mycenaean flask, Type B.M. 59;

$(f)$ fragments of a Mycenaean vase, Type B.M. 5 I;

(g) fragments of a Mycenaean vase, Type B.M. 57;

(h) fragments of a grey clay vase, Type I $28, \mathrm{ATP} / 39 / 198$;

(j) a small lunate gold ear-ring (AT/39/1 78 ) and gold caps for a cylinder seal.

\section{Inhumation Burials}

ATG/38/5. Inhumation burial dug into the ruins of Level I; a simple grave containing two bodies, one adult and one child, the latter resting on the former. Both bodies slightly contracted, on the left side, heads west. With them

(a) clay pot, Type $68 \mathrm{c}$, ht. $0.12 \mathrm{~m}$.; pink clay;

(b) 4 silver grape-cluster ear-rings (cf. AT/39/98, Pl. LXIXj), worn by the adult;

(c) an ear-ring of 2 strands of twisted bronze wire;

(d) 2 plain bronze bracelets, one worn on each arm of the adult; also on her right arm

(e) a string of carnelian beads and

$(f)$ a string of alternate black and white paste ring beads;

(g) a string round the neck of the adult, of mixed paste and steatite beads, tubular, wheelshaped, \&c., and

(h) another string of large frit beads (originally blue glazed) discoid with ribbed edges;

(i) 2 plain bronze bangles, one on each ankle of the child;

(j) a string of black steatite beads round the child's neck;

(k) a crescent-shaped stone pendant;

(l) 2 copper pins and 4 bone pins, all broken;

$(m)$ a small fragment of thin gold;

(n) a steatite cylinder seal, Pl. LXVII, No. I 40, AT/38/ I 27A;

(o) a second steatite cylinder seal, illegible, AT/38/ г 27 в.

ATG/38/6. A plain inhumation grave dug down into the ruins of room 2 of the Level I building, Sq. P I o. Body of an adult lying on its right side, legs strongly flexed, head west. With the body, three Mycenaean vases of Type B.M. 59, Pl. CXXVII, ATP/38/5-7.

Close to the vases there was a cooking-pot, Type I 52 , of coarse brown clay (broken), and with it 2 bone bodkins, a bronze kohl-stick (AT/38/ I 25 ), a steatite spindle-whorl, and a miniature clay pot, Type ro3a, of drab clay. It was not certain that these belonged to the grave.

ATG/38/10. Simple inhumation burial; body with head to west, on left side, slightly flexed, hands crossed over breast. In Sq. P I 2, dug down from Level I. On the body

(a) gold ear-rings with bead pendants, Pl. LXIXk;

(b) 2 silver ear-rings, penannular hoops with single ball pendant, cf. Pl. LXIX, AT/39/98;

(c) a plain bone finger-ring;

(d) 2 plain bronze toe-rings.

(All catalogued together as $\mathrm{AT} / 3^{8 / 163 .)}$

ATG/38/37. Simple inhumation grave dug down into a wall of Level I (Sq. H I 7). Skeleton of adult, legs flexed, head NW. With it

(a) a clay pot, Type Io $3 a$, of yellow clay with bands of black paint; ht. 0. I I 5 m., ATP/38/1 93;

(b) a bone needle (broken); 
(c) beads (worn round neck and wrist), small black and white paste rings, ball and lozengeshaped carnelians, I wheel-shaped paste bead with milled edges, 2 pierced gasteropod shells, AT/38/253.

ATG/39/72. Simple grave dug down into the ruins of Level II. Bones of a young adult, the legs flexed, head NW. With them

(a) a jug of drab clay, Type Io $3 a$, ht. $0.23 \mathrm{~m}$.;

(b) beads; white frit striated balls, I carnelian drop pendant, I pebble barrel bead, $\mathrm{AT} / 39 / 194$.

GRAVES BELONGING TO LEVEL II

\section{Inhumation Burials}

ATG/39/63. At I.00 m. below the Level II floor a simple burial of two persons, one adult and one child; most bones perished, the skulls left; adult apparently facing south. With them

(a) against the ear of the adult a bronze pin, Type P. 4, decayed;

(b) beads; large and small balls of glazed frit;

(c) jug of red clay, Type 62b, ATP/39/I I 3 .

ATG/39/64. In Sq. M I 3, at I.70 m. below ground surface, resting on the floor of the Level III room, the simple burial of an adult, lying on the right side, head N., legs flexed. With the skeleton

(a) paste cylinder seal, AT/39/163, Pl. LXV, No. IO2;

(b) beads; about I 4 eye-beads in polychrome glass paste, a number of carnelian disk and barrel-shaped beads, a pebble barrel, I Mycenaean 'hollow hub' bead, paste, and some paste balls, AT/39/164.

ATG/39/70. Simple burial of an adult; body on right side, NW. by SE., head NW., facing south; body flexed, hands close to mouth. With it

(a) a cup of fine drab clay, Type i i, ht. 0.06 m., diam. o. I 35 m., ATP/39/ I 49;

(b) vase of drab clay, Type I 58 , ht. 0.07 m., ATP/39/ i I 4C;

(c) cylinder seal of white steatite, AT/39/1 77, Pl. LXV, No. I06;

(d) beads; I crystal and I carnelian ball;

(e) a pair of bronze tweezers (broken), cf. Pl. LXXIII.

ATG/39/72в. Simple burial lying very close to ATG/39/70 and at the same level; skeleton of adult lying on right side, NW. by SE., head SE., the legs flexed, the hands brought up in front of the face. With it were beads ( $\mathrm{AT} / 39 / \mathrm{I} 80$ ), carnelian balls and ovate beads, striated balls and a short cylinder of white frit and a ball of glass paste.

GRAVES ATTRIBUTED TO LEVEL II

\section{Cremation Burials}

ATG/38/7. The grave could belong to Level III, but judging from its position Level II is rather more probable.

Cremation burial. At $2.00 \mathrm{~m}$. below the modern surface, in Sqq. R I 4-S I 3, just above the rubble of the Level IV palace, a finely painted amphora of Nuzu ware (ATP/38/ I P1. CII) containing semi-calcined bones, apparently of a not very young child, together with

(a) a bronze knife (?), fragmentary;

(b) fragments of a bone comb;

(c) beads; 5 of yellow paste (I rhomboid-shaped), 3 of quartz, 2 tubular and I ball, a glass ball and a copper tubular bead;

(d) a cylinder seal of greenish steatite, AT/38/1 39, much defaced. 
ATG/39/76. Cremation burial lying below Level II and belonging either to that Level or to Level I. A clay jug, Type 60 , ht. $0.33 \mathrm{~m}$., of reddish clay with horizontal bands of dark red paint, contained the cremated bones of a youth and

(a) twisted fragments of thin copper apparently from a cup;

(b) 2 paste beads.

ATG/46/8. Cremation burial lying about $\mathrm{I} \cdot 00 \mathrm{~m}$. below the foundations of the Level III walls; it could therefore belong either to Level II or to Level III. The urn had been placed in a pit about $0.60 \mathrm{~m}$. in diameter with wood ash and burnt animal bones (including a lower jawbone) round it. By the side of the urn were two small vases, one of red and one of black clay, both, like the urn, crushed and very imperfect; types not certain. It looked as if the pots had been broken before being put into the grave.

\section{Inhumation Burials}

ATG/37/26. Simple grave dug $0.90 \mathrm{~m}$. down through the Level II street and cutting into a Level III wall; it could therefore be of Level I but is more probably of Level II. Body of a child (young) lying with head NE. With it one clay jug, Type $44 a$, of coarse pinkish clay, $\mathrm{ATP} / 37 / \mathrm{I} 5 \mathrm{I}$.

ATG $/ 3^{8} / 3^{8}$. Simple grave dug into the ruins of the Level III town wall, $0.60 \mathrm{~m}$. below the present surface. The body, that of a young adult, lay slightly flexed with its head to the east. With it were

(a) a clay bottle, ATP/38/196, of Type i $30 a$, ht. 0.15 m., painted in Nuzu style with a white design on black, Pl. CIId;

(b) $\mathrm{ATP} / 38 / 205$, a pot, Type $\mathrm{I} 47$, of coarse red clay with smoother and lighter surface having bands of red paint round neck and shoulder; ht. $0.13 \mathrm{~m}$.;

(c) ATP/38/206, a pot, Type I 44a, of light reddish clay with much white grit engrais, painted with an all-over red wash; ht. 0.1 I $5 \mathrm{~m}$.;

(d) a plain bone spindle-whorl;

(e) beads; a large lozenge-shaped carnelian and a carnelian ball, a pebble bead tubular with central swelling, 2 paste beads and some broken glass ball (?) beads.

ATG/39/1 8. Judging from its relation to the house walls between which it lay the grave might almost as well belong to Level III as to Level II. The body lay with its head to the NE.

With it were

(a) a clay jug, ATP/39/23, of Type 49 , red clay, ht. $0.20 \mathrm{~m}$.;

(b) cylinder seal AT/39/49, Pl. LXV, No. I I

(c) a bronze pin, AT/39/50, Type P. I, 1. $0.08 \mathrm{~m}$;

(d) a bronze pin, Type P. 3, $1.0 .075 \mathrm{~m}$., broken;

(e) immediately below the bones but presumably belonging to the grave, a second cylinder seal, AT/39/54, Pl. LXV, No. 99.

ATG/39/90. Inhumation grave, disturbed, below Level II in Sq. L I 3; judged by its position it should belong to Ievel II, not to Level I. There were a few scattered bones and with them a cylinder seal, AT/39/2 I 5, Pl. LXIV, No. 85 , a crescent-shaped silver pendant and a number of glazed frit and carnelian ball beads, AT/39/2 I 9 .

GRAVES BELONGING TO LEVEL III

\section{Inhumation Burials}

ATG/39/ I 4. Simple grave, disturbed, only the skull and a few disintegrated bones left; position of body uncertain but direction $\mathrm{N}$. $\times \mathrm{S}$. with head north. With it

(a) a jug of red clay, Type 49, ht. 0.195 m., ATP/39/ I ; 
(b) a vase of red clay, Type Io3a, ht. 0.085 m.; broken;

(c) a small hone of grey stone.

ATG/39/48. Simple grave dug down into the wall of the Level IV house 39/B; adult body lying on right side, flexed, the hands brought up in front of the face, N. $\times$ S., facing east. With it

(a) a jug of burnished red ware, Type 60, much broken, ATP/39/8I; it was in front of the face;

(b) by the feet a jug, Type $48 a$, ht. approximately $0.26 \mathrm{~m}$., of burnished red ware, much broken;

(c) 2 bronze annular ear-rings;

(d) a plain silver ring found on the finger;

(e) 4 silver crescent-shaped ear-rings;

(f) fragments of a bronze pin, type uncertain;

(g) beads; 6 fly amulets of glazed frit, a flat discoid glass pendant, 2 hedgehog (?) glazed frit amulets, a large carnelian rhomboid, mixed beads, white crystal barrel-shaped, serrated balls of white frit, glass paste balls and spacers, AT/39/108.

GRAVES ATTRIBUTED TO LEVEL III

\section{Inhumation Burials}

ATG/39/7I. Simple grave dug down against a wall of Level IV, Sq. L I $2 ; 2.00 \mathrm{~m}$. below the Level II floor and therefore too deep to belong to that level. Skeleton of a youth, the body flexed, orientated N. $\times$ S. head north. With it

(a) a jug, Type $55^{b}$, of drab clay with all-over red wash whereon black paint horizontal bands with oblique hatching between bands on shoulder; ht. c. $0.20 \mathrm{~m}$. (broken), $\operatorname{ATP} / 39 / 155$;

(b) fragments of an ivory comb;

(c) fragment of ivory inlay;

(d) a silver pin, Type P. 4, $1.0 .08 \mathrm{~m}$;

(e) a silver finger-ring, plain, broken;

(f) a white steatite scaraboid roughly engraved, Pl. LXV, No. 95;

$(g)$ beads; 4 gold ribbed balls; carnelian, 3 date-shaped and 3 balls; crystal, I ball, I ring, I flattened oval, I cube and a square pendant; I I balls of glass or glass paste; white frit balls ( 3 ribbed), flattened oval and tubular; a number of mixed stone beads, steatite, serpentine and pebble; 9 cowries and a white paste pendant in the form of an animal's head; AT/39/1 89 .

ATG/39/82. Simple grave, 1. $0.90 \mathrm{~m}$., Sq. L I 4, $2.50 \mathrm{~m}$. below surface. Adult skeleton, tightly flexed, on left side, orientated N. $\times$ S., head facing west. With it

(a) a vase of drab clay, Type IO3b, ht. $0.125 \mathrm{~m} ., \mathrm{ATP} / 39 / 20 \mathrm{I}$;

(b) 3 jugs, all of Type 60 , reddish clay with all-over red wash, hts. $0.30 \mathrm{~m} ., 0.36 \mathrm{~m} ., 0.24 \mathrm{~m}$, I with incised lines round shoulder, ATP/39/202 A-C.

ATG/47/8. Simple grave in Sq. O I 5, level with the bottom of the foundations of the Level III temple. Body, adult, on its back, extended, head NW. With it

(a) a bronze pin, Type P. I, (broken) on the chest just below the neck;

(b) a few beads; large carnelian, amber, chalcedony, lapis lazuli and glass balls; rings and flattened lozenges and a paste scaraboid, $\mathrm{AT} / 47 / 76$.

ATG/46/3. Infant burial, against the foundations of the Level II wall in Sqq. K-L I 5 ; a mere hole into which the body had been put in anyhow, so that all the bones were in disorder. With it 
(a) a plain bronze bracelet (perished) on one arm;

(b) at the neck, beads; small paste balls, white and yellow, strung alternately, AT/46/320;

(c) 4 knuckle-bones.

\section{GRAVES BELONGING TO LEVEL IV}

\section{Inhumation Graves}

ATG/37/36. Simple grave, Sq. F i 8 , below the floor of room 6 in the Level IV house; orientated

E. $\times$ W. Body of young adult on right side, legs flexed, head west. With it

(a) bronze pin, Type P. 2, with engraved head, 1. $0.095 \mathrm{~m}$;

(b) gold finger-ring worn on right hand, a circle of flat metal $0.005 \mathrm{~m}$. wide with 2 rows of embossed dots, $\mathrm{AT} / 37 / \mathrm{i} 65$.

ATG $/ 37 / 37$. Simple grave under room 5 of the same building as the last, $0.70 \mathrm{~m}$. below the floor; orientated N. $\times$ S. Body of adult lying on right side, legs slightly flexed, head south. With it

(a) jug, Type 63, with all-over red paint wash, ht. $0.28 \mathrm{~m}$., ATP/37/326;

(b) bowl, Type I 5 , light red clay, diam. O. I 35 m., ATP/37/337;

(c) beads; quartzite cylinders, 4 carnelian rings, 2 date-shaped sards;

(d) cylinder seal, glazed frit, decayed; indecipherable.

ATG/38/33. Pot burial of a small child; Sq. U 6, a little below Level IV. The urn itself was fragmentary; with it

(a) a spindle-jar (Type B.M. 25) of burnished red ware, ht. $0.305 \mathrm{~m} ., \mathrm{ATP} / 38 / \mathrm{I} 84$;

(b) a cup of 'base-ring' ware with wish-bone handle, Type B.M. 22, ht. 0.095 m., $\mathrm{ATP} / 38 / 189$.

ATG/39/7. Simple grave in Sq. N 8 close to the Level III town wall; a Level III wall is built over the grave which therefore must be of Level IV. The body lay on its right side, the legs flexed, head south. Most of the objects were above the head. A second body, that of a small child, lay over the leg-bones of the first in a similar attitude looking east. With the bodies were

(a) a jug, Type 55 , of burnished red ware, ht. $0.22 \mathrm{~m}$., ATP/39/ I 3 ;

(b) a goblet, Type $93 b$, of burnished red ware, ht. $0.15 \mathrm{~m}$., ATP/39/35;

(c) a lekythos, Type B.M. 47, of burnished red ware, ht. 0.146 m. (broken), ATP/39/4 I;

(d) a jug of drab clay, Type $72 b$, broken, ATP/39/37;

(e) a vase of burnished red ware, Type B.M. 25, ht. 0.28 m., ATP $/ 39 / 34$;

$(f)$ a vase of drab clay, Type I 22, ht. $0.16 \mathrm{~m} ., \mathrm{ATP} / 39 / 36$;

(g) a goblet, Type $93 b$, of burnished red ware, ht. O.I I 5 m., ATP $/ 39 / 38$;

(h) a vase, Type B.M. 26, of black clay, ht. O. I 35 m., ATP/39/39;

(j) a lekythos, Type B.M. 47, of burnished red ware, ht. ०. 16 m., ATP/39/40;

(k) a vase, Type B.M. 25 , of burnished red ware, ht. O. 15 m., ATP/39/33;

(l) a vase, Type B.M. 24, of red ware, ht. O.I 68 m., ATP $/ 39 / 42$;

$(m)$ a string of plain blue-glazed frit ball beads, all decayed;

(n) a number of glass paste ball beads, bleached white; AT/39/35.

ATG/39/ I 5. In Sq. F i 8, a hole containing disintegrated bones of a young child and

(a) a vase of drab clay, Type I 25, ht. $0.076 \mathrm{~m} ., \mathrm{ATP} / 39 / \mathrm{I} 60$;

(b) beads; glass double conoids, glass paste balls, pebble balls and frit tubular beads, $\mathrm{AT} / 39 / 46$.

ATG/39/3 I. Simple grave beneath the foundations of the Level III town wall which was built across it; the grave is at the same level as ATG/39/7 described above. Body of an infant laid on right side, facing east. With it 
(a) a jug, Type 57 , ht. $0.27 \mathrm{~m}$., of drab clay having a painted decoration of plain red bands round the neck and on the shoulder a row of 3 birds and a stylized tree, $\operatorname{ATP} / 39 / 72$, Pl. LXXXVII;

(b) a vase, Type I03, of drab clay, ht. ०. I 3 m., ATP $/ 39 / 67$;

(c) a bowl, Type 26 a of red clay (broken), ATP/39/ 74 ;

(d) 3 beads, I cylindrical and 2 barrel-shaped.

ATG/39/33. Pot burial underneath the Level III town wall, $2 \cdot 00 \mathrm{~m}$. distant from ATG/39/3 I and at the same level. The urn, of drab clay (ATP/39/1 $\left.5^{8}\right)$, was in fragments; in it, with the bones, a plain bronze finger-ring and a plain bronze bangle, both fragmentary; and

(a) beads, carnelian, I truncated date-shaped and 35 small balls, AT/39/9o.

Against the outside of the urn were

(b) a bowl of drab clay, Type 30, diam. O.10 m., ATP/39/55;

(c) fragments of a small jug of drab clay, type uncertain;

(d) fragments of a large vase or jug of red clay, type uncertain.

ATG/39/47. Simple grave close to ATG/39/3 I, under the foundations of the Level III town wall. Body (most of the bones disappeared) on left side, head north. With it

(a) pot of drab clay, Type I 22 , ht. 0. I 5 m., ATP/39/7 I;

(b) lekythus, Type B.M. 35, black clay, ht. O. I 2 m.;

(c) lekythus, Type B.M. 25, burnished red clay, fragmentary, ATP/39/72;

(d) from the neck, beads, balls of blue paste, small, in pairs interspaced by carnelian balls and white frit ovals;

(e) from the wrist, beads, 5 large white frit balls, 3 black frit striated balls, I grey frit dateshaped.

ATG/39/58. Pot burial of an infant, partly cut into by the foundations of the Level III town wall. The jar, fragmentary, was of drab clay with 2 plain bands in relief below a very solid rim square in section. In it

(a) fragments of 2 lekythi, Type B.M. 25, of burnished red clay;

(b) fragments of black clay (jar sealing?) with remains of the impression of a cylinder seal, $\mathrm{AT} / 39 / 146$.

ATG/39/60. Simple grave of an infant, close to ATG/39/58, under the foundations of the Level III town wall. With the bones

(a) jug, Type $42 a$, of drab clay, ht. O.I 7 m., ATP/39/97;

(b) beads, balls of blue glass paste, AT/39/ I 48 .

ATG/39/8 5. Pot burial of a child; dug down against a Level IV wall (Sq. K I 3) and I. $00 \mathrm{~m}$. below the room floor. The pot, diam. $0.50 \mathrm{~m}$., fragmentary, type uncertain. In it, with the bones,

(a) pot, Type ioza, of drab clay, ht. o. I I m., ATP/39/222;

(b) pot, Type I $30 b$, of greenish drab clay, ht. 0.70 m., ATP/39/2 I 4;

(c) fragments of a bottle of polychrome 'Phoenician' glass;

(d) beads; white frit ring, ball and tubular beads, 2 flattened tubes of red steatite and a glass paste ball, AT/39/238.

ATG/39/86. Simple grave in Sq. L I 3, dug down into the ruins of Level VI from Level IV; orientated N. $\times$ S. Body of youth with head to north, bones disintegrated. With them

(a) jug, Type $68 \mathrm{c}$ but with base ring, ht. 0.1 $6 \mathrm{~m}$., of red clay, ATP $/ 39 / 224$;

(b) lekythus, Type B.M. 24, of red clay with black surface, broken, ATP/39/2 I 8;

(c) goblet, Type I I $8 b$, Nuzu ware painted in white on brown with dotted scale pattern, ATP/39/2 I 7, Pl. CIV;

(d) cylinder seal, white steatite, AT/39/229, Pl. LXIII, No. 52; 
(e) bone needle, 1. 0.102 m., AT/39/34L;

(f) fragments of bronze pin, type uncertain.

ATG/39/93. Pot burial cut down from Level IV into a ruined Level V wall, Sq. J I 5 . In it the bones of one adult (apparently female) and one infant. Owing to the small capacity of the jar the bones would seem to have been inserted in it after the removal of the flesh; the two skulls lay on the top, the other bones in confusion beneath them. The burial urn was of red clay, apparently of Type 76, but it had been cut down to the level of the top of the handlesprobably the incurved rim was removed to make the insertion of the bodies possible; ht. without the rim $0.45 \mathrm{~m}$., diam. $0.28 \mathrm{~m}$. In it

(a) lekythus, Type B.M. 24, red clay, ATP/39/274;

(b) 8 bronze ear-rings, plain annular, but 2 of them having a single glass bead strung on the wire, $A T / 39 / 278$.

ATG/39/95. Simple burial, close to the last, dug down from Level IV into Level V; orientated roughly $\mathrm{E} . \times \mathrm{W}$. Body of a young adult, extended, on right side, facing south. With it

(a) bowl, Type B.M. 22, with wish-bone handle, of red clay, diam. o. I 6 m., ATP/39/285;

(b) bowl, Type 8, of fine black clay, diam. 0.I 7 m., ATP/39/286.

ATG/47/5. Simple grave; part only of a child's body, in disorder, set in a cavity (not a properly constructed grave) in the floor of Level IV. With it

(a) bowl, Type $94 a$, of reddish-buff clay with 3 bands of dark red paint, ht. O. I $43 \mathrm{~m}$., $\mathrm{ATP} / 47 / 27$

(b) pot, Type I 02, of reddish-buff clay with 5 bands of plum red round the body and radial strokes round the rim; ht. $0 \cdot 104 \mathrm{~m} ., \mathrm{ATP} / 47 / 28$;

(c) jug, Type 68c, of drab clay, ht. $0.148 \mathrm{~m}$., ATP/47/29.

ATG/47/6. Simple grave under the Level IV floor, Sq. P I 5 . Body of adult, laid on its left side, legs sharply flexed, head east. With it

(a) jug, Type I6o, of drab clay, ht. $0.095 \mathrm{~m}$., ATP/47/34;

(b) a bronze toe-ring;

(c) 2 bronze pins, decayed.

ATG/47/8. Infant burial, disturbed, in Sq. O I6, dug down to Level VI from Level IV. Only the skull left and with it

(a) pot, Type I $04 b$, of red clay, roughly made, ht. $0.096 \mathrm{~m} ., \mathrm{ATP} / 47 / 44$;

(b) jug, Type $69 a$, of red clay, ht. $0.24 \mathrm{~m}$., ATP/47/45. Immediately below this was a second body, of an adult, laid on the left side, body tightly flexed, hands before face, head west (only a few bones surviving); the head rested on a roughly quadrangular stone. With it

(c) a bronze toe-ring;

(d) by the neck, 2 bronze pins (decayed);

(e) beads; large balls and flattened lozenges of carnelian, chalcedony lentoids, glass balls, paste rings and a paste scaraboid, $\mathrm{AT} / 47 / 76$.

GRAVES ATTRIBUTED TO LEVEL IV

Cremation Burials

ATG/39/74. Cremation burial in Sq. M I 3; its depth showed it to be earlier than Level II and the pottery with it favours a date in Level IV rather than in Level III. The urn was

(a) a jug, Type 68c, of drab clay, ht. $0.30 \mathrm{~m}$. ATO/39/19I, containing the burnt bones of a young person; in the mouth of the urn was

(b) a vase, Type I 58 , of drab clay, ht. $0.07 \mathrm{~m}$., ATP/39/ I I 4 D. No other objects. 


\section{Inhumation Burials}

ATG/37/I. Simple grave orientated NW. $\times$ SE., the body on its right side sharply flexed, the hands crossed over the stomach, head SE. With it

(a) pot, Type $9 \mathrm{r} b$, yellow clay, ht. O. I I m., ATP $/ 37 / 46$;

(b) pot, Type I 6o, red-brown clay, ht. ०. I $5 \mathrm{~m}$., ATP/37/66;

(c) pot, Type $7 \mathrm{I}$, red-drab clay, top gone, $\mathrm{ATP} / 37 / 3 \mathrm{I}$.

ATG/37/2. Simple grave orientated N. $\times$ S.; body on left side, head south, legs sharply flexed.

With it

(a) jug, Type $48 a$, of drab clay with all-over red wash, burnished; ht. $0.33 \mathrm{~m} . ;$ ruined by salt;

(b) jug, Type $69 a$, of brownish drab clay, ht. 0.1 $5 \mathrm{~m}$;

(c) fragments of a bronze bracelet with raised central rib;

(d) fragments of a bronze pin, type uncertain.

ATG/37/I 3. Simple grave under the street of Level IV against the house wall, orientated NE. $\times$ SW., the body with head SW. With it

(a) jug, Type 60, with all-over wash of brown paint, burnished;

(b) bronze pin, Type P. 6.

ATG/37/33. Simple grave, Sq. F 2 I, close to Level IV house wall, orientated N. $\times$ S.; body with head south, legs flexed. With it

(a) jar, Type $48 a$, of red clay, ht. 0.285 m., ATP/37/3I 8 (Pl. XCIXk);

(b) beaker, Type 93 , red clay, ht. $0 \cdot 175 \mathrm{~m} ., \mathrm{ATP} / 37 / 308$;

(c) jug, Type 6ob, red clay, ATP/37/3 I 7 (Pl. XCIXj);

(d) fragments of a large bowl, type uncertain, with bands of black paint;

(e) cylinder seal, haematite, AT/37/ i 8 I, Pl. LXIII, No. 63;

$(f) .2$ finger-rings, plain, I silver, I bronze;

(g) bronze ear-ring, a small hoop with 4-grain cluster pendant;

(h) a shell spindle-whorl;

(j) a serpentine duck-weight;

(k) fragments of a bronze pin, type uncertain;

(l) beads; 4 large date-shaped and 2 balls of crystal, 5 carnelian balls, I date-shaped, I discoid, 4 tubular of paste, I glass tube, and a glazed frit amulet in form of a lion's (?) head. (All these catalogued as AT/37/I 82.)

ATG/37/34. Simple grave close to the last; a child's body, head west, bones in disorder. With it

(a) jug, Type $55 a$, with all-over red paint wash, ht. $0.145 \mathrm{~m} ., \mathrm{ATP} / 37 / 33^{\mathrm{I}}$;

(b) a miniature vase in pink stone, ht. $0.023 \mathrm{~m} ., \mathrm{AT} / 37 / \mathrm{r} 68$;

(c) bronze pin, Type P. I, 1. ०. IO m.;

(d) beads; carnelian balls, frit striated tubular and frit rings, AT/37/168;

ATG/38/ 5 . Pot burial of a child in Site $\mathrm{H}$ at $\mathrm{I} \cdot 20 \mathrm{~m}$. below surface; the bones not burned. With them

(a) pot, Type 57 a, of brown clay, ht. $0.13 \mathrm{~m} ., \mathrm{ATP} / 38 / \mathrm{I} 5^{8}$;

(b) a second, similar, in fragments;

(c) lekythus, Type B.M. 25, burnished red clay, ht. $0.26 \mathrm{~m} ., \mathrm{ATP} / 38 / \mathrm{I} 6 \mathrm{IA}$;

(d) lekythus, fragments of a second, similar, ATP/38/I6 I B;

(e) pot, Type I07a, yellow clay, ht. $0.085 \mathrm{~m} ., \mathrm{ATP} / 38 / \mathrm{I} 48 \mathrm{M}$;

( $f$ ) pot, Type I0 $4 b$, brown clay, ht. $0.09 \mathrm{~m}$., ATP/38/148P;

$(g)$ beads; 4 strings; cylindrical in quartz, steatite, chalcedony, carnelian, and paste, and 2 large yellow paste balls, AT/38/222. 
ATG/38/16. Simple grave, Site H, orientated E. $\times$ W.; body of young adult on right side, head west. With it

(a) bottle, Type $106 b$, brown clay, fragmentary;

(b) jug, Type 69c, drab clay, ht. O. I 2 m., ATP/38/ г 20B;

(c) pot, Type I 37 , black ware, ring burnished, ht. ०. I 4 m., ATP/38/ I 5 I в;

(d) lekythus, Type B.M. 25, burnished red ware, ht. 0.27 m., ATP/38/1 47 .

ATG/38/ 7 . Pot burial of a child, site $H$, the body laid on its left side with knees to chin, head north. Outside the urn

(a) 2 lekythi, Type B.M. 25, broken, burnished red clay; ATP/38/163в and c;

(b) jug, Type $57 b$, light red clay with creamy slip, ht. $0^{\circ} \mathrm{I} 7 \mathrm{~m}$., ATP/38/1 49;

(c) lekythus, Type B.M. 26, black burnished ware, ht. $0.12 \mathrm{~m}$;

(d) spouted jar, Type $2 \mathrm{I} c$, light drab clay with engobbage surface on which rough streaks of black paint; ht. $0.075 \mathrm{~m}$., ATP $/ 38 / 167$;

(e) lekythus, Type B.M. 25, burnished red ware, broken;

(f) cup, Type B.M. I 9, 'base ring' ware, ht. $0.08 \mathrm{~m}$., ATP/38/1 50;

$(g)$ beads; small black and white steatite rings, I bronze ball, 2 carnelian and I large paste ball.

ATG $/ 38 / 34$. Simple grave orientated NW. $\times$ SE.; Site H, at $2.30 \mathrm{~m}$. below the surface. Body on left side, head NW. With it

(a) saucer, Type $6 a$, red clay;

(b) jug, Type $48 a$, of red clay, ht. $0.28 \mathrm{~m} ., \mathrm{ATP} / 38 / \mathrm{I} 85$;

(c) jug, Type 60b, drab ware with brown slip, burnished, ht. $0.38 \mathrm{~m} ., \mathrm{ATP} / 38 / \mathrm{s} 86$ (Pl. $\mathrm{XCIXl)}$

(d) saucer, Type $6 a$, pink clay with band of red paint round the rim; incomplete, $\mathrm{ATP} / 38 / 6 \mathrm{IF}$

(e) saucer, Type $163 b$, pink clay, fragmentary;

(f) milk-bowl, Type B.M. 30, 'ladder' design, fragmentary, ATP/38/1 83B;

(g) milk-bowl, Type B.M. 30, 'ladder' design, diam. O• I I m., ATP $/ 3^{8} /$ I $^{8} 3^{\mathrm{A}}$;

(h) jug, Type B.M. 23 , fragmentary, 'Base-ring' ware but lacking normal relief on body, ATP/38/195;

$(j)$ beads; carnelian lozenge-shaped and yellow paste balls.

ATG/38/35. Simple grave orientated NW. $\times$ SE., Site H. Body with head to NW. With it

(a) pot, Type I 59, light red clay, ht. $0.085 \mathrm{~m}$., ATP/38/190;

(b) fragments of a jug, type uncertain.

$\mathrm{ATG} / 38 / 36$. Simple grave adjoining $\mathrm{ATG} / 3^{8} / 34$ and 35 , at the same level; the grave ruined. In it only the fragments of one pot, Type IO2, light red clay, ht. $0.08 \mathrm{~m} ., \mathrm{ATP} / 38 / 57 \mathrm{~B}$.

ATG/39/1 7. Simple grave, disturbed, containing only the skull of a child and with it one vase, Type $104 b$, of red clay, ht. $0.086 \mathrm{~m}$.

ATG/39/30. Simple grave orientated N. $\times$ S., in Sq. F I 7, below the Level IV floor. Body of a child laid on its right side, legs flexed, head north. With it

(a) vase, Type I० $3 a$, of drab clay, ht. $0.085 \mathrm{~m} .$, ATP $/ 39 / 29$;

(b) lekythus, Type B.M. 25 , of burnished red ware, ht. 0.32 m., ATP/39/30;

(c) beads; balls and tubes of glass paste, blue paste balls, a frit amulet in form of a ram's (?) head, a shell hung on a bronze ring, AT/39/80.

ATG/39/32. Simple grave in Sq. L Io, below foundations of a Level III wall. Child's skull, rest of body disintegrated; with it

(a) vase, Type $93^{b}$, of red clay, ht. 0.07 m., ATP/39/ г2; 
(b) lekythus, Type B.M. 25, black ware, ATP/39/1 5;

(c) one bead.

ATG/39/35. Inhumation grave containing three bodies, one of an infant and two of young adults; the bones (other than skulls) much decayed and position not certain; it might be two overlapping graves, but if so they were almost contemporary. The grave was orientated $\mathrm{NW} . \times \mathrm{SE}$. and the bodies had lain with heads NW. It lay (in Sq. N 8) immediately above the ruins of the Yarim-Lim palace. In it

(a) lekythus, Type B.M. 25, of burnished red ware, ht. 0.3 I 5 m., ATP/39/59A;

(b) bowl, Type 93a, of drab clay, ht. $0.09 \mathrm{~m}$., ATP/39/60; in it was the infant's skull;

(c) jug, Type i 28 , of red clay, ht. 0.22 m., ATP $/ 39 / 6 \mathrm{I}$;

(d) jug, Type 56, drab clay, with red-brown paint on rim, shoulder and handle; ht. ०. I 8 m., $\mathrm{ATP} / 39 / 62$;

(e) jug, Type $6 \mathrm{I}$, of red clay, ht. o. I 9 m., ATP/39/63;

(f) lekythus, Type B.M. 25, of burnished red clay, ht. $0.34 \mathrm{~m} ., \mathrm{ATP} / 39 / 59 \mathrm{~B}$;

(g) lekythus, Type B.M. 25, of burnished red clay, ht. 0.3 I 5 m., ATP $/ 39 / 59 \mathrm{C}$;

(h) lekythus, Type B.M. 25, burnished red clay, fragments;

(j) lekythus, Type B.M. 26, black ware, broken, ATP $/ 39 / 64$;

(k) lekythus, Type B.M. 24, red ware, broken, ATP $/ 39 / 65$;

(l) jug, Type $48 b$, of red clay, ht. 0.23 m., ATP/39/66;

(m) cylindrical bone box, ht. $0.055 \mathrm{~m}$., diam. $0.037 \mathrm{~m}$., having round the sides 2 bands of guilloche pattern incised between double lines, and on the lid a 6-petalled rosette, AT/39/9 I, Pl. LXXVIIg;

(n) (from the infant's skull) two gold ear-rings, hoops with granulated cluster pendants, AT/39/9 I, Pl. LXIX;

(o) beads; from the infant's skull, yellow frit balls and rings and double multiple ring, a white glazed frit ring and crescent pendant. From the adult skull B, gold fluted balls, carnelian, white frit and blue paste balls, glass rings and a lapis lazuli ring, AT/39/9 I .

ATG/39/37. Simple grave I.00 m. west of ATG/39/35, and at the same level; much disturbed. In it

(a) bowl, Type I $4 b$, of red clay, diam. $0.43 \mathrm{~m} ., \mathrm{ATP} / 39 / 75$, in which was the skull;

(b) jug, Type $62 b$, of drab clay, ht. $0.19 \mathrm{~m}$., ATP $/ 39 / 74$.

ATG/39/38. Simple grave below town wall, orientated N. $\times$ S. Body of young girl, on left side, legs flexed, hands in front of breast, head north. With it

(a) jug, Type 53, of drab clay, ht. O. I 6 m., ATP/39/52;

(b) lekythus, Type B.M. 35, red ware, burnished, ht. ०. I 3 m., ATP/39/53;

(c) bronze finger-ring, plain;

(d) bronze ear-ring, plain annular;

(e) beads; white frit balls and tubes and flat figure-of-eight-shaped beads, green frit tubes, and a glass ball.

ATG/39/4 I. Pot burial of a small child, Sq. M I I, below floor of Level IV room. The urn $(\mathrm{ATP} / 39 / 68)$ much broken. By it

(a) jug, Type $62 a$, of drab clay, ht. 0.22 m., ATP/39/69;

(b) vase, Type 9 I $a$, of red clay, ht. 0.074 m., ATP $/ 39 / 70$.

ATG/39/45. Simple grave immediately below and disturbed by ATG/39/4 I. Bones scattered, but apparently the body lay on its right side with head north. With it

(a) a gold ear-ring, penannular with 3-grain cluster pendant, AT/39/98, Pl. LXIXj;

(b) beads; about I 20 rings of blue-glazed frit, AT/39/98. 
ATG/39/42. Simple grave between houses $39 / \mathrm{A}$ and $39 / \mathrm{B}, 0 \cdot 80 \mathrm{~m}$. below wall foundations; orientated NW. $\times$ SE. Body, adult, extended on right side, head NW., hands in front of face. With it

(a) jug, Type I 37, of red clay, ht. o. I 2 m., ATP $/ 39 / 78$;

(b) 2. bronze pins, Type P. I, 1. O.I I $7 \mathrm{~m}$. and $0.108 \mathrm{~m}$., lying below the level of the chin, apparently on the left shoulder;

(c) I ball and I tubular white frit bead.

ATG/39/49. Simple grave orientated N. $\times$ S., $0.50 \mathrm{~m}$. below ATG/39/4I. Body, youthful, prone and extended, head south. With it

(a) jug, Type 6oa, of drab clay with yellowish slip and decoration in red paint, ht. $0.175 \mathrm{~m}$., ATP/39/90, Pl. LXXXVII;

(b) bowl, Type I02, of red clay, diam. 0. I 2 m., ATP/39/77;

(c) remains of bronze pin by neck; type uncertain;

(d) beads; tubular, date-shaped and ball in pale blue and in white (bleached?) glazed frit, $\mathrm{AT} / 39 /$ IOI.

ATG/39/5 I. Simple grave dug down into the ruins of Yarim-Lim's palace, room 9. In it a few bones of a small child and

(a) lekythus, Type B.M. 25, burnished red ware, broken, ATP/39/86;

(b) vase, Type IO3a, of red clay, ht. $0.07 \mathrm{~m} ., \mathrm{ATP} / 39 / 87$;

(c) 2 large flattened oval carnelian beads.

ATG/39/62. Pot burial of an infant. The urn was a jug, Type I I , of red clay, lightly burnished, ht. 0.4 I m., ATP/39/I 8 I. In it, with the bones (not burned) were

(a) a bronze arrow-head, Type Ar. 5, 1. 0.078 m., AT/39/16P;

(b) beads; agate barrel-shaped, 2-coloured paste imitation agate barrel-shaped, serpentine cylinder, white paste scaraboid, brown and grey pebble barrel-shaped, and white frit balls and disks, $\mathrm{AT} / 39 / \mathrm{I} 5 \mathrm{I}$.

ATG/39/77. Simple grave orientated N. $\times$ S.; body, adult, on right side, slightly flexed, head north. With it

(a) jug, Type 68c, drab clay, ht. 0.2 I m., ATP/39/208, containing the bones of an infant;

(b) bronze pin, Type P. I, 1. $0.075 \mathrm{~m}$. (broken);

(c) beads; green paste tubular spacers for 4 strings, 70 carnelian balls, I white and 2 yellow paste balls, and a yellow paste cube and ring; found at the neck of the body, AT/39/224.

ATG/39/IOI. Simple grave dug down into Level V, orientated NE. $\times$ SW. Body of young adult on right side, extended, head SW. With it

(a) jug, Type $73 a$, of drab clay with black paint, ht. O. I I m., ATP/39/280;

(b) pot, Type I 04a, but with flattened base, of red clay, ht. $0.065 \mathrm{~m} ., \mathrm{ATP} / 39 / 28 \mathrm{I}$;

(c) lekythus, Type B.M. 25, of burnished red ware, ht. 0.29 m., ATP/39/282;

(d) jug, Type I64, reddish clay, ht. $0.20 \mathrm{~m}$., ATP/39/283A;

(e) jug, Type I 64 , reddish clay, ht. 0.20 m., ATP/39/283 в;

(f) (found in the last two jugs) i 8 knuckle-bones;

$(g)$ beads; 25 plain white frit rings.

ATG/48/6. Simple grave of a small child, in disorder, containing one vase, Type I०3a, white clay, ht. $0.08 \mathrm{~m}$.

GRAVES BELONGING TO LEVEL $\mathrm{V}$

ATG/37/27. Simple grave in Sq. D I 8, I.85 $\mathrm{m}$. below the foundations of the Level III house wall; probably of Level V. Body of child laid tightly flexed on left side, NE. $\times$ SW., head SW. With it 
(a) cup, Type $67 a$, of rather coarse red clay, ht. $0.13 \mathrm{~m}$;

(b) 5 copper ear-rings, plain wire hoops;

(c) bronze pin, Type P. I I, $1.0 .085 \mathrm{~m}$.;

(d) beads; very small white paste rings, white paste striated date-shaped and short thick cylinder of blue paste;

(e) half of a paste cylinder seal with a row of birds. (All catalogued as AT/37/ I 80.)

ATG/39/56. Simple grave orientated N. $\times$ S., $0.40 \mathrm{~m}$. below the floor of the Level V building, house $39 / \mathrm{B}$. Adult body extended on left side, head north. With it

jug, Type 67 a, drab clay, ht. 0. I 25 m., ATP/39/43в.

ATG/39/80. This is really two simple graves of which one was disturbed by the second (intact) interment, the skulls being only $0.20 \mathrm{~m}$. apart. The graves lay in Sq. M I 2 , just above the ruins of the Yarim-Lim palace, and were orientated approximately N. $\times$ S. The time interval between them must have been short. The later body was extended on its right side, head north; the earlier (skull only in situ) had apparently been in the same position. With the earlier was (a) vase, Type 9 i $b$, of red clay, ht. 0. I 35 m., ATP/39/ I 96.

With the later burial were

(b) jug, Type 55a, but with the body more pear-shaped, of red clay, ht. 0.237 m., $\mathrm{ATP} / 39 / 195$

(c) bottle, Type I 3 I (approximately) covered with blue glaze, ht. 0. I 8 m., ATP/39/I 97, Pl. LXXXIII;

(d) 2 bronze needles, $1.0 .092 \mathrm{~m}$. and 0.1 I I m., broken;

(e) cylinder seal, white steatite, AT/39/205, Pl. LXII, No. 40;

(f) cylinder seal, white steatite, AT/39/206, Pl. LXII, No. 4I;

(g) cylinder seal, white steatite, AT/39/207, Pl. LXII, No. 42;

(h) beads; carnelian balls, frit cylindrical, blue paste cylindrical, and 2 white frit nasturtiumseeds, AT/39/208.

ATG/39/97. Simple grave dug down from late Level V into an earlier Level V wall, Sq. K I 5 . Infant's grave, only $0.60 \mathrm{~m}$. long, orientated $\mathrm{E} . \times \mathrm{W}$. Infant's body on left side, head west, flexed. With it

(a) jar, Type $55^{a}$, of drab clay painted on the shoulder with 4 red bands and vertical hatching between the bands, ht. O.I 7 m., ATP/39/289;

(b) a silver ear-ring, disintegrated;

(c) on the right leg a bronze bangle, plain, diam. $0.053 \mathrm{~m} ., \mathrm{AT} / 39 / 289$;

(d) beads; glass paste tubular and ball beads, decayed.

(e) a small cylindrical bone box, ht. 0.03 I m., diam. $0.036 \mathrm{~m}$., decorated with incised bands and running spirals, AT/39/29 I, Pl. LXXVII.

ATG/39/99. Simple grave dug down from Level V into the ruins of Level VI, Sq. K I 4. Infant burial, bones decayed. In it

(a) vase, Type I03b, drab clay, ht. $0.085 \mathrm{~m} ., \mathrm{ATP} / 39 / 292$;

(b) 3 silver ear-rings, plain hoops, AT/39/296;

(c) bronze pin, Type P. I I, broken;

(d) beads; small paste balls, decayed.

ATG/39/107. Simple grave orientated E. $\times$ W., dug down into the ruins of Level VI, Sq. K I 5. Body, adult, extended on left side, head west. With it

(a) lekythos, Type B.M. 25 , burnished red ware, ht. 0.25 m., ATP/39/295A;

(b) jug, Type I $44 a$, drab clay, ht. $0 \cdot 20$ m., ATP/39/296;

(c) lekythus, Type B.M. 25, burnished red ware, ht. 0.26 m., ATP/39/295B; 
(d) jug, Type B.M. 24, fine black burnished ware, fragmentary;

(e) in front of the body had been a wooden box inlaid with bone in a design of rosettes between bands of triangular pieces set alternately upright and inverted; there were also small square and semicircular pieces whose arrangement could not be traced. $\mathrm{AT} / 39 / 32 \mathrm{I}$.

ATG/39/108. Simple grave of an infant, dug down into Level VI, Sq. M I 3. Body disintegrated and grave disturbed. In it

(a) vase, Type B.M. 25 (?) of red clay, neck and rim missing, ATP/39/258;

(b) beads; carnelian balls, AT/39/263.

ATG/39/109. Simple grave dug down into Level VI, Sq. K I 5. In it the skull of an adult, body bones disintegrated, and

(a) jug, Type $68 a$, of thick reddish-brown clay, ht. o. I 6 m., ATP/39/30 I ;

(b) 2 plain annular bronze anklets, AT/39/297A and B.

ATG/39/ I I . Simple grave dug down into Level VI, Sq. K I 5, orientated E. $\times$ W. Body, adult, apparently supine, head west, but bones disturbed. With it

(a) jug, Type 52, of red clay, ht. $0.20 \mathrm{~m} ., \mathrm{ATP} / 39 / 300$;

(b) bowl, Type 24, of red clay, diam. 0.07 m., ATP/39/310;

(c) goblet, Type 94b, but with ring base; red clay, ht. 0. I 47 m., ATP/39/309;

(d) fragments of a very thin bronze ring;

(e) I large glass ball bead;

(f) bronze pin, Type P. I, 1. 0. I03 m., AT/39/50M.

ATG/46/I. Simple grave in Sq. L I 5, orientated N. $\times$ S. Body of a child, extended, prone, head south. With it

(a) pot, Type $5 \mathrm{I}$, of reddish clay with bands of brown paint, ht. $0.25 \mathrm{~m} ., \mathrm{ATP} / 46 / \mathrm{I} 26$;

(b) pot, Type 55 a, of reddish clay, ht. $0.2 \mathrm{I} \mathrm{m.,} \mathrm{ATP} / 46 / 208$;

(c) pot, Type B.M. 24, of red clay, ht. 0.1 6 m., ATP/46/204.

ATG/46/2. A wooden coffin set $\mathrm{N}$. $\times$ S. wherein an adult body extended on its back, the right arm by the side, the left hand over the pelvis, head north. By the head were

(a) jug, Type 55a, of reddish clay, ht. 0.2 I m., ATP/46/208;

(b) bowl, Type 8, of fine thin burnished black ware with umbilical centre, ht. $0.08 \mathrm{~m}$., $\mathrm{ATP} / 46 / 194$;

(c) inside the last, the knuckle-bone of an ox;

(d) jug, Type B.M. 24, of 'base-ring' ware, ht. ०.1 6 m., ATP/46/206.

$\mathrm{ATG} / 46 / 4$. Infant burial dug down into the Level VII courtyard, Sq. L I 4, from Level V. With it

(a) a miniature vase, resembling Type I 38 but originally affixed to a second similar as a twin vase; of greenish white clay with traces of a herring-bone pattern in red paint down the side;

ht. 0.07 m., ATP/46/325;

(b) silver ear-ring, a plain wire hoop, AT/46/319;

(c) beads; some small double tubular beads of glass now bleached white, and large beads, oblong, hemispherical in section, of banded polychrome glass; decayed, AT/46/3 I 8 .

ATG/46/7. Simple grave dug into Level VII from Level V, Sq. L I 4. Body, adult, strongly flexed, in left side, head NW. With it

(a) pot, Type I 37 , of grey clay, ht. $0.08 \mathrm{~m} ., \mathrm{ATP} / 46 / 202$;

(b) pot, Type i 46 , of drab clay, ht. o. Iо m., ATP/46/2 I 4 .

ATG/46/9. Cremation burial. The hole for the urn was dug down below the level of the foundations of Level VII (Sq. K-L I 4) from Level V (or possibly from Level VI?). It had been 
disturbed and the upper part of the urn was missing and the only pot found in the grave was fragmentary; the urn may have been imperfect when deposited in the grave. The bottom of it contained the bones, all heavily burnt and reduced to small fragments. With them, fragments of a clay pot, type uncertain, drab ware with slight geometric decoration round the shoulder -4 plain narrow bands and some diagonal cross-lines. ATP/46/309.

ATG/46/IO. Pot burial of an infant; in Sq. K I 4, against wall-foundations of Level VIII. The grave should be Level $\mathrm{V}$ but might be Level VI.

(a) 'marmite', Type I 54, of normal cooking-pot ware, black clay reddened on surface, with cord pattern round shoulder; broken, ATP $/ 46 / 227$;

(b) miniature vase, Type I07b, drab clay, ht. 0.04 m., ATP/46/228.

ATG/46/I I. Simple grave in Sq. L I 4, dug down into Level VI. Body, adult, lying with head to north, hands on pelvis, legs strongly flexed with knees on line of lowest rib and heels against pelvis. With it

(a) (by the right shoulder) vase, Type Io4b, drab clay, ht. $0.09 \mathrm{~m} ., \mathrm{ATP} / 46 / 326$;

(b) (under the last) bowl, Type I 5 , buff clay, broken, ATP $/ 46 / 25^{2}$;

(c) by the side of the right cheek a copper pin (decayed, type uncertain) which must have fastened a cloak on the right shoulder.

ATG/46/I 4. Simple burial of an infant, Sq. K I 3, dug down into Level VI. With the bones

(a) pot, Type I 37 , drab clay, ht. $0.093 \mathrm{~m}$., ATP $/ 46 / 26 \mathrm{I}$;

(b) pot, Type I 06 , drab clay with 3 incised rings round the base of the neck; ht. $0.087 \mathrm{~m}$., ATP $/ 46 / 262$.

ATG/46/ I 7. Simple grave, Sq. L I4, dug down into Level VI. Body, disturbed and imperfect, with head to SW. With it

pot, Type I 36 , but with the addition of a small lug handle; drab clay, ht. $0.099 \mathrm{~m}$., ATP/46/263.

ATG/46/20. Simple grave, Sq. L I4, dug down into Level VI; body of a child, disintegrated. With it

(a) pot, Type I 66, pinkish-buff clay with 2 narrow bands of red paint on the shoulder; ht. $0.094 \mathrm{~m} ., \mathrm{ATP} / 46 / 264$

(b) jug, Type B.M. 25 , buff clay, ht. 0.22 m., ATP $/ 46 / 265$.

ATG/49/I. Simple grave cut into the floor of the Level V fortress building. Two bodies side by side, an adult and a child, apparently flexed, heads SE. With the child

(a) vase, fine ivory-coloured clay, Type ro6b, broken;

(b) a few small ball beads of glazed frit, 2 large bugles, a 2-hole spacer, and a rabbit amulet, $\mathrm{AT} / 49 /$ i 9 .

With the adult

(c) a very small bottle, in fragments, Type 47, (?) of brown paste with smoky grey surface, very lightly fired and almost of the consistency of mud; it was badly laminated. It resembled Tell el Yahudiyeh ware more closely than anything else found on the site, but was in too bad a condition for identification;

(d) bronze pin, AT/49/20, Type uncertain (decayed).

ATG/49/4. Simple grave cut into the floor of Level V and into the wall of the Level VI fortress building. Body of a child, contracted, head SE. With it

(a) vase, Type I 39, pinkish clay with white engobbage surface, ht. $0.055 \mathrm{~m}$., ATP/49/33;

(b) vase, Type I00, whitish clay with fine engobbage surface on which one or two rings of burnish, ATP/49/32;

(c) 2 knuckle-bones. 
ATG/49/5. Simple grave like the last, body contracted, head SE.

(a) bronze pin, Type P. I I, by the neck;

(b) beads; black and white paste balls, I lapis paste bugle, I faience cog-wheel bead, $\mathrm{AT} / 49 / \mathrm{I} 8$;

(c) a terra-cotta figurine, AT/49/1 $7, \mathrm{Pl}$. LIV.

ATG/49/6. Simple grave like the last; the only object was a clay jug, Type $67 a$, of drab clay with light engobbage surface, ht. O. I I m., ATP/49/34.

ATG/49/7. Simple grave like the last. With the body

(a) (b) two vases, Type Io6b, of whitish clay with fine engobbage surface, one pebbleburnished, the other water-smoothed only; hts. O. I I m., 0.095 m., ATP/49/38 A and B;

(c) finger-ring of thin copper wire;

(d) bronze rod with radiate star head, AT/49/2 I, cf. AT/38/274, Pl. LXX;

(e) some pierced cowrie shells.

\section{GRAVES ATTRIBUTED TO LEVEL V}

ATG/37/28. Simple grave dug down into Level VI. Body, adult, lying on right side, head NW., hands raised and holding the jug to the mouth. With the body

(a) jug, Type 45, burnished black (smother-kiln) ware, ht. 0.1 8 m., ATP/37/2 I 4;

(b) I bronze ear-ring, plain hoop;

(c) 3 carnelian beads.

ATG/38/2 I. Simple grave, Site H; body, adult, on left side with head to south. With it (by the head)

(a) pot, Type I03a, yellow clay, ht. 0.09 m., ATP/38/63D;

(b) pot, Type I 37 , burnished black ware, ht. O I 3 m., ATP/38/1 5 I D.

ATG/39/87. Pot burial of an infant, lying $\mathrm{I} \cdot 00 \mathrm{~m}$. above the floor level of the Yarim-Lim palace, room I 8 .

(a) (the burial urn) 'marmite', Type I 53, of thin coarse grey clay with grit engrais, ht. $0.23 \mathrm{~m} ., \mathrm{ATP} / 39 / 226$.

By the side of this, and probably belonging to it, were

(b) pot, Type I 52 , reddish drab clay, ht. $0.37 \mathrm{~m}$;

(c) vase, Type IO4b, drab clay, fragmentary;

(d) bowl, Type 27, red clay, broken, ATP/39/227;

(e) a kohl-pot of grey steatite, ht. 0.045 m., AT/39/25 I, Pl. LXXX.

ATG/39/89. Simple grave lying $\mathrm{I} \cdot 50 \mathrm{~m}$. above the floor of the Yarim-Lim palace, room I9, orientated E. $\times$ W. Body of child, extended on left side, head west. With it

(a) jug, Type 75 , of red clay, ht. 0.I 4 m., ATP $/ 39 / 237$;

(b) beads; glass paste balls and blue-glazed frit 'cluster' beads, AT/39/245.

ATG/39/I03. Simple grave dug down into Level VI, Sq. K I 5. Young adult, apparently on left side, in flexed position, head west; only skull and a few fragments of bone left. With it

(a) jug, Type B.M. 25, red clay, ht. 0.207 m., ATP/39/290;

(b) haematite weight, AT/39/292.

ATG/39/44. This, and ATG/39/46, might be regarded as one grave, the bodies being directly one above the other; it appeared as if the original grave $(46)$ had been reopened for the second interment, and the fact that the former was not plundered or disordered would imply that the interval between the burials was short enough for disturbance to be reckoned as sacrilege.

Simple grave orientated NW. $\times$ SE, dug down actually into the top of a standing wall of 
the Yarim-Lim palace (Sq. M Io). The body, adult, lying on right side, flexed, head SE. With it

(a) jug, Type 54a, drab clay, ht. O.I 77 m., ATP/39/79;

(b) silver pin, completely decayed;

(c) 2 bronze pins, broken and decayed, type uncertain;

(d) 8 silver ear-rings, plain hoops, found at the head;

(e) 2 bronze ear-rings, ditto;

(f) I bronze finger-ring, plain;

(g) glass figurine of a nude female clasping her breasts, ht. $0.08 \mathrm{~m}$., cf. AT/48/4, Pl. LVIb. (Tomb group catalogued AT/39/106.)

ATG/39/46. (See above.) Body extended on right side, head NW. With it

(a) jug, Type B.M. 35, white slip ware with 'ladder' pattern in brownish-black, ht. ०. I 55 m., $\mathrm{ATP} / 39 / 80, \mathrm{Pl}$. CXXV;

(b) 3 silver ear-rings, plain hoops;

(c) 5 bronze ear-rings ditto;

(d) scaraboid of blue-glazed paste, poor scratchy design of snake and flower (?), AT/39/107.

ATG/39/I I . Simple grave dug down into the south wall of room i 9 of Yarim-Lim's palace, at about I.00 $\mathrm{m}$. above the floor-level (the grave could be of Level VI). Only the skull left. With it

(a) vase, Type I o6b, drab clay, ht. O. I 3 m., ATP $/ 39 / 265$;

(b) 2 bronze pins, Type P. $4, \mathrm{AT} / 39 / 32 \mathrm{M}$ and $\mathrm{N}$; lengths $0.09 \mathrm{~m}$. and $0.075 \mathrm{~m}$.;

(c) beads; carnelian balls, frit tubular and fluted balls, and 2 frit pomegranate pendants, $\mathrm{AT} / 39 / 27 \mathrm{I}$.

GRAVES BELONGING TO LEVEL VI

ATG/39/9 I. Simple grave orientated E. $\times$ W., Sq. L I 3. Body, adult, extended on left side, head west. With it

(a) cylinder seal, white steatite, AT/39/23I, Pl. LXI, No. 26;

(b) bronze pin, Type P. 7, broken;

(c) bronze needle, broken;

(d) bronze bangle, plain hoop, broken.

ATG/39/92. Simple grave (Sq. L I 4) with body, adult, legs apparently flexed, but bones much disintegrated. With it

(a) mug, Type 75, of red clay, ht. O. I 5 m., ATP/39/230;

(b) beads, a few balls of (bleached) paste.

ATG/39/I I 2. Pot burial of infant (Sq. K I 5); the bones in a 'marmite', Type I 55, coarse reddish clay with grit engrais, ht. 0.27 m., diam. 0.235 m., ATP/39/304.

GRAVES ATTRIBUTED TO LEVEL VI

ATG/39/8I. Simple grave dug down into the passage of Yarim-Lim's palace. Child's body extended (?) on left side, head NW.; bones much decayed. With it

(a) pot, Type I $04 a$, drab clay, ht. 0.07 m., ATP/39/209;

(b) cylinder seal, white steatite, AT/39/226, defaced Pl LXI, No. 30;

(c) beads; 4-string tubular spacer of glass paste, glass cubes, white frit rings and tubular beads.

ATG/39/106. Simple grave dug down into Level VII, Sq. K I 4. Body of infant, apparently flexed, facing south. With it 
(a) feeding-jar, Type $72 b$, drab clay, ht.'०. I 4 m., ATP/39/236;

(b) beads; glass paste balls, all broken.

\section{GRAVES ATTRIBUTED TO LEVEL VII}

ATG/37/23. Simple grave $2.50 \mathrm{~m}$. below a Level IV floor, Sq. C 20. (The evidence of position is not decisive and the grave could be of Level VI, but Level VII is more probable.) Body of small child with its head to SW. With it

(a) bottle, Type I 37, burnished grey-black clay, ht. ०.105 m., ATP/37/163;

(b) pot, Type ro7a, of rather coarse drab clay, ht. 0.079 m., ATP/37/ 3 I.

$\mathrm{ATG} / 37 / 24$. Simple grave I. I $5 \mathrm{~m}$. below the same floor as last; the grave might equally well be of Level VI. Body of a small child. With it

(a) pot, Type I 39, of fine pink clay, ht. 0.095 m., ATP/37/ I6 I;

(b) vase, Type I04b, of fine buff clay, ht. $0.068 \mathrm{~m} ., \mathrm{ATP} / 37 / \mathrm{I} 62$;

(c) pot, Type i $06 b$, of fine grey-yellow clay, ht. 0.097 m., ATP/37/ I i 7, Pl. XCIXe;

(d) bronze pin, fragmentary, type uncertain;

(e) beads; carnelian, steatite, and paste balls.

ATG/38/22. Simple grave in Site H; body, adult, on right side, hands before face, legs flexed, head SW. With it

(a) jug, Type 66, of yellow clay, ht. 0.205 m., ATP/38/199;

(b) vase, Type I $66 b$, yellow clay, ht. 0.095 m., ATP/38/1 48;

(c) bottle, Type I 37 , of ring-burnished black ware, ht. O. I 2 m., ATP/38/ I 75 .

ATG/48/I. Simple grave in Site $H$; bones of an adult, in disorder. With them

(a) vase, Type I 66 , light drab clay, ht. 0.15 m., ATP/48/43;

(b) amphora, variant of Type 76 , in fragments;

(c) bronze pin, Type P. I, broken;

(d) bronze 7 -rayed star on stem, AT/48/88, cf. AT/38/274, Pl. LXX;

(e) beads; about Io cylindrical and lentoid, of glazed frit.

ATG/48/7. Pot burial of an infant. The 'urn' (a) was a bath-like basin resembling Type 27 but with a flatter rim, and oval, $0.47 \mathrm{~m} . \times 0.37 \mathrm{~m}$., instead of circular. It was much broken. Inverted over it, as a lid, was

(b) a plate, Type 5, of blackish-grey clay, pebble-burnished, diam. $0.35 \mathrm{~m} ., \mathrm{ATP} / 48 / 60$.

GRAVES BELONGING TO LEVEL VIII

ATG/47/I. Simple grave dug down into the top of Level X, Sq. L I 4. Body of adult apparently placed in sitting position as the skull was on the top of other bones (decayed), but possibly disturbed. By it the bones of a small child lying on its left side, legs tightly contracted, head to south. With the latter

(a) pot, Type I00, of drab clay with light ring burnish, ht. $0.08 \mathrm{~m} ., \mathrm{ATP} / 47 / 5$;

(b) bottle, Type I 37, of burnished black ware, broken, ATP $/ 47 / 6$.

ATG/47/2. Simple grave dug down $0.30 \mathrm{~m}$. below the top of the Level X walls, Sq. K I 5. Body of child, lying on its left side, legs sharply contracted, head to east. With it

(a) bottle, Type I 37, of burnished black ware, broken and decayed, ATP/47/7;

(b) pot, Type $57 b$, of drab clay, poorly made with the rim almost vertical instead of fla:ed, ht. $0.055 \mathrm{~m} ., \mathrm{ATP} / 47 / 8$;

(c) beads; I white paste ball, I black tubular.

ATG/47/3. Simple grave re-used for a second interment. The first burial was of an adult, body on left side, legs sharply flexed, lying E. $\times$ W., head west; the second also of an adult lying on 
the left side, legs sharply flexed, the head to the east; the legs of the second body overlapped those of the first. By the head of the first was

(a) pot, Type ioo, of drab clay, ht. 0.085 m., ATP/47/3.

Between the knees of the two bodies was

(b) pot, Type $57 b$, of coarse gritty red clay, ht. $0.06 \mathrm{~m} ., \mathrm{ATP} / 47 / 4$.

Behind the head of the second body were

(c) bottle, Type I 37, of burnished black ware, ht. O. I $\mathrm{m} ., \mathrm{ATP} / 47 / \mathrm{I} \mathrm{I}$, and

(d) pot, Type I00, but lacking the everted rim, of drab clay, ht. $0.075 \mathrm{~m} ., \mathrm{ATP} / 47 / \mathrm{I} 2$.

ATG/47/4. Simple grave lying below the pebble floor of Level VIII, Sq. K I 4. Adult body lying on its left side, head to the east; position of legs uncertain as bones unrecognizable. With it:

Bowl, Type $97 a$, of reddish-buff clay, ht. $0.08 \mathrm{~m} ., \mathrm{ATP} / 47 / 9$.

\section{GRAVES NOT ACCURATELY DATED}

ATG/39/23. The grave was in Sq. M Io, at a level $0.50 \mathrm{~m}$. below the top of stone wall-foundations belonging to Level IV. The remains here were much disturbed by successive reconstruction; the foundations themselves had been partly cut away to make room for the grave. This could have been done while the wall was standing, but more probably took place after its destruction; but the levels were so closely superimposed that there was nothing to show whether Level III or Level II was the more likely date for the grave.

The body, that of an infant, lay on its right side, head north; most of the bones had perished. With it

(a) pot, Type I $4 a$, of red clay, ht. $0.075 \mathrm{~m} ., \mathrm{ATP} / 39 / 24$;

(b) bronze bangle, plain hoop, diam. $0.05 \mathrm{~m} .$, broken;

(c) bronze ear-ring, plain oval hoop, diam. $0.03 \mathrm{~m}$;

(d) beads; blue paste balls, white frit balls and cylindrical, carnelian rings and pebble, $\mathrm{AT} / 39 / 66(5)$

(e) figurine of glass paste, ht. $0.08 \mathrm{~m}$., of a woman holding a vase against her breast, AT/39/66 (I), cf. AT/48/4, Pl. LVIb.

ATG/39/29. The grave was in Sq. N Io, at the level of the tops of the standing walls of the Yarim-Lim palace; in the disturbed conditions of this particular area it could belong equally well to Level IV, Level V, or Level VI, Level V being the most probable. The body was that of an infant wearing beads round the neck and waist. With it

(a) pot, Type I 39, but with flattened base, of red clay, ht. $0.08 \mathrm{~m} ., \mathrm{ATP} / 39 / 28$;

(b) bronze pin, Type P. I I, 1. 0.07 m., broken, AT/39/75 (2);

(c) beads; I carnelian date-shaped, 4 large balls of green glazed frit, 2 similar, white, and many smaller white frit beads including balls, tubular, date-shaped and cylindrical, AT/39/75 (3);

(d) terra-cotta figurine of a nude female with the left hand raised to the breast; ht. $0.108 \mathrm{~m}$., $\mathrm{AT} / 39 / 75$ (I), Pl. LVIc.

ATG/46/1 5. Simple grave containing two bodies, one on the top of the other. The grave was in Sq. L I 5 and one end of it had been cut away by a later rubbish-pit which contained nothing distinctive but could hardly have been later than Level IV. The grave therefore might be of Level VI (which is the more probable), of Level V, or of the early part of Level IV.

The upper body was an adult, female, lying on the right side, the legs flexed, the head to the NE. The lower body was apparently that of a child, its skull immediately under that of the adult at the NE. end of the grave. With the bodies

(a) pot, Type I0o, drab clay, ht. $0.055 \mathrm{~m}$., ATP/46/327;

(b) a second clay pot, fragments only; 
(c) 2 bracelets each made of a double twist of copper wire; diam. c. $0.05 \mathrm{~m}$., AT/46/322, 323;

(d) bronze torque, thin, with hooked ends (one end missing), AT/46/324;

(e) bronze pin, fragmentary and type doubtful, on left shoulder of adult (who also had the bracelets, one on each arm, the torque, and the beads worn as a necklace);

$(f)$ a single bead threaded on silver wire;

$(g)$ beads; mixed shapes, balls, lentoids, rings, in paste, carnelian, crystal; restrung in original order, $\mathrm{AT} / 46 / 32 \mathrm{I}$

(h) terra-cotta figurine of a naked woman, ht. $0.147 \mathrm{~m}$., AT/46/238, Pl. LIVg.

These three graves are of interest as tending to show that the figurines commonly found do not necessarily have a religious significance. It is true that in the last grave, ATG/46/I 5, the figurine, which is of a very old traditional type (see p. 244), might have belonged to the adult and been a birth-charm; but in the other two cases where only infants are concerned the figure should surely be a plaything.

ATG/39/8. Cremation burial in Sq. M I2, only $0.60 \mathrm{~m}$. below the modern surface; it is therefore most likely that it belongs either to Level I $\mathrm{C}$ or to Level $\mathrm{O}$. The urn, a jug of drab clay, was too broken to type; it contained the calcined bones and

(a) 8 poor quality frit and pebble beads;

(b) a finger-ring of twisted copper wire;

(c) a silver pendant, egg-shaped, upper tag rolled over for suspension, having on it an embossed triangle; AT/39/24, Pl. LXVIII (b) i I.

This last is of interest for dating purposes since it is of a type fairly common on north Syrian sites. At Ras Shamra it has been found in considerable numbers in levels Ugarit Récent $i$ and ii (I600-1450 and I450-1365), and Schaeffer would seemingly confine them to those limits; the Alalakh example would prolong the foruit of the type, which is really so simple that it was likely to continue in use or to be revived at any time.

ATG/39/27. Simple grave in Sq. N IO at a depth of $\mathrm{I} \cdot 30 \mathrm{~m}$. below a drain of Level IV; owing to the disturbed state of the soil here (see above, ATG/39/23) the position is not decisive and the grave could be of Level IV, V, or VI, an early date within these limits being the more likely. It was orientated E. $\times$ W.; the body, adult, lay on its right side, legs flexed, head west. With it

(a) jug, Type 62a, of red clay, ht. O.I 8 m., ATP/39/25;

(b) 2 beads; balls of white and green frit respectively;

(c) an ivory libation-spoon (?) with a human hand carved in relief on the under side; 1. $0.078 \mathrm{~m} ., \mathrm{AT} / 39 / 70$, Pl. LXXVII. I know of only one other example in ivory of what is a well-established series of libation-pourers, AT/39/304; clay examples were found at Atchana in Level IV (see AT/37/226, Pl. CXXV); numerous examples are known in steatite (cf. S. Przeworski in Syria, vol. xi, p. I 33). They have been explained as 'incenseburners', a theory which overlooked the fact that no traces of burning are to be found in the cups, and that steatite is a material non-resistant to heat. It is perfectly obvious that an ivory cup could not be used for burning incense, and our examples should therefore turn the scale in favour of the view that these objects are libation-cups. 


\section{CHAPTER VII}

\section{(a) ARCHITECTURE}

$\longrightarrow \mathrm{HE}$ material employed for the building of walls was exclusively mud brick; this is true for all periods. While the size and proportions of the bricks are not constant the changes are not so marked, as a rule, nor are they so uniform, as to constitute a criterion for dating such as is afforded by bricks in Mesopotamia; but it does seem to be the case that very large bricks occur only in the older periods (e.g. $0.54-0.57 \mathrm{~m}$. sq. in Level XVI, $0.50 \mathrm{~m} . \times 0.40 \mathrm{~m}$. in Level XIV), but even then they are used side by side with others of smaller size, while the normal brick-length is $0.43 \mathrm{~m}$.$0.39 \mathrm{~m}$. Burnt bricks were used only for a few special purposes, drains, vaults, \&c. Flat burnt tiles for floors were employed as early as Level XVI and, though they are never common, are found at intervals right up to Level I.

For wall-foundations stone was normally used, in the form of rough unshaped boulders of different sizes and sometimes, in private houses, so small as to be termed pebbles. They were laid in the trench dug for the foundation and usually rose just above the level of the ground, if the building was of good quality, but sometimes merely cover the trench bottom; in the best buildings the stonework might be carried up to a full course above floor-level, in which case they would be concealed by a cement dado. We did not find a single example of a wall built of stone. ${ }^{\mathrm{I}}$ On the other hand, for temples, palaces, and public buildings the dressed or polished stone orthostats along the wall base are very common; they are generally of basalt, rarely of limestone, and in size they differ from a height of $0.42 \mathrm{~m}$. (rooms I 4 and I 5 of the Level IV palace) to I. $65 \mathrm{~m}$. (Level VII town gate). The orthostats usually stood on a low plinth (the rough stone foundation) which was cement-faced, and cement was used for the mortar between them. The sides of the orthostats are often not vertical but slightly sloped, which means that the stones had to be carefully trimmed if there was to be a close join; this was really only feasible if the final dressing were done on the spot (as was the normal practice of Hittite builders; v. my - Carchemish, vol. ii, p. 145), which would require a good deal of shifting of these heavy blocks. I think that that explains the lewis-holes which occur in the flat tops of the larger stones and were long supposed to be for pegs that would key the stonework with the timbers in the wall above; at Atchana, as at Carchemish, the evidence is conclusive against the use of any such pegs; but for the constant manœuvring of the blocks to make sure of their fitting against one another the lewis-holes would be most serviceable. ${ }^{2}$

The use of timber in wall construction goes back to a very early period and persists until the last days of the city (indeed, into much later times), but is practically confined

1 The stone-lined shaft in room 17 of the Level VII palace is not really an exception to this inasmuch as merely a lining, backed against earth, not a free-standing wall.
2 By the use of a wooden or metal pole having a projecting knob that fits into the lewis-hole the stone can be tilted and twisted round at pleasure. 
to buildings of the better class, temples and palaces. In the early periods the practice is simple; sometimes, especially where a new wall is to be built over the trimmed stump of an old, a long beam is laid just above floor-level as a bedding for the brickwork; it has the obvious advantage of giving at once a true line for the wall-face and a flat bedding for the brickwork. Such beams (e.g. in the Level XIV temple walls) occur only along the face of the wall; but sometimes the timber forms a real foundation, a number of beams being laid on the ground, more or less parallel, and the spaces between them being filled with clay so as to make a solid platform on which the bricks could be laid (e.g. the Level XI temple). It is rare, in the early periods, to find any trace of woodwork high up in the walls; it is employed for foundations. But in the later levels we have the characteristic 'Hittite' half-timber construction fully developed; the timber now comes above the orthostats (if there be such) and is carried up, apparently to the full height of the wall, with long horizontal beams in the wall-face alternating with transverse timbers that run through the wall's thickness, Fig. 7I; the best example of this is room 32 of the Level IV palace, v. p. I 26 and Pl. XXVIIb.

Not infrequently we found a course of reed matting introduced into the middle of the brickwork. I at first supposed that this was normal wall construction and that the matting course was intended to give a better all-over bond and so prevent the flaking away of the wall surface which is apt to result from the use of square instead of oblong bricks, the rows of bricks not being dovetailed together. But matting is rarely if ever used in the body of a wall; it is generally if not always a foundation-course. Its regular use was where a new building was to be set up on the site (and often on the lines) of an old; the levelling might not be too well done and in any case the rubble filling of rooms would sink and make hollows between the old wall stumps; so reed mats (often in double or treble thickness) were spread over the area to give a better surface; good instances of this occur in the case of the various temple platforms and in the ramparts of Levels $\mathrm{V}$ and VI.

Fine white cement was used as plaster for walls and for floors from a very early time. For walls it formed the top coat over an under coat either of plain mud or of mud mixed with lime; a good illustration of the finger-print keying of the under plaster was given by room 4 of the Level VII palace; v. also Pl. XVII $b$. Where fresco decoration was employed it was true fresco on the newly laid wet plaster. A real concrete was used in Level VII for the foundation of the temple and also for floors, in which case it had a final dressing of white cement; it is curious that in the later periods concrete seems to have gone out of use.

The column was a common architectural feature. In Level XII we have the solid mudbrick column built of specially shaped radial bricks; this is certainly imitated from a foreign model, not endemic, and therefore it disappears from later Syrian architecture

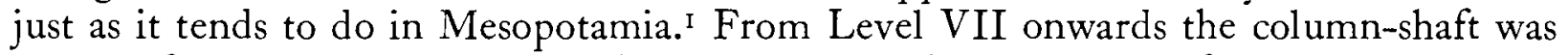
always of wood, resting on a stone (generally basalt) base circular in form with plain sides

\footnotetext{
I There are there later examples, e.g. of the Larsa period, were prone to attribute them to the Hellenistic period; e.g. but they are quite exceptional, so much so that archaeologists Hilbrecht, Exploration in Bible Lands, pp. 337-8. 

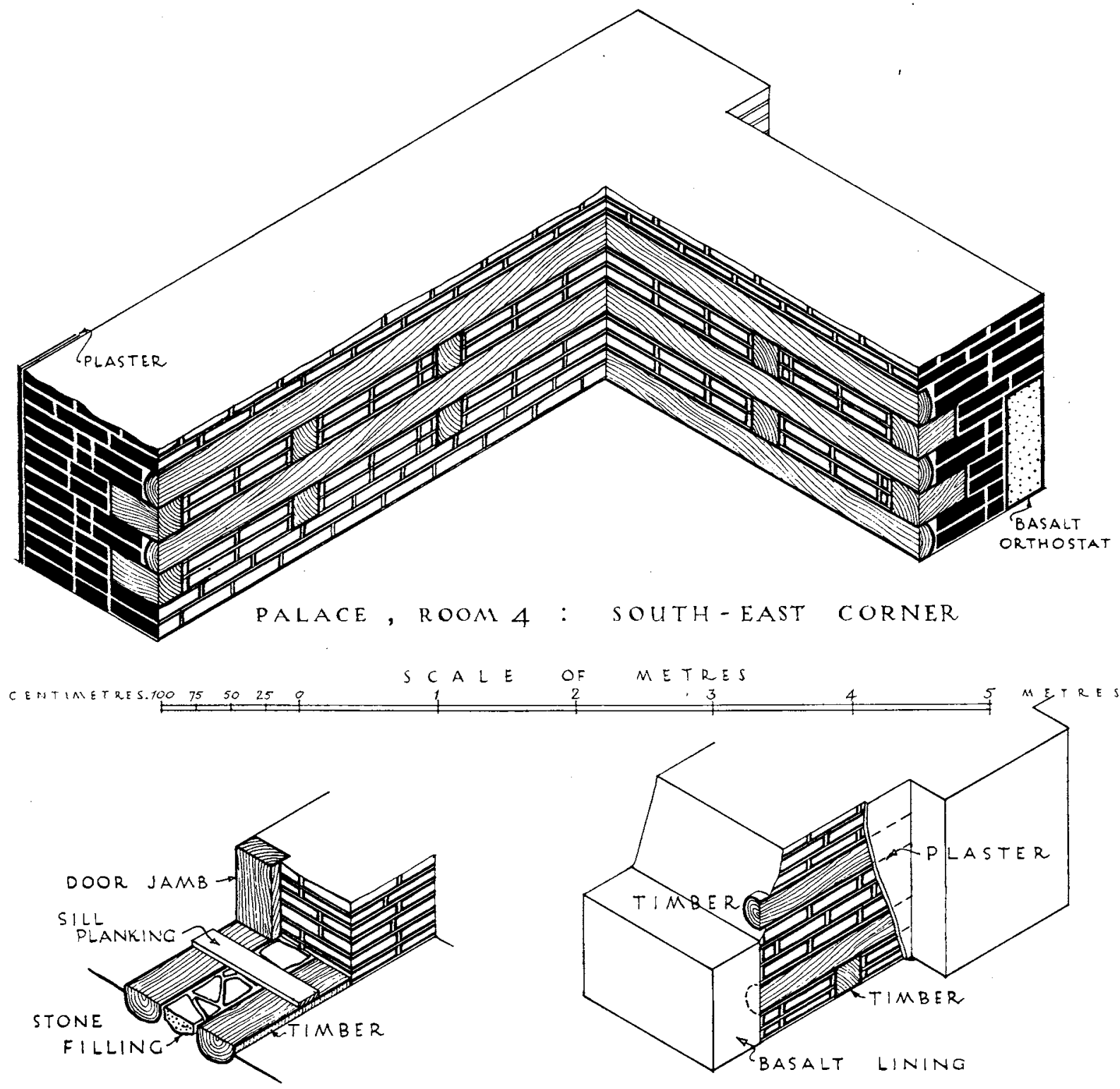

PALACE: THRESHOLD BETWEEN ROOMS C2 \& $C 3$ $M E T R E S$
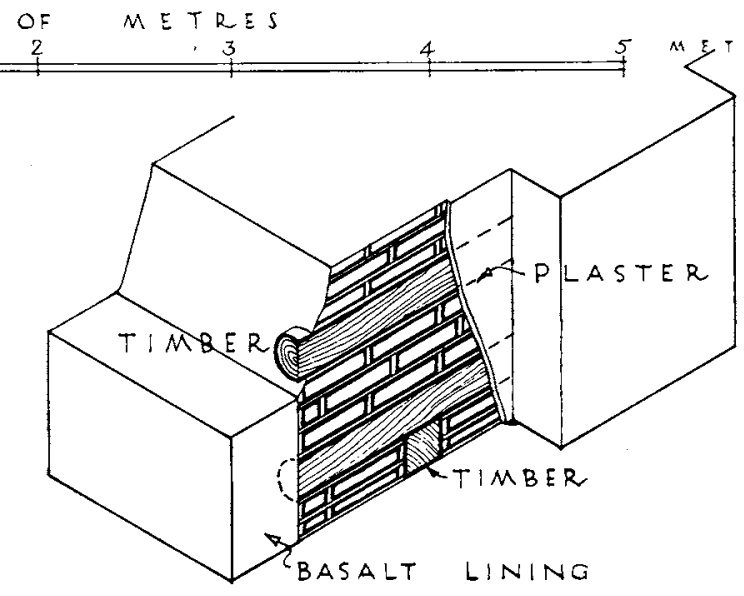

PALACE: ROOM 13

NORTH-WEST CORNER

FIG. 7 I. Methods of half-timber wall construction, Level IV 
sometimes gently curved, sometimes slightly conical-the elaborately carved base is a post-I 200 B.c. development.

In Level $\mathrm{V}$ we have (on Site $\mathrm{H}$ ) an example of an attached half-column used as a purely decorative architectural feature (Pl. XXXVIa), and in the Level II house 37/A half-columns of mud brick flank the doorway on to the street. Unexpected as this motive of the attached half-column is in Syrian architecture, it cannot be connected with the common Mesopotamian usage. In Sumerian and Babylonian temples-the feature is peculiar to religious buildings-the half-columns are not isolated as here but are contiguous, with no flat wall-surface between them, and they invariably have a T-shaped groove running down the centre which is lacking in the Atchana examples. I would suggest that it is derived very simply from the use of timber in wall construction. We have plenty of evidence to prove that the heavy timbers so constantly employed in wallbuilding were very often split logs with one flat and one rounded face; usually the rounded face is to the inside and it is the flat trimmed face that is exposed flush with the brickwork, but the beam has only to be turned round to give precisely the effect that we have here. At the same time the feature, however simple, was not common-we have only two cases of its use. It is noticeable that whereas the clay model of a temple (Pl. IX $b$ ) shows attached pilasters (?) and wall-reliefs, nothing of the kind was found in the course of our excavations; at Alalakh architectural ornament was certainly reduced to a minimum.

Roofs were generally flat. The rafters were close-set and over them was laid matting with earth above, in the fashion of the modern Arab house; where there was an upper story the upper floor was made in the same way, but in the case of a palace or very wealthy house concrete might be spread over the earth and given a top coat of white plaster ( $v$. room 2 of the Level IV palace, p. I I7). In Level XI (v. p. 30) some rooms had been vaulted with barrel-vaults in burnt brick, ${ }^{\mathrm{I}}$ but the custom did not last long; even in Level $\mathrm{X}$ the voussoirs salved from the previous building could be used as floor-tiles, and in later periods we find no suggestion of anything of the sort.

A window-sill was found in the Level XII temple, but generally the walls of buildings were not preserved to such a height that any evidence of windows could survive, though that they were freely used cannot be doubted; cf. the model temple illustrated on Pl. $\mathrm{IX} b$. But in the Level VII palace, whose walls stood up to nearly $3.00 \mathrm{~m}$., there were still no openings, e.g. room I 2 (q.v.), so that if there were windows in the ground-floor rooms they were set very high up. For the possibility of a three-light window in the upper story v. p. 94.

Doors, set in wooden frames, could be either single-leaf or double, the double-leaf door being found, as a rule, only in the big 'audience-chambers', where it divides the

\footnotetext{
I Numbers of the bricks were found lying on the floors against the side walls of the rooms; they were radially moulded voussoirs, thin, and provided on one side with no less than eight finger-print frogs. There can be no doubt as to their use. For building a barrel-vault without the support of centring a flat and large brick is preferable, and since until
}

the ring is completed the bricks forming it have a marked tendency to slip, being kept in position merely by the mortar between them and the sloped face of the previous ring, the extra frogs are an admirable precaution. For a detailed account see above, Chapter I, pp. 30-3I and Figs. I 5 and I 6. 
two sections of the room. The door-hinge was of the normal Eastern type with a hingepole held by a ring at the top and going down into a hole in the sill to rest on a plain socket-stone; two more elaborate hinges with bronze shoe and socket were found in the Level IV palace (Fig. 48 A).

An interesting form of construction is the clay- or lime-plastered glacis which we find in the case of the little Level V shrine (p. I75), of the city ramparts of Levels VII, VI, and V (and presumably III) and of the Level XII temple (v. p. 50 for description and note).

The very striking analogies afforded by the architecture of Alalakh alike in its materials, its building methods, and its planning, with the Minoan architecture of Crete have been remarked in various passages in this report and are indeed so obvious that it is not necessary to emphasize them further. They had long ago been anticipated by Arthur Evans; ${ }^{1}$ now that they are reinforced by the parallel of the frescoes (v. infra) they constitute unmistakable evidence for the influence exercised by western Asia on the development of Crete.

\section{(b) THE FRESCOES}

SMall fragments of coloured wall-plaster were commonly found in the ruins and give evidence of the use of fresco decoration from the time of Level IX at least right down to the last days of the city. Only in two cases, in the seventh-level palace of Yarim-Lim and in one private house of Level IV, was there enough preserved to show that there was not a uniform colour-wash over the entire wall but a polychrome design of which certain elements could still be distinguished; the striking resemblance of these remains to the Minoan frescoes of Knossos makes a detailed description of them necessary.

TECHNIQUE ${ }^{2}$

There was considerable variation regarding the initial process of preparing the ground. In room 4 of the Yarim-Lim palace the wall was covered with a thick coat of lime plaster roughly applied and smoothed and then pitted all over with finger-impressions to serve as a key for the final plaster; the latter was of very fine quality and fragments showed redand cream-coloured paint; this may correspond to the two coats of identical plaster (each coat about six millimetres thick) which were often, though not invariably, used in Crete. More often the ground-plaster was a single layer varying from four to eight millimetres in thickness applied either directly to the face of the brickwork or over a wall-coating of mud plaster. The ground-plaster itself is sometimes of fairly pure though not very fine-ground white lime, sometimes is of lime mixed with earth and therefore grey in colour, and occasionally it contains a certain amount of chopped straw.

The ground-plaster was rendered to a smooth surface over which the intonaco was laid. The latter is of pure rich lime and was used in the form of a weak solution so that

1 P.M. ii, pp. 268 sq.

2 I follow here, sa far as possible, the order of the descrip- tion given by Noel Heaton, 'The Mural Paintings of Knossos', in Journal of the Royal Society of Arts, January I 9 Io, p. 206. 
it should sink well into the (generally very similar) ground and form a very thin coating, never more than a millimetre in thickness; where the ground is white, with no earth admixture, the intonaco is difficult to distinguish in the section and it looks almost as if the extremely fine surface might have been obtained simply by 'floating' the ground, but this is certainly not the case and there was always a final coat of thin intonaco.

\section{COLOURS}

The colours used are black, red, yellow, blue, and grey-green. Specimens were submitted to Dr. Plenderleith, Keeper of the Research Laboratory of the British Museum, who kindly arranged for their examination by Mr. Barker; the report is given in extenso at the end of this section, p. 233. Mr. Barker has dealt with all the colours except the grey-green, of which no example could be submitted; this is a fugitive colour which appeared to me to be a mixture of yellow and blue on a white lime basis. It will be remarked that the colours appear to be identical with those used for the Knossos frescoes.

METHOD

As soon as the intonaco had been applied over the requisite surface a few guidinglines for the design were put in; a horizontal division of the field ${ }^{\mathrm{I}}$ would be marked by stretching a string tautly across in contact with the plaster, lifting the centre and letting it slap back so as to make a visible impression; the principle outlines would be sketched with a blunt point in the soft intonaco, ${ }^{2}$ but this only to the extent of the minimum that the artist considered essential; the greater part of the design was drawn freehand. ${ }^{3}$

The painting was done in the true fresco technique, the pigments being applied while the stucco was still moist; none the less, owing to the thinness of the intonaco it would dry very quickly, and the pigmentation is therefore not uniform. The penetration is nowhere very great, ${ }^{4}$ and although generally where a colour comes against the white (unpainted plaster) background the blurring of its edge witnesses alike to the dampness of that background and to the penetration of the pigment, in some places the plaster has evidently had time to dry and the pigment, failing to penetrate at all, has formed a superficial film which can flake away and expose the intonaco surface. This, however, is but a local accident ${ }^{5}$ and for the most part the colours applied to the stucco are very firm. That, however, is not true of the over-painting. Heaton could not observe in the Cretan frescoes any finishing in painting a secco on the frescoed ground, but the Alalakh painters

\footnotetext{
I e.g. on P1. XXXVII, to mark the lower edge of the ladder-like pattern which limits the white field.

2 Of the two slender stems on Pl. XXXVII that on the right hand has been so outlined on both sides; a curious result has been that some of the intonaco between the engraved lines, having lost cohesion with that on either side, has flaked off and exposed the ground-plaster.

3 This procedure is identical with that of Knossos; $v$. Evans, P.M. i, p. 534 .

4 Heaton was surprised at the "considerable amount of penetration' of the pigment into the intonaco in the case of the
}

Cretan frescoes, but this is not necessarily characteristic of true fresco. Baldwin Brown (Vasari on Technique, p. 288) says that "it is a mistake to speak of the pigment sinking into the wet plaster; it remains on the surface but is fixed there by a sort of crystalline skin of calcium carbonate which has formed on the surface of the plaster'. This would explain the flaking of some Atchana pieces.

5 The much greater thickness of the Cretan intonaco (according to Heaton) would mean that it remained wet much longer and would account for the greater penetration. 
indubitably employed that technique. Where there is over-painting in a light colour on a dark ground that ground was evidently dry; the light pigment does not penetrate at all, its edges are sharply defined, it has acquired with time a granular texture (through the releasing of the carbonate of lime which was the binding medium) and scales off very easily; it was always difficult and sometimes impossible to detect, on the fragments which we possess, the light painting on the red ground. This, however, may again be due to accident. Such details were the last to be added, and by then the plaster may have had plenty of time to dry. We need not suppose that the painter started with the deliberate intention of carrying out the later stages of his work a secco; but the fact of the ground being then already dry did not deter him in the least-he just went on painting. But there is one case of real a secco technique. On the fragment on Pl. XXXVII there are dark spots, apparently leaves, painted over the red ground with a thick viscous paint purplish-brown in colour; ${ }^{\mathrm{I}}$ it is not a paint that could be used in fresco work proper and it was certainly put on after the red paint was dry. This is the only technical difference that I can detect between the frescoes of Alalakh and those of Crete.

The fragments of fresco recovered from the great salon of Yarim-Lim's palace are too small for the subject of the paintings to be recognizable, but they do at least give certain details which allow of comparison with Cretan works. The two fragments reproduced on Pl. XXXVII were found lying together ( $v$. Pl. XXXVIb), and if they do not actually fit one to the other they must have been practically continuous. Of the lower fragment $(c)$ the greater part of the field is plain red which ends above, against a white ground, in a curiously irregular undulating line emphasized by an internal line, parallel with the edge, painted over the red in a greenish-grey now much faded. The undulating line is strongly reminiscent of the broad waved bands of red which in such Cretan frescoes as that of the cup-bearer ${ }^{2}$ are taken across the field and form the main background of the figures. Above the white ground comes red again, this time with.a straight horizontal edge on which is a 'ladder'-pattern in greenish-grey; at intervals from the upper side of the 'ladder' there rise slender curved lines, in groups of three, which might be the stalks of flowers-but the flowers, if there were such, are missing. At the right-hand end of the fragment the edge of the lower red mass dips down suddenly and the more or less triangular space between it and the 'ladder' was covered with a wash of pale greenish-grey on which twigs and leaves were painted in darker green; this is precisely the technique that we have in, for example, the 'miniature' fresco of the Sacred Grove at Knossos. ${ }^{3}$ This darker green colour, which was, of course, applied in tempera, has faded badly and is far less clear now than when it first came to light.

On the upper fragment ( $\mathrm{Pl}$. XXXVII $(b)$ ) the red ground is interrupted first by a broad mass of light colour (divided into two at the bottom by a red triangle) which expands above towards the left; the upper part is terribly broken ${ }^{4}$ and the colour has faded, leaving

I With time the pigment has become brittle and flakes off easily; the field notes show that when the fragment was first found there were more of these spots than now appear, and they were better defined.
3 P.M. iii, p. 67, and Pl. XVIII.

4 Several of the pieces here do not actually join, as the smaller bits had disintegrated, and have been replaced arbitrarily; they did, however, all come within this area. 
a pale greenish-grey with no detail whatsoever; when it was found I thought that I could distinguish leaves of a darker colour, but that is not certain. It is possible, if the two fragments go together as they appear to do, that we have here the trunk and main part of the foliage of the tree of which some leaves are better preserved on the other fragment. To the right of the 'tree-trunk' and slightly overlapping it is a festoon of leaves (?) in dark purplish-brown connected, apparently, by slender twigs painted in greenish-grey on the red ground; it is tempting to connect this very different foliage with the two more slender uprights to the right and to regard those as the stems of tall plants with drooping branches. At the extreme right end of the fragment is yet another upright, slightly curved in outline, ${ }^{\mathrm{I}}$ which again may be a tree-trunk.

From the same room came a number of fragments, found separated but all together, which obviously are of the same pattern; in two instances pieces actually fitted together, the rest were isolated; two fragments gave the base of the panel, three the top of it, ${ }^{2}$ and with this to start on it was easy to reconstruct the design (P1. XXXVIIIa). On the normal red ground there are represented, in creamy white, tall tufted grasses blown by the wind; the work is sketchy and impressionistic but the effect is admirably represented. I cannot quote an exact parallel to this from the Knossos frescoes, but it is unmistakably in the spirit of Cretan art. ${ }^{3}$

Also from the Yarim-Lim salon but from another part of it-probably from the NE. part beyond the columns that divided the room into two-came the fragments (Pl. XXXVIII b) showing a band of yellow, black, and purple on a white ground and, in one case, the horn of a bull. It is tempting to see in the bull design a further analogy with Knossos, but that is not necessarily the case. To the left of the horn, on the corner of the fragment, there can be seen on the white ground a black blotch with curved outline which seems to continue up as a circle over the yellow and purple band; it is possible that the horn is that not of a bull portrayed as a living animal but of a bucranium with a disk set between its horns; in that case parallels should be sought not in Crete but in the north Syrian culture-area where we find the. disk-bearing bull in the frescoes of Mari ${ }^{4}$ and bucrania have their far-off prototypes on the painted pottery of Tell Halaf. 5

Another example of fresco decoration was found in room 6 of house 39/A, Level IV; in this case the frescoes still adhered to the wall (P1. XXXIX $a$ and $b$ ) which was standing to a height of about one metre; the surface was in poor condition, but the design was for the most part clear and one section was so far preserved that it was possible to detach it and remount it on plaster; it is now in the Museum at Aintakya. The decoration of the whole room was uniform; it was best preserved in the south corner, i.e. to a width of c. $1.70 \mathrm{~m}$. on the SE. wall and of $3.00 \mathrm{~m}$. on the SW. wall; there were very scanty remains

1 A vertical guiding-line has been drawn here with a point in the wet plaster, but the line of the 'trunk' does not keep to it; the irregularity is intentional.

2 Both above and below the plaster ends in a straight line, the back of it showing that it was pressed into an angle, and the front bevelled slightly forwards; the painting occupied the space between an upper and a lower projecting frame. $\mathrm{Mr}$. Gadd has suggested to me that this might be the space be- tween two of the horizontal beams in the half-timbered wall.

3 Cf. the wind-blown anemones on a light-on-dark clay vase from Zakro, P.M. ii, p. 472 , Fig. 279.

4 A. Parrot, 'Les peintures du Palais de Mari' in Syria, xviii, p. $325, \mathrm{Pl}$. xxxvir, 2.

5 ø. M. E. L. Mallowan in Iraq, ii, P. I 54, where the persistence of this motive is discussed. 
on the two door-jambs, and on the NE. wall only one small patch near the middle and a larger patch (showing part of the red upper 'beam') in the north corner.

The walls of the room were of mud brick resting on shallow foundations of rubble and pebbles; on the stones, at floor-level, there were two transverse tie-baulks of timber running through the SE. wall only; the other walls showed no woodwork. The walls had been plastered with a mixture of lime and mud, and over this ground was spread the very fine white lime plaster intended to receive the colour; so far as I could tell the paint was applied while the plaster was still wet, i.e. the decoration was here, as in the older palace of Yarim-Lim, true fresco and not in tempera.

The design, as shown on PI. XXXIX, is architectural; it reproduces in colour the constructional features of the walls of temples or palaces-walls with a dado of basalt orthostats and with elaborate timbering in the upper brickwork. The basalt orthostats are represented by rectangles $0.7 \mathrm{I} \mathrm{m}$. long $\times 0.15 \mathrm{~m}$. high; the general colour is a dark purplish-black (obtained by laying a dark blue wash over a first wash of plain red) flecked with very small spots of red and green which give a marbled effect quite like basalt (Pl. XXXIXa); the 'slabs' are divided by vertical mortar-lines $0.05 \mathrm{~m}$. wide in yellow and a thinner mortar line only $0.0 \mathrm{I} \mathrm{m}$. wide runs over the top of them. Above the mortar-line is a band $0.14 \mathrm{~m}$. wide of deep red; this represents the wooden beam resting on the orthostats. Above this comes the plain wall surface, creamy white in colour; ${ }^{\mathrm{I}}$ at $0.65 \mathrm{~m}$. from the first beam there was a second horizontal timber represented by a red band $0.14 \mathrm{~m}$. wide on which are wavy horizontal lines in dark purplish-black (i.e. blue over the red), probably meant for the graining of the wood (Pl. XXXIXb). At intervals of about $\mathrm{I} \cdot 25 \mathrm{~m}$. there are, below the horizontal band but touching it, red rectangles (about $0.25 \mathrm{~m}$. wide by perhaps $0.40 \mathrm{~m}$. deep), ${ }^{2}$ which are apparently the ends of the transverse baulks running through the thickness of the wall. Above the horizontal timber there was again a plain white or creamy-white surface. This form of architectural decoration has its exact parallel in two examples of different dates at Knossos-in a corridor of the L.M. II West Porch of the Palace and in the M.M. III East Palace Border. ${ }^{3}$ The M.M. III Cretan fresco is, of course, much older than that of Alalakh; for the 39/A house belongs to the latter part of the Level IV period and must therefore be dated, in round figures, to about I 400 B.c. But in Alalakh as in Crete this scheme of decoration is traditional and we have found it used in room 5 of Yarim-Lim's palace, and there, as it occurs on the original plaster, under a later coat, it cannot be much later than $175^{\circ}$ B.C.

\footnotetext{
I It was a good deal yellowed with age, but seems to have been white originally.

2 These, coming high up on the ruined wall, were very
}

fragmentary and the measurements given of them, and of the intervals between them, are only approximate.

3 Arthur Evans, The Palace of Minos, iv, pp. 894, 896 . 


\section{EXAMINATION OF FRAGMENTS OF MURAL PAINTINGS FROM ATCHANA}

Report by MR. BARKER

The material submitted for examination consisted of a few small fragments of the plaster bearing the various coloured pigments used. In order to facilitate comparison it was requested that the examination should follow the lines laid down by Noel Heaton for the Cretan Murals. ${ }^{I}$ Information was therefore sought on the following points:

r. The nature of the stucco and its method of preparation and application.

2. The nature of the pigments.

3. The method of execution of the paintings.

\section{The Stucco}

The stucco from Atchana is about $\frac{1}{4}$ in. thick or slightly less. Chemical and spectrographic tests show it to be essentially calcium carbonate containing small amounts of magnesium, barium, and manganese and only a very slight trace of silica. This indicates the use of a lime plaster having no hydraulic properties. Specimens were sectioned, polished on ground glass, and etched with very dilute hydrochloric acid as described by Heaton. A photograph was made of such a section, Pl. XXXVII $a$. It is clear that unlike the Cretan fragments not only is there no indication of two layers of plaster but that many discrete particles, some of them quite large, are distributed throughout the material. These are a form of calcite and look very much like marble, but the services of a mineralogist would be necessary to confirm this. The use of marble dust as an ingredient of plaster is recommended in all the medieval records and it is recognized that the admixture of some such inert material is necessary for the production of a satisfactory plaster. In the case of the Cretan plaster Heaton was unable to find any evidence for the use of such inert material either in the form of optically active fragments or as unburnt lime, although the satisfactory nature of the plaster would seem to indicate that something besides pure lime must have been employed in its production.

\section{The Pigments}

In his examination Heaton mentions five colours, viz. white, black, red, yellow, and blue. The fragments from Atchana bore in addition to these a brown. Chemical and spectrographic tests showed that these various colours are closely similar to those from Knossos. The white is calcium carbonate, the black an aluminium silicate containing carbon (i.e. possibly a carbonaceous slate or shale), the red-brown and yellow are iron earths, and the blue a silicate of copper and soda, i.e. a glass coloured by copper.

\section{The Method of Execution}

The pigments are bound only by calcium carbonate; there is no evidence for the use of

I Noel Heaton, F. Royal Soc. Arts, i g ro, lviii. 206. 
gum or any other vehicle or binding medium. The method of execution is, therefore, like that on the fragments from Knossos, in true fresco.

The findings are summarized and compared with those on the Cretan murals in Table I.

TABLE I

Summary of Results and Comparison with the Cretan Murals

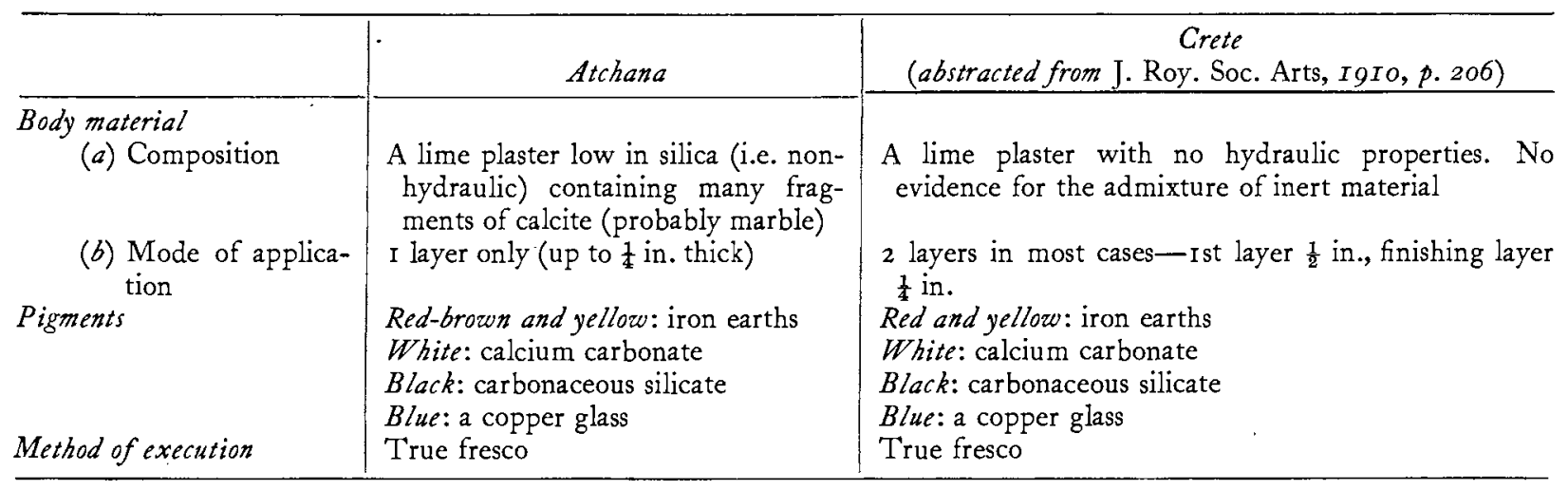




\section{CHAPTER VIII}

\section{(a) THE STONE SCULP'TURE}

\section{LEVEL VII}

AT/47/62. Pl. XL. Head of a statue of a beardless male; ht. $0.12 \mathrm{~m}$. Made of a reddish micaceous stone, probably ordinary basalt discoloured by fire. The head was made separately, to be fixed to a body of some other material; the eyes were inlaid. The hair, represented by close striations, is cut pudding-basin fashion in a straight line across the forehead and round the nape of the neck; the nose has been broken away but evidently was short and broad; the mouth is short but the lips are very full, so much so that the upper lip comes almost up to the nostrils; the chin is round and receding, the ears are flat but heavily lobed.

The use of inlay for the eyes, the disproportionately large size of the eye-sockets, and the downward slant of the eyes are all reminiscent of the archaic art of northern Mesopotamia as illustrated by the Khafaje statues; the poor modelling of the lips betrays the lack of skill of the local artist; but the whole effect is unmistakably Egyptian. It would seem that the extension of Egyptian influence into northern Syria in the time of the XIIth Dynasty (which brought actual Egyptian sculptures to Ugarit) compelled the Alalakh sculptor, trained in the Mesopotamian school, to adopt so far as he was able the artistic canons of the dominant Power.

From the Level VII temple.

AT/47/74. Pls. XLI, XLII. Head of a statue; ht. $0.165 \mathrm{~m}$.; black diorite. The base of the neck is broken, but apparently not much is missing, for a vertical tenon-hole shows that the head was made separately and was fixed to a body of a different material. A crack runs down the face but does not extend to the back of the head; the tip of the nose is missing and the chin and both ears have been slightly chipped; otherwise the condition is very good. The eyes were inlaid; the inlay of the left eye is missing, of the right eye the eyeball of white steatite remains (damaged by heat) but lacks the pupil.

The head is that of a comparatively young man. He wears beard and moustache, but these are scarcely more than indicated-the relief is extremely low, the surface perfectly plain and smooth, only the outline being sharply defined-which is in curious contrast with the elaborate treatment of the rest of the head and especially of the head-dress; my first impression was that the detail must have been rendered in paint on the plain surface, but it is more likely that a pastiche was used, a beard separately carved in stone, of the type illustrated by AT/47/77A, Pl. XLIIId, being fastened to the chin. Still more curious is the head-dress. At first sight, seen from in front or in profile, it would appear that the hair-rendered by finely engraved wavy lines-was brought down from the top of the crown to pass over a circular pad and 
be confined by a heavy rope-like fillet below which the ends are caught up so as to make a close roll across the forehead; only in front of the ears and round the nape of the neck a single row of short curls hangs down beneath the roll and fillet. But the back view is wholly different. The supposed 'hair' is cut away in a curve extending almost to the ears and exposes, above the fillet which encircles the whole head, a triple bandeau of plain rope above which can just be seen the real hair coming straight from the crown of the head to end naturally in the curls visible below the fillet. It is clear that the hair was confined by a threefold strand of rope wound round the head, not unlike the brim of the modern Arab, and that over this was worn a wig, open behind for convenience in putting it on and with a fillet to secure it which fitted below the head-rope at the back.

The head is undoubtedly a portrait; it is tempting to identify it as a portrait of King Yarim-Lim in whose temple it was found. As a work of art it is most remarkable. There is here none of the Egyptian influence that was so noticeable in the case of $\mathrm{AT} / 47 / 62$; whether there existed a local school of art capable of producing such a masterpiece we have no means of knowing, but did such exist it must have owed a great deal to Mesopotamia. Again we are hampered in our judgement by the lack of first-class examples of Mesopotamian sculpture contemporary with the YarimLim head, but there are historical precedents which should be conclusive.

For the wig, or head-dress in form of a wig, the obvious precedent (though remote in date) is the golden helmet of Meskalam-dug found at Ur. ${ }^{\mathrm{I}}$ The next in order of time is the bronze head (of Sargon of Akkad?) from Nineveh, ${ }^{2}$ and a still later example, dating probably to the time of Gudea, is the fragment of a dolerite head from Ur found by Dr. Hall ${ }^{3}$ which Mallowan cites for comparison. The wigs, of course, are not all of the same type; it would be indeed absurd to expect a fashion in hair-dressing to persist unchanged in different countries over a space of a thousand years; but the fact of the wig's being worn does speak for a common tradition; it is further interesting to note that in each case there is above the confining fillet a heavy roll which in the case of Yarim-Lim certainly and in the others probably is intended to accommodate the rope looped round the real hair. Common to all is the rendering of the individual hairs by finely engraved parallel lines, and the ringlets hanging down Sargon's neck behind his ears have a strong resemblance to those of YarimLim. If the Alalakh head be given, as it probably should be given, a long beard falling in tightly rolled parallel curls, its general resemblance to the Sargon head, allowing for the difference of material, is sufficient to warrant the belief that the former is the work either of a Mesopotamian artist or of a local artist trained in the traditions of the Mesopotamian school. The objection is, of course, that of date; granted that the convention of a royal head-dress may have been more or less constant throughout the centuries, was there in fact a school of sculpture in Mesopotamia contemporary with the Yarim-Lim dynasty from which the Alalakh head could have

I Ur Excavations, vol.ii, The Royal Cemetery. Frontispiece.

2 M. E. L. Mallowan in Iraq, iii, p. I04, Pls. vi, vir.
${ }^{3}$ H. R. Hall, $A$ Season's Work at Ur, Fig. I i6, B.M. No. 114197 . 
been directly or indirectly derived? The evidence is scanty; but a small head (of Nin-Gal?) in white marble, found at Ur and attributable to the IIIrd Dynasty of $\mathrm{Ur},{ }^{\mathrm{I}}$ does seem to be to the point. The treatment of the hair on the top of the head is similar, with the narrow parallel lines coming from the crown; there is the same plain rope-like fillet and below this the hair brought down low across the forehead, though, as this is a female head, it is here in long horizontal locks; more important is the identical rendering of the eyebrows, smooth and very heavy, meeting above the nose; the ears are similar, especially for the trilobed frontal line; the mouth is short and turned up at the corners exactly as in the Yarim-Lim head, and the modelling of the cheeks is not unlike. Considering that the marble head is the idealized representation of a goddess and the diorite head an individual portrait of a king-and incidentally a portrait full of character-the artistic resemblance between the two fully justifies, I think, the judgement that a superficial impression would suggest, that the Alalakh sculptor inherited or adopted the traditions which in Mesopotamia go back to the art of ancient Sumer. In view of the political relations between Yarim-Lim and Hammurabi of Babylon it is not surprising that the (essentially provincial) art of Alalakh should be indebted to the older civilization.

AT/47/73. Pl. XLIII $a$. Head of a bull; basalt, ht. O. I $55 \mathrm{~m}$. The back is flat, so that the head must have been attached either to a body separately made or to a piece of furniture; the horns and forelock-not represented in the stone-were added in some other material. The head is highly stylized, with all detail simplified or eliminated, the sculptor depending for his effect not on any sharp lines but on the play of light on graduated planes; technically the piece can be compared with the Level IV ram's head, AT/38/147, Pl. XLV.

Found on the floor of the Level VII temple.

AT/47/78. Pl. XLIIIb. Wig of an acrolithic statue; diorite, burnt to a deep red colour; $0.06 \mathrm{~m} . \times 0.048 \mathrm{~m}$. and $0.035 \mathrm{~m}$. high; from the Level VII temple. The hair is combed from the top of the head in gentle waves and ends in tight curls below a plain bandeau. The wig was made separately and attached to the head by a tenon.

AT/47/90. Pl. XLIIId. Wig of an acrolithic statue; diorite, one fragment of it burnt red, the rest black; $0.10 \mathrm{~m} . \times 0.08 \mathrm{~m}$. and $0.065 \mathrm{~m}$. high; from the Level VII temple. Similar to the last, but the hair is in sharp zigzags. There is a mortice-hole below, for attachment, and a hole through the side for a pin into the tenon.

AT/47/77. Pl. XLIIIe. Two fragments of beards, carved in black steatite, for attachment to a statue, one showing the greater part of one side of the beard, the other some of the side curls. The larger fragment could fit the head AT/47/62, but there is no proof that it actually belongs to it. Both were found on the floor of the Level VII temple.

AT/46/1 55. Fragment of a wig in grey steatite. The top and bottom edges are smooth, the ends broken, width $0.039 \mathrm{~m}$. It shows a plain fillet above which the hair is in

$$
\text { I } A . \mathcal{F} \text {, vi (October 1926), Pl. LxII. }
$$


finely combed zigzags; below it a row of ringlets and two rows of straight vertical hairs. Found in Sq. L 15 , Level V, but probably a stray. Pl. XLIIIc.

AT/47/79. Two eye-sockets for inlay in a statue; diorite, burnt red; $0.06 \mathrm{~m} . \times 0.04 \mathrm{~m}$. and $0.04 \mathrm{~m}$. deep, they must come from a figure half as big again as life-size. Found on the floor of the Level VII temple.

These various fragments are of interest as showing the popularity in the Level VII period of composite statues which are definitely in the Sumerian tradition. Black stone was used for hair, beards, and eyelashes, and it is fairly safe to assume that the faces were carved in white, i.e. in white steatite or, more probably perhaps, in ivory. Since no fragments of any bodies were found it may be that such were of wood plated with gold or other metal, which would account for their disappearance.

$\mathrm{AT} / 46 / \mathrm{r} 72-3$. Two fragments from a basalt statue, the former, $0.23 \mathrm{~m} . \times 0.20 \mathrm{~m}$, , showing part of the front and right side of the drapery, smooth, with a vertical border of fringed work and a plaited cord running at an angle, the latter giving the knuckles and bases of the fingers of the left hand $(0.08 \mathrm{~m} . \times 0.06 \mathrm{~m}$.); the statue was approximately life-size. Found in room 30 of Yarim-Lim's palace. Small as the fragments are, they are enough to show that the statue was of Sumerian type, resembling the well-known Gudea figures. Since the statue had been broken up in a workshop attached to the palace it may have been considerably older than that building; at any rate its destruction would imply that there had been a change in policy.

A very similar statue-fragment, $\mathrm{AT} / 48 / 9, \mathrm{Pl}$. LIII $c$, of diorite, giving part of the fringed border of a skirt, was found built into the stepped bench against the SE. wall of the shrine of the Level V temple; the find-spot naturally supplies no more than a terminus ante quem date, and the statue may well go back to Level VII or even earlier. At any rate these small fragments prove, what we should have suspected as the natural result of trade connexions in cedar-wood, \&c., that north Syrian art was, towards the close of the third millennium, much under the influence of that of Sumer.

LEVEL V

$\mathrm{AT} / 40-45 / 3,4$. Two basalt figures, Pl. XLIV $a, b$, ht. $0.85 \mathrm{~m}$., found together in the $\mathrm{NE}$. gate-tower of the city wall of Level V; v. p. 159 . Both figures have a groove representing the spine in the otherwise plain back; the female figure has a short pigtail. Mr. Ahmet Dönmes has kindly drawn my attention to a pair of basalt sculptures found in the Mardin gate of the city walls of Diyarbakir (v. Pl. XLIV, $i$ and $j$ ); the male figure there while almost as grotesquely rudimentary as ours is different in that he wears a beard and holds his arms less symmetrically, but the female figure ( $v$. Pl. XLIVi), practically identical in height (it measures $0.87 \mathrm{~m}$.), though she wears a necklace and holds something in her right hand, is the twin sister of the Alalakh goddess (v. p. 387).

AT/39/r I 9. Pl. XLIVc. Limestone, ht. $0.73 \mathrm{~m}$. Found near the shrine in Sq. H r 7 , probably Level $\mathrm{V}$ (possibly early in the Level IV period?). A triangular semi- 
baetylic stone on the upper part of which is crudely carved the face of a god wearing the horned cap, the rest of the stone being left in its rough natural state. It seems to represent the transition between the worship of the crude stone or baetyl and that of the iconic figure; it therefore marks, both artistically and from the point of view of religion, a retrograde step from the high level achieved in the time of Yarim-Lim such as can be accounted for only by the supposition that the kingdom had now come under the influence of a different and a far more backward power.

AT/46/95. Pl. XLIVh. Crude limestone figure, roughly triangular in shape with the facial features slightly indicated; $0.315 \mathrm{~m} . \times 0.20 \mathrm{~m}$. Found in Sq. L i 5 , Levels IV-V.

AT/39/276. Pl. XLIVd. Extremely crude figure in limestone, ht. $0.24 \mathrm{~m}$., found in Sq. M I4; it was attributed to Level IV, but the stratification here is bad (below Level III) and the object might just as well be of Level $V$.

AT/46/r 34. Pl. XLIVf. Very crude figure in limestone, ht. o.2 I m., found in a Level II 'pocket' artificially filled with imported material of which it can only be said that it comes from an earlier deposit. The figure shows a certain resemblance to AT/40$45 / 4$, and is on that account described here, but the evidence of level would rather favour a Level III date. See also below, AT/39/204.

LEVEL IV

AT/38/1 47. Pl. XLV. Ram's head in polished white stone; ${ }^{1}$ ht. $0.32 \mathrm{~m}$. It is pierced vertically by a hole, diam. $0.04 \mathrm{~m}$., bored from both ends, not too accurately, the holes meeting at an angle. The back of the head and the conical part above the horns is left fairly rough, all the rest being finely polished; this suggests that the head formed the spout of a large pipe and did not stand free but was against a background, either vertical or inclined at an angle; the nostrils also must have been in another material.

As a work of art this piece is remarkable; there is a complete absence of naturalism although the character of the animal is unmistakably conveyed. The face is on two almost flat planes meeting at a very slight angle; the eyes, unnaturally close together, are in such low relief as to be scarcely noticeable with a front light although with an arranged side light they stand out boldly; the ridiculously small ears also are in low relief; only the great horns encircling the upper part of the face are bold both in relief and in the cutting of the rings. The first and last impression given by the head is that of style; it is not a primitive essay but the finished product of a long-established and sophisticated art that had learnt to carry to an extreme the principles of the simplification of form and could subordinate realism to pattern. Something

I This is the same material as is used for the Idri-mi statue; on the latter Mr. P. M. Game, Assistant Keeper of the Department of Minerals, Natural History Museum, South Kensington, reports that it 'is composed of dolomite (carbonate of calcium and magnesium) and magnesite (carbonate of magnesium). . . . It is likely that the magnesite occurs as a metasomatic replacement of the dolomite. Owing to the widespread occurrence of these minerals it is unfortunately impossible to suggest localities of origin.' 
of the same sort could be seen in the Level VII bull's head AT/47/73 described above; I know of nothing like it from any other part of the Near East, and the head would appear to illustrate a local north Syrian school of sculpture.

Found in the Niqme-pa palace, room 29, q.v.

AT/39/33I. Pl. XLVI. Seated statue of King Idri-mi; ht. c. I.IO m.; material as in AT/38/1 47 above. Complete except for part of the feet which, like the head, had been broken off. Found buried inside the Level I temple. A cuneiform inscription giving the biography of the king runs across the front of the statue from the side of the face to the bottom of the skirt. The figure, and the inscription, have been fully published in Sidney Smith, The Statue of Idri-mi, Occasional Papers of the British Institute of Archaeology in Ankara, No. I, I 949.

The statue was roughed out from the block with a tubular drill $0.015 \mathrm{~m}$. diam.; the photograph on Pl. XLVII $a$ shows how, in the deep hollow between the feet and below the hem of the skirt, the drill-holes remain, the projections between them not having been trimmed away. Generally the surface was cut and then ground and polished, the final shaping being done with the grinder. The eyes and eyebrows are inlaid with black stone and doubtless paint was freely used; thus the king's beard should be elaborately curled, and in Level VII period we have the stone beards (Pl. XLIIId) and stone wigs (ibid. $b$ and $c$ ) which were fixed to statues by metal pins, whereas here, although the outline of the whiskers is shown, whiskers, beard, and hair offer a smooth plain surface on which the detail must have been represented in paint. Similarly' the drapery, a chiton and a cloak with heavy roll border, is so simplified as to be really unintelligible-the two garments merge into one and do not correspond to any possible cut; here again paint must surely have been used. At the same time the entire absence of folds in the material implies that the sculptor was not interested in drapery as such, the whole value of the dress being, for him, that it supplied the necessary field for the inscription. ${ }^{\mathrm{I}}$ The extreme simplification of form, however, and the elimination of detail is in keeping with the style of the ram's head already described, and perhaps, too, is in the line of descent from the bull's head AT/47/73, PI. XLIII $a$. The statue is dated by its inscription to Level IV, but its exact place in that period is disputed; the question will be discussed hereafter, v. Ch. XIII, pp. 39 I sqq.

$\mathrm{AT} / 39 / 288$. Pl. XLVII $b$. Fragment of the basalt throne of a statue; $0.76 \mathrm{~m} . \times 0.56 \mathrm{~m}$. and $0.65 \mathrm{~m}$. high. The top is socketed to take the figure, and as it exactly fits the statue of King Idri-mi there can be no doubt but that they belong together and are contemporary. The lower part of the stone is plain, a solid support to which a set of steps seems to have been attached; on this is carved a chair of which the arms were supported by lions, the bodies carved in relief against the side of the chair, the heads projecting in the round; only the legs of the animals remain. The reconstruction is fully discussed in Sidney Smith, op. cit., p. 6.

I The same is, of course, true of much Sumerian sculpture. 
LEVEL III

AT/40-45/2. Basalt orthostat carved in relief on one side and one end; 1.0 .97 m., ht. $0.85 \mathrm{~m}$., width $0.28 \mathrm{~m}$.; Pl. XLVIII. Found re-used as a step between the lion sculptures in the Level I temple, g.v. The main scene shows Tutkhaliya, king of Hattusas, together with his wife, advancing in an attitude of adoration; in front of the king his name is given in very large hieroglyphs, the second title coming between the two figures. On the end of the slab is a single figure of an attendant (?) carrying a spear.

I am indebted to Dr. H. G. Güterbock for the following note on the inscription.

'The group of signs standing in front of the larger figure reads: "Tutkhaliya, the great-..., the king's son". Of the group which appears over the hand of the smaller figure, only the sign for "king's son" is clear.

"The title which is left without translation occurs, in the same combination with "great", on a seal impression from Tarsus (36-I I 73, to be published by I. J. Gelb) and, without "great", on some seal impressions found at Boğazköy (H. G. Güterbock, Siegel aus Boğazköy, ii, Nos. I I f., I 68, I 7 I ; cf. the sign-list, ibid., Nos. I 49 and 208). From the inscription itself it is not possible to determine which Tutkhaliya is meant.'

On historical grounds I should not hesitate to ascribe the monument to Tutkhaliya IV. The Old Empire certainly does not come into the question. We have no reason to suppose that there was any Hittite occupation of north Syria prior to the conquests of Suppiluliuma; the destruction of Aleppo by Tutkhaliya II seems to have been merely an incident of his war against Hanigalbat, and the archaeological evidence from Alalakh does not suggest any Anatolian influence in that period. Tutkhaliya III, a very unsuccessful ruler, was in no position to set up monuments of himself in north Syria. On the other hand, Tutkhaliya IV, in his wars against Tukulti-Ninurta of Assyria, was at pains to strengthen the hold over the country west of the Euphrates which his father had secured by the treaty with Ramses II, and the adornment of the temple at Alalakh with a carving in the Yasilikaya style would be a very natural symbol of his interest in the area.

This is a characteristic example of Anatolian Hittite sculpture, and if not actually imported is certainly the work of a Hittite artist; if it is unusual at all it is in the roughness of the work-in particular the ground behind the queen's figure has not been cut away to the level of the rest, so that the back of the queen seems to be rendered by relief en creux; there is also in the case of the queen a complete lack of inner detail, and even the king's figure is quite flat, the relief consisting of two planes only separated by sharply vertical lines with virtually no rounding of the edges. It must be remembered that in these Hittite reliefs we have preserved only the skeleton; as was so often the case in Egypt, the carving in stone was overlaid by a coating of fine plaster to which colour was applied. The actual appearance of the work as we have it bears therefore very little relation to its original appearance and is of small help in assessing the artistic qualities of Hittite sculpture. In the present instance the basalt is of poor quality, the surface deeply and irregularly pitted, so that even the 
outlines of the relief tend to be confused, and in addition there is a great deal of discoloration which also is confusing; for the purposes of photography therefore the stone has been 'mudded' (Pl. XLVIII $b$ ), the soft mud taking the place of the original stucco coating, so that at any rate the outlines are visible. They show the purely Hittite character of the relief, in style as well as in subject; as an imperial monument set up in Alalakh it is, of course, of yery great historical interest, but as a work of art it seems wholly alien from the local school of sculpture so far as that can be defined by such examples of it as we possess.

LEVEL III-II

The Tutkhaliya relief must be dated by historical evidence and the fact that it was found in the Level I temple does not have to be taken into account for chronological purposes; but the date of the other sculptures re-used in that late temple cannot be so fixed. Since fragments of lion figures ${ }^{\mathrm{I}}$ were found in the well of the Level I a temple, and another $(\mathrm{AT} / 46 / 30 \mathrm{I})$ under the foundations of a wall of the same building, the statues cannot be later than Level II; but there is always the possibility that they were re-used in the Level II temple and originally belonged to Level III. This was the case with the Tutkhaliya relief-though that was preserved only for base purposes-while the Idri-mi statue had been kept in the temple ever since the time of Level IV. I am inclined to attribute the lions to Level III, but must admit that the archaeological evidence is conclusive; the Idri-mi statue-base proves that the angle-lion was already in Level IV a motive employed by the Alalakh sculptor, but the tradition is so continuous that the analogy does not constitute a valid argument; it is enough to say that our lions come very early in that long series which carries us down to the last days of SyroHittite art.

AT/39/3 I 4. Pl. XLIX. Basalt corner-stone on one side of which the body of a lion is carved in relief, the head projecting in the round from the end of the block; the fore feet, which also projected, are missing. Over-all length, I.70 m., ht. I.00 m., width $0.36 \mathrm{~m}$. Found re-used against the side of the steps in the Level I в temple. The block was not big enough for the figure, and the rump of the animal must have been carved on the adjoining stone ${ }^{2}$ and the top of its back on the stone above; it is safe to conclude from this that already in the early period, as later in Syro-Hittite architecture of the ninth and eighth centuries, the orthostat reliefs were carved in situ when the stones were built into the wall. ${ }^{3}$

AT/39/3 I 5. Pl. L. Similar lion figure, but the left side of the body is carved in relief instead of the right side; the back of the block is broken away and the forefeet of the lion are also missing. Overall length $\mathrm{I} \cdot 35 \mathrm{~m}$., ht. I. I $3 \mathrm{~m}$., width $0.32 \mathrm{~m}$.

$\mathrm{AT} / 40-45 / \mathrm{I}$. PI. LI. The fore part-head, shoulders, and forefeet-of a basalt lion figure; ht. 0.94 m., width $0.30 \mathrm{~m}$. Found in the well of the Level I A temple.

I $\mathrm{AT} / 40-45 / \mathrm{I}$ and 5 .

2 For an interesting parallel to this $v$. the lion relief, Carchemish, iii, Pl. B. $55^{(a)}$, where the tail is not only on a separate block but on a block of a different sort of stone.

3 Cf. Carchemish, iii, p. I93. 
AT/40-45/5. Fragment of a basalt lion figure, the two front paws only. Found in the well of the Level I a temple.

$\mathrm{AT} / 46 / 30 \mathrm{r}$. Fragment of a basalt lion figure, the left fore-paw only. Found in the foundations of the Level I a temple.

Whereas the three lion statues differ greatly from one another they are alike in one respect: they are highly conventionalized, and the convention is one not met with in the later gateway-lions of Syro-Hittite sites. Quite apart from the fact that the lion is represented as crouched instead of erect, there is here a studied avoidance of realism and a translation of curved surfaces into flat planes and sharp angles which shows a definitely architectural intention. If the lions are seen from above, as they were when re-used in the Level I в temple ( $\mathrm{Pl}$. XI $b$ ), they appear childishly crude and grotesque; but if their heads are above the eye-line ( $v$. Pl. La) the effect is very far from childish; they are in fact very sophisticated works of art. The extreme stylization is akin to that which in the case of AT/38/1 47 turned a ram's head into a geometrical pattern, and such abstraction may well be characteristic of the early local school of sculpture in north Syria. Elsewhere, and in the Syro-Hittite period which is so much better documented, the influences both of Anatolia and of Assyria result in a more composite style; but the native element would seem to be represented in an uncontaminated form by these early sculptures of Alalakh. AT/46/89. Pl. XLIVg. Small crude stone figure of the 'violin' type with back-slanted head and the facial features very slightly indicated. Found close to the hearth in shrine B of the Level III temple (Sq. M I 5), but slightly above floor-level; it probably belongs to Level III, but might be later. Ht. $0.23 \mathrm{~m}$., width $0.15 \mathrm{~m}$.

AT/39/3I 9. Pl. XLIVe. Very crude limestone figure with the facial features roughly indicated. Ht. O.I 7 m. Found on the site of house 39/A, Level II-III.

UNDATED SCULPTURES

AT/39/287. Pl. LII $a$. Basalt altar, ht. 0.89 m., $0.48 \mathrm{~m}$. sq., the sides carved in relief. By the carving the altar is represented as a table supported by legs in the shape of the necks and heads of swans, the heads downwards and out-turned to form the feet; these again rest on a lower table or base having a plain top and square legs at the corners. The altar, which is intact, was found in the ruins of the Level I temple, in the NE. annexe, but it is impossible to say whether it originally belonged to that temple or was inherited from an older building.

$\mathrm{AT} / 39 / 3$ I 7. Pl. LII $b$. Limestone statue of a seated goddess; ht. $0.46 \mathrm{~m}$. The figure has been intentionally defaced; it is seated on a high-backed throne, the hands resting on the knees, but all detail has disappeared. Found in the Level I temple.

AT/40-45/6. Pl. LIII $a$. Fragment; the right side of a man's face in diorite; ht. $0.099 \mathrm{~m}$., width $0.087 \mathrm{~m}$. The face, preserved down to the upper lip, has been split off from a basso rilievo; a small fragment of similar material (AT/39/333, Pl. LIIIb, $0.125 \mathrm{~m} . \times 0.09 \mathrm{~m}$.) carved in relief with what seems to be the edge of a tasselled robe, might possibly belong to the same sculpture. 
$\mathrm{AT} / 39 / 204$. Crudely, carved limestone figure, ht. $0 \cdot 20 \mathrm{~m}$.; the block is almost shapeless, but the facial features are suggested and towards the base there are projections which may represent either the arms crossed in front of the body or legs. Found loose in the soil, approximately between Levels IV and III, but real date unknown.

$\mathrm{AT} / 39 / 333$. A fragment, $c .0 .125 \mathrm{~m} . \times 0.09 \mathrm{~m}$., of grey schist showing part of the drapery of a large figure of Mesopotamian style, horizontal folds with a fringe of sloped tassels, Pl. LIII $b$. It was found in the Level II temple, but there was no evidence for its real date.

\section{(b) THE TERRA-COTTAS}

RATHER more than 150 terra-cottas, for the most part very fragmentary, were catalogued in the course of the excavations. About a third of them were animal figurines, two-thirds human. The vast majority, including all the animals, were hand-modelled more or less in the round in what is called the 'snow-man' technique, i.e. the clay is pinched into shape with the fingers and details are added by sticking on small pellets of clay, as well as by incision with a blunt stick or (as is very common at Alalakh) by dotted lines made with a roulette. Relatively few figures are cast in relief from a one-piece mould.

By far the most common type is that illustrated on Pls. LIV and LV, e.g. AT/46/238, $\mathrm{AT} / 46 / \mathrm{r} 60, \mathrm{AT} / 49 / \mathrm{r} 7, \& \mathrm{c}$. This is a nude female figure, generally flat behind (a few examples have an incised line down the back and holes in the buttocks, e.g. AT/48/6), the hips very wide, the pubic triangle strongly accentuated, the navel rendered by a holed pellet, the arms outstretched and reduced to short pointed stumps, the legs, often very short, ending in a point with no indication of feet, the nose pinched out into an exaggerated beak, no mouth, the top of the head flattened and carried up into a square or domed form pierced by two or three holes (perhaps for the attachment of a thread wig?), the ears large and projecting, pierced with two holes for ear-rings, the eyes and breasts rendered by pellets, while a necklace is generally shown by an applied roll of clay sometimes enriched by roulette-incised lines. It is a type well known in Syria. The same technique is, of course, employed in Mesopotamia, but the figure produced by it there is very different, ${ }^{\mathrm{I}}$ and one need not hesitate to regard the type as definitely Syrian. It was long-lived. One example was found in Level XII, one in Level XI, two in Level X, seven in Level VIII, six in Level VII, four in Level VI, seven in Level V, one from Level IV-III, three in Level III, five in Level II, and one (the rather sophisticated head $\mathrm{AT} / 3^{8 / 228}$ on Pl. LIV) from Level I, while at least two more, found in the top-soil, are probably of Level I but are not accurately dated, as was the case with many other examples. Accordingly the type was in vogue for at least a thousand years, during which time it was not modified to any appreciable degree; a given example may be dated by the

I In Mesopotamian figurines the hair is normally represented by heavy rolls of clay which throw the face into shadow; the feet are not reduced to a point, the arms are modelled as such and generally are bent so that the hands come under the breasts; therefore even though the outlines may appear similar (e.g. L. Legrain, Terra-cottas from Nippur, No. $65, \mathrm{Pl} . \mathrm{x}$ ), the character is far from being the same. 
conditions of its discovery to a definite level ${ }^{\mathrm{I}}$ and even to a definite century, but if its archaeological horizon be unknown, then, on the internal evidence of style, it can with equal justification be attributed to the twenty-fifth or to the thirteenth century B.c. That conservatism which so prolonged the floruit of the early painted pottery ( $v \cdot \mathrm{p} \cdot 34^{2}$ ) was operative in the case of the figurines also.

A number of nude female figurines modelled in the same technique and in other respects similar in character to the above differ from them in having the legs less conventionally abbreviated and the arms fully developed; generally the arms are brought across the body and the hands hold the breasts (v: AT/47/29 and AT/48/24 on Pl. LV), but in one case one arm is straight and hangs down by the side of the body (in a second possible case one arm is missing). At first sight these variants seem to come much closer to the familiar Mesopotamian type of 'naked votaress', and there is indeed a resemblance, but it is easy to exaggerate the analogy; nearly all the 'votaress' figures are cast from moulds, not modelled in the 'snow-man' technique, and generally.the hands either hold an object to the breast or are clasped below the breasts in the attitude of adoration; there are a very few hand-modelled figures which do hold the breasts as in the Syrian terracottas, but even then the treatment of the head is quite different (as noted above) and in view of their rarity they might be thought to be influenced by Syrian prototypes rather than to be themselves the original.

One group of ten terra-cottas in the 'snow-man' technique forms a distinct class; some are male and some are female, but all alike are represented as seated, supported by a peg behind; in some, both hands are raised to the breast, in some they lie on the lap or come down in front of the body. All are more or less fragmentary and the type has to be got by a combination of fragments, but it does seem to constitute a definite type. Two examples, AT/46/232 (v. Pl. LIV) and 233 , come from Level VIII; one, AT/46/1 9 I, from Level VII; two, AT/46/174 and AT/48/52 (v. Pl. LVI), are definitely from Level V; two, AT $/ 38 / 2$ I 6 and 2 I 9 (v. Pl. LVI), coming from Site $\mathrm{H}$, are probably of Level V; and three, AT/48/83,84, and 86 ( $v$. Pl. LVI), come from an extension of the $\mathrm{H}$ site where everything was of Level $\mathrm{V}$ or earlier. It is therefore fairly safe to say that the type has a vogue limited to the period of Level VIII to Level V; certainly it does not continue after the latter date.

The definitely male figurines are not nearly so numerous as the female and, so far as one can judge from the fragments, are much more individual. The principal examples are illustrated on Pls. LIV and LVI.

$\mathrm{AT} / 46 / 237$, Pl. LIV. From Level IX, is in 'snow-man' technique; the tall head-dress suggests the high crowns of the Yasilikaya reliefs but is, of course, paralleled by many north Syrian bronzes, e.g. Schaeffer, Ugaritica, i, Pl. xxı.

$\mathrm{AT} / 46 / 2$ i 9, Pl. LIV. From Level V; he wears a flat-topped cap, has a necklace, and carries a

\footnotetext{
I The provenance of the examples illustrated on the plates is as follows: $\mathrm{A}^{\prime} \mathrm{T} / 47 / 40$ from Level XI; $\mathrm{A}^{\prime} \mathrm{T} / 47 / 28$ from Level X; AT/48/25 from Level VIII; $A^{\prime} T / 39 / 255$ and $\mathrm{AT} / 48 / 24$ from Level VII; AT/46/238 from Level VI; $\mathrm{AT} / 46 / 160,198,203$, and $\mathrm{AT} / 49 / 17$ from Level V;
}

AT/39/I99 from Level II; AT/38/228 from Level I. $\mathrm{AT} / 49 / 5$ was found in the surface soil near the city gate and its date is doubtful; it is one of a very small class of miniature figurines of which AT/46/160 (above) and a fragment, $\mathrm{AT} / 46 / \mathrm{I} 59$, are dated to Level V. 
lituus over his shoulder; deep lines across the sides of the face seem to give the outline of closely trimmed whiskers.

AT/39/7I, Pl. LVI. From the 39/A house site and possible to be assigned to Level IV, but the stratification was not good and Level $\mathrm{V}$ is almost equally likely. The man is bare-headed and his hair is dressed in short tight curls across his forehead; he wears a necklace and with both hands holds an object against his breast.

$\mathrm{AT} / 48 / 84$, Pl. LVI. A bearded man wearing a conical hat and a tightly fitting jerkin cross-laced up the front and secured by a belt; its horizon was between Level V and Level IV.

Besides these, three male figures were found in Level VII, one more in Level V, one in Level IV, one in Level IV-III, and one in Level II. The distribution in time therefore seems to have been much as in the case of the female figures, but here we have no one persistent type.

A few hand-modelled figurines are so crude as not to fall within any category; some of them indeed have lost all pretence to human form and perhaps should not be reckoned as figurines at all.

AT/37/ I 92, Pl. LV. Found in the filling of the Level VII city rampart and therefore at least as early as Level VIII. The head and right arm are missing; a female (?) figure very roughly modelled, with no legs; across the hips in front there are three stamped circles (rows of dots between plain lines, and a dot centre) and on the back a single stamped circle done with a different die. $\mathrm{AT} / 3^{8 / 1} 3^{8}, \mathrm{Pl}$. LV. Also found in the upper soil; has a face, but the body is practically shapeless. $\mathrm{AT} / 38 / 254, \mathrm{Pl}$. LV. Found together with tablets in room 33 of the Niqme-pa palace; Level IV. Both this and the last figure might be related to the curious 'Eye-idols' from Brak (M. E. L. Mallowan, 'Excavations at Brak and Chagar Bazar', in Iraq, ix, part I, Pl. LI), but they have no eyes and therefore could at best be only the ultimate degeneration of a type.

$\mathrm{AT} / 48 /$ I 8 , Pl. LV. From Level V. The nose is not pinched out as usual but is, like the eyes, an applied pellet. It should perhaps be classed with $\mathrm{AT} / 3^{8 / 1} 3^{8}$ above.

$A T / 46 / 239, \mathrm{Pl}$. LV. From Level V, made of unbaked clay. The figure is a mere cylinder rounded above; the eyes are hollows, not in relief, the nose is slightly indicated; a band of large and small pellets presumably represents a necklace.

AT/49/2 3, Pl. LVIIIe. From Level XVI. A phallus crudely modelled in very hard unbaked clay and after modelling trimmed with a round-pointed stick.

MOULDED HUMAN FIGURES

As was the case with the hand-modelled figures, the majority of the relief figures cast from one-piece moulds represent the nude votaress (or goddess?) standing and holding her breasts with both hands; here, too, there is the variant in which she holds her breast with one hand while the other hand hangs at her side, and there is another variant in which both arms hang straight down; in view of the fragmentary state of most of the figurines it is not possible to establish the numerical proportion of the three sub-types, but there is no doubt but that the first is the most common while of the straight-armed figure only one certain example was found.

The earliest examples (holding both breasts) came from Level VII, part of the decoration of the remarkable brazier found in the temple of Yarim-Lim ( $v$. below, and Pl. LVIII). Of the same type eight more or less fragmentary examples came from Level $\mathrm{V}$, one from Level V-IV, one from Level III-II, and three from Level II. One example, 
$\mathrm{AT} / 38 / 294$, applied to a vase, was found in the top-soil and may belong to any of the later levels; v. p. 353. Naturally the figures were struck from different moulds and differ one from another in minor details, e.g. AT/48/6 I, Pl. LIV, and AT/37/77, P1. LVId; but as a general rule the hair is dressed in a flat-topped straight-sided mass (unless this is meant to represent a cap) and in the ears are heavy-generally triple-ear-rings ${ }^{1}$ and the woman wears a necklace, and bracelets on her wrists. The body is much more naturalistic than in the hand-modelled figures, the legs and feet are reasonably lifelike, and the gross exaggeration of the pubic triangle is greatly modified. There is no mistaking the resemblance of these moulded figures to the clay 'naked votaress' reliefs so common in Mesopotamia; it extends even to details such as the multiple ear-rings and must imply a very definite connexion.

Figures of the same type, struck in similar moulds, were made in materials other than clay. Just inside the west corner of the Level VI temple there was found a 'naked votaress' of pale blue glass (AT/48/4, Pl. LVIb) identical with those in terra-cotta except for the fact that it was pierced through the base with a hole for suspension. From a Level II grave (ATG/39/23) comes a similar example in glass paste, AT/39/66. A fragmentthe head only-of another glass paste figurine $(\mathrm{AT} / 47 / 5)$ belongs either to Level I or to Level II, its exact horizon being uncertain; another head, AT/37/243, comes from the I 937 house site and belongs apparently to Level II, and yet another head, this time in blue-glazed frit, AT/46/1 4, Fig. 62b, I0, is definitely of Level II, having been found on the floor of a ruined house of that date in Sq. O I 2 . This head differs from the other in that it is not a fragment but was moulded separately as part of a composite figure possibly for inlay; but as a moulded head it may rank with the rest. A different type is given by a faience mask AT/39/I I I, Pl. LVIe, which bears a certain resemblance to the faience Snake Goddesses from Knossos-the flat top of the head may imply that the figure wore a polos crown, in which case the parallel with Crete would be very close. It is distinguished from all the other glass or glaze figures from Atchana by its early date, for it was found in room 2 of the Yarim-Lim palace and so belongs to Level VII.

Only two moulded terra-cottas of types other than the 'naked votaress' were found. One of them, AT/38/260, Pl. LIV, shows the lower half of a male figure standing with his arms by his sides, wearing a skirt girdled by a heavy belt; this comes from Level II. The other, AT/39/240, Pl. LIV, comes from Level III; it shows a naked goddess wearing the tall Hittite crown surmounted by a winged disk and standing on the head (or skull?) of an antelope whose horns rise up on either side of her and their tips seem to support the disk; with each hand she grasps a horn, and on each horn, just above her hand, is perched a bird; from either hand a line in relief comes down obliquely and ends in a roll against the knees of the goddess; presumably this is the edging of the cloak or veil which she has drawn apart so as to expose her person. The figure, in its vesica-like setting, is quite remarkable. Such analogies as there are ${ }^{2}$ would suggest a Hittite origin

I Replacing the actual copper rings worn by the handmodelled figures.

2 e.g. Tahsin Özgüç, Kültèpe Kazisi Raporu, I948 ('Türk

Tarih Kurumu Yayinlarindan V. Seri., No. ro), Fig. $437 a, b$, and p. 206. 
for the figure, and the level at which it was found, corresponding to the period of Hittite domination over Alalakh, harmonizes with that suggestion.

Since the use of the terra-cottas so common on Near Eastern sites ${ }^{I}$ has been often questioned, the find-spots of the Alalakh examples have a certain interest. The most curious indication of use is given by the brazier or pot-stand $\mathrm{AT} / 47 / \mathrm{I} 28, \mathrm{Pl}$. L.VIII, found in the Level VII temple; it is of normal shape but unusual size, being $0.26 \mathrm{~m}$. high with a base diameter of $0.36 \mathrm{~m}$., and the sides are pierced with two rows of holes between plain raised bands and against the projecting rims at the top and bottom there are two bands of rope-pattern in relief; against the sides are fixed terra-cotta figurines, five of them (cast from the same mould) are of the 'naked votaress' (or 'goddess'?) type with the hands holding the breasts, distinguished by their high and elaborate headdresses, and one is a male figure, hand-modelled, showing a warrior clothed in a short skirt apparently in the act of falling. Here then we have terra-cottas of both typesmoulded and hand-modelled-used as the decoration of a piece of temple furniture; ${ }^{2}$ it can, of course, safely be assumed that they are not mere decoration but possess some religious significance; I suspect that together they illustrate some legend unknown to us but recognizable by worshippers in the temple. ${ }^{3}$ Had there been only female figures it would have been possible to regard them as human votaresses; either the donor or the temple servitors might have been so represented; but the presence of the male figure (and his dramatic posture) rules out that suggestion and must mean that they are goddesses, or repetitions of the same goddess.

A somewhat similar case is that of $\mathrm{AT} / 38 / 294$, where a complete 'naked votaress' relief of normal type has been applied to the outside of a large clay vessel of which, as only the single sherd was found, the shape is unknown. It comes from the house site, Level I. Another isolated sherd, also from the house site, Level I or II, AT/37/5 I, has a hand-modelled head with pellet eyes; the sherd is vertically pierced and it is impossible to say whether it is a fragment of a vessel or of a plaque. In any case two examples are enough to prove that the terra-cottas could be attached as religious symbols to an otherwise ordinary object, thus dedicating it to religious uses. On the other hand, four of our terra-cottas were found in graves; AT/49/1 7 comes from grave ATG/49/5, which was the grave of an adult; AT/46/238 from grave ATG/46/1 5, in which there were two bodies, one of an adult and one of a small child, and graves ATG/39/23 and ATG/39/29, from which come the figurines $\mathrm{AT} / 39 / 66$ and $\mathrm{AT} / 39 / 75$ respectively, were both the graves of infants. There is an interesting parallel to this at Carchemish where in the Iron Age cemetery the cremation-urns of children are accompanied, in the case of little girls, by female terra-cottas and, in the case of boys, by clay riders on horseback or by riderless horses; ${ }^{4}$ nothing of the sort was found in connexion with the graves of adults. In both

I At Ur we catalogued about 2,000.

2 The brazier had been deliberately smashed; we collected a hundred fragments and even so many were missing. The figurines had been broken off, but in some cases parts of them, e.g. the feet, still adhered, and in other cases the attachments at the back were found to fit; there has been no arbitrary restoration.

3 For a long time the fragments found gave us only the male figure and three goddesses, and one thought of $\mathrm{Mt}$. Ida and Paris collapsing in astonishment; the discovery of two more goddesses disposed of that identification, but a mythological explanation does seem to be necessary.

4 Liverpool Annals, vol. xxvi (1939-40), Pl. vi, I, and Pl. vili, I, and, for the figures, Pl. xviri. 
instances, at Alalakh and at Carchemish, the terra-cottas would seem to be simply children's toys. But that interpretation, which follows naturally from their association with children, would not apply to all the terra-cottas. While those found in the ruins of private houses might-but need not-be playthings, that can scarcely be true of those found in temples. Of the various types described above eleven examples are from the temple sites, i.e. inside the buildings, and fragment of nine more were from rubbish-pits which were quite certainly associated with the temple of Level V; these must surely be ex votos, as were most of the very similar 'naked votaress' figurines of Mesopotamia. It should not be surprising that the same figures should be used indifferently as toys and as media for prayer or symbols of religion. The wax doll, provided with wings for the occasion and tied to the top of the Christmas-tree, can pose as the Angel of the Nativity and yet return on the next day to the nursery. In so far as the figures are symbolic, the ex voto can fairly be interpreted as representing the hierodule who thereby dedicated her body to the service of the deity; ${ }^{1}$ but just because they insist on the body's features they meet the realistic requirements of children.

\section{ANIMAL FIGURINES}

Of the catalogued examples ${ }^{2}$ one came from Level XIV, one from Level XII, three (amongst them AT/47/26, Pl. LVII) from Level X, seven (amongst them AT/39/ I 27, Pl. LVII) from Level VII, five from Level VI, one from Level V, five (amongst them $\mathrm{AT} / 39 / 272$, Pl. LVII) from Level IV, four from Level III, seven from Level II, all of normal type, i.e. small figurines very roughly modelled by hand with details, where there are any, added in the 'snow-man' technique (with little clay pellets) or, occasionally, incised. The beasts represented are the humped buffalo, the domestic ox or cow, the sheep (?), the horse, the ram, perhaps the pig, the dog, and, once at least, the monkey; but the modelling is so crude that very often it is impossible to distinguish the species intended-if indeed the maker had any particular species in mind. The humped buffalo is, of course, easy, and the horse may be identifiable by his having a saddle or a bridle or, in one case, a rider; but, as the illustrations on PI. LVII show, the majority of the figures do not merit any detailed discussion. There were two examples of painted figures; $\mathrm{AT} / 38 / 230$, Pl. LVII, from Level II, has simple black markings down the forehead and cheeks and under the chin; it is more carefully modelled than most; AT/48/43, on the same plate, of uncertain horizon but probably from Level IV (it lay above the ruins of Yarim-Lim's palace and below the bottom of the Level III foundations), is a ram's head the top of which is painted in the Nuzu technique with a design in white on a purplishblack ground; another Nuzu fragment, AT/37/I90, Pl. CVI, gives the front leg of an animal, apparently a feline, with vandyke pattern representing the hair; this was probably a figurine, not a zoomorphic vase.

I I do not forget Timarete, who signalizes the end of her childhood by dedicating her dolls (and all the dolls' clothes) to Artemis (Incerti, Anthologia Palatina, ed. Dübner, vi. 280); but it would be dangerous to argue from classical Greece to Alalakh in the second millennium в.c.
2 A great many fragments, generally scarcely recognizable, were found in unstratified conditions and were not catalogued. Only those were recorded which possessed some intrinsic interest or could be attributed to a definite level. 
One piece, a gryphon's head in burnished brown clay (AT/48/36, Pl. LVIII), from Level V, found under the floor of the central courtyard of Niqme-pa's palace, ought not, perhaps, to be classed with the figurines; it may well have been the applied ornament of some very elaborate clay vessel. It is hand-modelled and tool-finished, and in spite of the fact that its ears and horns have been broken off it is a most impressive work of art.

As of the human figures so of the animals it is difficult to say to what extent they are toys and to what extent votive offerings. In a Level $\mathrm{V}$ rubbish-pit there was found a fragmentary model chariot (AT/49/3) which would imply that some were playthings, but more than that cannot be said.

\section{(c) A MODEL LIVER FOR DIVINATION \\ By c. J. GADD}

THE clay object $A T / 47 / 75$, known to me only from the photographs reproduced here (Pl. LIX, A, B, and C), certainly belongs to the class of models imitating (roughly) internal organs of the sheep for the purpose of instruction in the 'science' of divination by the entrails. Most of the extant examples obviously depict the liver, the principal mirror of fate, but the Atchana model (hereafter called AT) belongs to a smaller class represented most clearly by two in the Yale Babylonian Collection, illustrated in A. Goetze, Old Babylonian Omien-Texts, Pl. cxxxiv, Nos. 4 and 5, the texts inscribed upon which appear in the same book, Pl. III, and some remark upon their character in the Introduction, p. 4; these may be called for brevity $\mathrm{Y}_{4}$ and $\mathrm{Y} 5$. The most striking points of resemblance among all these three are the coarse ridge which runs along the middle of the back in each, and the equal and homogeneous 'wings' on either side of this, though in AT these are closed rather than extended. Another probable feature of resemblance is that AT appears to have had (at the left end in B, right in c) a blunt point terminating the ridge, but now broken; this is marked in $\mathrm{Y}_{5}$, present in $\mathrm{Y} 4$. The latter has two moulded protuberances unevenly placed on the internal surface, $\mathrm{Y}_{5}$ has one on the central axis of this surface, AT has one very large and prominent on this central line, and originally had another, which was separately inserted and has now fallen out, leaving a clear circular depression. These two bosses were so placed that they divided the central axis into three roughly equal parts. Though there can be no doubt that all three models represent the same organ, their differences are noticeable. But while between $\mathrm{Y}_{4}$ and $\mathrm{Y} 5$ these may be called minor, AT has very prominent features completely absent from the others. First is the wavy edge (photograph c) of the 'wing', which is preserved, and it may be assumed that the other was similar. Three regular indentations divide the edge into four more or less symmetrical scallops, which are emphasized by the vertically incised lines similarly dividing the whole external surfaces of both 'wings'. This division, by three vertical and one horizontal line upon each 'wing' (for enough is visible in photograph в to prove that both were alike in this respect), is the second obvious difference 
between $\mathrm{AT}$ and the $\mathrm{Y}$ pair. The two 'wings' of AT are thereby marked off into eight (each) roughly equal areas, evidently for the purpose of instructional denomination, for it is needless to observe that no organ of the animal, whichever be intended, has in nature a neat rectilinear division of this kind. The third peculiarity of AT is the frequent presence within the sixteen areas thus delimited of chevron or 'broad-arrow' marks interspersed with a smaller number of little circular holes. The chevrons are made by two converging impressions, many of which are clearly cuneiform in shape, and may be taken as incised with one of the stili in a scribe's outfit. The holes are drilled with a thin round rod, probably of metal; all appear to be of a certain depth, but photograph A reveals a peculiarity of the four placed near the edge in the middle of the four scallops described above. These four holes penetrate to the interior, where each has below it one of the chevrons. None of the other holes pierces to the inside, although it may be assumed that a similar four would have been found at the other edge, had it been preserved. It may be suggested that the total perforation was intended to show that the flesh was thinner at the edges than in the middle of the organ, and indeed the photograph appears to establish that the edges are made thinner in the model. The inside is mostly plain, but has certain features of its own; first, the holes. and chevrons just described, then the one remaining and the one lost boss on the central axis. This boss is itself divided and marked like the outside of the 'wings'. Incised lines crossing at right angles divide its surface into four, and in each of these compartments there appear to be (though $\mathrm{A}$ is not altogether clear) two chevrons in the vertical line with their points confronted. As a fourth difference between AT and the Y models may be counted that, while AT has upon its internal boss(es) the marks described, but without inscription, $\mathrm{Y}_{4}$ and $\mathrm{Y}_{5}$ have these features unmarked but accompanied by inscriptions, namely, the appropriate 'omens' which those features, when disposed as in the model, were thought to indicate.

To consider first the shape of AT: the scalloped edges, at least in the form they have here, are unique. The nearest resemblance among the diviners' models is in one of those found at Maeri, ${ }^{1}$ No. 4 , and less markedly No. 2 . But these are no more than deep nicks in two rough roundels of clay, and No. 4, although if bent double it might bear some likeness to AT, cannot be called really similar and lacks all the other characteristics. One edge of the model Va.T. $7688^{2}$ appears indeed very like that of AT, but it is hardly possible to judge from the published copy whether this edge is original and intentional or the result of a break; the inscriptions are virtually complete, which certainly suggests that the edge is in fact original. This model has a further claim to likeness in that the two marks, the 'hole' and the 'weapon' which, as described below, are so numerous upon AT, appear also, with omens, upon Va.T. 7688. There was sometimes found upon the left lobe of the liver a mark with the technical name of manzazum (i.e. 'standing-place', perhaps of the god while he surveyed the surface upon which he was to 'write'), and this had occasionally, in the fancy of the haruspices, the shape of a saw-edge (KA-TAG-GAM$\mathrm{ME}$, sinni šarsarri, 'teeth of a saw'), but the manner of its illustration upon the models from Boğaz-köi proves that it was an internal not a marginal shape, and the same

I M. Rutten in R.A. xxxv, Pls. I, 2.

2 Keilschrifturkunden aus Boghazköi (K.U.B.), iv, No. 74. 
comparison is not infrequently made for parts which are certainly not upon the periphery. When this formation was noticed it was always said that the place in question was 'split' (pataru), which in itself would not be inapt to the indented edges of AT. But in general it must be repeated that all the various 'splits' appear to have been nicks or cracks upon the surface of a feature, not the outline of a whole organ. Nevertheless, the technical terms 'split' and 'saw-edge' are undeniably the most readily applicable to the scalloped edges of AT, and there is plenty of evidence for splitting into four, which is the number of the scallops; the number of four, in this connexion, was of ill omen, ${ }^{2}$ according to the examples.

If it has not been possible to find a complete parallel to the quadrifoil edge of $\mathrm{AT}$, the eightfold marking of the 'wings' by rectilinear division seems to be unique. None of the observed 'splits' are eight in number, they do not in any case signify an area, and indeed it would be vain to seek a natural basis for this subdivision in the model, for the scheme is obviously artificial, as said above. It may be worth while to point out here the fallibility of a seeming parallel; the second of the divinatory models in the British Museum, $\mathrm{Rm} .620,{ }^{3}$ which has now ${ }^{4}$ been brought prominently into the discussion of anatomical topography in the animal, has one of a pair of fragmentary inscriptions, designated by Boissier as VII, which he has copied indistinctly as 7 , printed as 8 , and translated as $7 . .^{5}$ The whole reading is, however, wrong-this fragmentary note is the correlative of another which stands on the opposite side of a middle dividing line, and the true purport of these is respectively $[\ldots \ldots B] I$ imnu and $[\ldots .] A-.B I$ sumelu. The restoration, which might be guessed, is put beyond doubt by another fragmentary model published as K.A.R. ${ }^{6}$ No. 444 (upper), where on each side of a division by double line down the middle are the following descriptions: (i) PA. BIR. HUR ša imni, $k a-l u-\check{s} u-m a$ imnu, and (ii) PA. BIR. HUR ša šumeli, ka-lu-šu-ma šumelu. These suggest at once the restored reading of Rm. 620, the places of $k a-l u-s ̌ s-m a$ being taken by its common equivalent Dù-A-BI. The nearest allusion to a multipartite division of a whole surface is made by an unpublished text which, between a double line as in K.A.R. No. 444, has the following: šumma(BAD) amutu(Eš) arki-ša ana VII zi-za-at imnu u šumelu KU-un, if the "oracle", has its back divided into 7 , right and left are fixed.' 7 How this sevenfold division was effected there is nothing to show, and in any case the number is clearly 7 , not 8 . But the use of $z \hat{a} z u$ is noteworthy as much more suitable than pataru $\mathbf{z}^{8}$ to a division of a whole surface.

I Several references are given by $\mathrm{J}$. Nougayrol in $R . A . \mathrm{xl}$. 70 ; and see A. Boissier, Mantique babylonienne et mantique hittite, $20 \mathrm{ff}$.

2 e.g. R.A. xliv, p. 30 , line 47 (sacrilege in the temple, disappointment of the king, death of the subject); K.U.B. iv, No. 73 (four nicks in the manzazu: disaster upon a military expedition); cf. also A. Boissier, Documents assyriens, p. 47, I; F. Thureau-Dangin, Tablettes d'Uruk, I, obv. 25.

3 A. Boissier, Note sur un nouveau document se rapportant à l'extispicine (I9OI), and Choix de textes relatifs à la Divination assyro-babylonienne (1 905 ), $76 \mathrm{ff}$.

4 A. Goetze, Old Babylonian Omen-Texts, p. 4, and J.
Nougayrol, R.A.xl. 92, xliv. 5 .

5 Amended in his Mantique babylonienne, \&c., p. I4, but still faulty.

${ }^{6}$ That is E. Ebeling, Keilschriftuexte aus Assur religiösen Inhalts.

7 Understanding $K U_{-u n}$ as phonetic, kûn; cf. the preceding description upon Rm. 620 and $K . A . R .444$, "the whole of it is right (left)', not variable.

8 The distinction of these two words is nevertheless not easy to grasp; compare e.g. A. Goetze, Old Babylonian OmenTexts, No. 40, line 20, uban hasi qablitum a-na si-na zi-za-at with $R . A$. xliv. 30 , line 47 , naplastum a-na 4 pu-ut-tu-ra-at. 
Though no other examples of the 8-division are known, the scheme of marking off the whole of a surface into 'squares' is, of course, a prominent feature of the most celebrated of all liver-models, that numbered 92668 (Bu. 89-4-26, 238) in the British Museum. One side of this is marked off into small areas, most of which are approximately square, and each has in its middle or on the dividing lines a hole similar to those which occur in AT, where several stand in each of the squares interspersed with the chevronmarks; these contained features will be described below. 92668, unlike AT, is inscribed with 'omens', most of which are the apodoses only. The reason for this, as a recent writer has pointed out, ${ }^{\mathrm{I}}$ is that the significant position of the hole is defined visually by the squares on the model. The diviner, in short, had only to look at the model in order to see what was the meaning of a hole in a certain place when he might have found such a hole in the liver which he was examining. Both the squares and the holes are much more numerous in 92668 than in $\mathrm{AT}$, and it is not possible, especially with the incomplete view of AT afforded by the photographs, to trace any connexion between the numbers on each of the models, nor would such an attempt be justified unless it were demonstrated that both are models of the same organ, an hypothesis which would, in the opinion prevailing at present, be denied. This important question must be postponed; for the moment it suffices to point out that AT is closely related to 92668 in several particulars: (a) both are indicative of position upon the organ by rectilinear divisions; $(b)$ both were made for instruction, but whereas 92668 , being inscribed, might thereby serve to 'read off' the predictions of similarly placed marks, AT could afford only instruction in the posture and appearance of such marks; (c) the feature indicated, exclusively in 92668 , and jointly with one other in AT, is a perforation in the flesh which, in both models, is sometimes complete, coming out on the other side, and sometimes partial, ${ }^{2}$ only a depression in one side.

To pass on to the marks inside the squares of AT, these, as already observed, are of two kinds, and there is now little or no doubt how they were understood and named in the 'science' of the diviners. First, the hole, in nature the work of a parasite upon the liver of sheep, ${ }^{3}$ was called silu 'hollow, depth', a word which is written fully in the ancient texts as $\check{s i}-l u-u m,{ }^{4} \dot{s} i-l u m,{ }^{5} \check{s} i-l u,{ }^{6} \dot{s} i-i-l u ;^{7}$ the identity of this with the round hole is proved by the first of the examples here quoted, a liver-model with its sole feature a hole pierced from side to side, accompanied by an inscription which explains its significance as follows: 'If this hole (silum annum) exists (?) the enemy will approach and ......., and together with his reinforcements and his allies he will lay siege to a city of thine, and by

I J. Nougayrol in R.A. xxxviii. 77 ff.

2 In AT only four holes now survive which are visibly perforated, and four more may be assumed at the opposite edge (missing). In 92668 not all of the holes go right through -those which do not (according to the numbering of R.A. xxxviii. 77 ) are 27,46 , and another unmarked in that sketch, which lies a little above a line connecting $4 \mathrm{I}$ and 44 . In addition to these there are many small but intentional pits on the upper part of the model and over the 'finger'; several can be seen by the photograph in C.T. vi. All of these holes, of both kinds, are in addition to the three long passages through the model which fan out from above holes 27 and 33 to three widely separated points on the 'upper' surface.

3 A. Boissier, Mantique babylonienne, \&c., p. 14.

4 A. Goetze, op. cit., P1. II, No. 3, a model where the mark explained is a round hole.

5 Ibid., No. I 8, lines 50 ff.; K.U.B. iv, No. 74 .

6 Ibid., lines 65 ff., and $R . A$, xl, p. 85 , lines I I, $\mathrm{I} 2$.

7 K.A.R. No. 448,5 . 
battery (?) will enter into the midst of it'-the hole bored in the liver indicating the breach forced in the wall of the city. Another liver-model, from Bogaz-köi, shows a similar hole with the accompanying words: "If the "standing-place" is not there but in its room is a silum šutebrum, the king's city of residence will be captured, \&c.' Next to this omen is found a smaller hole with the following explanation: "If the "standing-place" is not there but in its room $U R U$, the king will die, \&c.'; there is yet another inscription to a similar effect but the mark is obscured by a break. This model provides the transition from the ancient writing silum to the 'ideogram' of the Assyrian omen-texts; these are full of references to a feature called $U$, which, in one of its senses at least, ${ }^{\mathrm{I}}$ is thus seen to denote a hole in the liver, ${ }^{2}$ and the $U R U$ of the Boğaz-köi model and of the Assyrian texts renders the si-lum $n a$-di of the Old Babylonian omens, literally 'a hole falls'.

The second kind of mark within the 'squares' of AT is that described hitherto as a 'chevron'. It represents in nature a slight pointed protrusion upon the surface of the organ, perhaps caused by an adhesion. This was the common feature which the diviners called a 'weapon', GIš. KU, $(i s u) k a k k u(m)$, very prominent in the extispicial texts of all periods. The form in which these were depicted upon an artificial (clay) surface, tablet or model, can be seen in various ${ }^{3}$ original illustrations, and is vividly described in one passage 4 as 'like a bird's tongue'. The 'weapon' was the most narrowly observed of all the fortuitous marks on the internal organs, for it had a natural association with the military interests which are predominant in the liver-omens. Its positions, its characteristics, and its significances were legion, and there was a whole sub-series ${ }^{5}$ of omens in the official collection devoted to it, but it does not seem often ${ }^{6}$ to be closely associated with the 'hole' (silu), as it is in AT. In one place 7 a 'weapon' is said to have 'wide-open eyes', but this can hardly refer to the 'hole' at the base, as shown in AT. Probably the nearest descriptions are found in omens which tell of a 'hole' occurring in the 'area' of a 'weapon', ${ }^{8}$ the 'mouth' of a 'weapon' (i.e. its open end) being 'turned downwards' or otherwise; 9 but another possibility is that the constant relative position of the two in AT attempts to show a 'weapon' occurring within a 'hole', which was certainly observed in the omen-texts. ${ }^{\text {Io }}$ The only part of AT where the 'weapons' are not associated with 'holes' is on the interior boss, which.(whatever exact part of the anatomy it represents) would certainly have been called a 'finger'. Now the 'weapons' had a particular affinity with the 'fingers', for the

I In many other passages of the Assyrian omen-texts $U$ certainly stands for $u b a n u$ 'finger', a part of the organ, not a blemish in it; this latter use of $U$ is perhaps a mereabbreviation of the word, R.A. xliv. 22, n. I.

2 The use of this sign $U$ is clearly dictated by its original form, a circle impressed in the clay of a tablet by the round end of the stilus, and indeed the perforations in $\mathrm{AT}$ and other models may have been made by the same instrument.

3 Maeri models, Nos. 5, I5 (?), Boğaz-köi K.U.B. iv, No. 74 (the 'weapon' mentioned in the text of No. 72 is not illustrated): examples on tablets, C.T. xxxi. 9 (K. 2086, dupll. ibid., pl. I 5 and $x \times x .34$ ), where two or three 'weapons' are depicted in a group arranged either 'parallel' or 'in succession'; for these terms see W. von Soden in Orientalia,
I 947,440 .

4 C.T. xxx. 2I, 83-I-1 8, 467, obv.

5 Of at least three tablets, probably a sub-section of $5 u m m a$ ubanu...

6 But cf. A. Goetze, Old Babylonian Omen-Texts, No. 46, col. iii. $48-53$.

7 A. Boissier, Documents assyriens relatifs aux présages, p. 2 Ig, II I 2.

${ }^{8}$ C.T. xxx. I 3, K. 8496, rev. 4, šumma ina maš-gan-šu silu nadi....

${ }^{9}$ C.T. xxxi. I4, K. 2090 (with illustrations; cf. the duplicate K. 99 in F. Lenormant, Choix de textes cunéiformes, No. 947).

10 A. Goetze, op. cit., No. 46, col. v. Io. 
sub-section devoted to them in the official collection of omens seems to have been a part of the general chapter treating of the 'fingers', as observed above. The other feature to be noticed in the marks upon this boss is that the points of the 'weapons' (so far as can be seen from the photograph) all confront each other, ${ }^{\mathrm{I}}$ as they do also in certain cases on the sides of the model, and this may be taken as a presage of combat, when viewed in the light of the battles and other military occasions which are the main concern of the omens. The 'weapons' are often characterized as aridu (pl. ariduti), and although there is nothing to define this term² technically it should seem to mean 'pointing downwards', in which case the confronting (upturned) 'weapon' is perhaps indicated by a phrase (isu)kakku $a-[r i]-d u$ u ma-hi-ir-šs ana pan (ișu)kakki e-bi-ri ......., s though the meaning of 'its opposite' or 'its like' and the 'crossing weapon' in this passage is undefined.

Various forms and marks which appear in this model having now been described it is desirable to add a few more words on the subject of the organ represented. Until recently this would have been called a sheep's liver, but it is now believed with some confidence 4 that models of a shape resembling $A T$ are in fact meant to imitate the lungs of a sheep. What is certain, from the models $Y_{4}$ and $Y_{5}$, is that they depict that part of the entrails which was called hašum, now fairly well established as the phonetic reading of the sign HUR in the later texts. That AT belongs to this same class of models is indicated principally by its shape, and some confirmation is given by the original presence in AT of two protuberances, only one now remaining; this was an observed peculiarity of certain specimens of hasum. ${ }^{5}$ There has always been great difficulty in separating the meaning and. augural functions of two terms Eš $(a m u t u)$ and HUR $(h a \grave{s} u)$ in the omen texts, and it was formerly believed that they were practically synonyms, both meaning 'liver'.

The most obvious test of the identity of $\mathrm{HUR}($ hasum $)$ is the anatomical likeness of such models as $\mathrm{Y}_{4}$ and $\mathrm{Y}_{5}$ (explicitly stated to represent hasum), and by analogy of AT itself. But the decision of this point is apparently not so easy as it might be thought; at least, an eminent authority on veterinary science to whom the writer submitted the photographs of all these objects did not find himself able to pronounce with certainty which of the two organs, liver or lungs of a sheep, they were meant to depict, but he was more inclined, after careful consideration, to think the liver was intended. In AT he considered that photograph $A$ is the posterior aspect of the liver, the boss being the caudate lobe, and the rough fossa (i.e. the site of the lost feature) the position of the gallbladder. In photograph $\mathrm{B}$ he was inclined to see the anterior surface of the liver, the longitudinal groove and ridge representing the posterior vena cava.

To this criterion of natural and unchanging features, which thus proves inconclusive, a few observations may be added from the ancient evidence itself. The first concerns the fragmentary model Rm. 620 in the British Museum which, as said above, has recently

I Particularly across the lines of the 'squares', but sometimes also within them.

2 But note C.T. xxx. 44, 83-I-I 8, 4I5, 4, ... sepu saknat(at) ana pan a-ri-du silu nadi . . ., where aridu seems to be an independent term.

${ }^{3}$ C.T.xx. 44, line 48.
4 For a brief statement see A. Goetze, Old Babylonian Omen-Texts, Introd. 4, who quotes other literature, some of which is not available to me. Other recent authorities who agree with this opinion are J. Nougayrol (R.A. xl. 92 and xliv. 5) and M. I. Hussey, Fournal of Cuneiform Studies, ii. 25 .
5 R.A. xl. 93 . 
been brought again into the discussion of anatomical topography. This model is in any case, according to its own inscription, that of the $\mathrm{HUR}$, or at least gives prominence to that term. It has also been noticed above that its outward (convex) side has remains of inseriptions which reappear more fully in another fragmentary model Va.T. 9580, published in K.A.R. No. 444 (upper). This latter model represents the single deep longitudinal lirre of $\mathrm{Rm} .620$ by a narrow strip between two parallels and in addition names certain localities not marked on Rm. 620, narpaš HUR, karaš SAL.LA.HUR, [ti(?)]-tu-u-ri $i^{\mathrm{I}} \mathrm{HUR}$, $n a-k a p^{2}$ HUR, libitti(ti) ${ }^{3}$ HUR, but the identity of the two models is confirmed by the presence of SAL.LA.HUR in Rm. 620 at a corresponding place. It may therefore be confidently assumed that the models Va.T. 9580 and $\mathrm{Rm}$. 620 not only represented the same organ, but originally carried some of the same inscriptions. But while the inward side of Rm. 620 has only a peculiarly shaped 'finger' with its omen and one or two shorter inscriptions, ${ }^{4}$ the other side of Va.T. 9580 is very different. Most prominent of the marked features is the narrow and widening end of the gall-bladder, which not only appears unmistakable in itself but is repeatedly called șı in the inscriptions which cover it. Another notable feature is the two roughly rounded spaces marked TÙR (tarbasu) 'courtyard'. In various passages the areas so called are associated with the Níg.TAB (nasraptu), 5 with the ș (martu), ${ }^{6}$ with the martu and manzazu, ${ }^{7}$ with the dihu (or zihu) and the eristum ${ }^{8}$ also with the DI $(\tilde{s} u l m u) .{ }^{9}$ Whatever be the anatomical features bearing these several names (and the discussion is immaterial here), they have in common the property of belonging to the liver, not to any other organ. So much for the visible characters of the second side of Va.T. 9580-namely, its possession of the gall and of two 'courts', which the texts always associate with the liver. But also, among the various inscriptions of this second side of Va.T. 9580, the rest of which need not detain us here, there is one compartment (above the curve of the gall) marked íD.Eš (left and right). This 'canal of the liver', often mentioned, is a well-known feature; again, the specification Eš identifies it with the liver, and what seems of outstanding significance to the question now being discussed is that on one and the same model (Va.T. 9580) one side shows features of the HUR, and the other side a feature of the Eš. In face of this, how is the separation Eš, amutu, 'liver' against HuR, hašsu, 'lung' to be maintained, as recent writers believe? To this it may be added that an unpublished specimen of a diviner's model, mentioned once above ( $\mathrm{p}$. $25^{2}$ ), has at one end a completely similar convex shape, like Rm. 620, curving down to a sharp edge, and down this slope run the two parallel lines of Va.T. 9580 , corresponding with the single line of $\mathrm{Rm}$. 620. The convex surface of this model is freely inscribed: between the lines is the notice quoted above as to the sevenfold division of the 'back of the Eš', and other inscriptions refer not only to the Ěs (arki libbi nâr Eš) but to such well-

\footnotetext{
I Cf. A. Boissier, Mantique babylonienne, \&c., p. 22, and C.T. xx. I 8, S. I 520 , obv. 8 , summa padanu ti-tur-ri-e-ti $y_{a}$ seri ..., "if the "path" has crossings of flesh. ...'

2 C.T. xxxi, pl. 2, K. 70, obv. I 2, pl. 4, K. 70, col. iii. 29; pl. 8, 25 ff.; pl. 39 , ii. 20 ff.

3 C.T. xxxi, pl. 2, K. 70, obv. I 5.

4 Referring to kur.tur, cf. C.T. xxxi, pl. 4, K. 70, iii. 33 :
}

pl. $42,5 \mathrm{ff}$.

${ }_{5} C . T . \times x .50$, rev. 2.For the reading of Níg.TAB see fournal of Cuneiform Studies, ii. 27, and R.A.xl. 65 .

6 C.T. xxxi. 6, ii. 7, and as on Va.T. 9580.

7 K.A.R., No. 446, 4.

8 A. Boissier, Choix de Textes, p. I 24.

9 F. 'Thureau-Dangin, Tablettes d'Uruk, No. 3, rev. 30. 
established parts of the liver as ME.NI and ni-ri. But still further-the other (flat) side of the model has all the usual plastic features of the liver-models with inscriptions concerning, e.g. the niru, MÁY̌, ȘI, DI, ME.NI, and KAL.

For the present, it may be advisable still to call the object from Atchana what it was first supposed, a diviner's model of the sheep's liver. 


\section{(a) THE CYLINDER SEALS AND SEAL- IMPRESSIONS}

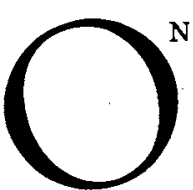
Plates LX to LXVII there are illustrated all the seals and seal-impressions found at Atchana which for their intrinsic interest or for their historical significance merited illustration. With a few exceptions, Nos. 132 to 144 , for which evidence was lacking, they are arranged in chronological order, that order being fixed not on stylistic grounds but by the external evidence of the levels in which they were found.

The arrangement by levels is, I think, essential, but it is not without its pitfalls. In the first place the levels being artificial divisions of the continuous life of the city, not necessarily corresponding to any sudden change in cultural development, they may cut misleadingly across the proper sequence of seals; e.g. seals found in Level III but belonging (though we have no evidence for this) to the beginning of that period may be survivals, characteristic of Level IV but not used during the greater part of the Level III period. In the second place seals were sometimes in use for a very long time, as is shown by the wearing of the surface, or old seals might be re-used ${ }^{\mathrm{I}}$ or even preserved as antiquities, as must have been the case with our No. 35, a loop-bored cylinder of Jamdat Nasr date which nevertheless was found in the ruins of the temple, apparently of Level V, where it presumably had been kept in the treasury for more than a thousand years. While therefore a cylinder, as dating evidence for a period, can give no more than a terminus post quem, conversely the fact that it is found in a particular level does not prove that it is of contemporary manufacture. We are on far safer ground with the impressions of seals on tablets belonging to a definite level, for such seals were obviously contemporary with the period if not in manufacture at least in use and are truly representative of it.

Most of the periods defined by our archaeological levels are relatively short, and one cannot therefore expect each of them to possess a distinctive character so far as the glyptic art is concerned. The recognized phases of that art in Mesopotamia, the home of the cylinder seal, or in the 'peripheral' countries, cover periods of far greater length, so much so that the total of our seven levels, VII to I to which the vast bulk of our cylinders belong, is represented by two stylistic phases only-the First Babylonian and the Kassite together with the contemporary Mitannian style of Kirkuk, ${ }^{2}$ the Middle Assyrian style of the fourteenth century and onwards having at Atchana very little influence (but see No. I 20). Atchana seems to give, for the first time, material so narrowly dated as to justify an attempt at closer subdivision, but I am far from thinking that it establishes a

I Sidney Smith in $A . \mathcal{F}$. xix, No. $\mathrm{r}$, pp. $4 \mathrm{I}, 43$, for the use by a king of the seal of his predecessor as a token of his legal claim to the throne.

2 See H. Frankfort, Cylinder Seals. 
norm which would in detail apply to other sites. Dr. Frankfort is undoubtedly right in refusing ${ }^{1}$ to 'postulate the existence of a Syrian glyptic style' in the second millennium B.C. in view of the different cultural provinces into which the country was divided; if the results at Atchana do not always agree with those obtained by excavation elsewhere, there is no need to dispute the facts in either case but every reason against regarding them as of more than local significance.

I have already mentioned our earliest cylinder, No. 35. Found out of its true horizon, it still is of interest as confirming what Dr. Frankfort says about Mesopotamian expansion in the Jamdat Nasr period as proved by the distribution of its seals, and also as tending to support the archaeological evidence for Jamdat Nasr connexions with Level XIV (see p. 379). The half-dozen seals found in situ in our early levels agree with the probable chronology suggested by the stratification. No. I from Level XIII has the banquet-scene with two people drinking through tubes which is one of the standard themes of the Early Dynastic period recurring at Tell Judeideh;'2 from Level XII No. 2 bearing the 'Lagash' emblem, the wings of the eagle hatched in regular 'peripheral' style, and No. 3 with the figures set in framed compartments are both typical of the phase dated by Frankfort between 2800 and I 800 B.c., ${ }^{3}$ and according to my reckoning should be of the twentythird or perhaps twenty-fourth century; the stamp seal No. 4 defies dating; it derives from the chalcolithic tradition as exemplified by Tell esh Sheikh which reappears sporadically at all periods. No. 5, unfortunately fragmentary, appears to me to be Sargonid, though I can cite no exact parallel for it. The equally fragmentary No. 7 shows the plaited ornament which is characteristic of, but not peculiar to, Syrian seals of the beginning of the second millennium, but has also a figure wearing a Hittite crown unusual at this date. No. 8 is an imported seal which alike for the grouping of the two figures, the space given over to the (erased) inscription, and for the drill-made sun rosette is typical of the latter part of the First Dynasty Babylonian style.

In Level VII (Nos. 9 to $2 \mathrm{I}$ ) there are points of historic interest. The seal of King Yarim-Lim shows, as one would expect from his political associations, a strong First Dynasty influence, but at the same time has a figure wearing the tall Hittite crown, while the ankh on this seal, as on Nos. 9, I4, and I 45, are reminiscent of the influence which XIIth-Dynasty Egypt had exercised over north Syria. The Hyksos scarab No. 20 seemed to belong to the very end of the period. Nos. I7, I8, and 2 I can be classed as 'Mitanni', i.e. they are of that Syrian style out of which the later Mitanni was to develop; it is interesting to compare No. 2 I with No. 52, which belongs to Level IV and should therefore be 300 years later.

In Levels VI and V all Egyptian symbolism disappears. In Level VI we find the Hyksos element (Nos. 32, 33), but the prevailing style is the local, i.e. the north Syrian. No. 23 would seem to have survived from an earlier period. It is worth noting that the two seals Nos. 25 and 26, which are almost identical, were found together in one grave; they are early examples of a numerous and widely distributed class in what Frankfort calls 'the popular style of Mitanni', the subject of which generally includes one or two
I Op. cit., p. $26 \mathrm{I}$.
${ }^{2}$ Frankfort, op. cit., Pl. $\operatorname{xxxix} f$.
3 Compare respectively his $\mathrm{Pl}$. $\mathrm{xxxIx} a$ and $q$. 
human figures, goats with back-turned heads (or birds), the 'staff with globes', and either a raised platform on which the animals are set or a guilloche beneath or above them; most of the cylinders are not cut but moulded in paste which was subsequently glazed; here Nos. 25 and 26 are of steatite, but No. 24 is of paste, as are such later examples as Nos. $36,46,85,89,90,98,99$, I 00, and I 5 . Dr. Schaeffer ${ }^{1}$ states that at Ras Shamra glazed paste cylinders of this sort occur first, and most commonly, in stratum Ugarit Récent 2, between I $45^{\circ}$ and I 365 , while a few rare examples, degenerate in style, appear at the bottom of Ugarit Récent 3 and must be attributed to the first half of the fourteenth century; other examples from south Syrian sites he would date exclusively to the fifteenth and the beginning of the fourteenth centuries. If, as is probable, these cylinders were manufactured in the Mitanni country ${ }^{2}$ and exported thence in all directions, it is only natural that at Atchana, closer to the centre of production, they should have enjoyed a longer vogue; there they first appear in the seventeenth century ${ }^{3}$ and are still found in Level II, i.e. in the latter part of the fourteenth and the beginning of the thirteenth centuries. It is clear that they cannot be used, wherever they are found, with the precision which conditions at Ugarit would suggest.

Level $\mathrm{V}$ can be described as wholly Mitanni or Syrian unless indeed the scratchily linear chariot-design of No. 44 be an exception.

In Level IV (Nos. 47 to 84 ) it is interesting to observe the difference between the royal seals and the 'popular' seals which form the bulk of the rest of the collection. The royal seals are naturally better cut than most and their subjects are dictated by tradition-the fight with wild animals (Nos. 47-5I) and the approach to the god (Nos. 64-7I), but whereas the rest are purely Syrian or Mitanni in feeling, the royal seals show the political bias of a dynasty that had been installed by Egypt, and the ankh is a normal symbol; in Ilim-ilimma's seal the god (No. 65) is frankly foreign and wears the double crown of Upper and Lower Egypt, token of a loyalty which was to cost the king his throne. One seal, No. 79, with its file of soldiers on the march, comes more closely to the Hittite, one, No. 56, has the bull-legged guardian demon who was to be so popular in Syro-Hittite reliefs. The few finely cut cylinders, such as Nos. 55, 57, and 75, illustrate the second school of Syrian glyptic wherein the Babylonian tradition is maintained so far as the general scheme and the leading figures are concerned but the subsidiary motives are predominantly of a non-Mesopotamian character. ${ }^{4}$ Typically Syrian, too, is the use of the plaited twist, not only in connexion with the subsidiary groups (No. 85 ) but framing and separating the main figures (No. 83) and as an all-over pattern; in the last case it is interesting to note the variety which the gem-cutter manages to introduce; in No. $8 \mathrm{r}$ the strand is single but the coils are rightly wound, in No. 82 the coils are looser and there is a filling-ornament of a three-petalled quirk, in No. 80 there is a double strand, a mere twist with no coils but a central dot, while in No. 83 the coils become plain circles enclosed and joined by spiral lines.

I Stratigraphie comparée, p. 409 .

2 So Frankfort, op. cit., p. 273 .

3 At Ur a paste cylinder of this type, with human figure, two gazelles with back-turned heads, and a globed staff (L.

Legrain, Ur Excavations, vol. x, Pl. 35, No. 580), was found under the brick pavement of a house of the Isin-Larsa period; it cannot have been later than the seventeenth century.

4 Frankfort, op. cit., p. 256, \&c. 
Of the comparatively few cylinders found in Level III only three, Nos. 92, 93, and 97, are of stone, and only the last is at all remarkable and that less for its subject than for the excessive drill-work, even more exaggerated than Frankfort's Pl. xLIIIg. No. 9 I is in the blue lapis lazuli paste which was occasionally used for the manufacture of luxury vases (v. Pl. LXXXIII, AT/48/1 5, and p. 297), while the rest are of the normal white paste, originally glazed, common in Level IV. The seal-impression, No. 96, is obviously derived from the Hittite bulla, but the inscription has here degenerated into mere ornament.

Level II, Nos. 99-I I 9, again has a fair proportion of glazed paste cylinders (Nos. 99, I०0, I०I, I०2, I०5, I08, I I 8), but their main vogue seems to be past. No. I०9 has the tree and winged disk common in Frankfort's 'Syrian seals of the Second Group', and to the same group should belong the very spirited No. I 20 which was on the border-line between Levels II and I. What is curious is that this level, representing as it does a prosperous period, should produce so many bad cylinders. No. I 08 , a white paste cylinder, has suffered from surface decay and so has the blue lapis paste cylinder No. I 3 -though certainly it was never good; but the actual cutting of Nos. I I 2, I I 4 , I I 5 , and I 6 is deplorable. 'This decadence continues in Level I- $v$. Nos. I 22, I 27, I 28 , and $130-$ side by side with a greater variety in the material of which the cylinders are made than had been observed in any older level; thus No. I 25 is of chalcedony, No. 126 of green serpentine enriched with gold caps, and the broken No. I 28 is of carnelian; No. I 22 is the only example of glazed paste.

Of the cylinders not dated by levels (Nos. I 35-44) the first is outstanding; no other instance of such thoroughgoing Egyptianizing was found on the site. It would seem to rank with Frankfort's 'Palestinian' class, or with his Hyksos group; personally I should attribute it to a Phoenician workshop such as Byblos in view of their known skill in imitating Egyptian designs and the equally well-known incompetence of the Palestinians. No. I 4 1 , on the other hand, may well be Palestinian, its technique being precisely that of Frankfort's Pl. xLIV $s$ and $t$. No. I 37 is a good example of the 'Second Syrian' group.

\section{CATALOGUE OF SEALS AND SEAL-IMPRESSIONS}

I. AT/47/I22. Black steatite, $1.0 .018 \mathrm{~m}$. Banquet scene with two figures drinking through tubes. House site, Level XIII.

2. AT/48/70. Black steatite, $1.0 .024 \mathrm{~m}$. On floor of Level XII temple.

3. AT/49/9. Mottled steatite, 1 . O.OI 9 m. In Level XII temple.

4. AT/48/73. Stamp seal, pillow-shaped, of grey steatite, $0.024 \mathrm{~m}$. sq. On floor of outer chamber of Level XII temple.

5. AT/47/27. Seal-impression on fragment of black clay jar-stopper. In the Level XI house ruins.

6. AT/47/I. Dark grey steatite entirely covered with an inscription, mentioning a scribe Adad-bani; the text is correct on the cylinder and therefore reversed on the impression. Level X house site. It lay rather high in the stratum of ruins but below the foundations of Level IX, so that its horizon was certain.

I Most of the worn or originally bad seals which did not merit reproduction here were found in the upper levels. 
Mr. Wiseman supplies the following note: The cylinder 'is a dedication to the gods UD, IM and Ishtar (probably to be read as Shamash, Adad and Ishtar) of a GUG-stone; the full text runs "To (d) UB, the great god, the great god IM, the god my creator, and Ishtar my creator, Adad-bani the scribe has dedicated a GuG-stone". The style of writing is unlike any other inscription from Atchana and may well be "Cappadocian" as Landsberger suggests. Adad-bani does not occur elsewhere among the proper names from Alalakh.' Professor Landsberger, to whom the stone had been submitted previously, was so emphatic regarding its 'Cappadocian' character as to say that the text might have been copied directly from a Kültepe tablet.

7. AT/48/26. Fragment of jar-stopper in dark clay with 3 partial impressions of a cylinder seal showing vertical guilloche and 3 persons, crowned. Level VIII, in the concrete foundations of the Level VII temple.

8. AT/47/I 32. Blue chalcedony, $1.0 .022 \mathrm{~m}$. The inscription has been erased. Level VII; found in the box against the foundations of the SE. wall of the Level VII temple.

9. Seal-impression, partial, on tablet ATT/39/73, from the Level VII temple.

IO. AT/39/169. Black steatite, $1.0 .017 \mathrm{~m}$. On the floor of the passage, close to stair-head, in the SE. block of Yarim-Lim's palace.

I I, I 2 A and в. Seal-impressions on tablet ATT/39/ I I 3, from Yarim-Lim's palace. No. I 2 is the seal of King Yarim-Lim. Wiseman, No. 7 .

I 3. Seal-impression on tablet ATT/39/26, found in Yarim Lim's palace, Level VII. Wiseman, No. 97.

I 4. AT/39/I 29. Black steatite, $1.0 .022 \mathrm{~m}$. From room Io of Yarim-Lim's palace, Level VII.

I 5. AT/47/96. Black steatite, 1. $0.024 \mathrm{~m}$. From Yarim-Lim's palace, Level VII.

I6. AT/39/ I 30. Handled stamp-seal in red terra-cotta, diam. of base $0.025 \mathrm{~m}$. In the courtyard of Yarim-Lim's palace, Level VII.

I 7. AT/39/ I 84 . Black steatite, 1. $0.02 \mathrm{I} \mathrm{m}$. From the store-room (I I) in Yarim-Lim's palace, Level VII.

I 8. AT/39/200. Dark brown stone, 1. 0.016 m. From the store-room (I I) in Yarim-Lim's palace, Level VII.

I 9. $\mathrm{AT} / 46 / 199$. Haematite, 1. $0.02 \mathrm{~m}$. From room 29 in Yarim-Lim's palace, Level VII.

20. AT/39/247. Scarab of white paste, originally glazed; Hyksos type with illegible inscription. L. $0.013 \mathrm{~m}$. Found rather high up in the debris of room 19 of Yarim-Lim's palace, Level VII.

2 I. AT/39/230. White steatite, $1.0 .024 \mathrm{~m}$. From Yarim-Lim's palace, to the west of room I 7 (Sq. N I 3), Level VII.

22. AT/39/223. Grey steatite, 1. 0.0 $5 \mathrm{~m}$. with crude animal (?) design. Levels VII-VI.

23. AT/47/I 72 . Black steatite, $1.0 .03 \mathrm{~m}$. From the fortress area, Level VI.

24. AT/47/85. White paste, $1.0 .022 \mathrm{~m}$. Level VI.

25. AT/39/23 I a. White steatite, $1.0 .02 \mathrm{~m}$. From grave 39/9 I, Level VI.

26. AT/39/23 I $b$. White steatite, 1.0 .02 I m. From grave 39/9 I, Level VI.

27. AT/39/233. White steatite, 1. 0.02 I m. Above Yarim-Lim's palace, Sq. L I 3, Level VI.

28. AT/39/65. Black steatite, $1.0 .022 \mathrm{~m}$., very much worn. From house ruins in Sq. N IO, Level VI.

29. AT/47/165. Scarab, white steatite originally glazed; human figure with 2 hooded adders. From house site, Sq. Q 9, Level VI.

30. AT/39/226. White steatite, $1.0 .018 \mathrm{~m}$. Very badly worn, design of men and animals. Grave ATG/39/8I, attr. to Level VI.

31. AT/39/299. Greenish-grey serpentine, 1. $0.027 \mathrm{~m}$. Level VI. 
32. AT/47/6I. Scarab (base of) in white steatite with traces of green glaze, Hyksos type. Sq. P I 4, Level VI.

33. AT/39/249. Scarab, white steatite. In the ruins of Level VI house site, Level VI.

34. AT/39/3I I. Stamp seal in black serpentine with rudely scratched design. From above Yarim-Lim's palace, Level VI.

35. AT/47/23. Dark steatite, $1.0 .025 \mathrm{~m}$., diam. $0.029 \mathrm{~m}$; t the cylinder is not pierced but loopbored at one end, the other end decorated with scratched criss-cross lines. It was found on the temple site, probably below the Level IV temple, but its true horizon was not marked and in any case is not to the point; if it did come from the Level V or VI building, as is likely, it had been preserved there as an antiquity. See p. 66.

36. AT/39/1 34. White paste, $1.0 .02 \mathrm{~m}$. From Sq. H I 5, Level V. Found at the neck of a body, not properly buried, under the Level $\mathrm{V}$ floor.

37. AT/39/286. Grey steatite, 1. 0.0 I 8 m. From Sq. K I 5, Level V.

38. AT/47/152. White paste, 1. $0.019 \mathrm{~m}$. Three human figures set horizontally and a winged gryphon upright. From the 'Via Sacra' area, Sq. U I2, Level V.

39. $\mathrm{AT} / 39 / 232$. Blue paste, $1.0 .02 \mathrm{~m}$. Three human figures set horizontally, and a fleur-de-lis staff, upright. Sq. $\mathrm{N}$ I I, Levels VI-V.

40. AT/39/205. L. $0.023 \mathrm{~m}$. $)$ Three white steatite cylinders found together in grave $39 / 80$, 42. AT $/ 39 / 206$. L. $0.022 \mathrm{~m}$. $39 / 207$. L. 0.02 I m. Three white

43. AT $/ 39 /$ I 3 I. Grey-green steatite, $1.0 .03 \mathrm{~m}$. From Sq. G I 6, Level V.

44. AT/46/2 i 3. Dark grey stone. From Sq. L i 6, Level V.

45. AT/48/37. Handled stamp seal of green steatite, the base $0.032 \times 0.022 \mathrm{~m}$. Temple site, Levels V-IV.

46. AT/39/53. White paste, originally glazed, $1.0 \cdot 024 \mathrm{~m}$. From Sq. N I I, Levels V-IV.

47. Seal-impression on tablet ATT/38/52; the seal of Shutarna, king of Mitanni. From the Niqme-pa palace, Level IV. Wiseman, No. I 3 .

48. Seal-impression from tablet ATT/38/ i 6. From the Niqme-pa palace, Level IV. Wiseman, No. 4 I 7 .

49. Seal-impression from tablet ATT/38/ I 84. From the Niqme-pa palace, Level IV. Wiseman, No. 424 .

50. Seal-impression from tablet ATT/38/25 I. From the Niqme-pa palace, Level IV. Wiseman, No. $25 \mathrm{I}$.

5 I. Seal-impression from tablet ATT/38/9. From the Niqme-pa palace, Level IV. Wiseman, No. I I I.

52. AT/39/229. White steatite, $1.0 .022 \mathrm{~m}$. From grave $39 / 86$, Level IV.

53. Seal-impression from tablet ATT/38/29, found in the Niqme-pa palace, Level IV. Wiseman, No. 230.

54. AT/38/1 84 . White paste, $1.0 .027 \mathrm{~m}$. Found in room 4 of the Niqme-pa palace, Level IV. 55. AT/38/83. White steatite, 1. 0.019 m. Found in room 7 of the Niqme-pa palace, Level IV.

56. Seal-impression from tablet ATT/38/29 (the same as No. 53). Level IV.

57. AT/38/92. White steatite, $1.0 .026 \mathrm{~m}$. Found on the floor of room i 6 of the Niqme-pa palace, Level IV.

58. AT/48/I. White steatite, $1.0 .02 \mathrm{~m}$. In the foundations of the central wall of the Level III temple, Level IV.

59. AT/38/28 I. White paste, $1.0 .02 \mathrm{~m}$. Niqme-pa palace, Level IV.

6o. AT/38/1 90. White paste, $1.0 .022 \mathrm{~m}$. Found in room C I of the Niqme-pa palace, Level IV.

6I. AT/38/1 9 I. White paste, $1.0 .028 \mathrm{~m}$. Found in room C I of the Niqme-pa palace, Level IV. 
62. AT/38/234. Green steatite; cutting shallow and surface worn; $1.0 \cdot 04 \mathrm{~m}$. Niqme-pa palace area, Level IV.

63. AT/37/ I 8 I. Black steatite, $1.0 .026 \mathrm{~m}$. From grave $37 / 33$, attributed to Level IV.

64. Seal-impression from tablet ATT/38/2 I 2; the seal of King Niqme-pa. Found in his palace, Level IV. Wiseman, No. I 53.

65-66. Two impressions from the seal of King Ilim-ilimma, from tablets ATT/38/3 I and 6I (the character of the left-hand figure is better seen on No. 65). From the Niqme-pa palace, Level IV. Wiseman, Nos. 75 and 48 .

67. Seal-impression from tablet ATT/38/2 I 0 . From the Niqme-pa palace, Level IV. Wiseman, No. $5 \mathrm{I}$.

68-69. Two seal-impressions from the same seal on tablet ATT/38/228. From the Niqme-pa palace, Level IV. Wiseman, No. 336.

70. Seal-impression from tablet ATT/38/254. From the Niqme-pa palace, Level IV. Wiseman, No. I 84.

7I. Seal-impression from tablet ATT/38/1 82. From the Niqme-pa palace, Level IV. Wiseman, No. 392.

72. AT/38/189. Blue paste (imitation lapis lazuli), $1.0 .022 \mathrm{~m}$. Found in room $\mathrm{C} 6$ of the Niqme-pa palace, Level IV.

73. AT/38/89. Black steatite, $1.0 .023 \mathrm{~m}$. From house site, Sq. G i 6, Level IV.

74. Seal-impression from tablet ATT/38/I09. From the Niqme-pa palace, Level IV. Wiseman, No. 329 .

75. AT/38/ I 9 . Haematite, $1.0 .028 \mathrm{~m}$. From room I 6 of the Niqme-pa palace, Level IV.

76. AT/39/72. Black steatite, $1.0 .023 \mathrm{~m}$. Found on the floor of room 2 in house 39/A, Level IV.

77. Seal-impression on tablet ATT/38/76. From the Niqme-pa palace, Level IV. Wiseman, No. 363 .

78. Seal-impression on tablet ATT/38/267. From the Niqme-pa palace, Level IV. Wiseman, No. 433 .

79. Seal-impression on tablet ATT/39/26. Level IV. Wiseman, No. 97.

80. AT/38/61. White paste, $1.0 .017 \mathrm{~m}$. From room 8 of the Niqme-pa palace, Level IV.

8 I. Seal-impression on tablet ATT/38/257. From the Niqme-pa palace, Level IV.

82. Seal-impression on tablet ATT/37/2 I 2 (the seal of the King of Tunip ?), Level IV. Wiseman, No. 2.

83. Seal-impression on tablet ATT/38/54. From the Niqme-pa palace, Level IV.

84. AT/38/20I. White paste, showing remains of red glaze, $1.0 .02 \mathrm{I} \mathrm{m}$. Found in the filling of room 26 of the Niqme-pa palace, Level IV.

85. AT/39/2 I 5. White paste, 1. $0.025 \mathrm{~m}$. Found in Sq. L I 3, Level III (?). It was near and perhaps belonged to a grave of that date.

86. AT/39/201. White steatite, $1.0 .024 \mathrm{~m}$. Found in Sq. L I 3, Level IV-III.

87. AT/39/93. White steatite, $1.0 .022 \mathrm{~m}$. Found in Sq. H I6, Level IV-III.

88. AT/39/277. White steatite, 1. 0.01 $4 \mathrm{~m}$. Levels IV-III.

89. AT $/ 39 / 73$. White paste. Found in Sq. G I 6, Level III or later.

90. AT/46/73. White paste, $1.0 .029 \mathrm{~m}$. Found in Sq. L I 5 , Level III.

91. AT/39/59. Blue paste (imitation lapis lazuli), $1.0 .025 \mathrm{~m}$. From house site in Sq. L I2, Level III.

92. AT/39/1 32. Black steatite, 1. 0.0 I $5 \mathrm{~m}$. Found in Sq. K I 2 against the face of the Level III city wall. Level III.

93. AT/38/53. Dark steatite, much worn; $1.0 .025 \mathrm{~m}$. Above the Niqme-pa palace, Level III.

94. AT/39/I 8 I. White paste, l. $0.022 \mathrm{~m}$. Below a Level II floor, Level III.

95. AT/39/1 89. Scaraboid, paste, from grave 39/I, Level III. 
96. AT/37/105. Seal-impression on a lump of clay; imperfect, Level II-I.

97. AT/39/43. Brown steatite, $1.0 .02 \mathrm{~m}$. From Sq. G I 7, Level III.

98. AT/39/1 9 I. White paste, $1.0 .02 \mathrm{~m}$. 'Below Level II'. Level III.

99. AT/39/54. White paste, $1.0 .02 \mathrm{~m}$. From Sq. L I I, apparently belonging to grave $39 / 18$, Level II.

I00. AT/38/25в. White paste, $1.0 .018 \mathrm{~m}$. Above the Niqme-pa palace, Level II.

IOI. AT $/ 38 / 45$. White paste, $1.0 .019 \mathrm{~m}$. Above the Niqme-pa palace, Level II.

I02. AT/39/I63. White paste, $1.0 .027 \mathrm{~m}$. From grave $39 / 64$, Level II.

I03. AT/39/1 70. Black steatite, $1.0 .027 \mathrm{~m}$. Found in Sq. N I 2, below a floor of Level I. Level II-III.

I04. AT/39/188. White steatite, 1. $0.027 \mathrm{~m}$. From Sq. L i 3, Level II.

105. AT/39/16I. White paste, $1.0 .02 \mathrm{~m}$. Below the foundations of the Level III town wall. Level III or IV.

I06. AT/39/1 77. White steatite, 1. 0.01 $8 \mathrm{~m}$. From grave 39/70, Level II.

107. AT/37/96. Grey steatite, $1.0 .019 \mathrm{~m}$. From the house sites, Level II.

108. AT/38/1. White paste, $1.0 .017 \mathrm{~m}$. From grave I; probably Level II.

I09. AT/38/39. Grey steatite, $1.0 .02 \mathrm{~m}$. From above the Niqme-pa palace, Level II.

I IO. AT/38/I44. Green steatite, $1.0 .022 \mathrm{~m}$. Found under room 2 of the Level I house in Sq. $P$ IO, Level II.

I I I. AT/46/26. Grey steatite, $1.0 .022 \mathrm{~m}$. Found below the stone foundation of the Level I A wall in Sq. O I 2, Level II.

I I. AT/39/49. Grey steatite, $1.0 .022 \mathrm{~m}$. From grave 39/1 8, attributed to Level II.

I 3 . AT/38/10. Blue paste (imitation of lapis lazuli), 1. $0.022 \mathrm{~m}$. Found above the Niqme-pa palace, Level II.

I I 4. AT/38/I 54. Green steatite, $1.0 .027 \mathrm{~m}$. Found above the Niqme-pa palace (Sq. P I I), Level II.

I I 5. AT/38/233. Dark steatite, $1.0 .022 \mathrm{~m}$., very rough work. Level II.

I 6 6. AT $/ 38 / 42$. Dark steatite, $1.0 .026 \mathrm{~m}$. Found above the Niqme-pa palace, Level II.

I I 7. AT/38/23. Handled stamp seal, steatite, ht. $0.026 \mathrm{~m}$., diam. $0.014 \mathrm{~m}$. Found above the Niqme-pa palace, Level II.

I I 8. AT/39/167. White paste, $1.0 .016 \mathrm{~m}$. House 39/C, room I 5, Level II.

I 19. AT/47/3. Scaraboid, red steatite, engraved on both sides; the main design shows a bird and leaf (see Pl. LXVI), the other, a crescent, dots, \&c. Found in Sq. O I 5, Level II.

I 20. AT/37/22. Dark steatite, $1.0 .022 \mathrm{~m}$. House site, upper soil, Levels II-I.

I 2I. AT/37/27. White steatite, discoloured by fire, $1.0 .026 \mathrm{~m}$. House site, upper soil, Level II-I.

I 22. AT/37/9. White paste, 1. $0.025 \mathrm{~m}$. Between the houses and the city wall, Level II-I.

I 23. AT/37/I. Gable seal, dark steatite, $0.03 \mathrm{~m} . \times 0.02 \mathrm{~m}$. From the 1936 sondage, Level II-I. I 24. AT/38/247. Dark steatite, $1.0 .022 \mathrm{~m}$. Found in Sq. G I6, Level I.

I 25. AT/38/ 7 70. Chalcedony, $1.0 \cdot 032 \mathrm{~m}$. Found above the Niqme-pa palace (Sq. Q I I), Level I.

I 26. AT/39/ I 76. Green serpentine, with gold caps, $1.0 .02 \mathrm{~m}$. From grave 39/68, Level I.

I 27. AT/39/1 40. Grey-green steatite, 1.0 .027 m., very rough work. Found in Sq. K I 5, Level I.

I28. AT/37/4I. Carnelian, incomplete; roughly cut. House site, Level I.

I 29. AT/37/42. Scaraboid, grey steatite, $1.0 .022 \mathrm{~m}$. House site, Level I.

I 30. AT/37/82. Dark steatite, roughly engraved; 1 . О. I $5 \mathrm{~m}$. House site, in building of Level I в. I3I. AT/37/47. Scarab, paste, bearing the cartouche of Ramses VI. Found in grave 37/2, Level O.

I32. AT/38/22 I. Scarab (incomplete) of white paste, inscribed Amen-Re, dating after Tuthmosis III. Loose in top soil. 
I 33. Scaraboid, white steatite, 1. 0.0I $3 \mathrm{~m}$. Egyptianizing style with bird and hieroglyphs. Loose in the top soil.

I 34. Scaraboid, paste, $1.0 .012 \mathrm{~m}$., with squatting monkey in a cartouche; rough work. Loose in the top soil.

1 35. AT/39/68. Haematite; Egyptian style with illegible cartouche. Found only $0.60 \mathrm{~m}$. below ground surface in the ruins of the city wall, Sq. G I 6 .

I 36. AT/48/32. Black steatite, $1.0 .019 \mathrm{~m}$. Found in spoil-heap, level unknown.

I 37. AT $/ 48 / 76$. Haematite, 1.0 .02 I m. Found in spoil-heap, level unknown.

I 38 . AT/37/2 I 4. White paste, $1.0 .02 \mathrm{~m}$. Above the Niqme-pa palace; level uncertain.

I 39. AT/37/20. Dark steatite; fragmentary. Loose in upper soil.

I 40. AT/38/1 27A. Steatite, 1. 0.1 $8 \mathrm{~m}$; m much decayed. From grave ATG/38/5, Level I.

I 4 I. AT/39/1 7. Grey steatite, $1.0 .026 \mathrm{~m}$. Found in Sq. N I I, about I.40 m. from surface; level uncertain.

I 42. AT/38/24I. White paste, $1.0 .024 \mathrm{~m}$. Found in Sq. T 7, level uncertain.

I 43. AT/39/2. Grey steatite, $1.0 .02 \mathrm{~m}$. Found on the surface at the SE. end of the tell.

I 44. AT/37/65. Glazed paste, decayed; $1.0 .027 \mathrm{~m}$. House site, level unknown.

I $45^{-1} 5^{2}$. AT $/ 39 / 184$. A selection of fragmentary seal-impressions from Level VII. With the exception of No. I 52 they occur on envelopes from tablets in the Yarim-Lim palace. No. I 45 shows the seal of King Niqme-epuh son of Yarim-Lim with its perpetuation of Egyptian symbolism, seen also in I 46 and I 50 , whereas ${ }_{4} 8$ is markedly Hittite, and I 5 I, with the god holding a vase out of which come streams of water, is as markedly Mesopotamian. Mr. Wiseman remarks that one of the inscriptions confirms his restoration (The Alalakh Tablets, No. 444) of a shorter version of the text proving that Abban was the son of Hammurabi.

BULLA SEALS WITH HITTITE HIEROGLYPHIC INSCRIPTIONS

Mr. R. D. Barnett has kindly supplied the following notes on the few bulla seals found in the course of the excavations.

I 53. AT/8/ I 36 (B.M. I 26 I 86). Brown steatite seal, pierced diametrically, with two flat circular faces incised with curious signs, evidently an unknown script akin to the Hittite hieroglyphs. The signs, singly or in pairs, are separated from each other by hatched bars. In the centre is an ankh. Perhaps prototypes of later Hittite hieroglyphs?

From the $W$. wall towards $S$. corner, from a small drain in room $C_{3}$ of the Niqme-pa palace but belonging to Level $\mathrm{V}$.

Diam. $0.033 \mathrm{~m}$.

R. D. Barnett, A.F. xix (Jan. I 939), Appendix I.

Dr. Bedřich Hrozný, id., Appendix II.

I 54. AT/37/2. Seal impression in baked clay. A Hittite hieroglyph (unfortunately illegible on the photograph) at the centre is surrounded by a circle of triangles and other ornamental figures.

From surface close to trench $\mathrm{C}$.

Diam. $0.002 \mathrm{~m}$.

I 55. AT/39/322 (B.M. I 30647). White steatite bulla, circular, pierced diametrically. Convex on both sides. An incised line runs round edge. One side plain, the other incised with Hittite hieroglyphs, 'Pa-lu-wa, son of the king, lord of the land'.

From temple site, Level I-II, Sq. M I 5 .

Diam. $0.0039 \mathrm{~m}$.

I 56. AT/38/1 35 (B.M. I26I83). Bulla, circular, pierced diametrically, convex on both sides. 
Double incised line round edge. Inscribed with Hittite hieroglyphs on both sides, reading A-wa-tas. Grey steatite.

From palace site, above destruction level of palace, Level III, Sq. S I 2.

O.OI 9 m. high.

R. D. Barnett, A.7. xix (Jan. I 939), Appendix I.

I 57. AT/46/ I 2. Bulla, circular, pierced diametrically, convex on both sides. A double incised line round the edge. Inscribed with illegible Hittite hieroglyphs on both sides. Plumred stone.

From SW. corner of temple courtyard behind basalt threshold. Level I-II, Sq. N i 6. Diam. 0.024; thickness $0.015 \mathrm{~m}$.

I 58. AT/39/3 I 8. Cube-shaped seal, grey steatite. Design of meaningless criss-cross lines.

OI 2 XOI 2 XOI 2 .

From '39 Temple, Sq. N I 5, Level I.

I 59. AT/38/1 53. Bulla, circular, pierced diametrically. Convex on both sides. An incised line round edge. On one side, in Hittite hieroglyphs, $\mathrm{Nu}$-followed by a sign of eight strokes only once encountered before (Sultan. Han, iii. 2, Fahrb. für Kleinas. Forsch., I950, pl. xx), and another, triangle with two strokes, probably a title (three strokes are more usual: see Alp, Zur Lesung von manchen Personennamen auf den H. H. Siegeln und Inschriften, p. 22); on the other side, $w a+$ water bird $+a$ and two strokes.

From the top soil above the Niqme-pa palace.

I60. AT/37/3. Terra-cotta hammer-handled stamp seal in baked clay. Incised figure of a bird (?) and other signs, which are unclear.

Size: diam. O.O $5 \mathrm{~m}$.

Found on the surface, below the tell.

I6 I. AT/39/38. Terra-cotta seal inscribed in Hittite hieroglyphs: 'the king's son, Pa-lu-wa+ ideogram'. The ideogram (cf. AT/ I 42 below) is usually taken as meaning 'gave', 'dedicated', and is thought perhaps to have the value of $p a$ or $p i$ forming a compound name. The name on this seal is clearly to be connected with that of I 55 .

Size: diam. $0.02 \mathrm{~m}$.

From upper soil, level doubtful.

I62. AT/37/105. Seal impression in baked clay with hieroglyph not previously recorded, enclosed in a circle.

Size: $0.025 \times 0.023 \mathrm{~m}$.

From upper soil, level doubtful.

I63. AT/37/ I 42. Seal impression in baked clay with three signs, $\Delta \Omega \mathbb{Z}$. The second sign occurs on an impression from Boğaz-köy, Güterbock, Siegel aus Bogazköy, ii. 88, 89. The first perhaps is $l u$, the third is an ideogram = 'to give'.

Size: $0.027 \times 0.020 \mathrm{~m}$.

From upper soil, level doubtful.

I64. AT/37/IOI (B.M. I 2607 I). Seal-impression in baked clay. Inside a ring of decorative patterns are five signs with 'tag' indicating a personal name. The first sign, consisting of three strokes, is usually an ideogram meaning 'chieftain', but when combined with a tag to the right (value $r$ ) is read as tar or ter, recalling Latin tres 'three'. This, however, does not justify us in giving the three strokes without tag the value te or $t a$. The name therefore should be read chiefTAin-qa-nu-ha-pa. Several names thus compounded with that of the goddess Hepa are known, especially from Hurrian milieux.

Diam. $0.015 \mathrm{~m}$.

From the main street, Level II.

R. D. Barnett, A. F. xix (Jan. I939), p. 34 . 
STAMP SEALS

The stamp seals that follow are of small interest but can scarcely be omitted. All are of late date.

165. AT/48/10. Black steatite, with lightly scratched design. Level IV temple.

166. AT/37/30. Steatite. From a Level II house floor.

167. AT $/ 37 / 158$. Baked clay, very roughly made. Upper soil above the Level IV palace.
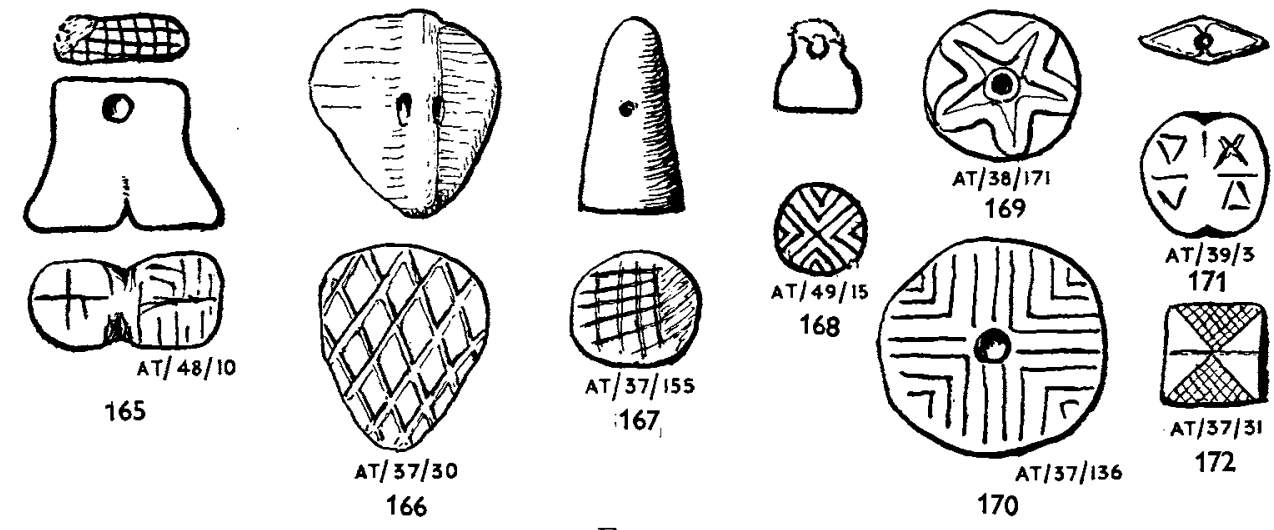

FIG. 72

I 68. AT/49/ i 5. Steatite; the loop broken. Upper soil, unstratified.

I 69. AT/38/1 7 I. Steatite; flat button-shaped with hole through centre, perhaps a button rather than a real seal. Below Level I, Sq. P I 2.

1 70. AT/37/1 36. Black baked clay with hole through centre, but the top is convex and has a second, loop-bored, hole. Level II.

I 7 I. AT/39/3. Grey steatite, gabled. Surface soil. Sq. I I I.

I 72. AT/37/3I. Dark green steatite with pierced knob handle like No. I48. Level II, house site.

\section{(b) THE BEADS AND AMULETS}

VERY many beads were found, and the range both of shapes and of material is wide (see P1. LXVIII $a$, but their historical value is less than might have been expected. The vast majority were found in graves, and since no early graves were discovered practically all the beads belong to the later levels, VII to I. Because they came from graves very many of the groups could be dated, by the position of the graves or by the pottery in them, and it was possible to attribute about sixty sets of beads, including virtually all the types, to successive levels covering the period from the eighteenth century to the beginning of the twelfth century B.c. That is a long period, and it is disconcerting to find that, as the figures on the type-list show, most of the types persist throughout the whole of it, or at least from Level V to Level I, and if they do not appear in Levels VII and VI it is probably only because very few graves and very few beads of any sort came from those levels. It is noteworthy that No. 7, the double conoid, which was by far the most popular type of bead in the Royal Cemetery at Ur, i.e. in Sumer about 2700 B.c., and characterizes at Ras Shamra the period Ugarit Moyen I, 2 100-I 900 B.C., ${ }^{1}$ occurs at Atchana as late 
as Level IV (fifteenth century) but not later-and as Levels III, II, and I between them account for more than half the total of beads the negative argument is in this case not indeed conclusive but at least significant. The multiple ring bead (No. 22) also stops short at Level IV, and it, too, has been recognized as an early type. ${ }^{1}$ On the other hand, the polychrome glass eye bead (No. 25) and the handled ball (No. 26), of polychrome glass, occur only late, in Levels II and I, and this would seem to accord with evidence from other sites. ${ }^{2}$ But the bead of polychrome glass other than the 'eye' bead comes as early as Level VII, examples being found in the temple of that period, and a ball bead of grey glass inlaid with white quatrefoils, AT/47/60, Fig. 74, ro, found in Sq. O I 3 , belongs either to Level VI or, less probably, to Level V.

The open-work 'hub' bead No. 28, in glazed frit, ${ }^{3}$ often associated with Mycenaean objects, would normally be assigned to the Late Helladic III period, I 425-I 230B.c. (according to Furumark; but for the terminus ante quem see my comments on pp. 3745), but the Atchana examples give a wider time range in that they go from Level I back to Level V, that is, to the sixteenth century and down to I I 90 B.c.; this does not, of course, in any way upset the dating of the Mycenaean specimens but does mean that the bead type cannot be used with such confidence as dating evidence on non-Mycenaean sites. ${ }^{4}$ Roughly made beads (or amulets) in the form of birds, in crystal, veined marble, and carnelian (AT/37/I 32, Pl. LXVIII b) were found in a ruined child's burial of Level I-or possibly of Level O. They closely resemble the faience bird beads from Brak and Chagar Bazar which are very much earlier in date.

On Pl. LXVIII are shown those types of beads which are either more common or difficult to describe adequately in words alone. The list exhausts practically all the shapes used, but there are variants such as flattened, square-section, and triangular-section dateshaped (No. 9), or striated lozenge-shaped (No. 8), or flattened barrel-shaped (No. 5).

I. Ball beads; found in every level from X to I. Materials, limestone, steatite, carnelian, chalcedony, banded sard, quartz, pebble, lapis lazuli, gold, copper, amber, lapis paste, glass paste, glazed frit, and variegated glass.

2. Striated balls. Levels III and II. Lapis paste, steatite, glazed frit.

3. Fluted balls or nasturtium-seed beads. Levels VII, V, IV, II, and I. Gold, glass paste, glazed frit.

4. Oval. Levels V and IV. Glazed frit.

5. Barrel-shaped. Levels V, IV, III, and II. Carnelian, agate, pebble, and paste imitation of agate.

6. Faceted oval. Level II (?). Carnelian.

7. Double conoid. Levels V and IV. Chalcedony, glass. Fluted variant. Level V. Glazed frit.

8. Lentoid or lozenge-shaped. Levels IV, I. Carnelian: flattened variant. Level X. Agate.

9. Date-shaped. Levels VII, V, IV, III, II, and I. Chalcedony, carnelian, steatite, sard, crystal, glazed frit. Striated examples in frit.

I It occurs in the Jamdet Nasr period at Brak; v. Iraq, Ix. ii, Pl. Lxxxiv, 2.

2 e.g. at Talyche, in Late Bronze 2-3, I450-I 200 B.C.; Schaeffer, 1.c., Fig. 227, 39, 4 I.

3 Sometimes in yellow glaze, looking as if they were copies of gold beads such as the example found in Tomb 2 at Mycenae by Schliemann; cf. A. J. B. Mace, 'Chamber Tombs at Mycenae', Archaeologia, lxxxii, I932, Pl. Ix.

4 e.g. in the Transcaucasus; $v$. Schaeffer, op. cit., P. 5 I 4. 
Io. Spindle beads. Levels $V$ and IV. Pebble.

I I. Cylindrical. Levels VII, V, IV, and II. Chalcedony, carnelian, steatite, quartz, serpentine, glazed frit, glass paste, lapis paste.

I 2. Tubular. All levels from VII to I. Gold, copper, quartz, red steatite, glazed frit, glass.

I 3. Square-section tubular. Level I. Shell, glass.

I 4. Tubular spacer beads. Levels V, IV, II, and I. Red steatite, frit, glass.

I 5. Rings. All levels from VII to I. Black or white steatite, carnelian, lapis lazuli, glass paste, frit. Rings differ much in size and are often very small.

I6. Cog-wheel beads. Levels Y, IV, and I. Glazed frit.

I 7. Spoked-wheel beads. Level III. Glazed frit.

I 8. Disk or plate beads. Levels V, IV, II, and I. Black and white onyx, limestone, glazed frit, white paste, amber.

I 9. Diamond-shaped. Level uncertain, late. Paste.

20. Cubes. Level VI, and uncertain late. Serpentine, paste.

2 I. Petalled tubular. Level II. Glazed frit.

22. Multiple ring beads. Levels $V$ and IV. Glazed frit.

23. Ovate. Levels II and I. Carnelian, glass.

24. Scaraboid (these show all stages of degeneration from real scarabs to the form here drawn). Levels VII, V, IV, III, and I. Glazed frit, glass paste.

25. Eye-beads. Levels II, I. Variegated glass, glazed frit.

26. Handled balls. Level X (gold). Level II. Variegated glass, glazed frit, shell.

27. Dumb-bell or figure-of-eight beads. Levels V, IV, I. Glazed frit.

28. Hollow hub beads. Levels V, IV, II, and I. Glazed frit.

\section{AMULETS (P1. LXVIII $b$ )}

I use the term 'amulets' without prejudice for the various small pendants attached to bead necklaces or otherwise worn either purely as ornaments or with some religious or magical significance. The distinction is difficult to draw. A plain metal disk pendant, such as is described below in the section on precious metals (v. p. 274), is surely nothing but an ornament; when it has impressed on it the sexual triangle (No. 14) it must as surely possess an amuletic character; but the form is identical in the two cases. Whether the animals roughly moulded in glazed frit are religious symbols or not it seems to me impossible to say; even where the same animals are used in other countries, such as Mesopotamia, and have there a definitely amuletic value, it does not follow that such is the case in north Syria, for the form may well be imitated for its own sake and without regard to its original content, just as the Egyptian scarab was imitated because it was popular in Egypt and for no more esoteric reason.

On a necklace from a Level III grave (ATG/39/48) there were six fly pendants and two hedgehogs, all in glazed frit; an isolated hedgehog (or porcupine?) was found in Sq. O I O in the Level VI-V stratum. There were several frogs, which are not represented according to the Mesopotamian convention; one, AT/37/ I 79, came from a late but undated grave $\mathrm{ATG} / 37 / 32$, and another, $\mathrm{AT} / 39 / 57$, also from a late but undated grave ATG/39/20; this in green glaze. A ram's head of white paste with grey-black eyes, $\mathrm{AT} / 37 / 83$ (No. 8), was found loose in the soil between Levels I в and II; another, $\mathrm{AT} / 38 / 28$ (No. 7), was from Level II, and a third, roughly made in frit, AT/39/80, 
came from a Level IV grave, $A T G / 39 / 30$. What may have been meant for a rabbit, in pale green glazed frit, AT/49/1 9, was from a Level V grave; a tortoise (?), AT/39/2 I 8, could by its position have belonged either to Level II or to Level III. A figure of a crouching lion carved in haematite, ht. $0.02 \mathrm{~m}$., broken, AT/37/1 47, came from the Level III stratum; a bronze head, perhaps of a pig, $1.0 .02 \mathrm{~m}$., was from Level V.

A glazed pendant in the form of a pomegranate, AT/39/27 I (No. 9), came with beads from a Level V grave, ATG/39/1 I0. AT/37/193 (No. 3) was a thistle-head pendant in yellow and blue glazed frit, 1. 0.02 I m., a characteristic piece of Egyptian glaze of the Tell et Amarna type; it was found against the foundations of a Level I wall and should therefore belong to Level II, which would be consistent with the date given to the Level II period.

$\mathrm{AT} / 47 / 170$ (No. 2), a vase-shaped pendant carved in grey steatite, was found in the castle, in the Level VI stratum. From Levels VI-V comes a green-glazed frit circular pendant with a dotted cross in the centre, AT/39/309 (No. 4), which is reminiscent of the metal disk pendants described elsewhere. $\mathrm{AT} / 39 / \mathrm{I} 2 \mathrm{I}$ (No. I), a leaf-shaped pendant in green steatite, was from the Level $\mathrm{V}$ house 39/B, and AT/38/165 (No. 5), also of steatite, was from Level I. The curious bugle-shaped pendant in white paste, AT/46/93 (No. 6), found with a few beads in Level II, should certainly be more than merely ornamental.

\section{SP INDLE-WHORLS}

If I devote a special section of my text to spindle-whorls I do so with apologies; my object is simply to clear the ground as expeditiously as possible of a mass of material of no great interest which would otherwise obtrude unduly. The scientific importance of spindle-whorls has been very much exaggerated. Their occurrence in early strata is, of course, a matter to be noted carefully as evidence of the ind ustries of a primitive people; but in later periods they are inevitable, and it is fairly safe to say that they show no ordered development of form or decoration. I suppose that it was Schliemann who first brought the spindle-whorl into prominence - a venial error in his case, but today there is no excuse for wasting space and money on this monotonous and profitless material. At Atchana spindle-whorls were found in very great numbers; they were found at all levels; the vast majority are plain; decorated examples are fairly common and belong to very different periods; the designs on them are more or less dictated by the form of the object-i.e. they either radiate from the centre or run parallel to the edges; where the same design occurs on more than one example the simple explanation seems to be that the whorls in question were found in the same building and presumably belonged to sets which were made for the same person. Whorls were made of baked clay (most common), steatite, bone, and glazed frit; in bone and steatite the plain conical form is the most usual, in baked clay the roughly biconical; decoration is for the most part reserved for those of the better materials. Decorated examples are illustrated on PI. LXVIIIc.

I In his Troy and its Remains thirty-two plates as well as a dozen or more cuts in the text are devoted to whorls. 


\section{CHAPTER X}

\section{(a) GOLD AND SILVER OBJECTS}

\section{P1. LXIX}

$\mathrm{N}$

o large objects and no great amount of precious metal was found, most things in gold or silver being small objects of personal adornment coming either from the house ruins or from graves; the main interest of them was really that of their technique.

It could in any case be safely assumed that such small objects-rings, ear-rings, pendants, beads, \&c.-were produced by local goldsmiths working exactly as do the goldsmiths in the sûk of any modern oriental town; in fact the assumption is unnecessary in view of the material evidence discovered. In room 5 of the Level I house $37 / \mathrm{B}$ there was a small hoard which constituted the working stock of a jeweller; a number of gold bars, $0.075 \mathrm{~m}$. long and $0.003 \mathrm{~m}$. thick, folded in half, round lumps of molten gold several of which had had bits snipped off them, and two pairs of gold ear-rings, of the types of Pl. LXIXj and $u$ respectively, AT/37/29. In the same level was found a small clay pot containing a quantity of silver and bronze, part of which had been melted down, part cut into strips for melting, and with this a few ear-rings, perhaps scrap metal. From Level II came a fragment of a stone mould (AT/39/I 50) for making ear-rings. From room C 8 of the Level IV Niqme-pa palace came the jeweller's mould AT/47/I 39, the two sides complete (Fig. 73), part of one side of a second mould AT/47/I 47 (Fig. 73), and one side of a third mould AT/47/ I 46, which was actually unfinished; either the goldsmith made his own moulds or the room was the workshop not of a jeweller but of a mould-maker. From Level V (in a rubbish-pit on the house 39/B site) came a bronze crucible, AT/39/I 43 (Fig. 73), which judging by its small size (diam. $0.02 \mathrm{~m}$., depth $0.03 \mathrm{~m}$.) must have been used for precious metals. From the Level XIV temple came half of a grey steatite mould AT/49/I I (Fig. 73).

The Alalakh goldsmith was reasonably expert and was familiar with the techniques of cloisonné, filigree, granulation, casting, and repoussé work, and with the making of very thin gold foil for application to a base of another material. The following examples will illustrate the different processes.

$\mathrm{AT} / 37 / 22 \mathrm{I}$. Ball bead, diam. O.OI $3 \mathrm{~m}$., of cloisonné work; scale pattern set with lapis lazuli and green and yellow stones. Pl. LXIX $a$. Level IV, from room 6 of the Niqme-pa palace.

$\mathrm{AT} / 38 / 52 \mathrm{~A}$. Gold roundel, diam. $0.03 \mathrm{~m}$., decorated with filigree work in gold wire; two concentric bands of joined spirals and a border of plaited pattern. Pl. LXIXd. Level I; from grave $\mathrm{ATG} / 38 / 2$.

$\mathrm{AT} / 37 / 204-5$. One complete and one fragmentary piece of tubular plating (for a staff?), $1.0 .024 \mathrm{~m}$., diam. $0.016 \mathrm{~m}$., decorated with a chevron pattern in very fine granulated work (each band of chevrons is made up of two lines of grains). Pl. LXIX $b$. Level IV, from the courtyard of the Niqme-pa palace. 
AT/38/103. Gold tassel (?) shaped as a fir-cone (it may be meant to be a fir-cone, as apart from the triangular decoration there are overlapping scales worked in the gold) enriched with rows of small triangles in granulated work; Pl. LXIXe. Level IV; from room i 6 of the Niqme-pa palace.

$\mathrm{AT} / 46 /$ I $8 \mathrm{I}$. Gold brooch (?) or other ornament; a tube with a disk in the centre; $1.0 .076 \mathrm{~m}$., the whole front covered with granulated work. Pl. LXIXf. Level V; from a rubbish-pit in the temple area.

AT/37/200c. Gold setting for a stone (?) with a border of granulated work. Level IV, from room 6 of the Niqme-pa palace.

AT/38/224. Gold ear-ring, Pl. LXIX $h$, with granulations round the ring and on the pendant. - From grave $A T G / 38 / 23$; date uncertain, but not later than Level IV.

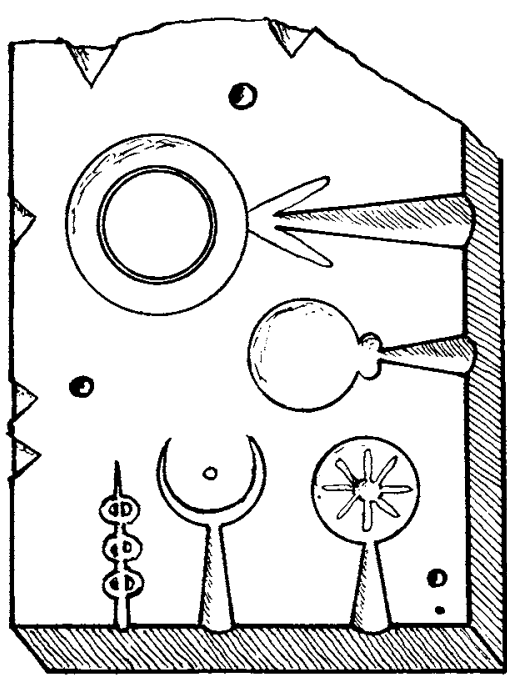

AT/47/147
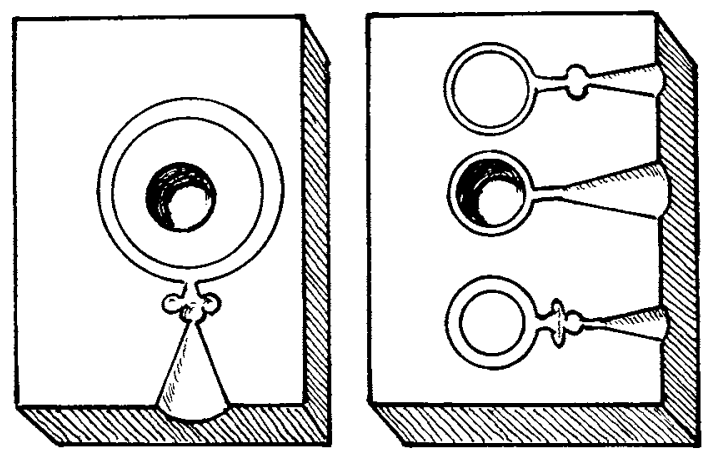

AT/47/139

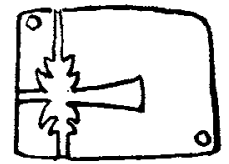

AT/49/11

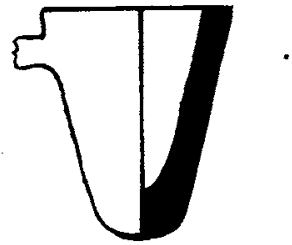

AT/39/143

FIG. 73

AT/39/9 I (I0). Two gold ear-rings, not quite alike, similar in type to AT/38/224, with granulation round the ring and on the pendant; Pl. LXIXg. From grave ATG/39/35, attributed to Level IV.

AT/39/98 (I). Gold ear-ring; a hoop open at the top and decorated with three minute balls at the base; Pl. LXIXj. This type of ear-ring was much favoured, but since real granulated work required time and skill a cheaper version having more or less the same effect was produced by direct casting. The mould AT/47/147 (Fig. 73) makes an ear-ring of precisely the same sort as this; other examples in gold were found, and some in silver and in bronze. From grave ATG/39/45, attributed to Level IV.

$\mathrm{AT} / 37 / \mathrm{I} 6$. Two gold ear-rings exactly like the last. From grave ATG/37/163; date uncertain, but either Level II or Level I.

$\mathrm{AT} / 38 /$ I 27 . Four silver ear-rings exactly like the last. From grave ATG/38/5; Level I.

A cast imitation of granulated work was, of course, possible only when the object was of more or less solid metal; where thin sheet gold was employed a granulated effect could be produced by a dotted pattern made by hammering or pressing with a pointed tool, generally on the back of the sheet. 
$\mathrm{AT} / 37 / 200$ A. Gold roundel, diam. 0.01 $5 \mathrm{~m}$., very thin metal, with embossed centre and round the rim dotted triangles giving a petalled flower effect. Level IV; from room 6 of the Niqmepa palace. Pl. LXIXn.

$\mathrm{AT} / 39 / 209$. Gold pendant, a roundel, diam. O.0I $4 \mathrm{~m}$., with rolled tang for the suspension-ring; thin metal; a central raised boss from which radiate six repoussé rays having smaller bosses between them; round the bosses and round the circumference of the roundel small dots imitating the effect of granulated work. Pl. LXIXq. Sq. L I 3, Levels IV-III.

$\mathrm{AT} / 37 / \mathrm{I} 66$. Gold pendant; a roundel, diam. $0.015 \mathrm{~m}$., slightly convex, with tang rolled for suspension; embossed on it a row of dots and a linear design (imitating filigree work) like a Cretan lily. Pl. LXIXm. From 37 house site, room 6, Level IV.

Simple designs were often impressed, a chisel-shaped tool and a hammer being used for the purpose on the front of the metal.

$\mathrm{AT} / 37 / 46$. Gold pendant; a roundel, diam. $0.017 \mathrm{~m}$., with rolled tang for suspension, impressed with a 'Union Jack' design; Pl. LXVIIIn. From the cremation-burial ATG/37/2, Level I.

$\mathrm{AT} / 39 / 282$. Gold pendant, oblong, ht. $0.02 \mathrm{~m}$., width $0.009 \mathrm{~m}$., with rolled tang for suspension; impressed with an ankh design. Pl. LXIXw. From Sq. K I 4, Level V.

$\mathrm{AT} / 46 / 7$. Gold pendant, pentagonal, ht. $0.015 \mathrm{~m}$., with rolled tang for suspension, impressed with a truncated triangle. From Sq. $\mathrm{N}$ i 6 , Level II.

$\mathrm{AT} / 39 / 24$. Silver pendant, oval, $1.0 .03 \mathrm{~m}$., with rolled tang for suspension, impressed with a triangle and line above, perhaps the vaginal triangle (cf. the last, AT/46/7); Pl. LXVIII. From grave $\mathrm{ATG} / 39 / 8$; date uncertain but late.

$\mathrm{AT} / 38 / \mathrm{s} 40$. Gold pendant, roundel, diam. 0.0 I $5 \mathrm{~m}$., with rolled tang for suspension; plain. Similar pendants in silver and in copper were fairly common (e.g. for copper, AT/38/37 and 283 ). They were found at various levels from IV upwards.

$\mathrm{AT} / 48 / 7 \mathrm{I}$. Gold spangle for sewing on to a dress; oval, $1.0 .0 \mathrm{I} 3 \mathrm{~m}$. with central hole for the thread; at either end a rayed disk, impressed; Pl. LXIXp. Date uncertain; from the temple site.

$\mathrm{AT} / 37 / \mathrm{I} 6 \mathrm{I}$. Gold ornament, lozenge-shaped, $1.0 .0225 \mathrm{~m}$., with a central boss and framed border of dots in relief (impressed from behind). Pl. LXIXs. From the 1937 house site, date uncertain.

AT/39/103. Gold pendant in the form of an inverted crescent, with rolled tang for suspension; diam. 0.01 m., Pl. LXIX $t$. From Sq. H I 7, Level IV. Pendants of the same form were found in silver, copper, and glazed frit (the last in grave ATG/39/35, attributed to Level IV); a silver example, AT/39/2 I 2, came from a late (post Level IV) grave, not exactly dated, and copper examples from Level I (AT/38/2 I 5) and Level III (AT/37/70).

Most of the finger-rings found were of silver, mere hoops of plain metal, usually quite thin; some were of copper. One of the latter (AT/39/ I 78, from house 39/C, Level IIIII) had a large flat bezel obviously intended for a seal but actually not engraved; another, $\mathrm{AT} / 3^{8} / 5^{2 \mathrm{G}}$, had a small ball soldered to the hoop. Three rings call for special notice:

$\mathrm{AT} / 37 / \mathrm{I} 65$. Gold finger-ring, diam. $0.015 \mathrm{~m}$., width $0.005 \mathrm{~m}$. Made of a strip of metal the edges of which have been rolled over to form a raised beading; on the flat band between them are two rows of embossed dots. From grave ATG/37/36, Level IV.

$\mathrm{AT} / 3^{8} / 5^{2 \mathrm{~F}}$. A composite ring formed of a plain gold hoop between two silver hoops; the only instance found of the two metals being used in combination. From grave ATG/38/2, Level I.

$\mathrm{AT} / 3^{8 / 22} 3$. Gold ring made from a rather wide strip of gold the edges of which are rolled back so that the ring looks as if made of two hoops soldered together. Pl. LXIXr. From grave ATG/38/24, not accurately dated but not later than Level IV. 
Plain ear-rings were common, usually made of silver and usually of lunate form; a gold example is AT/37/29, Pl. LXIXv, from grave ATG/39/68, Level I. The type is apt to degenerate into a mere twist of wire not perceptibly thickened in the centre. Occasionally the ear-ring is enriched by having a bead pendant, e.g.

$\mathrm{AT} / 37 / 28$. Gold ear-ring; a penannular hoop thickened in the centre and with pointed ends having in the centre a stoppered pendant whereon was strung a ball bead of blue paste; the total length of the ear-ring is $0.026 \mathrm{~m}$. Pl. LXIX $u$. The jeweller's mould AT/47/147 produces an ear-ring of precisely this type. Fig. 59. From the 1937 house site, Level I, room 2.

$\mathrm{AT} / 37 / 33$. Gold ear-ring identical in type with the last and also decorated with a blue bead. From the cremation-burial ATG/37/2, Level I. Silver examples were found in Sq. J i 5, Level IV $(\mathrm{AT} / 39 / 278)$.

$\mathrm{AT} / 3^{8} / \mathrm{I} 63^{\mathrm{A}}$. Pair of gold ear-rings like the last but more elaborate, there being three blue beads strung on each pendant; Pl. LXIXk. From grave ATG/38/io, Level I.

In proportion to the vast number of beads found the gold beads were surprisingly few. Almost always they were of very thin metal over a core, and usually in the form of ribbed or fluted balls; such occur as early as Level VIII (AT/49/7), in Level VI (AT/47/72), and in graves of Level IV (ATG/39/35), Level III (ATG/39/7 I), and Level I (ATG/ $37 / 2$ ). A very small ring-bead of solid gold (AT/47/65, Pl. LXIXo) came from Level $\mathrm{VI}$; it looked as if it might have been made by soldering pellets together in a circle.

AT/38/I I 5. A circular belt-buckle, diam. $0.077 \mathrm{~m}$., Pl. LXIXc. The buckle is made of a round plate of bronze with three loops behind for fixing it to the belt; the centre is silver-plated, plain except for a central boss and one impressed circle; round the edge is a band of cloisonné work inlaid with red and other coloured stones cut petal-shaped. Level IV; found in room I 6 of the Niqme-pa palace.

Much of the gold found was very thin gold leaf used as enrichment on some other material such as ivory or wood. One example of chryselephantine work was preserved (v. p. I 22, AT $/ 38 / 79, \mathrm{Pl}$. LXXVII) and three other gold cruciform rosettes of the same sort were found detached from the ivory. Very occasionally the gold foil retained something of the impression of an original pattern-e.g. rows of concentric circles-or was shaped as part of a design; but nearly always it was plain foil presenting no interest whatsoever.

A number of silver pins were found, of the same types as those of bronze.

\section{(b) METAL TOOLS AND DOMESTIC INSTRUMENTS}

\section{BRONZE OBJECTS}

The vast majority of the bronze objects found were tools and weapons, which can best be dealt with by their types. A few unusual or unique things, illustrated on Pl. LXX, call for special attention.

The four figurines possess no claim to artistic merit. They are crudely modelled and lacking in detail, but they do belong to different types all of which are fairly familiar as 
museum pieces purchased from Syrian dealers; but whereas the tendency has been, in the absence of any trustworthy dating evidence, to class them as 'Syro-Hittite', we have here specimens which can be assigned to definite periods all earlier than the SyroHittite age.

AT/38/277. A god borne by an eagle. The god, wearing a high pointed cap, stands, with both arms extended, on the back of the bird, which is represented as in full flight, the wings extended. Below the bird is a heavy pin for insertion in some sort of socket. Total ht., $0.07 \mathrm{I} \mathrm{m}$. Found on the floor of the Level VII town gate.

$\mathrm{AT} / 39 / 67$. Only the head and arms of the figure are represented, the rest of the body being reduced to a simple straight peg. The figure is that of a god wearing the high pointed crown, the ears are pierced to take copper wire ear-rings (one of which survives), the nose is long and sharply pointed, the eyes are rendered by pellets; the left arm is extended, the right bent forwards across the body. Ht. $0.12 \mathrm{~m}$. From Level $\mathrm{V}$, in the neighbourhood of the town gate.

$\mathrm{AT} / 47 / 42$. Figure of a goddess. She stands upright, her hands clasped over her breast; she wears a long plain garment reaching to the ground and letting only the feet appear, but the pubic triangle seems to be shown outside the dress. A V-shaped band over the shoulders is probably a necklace. The hair is dressed into a peak and projections at either side of the head may be the ears but may be heavy side curls. The features of the face are strongly and coarsely rendered. Ht. $0.065 \mathrm{~m}$. From the Temple area, Sq. P i 5 , Level V.

$\mathrm{AT} / 39 / 305$ is certainly a ritual object. It is a socketed spear-head, $1.0 .42 \mathrm{~m}$., the base of the blade proper being gripped by two lions moulded in the round. The addition of the animal figures is entirely against the practical use of the weapon; but it is curiously reminiscent of the wellknown 'Dagger God' of the Yasilikaya rock reliefs. The object was found on the floor of the Level I temple, but there is, of course, no saying for how long it had been preserved in the temple. It could be associated either with the divination-tablet of Boğaz-köy type which belongs to the temple of Level III or with the Tutkhaliya relief of Level II; in either case we have good warrant for asserting the Hittite connexion which the Yasilikaya resemblance suggests.

AT/36/4. This sword (it should be called a sword rather than a dagger, since it is half a metre in length overall) was found in our trial trench of I 936 above a Level II floor; it could belong either to Level II or to Level I, but the latter is the more likely. Except for the inlay of the hilt the weapon is intact and extremely well preserved; its outstanding feature is the lunate handle which seems to be a very late survival of an early type-it is found in the Royal Cemetery at Ur (Royal Tombs, Pl. I 54b), a fairly close parallel occurs in Egypt in the XIIth Dynasty (Petrie, Tools and Weapons, Pl. xxxin, D 4) and another fairly close parallel at Alaçahuyuk, all much older than our example; Schaeffer (Stratigraphie Comparée, Fig. 233) cites one from Lenkoran which might be contemporary, but the blade is of an entirely different type.

$\mathrm{AT} / 38 / 274$. Bronze pin (?) with ribbed stem and seven-rayed star head. Several of these were found, at different levels but not of the latest periods; one came from the Level VII city gate, one (AT/39/307) from room 24 of the Yarim-Lim palace, one (AT/48/88) from grave ATG/48/I, attributed to Level VII, another having eight instead of seven rays $(\mathrm{AT} / 48 / 53)$ is from the temple site, Levels VI-V and AT/49/2 I is from grave ATG/49/7, Level V.

$\mathrm{AT} / 38 / 200$. Part of a flat-bladed bronze implement having a handle in the form of a duck's head; 1. (as preserved) $0.082 \mathrm{~m}$. From room C 7 in the Niqme-pa palace, Level IV.

AT/49/20. Bronze pin (?) or ornament of unusual form, 1. $0.16 \mathrm{~m}$., from grave ATG/49/1, Level $\mathrm{V}$. 
Two bronze torques were found. One, AT/37/ 1 26, was of thin copper or bronze wire of uniform gauge round each end of which was wound a spiral coil of thinner wire brought to a loop to make the fastening. This came from Level II-I. A second (fragmentary) example, also of thin metal (AT/46/324), had the ends hooked over in the fashion normal with torques and was slightly thicker in the middle than at the ends; this was from a grave, ATG/46/1 5, attributed to Level VI or V. No examples of heavy torques were found.

The bronze vessels are illustrated on Pl. LXXIV; they were not numerous and generally not important. The most interesting is the little tripod base $\mathrm{AT} / 37 / 8$, which is quite characteristic of the Lake Van metal-work and shows early trade connexions between Alalakh and the Urartu region; parallels to this and to the large tripod cauldron AT/39/1 42 occur in the Aegean.

AT $/ 38 / 62$, ht. $0.065 \mathrm{~m}$, comes from room I 5 in the Level IV palace.

$\mathrm{AT} / 38 / 72$, diam. $0.195 \mathrm{~m}$., is from room 6 of the same palace.

AT/38/7I, diam. $0.18 \mathrm{~m}$., damaged and with a patch riveted on to its side, is from room 16 of the Level IV palace.

AT/46/4 I, a strainer (fragmentary), diam. $0^{\circ} \mathrm{I}_{4} \mathrm{~m}$., is from Sq. M I6, Level II.

AT/ $39 /$ I $_{4}$, total ht. $0.37 \mathrm{~m}$., has forked handles whose base-plates straddle the rim. It comes from room 7 of the Level VII palace.

AT/ $38 / 5^{2}$, ht. 0.07 m., comes from grave ATG $/ 38 / 2$, Level I.

AT $/ 37 / 8$, ht. $0^{\circ} \mathrm{I} 2 \mathrm{~m}$., from Site $\mathrm{H}$, was not accurately dated but probably belongs to Level IV or $\mathrm{V}$.

Apart from these, a hemispherical lead bowl, diam. $0.1 \mathrm{I}$ m., AT/46/68, was found in Sq. L I 5, Level III, and a shallow lead saucer, diam. 0.095, AT/37/ 43 , was found in the surface soil, undated.

\section{SPEAR-AND ARROW-HEADS}

\section{Pls. LXXI-LXXIII}

While certain metal blades are obviously spear-heads and others are as obviously arrow-points, there are many which it is difficult to assign to one category rather than to the other. A light throwing-javelin is not very different from an arrow; and arrows may be of many sorts according as they are intended for war, for the shooting of big game, or for the shooting of small birds, \&c. This practical consideration accounts for the fact that several different types of arrow-points are in normal use at the same time and for the fact that many seem to be on the border-line between arrows and spears. In drawing up the type-shęet on Pls. LXXI-LXXIII I was obliged to make a somewhat arbitrary distinction; where a blade seemed too long or too heavy for an arrow to be shot from a bow I have called it a spear; the shorter and lighter blades (which may differ very little in shape) I have classed as arrows; it is a matter of convenience only and I do not claim any finality for the arrangement.

Of spear-blades the two main categories are the socketed and the tanged. Type Sp. I, with its very long square-section blade, recalls the Sumerian 'poker-spear' but differs 
from that in being socketed instead of tanged; it is perhaps a butt rather than a point, as may be the curled Sp. 5 which I include amongst the spears on this supposition. The socketed types tend to be early; Sp. I is from Level IV, Sp. 2 is very late-it was found in the top soil above buildings of Level I-but Sp. 3 occurs in Level IV and twice in Level VII. I Of the tanged types Sp. 7 is found in Level I only and Sp. I I also is late; the rest have a vaguer floruit from Level IV onwards.

Arrow-heads can be distinguished technically as having a blade which is either flat or very gently curved, i.e. showing no pronounced medial line, as having straight sides sloped up from the edges to a sharp medial line (e.g. Ar. 6 and 8), or as having a more or less flat blade strengthened by a central rib. Across this division cuts a second distinction, that of form, whereby the blade is roughly leaf-shaped and simple or is provided with barbs. On the whole the barbed types tend to be the later; Ar. I 6 occurs once in Level IV (otherwise in Levels I and II), but the rest come in Level III at the earliest and are more characteristic of Levels I and II. All the simple leaf-shaped types are fairly distributed between Levels I and VII except that the long thick-headed Ar. 5 comes only in Level IV or just afterwards.

The SCALE ARMOUR is interesting because of its early date. One set, AT/37/37, is from Level I в and therefore can be compared with illustrations in the tomb of Ramses III, but $A T / 38 / 137$ was found in the ruins of the Level IV Niqme-pa palace, not at floorlevel but in the debris $0.50 \mathrm{~m}$. below the top of the standing walls, and must therefore belong to the time of the destruction of the building; this would make it nearly contemporary with the earliest example (temp. Amenhotep II) cited by Petrie ${ }^{2}$ from Egypt, to which country scale armour was imported from Asia.

Precisely similar scale armour is found in Level I at Nuzi ${ }^{3}$ which Starr would date after 1475 B.c. and H. W. Eliot would put earlier, as ending in 1475 . At Ras Shamra they belong to the period Ugarit Récent II, $1450-1365$ B.c. The dating evidence therefore is gratifyingly harmonious.

\section{DAGGERS AND KNIVES}

Kn. I-6, having two cutting-edges, may fairly be classed as daggers, while the singleedged types Kn. 7-I I are knives. With the exception of Kn. I, of which a single example was found, in Level I, having a slender tang that ran through the length of the handle, the daggers had handles made of two pieces of wood or other material riveted on to either side of a broad tang shaped as the handle. By far the most common thing was for this tang to be moulded with raised edges so that the woodwork of the handle was in fact inlaid (Kn. 4); in other cases projecting 'wings' were hammered out at the base of the blade and bent over the woodwork to give it a firmer hold (Kn. 3$) \cdot{ }^{4} \mathrm{Kn} .6$, which com-

\footnotetext{
I It is found in Tomb I at Mishrife-Qatna (Du Mesnil du Buisson, Le Site archéologique de Mishrife-Qatna) which Schaeffer (v. Stratigraphie comparée, p. I I 8 ) rightly on the ground of the pottery assigns to I $900-I 700$ B.C. in agreement with Dussaud (Syria, xxi, p. 227). This accords with our two examples from Level VII, but that from Level IV
}

gives a later terminus ante quem.

2 Tools and Weapons, p. $3^{8 .}$

3 R. F. J. Starr, NUZI, i, P1. I 26.

$4 \mathrm{Kn}$. 2, of which only one example was found in the higher levels (III to I) above the Niqme-pa palace, is peculiarly solid, there are no rivet-holes, and the 'wings' are not flattened 
bines the flat riveted handle-base with a slender tang beyond, probably had a wooden handle with a pommel in a different material. The standard type Kn. 4 was in use at least from Level VII to Level II, i.e. from I 800 to I 300 or later B.c. The single-edged types Kn. 7-I I are of the sort that anyone would carry about in his belt or use at home for domestic purposes; the slight differences of shape, chiefly concerned with the hafting, are not informative, and though most of the examples found are late-one of $\mathrm{Kn} .8$ comes from Level IV and the others range from Level III to Level O-this is more likely to be accidental than to reflect real process of development.

The fine AXE, AT/48/20, is from Level $\mathrm{V}$; this is consistent with findings at Ras Shamra, Boğaz-köy, \&c. The adze, AT/37/ I I, was found in Level II, and I suspect it of being out of its true horizon. The miniature AT/3 $8 / 57$ is from Level II. The fragment of a rapier, AT/39/1 25, is of interest because of its length-the fragment is $0.39 \mathrm{~m}$. longand early date, coming as it does from Level VII.

\section{TOOLS}

The chisels call for little comment. The differences of type are not evolutionary but are due to the varying demands of the craft; all or any would be in use at the same time and in the hands of the same workman. The solid more or less wedge-shaped types (Ch. I-3) would be used with a wooden mallet; they correspond exactly to the 'cold chisel' of the modern workshop. The slender two-ended chisel (Ch. 4) is obviously for hand use; it is a finishing-tool. The narrow-ended types (Ch. 5-7) might be socketed, set in a handle (as Ch. 7, which was found complete with its handle of bone) or not handled at all; they are the normal cutting-chisels of today, used either by hand or with a mallet or light hammer. The levels at which they were actually found are recorded in the tabular list, but have small importance.

Two fragments of bronze saws were found. Of AwLs the most common are short rods or even more or less unshaped sticks of metal pointed at one end; they were presumably mounted in handles from which only a short length protruded. These were not worth figuring. Two more elaborate types are shown here; both were set in handles.

The SPATULAE are for the most part of late date, but one example of Spat. 2 came from Level VII; others of the same type came from Levels II and I, and from Level I an example in iron.

The curiously shaped tool AT/38/33 I take to be stylus.

The three fibulae illustrated came from the surface soil and must belong to Level I or Level O; AT/39/20 is of iron.

PIns. Taken as a whole the pins found in the excavations are frankly disconcerting. This was first brought home to me by the Type P. 8 which was familiar to me from Ur where it is characteristic of the early third millennium-it was recorded from twentynine graves of which twenty-four belonged to the older series in the Royal Cemetery; but at Atchana two examples (only) were found, and they were both on the floor of a 
room in Niqme-pa's palace and therefore more than a thousand years younger than the Ur specimens.

The toggle-pins with straight pierced shafts and bulbous, flat discoid or conical heads (P. I-7) have been found so often in early settings that their date was considered certain and they were appealed to as a safe criterion for dating other objects. At Ras Shamra such pins do not seem to occur after Ugarit Moyen 2, i.e. after I 750 B.C., and the majority go back earlier than that; the pin P. I I with unpierced shaft and curled head Schaeffer finds as early as 2300-2 I00 B.C. Type P. I 8 comes in the 'Treasure of Byblos' dated by a pectoral of Amenemhet III, so that that example must date to soon after I 850 B.C. I had myself had no hesitation in putting the grave at el Hammam containing Types P. I, 3, and 6 before 1750 B.C. I Types P. 5 and I 5 are dated at Chagar Bazar to approximately I 700 and I 600 B.C. and were the standard types there at that period, 2 later than the Syrian coastal evidence would suggest, but none the less relatively early. At Alalakh we have an example of P. I from Level XIV and one of P. 5 from Level XIII which I have tentatively dated to something like 2600 B.C.; this then would more than satisfy Schaeffer's chronological requirements and would be in line with Du Mesnil du Buisson's date (2600-2400 B.c.) for his Tomb iv at Meshrife-Qatna in which a pin of Type P. I occurs. But of Type P. I one example comes from Level VII, one from Level V-VI, four from Level V, four from Level IV, and one each from Levels I and II which, even assuming that the last might be out of its horizon, brings the floruit of the type down to the fourteenth century at Alalakh. Type P. 5 comes also from Level V; P. 6 occurs five times in Level I, once in Level II, and never earlier; of the seven recorded examples of P. 3 four come from Levels IV and V, both of P. 2 from Level IV, the four examples of P. 4 are distributed over Levels III, IV, V, and VII, and the single example of P. 7 comes from Level V. Perhaps the most decisive evidence is given by P. I I (which Schaeffer dates, in the case of the examples found at Byblos, to $2300-2$ I 00 B.C. ${ }^{3}$ ) because the considerable number recorded eliminates that element of chance on which we should always reckon in the case of an isolated discovery; of twenty-six well-stratified specimens the distribution was: Level XIV, one; XIII, one; VIII, one; VII, five; VI, two; V, one; IV, three; III, one; II, seven; I, four. Nothing could be more clear than this. The type starts at a very early period, here as at so many Syrian centres; but instead of dropping out of use at the beginning of the second millennium it enjoyed at Alalakh an if anything increasing popularity down into the twelfth century B.c.

Nothing found at Atchana can alter the facts observed on other sites or invalidate the chronology based by excavators on those facts so far as their individual sites are concerned. Atchana has simply produced new evidence for the longevity of types originating in very early times which had been supposed to be relatively short-lived. Judging by the

I Liverpool Annals, vi, p. 94.

2 M. E. L. Mallowan in Iraq, Ix. ii, p. I 88. Mallowan refers to the Syrian analogies (dated much earlier) and explains that the discrepancy is due to the fact that "the coppersmiths were catering for a stock range of standardized requirements at that time. . . . It is the natural outcome of closed craftsmen's guilds working in circumscribed districts, and this is what makes it so dangerous to measure in time the stylistic criteria of one district by that of another.' It is a very timely warning. Schaeffer revises Mallowan's dates so as to make his data accord with those of Ugarit.

3 Stratigraphie comparée, p. 65 ; this on the analogy of Ugarit. 
evidence available (but it must be remembered that on no site is the available evidence necessarily exhaustive), it was the case that in some places those ty pes did not enjoy a very long vogue; but elsewhere the type did continue in production and it is always possible that from the producing centres isolated specimens found their way in the course of trade to places where they had long since ceased to be $\dot{a}$ la mode. It is also possible that some of those types, proved early at, for instance, Ras Shamra, were not manufactured at Alalakh until many centuries later when fashion dictated their revival, the early examples, when they occur there, being imports. If at first sight the dating of the Atchana pins seems iconoclastic it is only theories, not facts, that are upset; we had believed that the different types afforded a base for a chronological scheme fixed within narrow limits, and we find that they do not. It is a warning that we must not take the results gained from a single site, however well established and true they may be, as necessarily constituting the whole truth and giving a rule to which the phenomena of other sites must needs conform.

RAzors. All our examples are of late date; Rz. I comes from Level O, the rest, Rz. 2-6, from Levels I, II, and III. The large fan-shaped 'split' razor (Rz. 7, Pl. LXXIV) was found in Level I; Petrie cites it ${ }^{1}$ as an Italian type, but it has been found at Ugarit in the Ugarit Récent period, ${ }^{2}$ fourteenth century, and therefore rather but not seriously earlier than our isolated example.

The object AT/38/26, of which a dozen examples were found ranging from Level I to Level $V$, is described by Petrie ${ }^{3}$ as a rasp. As a carpenter's tool it would be ineffective owing to the softness of the metal, but as a grater for bread-crumbs, nutmegs, \&c., it has its exact parallel in the modern kitchen. At the same time it must be remembered that a precisely similarly shaped object served as a strainer at the end of the Sumerian drinkingtube.

The KoHL-sticks (as I imagine them to be) were fairly common; the two types shown are extremes between which the individual examples varied. They were found in Levels I, II, III, and IV.

BoDkINs were always heavy and clumsy instruments; either the head was slightly flattened and pierced for the eye, as in the illustration, or it was hammered out to a point which was then bent over, precisely as in the case of pin P. ro, and the tip sweated to the stem. The twenty-three examples recorded came from every level from I to VII. NEEDLES, similar in make to the bodkin figured here but very thin; more than forty were recorded coming, as is to be expected, from all levels from I down to VIII. The very slender rod with spoon-shaped head, A T/39/1 20 from Level V, I take to be an ear-pick. Of TWEEZERS only three examples were found, two in Level IV and one in Level II.

\section{TOOLS AND WEAPONS: ANALYSIS OF TYPES AS FOUND}

\section{(n.l. signifies that the level is unknown)}

SPEARS

Sp. I. $38 / 8$ I (n.l.); 37/2 Io (IV)

Sp. 2. $37 / 7$ (O)

I Tools and Weapons, Pl. Lx. 59. $\quad 2$ Syria, xviii, p. I44, fig. 9.

3 Tools and Weapons, p. 38, Pl. xuIv, I 34-5. 
Sp. 3. $38 /$ I I 8 (IV);39/202 (VII);39/24I (n.1.);39/254 (two) (VII)

Sp. 4. $37 / 43$ (II); 37/ 60 (IV); 37/162 (I в)

Sp. 5. $38 /$ I I 3 (n.1.)

Sp. 6. $37 / 209$ (IV)

Sp. 7. $38 /$ I 66 (I);38/167 (I)

Sp. 8. 37/ I 5 (I); 37/ I 28 (I-II); 38/227 (IV); 38/259 (II); 38/275 (II-IV); 39/236 (above VI); $46 / 55$ (III); $46 / 48$ (II); 46/163 (VII);47/I 3 (I-II); 47/37 (high level); $47 / 107$ (II)

Sp. 9. $37 / 106$ (n.1.)

Sp. Iо. $37 / 85$ (n.1.); 37/9 I (n.1.); 37/1 87 (III); 38/I I 4 (IV);38/205 (trench H); 37/92 (II) Sp. I I. $37 / 36$ (I); 37/ I I I (n.l.)

Sp. I 2. $37 /$ I 55 (n.l.); $38 /$ I 55 (n.l.); $38 / 26$ (II); 38/ I 55 (IV); $46 / 32$ (II)

\section{ARROWS}

Ar. I. $38 /$ I 56 (top-soil)

Ar. 2. $37 / 39$ (I);38/4 (three) (II);38/I99 (top-soil);38/23I (II-III);39/26 (n.l.);39/44 (III); 39/ I 98 (III)

Ar. 3. 37/I3 (O-I);37/38 (I); 37/40 (I); 37/93 (I-II); 37/102 (III); 37/I I 2 (I-II); $37 /$ I 67 (IV);38/3 (five) (IV);38/55 (II);38/97 (IV);38/ I 2 I (II);38/I 42 (two II, one IV); 39/I 6 (two I, nine II, four III-IV, one IV, two V, one VI); 39/324 (iron) (I-II); $46 / 220$ (V); 46/I I 5 (III); 46/I I 2 (V-VI); $46 / 80$ (III); $46 / 7$ I (II); $46 / 77$ (II); $47 / 64$ (V)

Ar. 4. 37/I 5 (I);37/I 28 (I-II);38/227 (IV); 38/259 (II);38/275 (II-IV); 39/2 36 (above VI); $46 / 48$ (II); $46 / 55$ (III); 46/I 63 (VII); 47/I 3 (I-II); 47/37 (high level); $47 / 107$ (II)

Ar. 5. $37 / 73$ (III-IV); 37/74 (three; III-IV); 37/1 52 (IV); 49/24 (V)

Ar. 6. 37/I 2 (O-I); 37/44 (II);37/127 (II);37/170 (O-I);37/188 (III); 37/240 (III); $38 / 27$ (II); 38/106 (II); 38/I 26 (IV); 38/I 3 I (II); 38/239 (IV); 38/262 (V-VII); $46 /$ IO2-3 (two; V); 46/104 (V); 46/IO5 (V); 46/162 (VII);47/43 (IV-V); $47 / 44$ $(\mathrm{IV}-\mathrm{V}) ; 47 / 8$ I (VI); $47 /$ I I 7 (II) $; 48 / 237$ (IV)

Ar. 7. $37 / 106$ (II-III); 39/I 28 (two IV; three V; one II); 39/294 (iron; II); 46/1 38 Ar. 8. $37 / 108$ (II-III) (below III); 46/1 24 (I); 47/92 (variant; VII); 49/4 (V)

Ar. 9. $37 / 4$ (n.l.); 39/1 86 (II)

Ar. IO. $37 / 72(\mathrm{IV}-\mathrm{V}) ; 38 / 26$ I (V)

Ar. I I. $37 / 64$ (n.l.); 39/25 (II-III); 39/33 (III); 39/ I 37 (V)

Ar. I2. 37/I IO (I-II); 37/I 75 (IV); $38 / 90$ (IV);38/104 (II); 39/1 87 (II); 46/1 54 (VII); $47 /$ I 8 (II)

Ar. I 3. $37 / 173$ (II);38/9 (II);38/246 (n.l.)

Ar. I 4. $37 /$ I 48 (I B); 37/I 7 I (O); $38 / 50$ (II-III); 38/I6I (I)

Ar. I 5. $37 / 56$ (n.1.); $37 /$ I 48 (I B); $38 / 105$ (II); 46/ I I I (III).

Ar. I6. $37 / 39$ (I); $38 / 4$ (three; II); $38 / 194$ (top-soil); $38 / 23$ I (II-III); 39/26 (n.l.); 39/44 (III);39/1 98 (III)

SCALE ARMOUR

All types; $37 / 37$ (I B); 38/ I 37 (IV)

\section{KNIVES}

Kn. I. $38 /$ I IO (I) 
Kn. 2. $38 / 265$ (n.1.)

Kn. 3. $38 / 282$ (VII)

Kn. 4. $37 / 57$ (III);37/I 86 (III); 38/2 (n.1.); 38/5 I (II); $3^{8 / 52}$ (ATG/38/2); $3^{8 / 54}$ (III); $38 / 63$ (IV); $38 / 70$ (IV); $38 / 95$ (IV); $38 /$ I I I (IV); $38 /$ I I 2 (IV); 39/203 (VII);

Kn. 5. $37 / 107$ (III) $39 / 262$ (VII); $46 / 57$ (III); 46/24 (n.1.); 49/I (V)

Kn. 6. 37/26 (upper soil); 37/I 72 (II)

Kn. 7. $37 / 69$ (II-III)

Kn. 8. 39/8 (one II-III; one IV); 39/10 (II-III)

Kn. 9. 39/165 (II)

Kn. I O. $37 / 24$ I (upper soil); $38 /$ I 86 (top-soil)

Kn. I I. $38 / 154$ (top-soil)

AXES

Axe I. $48 / 20(\mathrm{~V}) ; \mathrm{AT} / 36 / 5$ (I)

Axe 2. $48 / 57$ (II)

ADZE

$$
37 / \text { I I (II) }
$$

RAPIER

$$
39 / 125 \text { (VII) }
$$

CHISELS

Ch. I. 37/109 (two; I-II); 37/I 5 I (IV); 38/109 (I); 39/160 (II)

Ch. 2. $37 / 8$ I (II)

Ch. 3. $38 / 16$ (II)

Ch. 4. 39/290 (n.l.)

Ch. 5. 37/109 (n.1.); 37/53 (III)

Ch. 6. $37 / 89$ (II); 38/1 8 (II); 38/24 (II); 39/105 (IV); 39/162 (II); 39/30 (II); 39/302 (II);

$$
47 / 84(\mathrm{VI})
$$

Ch. 7. 39/100 (IV)

Ch. $8.38 / 15^{8}$ (top-soil)

\section{BRADAWLS}

Awl I. 38/1 72 (II)

Awl 2. 38/25 I (I); 39/3 I (IV); 39/1 53 (II); 48/79 (V); 49/14 (I)

STYLUS

$$
38 / 33 \text { (II) }
$$

SPATULAE

Spat. I. $38 / 5^{8}$ (I-II)

Spat. 2. $38 / 32$ (II); 38/252 (I);39/279 (VII); 39/283 (iron; I)

Spat. 3. 38/1 7 (II)

\section{FIBULAE}

F. I. $37 / \mathrm{I} 38$ (top-soil)

F. 2. $38 / 269$ (top-soil)

F. 3. 39/20 (iron; upper soil) 
FISH-HOOKS

H. I. $38 / 297$ (IV)

H. 2. $39 /$ I 82 (below II)

H. 3. $47 / 39$ (n.1.); 37/202 (IV)

H. 4 . $39 / 265$ (VII)

PINS

P. I. $37 /$ I 68 (IV); 39/50 (ATG/39/I 8 and $39 / 22 ; 42 ;-$ III; one II, one III, one IV, three V, one V-VI, one VII);47/50 (IV); 47/ I I 6 (with hole nearer to head; XIV)

P. 2. $37 / 165$ (two; IV)

P. 3. 37/230 (ATG/37/5A);37/IO3 (n.1.); 46/69 (III); 47/86 (V);39/32F (IV)

P. 4. 39/32A (III);39/32G (V); B, D, E (n.l.); C (ATG/39/I I); M, N, (VI); H (V); k (top surface); L (below VI)

P. 5. $48 / 49$ (V); 47/I I 9 (XIII);AT/45/49 (V)

P. 6. $37 / 84$ (I B);37/I I 3 (I); $38 /$ I 23 (three (I), one (II))

P. 7. $46 / 190(\mathrm{~V})$

P. 8. 48/ I 5 I (two; IV)

P. 9. 39/246 (VII); 46/1 83 (VII); 48/89 (n.l.; early)

P. IO. $37 / 35$ (n.l.); $46 / 92$ (III); $46 / 86$ (III); $46 / 44$ (I); $47 / 56$ (II) $447 /$ I 45 (lead; XIII)

P. I I. $37 / 25$ (n.l.); $37 / 55$ (n.l.); $37 / 95$ (two; II); 37/20 I (grave ATG/37/I 7); 38/56 (II); 38/107 (three I, one II); 38/108 (I); 39/I I (three II, one V, three VII); 46/22 I

P. I 2. $37 / 104$ (n.i.)

(VIII); 46/I 4 I (under III); 46/I 37 (VII); 46/I 35 (VII); 46/59 (III); 47/5 I (IV);

$47 /$ I $67(\mathrm{VI}) ; 48 / 45(\mathrm{IV}) ; 48 / 92(\mathrm{VI}) ; 47 / 100(\mathrm{XIII}) ; 47 /$ I I 5 (XIV); AT/48/92(VI)

3. $37 / 26$ (n.l.; late)

P. I $4.46 / 76$ (III); $46 / 70$ (III)

P. I $5 \cdot 38 / 27$ I (one II-III, one upper soii); $47 / 53$ (IV)

P. I6. $38 / 84$ (silver; IV); $46 / 274$ (V); $46 / 43$ (II) $; 47 / 104$ (XIII)

P. I $7.47 / 30$ (III)

P. I 8. 38/289 (grave 3 I, Site H); 38/209 (trench H); 39/32 (one II, two V, three VII, one grave $A T G / 39 /$ I I)

RAZORS

Rz. I. $46 / 79$ (III)

Rz. 2. $46 / 34$ (II); $37 / 242$ (I в); $38 / 236$ (n.l.)

Rz. 3. $37 / 90$ (II)

Rz. 4. $38 / 272$ (top-soil)

Rz. 5. $37 / 24$ (high level)

Rz. 6. $39 / 275$ (III-IV)

Rz. 7. $38 / 255$ (I). For the type see Petrie, Tools and Weapons, Pl. Lx, 58 (from Italy); found also at Ugarit, Syria, xviii, p. I 44 .

RASPS

$38 / 26$ (one I, one II, one II-III); $38 / 267$ (II); 39/I 2 (one II, one III-IV, two V); $46 /$ I 9 (III)

KOHL-STICKS

I and 2. $38 / 243$ (IV); 38/49 (II); $38 / 46$ (II); 38/ I 32 (II); 39/ 38 (top-soil); $39 / 48$ (one III, one before III); $48 / 2$ (III) 
BODKINS

37/35 (I); 37/94 (II); 37/II 7 (I-II); 37/I 50 (I в); 37/1 57 (III); 37/I4 (I-II); $3^{8 / 15}$ (six II, three III, one V-VII, one VII); $38 / 150$ (n.1.); 38/270 (VI-VII); $47 / 94(\mathrm{VI}) ; 47 / 46(\mathrm{IV}-\mathrm{V})$

NEEDLES

$39 / 6$ (twenty-seven from Levels I, II, III, IV, VI, VII); 46/207 (VIII); 46/96 (IV); $46 /$ I 5 I (n.l.); 46/I 3 I (under III); 46/130 (VII); 46/I 28 (V-VI); 47/25 (III); $47 / 3^{8}$ (III); $47 / 47$ (IV); 48/1 5 (VII); 48/66 (IV-V); 48/69 (V-VI); 48/9 I (VI)

EAR-PICK

$$
39 / 120(V)
$$

TWEEZERS

38/208 (IV); 39/104 (one II, one IV); grave ATG/39/70, Level II.

SICKLES

I. With bent-over tang, a small type, 1. O.I2 m., AT/39/228 (VII), from room I 8 of the Yarim-Lim palace.

2. With riveted tang, AT/ $/ 38 / 25^{8}$, large, $1.0 .23 \mathrm{~m}$. (I); AT/46/123, 1.0 .2 I $3 \mathrm{~m}$., of the same shape but rivet-hole doubtful (VI).

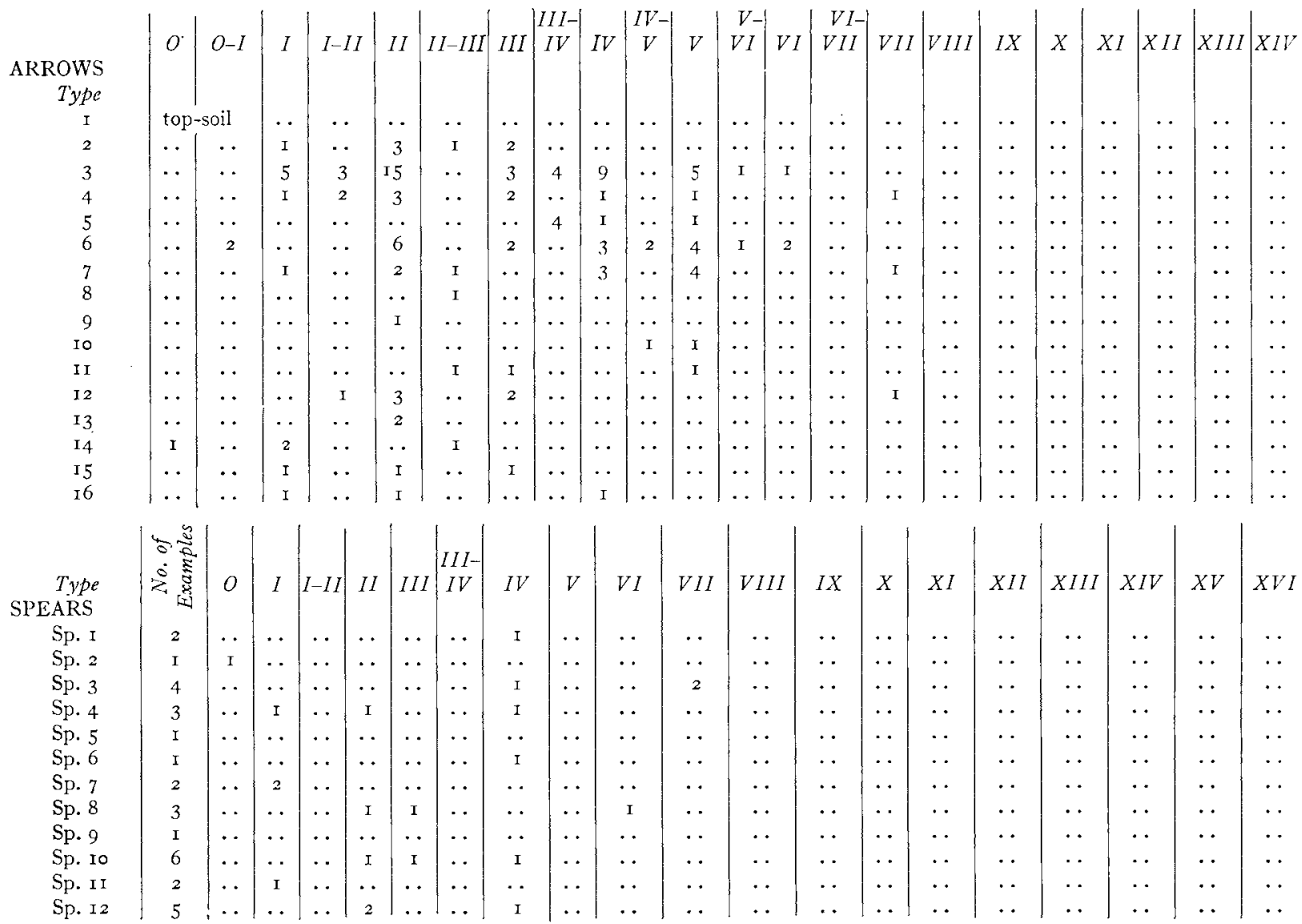




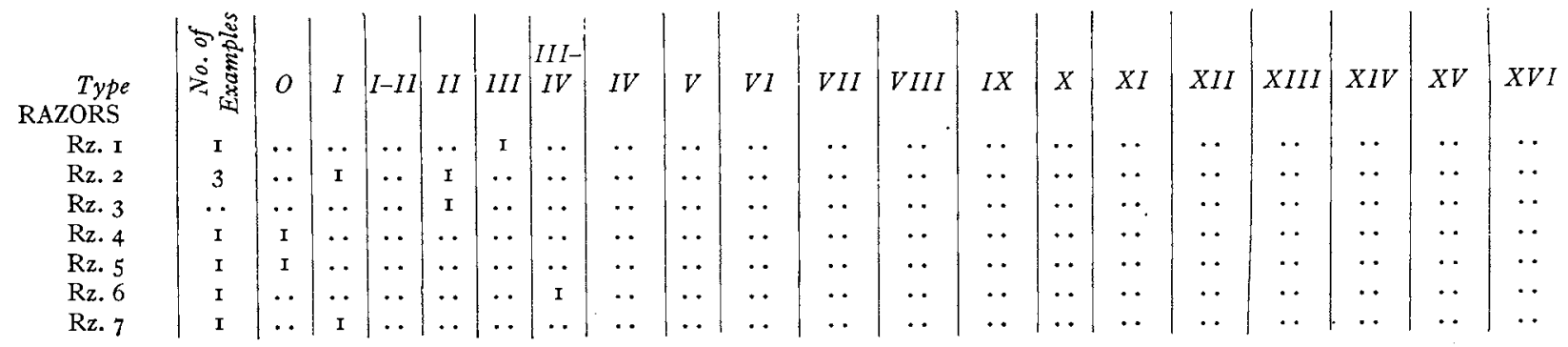

CHISELS

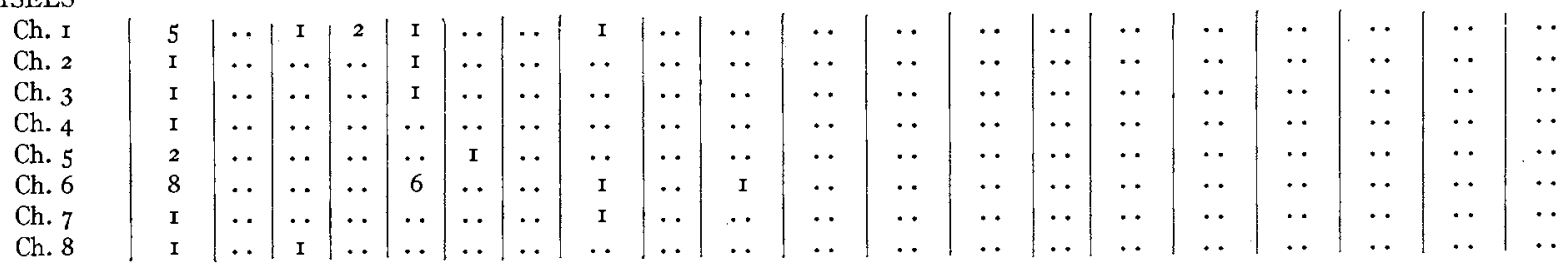
PINS

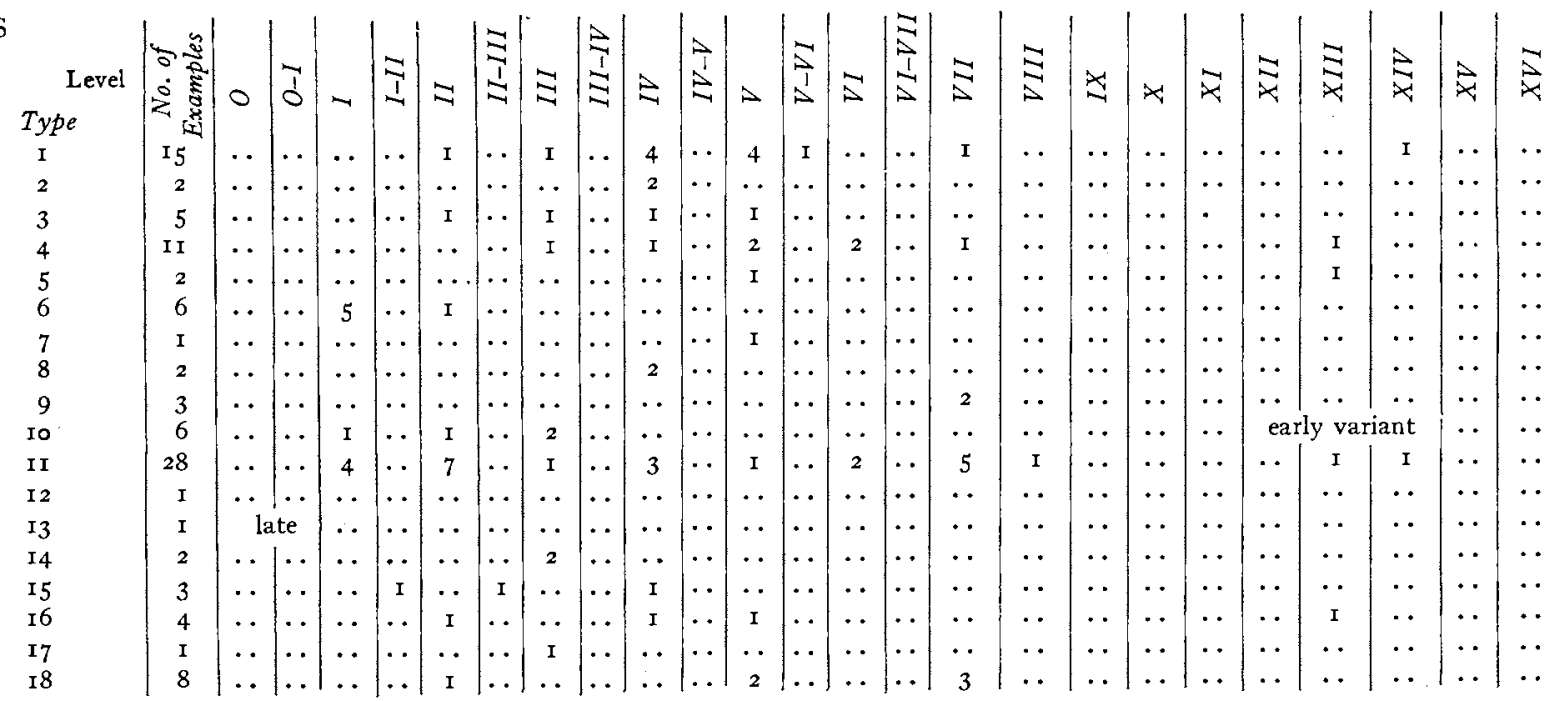

CHISELS

BODKINS
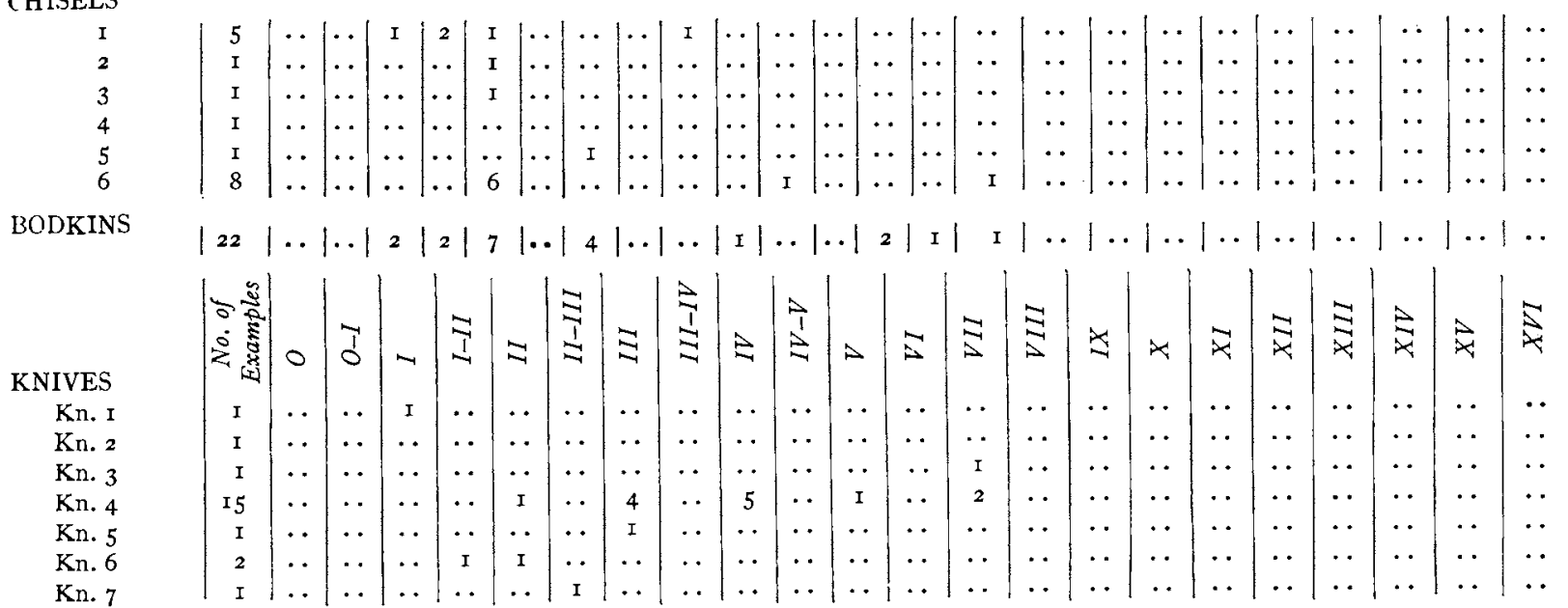
TOOLS AND WEAPONS: ANALYSIS OF TYPES 287

\begin{tabular}{|c|c|c|c|c|c|c|c|c|c|c|c|c|c|c|c|c|c|c|c|c|c|c|c|}
\hline IIVES & $\mid \begin{array}{ll}\overrightarrow{0} & \overrightarrow{0} \\
0 & 0 \\
z & 0 \\
0\end{array}$ & 0 & 1 & - & $\stackrel{I}{I}$ & $\Xi$ & $\underset{1}{\square}$ & $\lesssim$ & $\stackrel{1}{\vdots}$ & 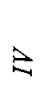 & $\begin{array}{l}\overrightarrow{1} \\
\vec{\lambda}\end{array}$ & 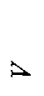 & $\Xi$ & 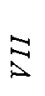 & $\Xi$ & $\underset{\sim}{\star}$ & 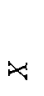 & $\ddot{\forall}$ & $\bar{\star}$ & $\underset{\Downarrow}{\Xi}$ & $\stackrel{\vec{x}}{\vec{x}}$ & $\vec{x}$ & $\overrightarrow{\vec{\Delta}}$ \\
\hline Kn. 8 & 3 & . & .. & . & . & $\cdots$ & 2 & $\cdots$ & . & I & .. & $\cdots$ & $\cdots$ & $\cdots$ & $\ldots$ & . & $\cdots$ & $\cdots$ & $\cdots$ & $\cdots$ & $\cdots$ & $\cdots$ & \\
\hline Kn. 9 & I & $\cdots$ & $\ldots$ & .. & $\ldots$ & I & $\cdots$ & $\cdots$ & .. & .. & $\cdots$ & $\therefore$ & $\cdots$ & $\cdots$ & . & . & $\cdots$ & $\cdots$ & $\cdots$ & . & $\ldots$ & $\cdots$ & • \\
\hline Kn. Io & 2 & $\cdots$ & I & $\because$ & I & .. & .. & .. & .. & .. & .. & $\cdots$ & $\cdots$ & . & $\cdots$ & .. & .. & . & .. & .. & .. & .. & • \\
\hline Kn. II & I & .. & I & $\ldots$ & . & .. & 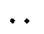 & . & . & .. & 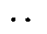 & . & $\ldots$ & $\ldots$ & 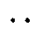 & $\ldots$ & .. & 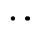 & 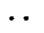 & & & & \\
\hline
\end{tabular}
AXES

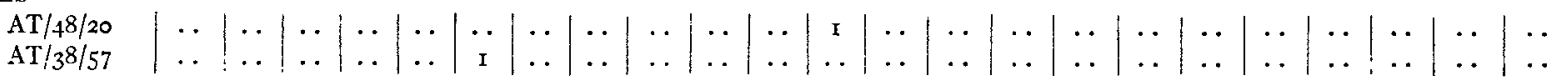

BODKINS

(one type) $|22| \ldots|\ldots| 2|=| 7|\ldots| 4|\ldots| \ldots \mid$ I $\mid \ldots$ 2 NEEDLES

(One type) 4I $\quad$ All levels to VIII

FISH HOOKS 


\section{CHAPTER XI \\ (a) IVORY OBJECTS}

A

Sidney Smith has pointed out, ${ }^{\mathrm{I}}$ Niya, which formed part of the territories of the king of Alalakh, was the elephant-reserve of north Syria and the source of commercial ivory. The trade routes of the time made it convenient if not necessary for the Niya ivory destined for export to Anatolia, the Aegean, Phoenicia, or Egypt to pass through the Amq plain, and political expediency would ensure its concentration at the capital. In the Yarim-Lim palace the remains of the store of tusks were found actually in situ (v. Pl. XVIb) and an elephant's jaw-bone was found above the ruins of the palace of Ilim-ilimma; there is therefore positive evidence for what would in any case have been likely.

It may be considered certain that the bulk of the ivory intended for export went in the form of raw material to be worked up elsewhere; the examples of ancient ivories that we possess are enough to prove that there were local schools of ivory-carvers in various countries and not a single centre of production supplying finished goods to the international market. But it is at least probable that a certain proportion of the tusks brought to Alalakh were used by the craftsmen of the town; although the ivories we have found there often show unmistakable foreign connexions, ${ }^{2}$ there is, I think, none of which we are bound to say that it is of foreign workmanship; there should be no great risk in treating all the ivories found at Atchana as coming from the workshops of Alalakh. ${ }^{3}$

Nearly all the examples of ivory working are decorative elements for appliqué or inlay, not independent works of art; it was rare for the whole object to be made of the same material, and where it was so made it was necessarily of small size. These are the real ivory carvings, executed by craftsmen possessed of a certain artistic sense and considerably technical skill who valued the material for its texture as well as its rarity. Most of the inlay, on the other hand, is 'worked' not at all or in the most mechanical manner; there the material was chosen merely for its colour, the effect aimed at being the contrast between the pure white and the dark tint of the wood in which it was set, and the design is worked out not on the ivory but by means of the ivory which is subordinate to the whole; colour and outline are all that the pattern demand. The exception to this, of which we have a few illustrations, is the enriching of the ivory by a species of niello, the ground being cut away, or lines engraved on it, in a subsidiary pattern and filled in with black paste; the same technique was almost certainly employed on some of the all-ivory objects with engraved designs. This technique seems to hark back to and may be inherited from the ivory-workers of ancient Sumer. ${ }^{4}$ Another method of enrichment was the

I The Statue of Idri-mi, pp. 49, 57 .

2 The mixture of foreign styles is natural in ivory-carving because of the peripatetic habits of the members of the ivorycarving guilds; on this $v$. R. D. Barnett, 'Early Greek and Oriental Ivories', in F.H.S. lxviii (1948), p. I.
3 Part of an elephant's bone showing saw-marks was found in Sq. L I 4 in Level VIII.

${ }^{4}$ Compare AT/38/204 or AT/47/130 with examples from the Royal Cemetery at Ur; Ur Excavations, vol. ii. Pls. 96-105. 
addition of gold to the ivory, of which we have one good example, AT/38/79, Pl. $\mathrm{LXXVII} a$; in that case the ivory is overlaid with gold, which is the normal chryselephantine procedure, but the two materials were also used side by side for inlay in wood, and the narrow strips of thin gold which are found not uncommonly were without doubt the edgings for pattern-inlay in ivory; the effect was precisely that obtained by the modern furniture-maker of Damascus with the combination of mother-of-pearl and brass wire.

In what follows I have included objects made of bone where the cheaper material has been employed for the same purpose as the genuine ivory; other bone objects such as spindle-whorls, pins, \&c., figure in the general catalogue. The objects are listed according to type and not according to date because they are not numerous enough to illustrate the history of the art over any length of time; but the level at which each was found is recorded.

AT/46/8. Ivory statuette of a nude female standing with arms by her sides; complete; ht. $0 \cdot 10 \mathrm{~m}$. The whole figure, and especially the head-dress, are Egyptian in style. Pl. LXXVI. Found in Sq. O I 3 below the foundations of a Level I wall; Level II.

AT/ $/ 38 / 3^{8}$. Ivory statuette of a nude girl, ht. $0.073 \mathrm{~m}$.; complete except for one side of the face. Pl. LXXVI. In its attitude and proportions the figure shows Egyptian influence, but the fashion of the hair is more characteristic of the Hittite. Found high up in the soil above the Niqme-pa palace, probably belonging to Level II.

$\mathrm{AT} / 38 / \mathrm{I} 52$. Ivory statuette of a nude female, ht. of fragment $0.07 \mathrm{I} \mathrm{m.;} \mathrm{the} \mathrm{head,} \mathrm{feet,} \mathrm{and} \mathrm{left}$ upper arm missing. Pl. LXXVI. The figure is similar to the last but rather more free in its treatment, showing a greater suppleness of the body. Found in the surface soil above the Niqme-pa palace, it must belong to one of the three latest levels but cannot be dated accurately to any one of them.

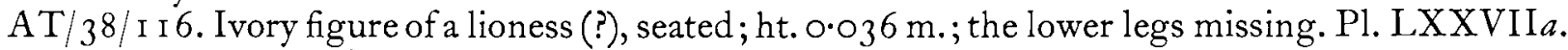
From room 8 of the Niqme-pa palace, Level IV.

$\mathrm{AT} / 38 / 74-6$. Ivory toilet-box, made in 3 pieces; the 'box' itself, a flat-topped circular jar, is cut out of a single piece of ivory; the swivel lid, engraved with a compass-drawn rosette, ${ }^{\mathrm{I}}$ is cut from a thin plate; to it was mortised a head carved in the round, in Egyptian style, serving as a handle for turning the lid. Greatest diam. $0.078 \mathrm{~m}$., ht. $0.032 \mathrm{~m}$. Pl. LXXVI. From room I 6 of the Niqme-pa palace, Level IV. The lower part of a similar but rather simpler box (AT/39/36) of which the foot was made separately was found in Sq. L I I and belongs to Level $\mathrm{V}$ or VI.

$\mathrm{AT} / 38 / \mathrm{I} \mathrm{I} 7$ and AT/37/236. Two ivory toilet-boxes in the form of a duck with its head turned round over its back, forming a handle; the body is carved in one piece, the head separately, and the neck was made up of alternate rings, strung together, of ivory and of some other material now perished; the swivel lid which is missing in the case of $\mathrm{AT} / 38 / \mathrm{I}$ I 7 was of the same material. Length 0.135 and $0.15 \mathrm{~m}$.; ht. $c .0 .06 \mathrm{~m}$. Pl. LXXVa and $c$. This form of toilet-box was popular and widespread $;^{2}$ certainly Egyptian by origin it was evidently adopted by the ivory-carvers of Phoenicia and Syria. Both the Atchana examples date from Level IV, being found in room 6 of the Niqme-pa palace.

$\mathrm{AT} / 46 / 15$. Bone inlay from a toilet-box more or less similar to the last; the head carved in the round, the wings and tail flat sheets silhouetted and engraved with a design of feathers The box itself was presumably of wood with a wooden lid to which the wings and tail were attached.

1. Cf. an example from Ugarit, Syria, xiii (1932), Pl. viIr.

2 e.g. Ugarit, loc. cit. 
Complete except for the tip of one wing. Length of wing, $0.10 \mathrm{~m}$. Pl. LXXV. Found in the Temple annexe of Level II.

$\mathrm{AT} / 48 / 75$. Bone head of a duck with a hole at the base of the neck for attachment; possibly from an object more or less similar to the last, i.e. a toilet-box in the form of a bird. Ht. $0.035 \mathrm{~m}$. Pl. LXXVIIIe. The carving is crude, with plain compass-drawn incised circle for the eye. From the early temple site, below Level VII, but its actual level uncertain.

$\mathrm{AT} / 47 / 24$. Two gazelles' heads, chin to chin, carved out of one piece of ivory. Length, $0.047 \mathrm{~m}$. Pl. LXXVI. The carving is very good, and details of eyes, mouths, ears, and horns were picked out in black pigment of which a good deal remains. The use is uncertain; at the base there are 2 large holes for round wooden (?) tenons and between them 2 small rivet-holes; it might be the head of a double staff. Level II.

$\mathrm{AT} / 48 / 62$. Bone, head of a gazelle; hollow, and with 2 small rivet-holes for attachment; complete and in fine condition. Length $0.063 \mathrm{~m}$. Pl. LXXVI. This, too, might be the head of a staff, or perhaps the end of a handle of a knife or similar instrument. Found on the temple site, south-west of the building, Level IV-V.

$\mathrm{AT} / 3^{8 / 94}$. Four bone handles (?) ending in snakes' or fishes' heads, roughly carved; at the other end is a hole for attachment. Lengths $0.049 \mathrm{~m}$.-0.055 m. Pl. LXXVIIle. From room I 6 in the Niqme-pa palace, Level IV.

$\mathrm{AT} / 39 / 304$. Ivory bowl of a libation-pourer carved in the form of a hand holding a cup, i.e. in the form usual for such pourers in steatite or pottery; cf. AT/37/226, Pl. CXXXI; on the broad upper rim is engraved a guilloche pattern with holes which seem to have been filled with coloured paste. The 'wrist' is pierced with a hole leading to the cup; it was originally socketed in an 'arm' of a different material. Length (the tip of the bowl is missing) 0. I I $5 \mathrm{~m}$. Pl. LXXVII. Temple site, Level I, found close to the column-base at the entry of the court.

AT/39/70. Ivory bowl of a libation-pourer; oblong bowl with human hand carved in relief on the under side; schematized design and poor workmanship. Length $0.078 \mathrm{~m}$. Pl. LXXVII. From grave $\mathrm{G} / 39 / 27$, q.v.; probably Level V or VI.

$\mathrm{AT} / 38 / 98$. Fragment of ivory carving; the fingers of a hand, about half life-size, the fingers bent at the joints and the hand apparently represented as closed; there was a large hole drilled through the centre, vertically, as if for something that the hand was holding. This might be part of a libation-pourer, the hand being fixed under a bowl of different material; but it might be the hand of a chryselephantine statue with, e.g. the right hand raised and held against the breast clasping an object. Width across the fingers, $0.034 \mathrm{~m}$. Pl. LXXVIII $h$. From room 7 of the Niqme-pa palace, Level IV.

$\mathrm{AT} / 38 / 73$. Circular ivory box, ht. $0.048 \mathrm{~m}$., diam. $0.045 \mathrm{~m}$., with plain mouldings at rim and base. Pl. LXXVIIIb. From room 6, Niqme-pa palace, Level IV.

AT/39/9 I. Circular bone box, ht. 0.055 m., diam. 0.04 m., with a band of bordered guilloche at rim and base and a 6-petalled rosette on the lid. Pls. LXXVII and LXXVIIIa. From grave $\mathrm{G} / 39 / 35$, attributed to Level IV.

AT/39/29 I. Circular bone box, ht. 0.03 m., with engraved design of running spirals. Pl. LXXVII. From grave G/39/97, Level VI.

$\mathrm{AT} / 38 / 225$. Ivory handle for a bronze implement, engraved with 'Aegean' design of implicated spirals. Pl. LXXVII. Found above the Level IV stratum in Sq. V9; should be Level III-II. On this $v$. H. Frankfort in B.S.A. xxxvi (1 936-7), p. I I 5 .

$\mathrm{AT} / 3^{8} / 79$. Ivory roundel, diam. $0.03 \mathrm{~m}$., carved in relief with a star and thunderbolt (?) design and bosses round the edge; the star and bosses overlaid with gold. Pl. LXXVII. A similar roundel, lacking the gold, and also the gold star overlay for yet another were found with this in room I 8 of the Nigme-pa palace; Level IV. 
$\mathrm{AT} / 38 / 293$. Ivory roundel, conical in shape, the flat base engraved with compass-drawn curved radial lines. Ht. $0.045 \mathrm{~m}$., diam. $0.05 \mathrm{~m}$. Pl. LXXVIIIf. Unstratified.

$\mathrm{AT} / 3^{8 / 204}$. The left half of a bone plaque originally measuring $0.06 \mathrm{~m}$. sq. The square was divided by diagonals each composed of plain borders and a central line of inlay; there was a plain border to the whole square. The 4 triangular spaces are carved in relief, the ground of the figures deeply cut away to take a paste (?) filling (when found, the bone was partly covered by a very hard lime deposit which filled all the hollows; it was apparently the original paste which in the course of time had decayed, swelled, and lost its colour). In the complete lefthand triangle a winged monster grasps and tramples on a prostrate animal (gazelle?) whose head is turned back and downwards; in the upper triangle a somewhat similar winged 4legged monster bestrides a supine bull (?) in front of which is a tree; in the lower triangle a small animal (rabbit?) is crouched under a tree; above its back is a flower with 3 stamens. The subjects show the influence of Sumerian and Hurri art. Pl. LXXVII. Found in the soil above the great fort; Level I or II.

$\mathrm{AT} / 47 / \mathrm{I} 30$. Fragment of bone inlay engraved with the figure of a seated monkey, the background cut away and filled with black paste; the head missing. Ht. $0.04 \mathrm{~m}$. Pl. LXXVIII $i$. On the floor of the antechamber of the Level VII temple.

$\mathrm{AT} / 47 / 178$. Pieces of bone inlay; strips with a design of arches and chevrons (? rock motive), the background cut away and the hollows filled with black paste which in some cases is preserved; some pieces have a single band of the pattern and some 2 rows (the former may, of course, have been set in pairs); widths 0.0 I I m. and $0.02 \mathrm{~m}$. respectively. Pl. LXXVIIIj Found, together with plain strips and some petal-shaped pieces, also plain, on the floor of the antechamber of the Level VII temple.

$\mathrm{AT} / 48 / \mathrm{I} 7$. Pieces of ivory inlay, all blackened by fire. The largest of them are fronds from a palm design common on ivory-carvings, cf. Carchemish, vol. iii, Pl. 7 I $f$; but in this case the surface is fluted. One fragment, engraved, resembles the Sumerian rock convention but might be a schematic rendering of the palm trunk. Pl. LXXVI.I With these were various shaned but plain pieces and corresponding fragments in carnelian and obsidian, and some gold strip. Found together in room $48 / 3$ of the Level VII Temple.

$\mathrm{AT} / 3^{8 / 145}$. Fragments of ivory inlay, plain, but cut in various shapes, Pl. LXXVIII $a$. These were found together with great quantities of plain narrow strip inlay and a lot of plain goldleaf in room 18 of the Niqme-pa palace. Petal-shaped pieces were found also in Levels $V$ and VI (AT/39/38B and AT/39/32 I, the latter being from grave ATG/39/107, associated with squares and triangles), and it is worth noting that the shield shape occurs in glazed frit in Level II (AT/46/40), in lapis paste in Level III $(\mathrm{AT} / 47 / 35)$, and the triangle in lapis lazuli in Level II (AT/46/39).

Strip inlay is found in many levels; sometimes it is engraved, more often plain; the patterns (Pl. LXXVIIIk) show:

AT/48/27, double concentric circles with dot centres; temple site, Level VIII.

$\mathrm{AT} / 48 / 104$, pairs of dotted circles; level uncertain, probably Level VIII.

$\mathrm{AT} / 46 / 33$, dotted circles joined by double transverse lines, between borders. Found in the back wall of the Level III temple, probably Level IV.

$\mathrm{AT} / 39 / 2$ I 4 , running diamonds with dot centres. Sq. L I 4, below Level II.

A number $(c .24)$ of plain bone rectangles $(0.035 \mathrm{~m}$. $\times 0.014 \mathrm{~m}$.) found in grave ATG/37/3, each pierced with 2 holes for fixing to the background, were accompanied by small bone pins with hemispherical heads making a row of knobs along the strip.

$\mathrm{AT} / 47 / 154$. A piece of ivory beading, semicircular in section, the ends cut diagonally; it is

I The paim motive recurs on a Cretan ivory (Evans, P.M. it is a curved plume from a head-dress, cf. for Cretan parallels ii. 778, Fig. 506a); an alternative explanation would be that op. cit., Figs. $504 a$ (plaster) and $505 b$ (ivory). 
pierced in the centre for a metal (?) stud; the ivory is blackened by fire. P1. LXXVIII $p$. The only possible use for this is as an element in a composite beading made up, e.g. of alternate pieces of white and black, giving a twisted cable effect. Exact parallels occur in Anatolian furniture of the I 8 th and I 9 th centuries. From Level IV, found in room I I of the castle.

Several ivory combs, more or less fragmentary, were found in different levels. ${ }^{\mathrm{I}}$ They may be quite plain, as AT/47/I 3 , found in the Level VII temple (Pl. LXXVIIIc), which is an example of the single comb; a double or two-sided comb decorated with a line of compass-drawn circles, $\mathrm{AT} / 38 / 82$, belongs to Level $\mathrm{IV}$, being found in room 7 of the Niqme-pa palace; a very different type with coarse teeth, the handle cut in rectangular cloissons which were presumably filled with a coloured paste, comes from grave AT/37/2, which postdates the fall of the city of Alalakh; Pl. LXXVIIId. Plain examples came from graves ATG/38/7 (Level II), ATG/39/7 I (Level III).

Two other objects that call for mention are:

$\mathrm{AT} / 48 / \mathrm{I} 4$. A small ivory tube with bell-shaped end which might have been the mouthpiece of a whistle or small pipe. Pl. LXXVIIIn. From the Level VII temple.

$\mathrm{AT} / 38 /$ I 3 . A bone leg for a small casket (?); it is slightly tapered, rectangular in section, the lower part deeply grooved, the upper part slotted (the hole does not go all the way through) on each side as if to take horizontal members. Pl. LXXVIII $m$. From Level II.

\section{(b) STONE VASES}

STONE vases were found in all levels from I to VII and a single fragment of one occurred in Level XI. Too much significance should not be attributed to this distribution. Apart from basalt mortars, plain or tripod, often very roughly made, which are common to all periods and being purely utilitarian form a distinct category, stone vases were objects of luxury rather than of everyday use; at no time would they be very numerous in an ordinary household. Consequently the bulk of our examples came from the royal palaces of Levels IV and VII; of the other high levels a large enough area of house and temple was dug for the finding of a few specimens to be natural; but from Level VIII downwards our excavations of private houses were strictly limited in scale, and the older temples had been swept so bare that virtually nothing of any sort remained to be found in them.

The shapes are given on the type-list, Pls. LXXXI, LXXXII. As can be seen, the majority are more or less of the standard forms which are familiar in Egypt and are regularly termed Egyptian; it would perhaps be wiser to avoid the implications of that term and to regard them as the product of the Middle East koinê, that partial but real uniformity of culture which, thanks to international trade, derived from and extended over Egypt, Syria, the Aegean, and Mesopotamia. ${ }^{2}$ In any case it would be wrong to conclude from the shapes that the bases were necessarily imported.

1 On the technical interest of the combs $v$. R. D. Barnett in F.H.S. lxviii (1948), p. 2.

2 Some of our Alalakh types can be paralleled just as closely in Sumer as in Egypt; some, e.g. the jug AT/47/34, No. I 9 , seem to be derived from Aegean metal-work. 
On p. Io9 is recorded the discovery in Level VII of the workshop of a maker of stone vases. According to the evidence available the man worked mostly, but not exclusively, in obsidian; but as only one room was dug the evidence may be incomplete. We found one exception only, AT/38/105; this was a disk of granite, diam. O.I 4 m., thickness $0.04 \mathrm{~m}$., of which the outside had been roughly chipped into the form of a shallow bowl, the sides curving to a base which had been flattened and ground smooth; the top was flat and the hollowing process had not been begun. All the other examples were in obsidian and, being the pieces on which the maker was still at work, ${ }^{\mathrm{I}}$ illustrated very well the whole method of manufacture.

There was in the shop plenty of the craftsman's raw material, obsidian of two sorts, one black, the other of a very dark bottle-green colour, so dark that the thicker fragments appeared black; both were of fine quality, clear, and translucent. Some blocks of it may have been unshaped lumps, but as the entire surface had flaked away with the heat of the fire that destroyed the shop, appearances might well be quite deceptive. Others retained the shape in which one may imagine them to have been imported; they were carefully cut rectangular blocks measuring $0.30 \mathrm{~m} . \times 0.20 \mathrm{~m} . \times 0.20 \mathrm{~m}$, , all the sides ground smooth; one or two may have been rather larger than this, ${ }^{2}$ and there were also flatter bits about $0.10 \mathrm{~m}$. wide, $0.14 \mathrm{~m}$. or more long, and varying in thickness from $0.20 \mathrm{~m}$. to $0.027 \mathrm{~m}$.; these, too, were smoothly ground. If obsidian was imported in this form we can only say that so much labour would not have been expended on preparing a refractory raw material for the market if it had not been highly prized, and so much having been spent it was bound to be costly.

Whereas in the more easily worked granite the outside was shaped first, the worker in obsidian seems to have started by hollowing out the interior of his vessel. This was done by boring holes close together with a round-headed drill $0.013 \mathrm{~m}$. in diameter and then breaking away the stone between the holes; thus in the case of $\mathrm{AT}^{\mathrm{T}} / 3^{8 / 1}$ I I , Pl. LXXXIII, apparently intended to become a leaf-shaped bowl, the work has gone no farther than the rough drilling of clustered holes to make the interior. The next stage is seen in $\mathrm{AT} / 48 / \mathrm{I} 00, \mathrm{Pl}$. LXXXIII, a tripod bowl of which the inside has, after drilling, been ground out to its final form, but not yet polished, so that the surface is matt and opaque; the outside has been roughed out by chipping but has not yet been ground. It would seem that the main difficulty was the hollowing out, when there was a risk of the stone breaking up; when once this was successfully done the craftsman could afford to vary the order of the finishing processes. Thus in AT/48/99, Pl. LXXXIII, we have a bowl with a broad upstanding rim which illustrates almost every stage. The inside has been bored and the stone broken away between the holes, but there has been no grinding and the bottoms of the drill-holes are still visible; the flat base seems to show the smooth-ground surface of the imported block with which the work started; the curved sides have been

\footnotetext{
I A male skeleton was found in the ashes and burnt rubble that filled the workshop.

2 Owing to the fire all the blocks were split into thousands of pieces; some of them retained their shape perfectly in the soil, and these we measured; some had broken apart and
}

accurate measurements were impossible. Unfortunately I was unable to lift any of the blocks; as soon as the pressure of the surrounding soil was removed they collapsed, and no methods of gluing sufficed to bind them together in situ as glue would not adhere to the glassy surface of the fractures. 
chipped roughly to shape; the rim, on the other hand, is almost finished, its vertical edge ground though not polished, its flat top smoothed, engraved with parallel grooves, and showing the first beginnings of polish. AT $/ 48 / 98$, a semicircular dish or box divided into two compartments (Pl. LXXXIII), is fully formed and polished.

The other objects found in the shop were a large rough stone weight, a polished celt, and several large lumps of red haematite, the last possibly used as a burnishing medium.

Fragments of obsidian vases were extremely rare, but two could, by exception, be assigned to a definite level, in both cases to Level VII. One (AT/39/I 35), apparently a shallow rectangular bowl with a spout in one corner, was in room 2 of Yarim-Lim's palace, the other $(\mathrm{AT} / 48 / 4 \mathrm{I})$, from a vase, was in the temple area attached to the same palace. Alabaster ${ }^{1}$ was the most common material used for vases, steatite of different. colours rather less so; it is noticeable that in the case of the lidded bowl AT/39/1 24, P1. LXXX, the bowl itself is of red steatite and the lid of green. One large bowl, AT/39/ I 54, was of black and white granite; marble occurred three times. I include with the vases the curious hollow stands in alabaster of which four examples were found, all apparently belonging to Level III. ${ }^{2}$

A remarkable object is the basalt columnar lamp of which fragments were found in the Level VII temple; parts of the base and of the bowl were recovered, but much of the column is missing and its original height cannot be fixed (AT/47/82, Pl. LXXVIIIg). Base and bowl were of the same diameter, 0.6 I 0 m.; the bowl had been made separately and fixed to the stem by a tenon; a slot in the upper part of the stem as preserved may mean that that also was in two pieces, though the slot may be decorative only, recalling the perforations in the stems of 'champagne-cups', to which the form of the stone lamp offers an exact parallel; seeing that the 'champagne-cups' were used as lamps (v. p. 6 r, Room 48/5), the resemblance cannot be accidental.

The other columnar lamp, AT/39/280, P1. LXXIX, which was found in Level II (v. p. I 9 I) but certainly belongs to a considerably earlier period, affords one of our best links with Cretan culture. The material is a red marble, apparently 'Rosso brecciato', 3 which is identified by Corsi ${ }^{4}$ as 'Marmor Lydium' found in Asia Minor; it seems to be the same stone as that which is commonly used for Cretan lamps and has been wrongly described as red or purple gypsum; the decoration in relief of 'tricurved arch network' is familiar in Cretan art, ${ }^{6}$ as are the petal pendants; the only unusual feature of the Alalakh lamp is that it is designed for twelve wicks-corresponding to each petal of the rosette capital there is a separate compartment of the tri-curved arch pattern, these communicat-

I I am following the popular (not the modern scientific) use in applying the name to the material for which it was invented by the Greeks.

2 It has been suggested that they are not stands but the pommels of daggers: that is quite possible.

${ }^{3}$ For information about the stones Iam indebted to Mr. W. Campbell Smith, Keeper of Minerals, British Museum (Natural History), South Kensington.

${ }_{4}$ Faustino Corsi, Catalogo Ragionato d'una Collezione di Pietre di Decorazione, Rome, I 825, p. 108.
5 I am indebted for this information to Mr. D. V. G. Harden, who submitted for analysis a fragment from the top of a standard lamp from Crete, now in the Ashmolean Museum, which had been described by Evans as of 'red gypsum'; Mr. N. R. Goodman, University Demonstrator in Mineralogy, reported that the material was red limestone, which, of course, is entirely different from gypsum, but does accord with the Atchana lamp.

6 e.g. Evans, P.M. ii, Fig. 457; iii, Figs. 50, 54, 59; Furumark, p. I 44 and Motive 62, p. 392. 
ing with each other and with the central reservoir by small holes drilled in the dividing walls so as to equalize the supply of oil. Had it been found at Knossos the lamp would have been regarded simply as a particularly fine example of a normal Cretan type, ${ }^{\mathrm{I}}$ and when it appears at Alalakh the natural assumption is that it was imported from the island. Against that assumption it must be urged that the red marble of which the lamp is made is apparently native to Asia and not to Crete, so that if the lamps found in Crete were manufactured in the island the stone for making them was imported; further, the bottoms of the compartments in the Alalakh lamp show the drill-holes ${ }^{2}$ which ought to have been but have not been obliterated by subsequent polishing; in other words, the lamp is to that extent unfinished, and it would be curious if a Cretan craftsman left unfinished an important piece of work intended for export. It is indeed quite possible that our lamp is of local manufacture, though whether in that case it was copied from a Cretan original or represents an Asian school which set the fashion for Crete there is no means of saying. ${ }^{3}$

\section{CATALOGUE}

Since the vases are few in number and really do not repeat themselves all the individual examples are figured on Pls. LXXXI-LXXXII and classified so far as possible, and are catalogued here in that order.

I. AT/46/87. Granite. Found loose in the upper soil of the ' $\mathrm{H}$ ' site and therefore not later in date than Level IV.

2. AT/47/129. Basalt. Level VI.

3. AT/47/169. Steatite. Level V, found below the floor of room I I of the castle.

4. AT/47/179. Basalt. Level IV, from room C 8 in the annexe of the Niqme-pa palace.

5. AT/39/1 47. Rather coarse grey steatite. Level VII. Found on the floor of room 9 of YarimLim's palace. Pl. LXXX.

6. AT/39/157. Black steatite. Level VII; found on the floor of room 2 in Yarim-Lim's palace.

7. AT/39/ I 24. The bowl of red steatite with a green steatite lid. Level VII; found in room Io of Yarim-Lim's palace in the rubbish above floor-level, probably fallen from an upper room. The lid is circular with 2 short lugs pierced for the strings that fastened it to the bowl through the corresponding holes in the big lugs of the body. Pl. LXXX.

8. AT/39/1 55. Alabaster. The form is restored from fragments found in room 2 of the YarimLim palace. Level VII.

9. AT/39/1 54. Black and white granite. Restored from fragments. Level VII; found on the floor of room 7 in Yarim-Lim's palace.

I . AT/39/i 56. Alabaster. Level VII. Found on the floor of room 2 in Yarim-Lim's palace.

I I. AT/39/26I. Alabaster. Level VII. Found at the bottom of the stone-lined shaft, room I 7 of Yarim-Lim's palace. Pl. LXXX.

I 2. AT/39/1 58. Alabaster. Level VII. Found on the floor of room 2 of Yarim-Lim's palace.

I Miss H. J. Kantor, 'The Aegean and the Orient in the Second Millennium в.c.', Archaeological Institute of America, Bulletin No. I, 1947, would make our lamp an import from the Greek mainland, believing that 'Crete was no longer an important commercial power after the close of the Middle Minoan period' ( $\mathrm{p} .74$ ); it is difficult to reconcile this theory with the Syrian evidence.

2 The hollowing-out was started with close-set holes made with a tubular drill (not a solid round-headed drill as in the Level VII workshop) and a chisel and a rasp were used for breaking away the divisions between the holes and for enlarging from them.

3 'The second hypothesis is difficult to maintain in view of the fact that the Alalakh lamp is unique on the Asian mainland. The earliest example of a columnar lamp was that with trefoil stem from Level XII A, AT/47/45, Fig. 8of. 
I 3. AT/39/252. Alabaster. Level VII. Found at the bottom of the stone-lined shaft, room I 7 of Yarim-Lim's palace.

I 4. Restored from fragments which were not catalogued. Alabaster. Pl. LXXX. Level VII, found on the floor of room 2 of Yarim-Lim's palace.

I 5. AT/39/244. Alabaster. Level VII. Found at the bottom of the stone-lined shaft, room I 7 of Yarim-Lim's palace. P1. LXXX.

I6. Restored from fragments which were not catalogued. Alabaster. Level VII; found on the floor of room 2 of Yarim-Lim's palace.

I 7. AT/38/66. Alabaster. Level IV. Found on the floor of room I 6 of Niqme-pa's palace. Pl. LXXX.

I 8. AT/39/25 I. Grey steatite. Level VII. Found above the floor of room I 8 of Yarim-Lim's palace, by and probably belonging to the Level V grave ATG/39/57. Pl. LXXX.

1 9. AT/47/34. White marble; fragment only. Level II, from the temple annexe.

20. AT/46/38. Alabaster, much burned and the neck and top of handle missing. Level I A (?); found embedded in the brickwork of the back wall of the temple sanctuary, probably as a foundation-deposit; v. p. 84 .

2 I. AT/48/64. Green steatite, highly polished. Fragment only; part of the handle of a jug of the form of No. 20 but more elaborate, the handle being fluted above with incised pattern below. Level V-IV, temple site.

22. AT/46/72. Alabaster; imperfect. Level I, found in Sq. N i 5 .

23. AT/38/240. Alabaster. Level V-IV (?), found in the top-soil of Site 'H' (Sq. V 2O) and therefore not likely to be later than Level IV. Pl. LXXX.

24. AT/49/I 2. Alabaster. Fragment only from the base of a 'spill-vase' with horizontally ribbed sides. Level XI, temple area.

25. AT/38/1 46. Grey and white marble. Level IV. Found on the floor of room 27 of the Niqme-pa palace. Pl. LXXX.

26. AT/38/77. Alabaster. A vase-lid; the hollow ring on the top probably was to receive a knobhandle in a different material. Level IV. Found in room 6 of the Niqme-pa palace.

27. AT/39/I 8. Alabaster stand or pommel (?). Level VI-V. Found in the levelling of the terrace above the ruins of the Yarim-Lim palace.

28. AT/39/27. Alabaster. Level III; found in Sq. G 7 .

29. AT/39/I 4. Alabaster. Level III (?); found above the Level IV stratum in Sq. N Io. A similar piece, $\mathrm{AT} / 39 / 264$, was found in Sq. K I 4 below the Level II stratum.

Apart from these there were a few fragments which did not give complete sections but agreed more or less with forms listed above; viz.

Form I. Fragments from a large marble dish (AT/38/203). Level IV. Found scattered in the Niqme-pa palace.

Form 6. Black steatite (AT/39/I 57). Level VII. Found on the floor of room 2 of the Yarim-Lim palace.

Form 8. Alabaster. Fragments (AT/39/I 55). Level VII. Found on the floor of room 2 of the Yarim-Lim palace.

Form I 2. Alabaster. Fragments (AT/39/ I $5^{8}$ ). Level VII. Found on the floor of room 2 of the Yarim-Lim palace.

Form I 3 (?). Green steatite. Fragment (AT/48/22). Level VII, temple site.

Form 20 (?). Alabaster. Fragments $(\mathrm{AT} / 38 / 289)$ with grooved handle but with ring base. Level IV. Found in room 6 of the Niqme-pa palace. 


\section{(c) GLAZED WARE AND.GLASS}

Vessels of glazed frit were not numerous at Atchana. The earliest dated examples came from Level VII, viz. the swivel lid of a toilet-box in light blue with black lines, AT/39/ 248 , Fig. $74 a$, found in room 20 of the Yarim-Lim palace, a human mask, AT/39/ I I I, Pl. LXVIe, from room 2, and a fragment of a libation-pourer the back of which shows the human hand in relief, AT/39/234, from room I 8 , and fragments of a small plain straightsided cup $0.05 \mathrm{~m}$. high with square base and circular rim, Fig. 74a, I, from room I 6 of the same Yarim-Lim palace. From Level VI came AT/39/52, Fig. 74a, 6, part of a bowl with a lotus-petal design in greenish-blue glaze and black, and another, AT/47/168, Fig. 74a, 4, with lotus-petals outlined in brown on a greenish-blue ground. A very similar fragment, AT/39/3 IO, Fig. 74a, 3, came from Level V, and from Level V or just below it came several pieces of polychrome goblets with lotus pattern, ATP/47/5I ; in the Level V stratum below house 39/B there was a fragment of a vessel in fine glazed frit, the surface covered with a seed-pattern moulded in relief (Fig. 74a, 5). Much the most important fragment from Level $V$ was AT/46/223, Pl. LXXXIII $a$ part of a bowl of blue-glazed frit (bleached white) decorated with lotus and quatrefoil patterns and a panel showing a seated figure of a man in front of a table covered with loaves of bread, accompanied by an inscription giving the normal offering-formula ( $v . p .7 \mathrm{I})$; since the design is not, as usual, in brown glaze but done after firing in some sort of water-colour paint, the bowl may well be a local product.

A fragment of a vase-handle, AT/47/1 74, Fig. 74a, 8, with blue rosettes inlaid in a white ground in the best Tell el Amarna style was found in the temple area in Level IV or early III. These are our only examples accurately dated to levels. It is perhaps surprising that at Alalakh glazed frit should have been so little used for vases (it was common enough for beads) when in Egypt faience vases were so popular.

It is possible that objects made of lapis lazuli paste (instead of the normal frit) were originally glazed; no trace of glaze survives, but the material as found is always soft and powdery, light-coloured, and with a matt texture, which certainly results from decomposition and was not an original feature. The best example found by us was AT/48/1 8 , Pl. LXXXIIIf, a slender vase with a handle in the form of a couchant lion. This came from the 'treasury' of the Level II temple but may well have been preserved there from a much older time. In Level VI there was found a small fragment (AT/47/I 73) of an open bowl of the same material the handle of which had been in the form of a couchant lion precisely like that of $\mathrm{AT} / 48 / \mathrm{I} 8$ in its modelling. An even finer fragment was AT/39/327, Fig. $74 a$, 9, part of the head of a bull probably though not certainly from a vase. The material was used also for making cylinder seals (e.g. Pl. LXV, No. 9I), for which purpose it was employed in Mesopotamia as early as the Kassite period.

\section{GLAZED EARTHENWARE}

Much greater importance attaches to the discovery of glazed earthenware in various levels from VI to I. 

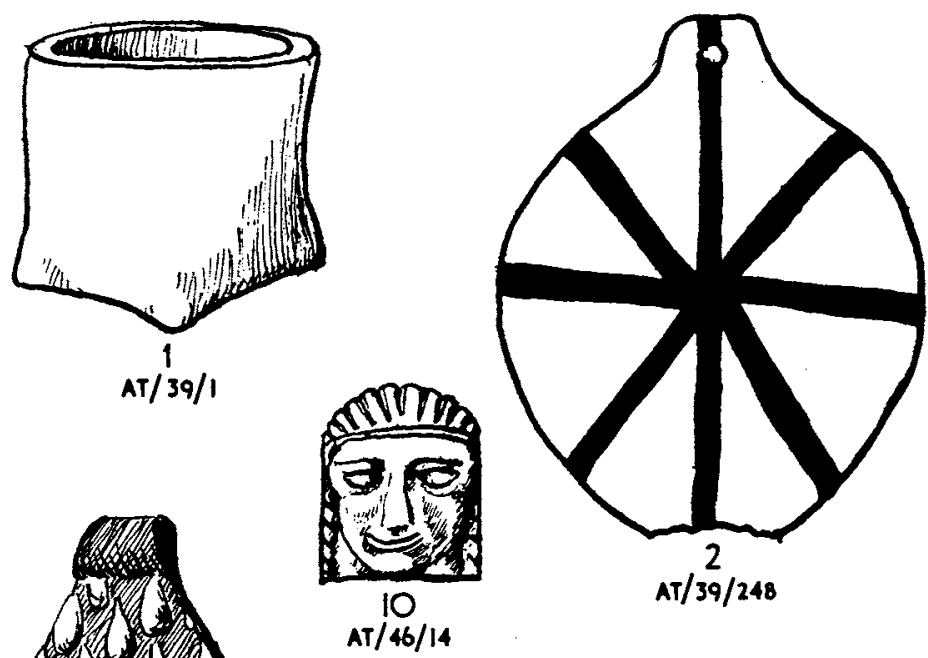

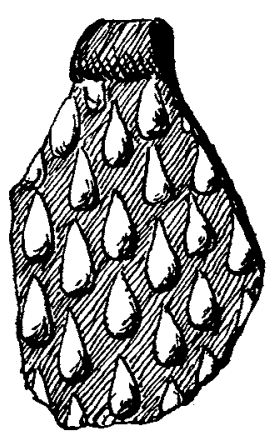

5 HOUSE 393

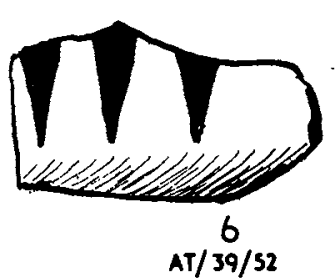

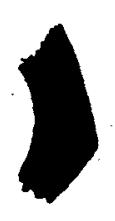

(a) Glazed ware
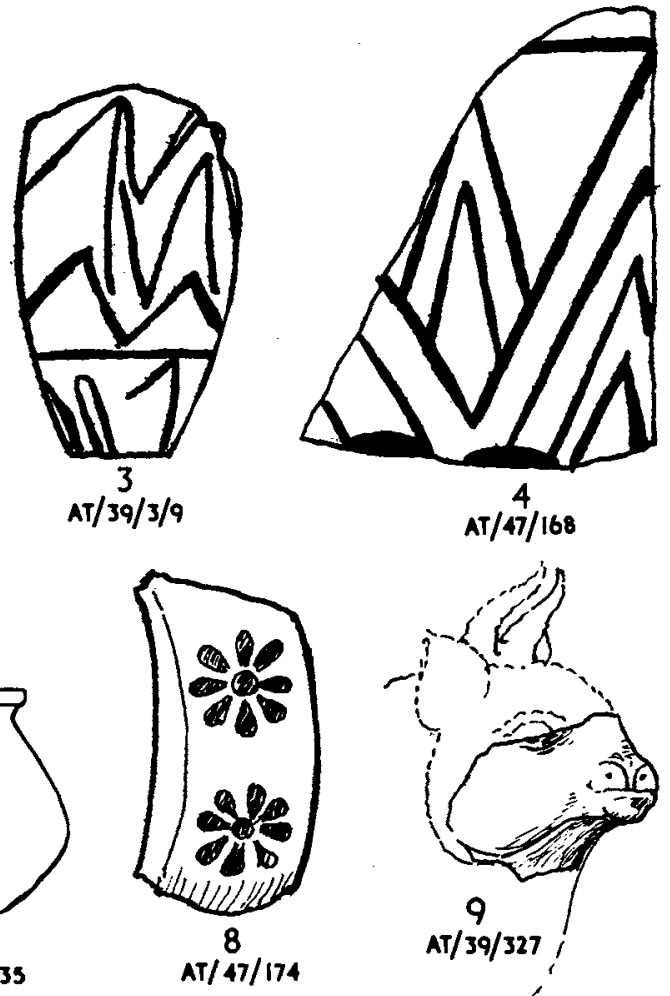

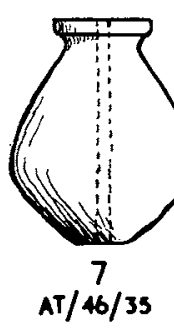

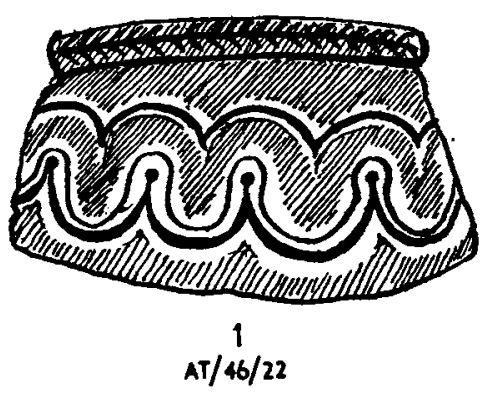
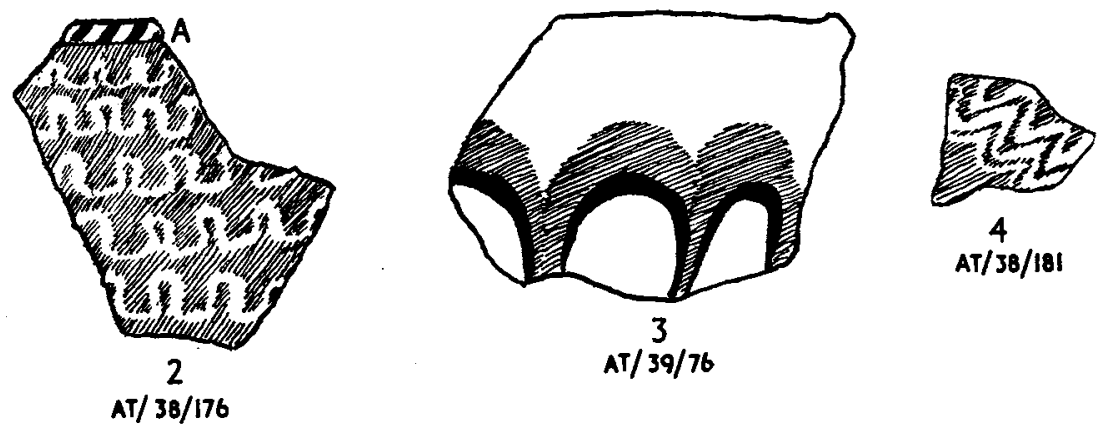

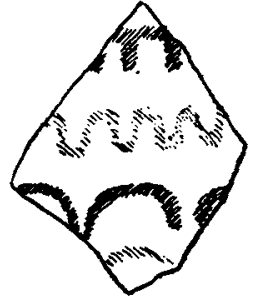

AT/39/149

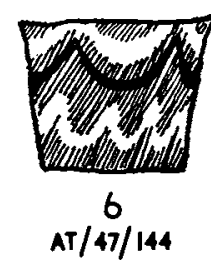

AT/47/144

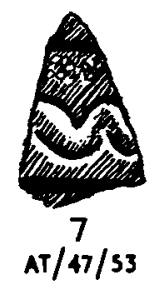

(b) Glass

FIG. 74

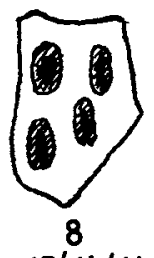

$A T / 46 / 44$
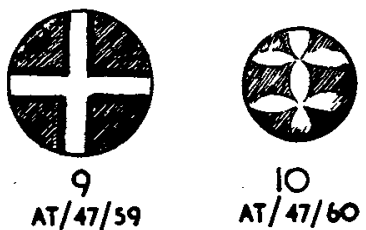
When we were excavating the courtyard of the late temple in I 946 we were disconcerted by finding fragments of a large pot covered inside and out with blue glaze, the body being of ordinary clay. Since I did not know of any glazed pottery having been attributed to a date anything like so early as that of our site I was at first anxious to believe that the fragments were intrusive; the soil here was admittedly disturbed, but it was difficult to explain how sherds which I assumed to be not earlier than the Roman period could have worked down to such a depth, especially as there was no late occupation of the site to justify the supposition of a rubbish-pit. When, however, fragments of the same pot were found about a metre away not in disturbed soil but under a patch of unbroken mud-brick paving of Level II, the authenticity of the early date had to be accepted. Actually this pot (AT/46/ I 8) does not stand alone. In the temple of Level I, phase A, a plumb-bob of green-glazed pottery (AT/46/35, Fig. 74a, 7) was found embedded in the brickwork of the NW. wall of the sanctuary; either it was deliberately placed between the bricks for some ritual purpose, in which case it is contemporary with the building of the temple, or it was accidentally present in the mud mortar, in which case it should belong to Level II. On the floor of room 30 of the Niqme-pa palace (Level IV) there were found the fragments of a bottle, nearly complete, $0.15 \mathrm{~m}$. high $\left(\mathrm{ATP} / 3^{8 / 2}\right.$ I 8$)$; it is of clay originally greenish-drab in colour though much discoloured by the fire that destroyed the palace, covered with a glaze once greenish-blue but now bleached which is much crackled and inclined to peel off from the body. A complete vase $0.18 \mathrm{~m}$. high (ATP/39/ I 97, Pl. LXXXIIIb) was found in a Level V grave, ATG/ 39/80. A few miscellaneous fragments of green- or blue-glazed pottery $(\mathrm{ATP} / 47 / 55)$ occurred in Level VI.

We have, accordingly, a small series of glazed earthenware vessels, each in a wellauthenticated setting, ranging from the thirteenth century back to the seventeenth. Hitherto excavations have given us no parallel to this. In Egypt there seems to be no record of glazed pottery before the Roman period, ${ }^{\prime}$ although there the use of silicate glaze on a frit body goes back to the First Dynasty. In southern Mesopotamia it is common enough in the Persian period, but I do not know of any example that can safely be assigned even to the Neo-Babylonian time. Toll, in his very detailed discussion of the subject, ${ }^{2}$ favours a very late date, but it must be remembered that Europos was founded too late to give any evidence for conditions prior to the present era. When Toll says of the cylindrical jar 'there is no positive evidence to place the beginning of this type before the Ist century B.c.' and of the shorter globular form 'the earliest specimens probably belong to the Ist century в.c.' (p. 54), he is presumably thinking of his own site rather than of north Syria generally; as a matter of fact both the types occur in the sixth-century cemetery of Deve Huyuk, ${ }^{3}$ where glazed pottery was not uncommon. On the other hand, Toll refers to the glazed bricks of Assyrian palaces,4 'In Mesopotamia the Middle-

I A. Lucas, 'Glazed Ware in Egypt', in Fournal of Egyptian Archaeology, xxii (1936), p. I 4 I.

2 N. Toll, Excavations at Dura-Europos, Final Report, Part I, Fasc. I, 'The Green-glazed Pottery'.
3 Liverpool Annals of Archaeology and Anthropology, vol. vii (I9I4-I6), p. I I 5 .

4 Tukulti-Enurta; v. Andrae, Farbige Keramic aus Assur. 
Babylonian and Assyrian period has polychrome glazed pottery which reached its acme in Assyria about the eighth century в.c.', and concludes that as regards the body material 'the transition from quartz to clay occurred in Mesopotamia at the beginning of the first millennium'. Evidently it is to north Mesopotamia that we must look for a parallel to our - Atchana specimens of glazed earthenware, but even so the time-gap between them and the Tukulti-Enurta bricks is disconcertingly wide and might induce us to question the validity of the Atchana dating were not the purely archaeological evidence supplemented by documentary records. Mr. Gadd has drawn my attention to two articles ${ }^{r}$ dealing with a seventeenth-century cuneiform tablet which gives recipes for the manufacture of glazed earthenware. There can be no doubt that the Atchana vases were made according to this prescription; the glaze is a lead glaze and the greenish tinge of the (light-coloured) body-clay of ATP/38/2 I 8 is the 'bloom' obtained by preparing the clay with a mixture of copper and vinegar.

The technique of glazing clay pots was then known at least as early as the seventeenth century B.C. That examples of it should be so rare as to make the Atchana specimens unique hitherto is not surprising. The Egyptian glazier, and the Syrian, using a silicate glaze, had never been able to overcome the difficulty of making it adhere to a clay body and therefore had to limit himself to frit or to steatite. The Assyrian discovered the secret of adding lead to the ordinary glass and of preparing the body-clay with copper acetate, but he jealously guarded this secret—-the 'art and mystery' of his trade-so much so that in his written recipe he 'purposely disguised his meaning by artifices of writing which amount to a form of cryptography' intelligible only to 'members of his Guild, who were doubtless privy to his peculiar cryptograms'. It was not until the seventh century (so far as the extant evidence goes) that the formulae were published in ordinary language, and it is then that glazed pottery came into general use in Mesopotamia.

\section{GLASS}

\section{See Fig. $74^{b}$}

Examples of polychrome glass vessels were not uncommon, but in all cases they were fragmentary and generally in bad condition. This, in the damp soil of north Syria, was to be expected. The technique of the manufacture of these vessels - the winding of glass rods of different colours round a clay core and their subsequent fusion-desiderates a metal that melts at a low temperature, and glass of that quality is peculiarly liable to decay by lamination; and since the subsequent fusion went no farther than was required for the purpose in view, the same process of decay was apt to attack the junctions of the ill-amalgamated rods and so affect the main substance of the glass. As a result, not only was the surface always disfigured by excessive iridescence but, very often, the whole object would collapse in minute crystals.

The earliest dated examples of polychrome glass occurred in Level VI, e.g. AT/39/ 225, with 'combed' pattern in white and blue. Some examples were not vases. AT/47/59

I C. J. Gadd and R. Campbell Thompson, 'A MiddleBabylonian Chemical Text', and H. Moore, 'Reproductions

of an Ancient Babylonian Glaze', in Iraq, iii, p. 87, and $x$, p. 26. 
(Fig. $74 b$, Io) was a roundel, perhaps for inlay, of green glass with a cruciform ornament in yellow and opaque white with four knobs in relief between the arms of the cross. Probably of the same date (it was found immediately above the destruction-debris of Level VII, but the stratification here, in Sq. O I 3, was confused) was AT/47/60, Fig. $74 b$, 9, a large spherical bead of grey glass with an interlocking quatrefoil design in white. ${ }^{\mathrm{I}}$

From the Level $\mathrm{V}$ house $39 / \mathrm{B}$ came a few fragments of vessels in light blue and yellow glass, AT/39/76. From just above the Level VII palace ruins, belonging either to Level VI or to Level V, came fragments of a vase with combed pattern in white, yellow, and dark brown or black. In the Niqme-pa palace, room 3 I, was found part of a bowl of fine quality having a waved pattern in yellow on blue; Level IV also gave us an entire (though broken) vase, found in a grave, ATG/39/85, a good fragment in grey (perhaps originally green), yellow, and opaque white (AT/47/I 44), and (AT/47/1 45) fragments of three bottles found together in a deposit just above the ruins of the Level V 'Mithraeum'; of these one in particular, a large flask with ribbed body and neck, was of the finest quality with the rich colouring that is typical of the examples found at Tell el Amarna in Egypt.

Level III produced a good example of the normal 'combed' pattern and one (AT/46/ I I 4) of a different technique, white glass with oval spots inlaid. ${ }^{2}$ The same technique recurred in Level II (AT/46/75), and it was in Level II that by far the greater number of pieces were recorded, some of them, e.g. AT/46/22, part of the rim of an open bowl with a diameter of $0.07 \mathrm{~m}$., exceptionally fine; one, AT/39/1 49, is of the comparatively rare class having the design (in pale green and yellow) on a ground of opaque white; $\mathrm{AT} / 47 / 33^{\mathrm{B}}$ combines the techniques of combing and of inlay.

No examples were recorded from Level I.

The evidence would seem to show that as soon as the manufacture of these highly decorative vases was developed (in south Syria, so far as we can judge) Alalakh, as a royal city, began to import them as objects of luxury. By the middle of the fifteenth century at least they were in fairly common use and towards the end of the fourteenth century enjoyed their widest vogue; but they were at no time so numerous as to suggest that they were the product of a local industry rather than imports of a more or less costly sort.

The more important fragments found are illustrated on Fig. $74 b$.

No. I. AT/46/22. Part of a large open-mouthed bowl of polychrome glass of unusually fine quality; blue glass with festoons of white overlaid with yellow; the rim has a herringbone pattern in yellow. From the 'treasury' of the Level II temple.

No. 2. AT/38/ I 76. Blue (?) glass, much faded, with design in yellow; part of a bowl with reeded rim of darker colour. Level IV; in room 3 I of the Niqme-pa palace.

No. 3. AT/39/76. White glass, opaque, with design in yellow and dark brownish-black. Found immediately above the ruins of the Level VII palace; it belongs either to Level VI or to Level $\mathrm{V}$.

I Found with the fragment of a lapis lazuli paste bowl having a handle in the form of a couchant lion, AT/47/I73, in the Level VI temple area.

2 This is rather reminiscent of the familiar 'eye' beads. 
No. 4. AT/38/1 $8 \mathrm{I}$. One of several small fragments of a vase, the shape doubtful, found in and above room 30 of the Niqme-pa palace; the sherds first found, at the higher level, were attributed to Level III, but all seem to belong to Level IV. Blue glass with design in yellow.

No. 5. AT/39/149. Fragment from the neck of a bottle of opaque white glass with design in yellow and in pale green. Found in Sq. J I 5, Level II, $0.60 \mathrm{~m}$. below a Level I floor.

No. 6. AT/47/ I 44. Fragment of grey glass with design in yellow and white. Level IV.

No. 7. AT/47/33. Fragment with blue glass ground whereon horizontal yellow bands between which a festoon pattern in yellow and white and clusters of very small white spots. Level II, in the annexe to the temple.

No. 8. AT/46/ I I 4. Fragment of a vessel of white glass inlaid with ovals of green in slight relief. Level II, Sq. N I 9.

No. 9. AT/47/59. Disk (for inlay ?) slightly concave below, of green glass whereon a cruciform pattern of white bordered with yellow; between the arms of the cross are small knobs in relief. Level VI.

No. I0. AT/47/60. Bead, spherical, of grey glass inlaid with quatrefoil ornament in white. Level VI.

$\mathrm{AT} / 47 / 175$. Fragments of three bottles, more or less complete, of polychrome glass; one large flask is of very fine quality with vertical ribbing on neck and body. Found together in a deposit directly over the 'Mithraeum' and belonging to Level IV or possibly to early III-it was not possible to decide exactly the level from which the hole had been dug.

$\mathrm{AT} / 39 / 320$. A similar bottle, broken, was found in the Level IV grave ATG/39/85.

The technique of moulding in glass is illustrated chiefly by figurines, $\mathrm{AT} / 48 / 4, \mathrm{Pl}$. LVI, on which $v$. supra, p. 247, AT/37/77, AT/39/66, AT/46/I 4, all struck from the normal type of mould used for figurines in terra-cotta. The only vase fragment is $\mathrm{AT} / 46 / 2 \mathrm{I}, \mathrm{Pl}$. LXXXIII, part of the neck of a vase in deep blue glass on which are a pair of antelope horns moulded in relief, remarkably fine work. It comes from Level II, from the 'treasury' of the temple of that level. 


\section{CHAPTER XII}

\section{THE POTTERY}

\section{(a) WARES IN SUCCESSIVE LEVELS}

$\longrightarrow \mathrm{HE}$ best evidence for the sequence-dating of the early pottery was given by the great 'stratification pit' dug in 1946 ( $v$. p. 10). This produced abundant material ranging from Level XI to Level XVI, at which point work was stopped by water. From the temple site (v. Chapter II) we recovered a great deal of fine pottery belonging to Levels XII and XIV and, since here we dug much more deeply, some that antedated Level XVI and illustrated the earliest wares used on the site. ${ }^{I}$ Illustrative material for these periods was forthcoming from the filling of the earth rampart underlying the Level VI citadel wall (v. p. I35), but this had no value for detailed sequence-dating. ${ }^{2}$ For Levels X, IX, and VIII we had rich and well-stratified deposits in rooms underlying the Level VII temple; the sherds here were very numerous and appeared to be throw-outs from the older temples. ${ }^{3}$ A few graves on the ' $\mathrm{H}$ ' site which could be assigned to Level VIII by the analogy of the pottery in them with dated specimens from the deposit and from the stratification pit added a certain number of vase-types. ${ }^{4}$

I As we were digging under water accurate observation of levels was not possible. Some of the sherds found immediately below water-level may belong to Level XVI, being throw-outs from the temple of that period; the lower sherds may very well represent more than one occupation-level, but since no evidence to that effect could be recognized in the semi-liquid mud, we perforce lumped them all together as 'Level XVII'.

2 This early pottery was first found by us in I 937 (our first season) in the earth rampart supporting the citadel wall. In describing it ( $A . \mathcal{F}$. xviil, pp. I 4 sqq.) I distinguished between the wares in the upper 'ash' stratum and those in the older core of the rampart, and I pointed out that the sherds in those two strata were on the whole closely akin, so much so that the time-gap between the constructions must be short; there was at that time no reason to suppose that the flornit of the painted pottery was very long; but the facts as we now know them invalidate my conclusion. A further mistake was due to the fact that the chronology of the levels had not then been in any way established. I noted that in the upper 'ash' stratum there occurred fragments of small jars of very light, almost white, clay (Type Io6b) which appeared also in certain inhumation-graves in the town; I rightly dated them to the early part of the second millennium B.c. but wrongly attributed them to Level IV, which I was then putting too early. Consequently I thought that they established a link, though a tenuous one, between the fottery in the later rampart and Level IV, but stated that the painted wares were proved by the conditions in which such sherds occurred in the building-levels to be definitely earlier than Level IV. The truth is that the graves are of Levels $\mathrm{V}$ and VI, and the pottery 'Type ro6 does indeed occur in those levels but not in Level IV and is much more characteristic of Level VIII.

3 The number of types was in consequence very limited, and the deposits can scarcely be called representative of the pottery of the time as a whole.

4 In the I 938 season sherds of painted pottery just like those from the rampart were found commonly in the occupation-levels of the outlying site $H$ (see P. I 39). Here we dug at least four successive building-levels all of which were seen to be older than Level IV and more or less contemporary with the two stages in the construction of the citadel rampart excavated in I937; these were labelled Levels V, VI, VII, \&c., and it was rightly suggested that a tablet of the time of Hammurabi found out of its horizon might properly belong to Level VII. Unfortunately the lack of criteria for early pottery prevented me from making a correct analysis of the graves found below the house floors, and these were therefore lumped together as all belonging to one period, whereas in fact they range from Level IV to Level VIII. The soil therefore into which the grave-shafts were sunk represents a period older than the graves and the painted sherds in the earth should on purely archacological grounds range from Level $\mathrm{V}$ to Level $\mathrm{X}$. 
For Level VII the main source of supply was the Yarim-Lim palace; here we have the advantage of a fixed date, and fortunately the pottery was fairly abundant. Most of the Level VI pottery came from rubbish-pits, a little from the house sites and the fortress area, and a few types from graves belonging or attributed to that level. For Level $V$ the house sites were much more productive, graves more numerous, and rubbish-pits equally helpful. An immense amount of pottery was found in Niqme-pa's palace, and a great deal in the private houses of Level IV; the graves, too, of this level were comparatively rich; the period is indeed far better represented than any other. None the less the houses and graves of Levels III and II gave us a clear picture of the pottery of those two periods; for Level I the disturbance of the top-soil made the evidence of the houses less satisfactory, but some rooms had their contents well preserved and further types came from the graves.

On Pls. CIX-CXXIV is given a corpus of all the vase types found, with the exception of the Mycenaean and 'Cypriote' which are dealt with separately. On pp. 332-40 is a tabular analysis showing the occurrence in the respective levels of all dated specimens (vases found in indeterminate conditions are not included) with the number of examples from each level. The corpus and the analysis, together with the brief notes on material given on pp. $322-32$, will, I hope, supply all necessary information and obviate the need of a detailed catalogue which would be of inordinate length.

Even a cursory examination of the analysis will demonstrate a fact which struck us greatly in the course of the excavations. Very few types continue in use throughout the early and the late periods; the dividing line is at Level VII. From Level XVI up to Level VIII there is a remarkable uniformity. With Level VII there comes an almost complete break with tradition and the introduction of a whole range of new shapes. Levels VI and V show in a limited degree a revival of old fashions, a certain number of Level VIII types reappearing for the time being (they die out towards the end of the period), while side by side with them some of the innovations of Level VII persist in use. Level IV marks another new departure, bringing in a very great many novelties, not a few of them being foreign imports or copies of such. Above this level innovations are rare and some at least of them seem to be due to foreign influences.

From Level XVI up to Level VIII the uniformity of the pottery both in shape and in technique is most striking. The first impression made by the mass of potsherds from our stratification pit was that throughout the whole of the long period represented there was no change at all. Later it could be recognized that although some of the most characteristic wares, especially those with painted decoration, are persistent and the fragments of such could be dated only by their occurrence in a particular level and not by any internal criterion of style, yet certain distinctions could be made; in Levels IX and VIII there were quite definite modifications of the old tradition, and Level XVII was exceptional in many respects, seeming to mark the beginnings of the style that was to hold its own through the later periods. At the same time the pottery is so homogeneous that a general description can be given applying to all levels alike; exceptions to the general rule will be detailed in the notes on the individual levels. 
All vessels are wheel-made, except for a few unusually large store-jars. ${ }^{\mathrm{I}}$

All vessels were fired in well-constructed kilns giving an equally distributed and clear heat. On a painted vase the paint often shows gradations of colour, but such are seldom very pronounced; the body-clay has a very even colour and there are few if any flares due to unregulated draught. The smother-kiln is practically not used. ${ }^{2}$

The clay is usually well levigated. The amount of engrais varies greatly in accordance with the use for which the vessel was intended; in the cooking-pots the proportion is high, in the finer wares there is none (N.B., painted decoration is applied only to the fine-grained wares having no engrais). The tempering is with grit of varying degrees of fineness; straw or grass tempering is never used.

The colour of the clay is either drab or pinkish-red, with the exception of the cookingpots, which are of brownish clay. The drab ware shows a fairly uniform section but the surface is often water-worked to a smooth finish which is greenish-grey rather than drab. The red ware shows a body clay of a light brick colour, but with water-working the surface becomes a lighter pink. In both cases the original clay was the same and the difference of colour is really due to a difference of heat; the potter fired his vessels to a greater or a less degree according to the use which they were intended to serve; the colour is therefore a by-product.

There is no use of slip.

An all-over haematite wash occurs in Level XVII, but thereafter not until Level IX. Burnishing is found in Level XVI and thereafter is virtually not used prior to Level IX, but a few fragments of lightly burnished brown ware came from Level XV. It is safe to conclude, since the brown wares are essentially of the cooking-pot class, that the burnish is not decorative but utilitarian, intended to make the vessel more waterproof. On the other hand, there are a few examples of decorative burnish, the best of which is the jug $\mathrm{ATP} / 47 / \mathrm{I} 29, \mathrm{Pl}$. LXXXIV; this is a painted vase with biscuit-coloured surface ragburnished after painting; it came from the Level XIV temple, as did the other example figured alongside it, A'T/47/1 42, and since a fragment with similar design to the last, in the same technique, was found in a Level XV house and nothing of the kind was found in other levels, we can assume that this, the finest type of painted pottery, is peculiar to the earliest periods.

There are three methods of decoration, by horizontal bands of rope pattern in relief, which is found on large vessels only, by combing, and by painting. The combed decoration usually consists of wavy bands round the shoulder of the vessel. The paint is haematitic and varies in colour from red through every shade of brown to black; the difference is entirely due to differences of temperature in firing and the whole range of tones may occur on a single horizontal band on one vase, but as a general rule where the body clay has been fired to reddish-pink the paint tends to be dark red, where the body clay has

\footnotetext{
I In some of the big jugs with narrow necks the clay was first pressed up vertically from the inside while the wheel was stationary and then the outside was shaped by turning; as a result the inside, near the base, looks as if it were hand-made,

B 2501
}

but the vessel was none the less made on the wheel. The only real exception is Type $13, q .0$.

2 An exception is a black example of Type 23 from Level XVII, v. Notes on Pottery Types, p. 323 . 
been fired to greyish drab the paint is dark brown or black. ${ }^{\mathrm{I}}$ Painting, if not confined to a very few shapes, seems at least to be most common on a very limited range. ${ }^{2}$

The forms of vessels that could be identified are given in the tabular analysis, p. $33^{2}$, but the list is, of course, not exhaustive. Handles are fairly common; bases are round or flat and there are also ring-bases; pedestal bases do occur, but are rare.

In order to obtain the maximum of evidence for development in the pottery all the sherds from each level were collected and classified. Only in relatively few cases could the shape of the vessels be determined, and even then it was seldom possible to give more than a general description-bowl, jar, or jug-without specifying the particular variant of that shape. The different types of base were recorded, ${ }^{3}$ as were the handles, and the number of examples of painted, combed, or rope-pattern relief decoration. Since the quantity of sherds varied greatly in the different strata a mere statement of the number of handles, ring-bases, \&c., would have been misleading as a basis for comparison; accordingly a rough estimate was made of the total number of sherds in the stratum and under each subheading of handles, \&c., was given the percentage of that total. But even

\begin{tabular}{|c|c|c|c|c|c|c|c|c|c|c|c|}
\hline $\begin{array}{c}\text { Number of } \\
\text { sherds }\end{array}$ & wols & lates & Fugs & Fars & Handles & $\begin{array}{l}\text { Ring } \\
\text { bases }\end{array}$ & $\begin{array}{l}\text { Flat } \\
\text { bases }\end{array}$ & $\begin{array}{l}\text { Stem } \\
\text { bases }\end{array}$ & Painted & Combed & Rope \\
\hline evel XVI & & & & & & & & & & & \\
\hline vel & $\begin{array}{c}58 \\
4.46 \%\end{array}$ & $?$ & $?$ & $\begin{array}{c}5 \circ \\
3.84 \%\end{array}$ & $\begin{array}{c}4 \\
0.03 \%\end{array}$ & $0.68 \%$ & $\begin{array}{r}3 \circ \\
2 \cdot 3 \%\end{array}$ & $\begin{array}{c}3 \\
0.24 \%\end{array}$ & $\begin{array}{c}35 \\
2.69 \%\end{array}$ & $\begin{array}{r}2 \mathrm{I} \\
\mathrm{I} \cdot 6 \%\end{array}$ & $\begin{array}{c}\text { Io } \\
0.76 \%\end{array}$ \\
\hline & $\begin{array}{r}165 \\
3.6 \%\end{array}$ & $\begin{array}{c}\text { I } 3 \\
0.28 \%\end{array}$ & $\begin{array}{l}? \\
\ldots\end{array}$ & $\begin{array}{r}226 \\
4 \cdot 9 \%\end{array}$ & $\begin{array}{c}\text { I2 } \\
0.26 \%\end{array}$ & $\begin{array}{c}34 \\
0.74 \%\end{array}$ & $\begin{array}{r}16 \mathrm{I} \\
3.5 \%\end{array}$ & $\begin{array}{c}5 \\
0.109 \%\end{array}$ & $\begin{array}{c}150 \\
3.28 \%\end{array}$ & $\begin{array}{c}209 \\
4.59 \%\end{array}$ & $\begin{array}{c}45 \\
0.98 \%\end{array}$ \\
\hline 6 , & $\begin{array}{c}240 \\
3.6 \%\end{array}$ & $\begin{array}{r}20 \\
0.3 \%\end{array}$ & $\begin{array}{c}3 \\
0.04 \%\end{array}$ & $\begin{array}{c}346 \\
5 \cdot 24 \%\end{array}$ & $\begin{array}{c}37 \\
0.56 \%\end{array}$ & $\begin{array}{c}70 \\
\mathrm{I} \cdot 06 \%\end{array}$ & $\begin{array}{c}\text { I } 9 \text { I } \\
2.89 \%\end{array}$ & $\begin{array}{c}14 \\
0.21 \%\end{array}$ & $\begin{array}{c}213 \\
3.21 \%\end{array}$ & $\begin{array}{c}329 \\
4 \cdot 99 \%\end{array}$ & $\begin{array}{r}\text { I06 } \\
\text { I. } 3 \%\end{array}$ \\
\hline $\begin{array}{l}\text { evel XIII } \\
\text { I I, } 500\end{array}$ & & 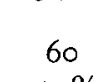 & 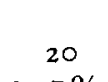 & & 38 & 90 & & 3 & & & 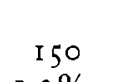 \\
\hline evel XI & & $0.52 \%$ & $17 \%$ & $7 \cdot 86 \%$ & $49 \%$ & $1 \cdot 7 \%$ & & $3 \%$ & I.99\% & $6.13 \%$ & $\mathrm{I} \cdot 3 \%$ \\
\hline 2, & $\begin{array}{c}146 \\
5.2 \%\end{array}$ & $\begin{array}{c}\text { I I } \\
0.39 \%\end{array}$ & $\begin{array}{c}4 \\
0.14 \%\end{array}$ & $\begin{array}{c}\text { I } 37 \\
4 \cdot 18 \%\end{array}$ & $\begin{array}{c}6 \\
0.21 \%\end{array}$ & $\begin{array}{r}37 \\
\mathrm{I} \cdot 3 \%\end{array}$ & $\begin{array}{r}98 \\
3.5 \%\end{array}$ & $0.1 \%$ & $\begin{array}{r}6 I \\
2 \cdot 1 \%\end{array}$ & $\begin{array}{l}168 \\
6 \%\end{array}$ & $\begin{array}{c}26 \\
0.92 \%\end{array}$ \\
\hline $\begin{array}{l}9,5 \\
\text { eve }\end{array}$ & $\begin{array}{c}508 \\
5 \cdot 1 \%\end{array}$ & $\begin{array}{r}20 \\
0.2 \%\end{array}$ & $\begin{array}{c}19 \\
0.19 \%\end{array}$ & $\begin{array}{r}436 \\
4 \cdot 4 \%\end{array}$ & $\begin{array}{c}53 \\
0.53 \%\end{array}$ & $\begin{array}{c}\text { I } 67 \\
\text { I.67\% }\end{array}$ & $\begin{array}{c}215 \\
2 \cdot 17 \%\end{array}$ & $\begin{array}{c}5 \\
0.05 \%\end{array}$ & $\begin{array}{r}550 \\
5 \cdot 5 \%\end{array}$ & $\begin{array}{r}377 \\
3.8 \%\end{array}$ & $\begin{array}{c}72 \\
0.72 \%\end{array}$ \\
\hline $5, \mathrm{IC}$ & $\begin{array}{c}247 \\
4.8 \%\end{array}$ & $\begin{array}{c}35 \\
0.68 \%\end{array}$ & $\begin{array}{c}6 \\
0.11 \%\end{array}$ & $\begin{array}{r}245 \\
4.8 \%\end{array}$ & $\begin{array}{c}\text { I } 8 \\
0.35 \%\end{array}$ & $\begin{array}{r}78 \\
\mathrm{I} \cdot 5 \%\end{array}$ & $\begin{array}{r}190 \\
3.7 \%\end{array}$ & .. & $\begin{array}{r}244 \\
4 \cdot 7 \%\end{array}$ & $\begin{array}{r}233 \\
4 \cdot 5\end{array}$ & $\begin{array}{r}75 \\
\mathrm{I} \cdot 4 \%\end{array}$ \\
\hline $\mathrm{I}, 60$ & $\begin{array}{c}83 \\
5.18 \%\end{array}$ & $\begin{array}{r}50 \\
3.1 \%\end{array}$ & $\begin{array}{c}10 \\
0.62 \%\end{array}$ & $6 \%$ & $\begin{array}{c}14 \\
0.87 \%\end{array}$ & $\begin{array}{c}3 \mathrm{I} \\
\mathrm{I} \cdot 93 \%\end{array}$ & $\begin{array}{c}30 \\
\mathrm{I} \cdot 87 \%\end{array}$ & $0.18 \%$ & $\begin{array}{r}104 \\
6.5 \%\end{array}$ & $\begin{array}{r}73 \\
4.5 \%\end{array}$ & $\begin{array}{c}19 \\
\text { I.I } 8 \%\end{array}$ \\
\hline 2,2 & $\begin{array}{c}265 \\
\text { I } 2 \cdot 04 \%\end{array}$ & $\begin{array}{r}86 \\
3.9 \% \\
\end{array}$ & $\begin{array}{c}10 \\
0.45 \%\end{array}$ & $\begin{array}{c}78 \\
3.54 \%\end{array}$ & $\begin{array}{r}28 \\
\mathrm{I} \cdot 2 \% \\
\end{array}$ & $\begin{array}{c}38 \\
\mathrm{I} \cdot 72 \%\end{array}$ & $\begin{array}{r}53 \\
2 \cdot 4 \% \\
\end{array}$ & $\begin{array}{c}5 \\
0.22 \% \\
\end{array}$ & $\begin{array}{c}186 \\
8.45 \% \\
\end{array}$ & $\begin{array}{c}40 \\
\mathrm{I} \cdot 8 \mathrm{I} \% \\
\end{array}$ & $\begin{array}{c}17 \\
0.77 \% \\
\end{array}$ \\
\hline
\end{tabular}

I There are a few cases of real polychrome ware with red and black paint on the drab ground. This implies not the use of different pigments but the use of a thin solution to produce the red and a thick solution of the same pigment to produce the black.
2 As we have to judge mostly from fragments, generalizations must be made with caution.

3 Round bases were not recorded because, owing to the difficulty of recognizing the fragments of them, numbers would not have been reliable. 
in dealing with percentages one must remember that different fragments, e.g. of combed ware, may really belong to a single vase; when this clearly was the case with two or more sherds only a single entry was made, but much more often there could be no assurance on the point and therefore allowance for duplication must be made in reckoning the prevalence of decoration and, to a less extent, of flat or ring bases. Subject to this precaution the table drawn up by Ahmet Dönmez, supplemented by notes made at the time, is the best criterion available.

This tabular analysis well shows the uniformity of the levels already mentioned. 'The proportion of painted wares seems to increase slightly at the expense of combed decoration; that of the rope pattern in relief is much the same throughout, probably because it is peculiar to large store-jars the number of which required by a household would be fairly constant. The increased popularity of the bowl forms in Level X is consistent with what we shall see for Levels IX and VIII.

LeVEL XVII. Nearly I,500 fragments were examined. Of the plain wares a bottle, ATP/49/42, Type I 33, of pinkish drab clay with mica tempering, closely resembled one from Tabara al Akrad; two fragments of very shallow bowls with simple flat rim, of buff clay with a greenish engobbage, were of a type not found in other levels at Atchana but common at Tabara al Akrad. Two fragments from bottle- or jug-shaped vessels of buff clay had the upper part of the body covered with an engobbage rather paler in colour, lightly rag-burnished, on which a reticulated pattern (diamonds) in pale brown paint; these are identical in technique, paste, and appearance with a side-spouted jug from the top level at 'Tabara al Akrad. A bowl of'Type 23 but in burnished grey smotherkiln ware and another bowl fragment with a strongly carinated rim of very thin glossy black smother-kiln fired and ring-burnished ware were unlike anything found in the levels above; other bowl types, on the other hand, such as $23 a$ or with rims like those of Types $7 b$ and 24 , and a bowl with a low pedestal foot, apparently a variant of 'Type I 9 , made of red clay with white grit engrais and water-smoothed surface, are both in shape and in technique regular Atchana products. But it was in the decorated wares that Level XVII differed most from the rest. The proportion of painted to plain fragments was small, only about 2 per cent., but practically none of it was quite in the normal style of later levels and much of it was without any parallel there. A few bowl rims, apparently of Types II 9 and 234, with diagonal stripes of red-brown paint, and several jars of 'Type 100 with narrow bands of paint below the neck, all of very fine drab clay, were like later examples; but a fragment of a jug (?) with hatched triangles recalled in its technique the pre-Atchana wares. One fragment seemed to show an all-over decoration in red paint; there were several fragments which had been painted all over with brown paint but with a broad brush which had been dipped into the paint sideways so that one end carried much more pigment than the other; this produced broad bands very dark above and light below (showing the brush-marks) which overlapped so as to give an allover effect which was at the same time highly variegated. There were two pieces of 'reserved paint' decoration; in one, with red paint on pink clay, some of the colour had been wiped off with a dry brush in sweeps and curves, in the other the paint had been 
removed in irregular splodges with some kind of soft pad, the effect being that of the 'sponge-print' patterns of the M.M. II $a$ pottery of Crete; ${ }^{\text {I }}$ this might be accidental but is more likely to be an intentional design. The reverse of it was given by a fragment from the neck of a jug having irregular splodges of red paint closely set on the drab ground. A very open jug with trefoil mouth had an interior decoration of red bands roughly drawn parallel to the rim; a fragment from a large jar bore parallel diagonal lines of black paint, another had what seemed to be a 'drip' pattern of vertical lines; one bowl rim had, in black on light drab, circular spots with clear centres and another a band of roughly drawn running circles in red.

I have recorded the Level XVII pottery in detail in order to bring out the facts that while it presents analogies on the one side with the pre-Atchana pottery of Tabara al Akrad and on the other with the later wares of Atchana itself, it none the less differs greatly from the norm of Atchana and has not developed that style in painted wares. which was to be characteristic of all Atchana levels from XVI to VIII and even to V. It seems to me to represent the tentative stage from which the later wares take their genesis, and if that be so it would appear that the later painted pottery is really native to the Amq plain.

LEVEL XVI produced actually fewer sherds than did Level XVII, and again the proportion of painted wares was only $2 \frac{1}{2}$ per cent. of the total; but there was enough to show that the character of the Amq pottery was by this time established (Pl. XC). There was one unique specimen of plain ware, ATP/47/1 9 I, part of a cooking-pot bowl with heavy incurved sides (it was too fragmentary to be typed) of reddish-brown clay tempered with white quartz grit, hand-made and pebble-burnished; also a fragment with 'reserved paint' decoration, the body of very fine drab clay with brownish-red paint wiped off so as to give a marbled effect; a small fragment of highly burnished red ware (inside and out) was a rarity, but a similar piece occurs in Level XIII. For the rest, we have the ropepattern in relief on large jars, the combed ware familiar in the higher levels, and the normal bowls (Type $23,8 \mathrm{c}$.) with painted rims (cf. Pls. LXXXIV, XCI, and XCII).

LEVEL XV gave a number of identifiable types ( $v$. the tabular analysis), two painted bowls of Type 23 (ATP/47/1 53, 173), and two examples of three-colour decoration, black and red paint on a buff ground.

LEVEL XIV was rich in pottery and produced the finest examples of painted decoration in the two vases already mentioned, viz. ATP/47/129 and $142, \mathrm{Pl}$. LXXXIV. Other painted fragments were of Types $70,7 \mathrm{I}$, and I I 9 , v. an example on $\mathrm{Pl}$. XCd. There was one example of 'reserved paint' decoration, ATP/48/24. One of the bowls, Type 23 , is unusual in that the design is in black on a burnished red ground-burnishing being a feature of ATP/47/ 29 also-and another has a row of birds instead of the normal geometrical patterns (Pl. LXXXIVc). A fragment of a large bowl had a curious handle, a flattened knob cut out crescent-fashion, and a vase foot had a cross in red paint on its base, perhaps a maker's mark, Pl. XCI, ATP/47/I I 9. The most remarkable feature of Level XIV was the presence, on the floors of the rooms, of several bowls,

$$
\text { I Evans, P.M. iii, p. } 362 \text {. }
$$


Type I 3 , hand-made of drab clay with straw temper, with flat bases, straight sides, and rims trimmed to an outward slope with a knife; they are identical with bowls found at Ur, Carchemish, Warka, Nineveh, Brak, Tell Judeideh, and other sites, and it is generally agreed that they come just before and overlap with the Jamdat Nasr period in Mesopotamia. ${ }^{\mathrm{I}}$ At Atchana they do not occur in any other level.

From Level XIII came no less than five examples of the bowl Type 23, four of them having flat bases; two jugs of Type 70 , both painted (ATP/47/78 and I I I, Pl. XC), and two bowls of Type 23 of which one was painted (ATP/47/67) and the other plain; a fragment of a painted jug (?) from this level, ATP/47/ I 55, was of red clay with waterworked light buff surface lightly rag-burnished.

LeVeL XII c produced a painted bowl of Type 29 but with double instead of single lug handles (ATP/47/ I I , Pl. XCII) and another painted bowl of Type 23 (ATP/47/ 64 , Pl. XCII). LEVEL XII в had a stemmed goblet of Type I I 5 , two painted bowls of Type 29 (ATP/47/I I 4 and I 75), one of Type 34, also painted (ATP/47/ I I 9), and two of Type 23 , both painted (ATP/47/I 48 and I 49), the latter remarkable as having its surface lightly rag-burnished. The bowl AT/48/33, Pl. XCII, was unique in having painted decoration on the outside while on the inside there was painting on the rim but near the base a decoration of impressed grooves and triangular slashes; the bowl had two (or three?) small lug handles, and there was a cross in red paint under the base, as was the case with the similarly painted but loop-handled bowl of Level XII, AT/47/ I i 9 , Pl. XCI. From Level XII a came a plate of Type $3 b$, three painted jugs of Type 70 , ATP/47/56, I 74 (Pl. XC), and I79, a fragment of a bowl apparently like Type 26, painted but unusual in having two bits of appliqué ornament on rim and shoulder, ATP/47/I I 3 , Pl. CVIIIb, painted examples of Types $55^{b}$ and $57(\mathrm{ATP} / 47 / 39,52)$, a hand-made miniature of Type I I 5 in grey clay having on the outside of the bowl irregularly spaced punctures which do not go through the sides and therefore are purely decorative; a fragment of a painted example of Type I40; a roughly hand-modelled example of Type I 32 (fragmentary; the hand-modelling may be confined to the interior, cf. p. 305 note); three painted examples of Type $23 b$ (ATP/47/49, I 50, and I 5 I; Pl. XCI) and one painted bowl of Type $23 c$ (ATP/47/I69). Some of the painted fragments from this level are illustrated on Pl. XC. From the temple came the earliest example of the 'champagne-cup', Type I I 3 (ATP/47/I 2I), which is chronologically important, since the type, which is widely spread, begins as early as 2300 B.C. ${ }^{2}$ (and possibly earlier); the date agrees well with what I suggest for our Level XII.

From LeveL XI there came unpainted examples (one of each) of Types 23, I I 5 , and I 35 ; the fine painted fragment (Type $70, \mathrm{ATP} / 47 / 22, \mathrm{Pl}$. XCII) came from a pit in room 2.

LEVEL X produced examples of Types 23, I06 (painted with plain horizontal bands), $4 a$ (two miniatures), 3 , and $\mathrm{I} 6$; the sherds from the rubbish strata in the courtyard at the

I Mallowan, 'Excavations at Brak and Chagar Bazar', in Irak, ix. 2, p. $22 \mathrm{I}$.

p. 224, for the Carchemish evidence; cf. Schaeffer, Stratigraphie comparée, p. 81. For Mesopotamia v. E. Mackay, $A$

${ }^{2}$ See my 'Hittite Burial Customs' in Liverpool Annals of Sumerian Palace and the ' $A$ ' Cemetery at Kish, Part II, Art and Archaeology, vi (I914), p. 87, and Carchemish, iii, PIs. xlix, L. 
SE. end were nearly all from bowls of or closely resembling Type 23 , these not painted, whereas the only example of the type found in an earlier level (Level XII) was painted, so that we have here a definitely new departure. In the painted pottery also there seem to be signs of progress; the fragments ATP/47/I4, I 5,17 , and 18 , illustrated on Pl. XCIII, appear to be more consciously stylized than the earlier drawings of similar subjects; these are not so much drawings as designs, and their decorative intention is in three cases emphasized by the 'filling' ornament of dotted rosettes in the background.

LEVEL IX in the stratification pit produced very little pottery, but what there was included one new departure, a bottle of Type $\mathrm{r} 37$ in black clay (ATP/47/2 r); a similar bottle, black and burnished, was found in Level VIII (ATP/47/16); also represented were Types 23 and 100 , and let into the floor of the furnace-room (2) in the NW. building was a large jar $0.50 \mathrm{~m}$. high of Type $15^{2}$ with a band of rope pattern in relief round the shoulder.

The lower stratum of the filling of the earth rampart of the city wall (see above, p. I 35) was rich in pottery fragments illustrating the periods of Levels XVI to X or. IX; ${ }^{I}$ the pottery was uniform in character, in view of the many analogies it presented with the pottery of the stratification pit there could be no doubt as to its general date, but it added some types which happened not to be represented in the pit strata. By far the most common shape was the bowl with carinated lip, sharply keeled shoulder, and belly tapering in an almost straight line to a ring base-Types 23 and 26 . These were found in all sizes; the quality of the clay was good, especially in the smaller examples; the larger bowls often had two or more pairs of vertical elongated bosses attached to the shoulder, apparently for decoration (cf. under Level XII c above); a unique piece was a shallow bowl with 'tied strip' handles, Type 35. A great many of the bowls were painted; the normal decoration was, on the flat top of the rim, radiating dashes, on the shoulder two single or double lines in the space between which are groups of vertical lines ('triglyph' ornament) enclosing panels which may be plain, filled with horizontal or vertical wavy lines or tree patterns (v. Pls. XCI, XCII), or there may be instead of the triglyphs a row of hatched or outlined triangles. Next to the bowls the commonest form is the jug, Type 70 , with trefoil mouth and plain or double-reeded handle (on the plain handle the double reeding is often represented in paint), eyes below the spout, and a band of decoration painted round the shoulder; the designs are similar to those on the bowls but more elaborate, and include bird and animal motives. The comparatively scarce Type roo has painted decoration confined to simple bands round neck and shoulders; a single (incomplete) example was found of a painted spouted jar (ATP/379). There were numerous fragments of very large store-jars (Type 152 ) of which the flat-topped rim was generally ribbed and the upper part of the body decorated either with widely spaced bands of three or four incised lines, or with bands of rope pattern in relief. Rope pattern occurs once on a fragment of a painted bowl (ATP/37/380), and another bowl fragment (ATP/37/ $38 \mathrm{r})$ has applied decoration resembling a tassel, Pl. CVIII $a, f$.

Judging by the types, it would seem that the part of the rampart which we happened

I All the 'unstratified' sherds, ATP/8/208 and ATP/8/209 on Pls. XCVII and XCVIII, come from the city wall excavation. 
to dig was formed from spoil taken for the most part from the ruins of Levels XII to IX; but it must be emphasized that the material has an illustrative value only and cannot safely be used as a basis for the classification of the early wares. On the other hand, a small excavation (it was little more than a pit) in Sq. $\mathrm{N}_{\text {I }} 3$ gave excellent evidence for the pottery of Levels X, IX, and VIII.

In the north corner of the Level VII temple court and at $1.50 \mathrm{~m}$. below its floor there was a horizontal drain, partly of terra-cotta pipes, partly built with old burnt-brick voussoirs re-used, probably taken from a Level IX building; the drain ran under the foundations of a mud-brick wall and ended over a splash-stone; close by was the brickbuilt intake of a vertical drain; both of them necessarily belonged to Level VIII, lying as they did underneath the cobbled floor of Level VII and below its wall-foundations. The first drain ran NW. $\times$ SE., part of it under room $48 / \mathrm{I}$ of the Level VII temple; $0.70 \mathrm{~m}$. away was yet another drain, stone-built, running NE. $\times \mathrm{SW}$. below the NE. wall of the Level VII court; this also belonged to Level VIII, and the evidence was fairly conclusive that the Level VII building was a reconstruction on much the same lines of a Level VIII building which, too, was presumably part of the temple of that date. On the level of the drains there was a good deal of broken pottery lying on a rather irregular surface. Below this came mud-brick walls belonging to a room of Level IX; in the room on a surface too irregular to be called a floor but showing discoloration due to exposure (i.e. the room was never properly paved) there was a mass of pottery including complete vessels which seemed to have fallen from a shelf. Beneath this surface there was fairly clean soil to a depth of about $0.40 \mathrm{~m}$. and then came the tops of the walls of Level X; associated with those, from the level of the bottom of the foundations of the Level IX walls downwards, was pottery of Level X.

The pottery of Level $\mathrm{X}$ was not very abundant; it was entirely consistent with that from the stratification pit and added only one new form, Type i I 5 , in the plain wares. But there were found here several widely scattered fragments belonging to a single vase, Type 92, which is painted in a style absolutely different from the normal; the vase (ATP/48/4I , Pl. XCIII) shows a free composition, a hunting scene with a man, animals, and a bird, which stands quite outside the stereotyped 'metope' scheme of decoration; it might be regarded as a freak drawing paralleled only by the equally individual and unclassifiable design on a Level V vase, ATP/39/279, illustrated on Pl. XCV (v. p. 56).

In Level IX there was a deposit about a metre thick composed almost entirely of pottery, including many intact or only slightly broken vases. Of painted wares there were only a few isolated sherds. The vast bulk were bowls of Types 2 I and 23 ; sixteen complete or nearly complete examples were found and the complete profiles of as many more; the total number in this small area may well have been over 100 . The bowls are well made of fine, rather sandy clay, usually buff shading to pink but sometimes greenish or white; the walls are thin but often rather irregular, the vessel being oval instead of round or somewhat lop-sided; the surface is rough, not water-worked, and there is no decoration. The bowls vary from $0.10 \mathrm{~m}$. to $0.18 \mathrm{~m}$. in diameter; the shapes are constant, but there is some variety in the rims, which occasionally approximate to true bead 
rims. A few examples are sharply carinated instead of having the normal rounded shoulder. Flat bases outnumber ring bases in the proportion of 7 to $\mathrm{I}$, the ring base being virtually confined to the smaller examples. Rims and ring bases were found of three examples of the shallow bowl Type 5 and fragments of seven examples in plain ware of variants of Types 5 and 9; one fragment of a deep bowl Type Ioo (characteristic of Level VIII), and a fragment of Type 100 with horizontal bands of red paint. Two fragments of pedestal bowls, Type I I 5, were reminiscent of Level X. There were rims and ring bases of at least two bowls akin to Type 5 in dark grey ware with a rather summary pebble burnish, and a few fragments of bowls and jugs very well made of a grey to orange clay with a haematitic surface, orange to red, highly pebble-burnished. Jugs were fairly numerous, judging by fragments, several having trefoil mouths as in Type 69; one jug of red burnished ware had a cut-away neck with traces of attached handle, reminiscent of Anatolian types. Rims of 40 or 50 large jars (or deep bowls) were recovered, ten of them flat with reed moulding; on these, bands of incised lines or rope pattern in relief were common. There was a fragment from a flat-shouldered jar with a horizontally pierced lug handle, and a fragment of a jar lid. The few painted fragments (PI. XCIII), which include the neck of a jug and the rim of a fairly large jar, are not burnished, the paint is matt (red or brown), and the designs where preserved are of the metope sort with a tree motive and a St. Andrew's cross. One painted fragment (AT/48/ 48 , Pl. CVIII e) had on the shoulder, above the normal painted zone, applied clay figurines of an animal and what may have been a bird or a human being-both of them unfortunately broken. Another fragment, AT/48/30, had a sun and crescent moon in applied clay. Part of the rim of a plain bowl (AT/48/29, Pl. LVII $a)$ had on it a roughly modelled figure of a crouching lion (?), this modelled in the round and standing up from the top of the rim. A fragment of a normal 'goddess' figurine (AT/48/28) occurred in the same deposit.

LEVEL VIII. The pottery fragments lay in two more or less distinct strata due to the rise in level of what had clearly been an open court. Both strata apparently belonged to the Level VIII building, but they were recorded separately so that the distinction between earlier and later wares should illustrate the development of Level VIII from Level IX. In the lower stratum (A) the commonest form is the bowl, Types $2 \mathrm{I}$ and 23 , which is characteristic of Level IX but is virtually absent from stratum B. These are of greenish-white, drab, buff, or orange clay with the surface unsmoothed. Both flat and ring bases occur. The diameter ranges between $0.10 \mathrm{~m}$. and $0.15 \mathrm{~m}$., but there is one miniature example measuring less than $0.05 \mathrm{~m}$. across. Bowls or plates of Types 56, 96, and $\mathrm{I} 68$ and small jars of Type $\mathrm{r} 00$ in grey ware smoothed or burnished are fairly common, these being characteristic of stratum $B$. The grey wares include the rim of a thickwalled bowl in burnished black clay; a few examples of Type 5 in the light-coloured wares are also lightly burnished. The painted wares include a few examples of bowls of Type 264, but most of the sherds come from larger vases, probably jugs, and one has the eyed trefoil mouth of Type 70. The clay of these varies from greenish-white to buff and orange and the surface is often lightly burnished before painting; but three pieces, one 
painted in red on buff with a variety of the 'double axe' motive, have been highly burnished after painting so that the paint, too, is lustrous. The trefoil mouth of one jug is of well-polished red ware. There was one fragment of a goblet (Type I I 5) familiar in Levels XII and XI, and one example of the twin saddle lug.

In the upper stratum (B) the Level VIII pottery is seen fully developed. Of the Types $2 \mathrm{I}$ and 23 which formed the bulk of the Level IX deposit we could recognize only a single rim fragment. There were three main classes of pottery. (1) Vessels of grey clay, smother-kiln fired, the surface generally dark grey or black, pebble-burnished all over, nearly all bowls of Types 16 and 9 (the most common) and 5, with a single example (apparently) of 'Types I62; there were the necks of two small bottles, Type 137 , and a fragment of a jug, possibly Type 45; a few fragments of small vases highly burnished, and the base of a tubular spout and two cylindrical lugs with upturned ends. Of the bowl shapes above mentioned there were a few fragments in buff clay shading to orange, slightly burnished or not burnished at all. (2) Jars of Type I o०, of greenish-white, buff or orange clay, the surface slightly burnished; most of Type roo, as also bowls of Type 26, have horizontal bands of red or brown paint round the body (cf. Pl. LXXXVII $b$ ). (3) Large vessels, jugs or jars, of light clay ranging in colour from greenish-white to orange, the surface left unburnished or only slightly burnished, decorated with painted designs-bands of rectilinear pattern including the tree and 'double axe' motives; there are no curved or waved lines, but one piece has chevrons with dots between the lines and one (ATP $/ 48 / 38$, Pl. XCIII) has the head of a fish with cross-hatched body. One polychrome fragment was found, with red and black bands on a drab ground; one fragment $\left(\mathrm{ATP} / 48 / 3^{2}\right)$ had the whole surface painted black (the paint partly wiped off in the technique of reserved slip ware) with a single thin line of white paint across the black. One painted sherd, red on orange clay, had been burnished after painting. There were two pieces of sgraffiato decoration, one with a double row of zigzags (cf. Pl. CVIIIm) and one with straight lines with crescents between them cut through the paint into the drab body-clay. One fragment was of White Slip ware, part of a bowl with a handle like a Cypriote milk-bowl having dark brown diagonal streaks and a ring of bright yellow round the base of the handle. Two examples of the three-strand twist handle were found.

LEVEL VII. According to the original classification of the pottery ${ }^{\mathrm{I}}$ Level VII produced forty-two types, the vast majority of them coming from the Yarim-Lim palace and from his temple. Of the forty-two types or variants only eleven had occurred in the lower levels and of those three went out of use in Level VII; ten types are peculiar to Level VII; twenty-one types originating in Level VII continued in use in later levels, but even so several of them were shortlived and only fifteen persisted beyond Level IV. So far as the shapes of vessels go, therefore, this level marks a striking break in the ceramic tradition.

Not less striking is the disappearance of the painted pottery which had held the field

1 This was more detailed than the published classification. As it could not be told at the outset to what extent a minor modification of shape might be a criterion of date, a good many types were recorded separately which it was subsequently found could safely be. regarded as variants of the samè type. 
ever since Level XVI; as a luxury ware we should have expected to find it in the palace and the temple, but we did not, ${ }^{I}$ and its absence is emphasized by its revival in Level VI. One jug (ATP/39/I 99) of Type 6o with its shoulder covered with a plain wash of red paint was found rather high up in the filling of room i 8 of the palace and was judged to belong to it, though it might have been of Level VI. A bowl (ATP/39/I 57B) of Type $2 \mathrm{I}$ had a trickle-pattern in black paint. The only examples of real painted decoration were the large fragment $\mathrm{ATP} / 47 / 97, \mathrm{Pl}$. XCIII, found in the Level VII temple, and a beaker (ATP/39/307) of Type 94 with horizontal bands of red and black alternately on the buff body-clay; but the latter only confirmed the general rule in that the type is a new one and neither shape nor decoration have any parallel in the older levels.

A characteristic of the Level VII pottery is the relatively high proportion of grey or black smother-kiln ware. Of the five or six types of such ware that had been used in Level VIII four ${ }^{2}$ are kept on in Level VII, and of the new types introduced eight ${ }^{3}$ have examples in smother-kiln technique. Not all of these are burnished, some are indeed rather rough, but a representative collection of Level VII pottery differs from that of earlier levels in colour almost as emphatically as in its shapes.

The smother-kiln technique was not in the native Alalakh tradition, and when it is first introduced (in Level IX) it is clearly due to foreign influence. That its sudden popularity in Level VII was not merely the result of development in the local industry is shown by the fact that it is applied to forms also unknown in the past. It is indeed interesting to observe how many of the new Level VII shapes are paralleled in other areas. The painted beaker described above (Type 94) is found, with the same decoration, at Brak, and the form occurs at Beit Mersim in Palestine also. The other beaker shape, Type i 8 , comes at Tepe Gawra and-though with a less slender foot-at Jericho. At Jericho, too, we find parallels for Types 67, I06, and 2 I $b$, the last occurring also in Palace II at Gaza. Type I 39 is probably the same as a (fragmentary) example from Beit Mersim, Type I 63 comes at al Hammam; and in all these cases the dates are consistent with that at Atchana, only the Gaza Palace II being later than the eighteenth century. In two cases it can be said without hesitation that we have to deal with actual imports; these are the two wish-bone handles from milk-bowls found in the Yarim-Lim palace 4 and two examples of the very tall lekythus in polished red ware (Type B.M. 25) which is generally supposed to have originated somewhere in Syria but is certainly not native to our site. ${ }^{5}$ I should regard the painted Brak beaker, too, as an import; but the other types are foreign only by inspiration-they were simply taken over by the Alalakh potters and incorporated in their repertoire; the vases themselves are of local make. None the less we have here unmistakable evidence to show that the break in local tradition at the beginning of Level VII reflected a reorientation of politics which must be associated with the rise to power of the new dynasty.

I In room 16 of Yarim-Lim's palace there was found a small fragment of a jug of Type 70 with the eye painted below the trefoil mouth; but an isolated sherd of the sort (a) may well be intrusive, and (b) if not intrusive might be from an 'antique' preserved from the not very distant past; it

certainly cannot be accepted as proof that the type was being manufactured in Level VII.

$23,5,100,137$.

3 I 7, 3 I, 7 I, I I 8, I 23, I 39, I 5 I, I 63 .

4 ข. p. 364

5 ข. p. 360. 
Level VI. The violent overthrow of the Yarim-Lim dynasty was followed in the sphere of ceramics by what can fairly be called a nationalistic revival. Of the pottery types introduced in the Level VII period a third is dropped completely, but of the eleven old types which had continued in use in that period eight remain current, and in addition we find in Levels VI and $V^{r}$ brought back into favour no less than fifteen old types which had not appeared in Level VII. So far, therefore, as the shapes of the vessels are concerned Level VI, in spite of innovations and omissions, resembles Level VIII more closely than it does Level VII. Even more striking is the revival of the old painted ware. Examples of this, illustrated on Pls. LXXXVI, XCIII-XCIV, show that the tradition was faithfully maintained; the same designs are used, and they are applied to the same shapes of vase. It is true that occasionally we find painted vessels of types which are either new or in the older periods were not decorated, and true also that the style has changed slightly-the painting is generally coarser and the drawing tends to be more free and impressionistic, partly because a wider field was reserved for decoration and a bigger brush used-but there is no mistaking the fact that the painter was following the conventions of the school which had flourished from Level XVI to Level VIII and had been temporarily suppressed in Level VII.

Over the greater part of the site it had not been easy to differentiate between Levels VI and $\mathrm{V}$; the buildings were so closely superimposed that the attribution of pottery fragments was only too often unreliable and the two periods had to be considered together rather than characterized separately. In the fortress area, however, where there were two buildings of each period, the stratification was much more satisfactory, and although the pottery was not particularly abundant there was enough of $i^{2}$ to bring out the character of the level.

The most obvious link with Level VIII was given by a fragment of a bowl of Type I I 9 with painted nicks round the rim and on the shoulder a design of triglyphs and saltires between horizontal lines. Fragments of jugs (Type 55 or 70 ?), with shoulder decoration of radial strokes or of cross-hatching and dots between horizontal bands, were scarcely less convincing. One jug (Pl. XCVIIIm) showed the conventional vandyck design but executed in very fine lines giving an unusual effect to a familiar motive, but most of the decoration was very rough and done with a coarse brush; one bowl (perhaps Type 8 but the base was missing) had a painted band of straight lines and chevrons, one was very coarsely cross-hatched all over, one small and heavy bowl had a band at the rim, and one lower down with vandycks between them. Other painted vases from this level are illustrated on Pl. LXXXVI.

A new feature was a fragment of a goblet (Type 94) very roughly painted with chevrons between plain bands, and there was a fragment of Type ${ }^{6} 3$ with an all-over red wash; there was one example of sgraffiato decoration, zigzags cut through a band of

I As the total amount of pottery from Level VI is not very great I have here combined the evidence of the upper levels in order better to demonstrate the extent of the revival.

2 A collection of all painted or unusual fragments gave us $25^{\circ}$ pieces. A few of these may have been, and probably were, infiltrations from Level $V$ or even higher, since there had been a certain amount of disturbance of the soil by foundationtrenches and by grave-digging; but the general picture should be fairly correct. 
black paint, cf. Pl. CVIII $n$ and $o$. Rag-burnished red haematitic ware was not common, but what there was was of good quality; there were two examples of small black jugs (probably of Type 46 or 47 ) in very fine black smother-kiln ware, rag-burnished. Two small chips of goblets of black impressed ware (Type I 20) were perhaps out of their true horizon; four small fragments of Nuzu ware with white decoration on a brown ground looked early but might have come from Level $V$; their attribution was made doubtful by the finding, close by, of a piece of Level II 'Atchana' pottery with the Minoan style of decoration.

The same fortress area produced thirteen fragments of milk-bowls in White Slip ware and one in Base-ring I ware, as well as a wish-bone handle in rather coarse reddish clay, apparently local, knife-trimmed. It produced also five Mycenaean fragments, one certainly and one probably from flasks with the vertical concentric circle pattern (B.M. 59), one from a rather large piriform vase (either B.M. 5 I or B.M. 55); one very small fragment painted in a rather more free style looked to me earlier but must be classed as L.M. III; lastly there was the mouth and handle of a copy in local clay of a Mycenaean stirrup-vase.

Of fragments (mostly from other areas) that can safely be attributed to Level VI several call for special comment.

The fortress produced two pieces from a large amphora (Pl. XCIVb) with polychrome decoration, red and black paint on a buff ground; the design includes the 'Union Jack' motive which is common in the polychrome pottery of Palestine ${ }^{2}$ at the beginning of the Late Bronze Age and at Ugarit, ${ }^{3}$ in both of which places it appears directly after I 600 B.c., and was at a rather later date imitated in Cyprus; 4 this is its first appearance at Atchana. A unique polychrome piece-or rather two pieces probably from the same vase-came from a Level VI rubbish-pit. This had been a large jar with a raised rib at the base of the neck and bosses in relief below it; on a dark red ground there was a design of animals and plants painted in black and white (Pl. XCIV $a, j)$. Another large jar, probably of Type 82, had an animal and bird design (P1s. XCIVa, and LXXXVI) in which only one colour-deep red-is employed on the light reddish-buff ground, but contrast is obtained by an ingenious alternation of solid colour with very finely drawn lines. In this case we have a notable departure from the artistic conventions that had governed the painted pottery of the early periods; the old metope arrangement has been discarded in favour of a free pattern admirably adapted to the form of the vase; the isolated figure gives place to a genre picture full of life and action; the treatment of detail is deliberately grotesque. On the other hand, it must be admitted that other periods do give us composite pictures and the spirit of caricature; the vase ATP/48/4 I (P1. XCIII) from Level X and ATP/39/279 (Pl. XCV) from Level V and ATP/47/I 38 (Pl. XCVI) from Level IV are cases in point.

The fragment of pottery illustrated on Pl. XCIII $p$ was found immediately above the

I Information kindly supplied by Mr. Stubbings. It will be noted that the presence of any one of these fragments in Level VI is quite inconsistent with the accepted chronology for Mycenaean pottery.

\footnotetext{
2 Petrie, Gaza, i, Pls. xxvın-xxxı.

3 Schaeffer, Stratigraphie comparée, p. 379.

4 Id., Missions en Chypre, I 936, pp. 39-58.
} 
destruction-level of Yarim-Lim's palace and is therefore best attributed to Level VI, although the confused stratification of that area is against absolute certainty. It comes from a wheel-made vessel of very fine light grey clay decorated with lustrous black paint which covers the greater part of the surface, leaving the grey ground showing only as thin lines which define the pattern. Nothing else at all resembling this was found at Atchana and presumably therefore the vessel was a foreign import.

A curious instance of symbolism rather than of picture-drawing was ATP/47/ I 54 (Pl. CVIIIj), part of the splayed rim of a wide-mouthed jar, on the inside of which was a roughly incised pattern; above, a double row of small triangular dots, then a boldly waved band of combed work, and below that a crudely scratched vandyck and another row of dots; under the curve of the combed band is incised a double-yoked plough and a curved line which may represent the furrow.

LEVEL V. Generally speaking, the pottery of Level $V$ is of the same character as that of Level VI; there are a good many new types, but that may be due in part at least to the fact that both the building sites and the graves of Level $V$ were far more productive. The main difference is the greater popularity of imported wares and, especially, the appearance, or at any rate the development, of the black impressed pottery; if there is any change in the traditional painted wares it would seem to be the growing preference for geometrical patterns of a mechanical type.

For the purpose of comparison with Level VI it is best to consider first the wellstratified sherds from the fortress area. Level $V$ в, the more productive, yielded plenty of fragments of painted jugs, usually with groups of diagonal strokes between horizontal lines, one of them having on the shoulder the vandyck pattern drawn with very thin lines exactly like the Level VI example, Pl. XCVIIIm; two of the jugs had double reeded handles, one a twisted two-strand handle with diagonal strokes in red paint; one jug at least had the trefoil mouth of Type 70 . Other painted shapes included a single example of the very early Type I I 9 , Type 23 , several examples of Type 104 with plain horizontal bands, and one of Type i r. There was one piece of polychrome decorationa small jug with alternate red and black bands and a black vand yck scrawled across them, on a pale buff ground-and one of 'reserved painting', a dark all-over paint removed in streaks with a dry brush. Of Nuzu ware there was one fragment only, painted in yellowishwhite on a red ground with an unusual design of birds and animals marked by the comic exaggeration of the feet ( $\mathrm{Pl}$. CVIIe) that we see in the Level IV 'demon dance' vase on Pl. XCVI. This is one of the earliest examples of Nuzu ware about whose horizon there can be no doubt at all. There was one good large sherd of black impressed ware, the normal beaker shape. Of Mycenaean pottery there were three fragments, one from the base of a piriform jar, one with grouped vandycks between broad horizontal bands, and a

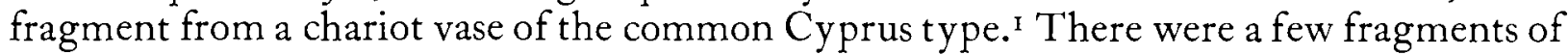
finely burnished black smother-kiln ware, small bottles (as in Level VI); to these, Level

I The date here is a stumbling-block, the earliest of the Cypriote chariot-vases being assigned to Late Cypriote II A (I 400-I 350 B.C.) and the majority to Late Cypriote II B

( $135^{\circ}-1275$ B.C.), whereas the end of Level $V$ cannot be much later than I 500 B.C. 
$\mathrm{V}$ B added the base of a polished red ware spindle-shaped jug of the type found in Cyprus (B.M. 25), another piece of polychrome ware, an unusual piece of combed decoration, and, in plain pottery, a lamp of Type 1676 .

The temple site produced in Level $V$ part of a kernos in painted Nuzu ware, and a rubbish-pit in that area, well dated to Level $\mathrm{V}$, contained two painted goblets, ATP/ 49/I $3_{A}$ and B (Pl. LXXXVII). The two latter may illustrate the tendency towards purely geometric ornament which produced ATP/46/225, Pl. LXXXVIII, the major decoration of $\mathrm{ATP} / 39 / 279, \mathrm{Pl}$. XCV, and part of that of $\mathrm{ATP} / 46 / 336, \mathrm{Pl}$. XCV; but it is curious that in the first of these the mechanical pattern of triangles and hatching is combined with an absolutely free drawing of a hunter and his mixed quarry, while in the second case the painter, tired perhaps of the conventional design which he had just finished on the outside of his beaker, has sketched on the inside a grotesque figure ${ }^{\mathrm{I}}$ of a hunter presumably lying in wait for the birds on the outside. It will be evident from the plates that on the whole the drawing on the vases is very much like that of Level VI, done on a bold scale with a thick brush, e.g. the polychrome vase with a bird and fish in the Palestinian style, ATP/48/62, Pl. XCV; the 'Union Jack' motive recurs several times (Pl. XCVI), and it is interesting to note the technical detail of a bird's beak sometimes (e.g. ATP/46/94, Pl. XCVII $p$ ) being the continuation of the line defining the under side of the head and neck, which is common both to Palestine and to Brak. ${ }^{2}$

On ATP/46/27I, Pl. XCVI, the use of white paint recalls Level VI, and it is curious that in both cases the body-clay of the vase is coarse and the painting very roughly executed; I suspect that both are imports.

LEVEL IV. With Level IV there comes a remarkable change in the pottery. Virtually all the luxury ware is of the 'Cypriote' type-base-ring. jugs, White Slip ware bowls, \&c.- - and towards the end of the period the white-painted Nuzu vases begin to be popular, and this to the suppression of the traditional style with its triglyph design and horizontal zones containing bird or animal motives. There is still plenty of local painted ware, but the decoration is purely perfunctory. Large flat plates have wide borders of red, or, more characteristically, concentric circles over the whole of the inside (Pl. LXXXVIII); beakers have a series of simple broad bands of red or black (Pl. LXXXVIII) -at most, the bands may be alternately straight and waved or alternately black and red. One jug, ATP/39/I 99, Pl. LXXXVI, which preserves the old scheme of decoration, a beaker, ATP/39/273, with birds and to a less extent another beaker (Type 94), ATP/ $38 / 142$, with a plant motive, and an amphora (Type 82) with geometrical design and a single bird, are so alien to the contemporary wares that they may be literally survivals. One real exception is the beaker ATP/37/1 $38, \mathrm{Pl}$. XCVI, which would be remarkable in any level; both the animal and the human figures, the latter with grotesquely exaggerated hands, are deliberate caricatures and cannot be judged by any criterion of style.

Excluding the 'Cypriote' vases, the analysis of types shows that there were 120 types

I The proportions of the body may be due to the difficulty of drawing inside a small bowl with vertical sides.

2 M. E. L. Mallowan in Iraq, ix (1947), part 2, p. 243 , note 4 . 
or type variants actually found in Level IV, nearly all of which must be accounted local. While most of them are properly described as of plain pottery, an all-over red or brown wash is not uncommon and where that is used the surface is often burnished, either ragburnished or (especially in the case of plates) pebble-burnished in rings or spirals; the black smother-kiln ware, burnished or plain, has disappeared, ${ }^{\mathrm{I}}$ as has the special variety of it, the impressed black ware. The multiplication of types, however, does not alter the fact that the general character of Level IV pottery is quite different from that of earlier levels; certain shapes predominate, and precisely those which in the early levels were rare or non-existent. By far the most common shapes are flat open plates and hemispherical handled bowls (the 'Cypriote milk-bowl'), both of which are relatively new, ${ }^{2}$ and to a less extent the beaker and the 'Base-ring ware' jug; there must have been a change in table manners if not in diet.

LEVEL III. A few vases and fragments of painted ware suggest that an attempt may have been made to revive the old ceramic tradition; two fragments shown on Pl. XCVII are akin in style, while the jug ATP/39/ I 55, Pl. LXXXVIII, with its decoration of red lines bordered with black, is in the Palestinian tradition of polychrome pottery. The 'Cypriote' pottery continues to be common but now faces much more serious competition by the Nuzu ware with its white painted decoration on a brown or black ground. For the rest, the Level IV fashions are still in vogue, though on such evidence as we possess it would seem that the flat open plate was going out of use; but the total amount of pottery accurately dated to Level III is scarcely large enough to justify any broad generalizations.

LEVEL II. In the local wares (by now very nearly synonymous with 'plain wares') there does not seem to be any great difference between Levels II and III. It is true that of the thirty-eight types or variants definitely belonging to Level III eleven were not found in Levels II and I, and that in Level II fifteen types occurred that had not been found in Level III or earlier; but as in the majority of cases the type was represented by a single example only, and as in one case only (Type 32 ) was there any great disparity between the numbers of examples found in the two levels, the argument from figures cannot be stressed. The real difference is that 'Cypriote' pottery has gone completely out of favour; Mycenaean pottery is being freely imported; the Alalakh potters, inspired perhaps by a Cretan antiquity preserved in a temple treasury or in a private collection, are using the Nuzu technique for making vases decorated in Minoan style. A few fragments (see Pl. XCVII $c-i$ ) found in Levels I в and II would imply that something of the old tradition of local painted ware did survive in a degenerate form, but it is the pottery imported or inspired from abroad that is characteristic of the latest levels at Alalakh.

LEVEL I calls for no special notes other than those in the appendixes on the 'Cypriote', Mycenaean, and Nuzu wares; for the plain pottery the analysis of types gives all the information available. The large jugs used for cremation burials have generally plain

\footnotetext{
1 In the Niqme-pa palace a number of plates and vases had been burnt black, but this was accidental, due to the burning of the building.
}

2 A deep plate or shallow bowl, Types 3 and 5 , had been characteristic of Level $\mathrm{V}$ and earlier. 
bands of reddish-brown (ATP/37/38, Pl. LXXXIX) and there is one example (ATP/ $38 / 25, \mathrm{Pl}$. LXXXIX) of a small amphora with roughly painted horizontal bands.

\section{(b) POTTERY TYPES}

A type-list of early pottery is bound to be open to criticism. In the first place it cannot well be reduced to a logical scheme arranged under such obvious headings as 'plates', 'cups', 'bowls', 'jars', \&c., for the simple reason that these forms merge into one another; the plate deepens into a bowl, the mouth of the bowl contracts until it becomes a jar, and it is impossible to draw a hard-and-fast distinction between them. The second difficulty is in deciding what is meant by a 'type'. The skilled English potter could throw upon the wheel 500 cups with not a millimetre of difference in their measurements; the ancient potter might possess equal skill, but his Middle Eastern clients were not at all interested in strict uniformity and as a result he seldom made two pots exactly alike. There were, of course, certain more or less standardized forms, answering to the demands of particular tasks in the kitchen, \&c., to which the individual vessels tended to conform, but they conformed generally and not necessarily in detail. Some of those forms enjoyed only a temporary popularity, others were in fashion for a very long time during which various modifications might almost insensibly be adopted. In drawing up a type-list of pottery forms one danger is that by laying too much emphasis on minor differences we make the list one not so much of types as of individual vessels; the other danger is that by disregarding minor differences which do in fact correspond to differences in date we may make the list of little practical use to scholars. Since while working at Atchana we were dealing all the time with new material and had no grounds for judging the historical importance, if any, of divergences from type, all such were regarded as constituting new types, with the result that over 350 shapes of local pottery ${ }^{1}$ were recorded.

This very full corpus was most valuable as a working instrument, but for publication was unduly long. It was shortened by grouping together what might be regarded as variants of one basic type and checking the result by the recorded dates of each variant; where they were found to be contemporary the differences between them could safely be regarded as accidental and having no historical significance, but in order to give the range of the type the two or more most divergent variants are figured in the list; where the floruit of one variant overlapped with but was found to be on the whole earlier than that of another so that the second might be regarded as a development of the first, both required to be illustrated but as variants of one type, e.g. Type 6. But if there was a marked time-gap between the occurrences of vessels differing only in minor details, such details were taken to be essential and the vessels received different type-numbers, e.g. Types I 46, I 47. On this principle, to which I have adhered as far as possible (though I cannot claim to have been entirely consistent), the number of types has been reduced to the more reasonable total of $\mathrm{i} 68$.

I am aware that the arbitrary suppression of the minor characteristics of individual vases may be criticized as violating the scientific canons of up-to-date archaeology, but

I This did not include the Mycenaean and 'Cypriote' wares for which references to standard publications sufficed. 
I feel that the canons have tended to disregard the human element in archaeological material. As has been said above, the ancient craftsman seldom made two clay pots exactly alike, so that our 'types' are at best approximations; but it is also true, and for the same reason, that the variants of one maker are more or less reproduced by the potters of successive generations, so that minor differences do not necessarily possess historic value. At Atchana much labour was conscientiously devoted to supplementing our drawings of pot types by sections of the rims of fragmentary (and therefore generally untypable) vessels; over 500 such sections were drawn, and the result was disappointing. A comparison between the sections from Levels VIII-IX with those from Level XVIi.e. from periods separated by something like 500 years-shows that about 20 per cent. are so similar that they can be called typologically identical, and the main point that emerges is that bowls with a carinated profile are considerably more common in the early period and that in the later period the rims of jars are more commonly flat at the top; both points had been made equally clear by the comparison of complete vase-types. A demonstratable difference in date is good reason for emphasizing a relatively slight difference in form, but it is unsound to assume that a relatively slight difference in form implies a difference of date; in any case we should take into account only those characteristics which are common to the general run of contemporary vessels, i.e. should deal with types and not with individuals. ${ }^{1}$ As we are fortunate in having at Atchana a very great number and range of complete pots, ${ }^{2}$ we have ample material for a type-list without having recourse to the dubious assistance of fragments.

The type-list is intended to be used together with the 'Notes on Types' on p. 322; the latter are condensed from the catalogue descriptions of all the individual vases summarized under the type and should give a fair idea of the colour and texture of the ware, the surface treatment, the relation of painting to vase-form, \&c., without which the mere form may be even misleading. The dates of the types, i.e. their occurrence in the different levels, is given in schematic form on pp. 332-40. In that scheme occurrences are recorded only when (as was not by any means always the case) there was no reasonable doubt as to the attribution of the pot to a particular level; a large number of pots actually found but whose horizon was doubtful are not included in the scheme, and there are types under which no entries are made because no specimen of the type was accurately dated. The scheme gives all the chronological evidence which we obtained from the excavations but it is, of course, not final, being subject to the accidents of discovery; for instance, it happens that the total amount of pottery that we could assign to Level VI was small-very small compared with the vast quantities from Levels VII and IV-and Level VI therefore appears to be relatively poor in pottery types; but that poverty reflects the conditions of our work and not necessarily the conditions of the period. In spite of this the analysis is on the whole gratifyingly consistent and does bring out facts as to the

I This is particularly true of rim-sections. The thickness of a rim and the amount of its overhang are largely dictated by the amount of clay the potter has still at his disposal when his pot has been brought to the required height; to that extent B 2501 they are accidental. But in the drawn section these accidental differences may assume proportions which are most deceptive.

2 The pottery catalogue runs to $\mathrm{I}, 600$ numbers, nearly all being complete or giving a complete section. 
introduction, prevalence, and disappearance of types which we can provisionally accept as historically correct for Alalakh and its immediate neighbourhood.

\section{NOTES ON POTTERY TYPES}

Type I. Red-drab clay, poor surface.

Type 2. (a) The early (Level XIV) example is in cooking-pot ware, black clay with mica engrais; the Level V examples generally of orange clay, burnished on the outside, but 2 of grey smother-kiln ware. (b) Of greenish-white clay, water-smoothed but not burnished.

Type 3. (a) Generally rather coarse, clay of all colours but never grey or black; surface sometimes water-smoothed, only 2 examples burnished, never painted. (b) Yellow, drab, pink, and red clay (never grey) sometimes with all-over wash of red-brown paint on the inside, often with concentric circles of red or brown. Pl. LXXXVIII $e$.

Type 4. (a) Roughly made miniature in red clay. (b) Generally of plain ware, drab, red or yellow; 2 examples with painted concentric circles; mostly of coarse clay not well finished. (c) One with single band or orange paint round the rim, the rest plain, one with much white grit tempering; the Level XVII example is a miniature.

Type 5. Examples about equally divided between those of clear colours-greenish-white, drab, or reddish clay - and smother-kiln ware with (sometimes) pebble ring-burnish on the inside, these in Level VIII and Level $\mathrm{V}$ alike.

Type 6. (a) One example of smother-kiln ware with vertical burnish on the outside, several with band of red paint on rim and sometimes a red disk in the middle; the majority plain in clear colours, but 3 with all-over red wash. (b) Always plain.

Type 7. Both variants plain and usually rather coarse; but the $7 b$ example from Level $V$ is of orange clay, thin-walled, and ring-burnished; the Level XIV, ATP/47/70, Pl. XCIX, example is a miniature (diam. $0.09 \mathrm{~m}$.) and only approximates to the type.

Type 8 . Very finely turned almost egg-shell ware, with curious umbilical point, generally burnished inside and out; one Level VI example probably of this type is of light ware with painted bands and chevrons. v. Pl. XCIX, ATP/46/194.

Type 9. (a) Black smother-kiln ware, burnished. (b) and (c) Plain drab or light red ware.

Type Iо. Buff ware with design outside and on rim in red-brown paint; Level XII в; ATP/ 47/1 52 , Pl. CIX.

Type I I. Examples vary greatly, always of light-coloured clay but some coarse and some fine, occasionally water-smoothed, twice burnished and once (from Level III) in Nuzu style with meander and zigzag decoration in white on black, ATP/37/357.

Type I2. The Level $V$ examples water-smoothed and pebble-burnished on the outside, a later example $(\mathrm{ATP} / 37 / \mathrm{I} 74)$ of coarse pink clay, rough.

Type I 3. Hand-made with knife-trimmed bevelled rim; v. p. 309.

Type I4. Rather heavy-walled utilitarian basins, plain.

Type i 5 . Some of the Level V examples are water-smoothed or burnished, that from Level VI water-smoothed; all later examples are plain, and those from Levels III-II are very coarse. All of buff, drab, or red clay.

Type I6. Black ware, smother-kiln fired and burnished.

Type i 7. Always roughly made in coarse clay.

Type 18 . Plain clay, well turned and thin-walled. 
Type i 9. Apparently a late type-7 examples found in the upper soil as against $\mathrm{I}$ in Level IV. All of light-coloured clay and generally rather roughly made.

Type 20. Like Type I 9 but with sharper outline, larger and better made, but surface not finely finished.

Type 2 I. (a) Always plain and often rather coarse ware; (b) is of plain light ware, one example with a broad reeded rim, and one with trickle-pattern in brown paint, but the Level $V$ piece is of cooking-pot ware, red in section, grey-brown surface, with straw engrais; $(c)$ is a miniature rather roughly made of light drab clay with engobbage of the same colour.

Type 22. Plain light ware, whitish drab, well turned.

Type 23. The most characteristic of the early types; there are wide variations in detail which are illustrated by the examples in the type-list, "e.g. flat or ring bases, carinated or curved sides, $8 \mathrm{c}$., but the basic type is unmistakable. It is, of course, the precursor of the late Type 22, but whereas that may be a large bowl No. 23 is always small, and Type 23 is, in the great majority of cases, painted - it is, in fact, one of the very few shapes to which in the early periods painted decoration is regularly applied. There are exceptions to this; in Level XVII one example is of red clay, the outer face rough and the inner water-smoothed, one is of thin grey and one of thin black (smotherkiln) ware, both burnished, and there are plain examples which seem to become more common in Levels IX and X; but a very large proportion are painted ( $)$. Pls. XCI, XCII) with geometrical designs of the triglyph order below the rim and on the top of the rim nicks of paint set radially; we have only one example of zoomorphic design, $v$. Pl. LXXXIV $c$. The clay is usually either a light whitish drab or buff or a light red; the paint reddish-brown or nearly black; most are well water-smoothed, and the process has often produced a greenish-white effect.

Type 24. Well turned and smoothly finished in the natural colour of clay except for one smother-kiln example from Level $\mathrm{V}$.

Type 25. Drab clay, rather coarsely made.

Type 26. The type runs through the Levels XIV to III with very little change, though the later examples seem to become more nearly hemispherical (contrast $(a)$ and $(b)$ ). Three early examples found in the filling of the Level VII city rampart are painted with the triglyph design and bird or animal motives and one has, between the triglyphs, small clay pellets affixed whereon horizontal painted hatching, but the vast majority are plain and sometimes quite coarse though fairly thinly walled in proportion to their size. (b) The single late painted example in the slap-dash style characteristic of Level III seems to be a throw-back, ATP/38/94, Pl. LXXXIX.

Type 27. Coarse drab clay, plain.

Type 28 . This more open bell-shaped type is carefully made, thin-walled, and of fine smooth clay fired to a clear pale pink.

Type 29. All 3 examples are of greenish-buff clay and are painted ( $v$. ATP/47/I I 4) and all have knuckle-bone handles.

Type 30. Bowl with single short lug handle; one example only found, $\mathrm{ATP} / 39 / 55$, of plain drab clay.

Type 3 I. Heavy shallow bowl with 2 lug handles. The Level VII example, a variant with shorter handles and rim more sharply in-turned, is of coarse grey smother-kiln ware; the later are roughly made of coarse gritty clay, red or buff.

Type 32. Level XIV produced a fragment of a very large example in coarse smother-kiln ware (the firing possibly accidental), but the later examples were all of red clay; some of those may have been rather earlier than Level III (Level III-IV) since the stratification of Sqq. K I $3^{-1} 4$ in which they were found was somewhat confused. 
Type 33. Coarse pink or drab plain ware.

Type 34. Two examples, both painted. That from Level XII в (ATP/47/I I 9) figured in the type list, Pl. CXI, had a painted cross under its base, grey-buff ware with design in reddish-brown; a fragmentary example from Level XIV had 3 or 4 handles and was rather shallower but similar in type; buff clay (ATP/48/33).

Type 35. Very carefully made of finely levigated salmon-pink clay; dashes of brown paint across the flat rim and down the outer edge.

Type 36 . A single example (ATP/46/64, Pl. XCIX a) finely made in yellowish clay.

Type 37. One example only, coarse greenish-drab clay.

Type 38 . One example only; coarse greenish-drab clay.

Type 39. Very large vessel (ht. $0.88 \mathrm{~m}$.) of plain drab clay, well made but not well finished.

Type 40. Buff or greenish-drab clay; the base sometimes more and sometimes less pointed.

Type 4I. A late jug with sub-variants as shown, though of $(c)$ only a single undated example was found; all are plain, of rather coarse clay with loose sandy texture. Two, not entered in the list, were in the top-soil and so are likely to belong to Level I.

Type 42. A miniature jug, always roughly made of coarse clay, usually drab, sometimes red; in one or two cases the body from the shoulder down has been knife-trimmed, like the 'Cypriote' juglets; I suspect that in both countries we have to deal with imports or with local copies of foreign imports.

Type 43. Jug with flattened almond-shaped body, moulded in two pieces and fixed together. One example only, in drab clay.

Type 44. The 'pilgrim-flask', distinguished from Type 43 by having a circular instead of an almond-shaped body; variants have knobs $(b)$ or knobs and small handles for suspension $(c)$. The type recurs in Cyprus. One example of $(b)$ is of buff clay with an all-over red wash (partly burnt black) burnished; one of $(c)$ is similar, from Level IV; most are of red clay, water-smoothed, one of biscuit-coloured clay burnished.

Type 45 . Smother-kiln ware, usually, if not always, burnished.

Type 46. One example only, of drab clay.

Type 47. The form is very much that of the 'Cypriote' Base-ring ware, but the fabric is quite different, more like the Tell el Yahudieh pottery, black clay, smother-kiln made, with pebbleburnished surface.

Type 48. A form coming close to the 'spindle-vase' of Cypriote excavations (in the case of (a), but in its variants, especially (c), taking on a more local character) and, like the Cypriote examples, always burnished. The material is most often a red clay, the colour heightened by water-smoothing, but often there is an over-all wash of red or purplish-red paint; but in (a) we have 2 examples of light yellow or buff pebble-burnished ware and I (from Level VI) in black smother-kiln fabric, rag-burnished. $\mathrm{Pl}$. XCIX $k, l, n$.

Type 49. Red or greenish-white clay, the surface rather rough.

Type 50. Reddish-buff clay, well turned, plain.

Type 5I. One example only, reddish-buff clay with bands of brown paint round the body.

Type 52 . One example only, red clay with an over-all wash of red-brown paint, matt surface.

Type 53. One example only, a rather coarse little jug of greenish-drab clay, poor surface.

Type 54. Of this funnel-necked high-shouldered jug there are only 3 examples, all plain and of light clay. Pl. XCIXm. 
Type 55. This form with the rounder body is much more common and is characteristic of Levels V and IV. Of I 2 examples of $(a) 9$ are of plain clay, red or drab, I has a deep red over-all wash, rag-burnished, I has 3 horizontal bands of red paint, and I red bands joined by vertical strokes; 2 examples of $(b)$ are both painted with red or black bands, I has both bands and oblique strokes between them; the painted jugs come from Level IV or, in one case, III-IV.

Type 56 . One example only, drab clay with brown bands painted on rim, shoulder, and handle.

Type 57. A type occurring sporadically. An apparent example (it is imperfect) from Level XII has brown bands painted at the base of the neck and round the shoulder with radiate lines between the bands; later examples are plain, but I from Level VII has a creamy slip over a red body-clay.

Type 58 . Both examples were unusually hard-fired, the surface of the pot being light brick-red, the inside, in section, black; I has a red paint wash over the whole of the upper part. The second specimen though not accurately dated is probably contemporary with the first-Level IV-V.

Type 59. The 2 examples, though not dissimilar, can scarcely be connected. (a) From Level XII-XIV (its exact horizon uncertain) is painted in red on pinkish drab and has a very heavy handle; $(b)$, of plain light red clay, Level II-III.

Type 60. The main foruit of the type is in Level IV. and, in accordance with the character of that period, nearly all the examples are decorated. Pl. LXXXVII. In some cases the natural clay (nearly always red) is smoothed and burnished, the body burnishing generally vertical and often spaced for effect; in others there is a red or purplish-red over-all wash with or without burnish; 5 examples are painted with red-brown horizontal bands, on the pink or buff clay or, in one case, on a creamy slip laid over the red body. Of 27 examples found only 6 were plain, $\mathrm{Pl}$. XCIX $j$.

Type 6I. One example is in smother-kiln ware, not burnished, I (from Level IV-V) of yellow clay burnished; others are of plain red or drab clay.

Type 62. Both examples of (a) are painted, I with an all-over red wash, I with black bands round the belly and vertical strokes on neck, shoulders, and handle, ATP/37/40; Pl. LXXXIX $b$; examples of $(b)$ are plain red or greenish drab.

Type 63. Always decorated; 3 examples with over-all red wash, vertical burnish; 3 have horizontal bands of red paint on a buff ground. Pl. LXXXIXc.

Type 64 . A plain type in drab or red clay; but I example, from the Niqme-pa palace (ATP/38/ $37 \mathrm{~B})$, has the rare decorative technique of reserved slip.

Type 65. One example only, of light drab clay, water-smoothed, with double reeded handle.

Type 66. One example only, of light yellow clay.

Type 67. This open-mouthed jug with or without a rim is usually rather heavily made, thickwalled, of coarse drab clay; in 2 examples (I (a), I (b) variants) the surface is well water-worked to a smooth greenish-white flared in places to pink, but generally the finish is rough.

Type 68. The standard type of jug throughout the later periods from Level V onwards, flatbased and trefoil-mouthed, the variants differing in the curve of the body which tends to become more angular $(b)$ in the upper levels. All colours of clay appear except black or dark grey-there is no smother-kiln example nor any decoration of any kind, though one late example has a creamy slip over the body-clay. In the majority of cases the clay is described as coarse and only once as 'fine'; these are in fact purely utilitarian household jugs.

Type 69. Distinguished from the last type by having a rounded base, nearly as common and of the same date, but apparently used for different purposes since a certain amount of decoration is not uncommon. One example is covered with a red slip, 2 are burnished, and 3 have plain bands of dark paint round the shoulder; $\mathrm{I}$ has a ring of clay in relief round the neck; the rest are plain, of greenish-white, drab, or red clay. The variations in form have no chronological significance. 
Type 70. The standard type of jug throughout the early periods. There is a good deal of variety in the details of form, e.g. the neck may be proportionately longer and more sharply differentiated from the shoulder than in the type drawing (v. ATP/47/I 29, Pl. LXXXIV), but the dominant features are the almost globular body, the sloped handle, the flat or ringed base, and the trefoil mouth decorated with a painted eye. The jugs are always painted, generally with the triglyph design including bird or animal motives, $v$. Pls. XCI, XCII. The clay is generally of a buff or pinkish-buff colour, occasionally burnished; the paint varies from red to brownish-black; the potting is good; handles are sometimes of the flat ribbon type, sometimes 2-strand twists. The type is remarkably common in the periods XVI-XII and continued in use certainly up to Level VIII; the Level VII example was a fragment found in the filling of room 16 of the Yarim-Lim palace, and though its presence might be accidental it more probably shows a real survival up to that date. Throughout this very long period there was no sign of development or modification of shape or ornament.

Type 7 I. Distinguished mainly by the form of the handle and the absence of the eye motive on the mouth, it is definitely later in date than Type 70. The Level VII example is of fine grey clay, burnished; others are of coarse pink clay, undecorated.

Type 72. Basket-handled jugs. Type (a) with trough spout and filter was represented by a single example in drab clay; the Level VII example of $(b)$ had a bridge-strut from the base of the handle to the tip of the spout, drab clay; of other 9 examples I, from a Level IV grave, ATG/39/7, was painted with black horizontal bands and radiate lines in sets of 3 between the bands, 2 (ATP) $38 / 130 \mathrm{~A}$ and $\mathrm{B}, \mathrm{Pl}$. CVI) from the Niqme-pa palace were painted in Nuzu style, I, also from the palace, was of burnished brown clay; this last had its spout much blackened by fire, implying that it had been used as a lamp, which is a perfectly possible explanation of these small vessels.

Type 73. Of (a) 2 examples are roughly painted in black with horizontal bands and radial strokes between them; a plain example has the spout at right angles to the handle instead of opposite to it; in (b) the base is round.

Type 74. Coarse domestic ware, drab or red.

Type 75. One example in fine orange clay, others rather rough; the rim is sometimes everted instead of vertical.

Type 76. Large plain amphora of buff or red clay.

Type 7.7. Only I example found; drab clay, rather heavy potting:

Type 78. Generally plain heavy drab domestic ware: I painted with Nuzu design, ATP/38/1 7, Pl. CII.

Type 79. Coarse drab ware very roughly painted with black bands, ATP/38/25, Pl. LXXXIXe.

Type 80 . (a) With 4 handles and the rim slotted to take a lid; the 'handles' are probably meant to take the cord securing the lid in place; rather rough light red clay. (b) has a flat rim and 4 'handles' and is of red clay water-smoothed to a bright surface.

Type 8I. One example in brown clay, burnished, 2 of coarse pinkish clay with an all-over wash of purplish-red paint, burnished. The burnish in such cases is probably utilitarian, not decorative, intended to make the vessel more waterproof.

Type 82. Large amphora characteristic of the later levels. The earliest example is in the black impressed ware (ATP/39/14, Pl. C). In Level II it was commonly used for painting in the 'Atchana' style (ATP/37/230, ATP/37/232-3-4, ATP/38/95, ATP/47/73, v. Pl. CIIIf); other painted designs occur on $\mathrm{ATP} / 37 / \mathrm{I} 92$ and $\mathrm{ATP} / 38 / 95$, and many examples have an allover wash of colour. Two differ from the normal type in having short tubular spouts rising from the shoulder. Thirty or more examples were recorded (not all datable, but all from the higher 
levels) and they showed minor variations, some being more squat than the type drawing, one having knobs on the handles and a raised band at the base of the neck; but all generally conform to this single type.

Types 83-89. All ring-stands are relatively late, the earliest ${ }^{\mathrm{I}}$ coming in Level VI, and although the simple type 85 is by far the most common, the different forms seem to have been made, and used, indifferently, the only exception being Types 88 and 89 , with openings in the sides which must have served some particular purpose; they were perhaps braziers.

Naturally, considering their use, the ring-stands are plain and for the most part rather roughly made; there is, however, one exception, a fragment of Type 85 , painted in white on black in Nuzu style, which parallels the more elaborate vase-stand ATP/8/2O2 figured on Pl. CVI.

Type 90. All 5 examples ( $\mathrm{r}$ undated) are of coarse clay, usually pinkish in colour; $\mathrm{I}$, in greenishwhite, is knife-trimmed.

Type 9I. Two examples show the squat form (a), I of them of pale grey clay water-smoothed; the very common form $(b)$ is widely distributed though most frequent in Level IV. One Level IV example has 2 bands of thin orange paint, I from Level II has an all-over red wash, but all the rest are plain and many of them poorly made with rough surface. All are in buff, pink, or red clay; there is no smother-kiln example.

Type 92. The only example is the very remarkable (but fragmentary) ATP $/ 48 / 4 \mathrm{I}, \mathrm{Pl}$. XCIIIa, painted in black on fine greenish-drab clay.

Type 93. Of (a) there is only I example, ATP/39/60, very heavy and clumsy, apparently handmade. The type is a late one, starting in Level $\mathrm{V}$, and is one of the better-class wares of the late period. The form $(b)$ has 3 examples with painted horizontal bands, I (of pinkish-buff clay) with an over-all wash of purplish-red, I with a light brown slip, and nearly all are burnished, the clay being red or, more often, brown; only 4 were of plain clay. The more slender form (c) has 3 examples, all painted, I with plain bands (Pl. LXXXIXa), 2 more elaborately, ATP/39/273 and $\mathrm{ATP} / 39 / 279, \mathrm{Pl}$. XCV.

Type 94. A variant of the last type and, like it, one of the better-class vases characteristic of the late period, running from Level VII to Level II. Eleven examples have horizontal bands of paint, I is painted red over the whole of the upper part $(\mathrm{Pl}$. XCIX $g), 5$ are burnished, including I in coarse black ware from Level VI, 2 have painted designs, ATP/38/142 and ATP/47/I 38 , Pl. XCVI $e$, and 2 are painted in the Nuzu technique with white paint on black, $A T P / 47 / 38$, Pl. CVI, and ATP/38/1 8, Pl. CIIb.

Type 95. This is probably a local type derived from a Mycenaean original, though there does not seem to be an exact parallel in L.M. III pottery. All examples are of light-coloured clay, drab or brown, with dark red or brown-black bands; the paint is less lustrous than most of the L.M. III paint. Judging by the levels, one would suppose that the local potter set himself to copy some of the earliest Mycenaean imports. Pl. LXXXVIIIf.

Type 96. A hand-made vase of light brown clay with water-smoothed surface; the one example, $\mathrm{ATP} / 47 / \mathrm{I} 4 \mathrm{I}$, was found in the filling of the Level XIV temple sanctuary and might belong to that level or to Level XIII or possibly XII.

Type 97. Always of plain clay, the only decoration being that I example of $(b)$ from Level IX has a band of rope moulding round the shoulder.

I This is true of the specimens, 69 in all, which were (a) complete and $(b)$ definitely dated to a level. One example found loose in Sq. N I 4 might, from its level, have been earlier than Level VI, but the evidence was not good. A field note records that 8 large sherds from different examples of
Type 85 , all of reddish-buff clay finely water-smoothed, were found in Level $X$. The fine finish would be most unusual, and it is possible that we wrongly identified the type from the fragments; but a caveat is required by the categorical statement in the text. 
Type 98. One example only, of coarse pink clay with an over-all wash of deep orange paint.

Type 99. A late type with very limited range; it should be noted that of the common form (c) 2 examples came from the Niqme-pa palace and all the rest from private houses, so that it was evidently in general domestic use at the time. One example had an over-all red paint wash and I, of fine pinkish-buff clay, was knife-trimmed; all the rest were of plain clay and generally rather coarse.

Type I00. A characteristic early type with a long floruit. The pots are generally well made, occasionally of pink or reddish-buff clay but much more often of a very light-coloured clay which with water-smoothing has a greenish-white surface. The rim is usually but not always ribbed. The earliest examples, numerous fragments from Level XVII, are of fine drab ware with painted bands below the neck; similar painted examples were common in the filling of the city rampart and appear to belong to Levels XIV-XII; fragmentary examples were found in most of the early levels but they become common in Levels IX and VIII; by that time about half still have the painted bands and about half are plain; after Level VIII they are all plain except for I, ATP/48/62, a fragment which may be of not quite the same type. Even the later examples are always well made and light in colour.

Type го . Coarse heavy ware, one with 3 bands of dark red paint on pinkish-buff clay.

Type I02. Earlier examples plain and sometimes quite rough; in Level IV Grave ATG/47/5 there was an example with painted bands round the body and radial strokes on the rim, and another from Level IV-III had been painted in the Nuzu technique, ATP/37/9 I.

Type I03. Characteristic of the later period. Three examples, all from Level V, are burnished over a slip-in I case brown, in 2 greenish-white; all the rest are plain, and nearly all are in lightcoloured clay.

Type 104. One example, ATP/47/57, of Level VI, has bands of red-brown paint on buff clay, 5 from Level $V$ are pebble-burnished; but in 9 cases it is particularly remarked that the surface was rough or coarse and only 2 are described as being well finished. All colours of clay are represented.

Type 105. One example only, rough drab ware.

Type i 06. Form (a) is well made of light-coloured clay; 2 examples have double bands of red paint on the shoulder. Form $(b)$ is always in light-coloured clay of fine quality, often white or greenish-white and water-smoothed, never painted. The type had a short vogue, apparently, but in that time was very common; over 40 examples were recorded. Pls. LXXXVII and XCIXe.

Type 107. Almost always of light-coloured clay, pale buff or whitish drab, the surface sometimes water-smoothed but not as a rule carefully finished; as was the case with Type Io6, the majority of the (I6) examples found came from graves.

Type I08. One example (a) was of brownish-red clay with natural surface, but the others had either an over-all brownish-red paint wash or a slip of the same colour and were burnished $(b)$; of the handled form $(c)$ a single example was found.

Type I09. Plain rather rough ware.

Type I IO. The shape is so obvious that its occurrence in Level XIV does not necessarily mean a tradition revived in Level IV. Two examples, ATP/37/5 and $34 \mathrm{I}, \mathrm{Pl}$. CVI, are painted in Nuzu technique; I, from Level IV, has 3 bands of brown paint, the others are plain but of fine clay.

Type I I I. Large pots of coarse clay, light in colour; I has 2 rows of incised nicks round the shoulder; a flat foot instead of a base ring is not uncommon.

Type I I 2. Only I example, pink clay with smooth pink engobbage and bands of red paint. 
Type I I 3. The 'champagne-cups' are grouped as one type whether they have slits in the stem or not because in several cases where only fragments were concerned the stem was missing; experience on other sites shows that the variants are contemporary. That the type is curiously long-lived (Levels XIV to II) may be explained by its connexion with the temple; all were found in the temple area. They are made in drab or red clay, not very well finished.

Type I I 4. One example only, of red clay with rough horizontal burnish.

Type I I 5. Very characteristic of the early periods from Level XIV to Level VIII, after which it disappears. It is generally rather roughly made with no surface finish, in buff or red clay.

Type i i6. One example only, roughly made of very light drab clay; it came from a grave ( $A T G / 38 / 20$ ) for which there was no good dating evidence, but it was most probably to be assigned to Level VII.

Type I i 7. Two examples of (a), both painted, were found together, ATP/49/ I 3, Pl. LXXXVII; form $(b)$ had 2 examples, both plain. It seems to be a definitely Level $V$ type and is well made and finished.

Type I I 8 . Form (a), which is well made in plain ware (only I case of smother-kiln ware and one, Pl. XCIX $h$, of red over-all wash and burnish) seems to have been ousted by the more popular form $(b)$ which is the principal 'luxury' form of the later periods. Only 2 undecorated examples are recorded; in Level IV decoration starts with designs painted in dark on light, and then the form becomes the regular vehicle for the Nuzu technique, v. Pl. CII, CIV, and CV. The potter always used a very light-coloured clay which he generally water-worked to a smooth and nearly white surface, but in some cases used an engobbage or even a slip to secure the same effect. It is worth noting that the type never occurs in Level I; it stops together with the Nuzu (or 'Atchana') technique.

Type I I 9. This was probably far more common than the tabular analysis implies because it was impossible to differentiate between fragments of the bowl of Type I I 9 and those of Type 23, q.v., only where the pedestal was forthcoming could we be certain of the type. Such a pedestal was found in Level XVII, I occurred in Level VI, and it is likely that some of the examples (undated) found in the filling of the city rampart belong to the intermediate Levels XI to VIII, but for Levels XI to VIII no decisive evidence was obtained. It can, however, safely be assumed that this is one of the painted types characteristic of the early periods and lasting on, probably, to Level VIII (though by that time it was certainly uncommon) with perhaps an archaistic revival in Level VI. The vessels are always of light-coloured clay, buff or pink, well finished and sometimes highly burnished, and they seem to have been invariably painted; for examples of the decorative motives $v$. Pls. LXXXIVd, XCII.

Type $\mathrm{r} 20$. This type (sometimes with the modification of a simple rim instead of the accentuated form shown on the type-list) is peculiar to Level $V$ and is invariably of black (smother-kiln) burnished or matt ware with impressed decoration; v. Pl. C.

Type I 2 I. One example only, in fine greenish-buff clay, plain; found in a grave (ATG/37/2 I) apparently dating between Levels $V$ and $I V$, this vase seems to represent the last phase of Type I 20 , being much smaller, in a different clay differently treated, and without the characteristic ornament.

Type i 22. All 4 examples are in drab clay with plain surface.

Type I 23. Except for the foot, the two forms are very similar; but (a), found only in the low Levels XIV-XII, seems to be associated with Type I I 5 , whereas the only example of $(b)$ was in Level VII, in the Yarim-Lim palace; it is of grey clay while the older examples (a) are generally drab. Pl. LXXXVII.

Type I 24. One example only, of drab clay with bands of brown paint on the shoulder. 
Type i 25. Two examples, I of drab, I of reddish clay, well made and finished, both found in graves, ATG/39/I 5 and I 7 .

Type I 26. A single example, in orange clay, plain.

Type I 27. A 'luxury type' mostly found in Level V. The clay is generally a light drab which with water-smoothing has given a greenish-white surface; where a pink or red clay was used a creamy white slip was added; the vase is generally rag-or pebble-burnished. Two examples are painted with brown bands, I had an all-over decoration in Nuzu technique, ATP/37/2 77, Pl. CVI.

Type I 28. A development of the last, with a very long neck; only I example, of fine greenish clay with white slip, painted in the Nuzu technique, ATP/38/72, Pl. CVI.

Type I 29. (a) Very heavy and clumsy bottle type suggesting a crucible; I example has a small hole through the bottom; all are roughly made of coarse clay; form $(b)$ is quite well made but the surface not carefully finished; I example has a small hole through the bottom; $(c)$ is a miniature in drab clay, perhaps a derivative.

Type I 30. (a) is fairly well made, but $(b)$ and $(c)$ are both thick-walled and clumsy forms, made in greenish or buff clay with no surface finish. One example of $(a)$ is in Nuzu ware, ATP/38/1 96 , Pl. CIId.

Type i 3 I. Carefully made, especially the (a) form, which has a well-moulded rim and is decorated with grooved lines round neck and shoulder. One example (from the Yarim-Lim palace) was fired at an unusually high temperature-the clay is grey-black in section with a clear red surface.

Type I 32. Large store-jars, rather roughly made of drab clay; an example of $(b)$ had a small hole through its bottom.

Type I 33. The one example found, ATP/49/42, came from low down in Level XVII, only just above virgin soil; it is of pinkish drab clay with natural surface. It closely resembles specimens found at Tabara al Akrad.

Type I 34. The one example of (a) is of light pink clay with bands of red paint. Of form (b) the Level XIV example is of grey-buff clay, roughly made with coarse surface; the late example is well made, of whitish drab clay with a slight ribbing round the neck; the resemblance of these two is perhaps fortuitous.

Type i 35. A well-made vessel with flat or ring base; the colour of clay varies with each specimen, the surface smooth but plain.

Type I 36. Very carefully made, suggesting the use of a templet; some examples are ribbed either round the base of the neck or round the shoulder; I has a small lug rising from the shoulder. The clay is of a natural colour, red, drab, \&c., but I example from a grave has a creamy slip over the light brick-red clay.

Type I 37. A highly specialized type. Of 29 examples recorded 5 are in natural clay, drab, reddish, or buff, and all the rest are smother-kiln fired, grey or black, and all or nearly all are burnished with rag or with ring or vertical pebble burnishing. The clay is of a fine even texture, hard, and not as a rule inclined to flake as does the clay of the Tell el Yahudiyeh pottery to which this type might naturally be compared. $\mathrm{Pl}$. XCIX $f, \mathrm{ATP} / 37 / \mathrm{I} 58$.

Type I 38 . One example only, in drab clay. It might be the precursor of the next type.

Type I 39. Carefully made and always well finished, but in an unusual variety of wares; 2 have a creamy engobbage, I is of drab clay burnished (ATP/37/I 59, Pl. XCIX $d$ ), I is smother-kiln fired, and I is painted with brown bands on a grey-buff clay; others are of plain pink, red, or buff ware with no special surface treatment. One example has a flat instead of a ring base (this from an undated grave ATG/39/29). 
Type I 40. A painted example of the angular form (a), incomplete, comes from Level XII; it is of reddish drab clay with design in dark red matt paint. Four examples of $(b)$, in drab or orange clay, are rather rough.

Type I 4 I. One example has creamy slip over a red body clay, another, of drab clay, is lightly burnished.

Type I 42 . One example only, of rather coarse drab clay, the surface worked up with a creamy white engobbage.

Type I 43. The clay varies; the Level V example is of very fine orange clay, I from Level IV also of fine clay, pinkish-buff; but others are definitely coarse. None have any decoration.

Type I 44. (a) is of light red clay heavily tempered with white grit, the surface covered with an all-over red wash. $(b)$ is of pinkish drab clay with broad bands of red paint, ATP/38/193, Pl. LXXXIXd.

Type I 45. Really a miniature, sometimes only $0.06 \mathrm{~m}$. high, very roughly made in coarse clay.

Type i 46. A small, sometimes miniature, pot (examples $0.06 \mathrm{~m}$. high), always roughly made of coarse clay.

Type I 47. A sophisticated version of the last two types; it is much better made, 2 examples have red paint bands, I an over-all orange-brown wash; others are in red clay.

Type I 48. (a) A single example in light red clay with vertical pebble-burnishing. The one example (b) is plain, of coarse salmon-pink clay.

Type 149 . One of the limited number of types decorated in the Nuzu painting technique. Of 6 recorded examples 4 are so painted ( $v$. ATP/37/240, Pl. CIII $a$, ATP. 8, Pl. CVII). A great many fragments probably belonged to vases of this type but could not be safely identified.

Type I 50 . Well made and neatly finished but not decorated in any way; the clay red or drab.

Type I 5 I. Well made of light-coloured clay worked up to a good surface: I case of smotherkiln ware.

Type I 52. Big basins used for storage (and sometimes for infants' burials) often decorated with a band of rope moulding in relief. The surface is often water-finished to make the pot less porous.

Types I 53, I 54, I 55. All these are varieties of cooking-pots, i.e. pots made of a clay heavily tempered with white grit or sand, thin-walled and hard fired, the section generally showing a red centre with black or grey outside, though sometimes they are black all the way through; occasionally they have round the shoulder a raised ridge with nicks or impressed marks giving the effect of a rope moulding. A few examples, perhaps meant for kitchen use but not for actual cooking, were made in ordinary ware and even had cross-hatched triangles roughly painted on the shoulder, but such are rare exceptions. The different types, handleless, with horizontal or with vertical handles, do not alter the essential character. It should perhaps be remarked that the type-list, dealing as it does only with shapes of vessels, does not take into account untypable fragments; and since no complete or nearly complete cooking-pots were found by us in the lower levels, the list gives the impression that such did not occur before Level VII. That impression is mistaken. The analysis of pottery from the lower levels (p. 306) shows that the ware was in use at least from Level XVI upwards; but we were not able to identify individual shapes.

Type I 56 . A single example in coarse clay, thick-walled and clumsy.

Type I 57. A single example in coarse pink clay.

Type I 58 . Very common after Level IV. A miniature pot in most cases (ht. as little as $0.05 \mathrm{~m}$.), it is always plain and often roughly made in coarse clay of any natural colour, the surface poorly finished. 
Type I 59. A single example, well made and finished in pinkish drab clay.

Type I60. A 'feeding-pot', in one case roughly painted, in another well made and watersmoothed, but generally of coarse clay with no surface finish.

Type I6 I. A single example, of brownish creamy ware lightly burnished; from the Niqme-pa palace.

Type I62. Grey-drab clay well made and finely water-smoothed.

Type I63. Of the large variant, (a), examples in red and drab clay. The small variant $(b)$ was extremely common in Level IV; a large proportion was either painted with an all-over red wash or was burnished either on the wash or on the natural clay; all were neatly made and nearly all were well finished. The Level VII example was in smother-kiln ware.

Type I 64. Colander with ring base and holes in the upper part of the sides only; I example has 3 small ring handles. Red or drab clay, plain.

Type i 65. Colander with holes down to the rounded base, plain ware, but generally well finished.

Type I66. Heavy flat bowl with a wide groove round the base inside; possibly a mixing-bowl. The same type occurs in Mesopotamia in the Early Dynastic period (Ur Excavations, ii, Pottery Type I) and at Atchana it first appears in Level XIV. The latest example is a miniature, diam. only $0.047 \mathrm{~m}$. Plain clay, drab, the earliest with water-smoothed inner surface but I Level V specimen quite rough.

Type i 67. Lamps; (a) is the normal type, common from Level IV onwards, the carinated form (b) occurred only once, between Levels XIV and XII, its exact horizon indeterminable, and the more upright and less accentuated form (c) only in Level III. They are of various natural-coloured clays, never very well finished.

Type i68. Handled dish-cover, buff clay.

\begin{tabular}{|c|c|c|c|c|c|c|c|c|c|c|c|c|c|c|c|c|c|}
\hline & I & $2 a$ & $2 b$ & $3^{a}$ & $3^{b}$ & $4 a$ & $4 b$ & $4 c$ & 5 & $6 a$ & $6 b$ & $7 a$ & $7 b$ & 8 & $9^{a}$ & $9^{b}$ & $9 c$ \\
\hline \multicolumn{18}{|l|}{ LEVEL } \\
\hline $\mathrm{O}$ & $\ldots$ & . & $\ldots$ & $\ldots$ & .. & .. & $\ldots$ & .. & .. & .. & $\cdots$ & .. & .. & .. & .. & .. & . \\
\hline I & .. & $\ldots$ & .. & . & I & $\ldots$ & I & .. & .. & $\ldots$ & I & 2 & I & . . & . & $\ldots$ & .. \\
\hline \multirow[t]{2}{*}{ II } & I & . & . & . & . & . & 3 & I & $\therefore$ & . & . & .. & I & .. & . & . & .. \\
\hline & .. & .. & .. & $\ldots$ & I & $\ldots$ & . & .. & .. & $\ldots$ & $\ldots$ & $\cdots$ & $\ldots$ & .. & .. & . & .. \\
\hline \multirow[t]{2}{*}{ III } & . & $\ldots$ & .. & . & . & $\ldots$ & 2 & $\ldots$ & . & . & I & . & . & .. & . & .. & .. \\
\hline & .. & .. & .. & 3 & $\ldots$ & $\ldots$ & $\ldots$ & $\ldots$ & .. & I & .. & $\ldots$ & $\ldots$ & .. & .. & $\ldots$ & .. \\
\hline IV & $\ldots$ & I & .. & 6 & 82 & $\ldots$ & 38 & 4 & .. & 28 & 4 & 2 & 5 & I & .. & .. & .. \\
\hline \multirow[t]{2}{*}{$\mathrm{V}$} & $\ldots$ & I9 & .. & 45 & 2 & $\ldots$ & . & $\cdots$ & 26 & 2 & 2 & I & I & I & $\cdots$ & I & 9 \\
\hline & $\ldots$ & .. & $\ldots$ & . & $\ldots$ & $\ldots$ & $\ldots$ & $\ldots$ & .. & I & $\ldots$ & . & $\ldots$ & .. & .. & $\ldots$ & .. \\
\hline VI & .. & . & .. & $\ldots$ & $\ldots$ & $\ldots$ & .. & .. & 7 & 2 & . & . & $\ldots$ & 2 & .. & $\ldots$ & I \\
\hline VII & .. & . & I & $2 \mathrm{I}$ & 8 & $\ldots$ & . & .. & 2 & .. & .. & . & $\ldots$ & .. & . & .. & .. \\
\hline \multirow[t]{2}{*}{ VIII } & $\ldots$ & .. & 2 & 6 & $\ldots$ & . & .. & $\ldots$ & $2++$ & $\ldots$ & $\ldots$ & .. & .. & .. & $\mathrm{I}++$ & .. & .. \\
\hline & $\ldots$ & $\ldots$ & $\ldots$ & 5 & $\ldots$ & $\ldots$ & .. & .. & I & $\ldots$ & $\ldots$ & .. & $\ldots$ & .. & . & $\ldots$ & . \\
\hline IX & $\ldots$ & $\ldots$ & $\ldots$ & $\ldots$ & $\ldots$ & $\ldots$ & . & $\cdots$ & $5+$ & $\ldots$ & $\ldots$ & . & .. & .. & $3+$ & $\ldots$ & .. \\
\hline $\mathrm{X}$ & $\ldots$ & .. & $\ldots$ & I & $\ldots$ & 2 & .. & .. & .. & $\ldots$ & $\ldots$ & $\ldots$ & .. & .. & $\ldots$ & I & . \\
\hline XI & .. & .. & .. & $\ldots$ & $\ldots$ & $\ldots$ & $\ldots$ & .. & $\ldots$ & $\ldots$ & $\ldots$ & .. &.. & .. & .. & .. & .. \\
\hline XII & .. & $\ldots$ & .. & $\ldots$ & I & $\ldots$ & .. & . & .. & .. & . & .. & .. & . & . & $\ldots$ & .. \\
\hline XIII & $\ldots$ & . & .. & $\ldots$ & .. & . & . & . & . & $\ldots$ & . & .. & .. & .. & $\ldots$ & .. & .. \\
\hline XIV & .. & .. & .. & .. & $\ldots$ & $\ldots$ & .. & .. & . & $\ldots$ & $\ldots$ & .. & I & .. & .. & .. & .. \\
\hline $\mathrm{XV}$ & $\ldots$ & . & $\ldots$ & .. & $\ldots$ & $\cdots$ & . & .. & . & $\ldots$ & $\ldots$ & .. & .. & $\ldots$ & .. & .. & . \\
\hline XVI & .. & $\ldots$ & $\ldots$ & $\ldots$ & $\ldots$ & $\ldots$ & .. & .. & $\ldots$ & $\ldots$ & $\ldots$ & .. & $\ldots$ & $\ldots$ & .. & $\ldots$ & .. \\
\hline XVII & $\ldots$ & $\ldots$ & . & . & $\ldots$ & .. & . & I & . & $\ldots$ & $\ldots$ & .. & & $\ldots$ & $\ldots$ & $\ldots$ & .. \\
\hline
\end{tabular}


NOTES ON POTTERY TYPES

\begin{tabular}{|c|c|c|c|c|c|c|c|c|c|c|c|c|c|c|c|c|}
\hline & Io & I I & I 2 & I 3 & I $4 a$ & $14 b$ & I 5 & I 6 & I 7 & I 8 & I9 & 20 & $2 \mathrm{I} a$ & $2 \mathrm{I} b$ & $2 \mathrm{I} C$ & 22 \\
\hline \multicolumn{17}{|l|}{ LEVEL } \\
\hline $\mathrm{O}$ & .. & .. & . & $\cdots$ & .. & $\ldots$ & $\ldots$ & $\cdots$ & $\cdots$ & $\ldots$ & .. & $\therefore$ & $\cdots$ & . & & \\
\hline I & $\ldots$ & 2 & . & . & I & $\ldots$ & $\ldots$ & $\ldots$ & $\ldots$ & I & . & . & . & $\ldots$ & .. & $\ldots$ \\
\hline II & . & 2 & . & . & .. & . & I & $\ldots$ & $\ldots$ & I & . & . & . & I & .. & 2 \\
\hline & $\cdots$ & $\cdots$ & $\ldots$ & $\cdots$ & . & . & 4 & $\cdots$ & $\ldots$ & $\ldots$ & . & .. & $\ldots$ & $\ldots$ & .. & \\
\hline III & . & 2 & . & . & .. & . & . & $\ldots$ & . & I & . & . & I & . & .. & I \\
\hline IV & $\ldots$ & 3 & . & . & . & I & 5 & . & I & $\ldots$ & I & .. & I & $\ldots$ & .. & 4 \\
\hline & $\ldots$ & $\cdots$ & . & . & .. & .. & $\cdots$ & $\cdots$ & $\cdots$ & . & .. & . & . & I & .. & I \\
\hline V & $\ldots$ & I & 2 & . & .. & .. & I I & . & . & . & . & $\cdots$ & .. & $\ldots$ & I & 2 \\
\hline VI & . & I & . & $\ldots$ & .. & . & I & $\ldots$ & .. & .. & .. & .. & .. & $\ldots$ & .. & .. \\
\hline VII & . & .. & .. & $\ldots$ & $\ldots$ & $\ldots$ & .. & . & I & $\ldots$ & . & .. & 9 & .. & 7 & .. \\
\hline VIII & $\cdots$ & . & . & $\cdots$ & . & . & I & $\mathrm{I}++$ & . & . & . & . & $6+$ & . & .. & 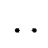 \\
\hline & $\cdots$ & . & . & .. & . & $\cdots$ & $\ldots$ & $\cdots$ & $\cdots$ & . & $\ldots$ & . & 6 & $\ldots$ & .. & $\cdots$ \\
\hline IX & $\cdots$ & . & . & $\cdots$ & . & .. & $\ldots$ & .. & $\cdots$ & $\cdots$ & . & $\cdots$ & $28++$ & $\cdots$ & . & . \\
\hline $\mathrm{X}$ & . & . & .. & $\ldots$ & . & .. & . & I & . & . & .. & . & .. & .. & . & .. \\
\hline XI & $\cdots$ & . & . & $\ldots$ & . & $\ldots$ & $\ldots$ & .. & $\ldots$ & $\ldots$ & $\ldots$ & . & .. & .. & $\ldots$ & . \\
\hline XII & I & . & $\ldots$ & . & .. & $\ldots$ & .. & $\ldots$ & .. & .. & $\ldots$ & + & + & .. & .. & .. \\
\hline XIII & . & . & .. & .. & . & .. & $\ldots$ & $\ldots$ & .. & . & . & + & . & .. & .. & . \\
\hline XIV & .. & . & . & $5++$ & . & .. & $\ldots$ & .. & $\ldots$ & $\ldots$ & $\ldots$ & + & I & .. & .. & .. \\
\hline$X V$ & .. & .. & .. & $\ldots$ & $\ldots$ & .. & . & .. & . & $\ldots$ & $\ldots$ & .. & .. & $\ldots$ & .. & .. \\
\hline XVI & $\cdots$ & . & . & . & $\ldots$ & .. & $\ldots$ &. & .. & $\ldots$ & $\ldots$ & .. & . & .. & .. & . \\
\hline XVII & . & .. & . & . & .. & .. & $\ldots$ & . & .. & $\cdots$ & $\cdots$ & $\ldots$ & .. & $\ldots$ & . & .. \\
\hline
\end{tabular}

\begin{tabular}{|c|c|c|c|c|c|c|c|c|c|c|c|c|c|c|c|c|c|}
\hline & $23^{a}$ & $23 b$ & $23 c$ & $23 d$ & 24 & 25 & $26 a$ & $26 b$ & 27 & $28 a$ & 286 & 29 & 30 & 3 I & 32 & 33 & 34 \\
\hline \multicolumn{18}{|l|}{ LEVEL } \\
\hline $\mathrm{O}$ & $\cdots$ & $\cdots$ & $\cdots$ & .. & $\cdots$ & $\cdots$ & $\cdots$ & . & .. & .. & $\cdots$ & .. & . & . & & $\cdots$ & \\
\hline I & . & $\ldots$ & $\ldots$ & $\ldots$ & $\ldots$ & . & .. & .. & .. & .. & . & . & . & $\ldots$ & $\ldots$ & I & $\ldots$ \\
\hline II & . & . & . & .. & . & I & .. & $\ldots$ & $\ldots$ & .. & .. & . & $\ldots$ & . & .. & .. & $\therefore$ \\
\hline & .. & .. & . & . & $\ldots$ & $\ldots$ & . & $\ldots$ & .. & .. & .. & $\ldots$ & $\ldots$ & I & 3 & .. & .. \\
\hline III & $\cdots$ & . & . & .. & $\ldots$ & $\ldots$ & I & I & .. & $\ldots$ & . & . & . & $\ldots$ & 29 & $\ldots$ & .. \\
\hline & . & . & . & .. & . & $\cdots$ & . & .. & . & .. & $\ldots$ & . & . & I & $\ldots$ & . & 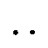 \\
\hline IV & $\cdots$ & . & $\ldots$ & . & . & . & 6 & . & . & . & .. & . & I & $\ldots$ & . & I & $\cdots$ \\
\hline & $\cdots$ & $\cdots$ & $\cdots$ & $\cdots$ & $\cdots$ & $\cdots$ & $\cdots$ & . & $\cdots$ & $\cdots$ & .. & . & . & I & $\cdots$ & . & .. \\
\hline V & I & . & $\cdots$ & . & 2 & $\cdots$ & 4 & . & . & . & . & .. & $\ldots$ & . & . & . & . \\
\hline & $\cdot \cdot$ & $\cdots$ & . & $\cdot$ & I & $\cdots$ & . & .. & $\cdots$ & .. & I & $\cdots$ & . & . & $\cdots$ & . & $\cdots$ \\
\hline VI & $\cdots$ & . & $\cdots$ & $\cdot \cdot$ & I & $\cdots$ & $\cdots$ & . & $\cdots$ & . & I & $\cdots$ & . & . & I & $\cdots$ & $\cdots$ \\
\hline VII & $\because$ & $\cdots$ & $\cdots$ & - & $\cdots$ & $\cdots$ & $\cdots$ & $\cdots$ & I & . & . & $\cdots$ & . & I & $\cdots$ & $\cdots$ & * \\
\hline VIII & $7+$ & $\cdots$ & $\cdots$ & . & $\cdots$ & $\cdots$ & 4 & $\cdots$ & $\cdots$ & . & .. & $\cdots$ & $\cdots$ & $\cdots$ & $\cdots$ & $\cdots$ & $\cdots$ \\
\hline & $\begin{array}{c}\text { I I } \\
25++\end{array}$ & $\cdots$ & $\cdots$ & $\cdots$ & $\ddot{.}$ & $\begin{array}{l}\cdots \\
\ldots\end{array}$ & $\begin{array}{c}3 \\
. .\end{array}$ & $\begin{array}{l}\cdots \\
\ldots\end{array}$ & $\begin{array}{l}\cdots \\
.\end{array}$ & . & . & $\begin{array}{l}\cdots \\
\ldots\end{array}$ & $\begin{array}{l}\cdots \\
\ldots\end{array}$ & $\cdots$ & $\cdots$ & $\cdots$ & $\cdots$ \\
\hline IX & $\begin{array}{c}25++ \\
\text { I }\end{array}$ & $\begin{array}{l}\cdots \\
\ldots\end{array}$ & $\begin{array}{l}\cdots \\
\cdots\end{array}$ & $\begin{array}{l}\cdots \\
\ldots\end{array}$ & $\ddot{0}$ & $\ldots$ & $\cdots$ & .. & $\begin{array}{l}\cdots \\
\cdots\end{array}$ & $\begin{array}{l}\cdots \\
\ldots\end{array}$ & $\begin{array}{l}\cdots \\
.\end{array}$ & $\ldots$ & 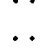 & $\ddot{*}$ & $\cdots$ & $\cdots$ & $\cdots$ \\
\hline $\mathrm{X}$ & 7 & .. & +++ & .. & . & $\ldots$ & . & . & .. & $\ldots$ & .. & $\cdots$ & . & . & . & $\cdots$ & 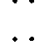 \\
\hline XI & + & . & . & .. & . & . & . & .. & . & .. & .. & .. & .. & . & . & .. & - \\
\hline XII & $4+$ & 7 & I & + & .. & . & $2+$ & . & .. & .. & . & 3 & .. & .. & .. & . & I \\
\hline XIII & $7+$ & . & .. & + & $\cdots$ & $\cdots$ & + & . & . & .. & . & . & . & .. & . & $\ldots$ & . \\
\hline XIV & $3++$ & . & 2 & + & I & $\cdots$ & $2+$ & . & $\cdots$ & . & . & . & .. & .. & I & $\cdots$ & I \\
\hline $\mathrm{XI}$ & 2 & - & $\cdot \cdot$ & - & $\cdots$ & $\cdots$ & . & . & $\cdots$ & $\cdots$ & . & $\cdots$ & . & . & .. & $\cdots$ & $\cdots$ \\
\hline $\begin{array}{l}\text { XVI } \\
\text { XVU }\end{array}$ & $\because$ & • & $\because$ & - & $\cdots$ & $\cdots$ & $\cdots$ & - & $\cdots$ & $\cdots$ & . & $\cdot \cdot$ & .. & . & .. & $\cdots$ & \\
\hline XVII & 4 & $\cdots$ & 2 & $\cdots$ & $\cdots$ & $\cdots$ & . & . & $\cdots$ & . & $\because$ & $\cdots$ & $\cdots$ & . & . & $\ldots$ & \\
\hline
\end{tabular}




\begin{tabular}{|c|c|c|c|c|c|c|c|c|c|c|c|c|c|c|c|c|c|c|}
\hline & 35 & $3^{6}$ & 37 & $3^{8}$ & 39 & $4^{\circ}$ & $4 \mathrm{I} a$ & 416 & $4 \mathrm{I} C$ & $42 a$ & $42 b$ & 43 & $44 a$ & $44^{b}$ & $44 c$ & 45 & $4^{6}$ & 47 \\
\hline LEVEL & & & & & & & & & & & & & & & & & & \\
\hline $\mathrm{O}$ & $\ldots$ & .. & .. & $\cdots$ &.. & .. & . & . & .. & .. & .. & . & . & .. & . & .. & .. & . \\
\hline & . & . & . & I & $\cdots$ & I & I & . & .. & 4 & . & I & . & .. & . & .. & .. & .. \\
\hline & $\cdots$ & . & . & .. & .. & $\cdots$ & .. & $\cdots$ & . & .. & $\cdots$ & . & 2 & .. & .. & .. & $\cdots$ & . \\
\hline II & . & I & .. & . & I & I & . & . & .. & .. & I & . & . & I & 3 & .. & . & . \\
\hline & . & . & . & . & . & $\cdots$ & $\cdots$ & . & .. & .. & .. & .. & I & .. & I & .. & $\cdots$ & . \\
\hline III & . & . & . & . & .. & $\cdots$ & .. & . & . & 2 & .. & .. & . & .. & $\ldots$ & .. & . & .. \\
\hline IV & .. & . & I & $\ldots$ & .. & I & 3 & I & $\ldots$ & 2 & 2 & .. & I & I & I & .. & $\ldots$ & .. \\
\hline & .. & . & . & $\cdots$ & $\cdots$ & $\cdots$ & . & . & . & .. & . & .. & . & . & 2 & .. & $\cdots$ & . \\
\hline V & .. & . & . & .. & .. & .. & .. & . & .. & $\ldots$ & .. & .. & .. & .. & I & .. & .. & .. \\
\hline & $\cdots$ & . & . & . & .. & . & . & . & .. & .. & .. & .. & . & $\ldots$ & .. & I & I & .. \\
\hline VI & .. & . & .. & $\cdots$ & .. & $\cdots$ & . & . & .. & .. & . & .. & .. & . & .. & .. & .. & I \\
\hline VII & $\ldots$ & $\ldots$ & .. & $\ldots$ & .. & $\ldots$ & .. & $\ldots$ & $\ldots$ & .. & .. & .. & .. & $\ldots$ & $\ldots$ & $\ldots$ & .. & .. \\
\hline VIII & .. & .. & .. & .. & .. & $\because$ & . & $\ldots$ & .. & .. & . & .. & .. & $\ldots$ & . & I & $\ldots$ & . \\
\hline IX & . & .. & .. & $\ldots$ & .. & .. & .. & . & . & .. & .. & . & .. & $\ldots$ & .. & .. & .. & .. \\
\hline $\mathrm{X}$ & .. & . & . & . & .. & $\ldots$ & $\ldots$ & $\ldots$ & $\ldots$ & .. & .. & .. & $\ldots$ & $\ldots$ & $\ldots$ & $\ldots$ & $\ldots$ & . \\
\hline XI & $\ldots$ & . & .. & . & . & . & . & . & . & .. & .. & . & .. & . & . & .. &. & .. \\
\hline XII & + & $\ldots$ & .. & $\ldots$ & $\ldots$ & $\cdots$ & . & $\ldots$ & $\ldots$ & .. & .. & $\ldots$ & $\ldots$ & $\ldots$ & . & .. & $\ldots$ & . \\
\hline XIII & + & $\ldots$ & . & $\ldots$ & . & $\ldots$ & .. & $\ldots$ & . & .. & .. & . & .. & . & $\ldots$ & $\ldots$ & .. & .. \\
\hline XIV & + & $\ldots$ & .. & $\ldots$ & $\ldots$ & $\cdots$ & $\ldots$ & $\ldots$ & $\ldots$ & $\ldots$ & $\ldots$ & $\ldots$ & .. & $\ldots$ & $\ldots$ & $\ldots$ & $\ldots$ & . \\
\hline$X V$ & $\ldots$ & $\ldots$ & $\because$ & $\cdots$ & $\cdots$ & $\because$ & . & .. & .. & $\ldots$ & . & $\cdots$ & .. & . & $\cdots$ & $\cdots$ & $\ldots$ & . \\
\hline XVI & $\ldots$ & $\ldots$ & .. & $\ldots$ & $\ldots$ & $\ldots$ & .. & $\ldots$ & $\ldots$ & $\ldots$ & $\ldots$ & . & .. & $\ldots$ & $\ldots$ & $\ldots$ & $\ldots$ & $\ldots$ \\
\hline XVII & . & . & . . & $\cdots$ & . & . & .. & $\ldots$ & .. & $\ldots$ & .. & .. & .. & .. & . & $\cdots$ & $\ldots$ & .. \\
\hline
\end{tabular}

\begin{tabular}{|c|c|c|c|c|c|c|c|c|c|c|c|c|c|c|c|c|c|c|}
\hline & $4^{8 a}$ & $48 b$ & $48 c$ & 49 & 50 & $5 \mathrm{I}$ & $5^{2}$ & 53 & $54 a$ & 546 & $55^{a}$ & 556 & 56 & $57 a$ & 576 & $5^{8}$ & $59 a$ & $59^{b}$ \\
\hline \multicolumn{19}{|l|}{ LEVEL } \\
\hline $\mathrm{O}$ & $\cdots$ & .. & . & . & $\cdots$ & $\cdots$ & . & . & $\cdots$ &.. & .. & $\cdots$ & . & . & .. & . & . & . \\
\hline I & I & .. & $\ldots$ & . & . & $\ldots$ & $\ldots$ & .. & . &.. & .. & . & .. & .. & .. & . & . & . \\
\hline \multirow[t]{2}{*}{ II } & . & . & I & I & . & $\therefore$ & $\ldots$ & . & . &.. & . & . & . & . & .. & . & . & . \\
\hline & $\ldots$ & $\ldots$ & $\ldots$ & : & . & $\cdots$ & . & $\ldots$ & I & . & . & ,. & $\ldots$ & $\ldots$ & . & .. & $\ldots$ & I \\
\hline \multirow[t]{2}{*}{ III } & I & $\ldots$ & $\ldots$ & $\cdots$ & $\therefore$ & $\ldots$ & $\ldots$ & $\ldots$ & . & $\ldots$ & . & I & $\ldots$ & .. & .. & .. & $\ldots$ & . \\
\hline & 7 & $\ldots$ & $\ldots$ & . & $\cdots$ & $\ldots$ & .. & $\ldots$ & .. & .. & . & I & 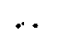 & . & $\ldots$ & .. & $\ldots$ & . \\
\hline \multirow[t]{2}{*}{ IV } & $\ldots$ & I & I & I & .. & $\ldots$ & $\ldots$ & I & I & I & 10 & 2 & I & .. & $\ldots$ & .. & . & . \\
\hline & 4 & $\ldots$ & . & .. & . & $\cdots$ & $\ldots$ & I & $\ldots$ & . & $\cdots$ & $\ldots$ & $\ldots$ & I & I & I & . & . \\
\hline \multirow[t]{2}{*}{ V } & .. & $\ldots$ & $\ldots$ & . & I & I & I & . & I & . & 4 & . & $\ldots$ & . & . & $\cdots$ & $\cdots$ & $\cdots$ \\
\hline & .. & .. & $\cdots$ & . & $\therefore$ & $\cdots$ & .. & . & $\ldots$ & . & I & $\ldots$ & $\cdots$ & . & . & .. & . & $\cdots$ \\
\hline VI & I & $\ldots$ & $\ldots$ & . & $\ldots$ & $\ldots$ & $\ldots$ & $\ldots$ & $\ldots$ & $\ldots$ & $\ldots$ & $\ldots$ & $\ldots$ & $\ldots$ & $\ldots$ & .. & $\ldots$ & $\ldots$ \\
\hline \multirow[t]{2}{*}{ VII } & . & . & . & . & . & . & .. & .. & .. & .. & . & . & . & . & $\ldots$ & .. & $\ldots$ & $\ldots$ \\
\hline & $\ldots$ & . & $\ldots$ & .. & $\ldots$ & . & $\ldots$ & $\ldots$ & .. & . & $\ldots$ & $\ldots$ & $\cdots$ & $\ldots$ & I & .. & $\ldots$ & . \\
\hline \multirow{2}{*}{ VIII } & $\ldots$ & $\ldots$ & $\ldots$ & .. & $\ldots$ & $\ldots$ & $\ldots$ & $\ldots$ & $\ldots$ & $\ldots$ & $\ldots$ & $\ldots$ & $\ldots$ & . & $\ldots$ & . & . & $\ldots$ \\
\hline & . & .. & $\cdots$ & . & $\cdots$ & $\cdots$ & $\cdots$ & . & .. & . & . & $\ldots$ & . & $\ldots$ & 2 & .. & . & .. \\
\hline IX & $\cdots$ & $\ldots$ & $\ldots$ & . & $\ldots$ & . & $\ldots$ & .. & $\ldots$ & . & . & . & .. & $\ldots$ & $\ldots$ & .. & .. & . \\
\hline $\mathrm{X}$ & .. & $\ldots$ & . & .. & $\ldots$ & $\ldots$ & .. & $\ldots$ & .. & $\ldots$ & . & $\ldots$ & $\ldots$ & $\ldots$ & $\ldots$ & .. & $\ldots$ & .. \\
\hline $\mathrm{XI}$ & $\ldots$ & $\ldots$ & $\cdots$ & . & . & $\ldots$ & $\ldots$ & $\ldots$ & .. & .. & $\ldots$ & . & . & $\ldots$ & $\ldots$ & $\cdots$ & $\ldots$ & $\ldots$ \\
\hline XII & $\ldots$ & $\ldots$ & $\ldots$ & .. & $\ldots$ & $\ldots$ & $\ldots$ & $\ldots$ & $\ldots$ & $\ldots$ & $\ldots$ & $\ldots$ & $\ldots$ & I & $\ldots$ & $\ldots$ & + & $\cdots$ \\
\hline XIII & . & . & . & . & . & . & .. & .. & . & . & . & . & . & . & .. & .. & + & .. \\
\hline XIV & $\ldots$ & $\ldots$ & . & . & . & . & .. & .. & .. & $\ldots$ & $\ldots$ & $\ldots$ & .. & $\ldots$ & $\ldots$ & .. & + & . \\
\hline XV & . & $\ldots$ & . & . & .. & . & . & .. & . & . & . & $\cdots$ & . & . & . & .. & $\cdots$ & $\cdots$ \\
\hline XVI & $\ldots$ & $\ldots$ & $\ldots$ & . & $\ldots$ & $\ldots$ & $\ldots$ & $\ldots$ & $\ldots$ & $\ldots$ & . & $\ldots$ & $\ldots$ & .. & $\ldots$ & .. & $\ldots$ & $\ldots$ \\
\hline XVII & $\ldots$ & $\ldots$ & . & . & .. & .. & . & .. & .. & .. & . & $\ldots$ & . & .. & .. & .. & . & .. \\
\hline
\end{tabular}




\begin{tabular}{|c|c|c|c|c|c|c|c|c|c|c|c|c|c|c|c|c|c|c|}
\hline & $60 a$ & $60 b$ & 6I & $62 a$ & $62 b$ & 63 & $64 a$ & $64 b$ & 65 & 66 & $67 a$ & $67 b$ & $68 a$ & $68 b$ & $68 c$ & $69 a$ & $69 b$ & $69 c$ \\
\hline \multicolumn{19}{|l|}{ LEVEL } \\
\hline $\mathrm{O}$ & $\cdots$ & $\cdots$ & $\cdots$ & . & $\ldots$ & . & . & . & . & $\ldots$ & $\cdots$ & . & .. & . & . & $\cdots$ & . & . \\
\hline I & .. & .. & .. & . & . & 2 & . & I & .. & .. & .. & I & .. & .. & 7 & I & I & $\ldots$ \\
\hline & .. & .. & $\ldots$ & .. & $\ldots$ & $\cdots$ & $\ldots$ & $\ldots$ & $\ldots$ & $\ldots$ & $\ldots$ & $\ldots$ & .. & $\ldots$ & . & . & 2 & $\ldots$ \\
\hline II & I & I & . & .. & 2 & . & I & I & .. & $\ldots$ & $\ldots$ & .. & .. & 5 & 3 & I & I & 2 \\
\hline & $\ldots$ & .. & .. & .. & $\ldots$ & . . & $\ldots$ & $\ldots$ & $\ldots$ & $\ldots$ & $\ldots$ & . & . & $\ldots$ & $\ldots$ & I & $\ldots$ & $\ldots$ \\
\hline III & .. & 2 & . & .. & . & I & .. & . & . & . & . & . & .. & I & . & I & I & .. \\
\hline & I & 3 & .. & .. & . & . & . & . & .. & $\ldots$ & . & . & .. & $\ldots$ & $\ldots$ & I & $\ldots$ & .. \\
\hline IV & 5 & 5 & I & 2. & I & 2 & 2 & I & .. & $\ldots$ & $\ldots$ & 2 & .. & . & I 5 & 3 & . & I \\
\hline & $\ldots$ & .. & I & .. & $\ldots$ & . & $\ldots$ & $\ldots$ & I & $\ldots$ & $\ldots$ & $\ldots$ & $\ldots$ & $\ldots$ & $\ldots$ & . & $\ldots$ & I \\
\hline V & . & .. & .. & .. & . & . & . & .. & .. & . & 7 & 3. & I & . & 3 & . & I & .. \\
\hline & . & 2 & . & . & $\cdots$ & . & . & .. & $\ldots$ & $\ldots$ & $\ldots$ & $\ldots$ & I & .. & $\ldots$ & . . & $\ldots$ & $\ldots$ \\
\hline VI & I & $\ldots$ & I & .. & $\ldots$ & . & I & $\ldots$ & $\ldots$ & $\ldots$ & $\ldots$ & $\ldots$ & .. & $\ldots$ & $\ldots$ & $\ldots$ & $\ldots$ & $\ldots$ \\
\hline VII & I. & . & . & .. & . & . & . & .. & . & I & $\ldots$ & 2 & .. & . & $\ldots$ & $\ldots$ & . & . \\
\hline VIII & .. & .. & $\ldots$ & .. & $\ldots$ & .. & $\ldots$ & $\ldots$ & $\ldots$ & . & .. & $\ldots$ & .. & . & $\ldots$ & $\ldots$ & $\ldots$ & .. \\
\hline IX & .. & . & . & .. & $\ldots$ & .. & $\ldots$ & $\ldots$ & $\ldots$ & $\ldots$ & $\ldots$ & $\ldots$ & .. & $\ldots$ & $\ldots$ & $\ldots$ & $\ldots$ & .. \\
\hline $\mathrm{X}$ & .. & . & . & .. & . & . & . & . & $\ldots$ &.. & $\ldots$ & $\ldots$ & .. & $\ldots$ & $\ldots$ & $\ldots$ & $\ldots$ & .. \\
\hline $\mathrm{XI}$ & .. & .. & .. & .. & $\ldots$ & . & $\ldots$ & $\ldots$ & $\ldots$ & $\ldots$ & $\ldots$ & .. & .. & .. & $\ldots$ & $\ldots$ & $\ldots$ & .. \\
\hline XII & .. & .. & . & . & $\ldots$ & .. & .. & .. & $\ldots$ & $\ldots$ & $\ldots$ & .. & .. & $\ldots$ & $\ldots$ & $\ldots$ & $\ldots$ & .. \\
\hline XIII & . & . & . & . & $\ldots$ & . & $\ldots$ & .. & . & $\cdots$ & . & .. & .. & .. & $\ldots$ & $\ldots$ & $\ldots$ & . \\
\hline XIV & .. & . & . & . & $\cdots$ & . & $\ldots$ & .. & .. & $\ldots$ & . & $\ldots$ & . & . & . & . & . & . \\
\hline$X V$ & $\ldots$ & .. & $\ldots$ & .. & $\ldots$ & . & $\cdots$ & . & $\cdots$ & $\cdots$ & .. & .. & $\cdots$ & . & $\ldots$ & $\ldots$ & $\ldots$ & \\
\hline$X V$ & .. & .. & $\ldots$ & .. & .. & .. & $\ldots$ & .. & $\ldots$ & .. & .. & .. & .. & $\ldots$ & $\ldots$ & $\ldots$ & $\ldots$ & .. \\
\hline XVII & .. & $\ldots$ & . & $\ldots$ & $\ldots$ & .. & $\ldots$ & .. & .. & .. & $\ldots$ & .. & . & $\ldots$ & $\cdots$ & $\ldots$ & $\ldots$ & $\cdots$ \\
\hline
\end{tabular}

\begin{tabular}{|c|c|c|c|c|c|c|c|c|c|c|c|c|c|c|c|c|c|}
\hline & 70 & 71 & $72 a$ & $72 b$ & $73 a$ & $73^{b}$ & 74 & 75 & 76 & 77 & 78 & 79 & $80 a$ & $80 b$ & $8 \mathrm{I}$ & 82 & 83 \\
\hline \multicolumn{18}{|l|}{ LEVEL } \\
\hline $\mathrm{O}$ & $\cdots$ & . & . & .. & . & . & $\cdots$ & $\cdots$ & . & .. & .. & $\ldots$ & .. & $\ldots$ & $\cdots$ & & $\cdots$ \\
\hline I & . & $\ldots$ & .. & .. & .. & $\ldots$ & $\ldots$ & $\ldots$ & $\ldots$ & $\ldots$ & $\ldots$ & I & $\ldots$ & . & $\ldots$ & .2 & . \\
\hline & . & $\cdots$ & .. & . & I & . & $\ldots$ & $\ldots$ & $\ldots$ & $\ldots$ & $\ldots$ & .. & $\ldots$ & $\ldots$ & $\ldots$ & $\therefore$ & .. \\
\hline II & . & .. & .. & $\ldots$ & .. & $\ldots$ & $\ldots$ & $\ldots$ & $\ldots$ & $\ldots$ & .. & $\ldots$ & $\ldots$ & .. & $\ldots$ & 3 & . \\
\hline & .. & .. & .. & . & .. & .. & $\cdots$ & $\cdots$ & $\cdots$ & I & I & . & .. & . & . & $\cdots$ & . \\
\hline III & $\ldots$ & $\ldots$ & I & . & . & .. & $\ldots$ & $\ldots$ & $\ldots$ & $\ldots$ & $\ldots$ & $\ldots$ & $\ldots$ & $\ldots$ & $\ldots$ & I & . \\
\hline & . & $\cdots$ & .. & .. & I & .. & $\ldots$ & . & $\cdots$ & $\cdots$ & . & .. & .. & . & $\ldots$ & .. & . \\
\hline IV & . & 2 & . & 4 & I & 1 & $\cdots$ & $\ldots$ & 4 & $\ldots$ & $\ldots$ & .. & 1 & I & 3 & 7 & I \\
\hline $\mathrm{V}$ & I & $\ldots$ & . & $\therefore$ & . & . & 2 & 2 & $\ldots$ & I & . & $\cdots$ & . & .. & $\ldots$ & I & . \\
\hline $\mathrm{VI}$ & . & . & . & I & . & . & $\cdots$ & 2 & . & . & .. & . & . & . & $\cdots$ & $\cdots$ & . \\
\hline VII & I & I & .. & I & . & . & $\cdots$ & . & $\cdots$ & $\cdots$ & $\cdots$ & $\cdots$ & . & . & $\ldots$ & $\cdots$ & . \\
\hline VIII & I & .. & .. & .. & .. & . & $\cdots$ & . & $\cdots$ & $\cdots$ & $\cdots$ & . & . & . & $\cdots$ & $\cdots$ & $\ldots$ \\
\hline & I & . & . & . & . & . & $\cdots$ & $\cdots$ & . & . & $\cdots$ & . & . & . . & $\ldots$ & $\ldots$ & . \\
\hline IX & .. & . & . & . & . & . & $\ldots$ & $\ldots$ & . & .. & . & . & .. & . & $\ldots$ & . & $\ldots$ \\
\hline $\mathrm{X}$ & + & . & . & . & . & . & $\cdots$ & $\cdots$ & . & . & $\cdots$ & . & $\ldots$ & $\ldots$ & $\ldots$ & $\ldots$ & . \\
\hline $\mathrm{XI}$ & + & $\cdots$ & .. & .. & . & . & $\cdots$ & $\cdots$ & . & . & . & .. & . & . & $\cdots$ & $\ldots$ & . \\
\hline XII & $3++$ & .. & .. & . & . & . & $\cdots$ & $\cdots$ & $\cdots$ & $\cdots$ & $\cdots$ & $\cdots$ & $\ldots$ & . & .. & $\ldots$ & . \\
\hline XIII & $2++$ & . & .. & .. & .. & . & $\ldots$ & $\ldots$ & . & $\ldots$ & $\ldots$ & . & $\ldots$ & . & $\therefore$ & $\ldots$ & . \\
\hline XIV & $\mathrm{I}++$ & $\ldots$ & .. & . & . & .. & . & . & . & $\ldots$ & .. & .. & .. & $\ldots$ & $\ldots$ & $\ldots$ & $\ldots$ \\
\hline$X V$ & + & . & . & . & .. & . & $\cdots$ & $\ldots$ & . & $\cdots$ & $\cdots$ & . & $\ldots$ & . & $\ldots$ & $\ldots$ & . \\
\hline XVI & + & $\cdots$ & . & . & .. & .. & . & $\ldots$ & . & . & . & . & . & .. & $\ldots$ & $\ldots$ & . \\
\hline XVII & .. & $\cdots$ & . & .. & . & . & $\cdots$ & . & $\cdots$ & $\cdots$ & . & . & $\cdots$ & .. & $\ldots$ & $\ldots$ & . \\
\hline
\end{tabular}




\begin{tabular}{|c|c|c|c|c|c|c|c|c|c|c|c|c|c|c|c|c|c|}
\hline & $84 a$ & 846 & $84 c$ & 85 & 86 & 87 & 88 & 89 & 90 & 9I $a$ & 916 & 92 & $93^{a}$ & $93^{b}$ & $93 c$ & $94^{a}$ & $94^{b}$ \\
\hline \multicolumn{18}{|l|}{$\overline{\text { LEVEL }}$} \\
\hline $\mathrm{O}$ & .. & .. & . & $\cdots$ & $\cdots$ & .. & . & . & $\ldots$ & . & . & $\cdots$ & .. & . & . & .. & . \\
\hline I & .. & I & $\ldots$ & 3 & $\ldots$ & .. & .. & $\cdots$ & . & .. & 4 & . & . & . & . & . & .. \\
\hline \multirow[t]{2}{*}{ II } & .. & I & 2 & I 5 & .. & .. & .. & .. & .. & .. & 3 & .. & . & I & $\ldots$ & I & 2 \\
\hline & .. & .. & 3 & . & .. & $\ldots$ & . & $\ldots$ & . & $\ldots$ & . & $\cdots$ & . & $\ldots$ & . & . & . \\
\hline \multirow[t]{2}{*}{ III } & .. & .. & .. & IO & .. & I & .. & .. & . & . & 2 & $\ldots$ & . & 2 & . & . & I \\
\hline & .. & . & $\cdots$ & . & . & .. & .. & . & . & $\cdots$ & . & $\cdots$ & . & . & . & . & I \\
\hline \multirow[t]{2}{*}{ IV } & I & . & $\ldots$ & I 6 & 2 & 3 & 4 & I & 4 & I & $\mathrm{I} 7$ & . & I & I 3 & I & 8 & 9 \\
\hline & .. & . & $\cdots$ & . & .. & .. & . & .. & .. & . & $\cdots$ & $\cdots$ & $\cdots$ & $\cdots$ & I & . & . \\
\hline V & $\ldots$ & .. & .. & I & .. & I & .. & .. & .. & .. & 2 & . & . & 2 & I & I & 5 \\
\hline VI & .. & $\ldots$ & $\ldots$ & 3 & .. & .. & .. & .. & .. & $\ldots$ & $\ldots$ & .. & . & .. & .. & .. & 3 \\
\hline VII & .. & . & .. & .. & .. & .. & .. & .. & .. & $\ldots$ & $\ldots$ & .. & . & .. & .. & .. & I \\
\hline VIII & $\ldots$ & . & . & .. & .. & .. & .. & . & . & . & I & $\ldots$ & .. & . & . & . & . \\
\hline IX & .. & .. & . & . & .. & .. & .. & .. & .. & $\cdots$ & . & $\cdots$ & $\cdots$ & $\cdots$ & $\cdots$ & $\cdots$ & .. \\
\hline $\mathrm{X}$ & $\ldots$ & . & $\ldots$ & .. & $\ldots$ & .. & . & .. & .. & $\ldots$ & $\ldots$ & I & $\therefore$ & . & $\ldots$ & .. & .. \\
\hline XI & $\ldots$ & . & $\ldots$ & $\ldots$ & $\ldots$ & $\ldots$ & .. & .. & .. & . & . & $\cdots$ & . & .. & $\cdots$ & .. & .. \\
\hline XII & .. & $\ldots$ & . & .. & $\ldots$ & .. & .. & .. & .. & $\ldots$ & $\ldots$ & $\ldots$ & $\ldots$ & $\ldots$ & $\ldots$ & .. & . \\
\hline XIII & $\ldots$ & $\ldots$ & $\ldots$ & .. & .. & .. & .. & .. & . & . & .. & . & $\cdots$ & $\cdots$ & .. & . & . \\
\hline XIV & $\ldots$ & . & $\ldots$ & .. & .. & . & .. & . & . & . & I & .. & . & .. & . & .. & . \\
\hline XV & .. & . & $\ldots$ & $\ldots$ & .. & .. & .. & .. & . & . & .. & . & . & . & . & $\cdots$ & . \\
\hline XVI & .. & .. & . & . & .. & .. & . & .. & .. & . & . & .. & . & . & . & . & . \\
\hline XVII & .. & .. & $\ldots$ & $\ldots$ & $\ldots$ & .. & . & . & . & $\ldots$ & .. & . & . & $\ldots$ & $\ldots$ & .. & .. \\
\hline
\end{tabular}

\begin{tabular}{|c|c|c|c|c|c|c|c|c|c|c|c|c|c|c|c|}
\hline & $95^{\circ}$ & $95^{b}$ & 96 & $97^{a}$ & 976 & 98 & $99 a$ & $99 b$ & $99^{c}$ & 100 & Ior $a$ & IOI 6 & $102 a$ & $102 b$ & $102 c$ \\
\hline \multicolumn{16}{|l|}{ LEVEL } \\
\hline $\mathrm{O}$ & .. & . & . & . & .. & . & .. & .. & .. & $\cdots$ & .. & $\cdots$ & $\cdots$ & $\cdots$ & . \\
\hline \multirow[t]{2}{*}{ I } & 2 & I & $\cdots$ & . & .. & I & $\cdots$ & . & .. & $\cdots$ & . & $\cdots$ & $\cdots$ & $\because$ & $\cdots$ \\
\hline & .. & . & $\cdots$ & $\cdots$ & .. & .. & . & . & I & $\cdots$ & $\cdots$ & $\cdots$ & $\cdots$ & $\therefore$ & . \\
\hline II & .. & . & .. & . & . & 3 & I & .. & .. & . & . & $\ldots$ & . & $\cdots$ & $\cdots$ \\
\hline \multirow{2}{*}{ III } & .. & 2 & .. & . & .. & .. & $\ldots$ & .. & .. & $\cdots$ & . & $\cdots$ & . & 2 & .. \\
\hline & .. & 2 & $\ldots$ & $\ldots$ & .. & $\ldots$ & $\ldots$ & . & . & . & .. & . & $\cdots$ & .. & $\cdots$ \\
\hline \multirow[t]{2}{*}{ IV } & .. & . & . & . & . & 2 & .. & I & 7 & $\cdots$ & I & $\cdots$ & I & 2 & $\cdots$ \\
\hline & . & .. & $\cdots$ & .. & .. & $\ldots$ & $\ldots$ & .. & .. & .. & . & .. & .. & I & . \\
\hline \multirow[t]{2}{*}{ V } & .. & .. & $\ldots$ & . & I & $\cdots$ & 2 & . & $\cdot \cdot$ & I & I & $\cdots$ & $\cdots$ & $\cdots$ & $\cdot \cdot$ \\
\hline & .. & . & 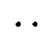 & $\cdots$ & .. & $\ldots$ & $\ldots$ & . & .. & I & . & $\cdots$ & . & . & $\cdots$ \\
\hline VI & .. & .. & $\ldots$ & I & .. &.. & . & .. & .. & $\ldots$ & .. & . & 2 & I & $\cdots$ \\
\hline VII & . & . & . & . & . & $\cdots$ & . & .. & .. & I & . & $\cdots$ & $\cdots$ & . & . \\
\hline \multirow[t]{2}{*}{ VIII } & . & .. & $\ldots$ & I & .. & $\therefore$ & $\ldots$ & . & . & $2++$ & . & . & . & $\cdots$ & $\cdots$ \\
\hline & .. & . & $\ldots$ & . & . & . & $\ldots$ & .. & .. & 4 & . & $\cdots$ & $\cdots$ & $\cdots$ & .. \\
\hline IX & . & $\cdots$ & . & . & I & .. & . & .. & .. & 3 & .. & . & .. & . & $\cdots$ \\
\hline $\mathrm{X}$ & . & . & . & . & .. & .. & . & .. & . & . & . & $\cdots$ & $\cdots$ & $\cdots$ & $\cdot \cdot$ \\
\hline XI & . & . & . & . & .. & . & $\ldots$ & .. &. & $\cdots$ & . & . & $\ldots$ & $\ldots$ & .. \\
\hline XII & .. & $\ldots$ & $\ldots$ & $\ldots$ & . & $\ldots$ & $\ldots$ & $\cdots$ & . & $\ldots$ & . & $\cdots$ & $\ldots$ & $\cdots$ & . \\
\hline XIII & .. & $\ldots$ & + & . & . & . & $\ldots$ & . & .. & + & . & $\cdots$ & $\cdots$ & $\cdots$ & . \\
\hline XIV & . & $\ldots$ & + & $\ldots$ & .. & $\ldots$ & $\ldots$ & .. & . & + & . & $\cdots$ & $\ldots$ & $\cdots$ & $\cdots$ \\
\hline XV & . & . & + & . & .. & . & . & . & .. & + & . & $\cdots$ & $\cdots$ & $\cdots$ & . \\
\hline XVI & .. & .. & . & . & . & . & .. & .. & .. & $\cdots$ & .. & $\cdots$ & . & $\cdots$ & . \\
\hline XVII & . & . & . & . & .. & . & $\cdots$ & . & .. & + & . & $\cdots$ & $\cdots$ & . & .. \\
\hline
\end{tabular}




\begin{tabular}{|c|c|c|c|c|c|c|c|c|c|c|c|c|c|c|c|}
\hline & Iо3a & $103^{b}$ & $104 a$ & $104 b$ & $104 c$ & 105 & $106 a$ & $106 b$ & $107 a$ & 1076 & $108 a$ & 1086 & $108 c$ & 109 & IIO \\
\hline \multicolumn{16}{|l|}{$\overline{\text { LEVEL }}$} \\
\hline $\mathrm{O}$ & $\ldots$ & $\cdots$ & . & $\cdots$ & . & . & $\cdots$ & $\cdots$ & $\cdots$ & $\cdots$ & $\cdots$ & $\cdots$ & $\cdots$ & . & $\cdots$ \\
\hline I & 2 & . & . & . & $\ldots$ & .. & $\ldots$ & $\ldots$ & . & . & $\ldots$ & . & $\ldots$ & . & .. \\
\hline II & I & $\ldots$ & $\ldots$ & I & $\ldots$ & $\ldots$ & $\ldots$ & $\ldots$ & I & .. & $\ldots$ & $\cdots$ & $\cdots$ & . & . \\
\hline \multirow[t]{2}{*}{ III } & 3 & . & . & . & . & . & . & . & . & . & . & . & . & . & 3 \\
\hline & .. & $\ldots$ & I & $\ldots$ & $\ldots$ & $\ldots$ & $\ldots$ & $\ldots$ & $\ldots$ & $\ldots$ & $\ldots$ & $\ldots$ & $\ldots$ & .. & .. \\
\hline IV & 6 & .. & I & 5 & $\ldots$ & I & I & . & .. & I & I & 3 & I & I & 3 \\
\hline $\mathrm{V}$ & I & 4 & . & $8++$ & . & . & 2 & 5 & 2 & 2 & . & . & $\ldots$ & . & .. \\
\hline VI & I & . & 3 & 2 & . & .. & . & 3 & . & . & . & $\ldots$ & $\cdots$ & . & $\cdots$ \\
\hline VII & I & $\ldots$ & 2 & 3 & $\ldots$ & . & .. & I I & $\ldots$ & $\ldots$ & $\cdots$ & . & . & .. & .. \\
\hline VIII & . & . & .. & $\ldots$ & .. & .. & .. & .. & $\ldots$ & . & $\ldots$ & $\ldots$ & . & . & $\ldots$ \\
\hline IX & $\ldots$ & $\ldots$ & $\ldots$ & $\ldots$ & $\ldots$ & $\ldots$ & $\ldots$ & .. & . & . & . & . & $\ldots$ & $\ldots$ & . \\
\hline $\mathrm{X}$ & . & . & . & . & . & . & I & .. & . & $\ldots$ & . & . & . & . & . \\
\hline XI & . & .. & . & $\ldots$ & $\ldots$ & . & . & .. & . & . & .. & .. & . & . & $\cdots$ \\
\hline XII & $\cdots$ & $\cdots$ & . & . & $\cdots$ & $\cdots$ & $\cdots$ & $\cdots$ & . & . & $\cdots$ & $\cdots$ & $\cdots$ & $\cdots$ & $\cdots$ \\
\hline XIII & $\cdots$ & . & .. & $\ldots$ & $\cdots$ & $\cdots$ & . & .. & $\cdots$ & .. & $\cdots$ & $\cdots$ & $\cdots$ & $\cdots$ & .. \\
\hline XIV & . & $\ldots$ & .. & $\ldots$ & $\ldots$ & .. & . & .. & $\ldots$ & . & $\cdots$ & $\cdots$ & $\ldots$ & $\ldots$ & I \\
\hline $\mathrm{XV}$ & $\ldots$ & $\ldots$ & . & $\ldots$ & . & $\cdots$ & $\ldots$ & .. & $\ldots$ & .. & $\ldots$ & $\ldots$ & $\ldots$ & $\ldots$ & .. \\
\hline XVI & $\ldots$ & $\ldots$ & $\ldots$ & $\ldots$ & .. & . & . & .. & . & .. & . & $\cdots$ & . & $\cdots$ & . \\
\hline XVII & . & . & . & . & . & $\cdots$ & $\cdots$ & . & . & .. & . & . & $\ldots$ & $\ldots$ & . \\
\hline
\end{tabular}

\begin{tabular}{|c|c|c|c|c|c|c|c|c|c|c|c|c|c|}
\hline & I I I & I I 2 & I I $3 a, b, c$ & I I 4 & I I $5 a, b$ & I I 6 & I $17 a$ & $117 b$ & I I $8 a$ & I I $8 b$ & II 9 & 120 & I 2 I \\
\hline \multicolumn{14}{|l|}{ LEVEL } \\
\hline $\mathrm{O}$ & . & . & $\cdots$ & $\ldots$ & $\cdots$ & . & $\cdots$ & . & . & .. & $\cdots$ & $\cdots$ & .. \\
\hline I & I & I & . & $\ldots$ & $\ldots$ & . & $\ldots$ & $\ldots$ & . & .. & $\ldots$ & $\ldots$ & .. \\
\hline \multirow[t]{2}{*}{ II } & I & .. & . & $\ldots$ & $\cdots$ & . & . & $\cdots$ & $\ldots$ & 8 & . & .. & .. \\
\hline & . & .. & I & $\ldots$ & . & .. & . & . & $\ldots$ & . & $\cdots$ & . & .. \\
\hline III & $\ldots$ & .. & .. & $\ldots$ & $\ldots$ & .. & $\cdots$ & $\ldots$ & $\ldots$ & 6 & $\cdots$ & $\ldots$ & . \\
\hline \multirow[t]{2}{*}{ IV } & 3 & . & . & I & . & . & . & . & 4 & 9 & . & . & .. \\
\hline & . & .. & . & . & .. & $\cdots$ & . & $\cdots$ & $\cdots$ & . & . & . & I \\
\hline V & .. & . & I & $\ldots$ & $\cdots$ & . & 2 & I & . & 2 & I & $5++$ & . \\
\hline VI & I & .. & .. & . & . & .. & . & . & . & I & 2 & . & . \\
\hline VII & I & .. & 8 & $\ldots$ & . & $\ldots$ & $\ldots$ & $\ldots$ & I & $\ldots$ & .. & $\ldots$ & . \\
\hline \multirow[t]{2}{*}{ VIII } & .. & . & 3 & . & 2 & $\ldots$ & $\ldots$ & . & . & .. & .. & .. & . \\
\hline & .. & .. & 2 & . & I & . & . & . & $\cdots$ & . & . & . & .. \\
\hline \multirow[t]{2}{*}{ IX } & . & . & . & . & 2 & . & $\cdots$ & . & . & .. & .. & .. & . \\
\hline & .. & . & $\cdots$ & . & I & $\therefore$ & $\cdots$ & $\cdots$ & $\cdots$ & . & $\cdots$ & $\cdots$ & . \\
\hline \multirow[t]{2}{*}{$\mathrm{X}$} & $\cdots$ & . & $\cdots$ & . & . & $\cdots$ & . & $\cdots$ & $\cdots$ & . & $\cdots$ & $\cdots$ & $\cdots$ \\
\hline & . & .. & $\ldots$ & $\ldots$ & 3 & . & .. & . & $\cdots$ & . & $\cdots$ & . & . \\
\hline XI & . & .. & . & . & I & $\ldots$ & . & . & $\ldots$ & . & . & . & . \\
\hline XII & .. & . & I & . & 3 & . & . & . & $\ldots$ & $\ldots$ & I & $\ldots$ & .. \\
\hline XIII & .. & . & .. & . & I & . & . & . & . & . & I & . & . \\
\hline XIV & .. & . & . & . & 2 & . & $\cdots$ & . & $\ldots$ & . & $2++$ & . & .. \\
\hline$X V$ & .. & .. & 2 & $\ldots$ & $\cdots$ & . & . & . & . & .. & .. & $\ldots$ & .. \\
\hline XVI & . & . & $\cdots$ & . & $\cdots$ & $\ldots$ & . & . & .. & .. & .. & .. & . \\
\hline XVII & . & .. & . & . & $\ldots$ & . & . & . & . & $\ldots$ & + & $\ldots$ & .. \\
\hline
\end{tabular}




\begin{tabular}{|c|c|c|c|c|c|c|c|c|c|c|c|c|c|c|}
\hline & 122 & I $23^{a}$ & $123 b$ & I 24 & I 25 & I 26 & I 27 & I 28 & I $29^{\circ}$ & I $29 b$ & I $29^{\circ}$ & I 300 & I $3 \circ b$ & I $30 c$ \\
\hline \multicolumn{15}{|l|}{ LEVEL } \\
\hline $\mathrm{O}$ & . & $\cdots$ & $\cdots$ & .. & . & $\ldots$ & .. & $\ldots$ & $\ldots$ & . & . & . & $\cdots$ & .. \\
\hline I & . & .. & .. & $\ldots$ & . & $\ldots$ & .. & 3 & I & .. & .. & .. & .. & .. \\
\hline II & $\ldots$ & $\ldots$ & .. & $\ldots$ & .. & . & .. & . & I & I & .. & I & .. & .. \\
\hline & I & . & $\cdots$ & . & $\cdots$ & . & .. & $\ldots$ & $\ldots$ & . & $\cdots$ & $\cdots$ & .. & . . \\
\hline III & .. & . & .. & .. & . & . & I & . & .. & . & . & .. & .. & .. \\
\hline & $\ldots$ & .. & .. & . & .. & $\ldots$ & .. & . & I & .. & .. & . & $\cdots$ & . \\
\hline IV & 2 & . & .. & . & 2 & . & .. & $\ldots$ & .. & .. & I & .. & 2 & I \\
\hline V & I & .. & .. & I & $\ldots$ & I & 7 & .. & $\ldots$ & $\cdots$ & $\cdots$ & $\cdots$ & .. & .. \\
\hline VI & $\ldots$ & . & . & . & . & . & .. & $\ldots$ & .. & .. & .. & .. & I & .. \\
\hline VII & $\ldots$ & .. & I & .. & $\ldots$ & $\ldots$ & .. & $\ldots$ & $\ldots$ & IO & .. & .. & $\ldots$ & .. \\
\hline VIII & . & $\cdots$ & .. & .. & .. & $\ldots$ & .. & .. & .. & $\ldots$ & . & .. & . & $\ldots$ \\
\hline IX & $\ldots$ & . & $\ldots$ & .. & . & . & . & . & $\ldots$ & $\ldots$ & .. & $\ldots$ & . & .. \\
\hline $\mathrm{X}$ & $\ldots$ & . & .. & . & .. & .. & .. & . & .. & . & . & . & . & . \\
\hline XI & . & . & . & $\therefore$ & . & .. & .. & . & .. & .. & . & .. & .. & . \\
\hline XII & . & + & . & $\cdots$ & . & . & $\cdots$ & . & . & .. & . & . & . & . \\
\hline XIII & . & + & .. & $\cdots$ & $\cdots$ & . & . & $\cdots$ & . & . & . & . & .. & . \\
\hline XIV & $\ldots$ & + & $\cdots$ & . & . & $\cdots$ & $\cdot \cdot$ & $\cdots$ & . & . & $\cdots$ & $\cdots$ & $\cdots$ & $\cdot$ \\
\hline XV & $\cdots$ & $\cdots$ & . & . & . & $\cdots$ & $\cdots$ & $\cdots$ & $\cdots$ & $\cdots$ & $\cdots$ & $\cdots$ & $\cdots$ & $\cdots$ \\
\hline XVI & .. & .. & . & $\cdots$ & $\cdots$ & $\cdots$ & $\cdots$ & $\cdots$ & $\cdots$ & $\cdots$ & $\cdots$ & $\cdots$ & $\cdots$ & - \\
\hline XVII & $\cdots$ & . & . & . & . & $\ldots$ & . & . & $\ldots$ & .. & . & . & . & . \\
\hline
\end{tabular}

\begin{tabular}{|c|c|c|c|c|c|c|c|c|c|c|c|c|c|c|c|}
\hline & I $3 \mathrm{I} a$ & I 3 I $b$ & I $32 a$ & $132 b$ & I 33 & I $34 a$ & $\mathrm{I} 34^{b}$ & $\mathrm{I} 35 a$ & $135^{6}$ & 136 & I 37 & $\mathrm{I}_{3}^{8}$ & I 39 & 1400 & $140 b$ \\
\hline \multicolumn{16}{|l|}{ LEVEL } \\
\hline $\mathrm{O}$ & $\cdots$ & $\cdots$ & . & $\cdots$ & $\cdots$ & .. & $\cdots$ & $\cdots$ & $\cdots$ & $\cdots$ & $\cdots$ & $\cdots$ & . & $\cdots$ & $\cdots$ \\
\hline I & $\ldots$ & .. & . & $\ldots$ & . & .. & .. & . & . & .. & $\ldots$ & $\ldots$ & $\ldots$ & $\ldots$ & $\ldots$ \\
\hline II & $\because$ & . & .. & . & .. & I & .. & .. & . & .. & . & .. & .. & .. & . \\
\hline III & .. & $\ldots$ & .. & $\ldots$ & . & .. & $\ldots$ & .. & .. & $\ldots$ & $\ldots$ & $\ldots$ & .. & .. & I \\
\hline \multirow[t]{2}{*}{ IV } & .. & I & .. & . & . & $\ldots$ & .. & . & .. & . & I & $\ldots$ & .. & .. & 4 \\
\hline & .. & .. & .. & $\ldots$ & .. & .. & I & .. & . & I & $\ldots$ & $\ldots$ & .. & .. & $\ldots$ \\
\hline V & $\ldots$ & .. & .. & $\cdots$ & . & $\cdots$ & . & .. & . & 4 & 4 & . & I & .. & .. \\
\hline VI & I & $\ldots$ & .. & . & $\ldots$ & $\ldots$ & .. & .. & I & $\ldots$ & 2 & I & .. & .. & .. \\
\hline VII & 2 & .. & 2 & . & $\cdots$ & . & .. & I & . & $\ldots$ & 5 & $\ldots$ & 3 & .. & .. \\
\hline VIII & $\ldots$ & $\ldots$ & $\ldots$ & $\ldots$ & $\ldots$ & .. & $\ldots$ & $\therefore$ & $\ldots$ & $\ldots$ & 6 & . & .. & .. & .. \\
\hline IX & .. & .. & .. & . & $\ldots$ & .. & .. & .. & .. & $\ldots$ & I & $\ldots$ & .. & .. & . \\
\hline $\mathrm{X}$ & $\ldots$ & .. & .. & . & . & .. & .. & . & .. & . & . & . & . & . & . \\
\hline XI & .. & .. & . & $\cdots$ & $\cdots$ & .. & .. & I & .. & $\ldots$ & $\ldots$ & .. & .. & . & .. \\
\hline XII & . & .. & .. & I & $\cdots$ & . & . & . & $\cdots$ & $\cdots$ & . & $\cdots$ & .. & I & . \\
\hline XIII & $\ldots$ & $\ldots$ & .. & . & $\ldots$ & . & . & . & $\cdots$ & $\cdots$ & $\ldots$ & . & . & .. & .. \\
\hline XIV & .. & . & . & $\cdots$ & . & . & I & . & .. & $\ldots$ & $\ldots$ & $\ldots$ & $\ldots$ & .. & I \\
\hline$X V$ & . & $\ldots$ & . & . & . & $\therefore$ & .. & $\ldots$ & . & $\ldots$ & $\ldots$ & .. & . & . & .. \\
\hline XVI & .. & . & .. & . & $\ldots$ & $\ldots$ & .. & .. & . & $\ldots$ & $\ldots$ & $\ldots$ & .. & .. & .. \\
\hline XVII & $\ldots$ & $\ldots$ & .. & $\cdots$ & I & . & .. & . & . & $\ldots$ & $\ldots$ & . & .. & .. & . \\
\hline
\end{tabular}




\begin{tabular}{|c|c|c|c|c|c|c|c|c|c|c|c|c|c|c|}
\hline & $\mathrm{I} 4 \mathrm{I}$ & 142 & 1430 & $143^{6}$ & I $44 a$ & $144 b$ & $\mathrm{I} 45$ & 146 & I 47 & 148 & I $49 a$ & $149^{b}$ & $15^{\circ}$ & I $5 \mathrm{I}$ \\
\hline \multicolumn{15}{|l|}{ LEVEL } \\
\hline $\mathrm{O}$ & $\cdots$ & $\ldots$ & $\cdots$ & . & $\cdots$ & .. & . & $\cdots$ & . & . & .. & .. & . & $\ldots$ \\
\hline I & . & . & . & $\ldots$ & $\ldots$ & .. & $\ldots$ & . & I & .. & . & . & . & . \\
\hline \multirow[t]{2}{*}{ II } & $\ldots$ & . & $\ldots$ & . & I & .. & . & I & 3 & . & 2 & . & . & . \\
\hline & . & $\ldots$ & $\ldots$ & .. & .. & I & $\ldots$ & $\ldots$ & $\ldots$ & . & .. & $\ldots$ & . & . \\
\hline III & $\ldots$ & $\ldots$ & $\ldots$ & $\ldots$ & . & $\ldots$ & $\ldots$ & $\ldots$ & $\ldots$ & I & I & . & I & . \\
\hline \multirow[t]{2}{*}{ IV } & . & I & 2 & . & . & .. & . & I & 2 & . & . & . & $\ldots$ & . \\
\hline & I & .. & .. & .. & .. & .. & $\ldots$ & $\ldots$ & $\ldots$ & $\ldots$ & .. & I & 2 & . \\
\hline $\mathrm{V}$ & 2 & $\ldots$ & I & . & $\ldots$ & $\ldots$ & . & 3 & . & . & . & . & . & $\ldots$ \\
\hline VI & . & $\ldots$ & $\ldots$ & . & . & $\ldots$ & . & $\ldots$ & . & . & . & . & $\ldots$ & $\ldots$ \\
\hline VII & . & .. & .. & .. & . & $\ldots$ & $\ldots$ & $\ldots$ & . & $\ldots$ & .. & . & $\cdots$ & 2 \\
\hline VIII & $\ldots$ & $\ldots$ & $\ldots$ & .. & . & $\ldots$ & $\ldots$ & I & $\ldots$ & $\ldots$ & .. & . & $\ldots$ & $\ldots$ \\
\hline IX & $\ldots$ & $\ldots$ & . & . & . & .. & I & . & $\ldots$ & . & . & . & $\ldots$ & . \\
\hline $\mathrm{X}$ & $\ldots$ & $\ldots$ & $\ldots$ & . & .. & $\ldots$ & . & $\cdots$ & $\cdots$ & . & . & .. & . & .. \\
\hline $\mathrm{XI}$ & . & $\ldots$ & $\ldots$ & $\ldots$ & . & $\ldots$ & $\ldots$ & $\ldots$ & .. & 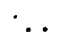 & . & . & $\ldots$ & . \\
\hline XII & $\ldots$ & $\therefore$ & $\ldots$ & . & . & . & . & . & . & . & . & . & . & . \\
\hline XIII & . & . & . & .. & . & .. & $\ldots$ & $\ldots$ & $\ldots$ & . & . & . & $\ldots$ & $\ldots$ \\
\hline XIV & $\ldots$ & $\ldots$ & . & . & . & . & $\ldots$ & $\ldots$ & . & . & . & . & . & $\cdots$ \\
\hline$X V$ & . & . & . & . & . & . & $\cdots$ & $\cdots$ & $\cdots$ & .. & .. & . & . & .. \\
\hline XVI & $\ldots$ & . & . & . & . & . & . & . & . & .. & $\ldots$ & . & . & . \\
\hline XVII & $\ldots$ & $\ldots$ & $\ldots$ & .. & . & $\ldots$ & . & $\ldots$ & $\ldots$ & .. & . & .. & $\cdots$ & . \\
\hline
\end{tabular}

\begin{tabular}{|c|c|c|c|c|c|c|c|c|c|c|c|c|c|c|c|}
\hline & $152 a$ & $152 b$ & $\mathrm{I} 52 \mathrm{c}$ & I 53 & I 54 & I 55 & I 56 & I 57 & 158 & I 59 & 160 & $16 I$ & 162 & $163 a$ & $16_{3} b$ \\
\hline \multicolumn{16}{|l|}{ LEVEL } \\
\hline $\mathrm{O}$ & . & . & .. & . & . & . & . & $\ldots$ & .. & . & . & $\cdots$ & . & .. & . \\
\hline I & I & . & .. & $\mathbf{I}+$ & .. & $\ldots$ & . & . & I & . & I & . & . & $\ldots$ & .. \\
\hline II & I & $\ldots$ & . & I & .. & $\ldots$ & $\ldots$ & $\ldots$ & 20 & .. & .. & .. & . & . & $\cdots$ \\
\hline III & .. & $\ldots$ & .. & 2 & .. & . & $\ldots$ & .. & I & .. & I & .. & $\ldots$ & . & .. \\
\hline \multirow{2}{*}{ IV } & I & .. & .. & I 2 & .. & $\ldots$ & $\ldots$ & I & 4 & I & 3 & I & $\ldots$ & . & $3^{2}$ \\
\hline & .. & $\ldots$ & . & .. & I & . & $\cdots$ & . & . & .. & $\cdots$ & . & . & . & . \\
\hline \multirow[t]{2}{*}{ V } & 2 & . & .. & I & .. & . & . & $\ldots$ & $\therefore$ & . & .. & .. & 2 & . & .. \\
\hline & . & . & .. & . & . & $\ldots$ & . & . & . & . & . & .. & . & I & I \\
\hline VI & .. & . & . & I & .. & I & . & . & .. & .. & .. & . & I & .. & 2 \\
\hline VII & I & $\ldots$ & 2 & 2 & .. & .. & $\ldots$ & .. & $\ldots$ & .. & .. & .. & . & I & I \\
\hline VIII & . & . & .. & $\cdots$ & .. & . & $\cdots$ & .. & . & .. & .. & .. & I & .. & .. \\
\hline IX & .. & . & .. & . & .. & $\ldots$ & $\ldots$ & . & .. & . & . & . & . & . & .. \\
\hline $\mathrm{X}$ & .. & I & .. & .. & .. & $\ldots$ & $\ldots$ & $\ldots$ & . & . & $\cdots$ & $\ldots$ & . & .. & $\ldots$ \\
\hline XI & .. & .. & . & . & . & $\ldots$ & $\ldots$ & $\ldots$ & . & . & . & . & . & . & . \\
\hline XII & .. & $\ldots$ & .. & $\cdots$ & . & $\ldots$ & $\ldots$ & $\cdots$ & . & . & . & $\cdots$ & $\cdots$ & .. & .. \\
\hline XIII & .. & .. & .. & . & . & .. & . & . & . & . & . & . & $\ldots$ & .. & .. \\
\hline XIV & $\ldots$ & $\ldots$ & .. & $\ldots$ & $\ldots$ & $\ldots$ & $\ldots$ & $\ldots$ & $\ldots$ & .. & $\ldots$ & . & . & .. & .. \\
\hline$X V$ & .. & . & .. & . & . & $\cdots$ & $\cdots$ & $\cdots$ & .. & . & $\cdots$ & . & . & . & .. \\
\hline XVI & .. & .. & .. & .. & $\ldots$ & $\ldots$ & $\ldots$ & $\ldots$ & $\ldots$ & .. & $\ldots$ & $\ldots$ & . & .. & .. \\
\hline XVII & . & .. & .. & . & $\ldots$ & .. & . & .. & . & . & . & .. & . & . & $\cdot$ \\
\hline
\end{tabular}




\begin{tabular}{|c|c|c|c|c|c|c|c|c|}
\hline & I 64 & 1650 & I65b & I 66 & 1670 & $167 b$ & $167 c$ & 168 \\
\hline \multicolumn{9}{|l|}{$\overline{\text { LEVEL }}$} \\
\hline 0 & .. & . & o & $\ldots$ & . & . & .. & . \\
\hline I & .. & .. & .. & $\ldots$ & I & .. & .. & .. \\
\hline II & 2 & .. & .. & $\ldots$ & 6 & .. & .. & .. \\
\hline \multirow[t]{2}{*}{ III } & .. & I & $\ldots$ & . & 2 & . & 2 & .. \\
\hline & .. & I & . & I & . & . & . & .. \\
\hline IV & I & I & I & I & 7 & . & . & . \\
\hline V & . & . & $\ldots$ & 2 & .. & I & . & .. \\
\hline VI & .. & .. & .. & .. & I & .. & .. & .. \\
\hline VII & .. & . & $\ldots$ & $\ldots$ & .. & . & . & .. \\
\hline VIII & .. & .. & .. & .. & .. & $\ldots$ & .. & .. \\
\hline IX & .. & . & . & .. & . & . & .. & .. \\
\hline $\mathrm{X}$ & .. & .. & . & . & . & . & . & .. \\
\hline $\mathrm{XI}$ & .. & $\cdots$ & .. & .. & .. & .. & .. & . \\
\hline XII & .. & .. & . & .. & . & + & $\cdots$ & . \\
\hline XIII & $\ldots$ & .. & .. & .. & .. & + & $\ldots$ & $\ldots$ \\
\hline XIV & .. & .. & .. & I & . & + & . & . \\
\hline XV & $\ldots$ & .. & .. & $\ldots$ & $\ldots$ & $\ldots$ & . & .. \\
\hline XVI & .. & $\ldots$ &.. & .. & .. & .. & .. & .. \\
\hline XVII & $\ldots$ & .. & .. & .. & . & . & .. & . \\
\hline
\end{tabular}

\section{(c) THE EARLY LOCAL PAINTED POTTERY}

The first examples of early painted wares were found by us in 1937 in the filling of the earth rampart of the city wall. These we were able to distinguish into two groups according as they occurred in the upper 'ash' stratum or in the older core of the rampart; ${ }^{I}$ the former I assigned, on the strength of certain plain pottery types found in the stratum, to Level V, and since the sherds in the two strata were on the whole fairly akin, assumed that the time-gap between them was not likely to be very.long. In 1938 more pottery of the sort was found in 'Site H', but in that area the stratification was so disturbed by trenching for the foundations of closely superimposed buildings and by the digging of graves that no satisfactory pottery sequence could be established to modify the conclusions arrived at in 1937 . On the evidence then available it seemed that the painted wares were in vogue in the sixteenth and in the first half of the fifteenth centuries B.C., and it was therefore natural to compare them with the painted 'Khabur' pottery found by Professor Mallowan at Chagar Bazar and at Brak and dated by inscribed tablets to just that period. The parallel was very far from complete-in particular, the shape most characteristic of Atchana is the handled jug, Type 70, whereas the Khabur potter never made a handle 2 - but it was difficult to exclude the possibility of a common influence having been responsible for the simultaneous development of painted pottery in the two areas. Nobody could then have anticipated the extraordinary longevity of the Atchana painted wares.

Excavation in depth, undertaken only after the war, has proved that the most typical

2 'The differences were rightly emphasized by Schaeffer, Stratigraphie comparée, p. I03. 
forms and schemes of decoration were evolved in Level XVI and continued with little or no change up to Level VIII; they fell out of use in Level VII but were to some extent revived in Level VI and linger on into Level $\mathrm{V}$, when they finally disappear, though echoes of their style of decoration may be detected as late as Level III. So uniform is the tradition throughout this long period that it is generally impossible in the case of an example of painted decoration not dated by its context to tell whether it belongs, for example, to Level XVI or to Level X, and conversely, given numerous examples dated by external evidence to different levels, it is impossible to deduce from them any criterion of style that would serve for the dating of other pieces. Indeed, I was at first induced to state that the wares from Level $V$ were indistinguishable from those of Level $X$; this is not literally true, as material subsequently found has shown-there are developments and there are real differences; but even in Level $V$ the tradition is disconcertingly constant; ${ }^{I}$ in view of it we can no longer suggest any dependence of the Levels VI-V painted wares of Atchana on the contemporary painted wares of the Khabur valley; whether the latter could derive in any degree from the old Alalakh tradition is another question, but the argument of difference in vase forms and of the absence of bird or animal motives from the Khabur pottery is against any close connexion. Up to the present the Alalakh ware stands alone and must be considered on its own merits and in the light of the evidence of the one site only.

The complete sequence from Level XVII to Level VII is afforded by our 'stratification pit' in the early house site (v. Ch. I (b), p. Io) and for certain levels, viz. Levels XIV, XII, IX, and VII in particular, is supplemented by the work on the temple site (v. Ch. II, p. 33); the sherds from the city rampart and those from Site $\mathrm{H}$ must be regarded as having no more than an illustrative value-they serve to fix the dates of the buildings with which they are connected, but they are not evidence for the history of the painted pottery. For the pottery of Levels VII to I we have the normal evidence of stratified house remains, rubbish-pits, and graves.

Throughout the early period painted decoration is confined to a very limited range of pottery forms. On the one hand we have the jug of Type 70 , with flat or ring base and trefoil mouth, on the other hand a shallow bowl with carinated sides and a flat or ring base (Type 23) which may be elaborated into a pedestal as in Type I I 9; at least 90 per cent. of the painted ware is in one or other of these shapes. The decoration is almost as rigidly conventionalized. On the jugs there is nearly always an eye motive painted on the mouth; round the body are two bands, plain or multiple, between which groups of vertical or oblique strokes make what one may call a triglyph scheme, and between the triglyphs there is a subsidiary motive which may be geometrical but is often a bird or animal form. On the bowls we generally have on the flat top of the rim a close-set series of radial strokes of paint; round, or above, the shoulder there are, as on the jugs, two horizontal bands with the grouped vertical or oblique strokes making the triglyph scheme; but the

\footnotetext{
I Nor is this conservatism confined to the pottery. On P1. LIV a there are shown terra-cotta figurines most of which date from Level $\mathrm{V}$, but one, which is identical in style, comes from
}

Level VIII; fragments of similar figurines occurred in yet earlier levels, v. p. 244 . 
subsidiary filling-ornament is very seldom there; we do have examples of the bird motive (v. Pl. LXXXIV $c$, and, more often, tree patterns or triangles or even dotted circles, ATP $/ 37 / 209, \mathrm{Pl}$. XCVIIb), but in the majority of cases the plain linear design was held sufficient for the shape of the vase. These forms thus decorated are current throughout the whole period up to Level VII, and so far as they are concerned there is no development. The finest examples, on which the surface of the vessel was burnished before painting (ATP/47/1 27, ATP/47/1 42, Pl. LXXXIV), came from the lowest levels, and we can say that by the time of Level XIV at any rate the ware had reached its zenith; but it maintained its quality remarkably well and, as the illustrations on Pls. LXXXIVXCIII make clear, there was very little falling-off in the technique of potter and painter right down to Level VII, though the trefoil-mouthed jug seems to have been going out of use. But side by side with the traditional types new fashions were introduced. The remarkable fragment $\mathrm{ATP} / 48 / 4 \mathrm{I}, \mathrm{Pl}$. XCIII, from Level X shows a naturalistic treatment unparalleled hitherto. In Level VIII comes the first example of polychrome painting and a drawing of a fish ( $\mathrm{ATP} / 48 / 38, \mathrm{PI}$. XCIII) which is not in the early style but anticipates that of Level VI, where the drawing is much more free and the artist tends to use a broader brush. These later developments which bring the pottery of Alalakh into relation with that of other Syrian sites will be discussed below, p. 386; their introduction meant the final disappearance of the old local painted pottery.

I cannot recall any instance of a relatively sophisticated painted ware having enjoyed so long a floruit. That it did so cannot be questioned, and even if my dating of the early Atchana levels be disputed, it must still be credited with a life of over a thousand years. It should, however, be noted that some of the plain pottery types were equally persistent, e.g. 26, I00, II 3 , I I 5, I I 9 , implying that the spirit of the industry was strongly conservative.

\section{(d) THE BLACK IMPRESSED WARE}

The ware is quite homogeneous. It is a smother-kiln fired pottery, black or greyishblack throughout, and the design is not incised but impressed, the tools used being chisels of different widths, wedges (for triangles), tubes of different diameters, and a small pointed drill for the punctured detail; the technique therefore is not that of the potter but of the worker in metal, and without doubt the vessels are reproductions in clay of metal originals. The surface of the vase is generally highly burnished (this again in imitation of metal) and the pattern was filled in with a white paste, a lime mixture which has in most cases now disappeared owing to the action of water on the lime, but sometimes survives. Only a very few shapes seem to have been made; by far the most common is the footed beaker (Type r 20), and next to this comes the big krater (Type 82); apart from these we have two instances of Type 93c, a single fragment coming from a straight-sided bowl having loop handles rising from the rim, and two fragments from (probably) a single vase in the form of a bottle with angular outline (an obvious metal form). If the forms of the vessels are limited the ornament is scarcely less so. All the basic motives employed are figured on Pls. C, CI, and they are simple enough; but the combinations 
of those motives are elaborate and ingenious in their variety and the finished pots have a lot of individual character.

Three exceptions to the general rule have to be noted. One is a fragment of a bottle of brownish-grey clay probably of the same shape as the example with impressed ornament already mentioned, but in this case (see $b, \mathrm{Pl}$. CI) the whole of the decoration is in punctured technique. The second is also a bottle (Type $13 b, \mathrm{ATP} / 39 / 284, \mathrm{Pl}$. CI) of reddish-brown clay on which the punctured technique again predominates and the design is mainly composed of two rows of dot-filled triangles; the third is the fragment shown on Pl. Cle. All of them, and more especially the second, recall, though they are not identical with, the Tell el Yahudieh ware, and it is possible that they may be a link between that ware and the essentially different impressed ware of Alalakh. ${ }^{\mathrm{I}}$ Both are of the same date as that ware. The first was found in a rubbish-pit cut down into Level VII together with a fragment from the rim of a large bowl (or amphora?) of the normal impressed ware; the second was found lying against the face of a Level V wall on a floor of the period, Sq. K 15 .

The manufacture of these vases, or rather their ornamentation, was a laborious process, seeing that it had to be built up piece by piece with separate tools for each element of the design; the ware therefore can fairly be called a luxury ware. Since the number of shapes was so limited it must have been made for a special purpose. No examples of it have been found in graves. All the complete or nearly complete examples of the beaker type were found in a series of rubbish-pits which lay within the area of the city temple and undoubtedly contained the 'throw-outs' from the temple, i.e. the vessels used in the temple service which had been broken or were no longer needed; there we found the greater part of five beakers and smaller fragments of half a dozen more. ${ }^{2}$ In the house sites of Levels IV to VI isolated fragments of the ware might occur at any point and it was on the house sites that we found one complete krater (ATP/39/I4, Pl. C) and fragments of two or three more-a type not represented in the rubbish-pits-but apart from that one krater all were scattered fragments. Compared to other wares, e.g. the local painted pottery, the number of black impressed sherds was small; either therefore the ware had a fairly long floruit but was always a rarity, or it was a prevailing fashion for a very short time. Now the temple rubbish-pits were all of one date; this was proved by the fact that in several cases the fragments of one pot were divided between two pits, and one vase was actually restored from fragments found in three separate pits. Consequently all the dozen or so vases of the kind represented in the pits had been thrown away at one and the same time; therefore they had all been in the temple in use at the same time; and since nothing like them occurs in other rubbish-pits connected with earlier or later temples, their vogue as ritual vessels seems to have been confined to the

\footnotetext{
1 Schaeffer, Stratigraphie comparée, p. 102, says of the latter 'elle ne saurait être rattachée à la poterie du type 'Tell el Yahoudiyeh. Les déductions chronologiques tirées de ce rapprochement ne sont pas à retenir'. With this I agree, but an exception must be made of the two vases discussed above, which are not strictly speaking of the same genre as the
}

impressed black ware but at the same time cannot be dissociated from it.

2 'The area of the rubbish-pits extended beyond the limits of our excavation, so that the number found may represent only a part of the discards. 
period represented by this series of pits. On the purely archaeological evidence observed during their excavation we had no hesitation in assigning the pits to Level V; they underlay Level IV, they were dug down into the ruins of Level VII, and the ground-level from which they were dug (though this is not always easy to determine) accorded with $\mathrm{V}$ and not with VI. Field observation was fully confirmed by an analysis of the other clay vase-types found in the pits; of sixteen varieties four are unknown elsewhere, five occur also in Level VI, ten in Level V, nine in Level IV; the pottery dates the pits to Level $\mathrm{V}$ and has more in common with the succeeding than with the preceding period.

The evidence for date from the house sites does on the whole agree with that of the pits. The area which produced by far the greatest number of black impressed sherds was that of the SE. quarter of Yarim-Lim's palace, Sqq. H-N I I-I 6. After the destruction of the palace the site long remained sparsely occupied, much of it being an open derelict site used as a rubbish-dump; only in the time of Level IV was it all properly developed as a building site, and then a great deal of levelling was necessary and was effected partly by the razing of such buildings as had stood here and partly by bringing in earth and rubbish excavated elsewhere. This platform filling therefore belongs for the most part, but not exclusively, to Level V, with an admixture from Level VI; but its lower contours are terribly irregular and often the only check upon the stratification was the surface of the undisturbed ruins of Level VII underlying the whole. ${ }^{{ }^{2}}$ In spite of this difficulty a certain number of fragments found in association with such house remains as there were could be confidently dated, and these are invariably of Level V. Similarly under house 39/B two sherds were found at the level of the Level IV wall-foundations, three more from the filling of the Level $\mathrm{V}$ house underneath, two more about $0.60 \mathrm{~m}$. above the stone foundations of the Level VI walls here, and half a dozen or more immediately above the Level VII ruin stratum. Three fragments were found in pits ascribed to Level V; three or four were under the Level III town wall-foundations and therefore less certainly dated; in the very much destroyed area south-west of house 39/B (Sqq. H I 8 , $\mathrm{J}$ I 8) two examples are recorded as 'from Level $V$ (or lower?)' and three as from 'the filling above the Level IV building', but the date of the building remains concerned was subsequently queried. On the temple site there was at $\mathrm{I} \cdot 40 \mathrm{~m}$. below the floor of the Level III courtyard a patch of burnt-brick pavement belonging to Level V; sherds of the black impressed ware occurred fairly freely above this pavement and on it and at its level were numerous. Under the intact pavement of the courtyard of Niqme-pa's palace lay poor walls of Level $\mathrm{V}$ and associated with them were three black impressed sherds, one from a beaker and one from a kernos. Another fragment of a kernos was found $\mathrm{I} \cdot 00 \mathrm{~m}$. below the foundations of those walls and on the grounds of its depth was attributed by us to Level VI, but in view of the condition of the soil the attribution is hazardous; the fragment is just as likely to belong to Level $\mathrm{V}$, and it is even possible that it

\footnotetext{
I For this reason the field notes written at the moment of discovery have to be used with caution. Thus in Sq. L I 4 three sherds are reported as coming $\mathrm{I} .00 \mathrm{~m}$. below Level VI; at this point there was later found to be a deep hollow in the
}

surface of the Level VII ruin field, whereas close by a building of Level VI had been set up on a higher mound. The relative depth of building and potsherds therefore means nothing. 
came from the same vase as the piece found at that level. In the fortress area, on the upper floor of Level VI, there was found a sherd from a vase not of beaker form of grey smotherkiln ware with a fine surface, rag-burnished, decorated with the normal 'running circle' design of the impressed pottery; but in this case although the circles are impressed all the straight lines are scratched with a fine point before firing. It would seem, judging by this specimen, that the Level VI Alalakh potter was trying to obtain the effect of the foreign ware but had not yet fully adopted its technique. Level $V$ B in the same area did, on the other hand, produce a good sherd of absolutely normal type.

Neither the Niqme-pa palace nor any private house of Level IV yielded a single example of black impressed ware in situ.

The evidence then can be taken as conclusive; the black impressed ware had a comparatively short life, and that life falls entirely within the period represented by Level $\mathrm{V}$. In so far as there are anticipations of it in Level VI, and no examples at all in Level IV, it is fairly safe to assume that its vogue fell early in the Level $\mathrm{V}$ period. Possibly the end of that vogue was signalized by the breaking and throwing away of such examples of the ware as had been dedicated in the temple.

The ware is not local in that it seems to have no past history on the site. We have from Level $\mathrm{V}$ one pot $(\mathrm{ATP} / 39 / 85$, Type 93, Pl. CI) decorated in the same way, but the shape is unusual and the clay is entirely different-a coarse drab clay, unburnished. From Level VI comes (ATP/48/46) a part of a triple vase standing on three short legs which has the normal impressed decoration but is of pinkish drab clay; it was found in a rubbish-pit underlying the courtyard of the Niqme-pa palace and the pit belonged definitely to Level VI, not to Level V. The vase therefore is older than any of the burnished black ware vessels to which by its decoration it is allied; but that does not mean that the burnished black ware was a local development from a pre-existing local drab ware; had such been the case we should surely have found in Level VI more than one example of impressed drab pottery, but in point of fact we found only this one. Again, from Level VII, the inner courtyard of Yarim-Lim's palace, we have a zoomorphic vase $(\mathrm{ATP} / 39 / 84, \mathrm{Pl}$. CI) with decoration part of which is incised and part impressed with the popular running-circle motive, and this, too, is in buff clay and unburnished. But this zoormorphic vase appears as exotic in its Level VII setting as does the burnished black impressed ware in Level V; the former is presumably an import, the latter may well be of local manufacture but if so is inspired by imported originals. At Alalakh it comes in suddenly with no local antecedents (for the isolated zoomorphic vase of Level VII cannot of itself constitute a precedent for home manufacture) and it disappears no less suddenly-in the enormous mass of Level IV pottery recovered from the site there is nothing at all like it. Somewhere or other there must have been a native centre of production from which the Alalakh ware is derived; but that source cannot be identified on the evidence at present available.

It is perfectly true that amongst the chalcolithic wares of Tarsus $^{\mathrm{I}}$ there is a burnished black pottery with impressed ornament which in technique and in its decorative motives

I Garstang and Goldman, 'A Conspectus of Early Cilician Pottery', in A.F.A. li (1947), p. 382 and PI. xc. 
bears a striking resemblance to what we have at Alalakh; and the Tarsus pottery is surely connected with an equally early black impressed ware with the running circles as a characteristic motive which comes in the lower Early Helladic I levels in mainland Greece. ${ }^{I}$ But any direct connexion between these chalcolithic types and the sixteenthcentury pottery of Alalakh is ruled out by the time-gap that separates them.

Sidney Smith and Mallowan ${ }^{2}$ have pointed out that the same pottery is found at Nuzi; this is true, but only to a limited extent, and it does not solve the problem. The Nuzi pottery ${ }^{3}$ is technically identical with ours, i.e. it is a burnished grey or black ware with an impressed ornament composed of circles, triangles, and straight lines; but there the resemblance ends. While the basic elements of ornament are the same (which, when they are so simple, is bound to be the case) the designs built up upon them are entirely different; for instance, the running circle is unknown at Nuzi.4 At Alalakh the decoration is, as we have seen, virtually confined to two forms, the beaker and the krater; at Nuzi also it is confined to about two forms, but these are bowls, which never occur at Alalakh, while the beaker and the krater never occur at Nuzi. As Sidney Smith remarks, there is also a time difference which it is difficult to surmount; at Nuzi the black ware is strictly contemporary with the painted Nuzu goblets; at Atchana the black ware is confined to Level V, whereas the Nuzu painted ware only begins to appear towards the end of Level IV and is most common in Level II; there is therefore at least a century and probably a good deal more between the black pottery of the two sites. It is impossible then to suppose that Alalakh obtained, or copied, its black impressed ware from Nuzi; and in view of the divergences already noted it is equally impossible that Nuzi should have derived its ware from the (earlier) Alalakh fabric. Mr. Starr is confident that the grey or black burnished bowls from his site were of foreign manufacture, or at least of foreign origin, but beyond pointing out that there had been a grey-black pottery tradition in Mesopotamia since the beginning of the Uruk period is unable to suggest where its source can have been. I had previously suggested an Anatolian origin on the strength of similar sherds found at Troy in Level VII; ${ }^{5}$ but the Trojan examples are probably later than ours and are so sporadic that here again they must be accounted as foreign imports. At Tarsus the black impressed ware appears in 'the late Old and early New Empire' period, i.e. at much the same time as at Atchana, and is identical in technique but, curiously, quite different in form; the prevalent shape seems to be the tall 'spindle' lekythus (B.M. $25, \mathrm{Pl}$. CXXX) ${ }^{6}$ which is unknown with us; and at Tarsus again it appears suddenly and with no recognizable local antecedents. It would therefore seem as if there were somewhere in Anatolia a centre of production which maintained its traditions for a very long time and that at different periods trade or migration from that

\footnotetext{
I Hetty Goldman, Excavations at Eutresis in Euboea, p. $8 \mathrm{I}$, fig. 97.

${ }^{2}$ Alalakh and Chronology, pp. 5-6.

3 R. F. S. Starr, Nuzi, vol. i, p. 402, and Pls. 91, 92.

4 An apparent exception to this, the sherd figured on $N u x i$, Pl. I I 5 G, is in a different technique, the ornament being incised, not impressed.
}

\footnotetext{
5 Dörpfeld, Troja und Ilion, pp. 302-3, and Figs. 2 I 7, 2 I 8. $\mathrm{My}$ attention was first drawn to this parallel by the occurrence at Troy of the ledge handle with impressed running circles which, except for the loop, is like ATP/37/I on Pl. cI from Alalakh.

6 Garstang and Goldman, op. cit., Pl. c. 7 .
} 
centre was responsible for temporary fashions elsewhere; the natural developments in its country of origin would explain the differences resulting from the interval of a century or more between the similar wares of Nuzi and Alalakh, and there is no reason why the tradition should not go back so far as to link up with the chalcolithic pottery of Tarsus.

I have already referred to the question of the Tell el Yahudiyeh pottery. This, with its incised and punctured white-filled decoration, is roughly contemporary with the Alalakh black pottery, is widely diffused over Palestine and Syria, and occurs freely so far north as Ugarit. Our excavations at Atchana cover the temple area and a considerable area of domestic buildings together with many rubbish-pits of Levels VI and $\mathrm{V}$, and the true Tell el Yahudiyeh pottery is lacking. In one Level V grave (ATG/49/I, q.v.) there were found fragments of a small bottle, Type apparently 47 , of brown paste with smoky grey (smother-kiln) surface, very lightly fired; the clay was laminated in a way reminiscent of Tell el Yahudiyeh ware, but that by itself cannot prove identity of fabric, and otherwise the vessel was in too bad a condition to admit of close comparison. I have suggested (p. 343) that the very rare examples of grey ware with punctured decoration, ATP/39/ 284 and fragment $(f)$ on Pl. CI, may perhaps constitute a link with Tell el Yahudiyeh; but the link is a tenuous one at best, and we can only conclude that for all practical purposes Alalakh lay outside the territorial zone affected by the makers of Tell el Yahudiyeh pottery.

\section{(e) THE NUZU WARE}

This pottery, distinguished by its decoration in white paint on a black painted ground, is a foreign (Mitanni) ware; it must have come to Alalakh originally as an import, but the style was quickly adopted by the local potters and probably all the examples found by us are of local manufacture however true to type they may be. It was first recorded at Nuzi and Mr. Starr's description of it ${ }^{\mathrm{T}}$ applies equally to most of the Alalakh examples. It was found at Tell Billa ${ }^{2}$ and again at Brak ${ }^{3}$ and, in the Amq plain, at Judeideh (in Level VI) 4 and on a number of less important sites; it is, with the exception to be noted hereafter under the heading 'Atchana ware', uniform in technique and in decoration, and the evidence for its date is consistent throughout.

At Alalakh we have found two, or perhaps three, examples of $\mathrm{Nuzu}$ ware dated to Level V; otherwise it only occurs towards the end of Level IV, is common in Level III, most abundant in Level II, and is completely absent from Level I. ${ }^{5}$

I R. F. S. Starr, Nuzi, pp. 394 sqq., and Pls. 78, 79.

${ }^{2}$ Bulletin of the American School of Oriental Research, No. 4 I (Feb. I931), p. 23.

3 M. E. L. Mallowan, Iraq, ix ( I 947), p. 20, Pls. LxxxviLxxxvi11.

4 R. J. Braidwood, Mounds in the Plain of Antioch, p. 6.

5 The evidence is as follows. One vase from a kernos (ATP/49/2) was found in a Level V rubbish-pit in the temple area; it is very roughly painted in white on black. In Sq. $\mathrm{K}$ I 3 we found (in I937) a pit cut down into Level VII containing sherds from a small vase which in spite of the fact that all the paint had flaked off was unmistakably Nuzu, together with fragments of several vases of 'Type 3 which hitherto had been found only below Level IV, on the strength of which the pit was attributed provisionally to Level V. Subsequently it was found that Type 3, though most common in Level V, does occur also in Levels III-IV; the attribution of the Nuzu vase to Level $V$ is therefore probable but not certain. Outside the entrance-door of the Yarim-Lim palace, just above floor-level, there was a quantity of pottery including a good fragment of Nuzu ware associated with Cypriote base-ring ware and white slip, impressed black, and local painted sherds; but this was an intrusion dating from the addition to the Level IV palace by Ilim-ilimma. Similarly a 
In the relatively short period covered by this pottery it could scarcely be reasonable to expect any marked process of development. It is indeed true that in Level II vases occur which might equally well belong to Level IV, but apart from the introduction of the entirely new design which characterizes 'Atchana ware' there does seem to be at least one tendency at work which gives to the later a somewhat different character, namely, the tendency to prefer for the white-painted design a black background to the brown or red background that had once been almost equally popular. That this was so was certainly the impression one gained from the mass of fragments that were encountered in the upper levels of the site; but the general impression is more than justified by facts. Of the twenty-five fragments which are recorded in the field notes as demonstrably belonging to Level IV fourteen have a black background and eleven have backgrounds variously described as red, yellow-buff, reddish-brown, brown, orange-brown, purple-red, and grey; in view of the comparative rarity of non-black backgrounds in the total collection of fragments found, this proportion is very striking. Of forty fragments recorded as demonstrably belonging to Level II thirty-two have a black background, four red, and four brown. ${ }^{I}$ Obviously there was a growing preference for the black-andwhite colour-scheme; that colour-scheme was used exclusively for the (late) 'Atchana' variant of the Nuzi ware.

Here, however, I must enter a caveat: the white-on-black effect was what the Alalakh potter aimed at, but he did not always obtain it. His kilns were faultily constructed and liable to draughts, with the result that 'flares' are common, and with the oxidization of the haematitic pigment a part of the black surface may be reduced to a reddish-brown. ${ }^{2}$ The statistics given above take no account of this purely accidental discoloration.

fragment found at floor-level in Room 5 of the Yarim-Lim palace associated with a sherd from a milk-bowl and fragments of local painted vases was intrusive.

In I937 two Nuzu fragments were recorded as lying under the NE. corner of the Level IV palace; in I 939 three fragments were found together against the outer face of the same palace wall $0.70 \mathrm{~m}$. above its inner floor-level; both finds must be discounted as referring only to the deep trench dug for the foundations of Ilim-ilimma's addition to the palace. The sherds therefore belong to Level IV. In I948 a single sherd was recorded as coming from Level $\mathrm{V}$ on the temple site. Since, however, the builders of the Level III temple excavated the site down to the base of the stone foundations of Level IV, which in their turn were sunk into the Level V ruins, no reliance can be placed on the find-spot of an isolated fragment. The Nuzu pottery was originally an imported foreign ware, and it is, of course, possible that single examples of it were brought to Alalakh long before the style became fashionable and was adopted by local potters. Provided that the manufacture had already started in the Khurri country, the occurrence of a single specimen in Level $\mathrm{V}$ could be admitted with equanimity; but it remains true that Nuzi ware only obtained a vogue and came into local production in the period of Level IV.

For the date of the ending of the vogue I would quote a typical field note of $\mathrm{x} 93^{8}$. "In Sqq. H $\mathrm{r} 7, \mathrm{~J}$ i 7 a good deal of the area was effectively "corked" by intact floors of Level I. The floors lay I.30 m. below the modern surface. In this top $\mathrm{I} \cdot 30 \mathrm{~m}$. we found not a single sherd of Nuzu ware; there were some Mycenaean fragments and parts of a Cypriote krater with the chariot scene. In Sq. J I 6 there was a white floor of Level I and about $0.30 \mathrm{~m}$. below this a rough floor of small pebbles' (this was Level I A, the white floor being Level I B) "very much like that in $\mathrm{K} \mathrm{I} 6$ and at the same level. . . . Above the cobbled floor and below the white floor there were ... fragments of a piriform Mycenaean vase (Type B.M. 5I) and fragments of Nuzu ware, one being painted in reddish brown on a white ground, i.e. the reverse of the normal type. In Sq. $\mathrm{K} I 6$, definitely below Level I, under the belt of pebbles were fragments of a piriform Mycenaean vase (Type B.M. 5I) and the lower part of a Nuzu goblet with a band of rosettes round the rim and a large flower at the base.' All the evidence from the site agreed with this.

I At Nuzu 'red, as a base colour, is uncommon, . . . brown is represented by but one example' (Starr, op. cit., p. 396), which may mean that there only the later stages of the ware are represented.

2 Mr. Starr (op. cit., p. 395) when he says 'the pigment was applied as a heavy, after-baking coating in varying degrees of thickness' seems to imply that the paint on the vases found at Nuzi was not itself fired. At Atchana this is emphatically not the case; the vessels were fred after being painted, and as 
As regards the decoration there is, as has been said above, very little evidence of change during the period. Bird and animal motives appear alike on vases of Level IV and on those of Level II; in both levels alike there are found vases with the decoration confined to a single band below the rim, and vases with the whole surface covered with ornamentsimplification and elaboration afford no criterion of date. The fact seems to be that by the time the ware was introduced to Alalakh, circa 1430 B.c., its evolution was already complete.

The source from which the decoration was evolved is, I think, clear; the black and white paint was an easy and a cheap medium for obtaining the effect of black burnished pottery with white-filled impressed ornament. Free-hand brush-work was bound to modify designs originally executed by impressing the clay with simple tools and to substitute curved for straight lines-thus the 'running circle' of the impressed ware becomes the running spiral of the painted vase; but subject to this condition a surprising number of the motives of the Nuzu decoration can be traced back to the impressed ware. One fragment, ATP $/ 37 / 397$, coming from a bottle-shaped vessel, is peculiarly reminiscent of the older technique; it might indeed even be thought to derive from Tell el Yahudiyeh originals. It was found on the floor of the Niqme-pa palace, so belongs to the earliest phase of the ware at Alalakh.

The forms of the vessels are interesting. While Type i 86 is by far the most common (v. Pl. CIV) we find also the krater (Type 82, Pl. CIII), the hemispherical bowl (Type I 49, Pl. CIII), the bottle (Type I 30 , Pl. CII), the vase-stand (Pl. CVI), the amphora, Type 78, the kernos, zoomorphic vases (Pl. CIII), the beaker (Type 94, Pl. CII), the disk, Types $9 b, \mathrm{r}$ I, the jar (Types $102, \mathrm{r} 08, \mathrm{I}$ I $0, \mathrm{Pl}$. CVI), the handled and spouted jar (Type 72, Pl. CVI), and the elegant vase of Type I 27 (Pl. CVI). This is in marked contrast to Nuzi, where the white-on-black painted decoration is limited almost exclusively to the 'high cup' (our Type i 86 ) and the 'shouldered cup' not represented at Alalakh; two jar shapes and a bottle (?) seem to be the sole exceptions. At Brak, Type I I $8 b$ is again almost exclusively employed; Mallowan signalizes only four fragments belonging to other types. ${ }^{I}$ I can suggest no reason for this except that the Alalakh potter was, as is proved by his invention of the 'Atchana' designs, less hide-bound by tradition and more prone to experiment ${ }^{2}$ than were his confrères of whom Mallowan says that they 'used a standard set of symbols which, for practical purposes, served as a pattern book'. When he goes on to say 'The ceramic, generally speaking, displays no great artistic merit. The style is an artificial revival; designs are often carelessly executed, unimaginative abstractions from nature, and there is little feeling for relating pot-design to potform' he goes rather farther than, I think, would most people who look at the illustrations on Pls. CII-CVII.

far as I could determine this was not a re-firing, but the paint had been applied to the pot when the latter had been thoroughly dried but not fired. Mallowan says of the Brak examples "there was poor fire control, and black sometimes turned to red on the same pot'.

I Iraq, Ix. ii, p. 237.

2 Apart from the 'twin' vase ATP/47/1 36, P1. cin, we found fragments from four multiple (kernos) vases mounted on rings, a form which at Alalakh is otherwise represented only by a fragment of the (foreign) black impressed ware; there were five different types of zoomorphic vase, and zoomorphic vases also are not common and two of those that were found were foreign ( $v$. p. $35 \mathrm{r}$ ). It would seem that the 'experiments' of the Alalakh potter were inspired not so much by local traditions as by imports that appealed to the local fancy. 
One set of vessels shown on those plates differs entirely from anything found on the eastern sites ${ }^{I}$ where Nuzu pottery is found. Level II at Alalakh has produced a variant of the Nuzu pottery so individual as to deserve the special name of 'Atchana ware'; it is characterized by a design (executed as usual in white paint on black) whose chief motives are streams of water, clusters of stylized papyrus plants, and a formal tree with lotus-like flowers springing from what seems to be a double axe, 'distant echoes of the patterns used on Minoan pottery of the 17 th century'.2 Between the Cretan vases and the 'Atchana' cups there is indeed a time interval which it is difficult to bridge; yet the Cretan character of the Atchana design is undeniable 3 and the fact that it was produced in the Amq plain, i.e. on the Aegean trade route, and not in the regions in which the pottery originated lends verisimilitude to the assumption. There is evidence at Ugarit of an archaistic revival of Minoan fashions long after they had disappeared from the island and our 'doubleaxe tree'4 may be a further manifestation of it; it should be noted that whereas the proportion of 'Cretan' to other sherds is, in Level II, very high, all these are repetitive, variants only in a minor degree of a single design, so that it might be argued that the pot-painter was not drawing on a corpus of Minoan ornament but copying a single pattern which happened to have survived and come into his hands; it caught the favour of his clients and was repeated, with variations, as long as the mode lasted.

The evidence for the dating of the Nuzu ware has been ably summarized by Mallowan and his arguments need not be repeated here. It was in full production in the East by I $45^{\circ}$ B.C., which would account for a sporadic example occurring in Level V at Alalakh; if there it first becomes popular only a little before the destruction of the Level IV palace, i.e. in the reign of Ilim-ilimma (Mallowan's reference to Atchana is based on a chronology of the site modified since he wrote), that is due simply to political conditions affecting imports. If it went out of use at Alalakh while it was still being produced in the East this again is due to politics; for its floruit the evidence from Atchana is perfectly in accord with that from other sites, and as regards its beginning and its end what is true of Alalakh, where it was after all a foreign fashion, need have no relation to its history in the lands of its origin.

\section{( $f$ ) ZOOMORPHIC VASES AND VASES WITH RELIEF OR INCISED DECORATION}

As constituting a type outside the range of normal wheel-made clay vessels the zoomorphic vases call for mention, the more so because such vases are sometimes assumed to have special importance as evidence for cultural connexions.

The vases are not common. Of the base-ring ware bull vase familiar in Cyprus in the

1 These are enumerated by Mallowan in Mélanges syriens offerts à $M$. Dussaud, vol. ii, pp. 887-894; where also the chronology is discussed.

2 Sidney Smith in Alalakh and Chronology, p. 46.

3 Evans, 'Some Notes on the Tal Atchana Pottery', F.H.S. Lvi. ii ( 936 ), p. I 33 .

4 I cannot see a possible derivation of the 'double-axe tree' of the Atchana vases from the Mari frescoes (Syria, xviii, P1. 39) as suggested by Mallowan; the expression does not seem to me to apply at all to the tree in that fresco, and M. Parrot himself (op. cit., p. 342) doubts any such interpretation. The rosettes, which also look very Cretan, may more probably be derived from Asiatic originals, but for the tree design Crete affords the only parallel. 
later Bronze Age half a dozen examples were found (v. p. 357 and Pl. CXXV); a bull vase with incised and impressed decoration (ATP/39/84, v. Pl. CI) came from the Yarim-Lim palace; in the Level VII temple foundations was a fragment (AT/48/59) the belly only - of a bull (?) vase which had had wheels instead of legs; it should belong to Level VIII. Another fragment (AT/39/19) giving only the rump of a bull (?) mounted on wheels was found high up, above Level IV, but its date must be considered doubtful, and it may possible have been a hollow statuette and not a vase. From Level VIII temple site came $\mathrm{AT} / 48 / 33$, part of an anthropomorphic vase in buff clay. From a pit belonging to Level $V$ came a bull's head, AT/46/20I, which is the spout of a vase, the head being hollow with an opening through the mouth; incised on the forehead is a dot-filled double-outlined triangle. From Level IV came AT/47/183, the body only of an animal bearing a vase on its back. From the top-soil in Sq. S I 3 came a cow's (?) head, $\mathrm{AT} / 38 / \mathrm{r} 60$, which also is a vase-spout; its date is uncertain, as is that of another spout, a bull's head, AT $/ 48 / 7$, found in the top-soil, whereas AT/38/280, Pl. LVII, belongs to Level II. A vase very crudely modelled in the form of a horse with saddle and bridle (Pl. LVIII), undated, was found in Atchana village, outside our excavations. In Nuzu painted ware we have a bird, ATP/39/46, Pl. CIII; a fragment of a fish, ATP/37/268; a vessel, incomplete, in the form of a hedgehog (?), ATP/38/4, Pl. CIII; a cow's hoof which must have belonged to a very large vase or perhaps a tripod stand; and the left fore-leg of a feline, AT/37/r 90 , solid and modelled in the round, which may be part of a figurine rather than of a vase. Under the floor of Level VII and therefore to be assigned to Level VIII there was a bird vase (the head missing), AT/46/I80, Pl. LVIII, with a funnel and strainer in the back; it was made of brown clay, burnished.

It will be noticed that nearly all these vases belong to ceramic groups which are not native to Alalakh. The Nuzu ware and the base-ring ware are certainly either imports or due to foreign influences. The bull vase from Level VII, with impressed ornament, may well be of local fabric but cannot be dissociated from the black impressed ware which is of foreign origin. Two of our examples, AT/48/59 and AT/39/1 9, are too fragmentary to be judged, the anthropomorphic $\mathrm{AT} / 48 / 33$ is rather nondescript, and only a single one, the brown-burnished bird, AT/46/180, is typical in clay and technique of Alalakh pottery. Obviously an isolated object, although locally made, may have been inspired by a foreign model, and this bird vase is curiously like examples from Susa II, \&c., cited by Frankfort ${ }^{1}$ as evidence for connexions between Egypt, north Syria, and Mesopotamia. He points out that vases of the type appear in different regions centring round eastern Anatolia and north Syria and regards the latter as the more likely. place of origin; the Atchana evidence certainly eliminates the Amq area, and while the Nuzu examples accord with Frankfort's hypothesis, the base-ring and impressed ware specimens seem to indicate a wider diffusion in Anatolia. At the same time it must be admitted that the bird vase and the anthropomorphic fragment, both of which may be local, are the earliest of the series, belonging to the nineteenth century B.c.; but had zoomorphic

I H. Frankfort, Studies in Early Pottery of the Near East, I. Mesopotamia, Syria and Egypt and their Earliest Interrelations, P. I I 3 , Pls. vin and Ix. 
vases really been endemic there would surely have been more of them executed in native style, and it would not have been the case that later examples should without exception belong to imported groups of foreign pottery.

\section{INCISED DECORATION}

(a) Sgraffiato Ware. This appears first in Level VIII (v. above, p. 3 I 5), where two fragments were found; two others, one a bowl-rim with three wavy bands between plain bands and one with a single zigzag on a narrow band of black paint, probably belonged to the same level. One piece was found in Level VI; two, also bowl-rims, in the Level V building on the $39 / \mathrm{B}$ house site (Pl. CVIIIn, o), one fragment against the foundations of the Level III temple, associated with Mycenaean and Nuzu sherds, and several fragments, also associated with Mycenaean, in Level I. в. On nearly all the design is the same - the dark paint has been applied in horizontal bands and straight and zigzag lines have been cut through the paint into the body clay before firing-and all seem to be from bowl types; but only small pieces were found, and very few of those, and if the find-spots are to be believed they cover a remarkably long period. ${ }^{\mathrm{I}}$ The ware appears to be the same as that which characterizes Period IX at Tell al Judaidah-'goblets with wavy comb incisions through painted bands', ${ }^{2}$ but they are there dated to between 2400 and 2000 B.c. whereas the Atchana examples range from the nineteenth century to the thirteenth. In view of their unusual character and of their rarity they would seem to be imports to Alalakh rather than a local product, whatever their date.

(b) Incised designs. While comb decoration was common, anything more elaborate than waved lines was extremely rare. From Level VI came a fragment of a large jar of reddish-drab clay which had near the rim two lines of punctured dots and lower down a band of double rope ornament in relief with oblique slashes; between the two was a boldly waved line of comb decoration, but under one of the curves there was an incised drawing apparently of a two-yoke plough with a long line cut beneath it which possibly represents the furrow (ATP/47/I 54, Pl. CVIII $j$ ). On the floor of room 32 in the Niqmepa palace was part of the base of a clay colander $\left(\mathrm{ATP} / 38 / 23^{\circ}\right)$ on which there had been incised (twice over) before firing the two signs (?) shown on Pl. CVlII $i$. From the surface of the tell near Atchana village, and therefore of unknown level, came a fragment of a large thick-walled vessel on which was incised before firing a rough sketch of the head of a boar (?), AT/39/1, Pl. CVIII $k$, and another fragment, possibly from a tripod base, $(\mathrm{AT} / 38 / 288, \mathrm{Pl}$. CVIII $h)$ with dots in relief and raised panels on one of which was a row of animals crudely incised before firing. These are the only real designs, though on a few vases, especially 'champagne-cups', there are incised vandykes, \&c. From Site H, not later than Level IV, came a clay roundel with incised signs, AT/38/226, Pl. CVIII/. Several plates (Type $6 b$ ) and one saucer (Type $3^{b}$ ) from the Niqme-pa palace bore on the base what are probably maker's marks incised before firing (ATP/38/229 and 99 , Pl. CVIII $m$ ).

I I admit the danger of relying too much on the stratification of isolated fragments; but the evidence is good for Level
VIII, and for the rest the distribution is at least consistent. 2 R. J. Braidwood, Mounds in the Plain of Antioch, p. 6. 
STAMPED DECORATION

Of this there were two examples only. AT/38/266 from room 6 of the Niqme-pa palace is a potsherd bearing impressions of a cylinder seal, rather indistinct, with a scene of two persons beside a conventional tree; the other, $\mathrm{AT} / 38 / 232$, from the upper soil of Site $\mathrm{H}$, probably Level IV (?), seems to be also a seal-impression on a large vase (Pl. CVIII $g$ ).

\section{APPLIED RELIEF DECORATION}

This also is extremely rare. The finest example is the pot-stand or brazier found in the Level VII temple, AT/47/1 28, PI. CVIII $a, b$, decorated with complete moulded figures (v. p. 248). From Level IX came a fragment of a painted jug (?) having on the shoulder above the painted decoration crudely modelled human and animal figures stuck on to the rather rough surface of the clay (Pl. CVIIIe, AT/48/48). From Level XII A came a fragment of a jar, probably of Type 26 , the shoulder decorated with horizontal bands joined by grouped vertical strokes in reddish-brown paint; at the junction of shoulder and neck there had been applied before painting two (or more) hand-modelled clay ornaments, one apparently a snake, the other uncertain (Pl. CVIIIb, ATP/47/I I 3 ). From the mass of pottery underlying the citadel wall, and belonging to Levels VIII and earlier, came two fragments of the same vessel, a bowl probably of Type 23 , having the usual 'triglyph' ornament in orange-brown paint and clay applique figures like that on $\mathrm{ATP} / 47 /$ I I 3 but touched up with paint (Pl. CVIII $a, f, \mathrm{ATP} / 37 / 3^{8}$ I A and B). Several bowls of the same type found in the wall deposit showed the triglyph design with, in the 'metopes', two flat appliqué clay disks either scored or painted with horizontal slashes (cf. ATP/37/382, Pl. CVIIIc). From the temple site, Level VIII-IX, comes AT/48/29, a fragment from the rim of a large pot on which rises the figure of a crouched lion, only the head rendered in any detail (Pl. LVIIc). In the Level VII temple was a fragment from a large amphora, part of the rim and the spring of the handle (AT/48/I 2, Pl. LVIIf), showing a snake climbing up the handle and looking over the rim into the pot.

All these examples are early, ranging from Level XII a to Level VII. From the upper levels we have only one example of genuine appliqué technique, a potsherd (AT/38/294) to which is affixed a moulded terra-cotta relief of the normal type of a naked woman complete with its background; unfortunately this was found in the surface soil above the main house site and cannot therefore be dated, though presumably it is relatively late, later at any rate than Level VII. In Sq. M I 4, between Levels II and III, there was a jarhandle of red clay with a crudely modelled animal extended along it (Pl. LVIId, $\mathrm{AT} / 39 / 270$ ). This is obviously derived from older originals such as the finely moulded lion-handle of the blue-paste vase AT/48/1 8, Pl. LXXXIII $f$, and is quite different from the applique technique. Different also is a small fragment, $\mathrm{AT} / 38 / 47, \mathrm{Pl}$. CVIIId, from Level II, which has a lion's head in relief; this seems to have been moulded directly on the vase. 


\section{(g) WHITE SLIP AND BASE-RING WARES (Pls. CXXV-CXXVI)}

Atchana has produced a very large amount of 'Cypriote' pottery and, as in the case of the Mycenaean ware, there is a certain discrepancy between the conditions in which it occurs there and the dating normally assigned to it in Cyprus. In my provisional report on the I 938 season, published in the Antiquaries Fournal , I dealt with the first case in point and said that the absolute chronology of Cypriote wares being admittedly nebulous, then, if the Atchana evidence was inconsistent with conclusions based on the evidence from Cyprus, either we must revise those conclusions or we must call in question the dictum $^{2}$ that throughout the pre-Mycenaean period in the island 'all the pottery is purely indigenous, the work of the original inhabitants of the island, without any admixture of importations', and look elsewhere for the origin of some of the wares. That dictum, which seemed to me inadmissible, is indeed rejected by modern scholars, ${ }^{3}$ but their admissions do not apply to the particular wares whose dating seems to be affected by conditions at Atchana; and though both Schaeffer ${ }^{4}$ and Sjöqvist maintain that there were on the Syrian coast centres of production of Cypriote vases, they consider that such were branch establishments founded to meet the demand for goods already popularized by the product of Cypriote factories-the mainland vases are therefore later, not earlier, than those first sent from the island.

As regards a revision of Cyprus dating, Sjöqvist ${ }^{5}$ very fairly insists on the difficult stratification of the part of the site on which my argument was based, as tending to invalidate my conclusions which contradicted 'homogeneous and well-established evidence' from archaeological work in Egypt, Palestine, Syria, and Cyprus (this was a rejoinder to my description of Cypriote positive chronology as 'admittedly nebulous'), and he decides to await further excavation before accepting so embarrassing a result. Dr. Schaeffer is less accommodating; one cannot, he says, uphold the observations made in the course of a small-scale and incomplete excavation on a single site against the harmonious evidence of a great number of sites excavated in Cyprus and in Syria, and if the vases illustrated were really found in Levels V and VI, then those levels cannot be placed farther back than I 600 in round figures; he is indignant that I should not be disposed to accept the validity of the absolute chronology based on the Cypriote pottery: ${ }^{6}$

I do not claim to possess expert knowledge of Cypriote pottery, but I cannot find proof of that validity. Schaeffer is at pains to show that his own chronological scheme put in tabular form agrees almost exactly (with a slightly different nomenclature) with that of the Swedish excavators. ${ }^{7}$ As both systems consist in subdivision of the same general field, as the subdivisions proposed by Sjöqvist are usually as short as fifty years, and as Schaeffer is prepared to accommodate his own system by the use of round figures (e.g. putting $135^{\circ}$ where he means I 365 and I 200 where he means I $25^{0}-1230$ ), it is very

\footnotetext{
I Vol. xix (1 939), No. I, p. I.

2 British Museum Catalogue of Cypriote, Italian and Etruscan Pottery, p.ix.

3 e.g. J. L. Myres, 'The Red Ware Culture of the Near East' in Cambridge Ancient History, i, pp. 89 sqq.; C. F. A.
}

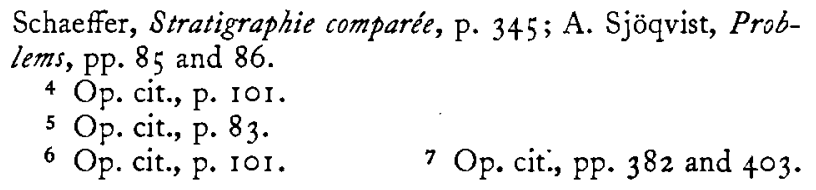


easy to regroup the Swedish phases so as to bring them into apparent harmony with his own classification. But what really matters is the content of those classes-the material, not the nomenclature-and there the agreement is not evident. The Swedish attributions are challenged all the way through, e.g. p. 383 , p. 398 , p. 390 , 'L'attribution au Late Cypriote II c ( $275^{-1200}$ ) de cet ensemble typique du Chypriote Récent II (I 450-I 350) est évidemment impossible', or p. 399 where he carries back the black punctured ware which Sjöqvist would put after $\mathrm{I} 600$ (Late Cypriote I A) into Chy priote Moyen III (1750-r600) and even into Chypriote Moyen II (r900-r750). On the ground of discoveries at Sedment ${ }^{1}$ Schaeffer puts the small Base-ring I jugs back to I 600, in which he agrees with Albright ${ }^{2}$ and Gjerstad, ${ }^{3}$ but Sjöqvist dates them after I $55^{\circ}$, i.e. in Middle Cypriote instead of in Late Cypriote. The fact is that the chronology of Cypriote pottery is not yet fixed, and Schaeffer is himself, in certain circumstances, the first to maintain that it has to be revised; on p. 40I, putting back the date of Basering II ware and White Slip II ware to about I $45^{\circ}$, he says explicitly, 'La date de I 400 antérieurement proposée' (by Sjöqvist) 'ne peut pas être maintenue à la lumière de découvertes récentes faites dans l'île et à Ras Shamra'; even more emphatically he says (p. 333), apropos of the Burnished Red ware, which on the base of his discoveries at Ras Shamra he would bring down in date from the generally accepted 3000 B.c. to 2600-2000, 'Que mes collègues soient assurés que c'est nullement un plaisir pour nous de devoir démontrer que certaines des dates jusqu'ici admises doivent être rectifiées. . . . Ce qui compte, ce n'est pas le prestige de tel ou tel système chronologique, mais le progrès de notre connaissance en une matière où nous ne progressons que par tâtonnements. Par rapport à l'exacte vérité scientifique qu'un jour nos successeurs atteindront, nous tous, aujourd'hui, sommes probablement en erreur.' I could ask for no better encouragement for putting forward what may be new material.

I propose to start with a catalogue of more or less complete vases for which there is definite external dating evidence, leaving out those for which such evidence is lacking. I have, however, sometimes included vases of doubtful date, or fragments, not for chronological purposes but to cover so far as possible the whole range of types common to Atchana and to Cyprus. The catalogue follows the accepted classification of the wares (for which I have used Sjöqvist's very clear definitions), and under the heading of each ware the forms are given also in accordance with Sjöqvist; to the latter I have added in brackets (B.M.S. ...) the type-number in the British Museum Catalogue 'Shapes of Vases' (Pls. $\mathrm{xxIx}-\mathrm{xxx}$ ) or, if there was no exact correspondence (B.M.C....), a reference to a particular example illustrated in that catalogue.

Middle Cypriote wares are very sparsely represented at Atchana.

\section{Red-on-black $W$ are}

A very few fragments of bowls, hemispherical, with a pinched-out trough spout, handmade, of drab clay with an all-over black slip (or wash) flaring to red, on which patches

I Petrie and Brunton, Sedment, i-ii, Pl. xuvi.

2 Annual of the American School of Oriental Research, xii
(1930), p. 36.

3 Studies, p. 333. 
either of criss-cross lines or of long or short vertical lines in deep red paint; the decoration might occur both on the inside and on the outside of the vessel. The type is not figured in the British Museum Catalogue; an example is represented in Schaeffer, Stratigraphie comparée, Fig. 46, T. A very large fragment was found in a rubbish-pit on the temple site which was dated to Level V or Level VI, and another considerable fragment in a rubbish-pit of Level VI underlying the south corner of the inner courtyard of Niqme-pa's palace.

\section{Incised Black Slip Ware}

Flask (B.M.S. 42), one fragment only, closely resembling B.M.C. 92 in decoration, belonging to the 'late degenerate' period, was found in conditions affording no dating evidence; a later incised example is dealt with under Base-ring ware (ATP/37/4r 3$)$.

\section{Monochrome Ware}

Bowl Type $2 b$ (not in B.M. Catalogue); ATP $/ 38 / 27$, light brown clay, very thin walls, wish-bone handle, concave base; Level IV (in room I6 of the Niqme-pa palace). ATP/47/63, deep red clay, similar type; Level VI, in rubbish-pit sunk into the floor of the Level VII temple.

Variant of bowl Type $2 b$, having a flat instead of a concave base (not in Sjöqvist); $\mathrm{ATP} / 37 / 4 \mathrm{I}$, hard compact brownish-red clay with slip of the same colour; Level IV, in room 8 of the Niqme-pa palace. ATP/37/409, light red clay with black slip flared in parts to red; Level IV, in room 6 of the Niqme-pa palace. ATP/39/219, red clay, burnished; low in Level V (possibly Level VI).

Base-ring I Ware

Bowl $\mathrm{I} b$, but with plain in-turned rim, wish-bone handle; ATP $/ 39 / 285$, fine red clay, burnished; Level IV, in grave G/39/95, dug down into Level V. ATP/39/2 I 9, red clay, thin walls; Level V. N.B., this may be monochrome ware; the base is missing.

Jug Type I (B.M.S. 23). ATP/38/195 and 24I; two examples; Level IV; both together in grave $\mathrm{G} / 38 / 34$.

Jug Type $2 a$ (B.M.S. 26). ATP $/ 38 / 233$, normal dark grey slip; Level IV, in room I 7 of the Niqme-pa palace. ATP/37/4I3, hard brown-red clay with black slip flared in parts to red; the handle is a flat ribbon handle and the body is decorated with a horizontal band and festoons of incised hatching reminiscent of Middle Cypriote technique; Level IV, in room 6 of the Niqme-pa palace. ATP/39/39, brown clay with black slip, burnished; Level IV, in grave $\mathrm{G} / 39 / 7$. ATP/39/64, brown clay with black slip, burnished; Level IV (probably), in grave G/39/35 - the grave might less probably be of Level V. ATP/39/274, bright red clay, burnished; Level IV, in grave G/39/93. ATP/ 46/204, red clay, no slip, lightly burnished; Level $V$, in grave G/46/I.

Jug Type $5^{c}$ (B.M.S. I 9 ) but lacking the thumb-piece on the handle. ATP/38/1 50 (Pl. CXXVI), light red clay covered with thin black slip (much pitted), lightly burnished; Level IV, in grave G/38/17. A handle of a jug apparently like Jug Type $5 d$, flat, with incised double herring-bone pattern on the outer side, of clay grey in centre 
and buff outside with brown slip (ATP/37/298), was found in unstratified conditions. It may be of Base-ring II ware.

Jug Type 6 (B.M.S. 20). ATP/48/2, grey clay with deep buff surface, water-smoothed (fragment); Level $\mathrm{V}$, in contemporary debris in the back room of the temple.

Bottle Type 2 (B.M.S. 25). ATP/39/1 5, coarse grey-drab clay with black slip; Level IV or $\mathrm{V}$, in grave $\mathrm{G} / 39 / 32$.

Bull-shaped vase. ATP/38/1 4 (Pl. CXXV), with vertical stripes of white paint on the black slip; Level IV, in room C 2 of the Niqme-pa palace. ATP/47/ I 25 , similar; Level IV, in $\mathrm{KP} / \mathrm{C} 8$. ATP/39/220, head only; Level VI. ATP/39/22I, two bulls' heads apparently from vases of the same type, but one is of drab and the other of red clay; Level VI.

\section{Base-ring II Ware}

Bowl Type I (B.M.S. 22). ATP/37/304, fine clay, brownish-red in centre and grey towards edges, covered with black slip flared to brown in patches; thin walls; Level IV, in room 8 of Niqme-pa palace. ATP/38/189 (Pl. CXXVI), brown clay fired to black, good engobbage surface; Level IV, in grave $\mathrm{G} / 38 / 33$.

Jug Type I $a$ (B.M.S. 24). ATP/47/ I24, reddish-buff clay partly flared to black, burnished surface, thin walls, two divergent relief ribs on front of body; Level IV, in house $\mathrm{KP} / \mathrm{C} 8$. ATP/47/ I 23, very thin walls, drab-black clay, water-smoothed surface; relief scrolls on body; Level IV, in house $\mathrm{KP} / \mathrm{C} 8$. ATP/38/224, similar to last, Level IV, room $\mathrm{C} 2$ of the Niqme-pa palace. Fragments of similar jugs, perhaps fifty in all, all of Level IV, from rooms I, 2, 6, 7, 8, I 3, I 4, I 6, I 7, I 8, 2 I, C I, C 2, C $3, \mathrm{C}_{5}$ of the Niqme-pa palace. ATP $/ 39 / 42$ (Pl. CXXVg), red clay, water-smoothed, with two relief scrolls on body, Level IV, in grave $\mathrm{G} / 39 / 7$.

Jug Type $2 a$ (B.M.S. 24). ATP/37/307 (Pl. CXXVe), fine clay, warm buff to dark grey, black slip flared to red-brown in patches; two incised grooves down handle, raised bands round neck and body; Level IV, in room 2 of the Niqme-pa palace. ATP/39/274, bright red clay, burnished, Level IV, in grave $\mathrm{G} / 39 / 93$. ATP/39/65, red clay with remains of black slip most of which has flaked away; double reeded handle; Level IV, probably, in grave $\mathrm{G} / 39 / 35$, which might less probably be of Level V. ATP/46/204, red clay, no slip, lightly burnished; Level $\mathrm{V}$, in grave $\mathrm{G} / 46 / \mathrm{I}$. Another, fragmentary, with black slip finely burnished; Level $\mathrm{V}$, in grave ATG/39/107. ATP/46/206, black clay with relief bands on neck and body; Level $\mathrm{V}$, in grave $\mathrm{G} / 46 / 2$.

Jug Type $2 b$ (B.M.S. 24). ATP/38/13 (Pl. CXXVI), blackish-grey slip, decoration in white paint, bands and concentric semicircles; Level IV, in room I 6 of the Niqme-pa palace. ATP/37/393, fragments of three jugs similar to last, Level IV, in upper debris of Niqme-pa palace.

Jug Type 3 (B.M.S. 26) with diagonal stripes of white paint on the lower part of the body; fragment found on house site, I 937; Level III or IV (stratification doubtful).

Jug (B.M.S. 35), type not given by Sjöqvist, ATP/39/53, of red clay, burnished; Level IV, from grave ATG/39/38. 
Jug, type not given by Sjöqvist nor by British Museum Catalogue. It has ring base and tilted neck like B.M.S. 26, but there is a deep groove round the body dividing it into two halves. ATP/38/1 55 (Pl. CXXVI), thin grey ware flared to black, apparently the same as the normal Base-ring II ware. Level IV, from the Niqme-pa palace, room $\mathrm{C}_{5}$.

$\mathrm{ATP} / 38 / 228$, v. Pl. CXXV $c$, krater, type not given by Sjöqvist nor by British Museum Catalogue, of Base-ring ware, reddish-brown clay flared in places to a deeper colour, having on each side of the body the same branching spirals in relief as occur on Jug Type I $a$. From room C 2 of the Niqme-pa palace.

\section{Red Lustrous Wheel-made Ware}

Bottle Type I $a$ (B.M.C. I I 6 ). ATP/39/40 and $4 \mathrm{I}$, two examples in burnished red ware, hts. $0.146 \mathrm{~m}$. and $0.16 \mathrm{~m}$. Level IV, in grave $\mathrm{G} / 39 / 7$.

Bottle Type $\mathrm{I} b$ (B.M.S. 25). ATP/38/52 A, B, and $\mathrm{c} ; \mathrm{ATP} / 38 / \mathrm{I} 24$; four examples all of fine red burnished ware (one burned completely black, but probably by the accident of the burning of the palace; others show partial discoloration); Level IV, Niqme-pa palace. ATP/39/33, 34, and 293 A and B, four examples from grave G/39/7, Level IV. ATP/39/59 E and F, two examples from grave G/39/86, Level IV. ATP/39/73, from grave $\mathrm{G} / 39 / 47$, Level IV. ATP/38/184 (Pl. CXXVI), red burnished with potter's mark incised on the base before firing; from grave $\mathrm{G} / 38 / 33$, Level IV. From graves attributed to Level IV on internal evidence come the following: $\mathrm{ATP} / 39 / 30$, from $\mathrm{G} / 39 / 30 ; \mathrm{ATP} / 39 / 59 \mathrm{~A}, \mathrm{~B}$, and $\mathrm{c}$, three examples (with fragments of others) from $\mathrm{G} / 39 / 35 ; \mathrm{ATP} / 39 / 282$ from $\mathrm{G} / 39 /$ IOI; $\mathrm{ATP} / 38 /$ I 47 , with potter's mark po incised on the base before firing; ATP/38/16 I A and B, two examples from G/38/1 5 (ATP/ $38 / 163 \mathrm{~A}-\mathrm{E}$, two with potters' marks $>$ and $\frown$ incised on the base before firing, from $\mathrm{G} / 38 / \mathrm{I} 7$ and $\mathrm{I} 8$ ). Of doubtful date there were three examples: ATP/38/1 78 (Pl. CXXVI) isolated in a grave probably of Level IV; ATP/39/19, according to stratification more likely to belong to Level $V$ than to Level IV; and ATP/39/323, which is black burnished but may originally have been red (there was nothing to account for a change of colour), unstratified. Two examples, ATP/39/295 A and B, came from the Level V grave G/39/107. One example was doubtfully assigned to Level V or VI. In Level VII fragments of one of normal type were found on the floor of room i 6 of Yarim-Lim's palace, and in the same room was the neck of a lekythus apparently identical in shape but with a well-burnished yellow slip, this being unique. An equally unexpected exception to the general dating of the type was the discovery of a normal burnished red example, in fragments, on the floor of room I4 in the Level II house $39 / \mathrm{C}$, associated with regular Level II types of pottery.

The 'Arm-shaped vessel' or libation-pourer. ATP/37/22 5-6, two examples in burnished red clay were found in Level IV houses (Pl. CXXVa).

Bottle Type $2 b$ (also found in Base-ring I ware). ATP/39/I I6, red clay, Level II. $\mathrm{ATP} / 39 / 184$, red clay, Level II. Fragment, red clay, Level II temple. ATP/37/340, fine grey clay with black slip, burnished, Level IV, Niqme-pa palace, room 2. Fragments, red clay, two found in Level V. ATP/47/79, buff clay, water-smoothed, Level V-VI. 


\section{Bucchero Ware}

Jug Type I $a$ (cf. B.M.S. 29). ATP/38/1 2 (Pl. CXXVI), blackish-brown ware, vertical ribs in relief on body; Level IV, in room $\mathrm{C} 3$ of the Niqme-pa palace.

\section{White Slip I Ware}

Bowl Type I (B.M.S. 31). ATP/37/403, hard brown-red clay, white slip, design in black, ladder pattern, running diamonds and festoons of hatched diamonds; ATP/37/ 404, greyish clay turning to red near surface, white slip with design in black, ladder pattern, dots and chains of hatched diamonds; ATP/37/406, hard greyish clay turning to red near surface, white slip, design in black and brownish-red, ladder pattern, straight and wavy bands, chains of lozenges and line-and-dot arcading; ATP/37/407, exactly like ATP/37/404; ATP/38/94, brick-red clay with creamy-white slip, design in black, chevrons and a line of dots between plain bands; ATP/38/14I, design in unusually thin lines, black and red on white; ATP/8/172, coarse red clay, creamy-white slip much of which has come away, design roughly painted (ladder pattern, \&c.) in red and black paint; $\mathrm{ATP} / 38 / 2 \mathrm{I} 4$, design in black on white, ladder pattern and band of lozenges; ATP $/ 38 / 2$ I 5 , exactly like the last: all these come from the Niqme-pa palace. ATP/47/ I 45, slip deep grey-green, design in black, ladder pattern and chains of lozenges; Level IV, KP/C 8. See also below, pp. 362 sqq., for evidence from other levels.

Jug Type $3 a$. ATP/37/303, fragments; hard red clay, white slip, design in black; outside, double chains of hatched diamonds between plain vertical lines, inside, near rim, a wavy line below which four rows of dots and four vertical lines grouped; stratification uncertain.

Jug type not given by Sjöqvist (B.M.S. 35). ATP/39/80, white slip with ladder pattern in black (Pl. CXXVb); from grave $\mathrm{G} / 39 / 46$, which is attributed to Level V.

Bowl type not given by Sjöqvist and not in B.M. Catalogue; milk-bowl shape but with two ring handles and tubular spout. ATP/37/405, accidentally burnt and one side fused; body clay now grey; design in black on white slip, hatched bands, pendants of ladder pattern and double chains of hatched diamonds; Level IV, Niqme-pa palace. $\mathrm{ATP} / 38 / 9$, similar, Niqme-pa palace, room C $3 . \mathrm{ATP} / 38 / 138$, similar, Niqme-pa palace, room $\mathrm{C}_{5}$.

\section{White Slip II Ware}

Bowl Type 2 (B.M.S. 3I). ATP/37/402 (Pl. CXXVd), hard brown-red clay, white slip, with design in brown-black paint, ladder pattern with a row of dots above; from Niqme-pa palace. Also from the Niqme-pa palace, ATP/37/1 33, ATP/38/92, 93, I 34 , I 37, I 39 , I 40, I 44, I 45, I 83,2 I I.

Bowl Type $3 b$ (with ring handle) (B.M.C. 238 ). ATP/37/305, clay coarse and hard, buff to grey, walls thick, design, ladder pattern, in black on white slip; below the pavement of the Niqme-pa palace, so Level V; ATP/37/306, hard grey clay, design in black on white slip, ladder pattern and a row of dots and a band of hooked lines; Level IV, in room 9 of the Niqme-pa palace. 
Certain other vessels should be noted here by reason of their shape, though in fabric they do not seem to have necessarily anything to do with Cyprus.

Form of White Slip II ware, bowl type 2. ATP/37/4 I , coarse drab clay with a thin purplish-red slip mostly worn off, no painted design; Level IV, Niqme-pa palace, room 6. ATP/37/408, coarse salmon-pink clay turning greenish on the surface; Level IV, Niqme-pa palace, room 6 . ATP/37/4I 2, exactly like the last, found in the same place. ATP $/ 38 / 2$ I 9, red clay, plain; Niqme-pa palace, room i 7 . ATP $/ 38 / 223$, two examples, fragmentary, in plain reddish-brown clay, from the Niqme-pa palace, room I 5 .

The chronology of the two countries concerned is as follows:

\begin{tabular}{|c|c|c|c|}
\hline & \multirow[b]{2}{*}{ Atchana ${ }^{1}$} & \multicolumn{2}{|c|}{ Cyprus } \\
\hline & & Sjöqvist & Schaeffer \\
\hline $\begin{array}{l}\text { I750 (or later) } \\
1600\end{array}$ & $\begin{array}{l}\text { Level VI } \\
\text { ? Level V }\end{array}$ & Middle Cypriote III & $\begin{array}{l}\text { Ch. Moyen III } \\
\text { Ch. Réc. I }\end{array}$ \\
\hline $155^{\circ}$ & & Late Cypriote I A & \\
\hline 1450 & Level IV & Late Cypriote I в & Ch. Réc. II \\
\hline 1420 & $\begin{array}{l}\text { Destruction of Niqme-pa } \\
\text { palace }\end{array}$ & & \\
\hline 1400 & & Late Cypriote II A & \\
\hline I 370 & Level III & & \\
\hline $135^{\circ}$ & ? Level II & Late Cypriote II в & Ch. Réc. III \\
\hline $\begin{array}{l}1275 \\
\text { I } 230\end{array}$ & Level I & Late Cypriote II c & Ch. Fer I \\
\hline I I 94 & End of Atchana & Late Cypriote III & \\
\hline
\end{tabular}

On the basis of this chronology it will be seen that there is a welcome agreement on many points in the evidence yielded by the two sites in the matter of Cypriote pottery, and I wish to emphasize this before dealing with the discrepancies.

The red-on-black ware, Middle Cypriote III, occurs at Atchana only before i 600 .

The monochrome ware, which goes back into Middle Cypriote III but is characteristic of Late Cypriote I and persists into II в, has the same range at Atchana.

The Base-ring I ware originates in Late Cypriote I $\mathrm{A}^{2}$ and comes to an end in II A. All the Atchana examples come from Level IV (the majority) and Level V; this is quite consistent. The only exception is in the case of the bull-shaped vases found in Level VI, and even that is scarcely an exception if Schaeffer's earlier dating for the start of the Late Cyprus age (his Chypriote Récent) be accepted.

Of Bucchero ware the single example found by us, dated to 1420 , is rather earlier than Sjöqvist would allow (Late Cypriote II A).

The statement that the Levanto-Helladic ware ${ }^{3}$ does not appear in Late Cypriote I, is relatively rare in Late Cypriote II A, and only becomes common in Late Cypriote II в agrees absolutely with the evidence from Atchana, where its absence from the Niqme-pa palace is most marked.

The Red Lustrous wheel-made ware, which is not Cypriote but imported into the

I See Ch. XIII.

2 But Sjöqvist cites an earlier example (I6th century) from Gezer (Problems, p. 4I).

3 See Ch. XII (h) on the Mycenaean pottery, p. 369. 
island, first appears there in Late Cypriote I A and continues into I B. This is the time when it was most in vogue at Atchana, though specimens had been imported there (for it is not a native product) a good deal earlier.

Base-ring II ware, according to Sjöqvist, only begins in Late Cypriote I в. Considering its extraordinary popularity in the Niqme-pa palace, this is rather surprising, but the favourite form there, the jug of Type $\mathrm{r}$, is specially characterized by Sjöqvist as a transitional form closely related to the I class. I The ware is not found in Level III, which agrees with its disappearance early in Late Cypriote II A. On the other hand, Atchana gives us an example of the (later) Jug Type 2 as early as Level $V$, but this again could be reconciled with Schaeffer's dating of the period.

The difficulty really is with the White Slip ware. According to the evidence on which the Cypriote chronology is based, White Slip I starts a little after I $55^{\circ}$ B.C., i.e. early in Late Cyprus I A and continues throughout I B, but in II A it is practically extinct, only one jug form surviving at all. White Slip II ware is doubtfully present in I в but may be considered to start at the end of that phase, though Sjöqvist prefers to put it as beginning in II A, and continues up to the end of II c, i.e. to the close of the Bronze Age. Obviously this does not harmonize with the evidence of the Niqme-pa palace. According to that evidence-which is indisputable-the White Slip I and II wares were in I 420 B.c. equally common; we have proof of an overlap which does not seem to be paralleled in Cyprus. This much is clear from the catalogue of more or less complete examples detailed above; the examination of the further evidence afforded by fragments brings out further disagreement with Cypriote conditions.

No other building found at Atchana was at all comparable to the Niqme-pa palace as a storehouse of pottery. Of milk-bowls alone we recorded there more than fifty examples, and the figure would have been much higher but for the fact that only the better specimens were preserved and for the rest we contented ourselves with noting the existence of innumerable fragments without attempting to calculate the number of vases which they might represent. In the private houses of Level IV milk-bowl fragments were extremely common though, because the houses had not been burnt as was the palace, complete vases did not occur. Of the very numerous graves belonging or attributed to Level IV only two produced milk-bowls, from which fact we must deduce that the type was not, as it is in Cyprus, popular as tomb furniture. Certainly it can be said that for household use the milk-bowl, whether of White Slip I or of White Slip II ware, was the standard bowl at Atchana in the fifteenth century B.c. The evidence for other periods must now be considered.

A field note on the house sites dug in our first season (1937) states that fragments of White Slip II milk-bowls 'are found commonly from Level III upwards', i.e. in the mixed upper soil; but this is a statement too vague for chronological purposes and was indeed not meant to be evidential-against the fact of the presence of loose fragments has to be set that of foundations of later buildings being dug down into strata particularly rich in such fragments, and the resultant confusion of evidence.

I Op. cit., p. I04. 
Level $I$. Actually not a single fragment of the White Slip ware was associated with this level; by circa I 275 B.c. the ware was no longer in use at Atchana.

Level II. In I 937 about half of a milk-bowl was found just above (not on) the floor of a Level II house; in I 947 two similarly large fragments of White Slip II ware (ATP/ 47/ I I , I I 8) with the ladder-pattern design in deep brown were recorded as coming definitely in Level II though not directly associated with buildings; neither case is decisive. In 1939 a clearly late piece of Syrian manufacture with coarse clay covered with a brownish-white slip and ladder design in matt paint was found on the house $39 / \mathrm{C}$ site between the two cement floors of Levels I and II respectively; this last case might seem decisive for the use of the milk-bowl in Level II; but the interval between Levels I and II was not great and the digging of foundations and the levelling of the ground for Level III might well have disturbed the soil below Level II, and as that soil is fairly rich in fragments of White Slip ware even the 'sealed' stratification between the two floors ought not to be over-emphasized; it is good evidence but not tantamount to proof. The most that can be said is that the facts are not inconsistent with a limited use of the ware in (probably the early part of) Level II, but are against its having been in anything like general use in that period.

No Base-ring ware and no other type of Cypriote pottery was found in Level II.

Level III. On the house sites fragments of milk-bowls were common immediately below. the Level II floors ${ }^{1}$ and there was plenty to show that they were strictly contemporary with the buildings; thus, on the cement floor of one Level III room there lay together three (broken) White Slip II ware bowls and a base-ring jug; on another a bowl and a second wish-bone handle, and so on. The field notes remark that a good many of these milk-bowls were coarsely made, with thick walls, a mealy surface with white of poor colour (tinted with green or brown), and matt paint; immediately below a Level III floor there is recorded an unusually fine piece of White Slip I ware. A Base-ring II ware jug of Type 3 with diagonal stripes of white paint above the base found on the 1937 house site could have belonged to either Level IV or III (it was in Level III but was only a fragment).

Level IV. Up to about the middle of this period, circa I 420 B.C., the milk-bowl is the normal bowl in domestic use, bowls of other fabrics occurring only occasionally; of the two wares in simultaneous use, White Slip I and II, the latter is rather the more common; the two forms of handle are in use side by side, but the wish-bone is much more common than the round loop handle. Forms of White Slip ware other than the bowl are not found -the Jug Type $3 a$ is uncertain ${ }^{2}$ - the Base-ring ware being preferred for jugs, \&c., but we find in the Niqme-pa palace three complete examples and fragments of a fourth of a spouted bowl with two handles which, judging from the evidence available, is not of Cypriote manufacture.

Level $V$. No complete milk-bowls were found in Level V. This is not surprising be-

I In my provisional report (A.F. 1938, vol. xviii, No. I) I stated that in Level II there were fragments of Mycenaean milk-bowls associated with the local pottery. This was, of course, literally true, but the fragments were undoubtedly thrown up from Level III; all subsequent evidence showed this.

2 Three fragments were found together in a trial trench in what was assumed to be Level IV (the stratification was not good); but even if the assumption be correct, the sherds might well be intrusive from a lower level. 
cause the buildings of that level had either been taken over and re-used in the following period (in which case their contents belonged to Level IV) or, since the vertical interval between the levels was small, had been very thoroughly destroyed to make room for the new constructions. No Level $\mathrm{V}$ graves contained milk-bowls, but as such were not normal grave furniture their absence means nothing. On the other hand, grave $\mathrm{G} / 39 / 46$, attributed to Level V, did produce a White Slip I ware jug, and on the house sites broken sherds of milk-bowls were very numerous and in some cases at least definite proof was forthcoming that they were in their true horizon. Thus, in house $39 / \mathrm{B}$, below the floor of the Level IV building, in Level V rubbish, there were fragments of White Slip I ware with unusually fine hard slip decorated with straight and wavy lines and dots in red paint; similar fragments were found on the floor and even below the floor-level of the Level V building; but it was noted that side by side with White Slip I ware pieces there were fragments with the plain ladder pattern in matt and running black paint on a soft mealy slip which should be White Slip II ware. In house 39/C fragments of White Slip I ware bowls (with 'dark brown wavy lines and black, brown, and light red' designs) occurred freely in Level $\mathrm{V}$; amongst the fragments was a wish-bone handle decorated with a combination of black and brown lines. Below the open courtyard of the Niqme-pa palace a sondage made in 1948 brought to light at the depth of a metre below the Level IV pavement walls of Level $V$ and associated with them fragments of White Slip I bowls with decoration in red and black, one piece having a design rather like that on the British Museum bowl C 216; elsewhere it is remarked in the field notes that 'at this level " $(V)$ " the bowls tended to have the extra ornament in red on white' and 'compare the British Museum examples C 2 I I and C 224'. Considering the generally ruined condition of the Level $\mathrm{V}$ buildings the positive evidence given here is as much as one can fairly expect; it is certainly sufficient to prove the use of the White Slip ware during the period. Moreover, it is not unduly straining the evidence to say that the ware was in reasonably common use; the mere number of fragments in the level showed that. In disturbed soil the tendency of sherds is to be thrown up above their true horizon rather than to be dug down below it; an isolated fragment may work down here and there, but that is not true of large numbers over a considerable area. The White Slip ware was not so abundant in Level $\mathrm{V}$ as it was in Level IV, but it was used freely.

Level $V I$. The ware still occurs in this level, but is not so common. One bowl about twothirds complete (fragments of it may have been overlooked) was found low in the stratum, actually lying on the top of a wall of Yarim-Lim's palace (Level VII); it was of the normal ladder-pattern type. Several fragments were associated in Level VI with the head of a bull-shaped Base-ring I vase ATP/39/220.

In the rubbish used to reinforce the city rampart there occur fragments of milk-bowls together with examples of the pottery Type I $06 b$, which is common to Levels V, VI, and VII. 'The reinforcement dates from Level IV and the rubbish which was utilized for the purpose must have been rubbish from Levels VI and V.

I In my preliminary report, $A . \mathcal{F}$. xviii, No. I (1938), p. I 9 , I stated that these vases appeared in inhumation graves of the fourth level; my dating of these graves was subsequently proved to be wrong, they being of Level V. In the 
The excavation of 'Site $\mathrm{H}$ ' in $\mathrm{r} 938$ led to the discovery of a fragment of a milk-bowl under the stone footings of the city wall of the earliest period represented on that site. There were four building-strata, and the uppermost was associated with graves which, on the strength of the pottery which they contained, largely Cypriote Ring-base I and Lustrous Red Wheel-made, I referred to Level IV. Since the milk-bowl sherd was 'by three building periods older' than the grave in question it must, I wrote, come quite early in the second millennium ${ }^{\mathrm{I}}$ and, assuming on the ground of simple arithmetic that the third building-stratum back from Level IV would be Level VII, suggested that the sherd belonged to the eighteenth century B.c.

It was this conclusion that both Sjöqvist and Schaeffer found themselves unable to accept (v. supra, p. 354), and I hasten to say that their hesitation, or refusal, was not without reason; Site $\mathrm{H}$ was excavated in the early days of the Atchana mission and the excavator's views in such a case are always liable to be modified by later experience. The facts as stated in my provisional report are, of course, correct; it is my reading of them that must be accommodated to subsequent knowledge, gained partly by further excavations on Site $\mathrm{H}$ and partly by work in other areas.

The graves on the site are not uniformly, as I had supposed, of Level IV; the majority are of Level IV but some are earlier, even as early as Level VII; but this does not alter the fact that the highest surviving house walls are not later in date than Level IV. But the crucial matter is the mud brickwork under which the milk-bowl fragment was found. In my original report I described this as occupying the position in which we should expect to find the bounding wall of the upper city, but 'it would seem to be not so much a wall as a platform from which the wall rose'; it was fifteen metres wide and 'its top may have sloped upwards towards the town'. We have now learnt (v. p. I 53) that the fortifications of Level VI included a mud-brick rampart of precisely this width and character, with a gently sloping top at the back of which rose the fortress walls proper; and further, that these fortifications, built in the early phase of Level VI, were modified in the course of the period and were reconstructed and again remodelled in the course of the period of Level V. While we have no absolute proof that the lowest building on Site $\mathrm{H}$ is to be correlated with the Level VI rampart in the fortress area, we are certainly relieved of the logical necessity of attributing it to Level VII; the 'three building periods' here may correspond to the remodellings of the rampart, and in that case the milk-bowl falls in line with the other fragments cited above as belonging to Level VI; we can assign it not to the eighteenth but to the seventeenth century B.C.

Level VII (I $780-1750$ в.c.). No White Slip ware was found in Level VII. ${ }^{2}$ On the floor of room 22 in Yarim-Lim's palace there were two wish-bone handles, one of red and

same report, however, I rightly said that 'the Hittites of the fourth level were not responsible for the raising of the rampart; they would seem to have inherited the earthwork defences of the town from an earlier generation'.

I Loc. cit., P. 3 I.

2 It was disconcerting at first to find a number of White Slip ware sherds practically at floor-level just outside the entrance-door of Yarim-Lim's palace; but a careful check proved that their presence there was due to the cutting back of the ruin-mound for the foundations of the outer wall of the new wing added by Ilim-ilimma to the palace of Niqme-pa; they have therefore nothing to do with Level VII but belong to the latter part of the fifteenth century. 
one of grey clay; to which particular shape of bowl they had belonged it was impossible to say. The ware did not seem to be Cypriote.

Level VIII (nineteenth century B.c.). In the upper stratum of potsherds thrown out from the Level VIII temple, ${ }^{\text {I }}$ i.e. in a homogeneous deposit well stratified and effectually sealed against intrusion by the undisturbed floor of the Level VII temple, there was found a fragment of White Slip ware, part of a bowl with a handle 'like a Cypriote milkbowl', i.e. a wish-bone handle, 'on the upper surface of which were diagonal streaks in dark brown paint and round its base a ring of bright yellow paint'.

The evidence afforded by Atchana for the dating of the White Slip ware-and, to a less extent, of the monochrome ware-does not agree with that obtained for Cyprus from the results of very many scientifically controlled excavations in the island, supported, so far as the positive dating is concerned, by relations with Egypt and by the material from Ras Shamra. The gap between the two systems is too wide to be bridged by a 'revision' of the accepted chronology. Nothing that is found at Atchana can alter the facts of Cypriote discovery or invalidate its evidence; on the other hand, the facts at Atchana cannot be upset by anything found in Cyprus nor disregarded in any general study of the wares in question; no theory about those wares can hold good unless it accepts and reconciles the evidence from both quarters.

In 1939 the abundance of White Slip milk-bowls in Level IV, the difficulty of packing and transporting in bulk vessels of this awkward shape and fragile nature, and the fact that in the Niqme-pa palace there were bowls identical with the Cypriote in shape but certainly not of Cypriote fabric, led me to suggest that these Cypriote Late Bronze Age types of pottery were made on the mainland before they were introduced to Cyprus. With the first part of this suggestion Dr. Schaeffer is in agreement-he had himself, as early as $1936,{ }^{2}$ found evidence of Cypriote potters plying their trade in a branch establishment at Minet-el-Beïda-and Sjöqvist comes independently to the same conclusion. ${ }^{3}$ But the second part of my suggestion, namely, that the types were mainland by origin and were only later introduced into Cyprus, is rejected by both scholars.

Schaeffer supports his rejection by pointing out that the fourteenth-century White Slip II milk-bowls from the Minet-el-Beïda atelier must be later than their Cypriote models, being distinguished from them by their markedly inferior quality; ${ }^{4}$ one accepts that fact, of course, but it has no bearing on the question of the origin of the early pottery; and can give no weight to the Atchana evidence as opposed to 'les indices concordants d'un grand nombre de sites fouillés en Chypre et en Syrie'. ${ }^{5}$ I quite admit that the Atchana evidence then put forward was isolated and difficult to accept; but I would urge that the many excavations to which Schaeffer appeals have amply proved that the pottery under discussion is the characteristic pottery of Cyprus during the Late Bronze Age and was freely exported from the island to Egypt, Palestine, and Syria, but have by no

\footnotetext{
I See p. 58 .

2 Syria, xvii (1936), p. 148. I had overlooked this when I wrote my own provisional report.

3 Problems, p. 8I. 'There must have existed one or more centres of manufacture on the Syrian and perhaps also
}

Palestinian coast, and as a matter of course these factorics have produced not only the small juglets and scent-bottles but also other types of Base-ring II ware.'

4 Stratigraphie comparée, p. IoI.

5 Quoted above, p. 354 . 
means proved that it is native to the island. If anything, the reverse is nearer to the truth, as I think Sjöqvist shows in his chapter 'On the Origin of the Different Classes of Pottery' from which I shall quote.

Monochrome $W$ are. 'The large deep bowl has no forerunners in the Cypriote stock of shapes.... The bowl of Type I and the jug of Type I are, on the other hand, closely linked up to the earlier shapes. The shallow shape and the soft outline of the bowl bring it in typological connexion with the classical bowl of Middle Cypriote times, first and foremost represented amongst White Painted III and IV ware', and he emphasizes the wish-bone handle which 'in the Middle Bronze Age is represented neither in Syria nor Palestine, but occurs in Cyprus. ... This seems to me a decisive typological item, tying the Monochrome ware down to Cyprus.' But the Middle Cypriote bowls have not got the umbilical base which is the peculiar feature of the Monochrome bowl, and the wish-bone handle occurs at Atchana in the eighteenth century.

The White Shaved Ware. 'The typology indicates no Cypriote affinities. The priority of the type on Syro-Palestinian ground is beyond doubt.'

Base-ring Ware. 'It is difficult to link up the shapes in the ranks of Middle Cypriote pottery tradition.' Sjöqvist maintains that 'still its Cypriote origin cannot be denied', arguing that the break in tradition is due to the potter's copying metal forms-'the highly appreciated new metal found its own new forms and the potter ... became an imitator instead of being an artistic creator', and he suggests that the gradual supplanting of Middle Cypriote wares by the Base-ring is in favour of its Cypriote origin. But Albright denies the Cypriote origin altogether; Sjöqvist himself decides that the Jug Type 3 of the Ring-base II ware was made not in Cyprus but on the Syrian coast-though by Cypriote settlers. As regards his argument about imitation of metal, undoubtedly some of the forms are derived from metal originals; but we are speaking of a Late Bronze Age ware; metal had been worked in Cyprus for centuries, so why did the Cypriote potter wait so long before copying it so whole-heartedly? In I 600 B.c. bronze was not a 'new metal' in the island, and its 'new forms' were already an old tradition. But Sjöqvist is probably right in seeing in the Base-ring shapes the reaction of potters to their first introduction to metal vessels.

The White Slip Ware. 'The White Slip I ware is not a very numerous group. It was a pioneer ware of high quality and enjoyed a fairly short life. In Cyprus its appearance is scarce but regular in all places of excavation covering the beginning of the Late Bronze Age. ... Such an even distribution over the island in early connexions is a sound argument in favour of Cypriote origin of the ware.' 'The White Slip II ware is organically developed from the I ware.' The only argument advanced here does not seem to me very sound; the general popularity and therefore the even distribution of a new and striking ware does not prove its indigenous origin; the fabric has no precedent in Cyprus and the milk-bowl is the only shape paralleled in Middle Cypriote pottery.

The Red Lustrous Wheel-made Ware. 'Occasionally called Cypriote, but this seems to me very unlikely.'

Bucchero Ware. 'The question of its origin is associated with that of the Base-ring 
ware. . . . To my knowledge, only three finds are recorded outside Cyprus. This fact gives a good picture of the genuine Cypriote character of the ware.'

'Cypriote pottery' of the Late Bronze Age is an archaeological commonplace, and to suggest for it a foreign origin is naturally a hard saying. This seems to me to be largely due to the accident of discovery. The ancient tombs of Cyprus had been plundered wholesale and its antiquities had been made familiar long before any excavations had been attempted on the neighbouring mainland. It was inevitable that pottery of a strongly individual type, unknown from any other source but found in Cyprus in overwhelming quantities, should receive the name of Cypriote; it was a very easy step to assume that it was the invention of the Cypriotes and, if similar pottery were subsequently to be discovered on mainland sites, to regard it as an import or a copy. ${ }^{\mathrm{I}}$ Had the order of discovery been reversed the ware would have been given a different name; when it came to be found in Cyprus its preponderance there might well have been attributed either to foreign invasion or to the enthusiastic adoption by the local potters of a foreign style of which imported examples had commanded a ready market. It is worth while here to remark that the red polished ware of the earlier Bronze Age was just as popular in Cyprus as the Base-ring and White Slip wares of a later date, but none the less is recognized to have been by origin a foreign product: its 'even distribution over the island' is not urged as an argument in favour of an indigenous character.

As a result of the very many excavations in Cyprus we find that some of the Late Bronze Age wares are admittedly imports or derived from abroad; others are claimed for Cyprus, but in no case has it been possible to prove this by tracing their development, in shape and in technique, from the earlier pottery of the island. It would be surprising if nothing whatsoever survived of the old traditions; however enthusiastically he adopted the new style, the potter was bound to be influenced by what he had always done in the past or by what he thought would commend itself to his more conservative clients; ${ }^{2}$ but such reminiscences do not alter the fact the Cypriote Late Bronze Age wares have no parentage in the island.

It is equally clear that they did not originate in the neighbourhood of Atchana. Neither the forms nor the technique betray any relation to the local wares; the wishbone handle appears indeed relatively early but is never used for anything but the milkbowl; what is most conclusive is that the potter of the Amq plain had been using the wheel since the beginning of the third millennium and could not therefore have been responsible for the invention of hand-made types of pottery about a thousand years later. The 'Cypriote Late Bronze Age' wares have no antecedents at Atchana ${ }^{3}$ and are definitely foreign imports.

I As has been remarked above, pp. 357-8, Atchana produces Base-ring ware in shapes which, hitherto at least, are quite unknown in Cyprus, so that neither importation from the island nor copying can be assumed.

2 It is interesting in this connexion to trace the vagaries of the 'Willow-pattern' in English pottery and porcelain since its introduction in $175^{\circ}$.

3 The only apparent exception really confirms the rule.

Room I 7 of the Yarim-Lim palace contained a stone-lined pit with a concrete floor $2.30 \mathrm{~m}$. below the floor-level of the adjoining rooms (v. p. 95). We dug through the concrete and at $1.40 \mathrm{~m}$. below it found a wall and floor which, judging from the stratification in our big excavation a little way to the SE., should belong to Level XII A and can scarcely be later than Level XI. Between this floor and the point $\mathrm{I} \cdot 60 \mathrm{~m}$. lower down at which our work stopped we found fragments 
As has been shown in detail above, the new facts are that the wish-bone handle of regular 'Cypriote' form, but not in the normal Cypriote Monochrome ware, first appears at Atchana in the eighteenth century B.c.; Base-ring.ware begins with a single example in Level VI, occurs sporadically in Level V, and is extremely common in Level IV; White Slip I ware, instead of being scantily represented and short-lived as in Cyprus, comes into use in Level VI (seventeenth century B.c.), is quite common throughout Level V, and in Level IV (fifteenth century) is still in great vogue, the bowls of that class being only less numerous than those of White Slip II; there are at Atchana a few vases which are definitely within the category of 'Cypriote' pottery, either by form or by technique, but have no parallels on the island; at Atchana all the Cypriote types go out of use at least seventy-five years and perhaps as much as I 50 years before the manufacture of them in Cyprus came to an end, and that in spite of the fact that Mycenaean pottery-Sjöqvist's Levanto-Helladic-which is generally supposed to have been made in Cyprus, was being imported in ever-increasing quantities. I can think of only one explanation that will reconcile those facts with the equally valid facts from Cyprus.

These hand-made monochrome slip or painted slip wares must have been evolved in some relatively backward country on the Asiatic mainland-relatively backward because the wheel was not used, on the mainland because it had easier access to mainland than to overseas centres. Its earlier exports came to Atchana in the extreme north of Syria and did not necessarily make their way any farther south; at Atchana they were appreciated, in spite of the fact that the local potters were technically more advanced, and the demand for them increased steadily. Later on the unknown makers extended their export trade to Cyprus, but there the local potters, finding that their traditional wares could not compete for popularity with these foreign goods, apparently set themselves to imitate them with the same thoroughness as their forefathers had shown in the case of the red polished pottery introduced from Anatolia, and in a very short time their factories seem to have made the island independent of imports. ${ }^{\text {I }}$ Since Cyprus had a merchant fleet and was in touch with Egypt, Palestine, and south Syria it was Cyprus, not the original centre of production, that introduced the mass-produced Base-ring jugs and White Slip milk-bowls to the southern markets-the dating of the examples excavated there is sufficient evidence of their Cypriote origin; but in time factories were established, as Schaeffer has shown, on the Syrian coast, and although Cyprus was still exporting it is, I think, likely that the bulk of the White Slip II bowls found at Atchana in Level III at least were of Syrian make. In the fourteenth century the political bias of Alalakh shifted

of painted pottery of the types normal in our early levels, but amongst them one in blueish-white slip with geometric designs (hatching \&c.) in black, looking rather like Cyprus White Slip ware'. I quote from the field notes, which are carefully non-committal; what was quite certain was that this fragment was totally different from the rest of the sherds and was recognizably an import, not a local fabric. It is possible that both in this case and in that of the sherd found in Level VIII we have to deal with early isolated imports from the source which later was to supply the normal White Slip wares.
I It would be tempting to suggest, though it is by no means essential to my argument, that the 'short-lived' White Slip I ware, which actually was made long before and for some time after it was used in Cyprus, is really the imported pottery (it has been found on as many mainland sites as sites in Cyprus) and that the White Slip II ware is the locally made imitation which killed the foreign product. Sir John Myres, on the other hand, thinks it unlikely that any of the White Slip Ware was ever made in Cyprus at all and attributes it all to import. 
to the north-east (v.p.397) and as a result the clumsy black-on-white painted milk-bowl is ousted by the vastly more attractive white-on-black painted Nuzu goblet, and of the Cypriote merchandise only the Mycenaean pottery could hold its own; at Ugarit and farther south, where the Nuzu ware could not penetrate, the milk-bowl continued in use until I 200 B.C.

Against this theory there is no valid argument in the fact that discoveries at Ras Shamra support the evidence of Cyprus and not the divergent witness of Atchana. Ugarit was, as Schaeffer has demonstrated, a Phoenician city in the Egyptian orbit enjoying close relations with Cyprus. Alalakh-was a north Syrian-perhaps one should say a Hurrian-city whose allegiance fluctuated between the Amorite lands to the east and the Hittite power in the north. Naturally the two places had different contacts, and even where the contacts were the same they were not necessarily synchronous. The weakness of the theory lies in my inability to point to the original centre from which first Alalakh and later Cyprus imported 'Cypriote' pottery. It was not in Syria; that it was not in Cilicia has been shown by Miss. Goldman's excavations at Tarsus and Professor Garstang's at Mersin; it was certainly not in central Anatolia, where numerous excavations have produced nothing of the sort; the possibilities therefore are limited, and I can only trust that research in the hitherto unexplored areas will prove my point. ${ }^{\mathrm{I}}$

\section{(h) MINOAN AND MYCENAEAN POTTERY (Pls. CXXVI-CXXIX)}

The amount of Mycenaean pottery found is considerable. Since this is a subject on which I can claim no special knowledge, and at the same time one of great importance for the chronology of the site, I have invoked the assistance of experts on Aegean wares and must here express my gratitude to them. Professor Wace, who examined the vases and fragments found in the seasons 1937 and 1938 , wrote: 'In my opinion all would come between I 400 and I 200 or rather soon after I 200 , i.e., the fall of Mycenae whenever that was. On the other hand the latest Mycenaean that just precedes and succeeds the fall of Mycenae is not present so far as I can see. Thus your Mycenaean pottery is admirably paralleled by Ras Shamra, which covers the same period, and by Level $V$ at Tell Abu Hawam which runs from the Amarna period to Merneptah. Thus if you put your date' (for the end of Level I) 'at I 200 I, at present, would agree.' In I $949 \mathrm{Mr}$. F. H. Stubbings supplied me with notes on the whole collection, and in answer to my particular inquiry as to the latest date possible confirmed Professor Wace's verdict: 'I would not be prepared', he wrote, 'to date any of these Mycenaean pots later than I 200 B.c. To put it in another way, they all belong to the L.H. III A or L.H. III в style, and there is not the least suggestion of L.H. III c. . . I think-what I believe is also your view-that the majority if not all of the Atchana Mycenaean came from Cyprus.' Mr. Stubbings's detailed comments are, with his kind permission, incorporated in what

\footnotetext{
I Sir John Myres points out that the production of White Slip Ware is conditioned by two natural resources, the white meerschaum (and its kaolin) which is found in north Anatolia but not in Cyprus, and the 'Sinopic earth', as the disintegrated

haematite was called by the ancients, which came from Cappadocia; these were the ingredients which made possible the geometrically painted Phrygian pottery, the Pazarli clay revetments, and the pottery of Gordion. 
follows; but they are placed between inverted commas so as to be distinguishable from my own statements.

In Level $\mathrm{V}$ on the temple site there was found a fragment of pottery $(\mathrm{ATP} / 48 / \mathrm{I} 6)$ of rather sandy drab clay on which is a spiral roughly drawn in red paint with a fairly coarse brush (Pl. CXXIX); it is unlike any local ware and has all the appearance of a M.M. III import. Since objects of very different dates would be preserved together in a temple treasury, ${ }^{\mathrm{I}}$ anything found on a temple site cannot be regarded as necessarily contemporary in manufacture with the level in which it occurs, which affords no more than a terminus ante quem; the sherd therefore is of interest not for dating purposes but as giving evidence of relations between Alalakh and Crete as early as the M.M. III period.

In Level VI there was found a small fragment (ATP/47/5०, Pl. CXXIX) of a squat three-handled vase with nautilus and rock design exactly like the British Museum specimen A. 65 I (B.M. Cat. I. i, Pl. virI) found in Egypt which is of L.H. II period;2 another small fragment, similar and probably from the same vase, was found close by but at a much higher level (the ground here had been much disturbed). Mr. Stubbings writes: 'This sherd seems to me the only Mycenaean piece from Atchana that can be dated earlier than L.H. III.'

All the other Mycenaean vases or fragments found were therefore of the period L.H. III; a fair number of them belong to the L.H. III A phase and come early in it.

In the Niqme-pa palace, at floor-level in room I6, there was found a fragment (ATP/ $38 / 179$ ) of a piriform jar with vertical handles (Type B.M. $5 \mathrm{I}$ ) painted with an imbricated design which is 'amongst the earliest Mycenaean III A pieces'. Wace wrote on it: 'There are three vases similar to it from Ialyssos (two in the B.M., A. 825, 826, and one

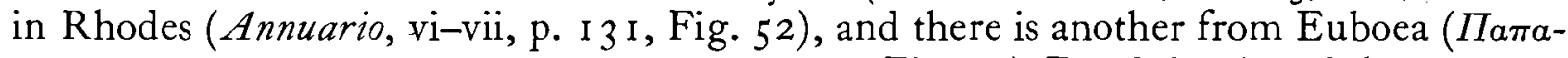

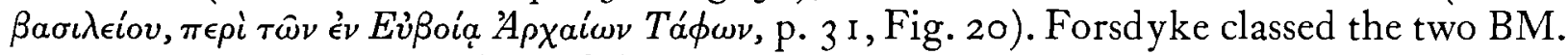
vases as Late Mycenaean (i.e. of the L.H. III period) and the evidence of the tomb in which the other Ialyssos vase was found and the Euboean vase too agrees with this classification, but suggests that they should be placed early in the period. In view of this it would be surprising if such a vase appeared in a deposit dated to I $45^{\circ}$ B.C.; on the other hand, the appearance of such a vase towards the close of the fifteenth century B.c. would hardly cause comment.' Since the sherd belongs to the last days of the palace, whose destruction should come somewhere about I 425 B.C., the facts of discovery agree perfectly with Wace's dating. Mr. Stubbings puts it rather later-'the fragment would be early-first half of the fourteenth century', which is more difficult to reconcile with the field evidence.

In our trial trench $\mathrm{D}$ there was found against a wall which was certainly as early as Level IV and might have been of Level $\mathrm{V}^{3}$ a sherd, ATP/37/288, with a very freely drawn large-scale pattern of foliage or flowers in the early L.H. III A style. A fragment

\footnotetext{
I For an illustration of this see p. 82 .

2 According to Wace and Blegen, 'Pottery as Evidence for Trade and Colonisation in the Aegean Bronze Age', Klio, xxxii, p. 137, n. 7 .

3 This was an isolated trench dug to test the area which
}

was to be used for a dump. The ground had been denuded down to Level IV and, while it was difficult to identify the strata exactly, objects in the upper soil could not be dated at all. 
with octopus design having spots of white paint on the tentacles (Pl. CXXVIII $h$ ), also early L.H. III A, was found on house site 39/B just under the foundations of the Level IV building; presumably it was thrown in when the foundations were being laid. Another bearing a very boldly drawn snake pattern with white dots (Pl. CXXVIII $j$ ) came from below the Level III foundations of the NE. wall of house $37 / \mathrm{D}$, i.e. in the debris of Level IV. Of the L.H. III Cypro-Mycenaean kraters the greater part of a fine chariot vase (ATP/46/307, Pl. CXXVIII $a$ ) was found on the temple site in Level II and similar fragments on the same site in Level III; these latter had possibly filtered down; fragments of one with octopus design ('early L.H. III'), ATP/37/286 (Pl. CXXVIII $i$ ), were scattered in Level II, one with a row of birds (ATP $/ 37 / 284$, Pl. CXXVIIIf; cf. B.M. C. 372; 'rather later, perhaps circ. I 300') and one (ATP/37/285, Pl. CXXIX) with an elaborate design difficult to identify, were found at about the same depth but not properly stratified.

Type B.M. 50. A single fragment (ATP/38/209, Pl. CXXIX) of this form was found, high up in the Niqme-pa palace area, Level III-II; scale pattern on shoulder; there is an incised mark on the handle; $\underline{\text { ' }}$ decorated in a peculiarly Cypriote manner; B.M. Cat. C. 430 is a close parallel'.

Type B.M. 5 I. Fragments of about seven are recorded as coming 'in the upper soil', i.e. late but not stratified; of the complete or nearly complete examples one is definitely attributed to Level I c; ${ }^{\mathrm{I}}$ one is from a cremation-burial (ATG/39/68) probably of I c; one is definitely of Level II; three (ATP/38/9-I I, Pl. CXXVII) were found together on a house floor of Level II; 'I would date circ. I 300 , which seems to agree with the date for this level'.

Type B.M. 53 was represented by three examples; one, ATP/39/200, plain, came from the Level I cremation-burial ATG/39/68; another, ATP/38/1 2, Pl. CXXVIIIb, with a cream ground and black bands round the body and a band of U-pattern round the shoulder, was also of Level I; the third, ATP/37/87, Pl. CXXVIII $c$, was from the upper soil, level uncertain.

Type B.M. 53, but without handles; it has plain bands of paint round the body. Of the three examples found ATP/37/90 is from the Level I cremation-burial ATG/37/3; A'TP/39/269 was attributed to Levels III-IV; ATP/39/4 was 'above Level IV'. Mr. Stubbings remarks that this is not a regular Mycenaean type and asks whether they could be local imitations; actually in the field notes two of them are so described and the third is probably also local.

Types B.M. 55, 57, and 59: general note. A very great number of fragments of these three shapes lay in the top-soil; the field note written in I937, 'commonly found in upper levels' (I-III) 'all over the site', was more or less repeated in every season in which work began at the ground surface. This record, however, dealing with 'all levels down to III' has to be interpreted, and corrected, in the light of local conditions. Level I c has almost entirely disappeared as the result of surface denudation; only in two spots were there

\footnotetext{
I In the field notes called 'Level $O$ ' as I had not at that time learnt to distinguish between Level $\mathrm{O}$ as given by the
}

latest reconstruction of the Temple and the top level in the residential area. The latter is properly called Level I c. 
found scanty remains of wall-foundations which could be assigned to it. Of Level I B also only occasional traces were found. Level I a has suffered greatly and in many places has ceased to exist. It is certain that in all three phases Mycenaean pottery was freely used. With the denudation the soil-decomposed mud brick, \&c.- has been washed or blown away, but the potsherds have, of course, been left. The confusion of stratification (so far as fragments are concerned) which normally results from the disturbance of the soil by the digging of new foundations, the excavation of rubbish-pits, \&c., in antiquity is therefore in this case complicated by the formation on the surface of the mound ${ }^{\mathrm{I}}$ of a stratum of heterogeneous potsherds, which potsherds were subsequently, by the process of agriculture, buried in the earth of the older level immediately below that surface. The Arab plough, it is true, does not go very deep (about $0.1 \mathrm{I} \mathrm{m}$.), but enough to allow of a disconcerting penetration of potsherds into an alien horizon; and the digging of liquorice roots means disturbance to a considerable depth. From the distribution of fragments therefore (except in a few special cases) we could conclude no more than that the pottery was in use perhaps in Level III, certainly in Levels II and I; for results more accurate than this we must look to the complete or nearly complete vases found in situ.

Type B.M. 55 is the taller form of stirrup-jar with pear-shaped body decorated with bands and fillets and a stylized flower motive on the shoulder. 'The two types of stirrupjar are characteristic of L.H. III A-B, the piriform stirrup-jar being less common in the B phase.' Of this a complete example (ATP/37/ I I, Pl. CXXVII $b$ ) was found in the house sites, Level I; 'it appears to me, from the decoration, little if at all later than I 300 , but perhaps in view of the level we could call it $1280^{\circ}$. A considerable fragment, not infiltered, was found in Level I above the Niqme-pa palace.

Of Type B.M. 57, the globular form of stirrup-jar, one example (ATP/39/1 86) came from a Level I cremation-burial (ATG/39/68); one (ATP/37/1 3, Pl. CXXVII $a$ ) from a Level I grave, ATG/37/2I; one $(\mathrm{ATP} / 38 / 226)$ from Level I above the Niqme-pa palace; one $(\mathrm{ATP} / 37 / 226)$ was found on the floor of a room in a Level II house; two were uncertain, one being apparently Level I, the other 'Level I or II'. The evidence, so far as it goes, would seem to show that the type, 'which persists almost throughout L.H. III and is often hard to date as between the A and B phases', was not imported during the period of Level III, was introduced in Level II, but only became common in Level I.

Type B.M. 59, the two-handled flask with the decoration of concentric circles on its flattened sides, is with us uniformly late. 'It is a very common shape at Amarna, so it may be only chance that makes it appear late at Atchana, though it does go down as late as, say, I 200.' Two examples (ATP/37/1 o, Pl. CXXVIII e and 39/186) were found in late cremation-burials (ATG/37/3, ATG/39/68); three, ATP/38/5-7, Pl. CXXVII, were in one inhumation grave of Level I c; three, $\mathrm{ATP} / 38 / \mathrm{I}-3$, were together in a Level I c

\footnotetext{
I I describe here the conditions on the top of the mound, from which virtually all the Mycenaean pottery came. On the SW. slope denudation had been far more severe, the highest surviving remains being of Level IV or even of Level
}

$\mathrm{V}$; but the confusion was less because most of the sherds, \&c., from the higher levels had been washed down to the foot of the hill. 
pit sunk into a Level I A room; one, ATP $/ 38 / 8$, found inside a large pot in a room of a Level I A house, may belong to that level or may have been buried here in the Level I $\mathrm{C}$ period; ATP $/ 37 / 9$, I I, I 2, Pl. CXXVIII $d, 225$ were all found in the 'top level', i.e. could belong to any phase of Level I. No example was found that could be attributed to Level II.

Type B.M. 63. A single example, ATP/38/1 5, Pl. CXXVIIIl, was found, with horizontal bands and a wavy snake-like line round the shoulder; it was in the upper soil, Level I-II. It had been accidentally burnt to a greenish-drab colour making it difficult to be sure of the original character of the ware; it may have been a local imitation of Mycenaean.

Type B.M. 64. One example, $\mathrm{ATP} / 38 / 15$, with two plain and one wavy bands of red paint, found above the Niqme-pa palace, Level II.

Type B.M. 7 I. A fragment of the type in salmon-pink clay having below the handles a purple band and between them a band of inverted V's was found 'in the upper soil'.

Type B.M. 73. Fragments of four were found; one, ATP/3 $8 / 2$ Io, with three or more plain bands above which running spirals roughly drawn, came from Level I-II; a fragment with plain broad and narrow bands inside and out, one with a band of flattened S-curves, and one with a plain band below which a row of V's alternately upright and inverted (ATP/37/29I) all came from the upper soil with no definite level.

In the 'upper soil', unstratified, was found a fragment, ATP/37/290, from the head of a painted terra-cotta figurine of a horse of the regular Mycenaean type.

Summing up the evidence we can say that virtually all the Mycenaean pottery from Atchana is L.H. III A or B, that all the dated L.H. III B examples came from Levels I and II, none of them from Level III, and that all therefore must be placed between the beginning of the Level II period and the destruction of Alalakh. If the dates assigned to some of the individual vases (e.g. ATP/37/I I I from a Level I house) appear to be rather late, the fact need not seriously disturb us; such anomalies are due simply to the accidents of the import trade. Mycenaean wares were widely current long before political conditions at Alalakh (at the beginning of Level II) allowed of their introduction to the city; the vases that were then brought in were valuable and likely to be carefully preserved, and some of the standard types may not have been shipped to Alalakh until the trade was well established-thus Type B.M. 59 which is very common at Tell el Amarna about $\mathrm{r} 35^{\circ}$ B.c. at Atchana occurs only in Level I, which must begin long after that date. The point that really matters here, and on which Atchana seems to throw new light, is the date for the ending of the Mycenaean series.

As is explained elsewhere (v. p. 398), our Level I is subdivided into three phases which end with the destruction of the city by the invasion of the Peoples of the Sea; our Level $\mathrm{O}$ comes after that destruction, being dated by a scarab of Ramses VI, so that it must be ruled out and we are left with Level I $\mathrm{c}$ as representing the last days of Alalakh. The Mycenaean pottery covers the whole of Level I and a number of specimens are definitely dated to Level I C, since the graves containing them cut through the walls and floors of Level I A and even of Level I B, i.e. were dug from a higher level; and here the 
argument of careful preservation can no longer be invoked, for the quantity of Mycenaean fragments in Level I shows that the ware was by now in common use, and, as the period of Level I $\mathrm{C}$ was decadent and the graves poor, it must have been cheap.

According to Furumark none of these vases should be later than I 230 B.C. when his Myc. III B gives place to Myc. III C. I, of which no examples occur at Atchana. That date is accepted, I believe, by Mr. Stubbings and is the latest allowed by Dr. Schaeffer. To adopt it for Atchana is extremely difficult.

The plundering and burning of the Level I c temple, as well as evidence of burning elsewhere, prove that the period ended in complete disaster ${ }^{\mathrm{I}}$ at the hands of an enemy, and that the destruction was wrought by the Peoples of the Sea cannot be doubted.

Alalakh, though it is not named in the records, must have shared the fate of so many other Syrian towns that fell before the invaders; they spared nothing, and here, as in the case of some other cities such as Ugarit, they made a complete end of things; in spite of the attempt made in Level $\mathrm{O}$, Alalakh ceased to exist. The invasion of the Peoples of the Sea started in the fifth year of Ramses III, i.e. about I I 94 B.C., with an attack on the west coast of the Delta in which the Sea Peoples served as mercenaries in the army of the king of Libya, and came to a head three years later when their land forces swept down through Syria, devastating the whole country, while their fleet raided Cyprus and the Syrian coastal towns. The land movement may have begun, in the north, as early as the Delta attack, though the records would associate it rather with the second phase only; but it certainly was not earlier than I I 94. I I 94 therefore is the earliest date that we can give for the fall of Alalakh, the earliest date for the close of the Level I c period to which the graves containing Mycenaean vases belong. From the point of view of field archaeology it is impossible not to attribute these burials to the last phase of the city's existence.

It is obviously difficult to reconcile the accepted date of I 230 for the end of the L.H. III B pottery with the facts at Atchana, and it is not only at Atchana that the difficulty arises. Ugarit has produced far more L.H. III B pottery than has Alalakh, the use of that pottery continues right down to the time of the city's destruction, ${ }^{2}$ and the destruction of Ugarit is confidently attributed to the invasion of the Peoples of the Sea. But Dr. Schaeffer is more firmly convinced than Furumark of an early date for the end of the Mycenaean pottery, putting it (at Enkomi) not merely 'towards I 200' but 'towards the middle of the thirteenth century'; Ugarit, he says, must have been destroyed between I $25^{\circ}$ and I 200 , the possibility of a slightly more ancient date not being excluded. ${ }^{3}$ In order to reconcile these inconsistent views he is obliged to change the date of the invasion and assume that it took place before the close of the thirteenth century. ${ }^{4}$ Personally I am convinced that no purely archaeological argument, no sequence-dating of pottery, justifies us in contradicting contemporary written records. The date of Ramses III is fixed, with a possible error of not more than five years, and his statement in the great Medinet Habu inscription is unambiguous. ${ }^{5}$ We cannot suppose that Ramses made a

\footnotetext{
I Between Level I $\mathrm{c}$ and Level $\mathrm{O}$ there was a considerable time-interval during which the site was uninhabited.

2 Though the Granary style does occur; $v$. Syria, xiv, p. 105 .
}

3 Stratigraphie comparée et Chronologie de l'Asie Occidentale, p. 39 .

4 Op. cit., p. 186.

5 Breasted, Ancient Records, iv. 
mistake of thirty years in dating the events of his own reign; nor are we entitled to assume, as apparently does Dr. Schaeffer (op. cit., p. 307), that he mixed up his own campaign with that of Merneptah-there is indeed nowhere any suggestion that in Merneptah's time ( $c$. I 229 B.c.) the attack on the west of the Delta was accompanied by any land movement in Syria. ${ }^{\mathrm{I}}$

At Tell Abu Hawam L.H. III B vases were found in stratum IVb, dated by the excavator between $c$. I 230 and I I 95,2 i.e. immediately before the invasion of the Peoples of the Sea; here again then we have the same difficulty as at Atchana.

In his monumental and astonishingly detailed work Furumark has evolved a typological sequence of Mycenaean pottery which is in itself impeccable and cannot but illustrate very accurately the historical development of the ware-even though one may suspect that the ancient potter sometimes forgot to observe the typological rules. But no typological and stylistic sequence can supply an absolute chronology; the fixed dates which are the essential skeleton for such have to be got from other sources. Accordingly Furumark, in his chapter on 'Absolute Chronology', adduces all possible evidence for dating the stages of his sequence; but he frankly admits ${ }^{3}$ that 'there is no definite evidence for the date of the transition from III B to early III C I'.4

In the absence of definite evidence Furumark arrives at his date of 1230 for the end of Myc. III B on the strength of three arguments:

(a) The 'Simple Style', a special class of derivative Mycenaean ware, fits on to the later phase of Myc. III B and has as its terminus a quo the later part of the reign of Ramses II, who died in 1232 B.c.

(b) Another category of derivative ware, the Philistine, corresponds, in its earliest stage, with the beginning of the later phase of the Myc. III C I style, and is well dated to $c$. I 200 B.c.'.

(c) The fact that no Myc. III B pottery has been found with dated objects later than the reign of Ramses II 'makes it permissible to place the threshold between the periods at $c$. I 230 B.c.'.

The argument $(a)$ I find difficult to follow. Furumark divides the 'Simple Style' ware into two phases of which the earlier falls 'within the time from I 280 to shortly before I 200', the second is 'contemporary with the Philistine ware'; chronologically therefore the earlier phase is contemporary with the later Myc. III B pottery and no evidence is

I Ramses (op. cit., iv. 64) traces the advance of the enemy: 'Not one stood before their hands, from Kheta (Boğazköy), Kode, Carchemish, Arvad, Alasa (Cyprus) they were wasted. They (the Northerners) set up a camp in one place in Amor. They desolated his people and his land like that which is not. They came with fire prepared before them, forward to Egypt.' It is clear that he is speaking of what happened in his own time, not thirty years before.

2 R. W. Hamilton, Quarterly of the Dept. of Antiquities in Palestine, iii, 1934, and iv, 1935 .

3 The Chronology of Mycenaean Pottery, p. I I 4.
4 'This real uncertainty may be illustrated by Dr. Schaeffer's shifting of the date of tombs 6, I 3 , and I 6 found by him at Enkomi. Originally he placed them between I I 50 and 1000 : 'après avoir repesé tous les arguments, nous voudrions proposer de remonter d'un siècle la date initiale de l'époque de ces tombes et de les placer ainsi entre 1250 et 1050 avant notre ère en chiffres ronds. Cette période correspond à la fin du Bronze Récent et au début de l'Âge de Fer en Chypre' (op. cit., p. 394). The change of view is clearly imposed by "notre schéma chronologique'. 
adduced to show that it ever supplanted it, ${ }^{\mathrm{I}}$ either in $\mathrm{I} 230$ or afterwards; and the second phase does not seem to bear upon the discussion.

The Palestinian pottery (with which the second phase of the 'Simple Style' is contemporary) is certainly derived from the Myc. III B wares of Cyprus and Rhodes and, as Furumark says, can confidently be attributed to the Philistines. As a Philistine product, it only came into existence in Syria after the arrival there of the Philistines, i.e. after I I 94-probably some little time after. The most that we can derive from it is that the earlier phase of the 'Simple Style' must date before I 194, which we knew already, and which is not conclusive. As regards argument $(c)$, the argument a silentio is always dangerous and in this case is particularly so; while we can be sure that Ramses II's long and glorious reign of sixty-seven years saw the hey-day of the Myc. III B pottery-in fact, covers the whole floruit that Furumark would allow to it-the number of instances in which that pottery has been found, together with dated objects bearing Ramses' name, is not such as to warrant a demand for similar evidence in the course of the thirty troubled years that followed, during most of which time Egypt had lost control of Syria. It would be pertinent to ask how many 'dated objects' of the reigns of Merneptah, Amenmeses, Siptah, and Seti II have been found on Syrian sites before we allow that the lack of such in association with Mycenaean pottery makes it permissible to assume that the latter had disappeared. My own point is that the occurrence of Myc. III B vases in the latest graves of a city which existed up to I 94 B.c. supplies just that 'dated evidence' which was lacking before.

Finally I would say that a modification of Furumark's chronology, bringing the end of Myc. III B down to the close of the twelfth century, is historically necessary. That 'standardized koine ware', although it 'bears witness to stagnation and gradual impoverishment of style', was none the less amazingly popular throughout the Middle East, so much so that it was imitated by local potters both before and after its disappearance. It did disappear, abruptly and completely so far as the great manufacturing centres of Cyprus and Rhodes were concerned, and we are bound to ask not only when? but why? We do not know of any historical event in or about 1230 B.c. that could so have affected Cyprus; ${ }^{2}$ even if the island sent a contingent of mercenaries to join King Meryey of Libya in I 229-and it is not said to have done so-the absence of the soldiers would not have interfered with the pottery trade; we cannot explain the collapse of the Mycenaean pottery industry at that date. But we $d o$ know that in I I 94 the Peoples of the Sea raided Cyprus. The evidence of Syrian sites seems to show that up to that time Mycenaean pottery was being imported into Syria; if we accept that evidence we make sense of history.

\footnotetext{
${ }^{1}$ As a locally made and therefore presumably a cheaper ware it may have found a ready market; but even if a provincial cemetery were to produce 'Simple Style' vases to the exclusion of real imported Mycenaean, this might be due to economic reasons and would not prove that the Mycenaean pottery was extinct.

${ }^{2}$ I am assuming here the correctness of the ordinary view
}

that most at any rate of the L.M. III B pots found in Syria are of Cypriote manufacture. I am aware that Sjöqvist (Problems of the Late Cypriote Bronze Age) rejects the term 'CyproMycenaean', but as he allows that his 'Levanto-Helladic' ware was produced in Cyprus as well as on the Syrian coast my argument applies equally to his theory. 


\section{CHAPTER XIII \\ CHRONOLOGY}

I F the record of Alalakh furnished by our excavations is to be brought into relation with the history of its more important neighbours-Egypt on the one side, Babylonia and Assyria on the other-which we are wont to express in terms of years and dates, then for Alalakh also something in the way of a fixed chronology is essential. For the time being, naturally, the word 'fixed' must be understood in a relative sense, for any conclusions arrived at must needs be checked by data obtained from other sites; the partial excavation of a single mound cannot give us finality; but if progress is to be made at all, the results even of so limited a work must be ordered as clearly as possible and duly evaluated. To do this it seems best to start with the purely material evidence provided by the successive archaeological levels and afterwards to test the probability of the chronological scheme thus suggested by inquiring how far it seems to agree with or to be explained by the historical conditions of each period.

Our record as a whole is divided into two parts distinguished by the different character of the evidence available. From Level VII onwards we have the advantage of written documents, the tablets belonging to various levels giving historical information which can be correlated with the known history of other countries. Since Yarim-Lim is found to be a contemporary of Hammurabi of Babylon, Levels VII to I fill the period between the eighteenth and the twelfth centuries B.c.; Niqme-pa of Level IV as a vassal of Saushsatar of Mitanni can be dated at or just after I 450 B.c. and, given the different characters of the successive levels, it should be possible to connect the changes with the changing political conditions of the time and so to arrive at a fixed chronology for our later period. ${ }^{\mathrm{I}}$ But for the period before the eighteenth century this is not possible. We have no tablets dating before Level VII, and purely archaeological evidence unaided by literary sources cannot supply positive dates; we must be content with round figures which are only approximations to the truth, justifying them so far as may be by the evidence of objects imported from or related to other countries whose chronology is better established.

I shall deal first with the early periods, but since Level VIII can be assumed to have ended in the eighteenth century and so gives us a more or less fixed point, I shall reverse here the order I have generally followed and, working from the known to the unknown, shall start from Level VIII and go downwards.

It should be noted that our local sequence defined by building strata is well established; the 'Levels', as given on the one hand by the successive temples and on the other by the residential or palace area, are quite consistent. Throughout the early levels the remarkable

I At Atchana this possibility is greatly increased by the fact that the palace site, both with its building vicissitudes and with the written testimony of its tablets, gives better and more

continuous evidence than can normally be obtained by the excavation of private house sites, graves, \&c. 
uniformity of the pottery, which is only partially broken down by the introduction of the smother-kiln-made and burnished wares of Levels IX and VIII, might be thought to show that the period of time represented by them was relatively short, but such a conclusion does not harmonize with the architectural evidence; the solidity of the buildings; the patching and rebuilding of walls, and the succession of floor-levels as well as the mere accumulation of debris all seem to demand a considerable length of time. Both facts have to be taken into account, but neither of them is in itself decisive; what is required is external evidence.

In the upper part of Level IX there was found the cylinder seal AT/47/1, Pl. LX, 6, which is inscribed in cuneiform with a text in the Cappadocian style. At Kültepe the earlier stratum producing tablets would be dated between about 1950 (on the strength of the Ibi-Sin seal-impressions) and $185^{\circ}-1830$ B.C., ${ }^{\mathrm{I}}$ the bulk of the tablets belonging to the latter part of that period. Assuming that our Atchana Level VIII ends in the eighteenth century B.C. ( $\operatorname{circa}$ I 7 I 5 on the shortest chronology), then that a date somewhat earlier than I 850 B.c. should fall within the Level IX period does not seem unreasonable.

For Level $\mathrm{X}$ we have no external dating evidence.

In the house ruins of Level XI was found the clay seal-impression AT/47/27, Pl. LX, 5, which could be as late as the beginning of the Sargonid period but can perhaps. equally well be assigned to the closing phase of the Early Dynastic; according to the reduced chronology Sargon came to the throne about 2320 B.C. so that the seal may date to about 2300. Granted that $(a)$ a seal may be in use for a long time and $(b)$ a sealed document may be, and often was, long preserved, this should still give us a date of circa 2300 B.c. as coming within the Level XI period-but quite likely towards its beginning rather than at its end.

From the Level XII temple come three seals. One of them, AT $/ 48 / 73, \mathrm{Pl}$. LX, 4 , is useless for dating, but AT/49/9 (ibid., No. 3) is of Early Dynastic type and AT/48/70 (ibid., No. 2), which was found in the ashes on the temple floor and therefore should be contemporary with its destruction, is of the 'Lagash' type and characteristic of Early Dynastic.

The most remarkable feature of the Level XII house site is the great mud-brick colonnade of the palace façade. This architectural feature is, so far as we know, unique in north Syria and is almost certainly inspired by a foreign model; the obvious source is Mesopotamia where two analogies present themselves, at Warka the great palace façade with its mosaic-sheathed mud-brick columns (the bricks are specially shaped, as are those of Alalakh) going back to the Uruk period, and for the Early Dynastic period the columned hall of the palace at Kish which, since its columns are plain, offers a closer parallel.

From the Level XIII house site came the seal AT/47/I 22 (Pl. LX, I) with the 'banquet' scene; it is definitely in the style of the seals of the Early Dynastic period of Sumer. The house had been twice refloored and the seal was lying on the highest floor, so that it is contemporary with the latter days of the building; the beginning of the 
Level XIII period should be a good deal earlier than the date of the cylinder, even allowing for the possibility of its long use.

In the houses of Level XIV (and in Level XIV alone) there were found several examples of the clay bowls of Type I 3 ; they are hand-made with a bevelled rim apparently trimmed with a knife. These bowls are found at Ur, where they come between al 'Ubaid III and Jamdet Nasr, i.e. in the Uruk period; at Warka, in Archaic V; at Nineveh in Nineveh IV, just after the Samarra and Tell Halaf period so that they are, according to Mallowan, of the Uruk-Jamdet Nasr time (they are associated with grey burnished pottery); at Carchemish, after the Tell Halaf period but some time before the incoming of the Bronze Age cist-grave people; at Judeideh, in Level XI, i.e. just above Jamdet Nasr. In every case their floruit seems to be brief. At Carchemish they have a ritual character and are associated with graves-being placed not in but above the graves, generally inverted, and at Nineveh also they are generally inverted and their ritual character seems assured; elsewhere this does not appear to be the case. We do not know the original centre from which this curious archaistic vessel spread so widely (it is found even in Susa) and it would be rash to assume that it reached all these places at exactly the same date; but it does seem certain that it is more or less contemporary with the Uruk period and overlaps into that of Jamdet Nasr; in that case it should belong to the very end of the fourth millennium. ${ }^{\mathrm{I}}$

Not so decisive but still of importance is the fact that the 'reserved slip' ware, which first occurred in Level XVII, is still found in Level XIV. Like the knife-trimmed bowls, it comes in Nineveh IV; it comes also in Tarsus III, in Judeideh XII (Jamdet Nasr level, before the knife-trimmed bowls), and at Carchemish in the 'late Chalcolithic' period, in the levels at which the knife-trimmed bowls 'begin to occur' (Carchemish, iii, p. 228). Because it originates in an earlier level these parallels cannot be regarded as absolute, but at least the ware, by its survival, supports the evidence of the bowls.

In a house of Level XVI was found the slate palette $A^{\prime} \mathrm{T} / 47 / \mathrm{r} 76$, which is of the common Egyptian form No. 57 in Petrie's Prehistoric Egypt, Sequence date 46 . Had we no other grounds for judgement I should hesitate to lay much stress on what is really a very simple form, even though the material and the use of the article support the analogy, but the evidence is so consistent that the argument of the palette seems admissible. Sequence-date 46 comes about the middle of the predynastic period and therefore falls well within the fourth millennium.

Of the facts cited above, the discovery in Level XIV of the familiar hand-made bowls

1 Albright, in B.A.S.O.R., No. 88, would make the Warka period begin in the 3 and and Jamdet Nasr in the 3 oth centuries B.C. His view is scarcely in accord with those of archaeologists who have had first-hand experience of the older Mesopotamian strata. Mallowan ("Excavations at Brak and Chagar Bazar', Iraq, ix (I947), p. 4) maintains that 'six hundred years is not an exaggerated length of time for fitting in the enormous amount of archaeological material which falls within the compass of the early dynastic periods' and supports this view by Egyptian analogies. The generally accepted equation (with which Mallowan agrees) that Jamdet Nasr = Egyptian Late Pre-dynastic plus Early Dynastic would still on Albright's dating (Menes, c. 2900 , min. 2800 , in his I 940 publication, now c. 283 B.C.) bring the beginning of Jamdet Nasr to 3000 B.C. Mallowan's positive date of 3000 for the end of Jamdet Nasr was admittedly based on the old date for Sargon (2370 B.c.) and must be reduced to harmonize with the shortened chronology, but its beginning would be in the fourth millennium. 
is the only one which, taken by itself, can be described as unimpeachable evidence; no archaeologist, I believe, would dispute the validity of the parallel, so that at least we have a definite correlation with a well-established phase in the sequence of Mesopotamian archaeology. I should not myself accept as conclusive the testimony of any one of the seals or seal-impressions, but if they be taken together, as they ought to be, their combined evidence is too consistent to be accidental-they mark points in a series which agree perfectly with the succession of the building-levels wherein they occur. On the strength of this, the only real archaeological evidence that we have, ${ }^{\mathrm{I}}$ I would date our levels as follows:

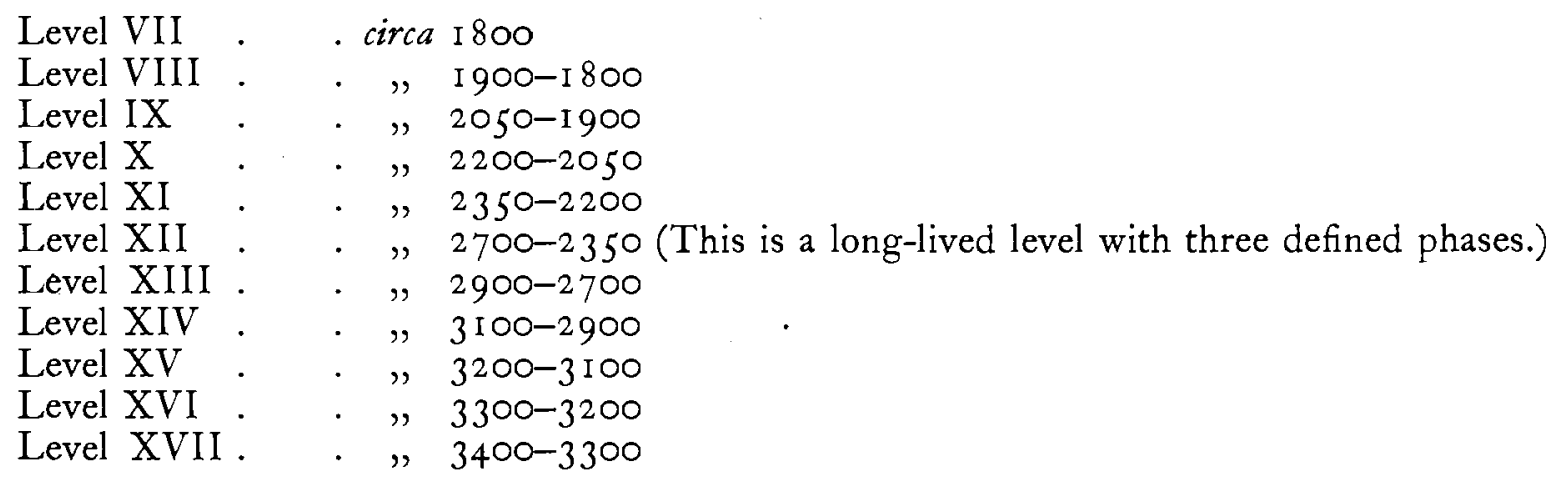

These figures will not easily win acceptance. I do not myself regard them as other than provisional, either in themselves or in their sum total; but back to Level XII at any rate the chronology goes hand in hand with that of Mesopotamia. Behind that the crucial question is the positive date of the Jamdet Nasr period, and although that remains conjectural, yet I doubt whether any Mesopotamian archaeologist would put the end of the period later than 500 years before the rise of Sargon of Agade. Assuming that the scheme put forward above is consistent with such evidence-meagre though it be-as the site itself affords, it would be well to test it by external conditions.

In the first place I would deal with an obvious objection. Since Level XVII, representing the first settlement of Alalakh, immediately succeeds Tabara al Akrad, ${ }^{2}$ the scheme would imply a date of something like 3400 в.с. for the pottery known as Khirbet Kerak

\begin{abstract}
I I have deliberately refrained from using the 'evidence' of the metal pins. Those found in Levels XIII and XIV are of types known from other sites and are recognized as belonging to the early part of the Bronze Age; but they give a sequencedate rather than a chronological date and their occurrence here is more important for dating the pin types by the buildings than for dating the buildings by the pin types. Thus Type P. I is found in Tomb vi at Meshrifé (Qatna) and attributed by Du Mesnil du Buisson to $2600-2400$ B.C.; Types P. 5, IO, and I I come from the lowest level at Byblus. Dr. Schaeffer puts Tomb iv at Meshrifé between 2200 and I 900 B.c., and the Byblus pins between 2400 and 2300 B.c. on the strength of his conclusions regarding Ugarit. Dating evidence at Ugarit is excellent so far back as the end of the Egyptian XIIth Dynasty, but beyond that point is purely
\end{abstract}

conjectural; a true chronology will only be established by combining the evidence from all the excavated sites, but not by forcing all into harmony with one site by the simple expedient of disregarding the conclusions of other excavators. I might remark that on the one hand the spiral-headed pin of Type P. I I occurs in Mesopotamia very much earlier than Dr. Schaeffer would allow; of I 2 examples found in the Royal Cemetery at Ur 5 were found actually in graves of the Early Dynastic period, 7 , being found loose in the soil, could not be dated, and none were in Sargonid graves; on the other hand, at Atchana Type P. I I occurs in Levels IV, III, II, and I, P. IO in Levels III, II, and I, Type P. 5 in Level V, and Type P. I in Levels IV, III, and II. Obviously such objects are not reliable as evidence.

2 ข. p. 7 . 
ware, a date considerably earlier than that agreed to by the excavators who have unearthed it in Palestine. ${ }^{I}$ But as the invaders who brought the Khirbet Kerak ware into Palestine came from the north and since they long resided in the Amq plain, the Palestinian settlements would ex hypothesi be somewhat later in date and exact synchronism with Atchana is not to be looked for.

A date in the fourth millennium for the founding of Alalakh and the introduction into the Amq plain of the full Age of Bronze may seem to be contradicted by all archaeological experience in Syria and, more particularly, in Palestine, where the beginning of 'Middle Bronze'z is sometimes put as late as 2100 B.c. ${ }^{3}$ But we are dealing with different countries whose history has very little in common, and the argument from Palestine, or even from Syria proper, simply does not apply.

From the very outset, when the pottery of 'Tell esh Sheikh shows the combined traditions of Tell Halaf and of al 'Ubaid, the Amq plain is linked, culturally, with the east and not with the south. In later days that connexion was maintained and strengthened by trade as well as by politics. The position of Alalakh, the royal city, was not due to accident; it lies on the main trade route, it has access to the sea, but in addition it commands the approach to the Amanus mountains, and thereby controlled the traffic in cedar-wood. The peoples of the Euphrates valley, forced to import any hard timber that they might require, did not have to discover the cedar-forests of the Amanus, for they inherited the knowledge (and perhaps the exploitation) of them from the time of al 'Ubaid. The Lebanon shipped its cedar to Egypt, and Egypt was at pains to control Syria largely with this trade in view; for Mesopotamia the source of supply was naturally in the north, and the Amanus timber was hauled overland to the Euphrates, via Alalakh and Aleppo, to be floated down-stream. ${ }^{4}$ The early cylinder seals found by us witness to

\footnotetext{
'Miss Kenyon kindly summarizes those views for me as follows: 'The evidence for its chronological position in Palestine seems to be reasonably clear. It occurs freely in Beth-shan XII, there is one sherd in Megiddo XVII-XVI and some sherds at Jericho "above III". All this would point to occurrence in Palestine E.B. III. Largely on the Ai evidence E.B. III seems to correspond with the Egyptian Pyramid Age, say 27 th to 24 th centuries, as E.B. I seems to be late pre-Dynastic and E.B. II to tie in quite securely with the Ist Egyptian Dynasty. In the fairly rich E.B. I and II deposits in Palestine there is no trace of Khirbet Kerak.'

Albright in The Archaeology of Palestine, p. 76, puts its Palestinian vogue between 2600 and 2400 B.C.; but he takes his dating from the Judeideh report which places Khirbet Kerak ware after instead of before Jamdet Nasr. The Judeideh evidence has not been published, but the conclusions were drawn from a stepped trench cut in the steep slope of the mound, one of the most difficult operations that an archaeologist can undertake from the point of yiew of correct stratification. This is not a case of positive dating but of correct historical sequence, and where the results at Judeideh and at Atchana are in direct contradiction I am bound to go by the simpler stratification of the latter site.

${ }^{2}$ I have in this volume avoided the stereotyped expressions
}

'Early', 'Middle', and 'Late Bronze Age' used for Syria and Palestine because they would seem to presume a synchronism of cultural development which is belied by the facts of history. The Middle East did not progress uniformly, and metal was freely used in one area when another was still in the chalcolithic or even in the neolithic stage. For a single and more or less homogeneous country such as Palestine the threefold division of Early, Middle, and Late Bronze is applicable and is perfectly well understood, but its extension is likely to be misleading. I have therefore preferred the terms 'Chalcolithic' and 'Bronze Age', and, because it is impossible to decide just when the metal became really common, have distinguished the two periods by the introduction of wheel-made pottery, which does seem to coincide with a metal age properly so called. Culturally (but not chronologically) my 'Bronze Age' correlates with the 'Middle Bronze' of the Palestinian archaeologist.

3 Albright, op. cit., but see Miss Kenyon in my note I above. I would point out that the introduction of 'Middle Bronze' does not follow immediately. on the Khirbet Kerak pottery phase; that belongs to the early part of 'Early Bronze III', after which comes 'Early Bronze IV'.

${ }_{4} \mathrm{Mr}$. Sidney Smith kindly supplies me with the following note: 'It is certain that Egypt obtained some hard woods from 
those Sumerian trade-relations. Sargon invaded north Syria and secured the sources of supply for himself; Alalakh must have become a vassal of Akkad, as indeed it did, for when, three generations later, Naram-Sin 'took 'Amanus, the mountain of cedar and the Upper Sea' he was not making a new conquest but crushing a rebellion. ${ }^{I}$ Even the minor rulers of Sumer would boast of the cedar-wood which they obtained from the Amanus for the building of temples. ${ }^{2}$ The orientation of the Amq plain was therefore eastward, and it was inevitable that culture there should develop and advance more or less in step with that of Sumer. The chronology which I postulate for Alalakh depends on that of Mesopotamia and its credibility must be judged in the light of what happened in that country; the facts of history rule out any parallel with the Palestinian backwater.

But the coincidence of the chronologies of Alalakh and Mesopotamia is indeed remarkable. The Tell esh Sheikh painted pottery period begins in the time of Tell Halaf and overlaps that of al 'Ubaid, which the Warka stratification proves to have been a very longlived culture. That painted pottery is at last supplanted in the Amq (witness Level VII of Tabara al Akrad) by the Uruk ware, precisely as is the case in Mesopotamia. Very soon after the introduction of the Uruk ware we have the Khirbet Kerak invasion, which therefore synchronizes with the early part of the Uruk period. Atchana Level XIV falls within the Jamdet Nasr period. All these are absolutely consistent. Of course, the actual dates I have suggested above are arbitrary, but the sequence is indisputable and the phases of it lasted a long time in each case; whatever figures be finally accepted for Mesopotamia must apply equally to the Amq, and no argument based on the archaeology of southern Syria or of Egypt can be admitted into court.

It is clear that the Bronze Age was introduced by the people who conquered the makers of the Khirbet Kerak pottery and founded a new city at Alalakh. According to the scheme I have suggested this took place not long after 3400 B.c. But we do not know who those people were. Their characteristic pottery, which was to enjoy so long a floruit. has not yet been identified outside the Amq plain, but as it is fully developed by the time of our Level XVI it must have had antecedents elsewhere, ${ }^{3}$ not necessarily very far away. The temple ruins of Level XVI, fragmentary though they be, are elaborate enough to bespeak considerable wealth, and if the Eygptian-type palette be admitted it would imply far-reaching trade connexions. But Level XIV, showing affinities with places so far removed as $\mathrm{Ur}$ and Nineveh, puts Alalakh in its true setting as an outlier of the Eastern civilizations, and for a very long time all its contacts seem to be with the East. In Mesopotamia the Uruk and Jamdet Nasr periods were evidently times of great prosperity and material advance; the Warka excavations testify to an architecture more brilliant than anything that was to follow; and architectural activity required and wealth

northern Syria, "the mountains of Naharina", see Schäfer, Sitzungsberichte der Berliner Ak. der Wissenschaften, phil.hist. Kl. xxv (1921), pp. 730-8: probably Anti-Taurus. In the early period cedar came not from Lebanon but Amanus.' I do not think that this seriously modifies the truth of what I have stated in the text on the strength of the cuneiform documents. In view of political conditions Egyptian trade with north Syria must have been intermittent at best.

I Ur Texts, vol. i, Royal Inscriptions, No. 275. The 'Upper Sea' must surely refer to the port at al Mina.

2 e.g. Gudea of Lagash; S.A.K.I. I6.B.28, p. 69.

3 I suspect the Aleppo district, but this is a mere hypothesis not at present worth arguing. 
made possible a great increase in the imports of hard-wood. This seems to be reflected in the building at Alalakh of a great palace in the Mesopotamian style; the rulers of Alalakh were benefiting by the expansion of international trade and naturally imitated the luxury of their business clients. The period had its ups and downs-the kings seem to have been impoverished for a while and later to have recovered their riches-but it lasted for a long time, long enough for its houses to be twice rebuilt, and was prosperous up to the end. That prosperity may have caused its downfall; it was based, if my theory be correct, very largely on the dues collected from the timber-trade, and while heavy dues, with trade on a large scale, meant riches, they were likely to annoy customers; the transition from Level XII to Level XI may well be due to Sargon's conquest. I should propose to correlate Level XI, roughly, with the Akkadian domination of the Amq area. Level X, which gives us the ruins of what was clearly a very fine palace, represents a period of prosperity and virtual independence. This corresponds well with the position in Mesopotamia, where the Guti were not interested in foreign conquest, but, as the Gudea inscriptions prove, trade with the Amanus area was flourishing. Throughout the time of the Ur III Dynasty conditions were equally favourable and are reflected in the building of the Level IX palace at Alalakh. The cylinder seal with inscription of the Kültepe type may be taken to mean that there was by this time a colony of Mesopotamian merchants established here as there was at Kültepe in Cappadocia; this may be thought too ambitious a conclusion to be based on the discovery of a single seal, but the Kültepe analogy shows that if there were such a colony it would be located not inside the city but in a special enclave outside its walls, and as our digging in this level was confined to the temple and the palace area no remains of any foreign merchant settlement were to be expected and in those circum-

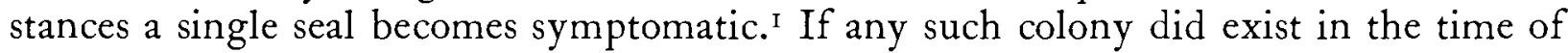
Level IX it was presumably not very long-lived, since it would not have been countenanced in the political conditions of Level VIII-in which level, incidentally, no Kültepe type of document was found-nor is there any reference to Alalakh in the Kültepe texts.

Level VIII ought, historically, to coincide with the extension over north Syria of the empire of XIIth Dynasty Egypt. We have not found at Alalakh any Egyptian royal monuments such as testify to the direct control of the Pharaohs over Ugarit ${ }^{2}$ and many other Syrian towns, but that Egyptian influence was strong there is proved by the style of the portrait head found in Yarim-Lim's temple (Pl. XL) and, yet more clearly, by the fact of an Egyptian scene of worship coming on the seal of a member of the royal house in Yarim-Lim's time (P1. LX, I 2). Judging by the Syrian evidence, ${ }^{3}$ which I

\footnotetext{
I Sidney Smith (Alalakh and Chronology, p. 33) expresses surprise that the Kültepe texts do not mention Alalakh although they do refer to Parga or Barga, known to lie near Aleppo. One reason for that may be that Alalakh lies off the direct road from the Aleppo area, or anywhere north of Aleppo, to Cappadocia, which runs along the northern edge of the Amq plain. Actually the texts do not witness to any trade with Aleppo either, and Aleppo and Alalakh were normally parts of one kingdom; so in the Igth century, to
}

\footnotetext{
which most of the Kültepe tablets are assigned, there may have been a political boundary preventing such trade.

2 e.g. Syria, xiii ( I932), Pl. xıv. I; xiv (I933), Pl. xv. 4; $\mathrm{xv}$ (I 934 ), Pl. Xiv.

3 Scarabs of Sesostris I have been found at more than half a dozen Syrian sites, from Gaza in the south to Ugarit in the north, and large-size stone monuments of Sesostris II at Qatna and-what is really conclusive-at Ugarit.
} 
think can be interpreted only in one way, the Egyptian conquest of the country was begun in the time of Sesostris I and completed by Sesostris II; the monuments of later kings show that the Egyptian domination continued until the collapse of the XIIth Dynasty about I 790 B.C.

From Level VII onwards we can avail ourselves of written documents, and so should achieve an historical exactitude impossible hitherto, but it is precisely here that difficulties begin. If the history of Alalakh is to be brought into proper relation with that of neighbouring lands exact dates are essential and at present the dates are in dispute. In I 940 Sidney Smith, starting from the fact that Yarim-Lim had been proved by the Mari texts to be a contemporary of Hammurabi of Babylon, tried to show that in view of the Atchana material in particular the date of Hammurabi must be reduced considerably from what had hitherto been assumed, and argued that it must now be reckoned as being from I 792 to I $75^{\circ}$ B.c. He had previously shown ${ }^{1}$ that Niqme-pa of our Level IV was a contemporary of Shaushsatar of Mitanni. He therefore put forward, with all due reserve, a chronological scheme as follows:

\begin{tabular}{|c|c|}
\hline \multicolumn{2}{|r|}{ about I 780 -after I 750} \\
\hline evel VI & \\
\hline Level V & after i $594-1483$ \\
\hline Level IV, Phase I & after I 483 -after $I_{459}$ \\
\hline$"$ & about I $45^{\circ}-$ about I 370 \\
\hline Level I & about I $35^{8}$-about I 285 \\
\hline Level Il & after I $275^{-a b o u t ~ I ~} 220^{\circ}$ \\
\hline Level I & about I 220 -about I I 90 \\
\hline
\end{tabular}

This scheme-'something approaching a historical sketch of the six centuries covered by the remains excavated in the palace area'-had the advantage that 'by a rare chance' it enabled him to connect changes in that area (i.e. changes in our levels) with known historical events which served to explain them.

This scheme I thankfully accepted ${ }^{2}$ subject to such modifications as might be required (I already realized that insufficient time had been allowed for Level I) in preference to anything that I had tentatively put forward myself in my preliminary reports of the excavations.

Unfortunately that uncritical acceptance is no longer possible.

After the appearance of Poebel's discussion, without publication, of the Khorsabad King-list, Professor Albright, accepting some (but not all) of Poebel's conclusions, raised the date proposed for Samsi-Adad I from I 726-I694 to about I 746-I 7 I 2, and arrived at a date for Hammurabi of Babylon of I 728-1686 B.C., the latter being an accidental and happy coincidence with an interpretation of the figures for dynasties in Berossos proposed by Cornelius. This view, which has been widely accepted, of course involves the modification of many subsequent dates in Mesopotamian history as well as that of Yarim-Lim.

I 'A Preliminary Account of the Tablets from Atchana' in A.F. xix (1939), p. $3^{8}$.

2 Fournal of the Royal Anthropological Institute of Great

Britain and Ireland, Ixxii, pp. 9-I 8; 'North Syria as a Cultural Link in the Ancient World', Huxley Memorial Lecture for I 942. 
In his publication of the Idri-mi statue-inscription, Sidney Smith discusses, and rejects, the reading in 1. 43 of the name Barat(t)arna in place of his own Sutarna and is thereby enabled to represent King Idri-mi as the grandson of Niqme-pa. Albright ${ }^{1}$ takes the opposite view, and since Idri-mi is thus seen to be a contemporary of Barat(t)arna, who 'must antedate Shaushshatar by a generation or so', identifies him with Idri-mi the father of Niqme-pa, and dates his reign to about $1480-1450$ B.c. This necessarily eliminates Smith's identification of Adad-Nirari, son of Idri-mi, with the Adad-Nirari of the Amarna letter No. $5 \mathrm{r}$. On the reading 'Barat(t)arna' certain other authorities share the opinion of Albright and while admitting that the texts available do not finally settle the question of the genealogy of the royal family favour the view that Idri-mi was the father and not the grandson of Niqme-pa. Consequently I am obliged to rule out of court the sketch of the history of Alalakh based on a scheme of fixed dates which I put forward in the Huxley Memorial Lecture of 1 942; my safest course is to pass in review the archaeological evidence given by the site for the successive Levels VII to III (which are those most affected by the changed chronology) and to see how they can be fitted in with the new dates.

Archaeologically speaking our Level VII is strictly conterminous with the palace; it was quite certain that the palace itself was built at more or less the same time as the temple, the city gate, \&c., and the simultaneous construction of such public works can fairly be taken as initiating a period; they were all destroyed at the same time, and with them the period manifestly ends. The progress of the work convinced us that the period was not a very long one. There were additions made to the palace, but the blocking of one gateway and the strengthening of the walls of one room were the only changes made in the original structure, and they might have been made at any time. Nowhere did the stratification imply a long time-interval. Moreover, the evidence of the tablets agrees with this. They are numerous enough and should be sufficiently mixed (for they are, of course, only the chance survivors of a vastly greater number) to give a fair idea of the contents of the palace archives; actually they all fall within three reigns-those of Hammurabi of Yamhad, Yarim-Lim and Niqme-epuh_and in the opinion of Mr. Wiseman cover no more than about fifty years. ${ }^{2}$ This term I take to be the duration of the palace, and therefore of Level VII. ${ }^{3}$

In its pottery Level VII shows a marked break with the past; the old painted ware goes quite out of fashion and a great many new shapes of vessels are introduced. The fact that

I In B.A.S.O.R., No. 88, 1942 .

$2 \mathrm{Mr}$. Wiseman gives the order of succession as

'Hammurabi of Yambad

Abban of Alalakh

Yarim-Lim

Niqmepub

while Ammitaku and Irkabtum, rulers of Alalakh and district, are living at the same time.' Since no tablets of Abban were found it is possible that he never actually reigned.

3 Dr. Schaeffer (Stratigraphie comparke, p. IO4) suggests that Yarim-Lim gives merely the terminus ante quem for the existence of the palace and level, the beginnings of which should go back in to the nineteenth century B.c., in support of which he quotes me as saying that the palace was contemporary with the Middle Minoan II period in Crete ( $1900-1700$ в.c.). I did not say, or mean, that it was coeval with M.M. II but only that it coincided with it. For Dr. Schaeffer's main contention there is no support whatever; it seems to depend partly on a misunderstanding of Sidney Smith's dating, which was based not on a single tablet of uncertain provenance but on the mass of tablets found in the palace, and partly on a desire to make the pottery of the period conform to the chronological scheme worked out for Ugarit. 
many of those did not continue in use in the Level VI period is, if not evidence for, at least consistent with Level VII's having been a short period-the new forms had not had time to get acclimatized. Of particular interest is the sculpture, because as a luxury product it would naturally reflect the political bias of the royal house; the composite statues with applique beards and wigs are essentially Mesopotamian, as is the style of hairdressing, and the fine portrait head (Pls. XLI-XLII) for all its individuality is in the Sumerian tradition. On the other hand, we have the Egyptianizing head AT/47/62, Pl. $\mathrm{XL}$, as evidence of very different political sympathies, and as further witness of this the seal of the king's brother bearing the figure of an Egyptian god with Egyptian emblems, Pl. LX, Nos. 9, i 2.

Level VII ended in complete disaster, all the public buildings being sacked and burned. Since the destruction involved the defences of the city it must have been the work of an outside enemy, not of some domestic rebellion. In the early part of the Level VI period there are no new types of pottery such as might result from an enemy occupation; on the contrary, the tendency is to revive the traditional styles of Level VIII and earlier; we are probably justified in saying that the city was laid waste and thereafter the surviving inhabitants were left to their own devices. This does not mean a desertion of the site, but it does suggest that there may have been a (fairly long) phase of poverty and weakness before the citizens could again make good their fortunes. We can prove the existence of a temple (though it is represented by the scantiest of ruins), but we found no trace of a palace; the houses were-in some areas at least-not built until some time after the end of the previous period, though when they were built they were of good quality; but on the other hand the castle was built ${ }^{\mathrm{I}}$ and rebuilt in the course of the period, and this in itself implies that the period was much longer than the house remains would lead us to suppose. An important point is the pottery of the later part of the period, mostly dated by being found on the upper floor of the castle; some of this bears polychrome decoration, principally consisting of red bands bordered with black on a pink or buff ground, which resembles that found in Palestine, e.g. at Megiddo in strata X ( $1650-155^{\circ}$ B.c.) ${ }^{2}$ and IX (I 550-I 480 B.c.). A single example occurred of the 'Union Jack' motive (Pl. $\mathrm{XCIVb}$ ) which also is common in Palestine and is there dated between I 600 and I 500 B.C. ${ }^{3}$ 'Two fragments of the Cypriote 'red on black' painted bowls came one from a Level VI rubbish-pit, one from a pit belonging either to Level VI or to Level V; the ware is dated i $800-$ I 650 B.c. 4

In Level $\mathrm{V}$ the castle was again built and rebuilt, implying a reasonable lapse of time;

I But the first building did not take place until some time
after the destruction of the Level VII buildings; $v$. P. I 53 .
The weathering of the. Level VII ruins in every case proves
that there was a very definite time-gap before the citizens of
Alalakh had the heart or the means to start on reconstruction.
We must allow for this in estimating the length of the Level
VI a period.
2 Dr. Schaeffer, arguing from the evidence of Ugarit,
would put these strata earlier, at I750-I 600 and I $600-1450$
B.c. respectively.
3 e.g. Gaza, Palace I; Heurtley ("A Palestinian Vase- painter of the I6th century B.c.', in Palestine Dept. of Antiquities Quarterly, v (I936)) dates the style I600-I 450 . Albright (A.J.S.L.L. I938, p. 345) puts it at 1700-I 500 B.c. but seems to have changed his mind later, for in $T$ the Archaeology of Palestine, p. 96, he puts it (for Palestine) at I $55^{\circ}-145^{\circ}$ B.c. Schaeffer dates it I600-I 500 B.c. at Ugarit. 4 Schaeffer, op. cit., p. 27: 'Chaque fois que les conditions stratigraphiques ont permis d'en préciser la date, cette céramique se révéla être antérieure à la période finale de l'Ugarit Moyen 3, c'est à dire antérieure à i 650 en chiffres ronds.' This agrees with the recognized Cyprus dating. 
the earlier version gives some evidence of its having been besieged ( $v$. p. I65). On the site later occupied by Niqme-pa's palace there was a large and well-constructed building which may well have been a palace. The city temple was reconstructed on a plan absolutely unlike that of any other temple of the second millennium B.c. known to us; the only parallel that I can cite is the much later Mithraeum, and the only excuse for citing it is that Level $\mathrm{V}$ roughly coincides with the establishment in the old Hurrite territory to the east of the Mitanni with their cult of the Indo-European gods; the temple might be a tribute to the Mitanni power. The introduction of extremely crude stone idols ( $v$. p. 238 and Pl. XLIV) also seems to denote eastern contacts, as do some of the pottery types. Throughout the period the polychrome ware with the 'Union Jack' motive is relatively common, following on its first appearance in Level VI. Peculiar to the level is the black impressed ware, an imported type of unknown origin; at Tarsus the ware occurs 'in the late Old and early New Empire', i.e. circa I $600-$ I 550 B.c., whereas the $\mathrm{Nuzu}$ variant seems to date from the fifteenth century. 'Two, or perhaps three examples of the painted Nuzu pottery come at the end of the period represented by the level. 'Base-ring' ware and White Slip I ware begin to be common and may point to contacts with the north. ${ }^{\text {I }}$ A unique object is the (unfortunately fragmentary) faience bowl, $\mathrm{AT} / 46 / 223, \mathrm{Pl}$. LXXXIII, with its Egyptian inscription.

Our archaeological Level IV starts with the building of the Niqme-pa palace but is not conterminous with the life of that building. The burning of the palace was an isolated event which did not affect the rest of the city-the private houses contemporary with the palace remained in use for a long time after its destruction. A study of the stratification of the 'parade-ground' and of the buildings of the Level IV city gate made it clear that the remodelling of the castle interior (v. pp. I 56 sq.) was carried out during the period of Level IV but after the burning of Niqme-pa's palace, not at the time of its construction. In the palace the painted Nuzu pottery was very rare, but on the upper floors of the Level IV houses it became quite common, anticipating its general use in the following periods; the White Slip and Base-ring wares are the normal domestic pottery of the palace but are not so general, although still common, in the houses of the latter part of the period. ${ }^{2}$ The terminus ante quem of our archaeological level is clearly fixed by two things- the destruction of the temple and its rebuilding on new lines, and the razing of the whole NW. quarter of the city, including the castle (which had already been destroyed by fire) and the site of Niqme-pa's palace, for the erection of the huge fortress of Level III. At the same time the city wall was rebuilt; this was not a case of repairing the old defences, which were perhaps beyond repair; an entirely new wall was put up, and it ran arbitrarily across the ruins of the private houses of Level IV.

The end of our Level IV is therefore clearly defined. Its beginning, the date of the foundation of a single building, might seem to be a too artificial or even accidental distinction in view of the fact that many of the Level $\mathrm{V}$ buildings continued in use with

\footnotetext{
I See p. 363. These wares cannot be used for dating the levels in which they occur; they have themselves to be dated by the levels; see Pp. 367-9.
}

2 They are still in use (White Slip II and Base-ring) in Level III and disappear altogether before Level II. 
little or no modification. It is true that the transition was a peaceful one, ${ }^{\mathrm{I}}$ but the building of a royal palace may well introduce a new social as well as political régime, and our best criterion for the character of the periods, the pottery, does show a marked difference between Levels $\mathrm{V}$ and IV. The complete disappearance both of the black impressed ware and of the old painted type inherited from the earliest days of the city makes a clear-cut distinction, while the vastly greater proportion in Level IV of the White Slip and Base-ring types which in Level $V$ were relatively rare emphasizes this; as regards the plain pottery, thirty types or variants which were current in Level $V$ fail to appear thereafter, while in Level IV we find sixty-four which are unknown earlier. To some extent the change must have been due to a gradual process, mere changes of fashion in the course of time; but there must also have been innovations due to altered political conditions, ${ }^{2}$ and the building of Niqme-pa's palace does usher in a new historical period. In that period, of course, come Niqme-pa and Ilim-ilimma, both of whose seals bear Egy ptian emblems.

The evidence of a purely archaeological character detailed above must now be brought into due relation with the accepted chronology put forward by Albright and others; ${ }^{3}$ this gives us:

Hammurabi of Babylon, I728-1686, which would put Yarim-Lim not earlier than c. I 7 I 5 , perhaps as late as I 700 B.c. Level VII, if we allow fifty years, would end I 665 -I 650 B.C.

Hittite sack of Babylon, I $55^{\circ}$ B.c. This followed immediately on the Hittite capture of Aleppo.

Alalakh Level IV;

\section{Egypt}

Tuthmosis I (c. I 525$)$

Tuthmosis II

Tuthmosis III (1490)

Amenophis II (1435)

Tuthmosis IV (c. I $4 \mathrm{I} 4)$

Amenophis III (c. I 406)

Amenophis IV (c. I 370$)$
Alalakh

Ilim-ilimma I

Idri-mi, c. I 490

Adad-nirari

Niqme-pa, son of Idri-mi

Ilim-ilimma II

Mitanni

Since our archaeological Level IV starts with the building of Niqme-pa's palacewhich presumably inaugurated his reign-his predecessors on the throne must be reckoned as belonging to Level $V$. Level IV then begins circa I 435. Levels V and VI must come between that date and a date not earlier than ${ }_{1} 665$ and perhaps as late as I $65^{\circ}$ B.c. We know that in the Level VII period Alalakh formed part of the kingdom of Yamhad, whose capital was Aleppo, and since in the following period Aleppo still

I I do not know why Schaeffer (op. cit., p. IOI) speaks of 'la destruction violente qui mit fin à Alalakh V', the reverse is the case. Schaeffer perhaps misconstrued Smith's expression 'a sharp break .... at the end of Level V' which meant that political conditions in the two periods were very different.
2 It is perhaps worth noting here that a quantity of black impressed ware together with the Egyptian faience vase were found in temple rubbish-pits and had been thrown out before the beginning of Level IV. See p. 70.

3 van der Meer, O'Callaghan, on the basis of Poebel. 
possessed a 'great kingship', the connexion can be assumed to have held good. That being so, the capture of Aleppo by the Hittite king Mursilis must have involved that of Alalakh also, and this event, deeply affecting the city, would account for the change from Level VI to Level V.

The time-framework for our levels is then:

$$
\begin{aligned}
& \text { Level VII . . I 7 I 5/I700-I665/1650 B.c. } \\
& \text { Level VI . . I665/I650-I550 B.C. } \\
& \text { Level V . . I } 550-\text { I } 435 \text { B.C. } \\
& \text { Level IV . . I } 435 \text {-I } 370 \text { B.C. }{ }^{\text {I }}
\end{aligned}
$$

Certain difficulties are at once apparent. The date of I $55^{0-1} 435$ for Level $V$ is not really consistent with the 'Union Jack' motive on the painted pottery (unless we accept Albright's later view, for which he adduces no evidence), nor with the polychrome decoration, nor with the Tarsus evidence for the black impressed ware. In fact all the pottery types characteristic of Level $\mathrm{V}$ are by the excavators of other sites where they have been found dated to periods which either precede altogether or overlap by but a little the period we propose for Level V at Atchana; and none of them occur freely in Level VI which, on the analogy of other sites, they ought to do.

For Level VI we have seen that the polychrome and 'Union Jack' decoration on pottery is only beginning to come in at the end of the period, from fifty to a hundred years or more after it is in use in Palestine or so close by as Ugarit. The 'red on black' Cypriote ware (one piece of which was on the border-line between Levels VI and V) should, on the analogy of other sites, antedate the period altogether. It is not possible to solve all the difficulties by abandoning the date $155^{\circ}$ B.c. as the point of transition between the two periods; if we put that point far enough back to accord with the dating of the polychrome and black impressed wares we should not leave to Level VI nearly enough time for the building and rebuilding of its castle, and we should still be unable to reconcile our chronology with the evidence of the 'red on black' pottery. For that pottery Level VI begins too late.

Our date for Level VII is, of course, fixed by the fact that Yarim-Lim was a contemporary of Hammurabi of Babylon whose date has been reduced to I 728-1686 B.c. In view of the relation between the two kings it is not surprising that the sculpture of Alalakh should show such unmistakable dependence on the art traditions of Mesopotamia. But side by side with the statues in Mesopotamian style we have one Egyptianizing head and Egyptian deities and symbols on the personal seals of members of the royal house of Alalakh. Egypt had not exercised any direct influence over north Syria since the time of 'the last strong king of the XIIth Dynasty, Amenemmes III, who died in 1795', and it is indeed curious that ninety years later, when Egypt was at its lowest ebb and was actually in the hands of the Hyksos invaders, a prince in the extreme north of Syria, who had nothing to do with the Hyksos (whose forces in Egypt did apparently conform to the local religion), should ostentatiously place himself under the protection of Egyptian gods. Yet our chronology shows that this was the case.

\footnotetext{
I I shall return to this point later, but it may stand for the moment.
}

2 Albright in B.A.S.O.R., No. 77, 1940. 
Dr. Schaeffer has been able to prove, by the discovery of actual monuments, that Ugarit was subject to the Egyptian kings of the XIIth Dynasty, and he has also been able to prove that the stratum containing the monuments of Amenemmes (Amenemhet) III was immediately succeeded by that representing the First Dynasty of Babylon; at Ugarit there was no interregnum of ninety years. Personally I cannot believe that Level VII at Atchana can be so far separated from the XIIth Dynasty. We have found no monuments of that dynasty at Atchana-it is possible that direct Egyptian control, established at Ugarit, did not extend to Alalakh-but the two cities lie not far apart and Alalakh could not fail to be influenced by her powerful neighbour. It seems to me that that influence of the XIIth Dynasty suzerains is the only plausible explanation of the use at Alalakh of Egyptian style and symbols in the Level VII period; but I cannot believe that it had not been dissipated long before the close of the eighteenth century B.C. The evidence of Atchana, in agreement with that of Ugarit, requires that the XIIth Dynasty of Egypt and the First Dynasty of Babylon should be brought much more closely together than Albright's chronology allows-Hammurabi of Yamhad must have risen to power quite soon after the collapse of the authority of Egypt; and when it is seen that for Levels VI and V also his chronology is incompatible with what we believe to be the established facts of archaeology, one cannot but suspect that there is something wrong with the chronology. Even if the 'established facts of archaeology' have to be revised and their dates reduced, ${ }^{\mathrm{I}}$ the difficulty of the gap between Level VII and the XIIth Dynasty remains; the scheme put forward by Sidney Smith (v. supra, p. 384) at least avoided that gap, and the resultant dating of Levels VI and V (his date for the sack of Babylon is I 595 в.c.) accorded perfectly with the archaeological evidence.

I believe, then, that Level VII must be put between circa i 780 and I $73^{\circ}$ B.c. What caused the destruction of the city in Niqme-epuh's time I do not know, unless, as Smith suggests, it was connected in some way with the Kassite invasion of Babylonia; it coincides also with the Hyksos invasion of Egypt, and in a moment of vast movements of the sort anything might happen. After the disaster Alalakh ceased to be a royal residence-the old palace was ostentatiously deserted and became 'a dung-hill', and we found no other. The city, however, gradually recovered, its defences were rebuilt, and in the latter part of the period at least objects of lapis-lazuli paste and millefiori glass show that it had become wealthy and prosperous. ${ }^{2}$ It presumably continued to be part of the kingdom of Yambad, whose capital was Aleppo. It was not playing any important political part, and the curious revival in the pottery of ancient local traditions which had been suppressed under the Yarim-Lim dynasty may perhaps result from this and express the nostalgia born of defeat.

The capture of Aleppo by Mursilis I, the Hittite, in or about I 595 B.C., involved the

\footnotetext{
I I suspect that Albright's change of opinion regarding the date of the 'Union Jack' motive is based not on archaeological considerations so much as on the need to harmonize it with his new system. The reduction in date is difficult in that the excavators concerned have generally based their views on Egyptian chronology, which is well enough established to
}

make a change of fifty years most improbable.

2 There is no foundation for Schaeffer's statement (Stratigraphie comparée, p. 107, 'Un hiatus sépare le Bronze Moyen d'Atchana du Bronze Récent; il s'étend à peu près de $165^{\circ}$ à I $55^{\circ}$ en chiffres ronds.' There was no hiatus, and the period he defines was a flourishing one. 
fall of Alalakh and the end of Level VI. The town does not seem to have suffered greatly; though its fortifications were dismantled; the Hittites retired and the north Syrians were left very much to their own devices. The pottery of Level $V$ shows that the town was now exposed to new influences and was trading with new clients; if it be the case that the White Slip ware originated in northern Anatolia (v. p. 369), it would mean that the Hittite raid had opened up a new market for business on a large scale, and the introduction of $\mathrm{Nuzu}$ ware and the character of the temple (if my theory regarding it be accepted) witness to the dependence of Alalakh on Mitanni. But meanwhile Egypt was pursuing a forward policy in Syria and about I $_{527}$ B.C. Tuthmosis I advanced to the banks of the Euphrates, into Naharina, the land between the Euphrates and the Orontes. The two Egyptian generals to whose tomb-inscriptions ${ }^{1}$ we are indebted for our knowledge of the campaign do not mention the capture of any towns (they were interested only in their personal exploits), but there is reason to think that Tuthmosis's great march was something more than a mere raid and that the capture or surrender of cities would have been followed by their organization as parts of the empire of the Pharaohs ${ }^{2}$-I would attribute the siege of Alalakh (of which we found evidence) to Tuthmosis I and regard the faience bowl as dedicated by the Egyptian Resident left in charge of the city.

Alalakh probably joined with its neighbouring states in renouncing allegiance to Egypt not so very long after it had been imposed by Tuthmosis I; the temple offering of the Egyptian Resident was thrown into a rubbish-pit. But after Tuthmosis III's victory at Carchemish in 1468 when he crossed the Euphrates, while he was in Niy the petty rulers of the cities off the line of his march made haste to come in and offer their surrender. Probably the king of Alalakh was one of them; at any rate, five years later Tuthmosis was receiving tribute from Alalakh, and it must have been then, or immediately after his victory, that he placed one Taku on the throne of Alalakh. ${ }^{3}$ But on the death of Tuthmosis III in I 447 Aleppo (and therefore Alalakh) revolted, and although Amenophis II punished the rebels he never regained control of north Syria; this I take to be the occasion of Niqme-pa's securing the throne. ${ }^{4}$ After his accession Egypt for all practical purposes disappears from the scene and, as one of our tablets proves, ${ }^{5}$ Alalakh becomes subject in turn to Khanigalbat and to Mitanni.

The longer chronology, i.e. the earlier dating for Hammurabi of Babylon, harmonizes very much better with the archaeological data from Atchana than does the short. This, of course, is not decisive, but I think that it is an argument to be considered.

In the case of Level IV it is not so much the positive dating that has to be considered in the light of the archaeological evidence as the arrangement within the period of the persons whose names appear on the tablets and on the inscription of the Idri-mi statue,

I Breasted, A.R. ii. 8I, 85 .

2 Tuthmosis III justified his campaigns in the same area on the grounds that the countries had rebelled; 'Behold, from Yeraza to the marshes of the earth' (i.e. the upper Euphrates) 'they had begun to revolt against his Majesty.' A.R. ii. 4 I 6 .

3 This depends on Adad-nirari, son of Idri-mi, being the Adad-nirari who wrote Tell el Amarna letter No. 5 I .

Taku is doubtful. Niqme-pa uses his seal; but Mr. Wiseman states: 'Abban (possibly Abba-il) is certainly to be placed in Level VII, where we have several mentions of his name in his contracts'. Smith (Statue of Idri-mi, p. 59) rightly observes that 'the retention in use of a royal seal after centuries seems unlikely'. Perhaps we must indulge in another duplication.

$5 \mathrm{ATT} / 3^{8 / 52} ;$ v. A.F. xix (I 939), p. 41.

${ }_{4}$ Whether there had been a King Abba-il in succession to 
i.e. whether the Idri-mi of the statue was the grandson of Niqme-pa (as held by Sidney Smith, who reads the name in 1.43 as Shutarna and identifies him with Shutarna II of Mitanni) or the father of Niqme-pa (as held by those who read the name as Barat(t)arna and identify him with an ancestor, probably the grandfather, of Saushshatar of Mitanni who seems to be mentioned in a Nuzi text).

Sidney Smith's chronological scheme is as follows: ${ }^{\mathrm{I}}$

\begin{tabular}{|c|c|c|c|}
\hline Dates (B.C.) & Egypt & Mitanni & $N i$ \\
\hline I $50 \mathrm{I}-1447$ & Tuthmosis III & & Taku \\
\hline I $447-$ I 422 & Amenophis II & Shutarna I & Abba-il \\
\hline & & Shaushshatar & Niqme-pa (son of Idri-mi) \\
\hline I $422-$ I 4 I 5 & Tuthmosis IV & Artatama I & Ilim-ilimma \\
\hline \multirow[t]{2}{*}{ I 4 I 5 -I 375} & Amenophis III & Shutarna II & Idri-mi (II) \\
\hline & $\begin{array}{l}\text { s. A } \\
\text { Dus }\end{array}$ & $\begin{array}{l}\text { Artatama II } \\
\text { shumara } \\
\text { atta }\end{array}$ & Takuwa \\
\hline I $375^{-1} 35^{8}$ & Amenophis IV & & \\
\hline
\end{tabular}

In the Level IV palace we found many scores of tablets all of which fall within two reigns, those of Niqme-pa and of his son Ilim-ilimma; Mr. Wiseman, who has studied all the tablets from Atchana, says of these that they reflect the conditions covering a period of, say, fifty years only, and he comments 'they add little to the chronological question. There are, however, additional indications that Idri-mi may be the father rather than the grandson of Niqme-pa. There is a reference to a treaty between Barat(t)arna and Idri$\mathrm{mi}$, and on a number of occasions Niqme-pa seals documents with a seal inscribed with Idri-mi's name. It is, of course, possible that these could all refer to the Idri-mi I postulated by Smith. ... However, in the light of the possible references to Baratarna in the statue inscription (denied by Smith) I am inclined to place Idri-mi before Niqme-pa.'

Working upon this basis and adopting the order of kings as given by Albright we have a continuous line of descent showing Ilim-ilimma I, Idri-mi (I $480-$ I 450 B.C.), Adadnirari, Niqme-pa, Ilim-ilimma II, and if we allow a maximum of fifty years for the period covered by the tablets the reign of Ilim-ilimma II must have ended by I 400 B.c.

Since Level IV begins with the building of Niqme-pa's palace his predecessors on the throne really come in our archaeological Level V; but since the transition from Level $\mathrm{V}$ to Level IV was a peaceful one there can be no objection to this. None the less there is a difficulty, although it may not be regarded as very serious.

None of the Level IV tablets antedate the accession of Niqme-pa. If it be urged that the older archives of the dynasty would not necessarily be kept in the new palace, I must point out that not nearly all the tablets came from the palace itself; a number were

I The Statue of Idri-mi, p. 59. He remarks that the dates of Egyptian reigns in the left-hand column are based on a conventional date for the death of Amenhetep III, and may be a few years wrong; the known minimum lengths of reigns are used, and may be too short. For the sake of clarity I have not taken over Smith's transliteration of names but have substituted the forms used elsewhere in this book. 
found in a separate building by the city gate which dated from the Level $\mathrm{V}$ period but was still in use in Level IV, and of them Mr. Wiseman writes: 'where evidence for dating is present these appear similar to others from Level IV, e.g. ATT/8/103, I06, I36, are contracts made before Niqme-pa. ATT/8/104 is a letter to Ballanuwa, who elsewhere appears frequently as witness to Niqme-pa's seal.' So far as the archives go there seems to be a definite break between Niqme-pa and anyone who preceded him. And the same is true of the palace itself. This occupies the site and incorporates a large part of an important building which may have been the palace of former kings (on this see above, pp. I I I sq.), but the new part is differently orientated from that or from any other building we have discovered, so that it presents a very anomalous appearance on the plan (PI. XXII). We could detect no material reason for this really striking departure from all the past traditions of the city's architecture; but it is possible that the departure was an end in itself and was intended to symbolize the beginning of a new régime. There would be no point in that if Niqme-pa merely succeeded his brother on the throne of his fathers; but if it were the case of a 'new' man, a member perhaps of the royal house but not the regular heir, assuming the throne as the result of some political change, then this striving after originality would be at least understandable.

On Albright's system, from the death of Ilim-ilimma II, circa I 400, to the end of the Level IV period in I 370 there is a gap in the history of Alalakh which we have no means of filling.

One point that must be seriously considered is the following: Idri-mi's inscription tells us that his father, Ilim-ilimma I's reign was ended by a rebellion; by saying later on that he himself on his return to Alalakh had to build a palace for himself he implies that the rebels had destroyed that of his father. ${ }^{I}$ The excavations at Atchana show that the reign of Ilim-ilimma II ended (about sixty years later) with a rebellion in the course of which the royal palace was destroyed. This historical repetition ${ }^{2}$ is too exact to be convincing, and the objection gathers force when we remember that there is no textual support for the existence of two Ilim-ilimmas; the duplication results from making the Idrimi of the statue the father of Niqme-pa. A further archaeological difficulty is the survival of the Idri-mi statue. It was found in the ruins of the Level I temple and must have been preserved, and venerated, for over 200 years; this is remarkable, but it is an indisputable fact. The fact becomes more remarkable if in the time of his grandson the people of Alalakh turned against the royal family and sacked and burned the king's palace but none the less respected the statue of the old king. It is possible, but it is one more unlikelihood.

\footnotetext{
I It might be suggested that the palace which we found was that built by Idri-mi after his return and was simply inherited (not built) by Niqme-pa; against this must be set the entire absence from the palace ruins and neighbourhood of any Idri-mi tablets.

2 The coincidence does not stop there. The Idri-mi inscription records that it was composed by the scribe Sharruwa; there is no parallel for such mention, and it can only be explained on the supposition that Sharruwa was 'an
}

extremely important and elderly minister of state. It is likely that he was alive in the reign of Ilim-ilimma, the father of Idri-mi, and he would even then be a scribe'. A scribe Sharruwa is mentioned also on tablets of Ilim-ilimma the son of Niqme-pa. The same man cannot have been a prominent person in the time of Idri-mi and still have been active sixty years later; so we are driven to the conclusion that the two Ilim-ilimmas were further alike in that each employed a scribe named Sharruwa. 
The whole problem of the historical order of the kings of Alalakh has arisen from the doubt as to whether the name in 1.43 of Idri-mi's inscription should be read as Shutarna, i.e. Shutarna II of Mitanni, or as Barat(t)arna, identified as an ancestor of Saushshatar, probably the father of Shutarna I. The question, together with its historical implications, has been discussed by Smith, Albright, and others, and on a matter of epigraphy I can, of course, express no opinion at all. Albright has pointed out that 'Smith arbitrarily identifies Ilim-ilimma father of Idri-mi with Ilim-ilimma son of Niqme-pa'; he might have gone on to say that Smith also identifies Adad-nirari son of Idri-mi with Adadnirari, writer of the Tell el Amarna letter No. 5 I (Smith now identifies Sharruwa the scribe of Idri-mi with Sharruwa the scribe of Ilim-ilimma II), and by distinguishing the father of Niqme-pa from the son of Ilim-ilimma he is obliged to posit two Idri-mis. All that is perfectly true, but it is also true that even if the reading Barat $(t)$ arna be correct the identification of him with the ancestor of Saushshatar is equally arbitrary; the identification of King Idri-mi with the father of Niqme-pa (to whom his son does not give the title of King) is equally arbitrary; Albright is obliged to posit two Ilim-ilimmas, and also two Adad-niraris, and two Sharruwas. None of this is impossible. Mr. Wiseman writes: 'There is abundant evidence from the texts that many of these names are common throughout the I 4th to I 6th centuries in Syria', so that duplication is allowable, though it should be invoked with moderation.

One fact, which has come to light since Albright's promulgation of his theory, is not indeed decisive but must be taken into consideration; this is the occurrence in the Level IV palace of a tablet (No. 47, Pl. LXII) bearing the seal-impression of Shutarna king of Mitanni. Since the palace archives are strictly limited to the reigns of Niqme-pa and Ilim-ilimma the regnal period of those two kings must needs overlap with that of the Mitanni king. Unfortunately there is no means of saying whether the king in question was Shutarna I or Shutarna II, so that both possibilities must be considered. If it be Shutarna I the evidence supports Sidney Smith, who makes him a contemporary of Niqme-pa, and disproves Albright's scheme whereby he would be contemporary with Idri-mi, none of whose tablets are found in the palace. If it be Shutarna II it disproves Smith's chronology, which equates Shutarna II with Idri-mi, but it is almost equally difficult to reconcile with Albright's system, for he makes Niqme-pa come to the throne circ. 1450 B.c. and Shutarna II begin to reign circ. I 400 B.C., in which case for Ilimilimma to overlap with Shutarna requires a prolongation of the combined reigns of Niqme-pa and his son which seems to me most improbable. ${ }^{\mathrm{I}}$

The opinion that I am entitled to express is that while Albright's system does not agree with the archaeological facts Smith's does. If Niqme-pa's father, Idri-mi, was not a king and Niqme-pa was the founder of a new royal line, this would fully explain the absence

\footnotetext{
I It is true that Mr. Wiseman allows anything up to fifty years for the period covered by the tablets, but this is a maximum figure and Albright's arrangement of the kings seems to demand something shorter. According to him, Niqme-pa succeeded his brother on the throne and so may well have been none too young at the time of his succession; Ilim-ilimma's
}

reign was certainly cut short by the events which led to the destruction of his palace. Even if we assume for the two reigns together the unlikely total of fifty years we have to make the further assumption that the seal-impression dates from the first year of Shutarna and the last year of Ilim-ilimma. 
of earlier tablets and, in some measure, the abnormality of the new palace. The Ilimilimma whose palace we found sacked and burned would be the Ilim-ilimma who was the victim of the rebellion described by his son and whose palace was destroyed by the rebels. Idri-mi after his return built a new palace for himself; we found that late in the Level IV period, after the burning of Ilim-ilimma's palace, the interior of the castle was remodelled on the lines of a palace, suggesting that a new ruler was taking precautions against more internal trouble. The time-gap between the destruction of the palace excavated by us and the end of the Level IV period, which Albright's system leaves void, is, as Smith has shown, adequately filled if Idri-mi and his successors are placed there-but that, of course, involves using Smith's chronology and not the shortened chronology of Albright. The political difficulties which Albright urges against Smith's order for the kings are based on his own chronology and do not apply to that of Smith who, using his own figures, gives a reasonable explanation of the history. Albright's order of the kings, taken in conjunction with his own chronology, does not escape political difficulties, e.g. circa I 5 I 5 B.c. Mursilis the Hittite sacks Aleppo, and after that his stepson Hantilis successfully fights the Hurri at Carchemish, but soon after 1490 'Barat(t)arna' the Hurri is king of Aleppo and overlord of Niy and Mukish; or again, Tuthmosis III in his $33^{\text {rd year makes }}$ himself complete master of north Syria 'in I 457 at latest', yet Idri-mi at the end of his reign-'I should date Idri-mi about I $480-$ I 450 B.C. with the minimal date for the end of his reign $c$. I 440 B.c.'-claims that he is and has been for over twenty years the vassal of Barat(t)arna of Mitanni. At that moment probably he was (according to Albright's dates) a vassal of the king of Egypt. Such historical difficulties can perhaps be met, but the archaeological inconsistencies involved in Albright's system cannot, so far as I can see, be explained away.

The occasion of the transition from Level IV to Level III is obvious. Threatened by the aggressive policy of the Boğazköy Hittites and anxious for help from any quarter the small north Syrian States (and amongst them Niy, if the Amarna letter $5 \mathrm{I}$ is indeed written by Idri-mi's son) bethought them of the old vassalage to Egypt, long neglected, and claimed the protection of Pharaoh as their overlord; but no aid was forthcoming. Adad-nirari presumably died and Takuwa succeeded him as king of Alalakh just as matters came to a head. In circa I 370 B.c. Suppiluliuma advanced in force and drove Dušratta from the throne of Mitanni and 'overpowered the land of Aleppo and the land of Mukish. Takuwa, the king of the city of Ni-ia (Niy) came back to the land of Mukish to my presence, saying "Peace!'.' Takuwa surrendered, but behind his back his brothers attempted further resistance, but this was crushed and steps were taken to prevent another such breach of faith; the castle and the late Level IV state rooms in it were burnt, over its ruins and over the site of Niqme-pa's palace a huge fortress-palace was erected, and a new temple was built in the Hittite style. These must have been the work of Suppiluliuma, and they mark the beginning of our Level III. ${ }^{\mathrm{I}}$

\footnotetext{
I Because it upsets the whole validity of my argument I must protest against an hypothesis put forward by Schaeffer (Stratigraphie comparée, p. I00) to the effect that 'le palais du
}

niveau IV d'Atchana fut détruit lors du tremblement de terre de I 365 en chiffres ronds, catastrophe qui avait sévèrement endommagé Ras Shamra et bien d'autres villes en 
In Alalakh and Chronology Sidney Smith published (p. 47) a dated summary of the stratification of the site which, he said, would have to be corrected in the light of further information. Since I 940 a great many new facts have been discovered which make correction of Smith's scheme necessary; in particular the short space of thirty years which he allows for the 'merely barbarous' Level I is found to be impossible, and his date of I 285 I 275 B.c. for the transition from Level III to Level II accords ill with the evidence of the pottery.

On the archaeological evidence I have always felt that Level III was a rather ephemeral period. Its great fortress-palace continued in use throughout the whole period of Level II, subject only to certain internal modifications which we have no means of dating. Its temple was burned, it would seem deliberately, and that, too, may have been done at any time after its foundation. The private houses of Level III contain no evidence of rebuilding or repair-e.g. we find in them no secondary floor-levels-but the houses of Level II are for the most part built on the foundations of those of Level III and in the main follow their lines; that is to say, by the time the mud-brick houses of Level III were falling into decay and needed to be rebuilt the Level III period was over, and the new editions of the houses belong to Level II. The floruit of the buildings could be stretched to cover the span of about seventy-five years suggested by Smith, but it is more consistent with a much shorter dating.

In the Level II temple was found the Cypro-Mycenaean chariot-krater, PI. CXXVIII $a$; fragments of a second came in the temple of Level III. In Cyprus these chariot-kraters are dated by Sjöqvist ${ }^{1}$ to Late Cypriote II B, i.e. to between I 350 and I 275 B.C.; imported examples found in the tombs at Ras Shamra are assigned by Schaeffer to the same date, the very latest belonging to the early part of the thirteenth century. ${ }^{2}$ In dealing with objects found in temples it is always necessary to bear in mind the possibility that they were heirlooms preserved in the temple treasury long after the time at which they were made; but a large and not particularly valuable clay vase is not so likely to belong to that category, and if its evidence be admitted it is certainly in favour of the Level II's temple having been standing in the fourteenth century, prior to the date circa 1275 postulated by Smith's scheme.

Dr. Schaeffer insists on the importance for dating purposes of cylinder seals made of

Syrie-Palestine et en Asie Occidentale en général. Cette hypothèse s'accorderait avec la date de 1370 proposée par M. Sidney Smith pour la fin du niveau IV.' The date I 370 is simply the date of the Hittite invasion which caused the transition from Level IV to Level III; it has nothing to do with the destruction of the Niqme-pa palace, which occurred long before, and nothing to do with any earthquake. The palace was destroyed by fire and not by an earthquake, for the private houses of Level IV bore no signs of damage at all. Dr. Schaeffer found at Ugarit perfectly good evidence, I think, for earthquake as well as for a fire occurring about the middle of the $14^{\text {th }}$ century and very properly connects his fire with the Amarna letter I 5 I of $c$. 1365 in which Abi-milki of Tyre reports to Pharaoh that "half the city of Ugarit has been destroyed by fire, half of it is not.' Abi-milki does not mention or imply anything about an earthquake-an earthquake may have started the fire but it was evidently the fire that was the destructive agent - nor does he write of any damage of any sort to any other town. Had there been such a widespread and devastating earthquake as Dr. Schaeffer posits Abi-milki's intelligence report would not have failed to announce it. There was no sign of earthquake at Atchana in the I4th century, nor at most of the Syrian and Palestinian sites quoted by Schaeffer; such signs were recorded at Jericho and at Gezer but were attributed by the excavators to very different dates.

I E. Sjöqvist, Problems of the Late Cypriote Bronze Age, P. I 12.
2 Syria, xiv, p. I05. 
frit, moulded and glazed, distinguished by their style as well as by their technique, which are found all over Syria and Palestine and as far afield as Cyprus and Persia; at Ugarit all or practically all belong to his period Ugarit Récent 2 ( $1450-1365$ B.c.); none are earlier, and only a very few with an inferior quality of engraving come in the earliest

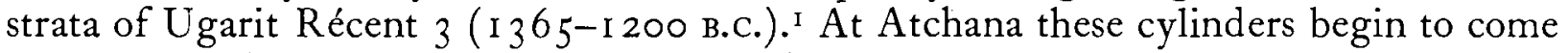
in at a somewhat earlier date than at Ugarit (Atchana was nearer to the original centre of manufacture), ${ }^{2}$ but the general conclusions are in harmony; single examples occur in Levels VI and V, then they become common; upwards of seven were found in Level II, none at all in Level I. According to this evidence again Level II should go back well into the fourteenth century.

The Nuzu painted pottery has been accurately dated by the excavations at Brak; ${ }^{3}$ it begins about 1500 , is in full production under Shaushshatar in $145^{\circ}$, and dies out (so far as the Upper Khabur Valley is concerned) in the course of the fourteenth century. At Atchana the ware first appears, sparsely, in Level IV, is common in Level III, and still more common in Level II, when it develops the peculiar 'Atchana' style derived from the Minoan; and it disappears altogether by the beginning of Level I. The parallel with Brak is exact if Level II overlaps into the fourteenth century; if, on the other hand, it is made to begin only after I 275 B.C. the parallel fails to hold good. Again, the Cretan inspiration of the 'Atchana' pottery is unmistakable, but it is difficult to explain if the ware dates from the middle of the thirteenth century, 200 years after the style had disappeared from Crete; but if it belong to the fourteenth century it becomes an illustration of the 'Cretan revival' which at Ugarit could influence such a masterpiece as the ivory

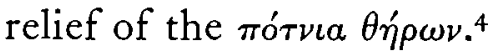

Any attempt to fix the time of the transition from Level III to Level II has to take into account the facts $(a)$ that the temple was burned and rebuilt on non-Hittite lines; (b) that the fortress-palace continued in use; these two together imply that the change was not due to foreign conquest (which would have involved the destruction of the fortress) but to a revolt against the Hittite suzerain power whose temple would naturally be desecrated to make room for a different ritual; and $(c)$ that the free import of L.M. III B pottery only began in Level II, probably in the latter half of the Level II period. Immediately after the death of Suppiluliuma the Hittite empire was in an uproar. It took Mursil II seven years of hard fighting to bring north Syria back into allegiance, and as he had to recover Carchemish, which had been his own brother's kingdom, it is not likely that Mukish had remained faithful. I would suggest then that Level II began about 1350 with a revolt against Boğazköy; the town was forced to submit to Mursil II but was leniently treated, ${ }^{5}$ so that its defeat has left no mark on the ruins; thereafter it owned a precarious allegiance to the Hittites which did not prevent intrigues with Egypt, but its cultural complexion was definitely north Syrian and not Hittite, as is

I Stratigraphie comparée, p. 409.

2 For the details $\%$. p. 260.

3 M. E. L. Mallowan, in Iraq, Ix. i, p. 20.

4 Schaeffer, Ugaritica, i, pp. 32, 97-98.

5 'The inhabitants of Syria were more fortunate than the
Khurri east of the Euphrates. The religious cults of the Syrian states were respected ...' (Sidney Smith, Alalakh and Chronology, p. 45). Thus at Alalakh there was no interference with the nonconformist temple which had replaced Suppiluliuma's orthodox shrine. 
shown by the Nuzu pottery; none the less the occurrence of Hittite bulla seals in Levels III to I bears witness to the Power which was throughout nominally paramount. ${ }^{\mathrm{I}}$

The buildings of Level I require a much longer space of time than the thirty years suggested by Smith. The temple was built at the beginning of the period, completely rebuilt later on, and after that it lived through a long-drawn age of decadence. The private houses show three distinct strata. The evidence of the pottery also is very strong. The bulk of the Mycenaean wares found at Atchana came from Level I, some of it definitely from the upper strata of that level, e.g. in graves dug down into the Level I A walls. I have elsewhere ${ }^{2}$ made it clear that I do not accept the theory that the manufacture of L.M. III B vases ceased in I 230 B.C., but I could not go so far against established views as to maintain that all the L.M. III B vases of Level I were made after that date; neither could I agree that they were all heirlooms. It must be conceded that the vases are fairly representative of the thirteenth century as a whole-of one, ATP/37/I I I, found in situ on the floor of a Level I A house, Mr. Stubbings writes: 'it appears to me little if at all later than I 300 , but perhaps in view of the level we could call it I 280 .'

Sidney Smith is undoubtedly right in supposing that the failure of Ramses II's attempt to regain north Syria and the subsequent submission of Aleppo to Muwatallis (c. I 280 в.с.) affected Mukish also and would account for a change of régime at Alalakh; but I think that the change is marked by the transition not from Level III to Level II but from Level II to Level I. Ninety years is not too long for the three phases of Level I.

With the treaty signed by Ramses II and Hattusil in I 273 the intrigues with Egypt, in which Aleppo, and probably therefore Mukish, had been dangerously involved, came to an end and the Hittite suzerainty was again acknowledged; the royal relief of Tutkhaliya IV found dishonoured in the Level I c temple (it may have originated in that of Level I A) should be a corollary to the treaty. For fifty years the city seems to have been prosperous, but thereafter-perhaps as a result of the breakdown of the Hittite power about 1220 B.C. - a phase of decadence set in which was to end with the final destruction of Alalakh wrought by the Peoples of the Sea.

There remains Level $O$. On this subject I have, in my provisional reports, been guilty of inconsistencies which have been strongly, and not unfairly, criticized by Schaeffer. ${ }^{3}$ In 1927 I was driven to postulate a Level $\mathrm{O}$ by finding a curved stone foundation overlying Level I (v. p. I 7 I) and graves which had been cut down through the walls of Level I A and Level I B; believing that Level I ended in I I 94 B.c. I attributed this Level $\mathrm{O}$ to a later date in the twelfth century. In 1938 , chiefly on the grounds that L.M. III pottery occurred in some of those 'Level O' graves, I went over to the view that Level $O$ was really a phase of Level I and belonged to the thirteenth century; I therefore omitted it in my stratification scheme, based on Sidney Smith's chronology, which I put forward

I Mr. Wiseman kindly supplies the following note: 'One classified list of personal names (ATT/38/239) found in W. 7 , Level III, has a different dialectical form for each of the names of classes, i.e. ebe for ebelena and la-ni-a-be for la-niia-hu; Asannu for Sannu. A number of names of a new form also appear in this text for the first time. Also from Level III comes a series of dockets listing distribution of grain. These employ Babylonian/Assyrian month-names and a different measure (the ga) from that employed in Level IV (which is $P . A$.$) . . . This link may have persisted into Level II, where$ the $H A R R A$ - hubullu texts $\left(\mathrm{ATT}_{3} / 38 / \mathrm{I} 8\right.$, I 9 , and ATT/47/25) were found.'

2 ข p 376

3 Stratigraphie comparée, pp. 107 and 577. 
in $1942 .{ }^{\mathrm{I}}$ The finding of temple foundations overlying the Level I temple and laid some considerable time after its destruction ${ }^{2}$ forced me to go back to my first opinion, since this could not be fitted into the time-limits of Level I. The problem was solved by the discovery that one of the late graves (not one with L.M. III pottery) contained a scarab of Ramses VI. ${ }^{3}$ It was then obvious that an attempt was made to recolonize the ruined city, and it was equally clear that the attempt was soon abandoned. Alalakh never recovered. ${ }^{4}$

The chronological scheme which seems to me to fit best the archaeological data is, then, as follows, the dates for all the early periods being put, approximately, in round figures, while for the later periods I take the longer chronology of Sidney Smith:

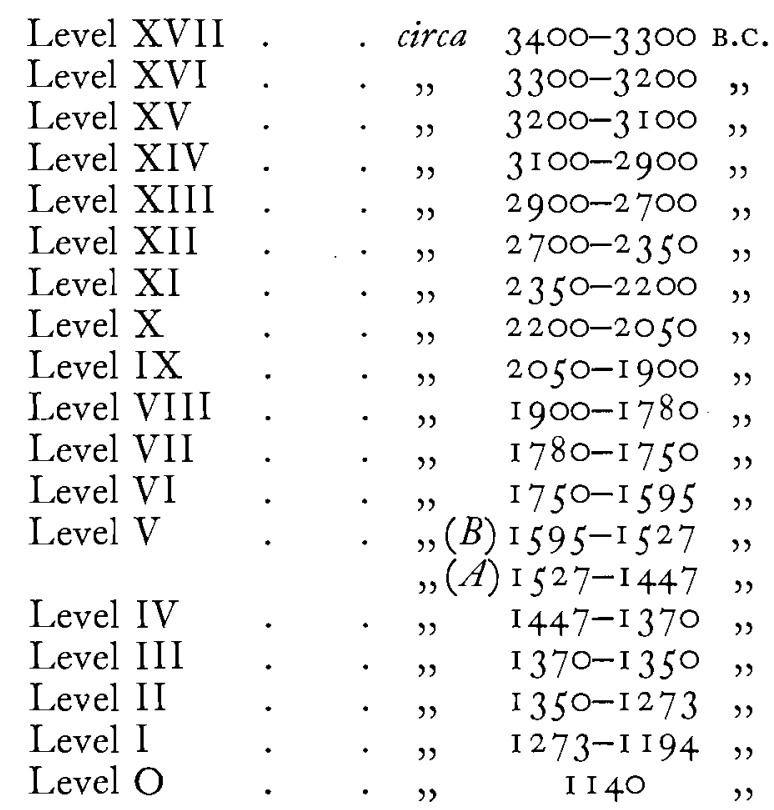

I Journal of the Royal Anthropological Institute, vol. 1xii.

2 See above, p. 90.

3 Pl. LXVI, No. I 3 I, from ATG/37/2. For this identification I am indebted to Mr. I. E. S. Edwards.

$4 \mathrm{My}$ repeated statement that, apart from an abortive attempt to resettle the site of Alalakh in the middle of the twelfth century B.C., the place remained deserted from the time of its destruction by the Peoples of the Sea, in I I 94 B.c., until the present day, may seem arbitrary. It is, of course, dangerous to rely upon negative evidence, and it is true that the natural denudation of the summit of the mound has increased the danger, but none the less does the evidence appear to me to be convincing. Most of our work has been done on the top of the mound. There the later buildings have disappeared, partly through the decomposition of mud brick, partly because ploughing has scattered the rubble foundations of walls; but in the middle of the flat hill-top a good proportion of the later potsherds ought to remain, since there is nothing to carry them away, massed just below the surface soil. We have trenched the gentle SW. slope of the mound from top to bottom, and at its base have excavated (Site $\mathrm{H}$ ) quite a considerable area just where the debris from the upper levels might be expected to accumulate. As a result of all this work we have found the following:

Fragments of a seventh-century Rhodian handled cup with cross and dots.

Five small fragments of east Greek vessels, a jug, a kylix, and two cups (two of the fragments seem to belong to the same vase).

One fragment from an Attic black-figured krater (?).

Two fragments of plain black Attic fourth-century ware, one having incised palmette decoration.

One fragment of Roman blown glass.

A bronze coin of Constantius (?)

A bronze minim, illegible.

A Byzantine copper coin.

A Kufic copper coin.

An Arab tobacco-pipe.

A Queen Victoria farthing.

Considering that the whole of the Amq plain was thickly inhabited throughout the Greek and Roman periods the above is no more than we should expect to be dropped by agricultural labourers or by picnic parties. It is assuredly not evidence of occupation. 


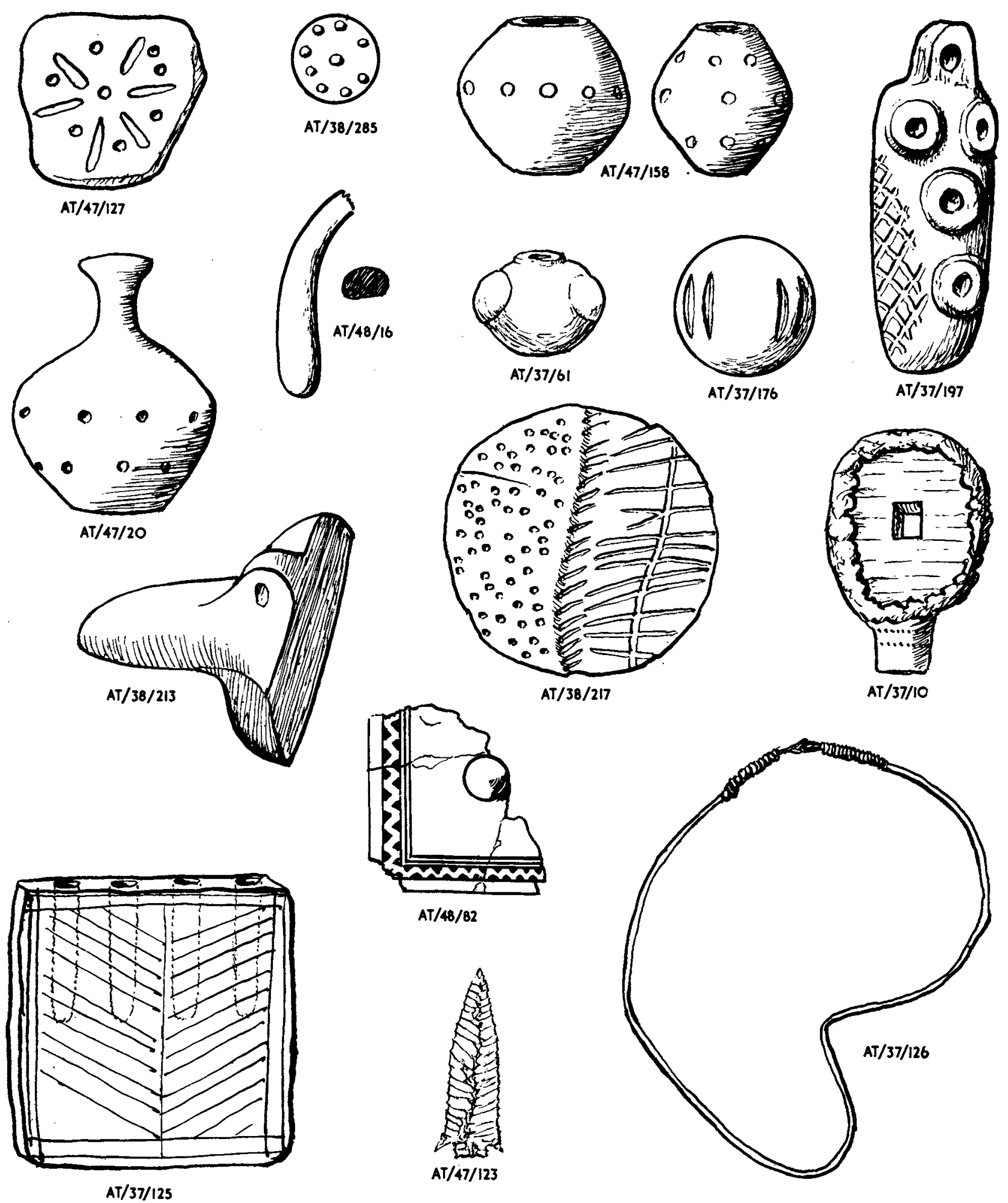

FIG. 75 


\section{CHAPTER XIV}

\section{RESIDUARY CATALOGUE}

T will be understood that very many objects of no intrinsic interest were included
in the Field Catalogue for the sake of their possible evidential value; in so far as they
have been utilized in the foregoing text they have fulfilled their purpose and require
no further notice.

Various categories of objects have been dealt with in special sections or chapters of this book; wherever necessary the catalogue number and description of the individual objects have been given there together with references to plates or types, and it would be pointless to repeat those details; such are accordingly omitted here.

I have also omitted here a certain number of objects of which a full description has been given under the heading of the buildings, graves, \&c., in which they were found.

$\mathrm{AT} / 37 / \mathrm{IO}$. The base of a stag's antler; the horn has been sawn off leaving the spring of the lowest tine which is pierced transversely with a square hole; a square hole is cut through the centre of the base also. Fig. 75. Use uncertain. Found in upper soil over the house site close to the town wall.

AT/37/45. Petal-shaped pieces of inlay in blue lapis-lazuli paste, presumably for flower-rosettes; $1.0 .04 \mathrm{~m}$. Found in upper soil. Level I-II.

AT/37/49. Bone stiletto, with tang for socketing; 1 . O. I I $2 \mathrm{~m}$. Level II.

AT/37/57. Bronze dagger, Type Kn. 4, $1.0 .27 \mathrm{~m}$. The handle was inlaid with wood, of which fragments remained. Found against the inner face of the town wall, Sq. B. 9 (Fig. 72), behind and below the Level I revetment.

AT/37/6I. Bead, or bulla, of baked clay, spherical with slight collars and 4 projecting knobs. Fig. 75. Cf. Schaeffer, Stratigraphie comparée, Figs. 237, 238, examples from Agha Eular Talyche, Iran.

AT/37/62. Celt of black pebble, polished. Upper soil.

AT/37/63. Celt, of black pebble, polished. Upper soil.

$\mathrm{AT} / 37 / 78$. Duck-weight of white quartzite, $1.0 .029 \mathrm{~m}$. Level II; in courtyard behind the town wall.

AT/37/I I 9. Lance-head of blackish-grey cloudy obsidian, roughly flaked; $1.0 .075 \mathrm{~m}$. Surface soil.

AT/37/ I 25. Kohl-pot, steatite; rectangular and flat $(0.058 \mathrm{~m} . \mathrm{sq} \cdot \times 0.015 \mathrm{~m}$. thick), the flat sides decorated with roughly incised herring-bone pattern; in the top edge 4 holes drilled for kohl. Fig. 75. Top-soil.

AT/37/I26. Bronze torque; made of thin wire uniform throughout; a thinner wire is wound spirally round each end and brought to a loop for the fastening. Fig. 75. Level II.

AT/37/1 40. Celt, of green pebble, polished. Top-soil.

$\mathrm{AT} / 37 / \mathrm{I} 53$. Bone pin; plain except for 2 grooves cut near the head; $1.0 .0875 \mathrm{~m}$. Level I в.

$\mathrm{AT} / 37 / 169$. Whetstone, of light grey stone, point broken, actual $1.0 .105 \mathrm{~m}$., diam. $0.012 \mathrm{~m}$. The handle is carved in the form of a pig's head, behind which the shaft is pierced for a suspension-ring of copper wire. Level I. B 2501 $\mathrm{D} d$ 
AT/37/I 76. Three flattened spheres of white steatite, diam. $0.022 \mathrm{~m}$; ; on each are incised two pairs of straight lines. Fig. 75. Use uncertain. Level IV.

$\mathrm{AT} / 37 / \mathrm{I} 97$. Plumb-bob, of drab stone, decorated with incised concentric circles and criss-cross pattern; 1. 0.075 m. Fig. 75. Surface soil.

AT/37/2 I 6. Celt, of dark volcanic stone, polished. Top-soil.

$\mathrm{AT} / 38 /$ I . Bronze tripod support for a vase; ht. 0. I I $5 \mathrm{~m}$., diam. of top $0.06-7 \mathrm{~m}$.; one leg missing. Found $0.70 \mathrm{~m}$. down on Site H; probably Level V. Cf. Pl. LXXIV, AT/37/8.

$\mathrm{AT} / 38 / 6$. Fragment of shell engraved on both sides. This, the only example found at Alalakh of a familiar and widespread type, was brought in as a surface find having no specific provenance or date. Pl. LXXXIII.

$\mathrm{AT} / 38 / \mathrm{I}$. Bone pin, plain, $1.0 .075 \mathrm{~m}$. Level II.

$\mathrm{AT} / 38 / \mathrm{I} 20$. Two bone bodkins, plain, $1.0 .08 \mathrm{I} \mathrm{m}$. and $0.094 \mathrm{~m}$. Level II.

$\mathrm{AT} / 38 / \mathrm{I} 62$. Bone twirl-pins from door-fastenings; roughly cut to diamond shape and centrally pierced; lengths $0.03 \mathrm{~m} .-0.05 \mathrm{~m}$. The use of these objects was made clear by our finding one actually in the doorway of a room; v. p. I77. Level II.

$\mathrm{AT} / 38 / \mathrm{I} 73$. Copper ingot (?). A bar of metal $0.37 \mathrm{~m}$. long $\times 0.04 \mathrm{~m} . \times 0.035 \mathrm{~m}$, rectangular section, bent into horse-shoe shape. Level II.

$\mathrm{AT} / 38 / \mathrm{I} 74$. A bulla or flattened sphere of white limestone, diam. $0.027 \mathrm{~m}$., on one face of which are 4 incised straight lines. Cf. above, AT/37/ 76 . Possibly a weight (?). Level II.

$\mathrm{AT} / 3^{8 / 1}$ 75. Two gaming-pieces and 6 counters (?). The gaming-pieces are cones, ht. $0.02 \mathrm{~m}$, of blue glazed frit with yellow spots in relief; the 'counters' are rectangles of bone $c .0 .02 \mathrm{~m}$. sq. with slightly convex faces. Found together, Level I-II.

$\mathrm{AT} / 38 / \mathrm{I} 80$. A flat-headed silver nail, 1. 0.0 I $7 \mathrm{~m}$. Level III-IV.

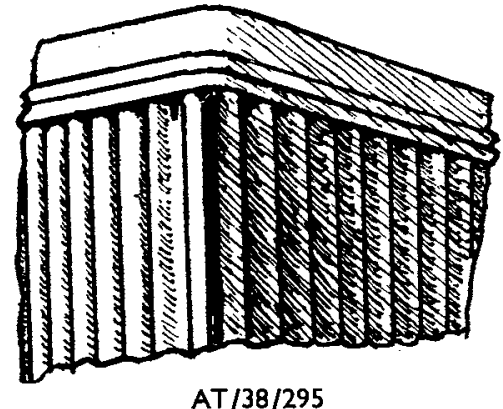

FIG. 76

$\mathrm{AT} / 38 /$ I 92 . Weight, haematite, date-shaped Babylonian type, 1. 0.0 I $7 \mathrm{~m}$., weight I 4 gr. Top-soil.

$\mathrm{AT} / 38 / 202$. Weight, haematite, lozenge-shaped with flat base; 1 . $0.038 \mathrm{~m}$. Top-soil.

$\mathrm{AT} / 38 / 2 \mathrm{I} 3$. Object of baked clay, of unknown use; $0.185 \mathrm{~m} . \times$ O. I 55 m. Fig. 75. Level IV.

$\mathrm{AT} / 38 / 2 \mathrm{I} 4$. Bone stiletto tanged for hafting; $1.0 .086 \mathrm{~m}$. Trench $\mathrm{H}$, probably Level IV-V.

AT/38/2 I 7. Disk of baked clay, diam. $0.062 \mathrm{~m}$., the top face divided into 2 parts of which one is punctured all over and the other roughly incised with a vertical and cross lines. Fig. 75. Trench H, probably Level IV-V.

$\mathrm{AT} / 38 / 235$. Duck-weight of green steatite, 1 . 0. I I $\mathrm{m}$. Level V.

$\mathrm{AT} / 38 / 244$. Pottery stand, tripod, in the form of 3 human (?) legs bound together at the ankles; crudely hand-modelled. Ht. $0.076 \mathrm{~m}$. Level V-VI.

$A T / 38 / 257$. White limestone knob, a flattened sphere, with a hole below to take a square tang and a cross-hole for a tie-pin; probably the pommel of a dagger. Level V.

AT/38/264. Celt, of diorite, polished. Level V-VII.

AT/38/273. Bone spatula, roughly shaped, $1.0 .14 \mathrm{~m}$. Level VII.

AT $/ 38 / 27.4$. Bronze object, pin-like, with head in the form of a seven-rayed star and tapering corrugated shaft, $1.0 .062 \mathrm{~m}$. Found in the Level VII town gate. Pl. LXX. Cf. AT/48/88. AT/38/276. Weight, haematite, date-shaped with truncated ends; $1.0 .043 \mathrm{~m}$. Level II-IV.

$\mathrm{AT} / 38 / 285$. Gaming-piece; a flat disk of faience once blue-glazed, on which yellow dots, I central, 8 in a circle round the rim; diam. $0.018 \mathrm{~m}$. Fig. 75. Level III-IV.

$\mathrm{AT} / 3^{8 / 295}$. Fragment of carved basalt, possibly the corner of a reeded square base or pilaster- 
the sides are fluted, above the fluting a horizontal feature of 2 semicircular mouldings with a plain fillet above. Fig. 79. Level VI.

$\mathrm{AT} / 38 / 296$. Two bone spoons or spatulae with long tapered handles and flat blades; 1 . O. I I $\mathrm{m}$. Level II.

$\mathrm{AT} / 39 / 22$. Clay rattle; battledore-shape with hole through handle, the hollow rattle part pierced with small holes; 1. O. I 5 m., width 0.05 m. Cf. Fig. 75, AT/47/20. Sq. M i I, Level IV.

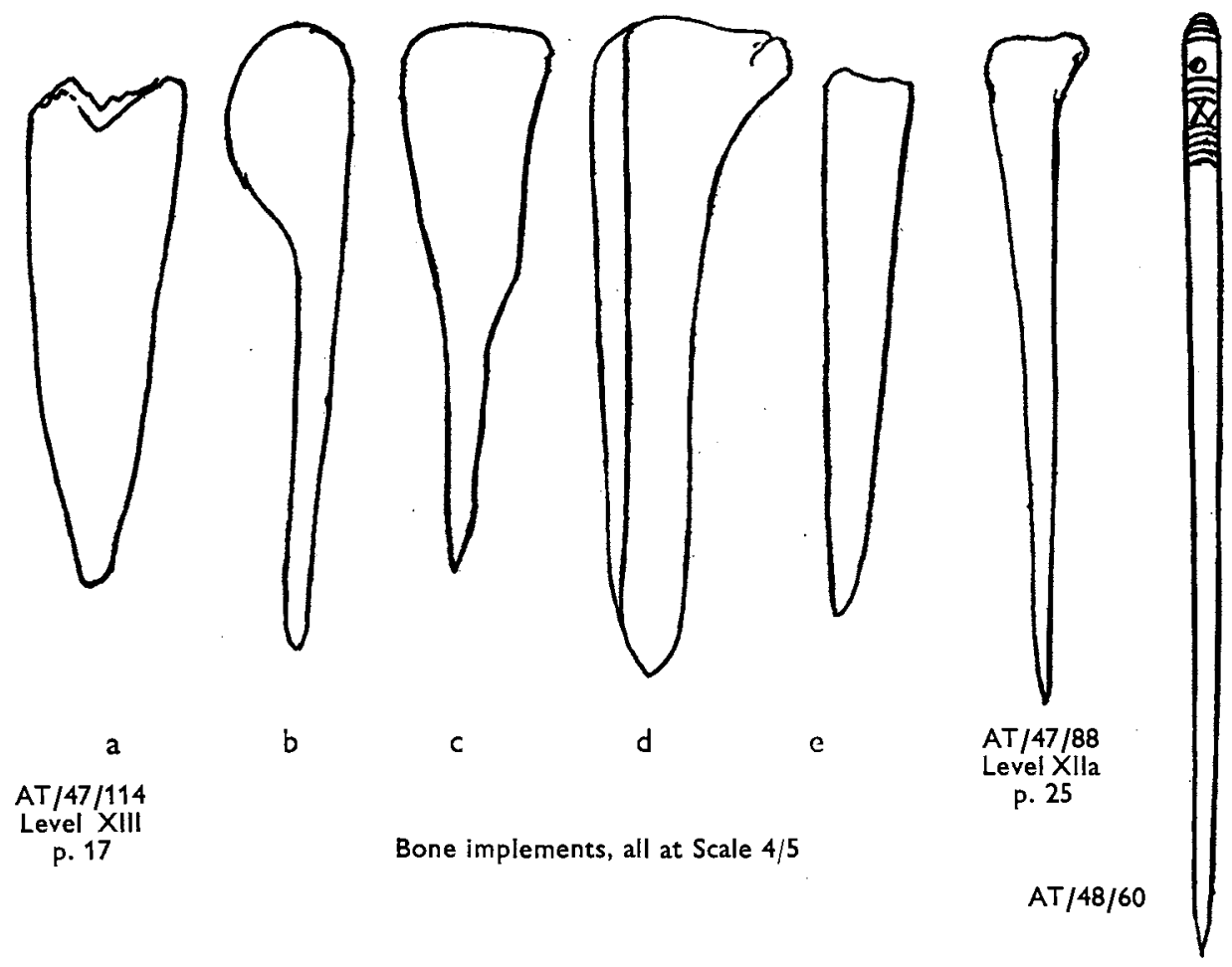

FIG. 77

$\mathrm{AT} / 39 / 34$. Bone pins, plain, lengths from $0.05 \mathrm{~m}$. to $0.108 \mathrm{~m}$.; 7 from Level V, 2 from Level III, I from Level II.

$\mathrm{AT} / 39 / 62$. Bone pin with decorated head (broken), 2 double incised rings with cross-hatching between them; $1.0 .082 \mathrm{~m}$. Level IV or later.

$\mathrm{AT} / 39 / 87$. Twirl-pin (for fastening a box-lid ?) in black clay; an oval with pointed ends centrally pierced; $1.0 .057 \mathrm{~m}$. Top-soil.

AT/39/95. Staff-head (or pommel) of grey steatite, socketed for tenon and with transverse hole for tie-pin. Level IV.

$\mathrm{AT} / 39 /$ I I 4. Weight, haematite, in the form of a frog very crudely rendered but with the eyes inlaid; $1.0 .025 \mathrm{~m}$. Level VII (room 7 of the Yarim-Lim palace).

AT/39/I I 5. Weight, haematite, truncated oval, 1. $0.047 \mathrm{~m}$. Level VII (room 7 of the Yarim-Lim palace).

AT/39/I I 6. Weight, haematite, date-shaped with slightly flattened base, $1.0 .02 \mathrm{~m}$. Level VII (room 7 of the Yarim-Lim palace).

AT/39/I I 8. Sandstone mould (fragment of) for casting bronze chisels. From House 39/B, Level V.

$\mathrm{Dd} 2$ 
$\mathrm{AT} / 39 / \mathrm{I} 26$. Weight, haematite, in the form of a lion's head; width $0.025 \mathrm{~m}$. Level VII (room 9 of the Yarim-Lim palace).

AT/39/1 59. Bone toggle with turned ends, 1. $0.048 \mathrm{~m}$. Upper soil.

AT/39/I 73. Two gaming-pieces, I hemispherical, of glass paste, I conical, of pebble. Level II.

AT/39/ I 74. Obsidian knife-blade, worked flake, 1. 0:047 m. Level II.

AT/39/1 97. Gaming-piece of grey basalt, conical with trimmed base, ht. $0.04 \mathrm{~m}$. Level II.

AT/39/2 I 3. Fragments of blue paste inlay, I scale-shaped, I tear-shaped. Level II.

AT/39/222. Cockle-shell containing blue paint. Sq. M I 3; Level III.

$\mathrm{AT} / 39 / 235$. Flint arrow-head, leaf-shaped with very finely serrated edge, 1. $0 \cdot 044 \mathrm{~m}$. Level VI or VII.

AT/39/2 37. Two instruments (?) of lead; rather heavy pin-shaped with one end flattened chiselfashion and pierced; the stem straight bit not pointed, 1. O. I I $5 \mathrm{~m}$. Level VI.

$\mathrm{AT} / 39 / 2$ 53. Gaming-piece, terra-cotta; cone-shaped with a human face (?) on the side, reversed. Level VII.

AT/39/2 66. Toggle, of black stone, $1.0 .032 \mathrm{~m}$. Level VII.

AT/39/284. Two elephant tusks; they are much splintered and disintegrated but have been fixed in plaster cases. Lengths $\mathrm{I} \cdot 60 \mathrm{~m}$. and $\mathrm{I} \cdot 40 \mathrm{~m}$. Found on the floor of room I I in the YarimLim palace. Level VII. Pl. XVI.

AT/39/328. Celt, of grey stone, polished, 1. $0.045 \mathrm{~m}$. Top-soil.

AT/39/334. Ear-plug, terra-cotta, ht. $0.015 \mathrm{~m}$., diam. $0.02 \mathrm{~m}$. Level VII (from room 22 of the Yarim-Lim palace).

AT/46/I. Weight, haematite, truncated date-shaped, 1. 0.029 m., marked with 2 scratched crescents, probably </'Twenty'; weight $9.5 \mathrm{gm}$. Temple site, upper soil.

AT/46/1 8. Vase of deep blue lapis-lazuli paste, with handle in the form of a couchant lion; the rim chipped but otherwise complete; ht. 0.1 $5 \mathrm{~m}$. Pl. LXXXIII. Found in the Level II temple, $v$. p. $8 \mathrm{I}$.

$\mathrm{AT} / 46 / 2 \mathrm{I}$. Fragment of a vase in dark blue glass paste decorated with a pair of gazelle's horns in relief; $0.05 \mathrm{~m} . \times 0.035 \mathrm{~m}$. Pl. LXXXIII. This and AT/46/45 are the only examples of moulded glass found on the site. From the foundations of the temple of Level I, phase $A$; it could therefore belong to Level II or to any older level since it may have been long preserved in the temple treasury. With it was a fragment of blue glass paste for inlay $(\mathrm{AT} / 46 / 23)$.

AT/46/24. Bronze dagger, Type Kn. 4; $1.0 .37 \mathrm{~m}$.; found in the core of the north or back wall of the sanctuary of the temple of Level I, phase A.

$\mathrm{AT} / 46 / 45$. Fragment of the rim of a vase moulded in blue glass paste; round the bevelled edge of the rim is a chevron pattern in relief. Sq. O I 2 , Level II.

$\mathrm{AT} / 46 / \mathrm{I}$ I 3 . Weight, of grey stone, cylindrical with rounded ends, $1.0 .024 \mathrm{~m}$, weight $5.8 \mathrm{gm}$. Level V-VI.

AT/46/I 25. Bone needle (?); straight and sharply pointed, the head pierced; double incised lines round the stem on each side of the hole, $1.0 .066 \mathrm{~m}$. Level uncertain.

$\mathrm{AT} / 46 / \mathrm{i} 42$. Clay sling-bolt, $1.0 .046 \mathrm{~m}$. Level IV.

$\mathrm{AT} / 46 /$ I 43 . Whetstone, grey schist (?), pierced for suspension, the hole countersunk on both sides; $1.0 .067 \mathrm{~m}$. Below Level III.

$\mathrm{AT} / 46 / \mathrm{I}$ 49. Mace-head of white limestone, laterally pierced with pin-holes to shaft. Ht. $0.03 \mathrm{~m}$. Fig. $80 j$. Level VII.

$\mathrm{AT} / 46 / \mathrm{I} 52$. Hammer-head; a spherical pebble pierced for shafting; diam. $0.09 \mathrm{~m}$. Sq. K I 5 . Level $\mathrm{V}$.

$\mathrm{AT} / 46 / 189$. Object of white marble, shield-shaped, of uncertain use; $1.0 \cdot 145 \mathrm{~m}$. Fig. $80 i$. From room 3 I of the Yarim-Lim palace, Level VII. 
$\mathrm{AT} / 46 / 2$ I 7. Terra-cotta disk, diam. $0.058 \mathrm{~m}$, the back plain; on the front the whole surface is covered with punctured dots and there is a pattern of uncertain meaning in low relief; it is possibly a model of intestines used in divination, showing a kidney (?) on the right and gall-bladder on the left. Fig. 78. Found in a Level V rubbish-pit near the temple (Sq. L I 3).

AT/46/254. Clay loom-weight, dome-shaped and transversely pierced; ht. $0.082 \mathrm{~m} . \times 0.078 \mathrm{~m}$. Sq. L I 4, Level VII.

$A T / 46 / 259$. Terra-cotta ladle, roughly hand-made, with handle pierced for suspension, $1.0 .03 \mathrm{~m}$. Level $\mathrm{V}$ rubbish-pit.

$\mathrm{AT} / 46 / 302$. Fragment of stone offering-table with 3 square sunken compartments, a round depression, and a 3-branched channel; $1 . \mathrm{I} \cdot 25 \mathrm{~m} . \times 0.604 \mathrm{~m}$.

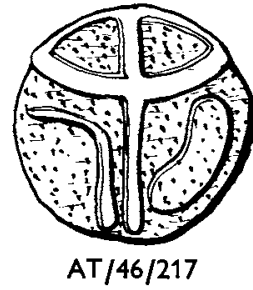

FIG. 78 Fig. 79. Sq. L I6, Level O. It appeared to be in situ against the wall of the Level $O$ temple.

AT/46/303. Fragment of stone offering-table with 2 square sunken compartments, a round depression, and a 2-branched channel; $0.72 \mathrm{~m} . \times 0.48 \mathrm{~m}$. Fig. 79 . It is of interest as showing, together with $\mathrm{AT} / 46 / 302$, the continuity of tradition. From Sq. L I 5 , Level III.

AT/47/20. Clay rattle; bottle-shaped, with 2 rows of small holes round the belly, the mouth stopped with clay; ht. 0.098 m. Fig. 75. Level VII.

AT/47/3 I. Duck-weight, bronze, $1.0 .028 \mathrm{~m}$. Found against the NW. wall of the temple annexe, Level II.

AT/47/36. Hollow cone of blue lapis-lazuli paste, ht. 0.023 m., diam. 0.0 9 m.; possibly a finial for a staff. Temple area, Level II.

AT/47/45. Basalt standard lamp with shallow circular bowl and clustered tripod foot; ht. $0.22 \mathrm{~m}$. Fig. $80 f$. From Level XII.

AT/47/80. Weight, haematite, truncated date-shape, 1. 0.032 m., weight I $9 \mathrm{gm}$. Level VI.

$\mathrm{AT} / 47 / 89$. Ivory rod, square in section, $0.035 \mathrm{~m}$. long with
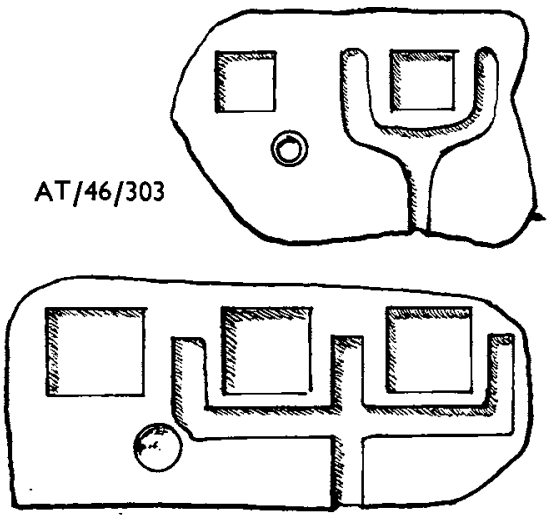

AT/46/302

FIG. 79 a short projecting peg at one end; each side is decorated with incised ornament, cross-hatching, \&c. Possibly a marker for a game. Level VI.

AT/47/98. Weight, haematite, date-shaped, 1. $0.039 \mathrm{~m}$.; weight I $5.05 \mathrm{gm}$. Level VI.

$\mathrm{AT} / 47 /$ I I 3 . Terra-cotta reel (?), one end having criss-cross ornament. Level II.

$\mathrm{AT} / 47 /$ I 23 . Flint arrow-head, barbed type, beautifully made of honey-coloured flint; the whole surface is ripple-flaked from alternate sides; the edge sharpened and the barb-notches made by fine pressure-flaking. The tang is broken. No other flint at all comparable to this was found on the site, 1. 0.04 I m. Fig. 75. Level II.

$\mathrm{AT} / 47 / \mathrm{I} 26$. Celt, of green stone, polished. Level II.

$\mathrm{AT} / 47 / \mathrm{I} 27$. Lead weight (?); a flat piece of metal $0.042 \mathrm{~m} . \times 0.037 \mathrm{~m}$., virtually unshaped, having on the upper surface an incised pattern of a 6 -petalled rosette. Fig. 75. Level III.

$\mathrm{AT} / 47 / \mathrm{I} 28$. Pottery brazier or vase-stand ( $v$. pp. 64 and 248 ). The shape is normal, ht. $0.26 \mathrm{~m}$., diam. of base $0.35 \mathrm{~m}$., of rim $0.30 \mathrm{~m}$., and there are the usual openings in the sides which suggest the use as a brazier. Under the rim and above the base there are bands of rope pattern in relief; between them are plain cavetto mouldings; against the sides are affixed terra-cotta figurines, 5 of the 'naked goddess' type with big fan-shaped head-dress, all 5 struck from the same mould, and I male figure, hand-modelled in the 'snow-man' technique, a warrior apparently in the act of falling. The object was found in more than Ioo pieces, 


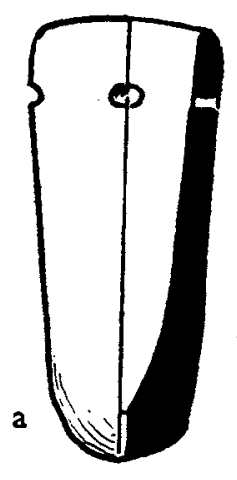

AT/47/157
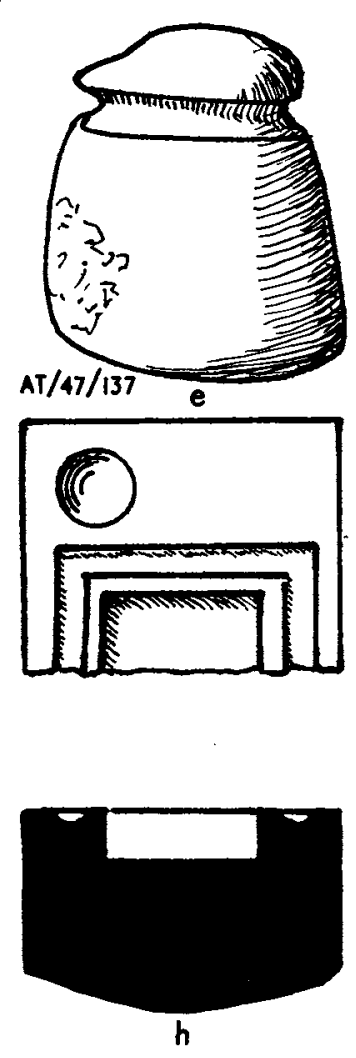

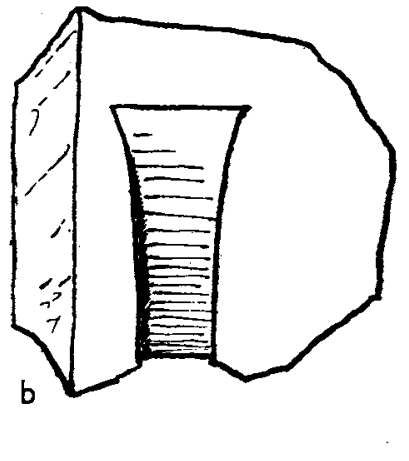

AT/47/162
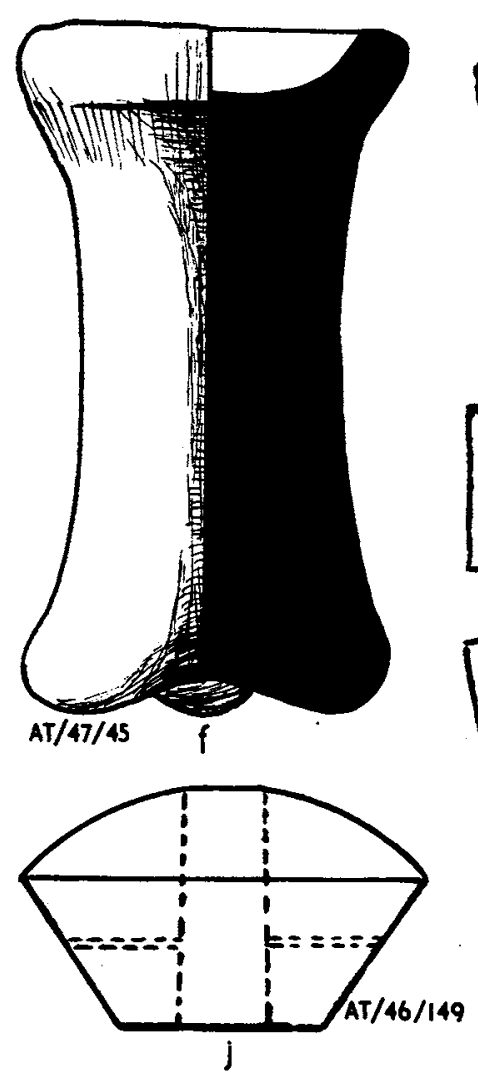

Fig. 80

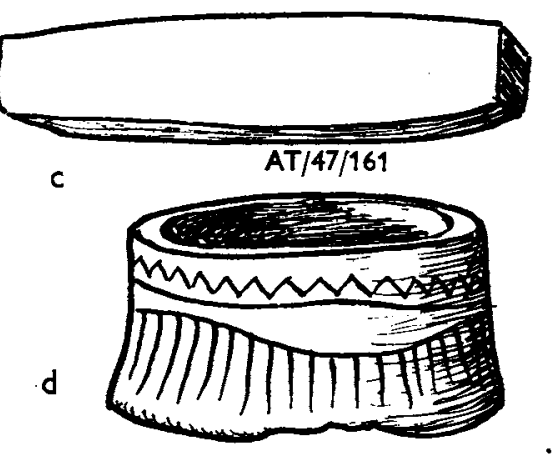

AT/47/133
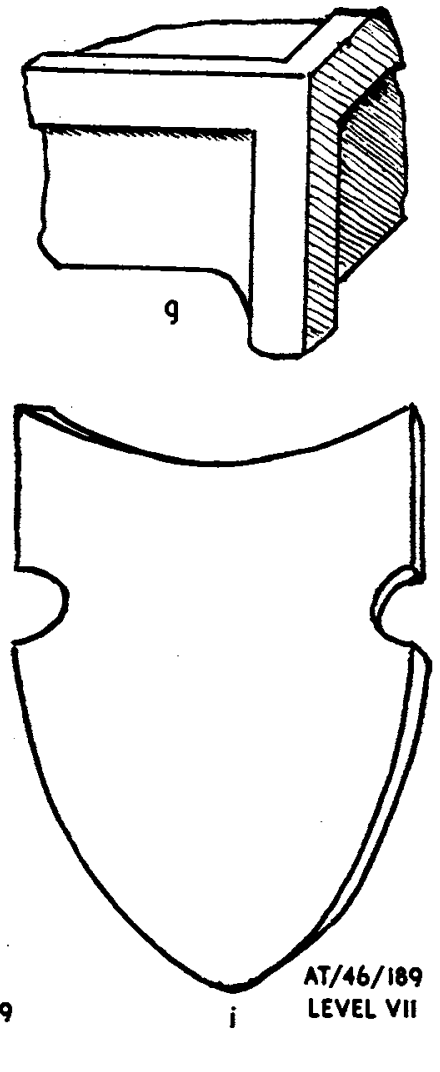
some of which were discoloured and distorted by fire and some missing; all the figures had been detached, but could be replaced without difficulty as the marks of adhesion were clear. Pl. LVIII. The brazier was found on the floor of the Level VII temple. It is tempting to suppose that the figurines illustrate some legend connected with the worship in the temple.

AT/47/I33. Basalt stand or bowl-the top concave-roughly made and decorated round the sides with incised pattern; ht. $0.02 \mathrm{I} \mathrm{m}$. diam. at top $0.037 \mathrm{~m}$. Fig. $80 d$. Level XV.

AT/47/I 37. Basalt hammer, grooved for hafting, $1.0 \cdot 122 \mathrm{~m}$. Fig. $80 e$. From Level XIV.

$\mathrm{AT} / 47 / \mathrm{I} 55$. A slender pointed rod (a pin?) of lead; $1.0 .04 \mathrm{~m}$. Level XV.

AT/47/ 57 . Basalt object, possibly a tool-handle, hollow and with a small hole at the apex; near the open base are four holes for pin attachments; $1.0 .052 \mathrm{~m}$. Fig. $80 a$. Level XVI.

$\mathrm{AT} / 47 / \mathrm{I} 5^{8}$. Two terra-cotta spindle-whorls with impressed circle decoration, hts. $0.033 \mathrm{~m}$. and 0.03 I m. Level XVI.

AT/47/I6r. Basalt hone, 1. 0.I29 m. Fig. 80c. From Level XVI.

$\mathrm{AT} / 47 / 162$. Basalt mould (incomplete) for casting bronze chisels; on one side is the mould for a blade, on the other side one for a butt. L. (as broken) $0.13 \mathrm{~m}$; $0.007 \mathrm{~m}$. wide. Fig. $80 b$. Level XVI.

$\mathrm{AT} / 47 / 163$. Celt, of green stone, polished. Level VI.

$\mathrm{AT} / 47 / \mathrm{I} 64$. Pestle and mortar (found together) of basalt; the mortar a plain shallow basin, diam. 0. I I m., ht. $0.06 \mathrm{~m}$., the pestle with one rounded and one flat end, $1.0 .10 \mathrm{~m} .$, diam. $0.07 \mathrm{~m}$. Level VI.

$\mathrm{AT} / 47 / \mathrm{I} 76$. A palette of grey steatite, egg-shaped, $0.14 \mathrm{~m} . \times 0 \cdot 105 \mathrm{~m}$. See p. I2. Level XVI.

AT/48/I I. Terra-cotta wheel, diam. $0.06 \mathrm{~m}$. Level IV temple.

AT/48/I 6. Black steatite object (the narrow end broken). Fig. 75; possibly the side lock of a sphinx, cf. Evans, P.M. iii, p. 42 I, Fig. 288. From the temple site, Level VII.

$\mathrm{AT} / 48 / 3 \mathrm{I}$. Eye-socket of a statue, in blue-grey schist, $1.0 .048 \mathrm{~m}$., so that the statue must have been well over life size. From the concrete foundations of the Level VII temple.

AT $/ 48 / 34$. Bone awl, plain, $1.0 .08 \mathrm{~m}$. Temple site, Level VIII-IX.

$\mathrm{AT} / 48 / 39$. Weight, haematite, truncated date-shaped, $1.0 .025 \mathrm{~m}$., weight I $46 \mathrm{gr}$. Temple site, Level III-IV.

$\mathrm{AT} / 48 / 40$. Mace-head, white limestone, half of; a plain sphere, originally polished, with central socket-hole. Temple site, Level V-VI.

$\mathrm{AT} / 48 / 42$. Bone needle, plain, $1.0 .05 \mathrm{~m}$. Temple site, Level IX-X.

$\mathrm{AT} / 48 / 46$. Bone needle, $1.0 .12 \mathrm{~m}$., the head decorated with incised bands and cross-hatching. Temple site, Level V-VI.

AT $/ 48 / 53$. Bronze decorative bolt-head (?), cf. AT/38/274, Pl. LXXX; only the 8-rayed head (imperfect), stem missing. Temple site, Level V-VI.

AT $/ 48 / 54$. Clay sling-bolt, $1.0 .035 \mathrm{~m}$. Temple site, Level V.

AT $/ 48 / 60$. Bone needle with incised decoration. L. O.I 2 m. Fig. $77 g$. From a pit of Level V or VI.

$\mathrm{AT} / 48 / 80$. Bone toggle, 1. $0 \cdot 04$ m. Fig. 8 I. Level V (below Niqme-pa's courtyard).

$\mathrm{AT} / 48 / 82$. Fragment of a rectangular box-lid (?) of lapis-lazuli paste; it had a moulded border of vandyke pattern and a knob handle. Fig. 75. Level uncertain, anything between $V$ and VIII.

$\mathrm{AT} / 48 / 88$. Bronze object, pin-like, with star head, cf. AT/38/274, Pl.

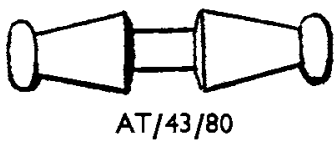

FIG. 8 I LXX. Found in grave ATG/48/1, Level VII.

AT/48/96. Celt, of black chert, the top end showing hammer-marks. From the stone-cutter's workshop (v. p. 293), Level VII.

AT/48/97. Weight, black granite, barrel-shaped, $1.0 .093 \mathrm{~m}$., diam. $0.067 \mathrm{~m}$. in middle, $0.044 \mathrm{~m}$. at ends. From the stone-cutter's workshop (v. p. 293), Level VII. 



\section{INDEX}

Note. This book has been arranged in such a way as to make a subject-index unnecessary for the most part; accordingly to the following index of proper names there have been added subject references only where the relative information has not been collected under a single heading in the text.

Abban, 266, 391.

Adad-nirari, 385 sqq., 39 I (note), 395.

Aegean connexions, 277, 290, 292, 346 .

Aintakya, see Antioch.

Alaca Höyük, 8.

Albright, W.F., 50 (note), $166,356,366,379,381,384$ sqq.

Aleppo, 172, 24I, 381, 388, 389, 390, 395 .

Museum, 49.

Amanus, I72, 381, 382 .

Amenemmes III, 389-9o.

Amenophis II, $39 \mathrm{I}$.

Amq Plain, 5, 8, 288, 347, $38 \mathrm{r}$.

Antioch, 5, 172, 231 .

Araxes valley, 8.

Archive room, I02-3, I I4, 126.

Ashur, 62.

Assyrian glazed pottery, 299 sq.

Atchana, mound of, 5,132 .

Babylonia, parallels with, 54, 62 .

Baetylic idol, I75.

Barat(t)arna, 38 5, 388, 392.

Barnett, R. D., 266 sq.

Beit Mersim, 202, 314 .

Bethshan, model shrines from, 62, 72.

Tell Billa, 347 .

Boğazköy, 9,49 (note), 78, 84, I 47-8, I68, 202, 24I, 25 I, $254,267,276,279,395,397$.

Boissier, A., 252.

Bowls, hand-made and knife-trimmed, 309, 379.

Braidwood, R. J., 5 .

Brak, 246, 269, 3 I 4, 3 1 8, 340, 347, 349, 397.

Du Mesnil du Buisson, 280.

Byblus, 261, 280, 380 .

Carchemish, 78, 86, 89 (note), I I 6, I 47, 202, 224, 248, 29I, $379,391,395,397$.

Catal Höyuk, 6.

Caucasus, 8 .

Chagar Bazar, 269, 280, 340.

Chapel of Level V, I 74-5.

Columns, I7 sq., 6 I (note), 68, 77, 78, 92, 94, I I 2, I I6, I $59,162,164-5,225$.

half-columns in architecture, I42, I 86, 227.

Concrete, use of in building, 59, 63 (note), 92, 100.

Cremation, 202 sq.

Crete, 25, I I6 (note), I I 9,228 sqq., 29I, 294, 308, 350, 370,397 .

Cyprus, 316-1 7, 354 section $(g)$ passim, 369 section $(h)$ passim.
Damascus, 289 .

Deve Huyuk, 299.

Diyarbakir, 238.

Dönmez, A., 6, 238.

Earthquakes, I O I (note), 395 (note).

Egypt, political influence of, 7 I, I66, 259, 260, 266, 297, $380,38 \mathrm{I}, 383,386,39 \mathrm{I}$.

stylistic influence of: faience, $7 \mathrm{I}$; glass, $30 \mathrm{I}$; glazed ware, 27 I, 299; ivories, I I 9, I 2I, 289; sculpture, 64, 235; stone, I 3, 292, 382 .

Enkomi, 375.

Euboea, 370.

Europus, 299

Evans, Sir Arthur, 228.

Forsdyke, Sir John, 370.

Foundation-deposits, 84 , I 58 .

Frankfort, H., 259, 261, $35 \mathrm{I}$.

Frescoes, 31-32, 64, 92, 94, I I 7, I74, I79, 228 sqq. keying of, 100,225 .

Furumark, A., 374 sqq.

Gadd, C. J., 300.

Game, P. M., 239.

Ganěs, 28.

Garstang, Prof. J., 369 .

Gaza, 3 I 4.

Gjerstad, E., 355 .

Glacis, 50 sq., I 33, I 37, I42, I 45, I 53, I $55,169$.

Goetze, A., 250.

Goldman, H., 369.

Goodman, N. R., 294 .

Gudea, 383 .

Güterbock, H. G., 24 I.

Guti, 383 .

Habur, 8, Io (note), 340.

Tell Halaf, gate at, I 47.

pottery of, 6, 7, I $5 \mathrm{I}, 23 \mathrm{I}, 38 \mathrm{I}$.

Hall, H. R., 236.

Hama, Io, 202.

Hammam, 280, 314.

Hammurabi of Babylon, 237, 377, 384, 388 sqq.

Hammurabi of Yamhad, 91, 99, 385 .

Hanigalbat, 24I, 391 .

Hantilis, 395 .

Harden, D. V. G., 294.

Hattusil, 398.

Tell abu Hawam, 369, 375 . 
Heaton, Noel, 228 sqq.

Hepa, 267.

Hilani, 49 (note), 78 .

Hittites, 8, 9, 49 (note), 86, 88, I 3 I, I66, 24I, 247, 260, $266,369,388,391,397$.

Hood, Sinclair, 6, 7, $7 \mathrm{I}$.

Hurrian influences, 291, 348, 369 .

Hyksos, 259, 389, 390 .

Talyssos, 370 .

Idri-mi, $33,70,89,385 \mathrm{sqq}$.

Ilim-ilimma, work on palace, I08, I IO, I I 2 ; date of, 392 sqq. Ingholt, L., Io.

Jamdat Nasr, 258-9, 309, 379, 380.

Jericho, 202, $3 \mathrm{I} 4,3^{8 \mathrm{I}}$.

Tell al Judaidah, 6, 9, 259, 352, 379 .

Kantor, H. J., 295 (note).

Kassite connexions, 258, 297, 390.

Kenyon, K., $38 \mathrm{I}$.

Khafaje, 235 .

Khirbet Kerak pottery, 8, 9, 380, $3^{81}$ sq.

Kirkuk, 258.

Kish, columns at, 378 .

Knossos, 230-2, 247; see also Crete.

Kuftin, B. A., 8.

Kültepe, 262, 378,383 .

Lamps, I6, 6i (note), 64, I 88, 294, 332. Cretan style, 25, I 9 I, 294.

Landsberger, B., 262.

Lenkoran, 276.

Mallowan, M. E. L., 236, 246, 280, 340, 349 sq., 379 .

Mardin, 238.

Mari, 23I, 25I, 350.

Mats, in brickwork, 54, 55, 57, 225 . in roofing, I I 7, 227.

Medinet Habu, 374 .

Meerschaum, 369 .

Megiddo, 386.

Merneptah, 375-6.

Mersin, 7, 369.

Meryey of Libya, 376 .

Meskalam-dug, 236.

al Mina, I 72.

Minet-al-beïda, 365 .

Minoan pottery, 7 I , 350, 370 .

Mishrife-Qatna, 278, 280, 380 .

Mitanni, 69, 258-9, 347, 377, 387, 39 I.

Mithras, 68 sq., 387.

Mukish, 9, 395, 397, 398.

Mursilis, 389, 390, 395, 397.

Muwatallis, 398 .

Mycenae, I 48.

Mycenaean beads, 86, 206, 269.

Myres, Sir John, 368-9.
Naharina, i66, 39 .

Naram-Sin, 382 .

Nineveh, 379, 382 .

Niqme-epukh, 9I, 266; date of, 385 sqq.

Niqme-pa, authorship of palace, I08, I IO, I I I. site of palace of, I08, I I I, I 57.

date of, $385 \mathrm{sqq}$.

Niya, 288, $39 \mathrm{I}, 395$.

Nuzi, 278, 346, 347 sq.

Obsidian vase-maker's shop, I09, 293.

Orthostats, first appearance of, 60,92 . trimming of, IOI.

lewis-holes in, I 18.

Palace site, 2o.

Palestine, 50. pottery of, 7, 8, 3 I6, 3 I 8-i 9, 386. seals of, $26 \mathrm{I}$.

'Peoples of the Sea', 374, 376, $39^{8}$.

Philistines, 375-6.

Plenderleith, H.'J., 229.

Ramses II, 24I, 375, 376, 398 .

Ramses III, $278,374$.

Ramses VI, 202-3, 373, 399.

Rhodes, 370,376 .

Sakje-geuzi, 7 .

Sargon of Akkad, $236,378,380,382-3$.

Saushshatar, $377,385,392$.

Scale armour, I 97, 278.

Schaeffer, C. F. A., 97, 245, 260, 276, 280, 340, 343, 354 section (g) passim, 380,385 sq., 395 (note).

Selemiyeh, model shrine from, 49, 62 .

Sesostris, 383-4.

Ras Shamra, 7, 97, 260, 268, 278-80, 369, 396; see also Ugarit.

Sharruwa the scribe, 393 .

Sikumal(?num), defences of, I 33 .

Sinjirli, I 47 .

'Sinopic earth', 369.

Sjöqvist, A., 354 section (g) passim, 396.

Smith, Campbell, 294.

Smith, Sidney, I I 2 (note), I66, 240, 288, 346, 38 I, 384 sqq.

Staircases, 28, 48, 52, 6 I sq., 68, 72, 75 sq., I 22, I I 2 (note), I 22, I 24, I 25, I 49, 195 .

Starr, R. F. S., 346,347 sq.

Stone foundations, $39,4 \mathrm{I}-42,60,70,73,80-82,89$, I 34 , I62, I67, I 7 I, 224.

Stubbings, F. H., 3 I6, 369 section (h) passim, 398 .

Sumer, connexions with, I6, 26, 28, 68 (note), 105, 237, $238,244,247,28$ r, 288, 29 I, 378, 382 .

Suppiluliuma(s), I I0, I I 4, I66, 395 .

Susa, $35 \mathrm{I}, 379$.

Sutarna, $385 \mathrm{sqq}$.

'Syro-Hittite' bronzes, 275 .

Tabara al Akrad, 6 sqq., 380,382 . 


\section{INDEX}

Taku, 39 I.

Takuwa, 395.

Tarsus, 7, Io (note), 241, 345-6, 369, 379, 387 .

Ta'yināt, 6, 9 .

Tekán, Ruhi, i 06.

Tepe Gawra, 3 I 4 .

Tukulti-Ninurta, 24I, 299, 300.

Tuthmosis I, II, III, I 66, 388, 39 I.

Tutkhaliva, 86, 24I-2, 276, 393 .

al 'Ubaid pottery, 7, $3^{8} \mathrm{I}$ sq.

Ugarit, 97, 235, 260, 28 I, 3 I6, 347, 350,369, 380, 383 , 390,397 ; see also Ras Shamra.

$\mathrm{Ur}, 201,236-7,260,276,279,332,379,382$.

Urartu, 277 .

Uruk pottery, 7,382 .
Van, Lake, 277.

Vaulting, 30, 227.

Voussoir bricks, 25, 28, 29 sq., 227.

Wace, A. J. B., 369.

Warka, 378,379 .

Water-level, 10-1 2, 35-36, 40, 303 .

Windows, 49, 93-94, I03, 227.

Wiseman, D. J., I 58 , I $59,262,385,392-4,398$.

Tell el Yahudieh, 50, 324, 343, 347.

Yarim-Lim, connexion with Level VII, 9 I . portrait of, 236 . evidence for revulsion against, 65, 106, 198. date of, $385 \mathrm{sqq}$.

Yasilikaya, 24I, 245, 276. 

PLATE II

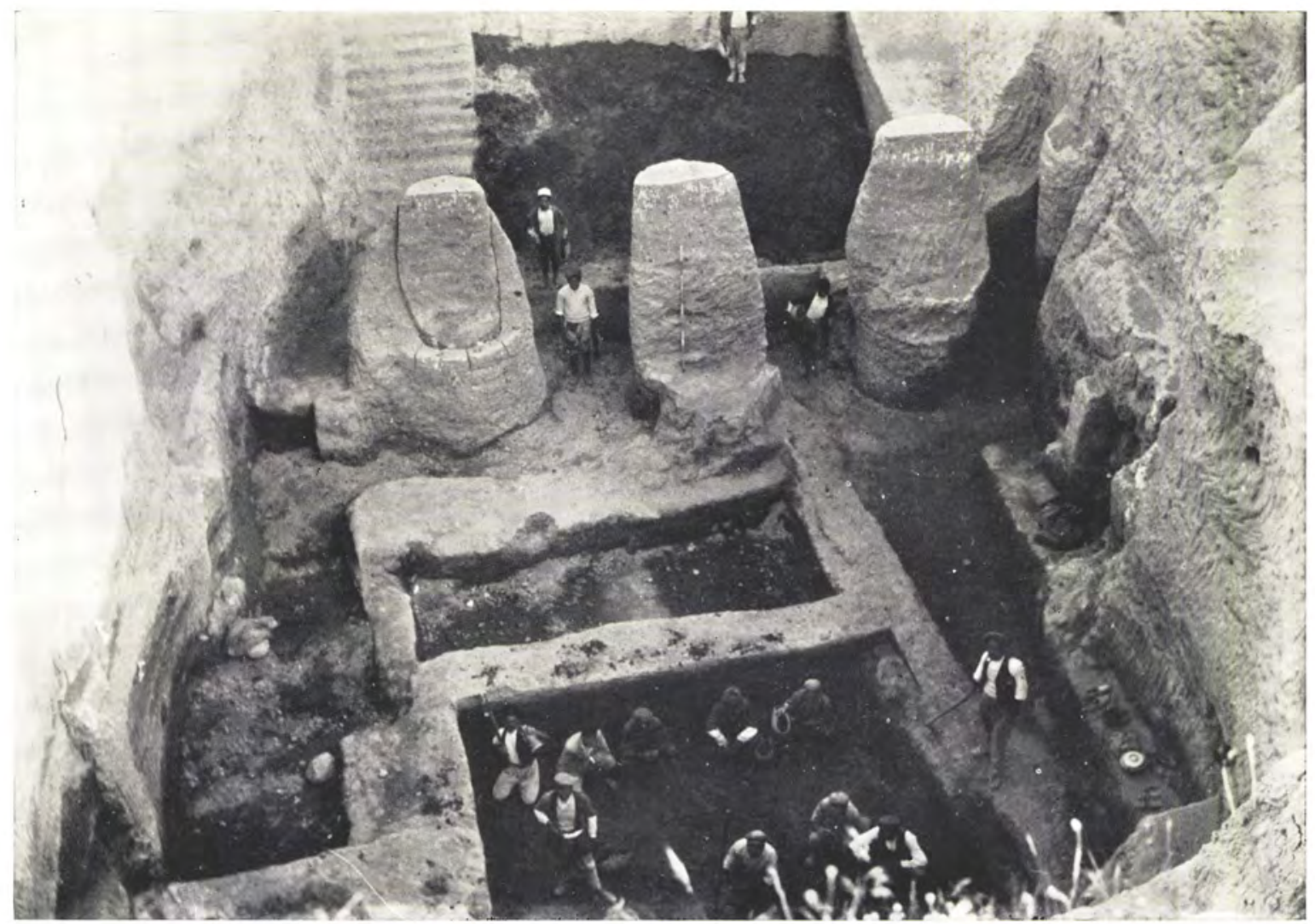

a. Level XV; the columns of Level XII are seen in section in the background p. 13

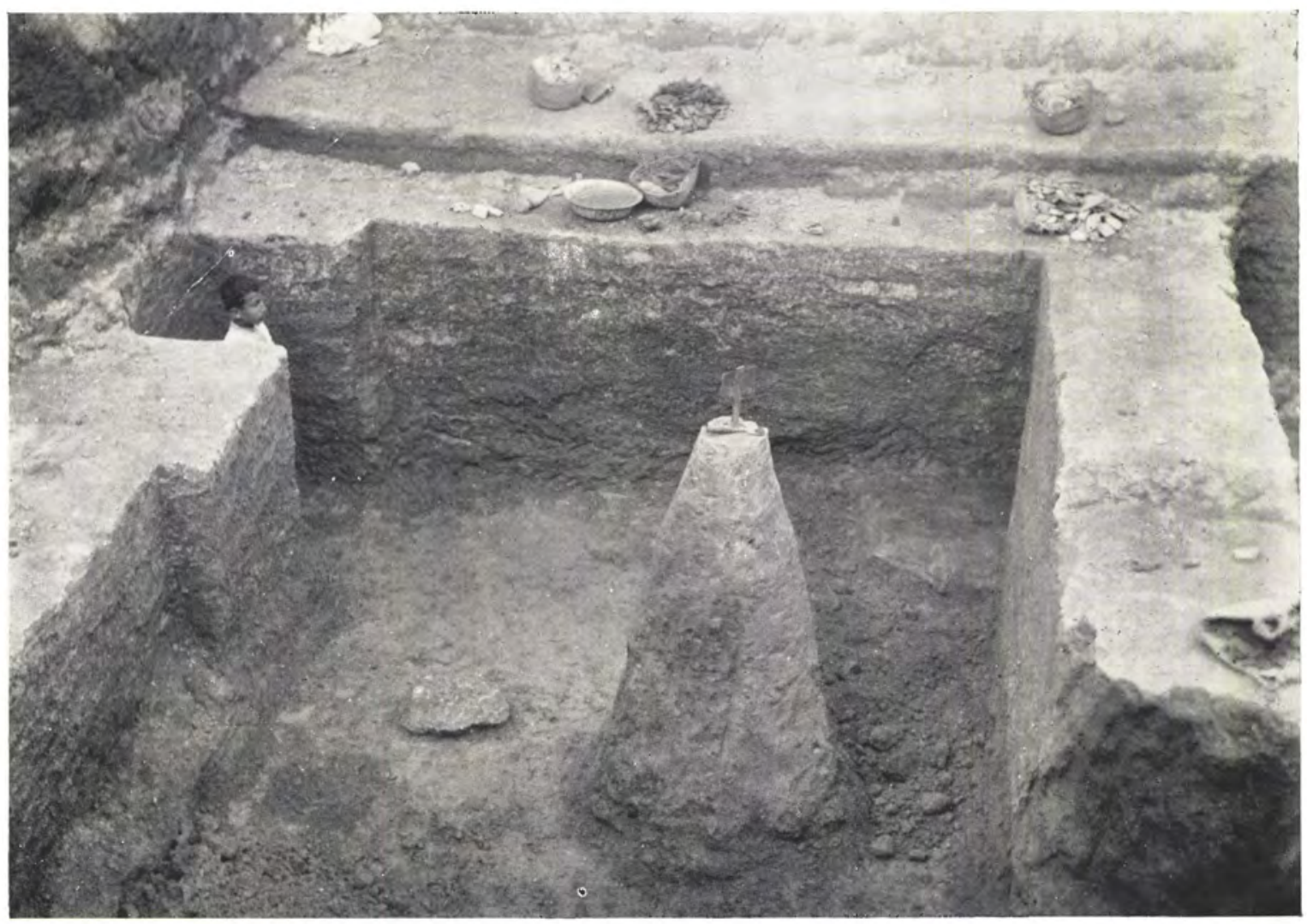

b. Level XIII; the NW. room (I) showing walls, doorway, and pot-base in corner (the earth pillar is only a bench-mark) 


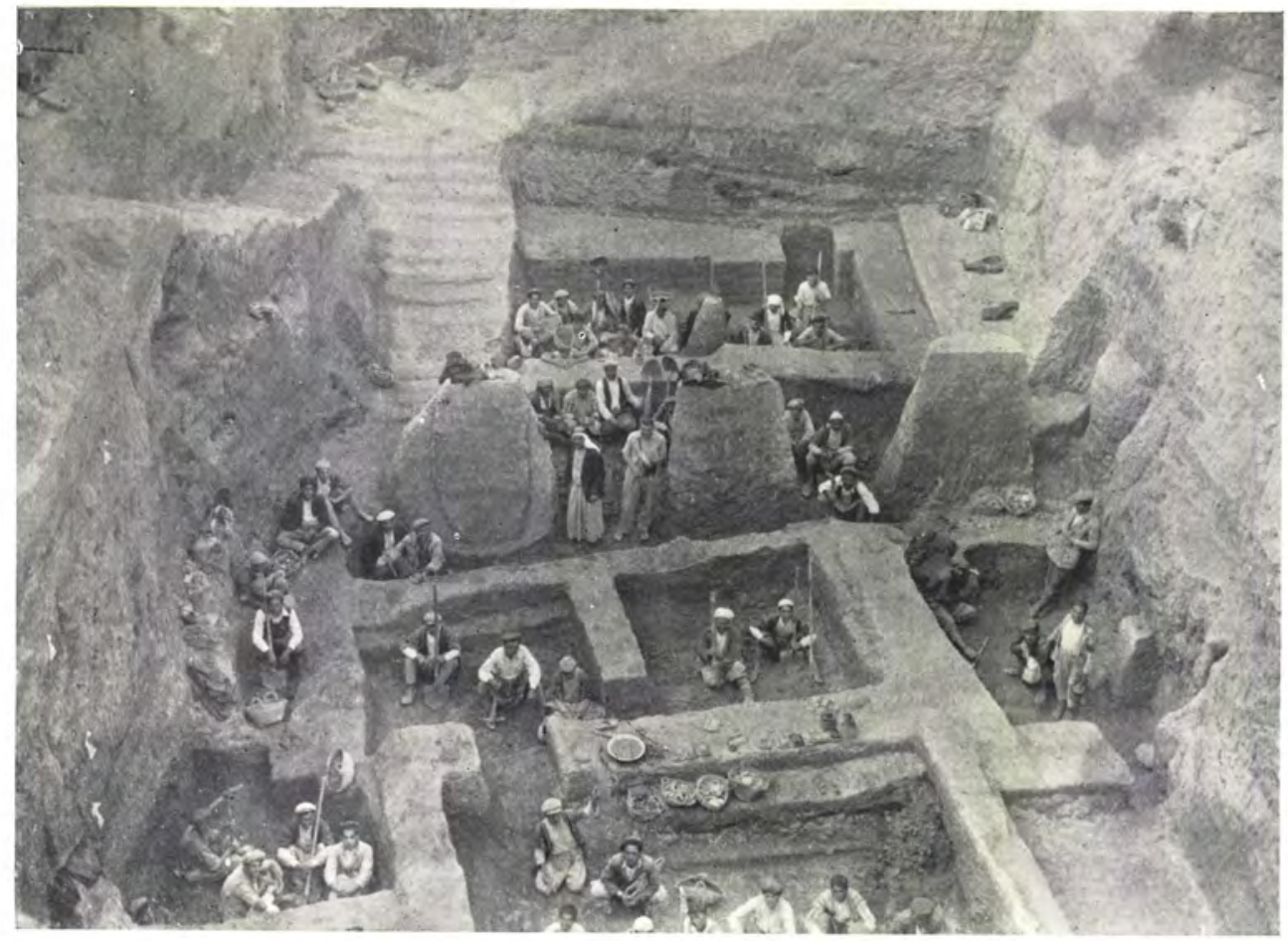

a. Level XIII; general view looking NW.

p. 14

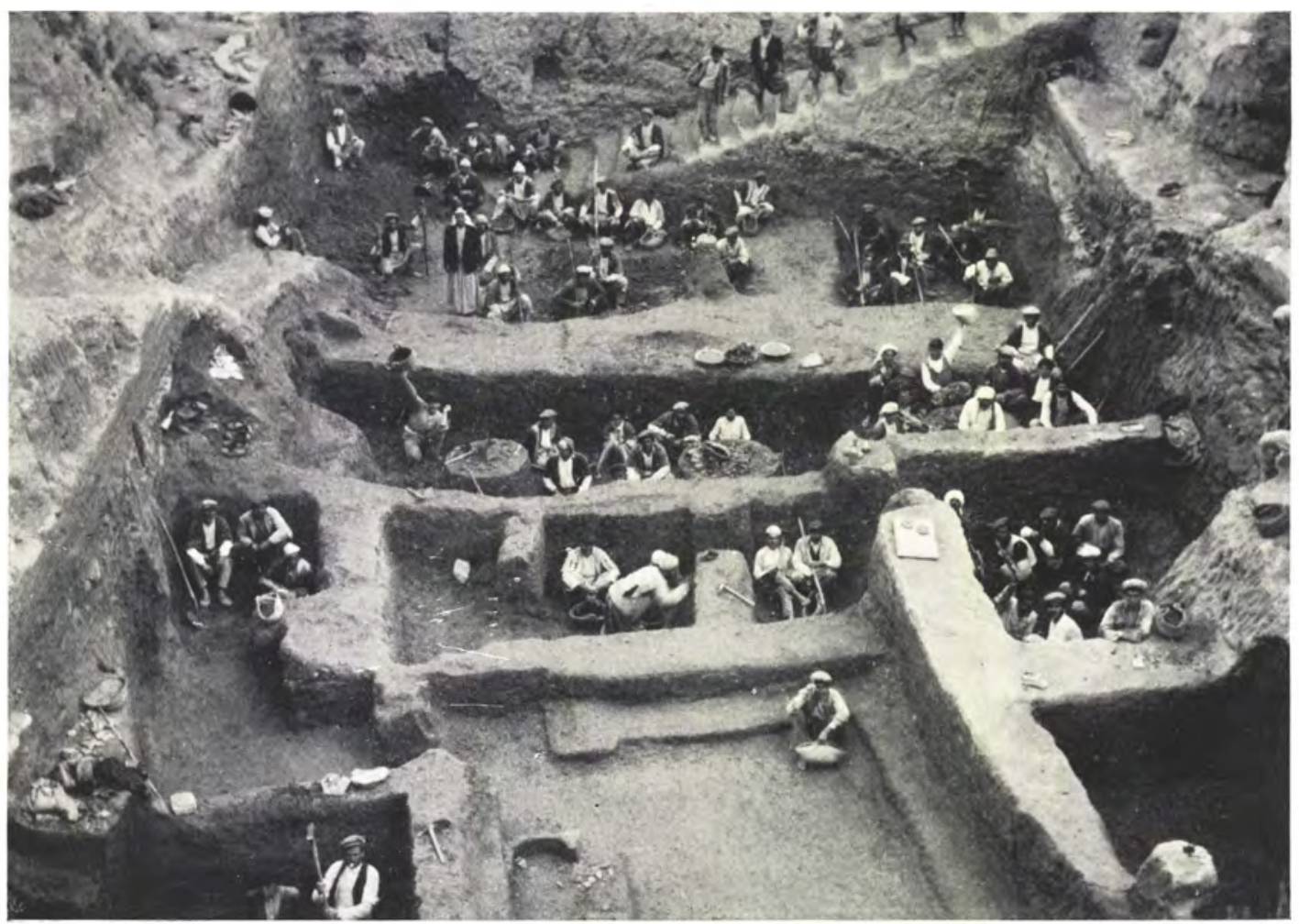

$b$. Level XII $b$; general view looking NW. 


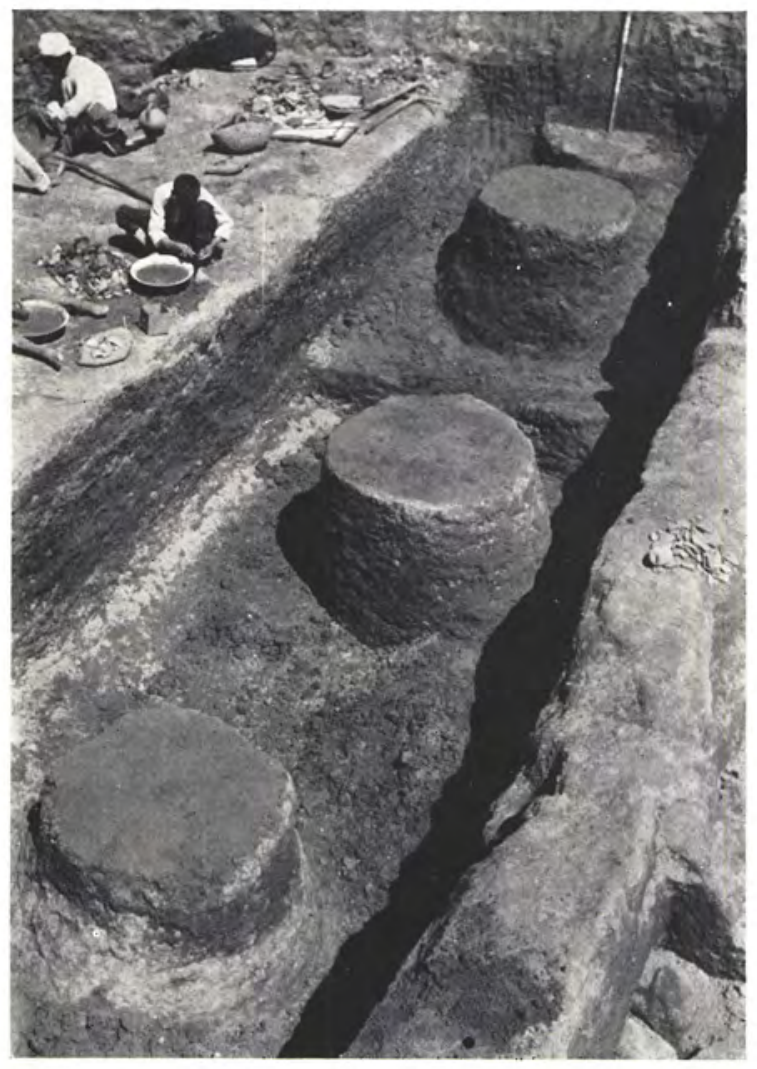

a. Level XII; the mud-brick columns as first seen

p. 17

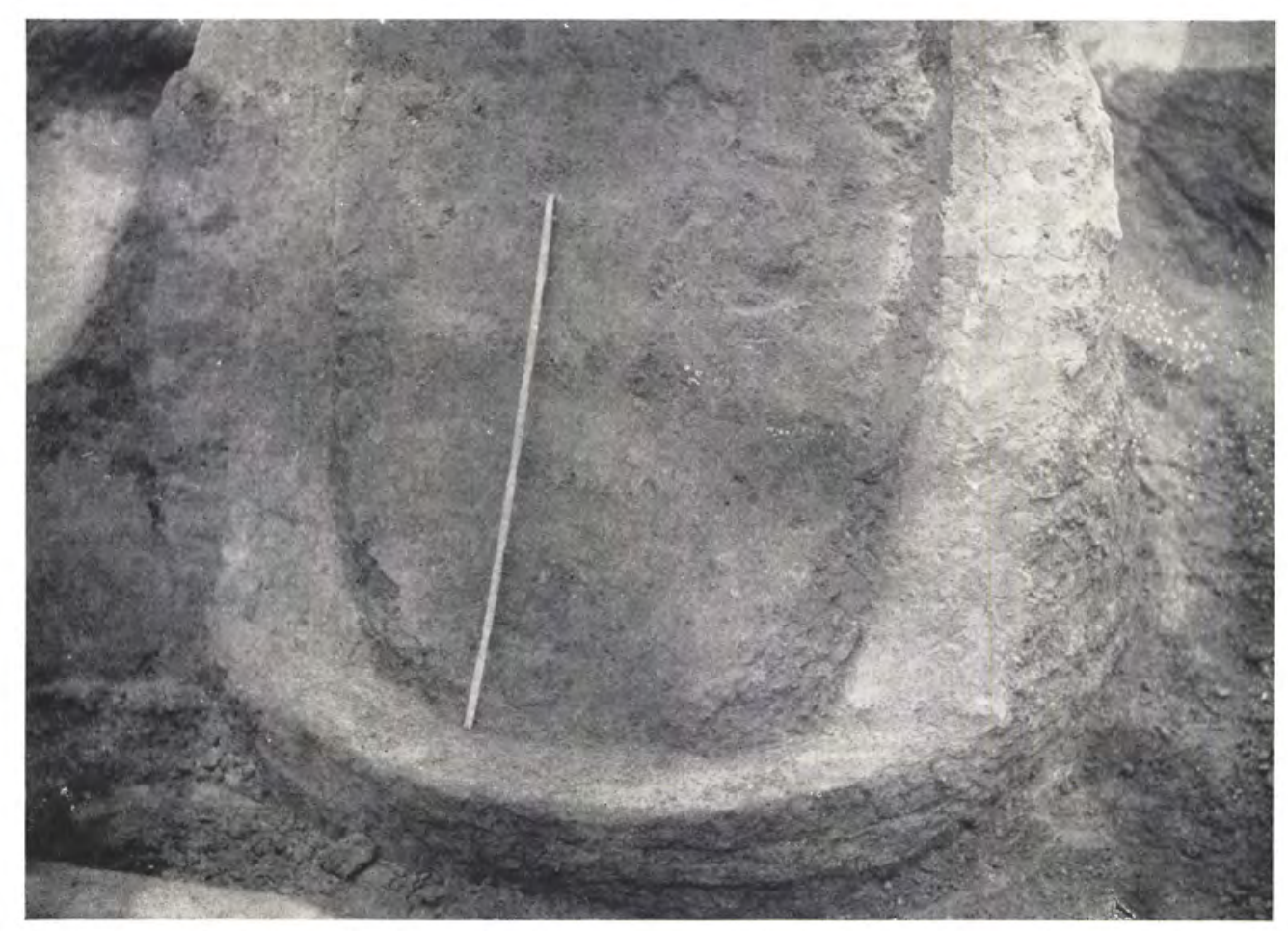

b. Section of column B, showing the new brickwork let into the old p. 19 
PLATE V

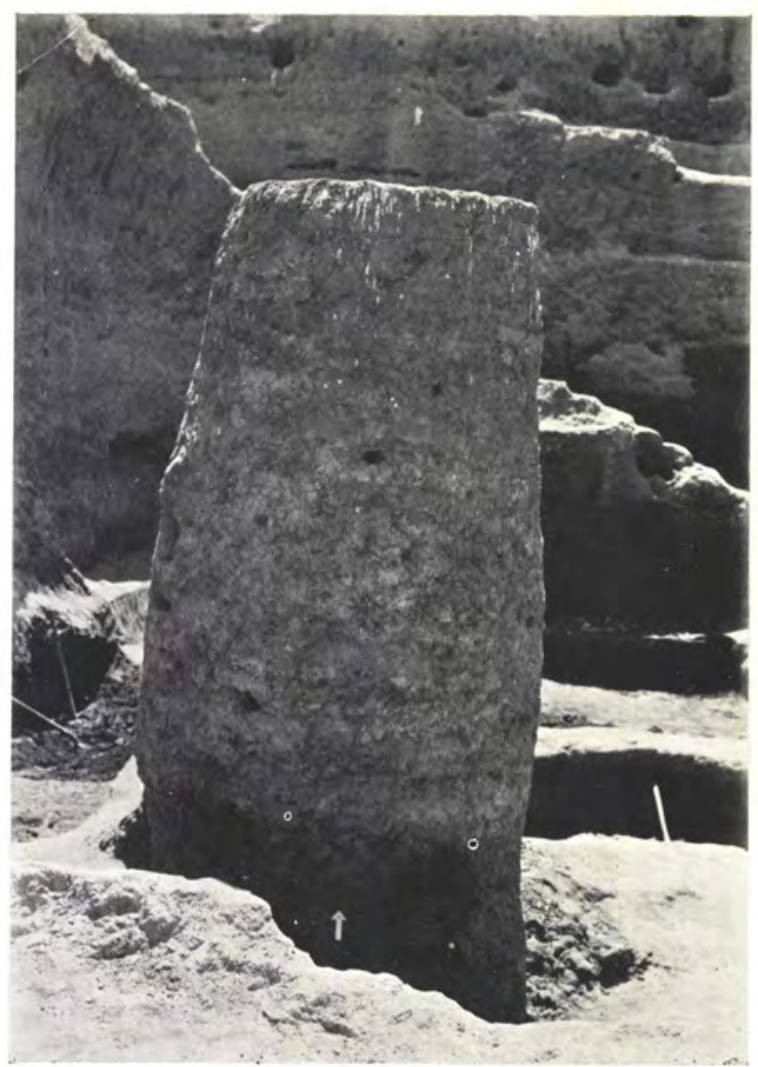

a. Column $\mathrm{C}$, showing $(\uparrow)$ the clay foundation below the brickwork

p. 19

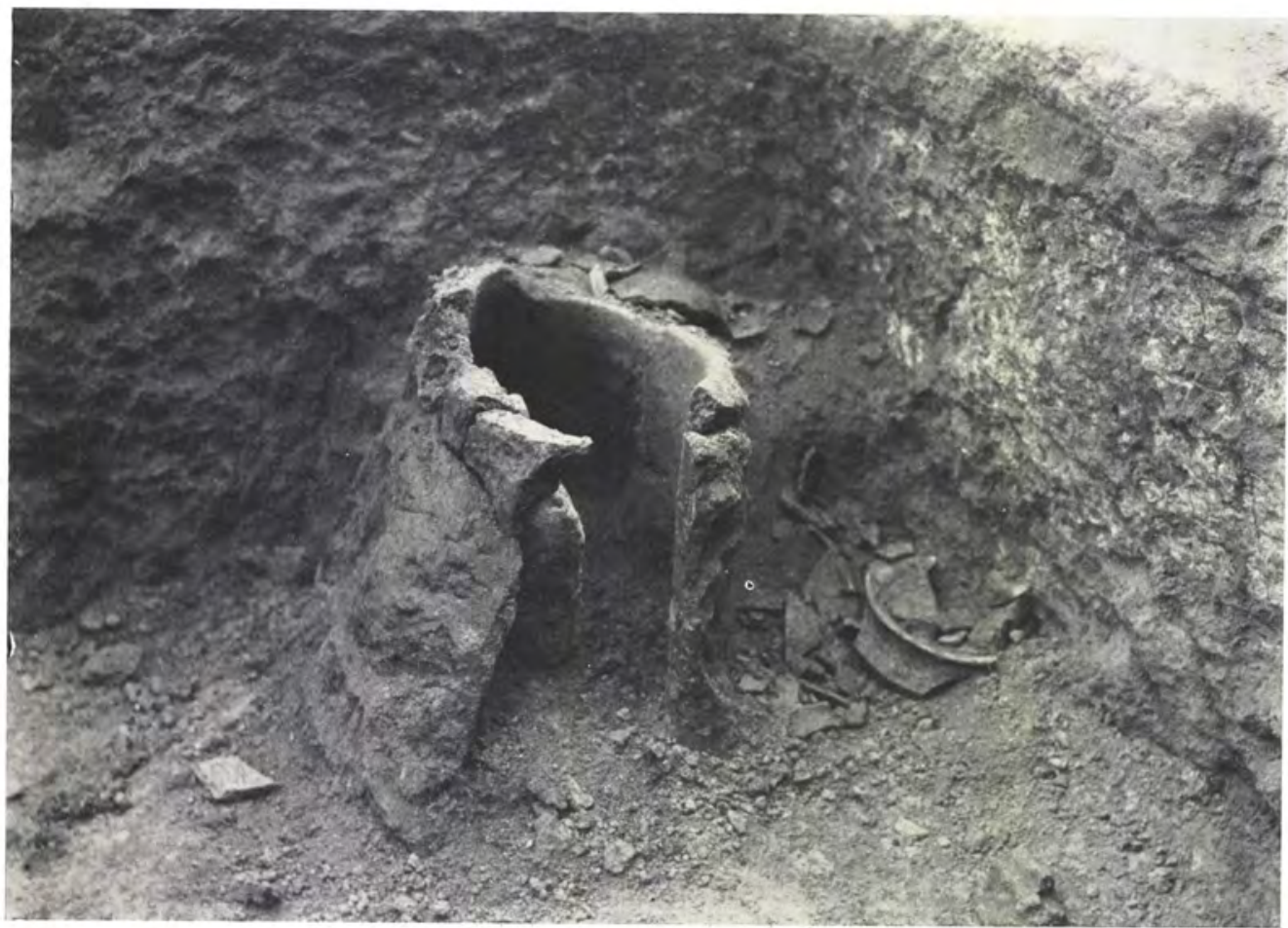

$b$. Level XII $b$; oven in room 3

p. 23 


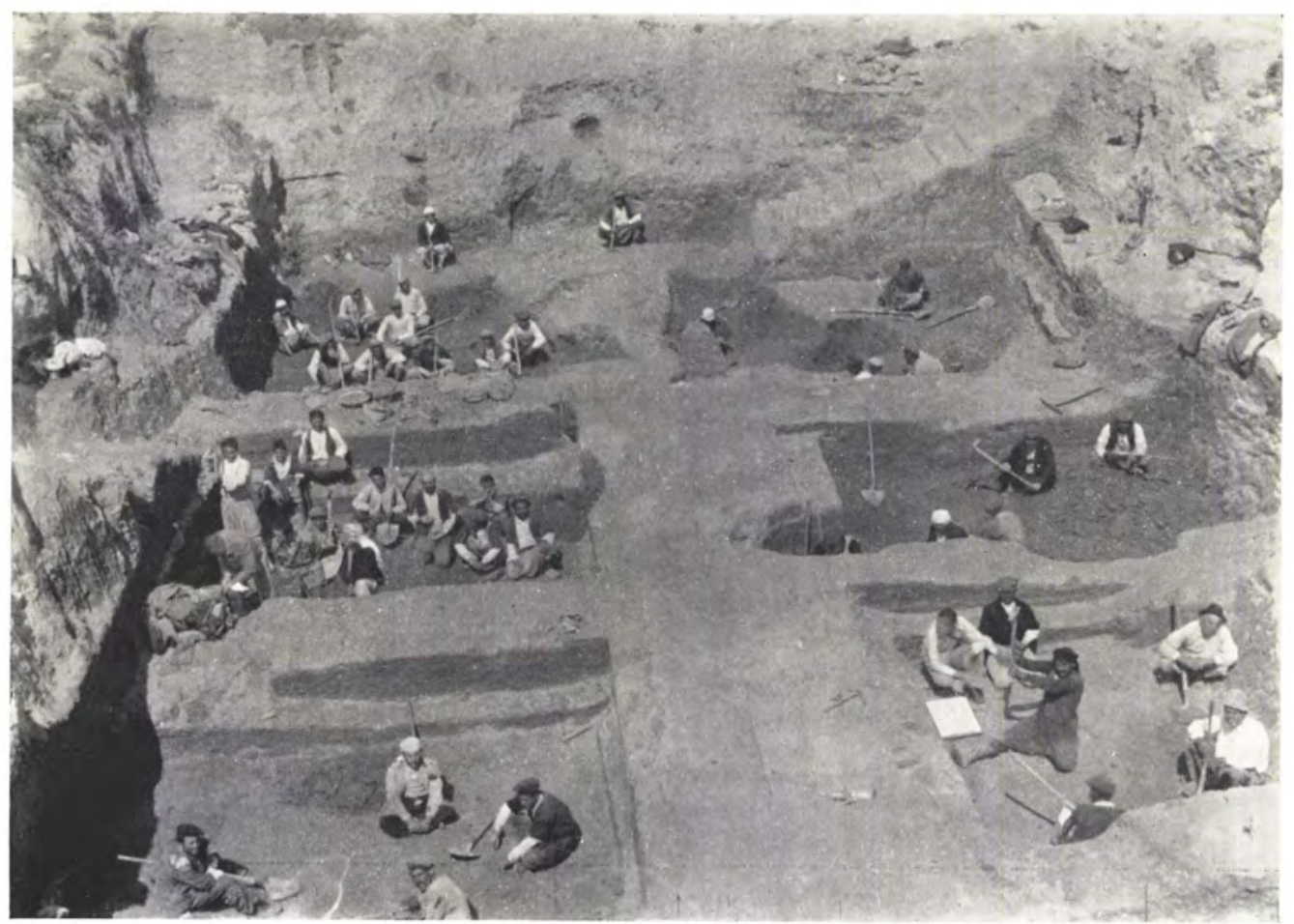

a. Level XI; general view looking NW.

p. 25

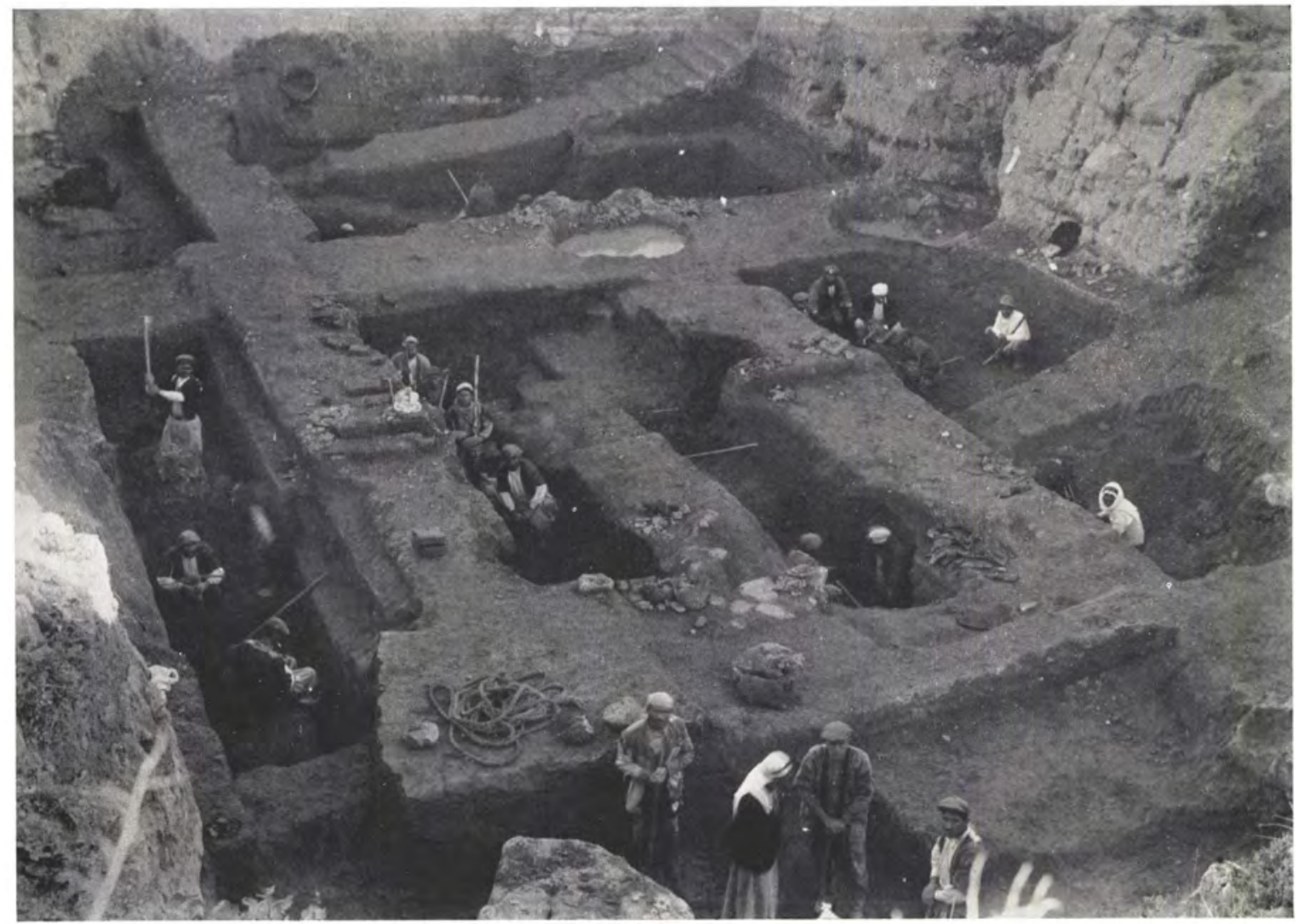

b. Level X; general view looking NW. 


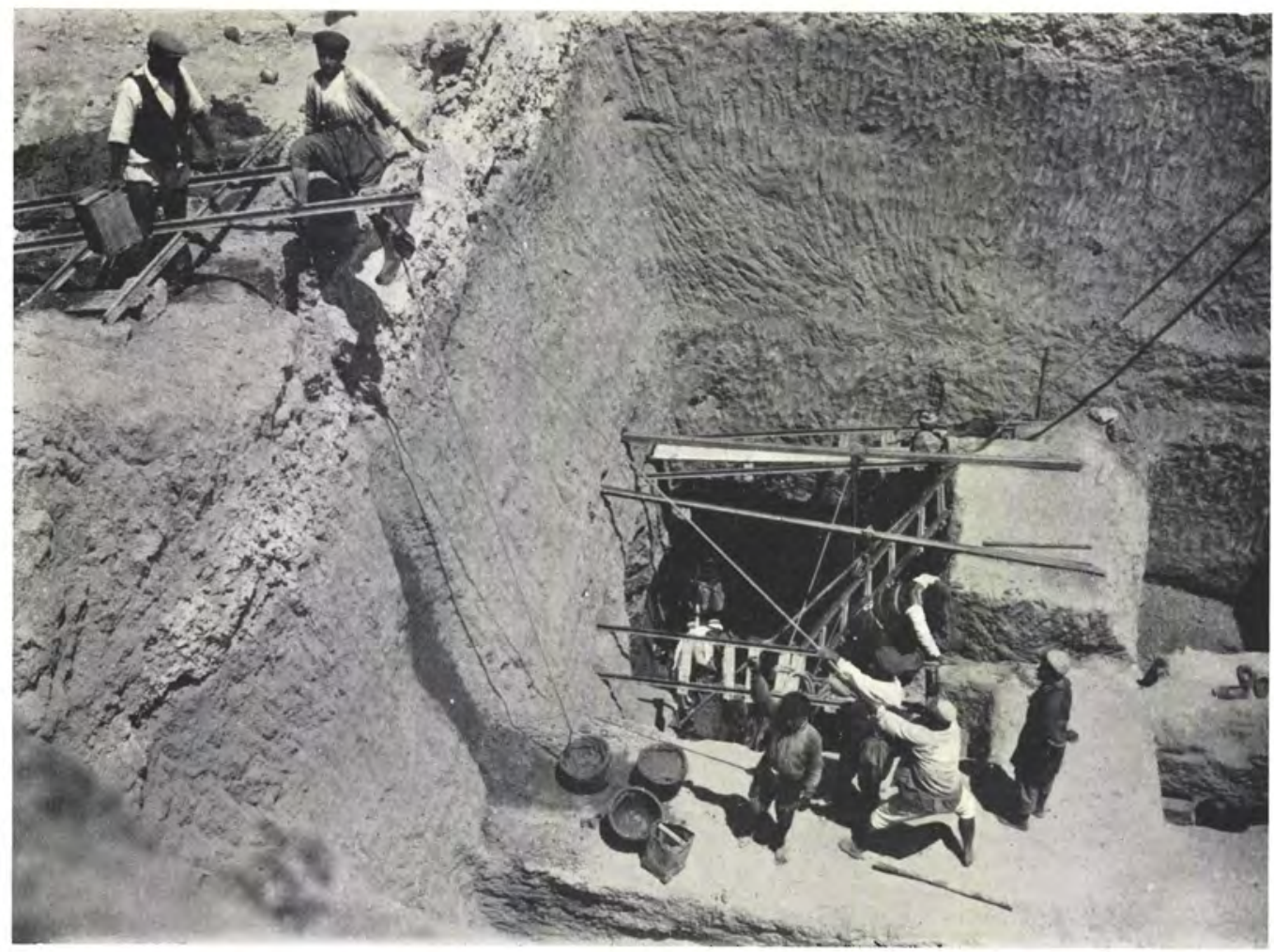

a. Excavations of 1947 ; digging below water-level p. 36

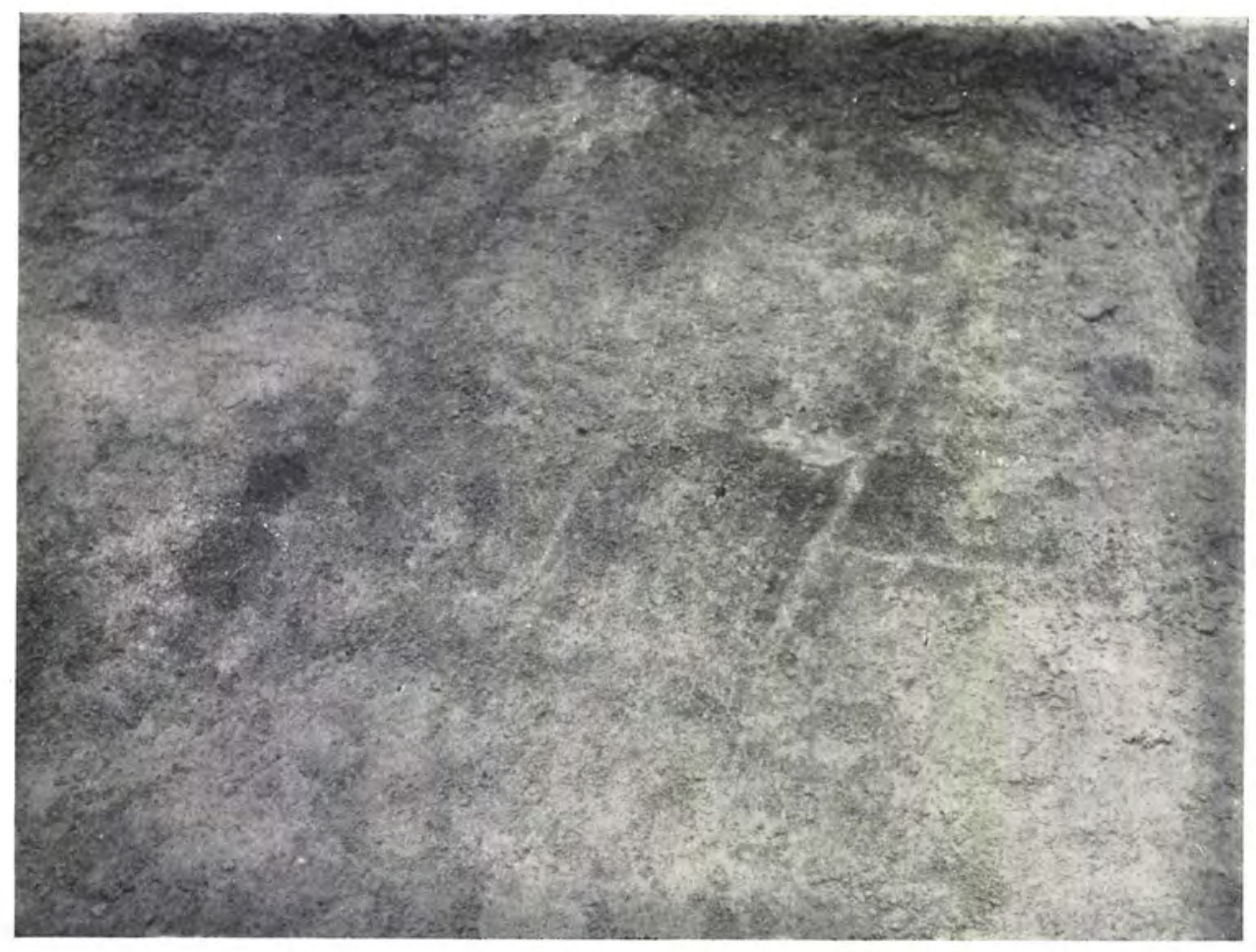

b. The Level XVI temple; the tiled floor

p. 37 


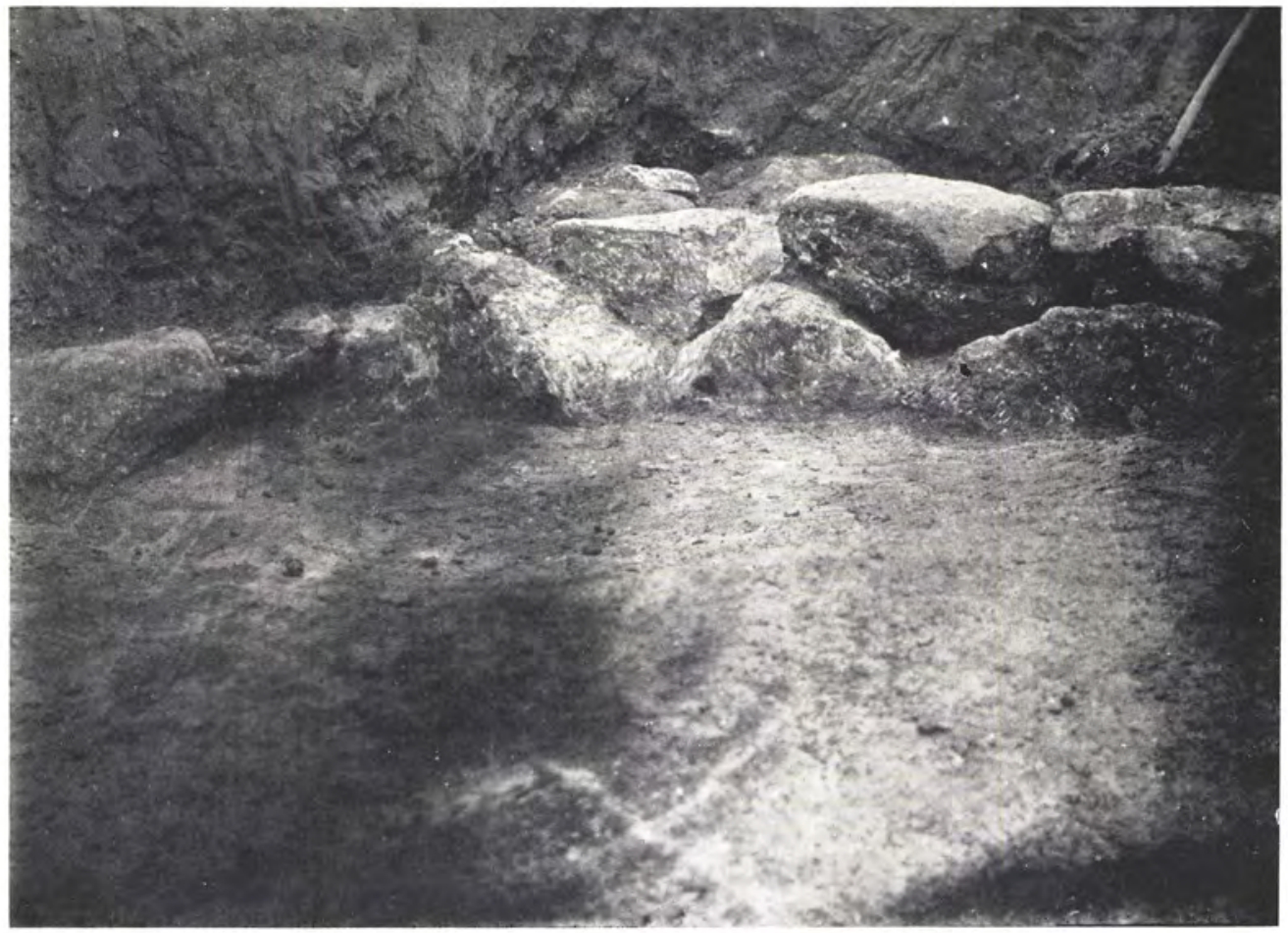

a. The Level XVI temple: stonework in front of the gabled block

p. 38

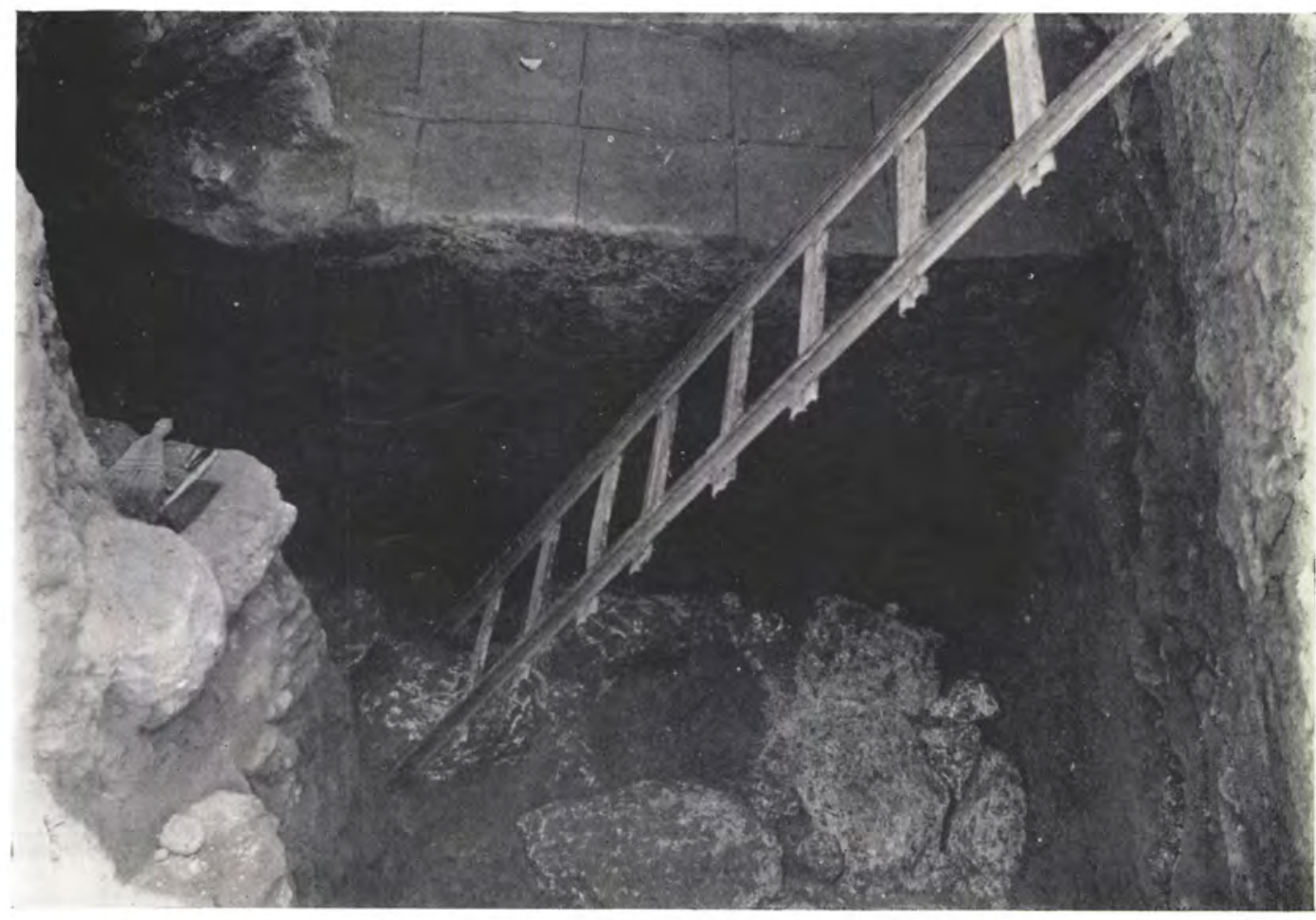

b. The top of the Level XVI 'mastaba'; in the foreground, the stonework of Level XV pp. 38 and 41 


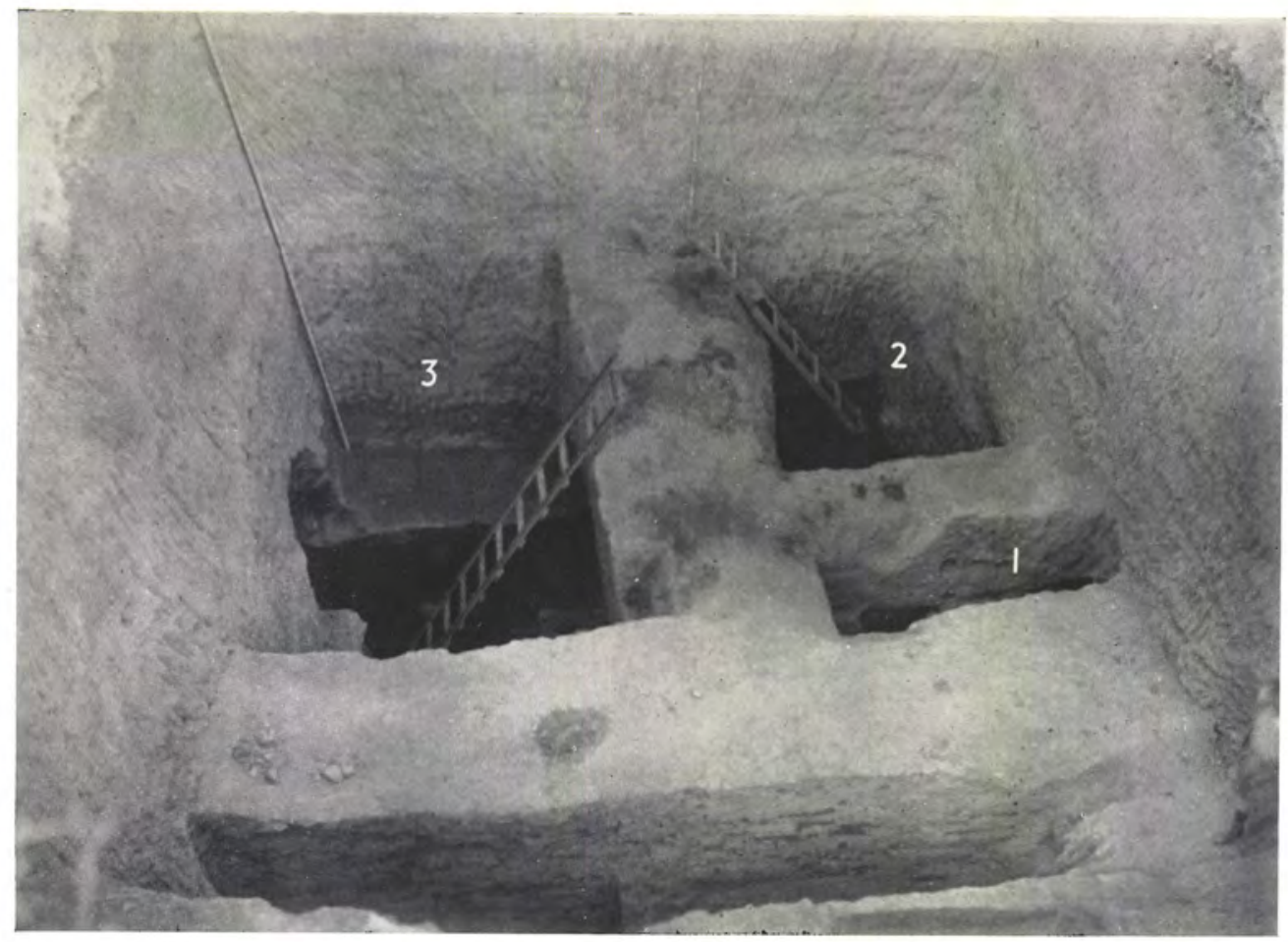

a. Level XII temple, looking down from the SW.: (I) the staircase cupboard with the door lintel visible; (2) the outer chamber; (3) the sanctuary, its floor removed to show the old 'mastaba'

p. 47

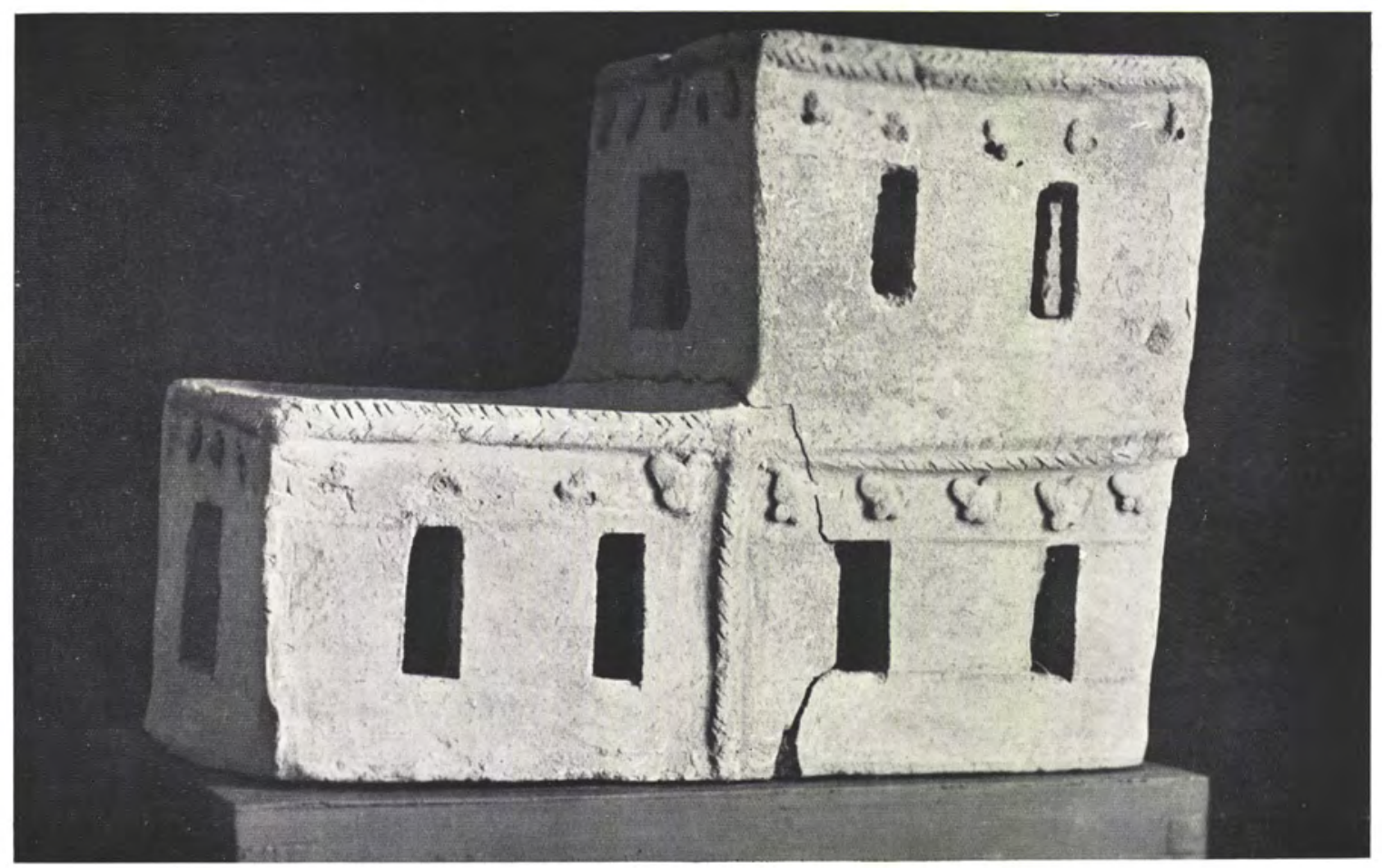

b. Clay model of a temple, from Selemiyeh, closely resembling the temple of Level XII 


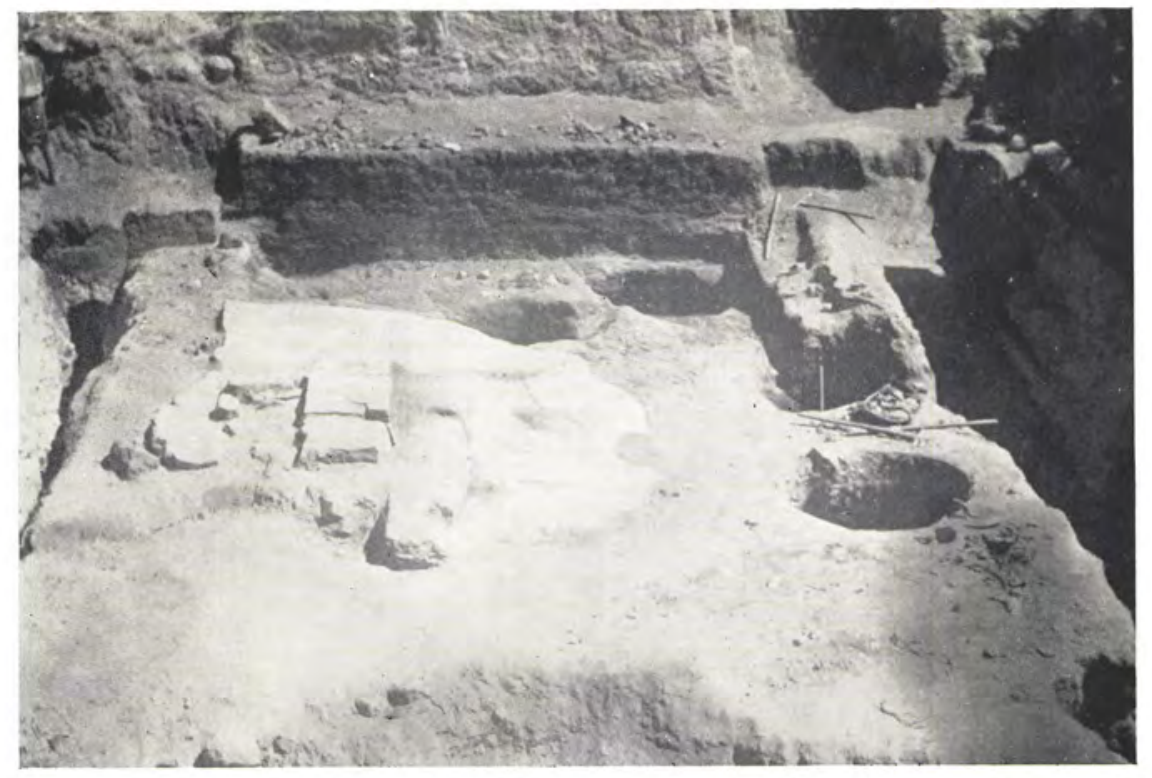

a. Level VII temple; general view looking NE., showing the altar, the troughs or boxes under the benches, and rubbish-pits of Level VI

p. 59

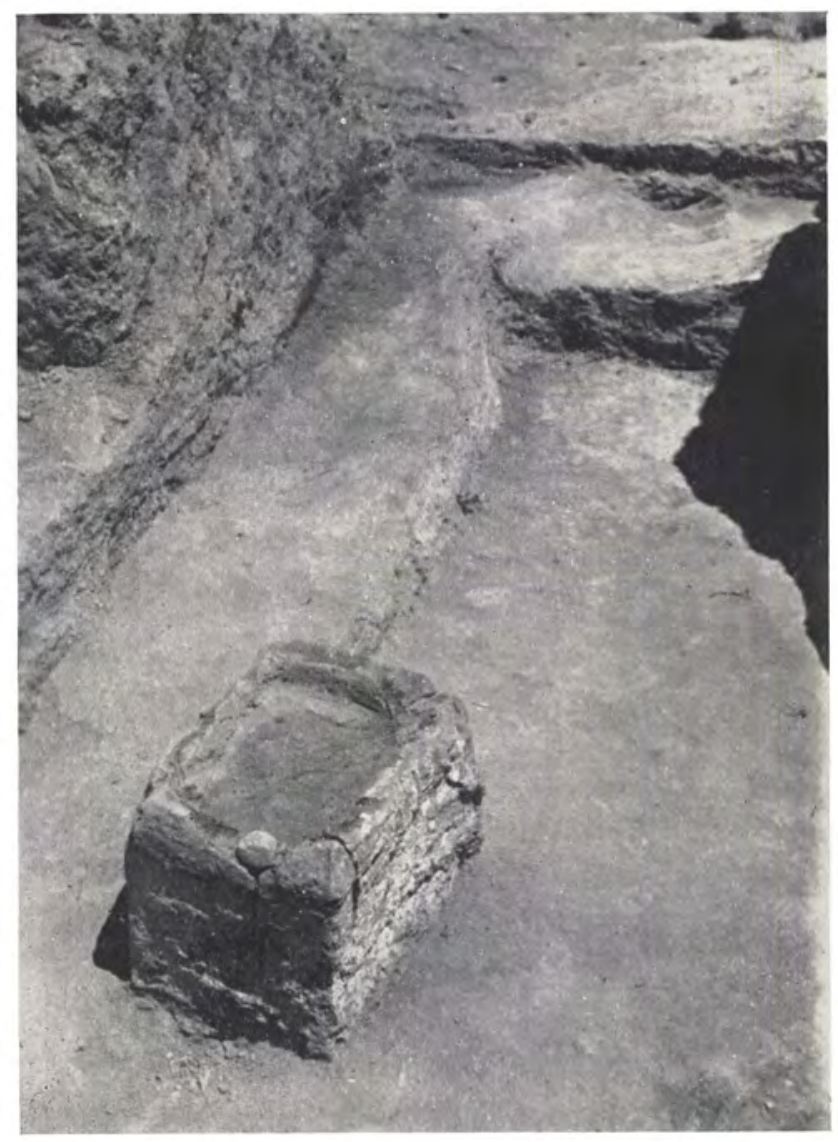

b. Level V: the fire-altar and benches of the Mithraeum p. 67 


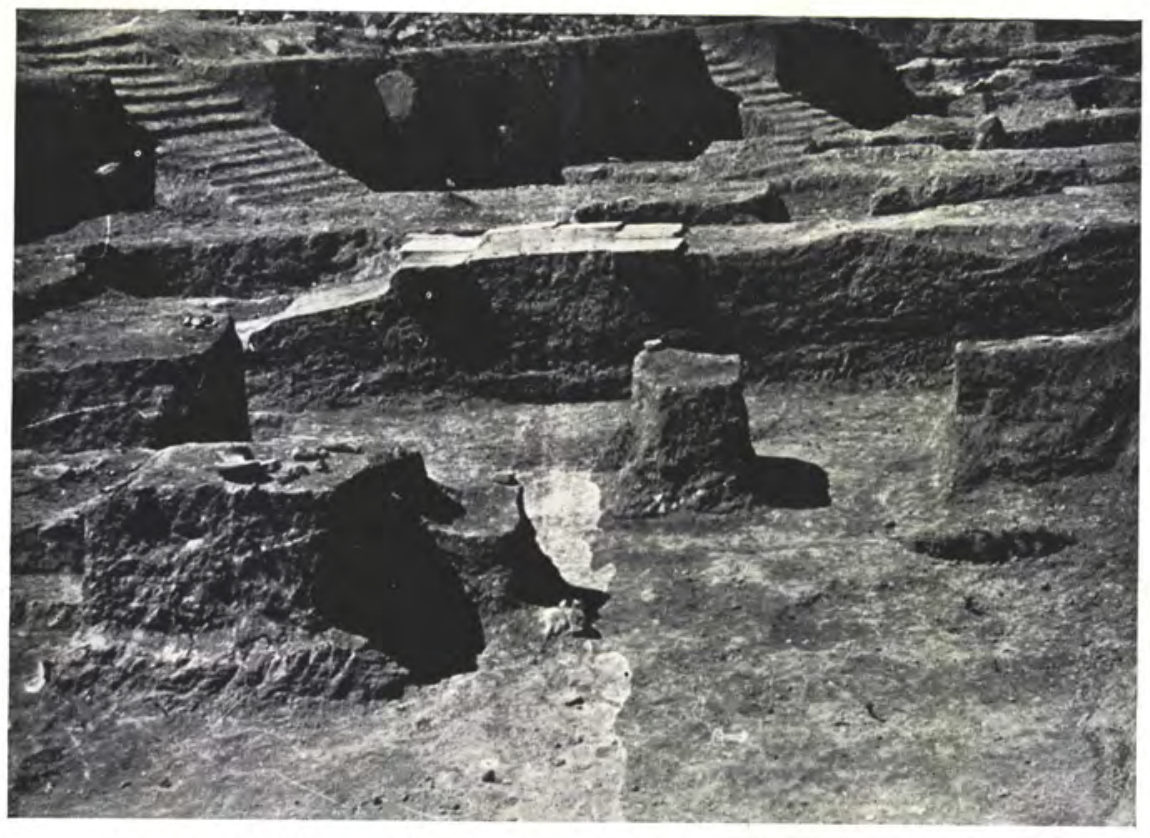

a. The Level III temple, showing the altar and threshold of Level II pp. 73 and 78

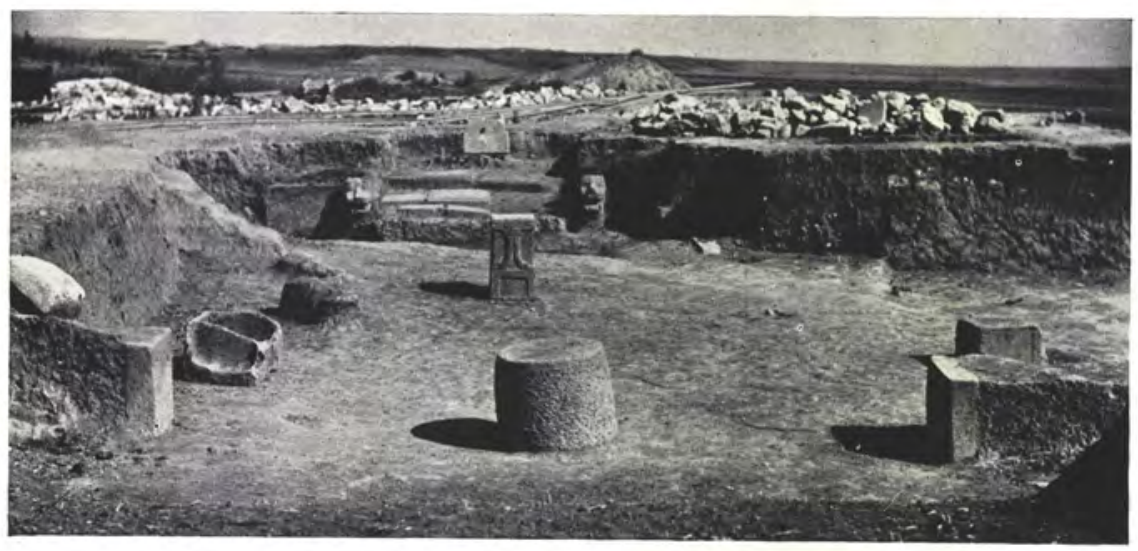

b. The Level I temple, general view pp. 82,85 


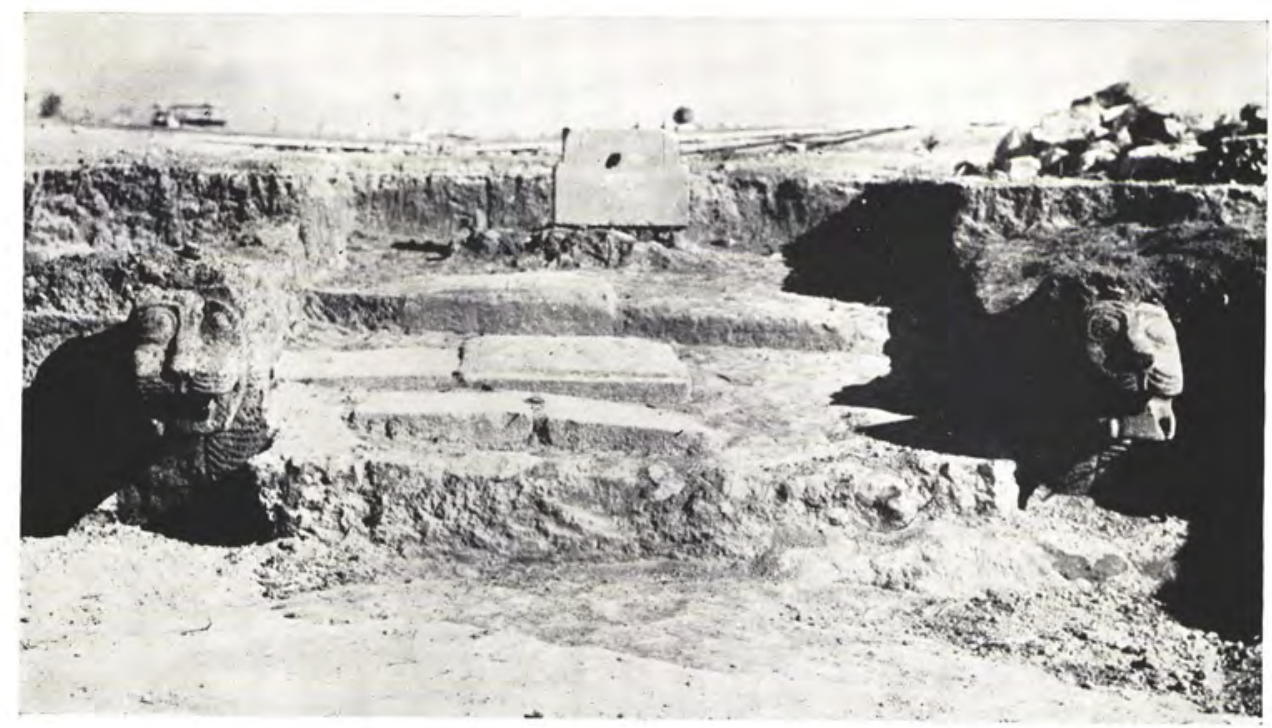

a. The Level I c temple; the sanctuary steps and lions

p. 89

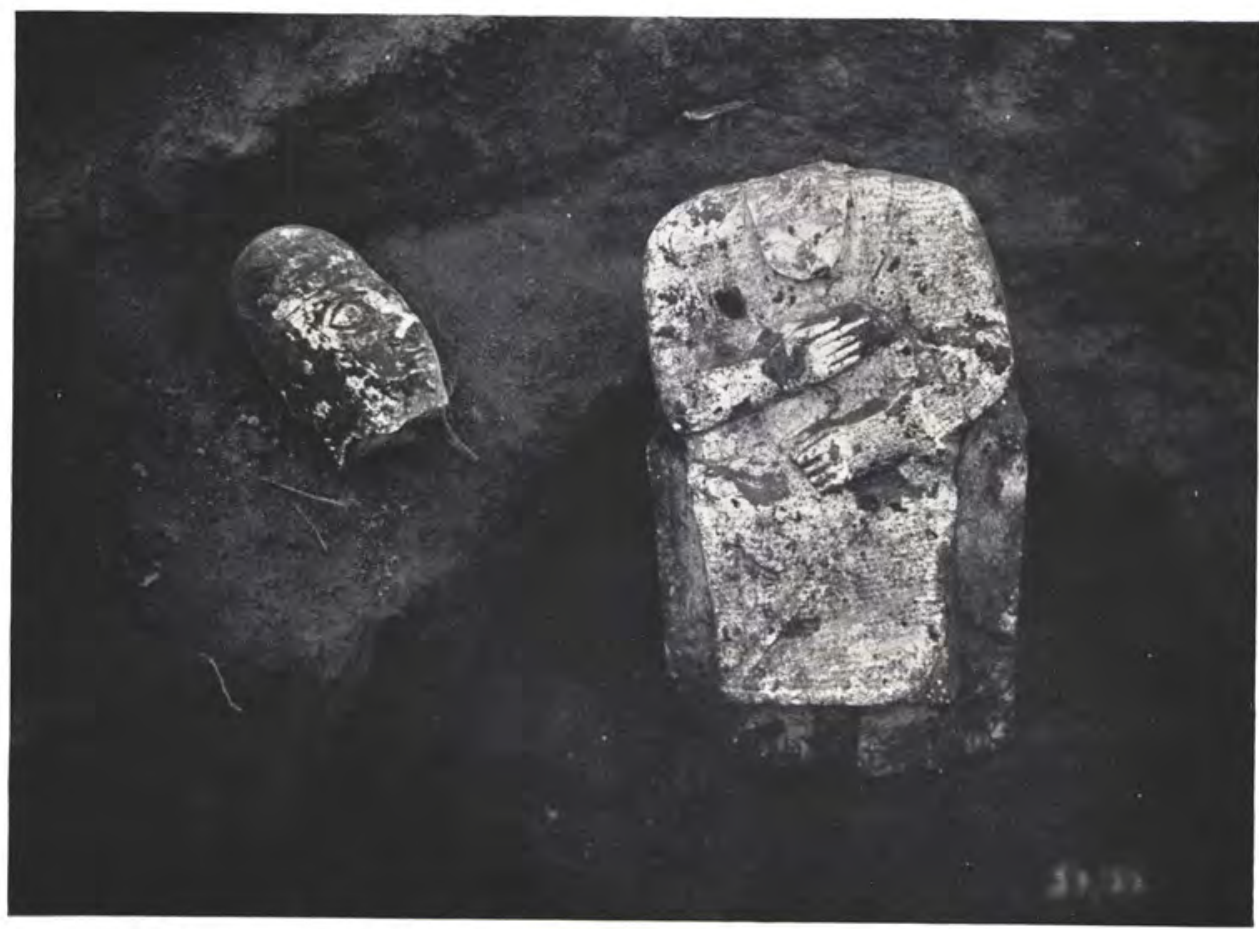

b. The statue of Idri-mi in the pit beneath the floor of the temple annexe p. 89 


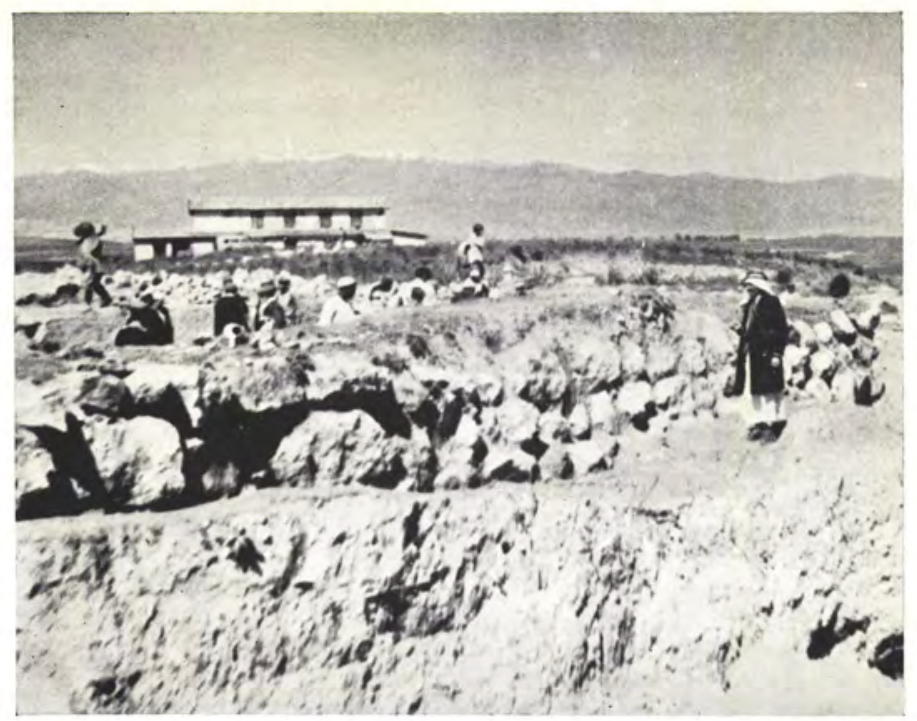

a. The foundations of the outer wall of the Level O temple. Expedition house in background

p. 89

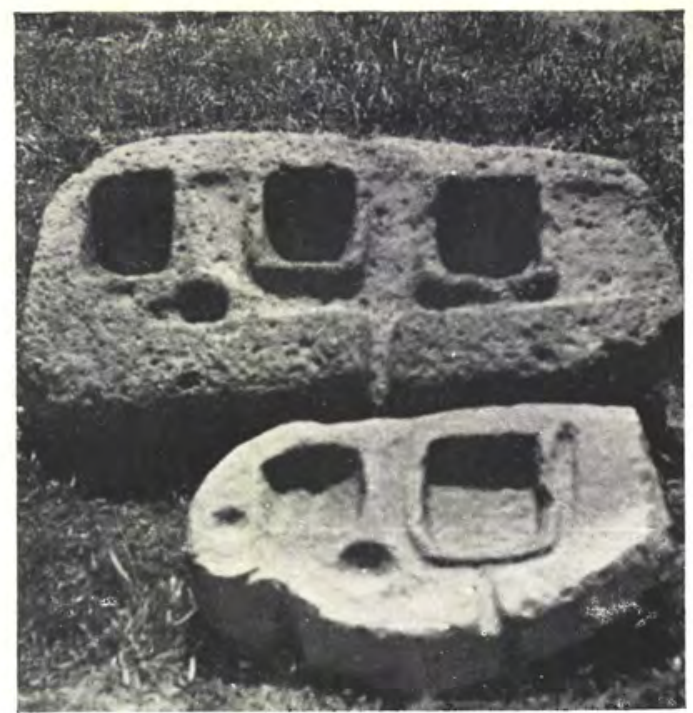

b. Basalt tables of offering from the temples of Levels I and $\mathrm{O}$

p. 89

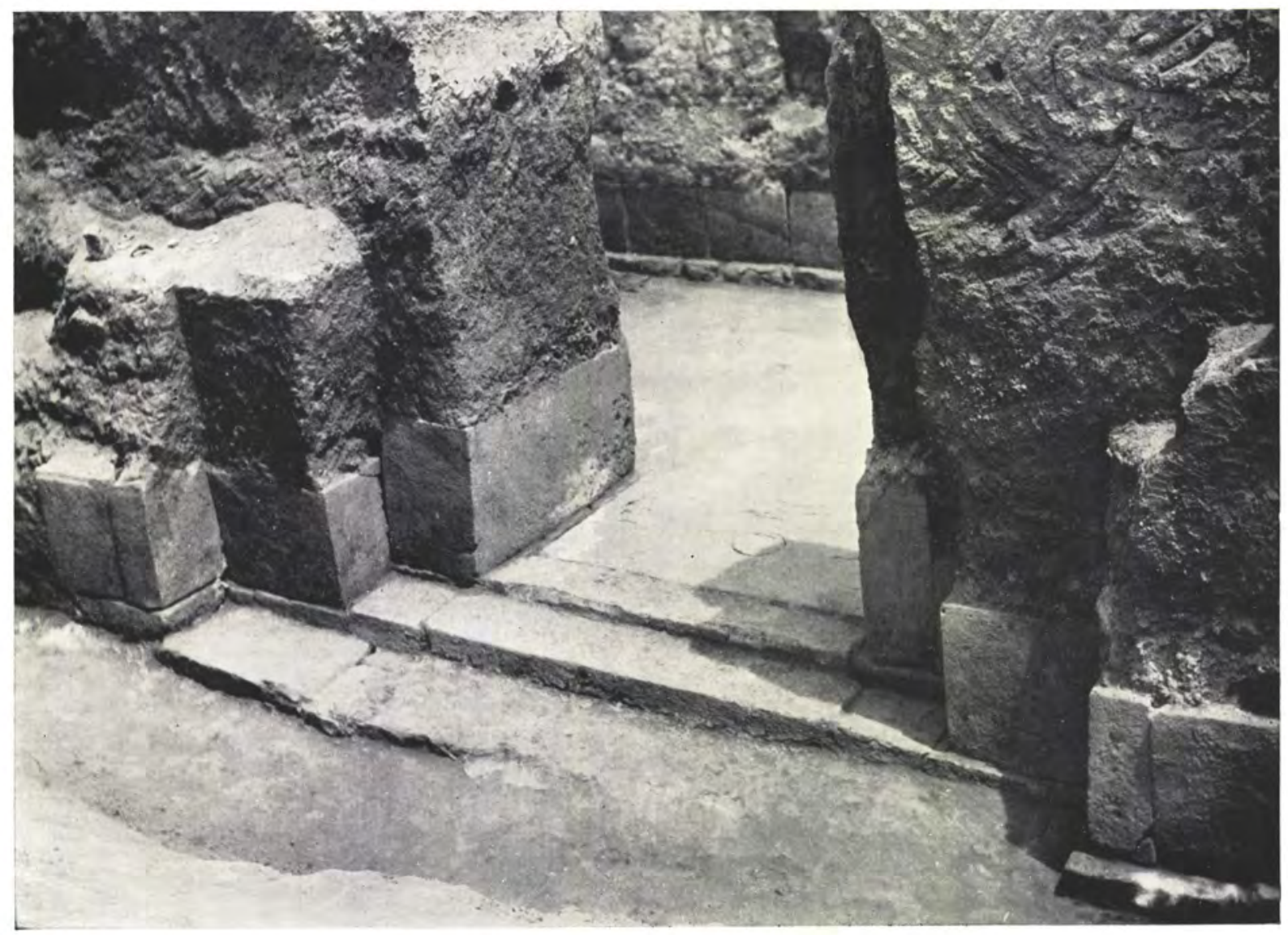

c. Yarim-Lim's Palace: the entrance-room (7) from the outside 


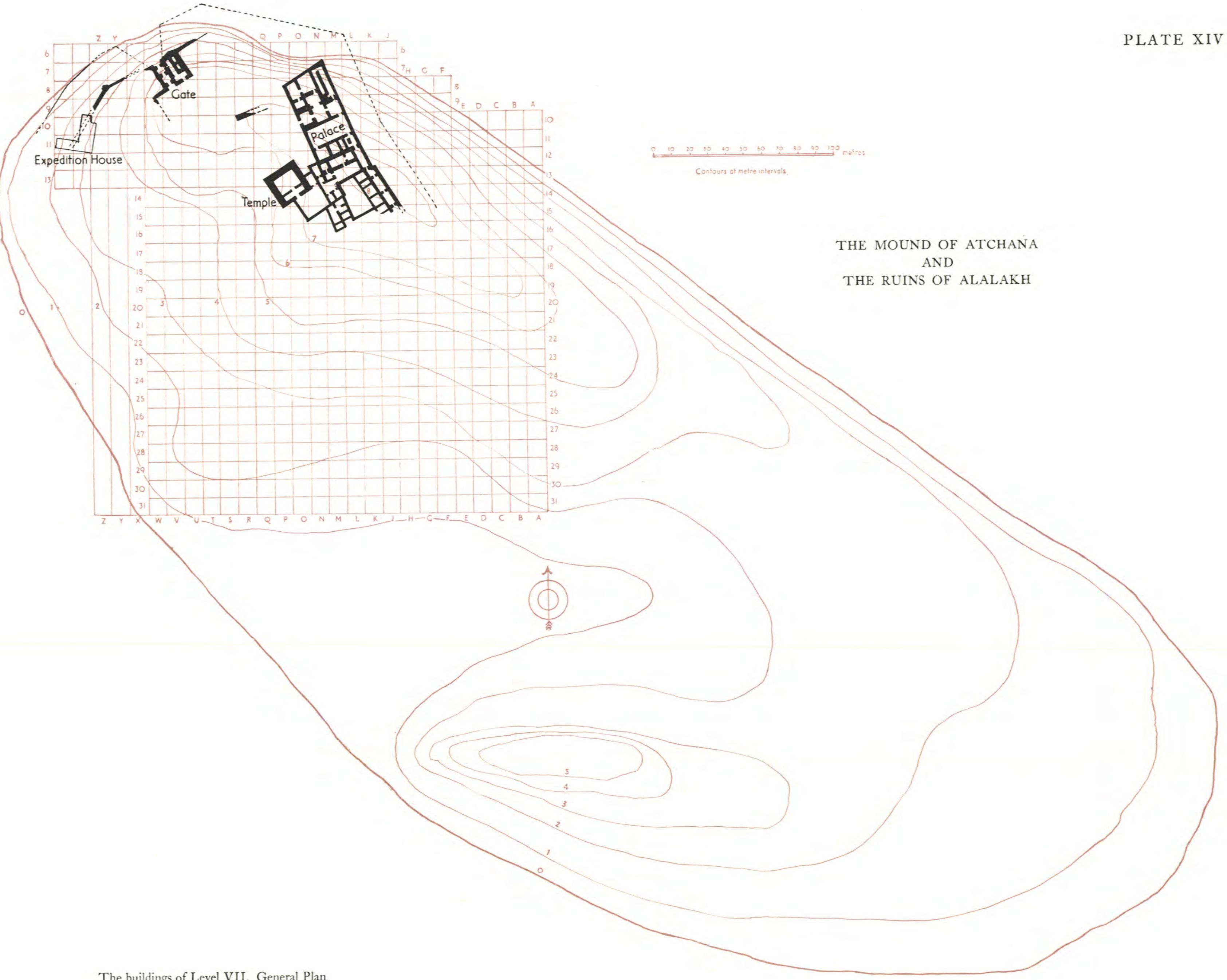




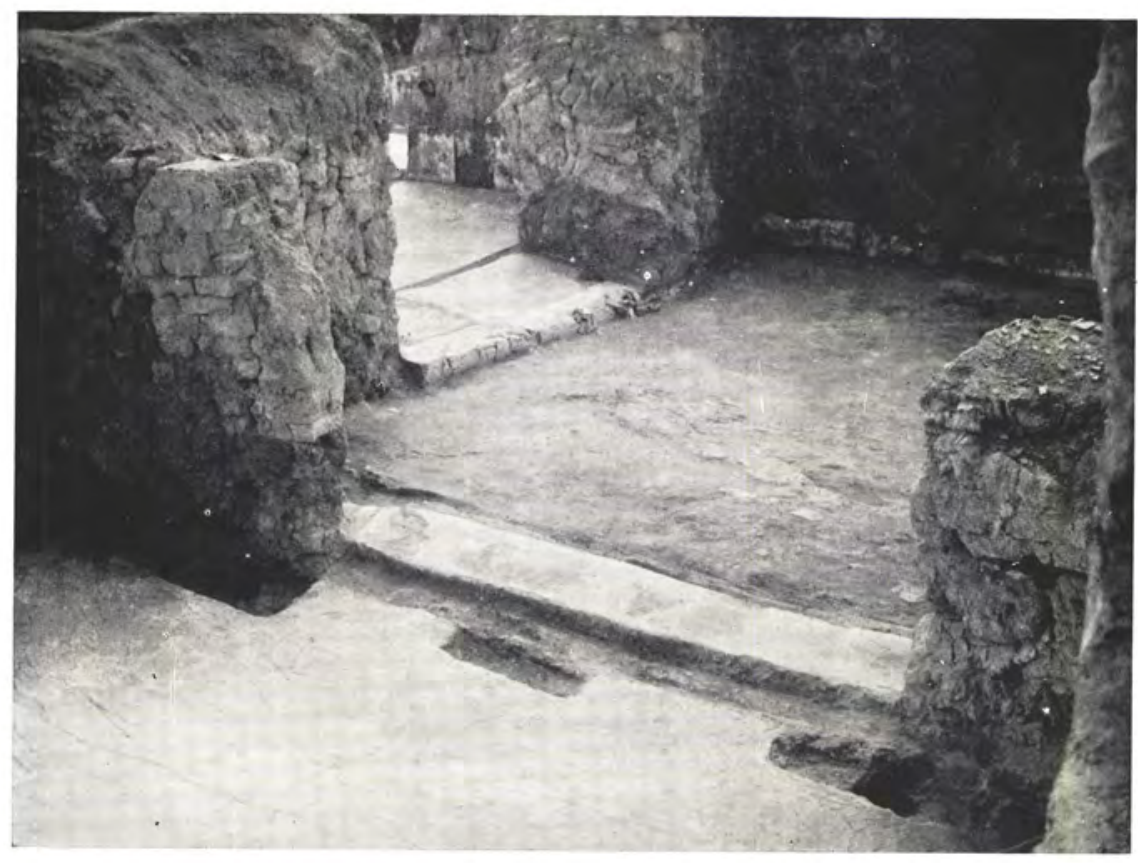

a. The cement threshold between rooms 5 and $5 \mathrm{~A}$ p. 100

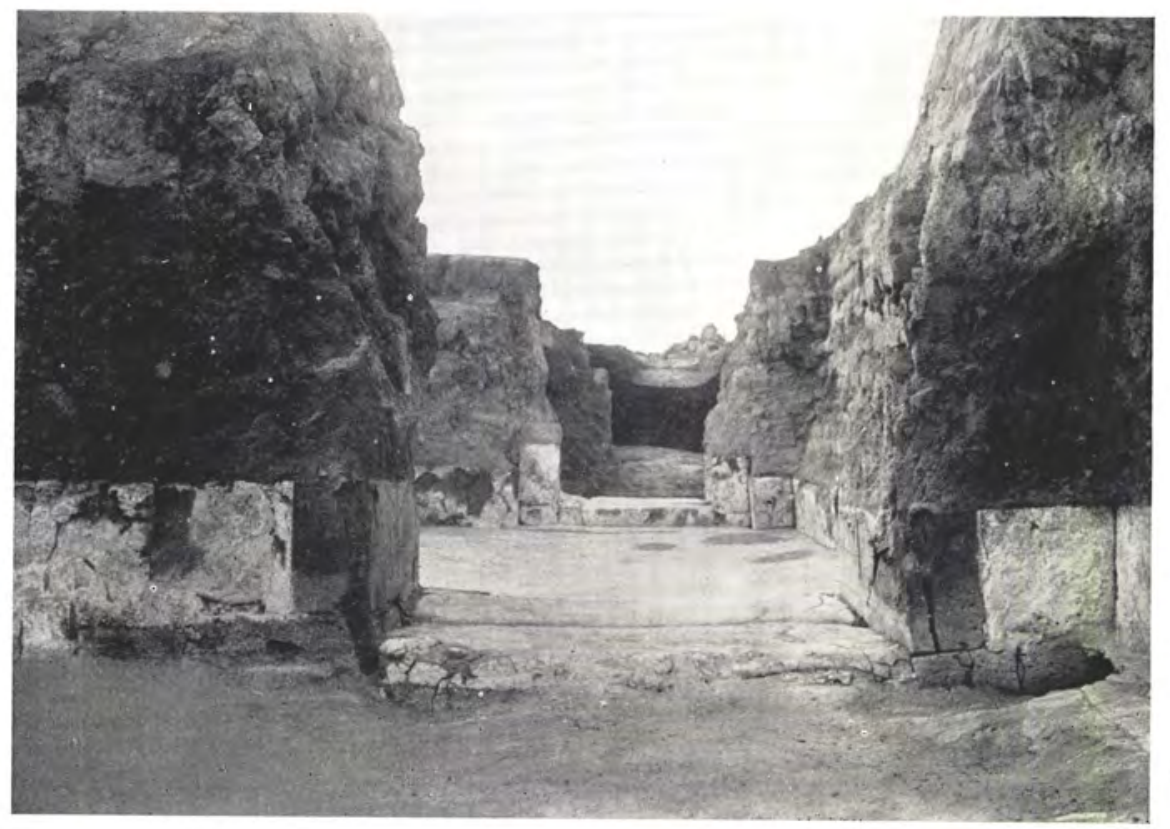

b. View from the courtyard across room 8 to the staircase p. $10 \mathrm{I}$

The Level VII palace 


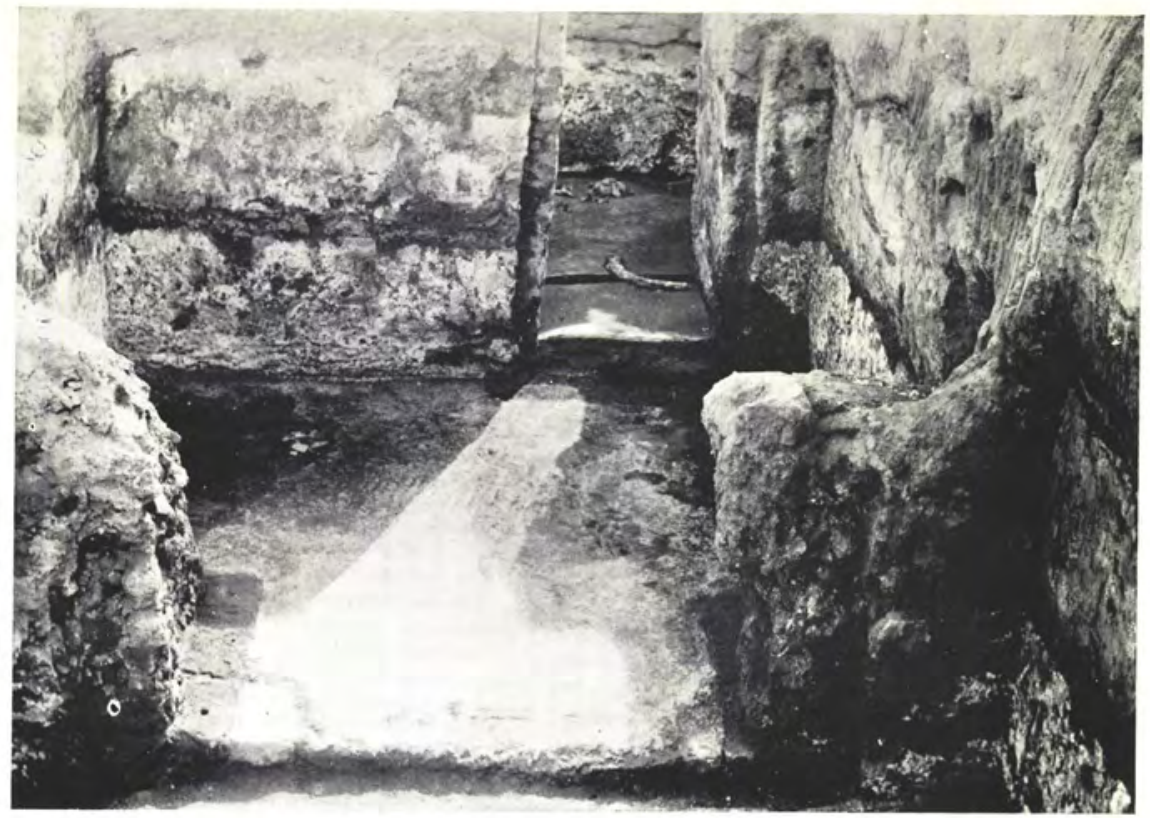

a. Rooms I 2 and II; an elephant tusk lies on the threshold p. 102

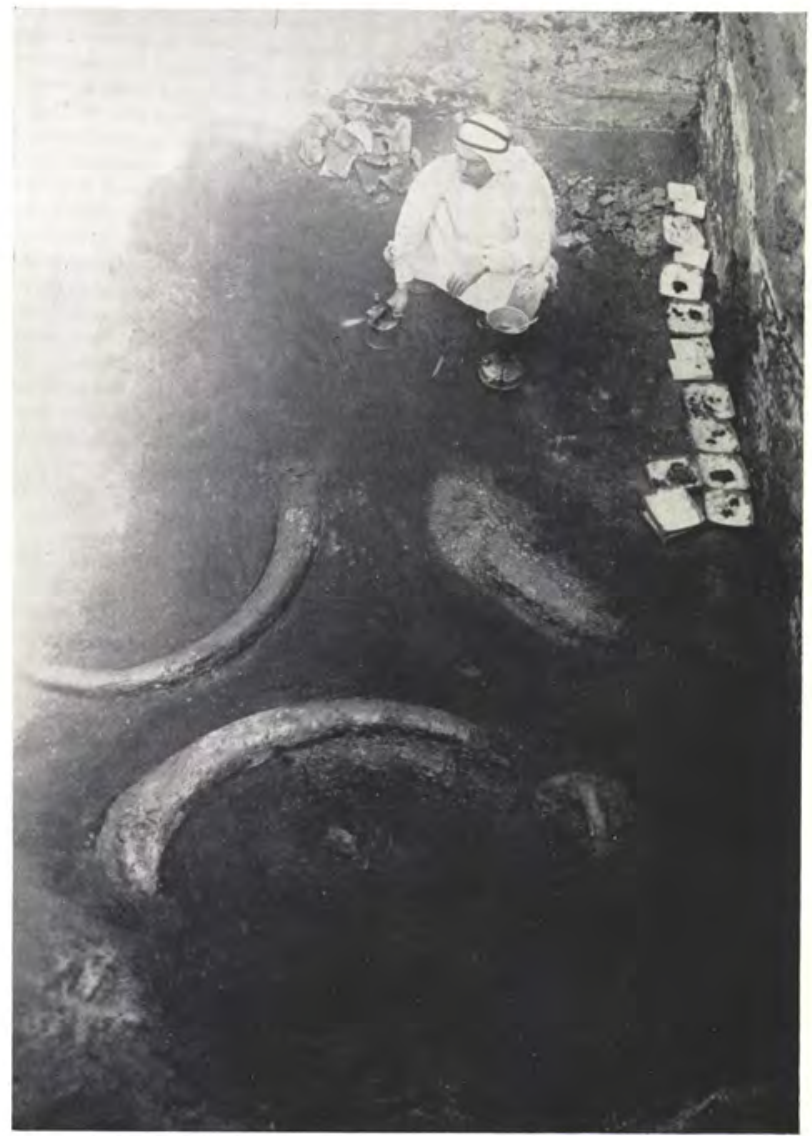

$b$. Room II; on the floor are tablets and elephants' tusks, the latter being waxed for removal by Alawi, junior foreman

p. 102

The Level VII palace 


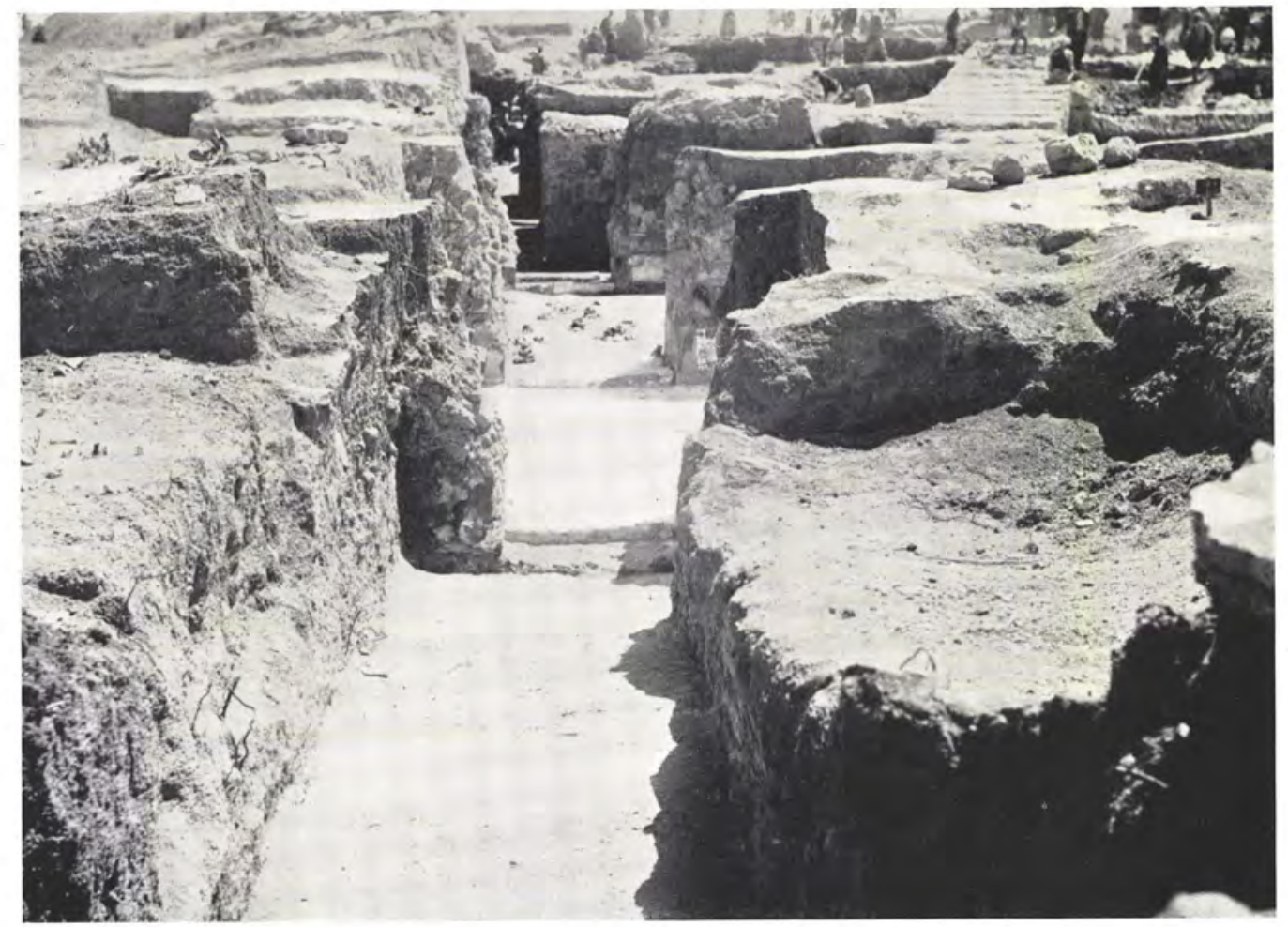

a. General view from room 3 through room 8 and across the courtyard (9) to the stair-chamber ( 10 )

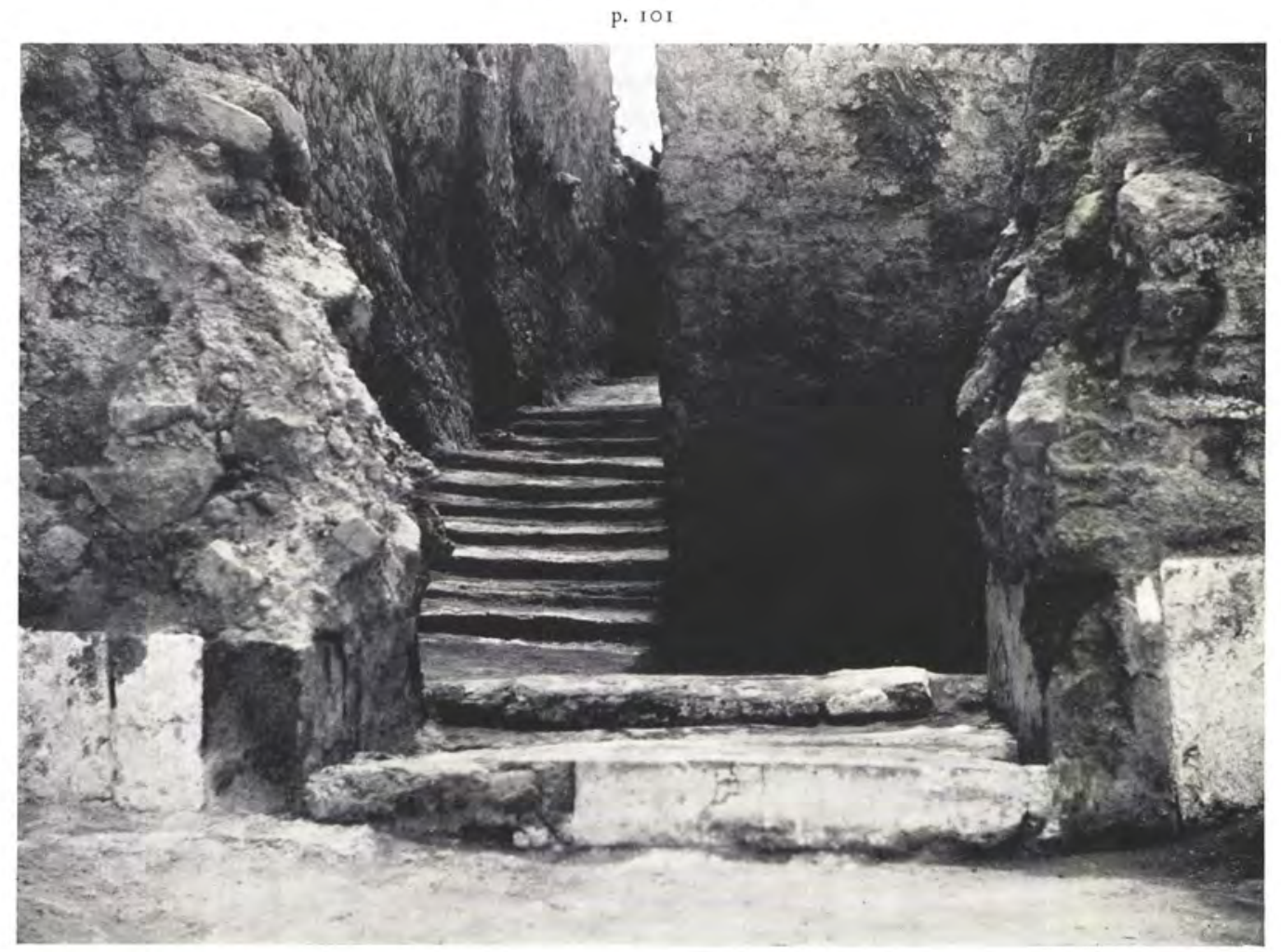

b. Room IO, the staircase: the first flight of the winding staircase and the steps going straight on to the passage (I 4 )

D. 102

The Level VII palace 


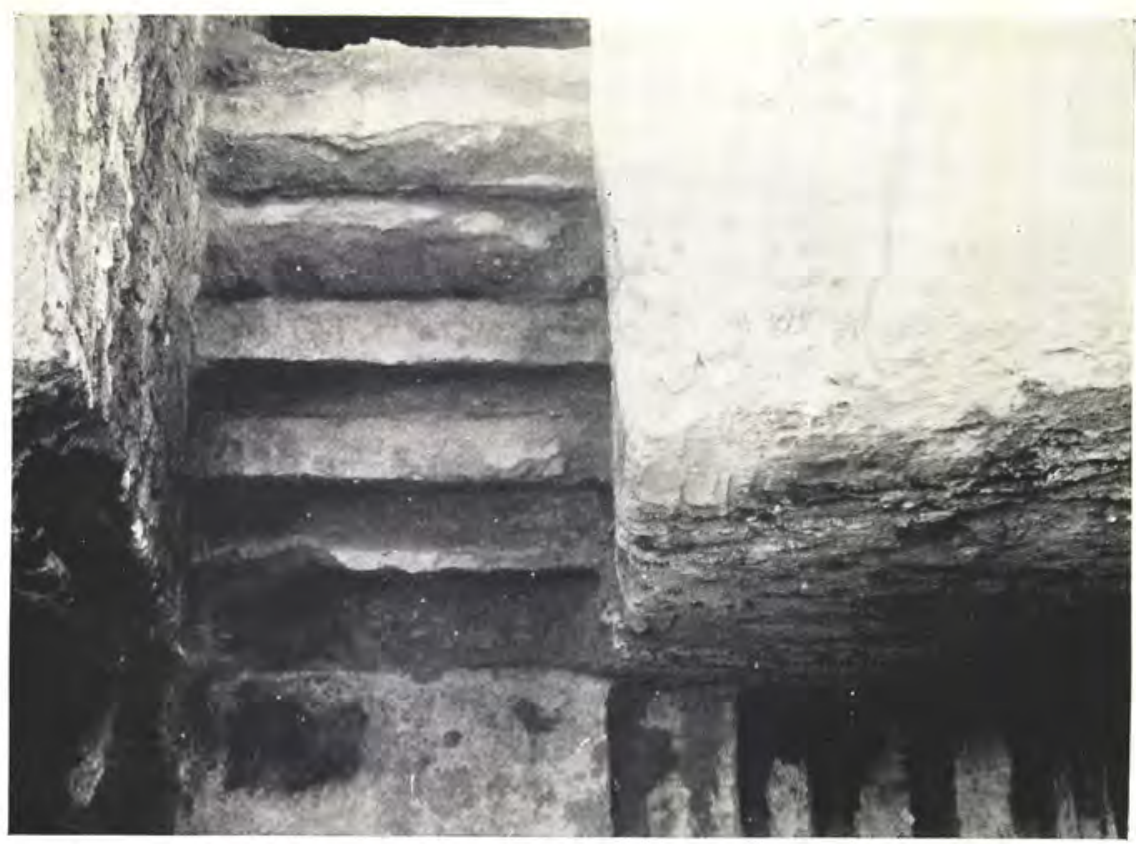

a. Room IO, looking down on the first and second flights of the newel staircase

p. 102

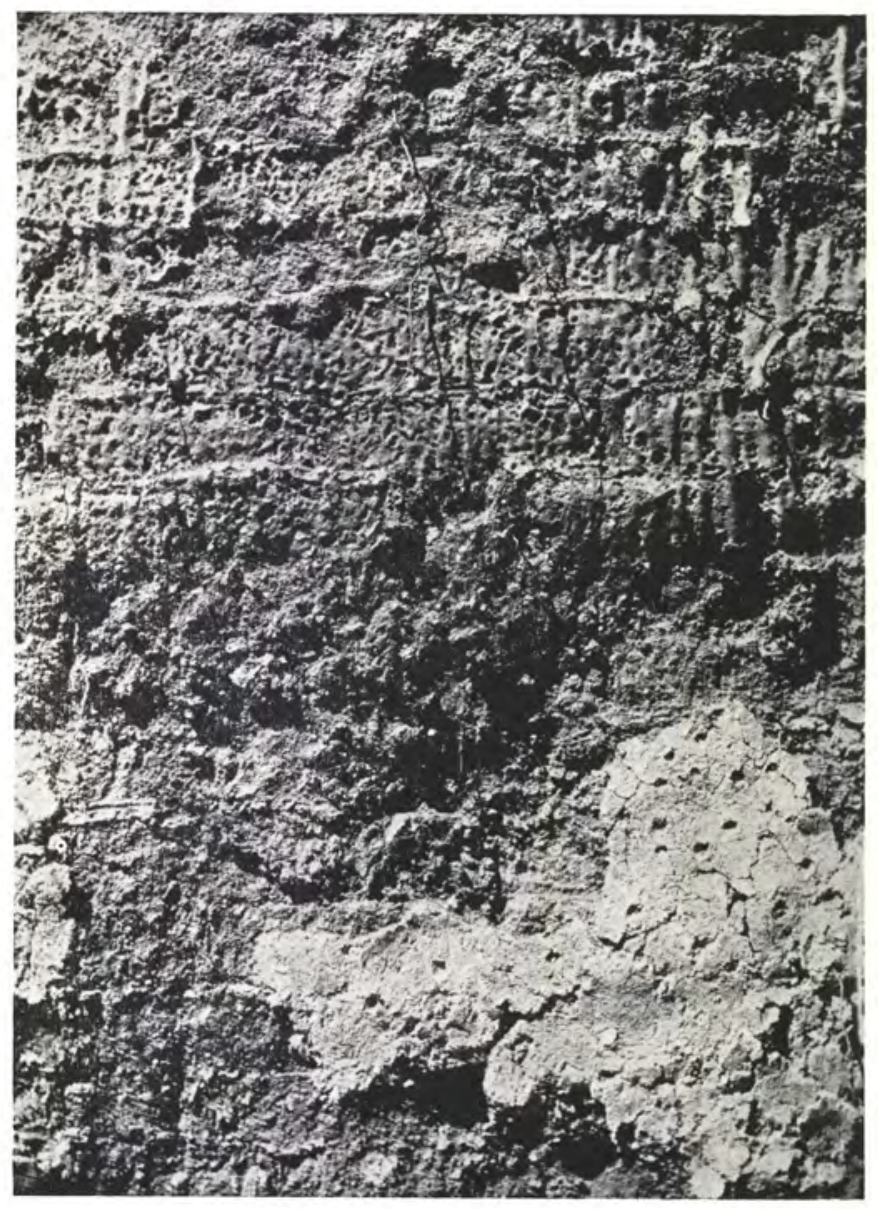

b. The staircase wall (room 3) showing vitrified brickwork: on the lower plaster is visible the finger-print keying for the intonaco

p. 99

The Level VII palace 


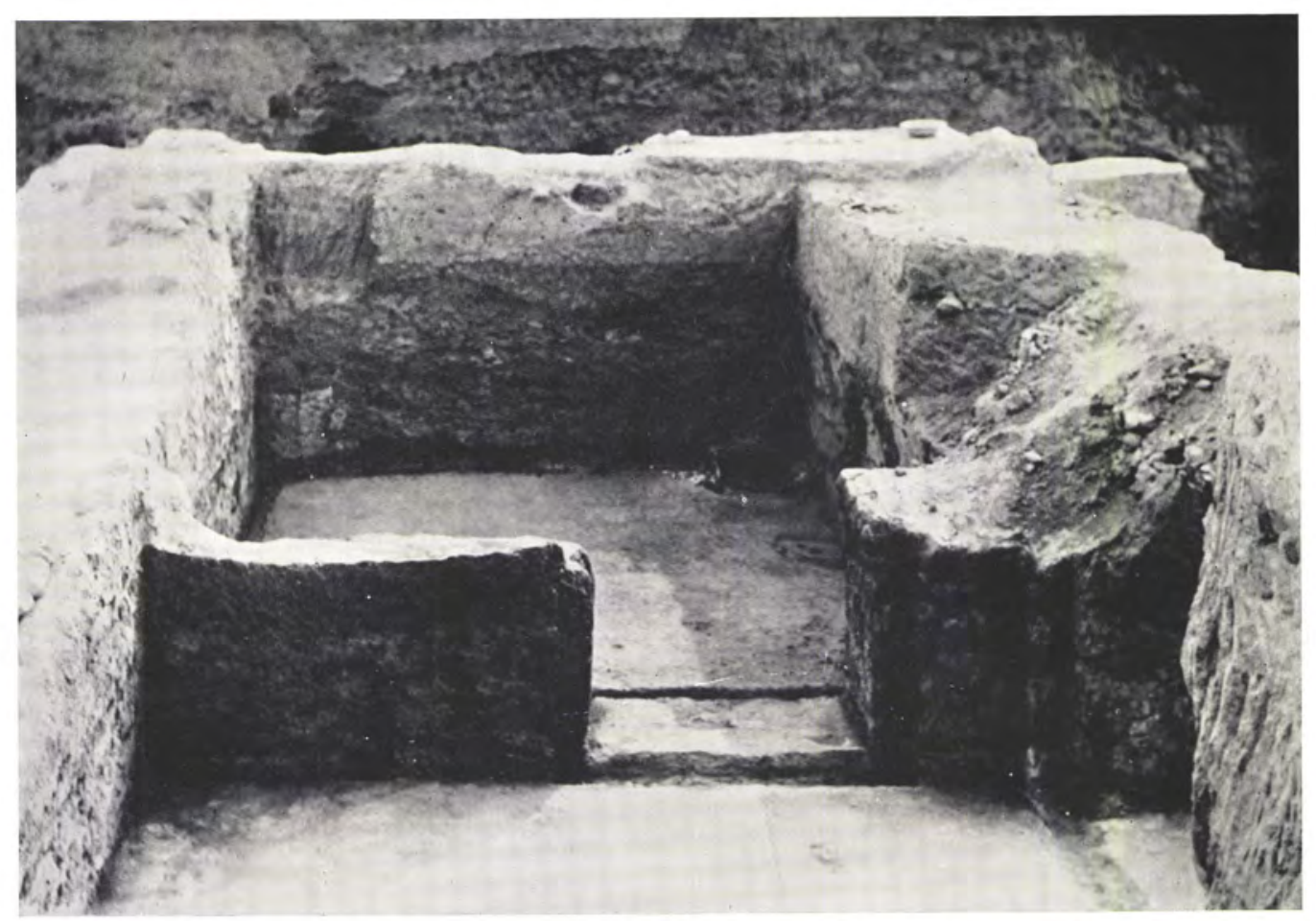

a. Room 15 , seen from room 16 ; in the background, the bath and drain in-take p. 103

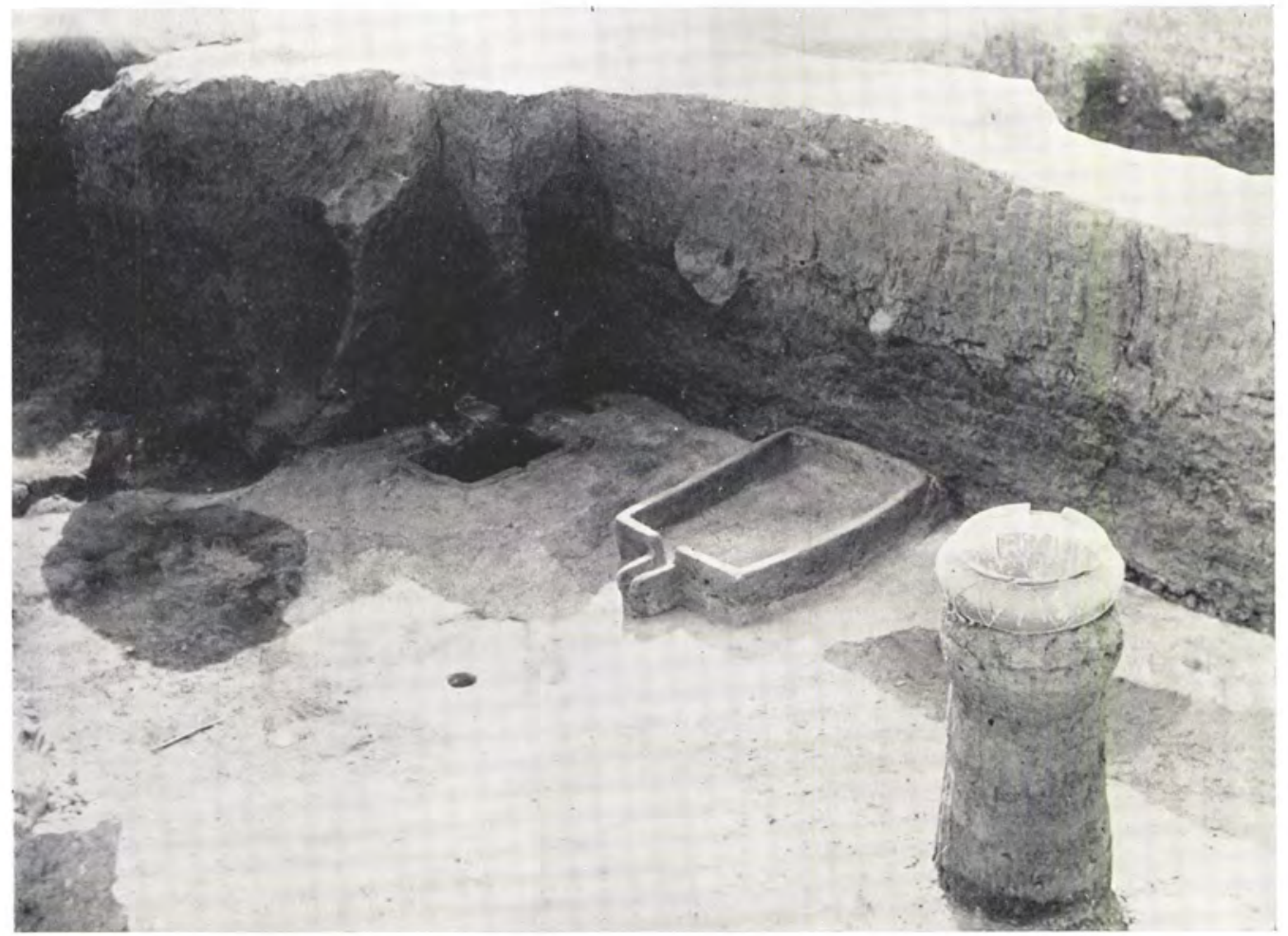

b. Room 18 , showing the sunken tank, washing-basin, and drain. The pot in the foreground belongs to Level VI-V

p. $\mathrm{IO}_{3}$

The Level VII palace 


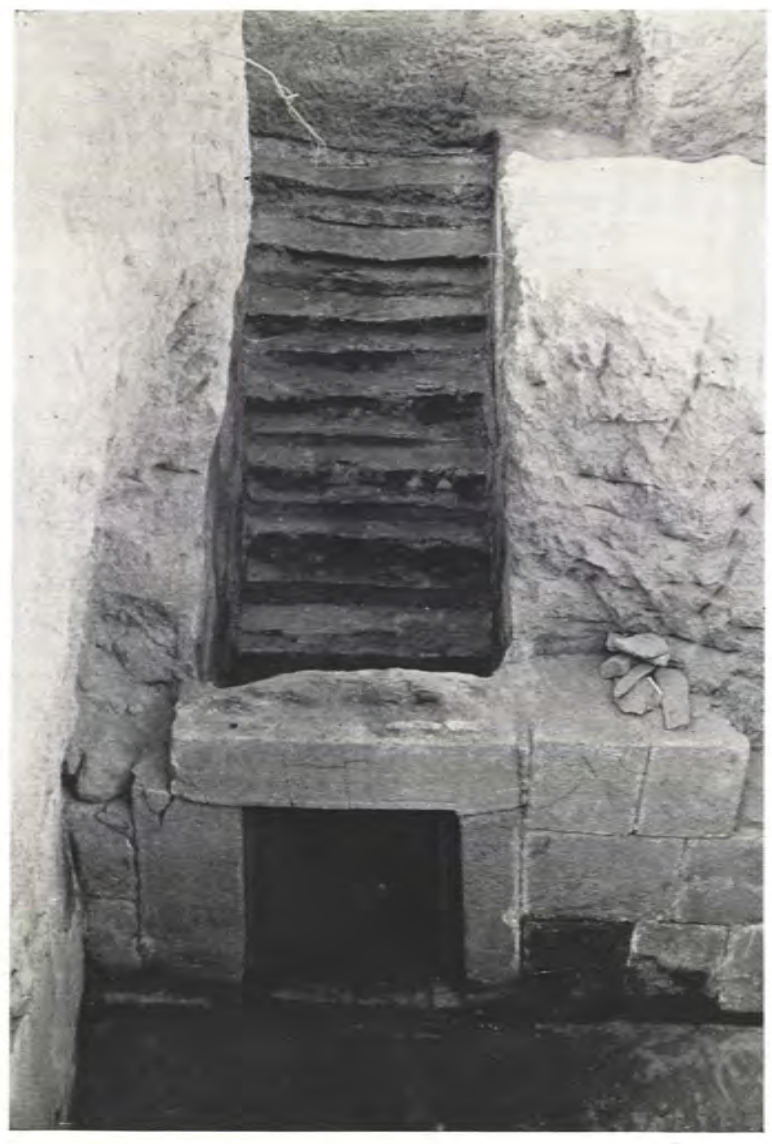

a. The staircase and shaft below room 17

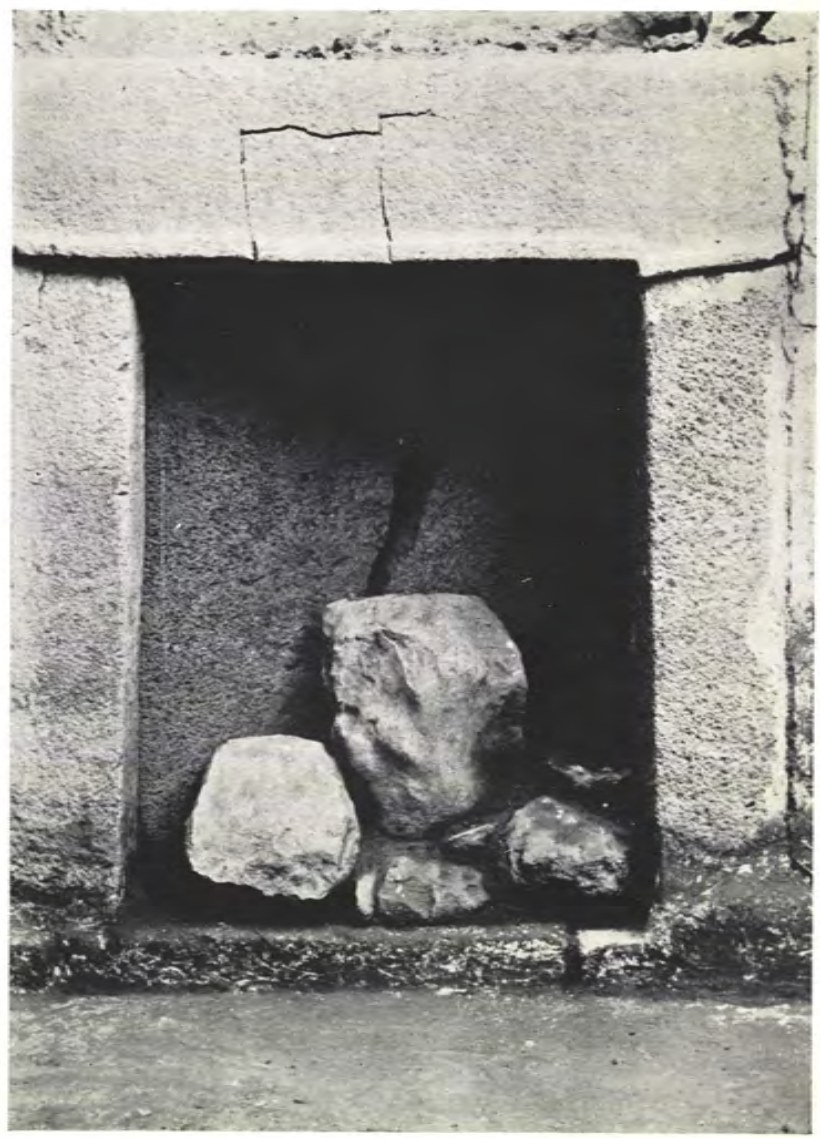

$b$. The stone doorway of the shaft blocked by boulders

p. 95

The Level VII palace 


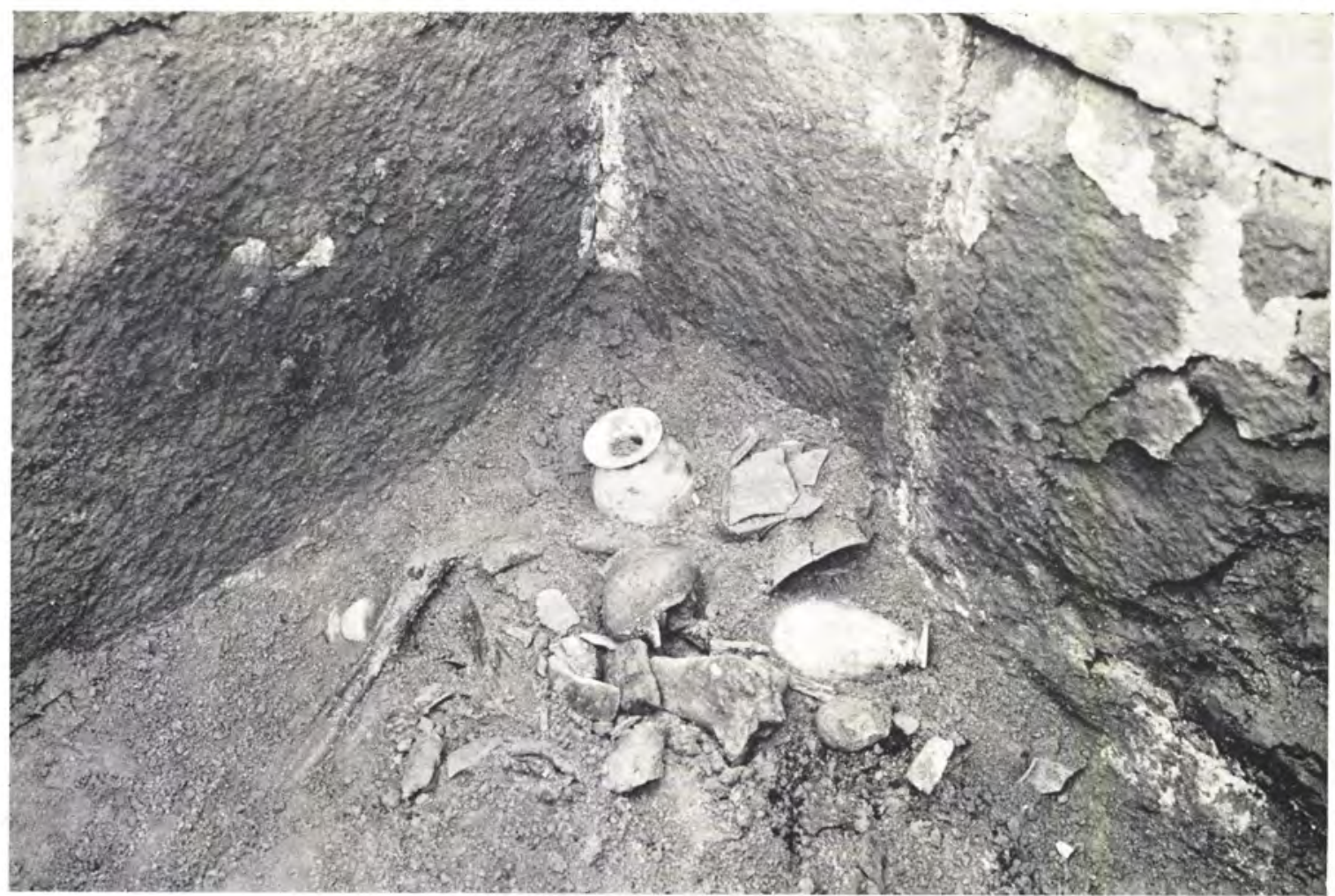

a. The shaft ( 17 ), showing burnt bones and stone and clay vases in the NE. corner p. 96

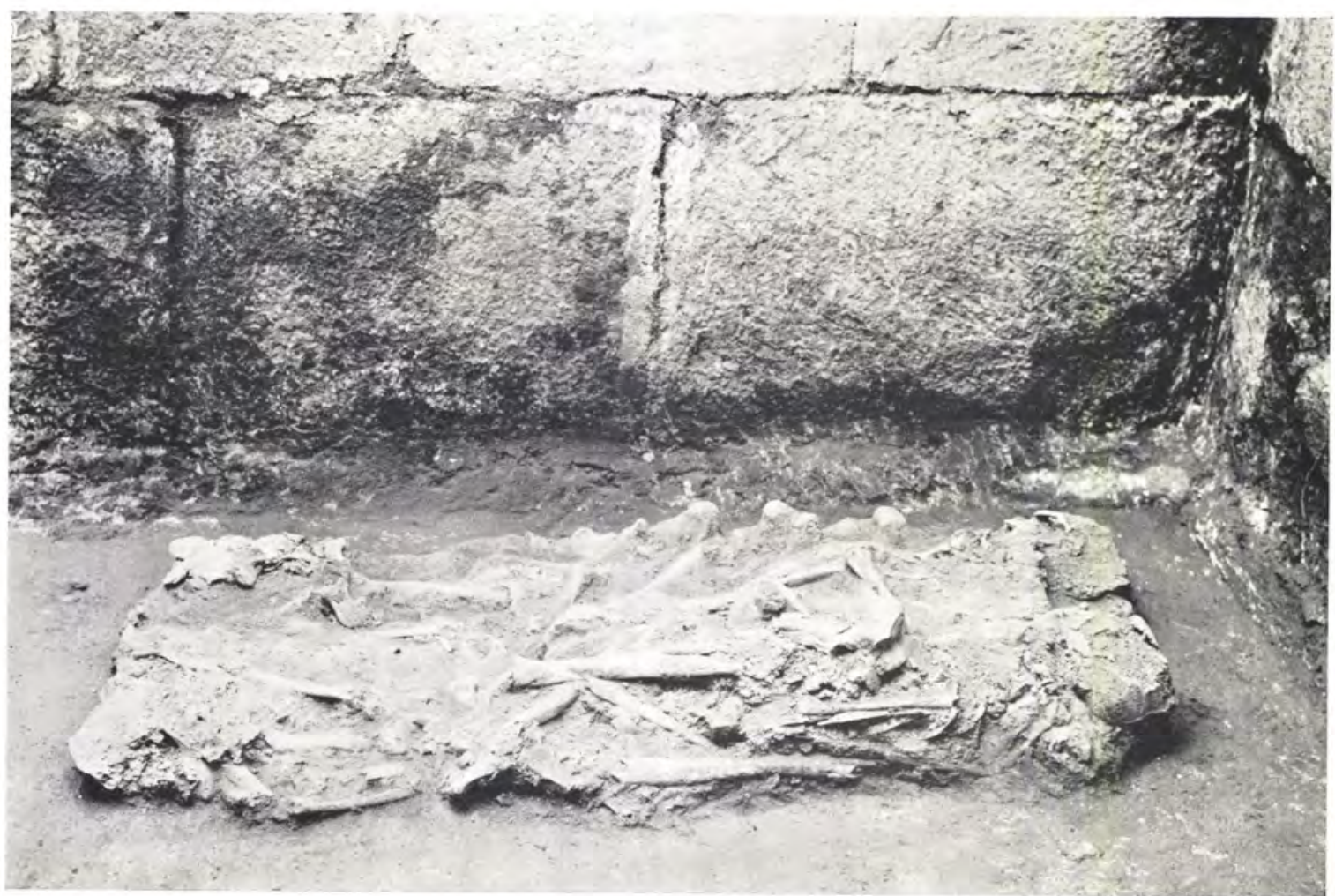

b. The shaft (17), showing the four bodies in a box 


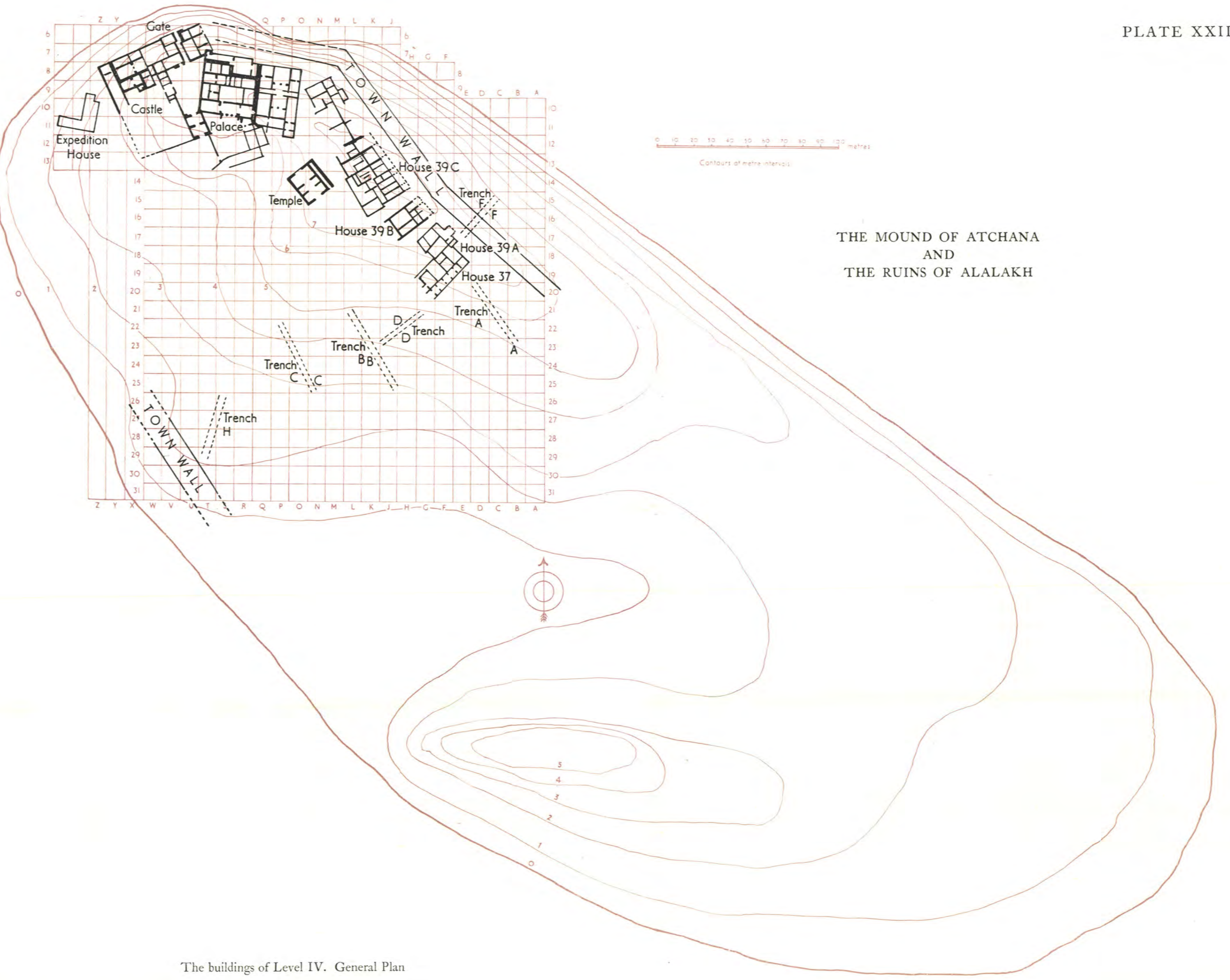




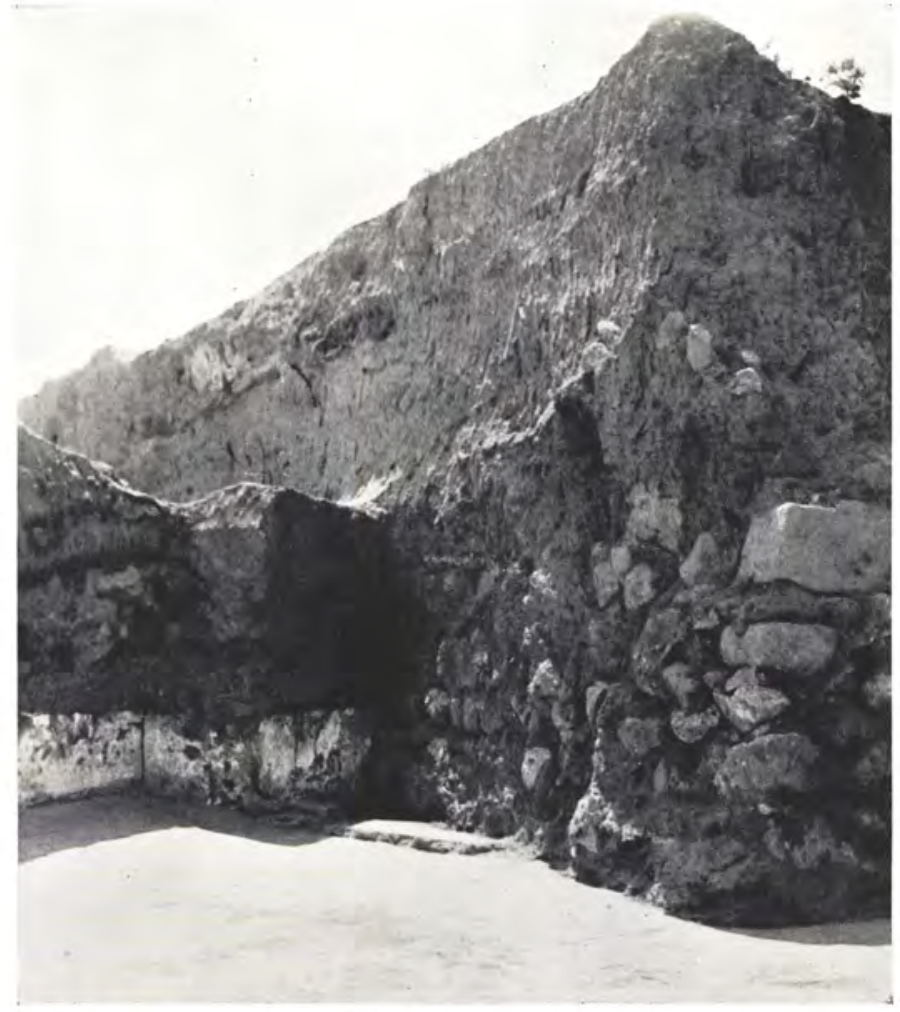

a. The foundations of the NE. corner cut down into room 2 of the Level VII palace

p. 112

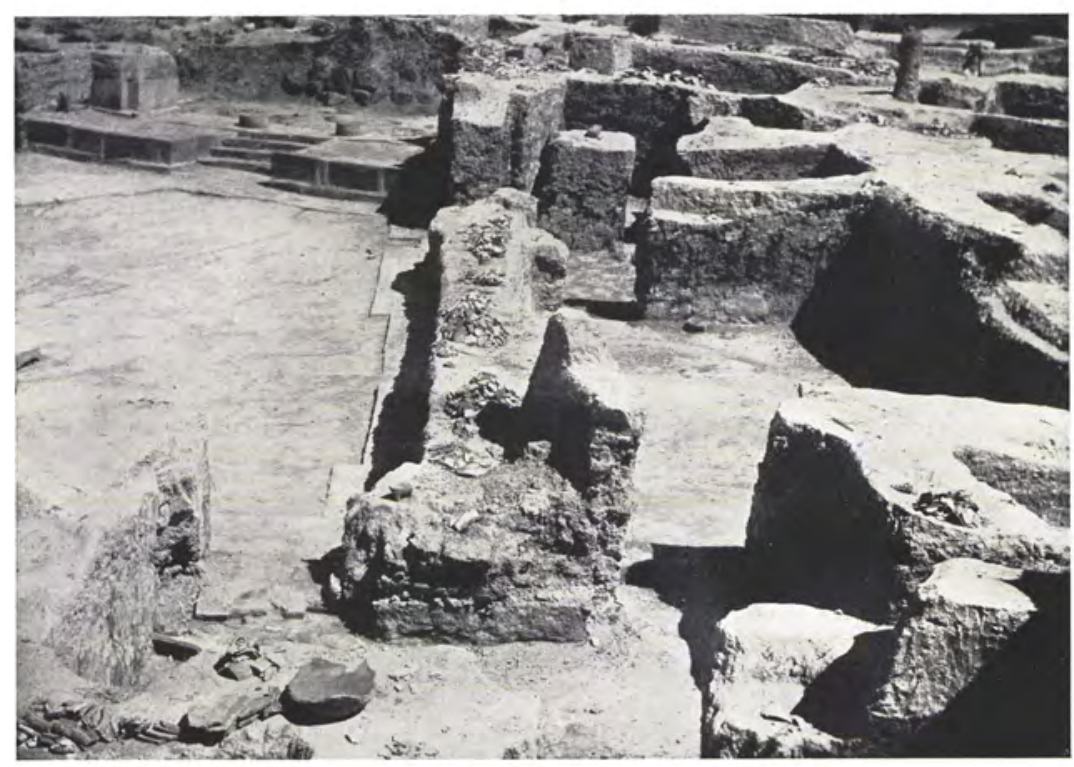

b. The domestic wing

p. 127

The Level IV palace 


\section{PLATE XXIV}

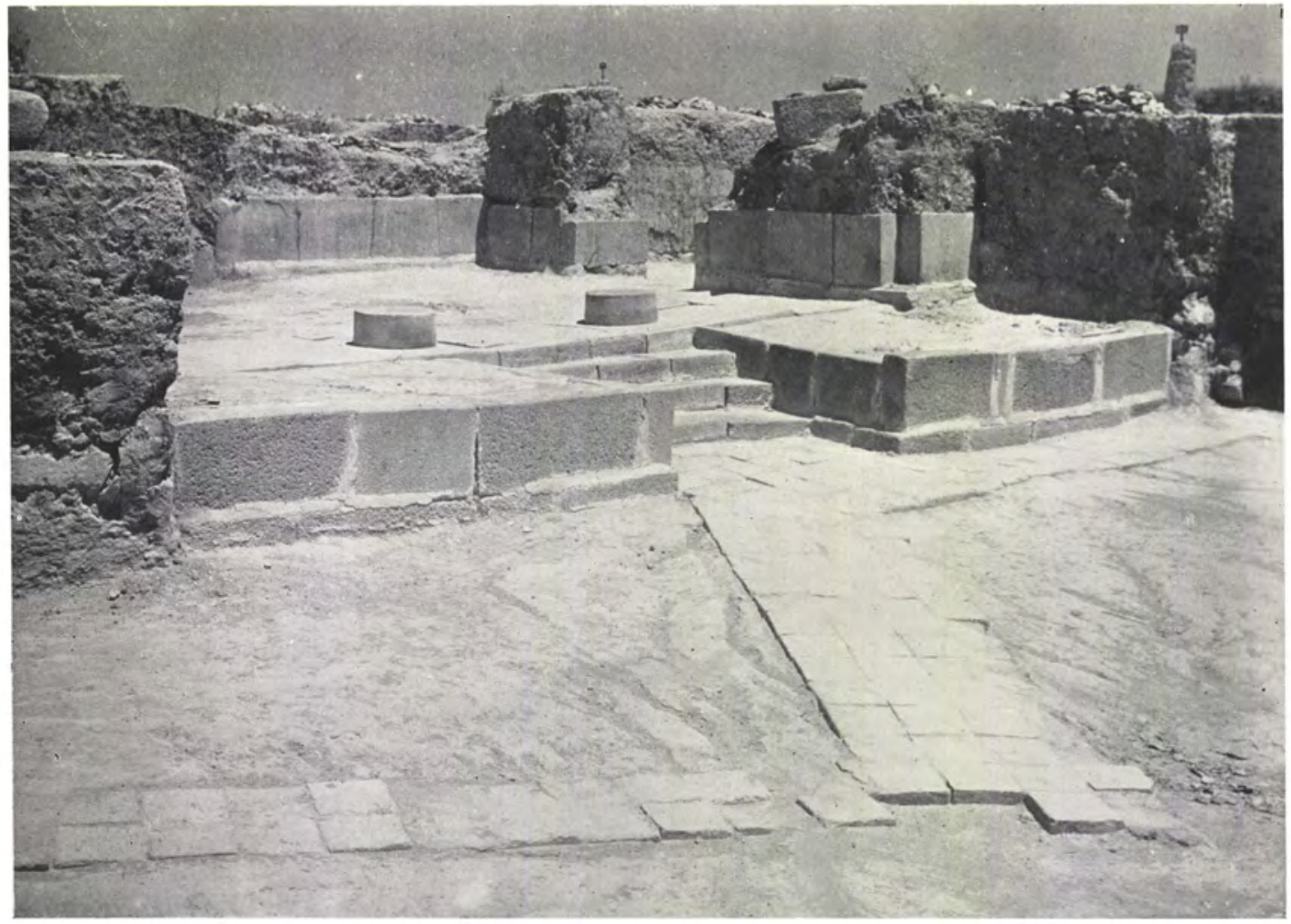

a. Forecourt and façade

p. II 6

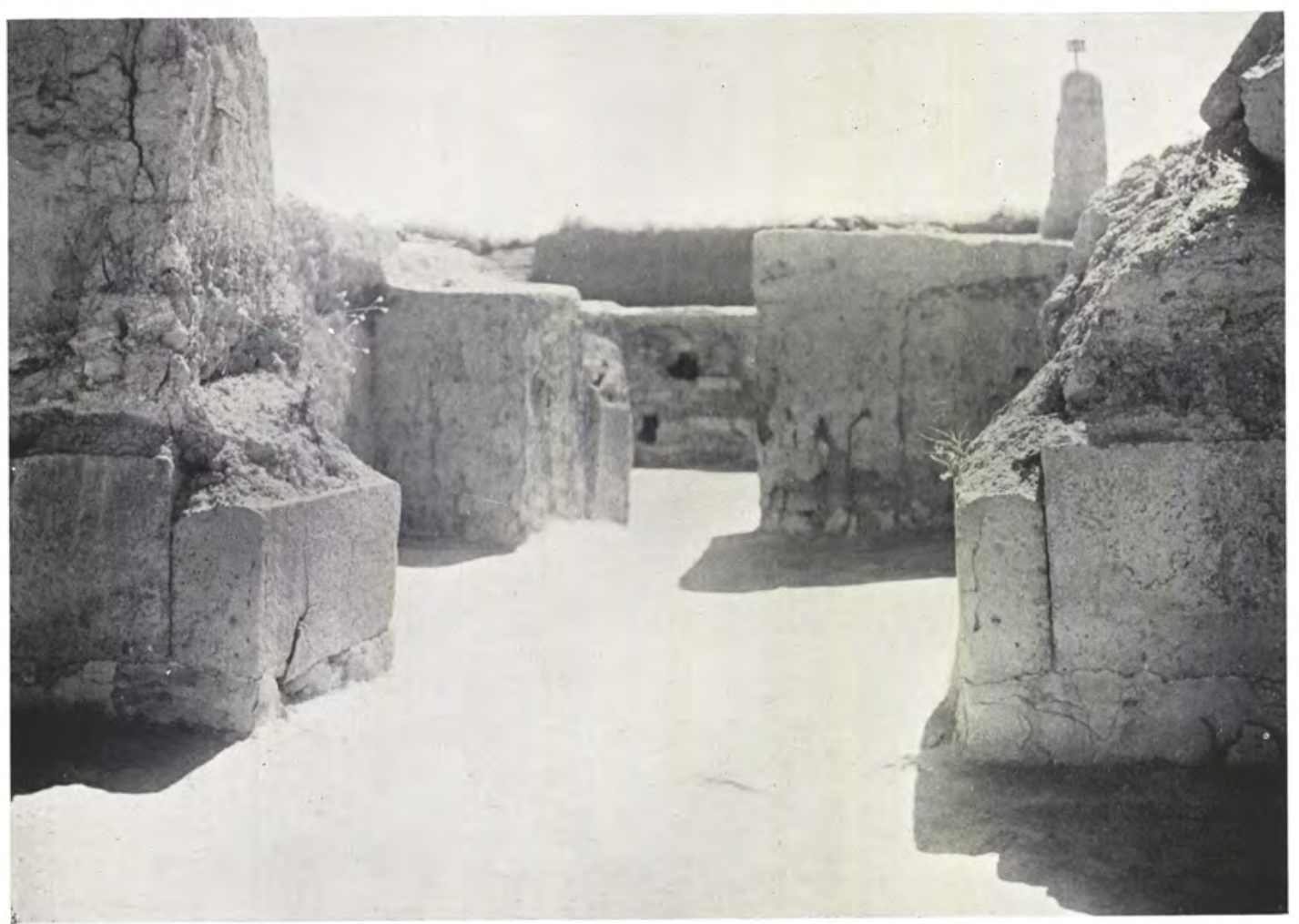

b. View from room 2 across room 13 to room 22

p. II 8

The Level IV palace 


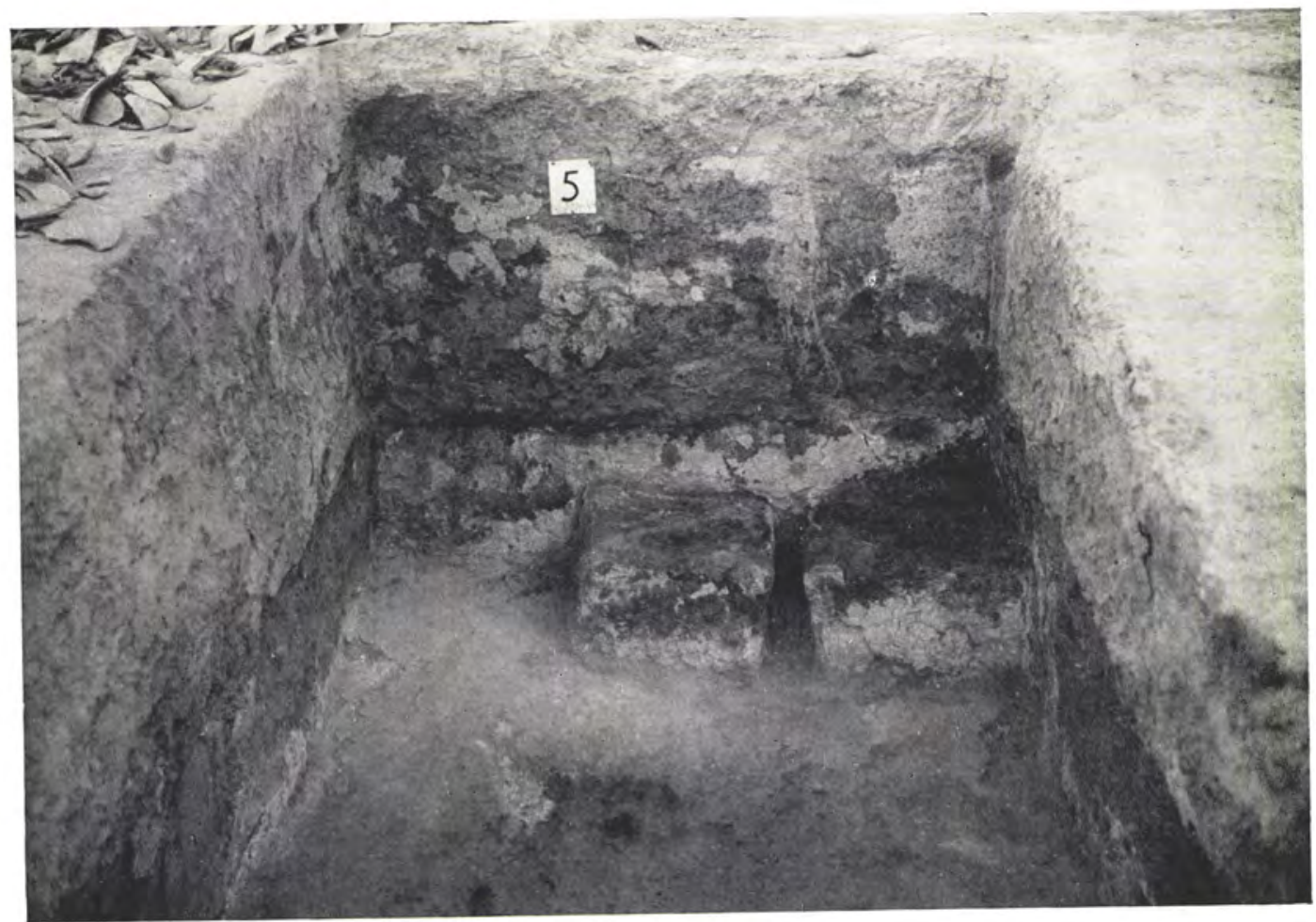

a. Room 5, the lavatory p. I 8

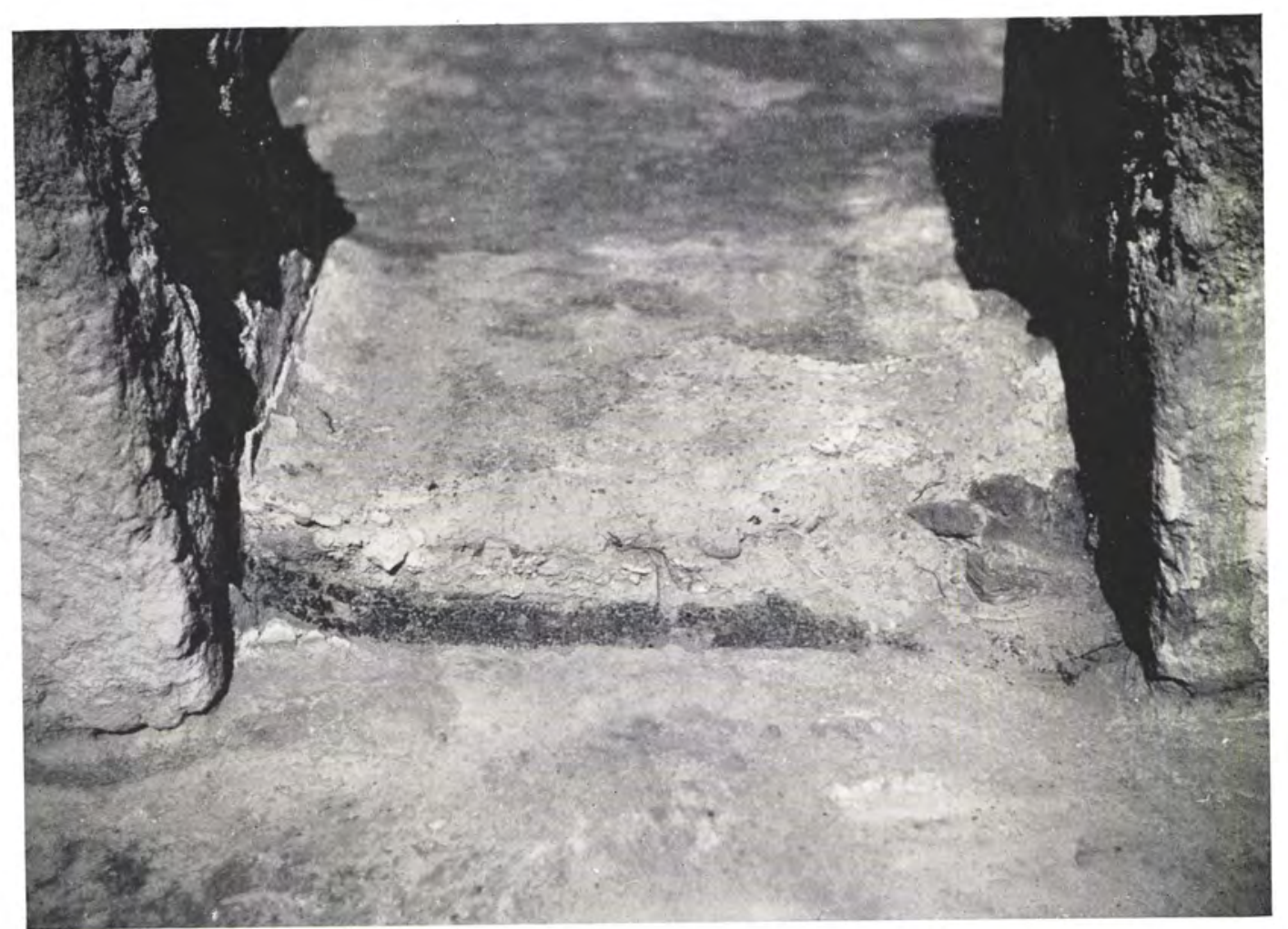

b. Room 9, the doorway, showing wooden sill-edge and the packing of the raised threshold p. 120 


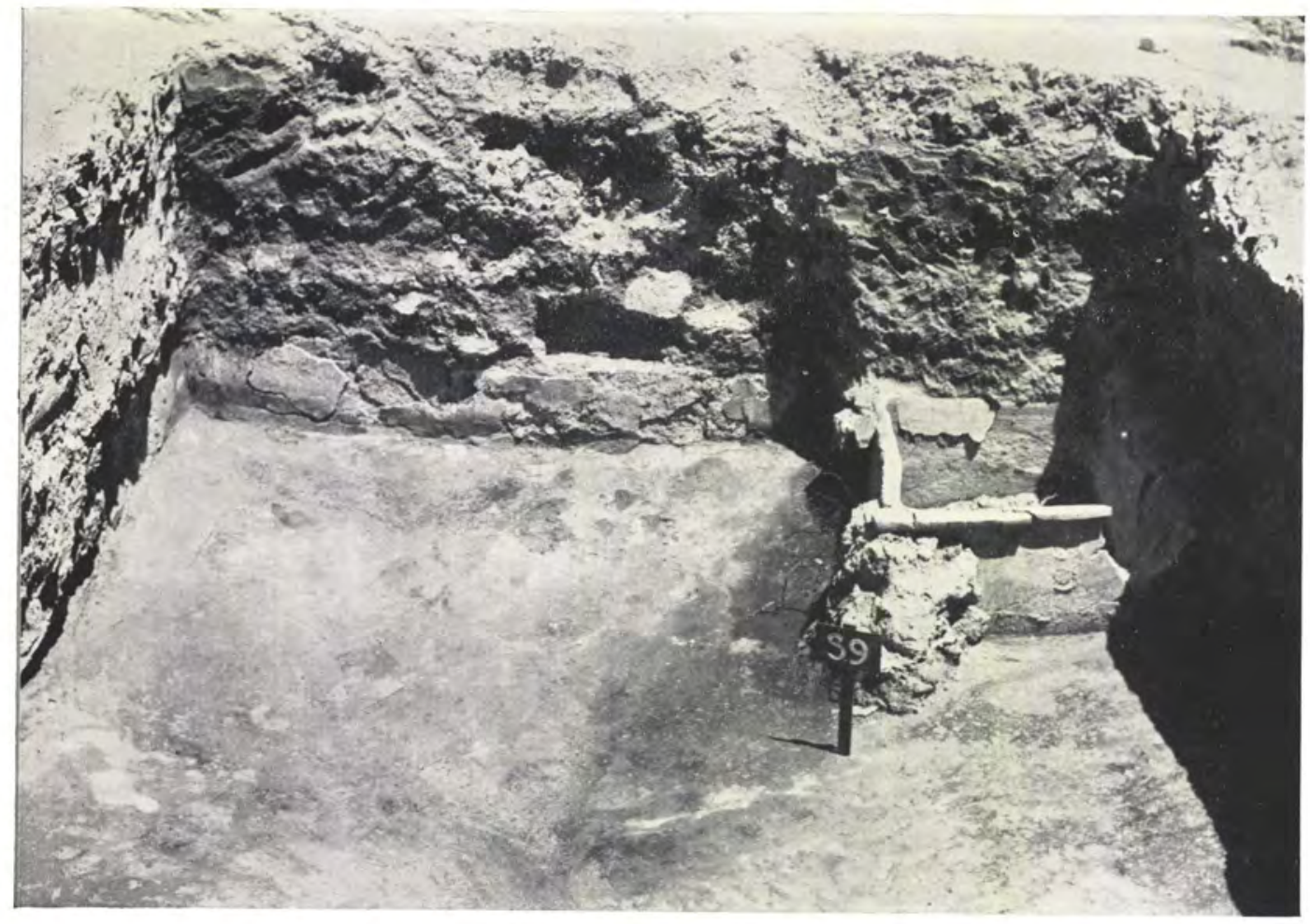

a. Room 9; the bath

p. 120

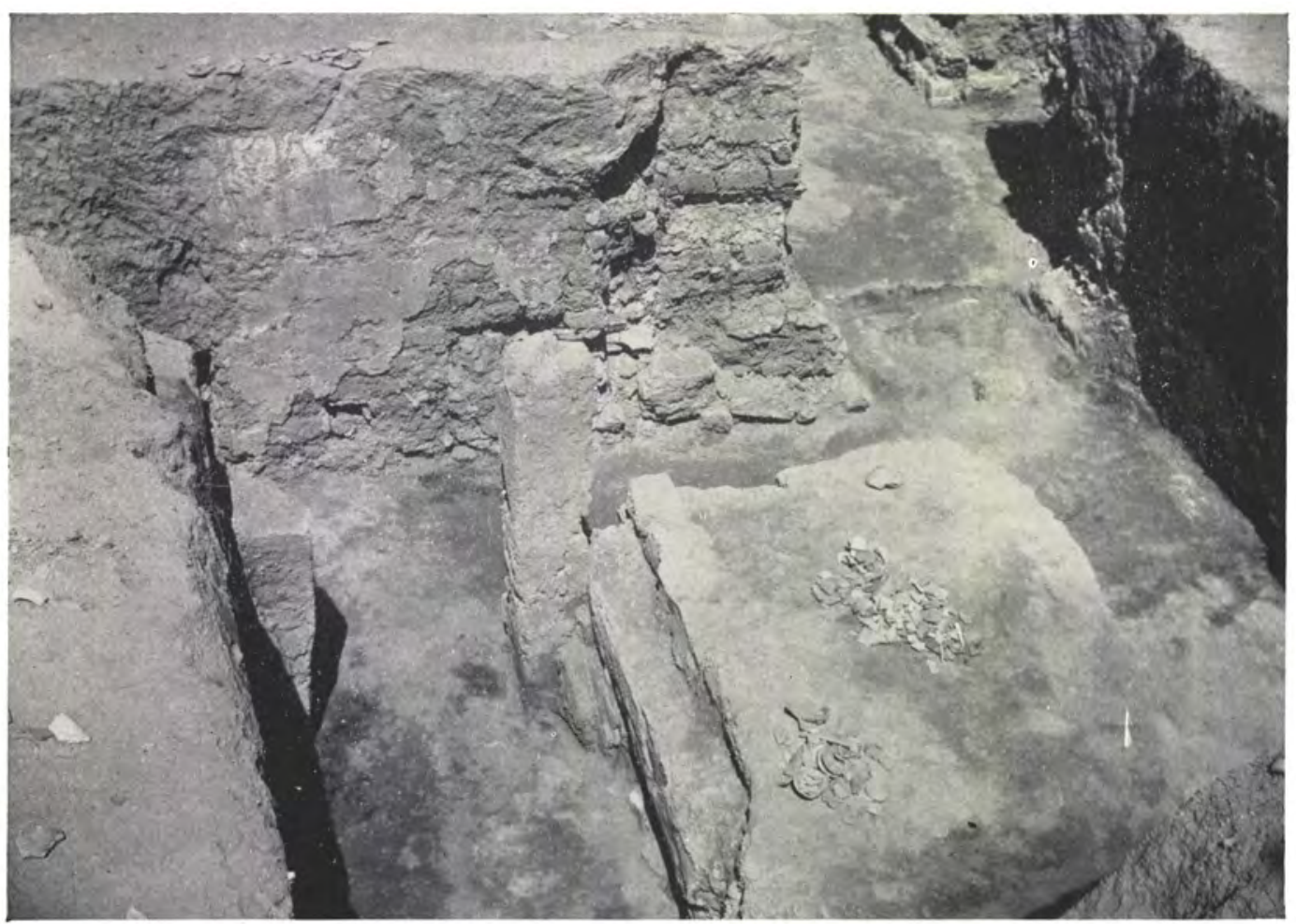

b. Room 27, seen from above, showing the stair newel and the cupboard below the stairs p. 124

The Level IV palace 


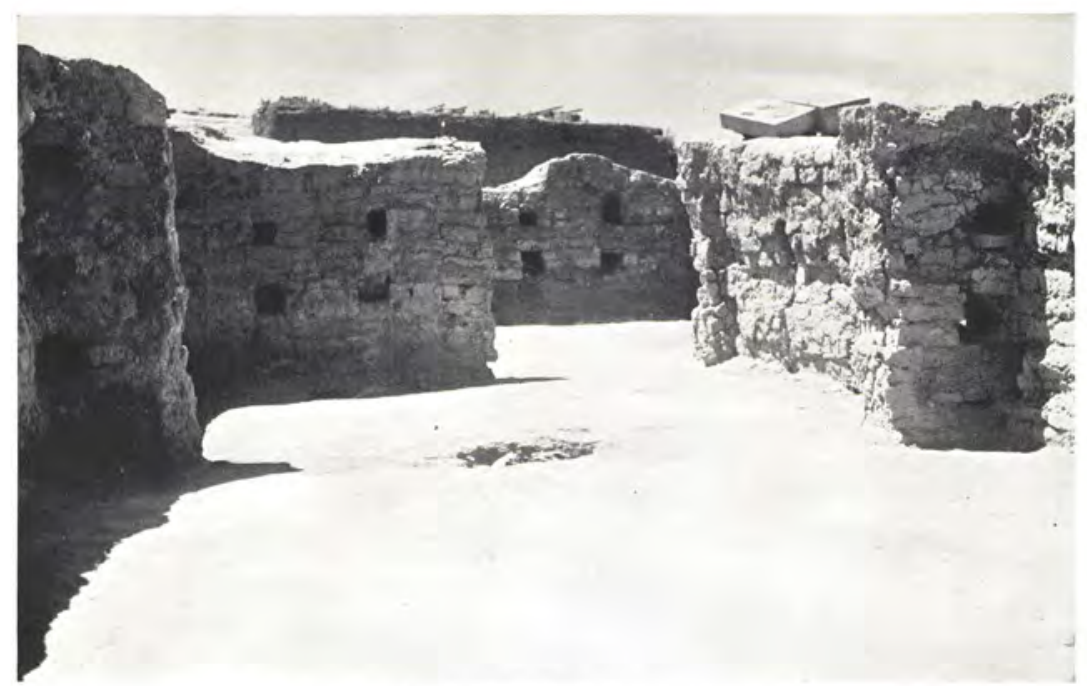

a. Room 28, with the sunken column-base

p. 124

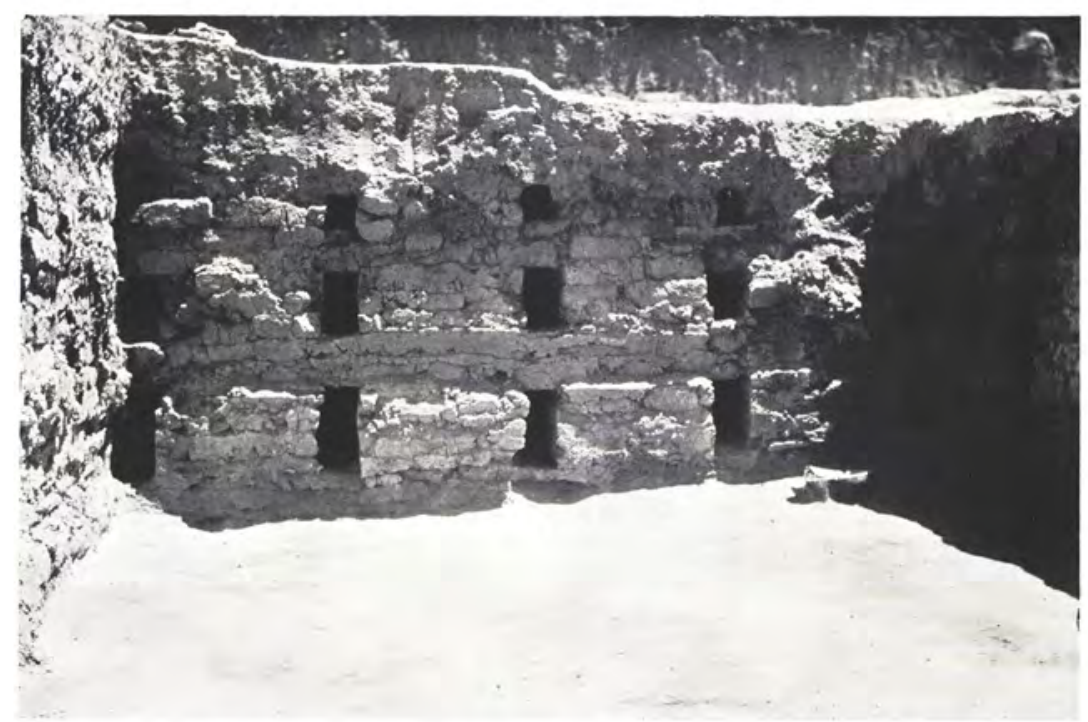

b. Room 32, showing the half-timber construction of the wall p. 125

The Level IV palace 


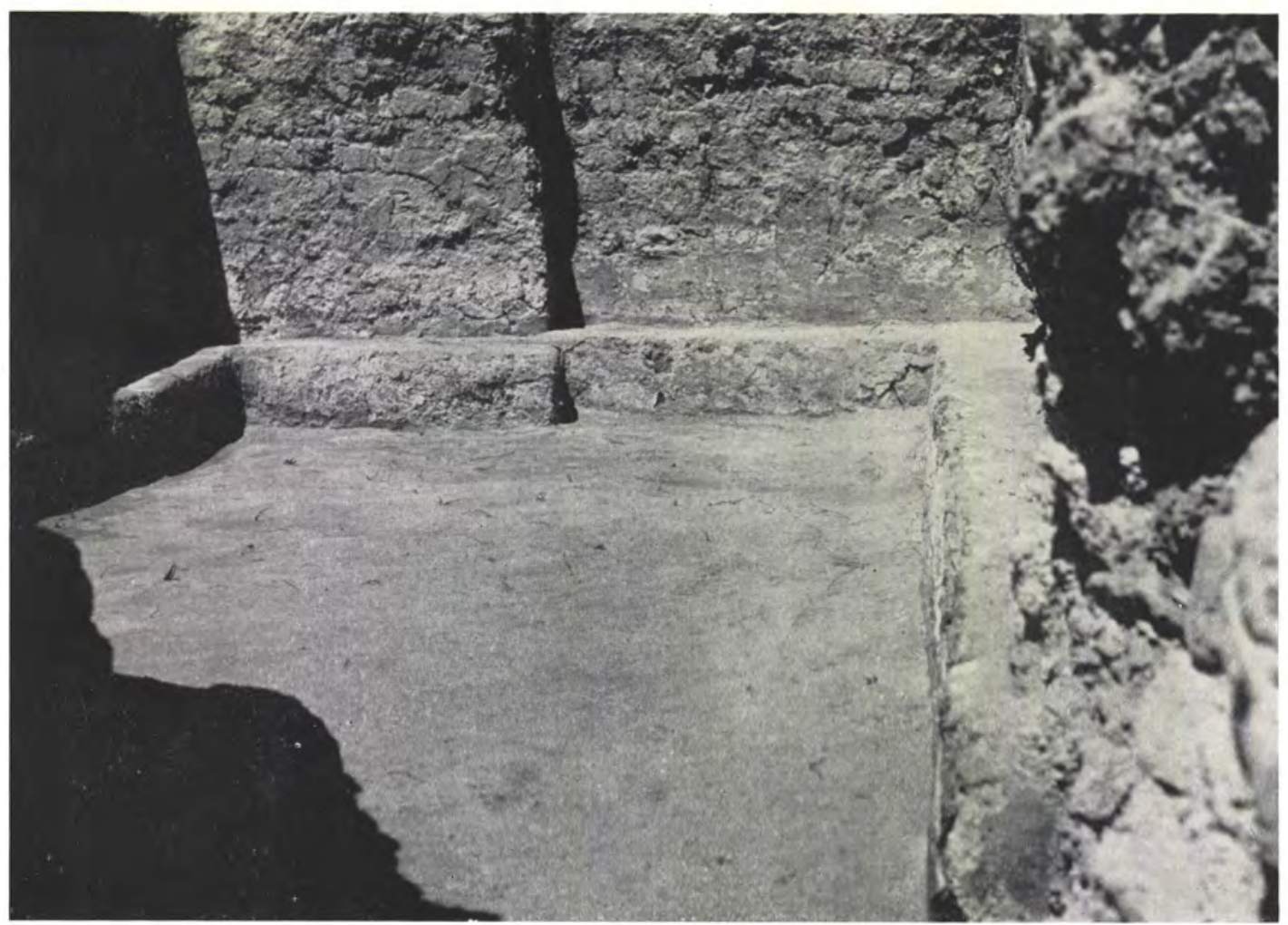

a. Room 33, the archive; round the walls runs a cemented shelf for storing tablets p. 126

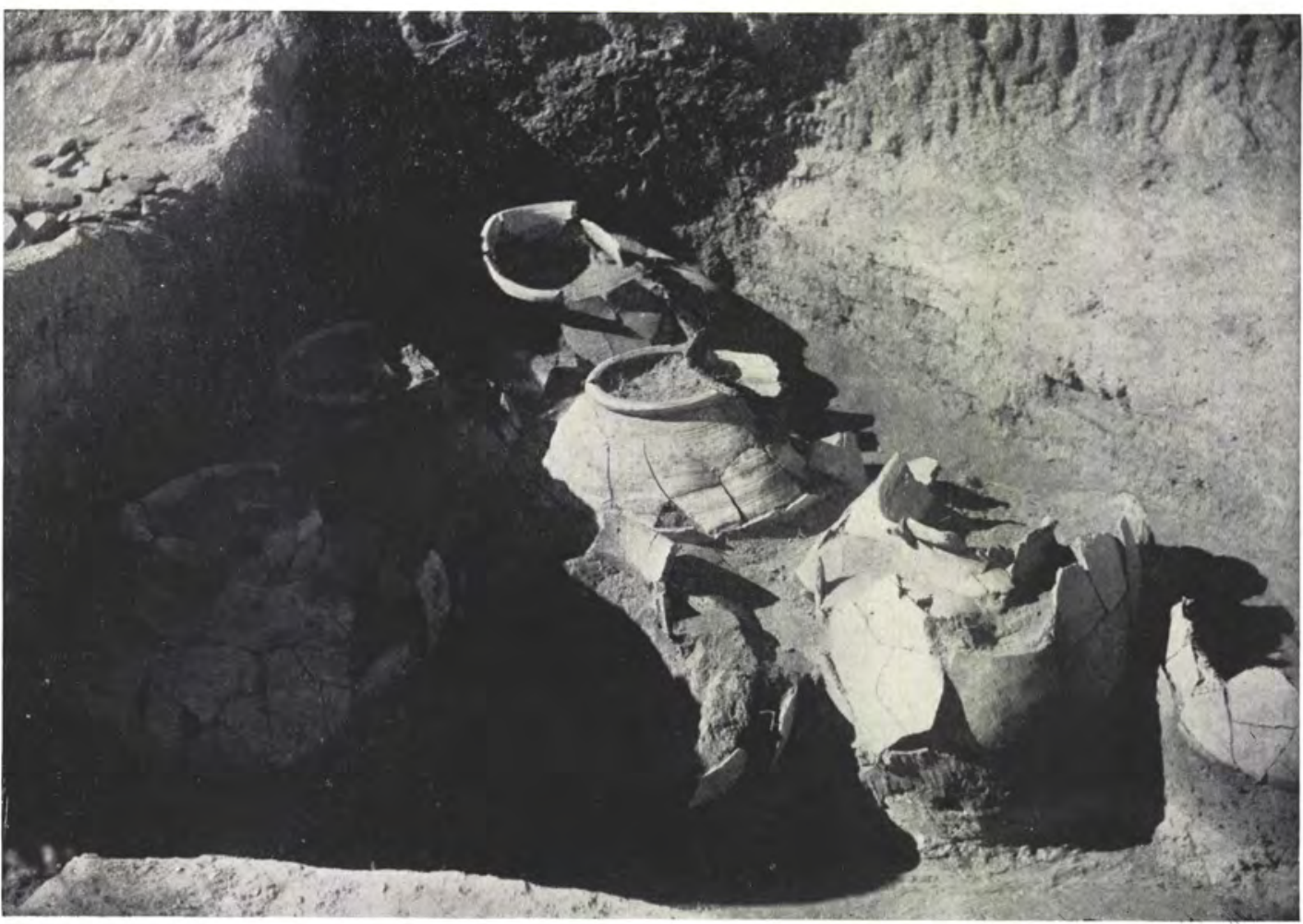

b. Room 35, the cellar p. 127

The Level IV palace 


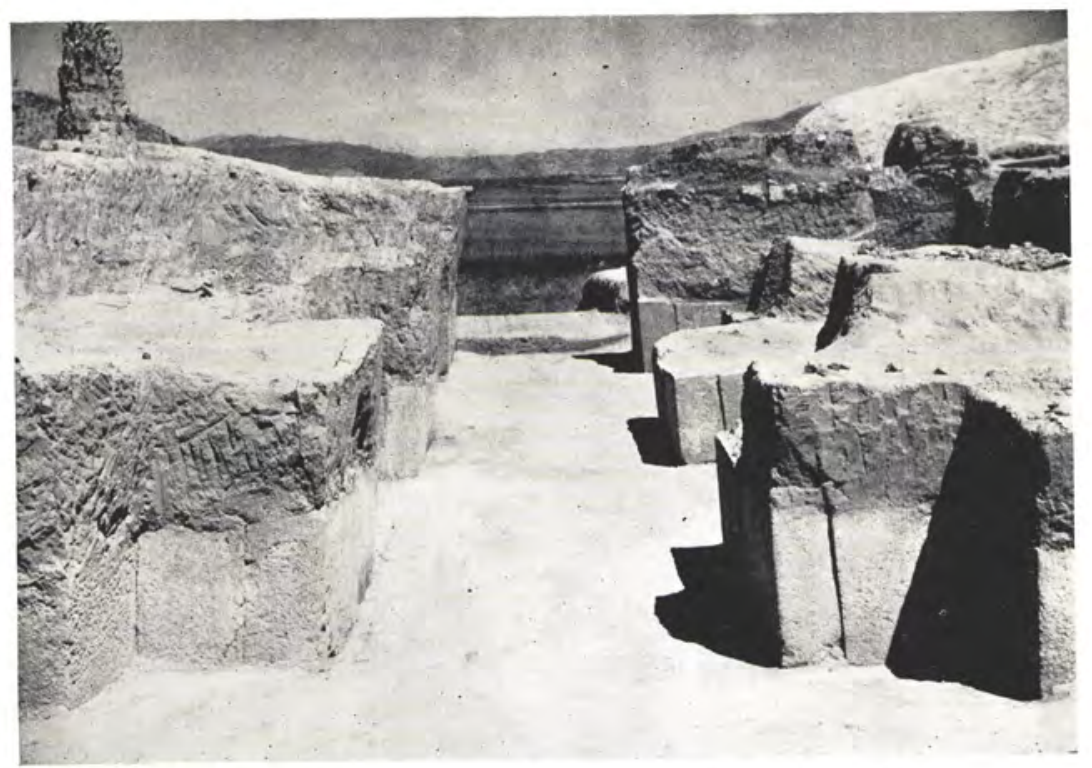

a. General view of the gateway from the inside p. 147

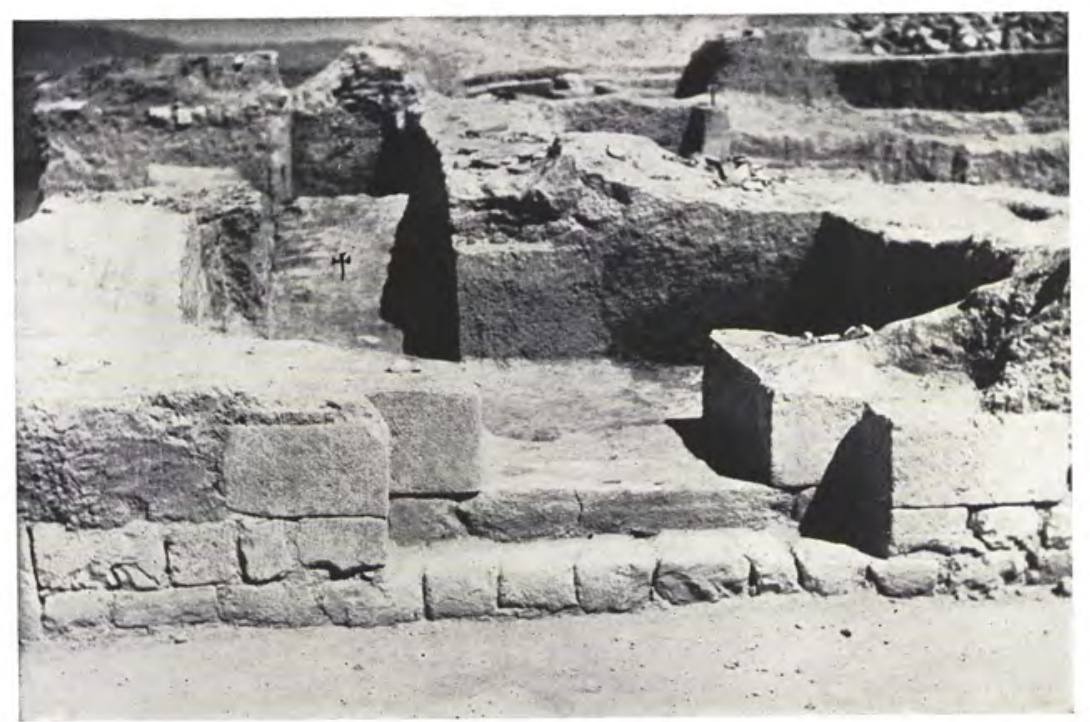

b. The guard chamber p. 148

The Level VII city gate 


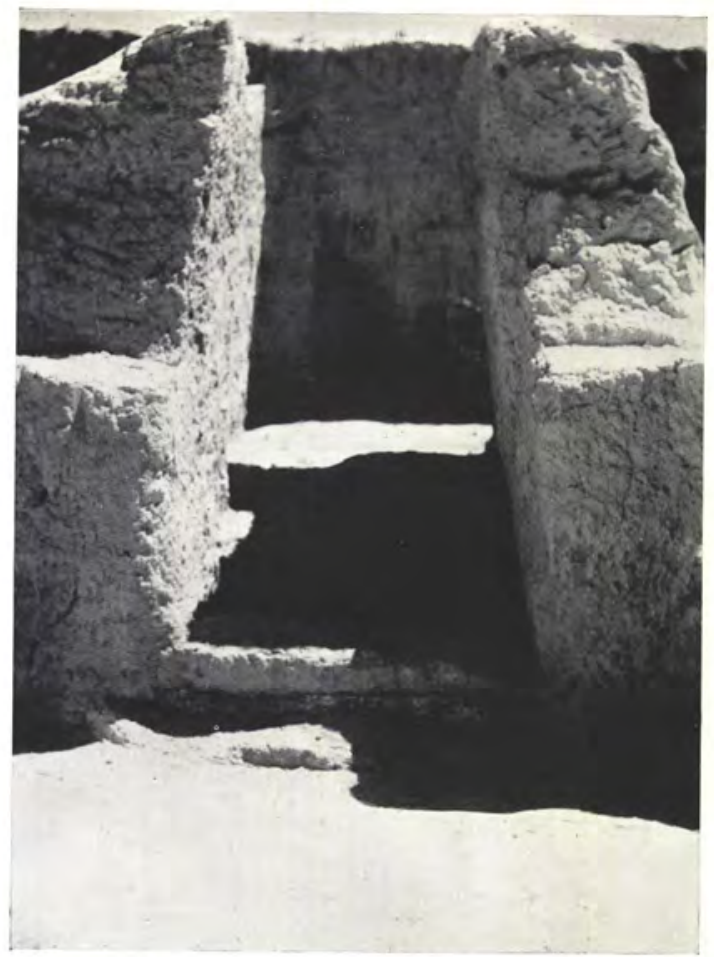

a. The Level VII city gate: the door of the sentry-box

p. 149

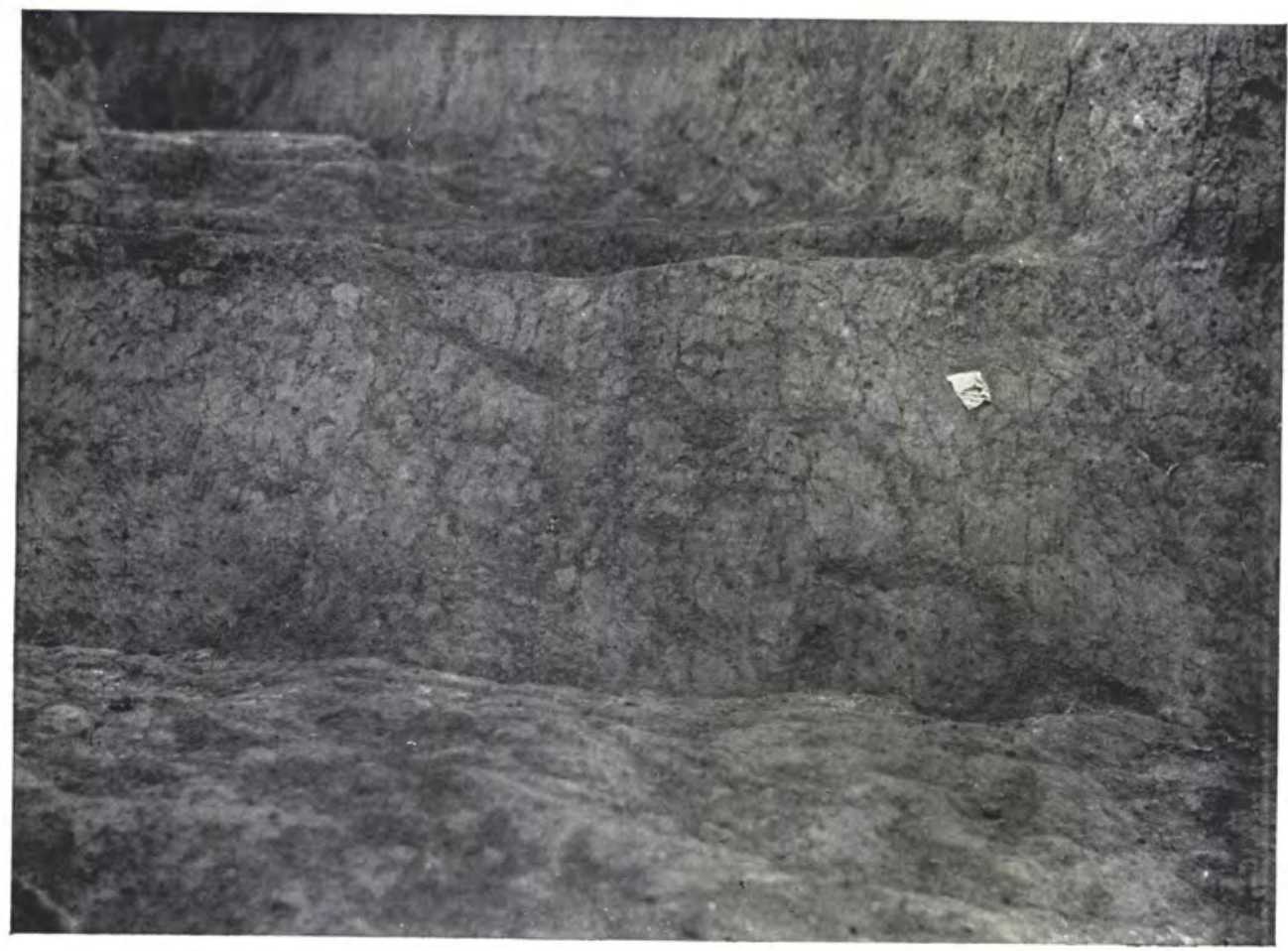

b. The glasis of the Level VI castle, front view p. 153 


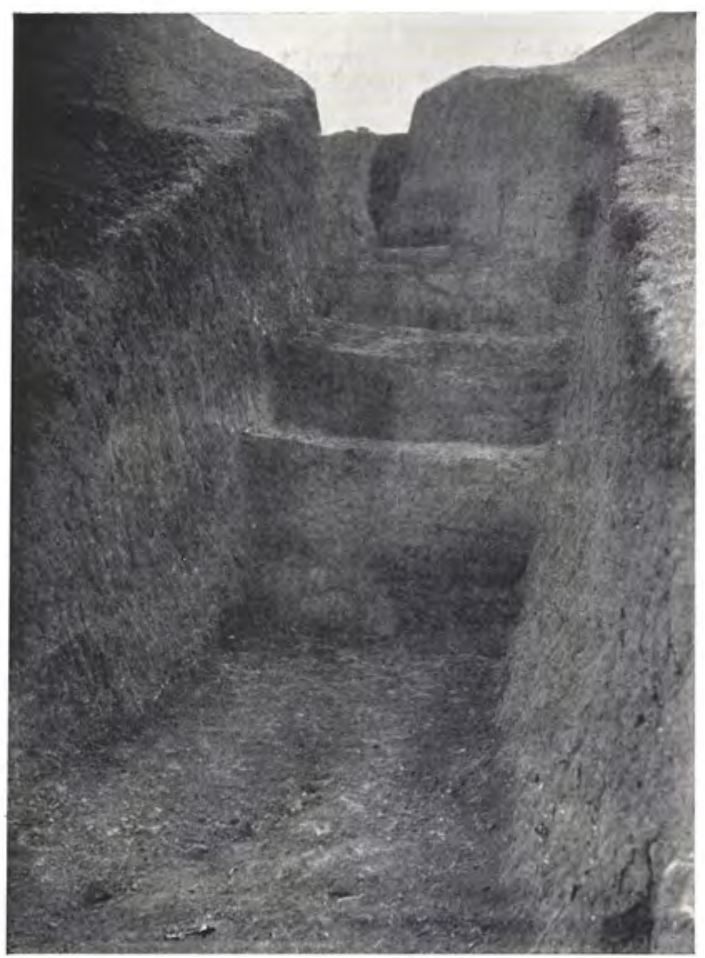

a. The fronts of the three successive glaçis of the castles of Levels VI, V, and III pp. 153 sqq. and 169

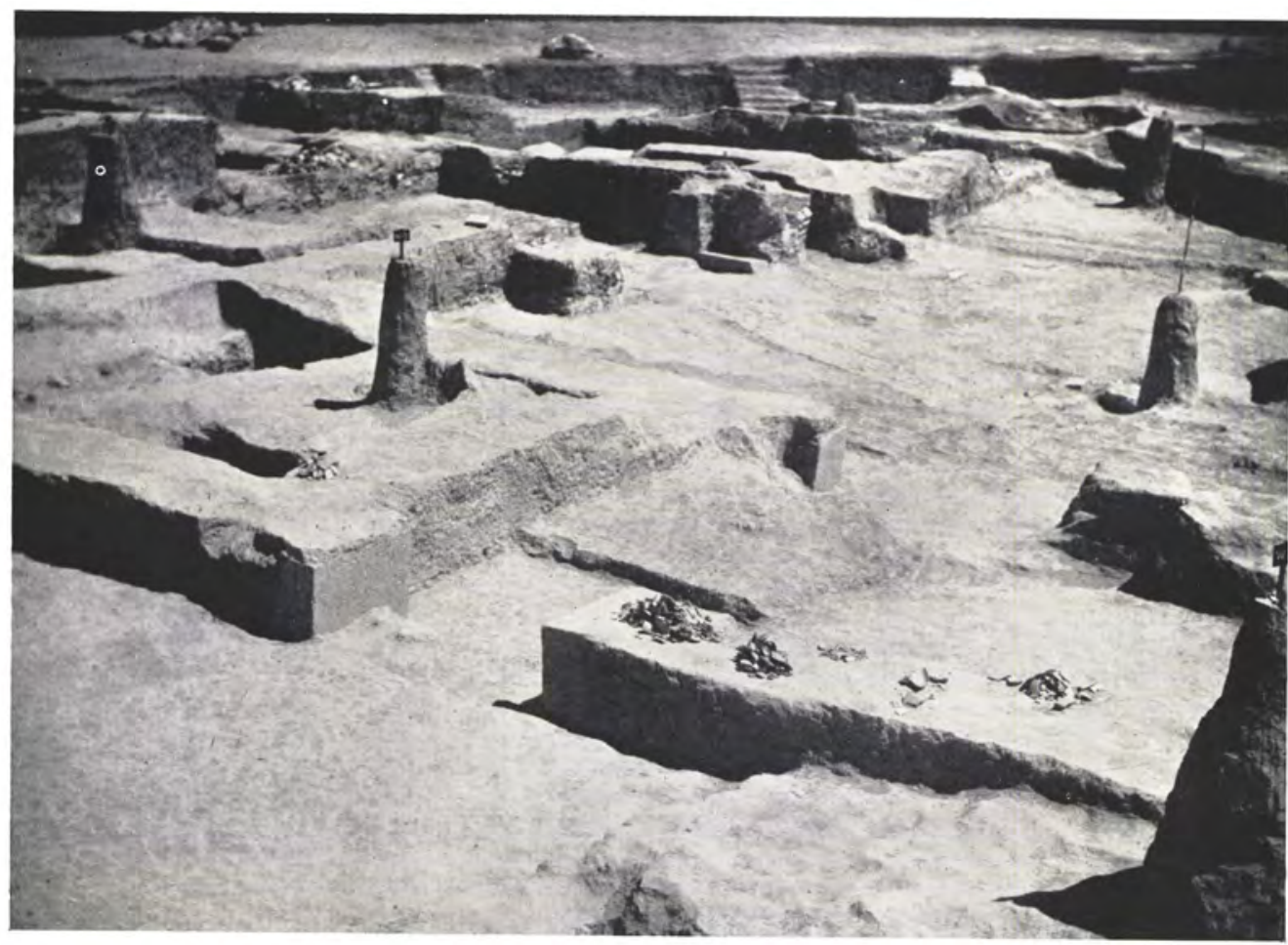

b. The Level IV castle, general view looking east. In the foreground room 6, then room $I$, and then the barrack square with room $W_{I}$ to the left 


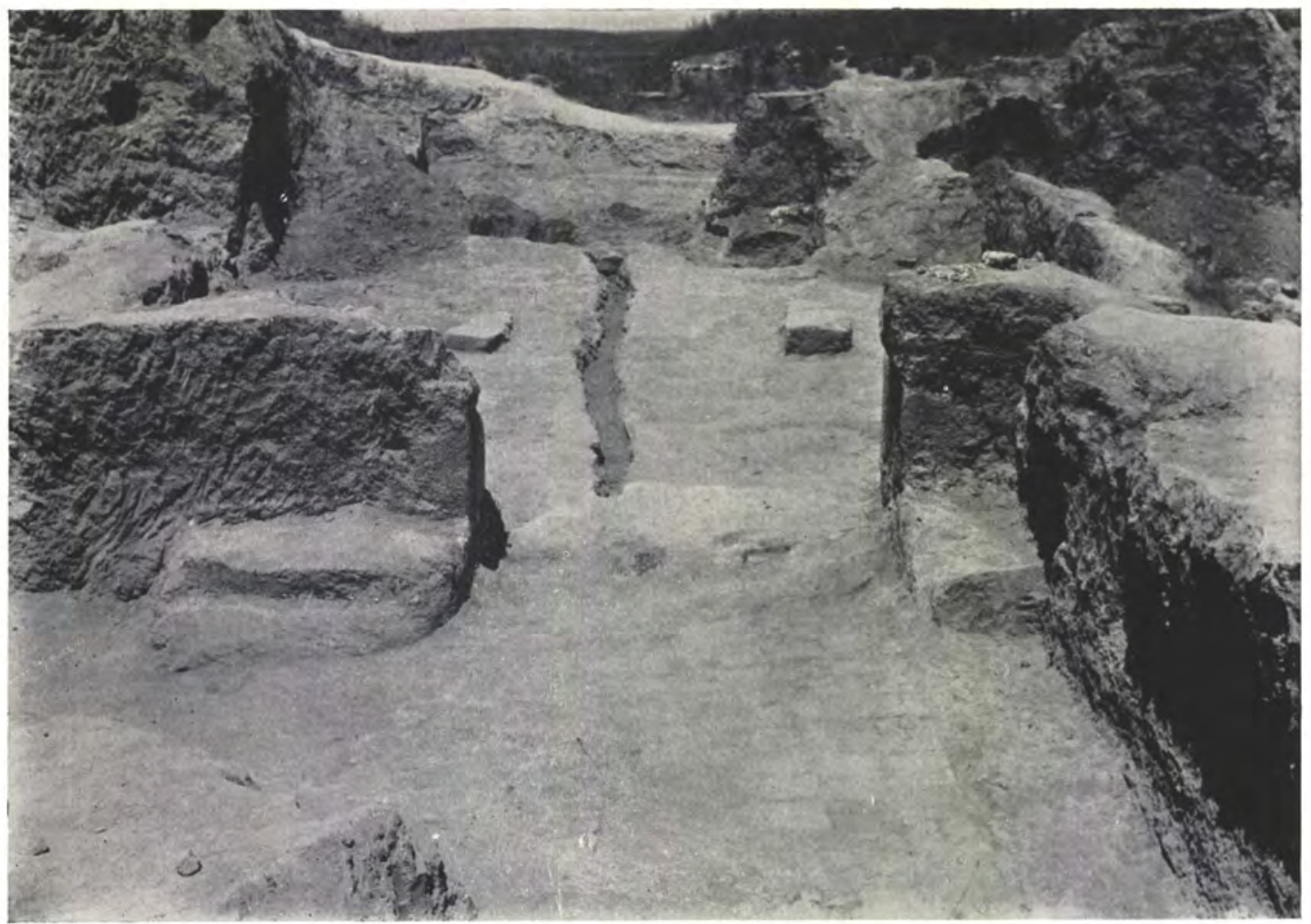

a. The triple gateway of the Level IV castle, seen from the outside p. I6I

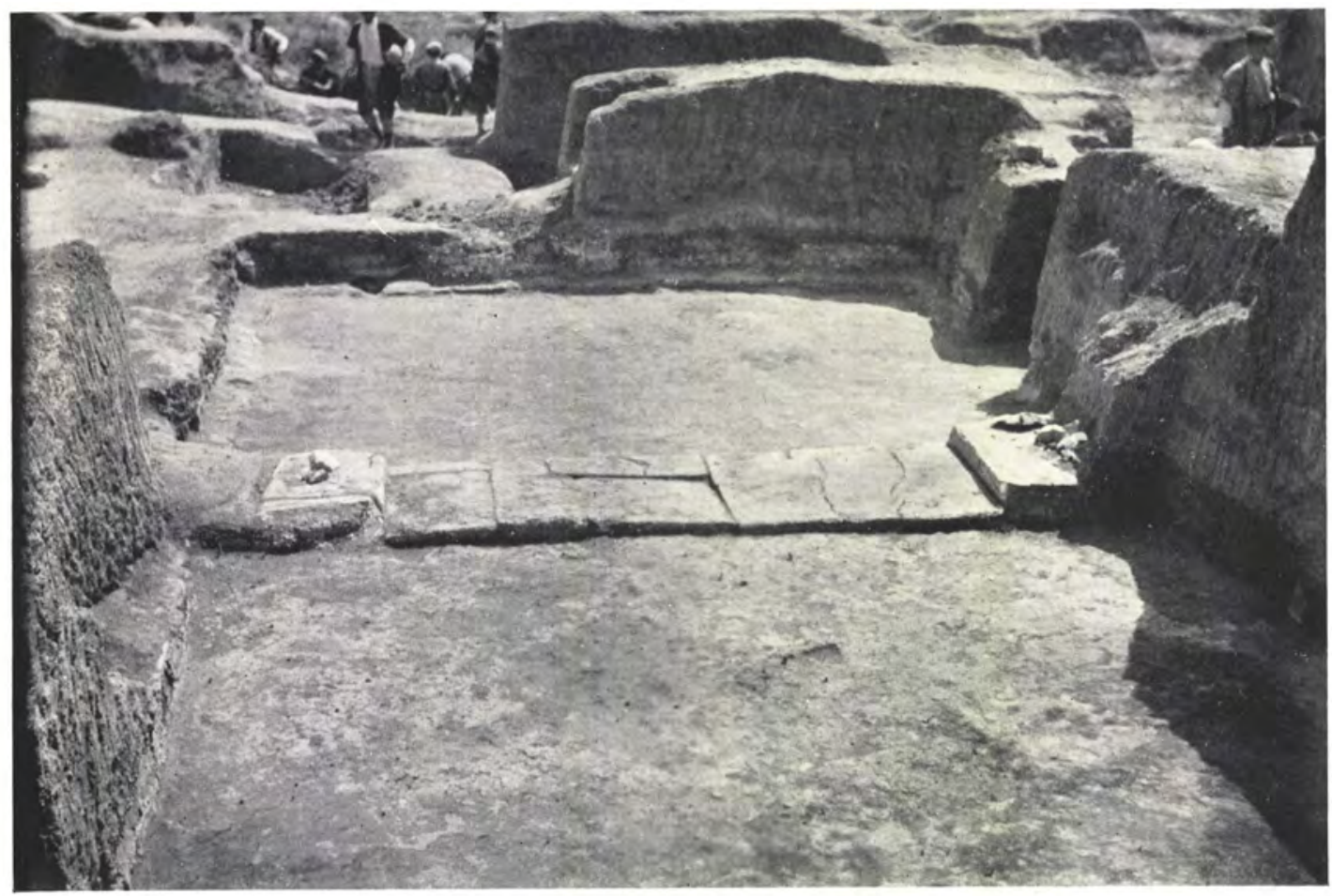

b. The Level IV castle; room I I

p. 164 


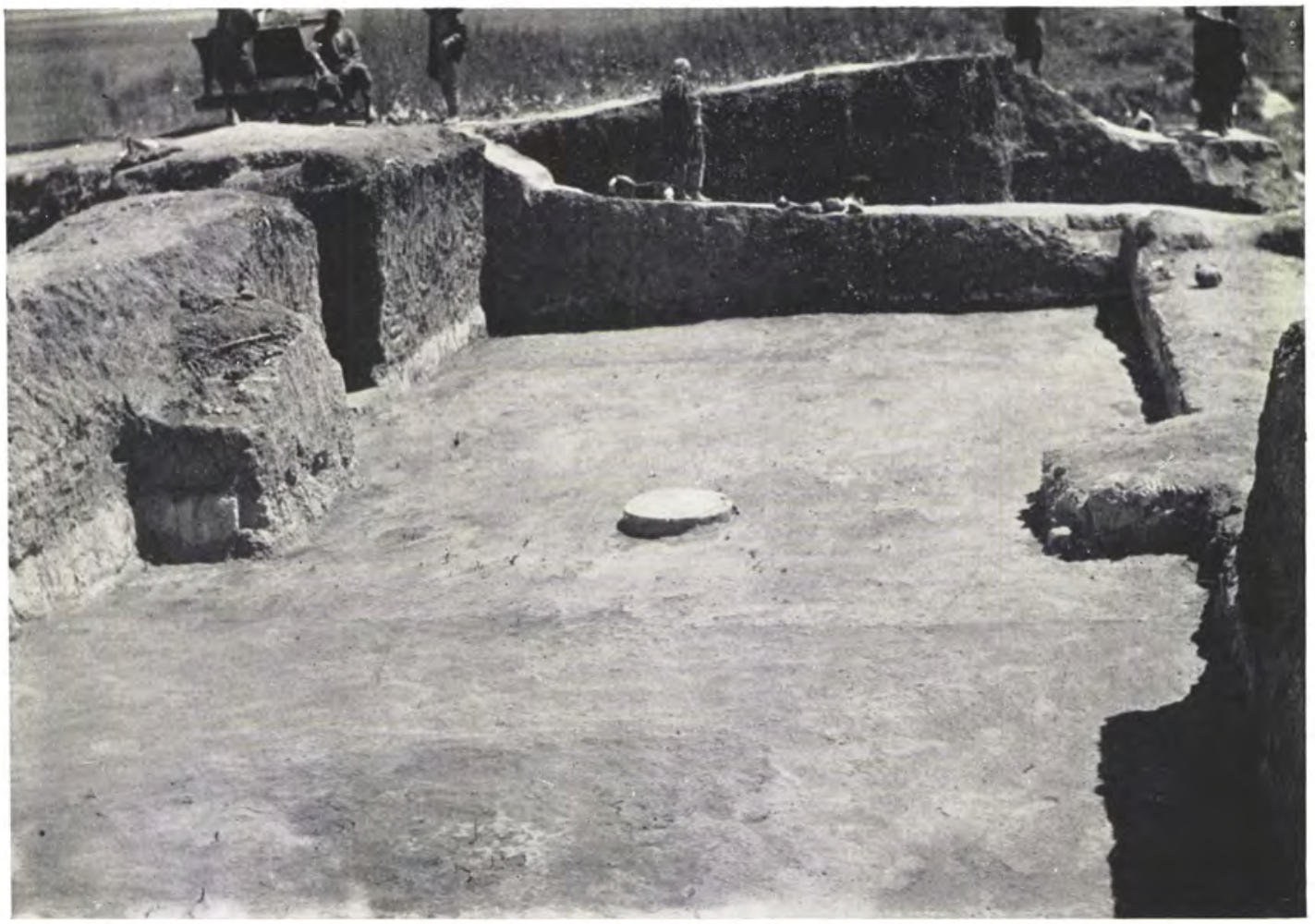

a. The Level IV castle; room I3

p. I 64

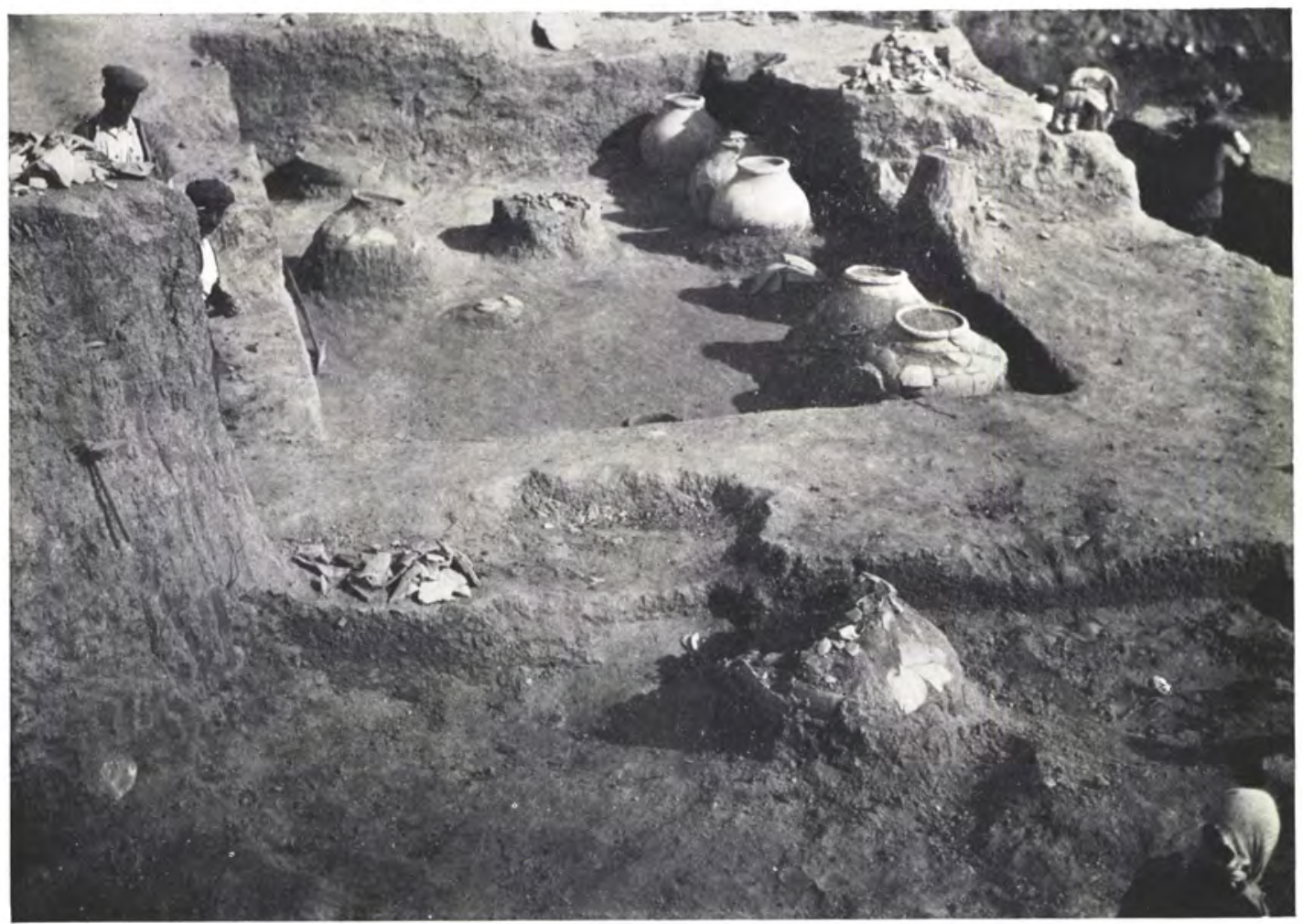

b. The Level III castle: the cellars 


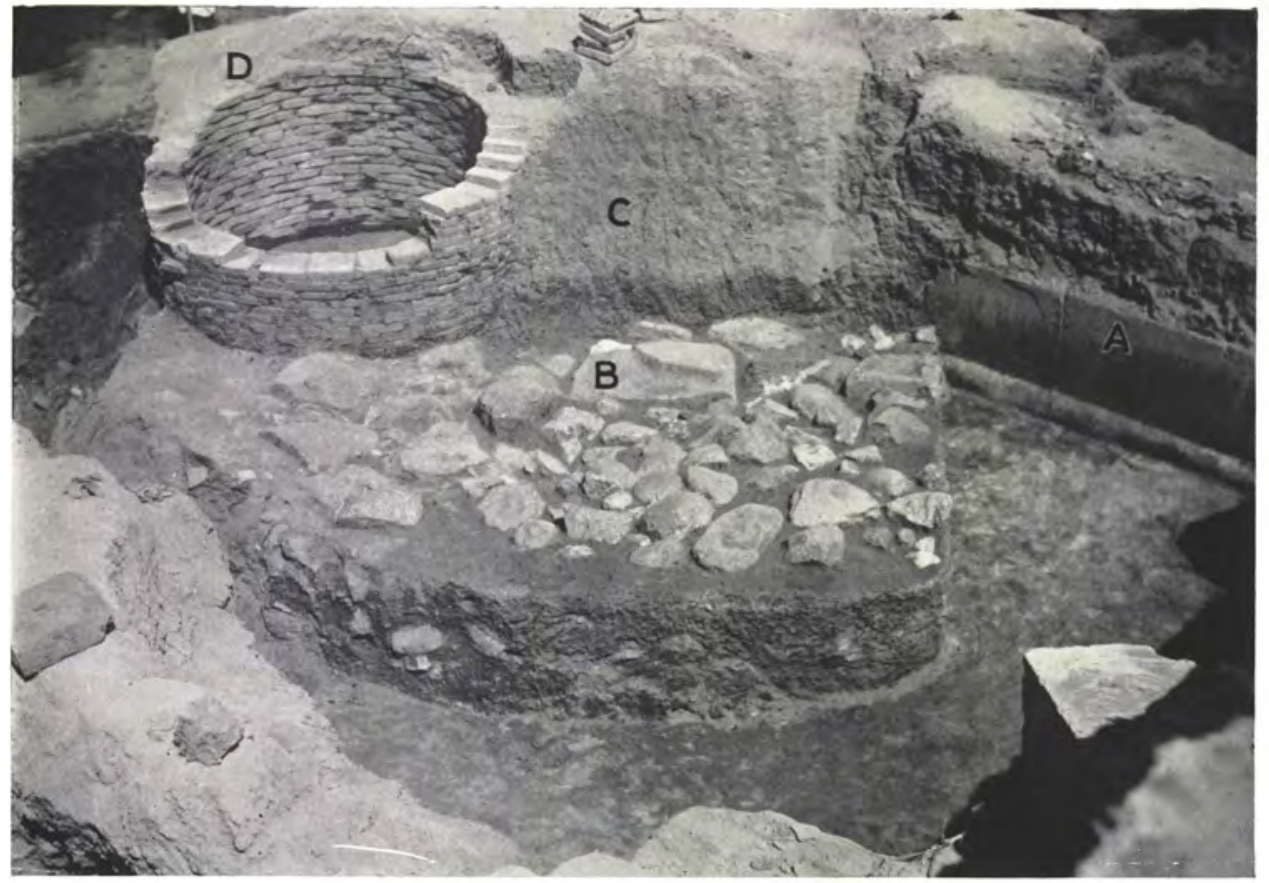

a. Stratification. A, orthostats of room 2 in Level IV palace; в, stone foundations and (c) mud brickwork of the Level III fortress; D, brick-lined sump-pit of Level I

p. 170

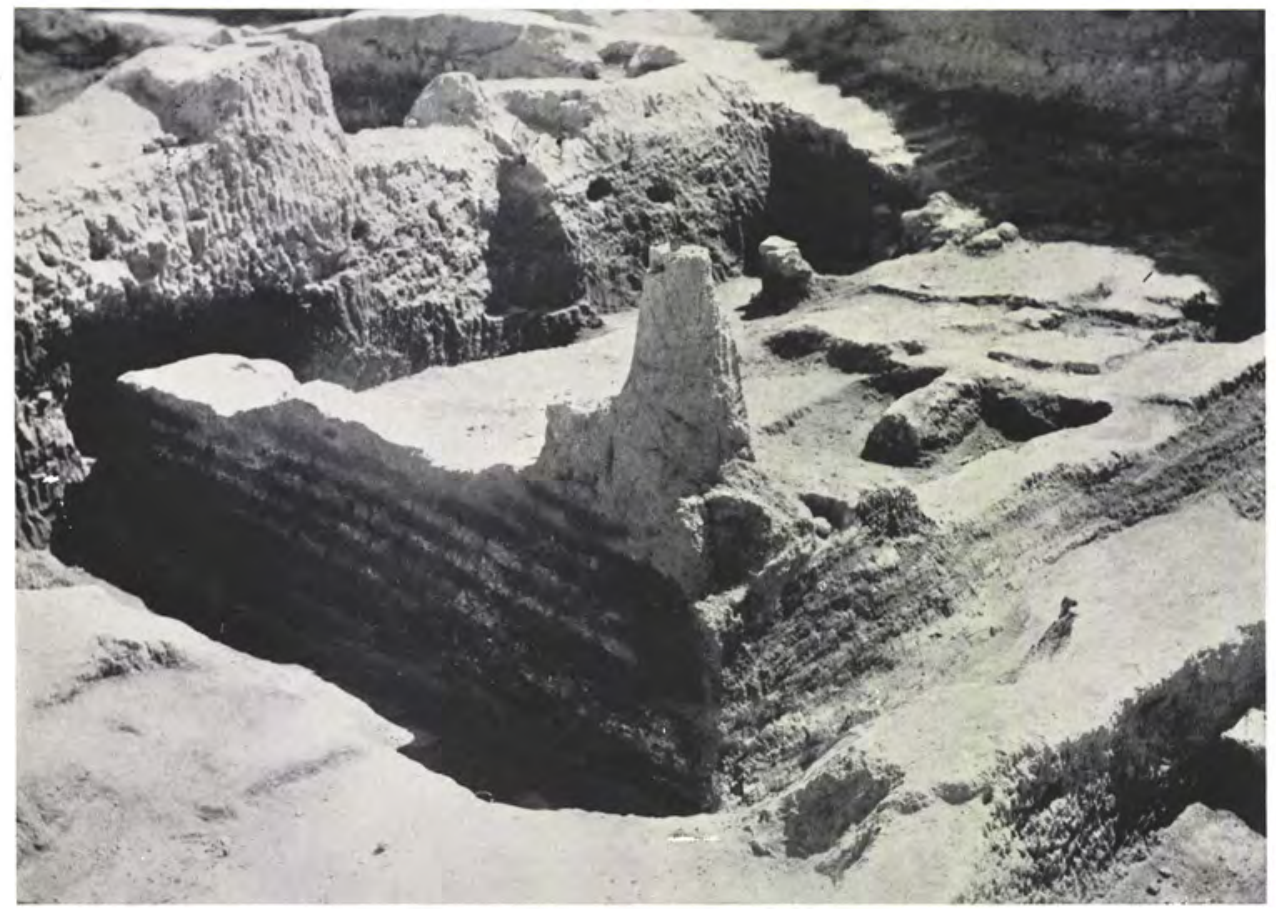

b. The podium of the Level V shrine 


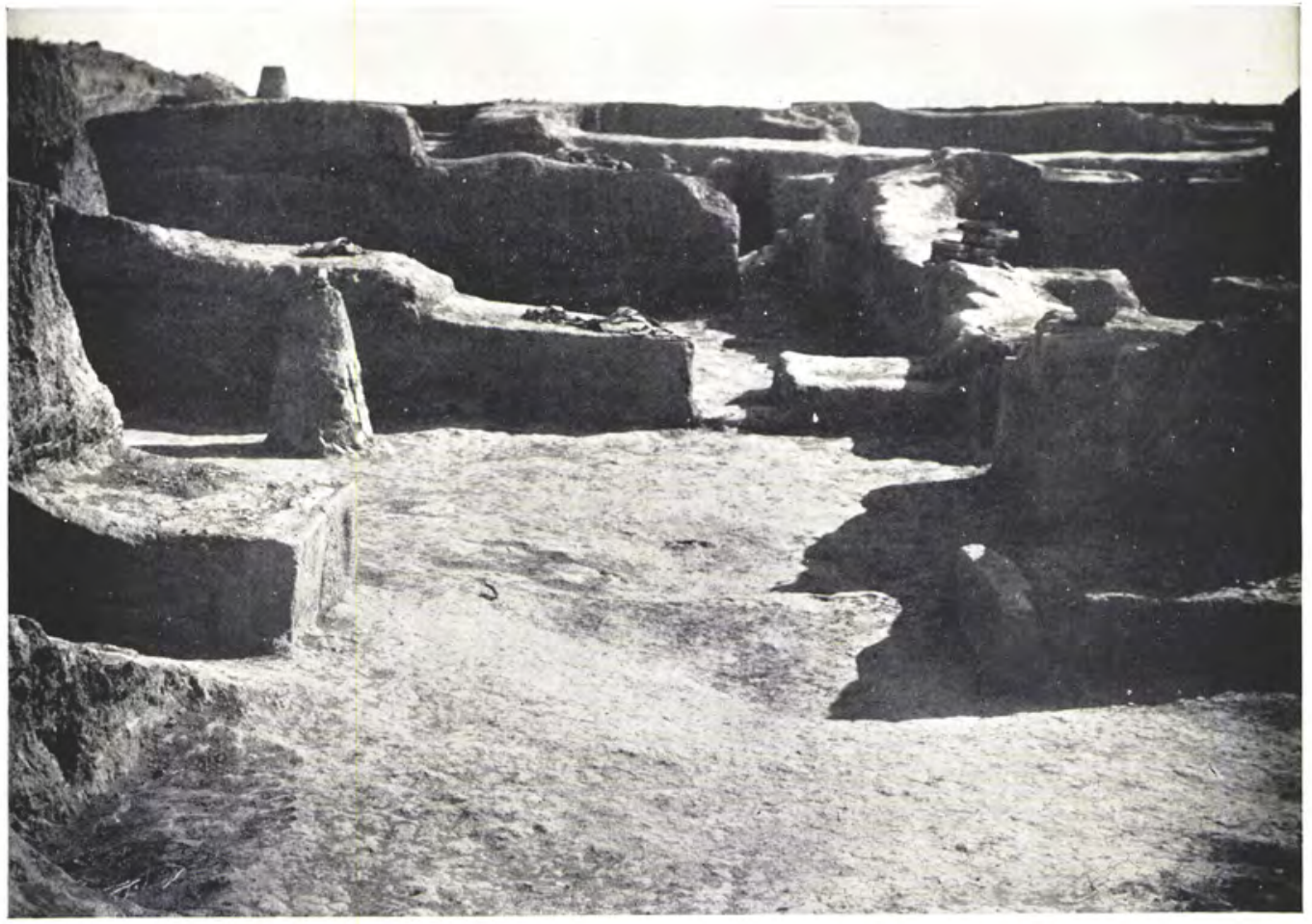

a. Entrance of the Level IV house 37

p. 175

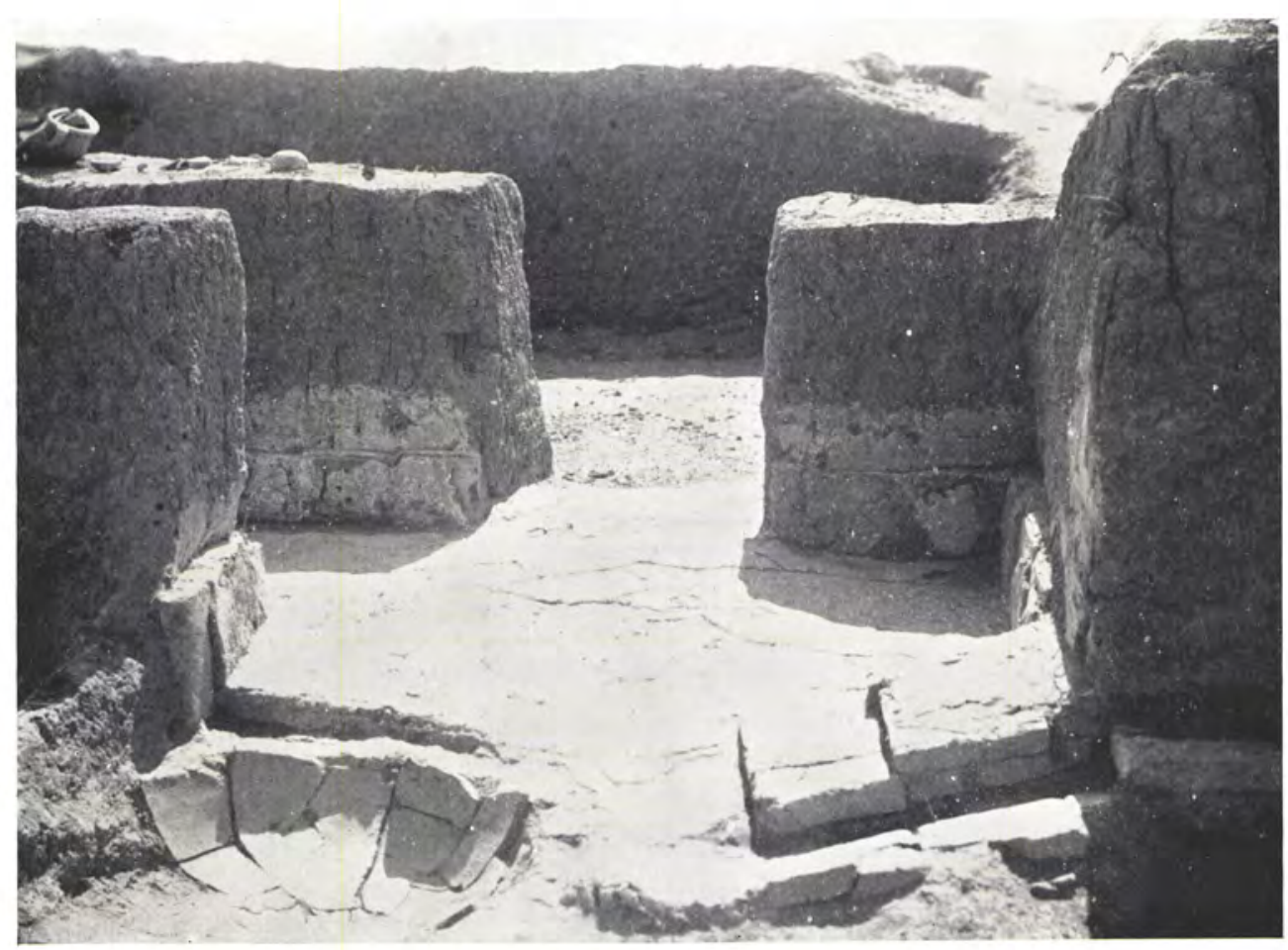

b. Level II, house $37 / \mathrm{C}$, room I 


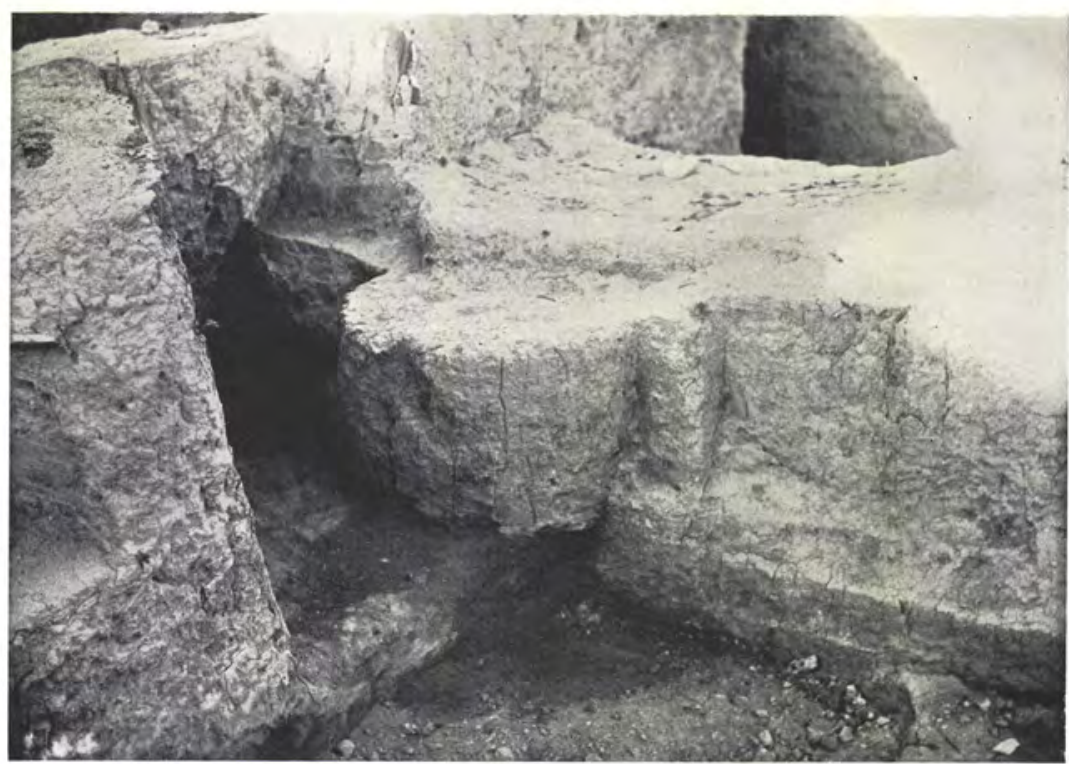

a. Site $\mathrm{H}$; attached half-column in the Level $\mathrm{V}$ gateway building pp. 142 and 227

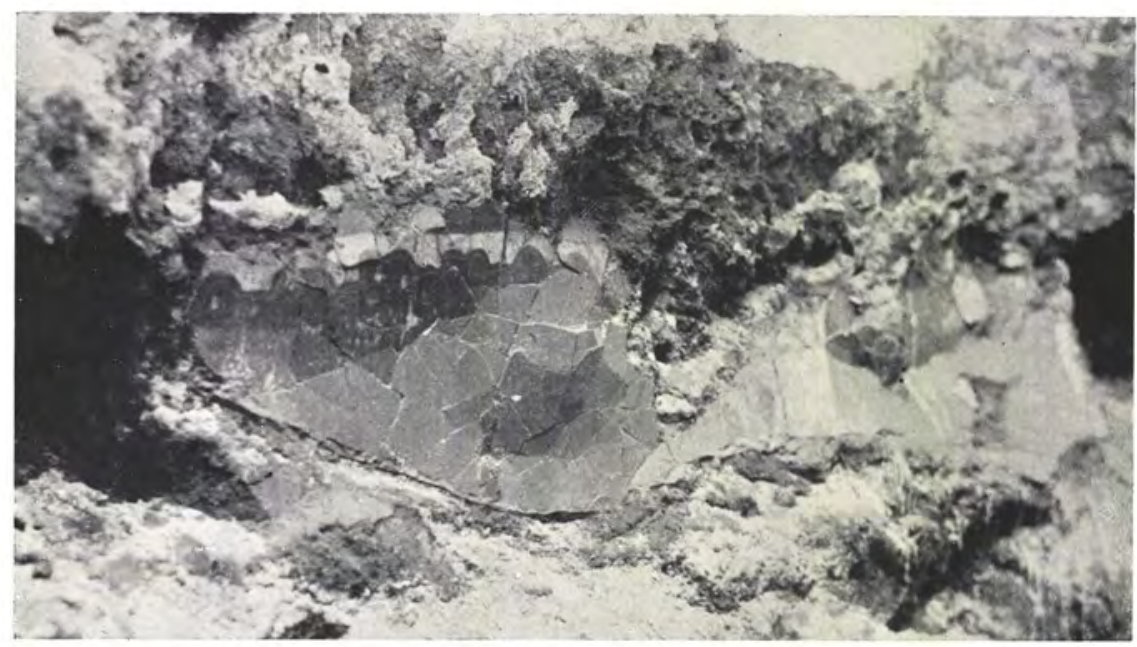

b. Fresco remains in situ in room I 2 of the Level VII palace

p. 94 


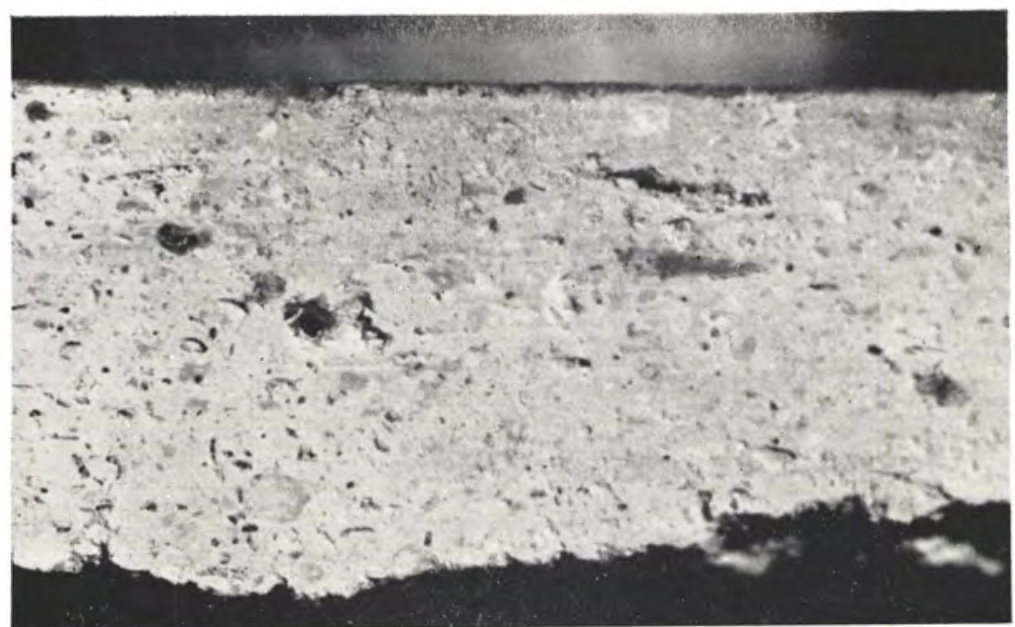

a. Section of fresco; v. p. 233

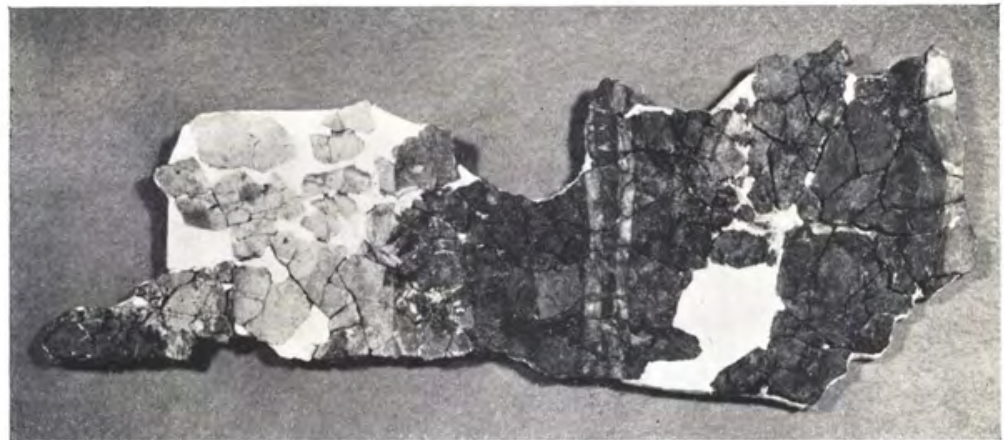

b. Fragment showing foliage (?)

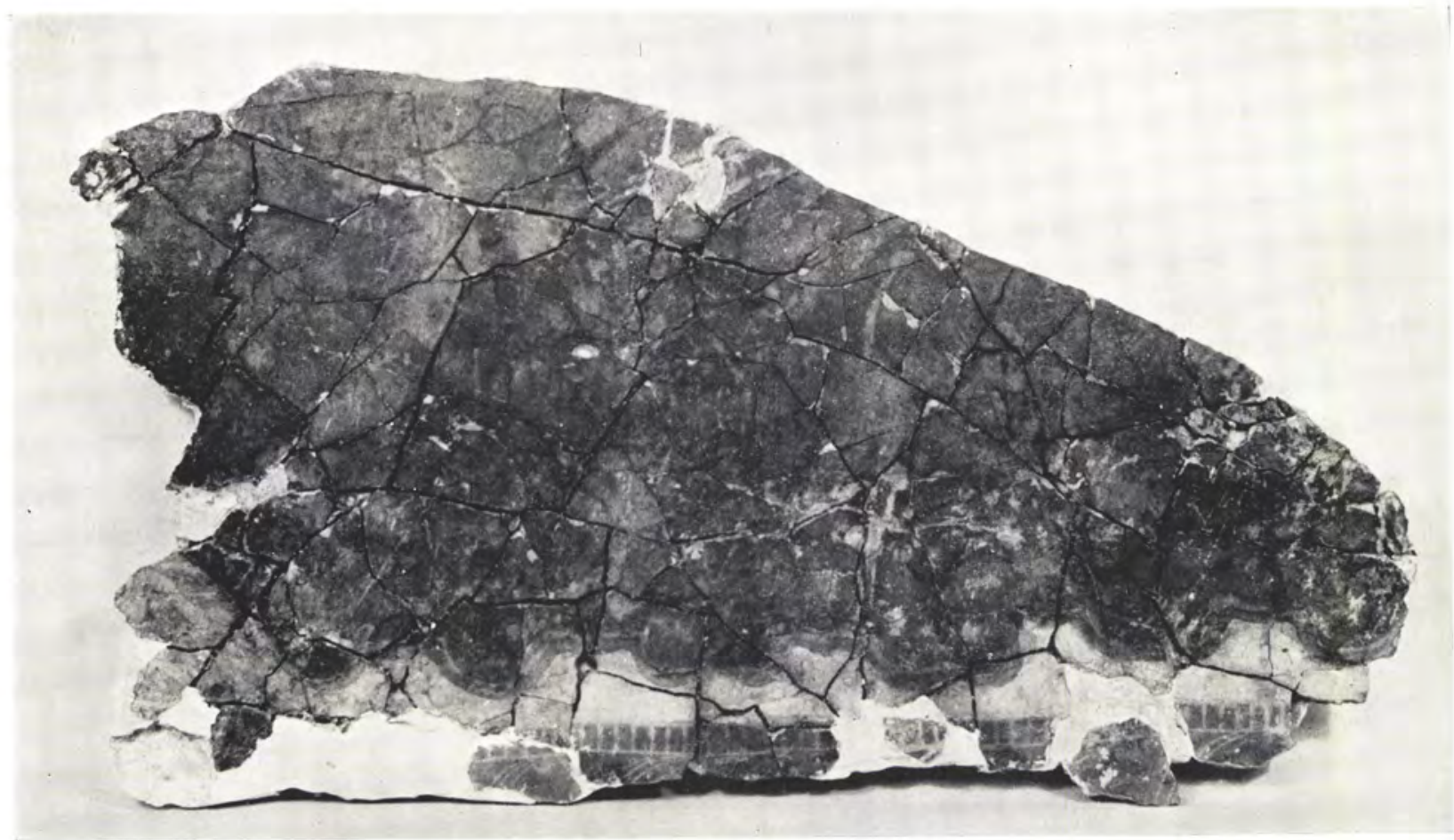

c. Fragment showing red background with waved border

Fragments of fresco from Level VII 


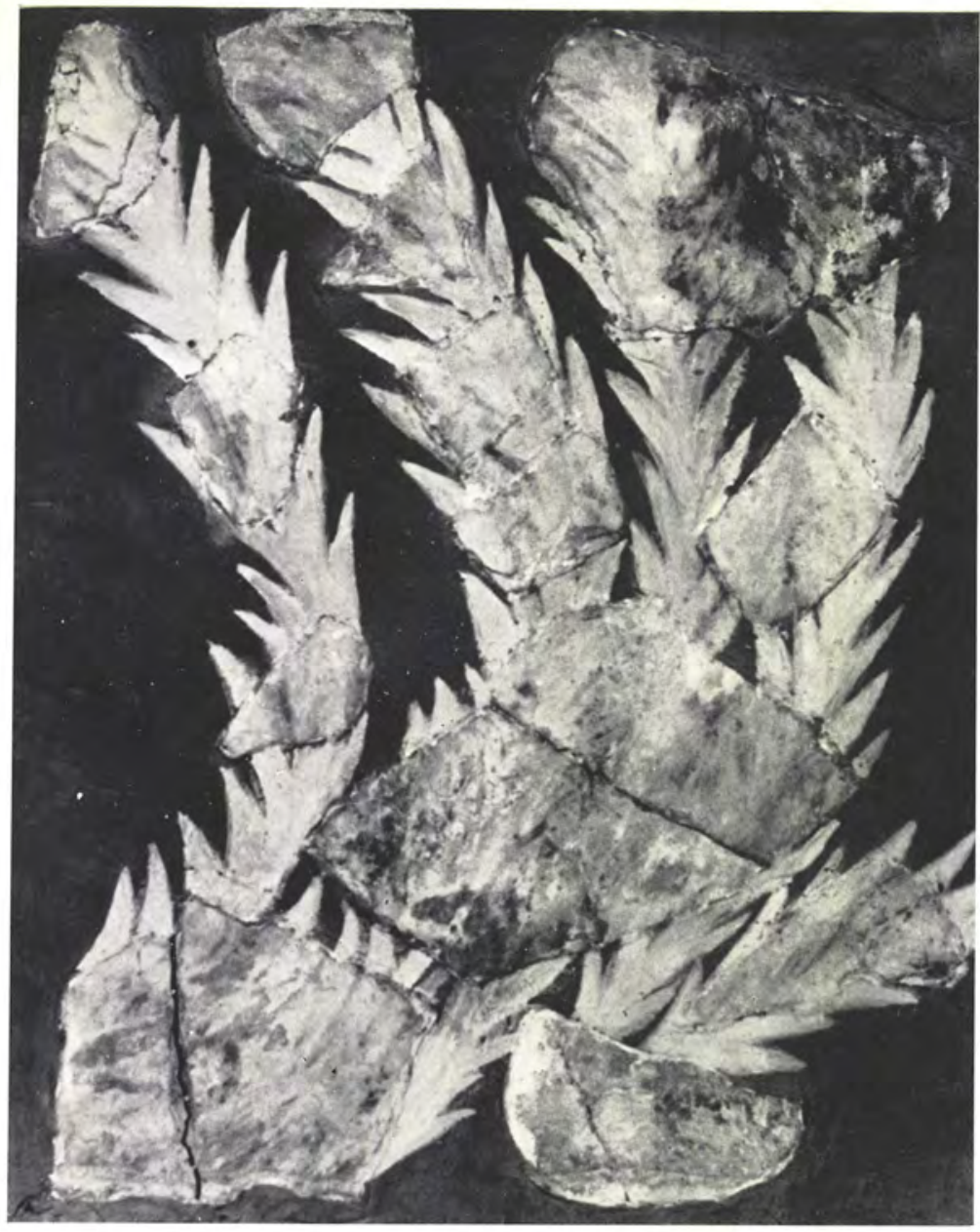

a. Naturalistic grass m.otive

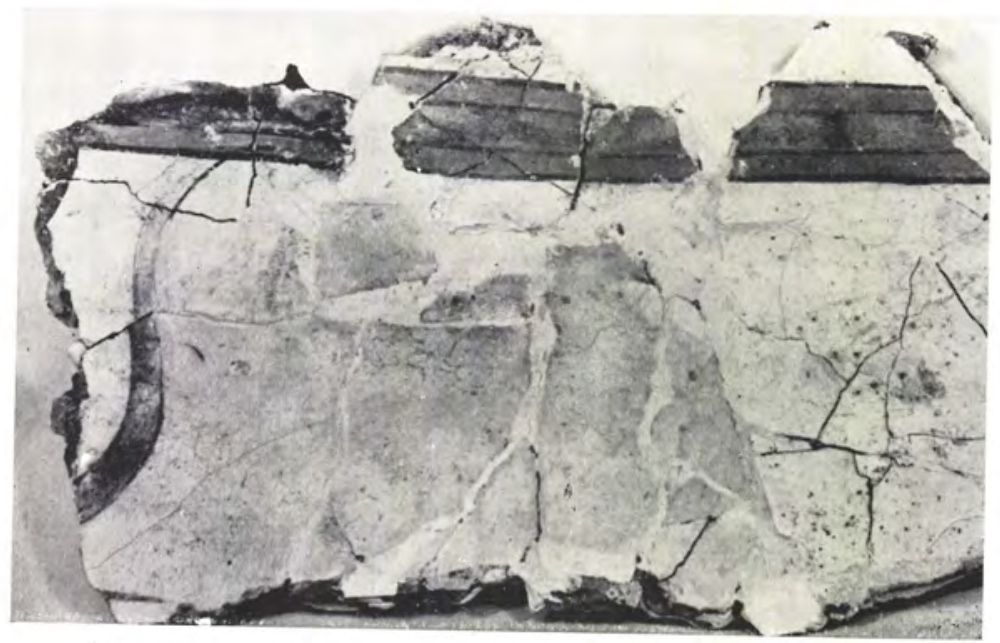

b. Frieze with bull's horn

Fragments of fresco from Level VII p. $23 \mathrm{I}$ 


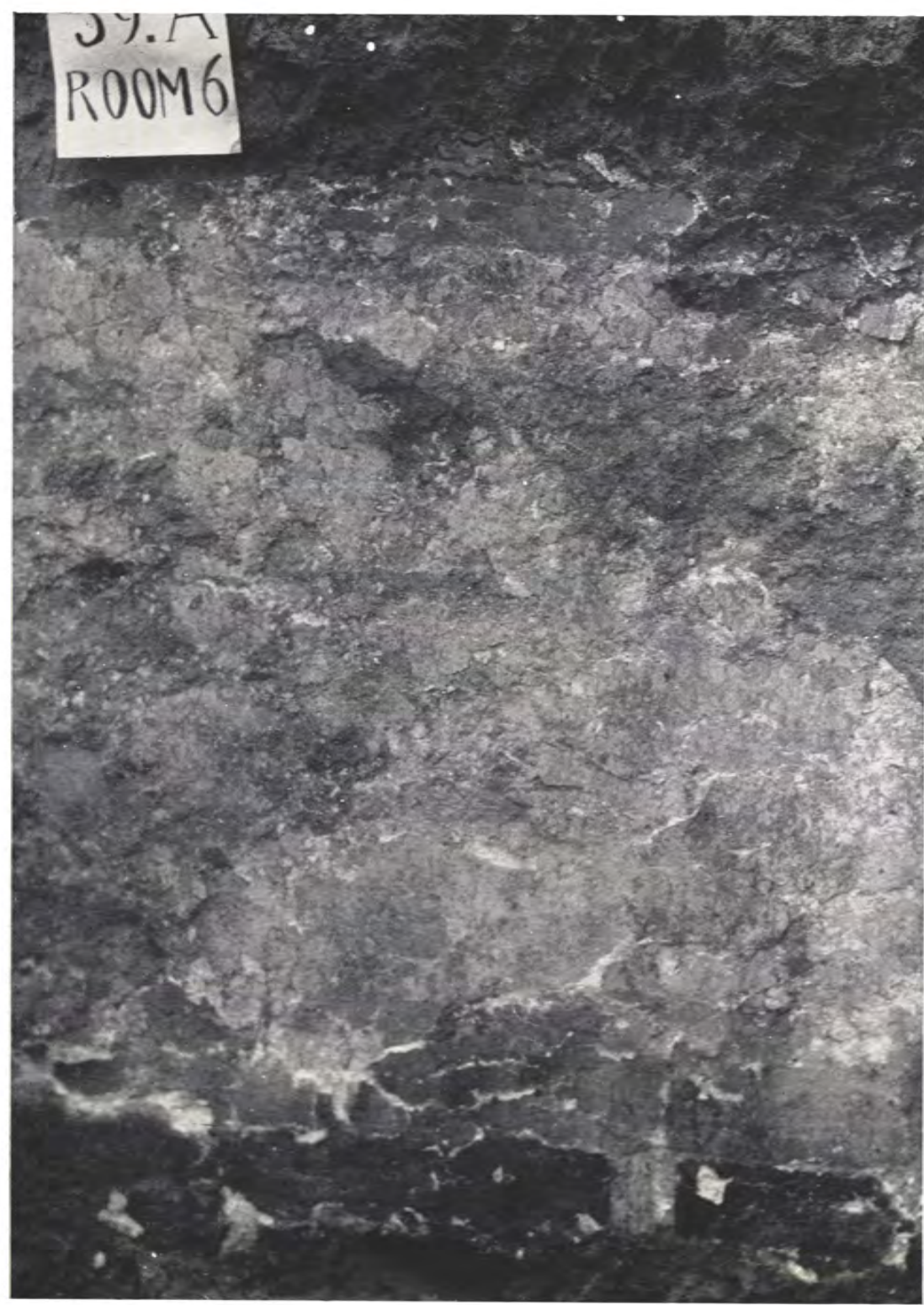

a. General view

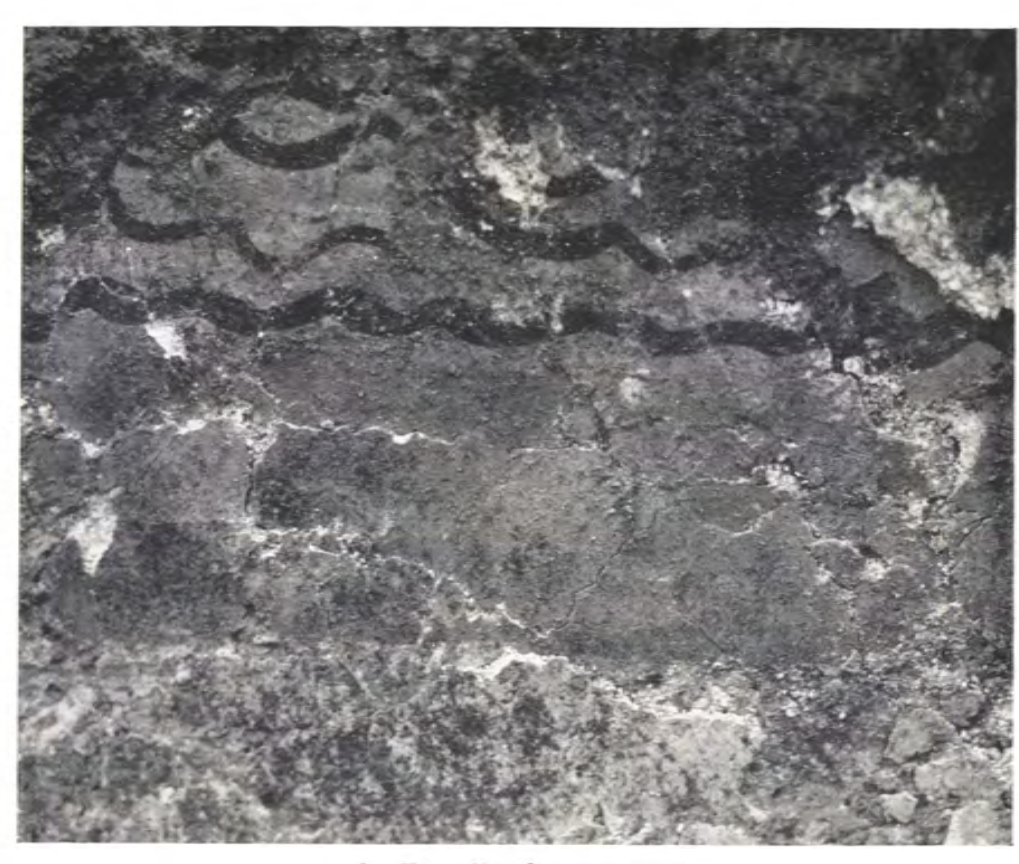

$b$. Detail of upper part

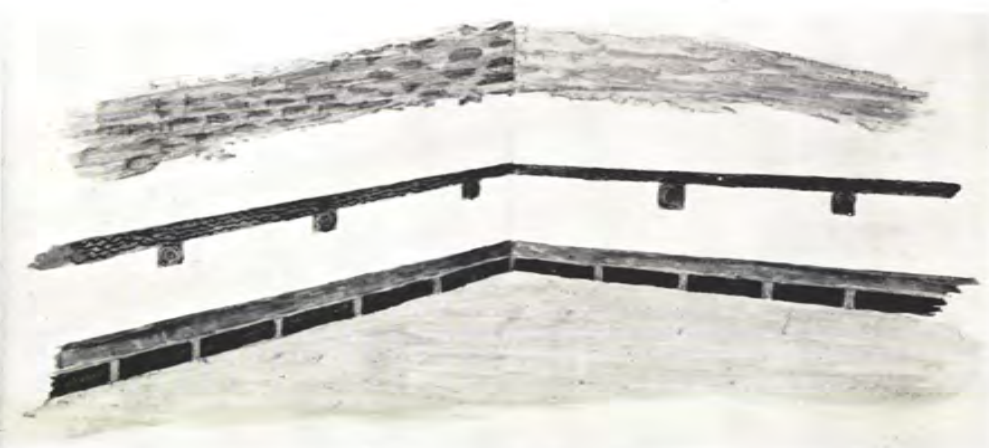

c. Restored sketch 
PLATE XL
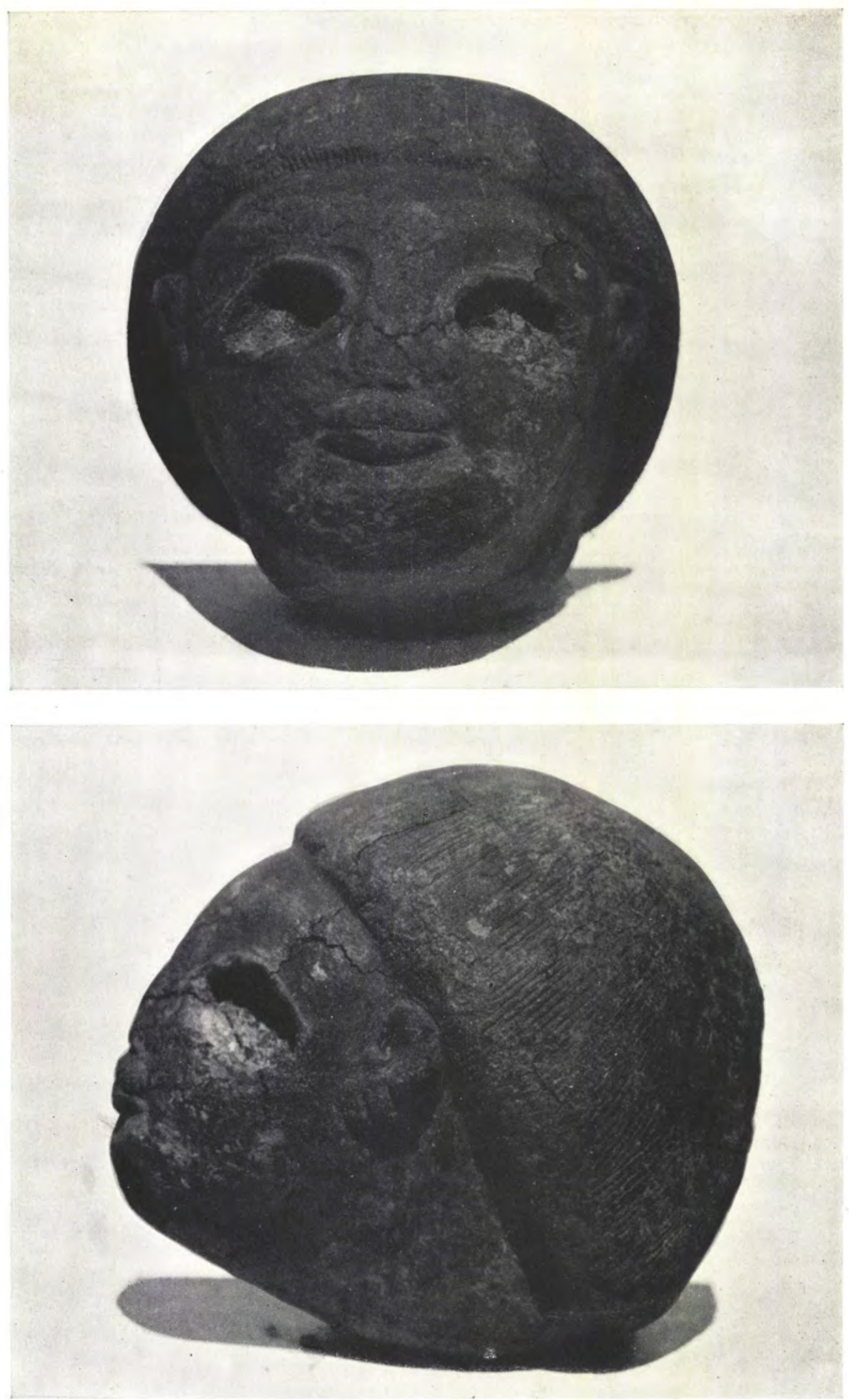

AT/47/62. Stone head from Yarim-Lim's temple p. 235 

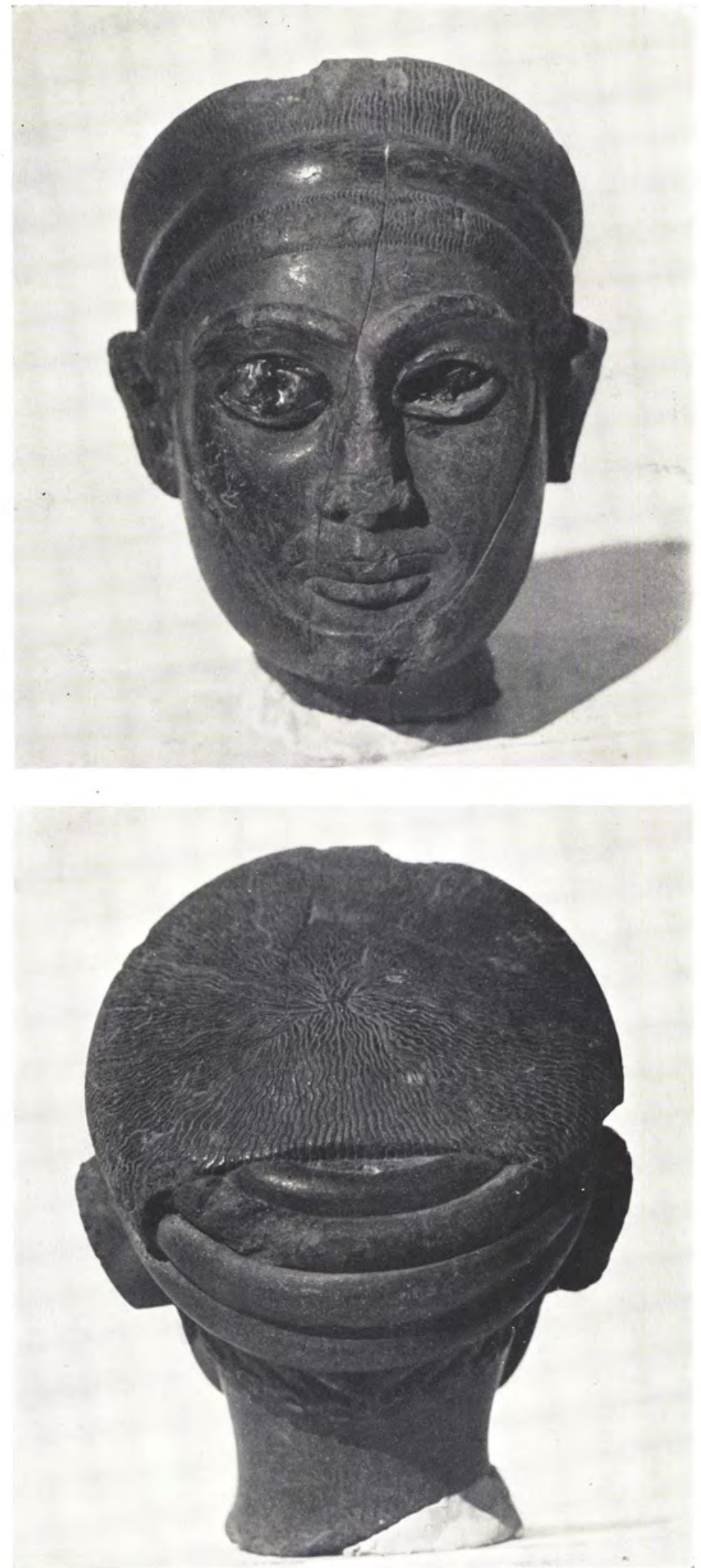

AT/47/74. Stone head from Yarim-Lim's temple p. 235 
PLATE XLII

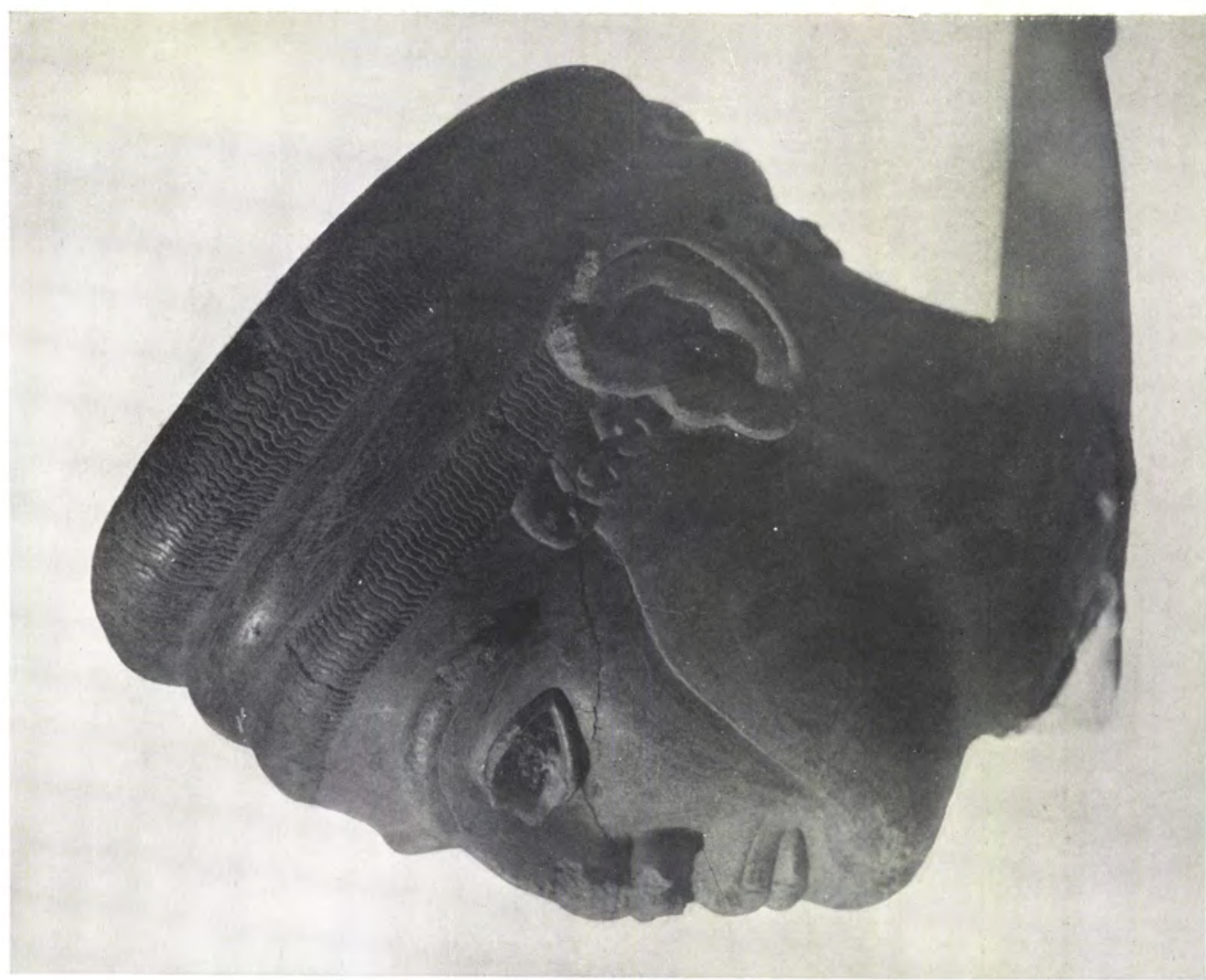

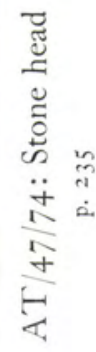

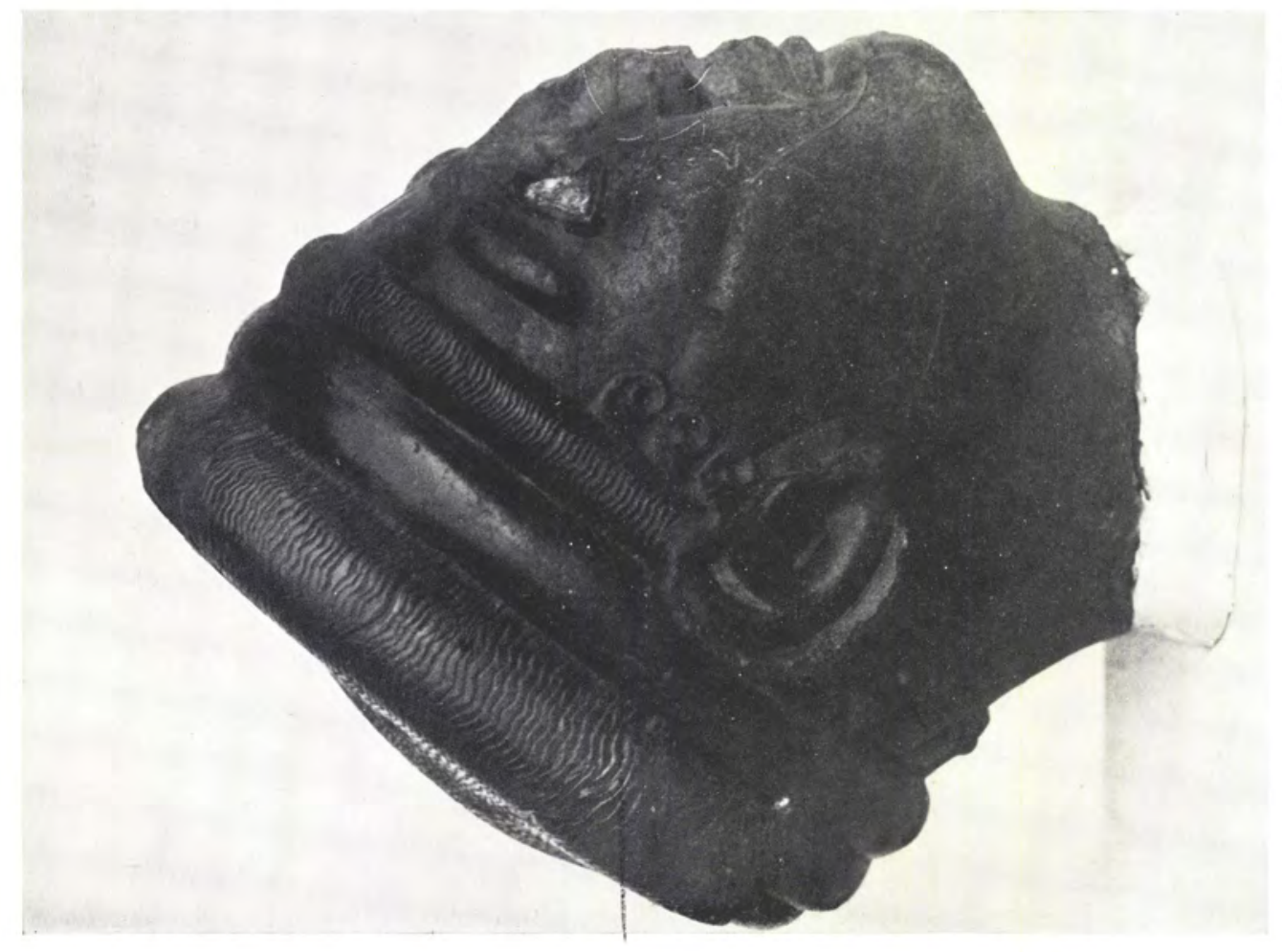




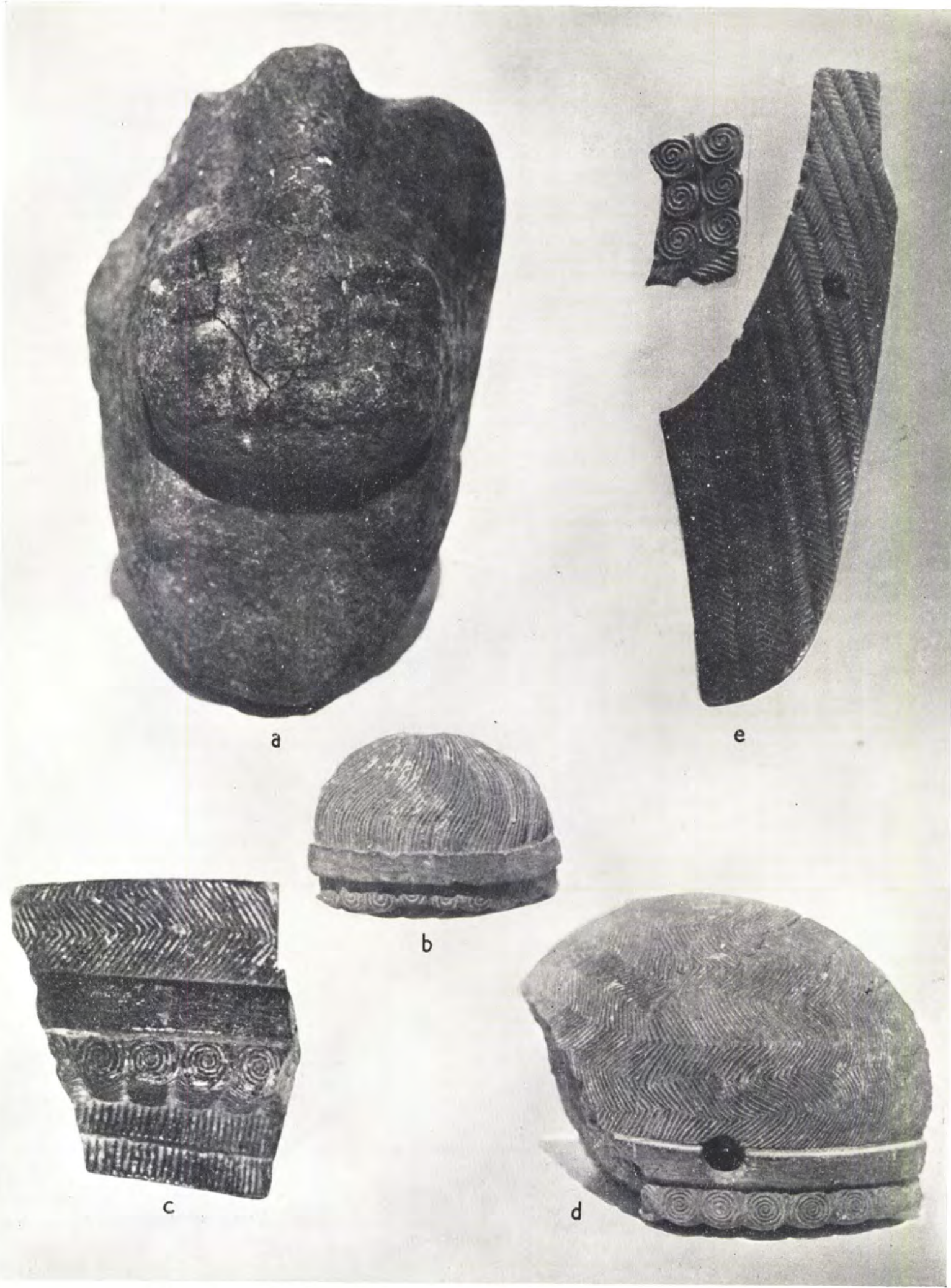

a. $\mathrm{AT} / 47 / 73 ;$ b. $\mathrm{AT} / 47 / 78 ;$ c. $\mathrm{AT} / 46 / 155 ;$ d. $\mathrm{AT} / 47 / 90 ;$ e. $\mathrm{AT} / 47 / 77$

p. 237

Fragments of stone sculpture 


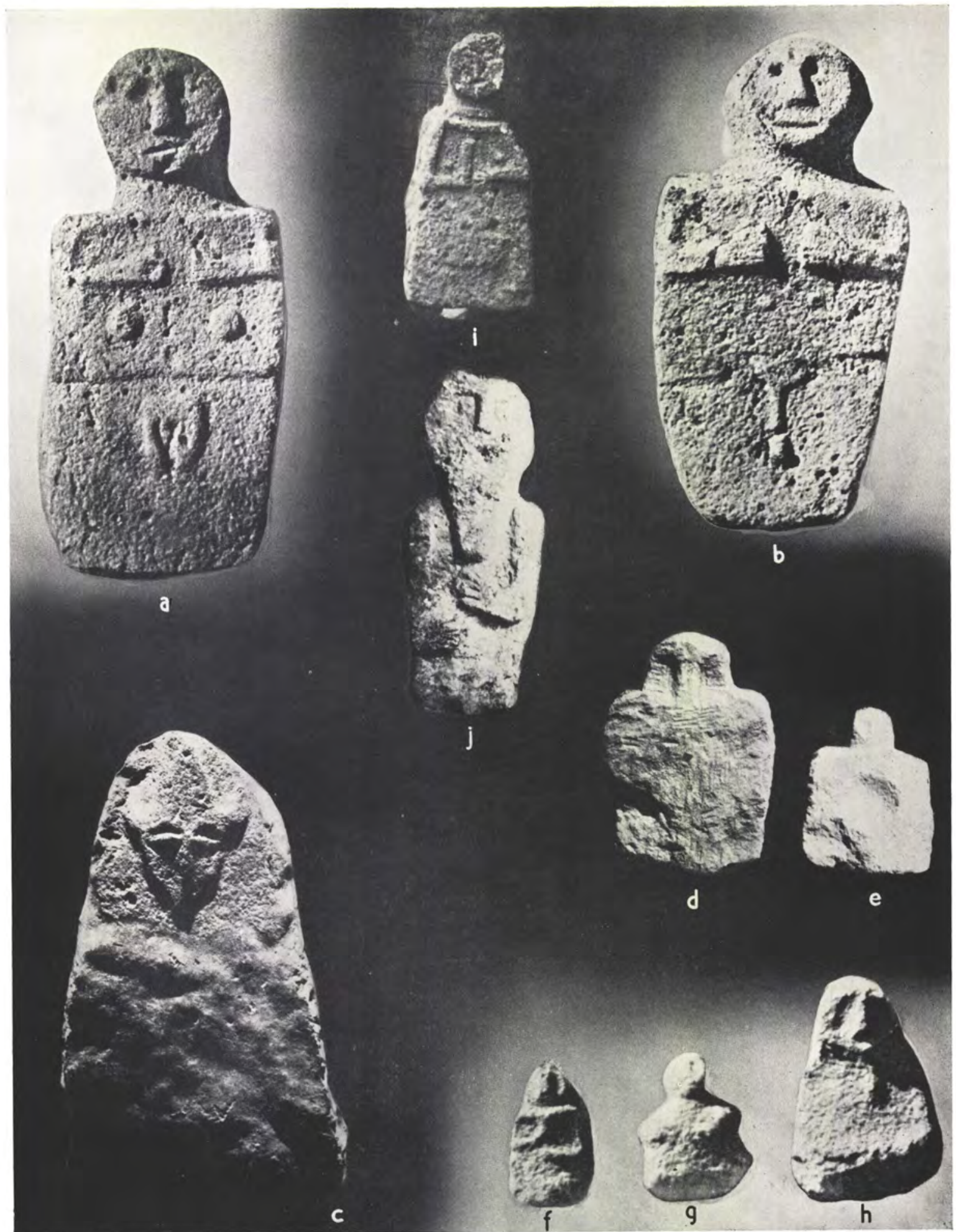

a. AT/43-5/4; b. AT/43-5/3; c. AT/39/II9; d. AT/39/276; e. AT/39/319; f. AT/46/134 g. AT $/ 46 / 89 ; h$. AT $/ 46 / 95 ; i, j$. Figures from Diyarbakir

pp. $238-9$

Crude stone figures 
PLATE XLV

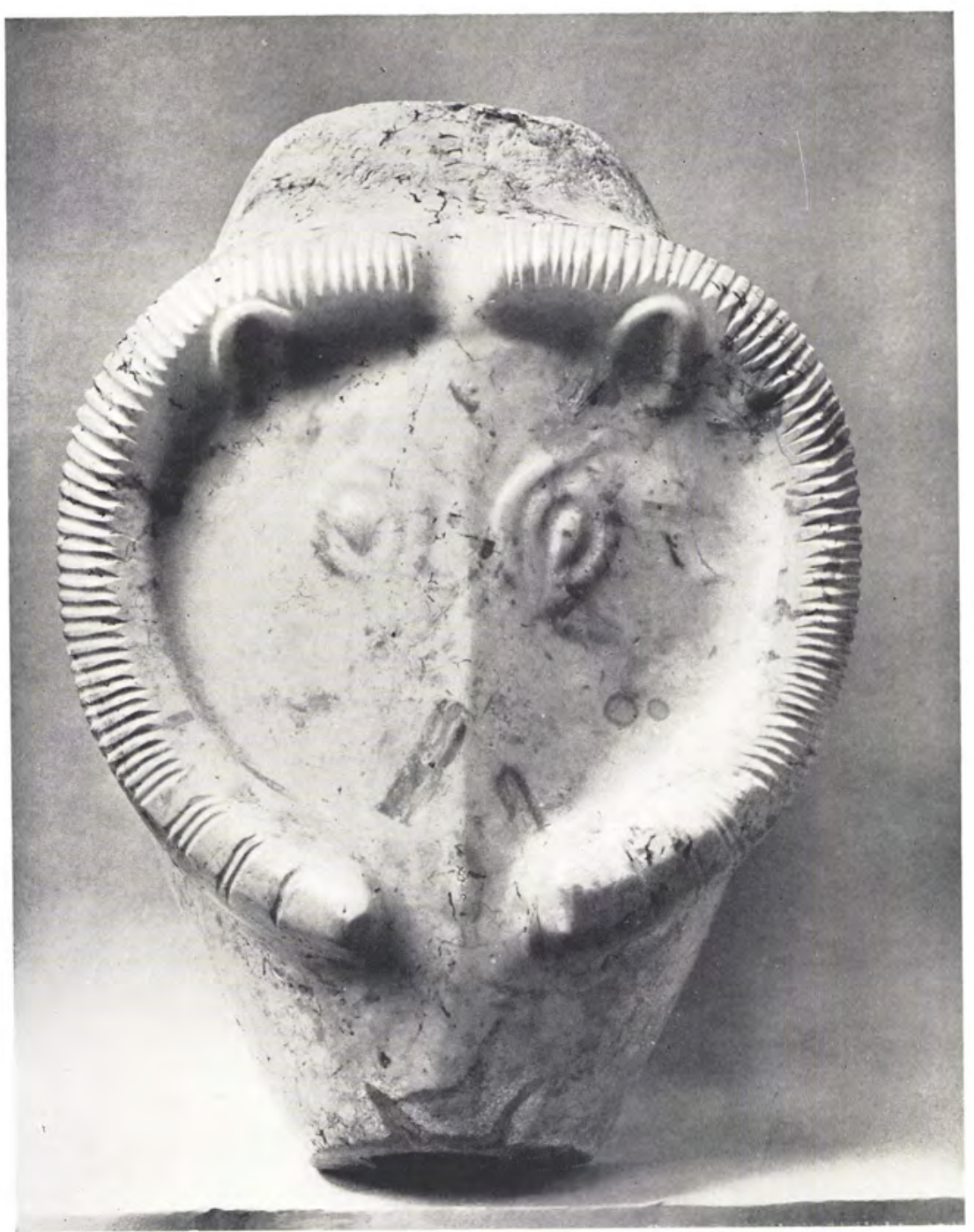

Ram's head carved in dolomite from the Level IV palace (AT/38/147)

p. 239 

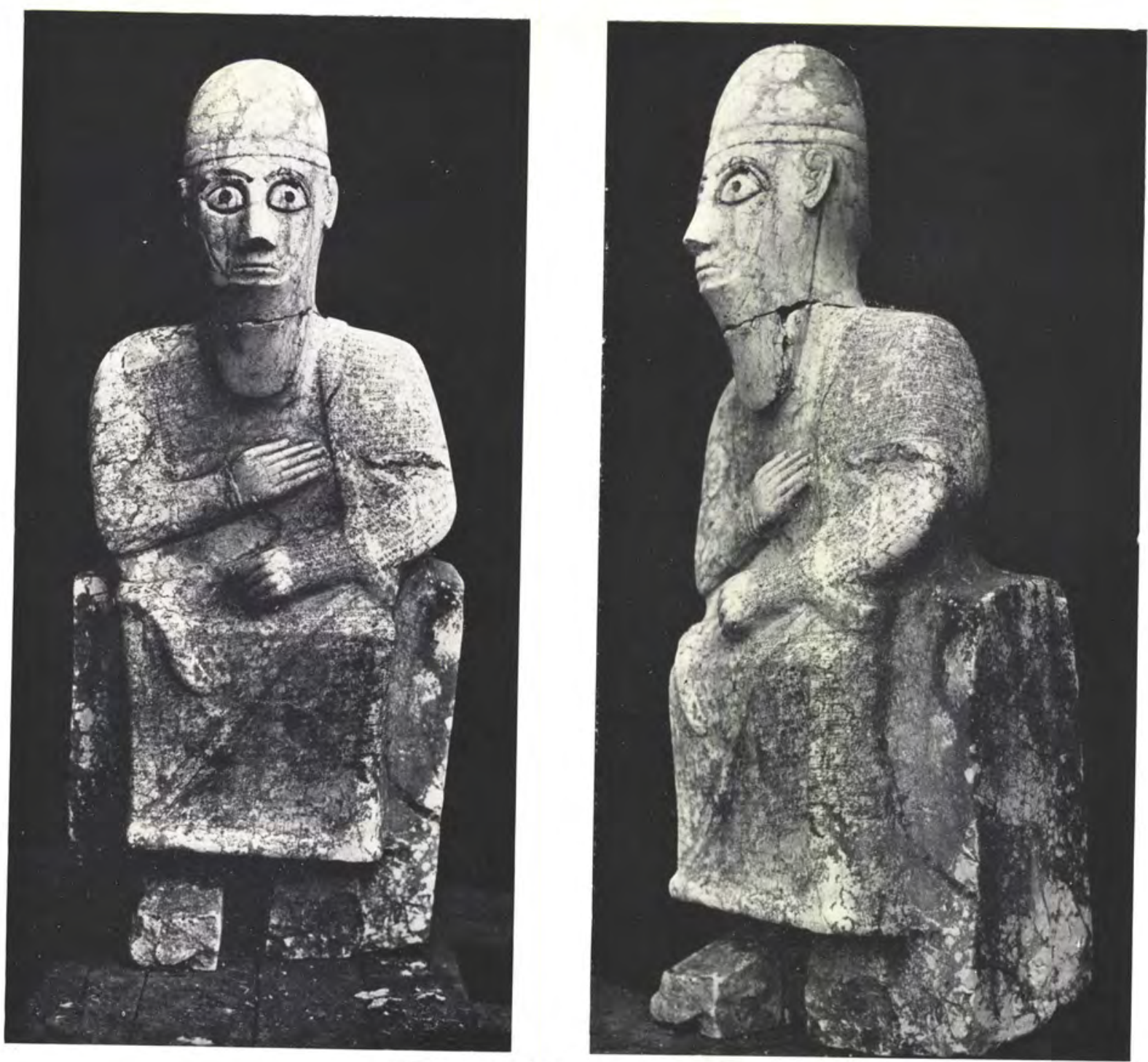

AT/39/331. The statue of Idri-mi

p. 240 


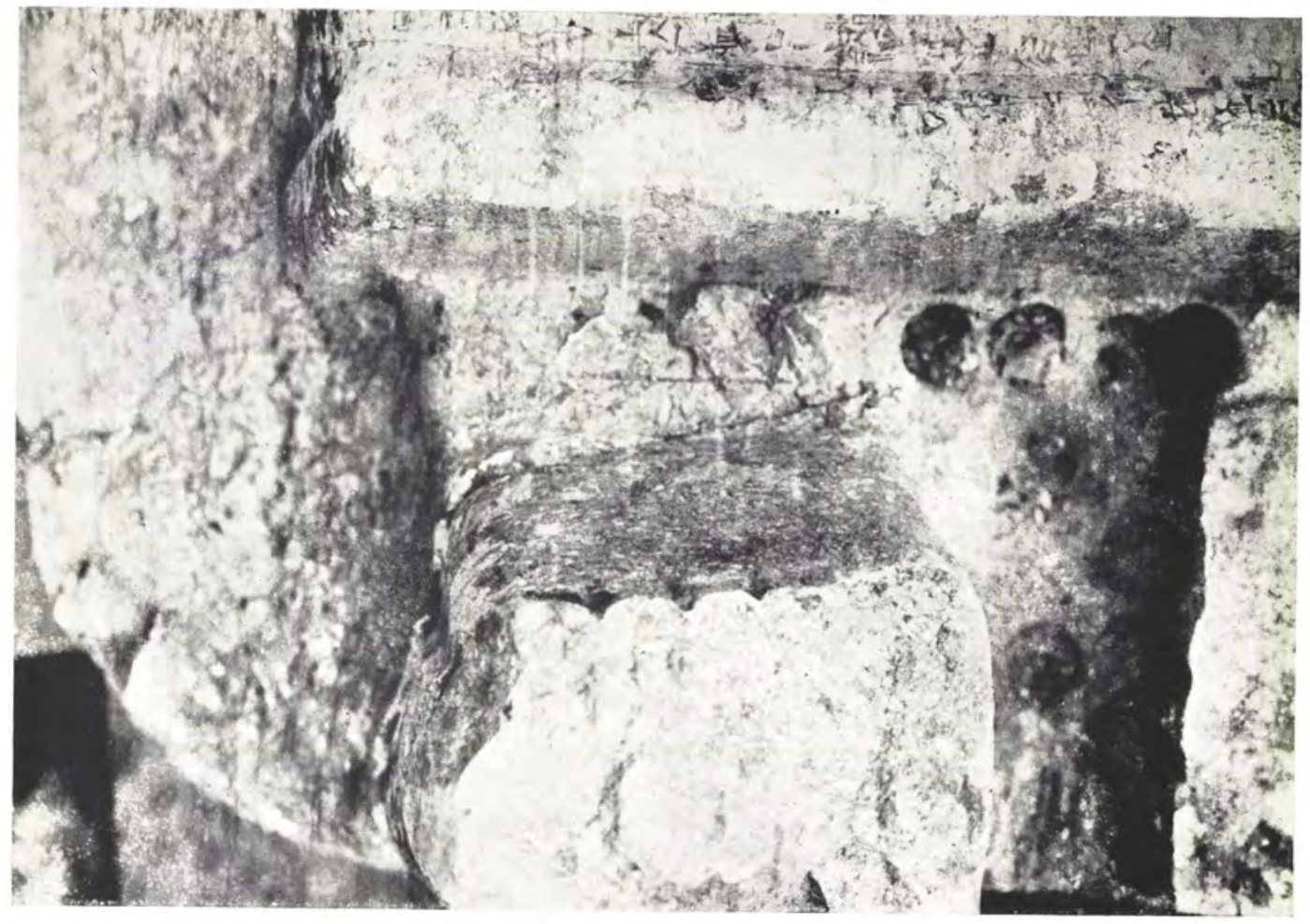

a. The feet of the Idri-mi statue, showing the carver's use of the drill

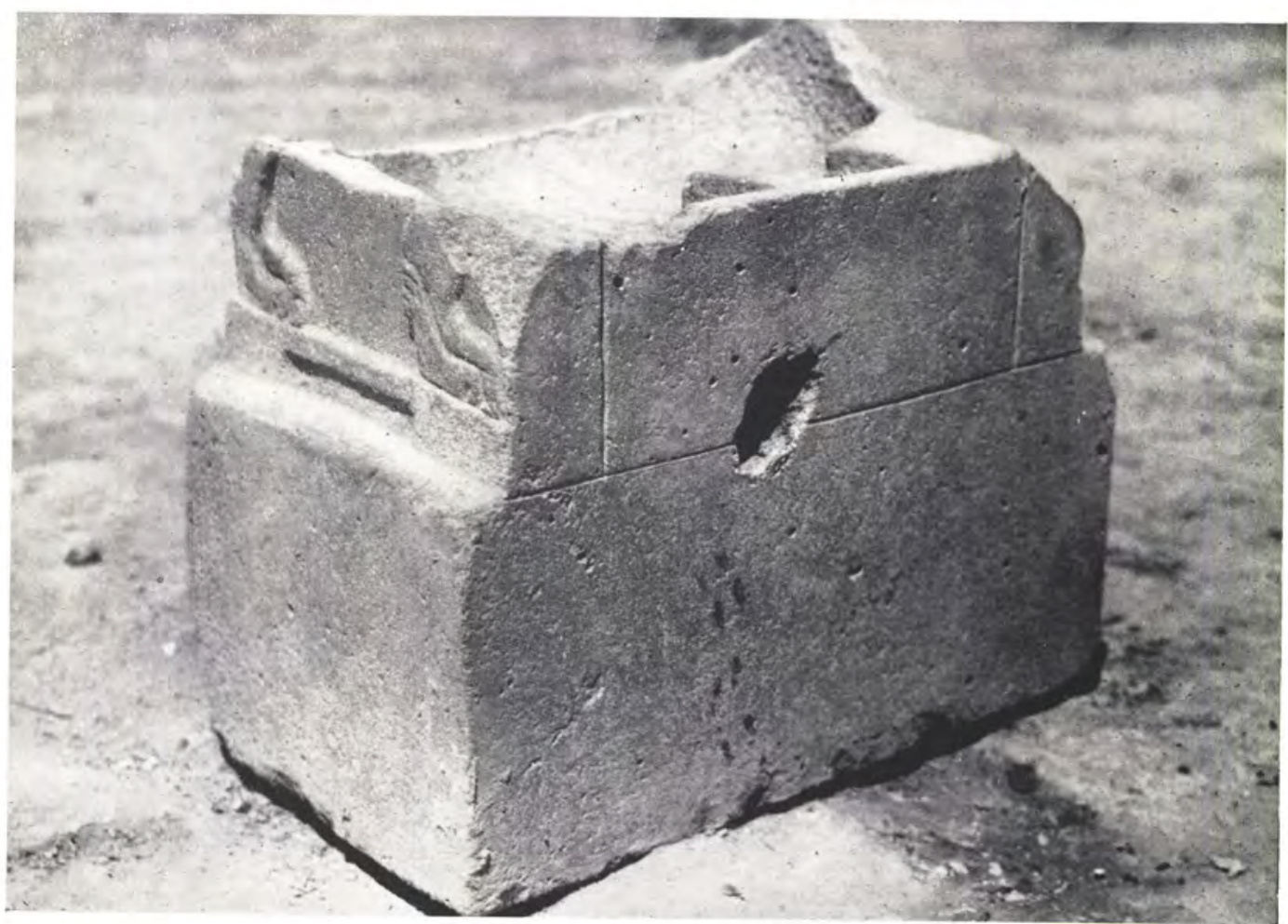

b. AT/39/288. The basalt throne of the Idri-mi statue 
PLATE XLVIII
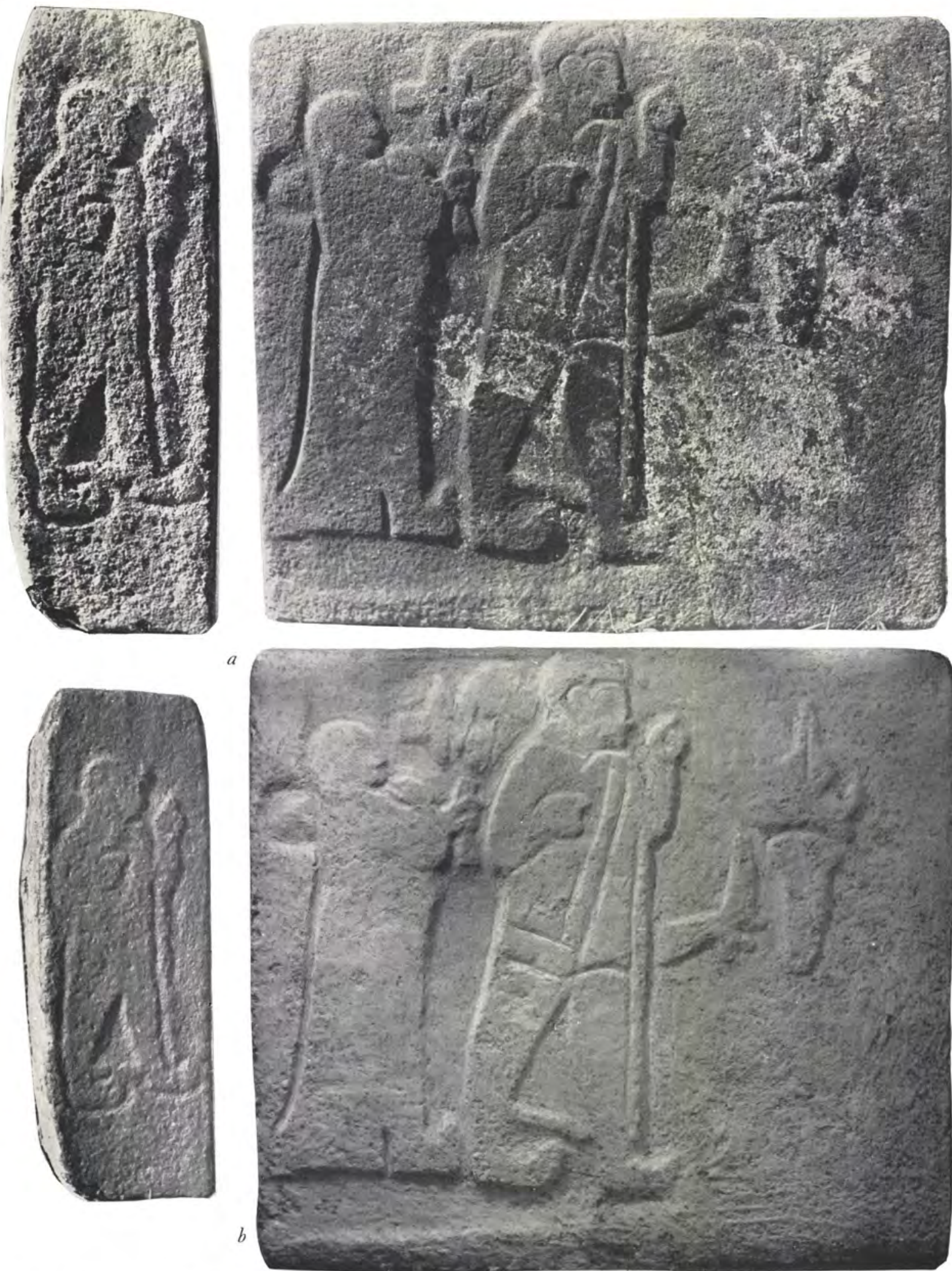

AT/40-5/2. Basalt relief of Tutkhaliya, side and front views: $(a)$ the stone as found, $(b)$ mudded p. $24 \mathrm{I}$ 


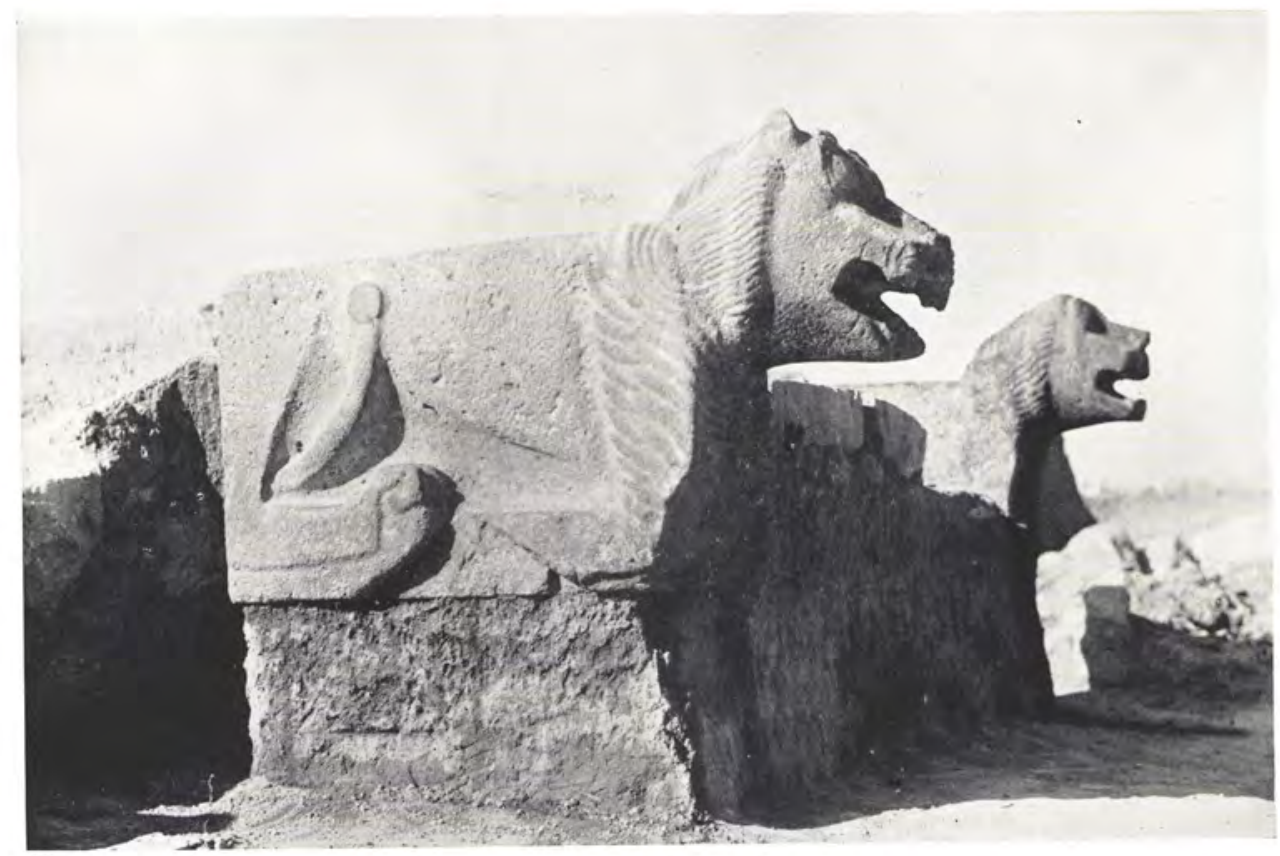

a. The lions in the Level I temple

p. 86

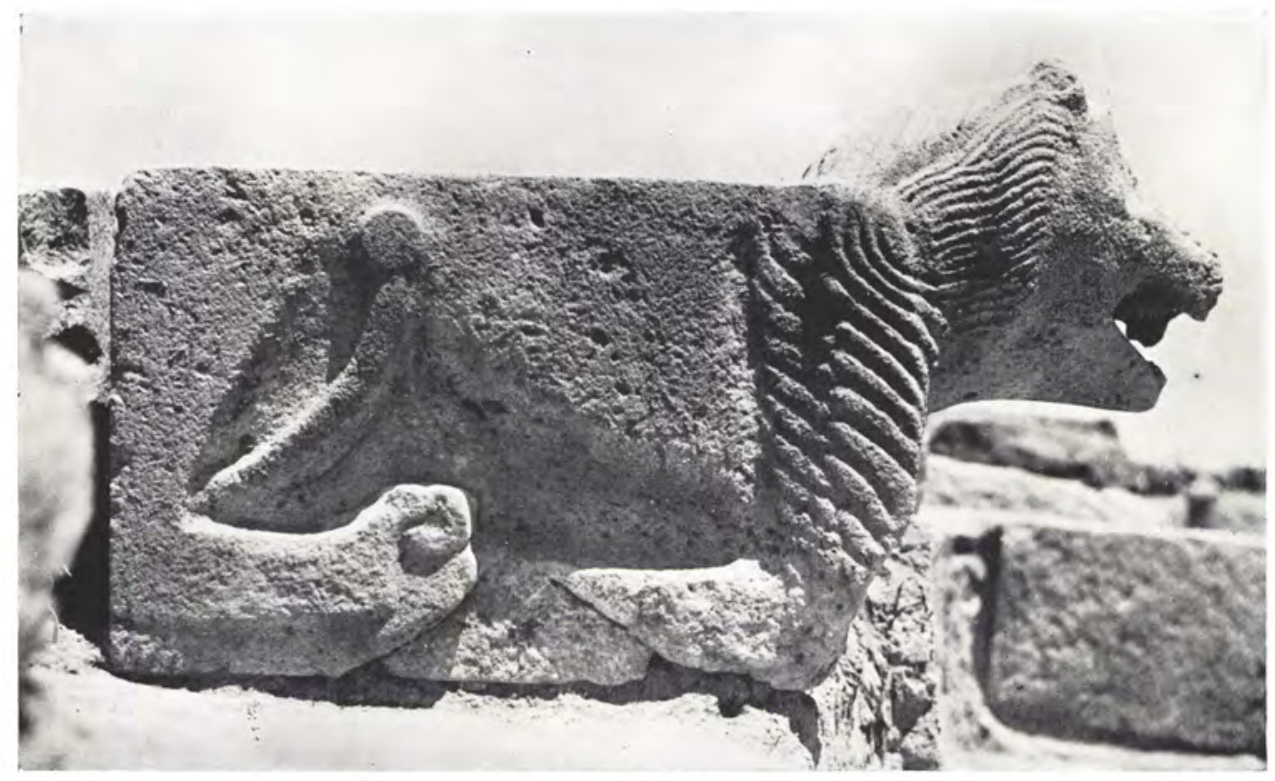

b. Lion figure AT/39/3I 4

p. 242 


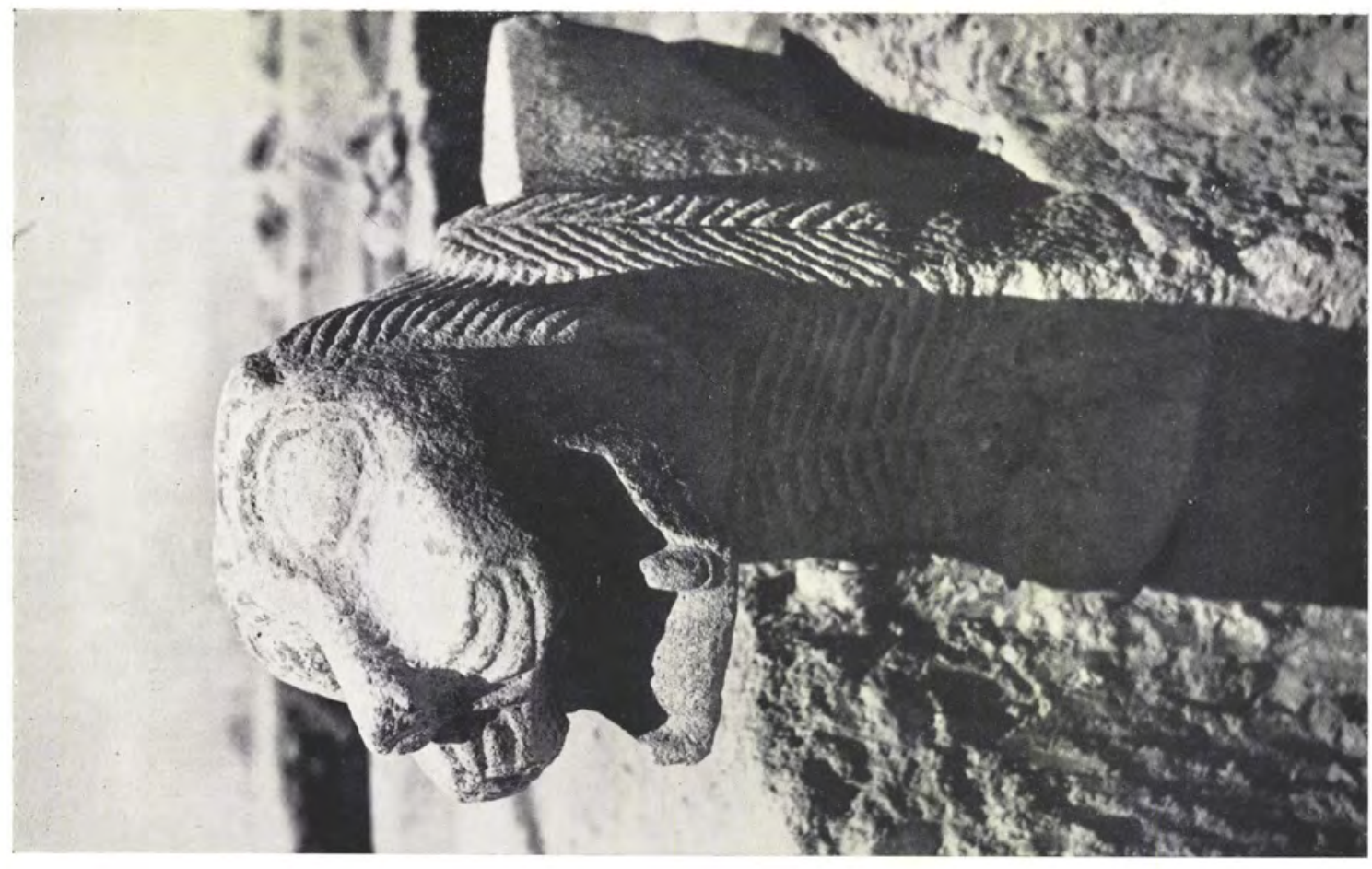

ำ

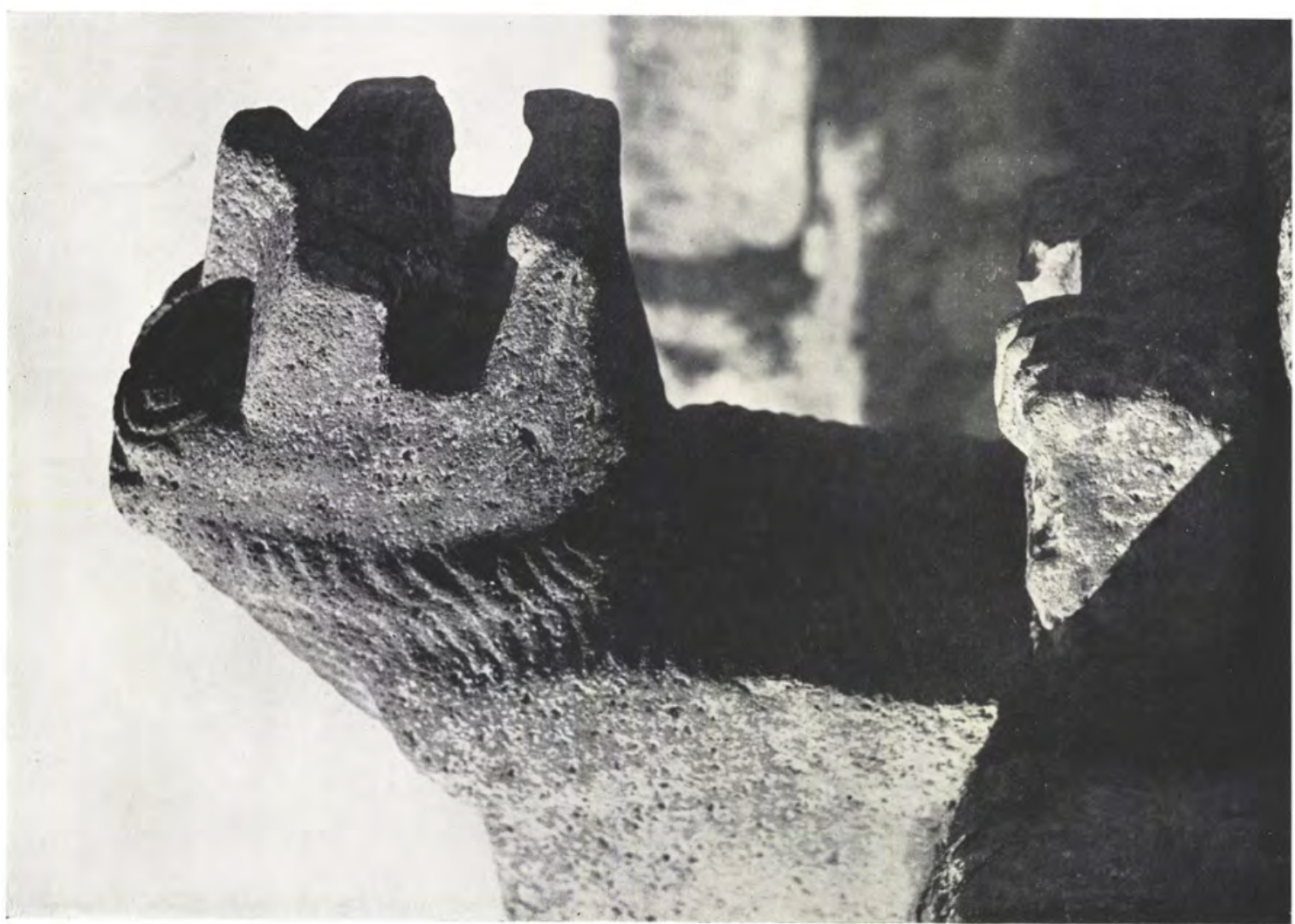



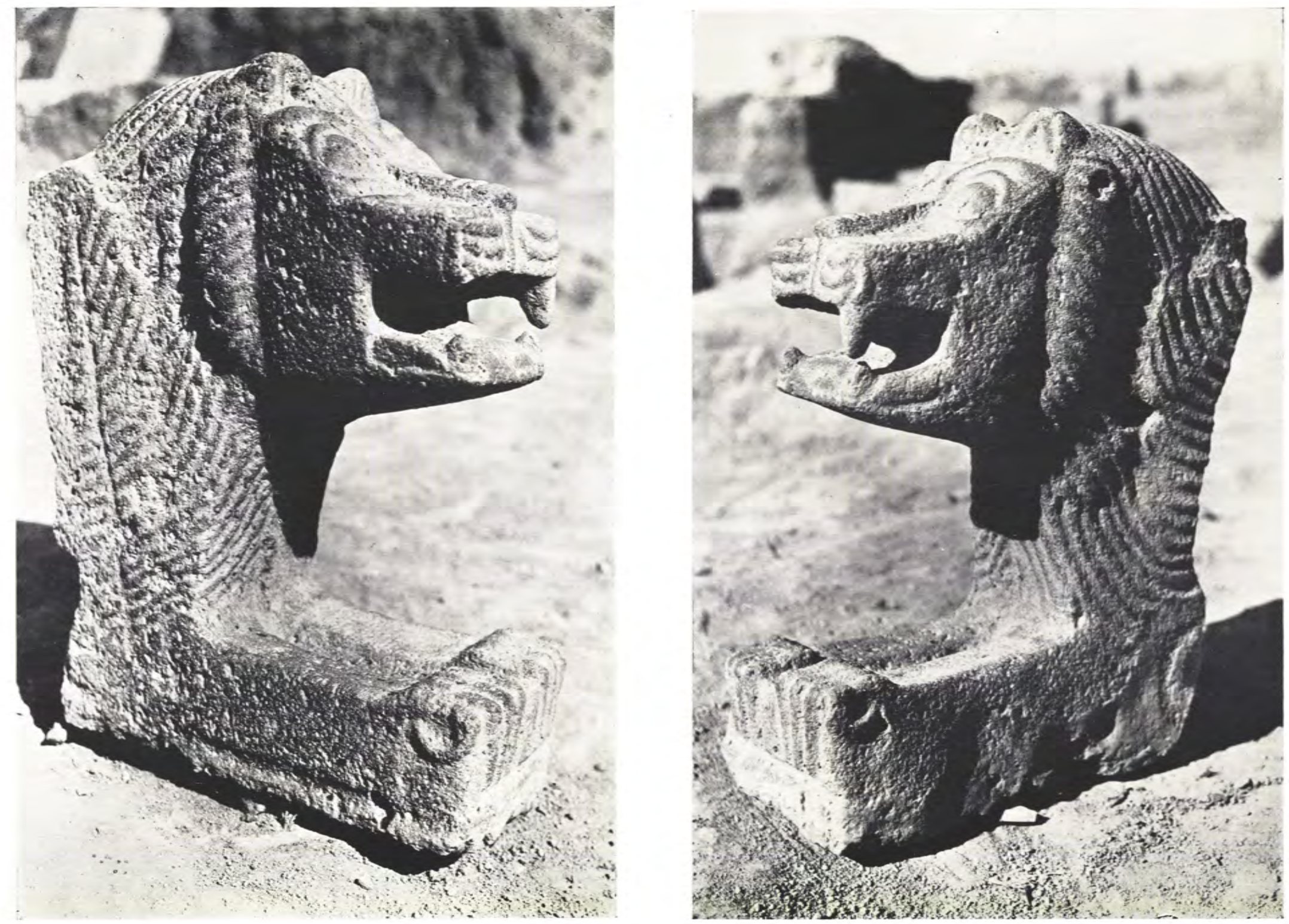

Fore-part of lion figure, AT/40-45/I

p. 242 


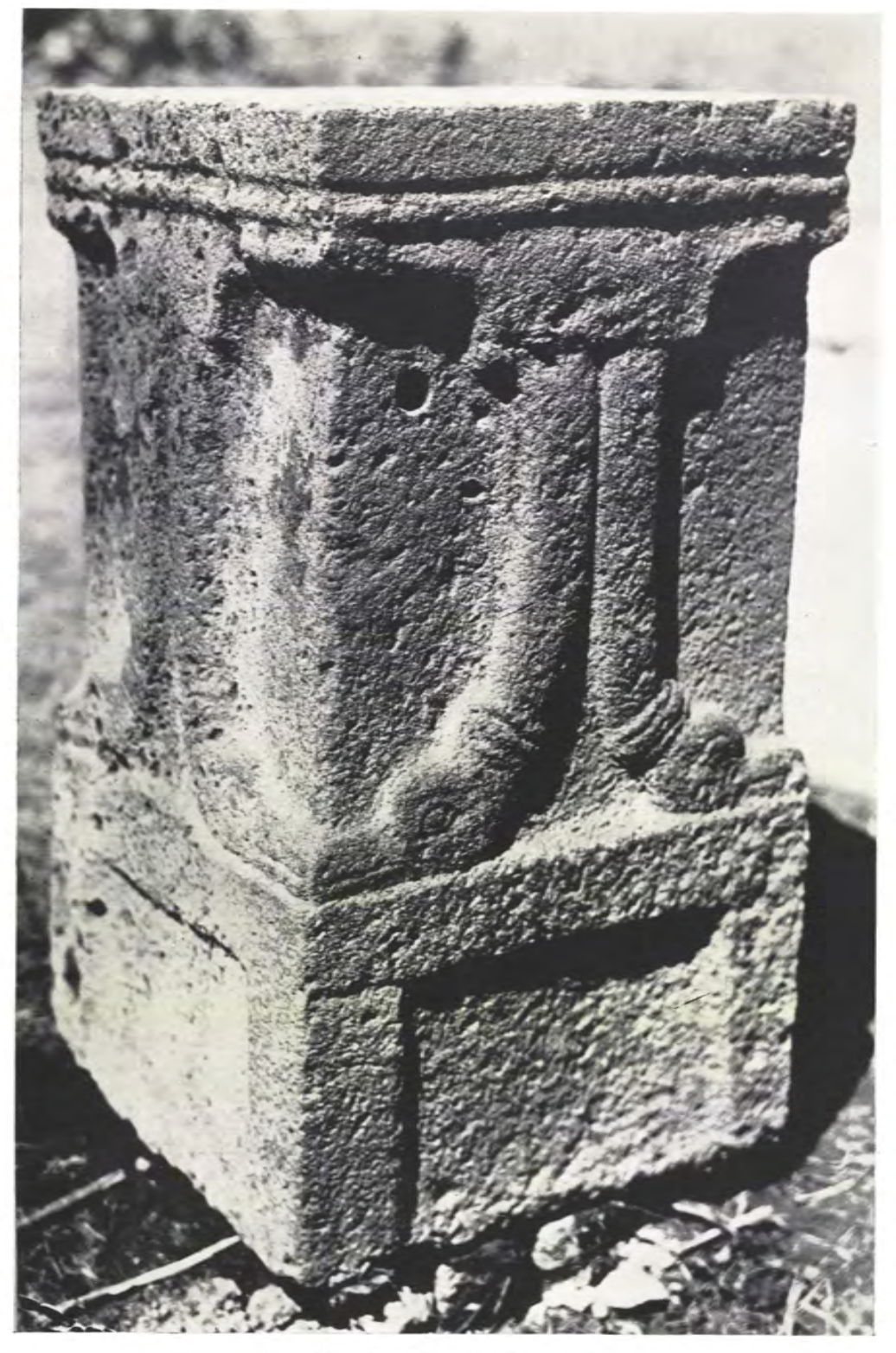

a. Basalt altar, AT/39/287

p. 243

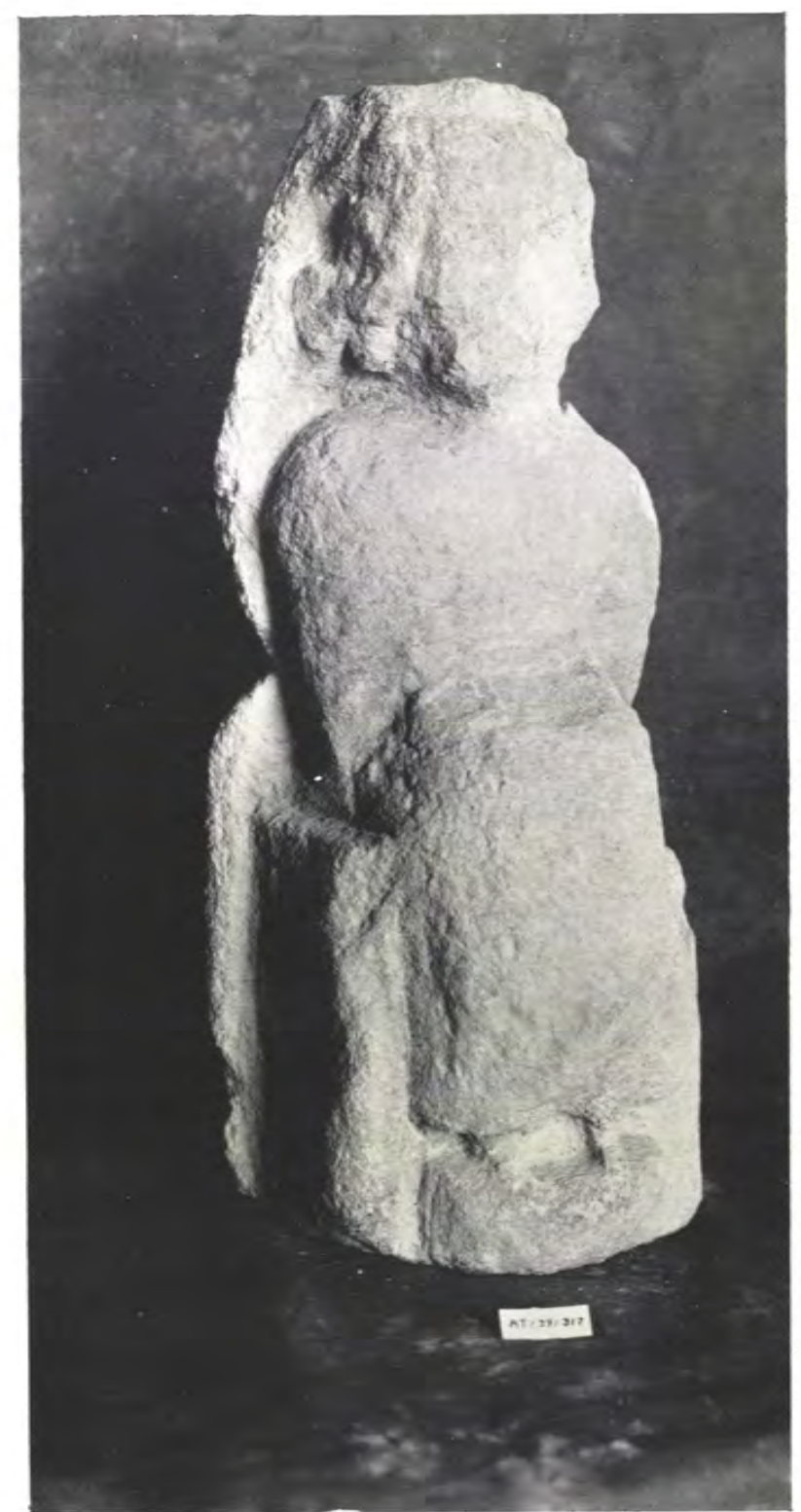

b. Limestone statue, $\mathrm{AT} / 39 / 317$ p. 243 
PLATE LIII

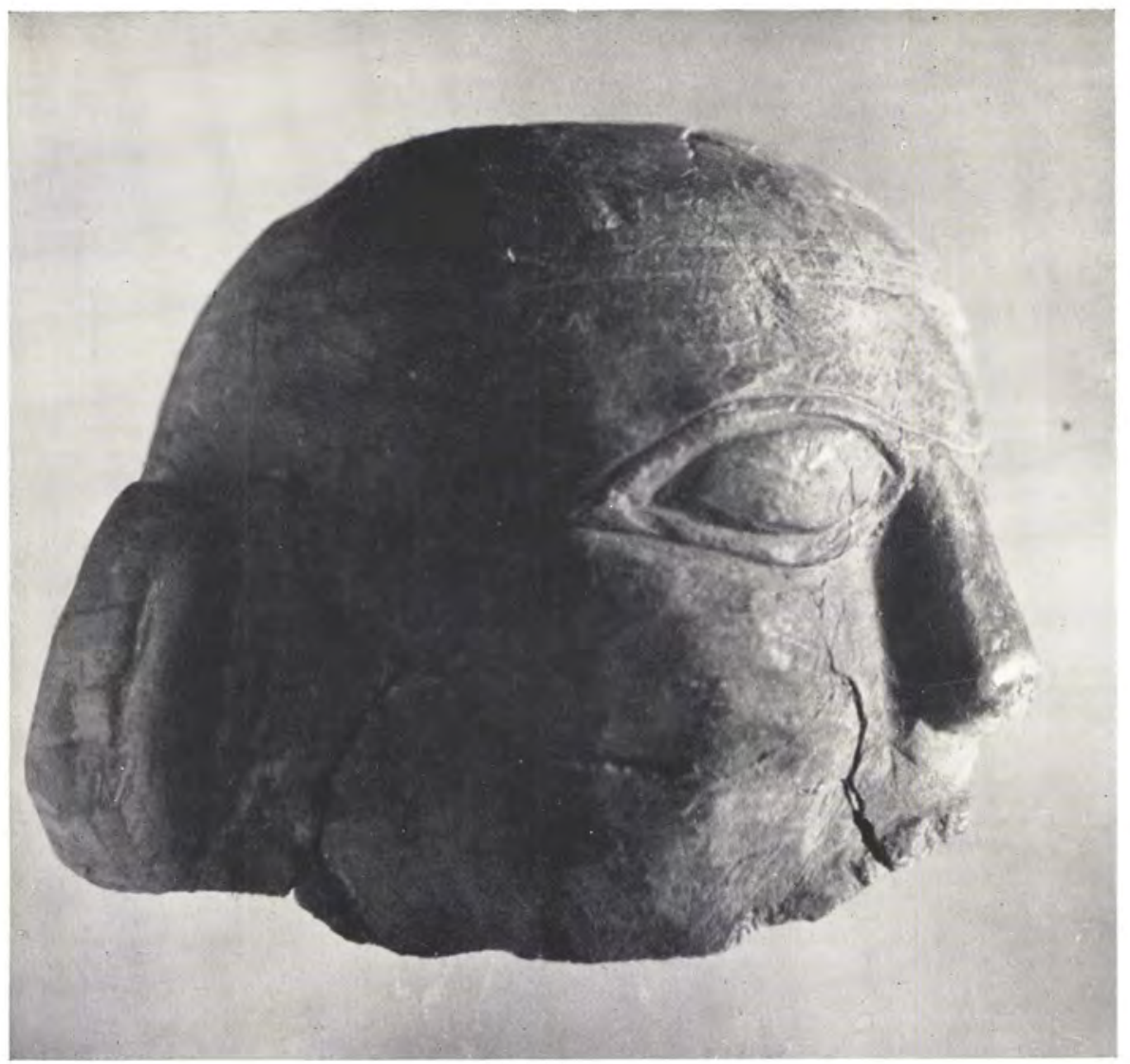

a. AT/40-45/6. Diorite head from a relief p. 243
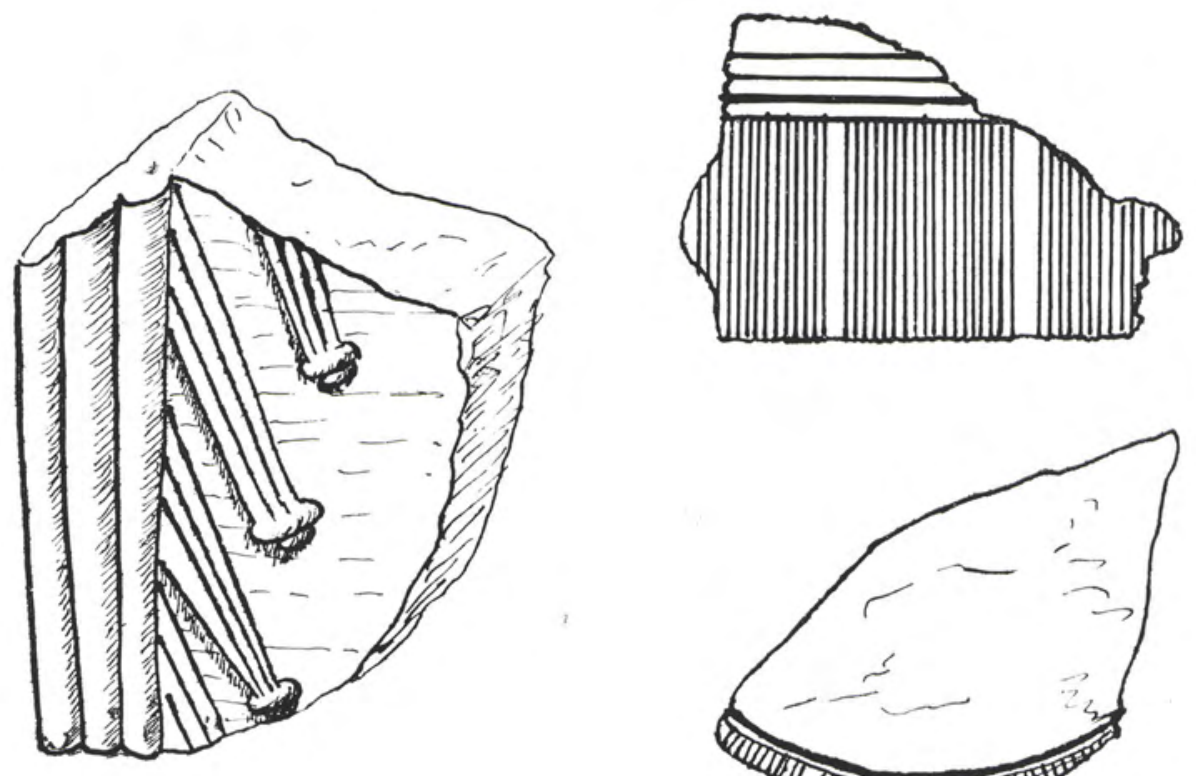
b. $\mathrm{AT} / 39 / 333$
p. 244

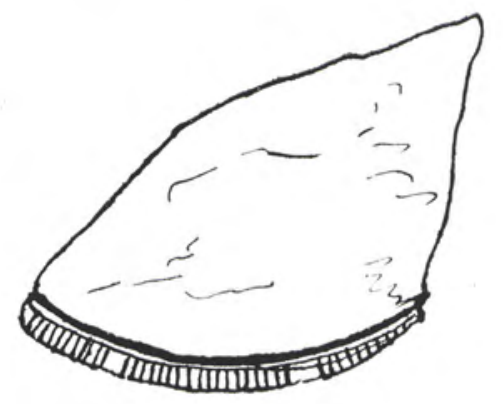

c. $\mathrm{AT} / 48 / 9$

p. 68

Fragments of stone carving 


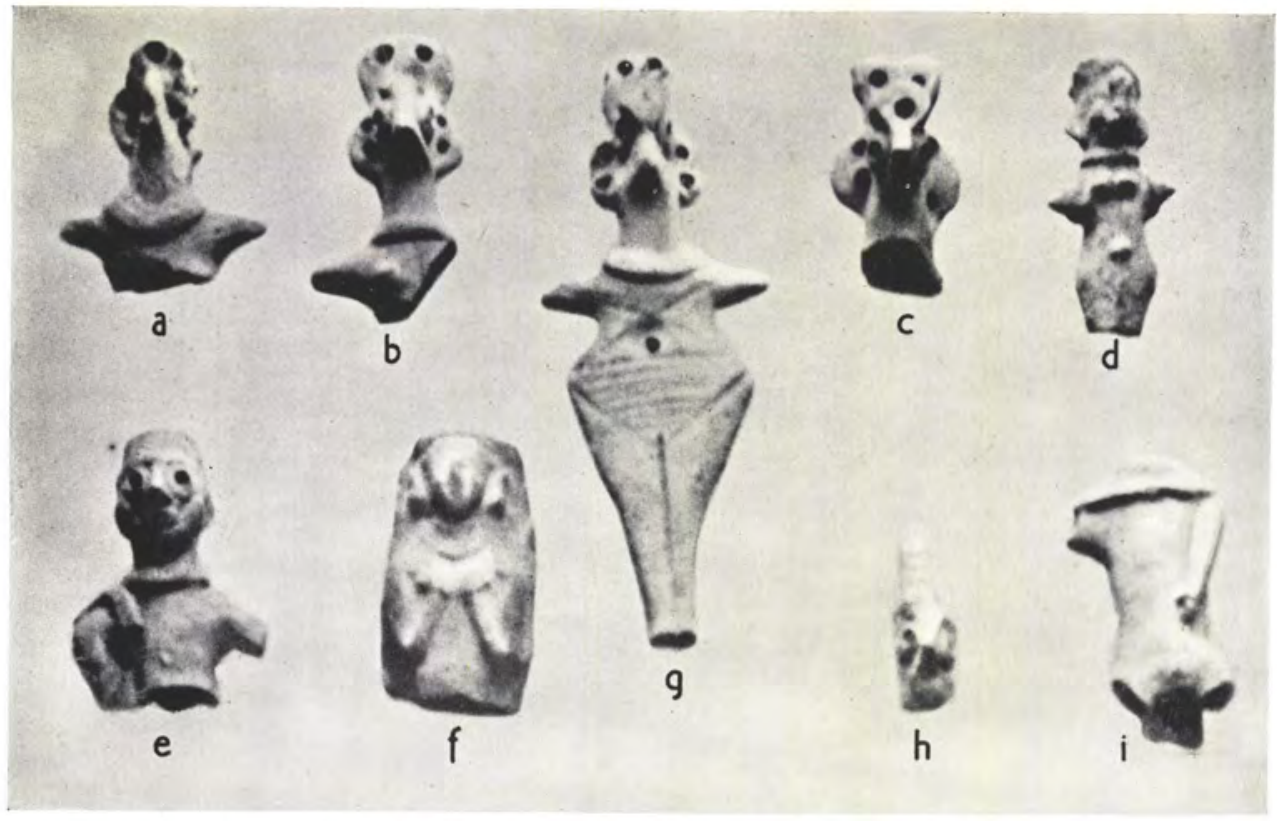

a. AT/46/203; b. AT/46/198; c. Not catalogued; d. AT/46/160; e. AT/46/219; f. AT $/ 48 / 6 \mathrm{I} ; g$. AT $/ 46 / 238 ; h$. AT/46/237;i. AT $/ 46 / 232$

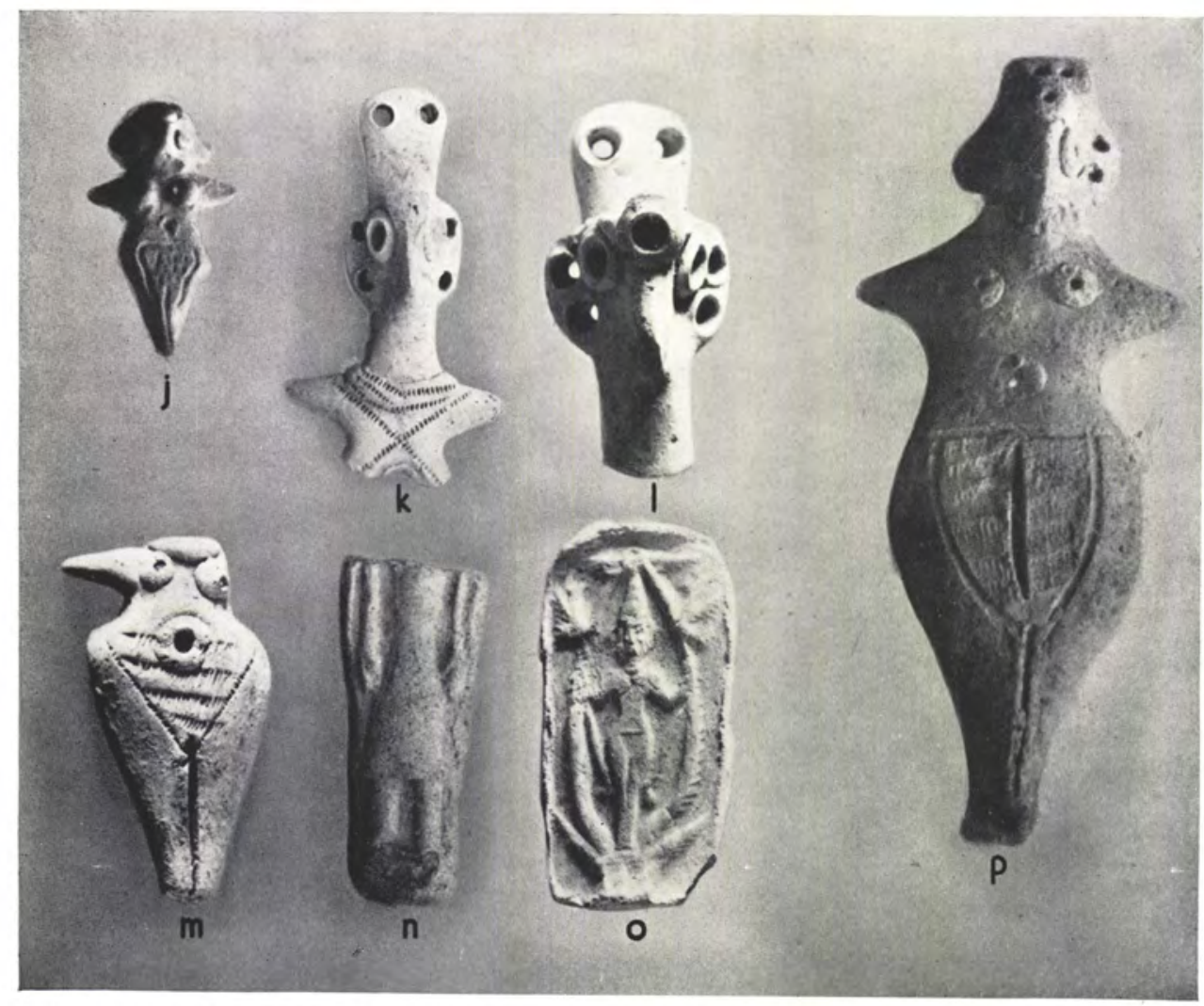

j. AT/49/5; k. AT/38/228; l. AT/39/255; m. AT/39/199; n. AT/38/260; o. AT/39/240; p. AT/49/1 7 p. 244

Terra-cottas 

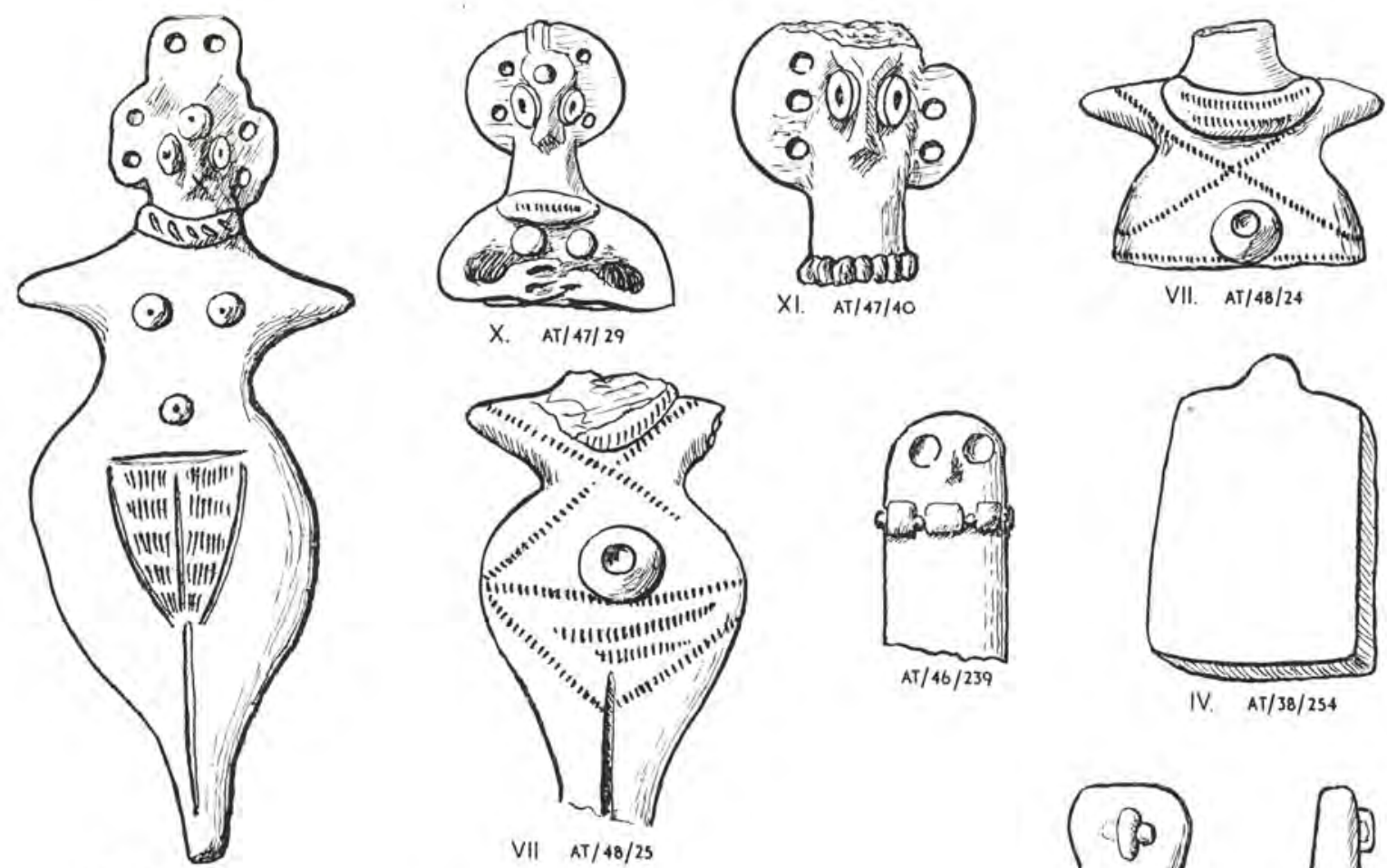

V. $A T / 49 / 17$
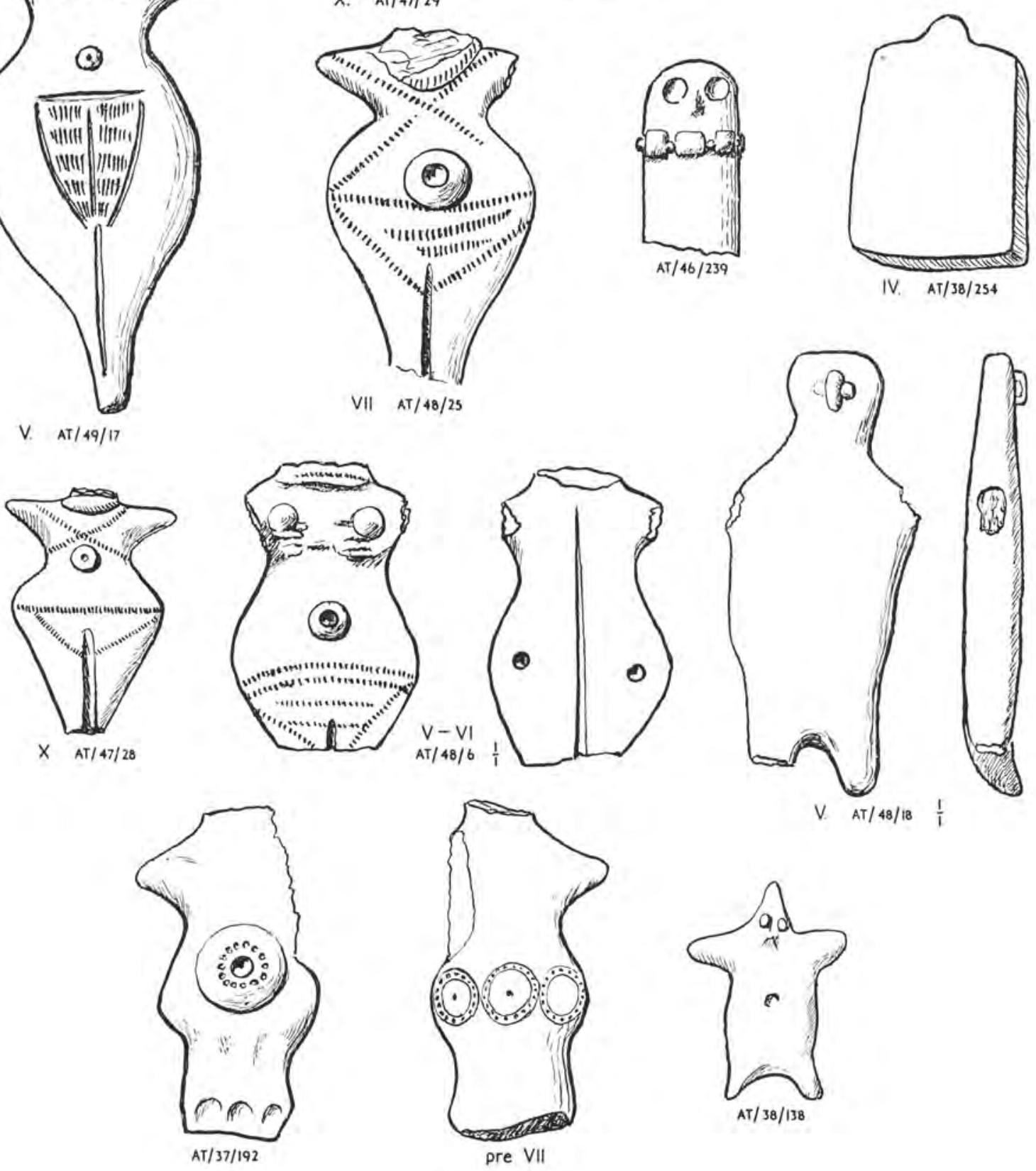

Terra-coitas

p. 244 


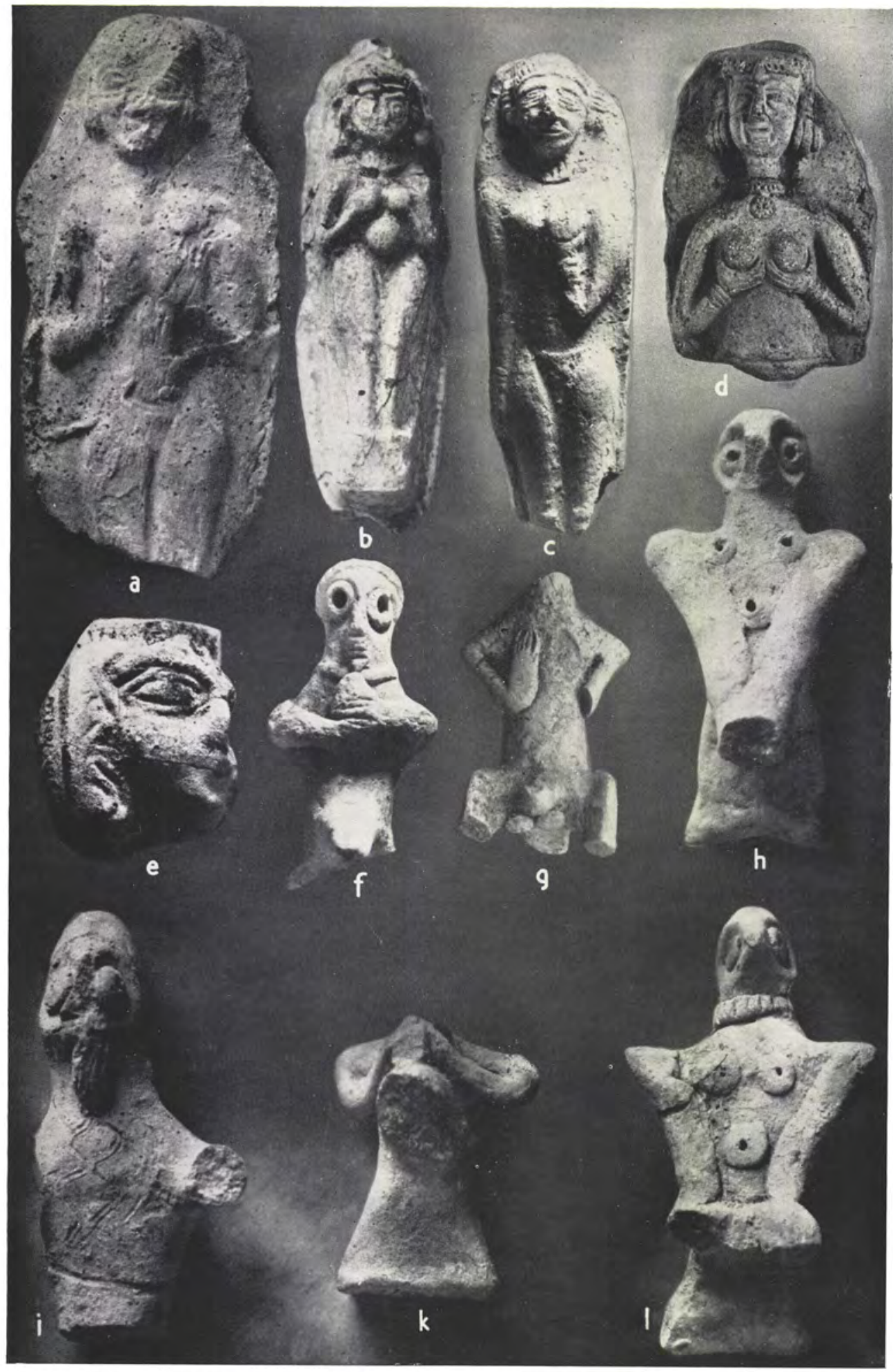

a. AT/48/6I; b. AT/48/4; c. AT/39/75; d. AT/37/77; e. AT/39/I II ; f. AT/39/7 I; g. AT/38/219; $h$. AT $/ 48 / 86 ; i$. AT $/ 48 / 84 ; j . \mathrm{AT} / 48 / 52 ; k . \mathrm{AT} / 48 / 83$

$$
\text { p. } 244
$$

Terra-cottas 


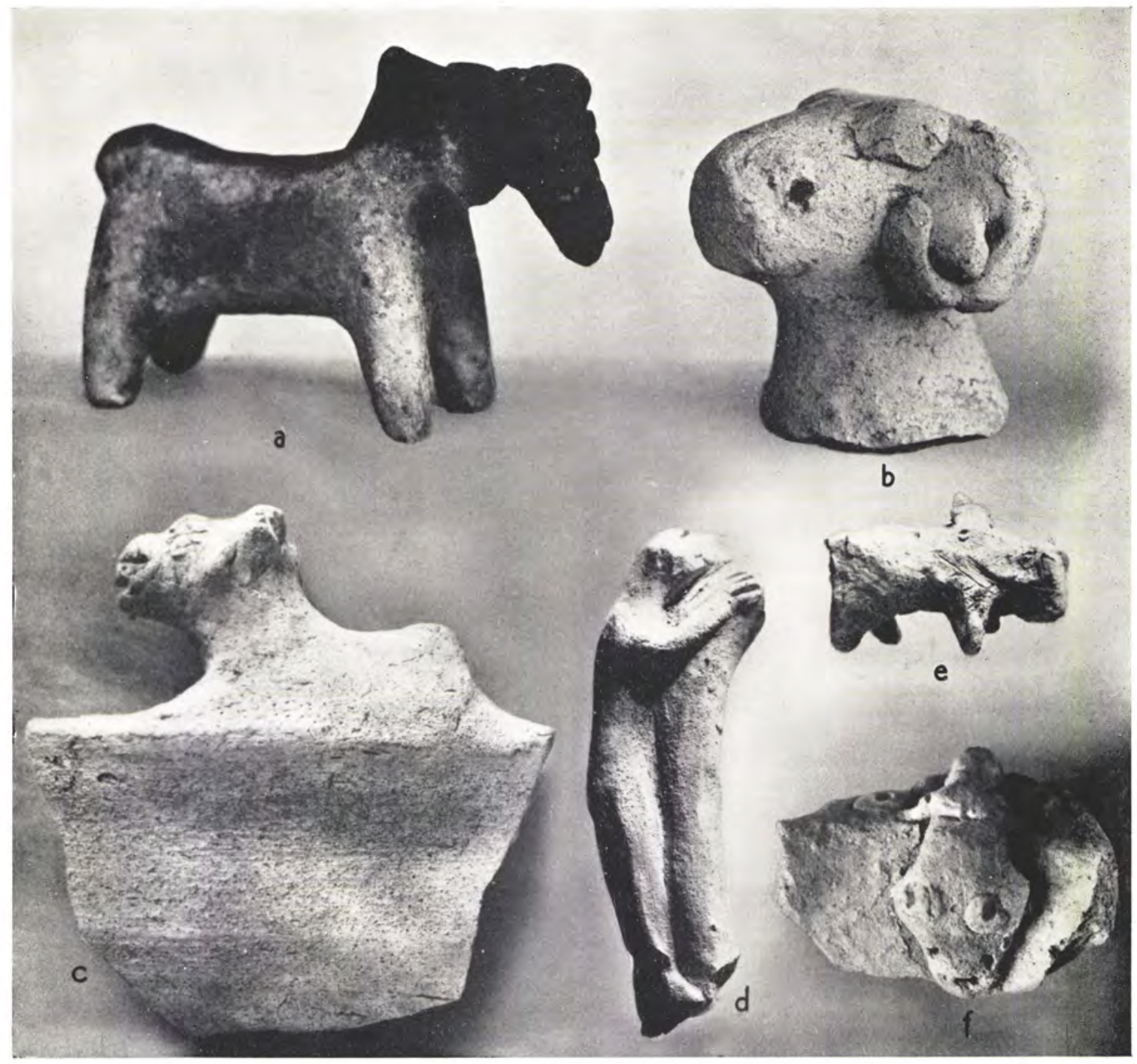

p. 351
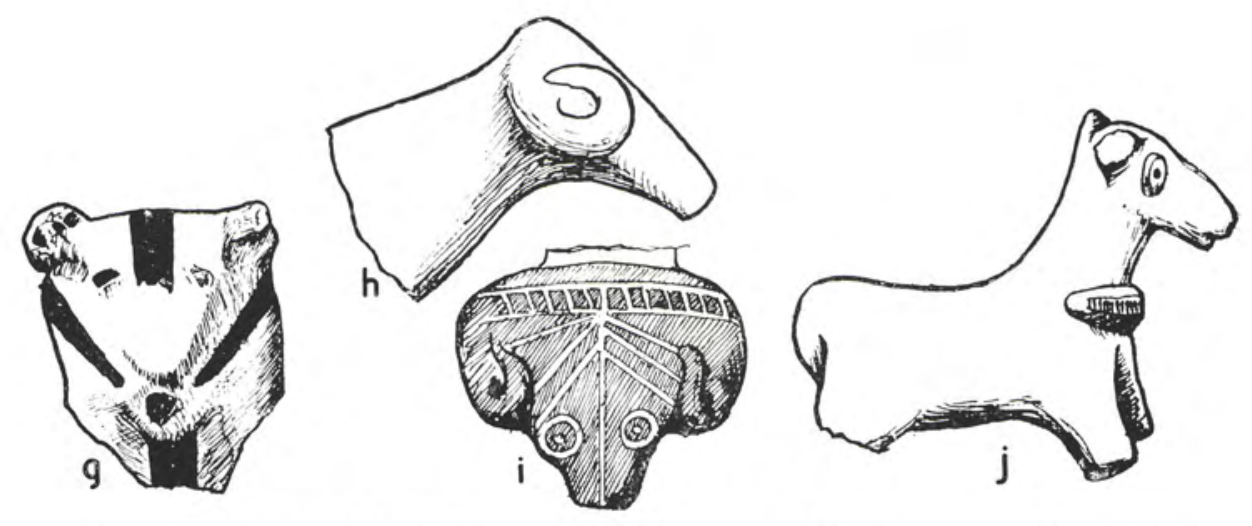

a. AT/39/127; b. AT/39/58; c. AT/48/29; d. AT/39/270; e. AT/39/272; g. AT/38/280; h. AT/47/106; i. AT/48/43; f. AT $/ 48 / 12 ; j . \mathrm{AT} / 47 / 26$ p. 244

Terra-cottas 

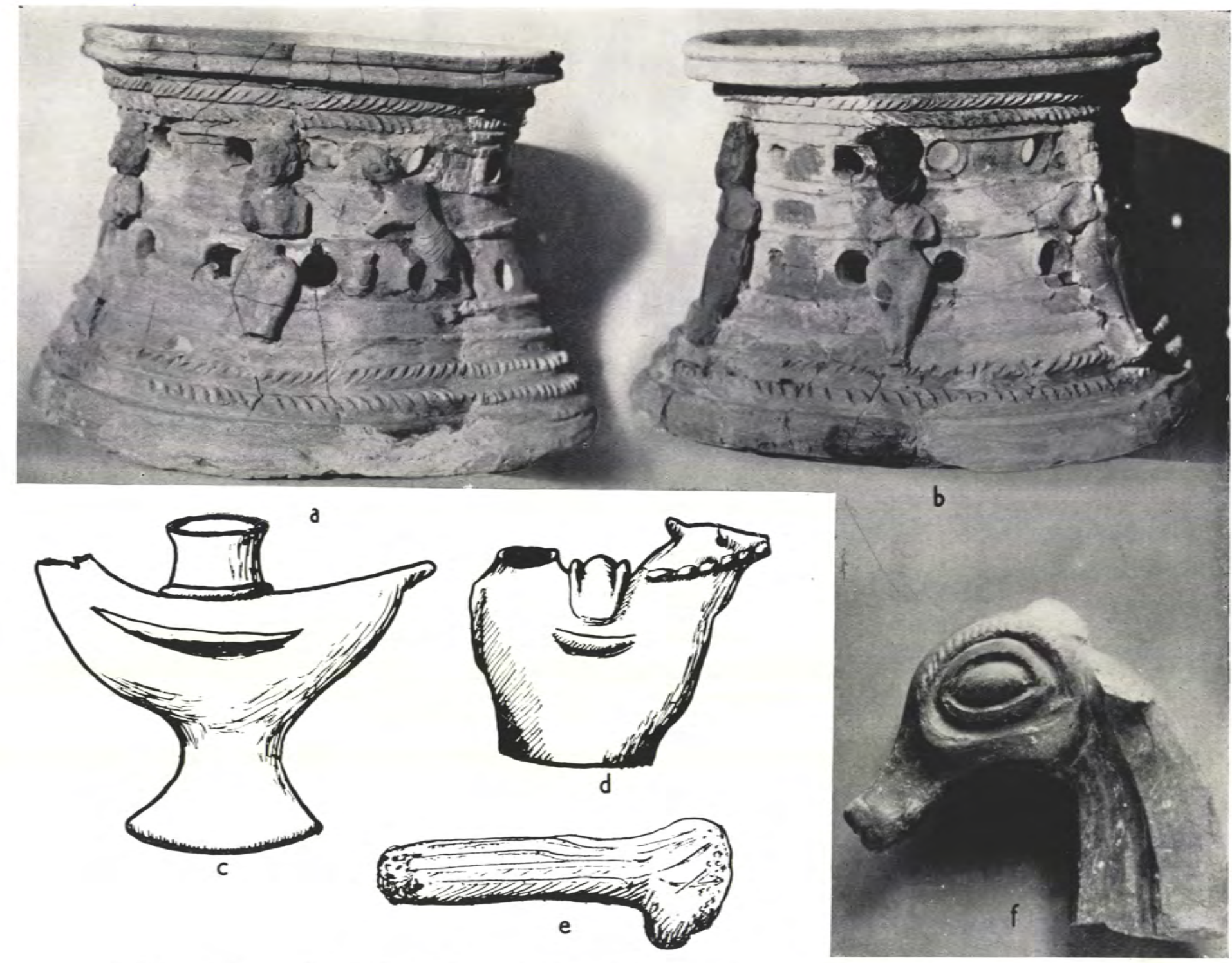

$a, b . \mathrm{AT} / 47 / 128 ; c . \mathrm{AT} / 46 / 180 ; d$. From Atchana, but not from the excavations; e. AT/49/23; f. AT/48/36 pp. 248,250 , and 351

Terra-cotta objects 


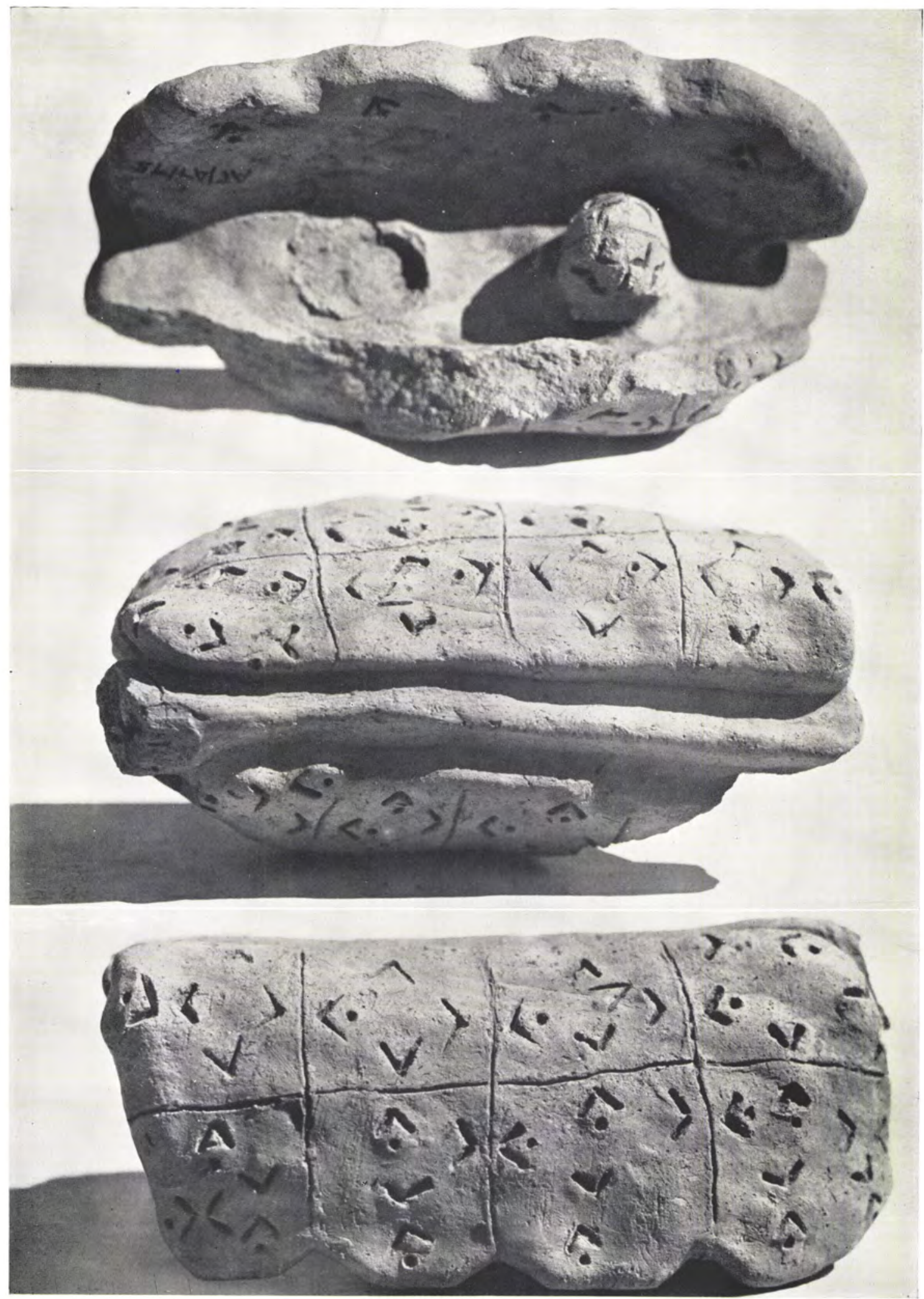

AT/47/75. Clay model of an ox liver pp. 250 sqq. 
PLATE LX
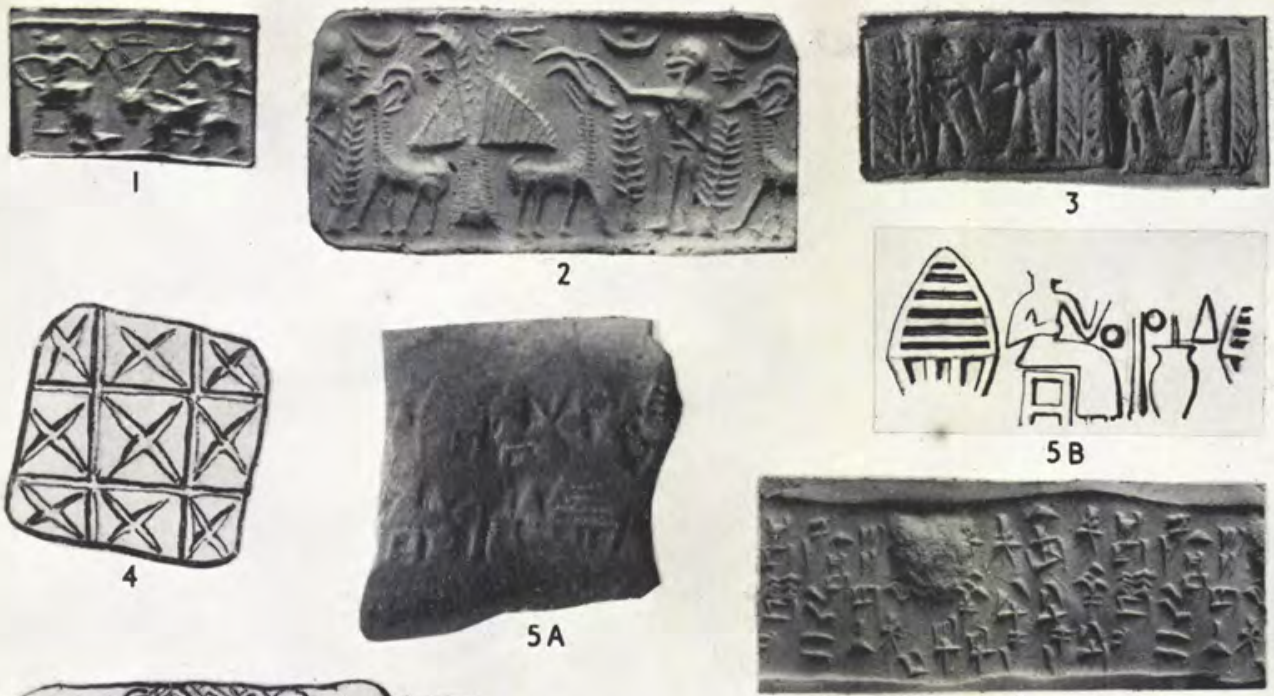
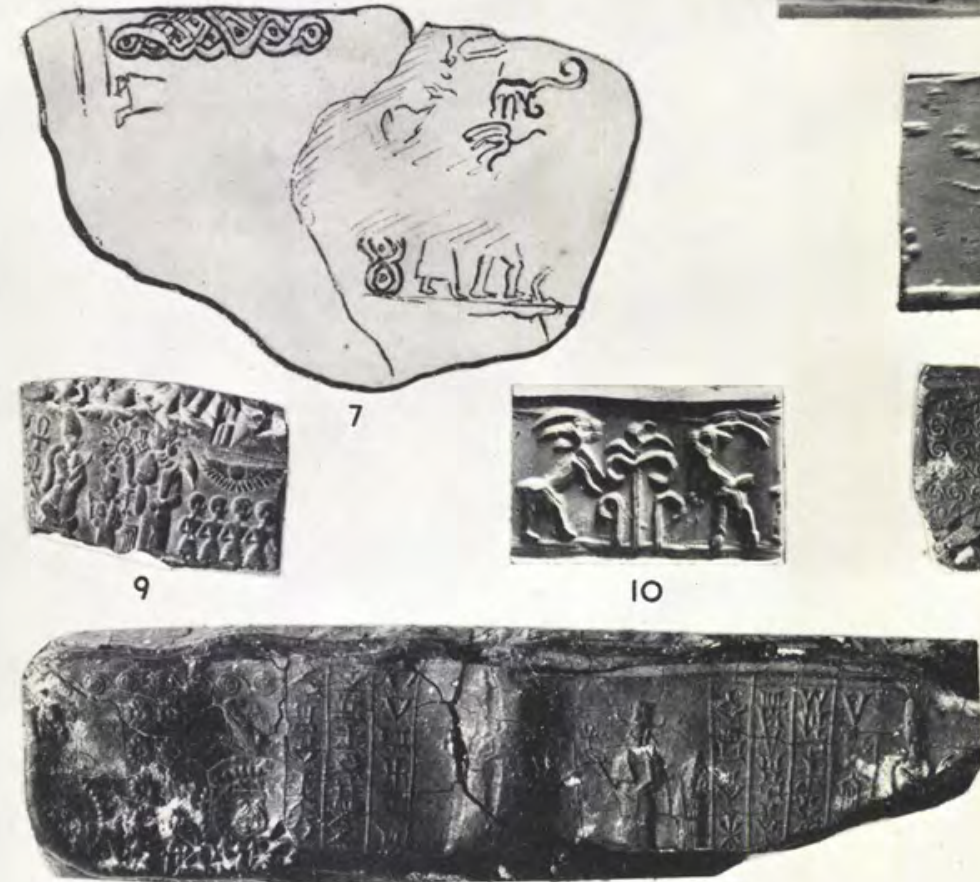

$12 \mathrm{~A}$

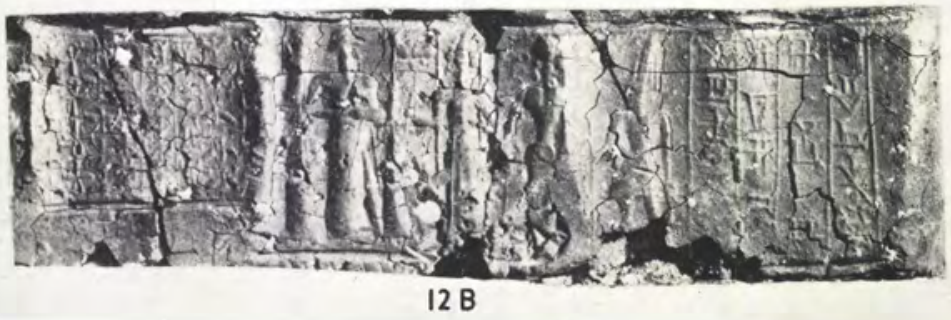

Seals and seal-impressions

pp. $258,26 \mathrm{I}$
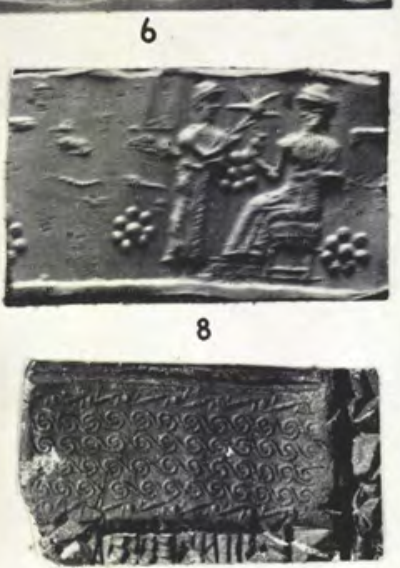

II

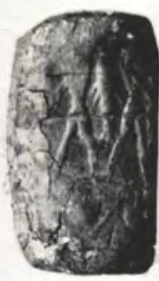

13

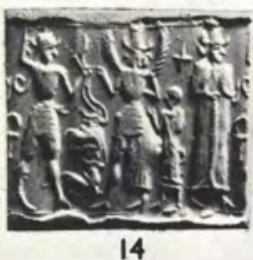


PLATE LXI
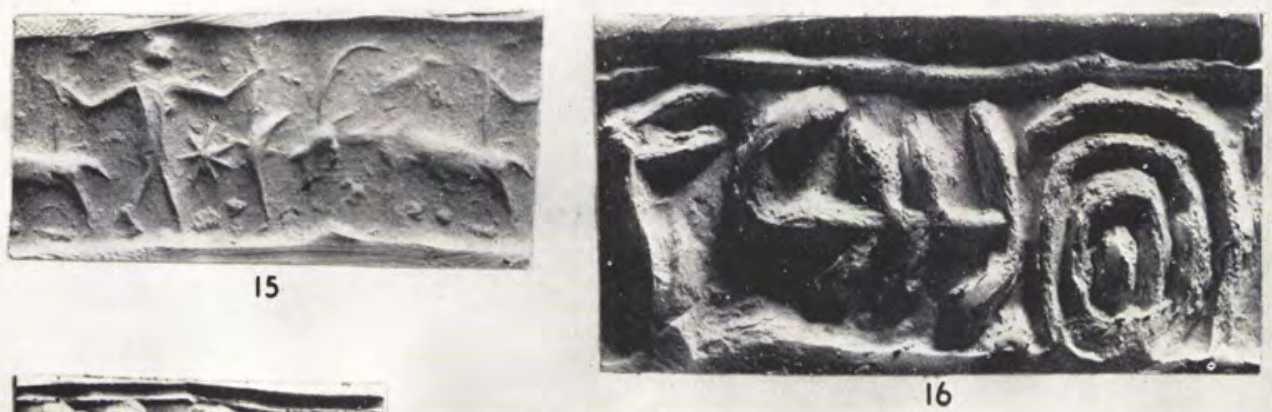

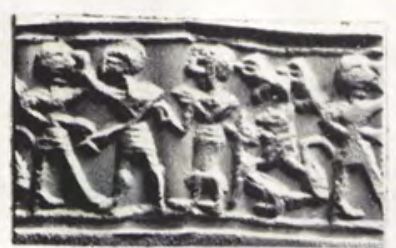

17
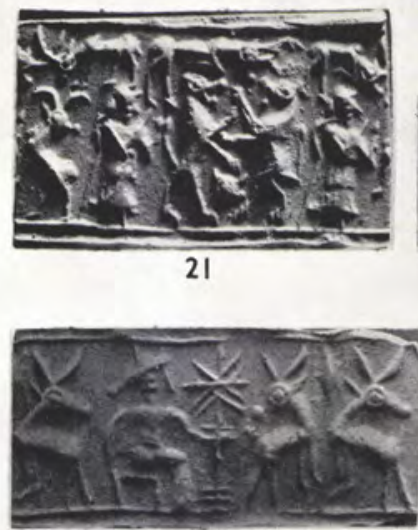

24

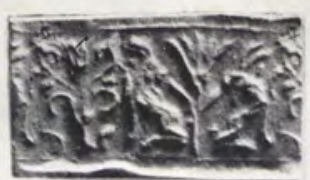

18

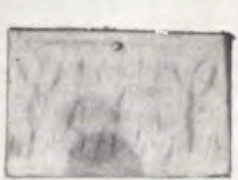

19

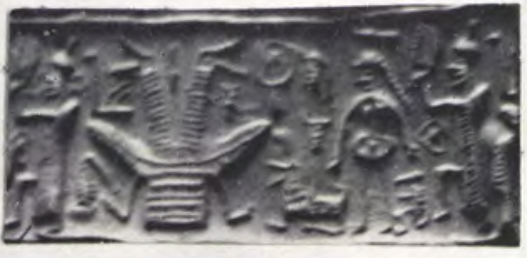

23

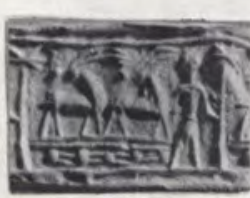

25

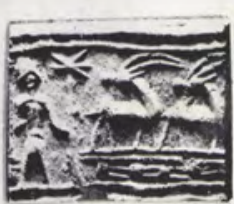

26

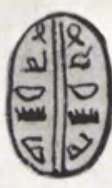

20

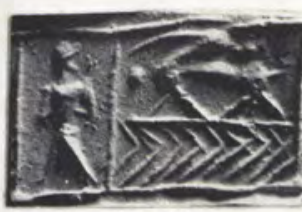

27

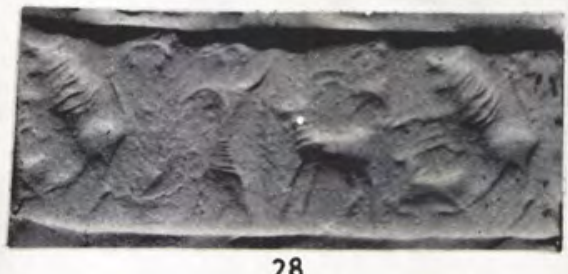

28

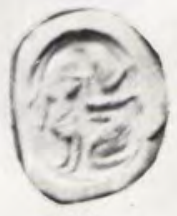

29

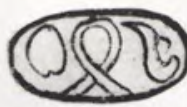

33
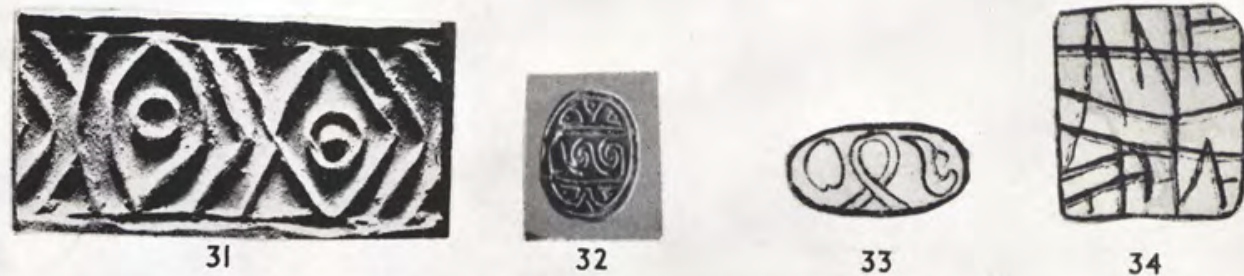

34

Seals and seal-impressions

pp. 258,262 

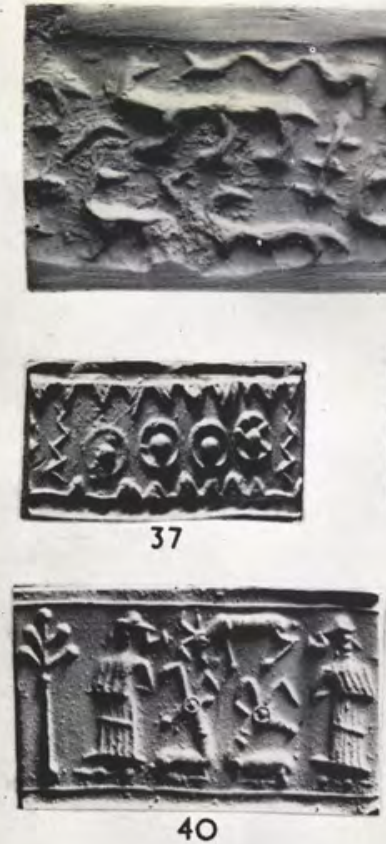

\section{5}

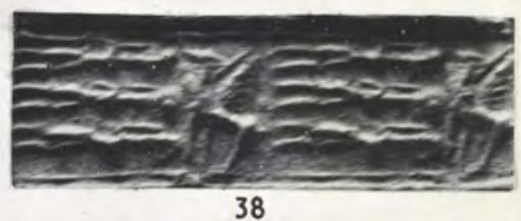

38
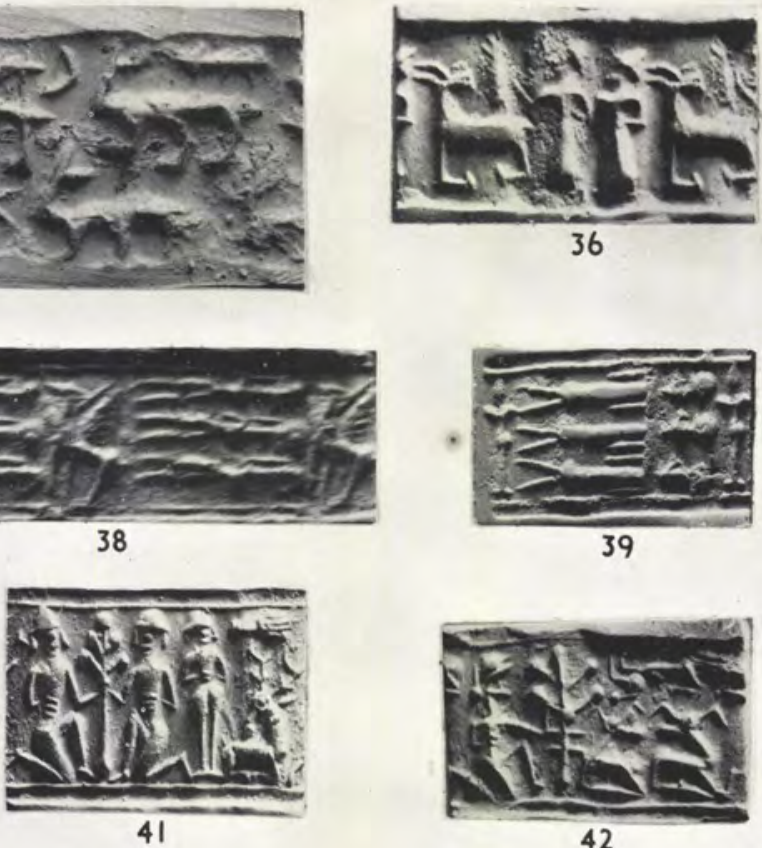

42

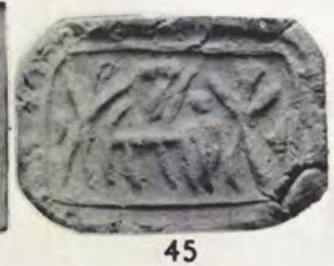

44

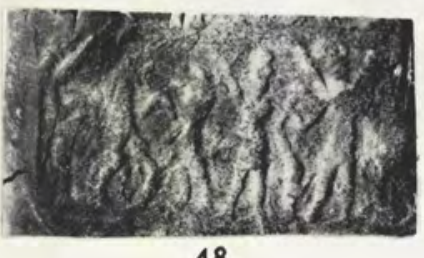

48

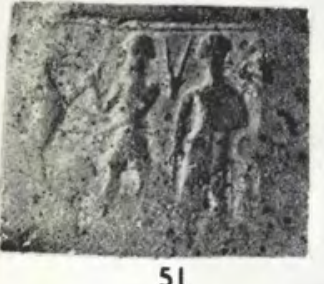

Seals and seal-impressions

pp. 258,263 
PLATE LXIII

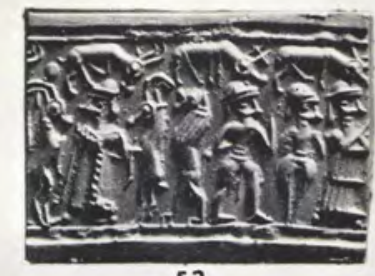

52

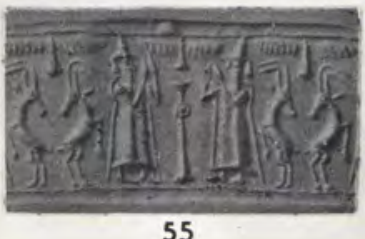

55

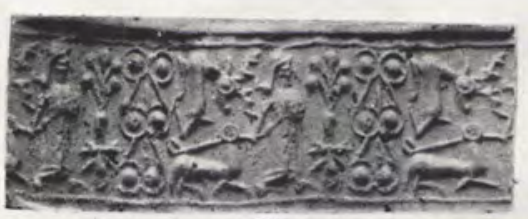

58

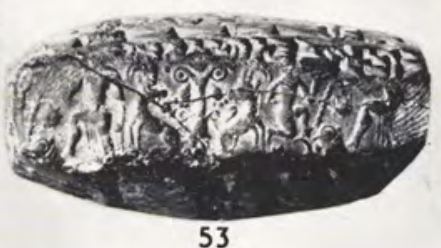

53

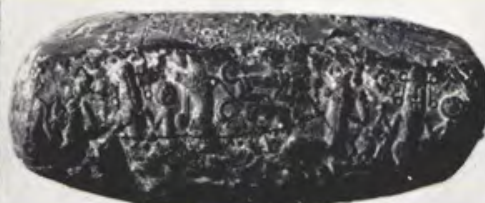

56

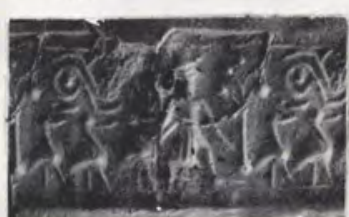

59
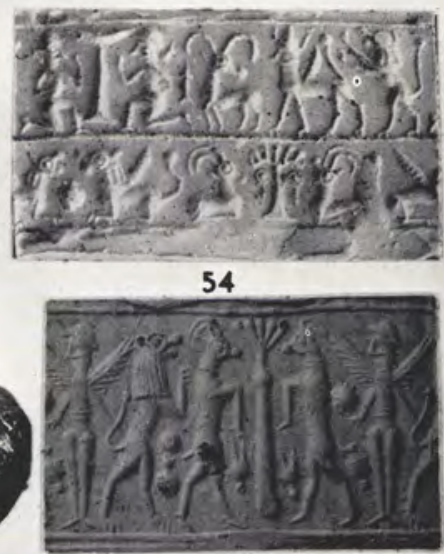

57

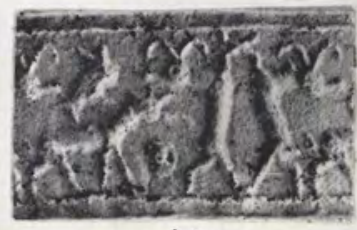

60

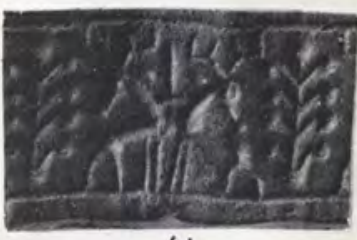

61

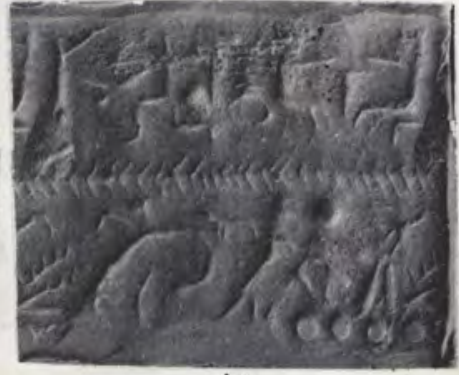

62

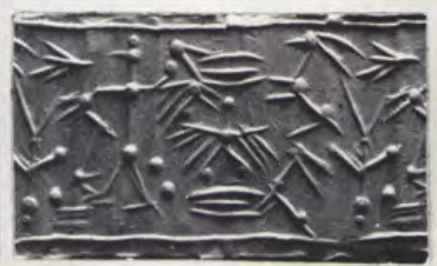

63

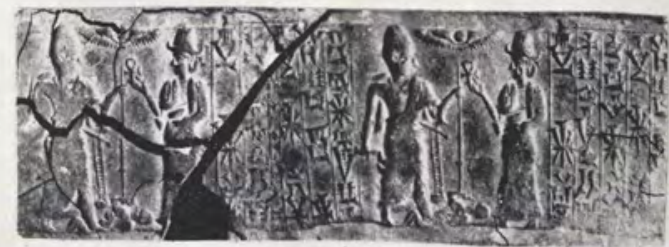

64

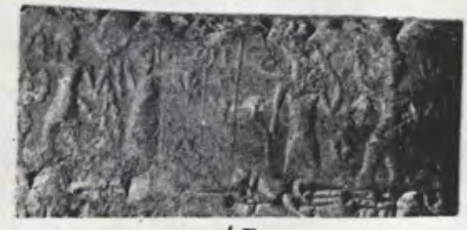

67

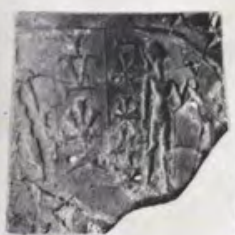

65

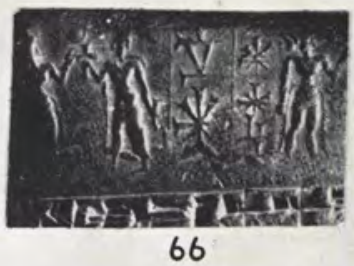

66
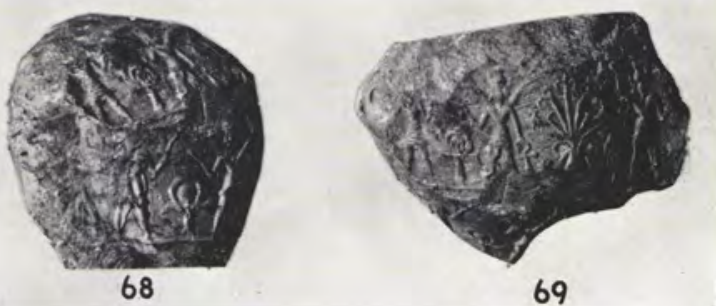

Seals and seal-impressions

pp. 258,263 

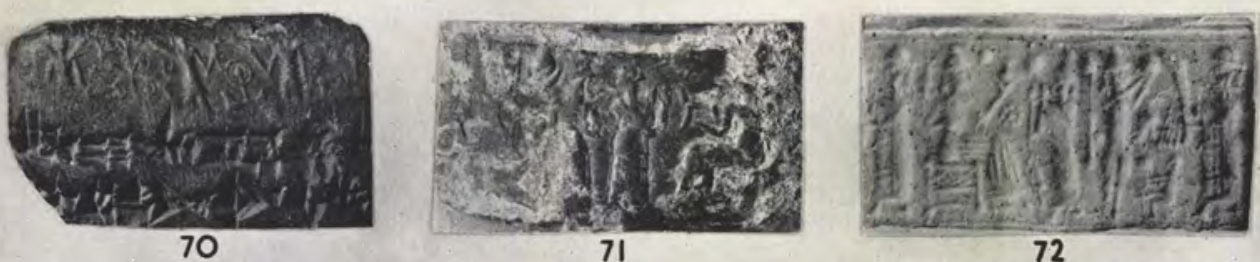

72
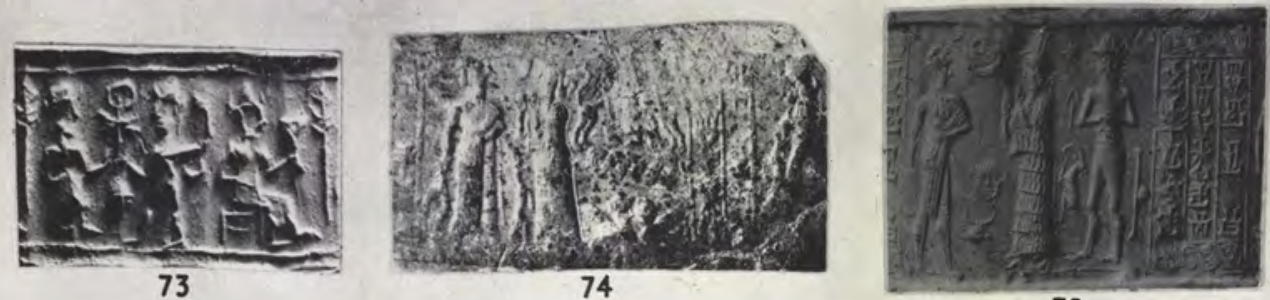

75
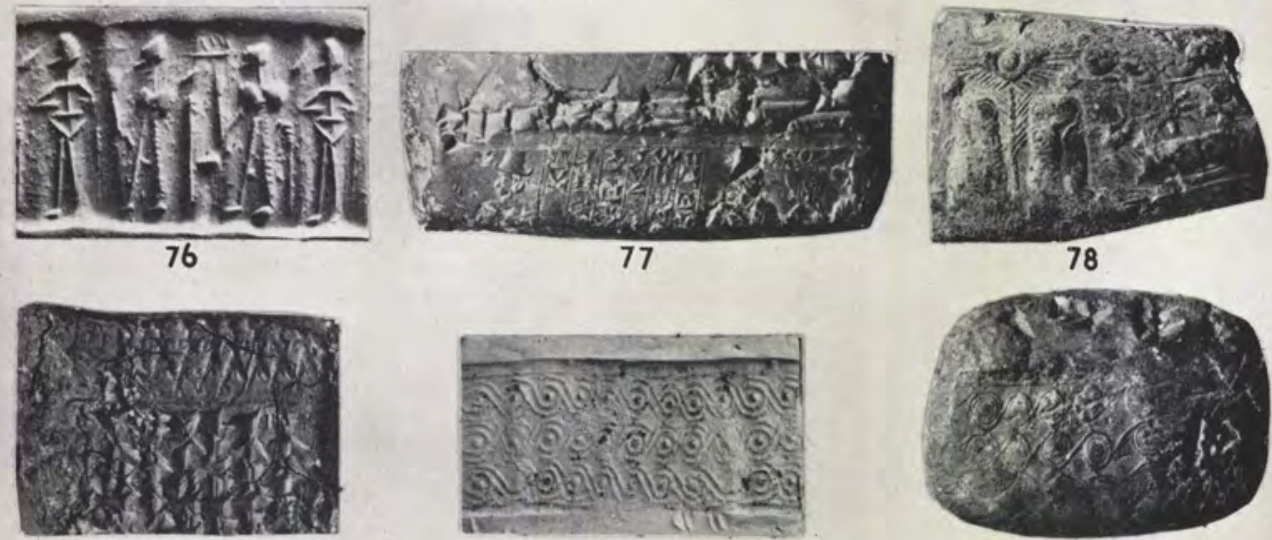

79
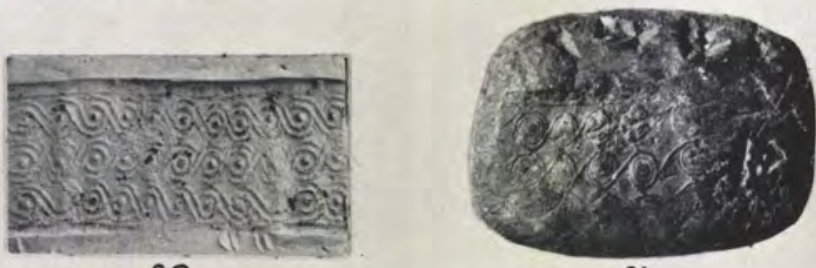

81

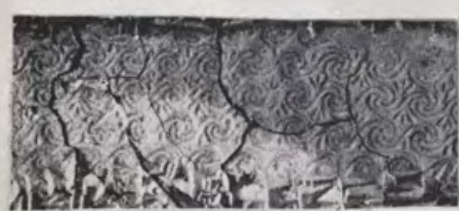

82

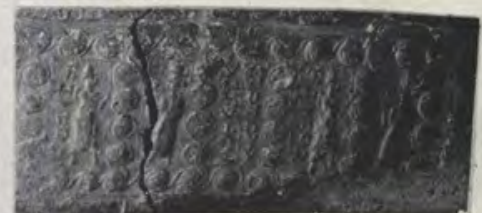

83

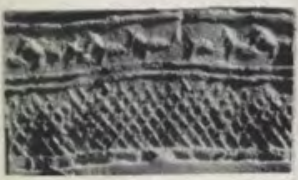

84
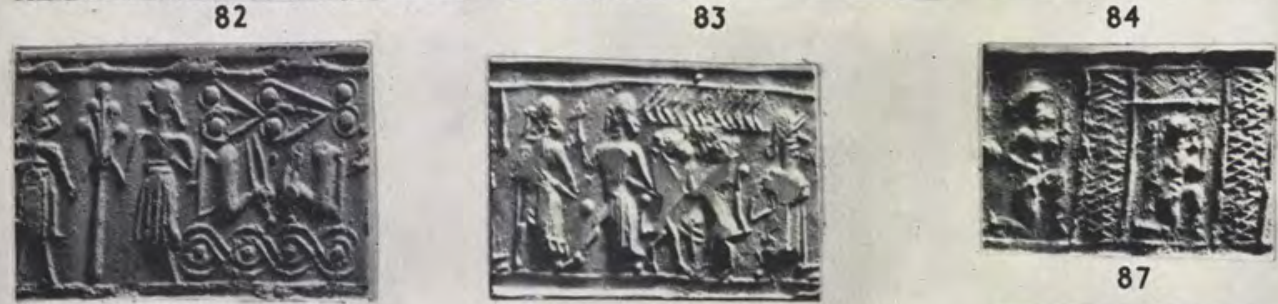

87

85

86
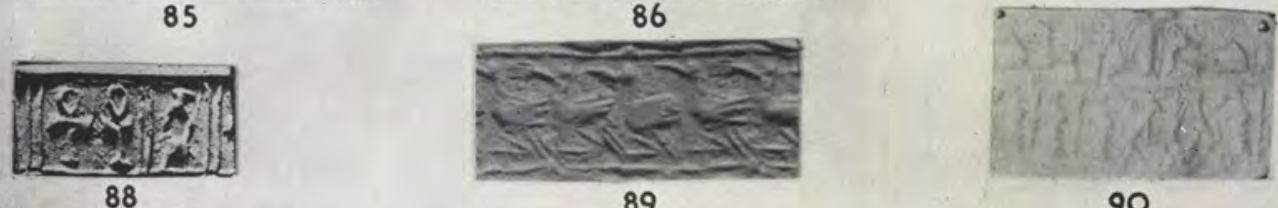

90

Seals and seal-impressions

pp. $25^{8}, 264$ 

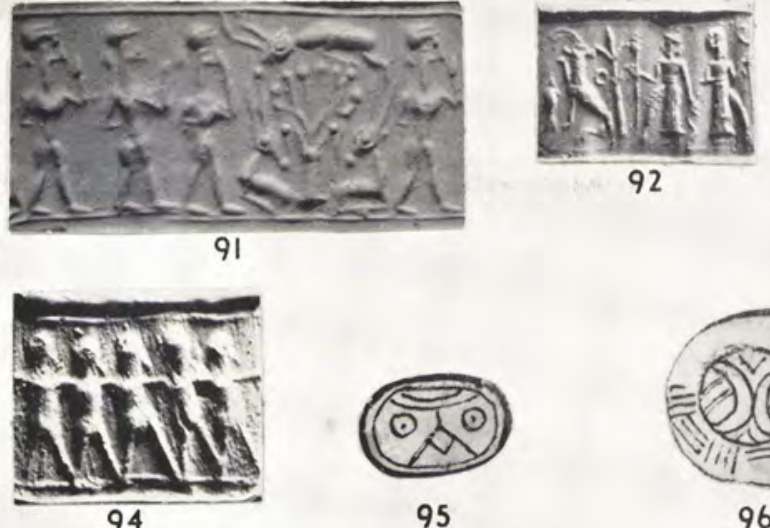

94
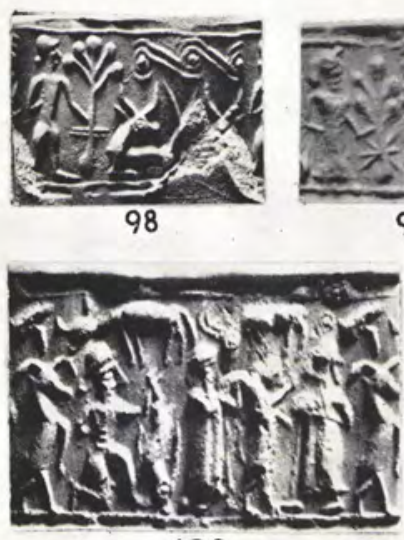

102

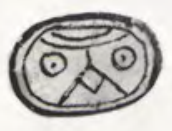

95

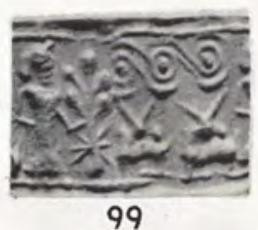

99

96

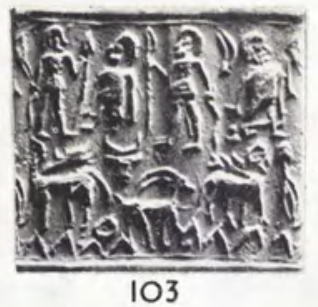

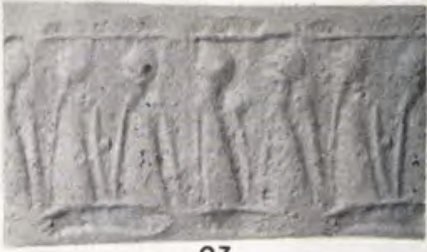

93
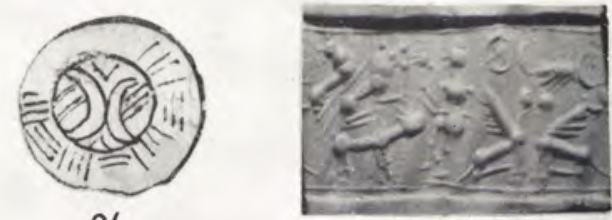

97
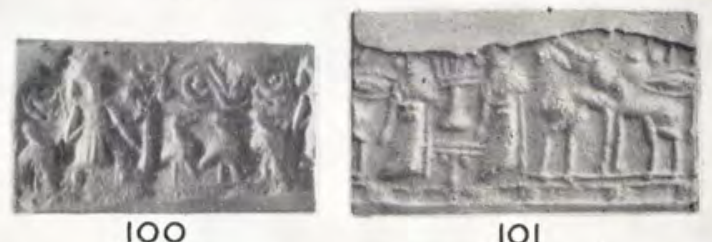

101
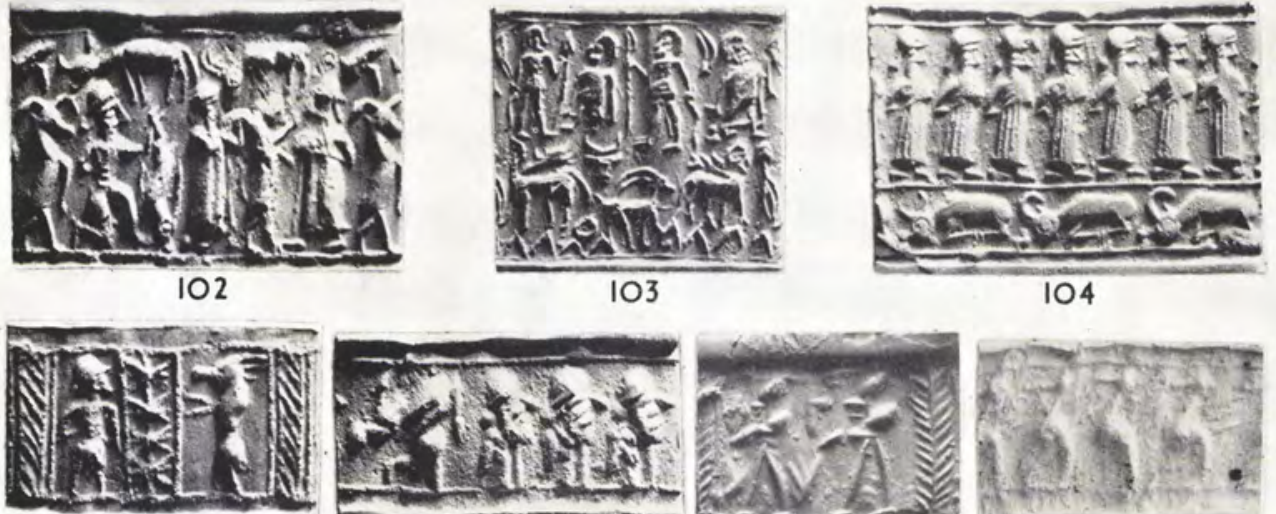

105

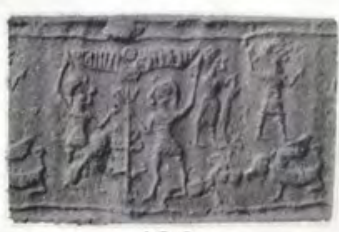

109

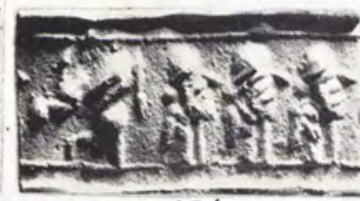

106

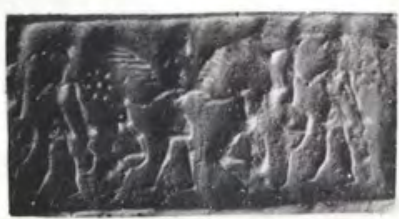

110

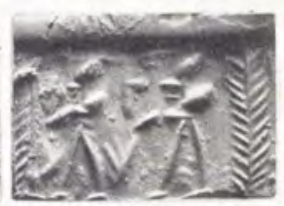

107
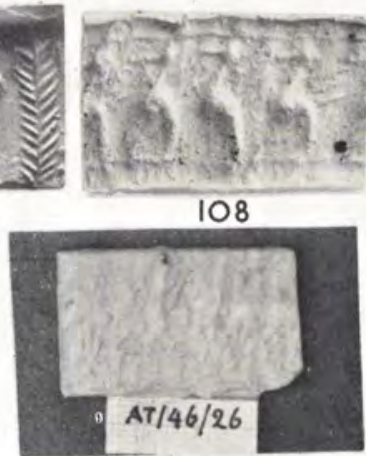

III
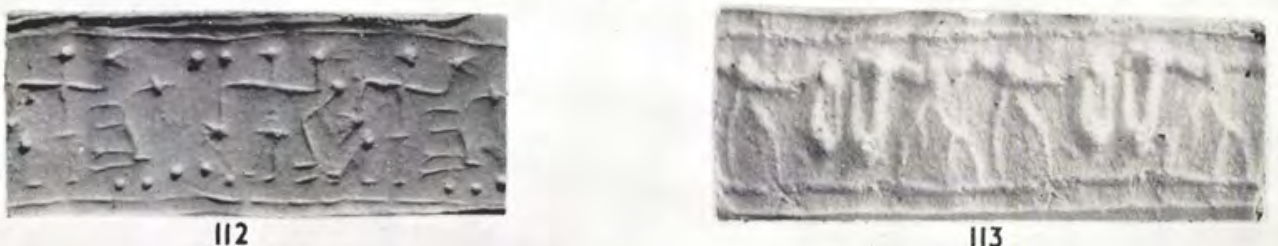

Seals and seal-impressions

pp. 258,265 


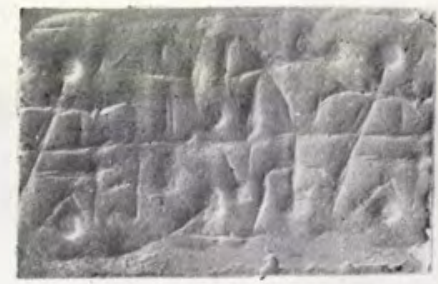

114

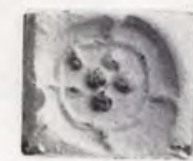

117

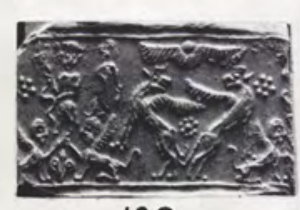

120

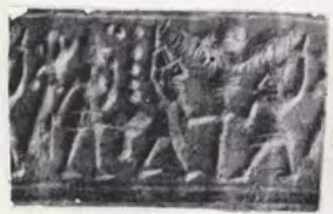

124

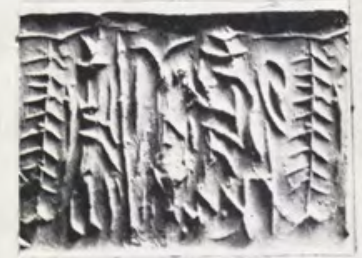

127

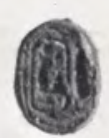

131

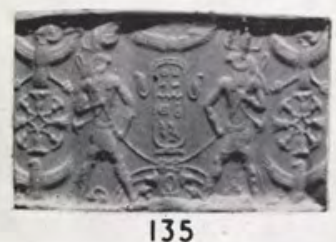

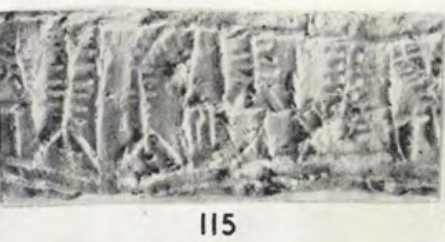

115
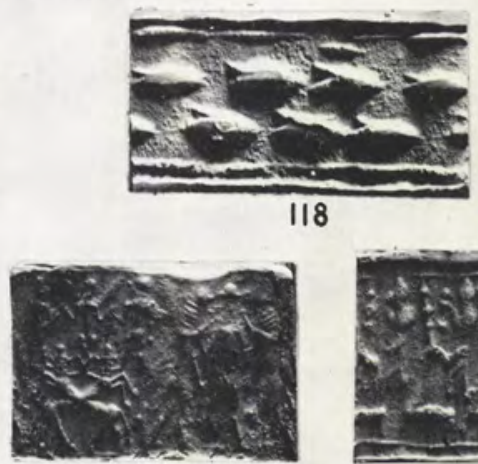

121

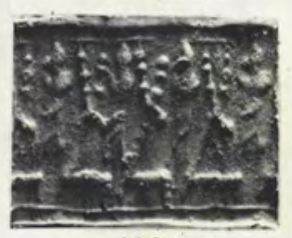

122

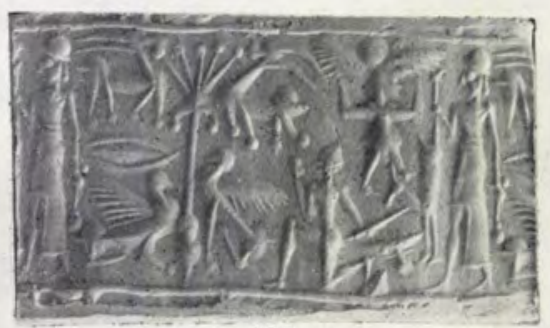

125

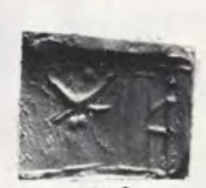

128
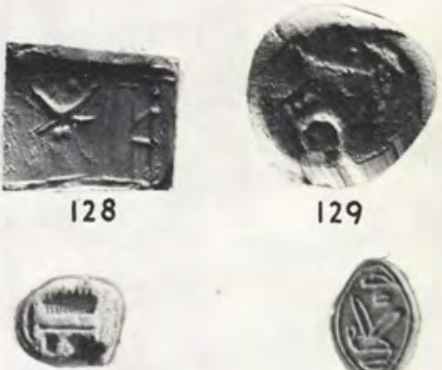

132
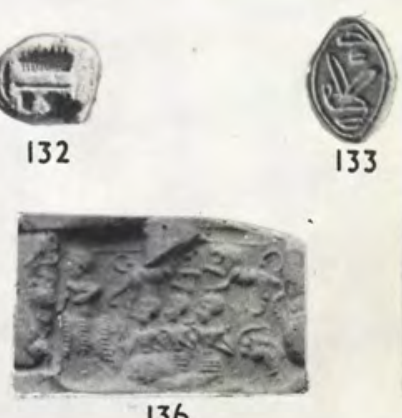

133

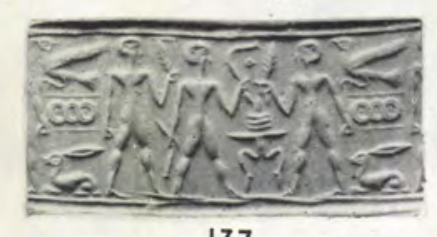

137

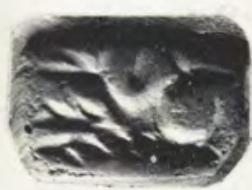

123
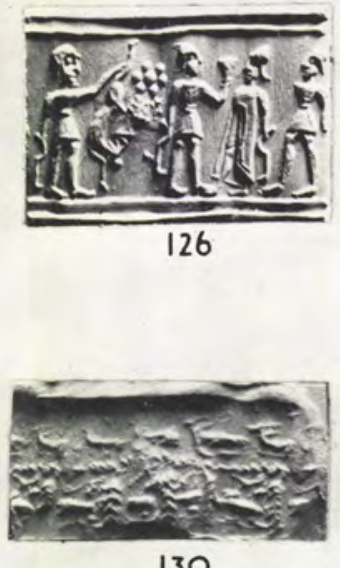

130

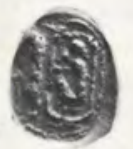

134

Seals and seal-impressions

pp. $25^{8}, 265$ 


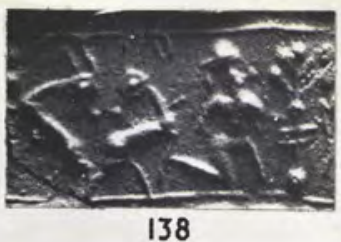

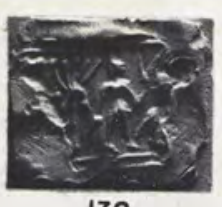

139

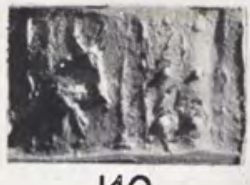

140

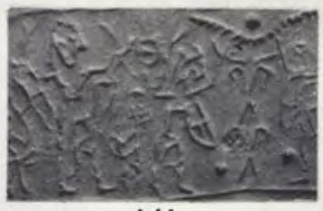

141

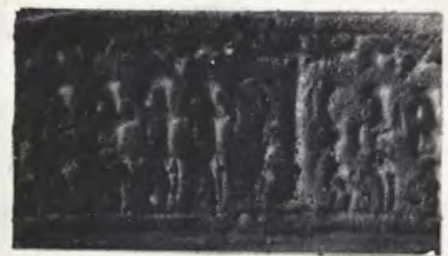

142

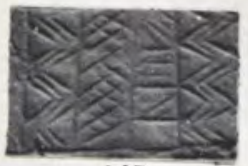

143

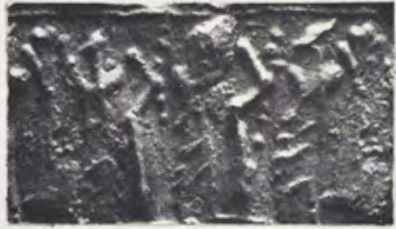

144

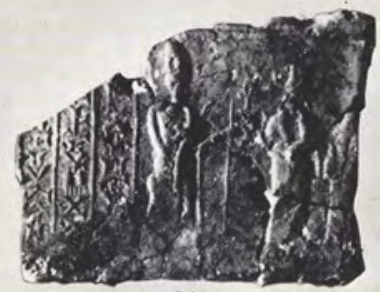

145

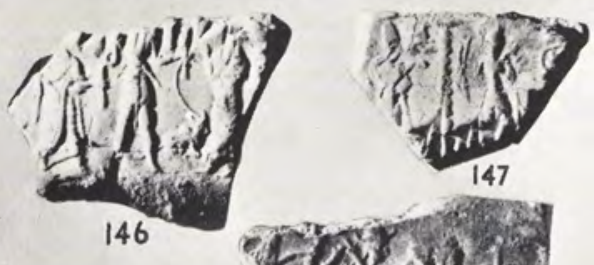

(1)

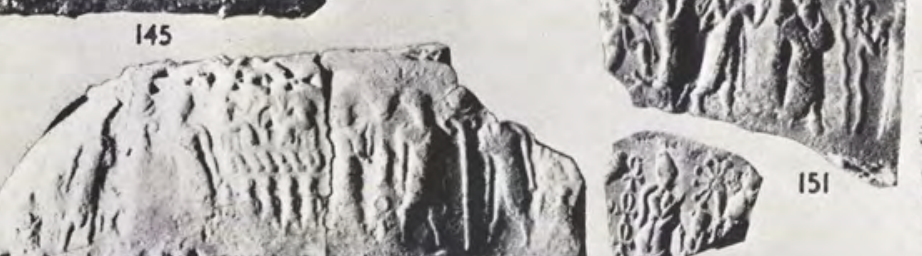

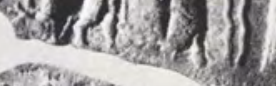

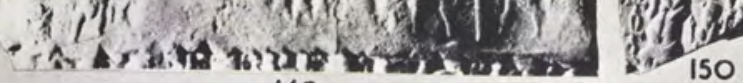
149
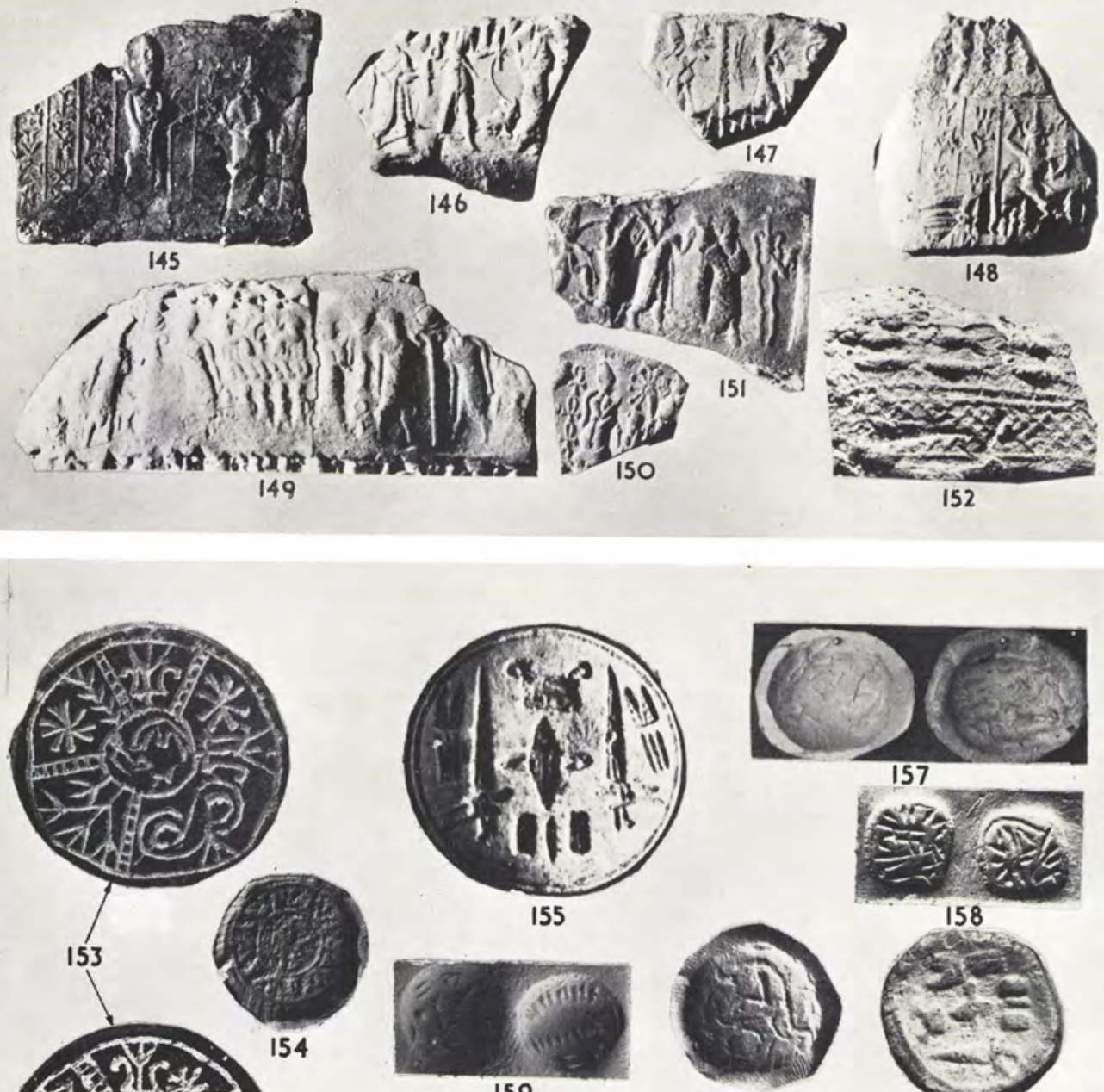

158
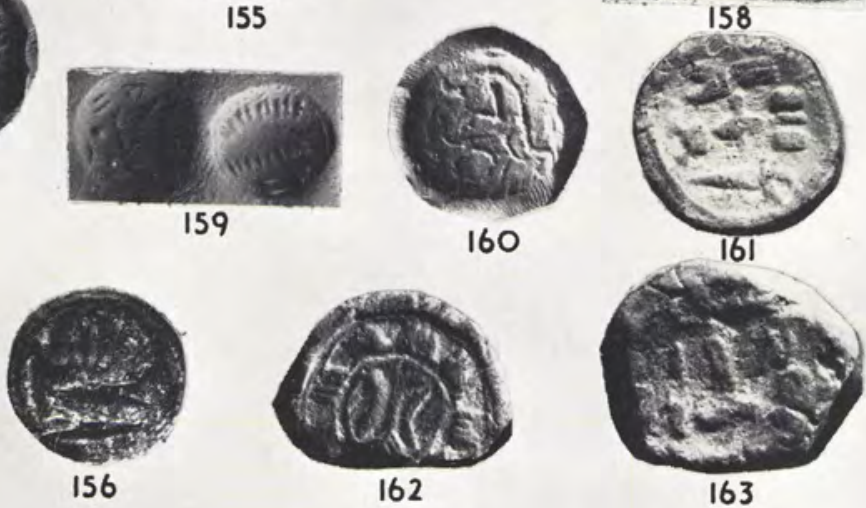

Seals and seal-impressions 
PLATE LXVIII
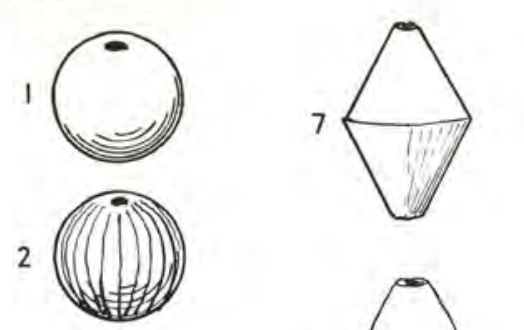

12

7
1
1

178
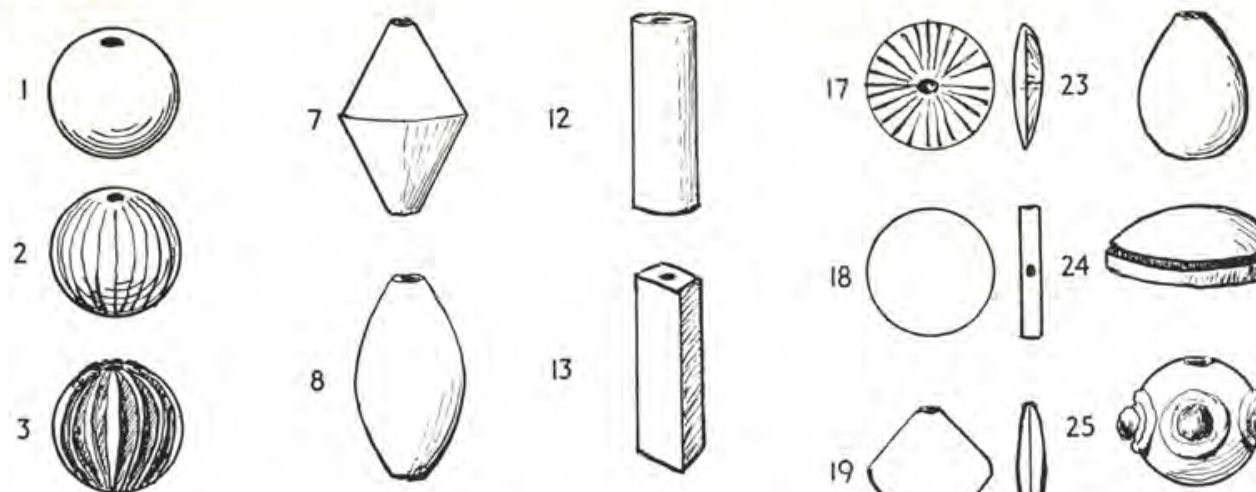

8

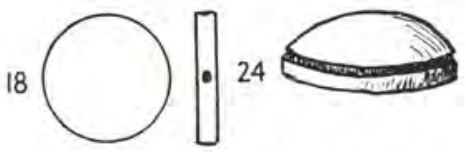

13
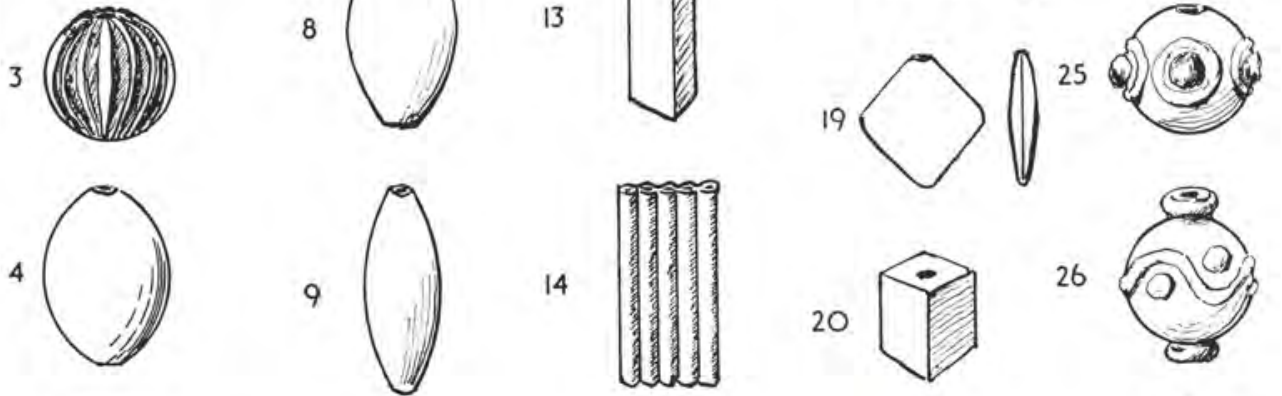

20
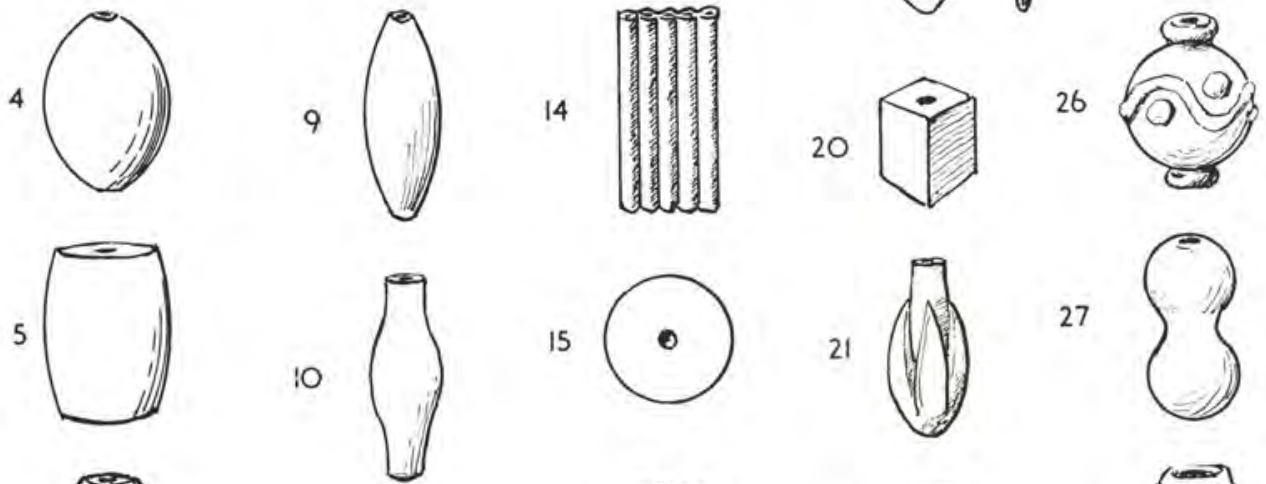

15<smiles>C1=CCCCCCCCC=C1</smiles><smiles>c1ccc(C23CC4CC(CC(C4)C2)C3)cc1</smiles>

27

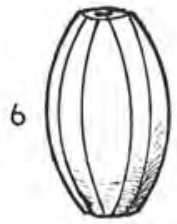

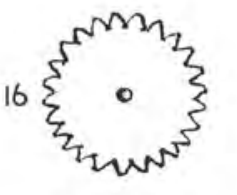

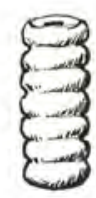

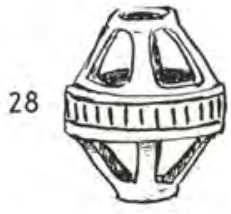

a. Beads p. 268

E谙? $\Delta \pi / 39 / 121$ 1.

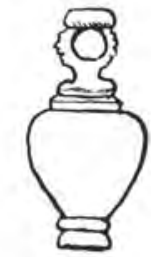

2. $\pi \pi / 47 / 170$
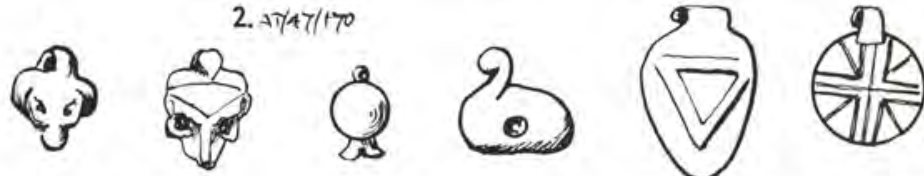

7. AT/ 3 日 $/ 2 B$
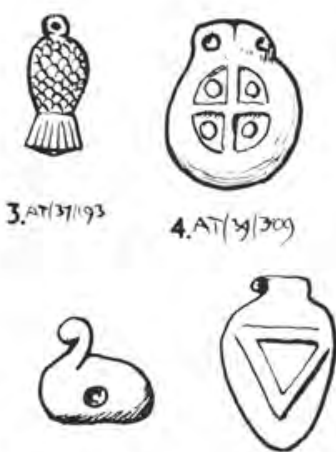

4. AT/ $3 / 300$

AT/39/24 b. Amulets p. 270

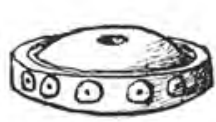

AT/37/159

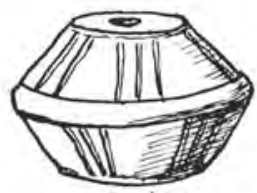

$\mathrm{Ar} / 37 / 32$
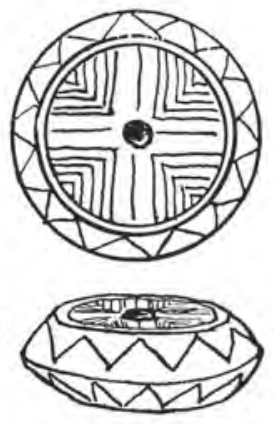

AT/37/99

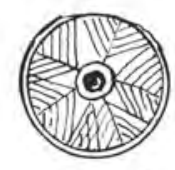

AT/37/198

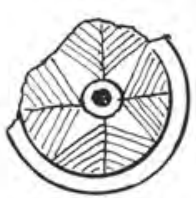

AT/37/198A

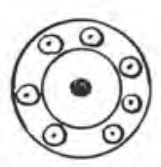
AT/37/207

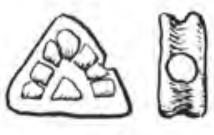

$5 . A T / 38 / 165$
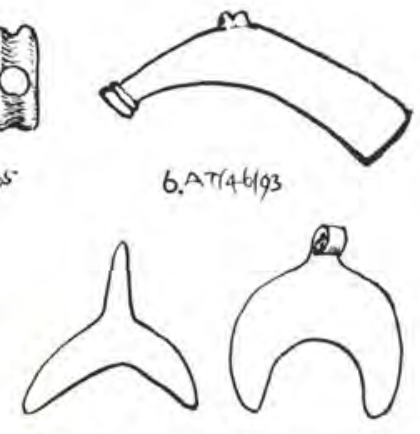

13. $A T / 39 / 212$

14. AT/36/215

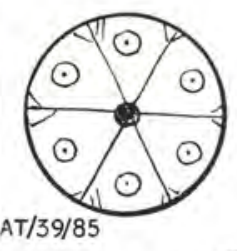

\section{c. Spindle-whorls}
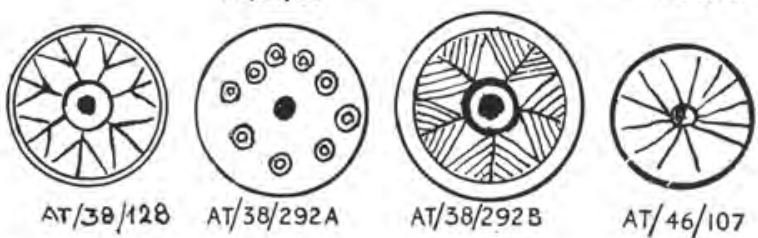


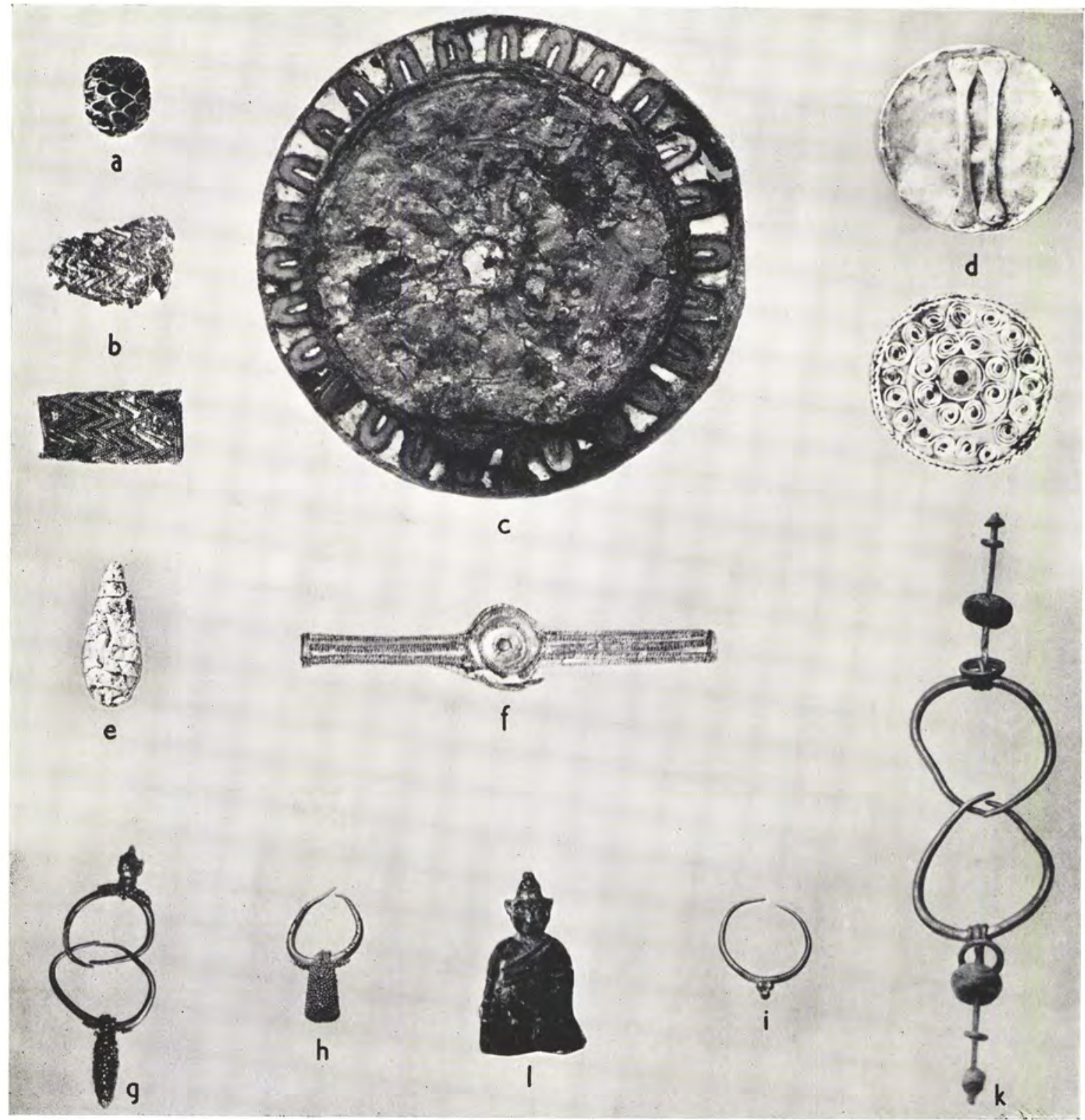

a. AT/37/221; b. Two fragments, AT/37/205, 204; c. AT/35/1 I $; d$. AT/38/52, front and back view; e. AT/38/103; f. AT/46/18I; g. AT/39/9I; h. AT/38/224; j. AT/39/95; k. AT/38/163; l. AT $/ 46 / 20$

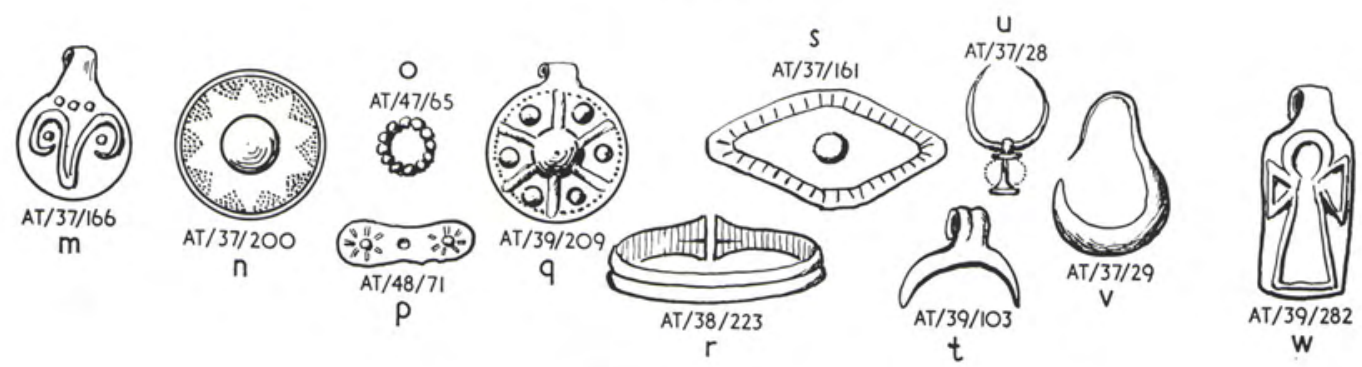

Gold objects, \&c. 


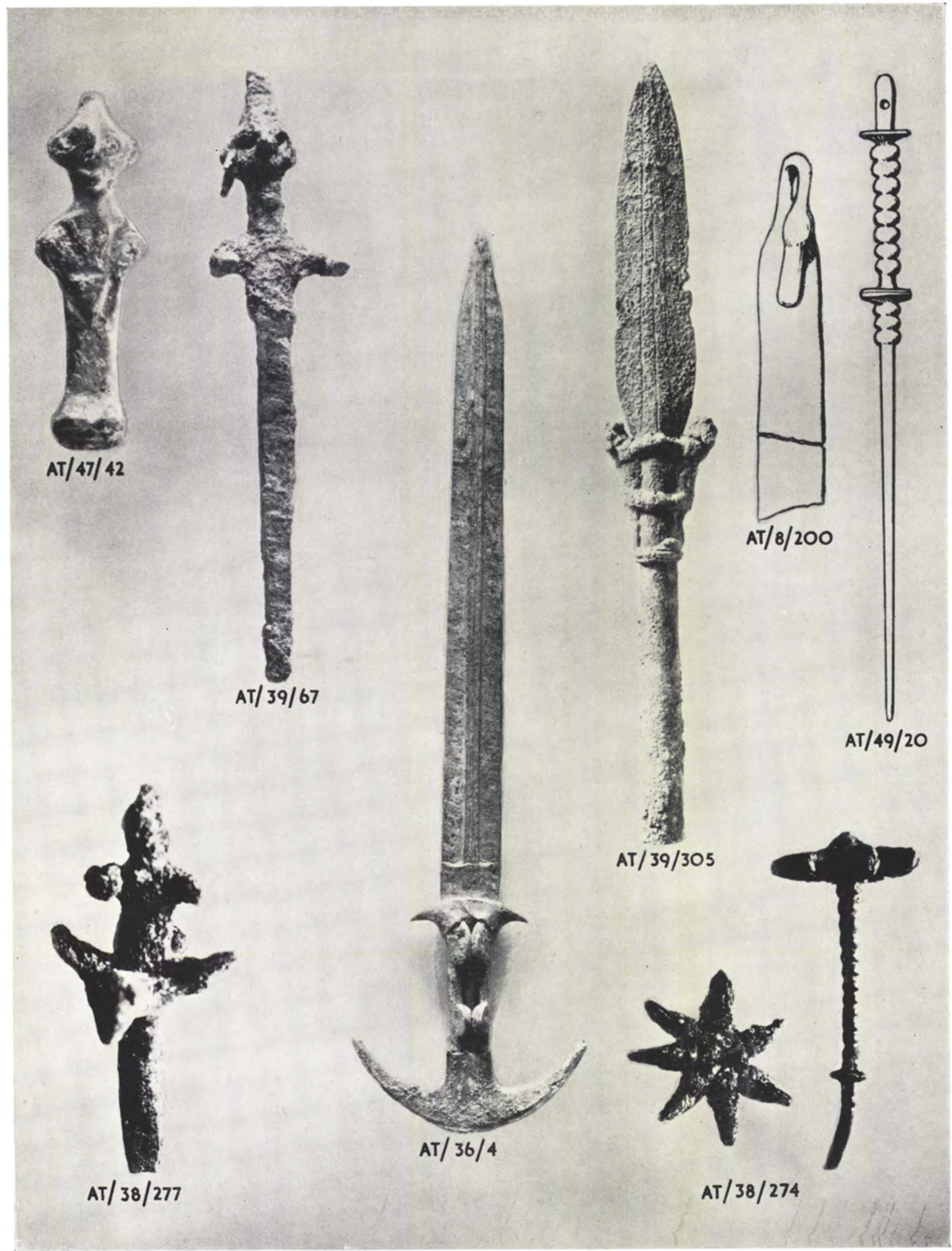

Bronze objects 
PLATE LXXI

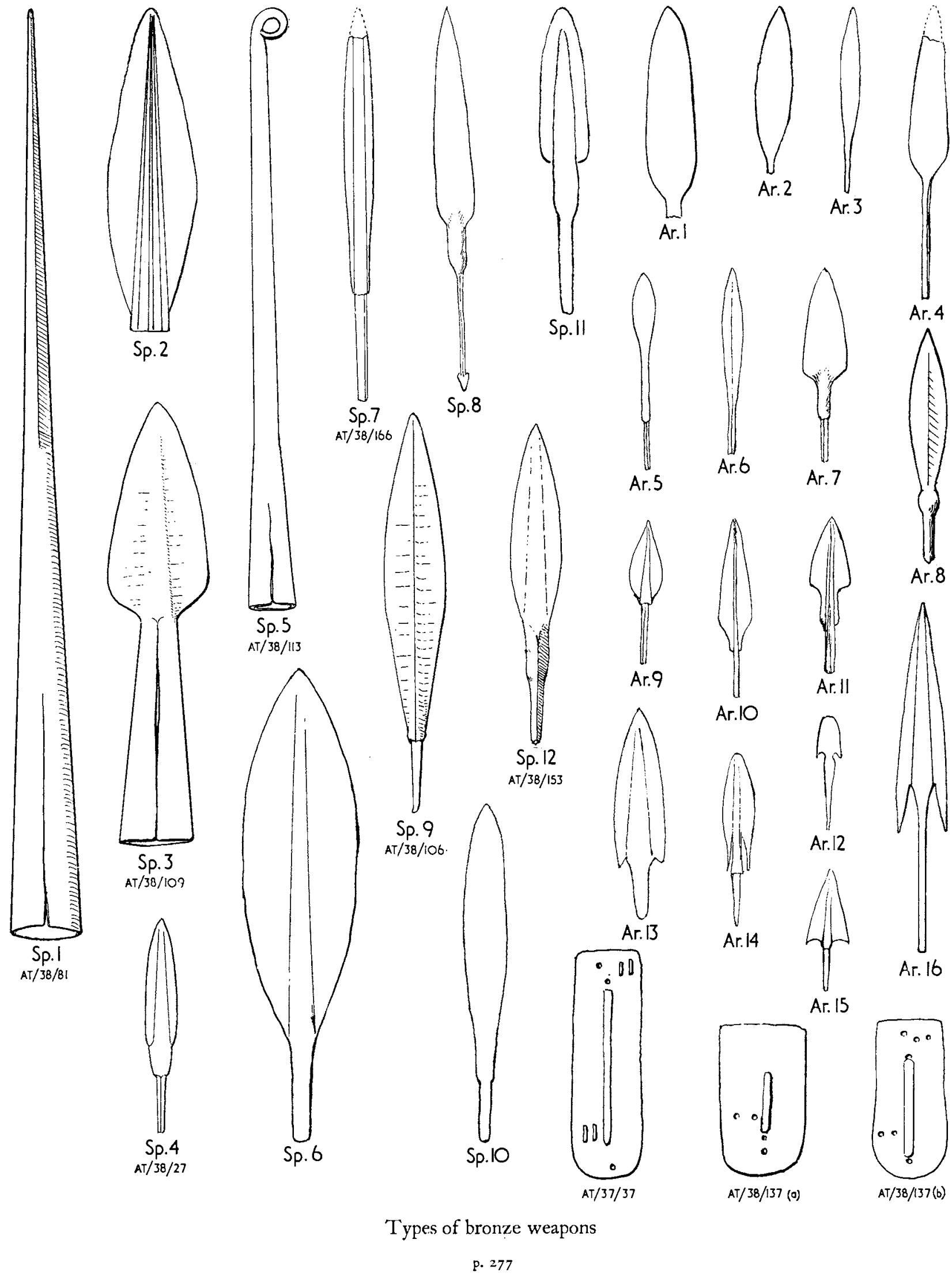




\section{PLATE LXXII}
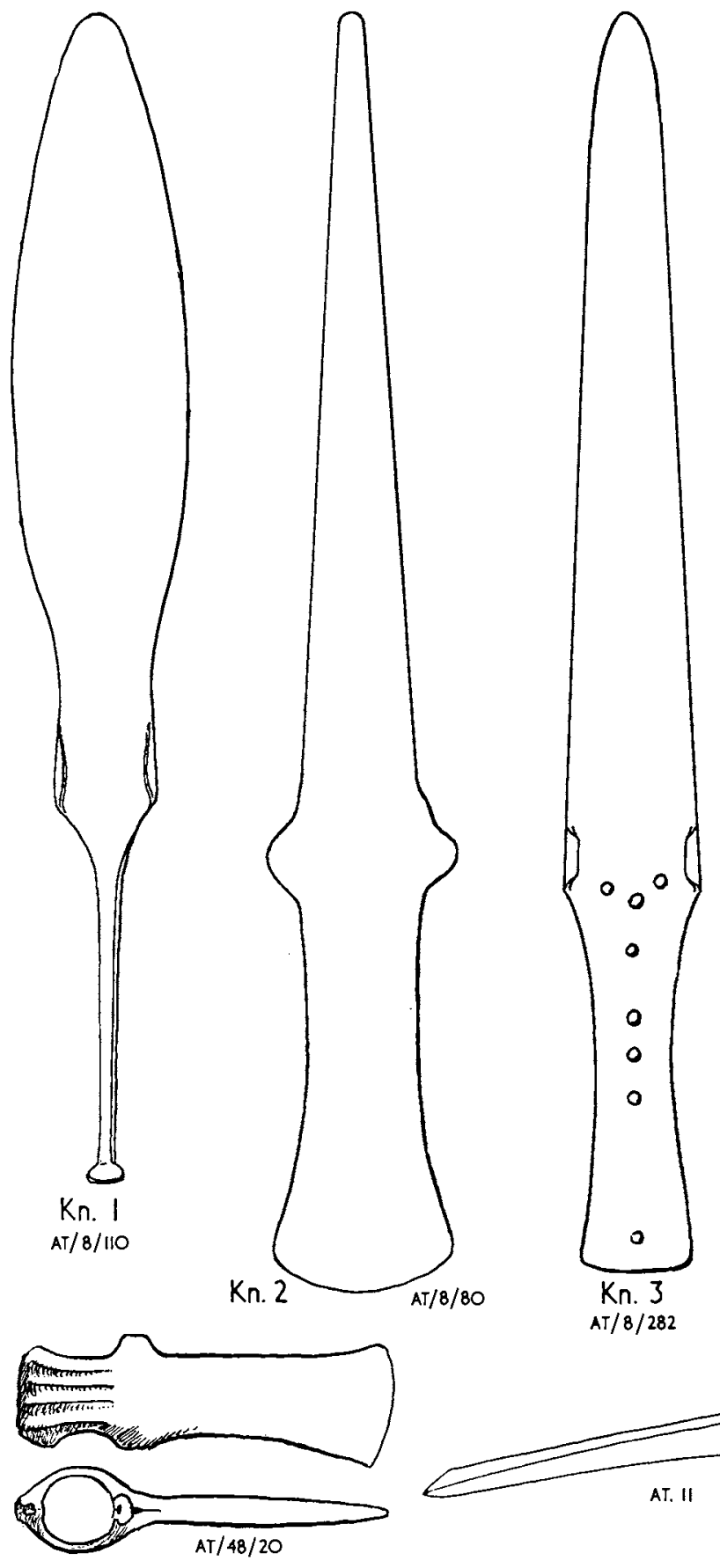

AT $/ 8 / 80$
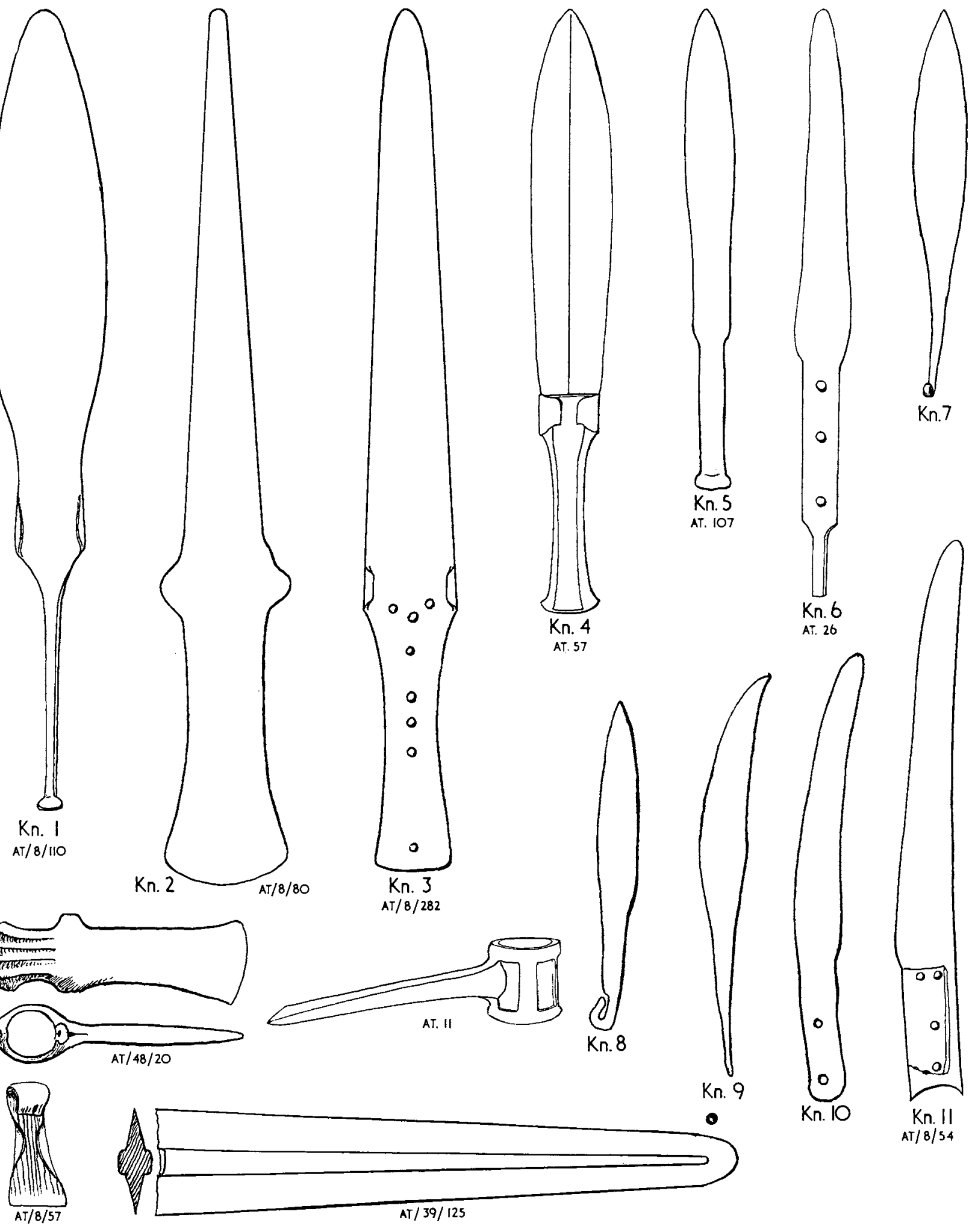

Types of bronze tools and weapons

p. 277 

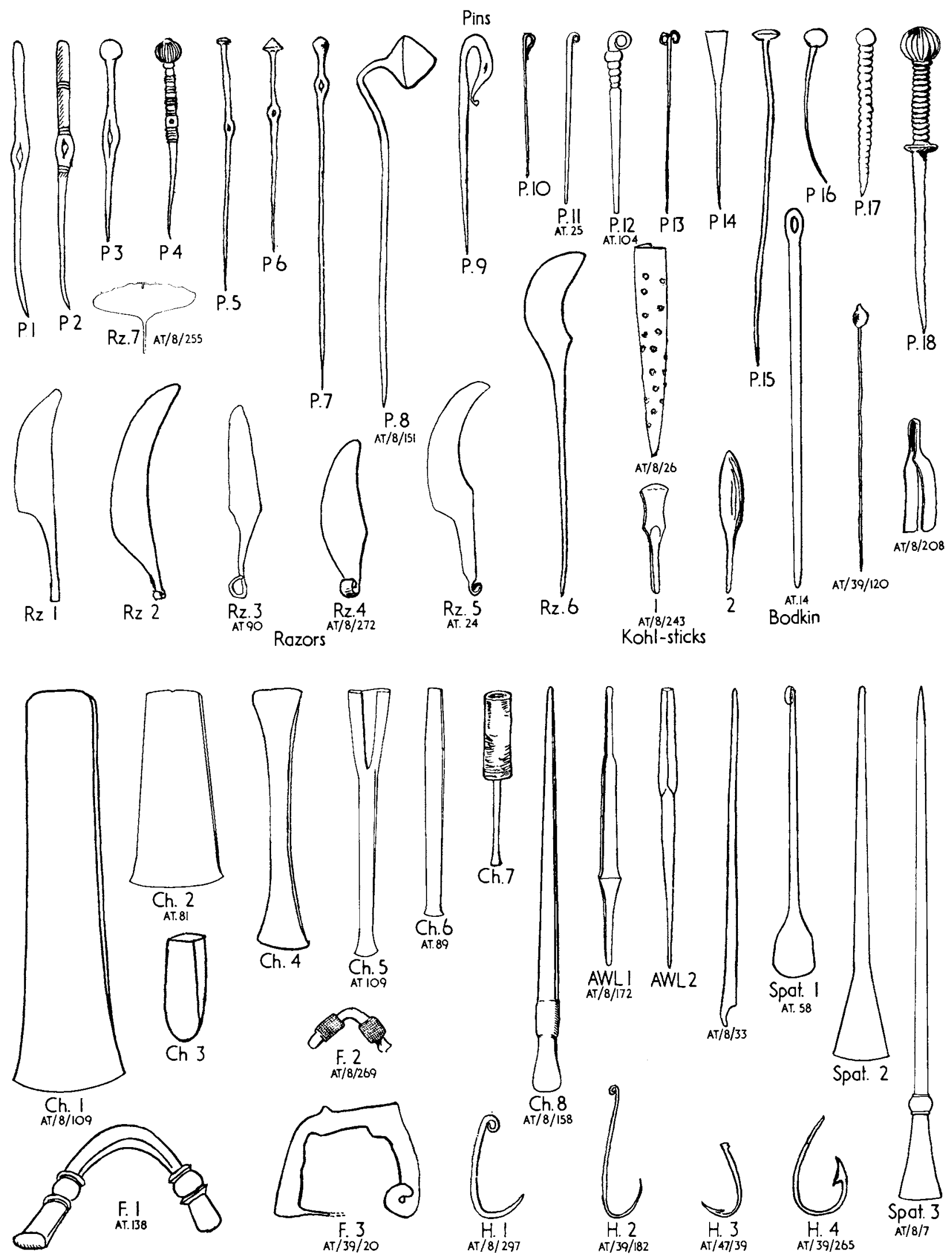

Types of bronze tools, \&c. 

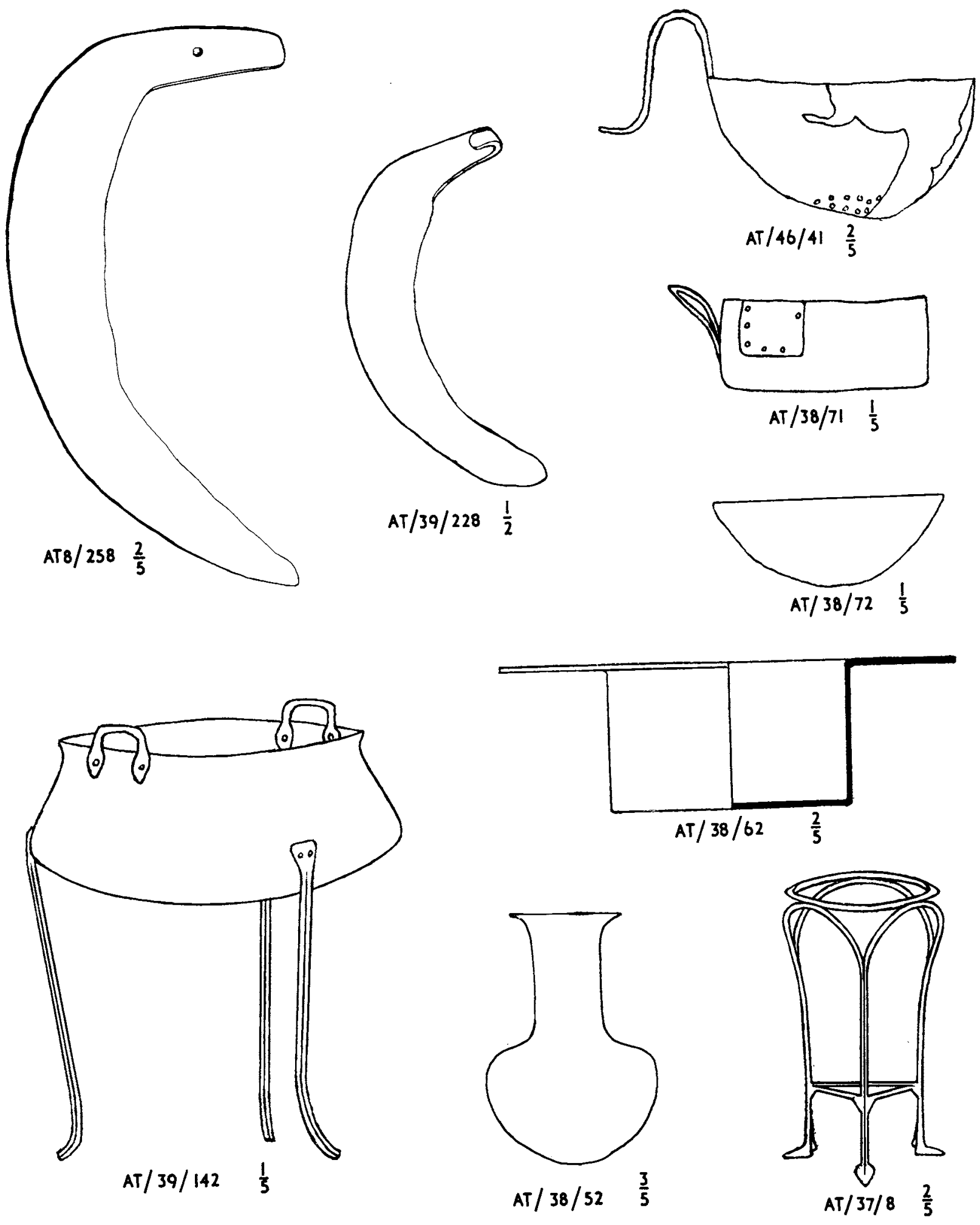

Sickles and types of bronze vessels 


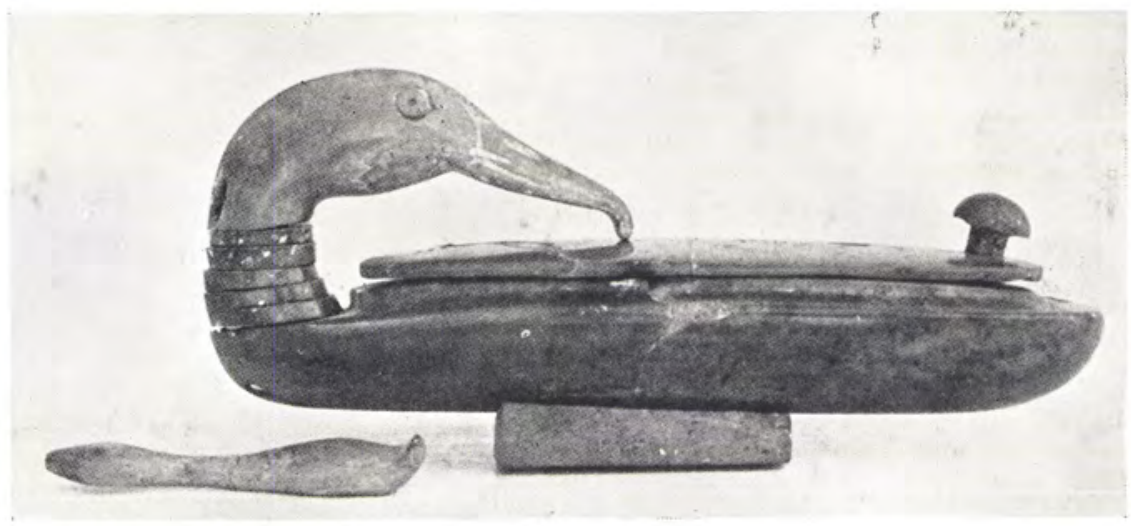

a. $\mathrm{AT} / 37 / 236$

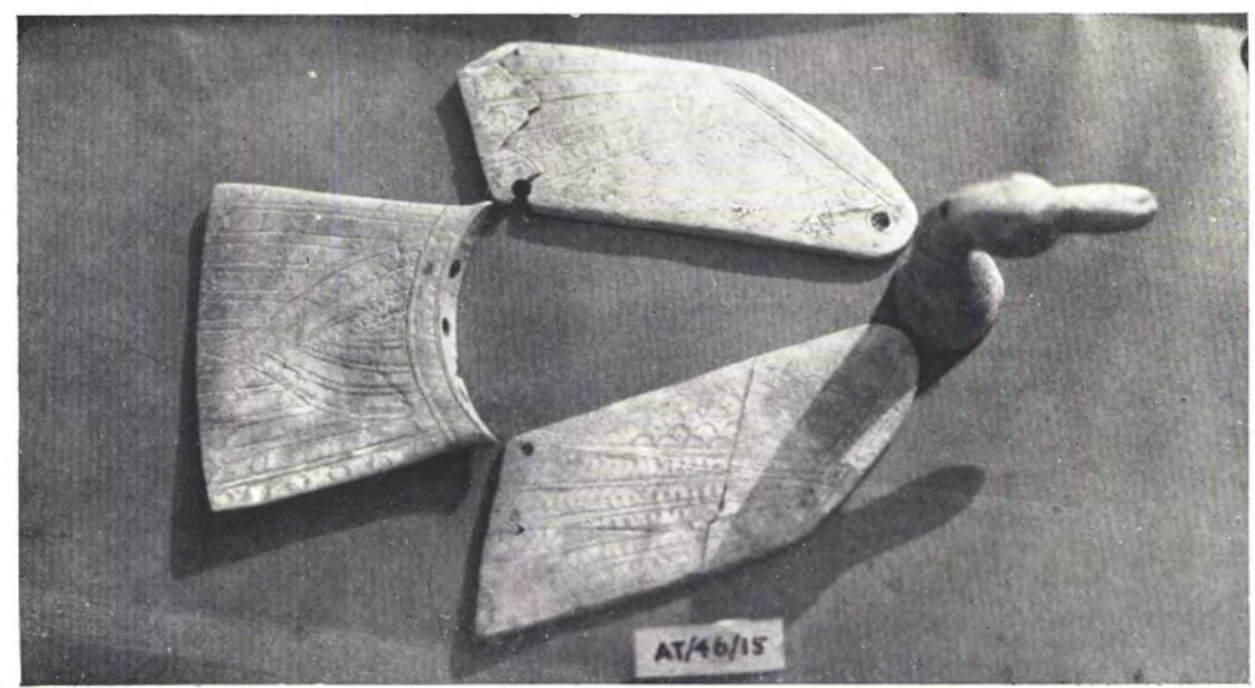

b. AT/46/15

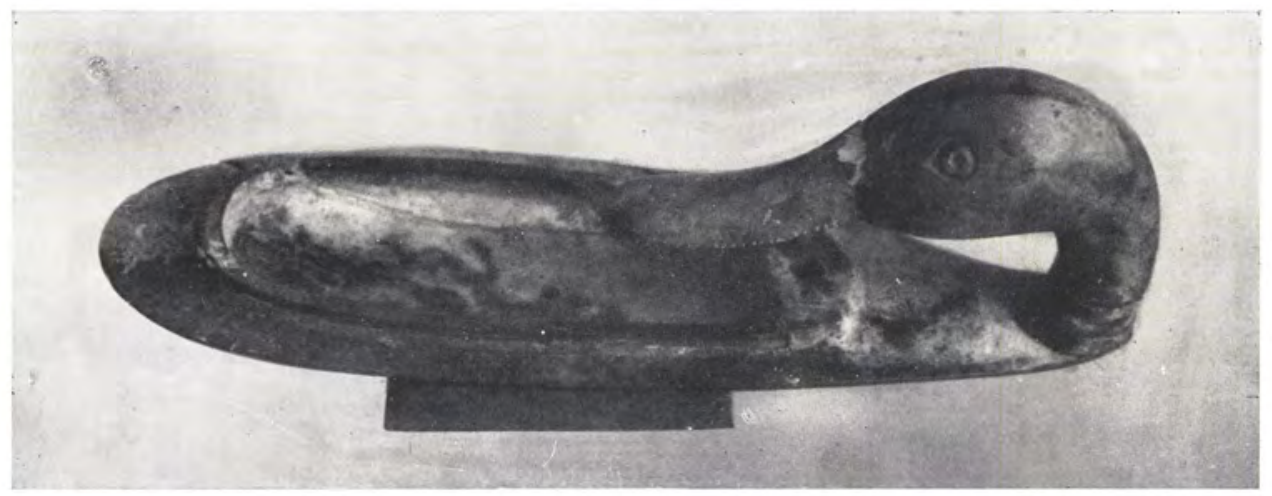

c. $\mathrm{AT} / 38 / 117$

Ivory toilet-boxes

p. 289 


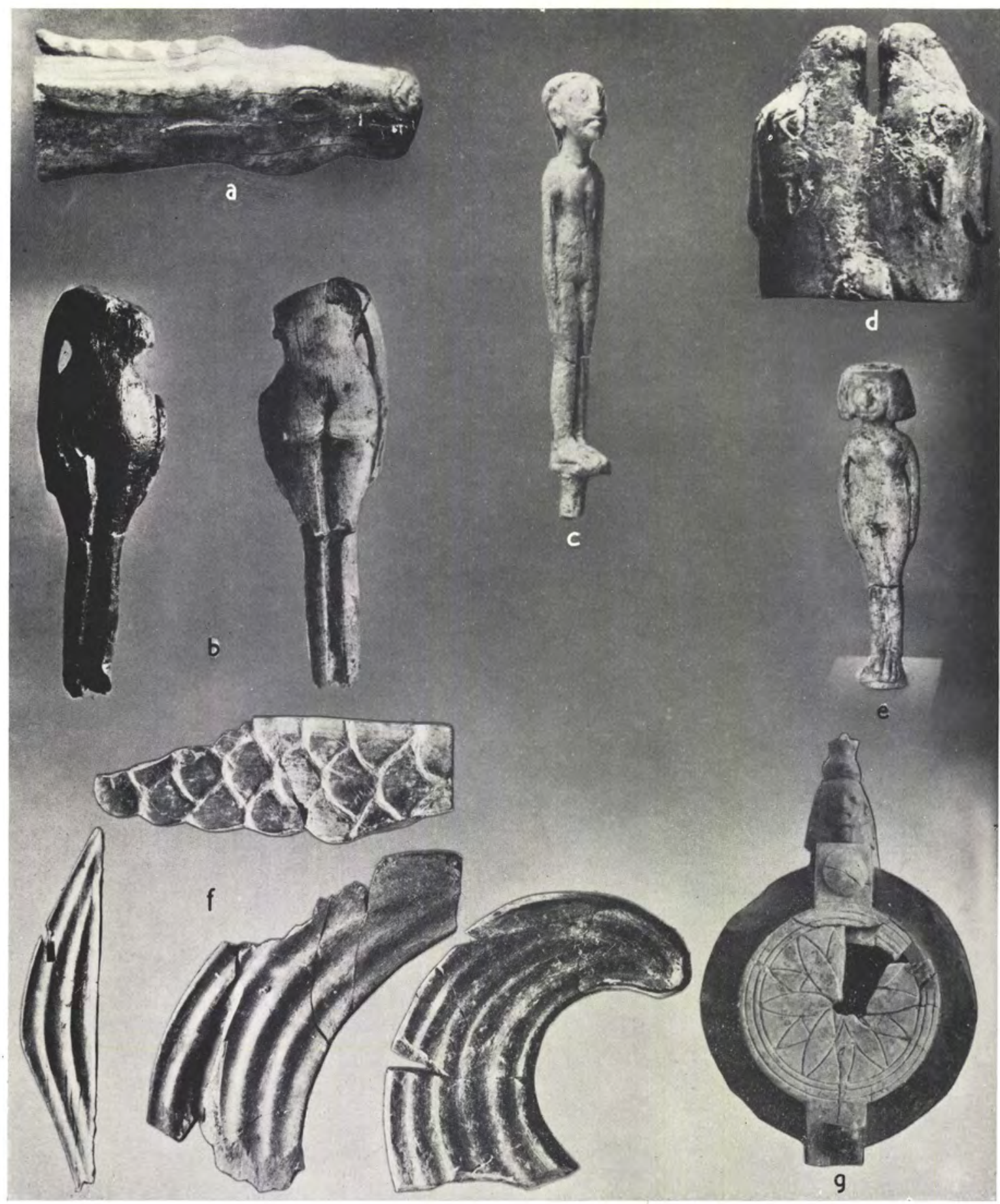

a. $\mathrm{AT} / 48 / 62 ; b . \mathrm{AT} / 38 / 152 ; c . \mathrm{AT} / 38 / 38 ; d . \mathrm{AT} / 47 / 24 ; c . \mathrm{AT} / 46 / 8 ; f . \mathrm{AT} / 48 / 26$; g. AT/38/74

Objects in bone and ivory pp. 289 sqq. 
PLATE LXXVII
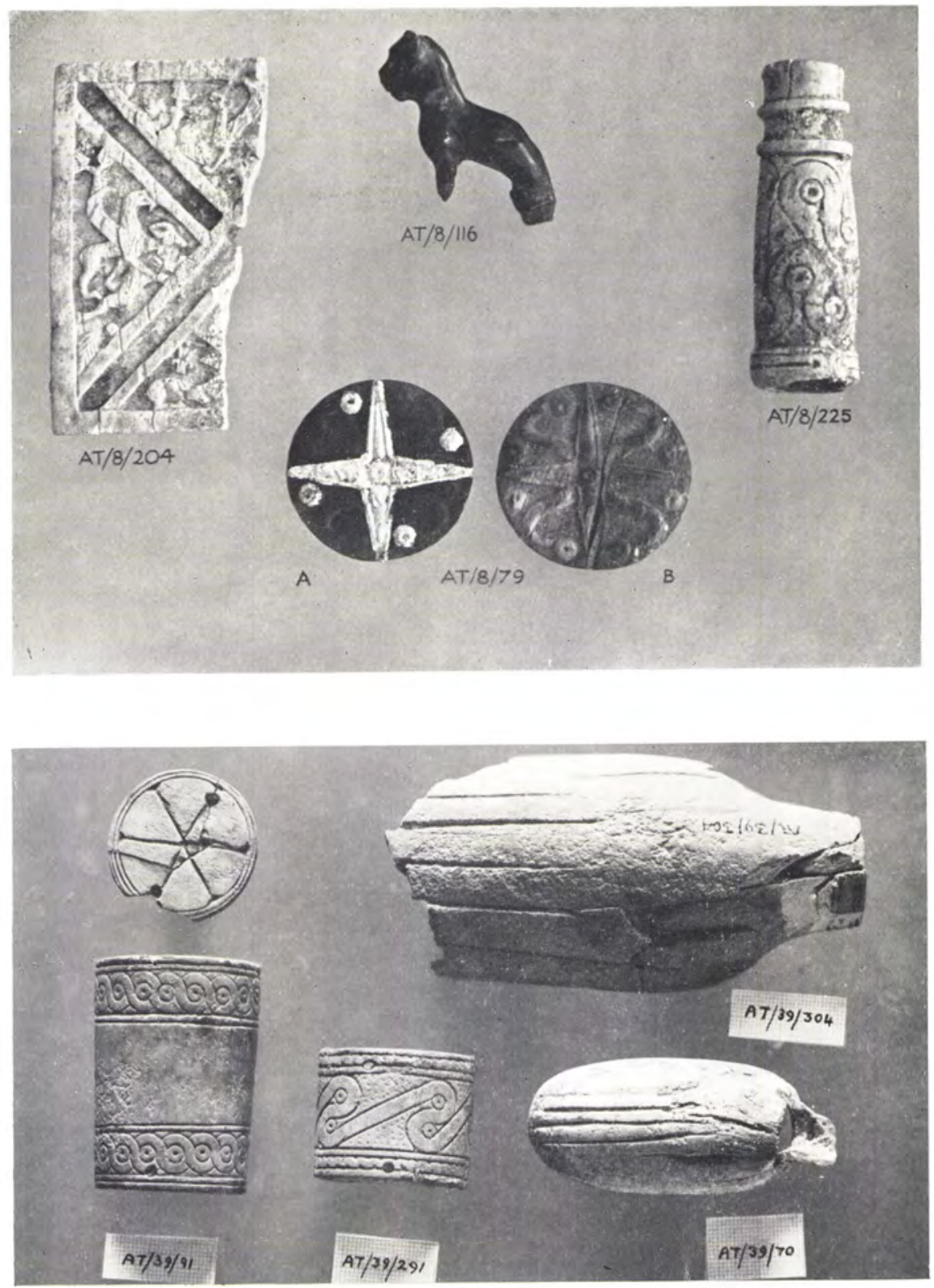

Objects in bone and ivory

pp. 290 sqq. 


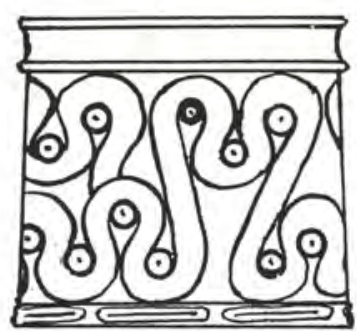

C. ${ }^{A T} / 38 / 225$

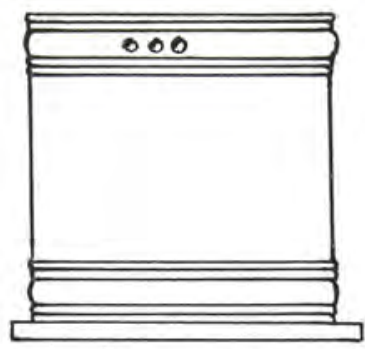

b. $A T / 38 / 73$

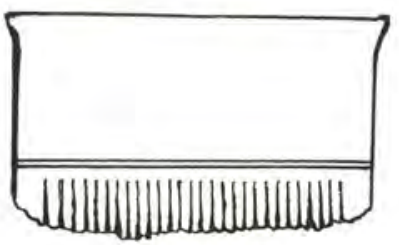

C. $A T / 47 /|3|$

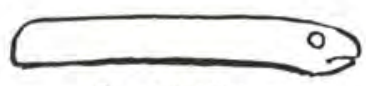

e. $A T / 38 / 94$
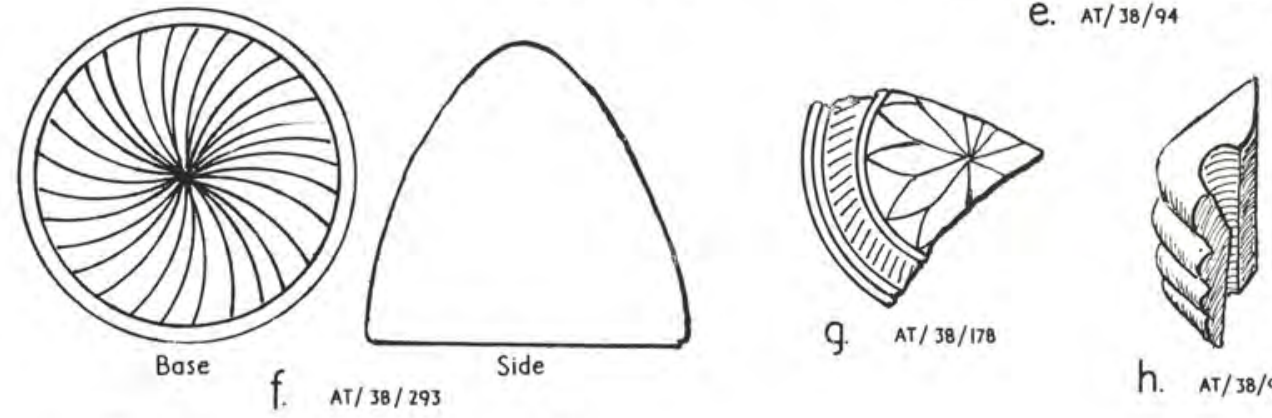

h.

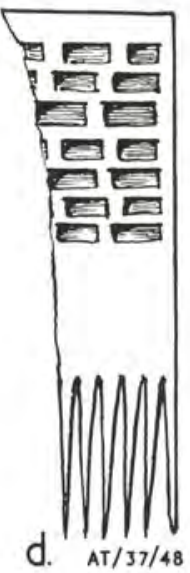

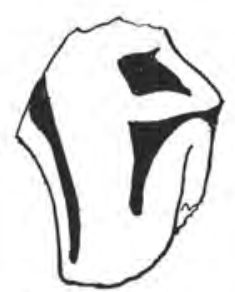

i. $A T / 47 / 130$

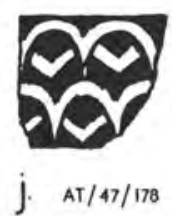

J. $A T / 47 / 178$
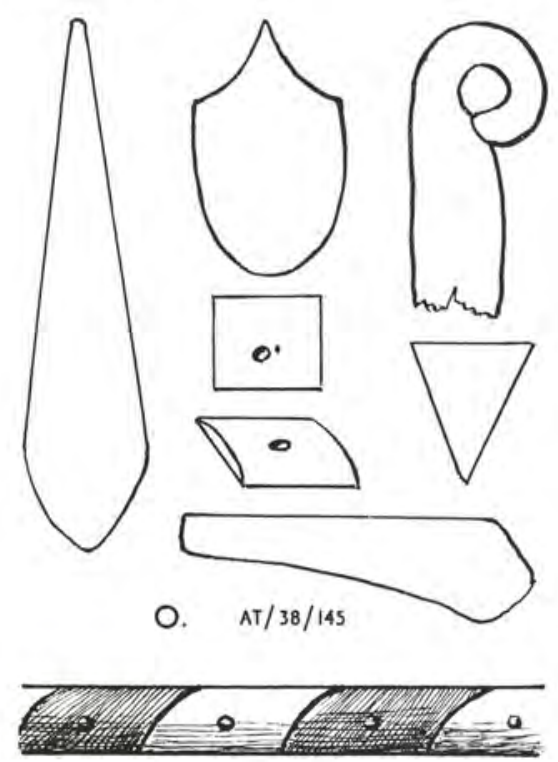

P. AT $/ 47 / 154$

O. $A T / 38 / 145$

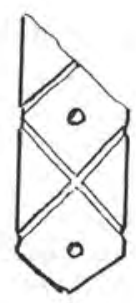

A

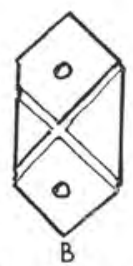

k. $A T / 39 / 214$
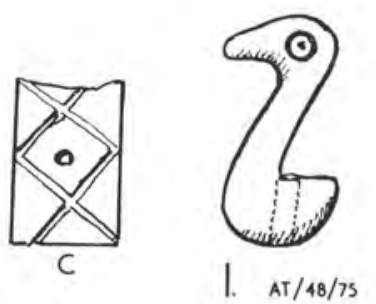

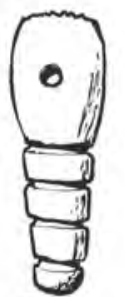

Front

m. ${ }_{\text {AT } / 38 / 13}$

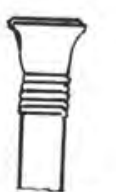

n. $A T / 48 / 14$

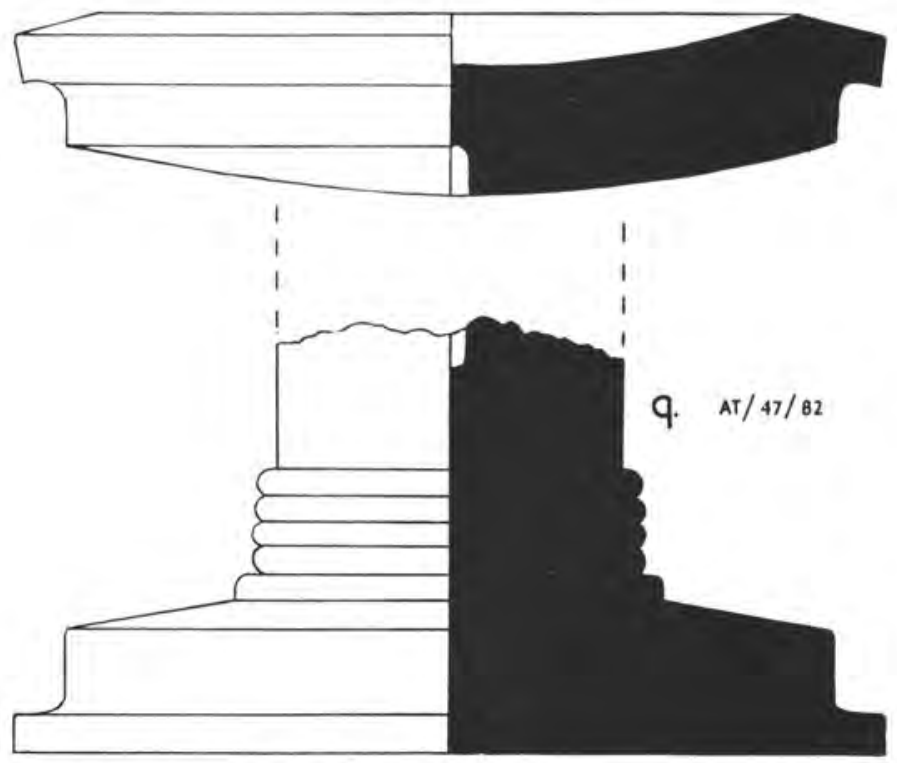

Ivory, bone, and stone objects

Scale $\frac{2}{3}$ rd except for $q$, which has a diameter of $0.65 \mathrm{~m}$. pp. 290,291 , and 294 

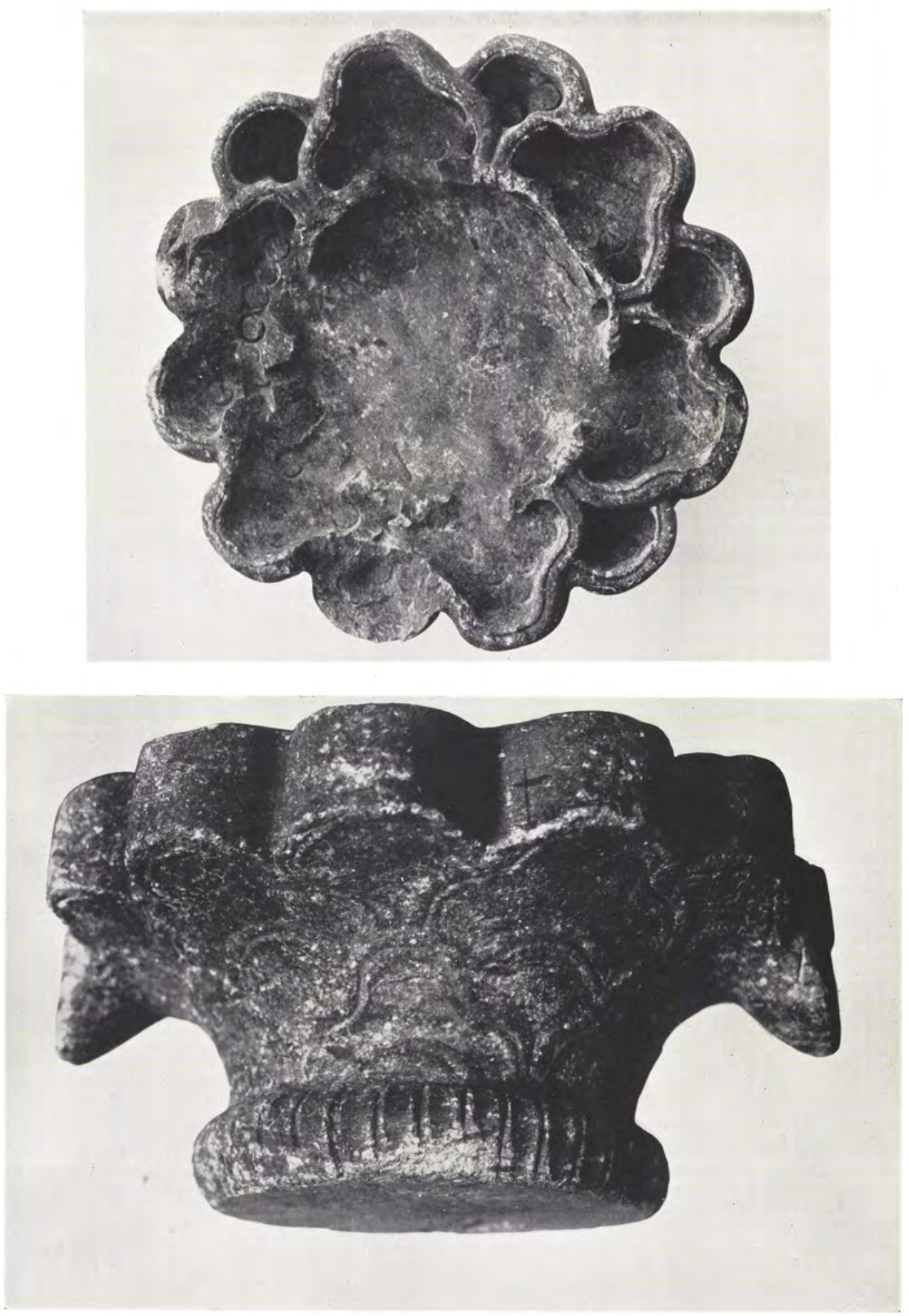

Red marble lamp of Cretan style. AT/39/280

p. 294 

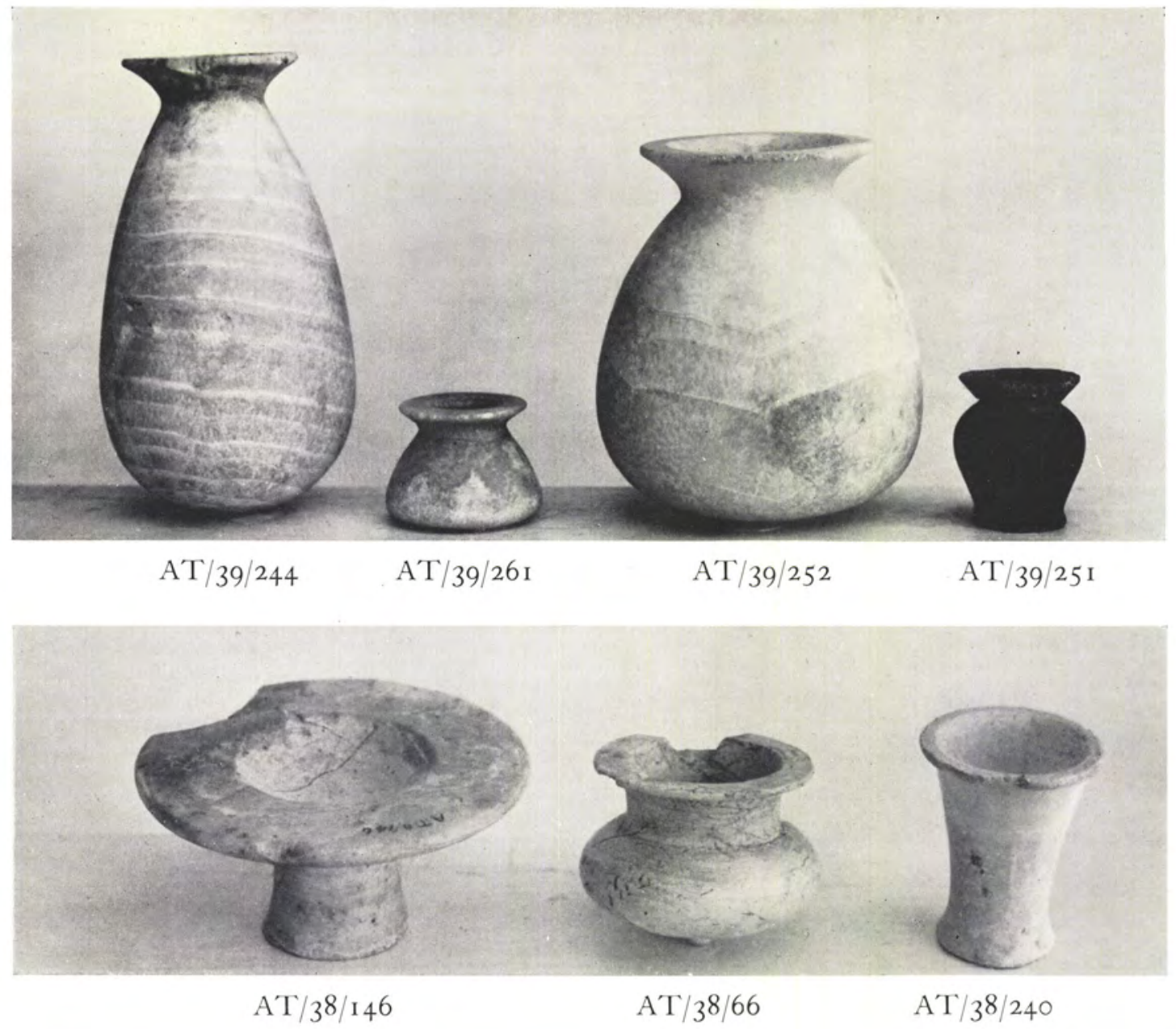

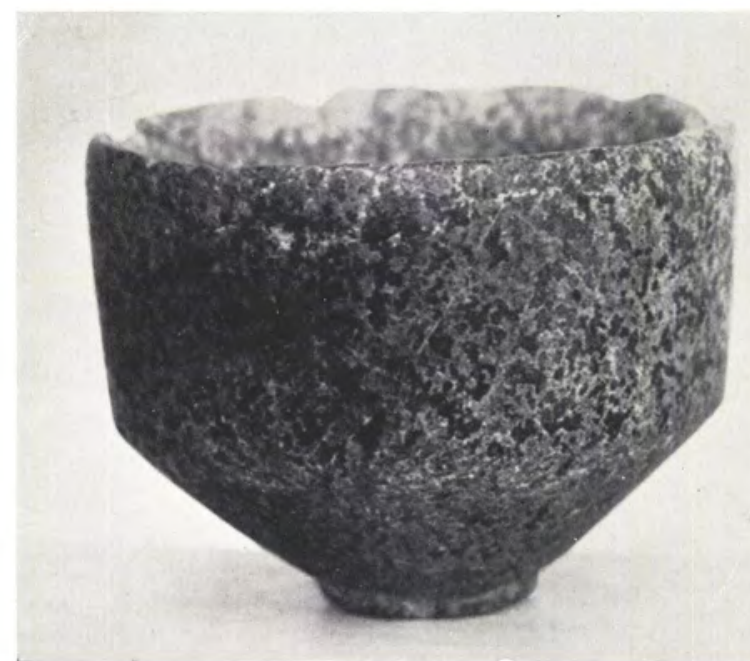

AT/39/1 47

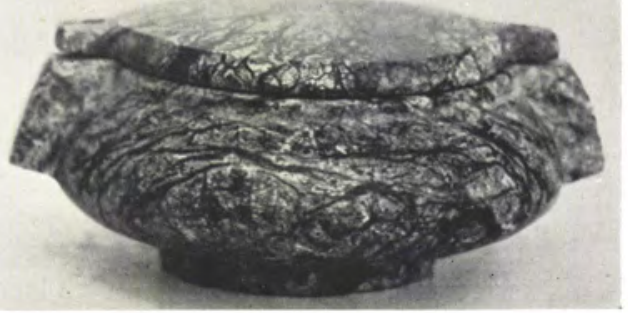

AT/39/1 24

Stone vases

p. 295 
PLATE LXXXI
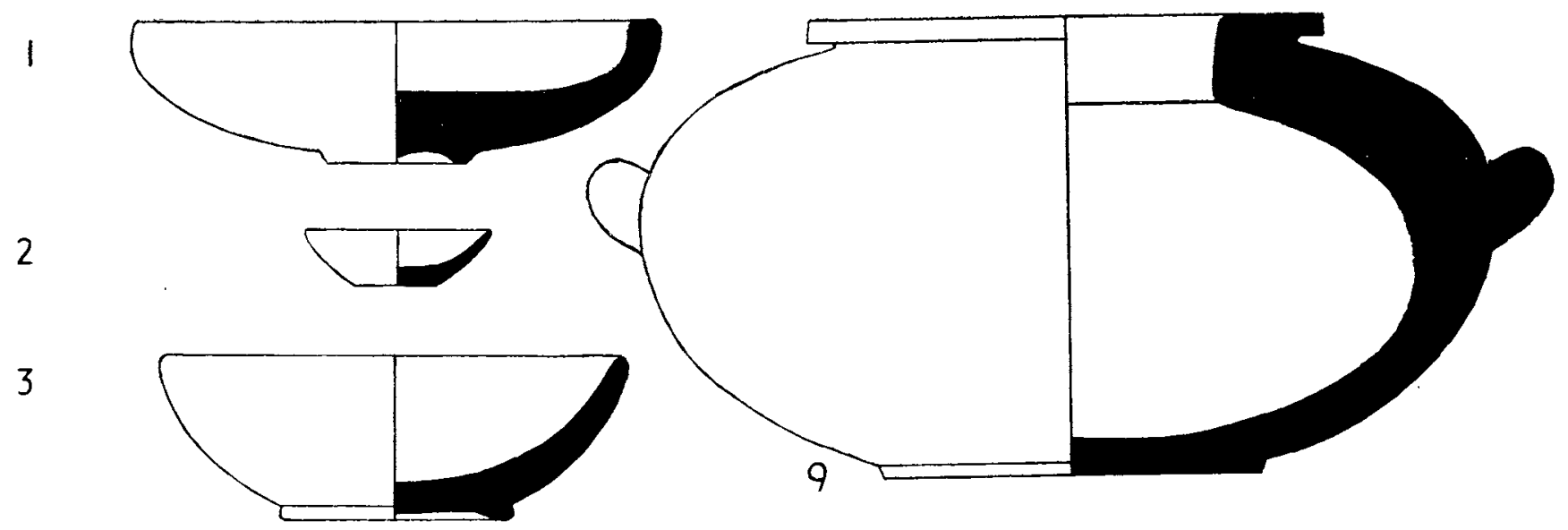

4

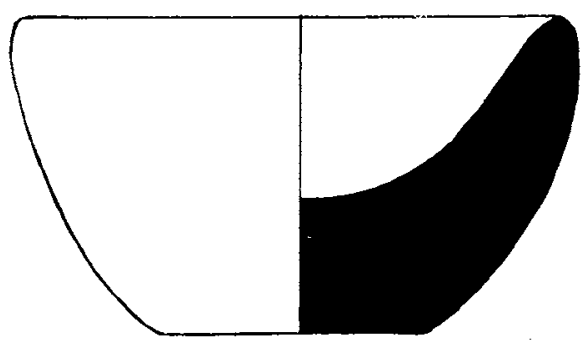

10

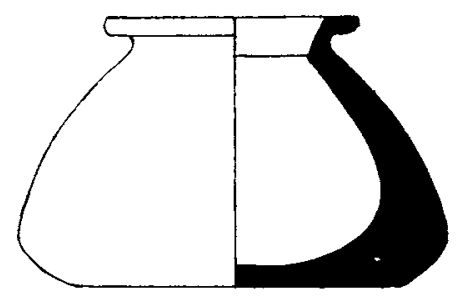

11

5
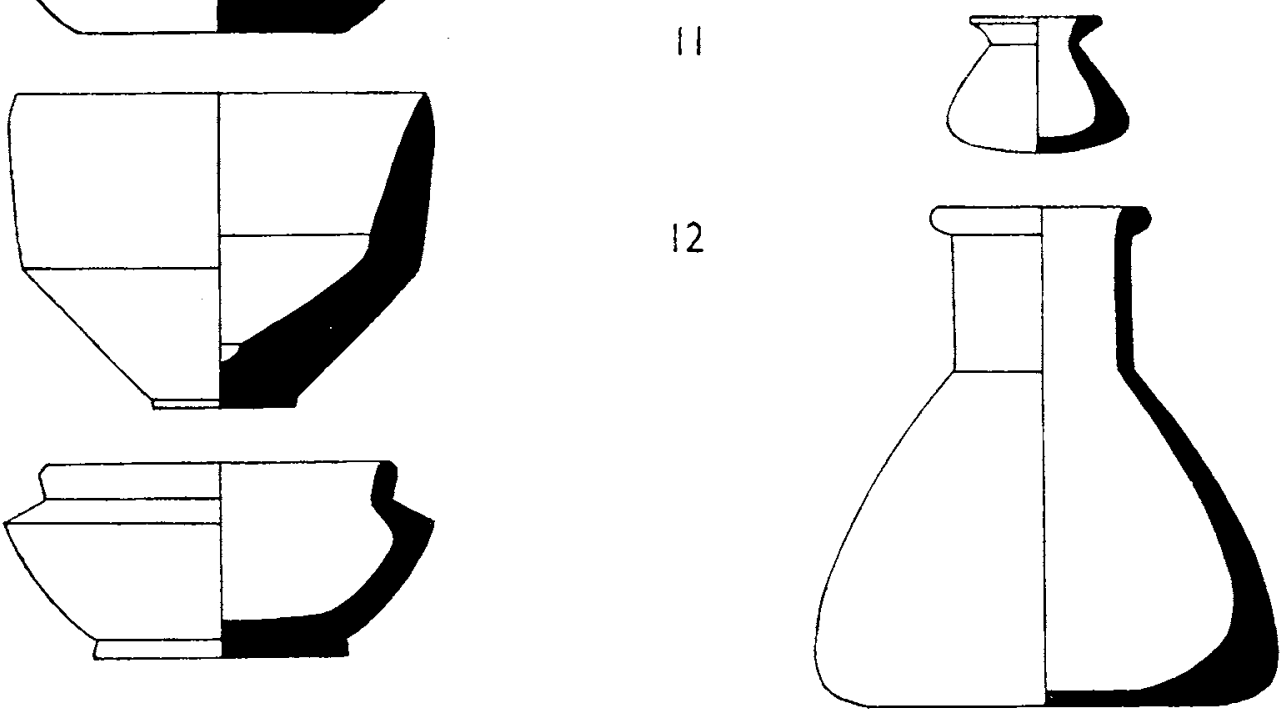

12

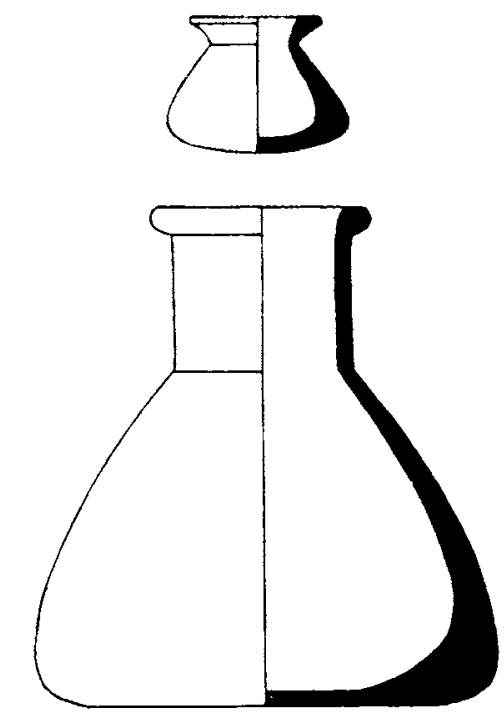

7

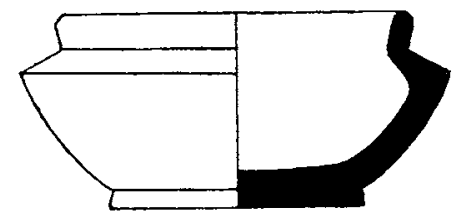

6
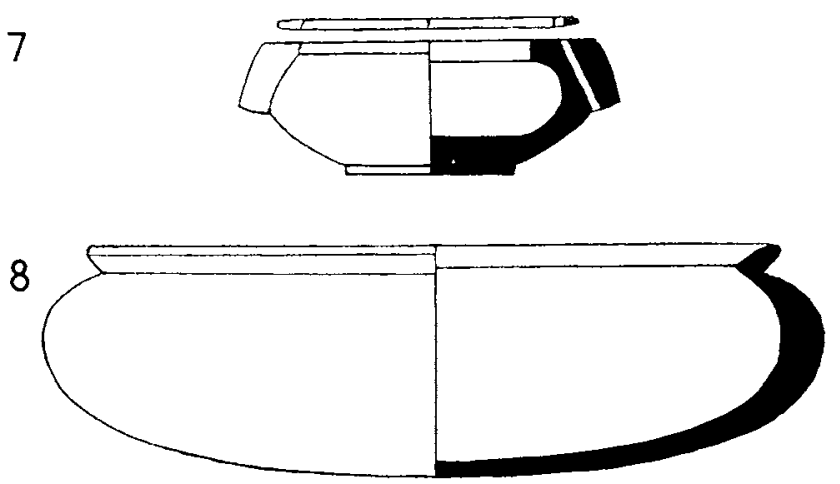

13

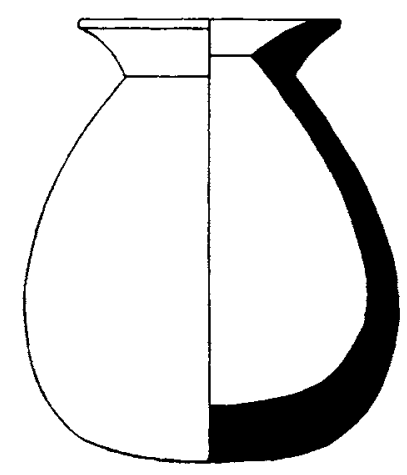

Scale throughout $\frac{2}{5}$

Stone vase types 
PLATE LXXXII

14

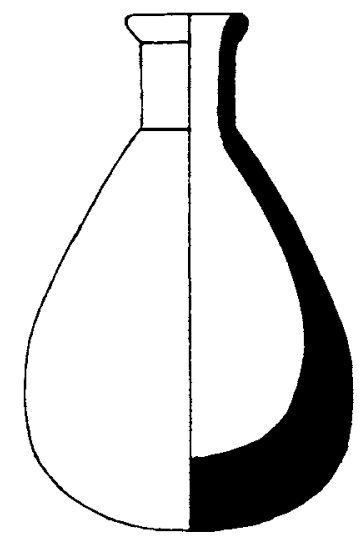

15

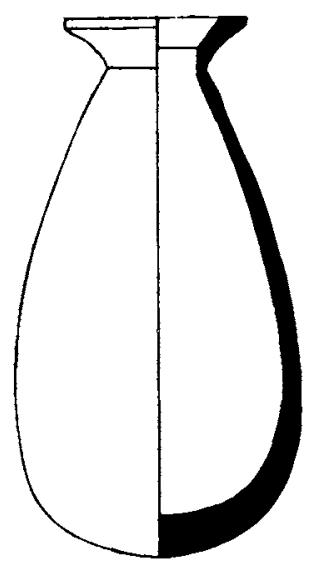

16

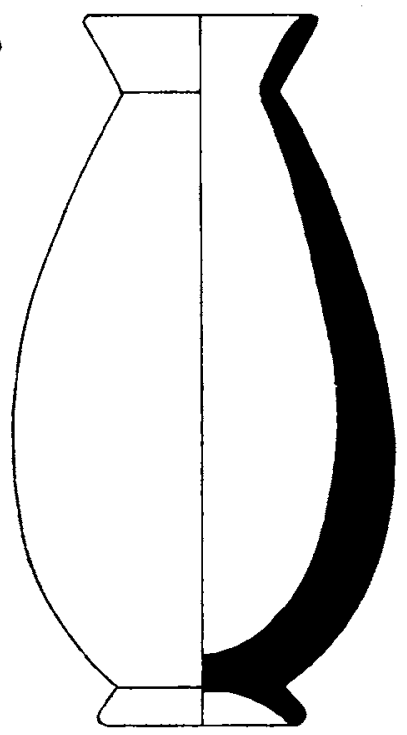

17

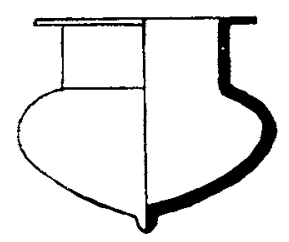

18

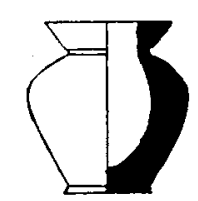

19

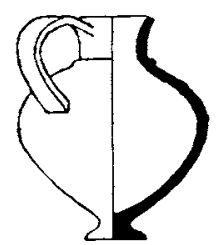

20

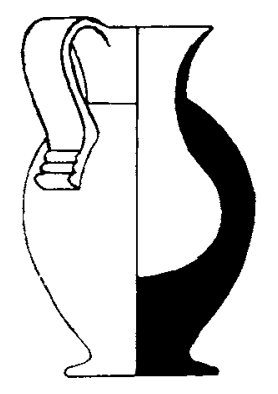

21

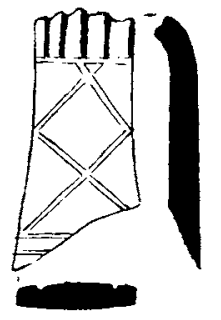

22

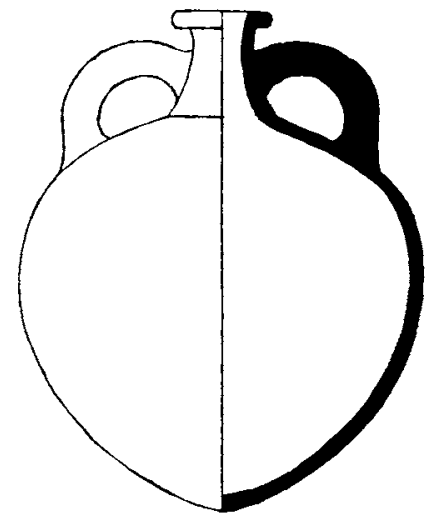

28

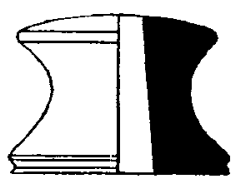

29

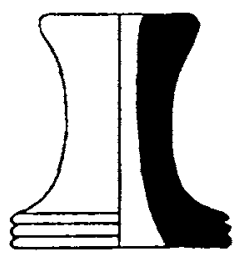

Scale throughout $\frac{2}{5}$

Stone vase types 


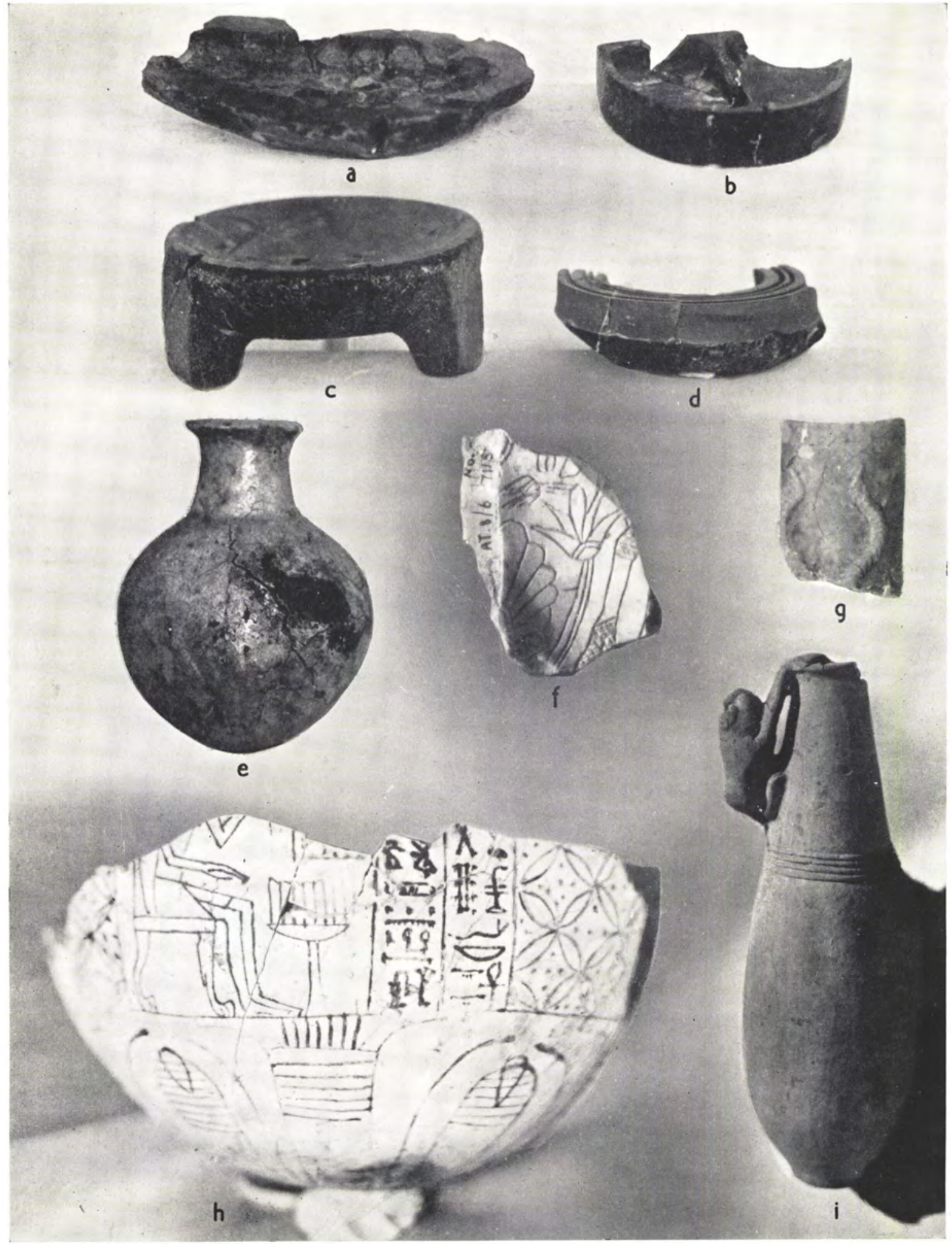

a. AT/48/10I; b. AT/48/98; c. AT/48/100; d. AT/48/99; e. AT/39/197; f. AT/38/6; g. AT $/ 46 / 21 ; h . \mathrm{AT} / 46 / 223 ; i$. AT $/ 48 / 18$

Vessels in obsidian, glaze, \&c.

pp. $293,297,299$ 


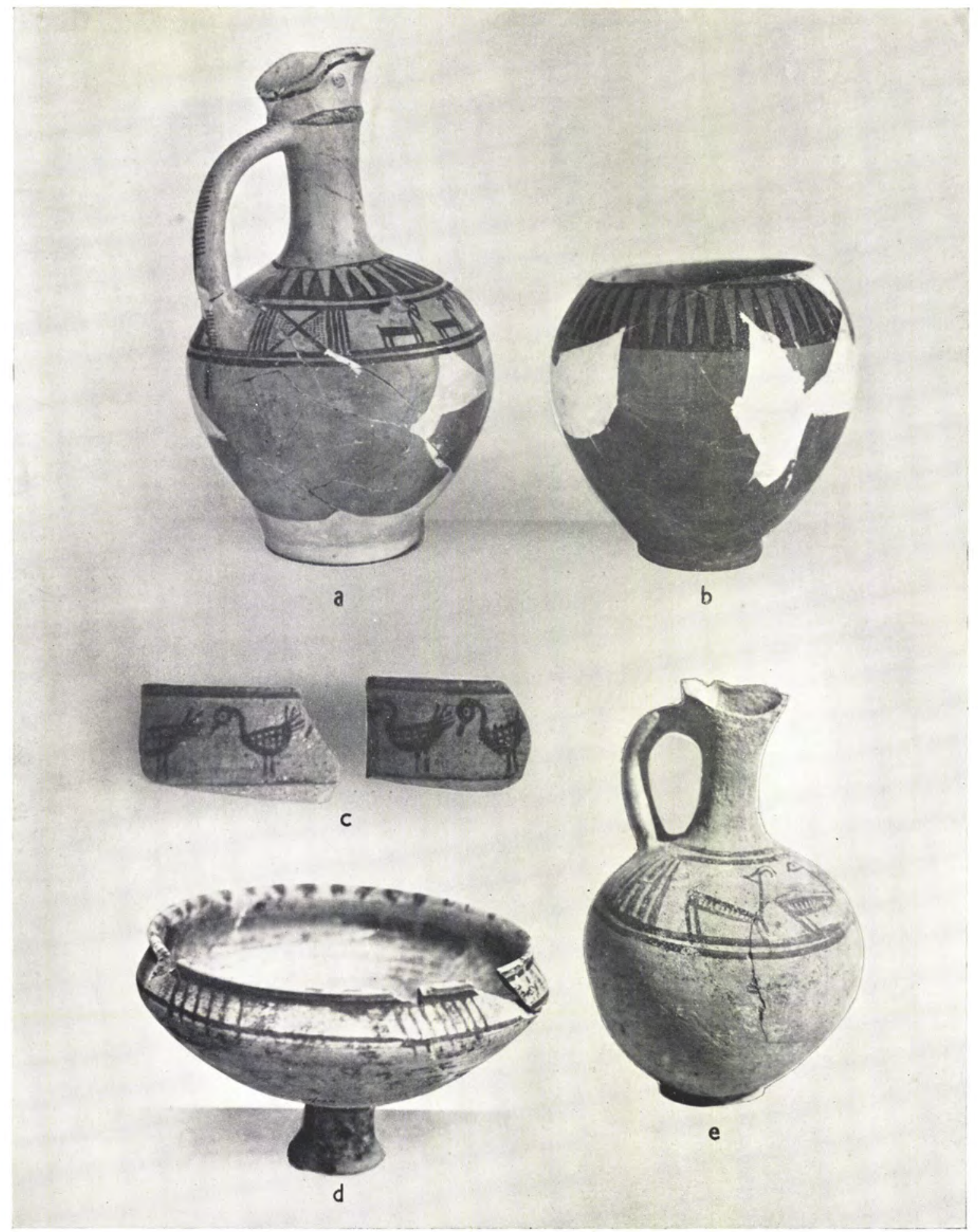

a. ATP/47/123, from Level XIV; b. ATP/47/I42, from Level XIV; c. From Level XIV; d. ATP/47/1 29, from Level XIV; e. ATP/47/78, from Level XIII

Local painted pottery

pp. 308,340 
PLATE LXXXV

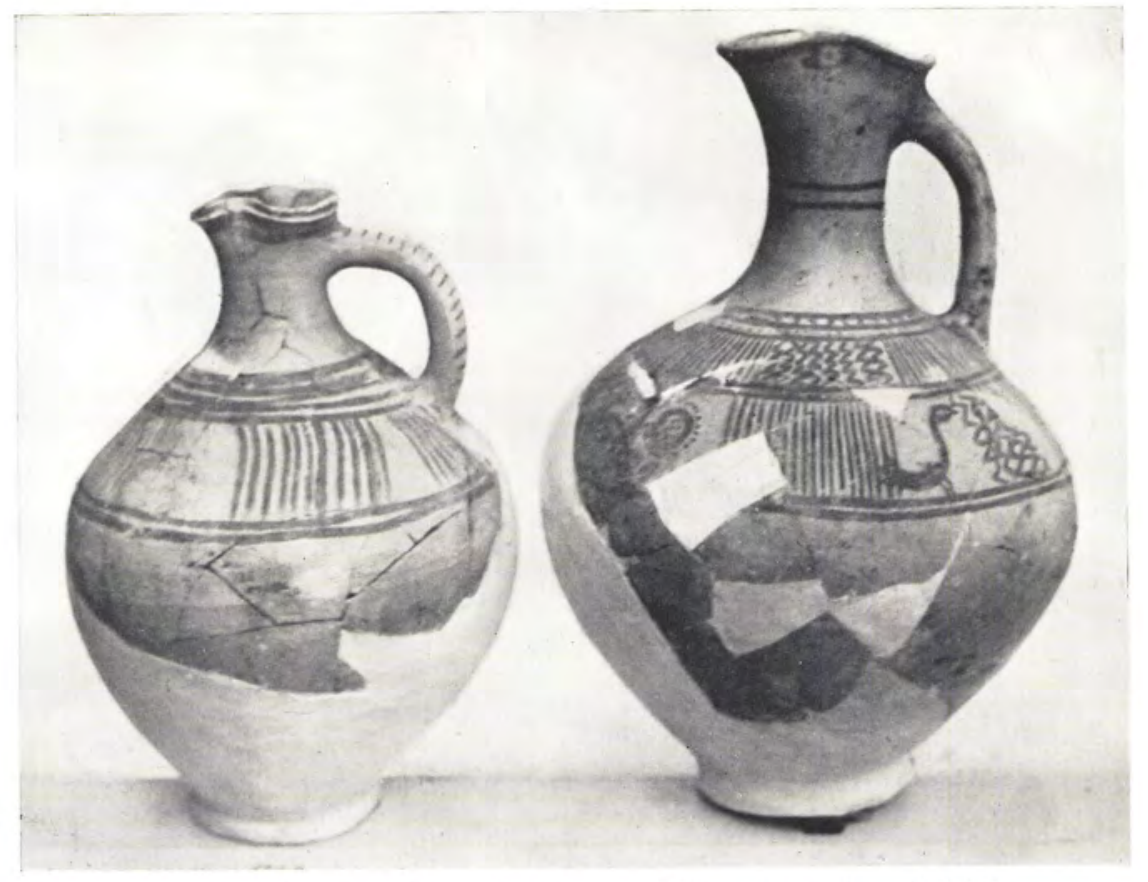

a. ATP/47/12, Level XI; b. ATP/47/1 II, Level XII

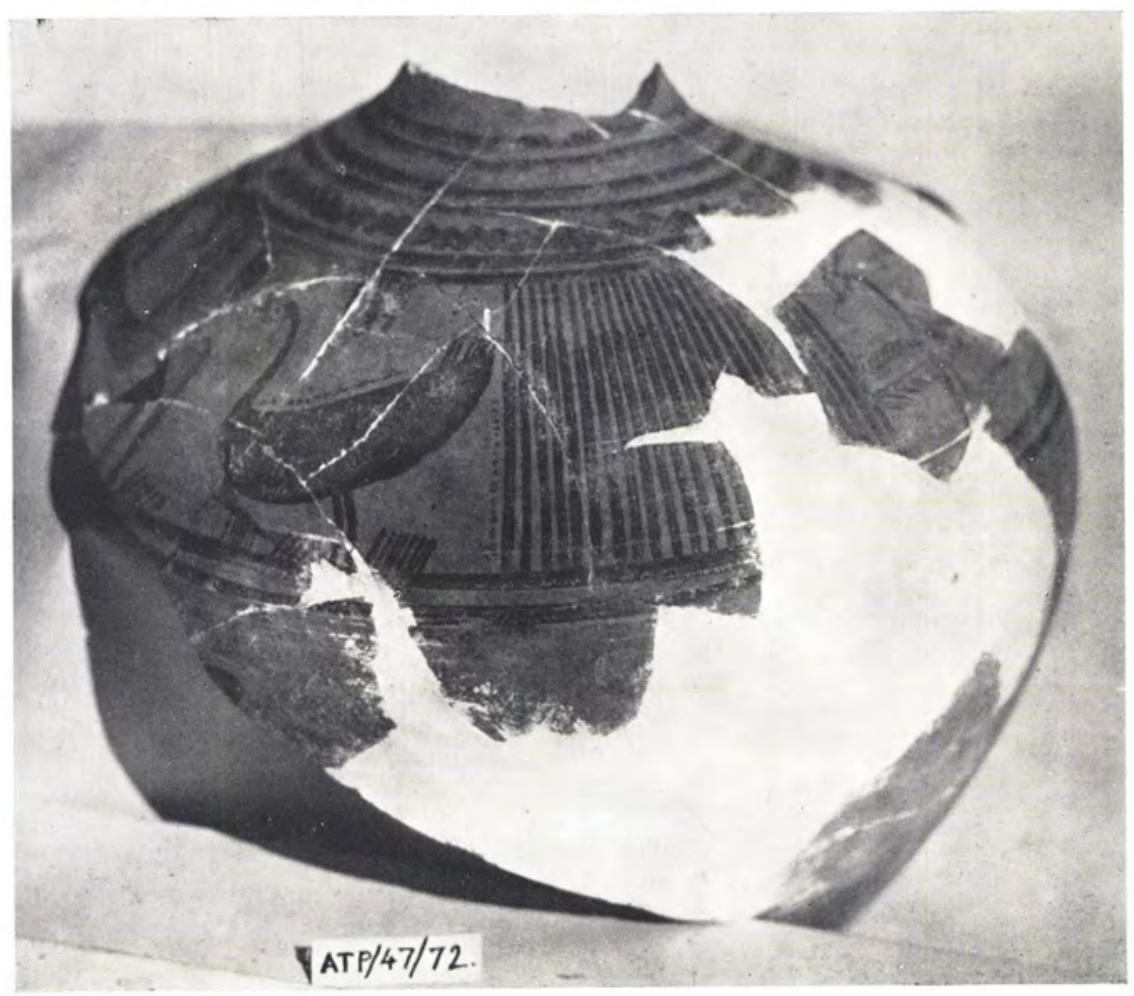

c. Level XI

Local painted pottery

pp. $309,34^{\circ}$ 
PLATE LXXXVI
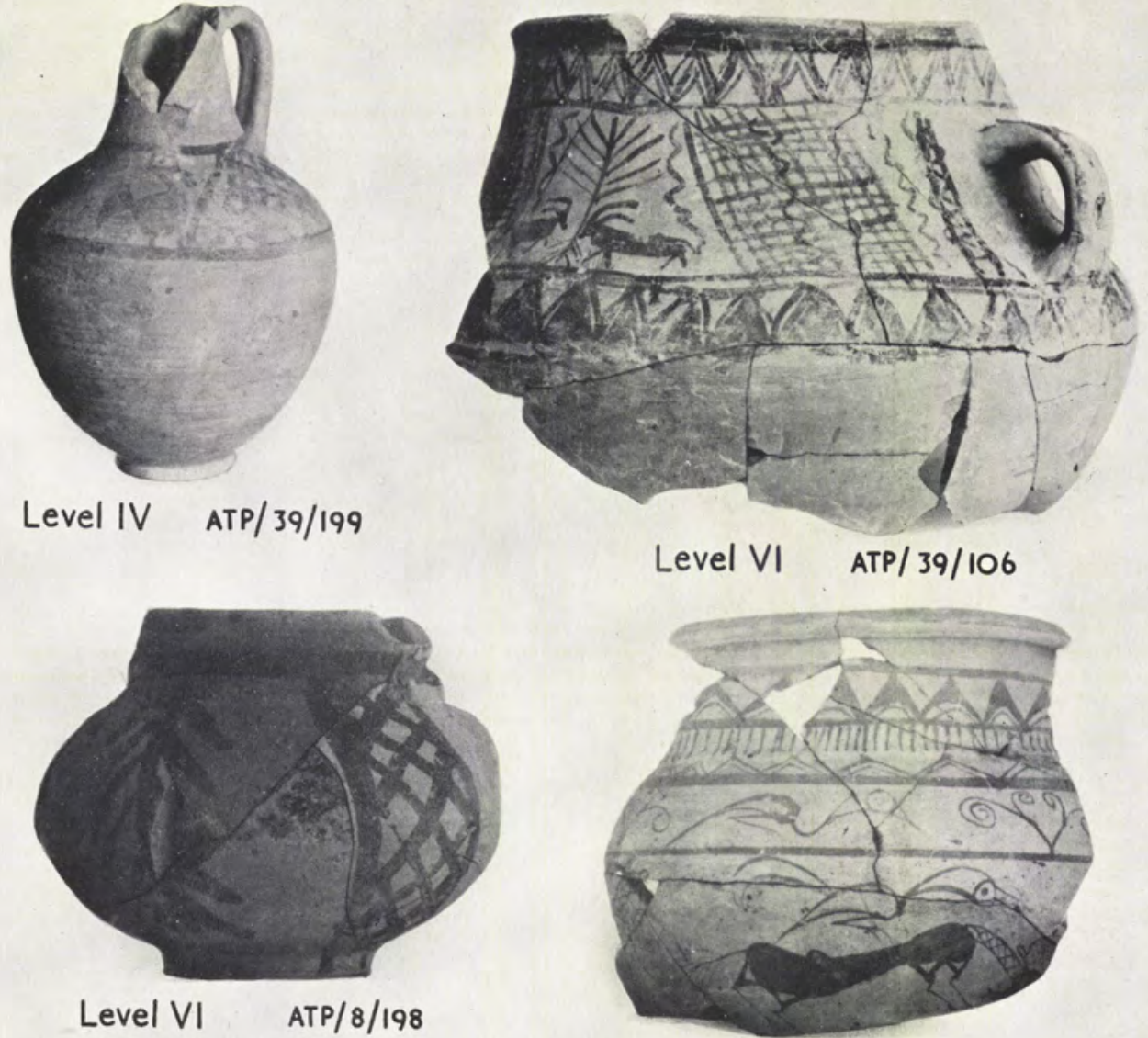

Level VI
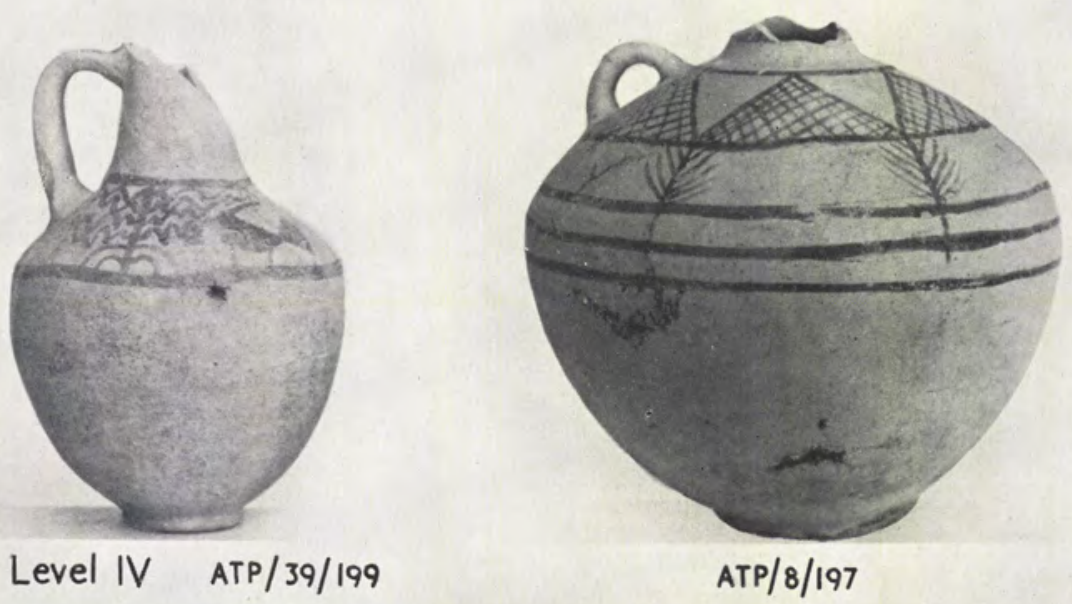

Local painted pottery

pp. $315^{-1} 8,340$ 


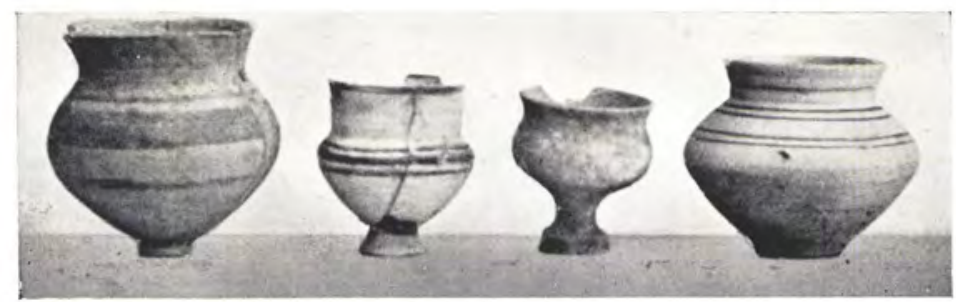

a. $\mathrm{ATP} / 46 / 246 \quad \mathrm{ATP} / 46 / 286 \quad \mathrm{ATP} / 46 / 264$ Type I27 Type I24 Type I23 Type 106a

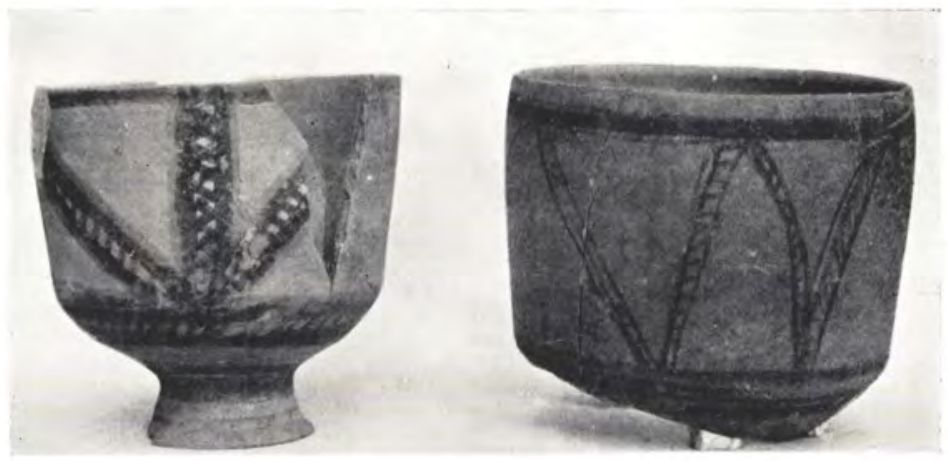

b. $\quad \mathrm{ATP} / 49 / 13 a$

Type I 7
ATP/49/1 $3^{b}$

Type 1 i 7

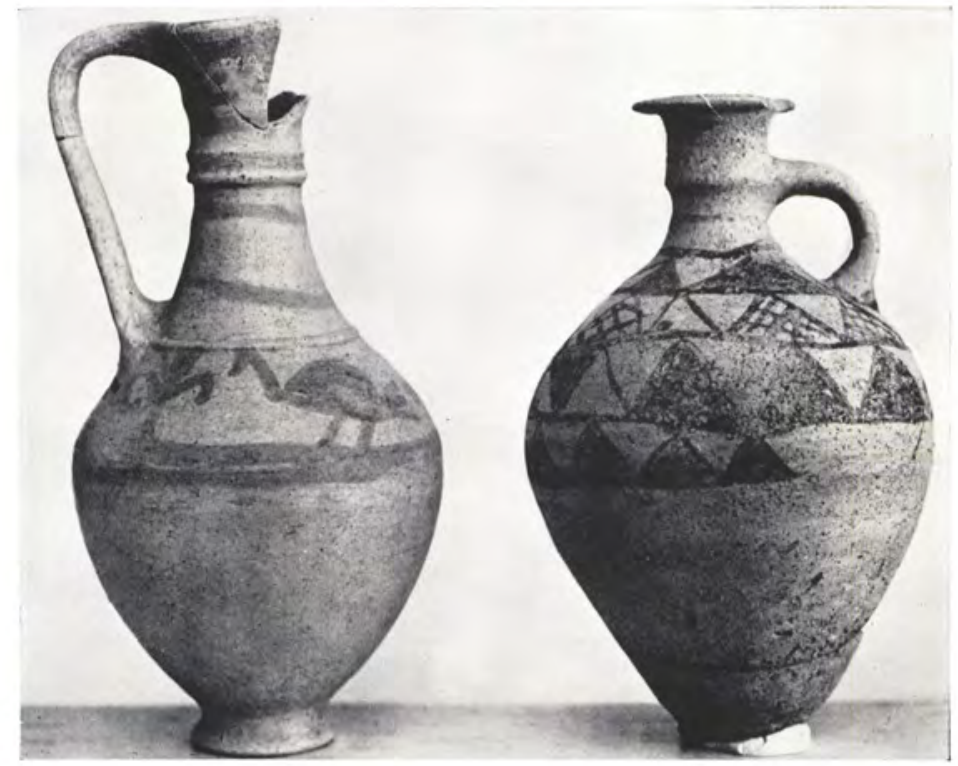

c. $\quad \mathrm{ATP} / 39 / 72$

Type $48 c$

ATP/39/90

Type 60

a. From Level V; $b$. From Level V; $c$. From Level IV

Local painted pottery

pp. $3^{17^{-1}} 8,340$ 


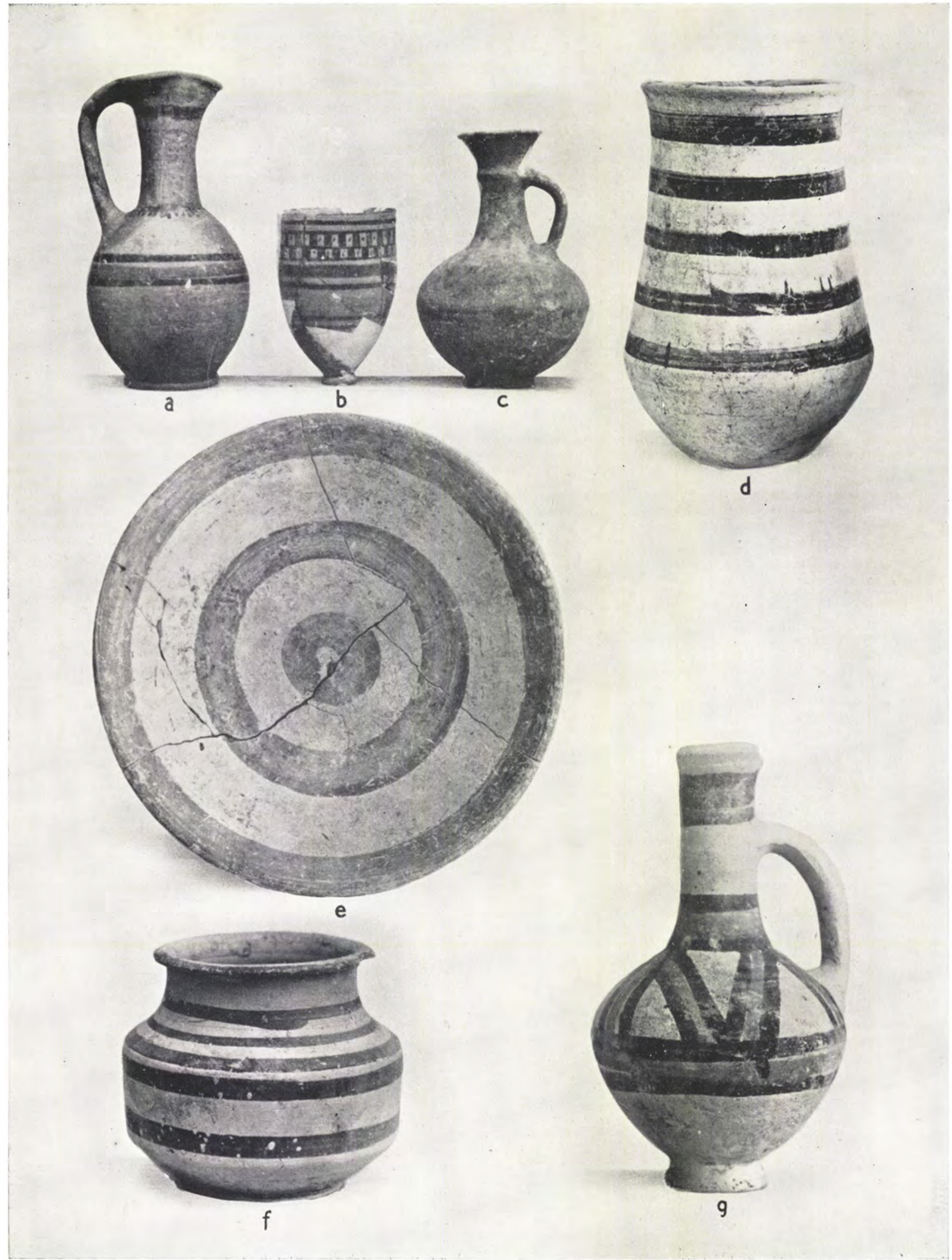

a. ATP/46/126, Тype 68; b. ATP/96/225, Type i 18; c. ATP/46/208, Тype 55; d. ATP/38/20, Type $94 ; e . A T P / 38 / 43$, Type $3 b ; f$. ATP $/ 39 / 4$, Type $95 b ; g$. ATP/39/155, Type $55 b$ $a-c$. From Level V; $d, e$. From Level IV; $f, g$. From Level III 


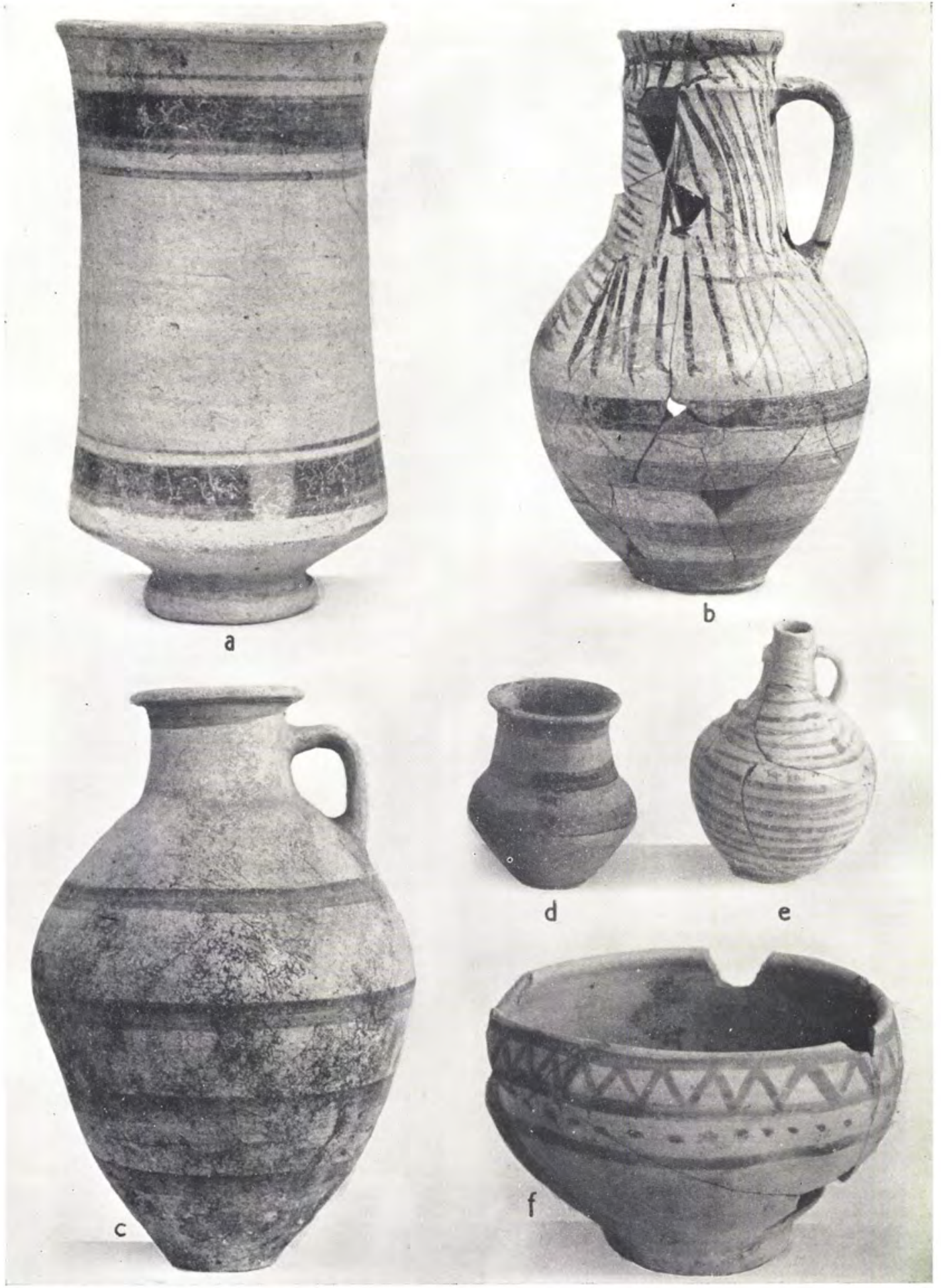

a. ATP/39/27, Level III-II, Type 93c; b. ATP/37/40, Level IV, Type 62; c. ATP $/ 37 / 38$, Level I, Type 63; $d$. ATP/38/193, Level I, Type 63; e. ATP $/ 38 / 25$, Level I, Type 79; f. A'TP $/ 38 / 94$, Level III, Type $26 b$

Local painted pottery

pp. 319,340 
PLATE XC

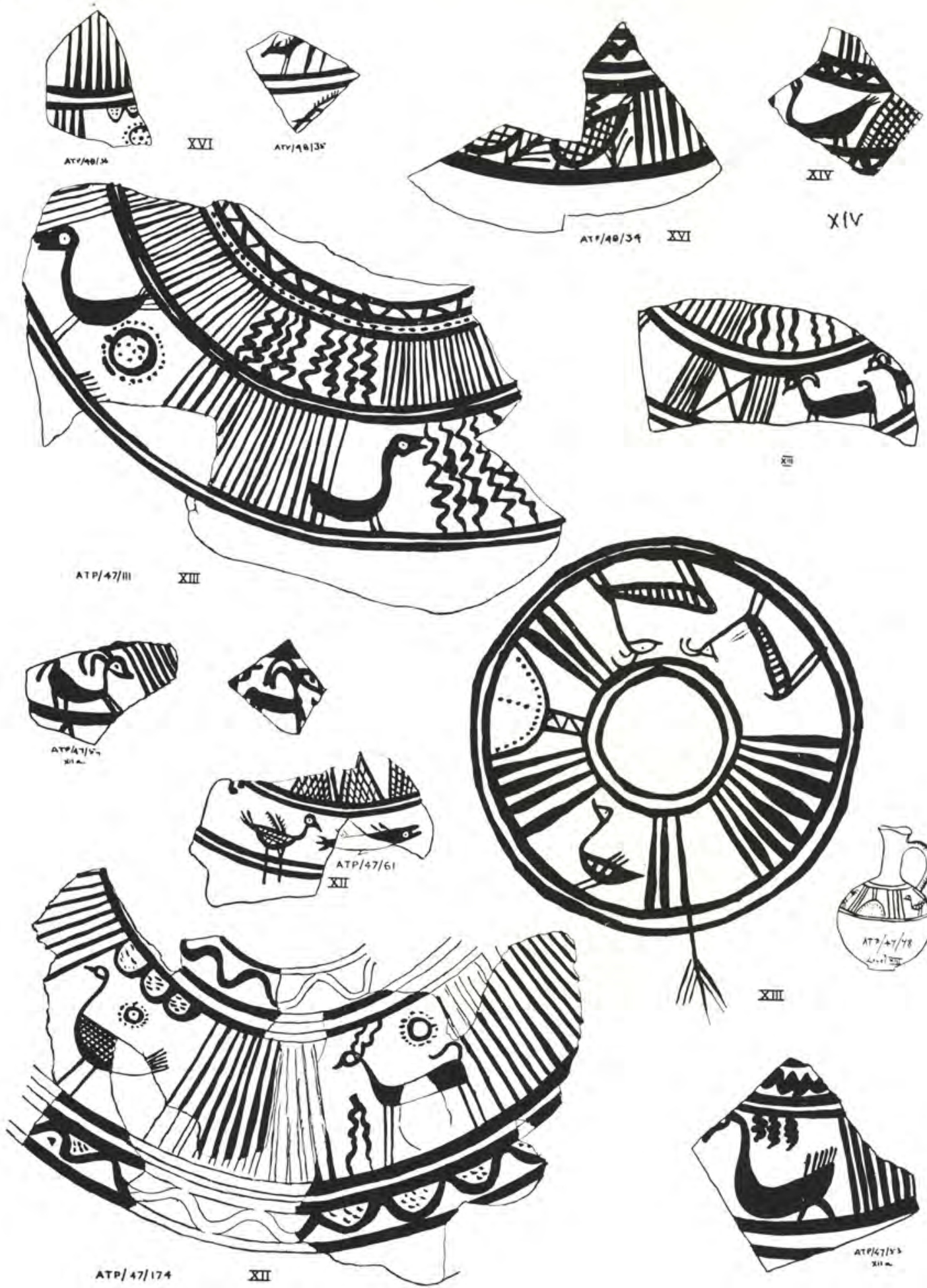

Designs on local painted pottery

(Levels as marked)

pp. 308-9 
PLATE XCI
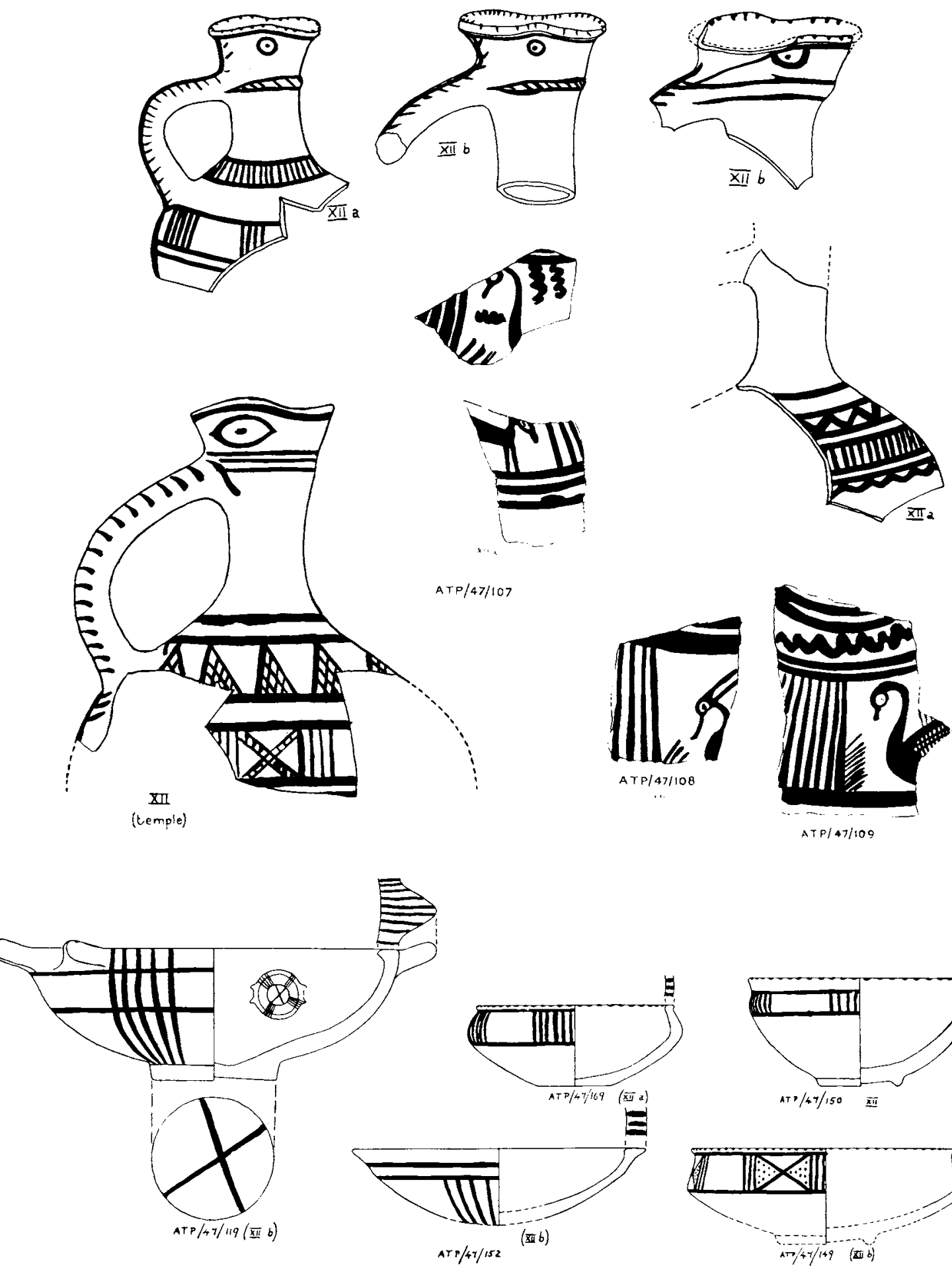

Designs on local painted pottery

(Levels as marked)

p. 309 


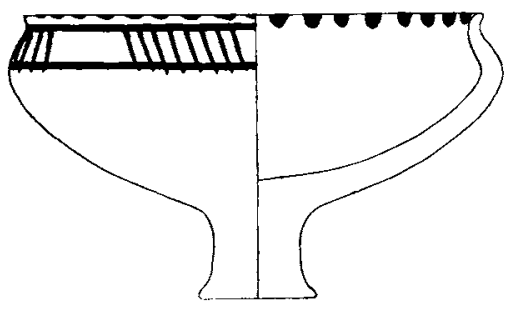

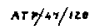
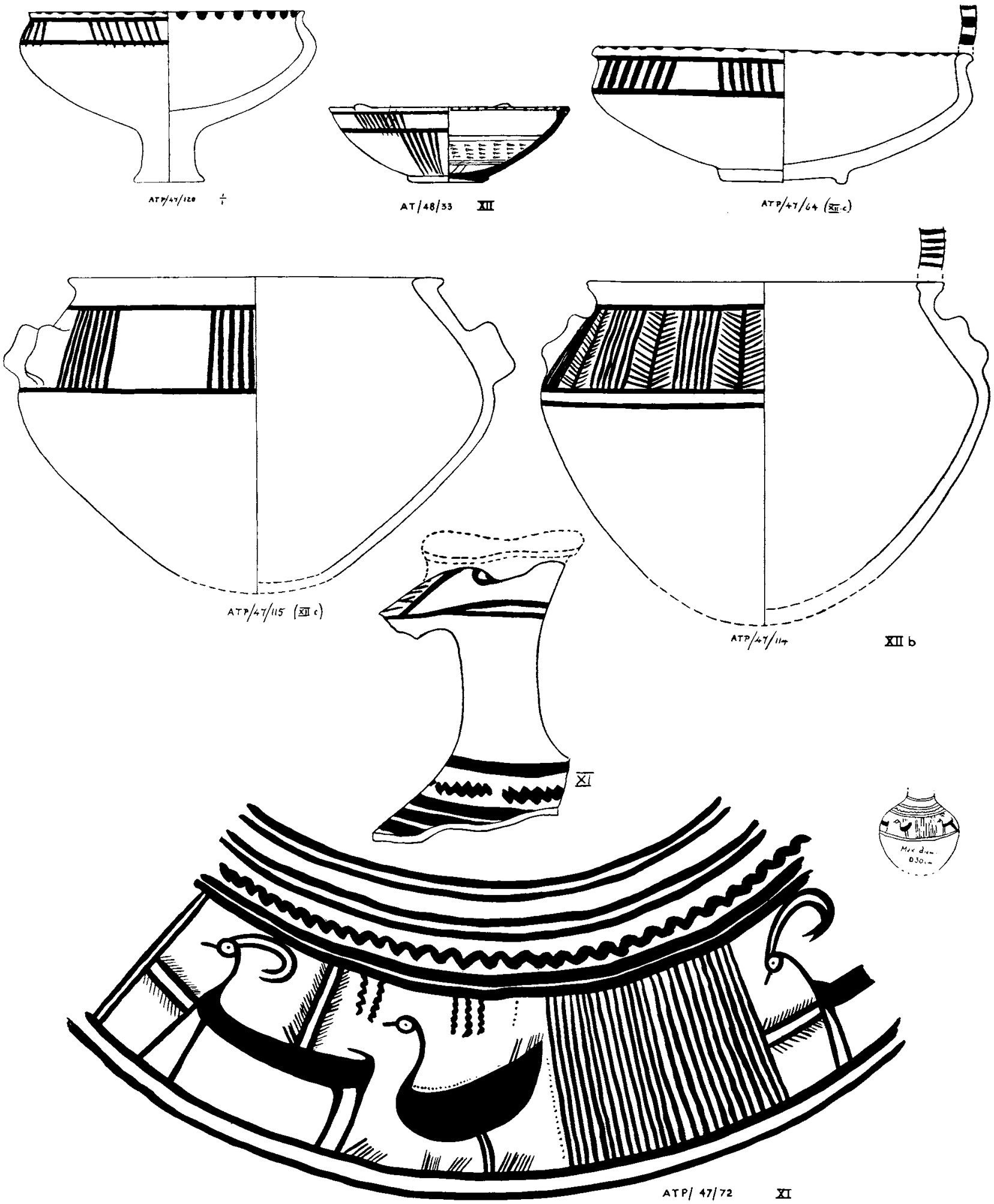

Designs on local painted pottery

(Levels as marked)

p. 309 

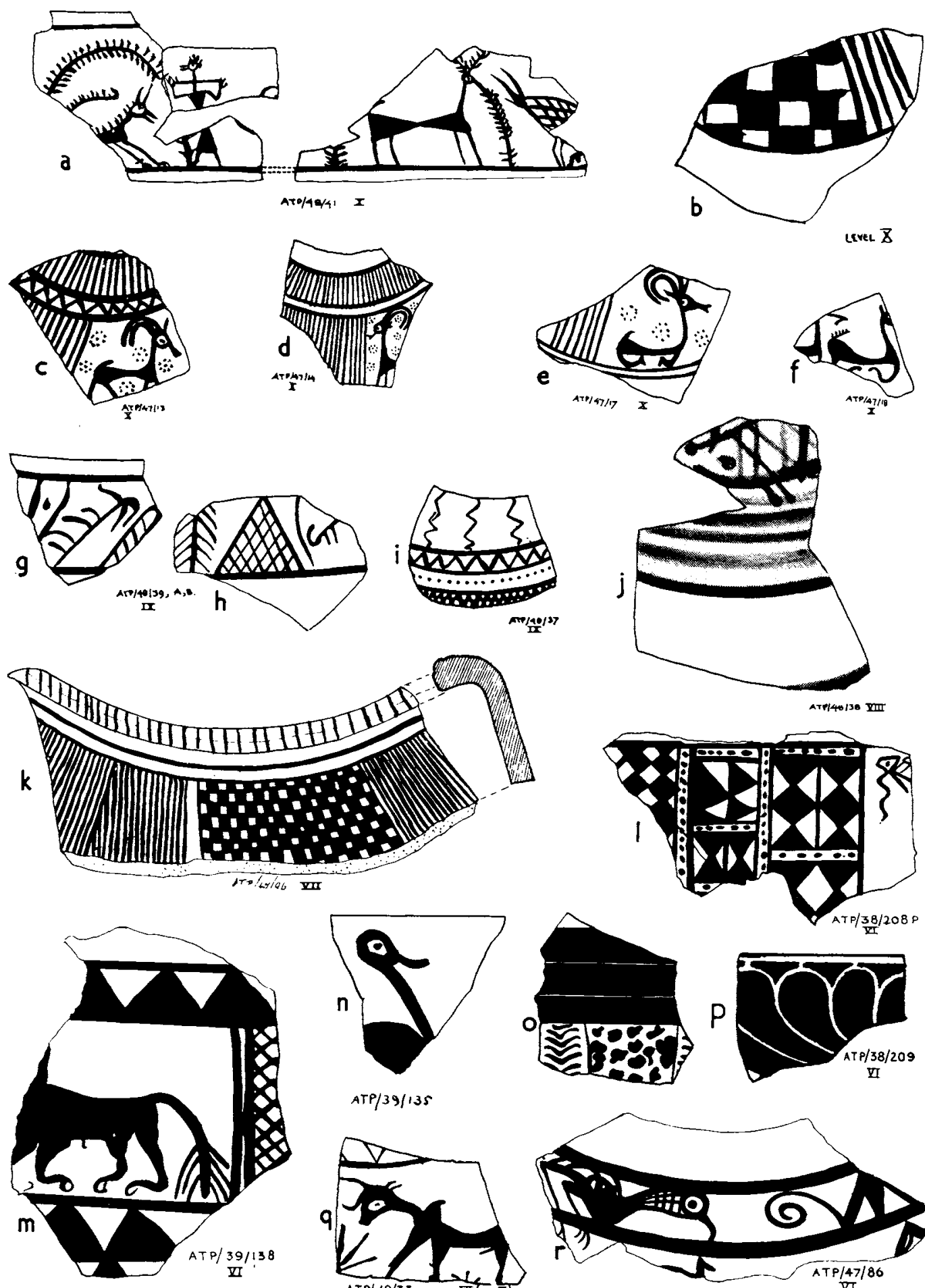

$$
\text { ATP/39/135 }
$$
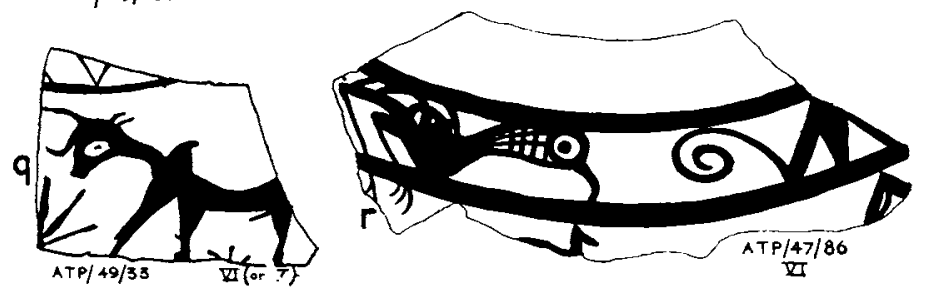

Designs on local painted pottery

(Levels as marked)

Pp. 3IO-I 5 

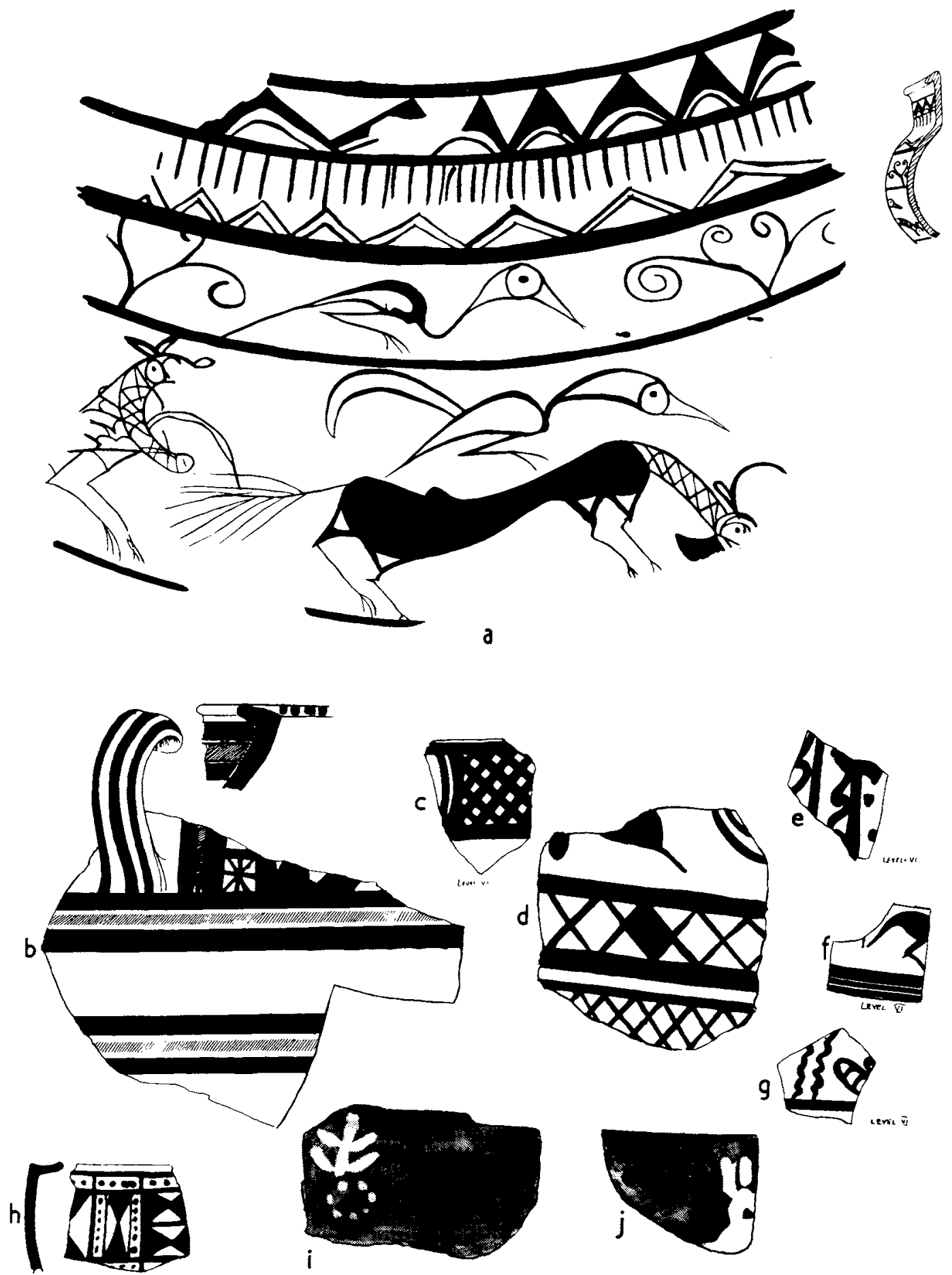

Designs on local painted pottery

(Level VI)

p. 315 


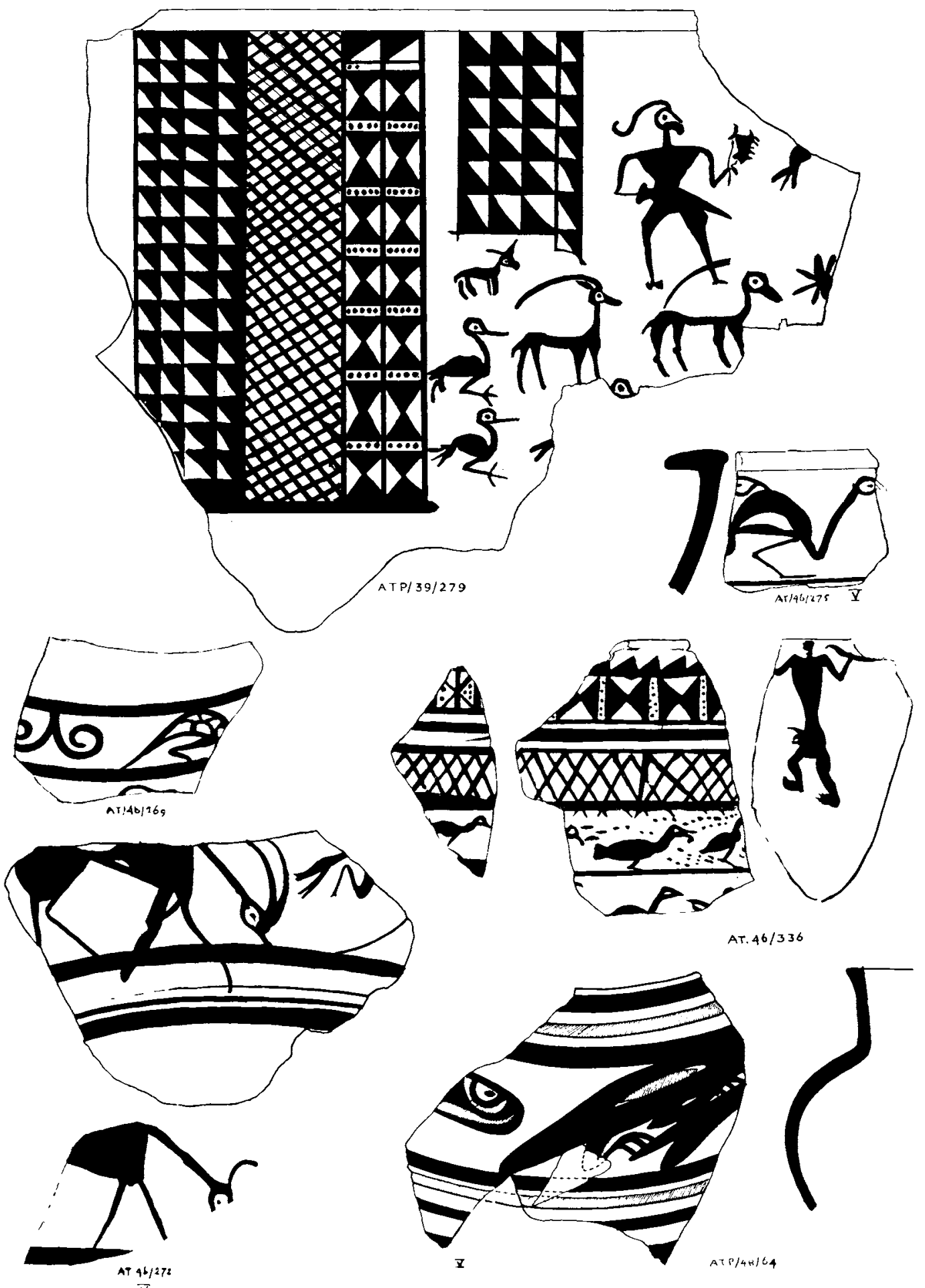

Designs on local painted pottery (Level V) 

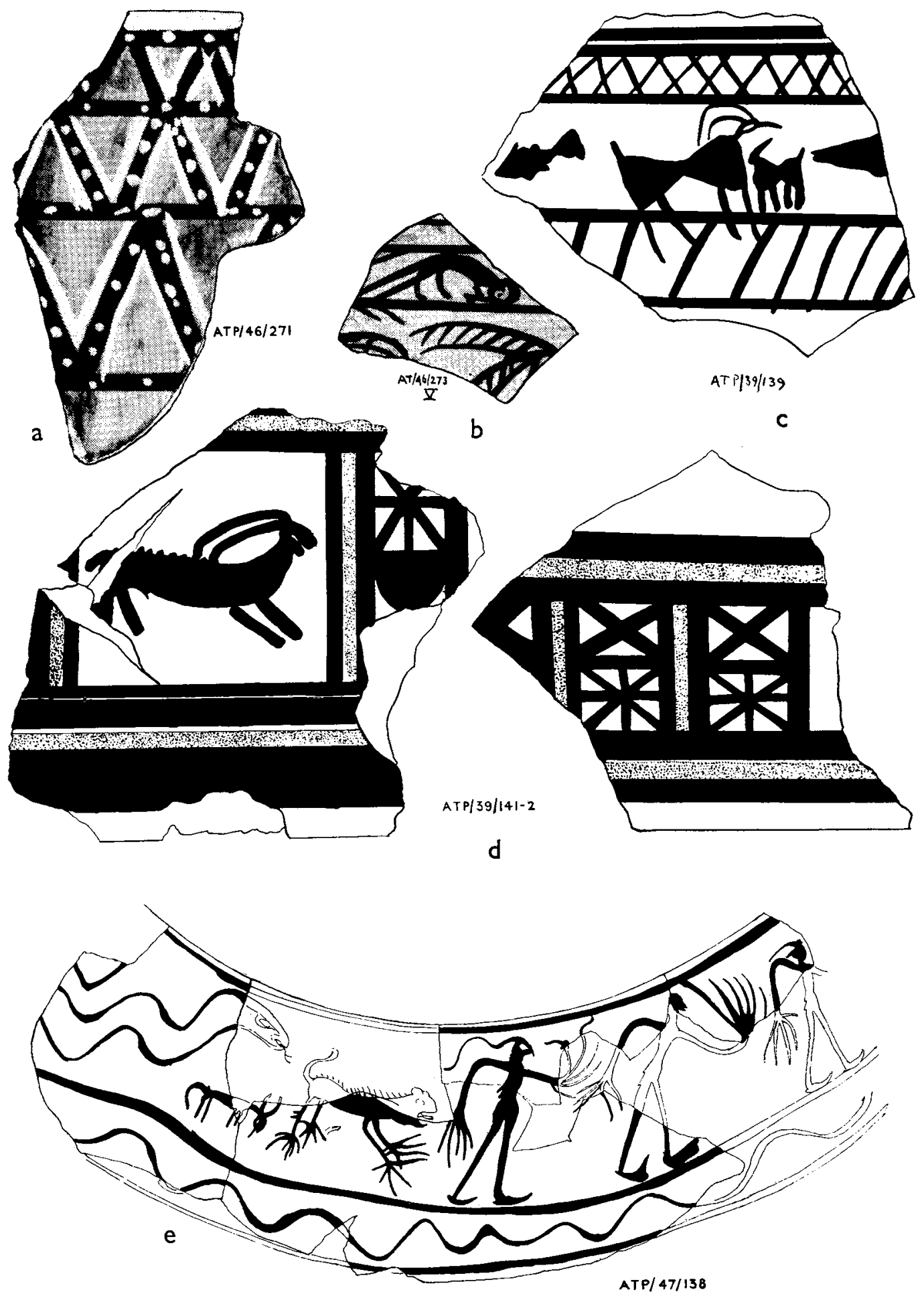

$a-d$. Levei $\mathrm{V}$; e. Level IV

Designs on local painted pottery

PP. 3 I 7-I 8 

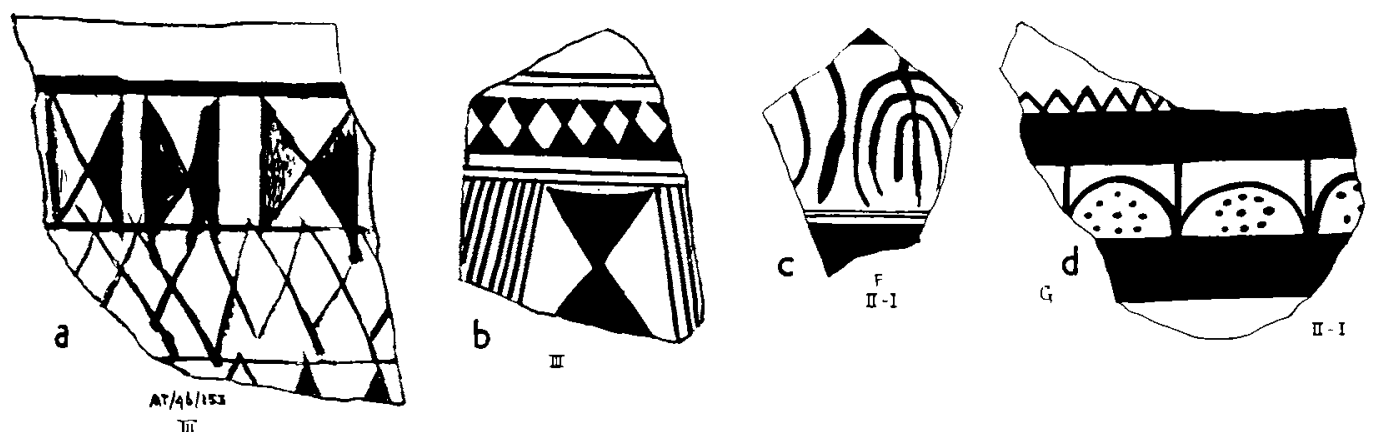
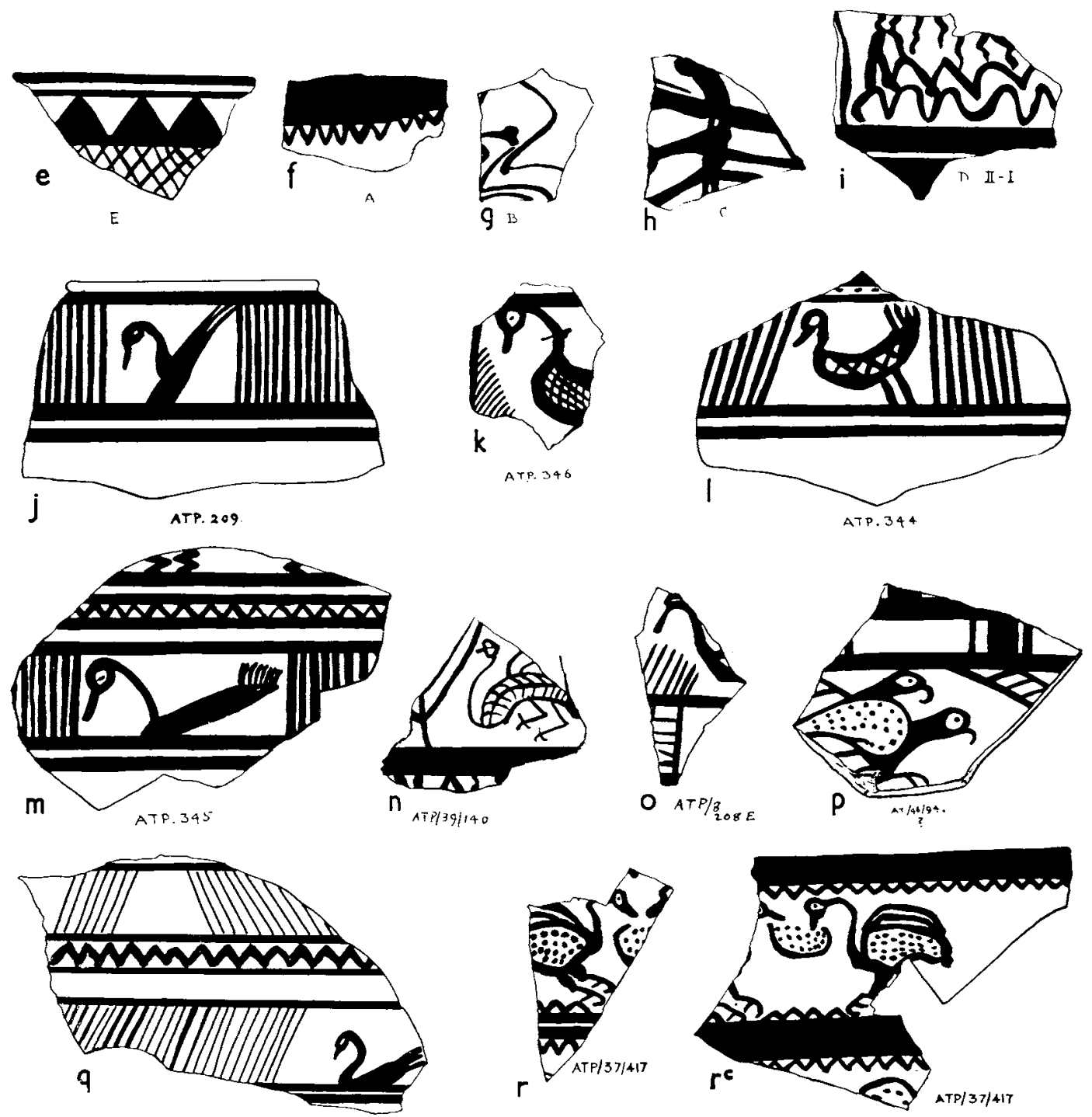

$a-b$, Level III; $c-i$, Level II-I; $p$, Level V; the rest unstratified Designs on local painted pottery 

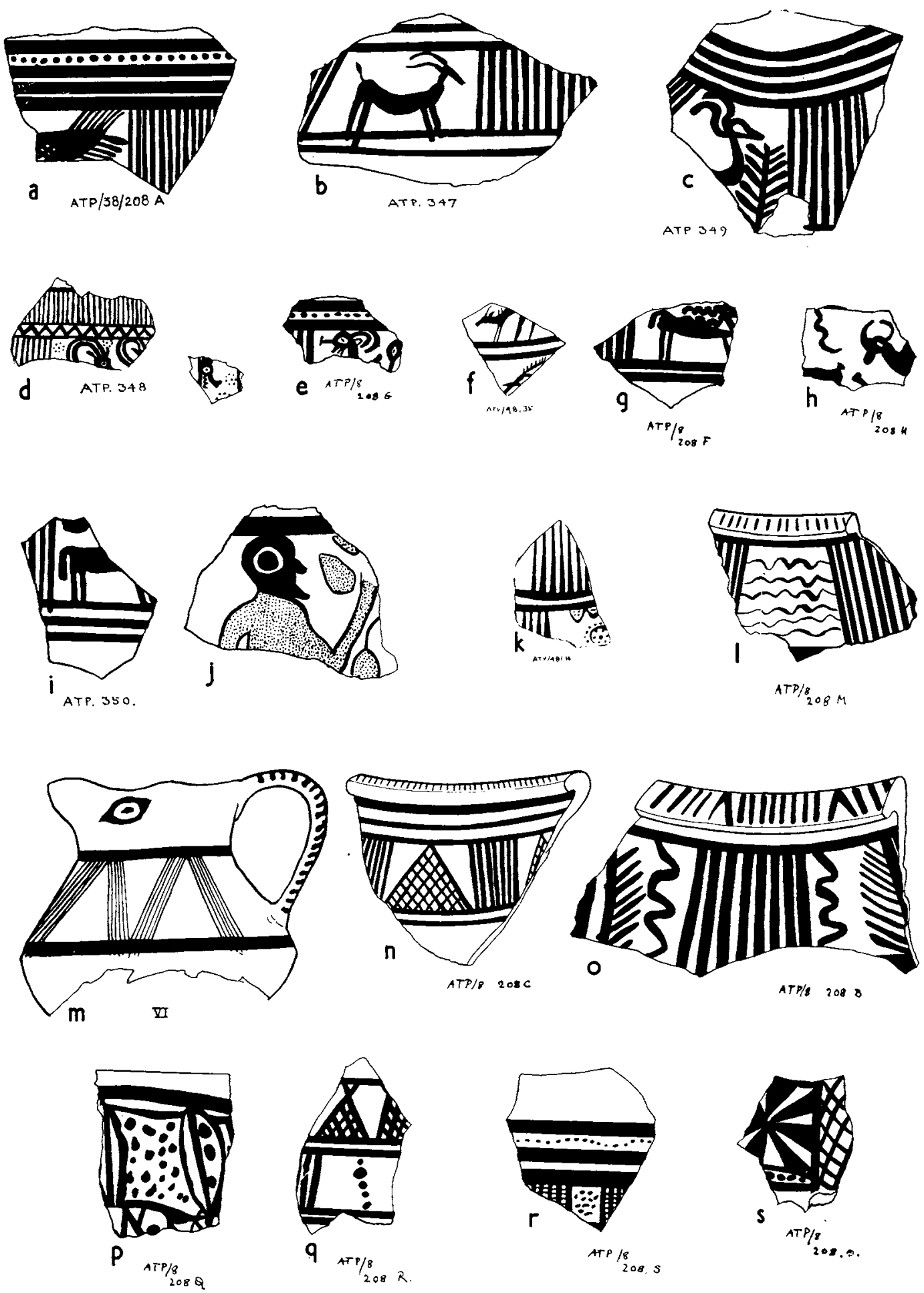

Designs on local painted pottery

(Unstratified sherds) 


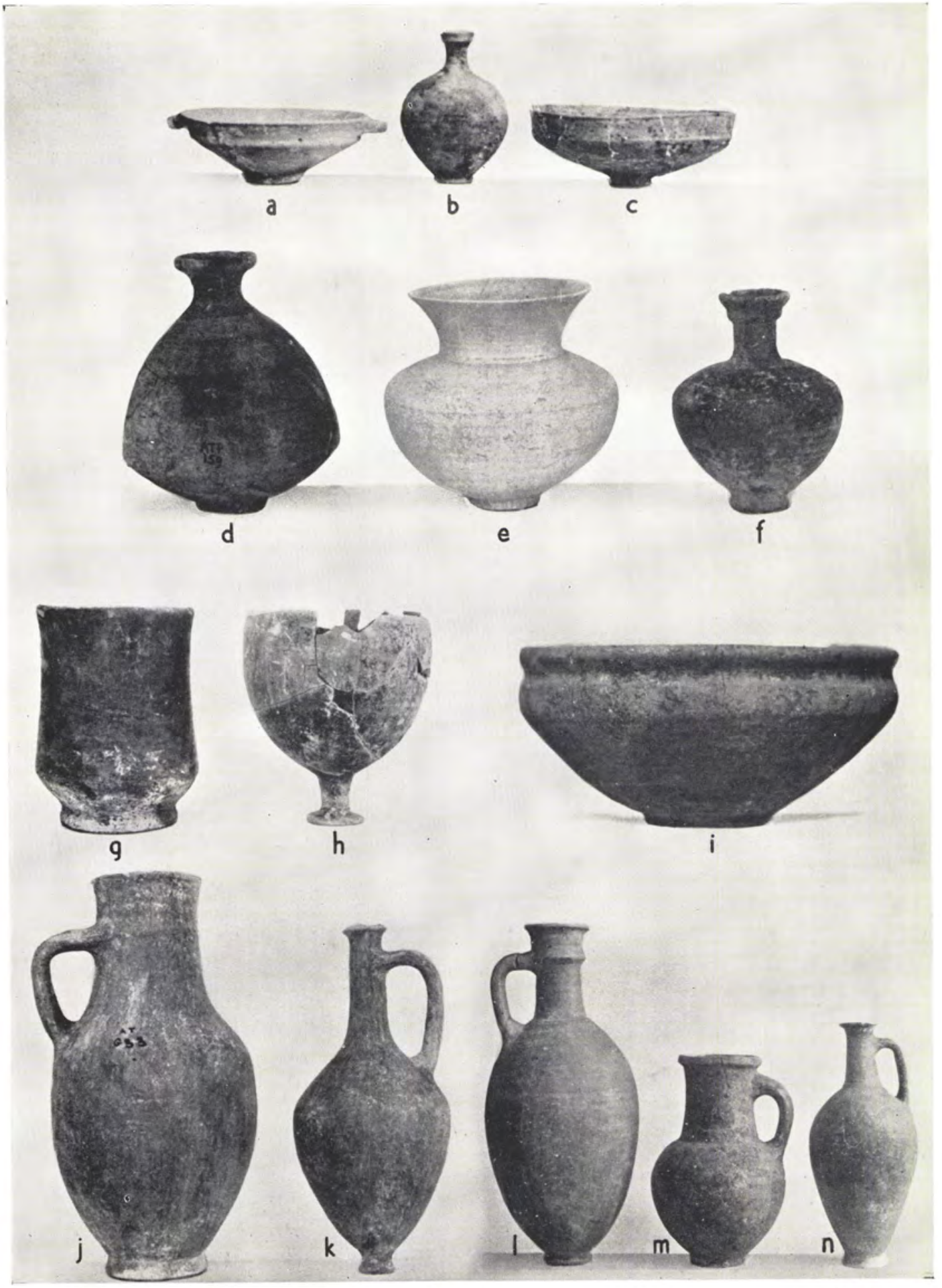

a. ATP/46/64, Level II, Type 36; b. ATP/46/2 I 2, Level VII, Type I 37; c. ATP/46/194, Level V, Type 8; $d$. ATP $/ 37 / 159$, Level VII, Type I39; ¿. ATP/37/1 17, Level VII, Type I06b; f. ATP/37/158, Level VII, Type 137; g. ATP/37/212, Level IV, Type 94; h. ATP $/ 37 / 167$, Level IV, Type I1 $8 a$; $i$. ATP/47/70, Level IV, Type 23a; $j$. ATP/37/317, Level IV, Type 60b; $k$. ATP/37/318, Level IV, Type $48 a ; l$. ATP/38/186, Level IV, Type $48 b ; m$. ATP $/ 38 / 73$, Level IV, Type $54 ; n$. ATP $/ 38 / 185$, Level IV, Type $48 a$ pp. 322 sqq.

Plain pottery 
PLATE C

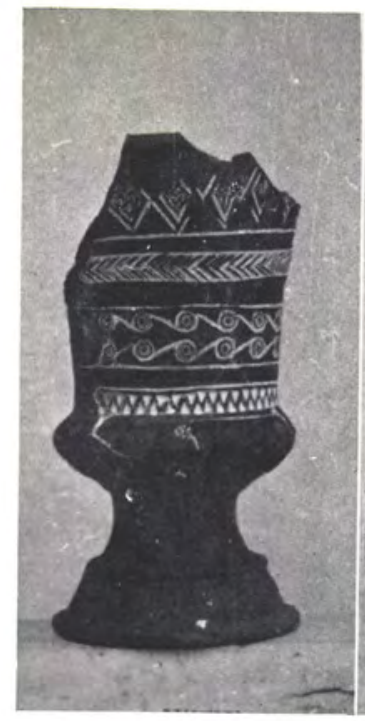

ATP/46/253

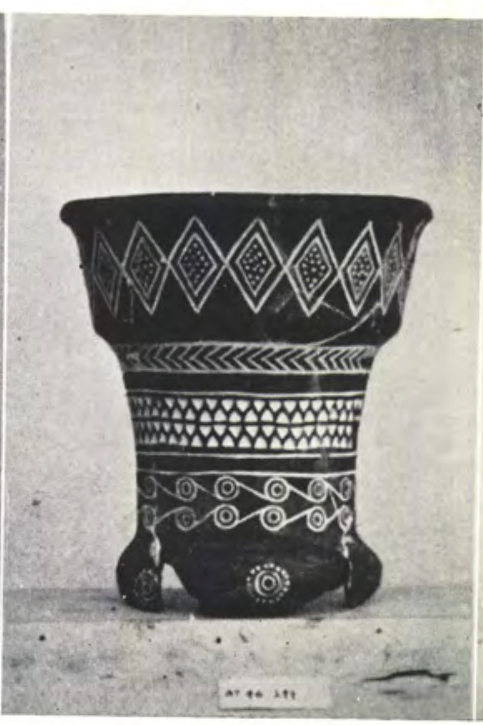

ATP/46/249

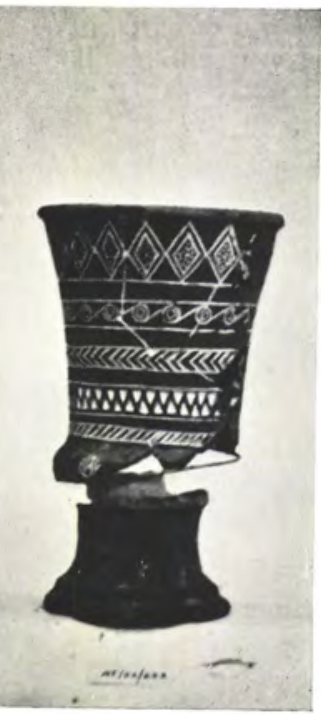

ATP/46/255

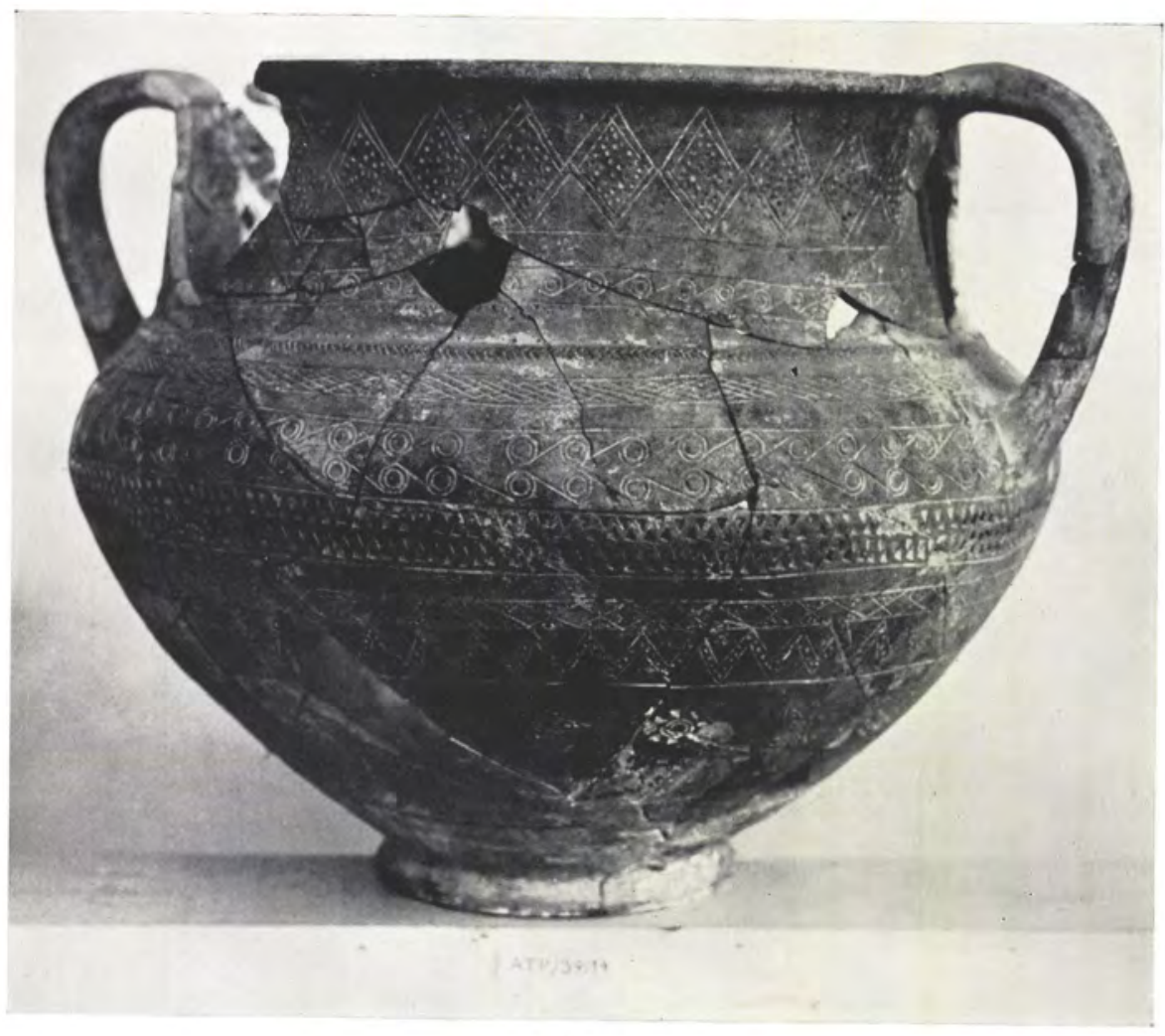

$$
\begin{gathered}
\text { ATP/39/I } 4 \\
\text { p. } 34^{2}
\end{gathered}
$$

Black impressed pottery 

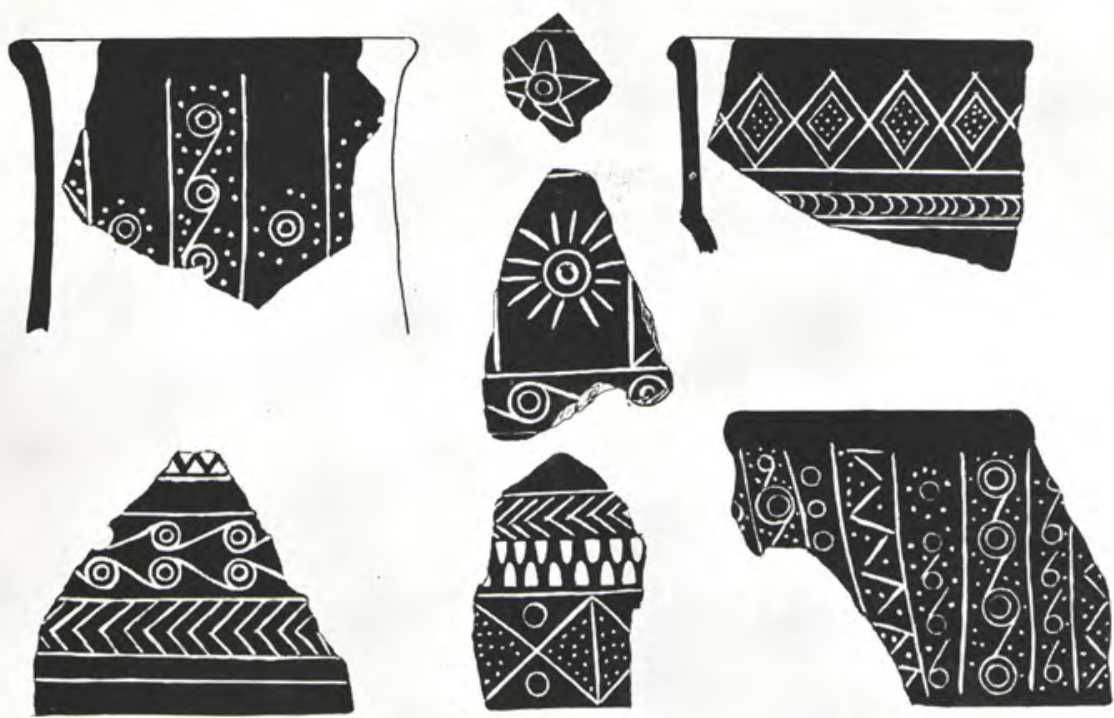

(a)
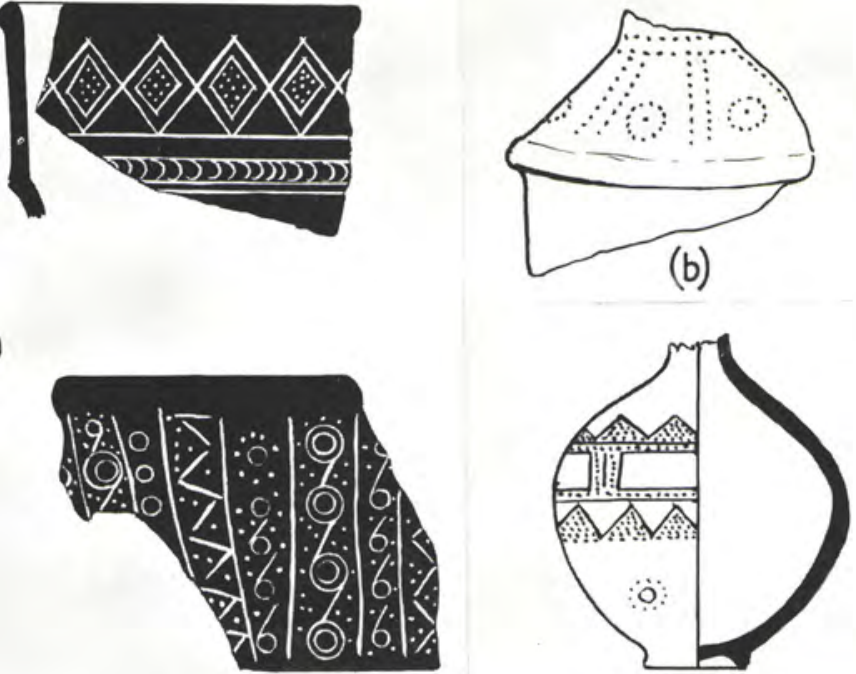

(c) $A T P / 39 / 284$

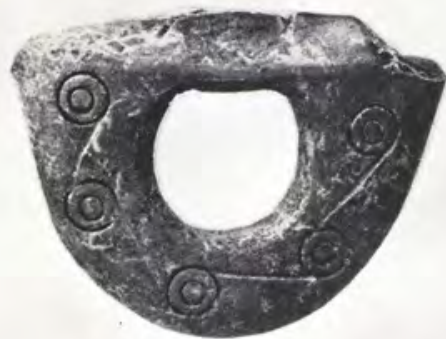

(d) $A T P / 37 / 1$

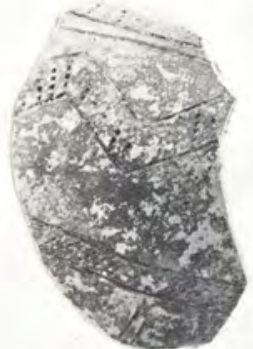

(e)
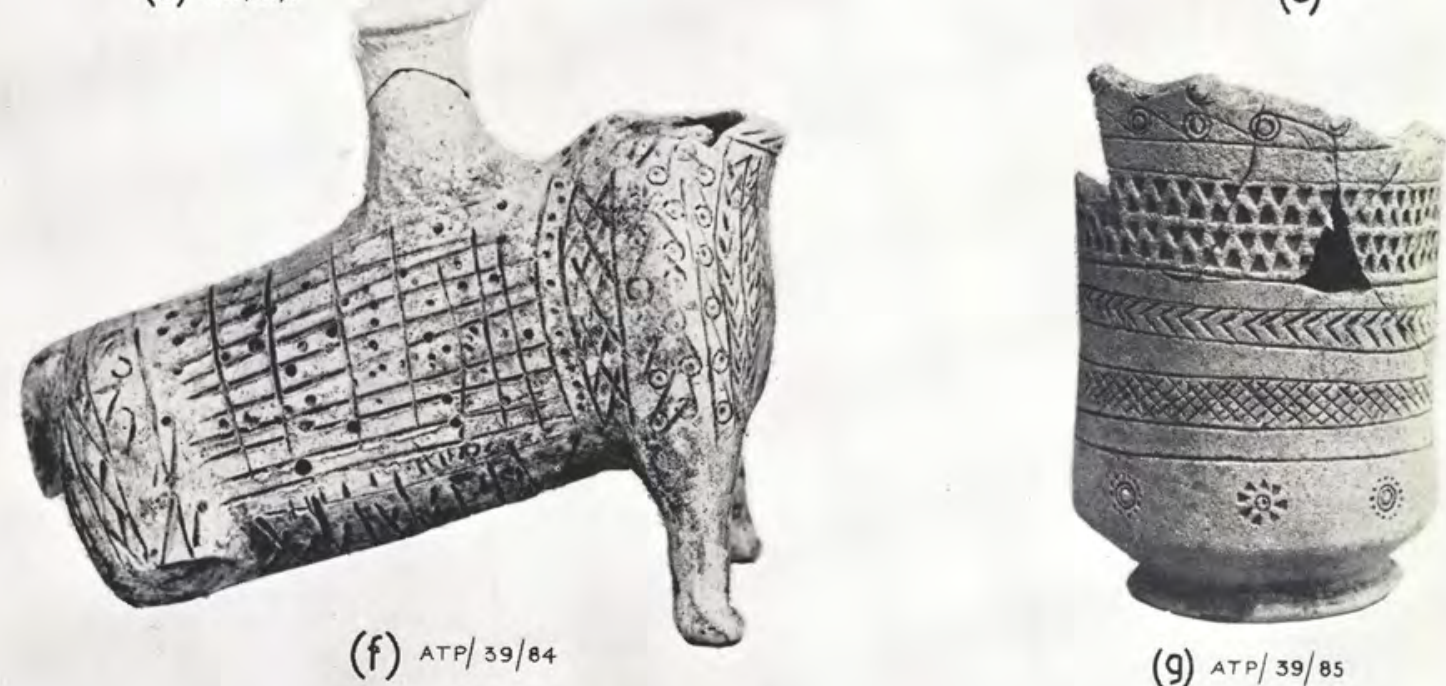

(g) ATP/ $39 / 85$

Black impressed pottery 

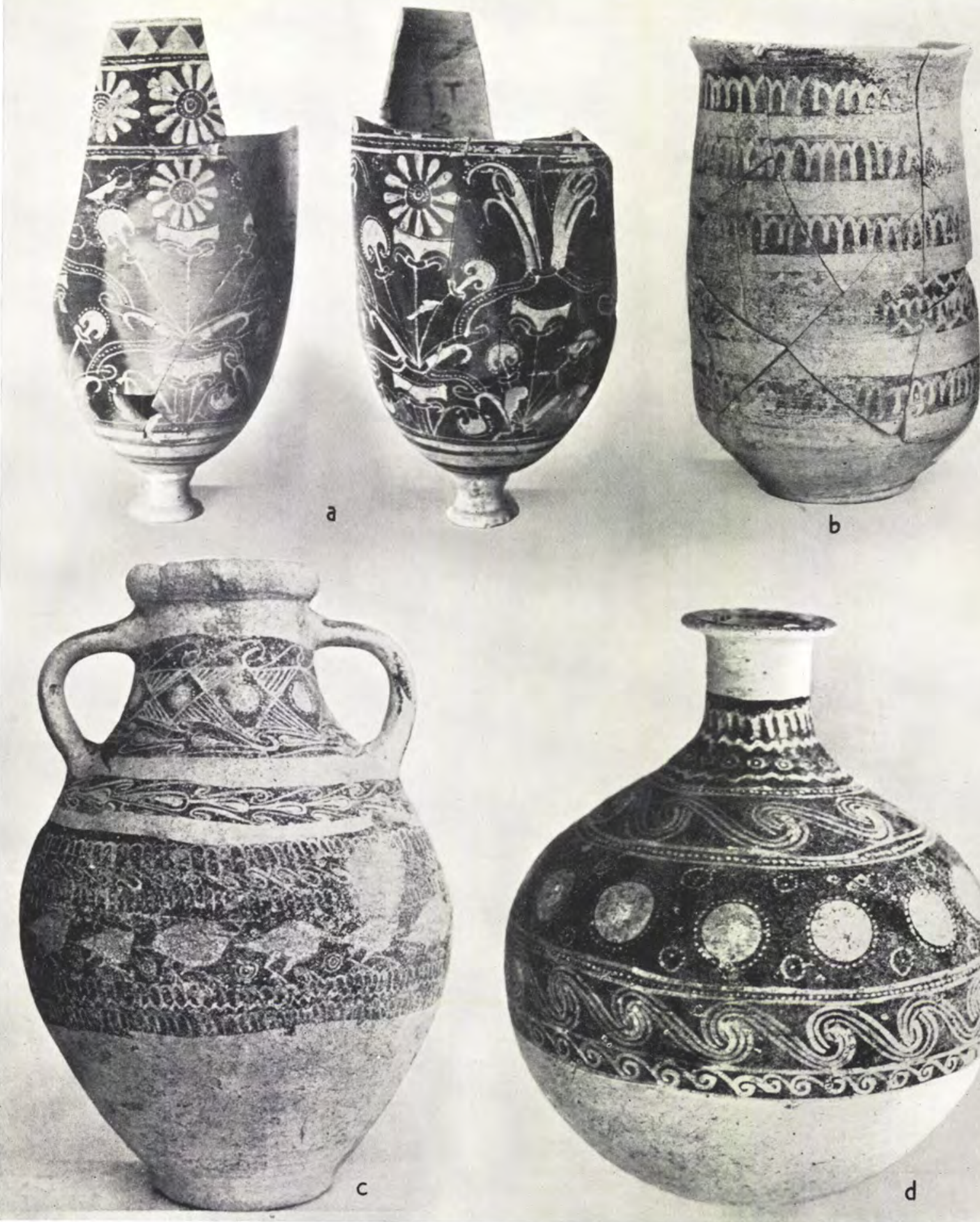

a. $\operatorname{ATP} / 37 / 2 ; b . \operatorname{ATP} / 38 / 18 ;$ c. $\operatorname{ATP} / 38 / 17 ; d . \operatorname{ATP} / 38 / 196$

'Atchana' and Nuzu pottery

p. 347 

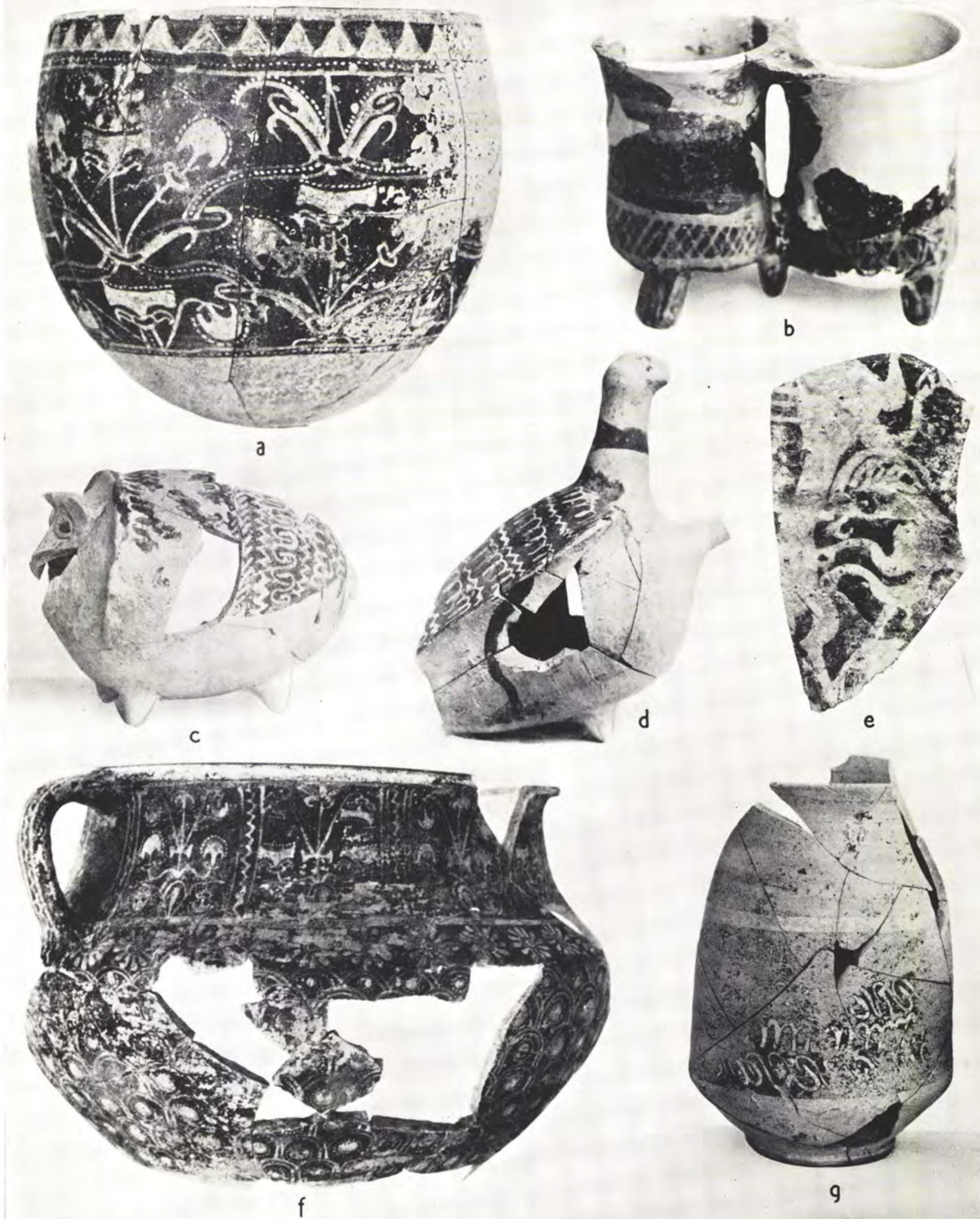

a. $\operatorname{ATP} / 37 / 240 ; b . \operatorname{ATP} / 47 / 136 ; c . \operatorname{ATP} / 38 / 4 ; d . \operatorname{ATP} / 39 / 46 ;$ e. $\operatorname{ATP} / 36 ; f . \operatorname{ATP} / 37 / 230 ; g \cdot \operatorname{ATP} / 37 / 4$ 'Atchana' and Nuzu pottery 

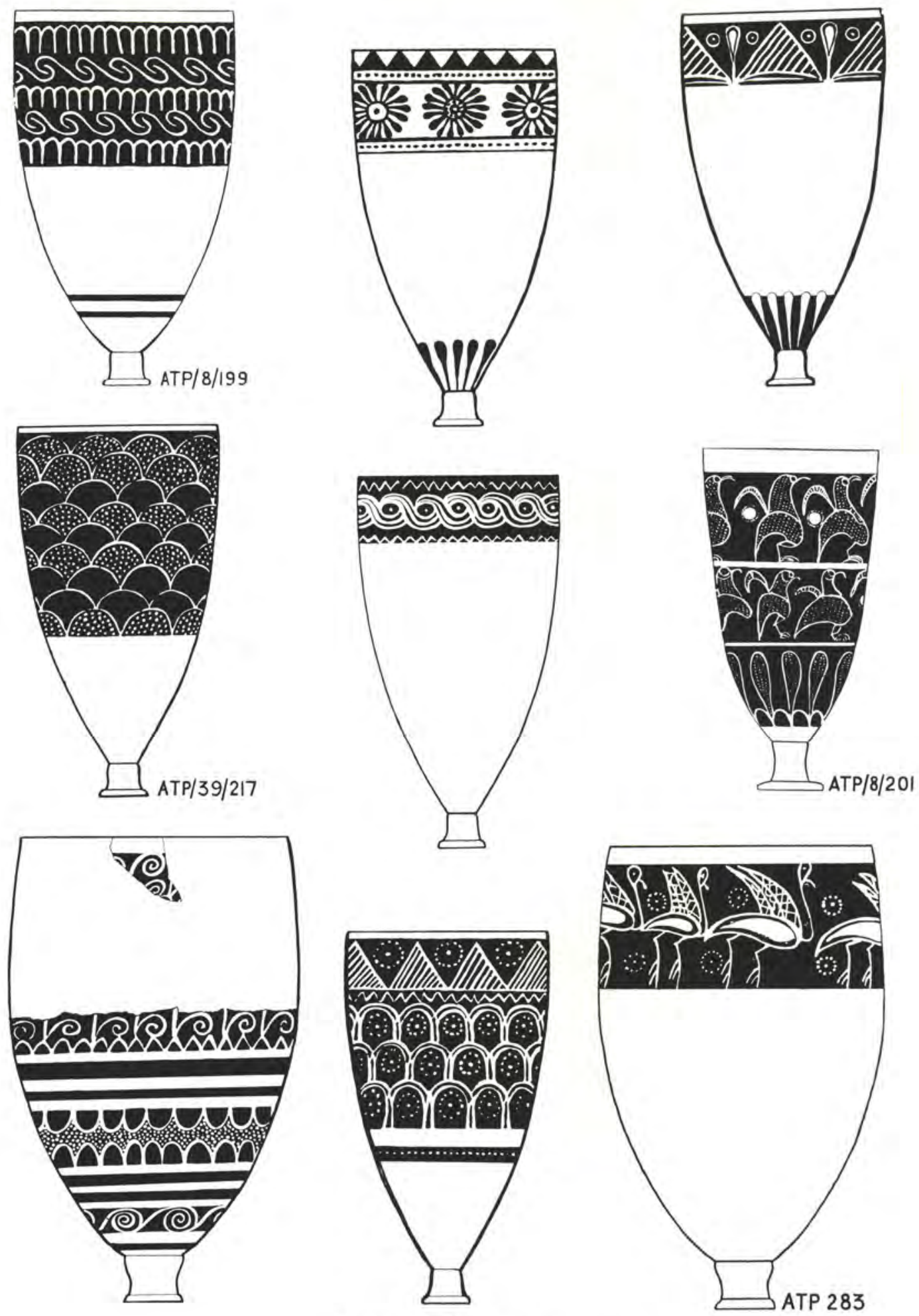

Designs on Nuzu pottery

(Uncatalogued examples are restored from fragments) 

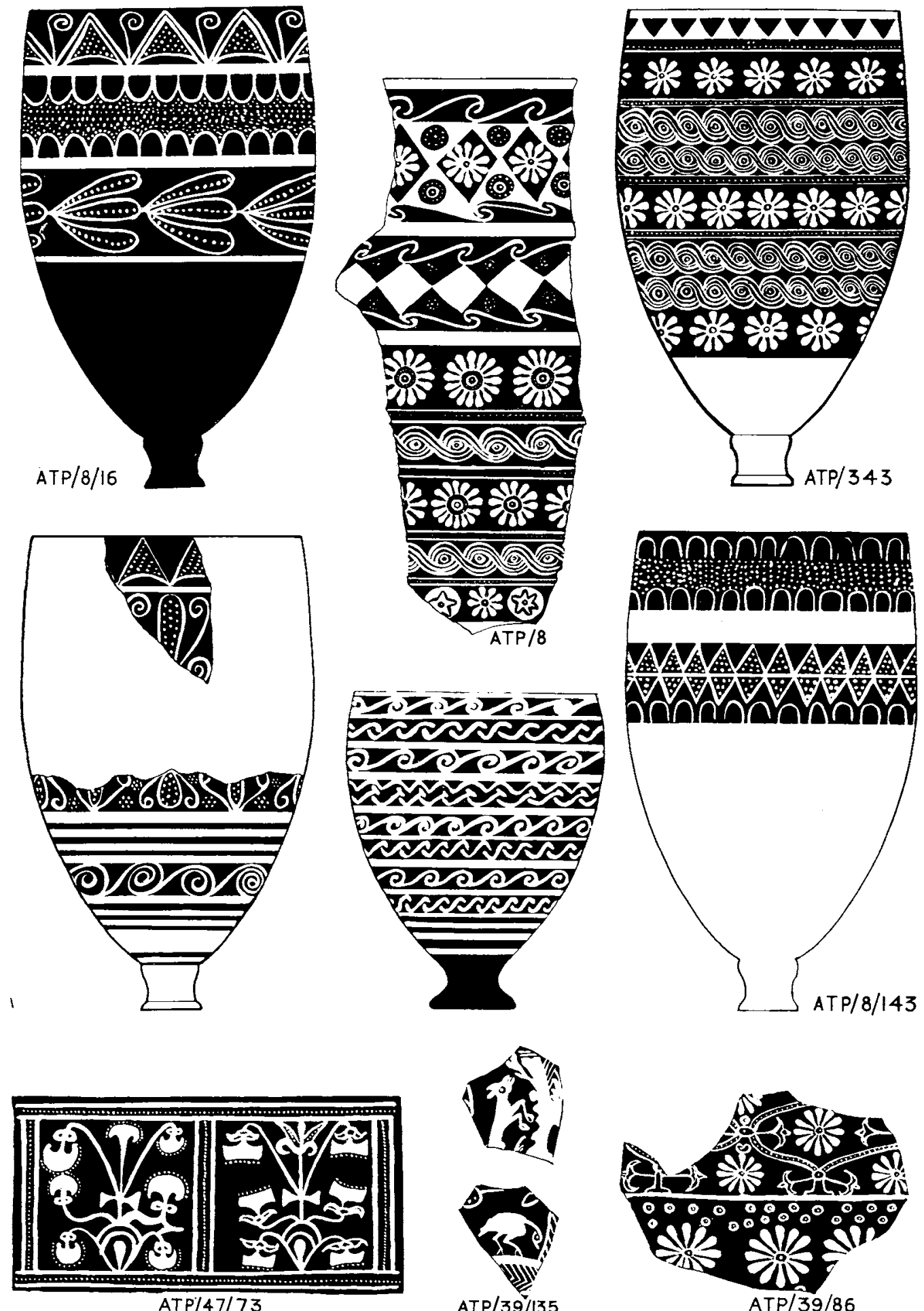

$A \in B$

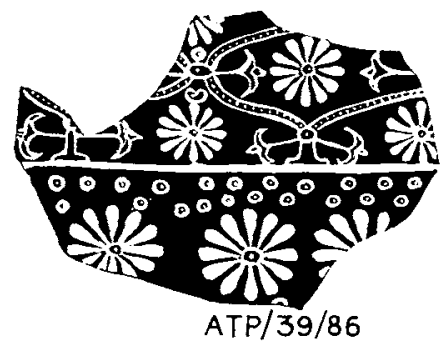

Designs on Nuzu and 'Atchana' pottery

(Uncatalogued examples are restored from fragments) 

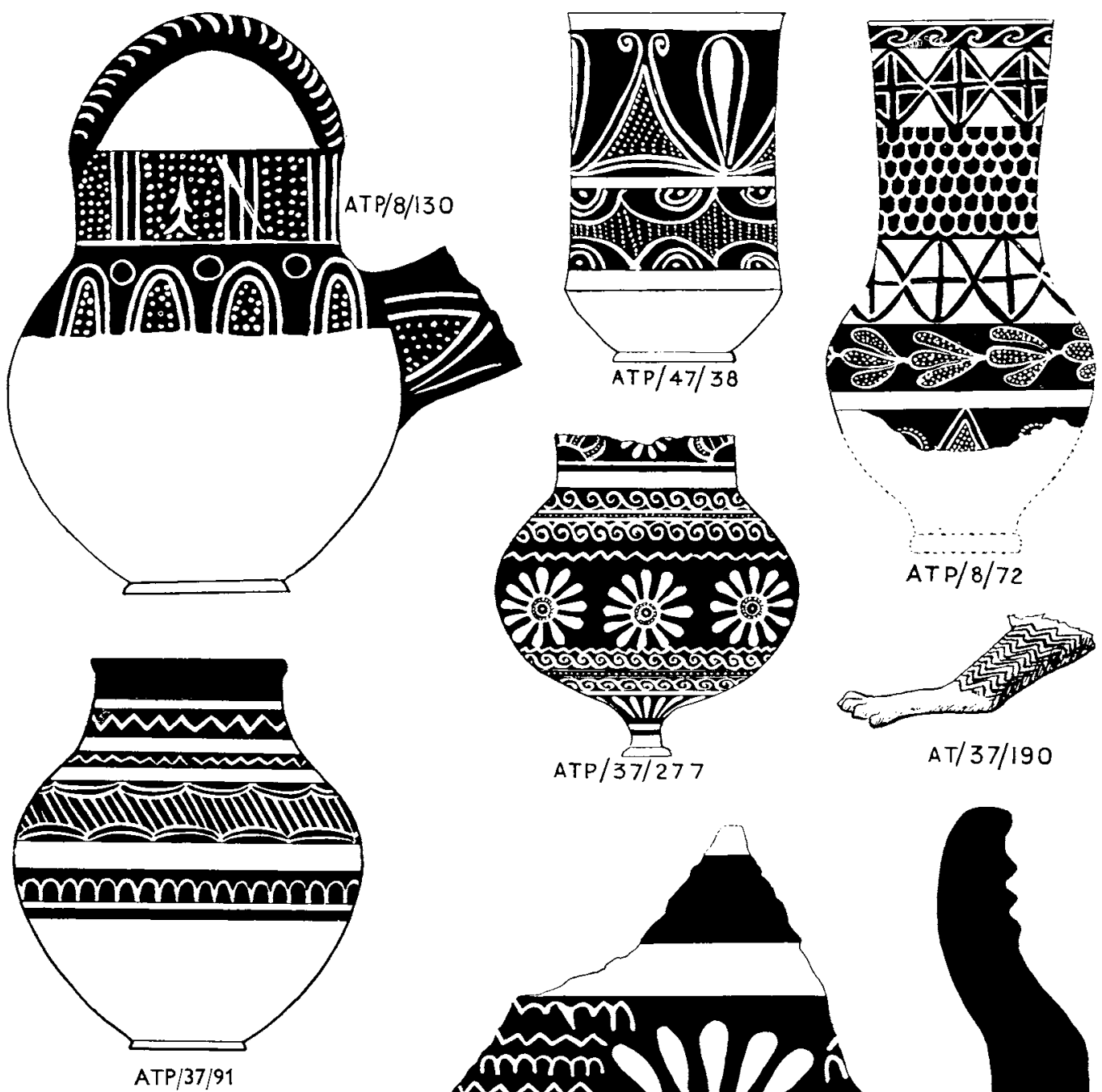

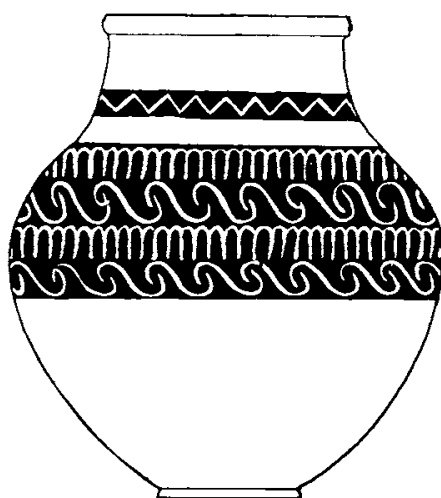

ATP/37/341

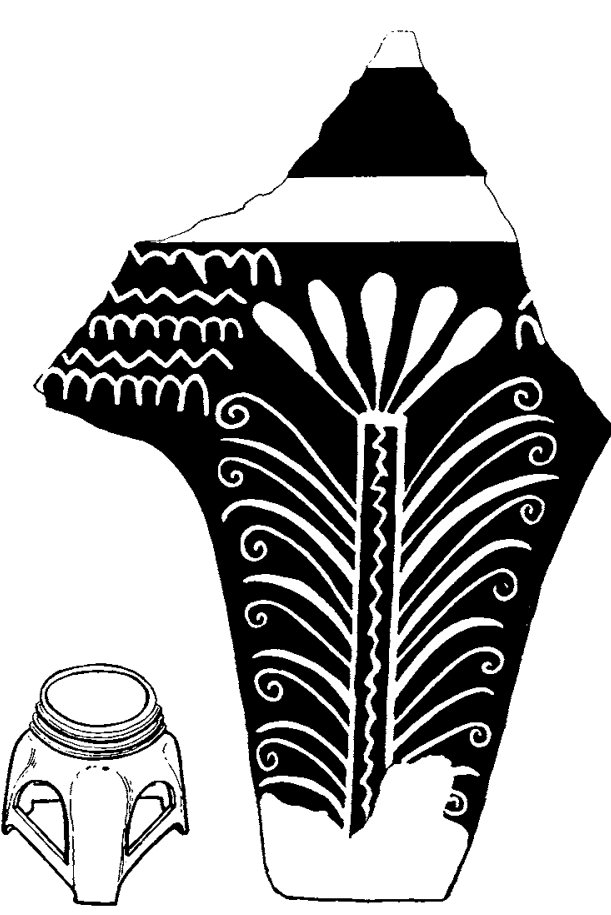

ATP/8/202

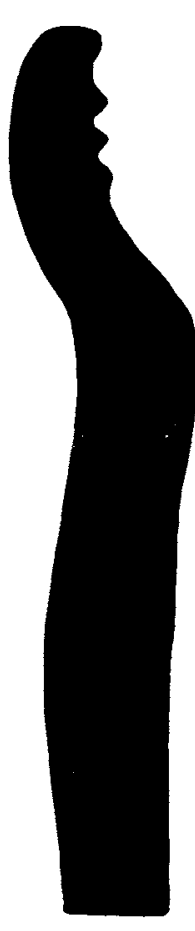

ATP/8/202

Examples of Nuzu pottery 
(a)
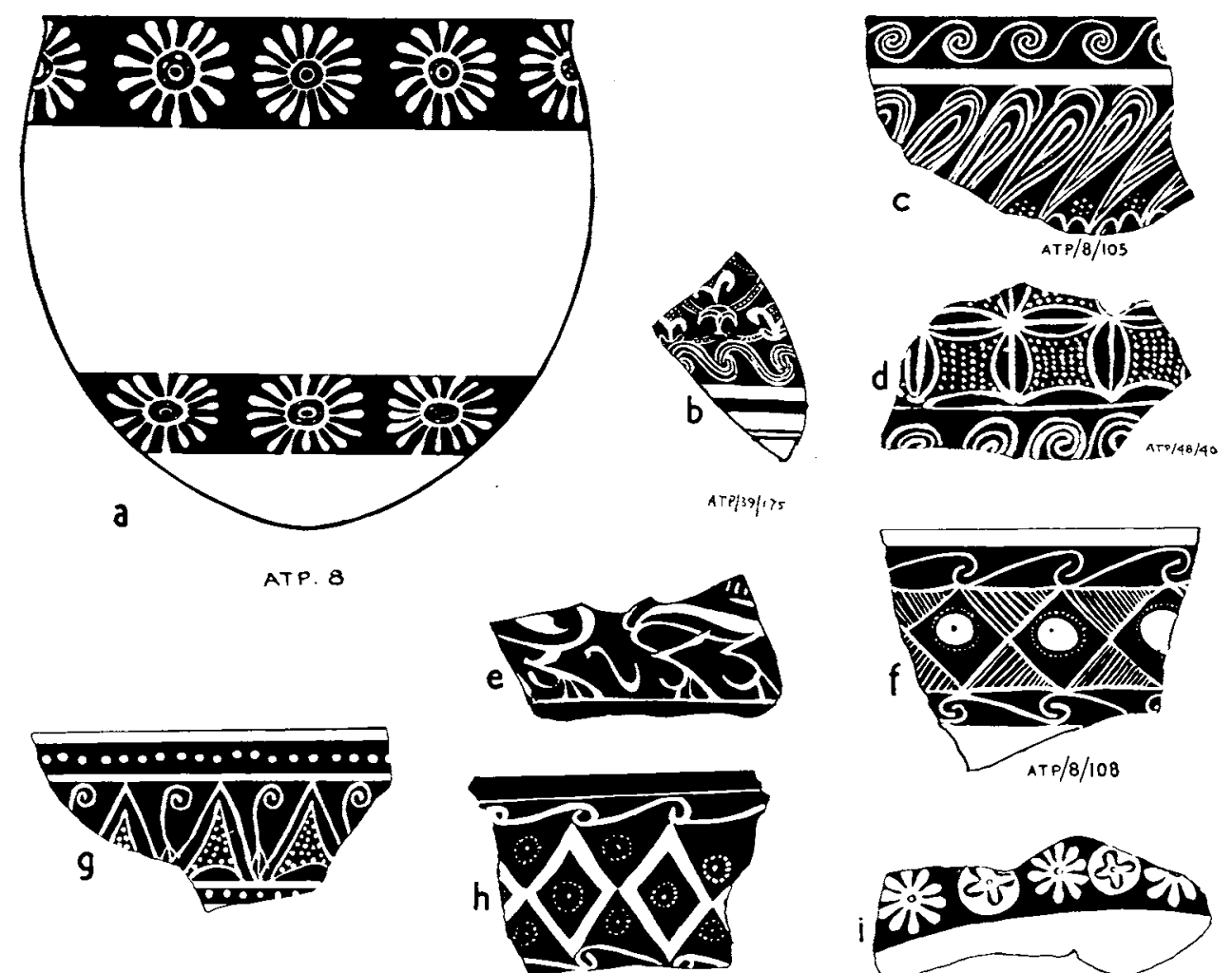

ATP. 239

(b)

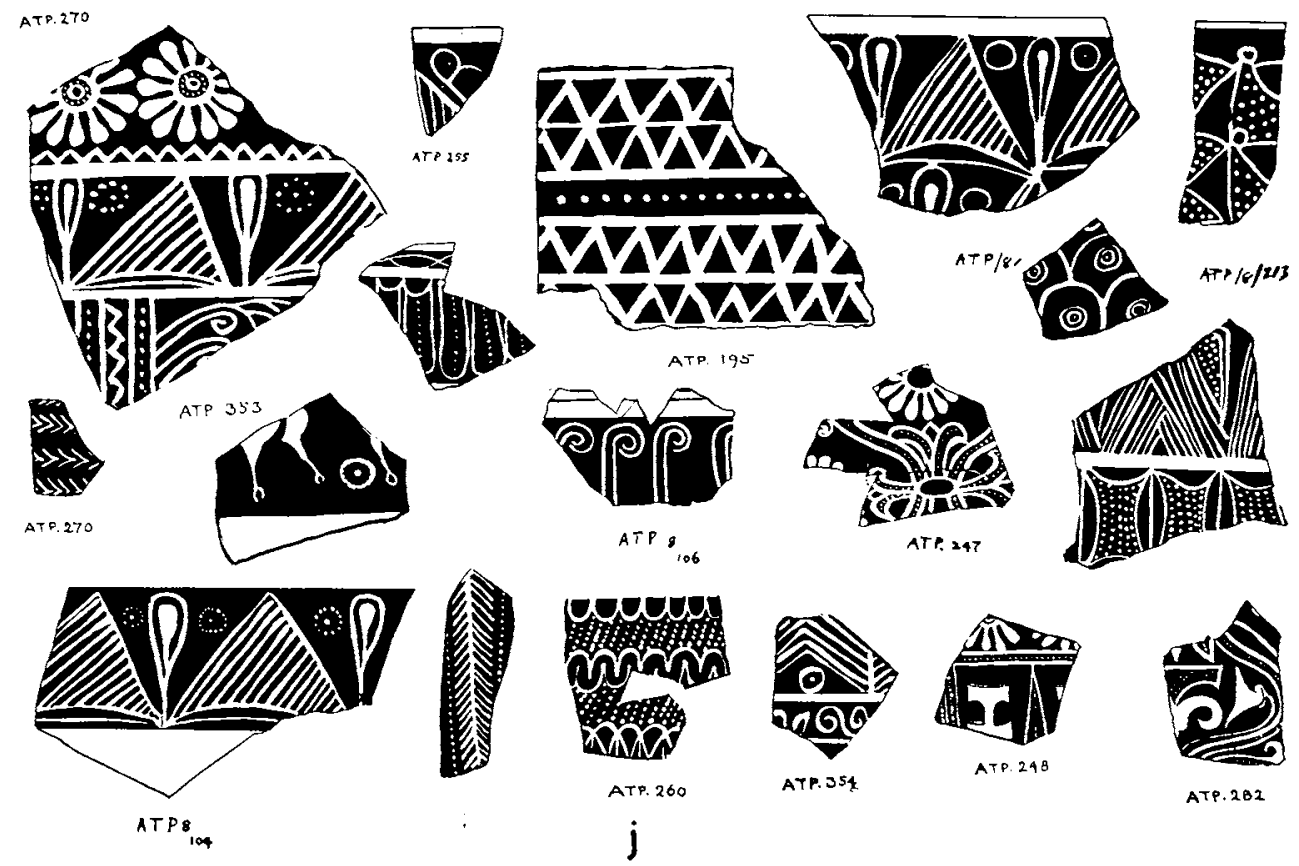

Examples of Nuzu and 'Atchana' pottery 

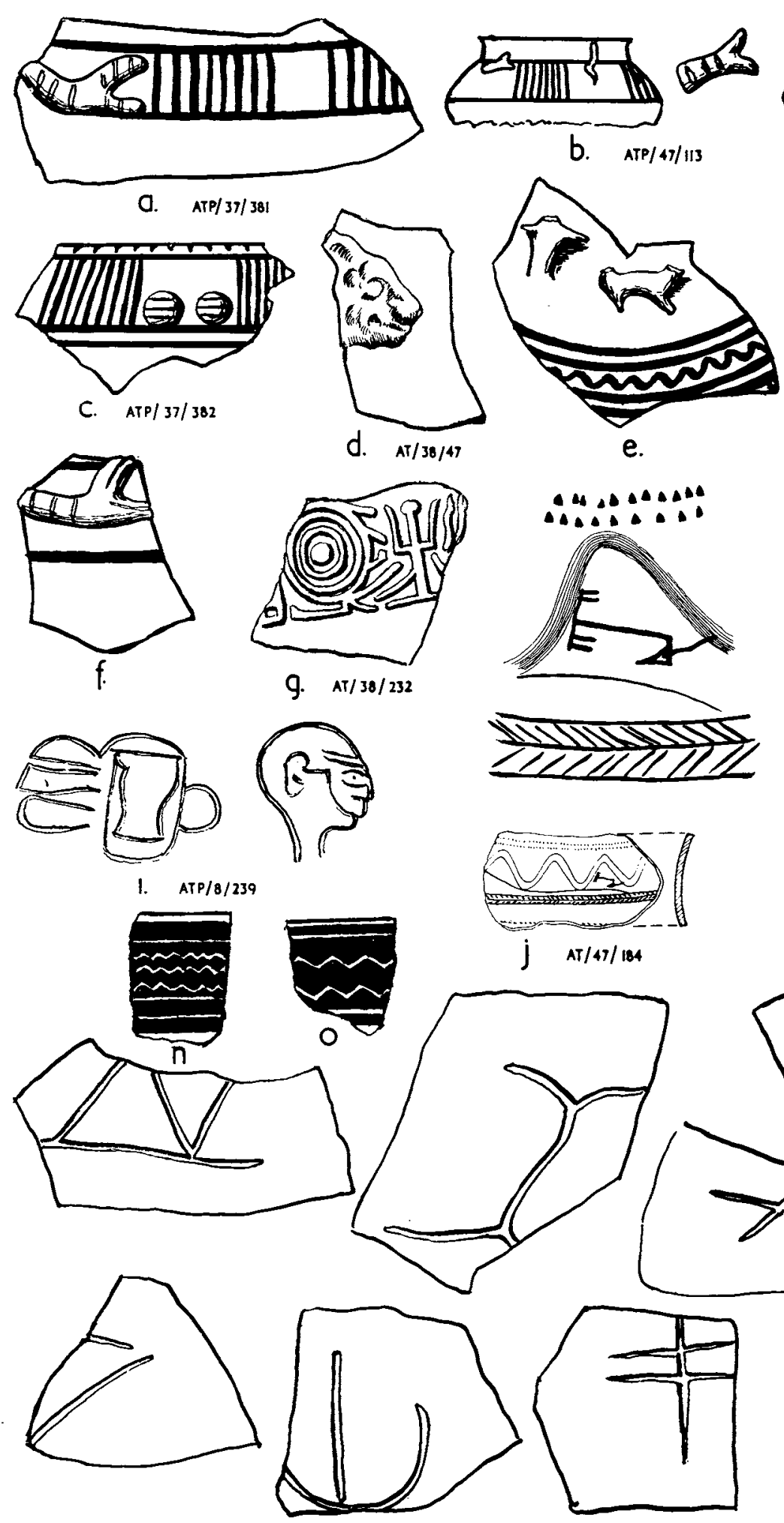

Relief and incised ornament on pottery, and potters' marks pp. $35^{2-3}$

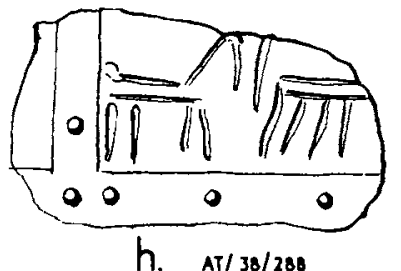

h. $A T / 38 / 288$
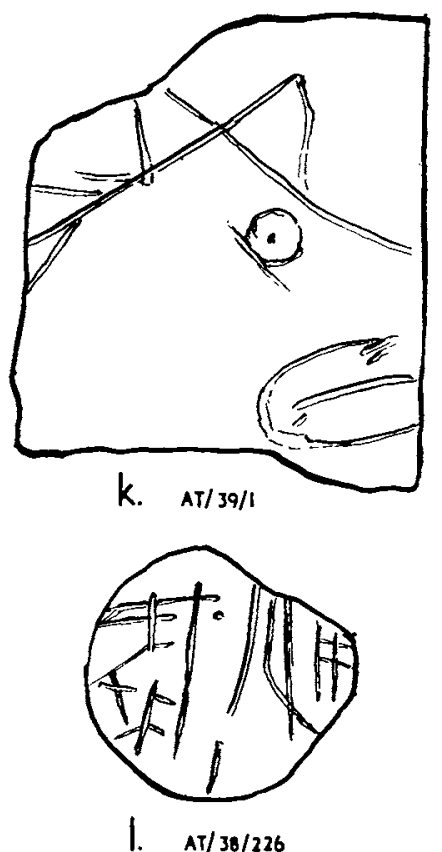

I. $A T / 38 / 236$

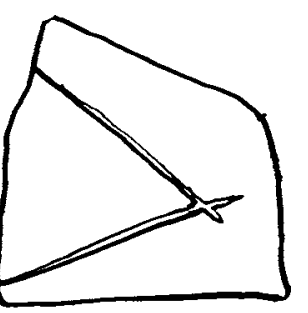

m. $A T P / 8 / 229$ 
PLATE CIX

1
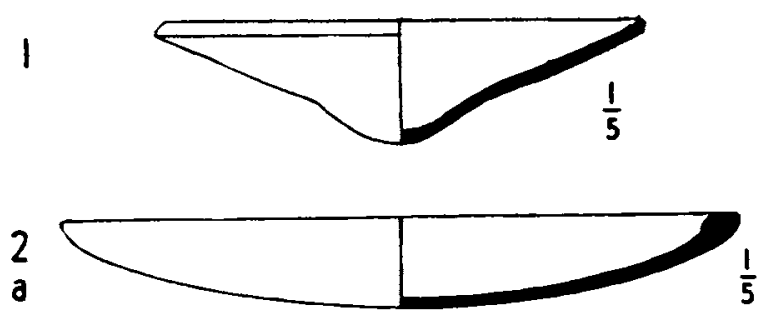

b

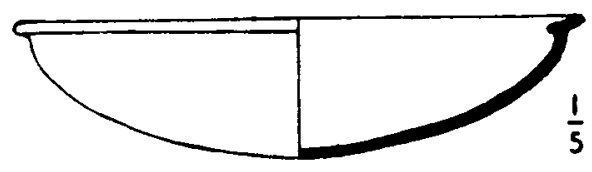

3

b

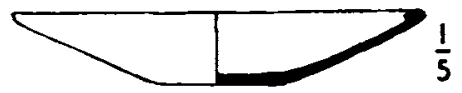

b

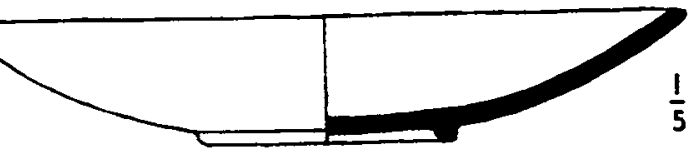

4
a

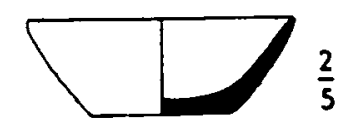

b

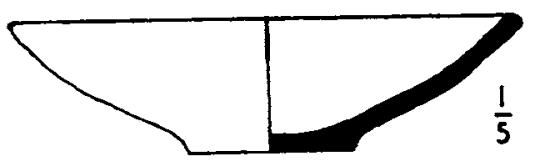

$c$

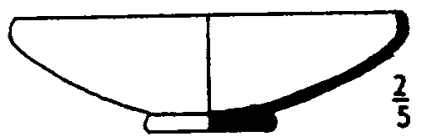

5

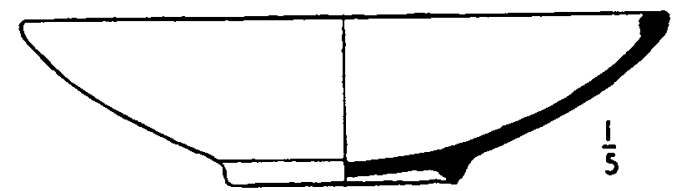

6

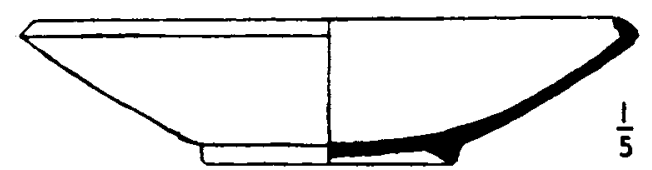

b

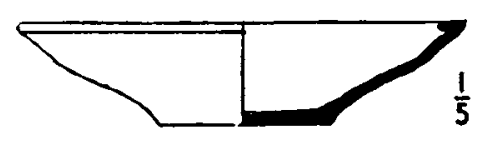

7

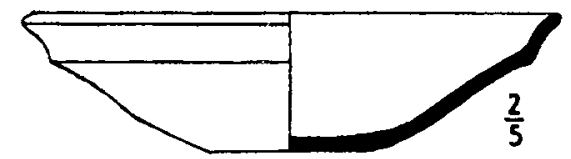

b

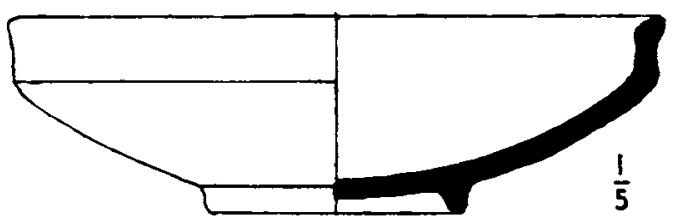

8

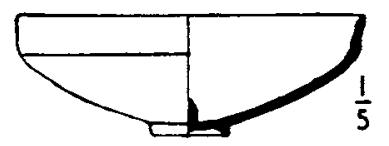

9

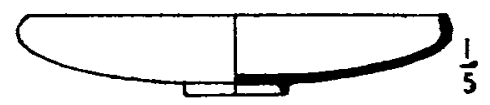

b

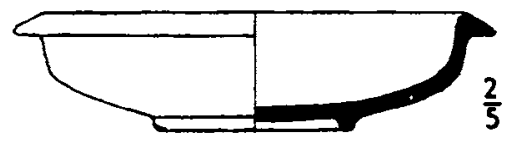

$c$

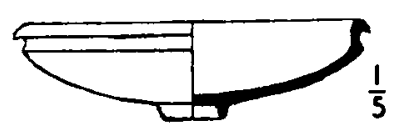

10

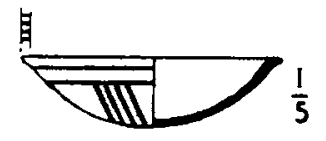

II

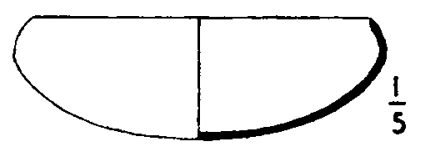

12

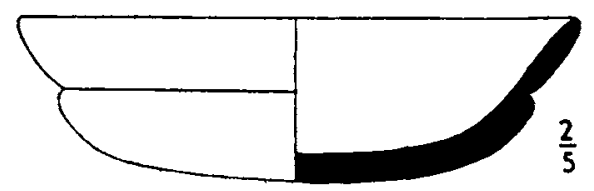

13

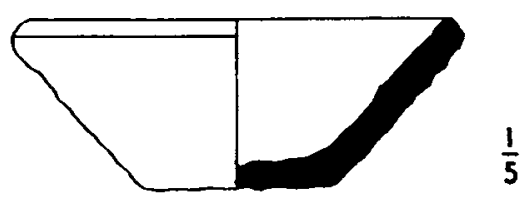

14

a

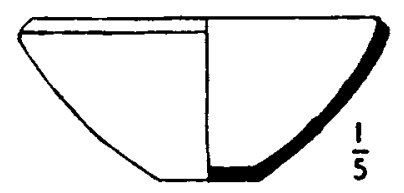

Types of local pottery

pp. 320 sqq. 
PLATE CX

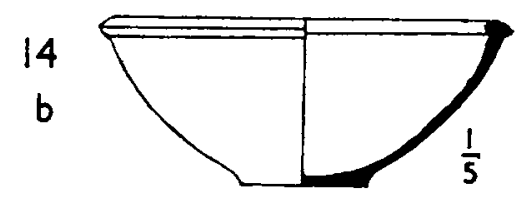

15

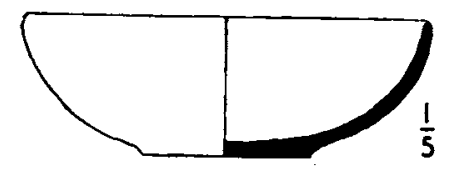

16

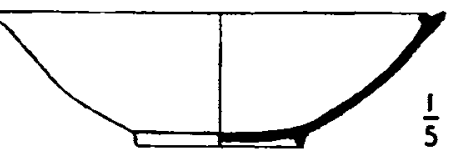

17

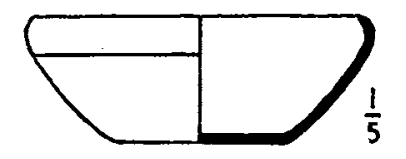

18

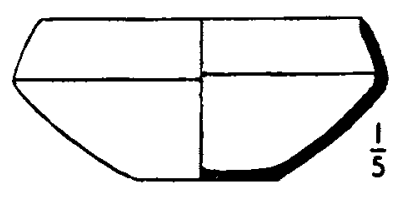

19

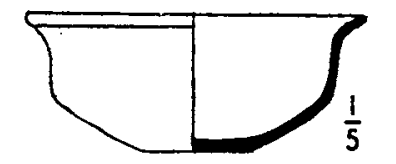

20

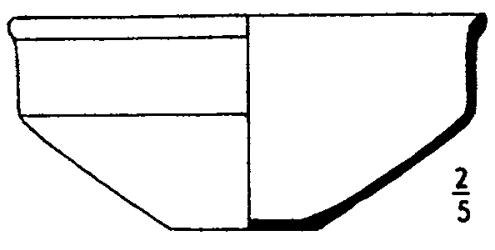

21
$a$

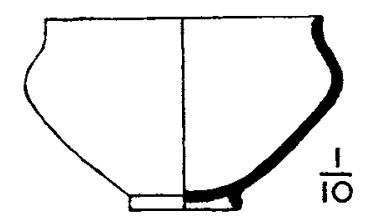

b

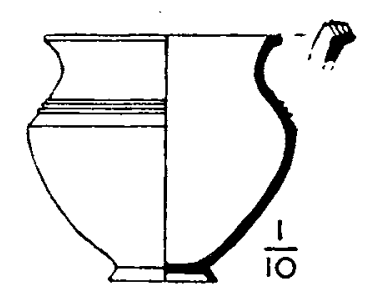

c

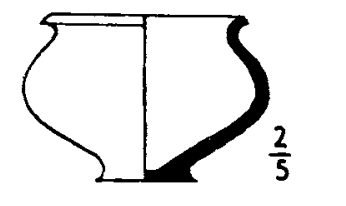

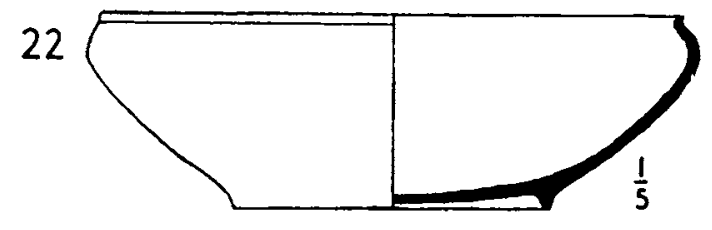

23
$a$

b
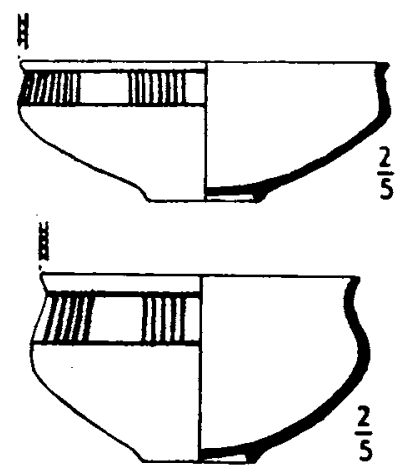

$c$

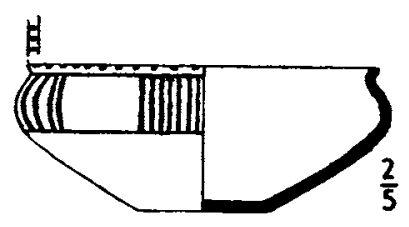

d
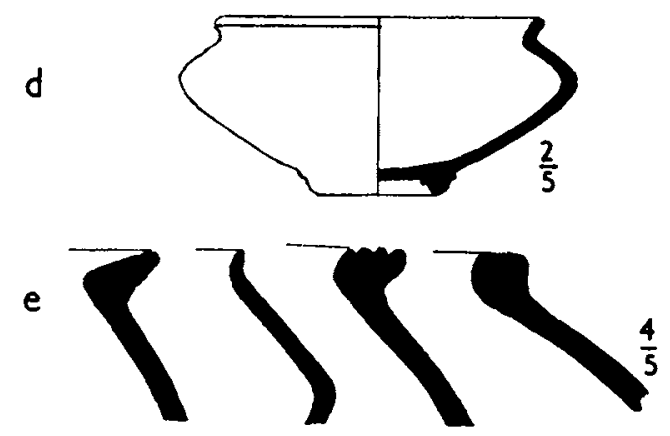

24

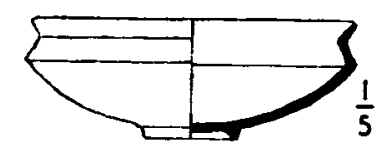

25

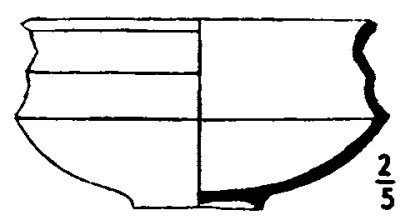

26
$a$

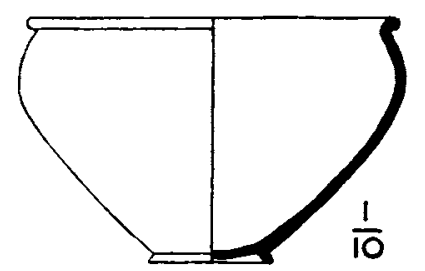

Types of local pottery

pp. 320 sqq. 
PLATE CXII
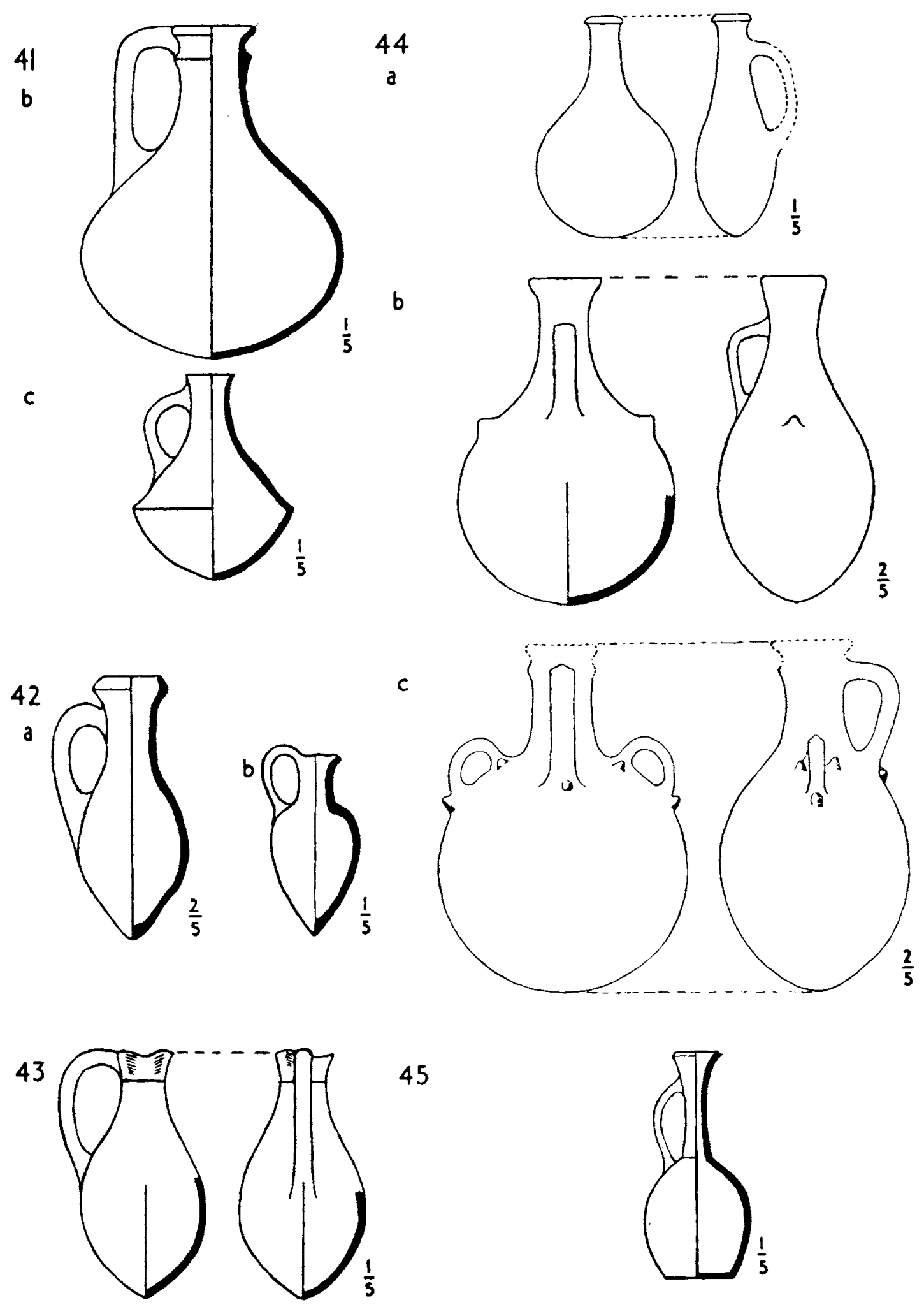

Types of local pottery

pp. 320 sqq. 
PLATE CXIII

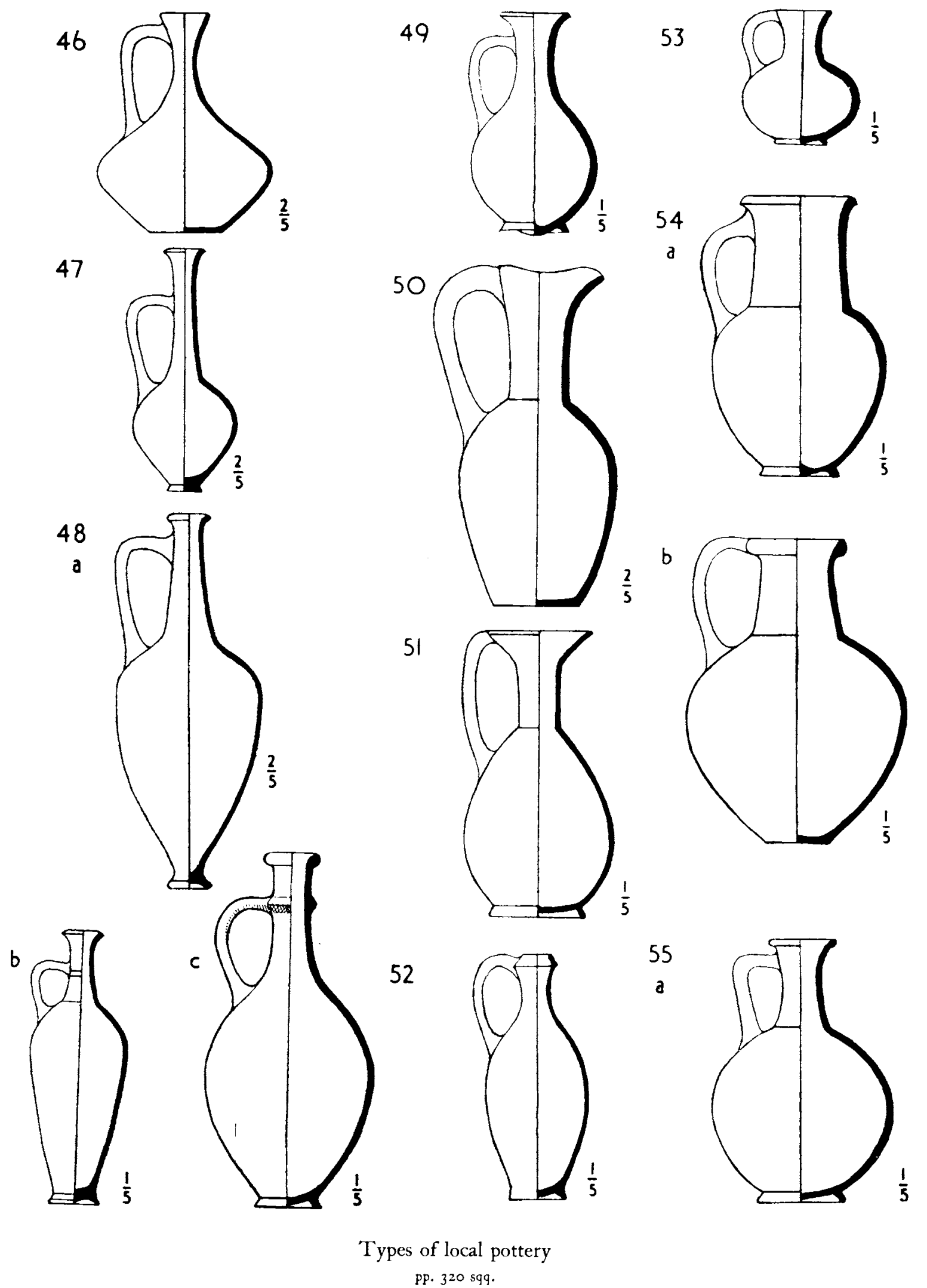


PLATE CXIV
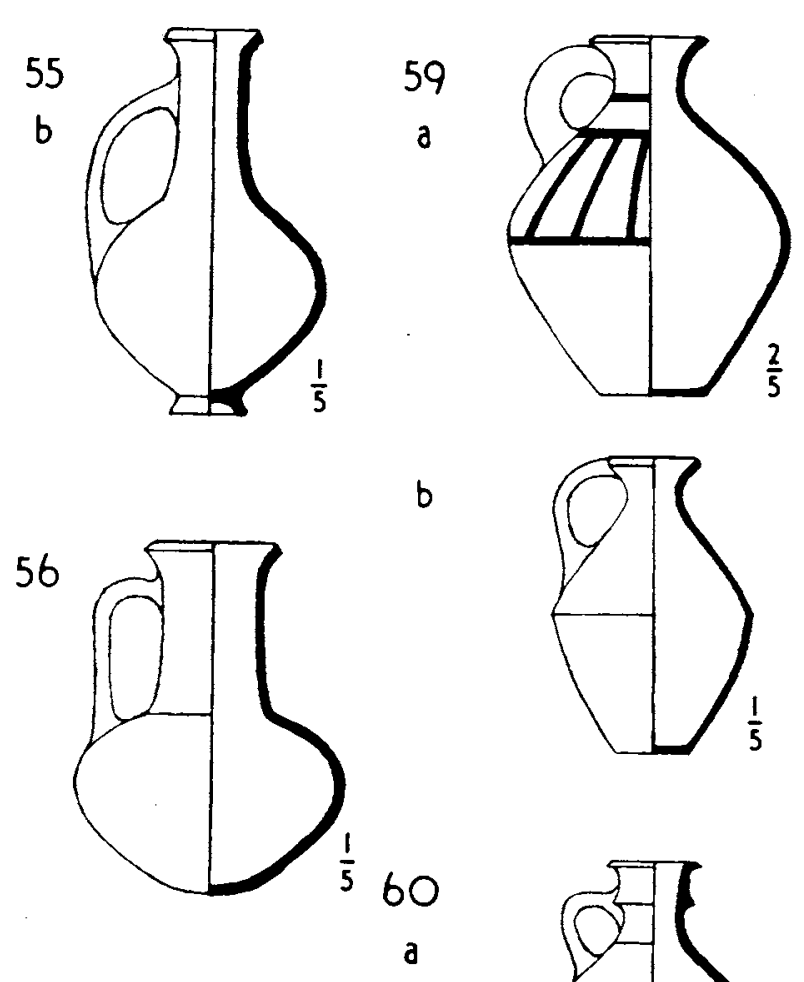

b
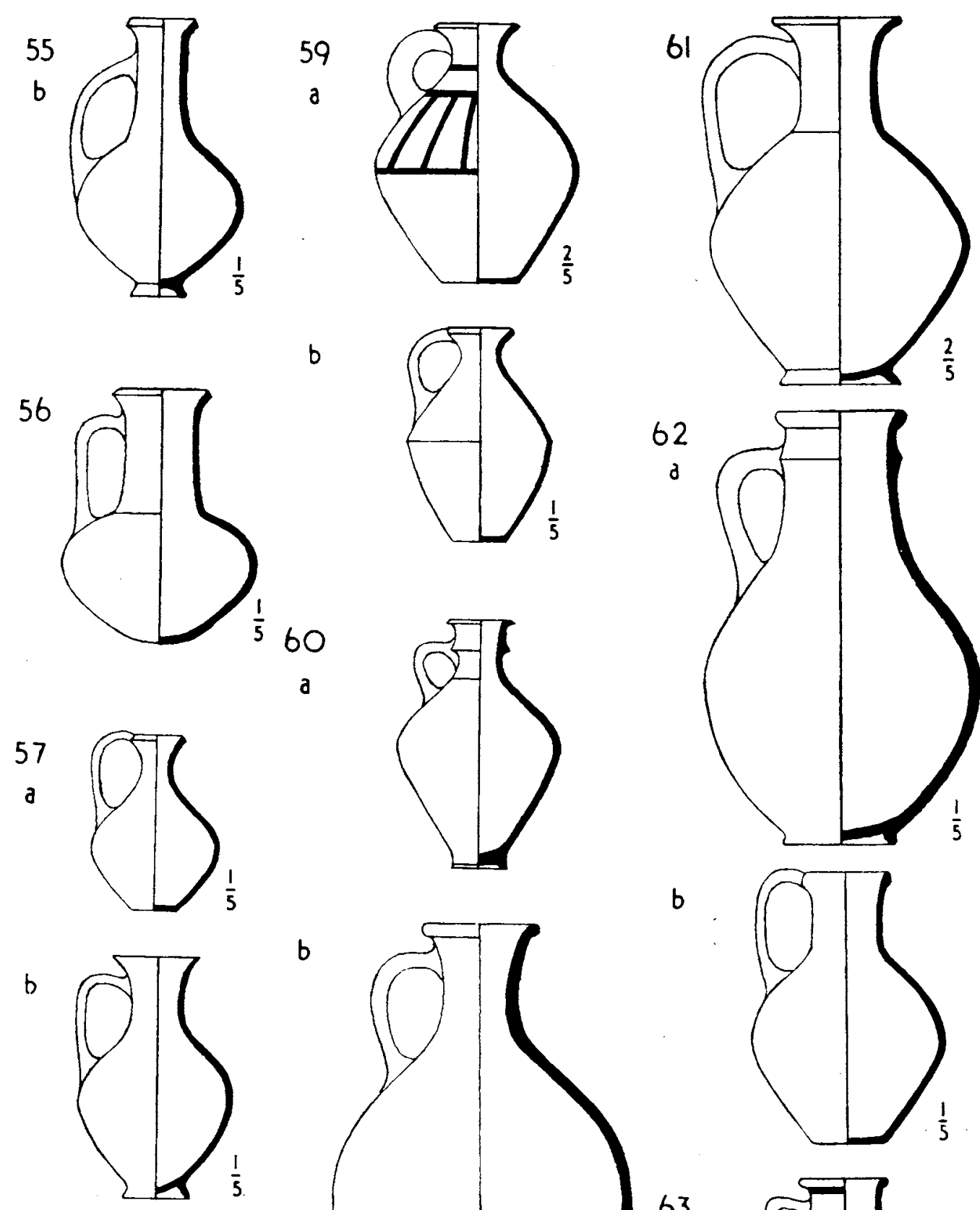

b

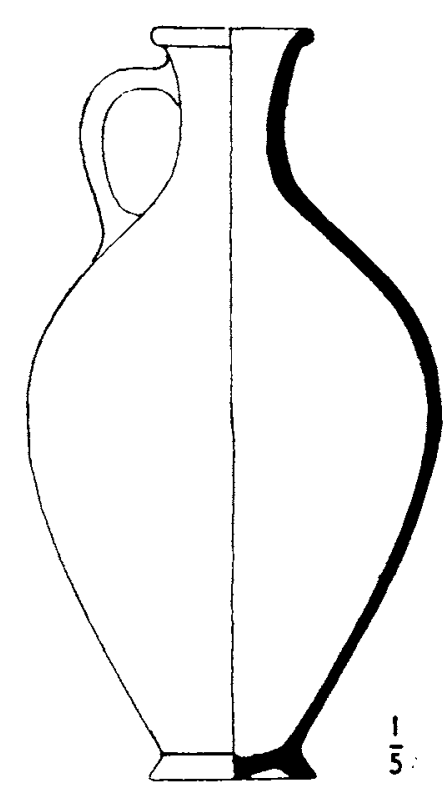

b
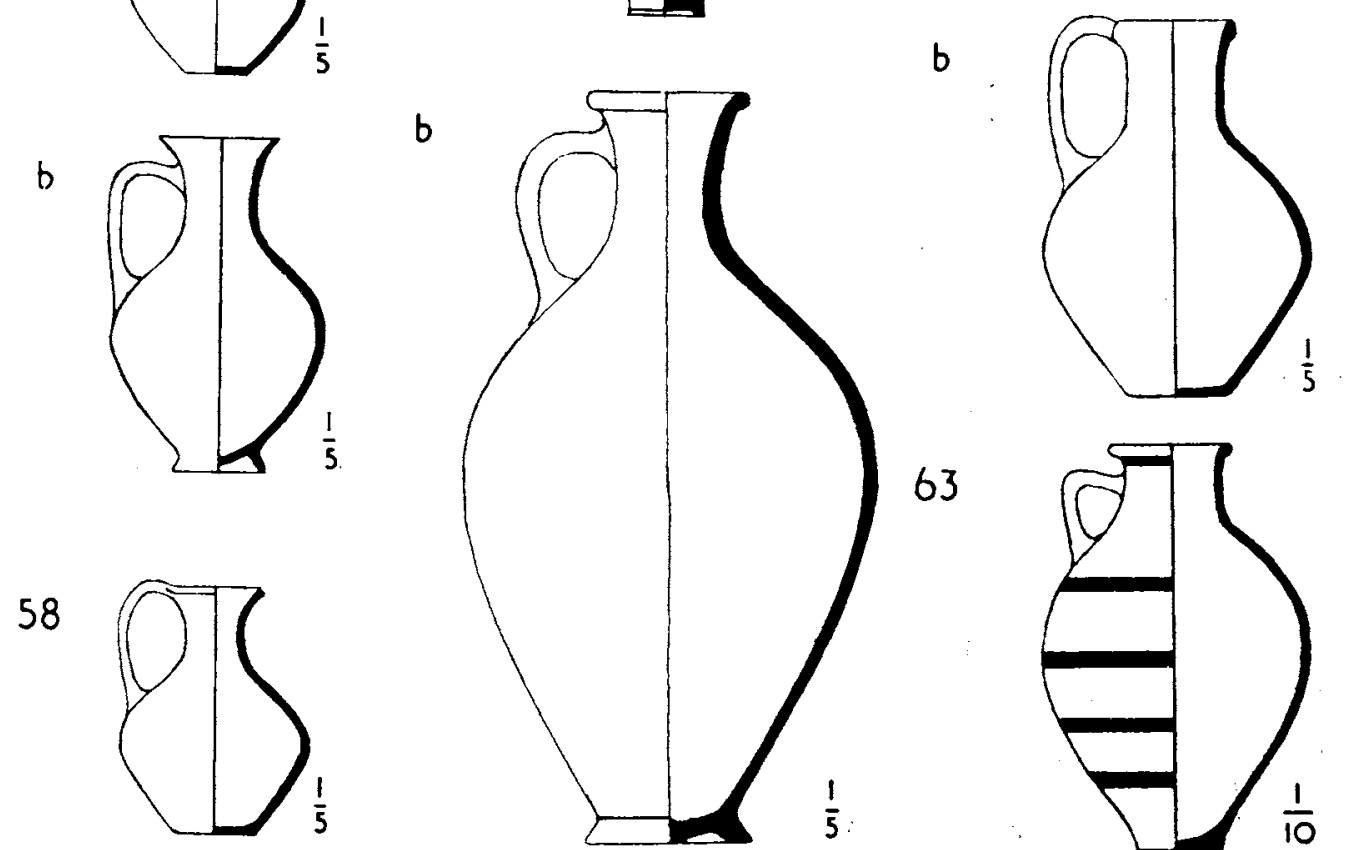

63

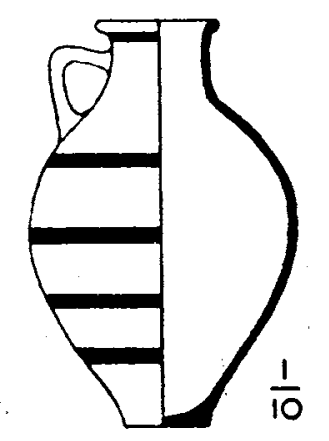

Types of local pottery pp. 320 sqq. 
PLATE CXV
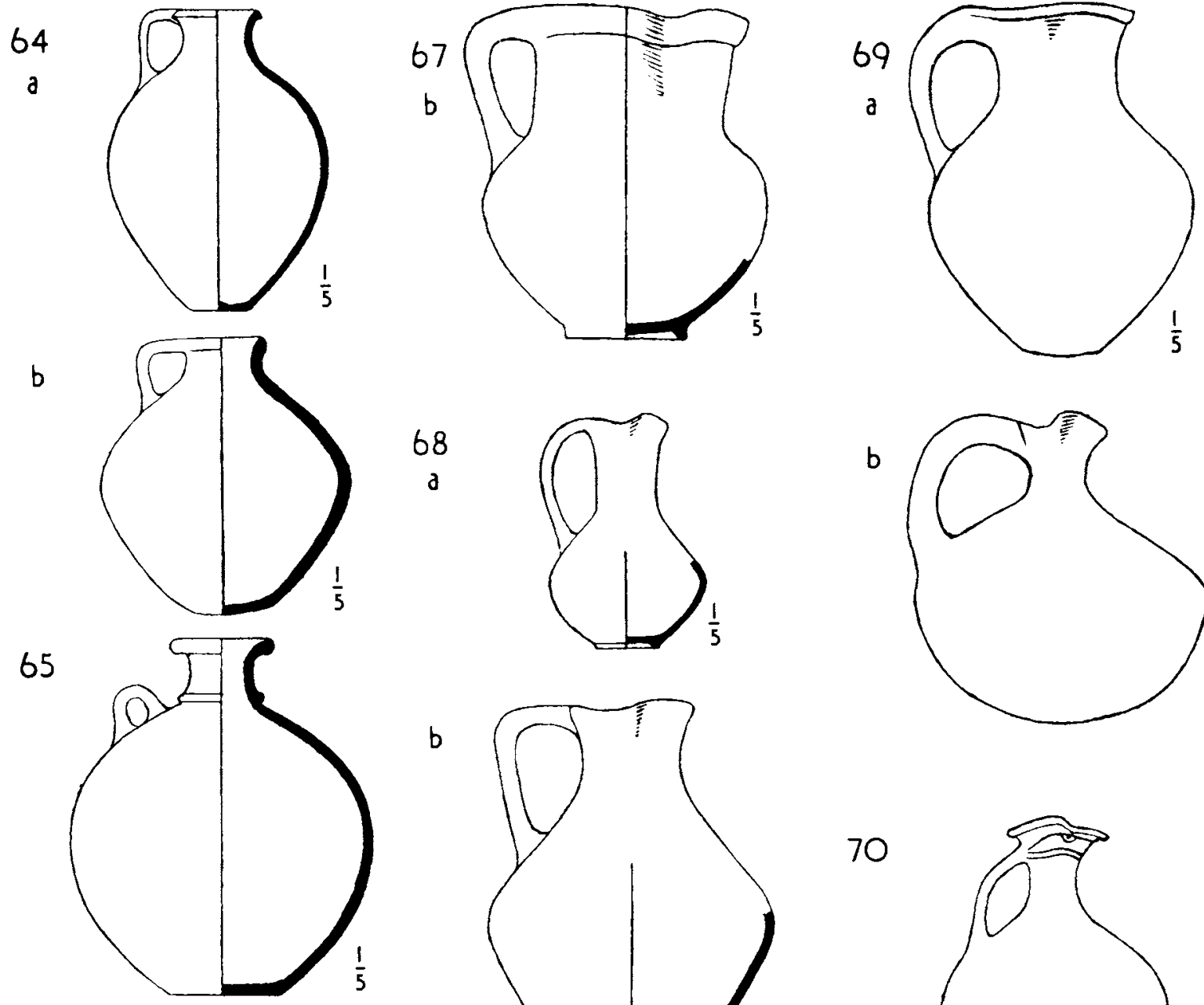

b

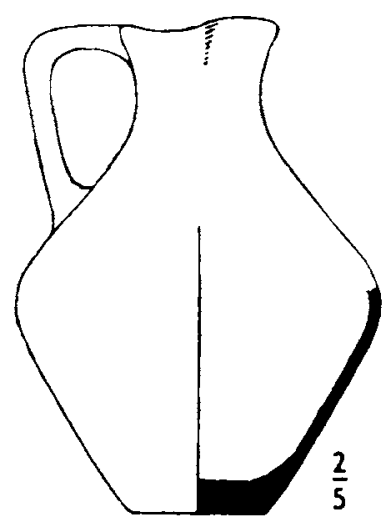

b
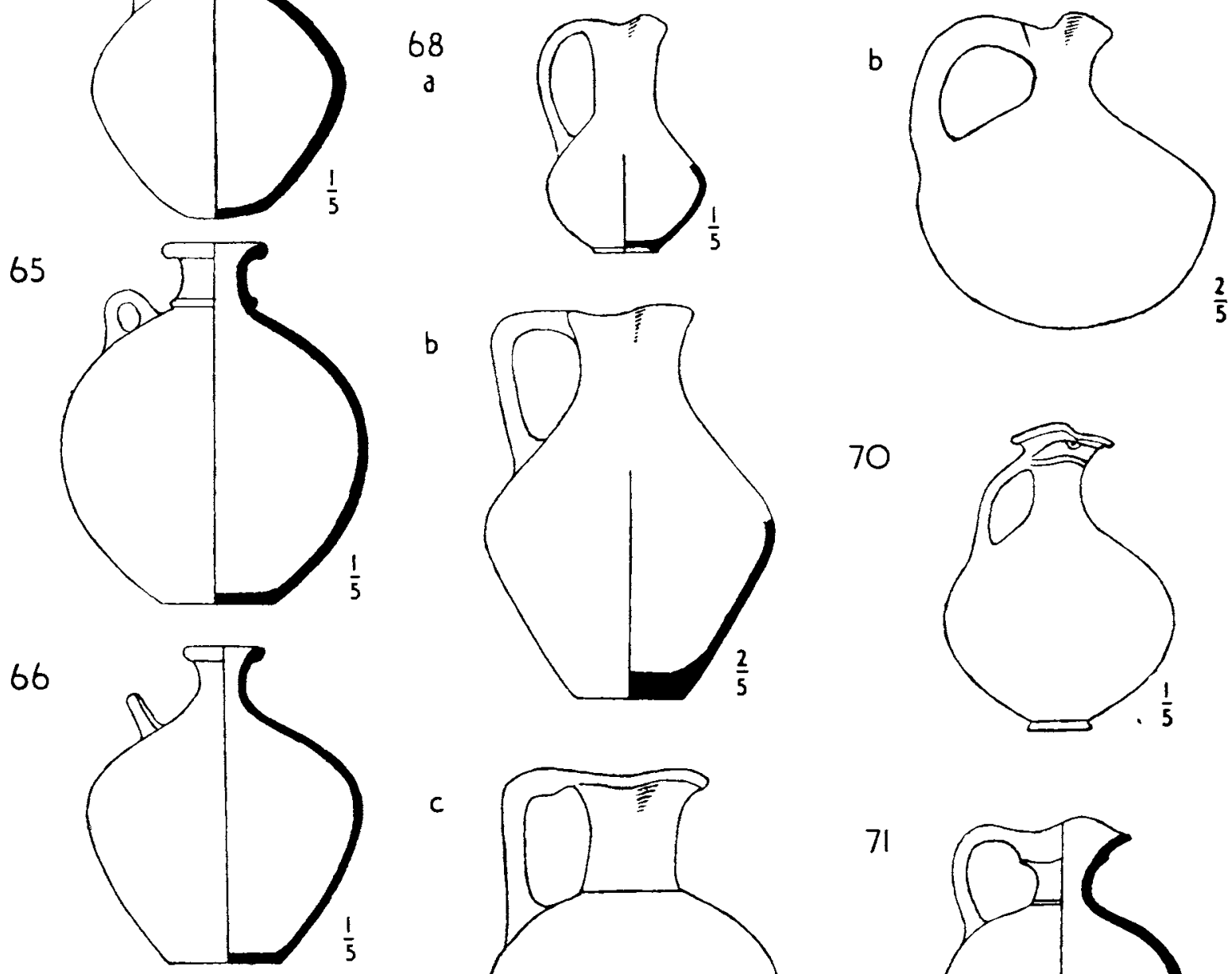

b
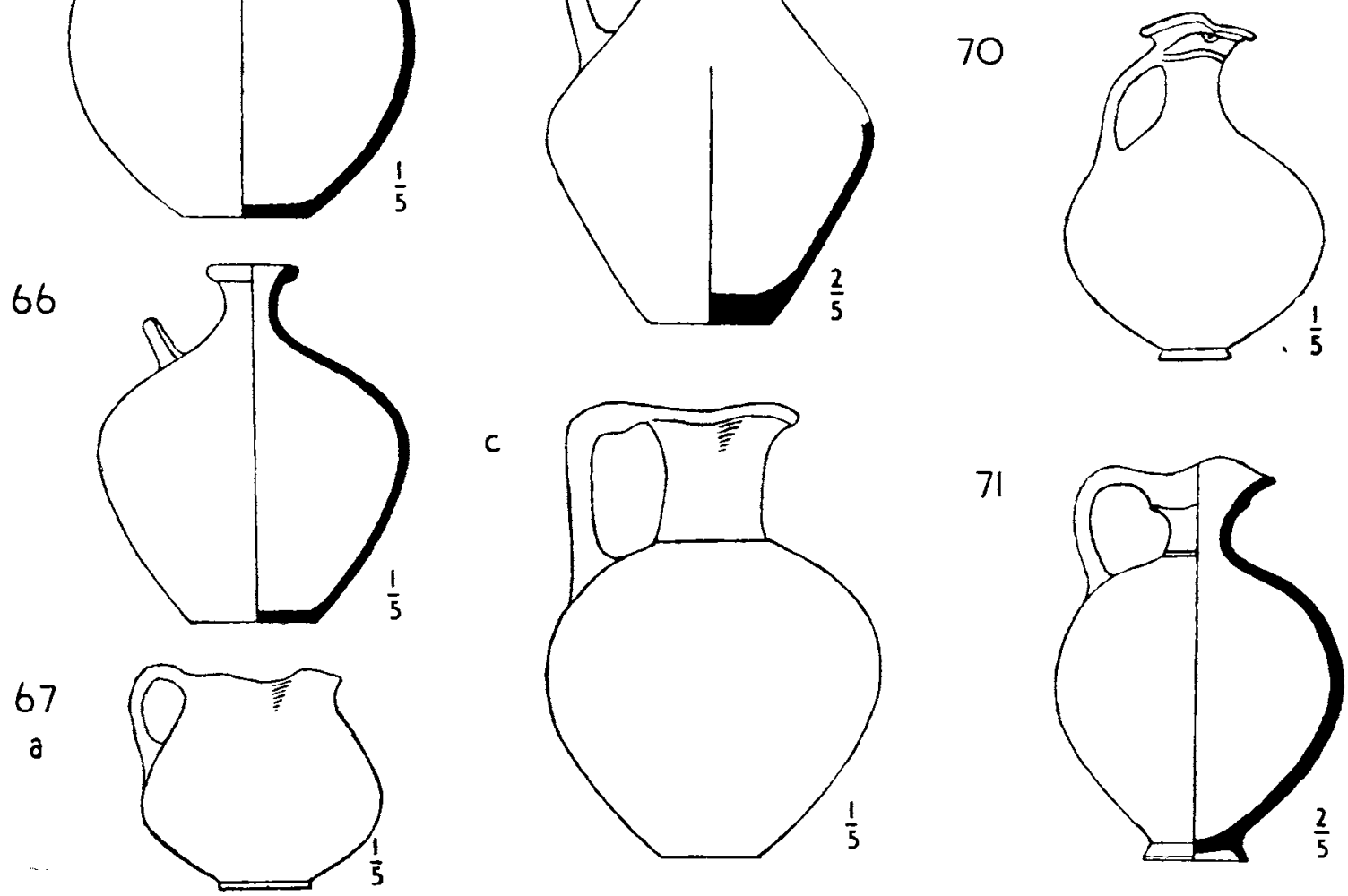

Types of local pottery pp. 320 sqq. 
72

a

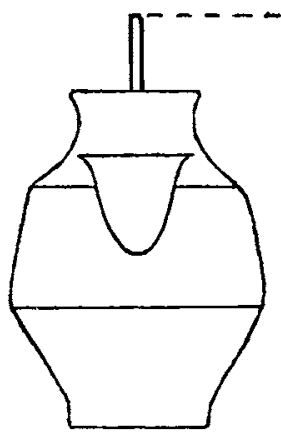

b

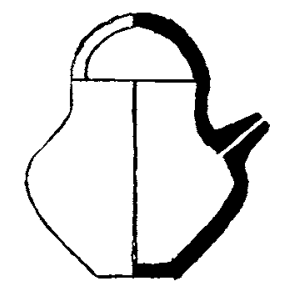

73

a

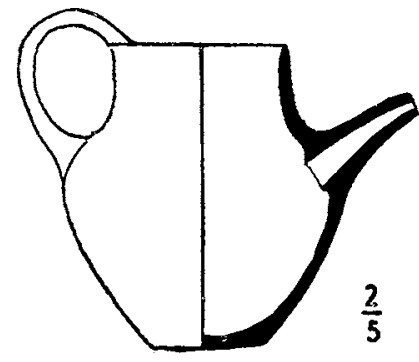

b

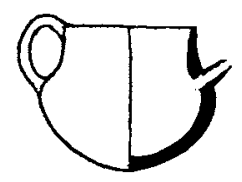

74

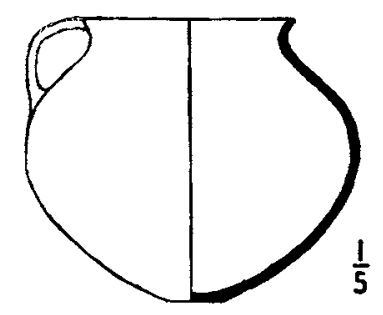

75

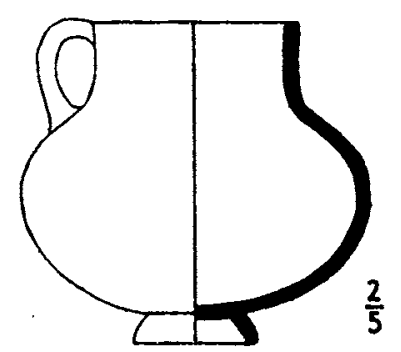

76

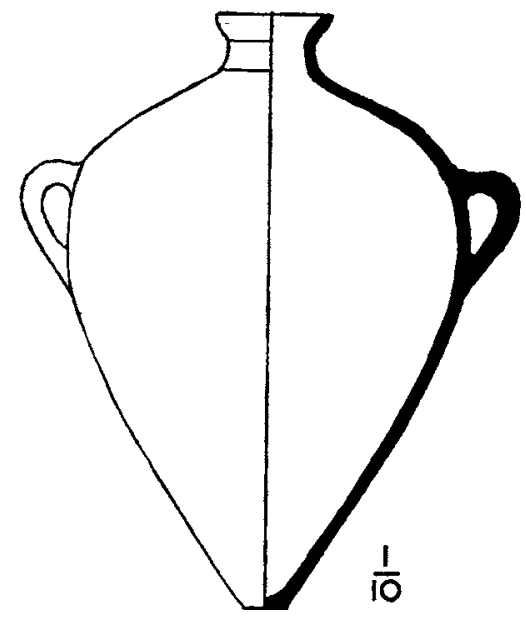

77

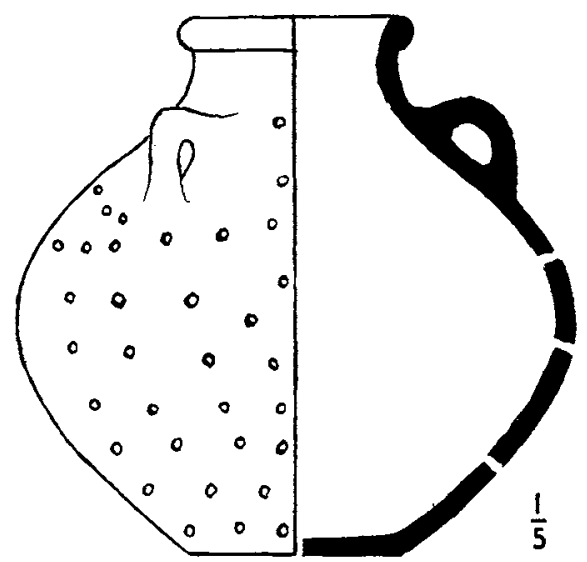

78

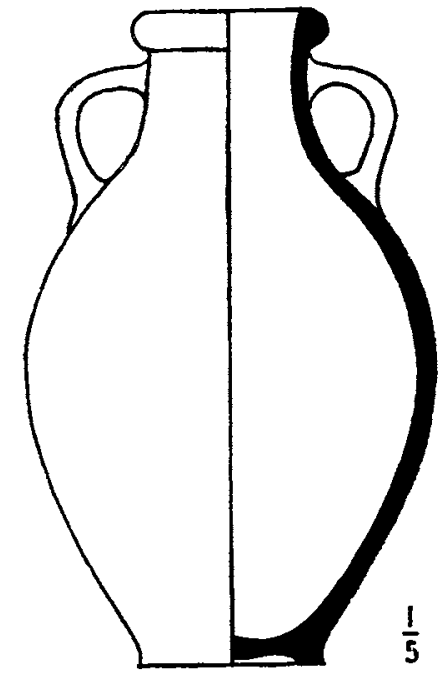

81
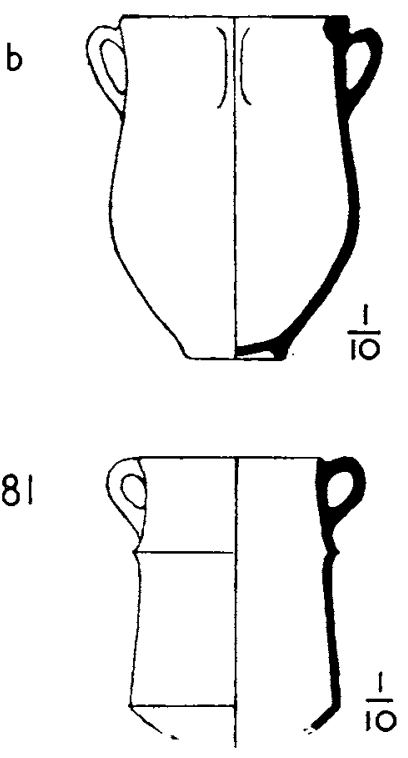

82

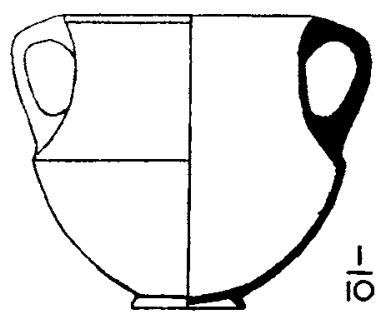

Types of local pottery 
PLATE CXVII
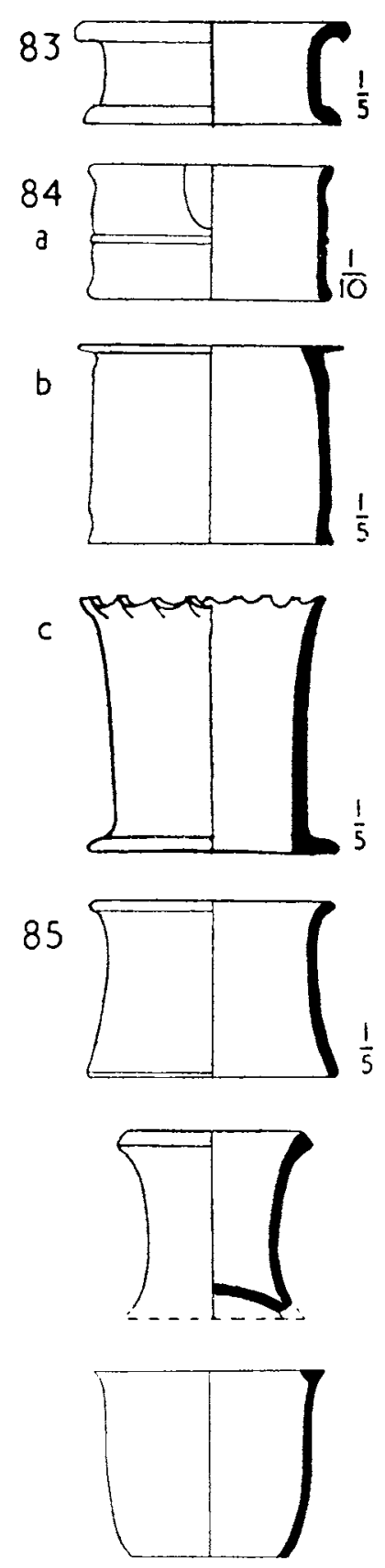

88

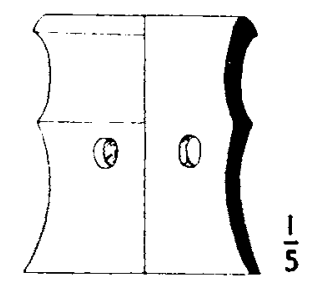

89

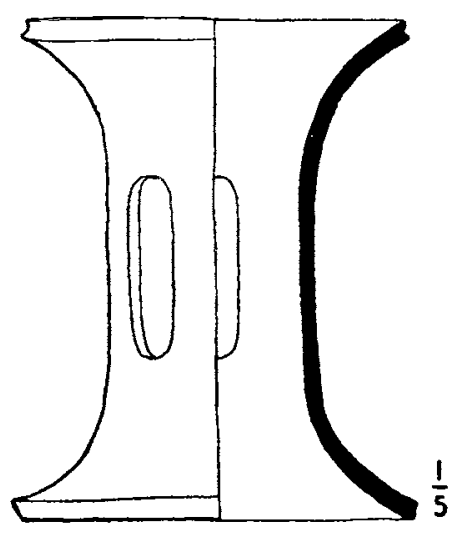

90

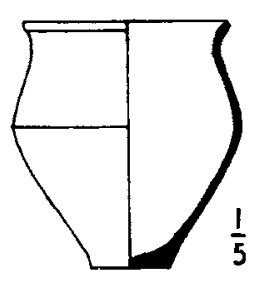

91 a

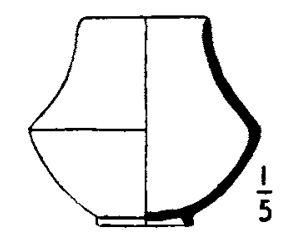

b

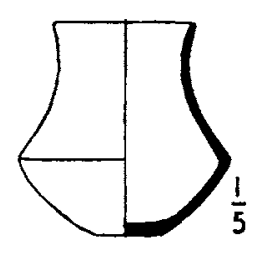

92
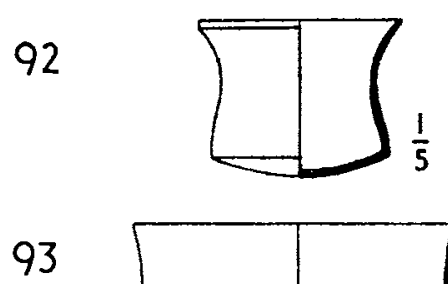

a

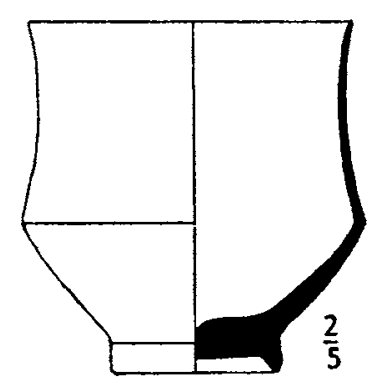

Types of local pottery pp. 320 sqq.

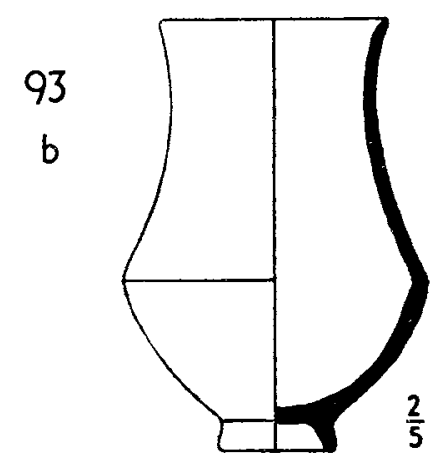

c

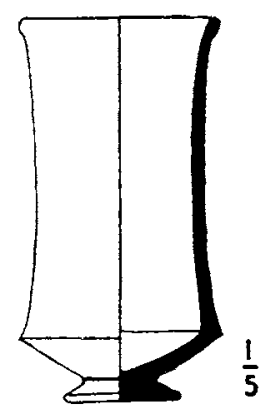

94
$a$

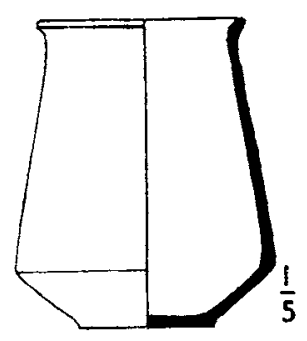

b
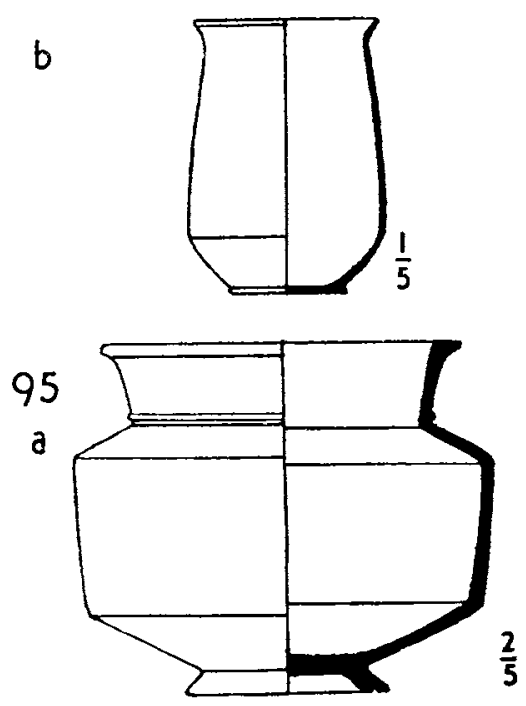
PLATE CXVIII
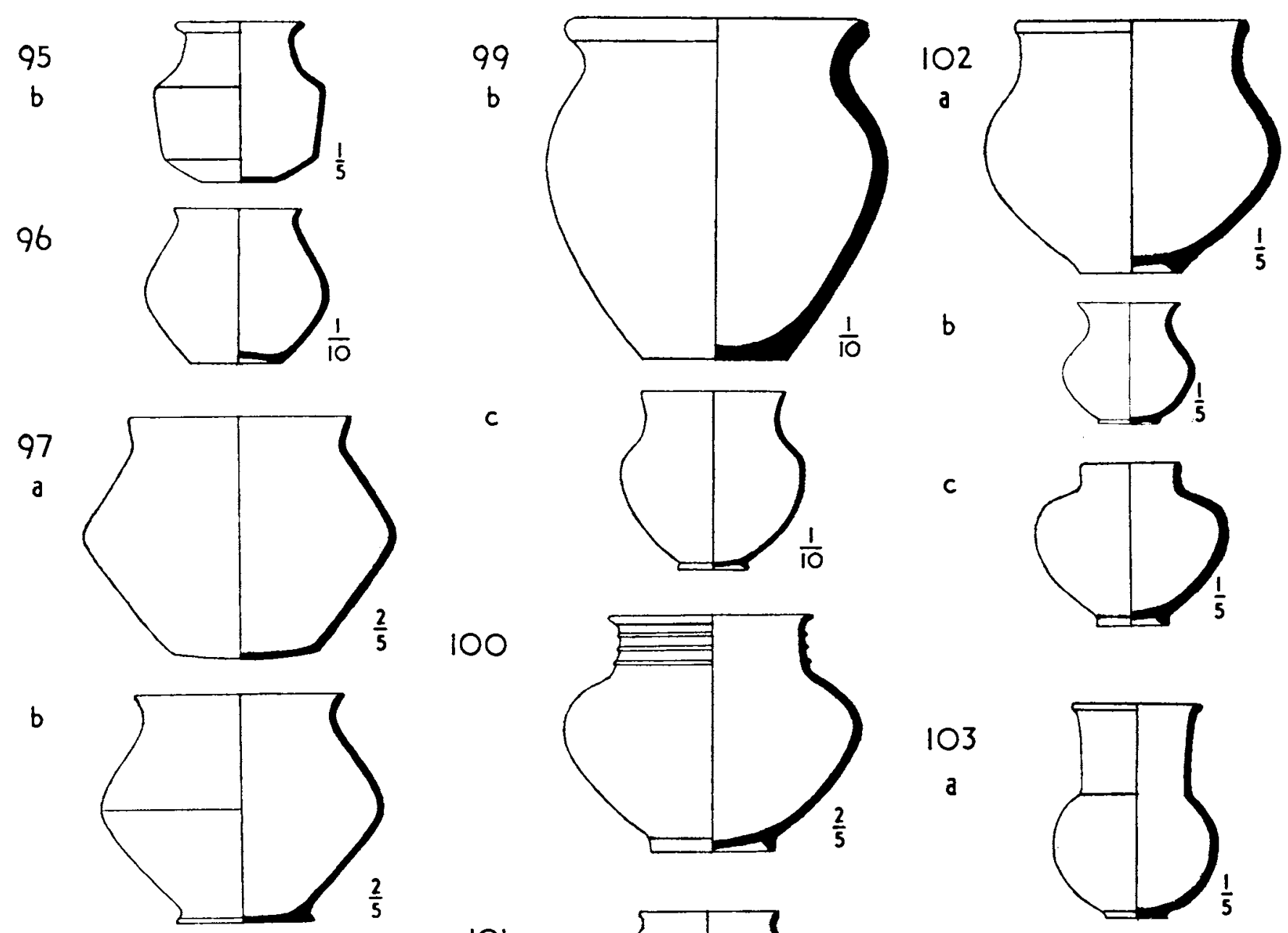

98
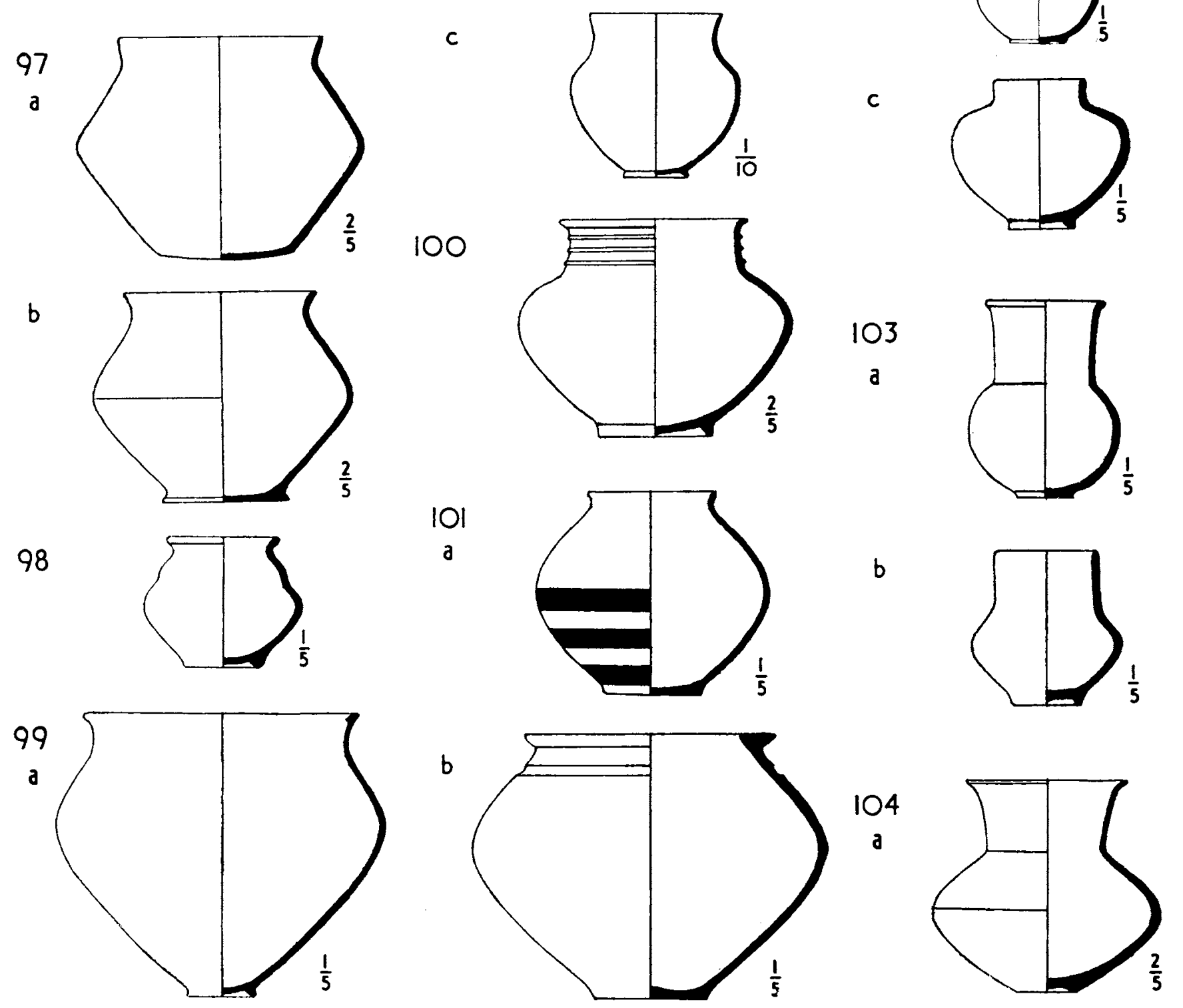

Types of local pottery pp. 320 sqq.

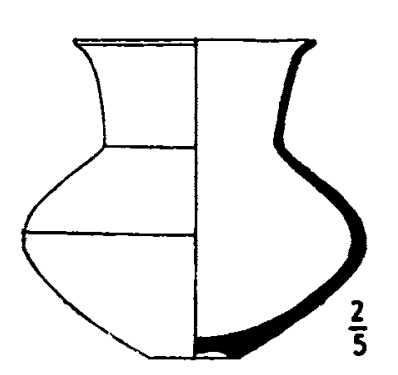


PLATE CXIX

104

b

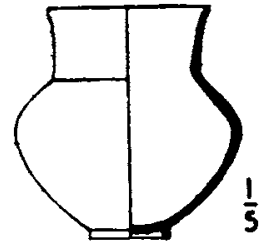

c

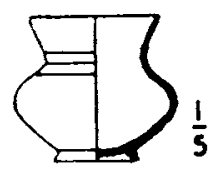

105

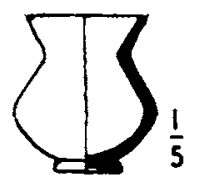

106

a

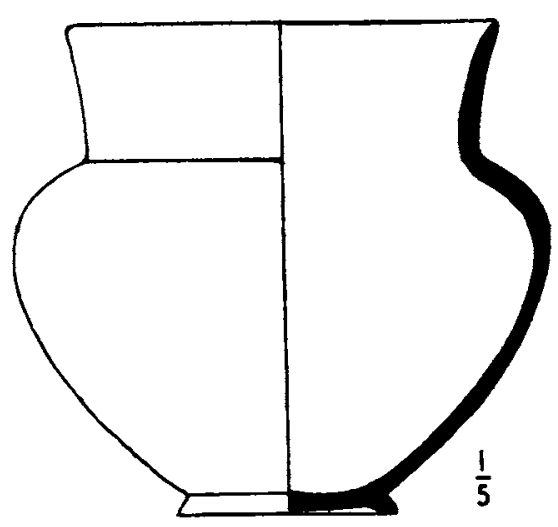

b

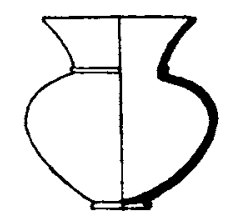

107

a

b
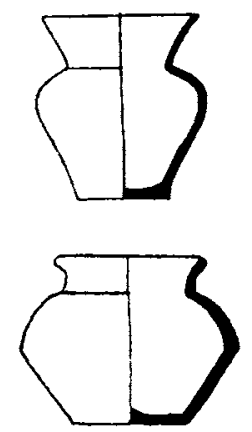

108

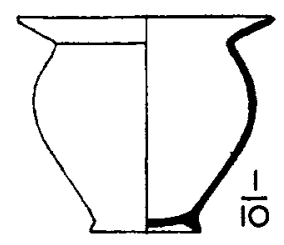

b

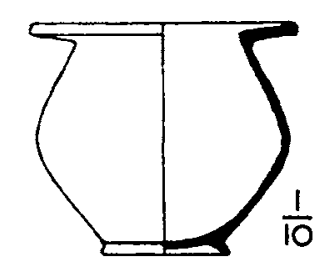

c

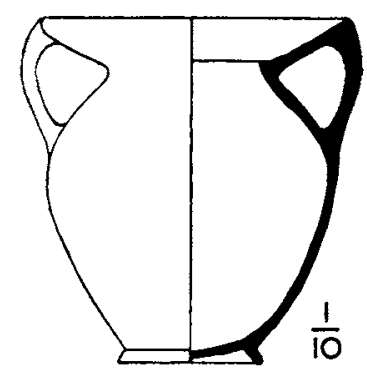

109

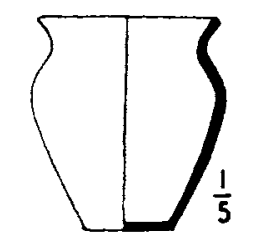

110

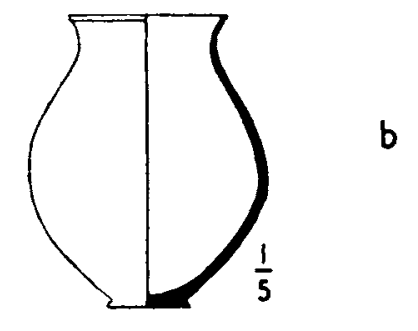

III

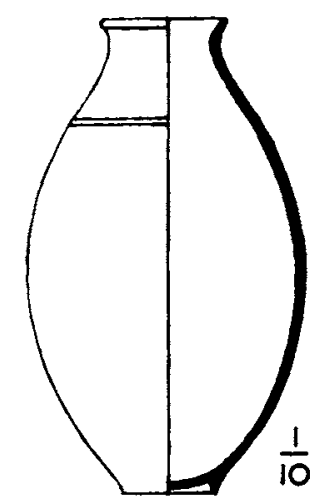

113

d

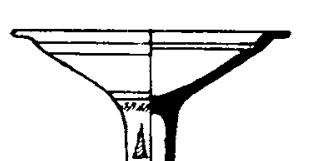

b
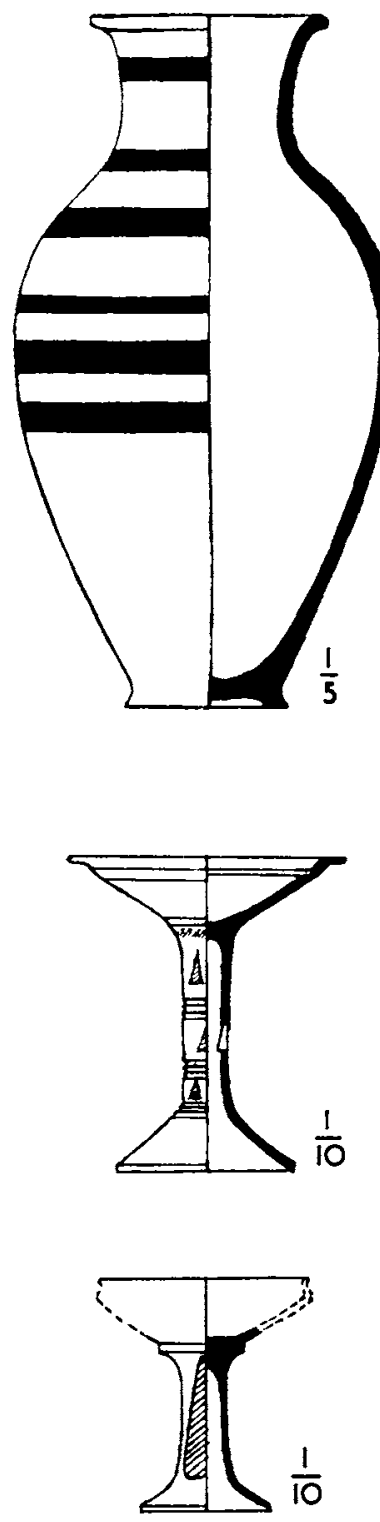

Types of local pottery

pp. 320 sqq. 
PLATE CXX
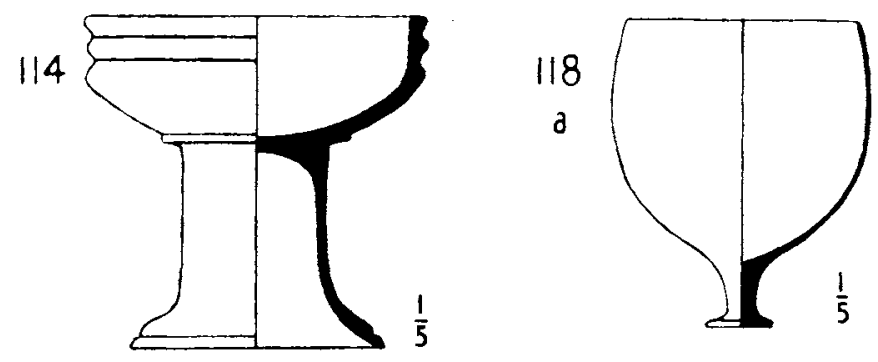

122

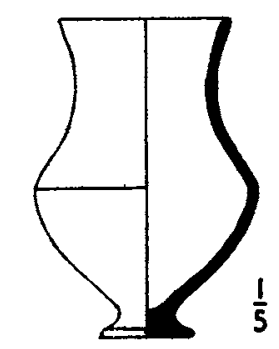

115

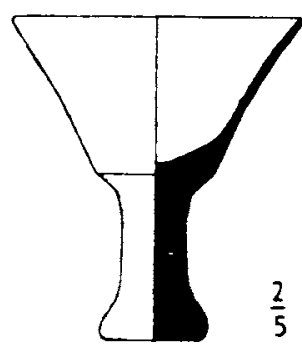

b

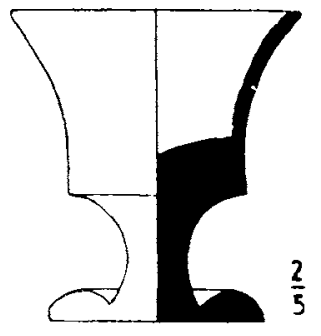

116

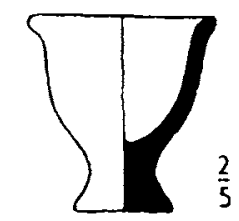

117

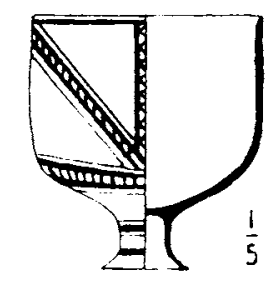

b

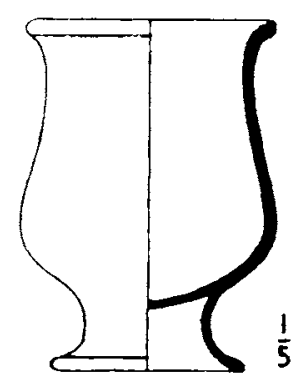

b

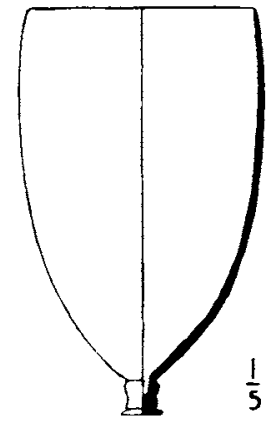

119

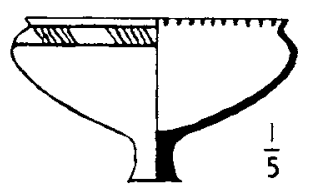

120

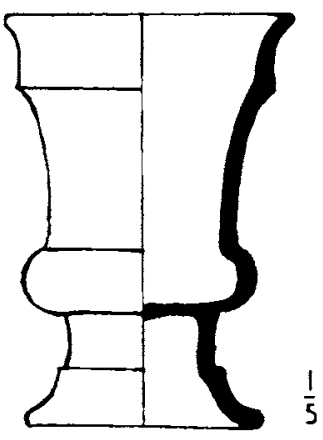

121

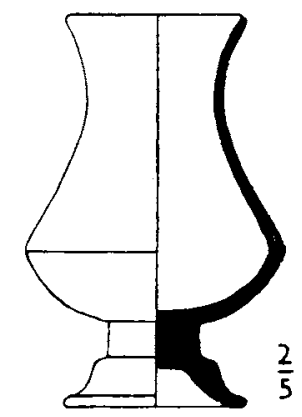

Types of local pottery pp. 320 sq9.
123

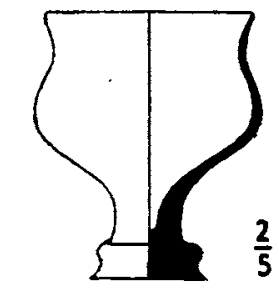

b

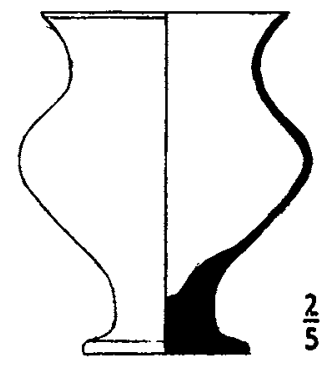

124

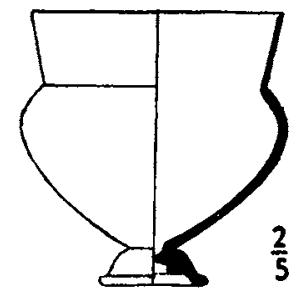

125

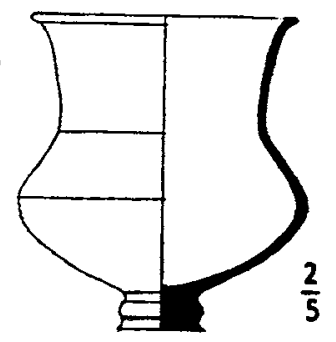


PLATE CXXI
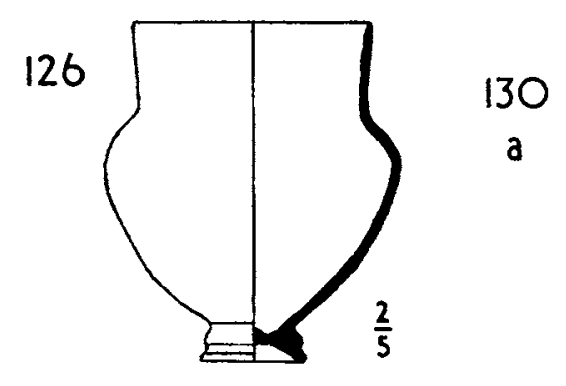

127

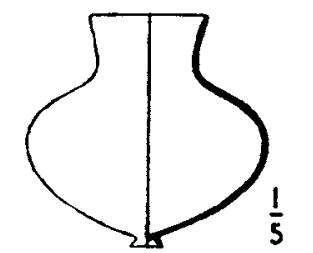

128

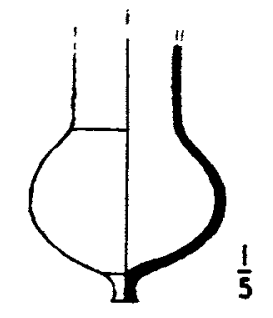

129

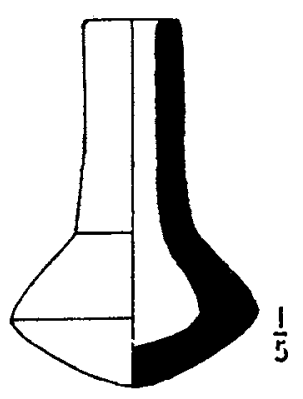

b

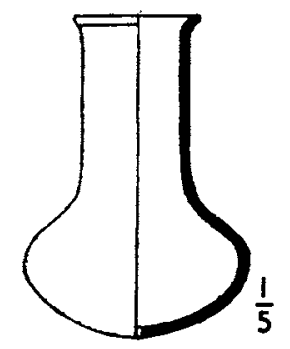

c

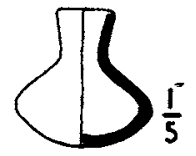

130

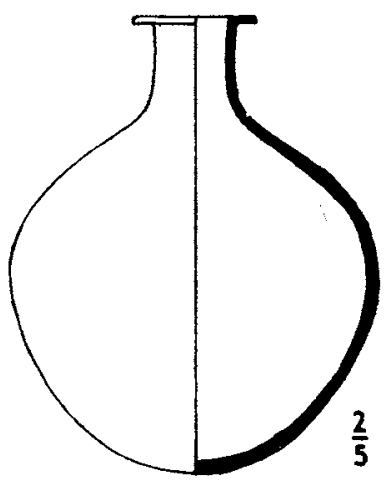

b

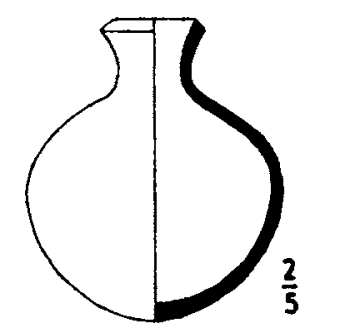

$c$

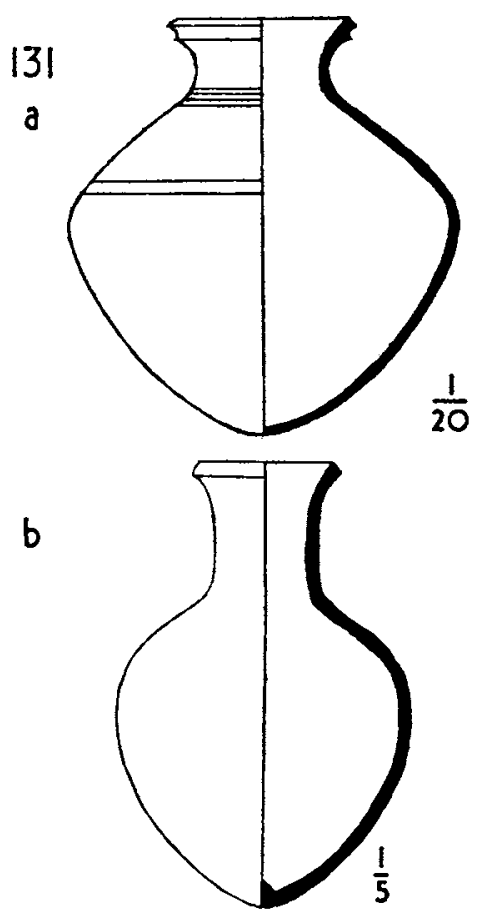

Types of local pottery

pp. 320 sqq.
132

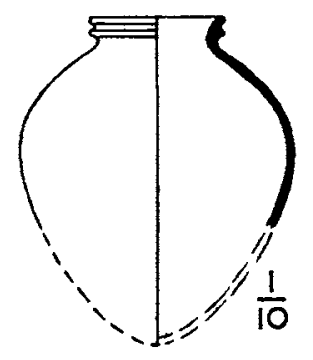

b

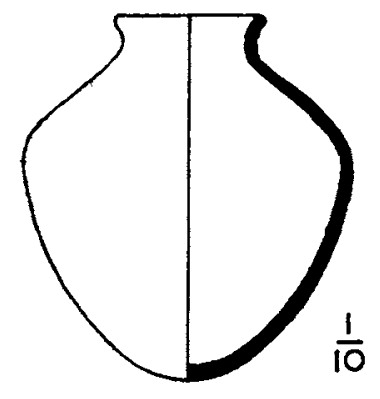

133

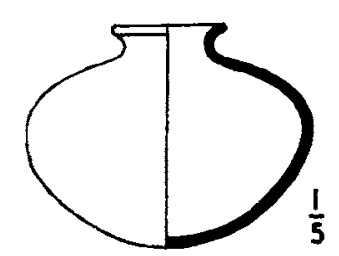

134

a

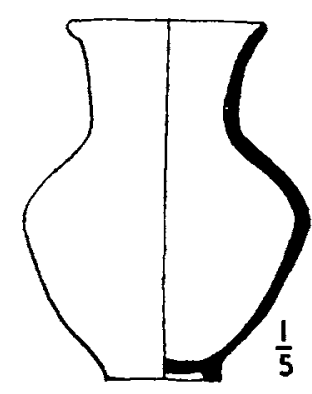

b

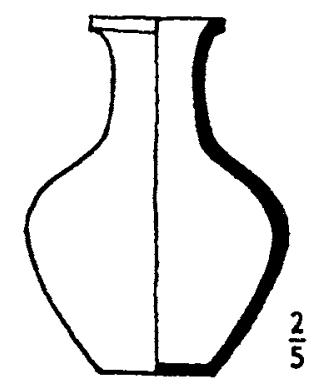


PLATE CXXII
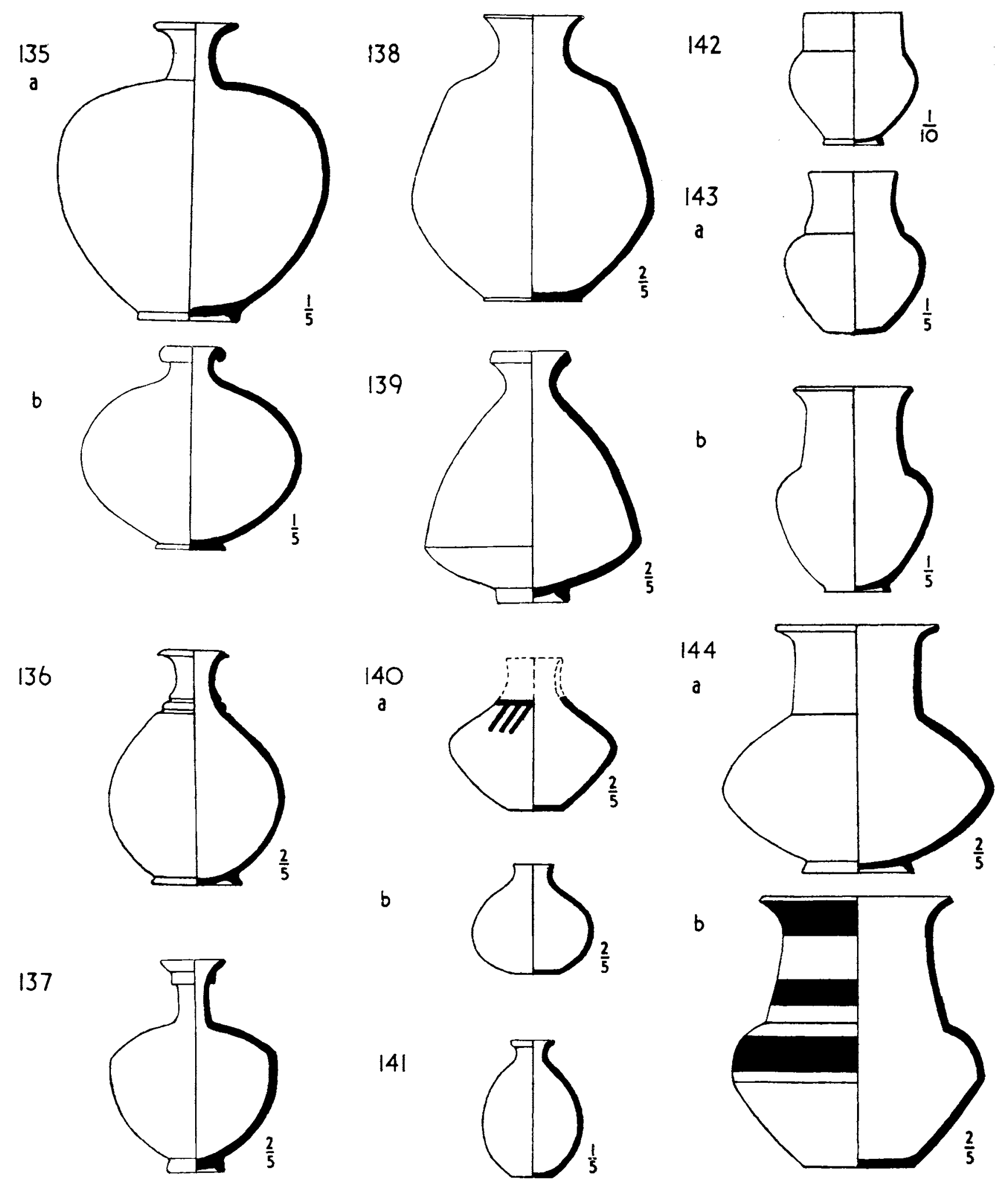

141
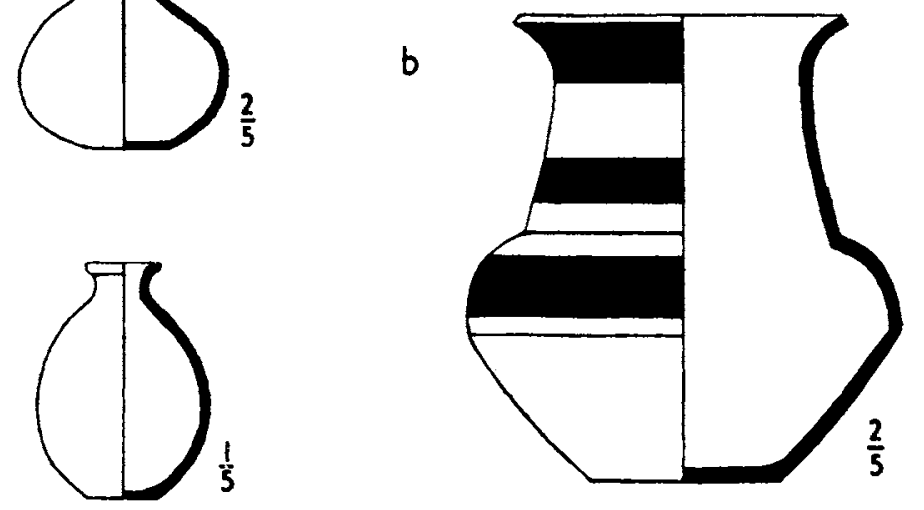

Types of local pottery pp. 320 sq. 
PLATE CXXIII

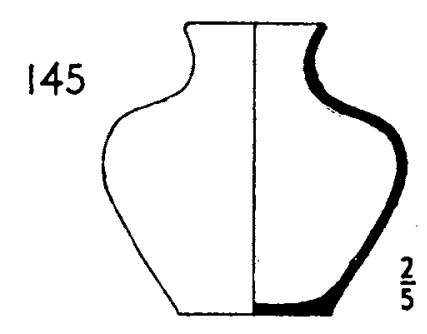

146

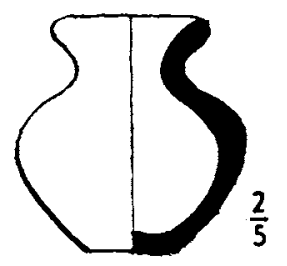

147

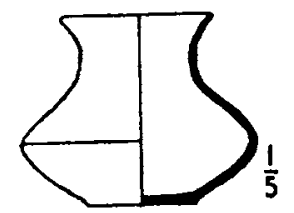

148

a

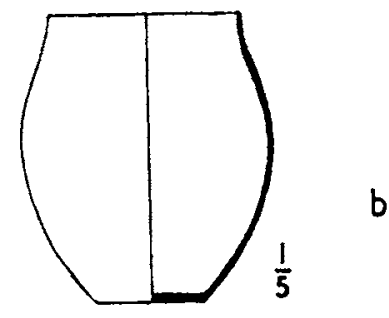

b

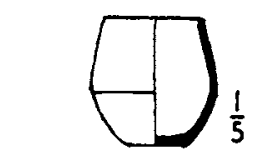

149

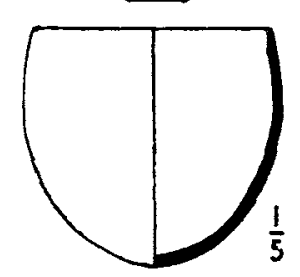

150

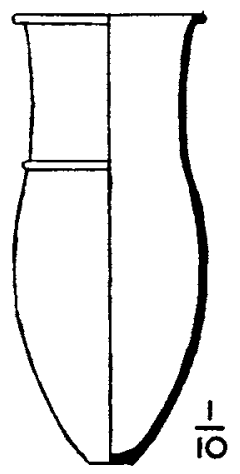

$|5|$

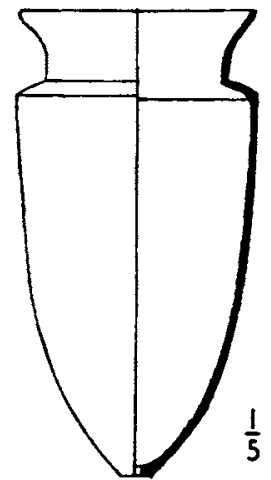

152

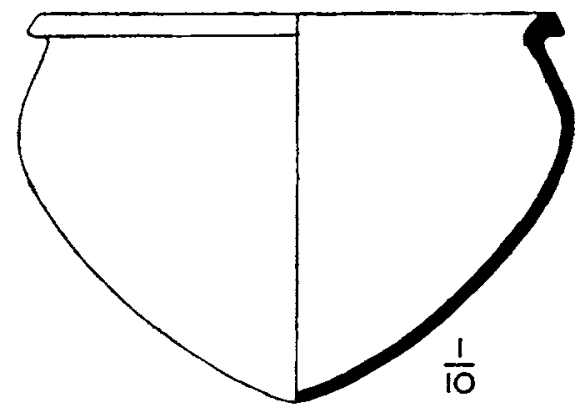

b

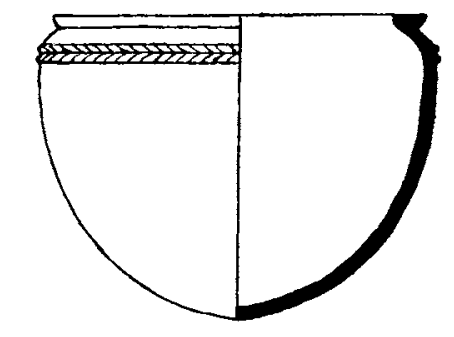

c

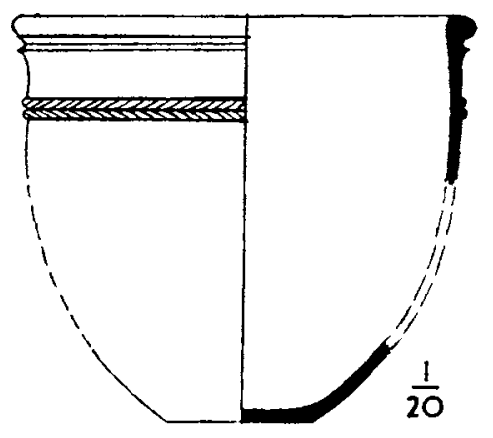

153

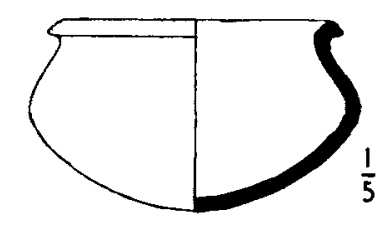

Types of local pottery

pp. $3 \geq 0$ sqq.
154

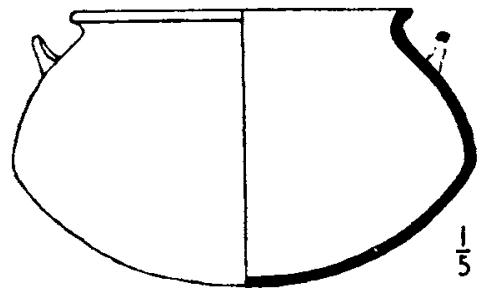

155

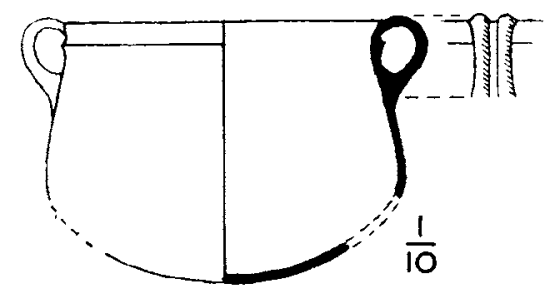

156

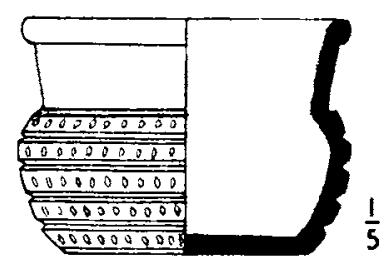

157

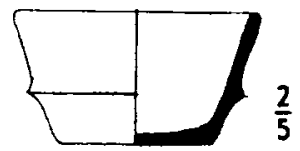

158

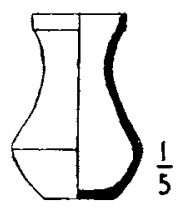

159

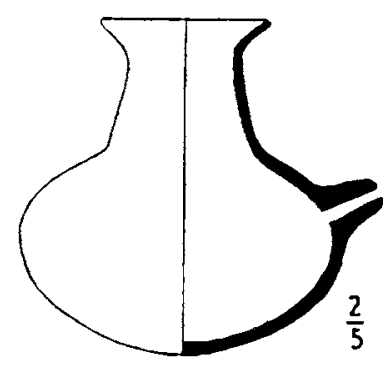

160

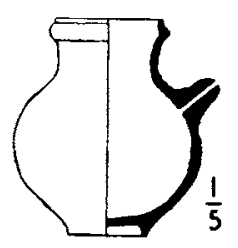



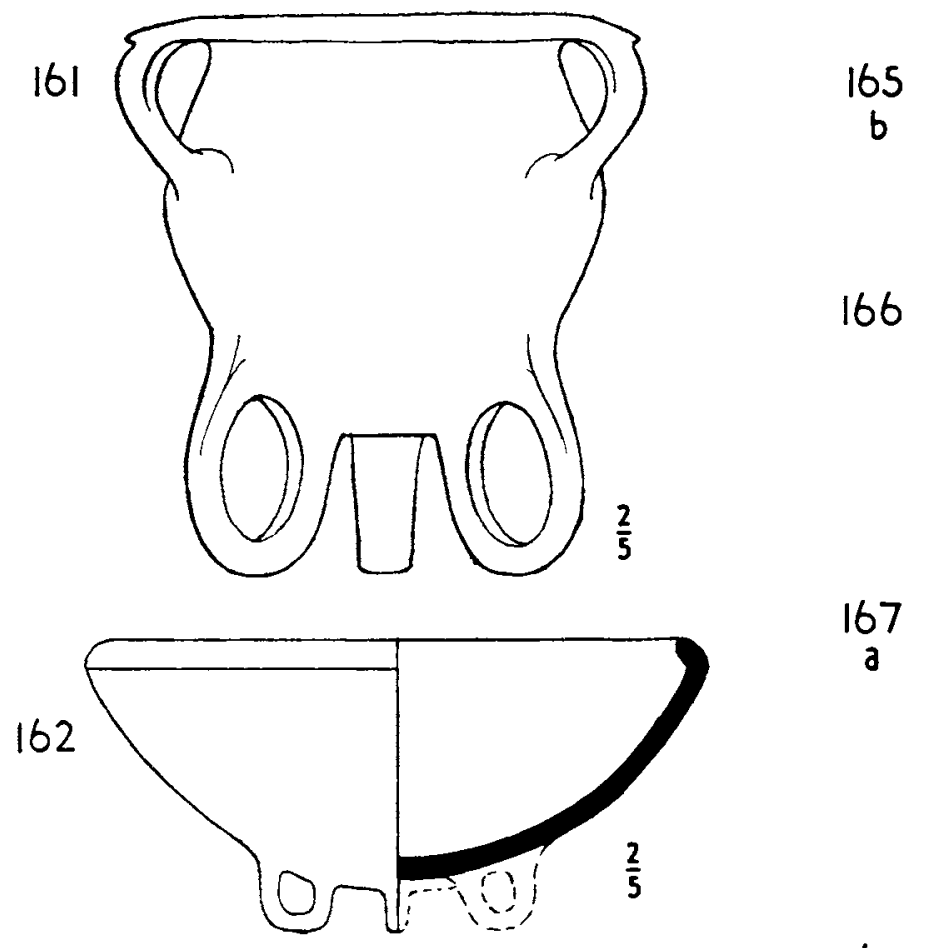

167
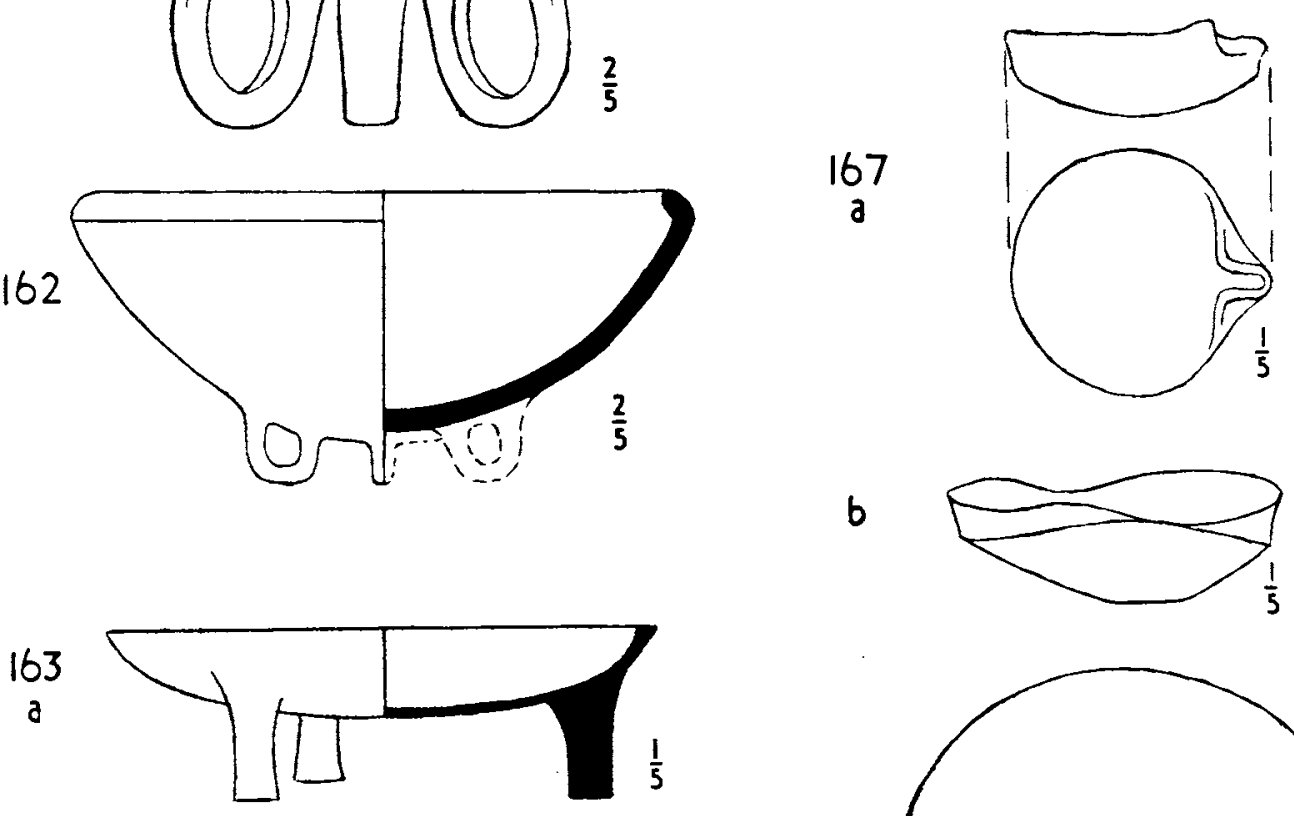

b
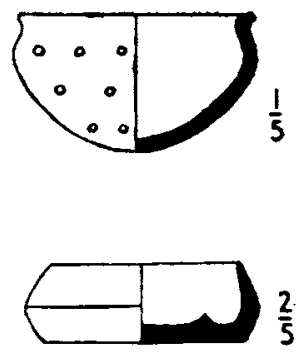

b

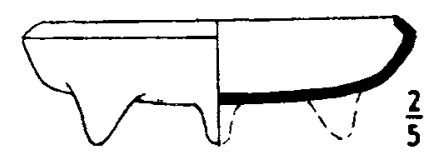

164
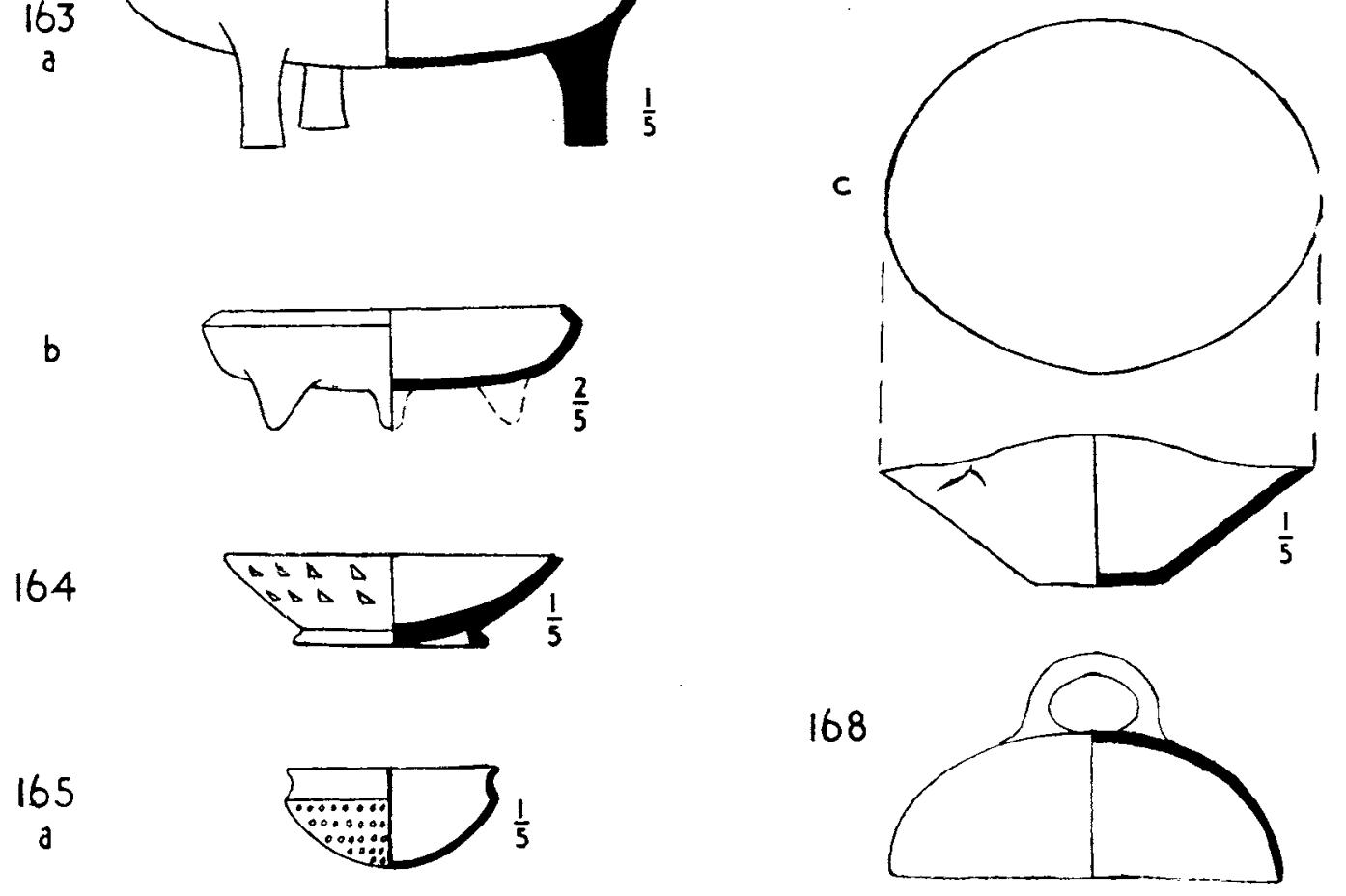

Types of local pottery

pp. 320 sqq. 


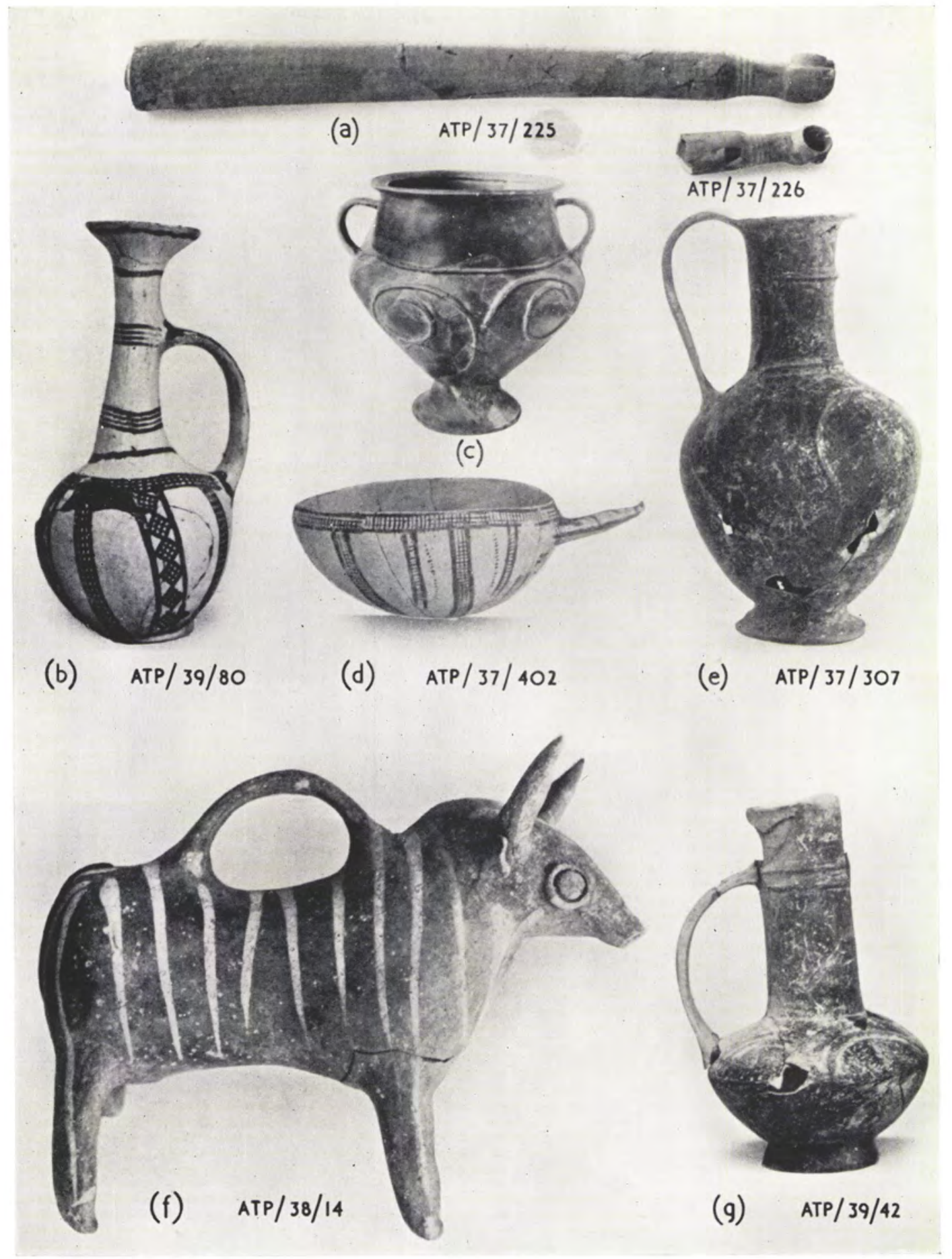

Base-ring and White Slip wares pp. 354 sqq. 

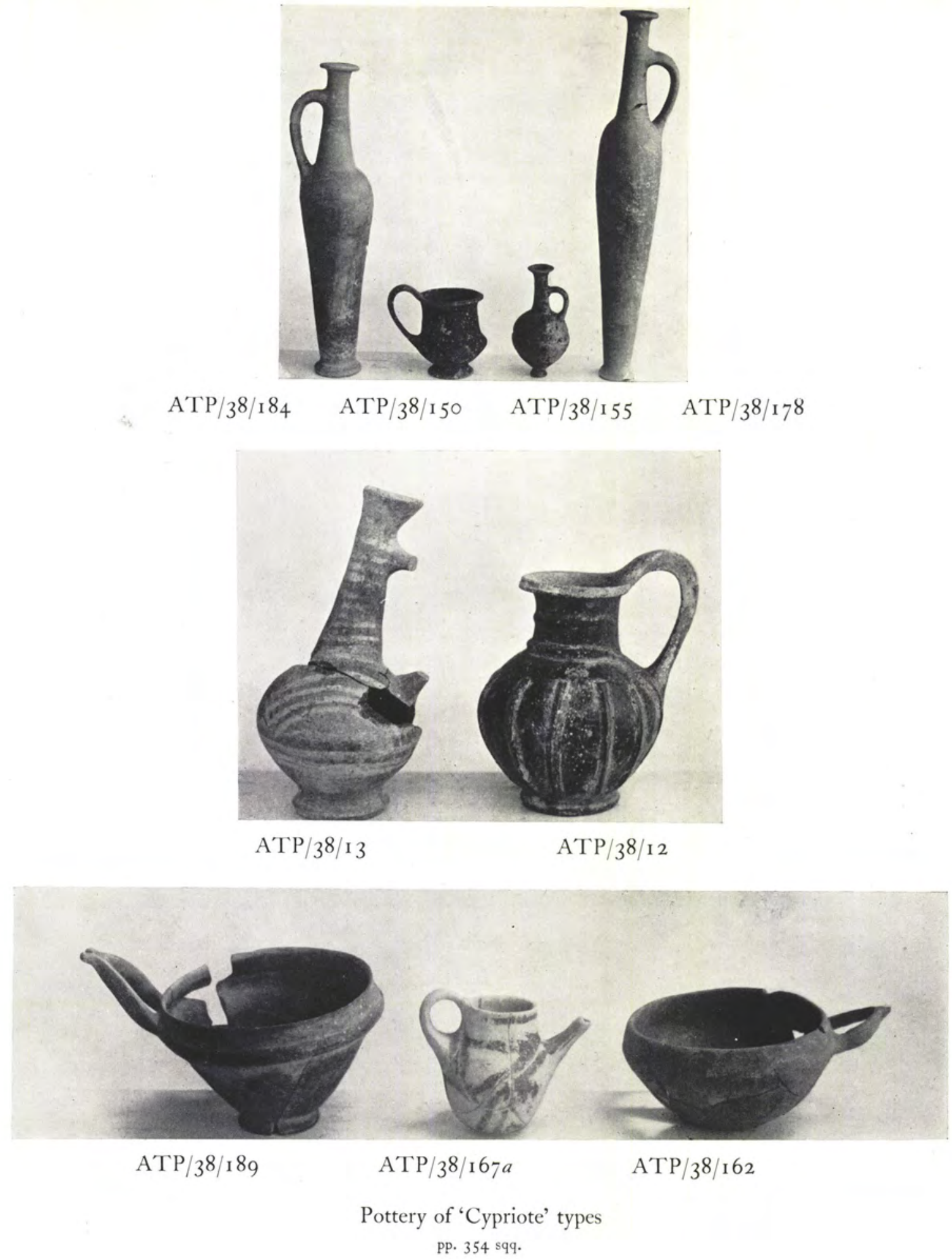
PLATE CXXVII
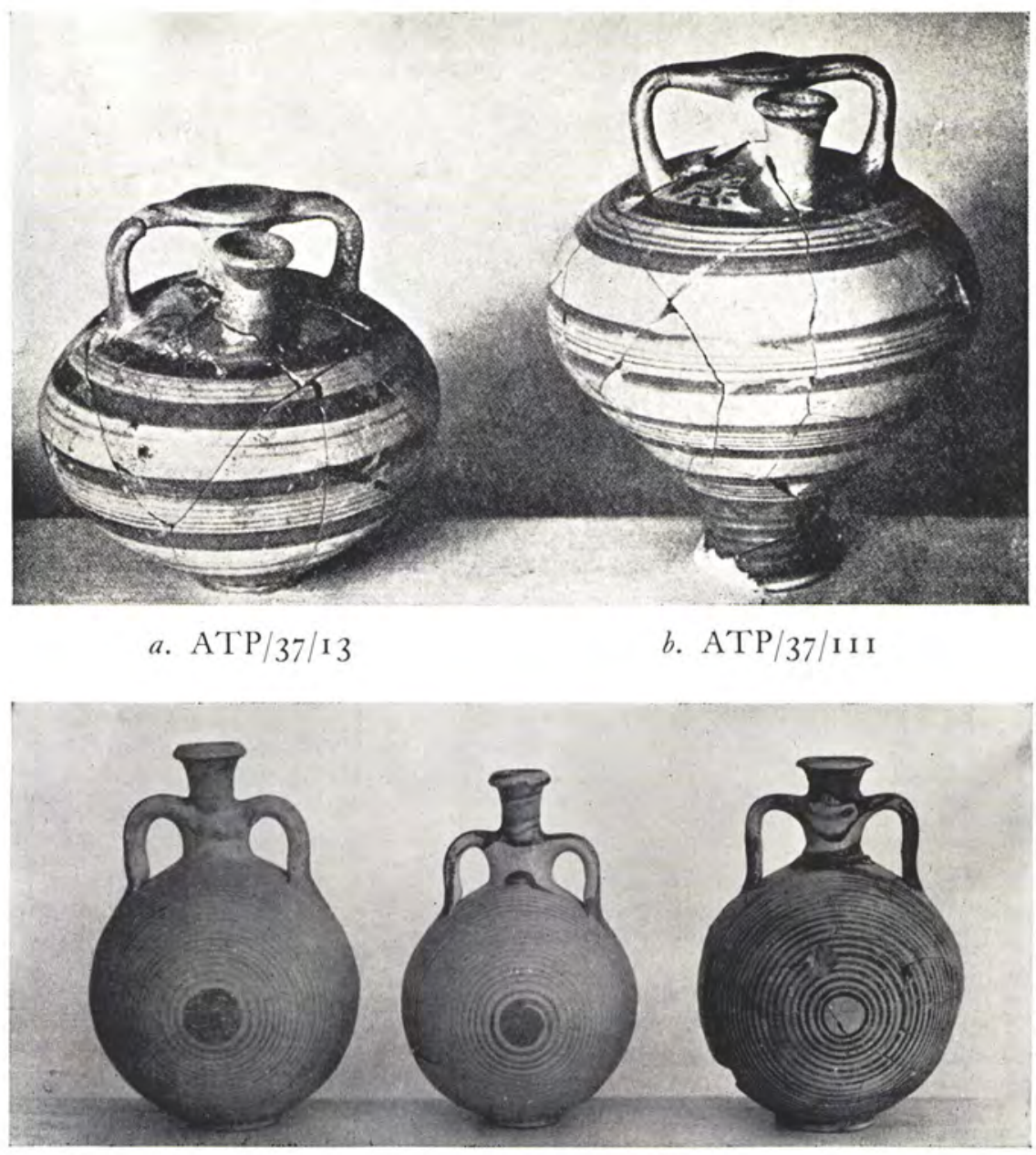

c. $\mathrm{ATP} / 3^{8 / 5}$

d. $\mathrm{ATP} / 3^{8 / 6}$

e. $\mathrm{ATP} / 3^{8 / 7}$

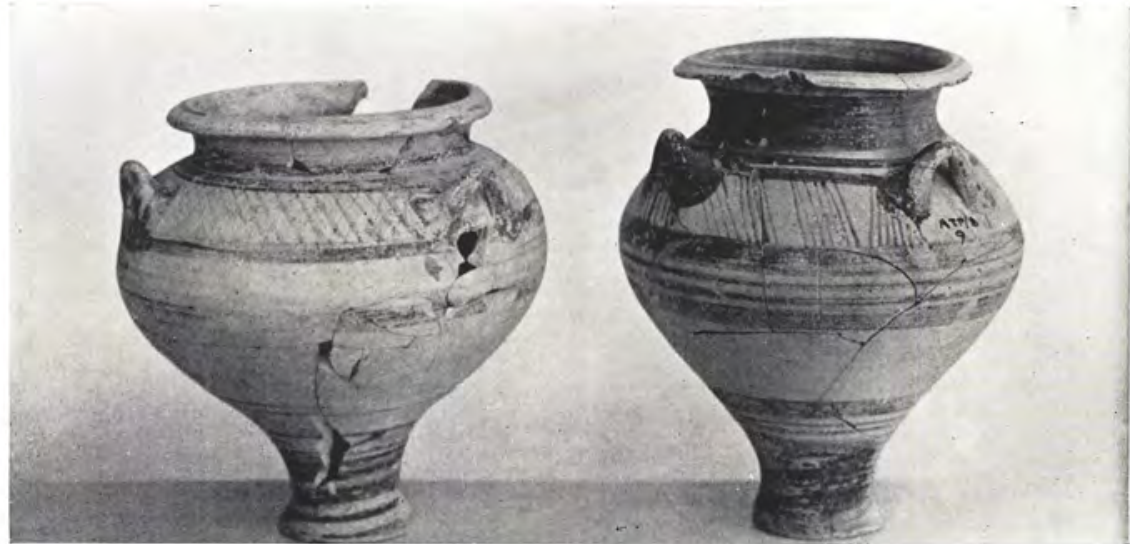

f. $\mathrm{ATP} / 3^{8 / 10}$

g. ATP $/ 38 / 9$

Examples of L.M. III pottery

pp. 369 sqq. 

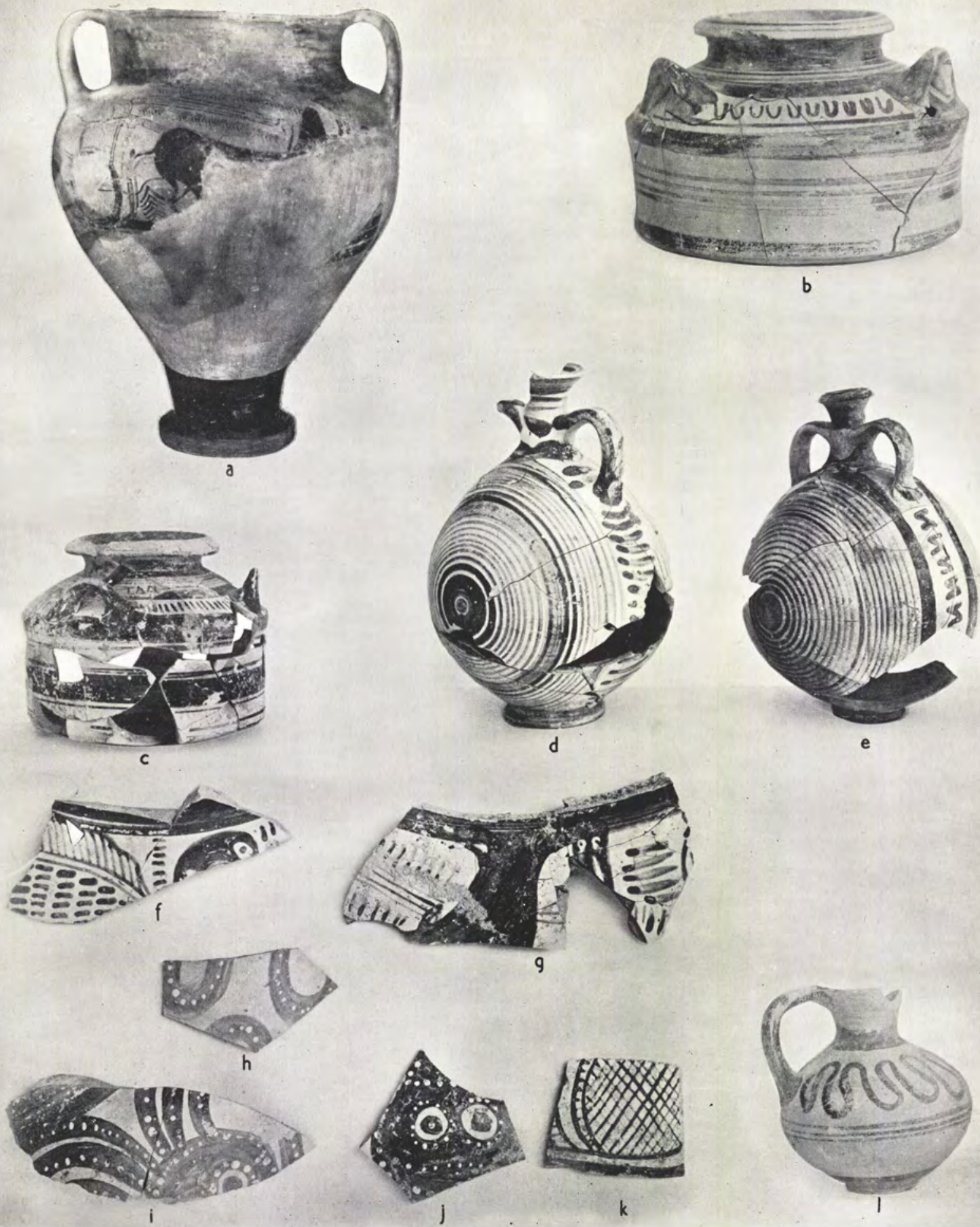

a. $\mathrm{ATP} / 46 / 307 ; b . \mathrm{ATP} / 38 / 12 ;$ c. $\mathrm{ATP} / 37 / 87 ; d . \mathrm{ATP} / 37 / 12 ;$ e. $\mathrm{ATP} / 38 / 10 ; f . \mathrm{ATP} / 37 / 284 ;$ g. ATP $/ 37 / 287 ; i$. ATP $/ 37 / 286 ; l$. ATP $/ 38 / 15$

Examples of L.M. III pottery

pp. 369 sqq. 

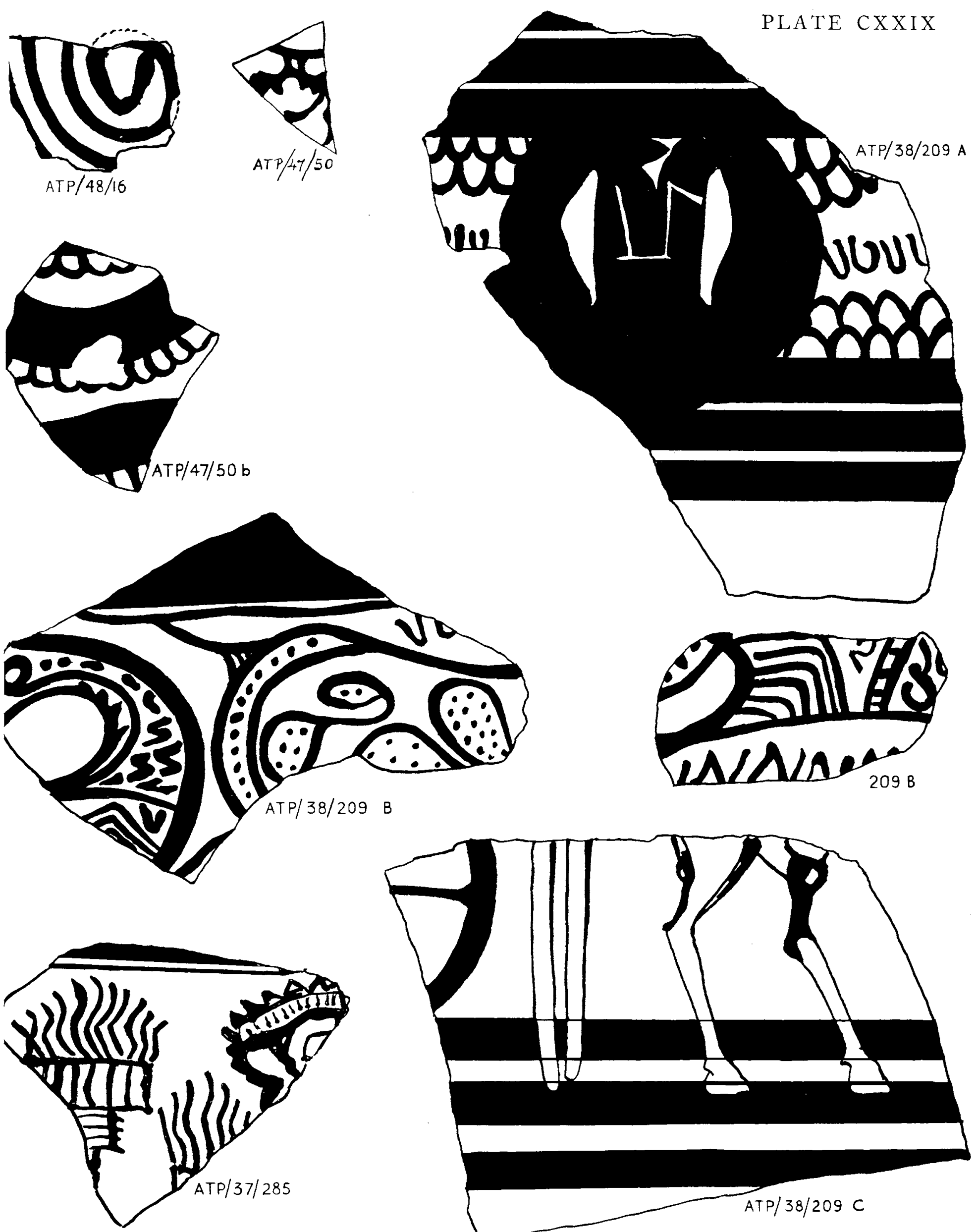

$B$

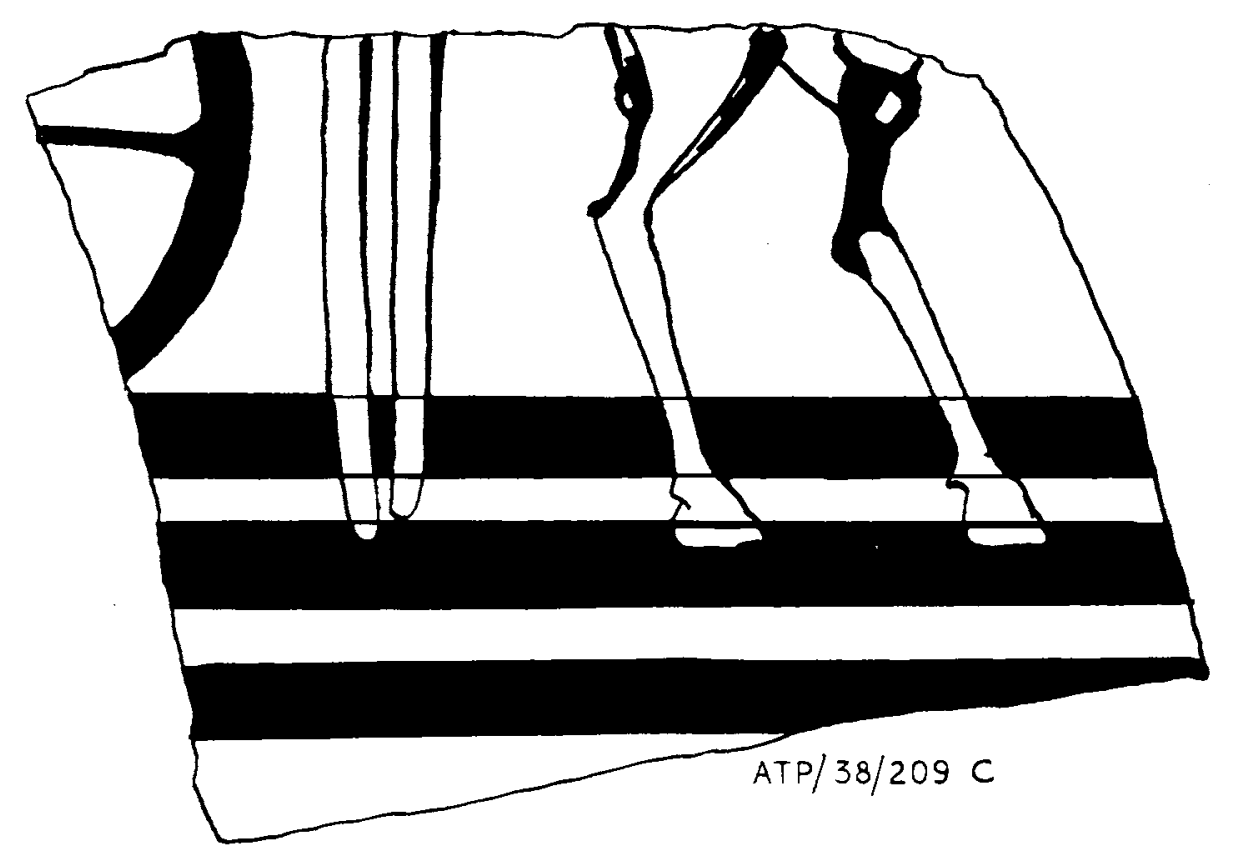

Examples of L.M. III pottery 
PLATE COX

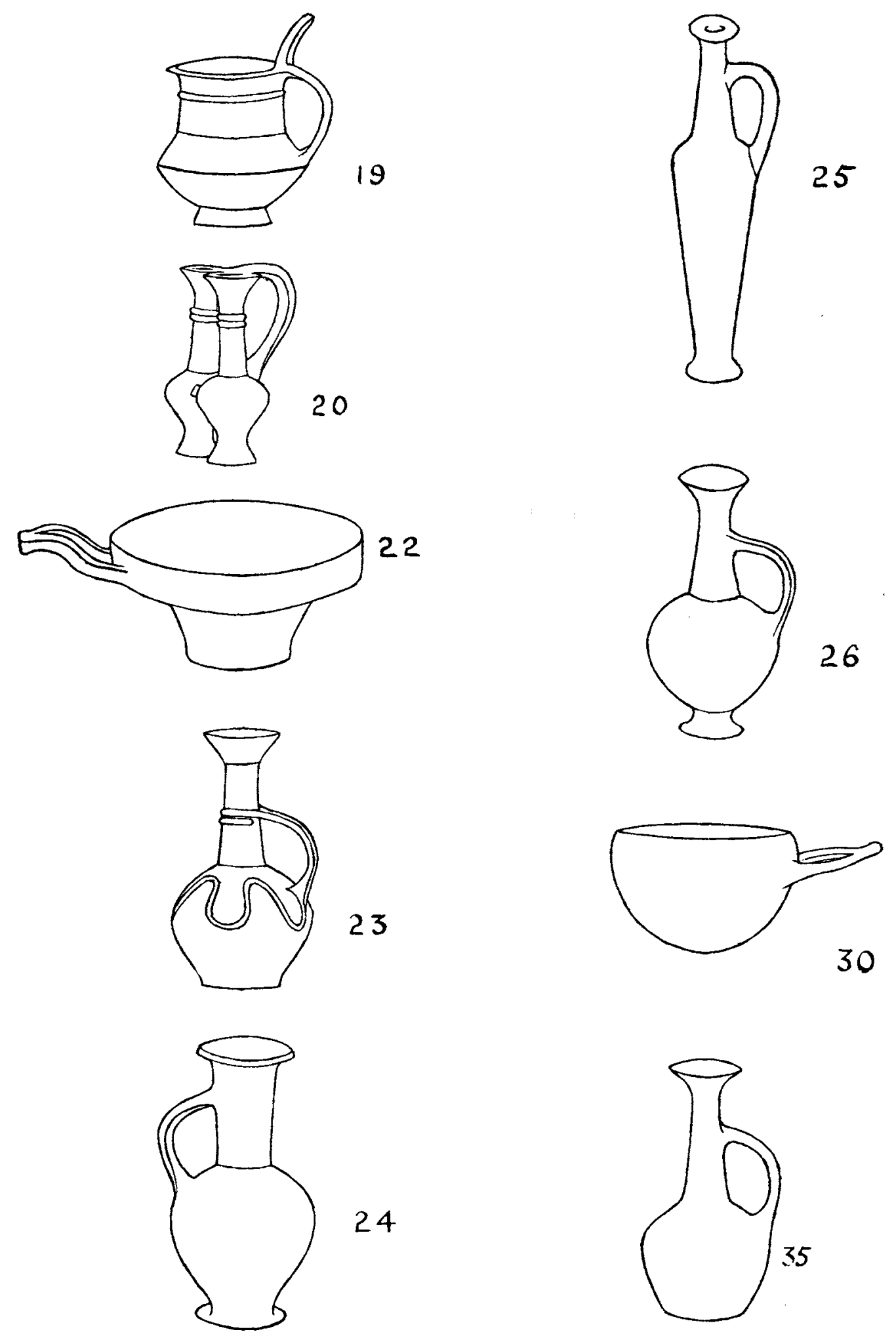

Types of White Slip and Base-ring wares

(The numbers are those of the British Museum catalogue)

$$
\text { pp. } 354 \text { sqq. }
$$


PLATE CXXXI
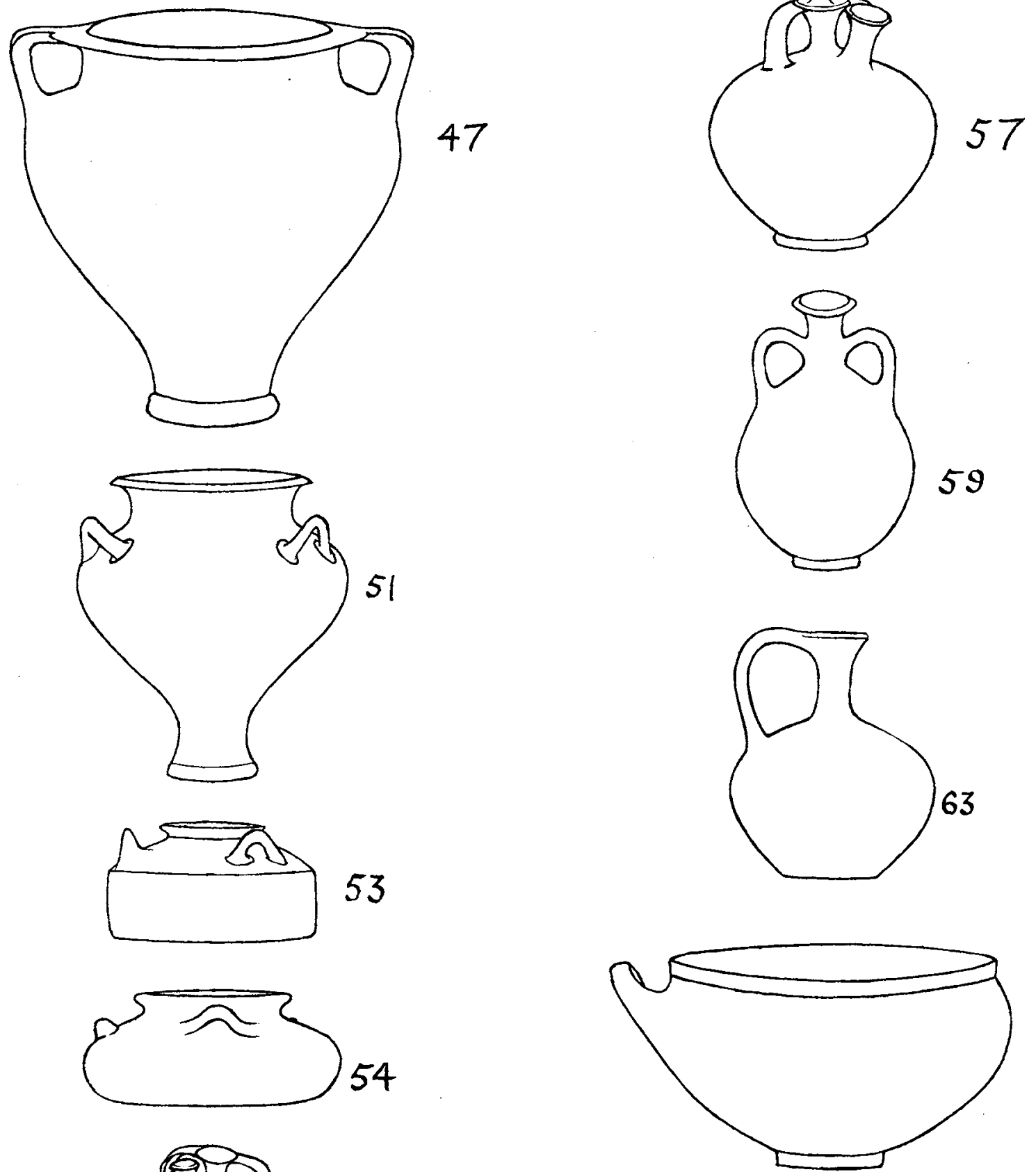

71
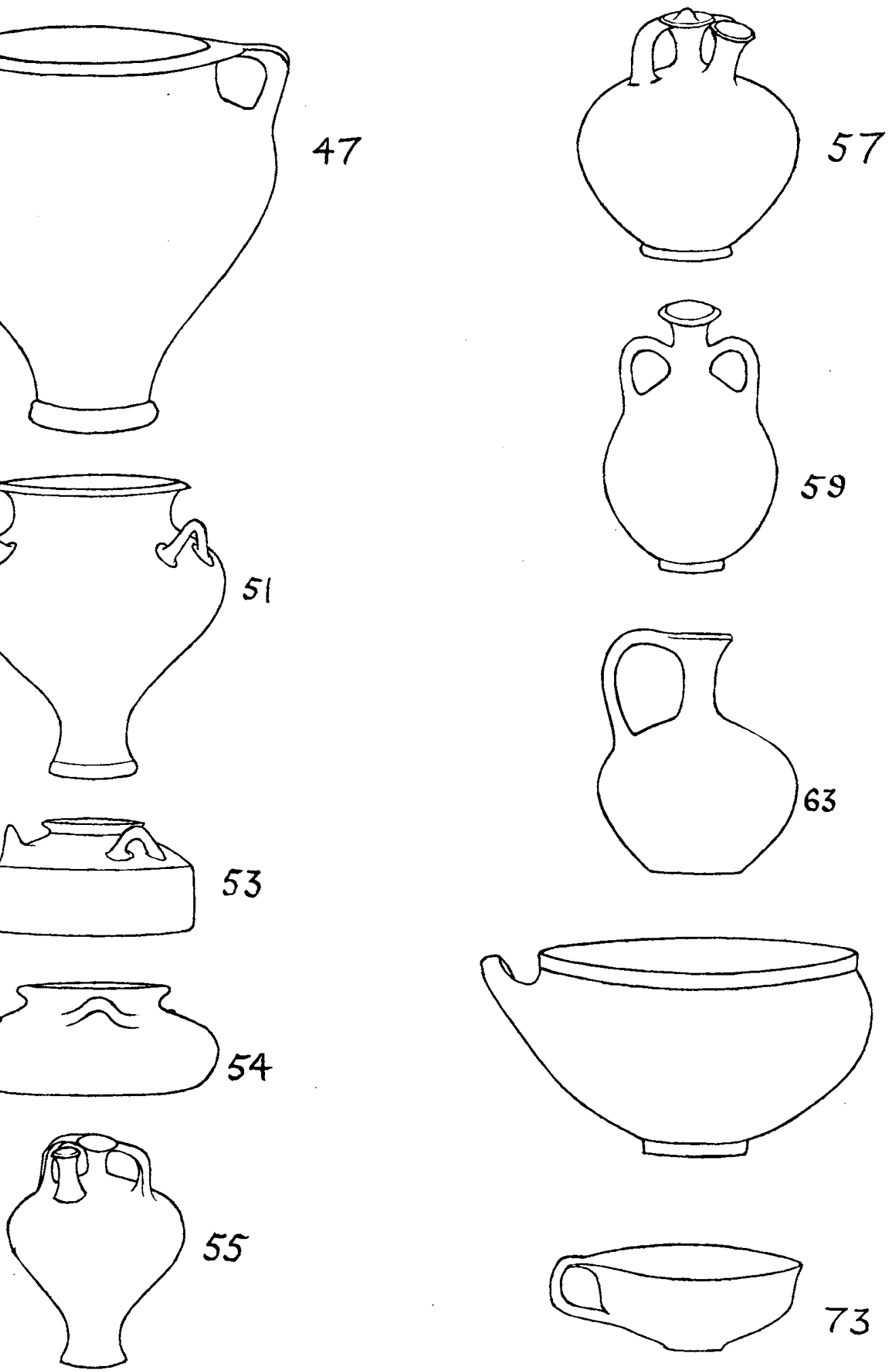
